\title{
Estudio de la interacción entre grupos \\ cazadores recolectores de Patagonia y las \\ plantas silvestres: el caso de la costa norte de Santa Cruz durante el Holoceno medio y tardío
}

Lic. María Laura Ciampagna

Directores:

Dra. Aylen Capparelli

Dr. Miguel Ángel Zubimendi

Tesis para optar al Título de Doctor en Ciencias Naturales

Facultad de Ciencias Naturales y Museo

Universidad Nacional de La Plata

2014 

"Se dice que sólo el Piche (armadillo), la Chingue (zorrino) y el Gato pajero tenían fuego. Eran tres que tenían fuego y eran amigos. Hacian de comer asado y churrasco con el fuego. Elal también estaba y dijo:

-Me parece que siento olor a humo: ¿cómo puede ser eso? ¿De dónde viene ese olor a humo? Yo no conozco nadie que tenga fuego. Sin embargo la Chingue tenía olor a humo, y Elal dijo -Esta mujercita tiene olor a humo, eso de fuego. Ella dijo -No, si no tenemos nada, nada tenemos. Cuando hacian de comer, tapaban el fuego para que no se viese el humo. -No, no, nosotros no tenemos nada, nada, nada, ... ¿Qué fuego vamos a tener nosotros?, - insistía la Chingue. Entonces Elal dijo: -Yo voy a buscar, voy a ver quién es el patrón. Ellos tienen su patrón que es el 'Aan(o)' (Piche). Elal fue a caminar y encontró al Piche haciendo fuego tapado. Le preguntó - ¿Vos tenés fuego?. -Yo no tengo nada. - ¡Cómo no! ¿Por qué no me dan un poco de fuego, un poco de carboncito quemado?. -No-dijo el Piche-, si no tengo nada. ¿Qué te voy a dar yo? ¡No tengo nada...!. -Vos tenés. Dame por favor. ¿No ves que la gente está comiendo carne cruda? ;Dame, por favorcito!. No habia nada que hacerle, el Piche estaba empacado. Entonces Elal se enojó, le pegó una patada y lo tiró lejos. Y ahí estaba el fuego; carbón quemado de leña de calafate. Elal se llevó el fuego, dejando al Piche sin él. Se lo llevó a los demás paisanos que así pudieron comer carne asada. Y Elal dijo-Ahora estás listo, ahora no va a tener más fuego y nosotros vamos a tener. Cuando Elal le sacó el fuego al Piche, le cortó el lomo por no habérselo querido dar, por eso tiene esas rayas en el lomo. Después el Piche se fue al campo y no volvió más junto a los paisanos. La Chingue y el Gato pajero también se fueron. Ahora el Piche come peritas y la Chigue cucarachas".

Bórmida y Siffredi 1969/70: 213-214. Informante Doña Ana Montenegro de Yebes

Dibujo de tapa basado en este relato realizado por la artista plástica Dolores Pardo 

A mis papás, por su amor y apoyo constante, A mis hermanos que son mis amigos del alma, A Aurorita y Antonio que siempre andaban entre las plantas experimentando, A Raquel y Evaristo que curaban con palán palán, A mis cuñas y mis duendes Nacho y Pili 



\section{Agradecimientos}

A mis directores Aylen Capparelli y Miguel Ángel Zubimendi, porque sin ellos no podría haber realizado este trabajo. Por su paciencia, su dedicación y su fé en mí. Muchas gracias, por el cariño y el afecto que me brindaron. A Alicia Castro, también mi directora, que me permitió desarrollarme en su proyecto, me guió en la arqueología de Patagonia y abrió las puertas de su casa y su laboratorio para mí.

A todo el equipo de Costa Norte de Santa Cruz y entiéndase que el orden no altera el producto: Pablo Ambrústolo, Verito Trola, Lucía Mazzitelli, Heidi Hammond, Leo Zilio, Marcelo Beretta, Lorena Corinaldessi y Analía Navarro. Leo Zilio realizó la mayor parte de los mapas de la presente tesis. Unas palabras especiales para Verito, quien me ayudó en el campo, me regaló su amistad y está presente a lo largo de estas páginas.

A los compañeros de la Diagonal Árida: Diego Andreoni, Verónica Lema, Analía Martínez y Natalia Petrucchi. A Mariela Garraza que pasó horas ayudándome y acompañándome. A Tany Pochettino siempre ayudandome y brindándome bibliografía y consejos.

A toda la comunidad de Puerto Deseado y Tellier, que abrieron sus casas y me regalaron sus relatos, gracias a los hombres y mujeres de la tierra Patagónica que luchan día a día en soledad. Comunidad mágica si las hay, rica a través de personas especiales y de historias. En primer lugar, al hombre que me regaló una madeja para que en cada puerta se desenrrollaran hilos: gracias Carlos Santos. A través de él conocí a Fortunato Llanca, quien con un mate me contó su vida, me habló del trabajo del peón rural y de su vida andariega. A Héctor Soto, quien me abrió la puerta de su casa y me hizo pasar sin saber quién era yo ni por qué iba. A Laura y Josefa Medallo que con su calidez repasaron su infancia, paisajes del Viejo y del Nuevo Mundo. A Violeta Martínez, otra tejedora de vínculos, quien me brindó muchísima ayuda. A través de ella conocí a Beatriz San Juan, ambas mujeres divertidas y emprendedoras. Gracias a Norma, Walter y Juan Pross por sus charlas y su amabilidad. A Pocho González quien me recibió en su casa y en su chacra, me enseñó sobre plantas y me mostró un poco su mundo. También a José Balmaceda y Amalia, Juan Mac Claud, Rubenillo Casanova por su predisposición y 
apertura. También mencionar con una sonrisa a Vicente Villagra, puestero de la Estancia 8 de Julio, quien me enseñó que no dejamos nada material sino lo que damos al otro y que eso es el recuerdo. Así es que con esta mención espero darle voz y transmitir su mensaje.

A todos los chicos de Consejo Agrario de Puerto Deseado, especialmente a Mario Ramos, que sin su ayuda no hubiera podido recorrer las chacras de Tellier, y que siempre estuvieron atentos a ayudarnos. También un agradecimiento a Mario Dos Santos Lopes, quien difundió mi trabajo y me brindó ayuda. A los muchachos del Ferrocarril que de tanto andar por ahí, me sugirieron nombres de personas que podían saber de plantas y por sus invitaciones a contarme de épocas pasadas cuando los trenes iban y venían.

A las chicas del Museo Mario Brozosky que tanto nos ayudaron para la organización de las campañas y siempre atentas a que no nos faltara nada. A los dueños de las estancias que nos permitieron trabajar en el campo. A César Gribaudo y los miembros del CADACE por recibirnos en Caleta Olivia.

A Laura Borrelli, tan generosa y cálida que me mostró sus conocimientos, me enseñó y me ofreció su amistad y gracias a toda su familia.

También a Laura Iharlegui y Anabela Plos del Herbario de Plantas Vasculares del Museo de Ciencias Naturales por responder a mis consultas y brindarme información. A Adriana y Adrián del Latyr que me permitieron utilizar el instrumental para la carbonización experimental y fueron tan amables conmigo. A Sergio Bogan y Diego Gobbo que siempre estuvieron dispuestos a ayudarme.

A todos mis amigos que me han tenido mucha paciencia en esta etapa y han sabido contenerme, siéntanse nombrados todos. Especialmente a Lumila Menéndez quien me acompañó en todo momento y me ayudó en el proceso de tesis y a Daniela Mansegosa también, ambas por su cariño y su amistad. A Irma y "el Negro" así como a toda su familia que fueron mi refugio en La Plata.

Y muchas gracias a los casi co-autores de esta tesis: mi familia, gracias por tanto aliento y fuerza que me dieron en este proceso. Y por su amor inmenso de siempre.

A los trabajadores de la Bibioteca Florentino Ameghino, a la Facultad de Ciencias Naturales y a CONICET. 


\section{Índice}

SECCIÓN I: INTRODUCCIÓN......................................................1

1. Introducción ................................................................................................................. 3

1.1. Objetivo general .......................................................................... 5

1.2. Objetivos específicos e hipótesis .............................................................. 6

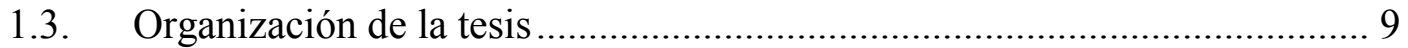

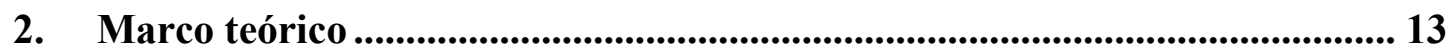

2.1. Las prácticas de recolección de plantas silvestres ....................................... 16

2.2. Prácticas de manejo del uso del fuego y el fogón como estructurador del

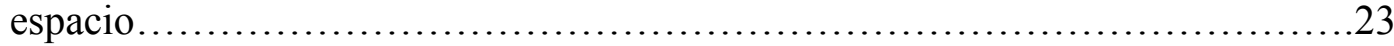

2.3. El uso de la analogía para la elaboración de hipótesis arqueológicas ........ 27

2.4. Antecedentes Arqueobotánicos en Patagonia Argentina.............................. 29

3. Área de Estudio y Antecedentes arqueológicos ................................................. 31

3.1. Caracterización ambiental del área de estudio .......................................... 31

3.1.1. Descripción fitogeográfica del área de estudio ...................................... 34

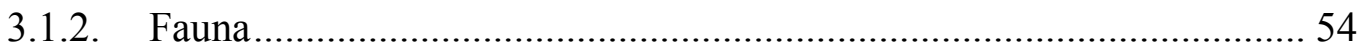

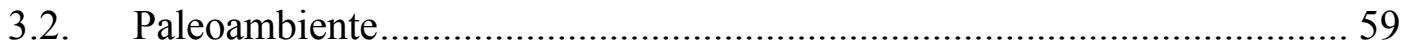

3.3. Antecedentes arqueológicos generales de la Costa Norte de Santa Cruz... 61

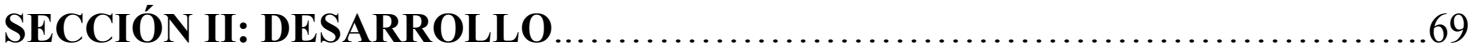

PARTE I: HISTORIA DEL USO DE LAS PLANTAS POR PARTE DE LAS PLANTAS QUE HABITARON LA PATAGONIA ARGENTINA ................71

4. Las prácticas de recolección de plantas silvestres a través de las fuentes bibliográficas.................................................................................................................... 73

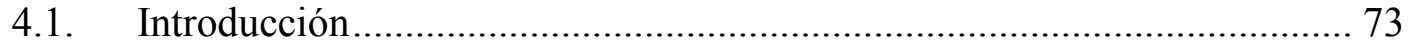

4.2. Material y Métodos.............................................................................. 75

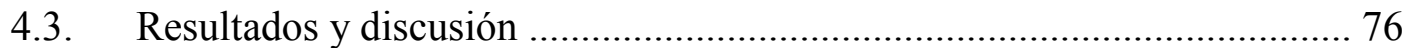

4.3.1. Las fuentes documentales escritas: en torno a las denominaciones y distribución de los grupos humanos que habitaron el área................................. 76

4.3.2. Plantas utilizadas por los grupos humanos ……….............................. 78

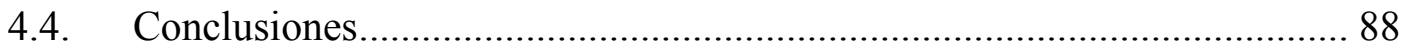


5. Las prácticas de recolección a través de la etnobotánica: de percepciones y saberes

5.1. Introducción. 111

5.2. Localidades donde se realizaron las entrevistas etnobotánicas dentro del

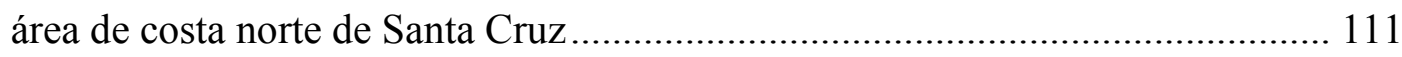

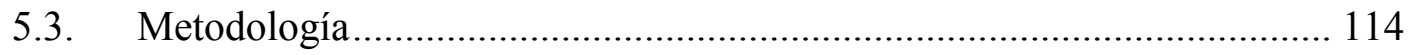

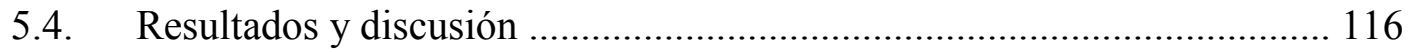

5.4.1. Recursos comestibles .................................................................... 118

5.4.2. Recursos leñosos ......................................................................... 119

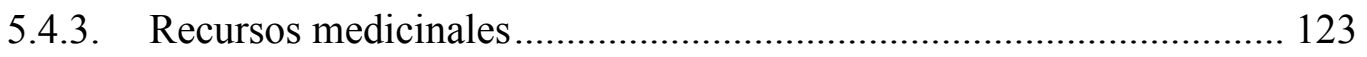

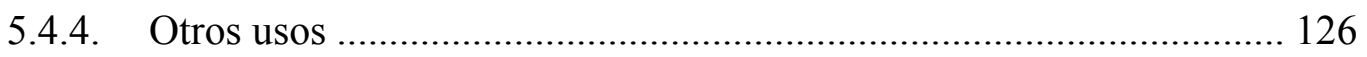

5.4.5. Conocimiento botánico tradicional ................................................ 127

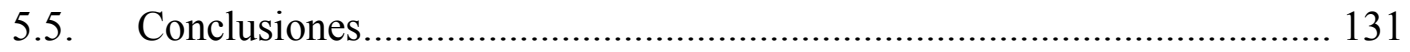

5.6. Construcción de un modelo de prácticas de recolección para contribuir a la interpretación del registro arqueobotánico de Costa Norte de Santa Cruz........... 139

5.6.1. Componentes del modelo y qué datos pueden utilizarse en la analogía

5.6.1.1. Las fuentes bibliográficas y la formulación de modelos para la interpretación del registro aqueobotánico

5.6.1.2. La etnobotánica y la formulación de modelos para la interpretación del registro aqueobotánico

5.6.2. Cuestiones a tener en cuenta en la interpretación de las prácticas de recolección de plantas silvestres a partir del registro arqueobotánico de Costa Norte de Santa Cruz

5.6.3. Expectativas sobre las evidencias materiales de prácticas de recolección que podrían encontrase en el registro arqueológico de Costa Norte de Santa

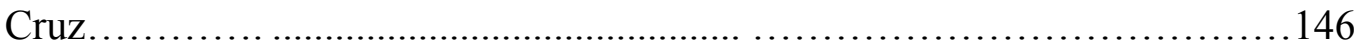

PARTE II: REGISTRO ARQUEOBOTÁNICO ...........................150

6. El registro arqueobotánico de Patagonia continental: análisis bibliográfico

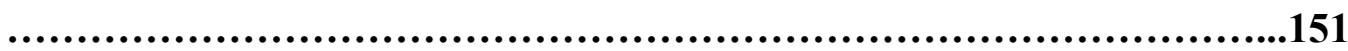

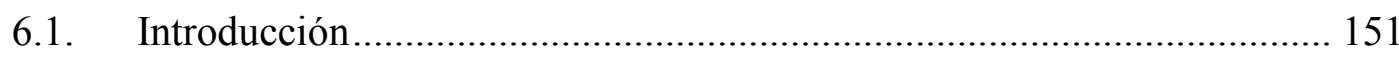

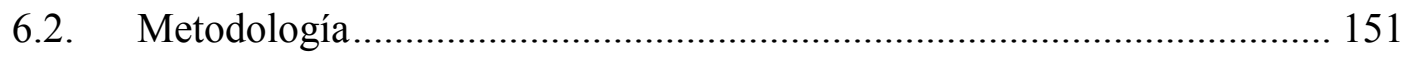




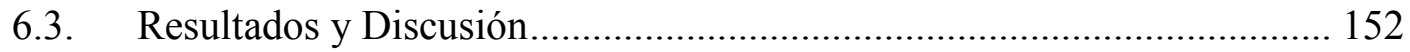

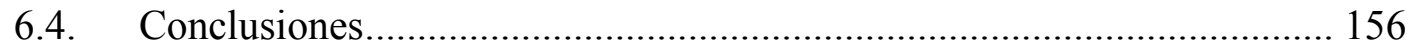

7. Colección de referencia de macrorrestos y Experimentación ..................... 165

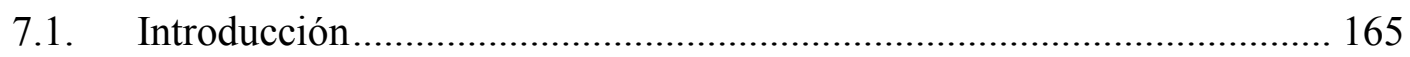

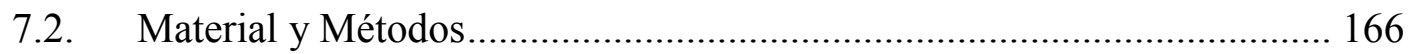

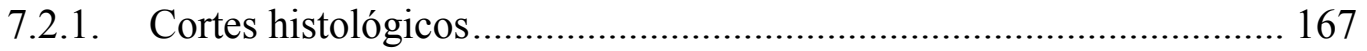

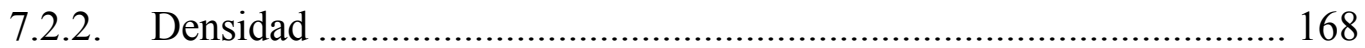

7.2.3. Protocolo experimental de carbonización controlada........................ 169

7.2.3.1. Identificación de los carporrestos ............................................... 170

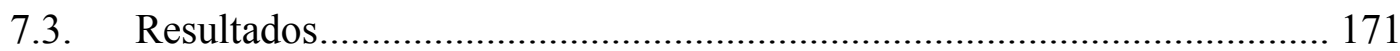

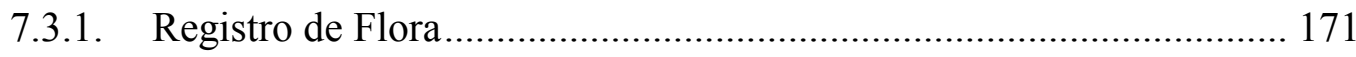

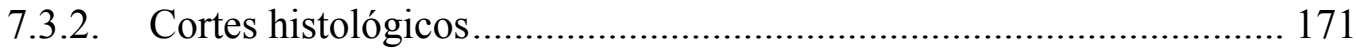

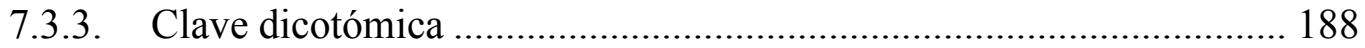

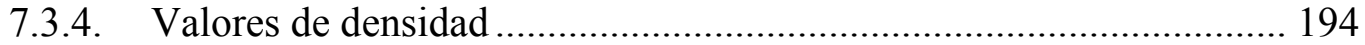

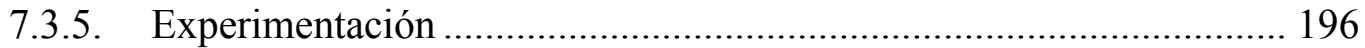

7.3.5.1. Carbonización experimental de los carporrestos ........................ 207

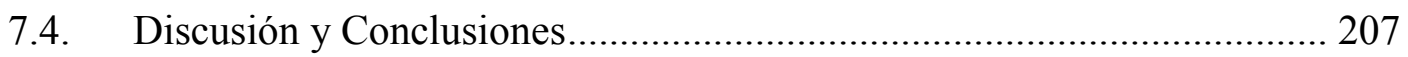

8. Registro arqueobotánico del sector del centro del Golfo San Jorge ........... 209

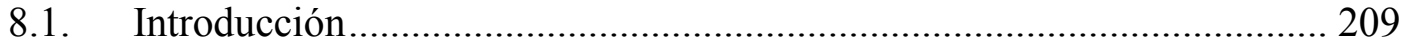

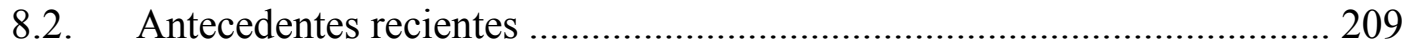

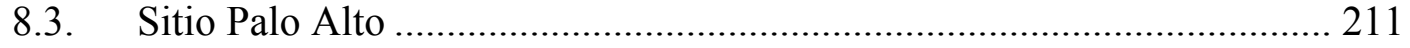

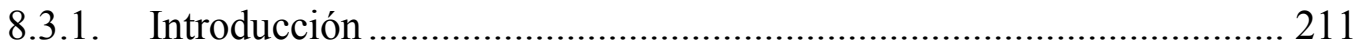

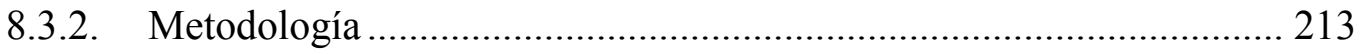

8.3.2.1. Excavación ................................................................................ 213

8.3.2.2. Recuperación de restos antracológicos ...................................... 214

8.3.3. Contexto estratigráfico ................................................................ 216

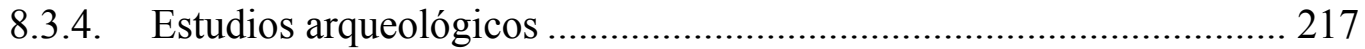

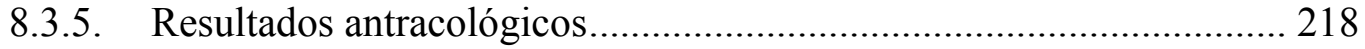

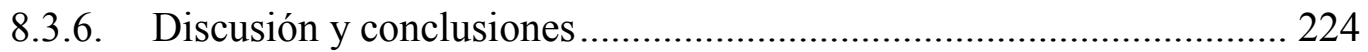

9. Registro arqueobotánico sector Cabo Blanco ............................................... 227

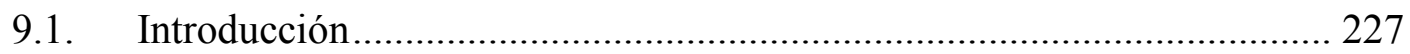

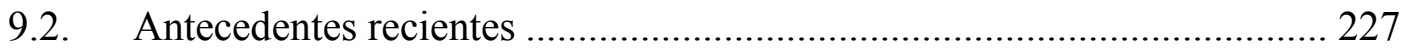




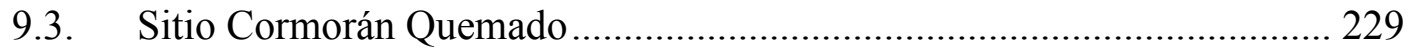

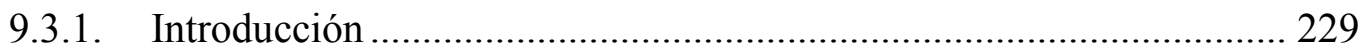

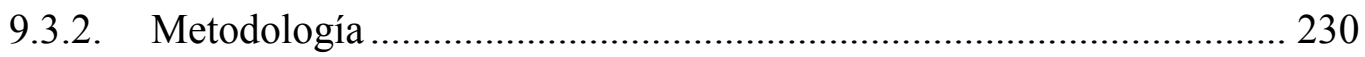

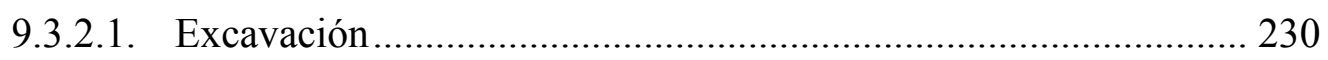

9.3.2.2. Recuperación de restos antracológicos ..................................... 231

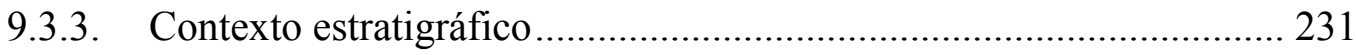

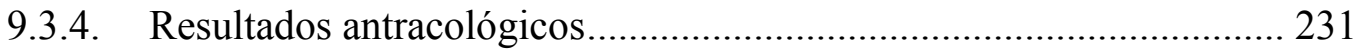

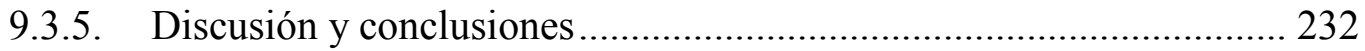

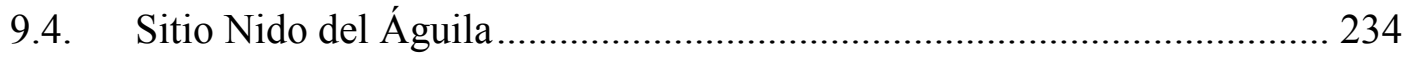

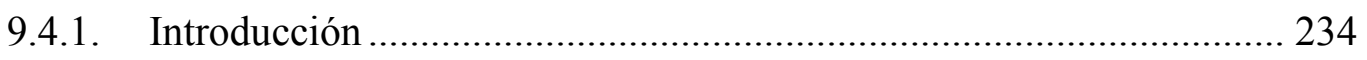

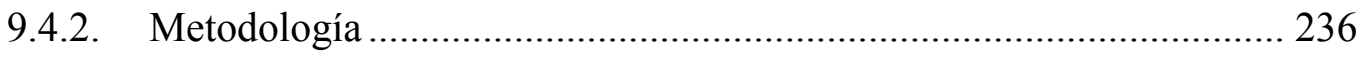

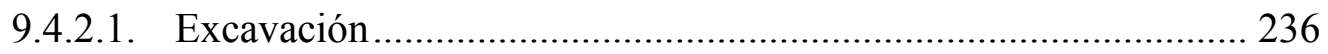

9.4.2.2. Recuperación de restos antracológicos ...................................... 237

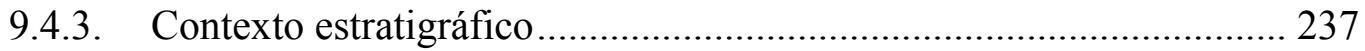

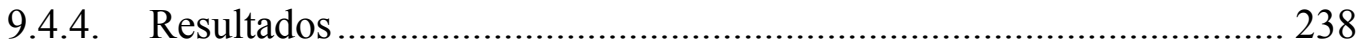

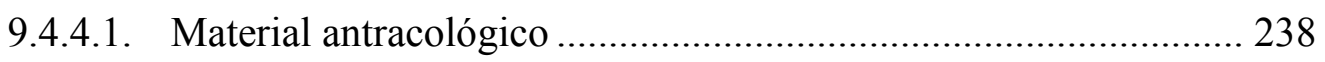

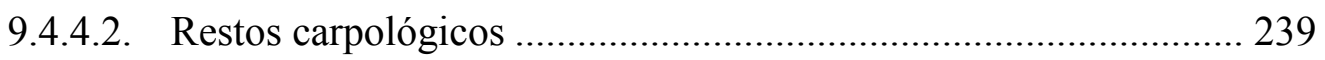

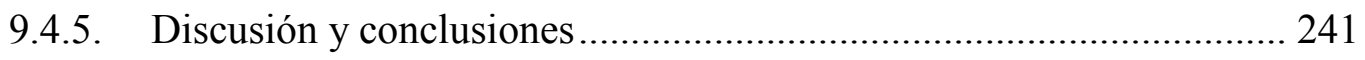

9.4.6. Análisis comparativo entre los taxa identificados en los sitios Cormorán

Quemado y Nido del Águila ......................................................................... 243

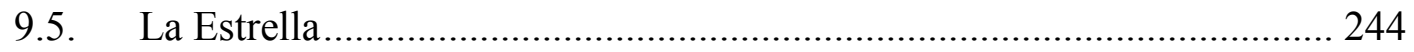

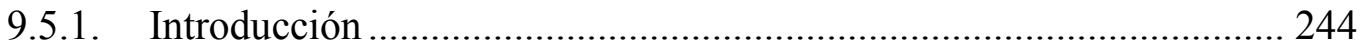

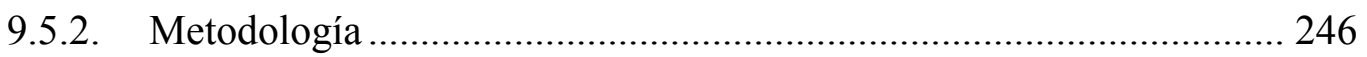

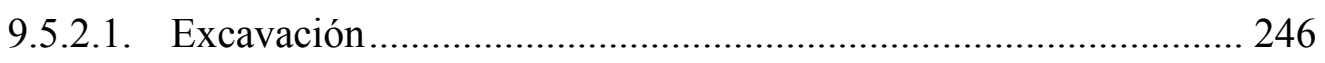

9.5.2.2. Recuperación de restos antracológicos ..................................... 246

9.5.3. Resultados antracológicos.............................................................. 246

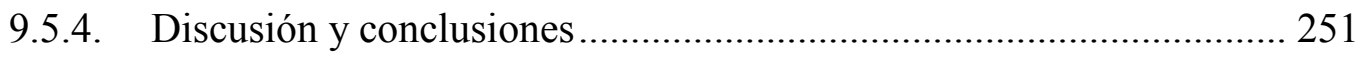

10. Registro arqueobotánico sector sur de la ría Deseado .............................. 253

10.1. Subsector Margen norte de la ría Deseado ............................................... 253

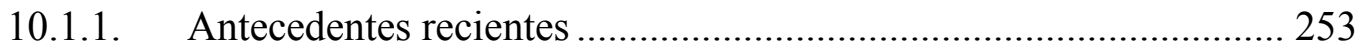

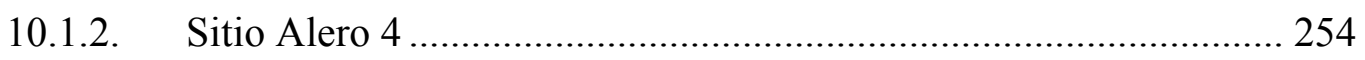

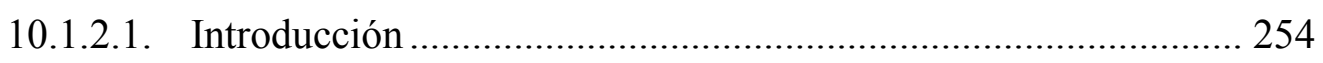


10.1.2.2. Metodología 257

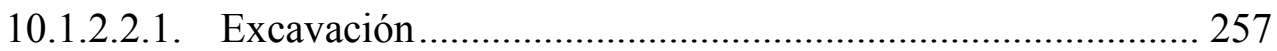

10.1.2.2.2. Recuperación de restos antracológicos .............................. 257

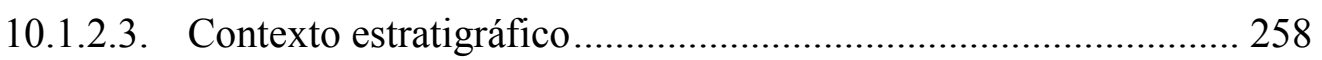

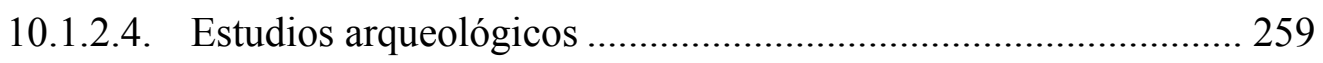

10.1.2.5. Resultados antracológicos.................................................... 259

10.1.2.5.1. Estructuras de combustión ................................................. 260

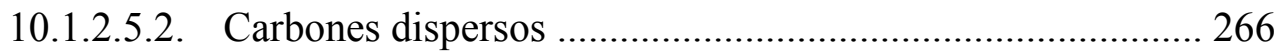

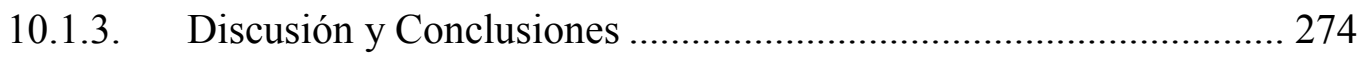

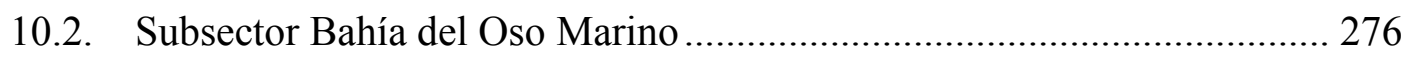

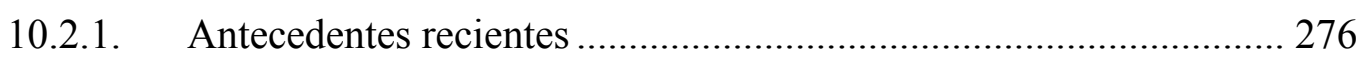

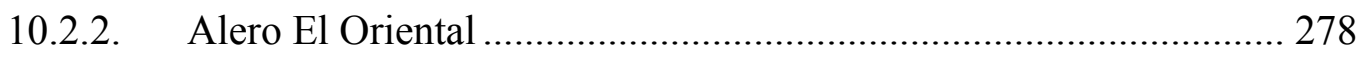

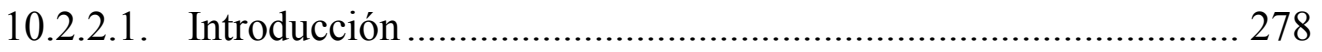

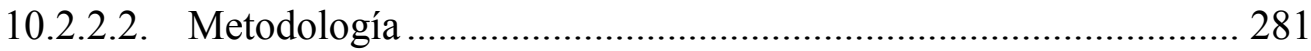

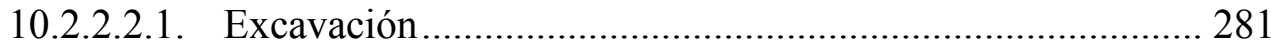

10.2.2.2.2. Recuperación de macrorrestos ............................................ 281

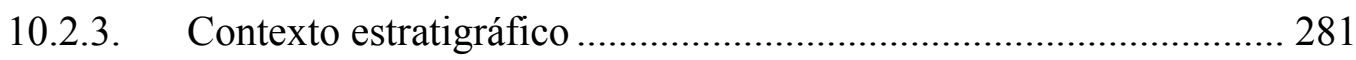

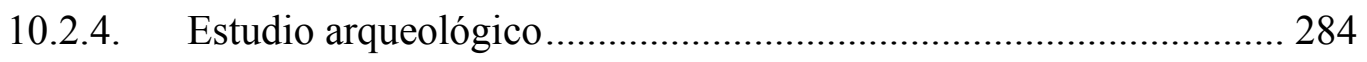

10.2.5. Resultados antracológicos ......................................................... 286

10.2.6. Discusión y conclusiones .............................................................. 299

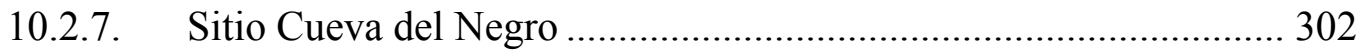

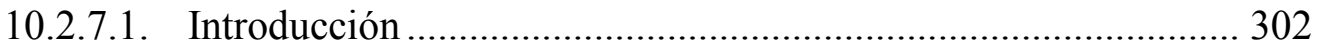

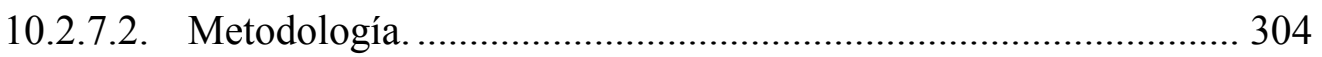

10.2.7.2.1. Excavación.......................................................................... 304

10.2.7.2.2. Recuperación de los restos antracológicos ......................... 304

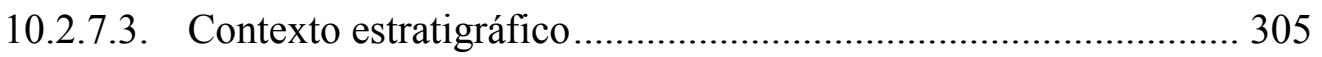

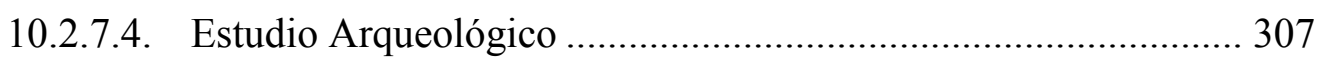

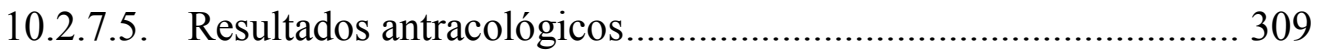

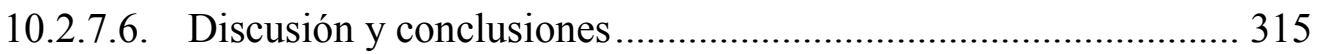

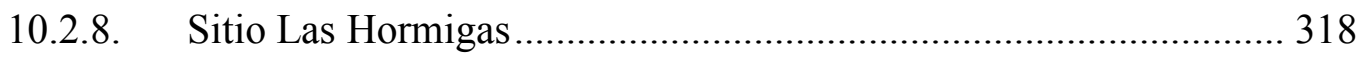

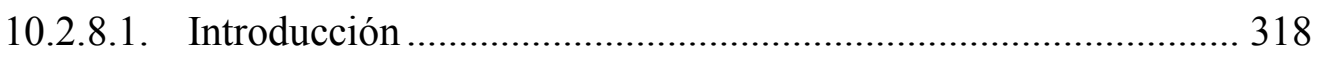

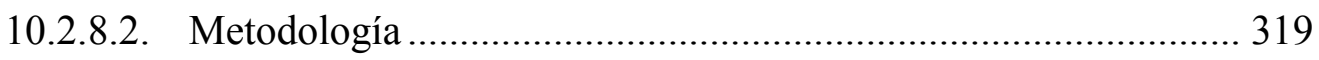


10.2.8.2.1. Excavación 319

10.2.8.2.2. Recuperación de restos antracológicos ............................... 319

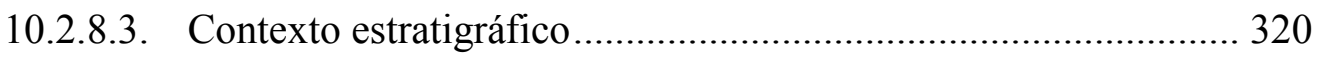

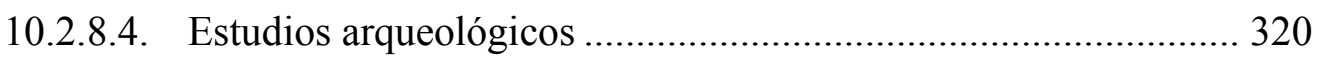

10.2.8.5. Resultados antracológicos.................................................... 321

10.2.8.6. Discusión y conclusiones ............................................................. 323

10.3. Subsector Isla Lobos.......................................................................... 324

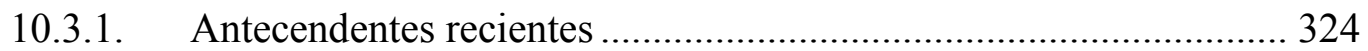

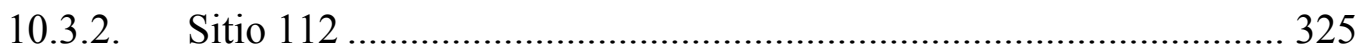

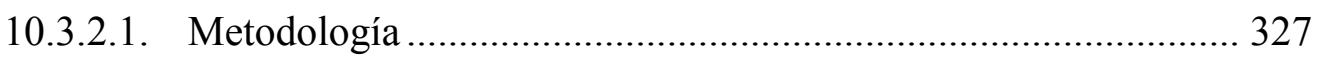

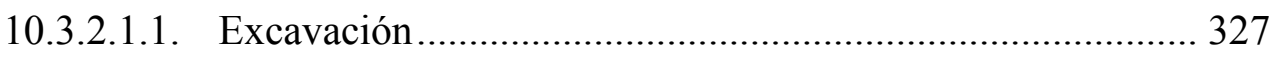

10.3.2.1.2. Recuperación de restos antracológicos .............................. 327

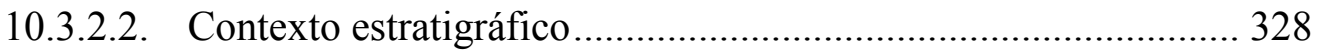

10.3.2.3. Resultados antracológicos........................................................ 328

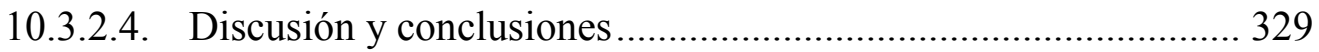

10.4. Subsector Punta Medanosa ........................................................................ 330

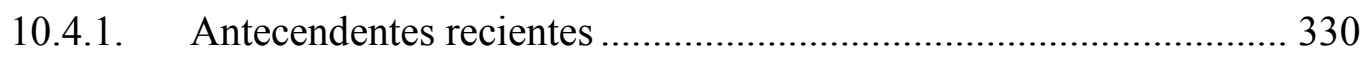

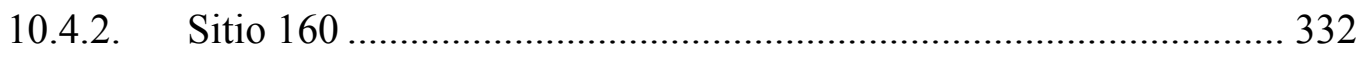

10.4.2.1. Metodología ........................................................................... 333

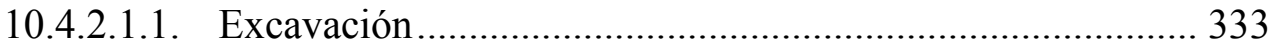

10.4.2.1.2. Recuperación de restos antracológicos ............................... 333

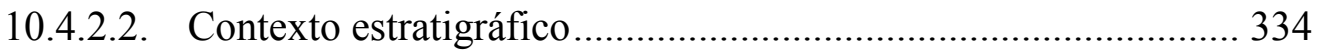

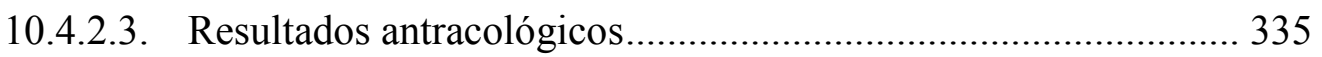

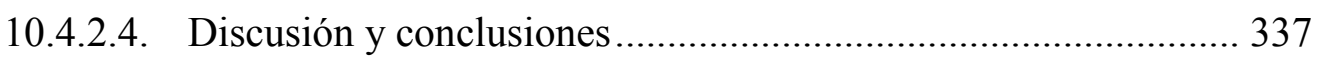

10.4.2.4.1. Ubicuidad de taxa en fogones y carbones dispersos del sector margen sur de la ría Deseado.................................................................... 338

11. Análisis de instrumentos de madera .................................................... 341

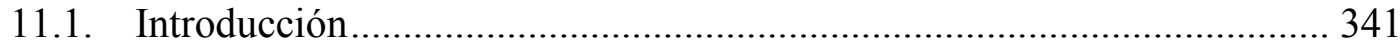

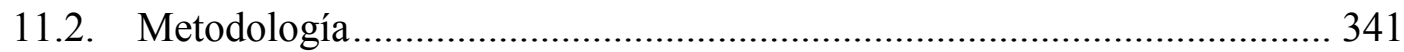

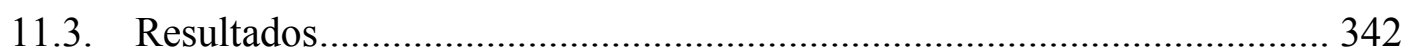

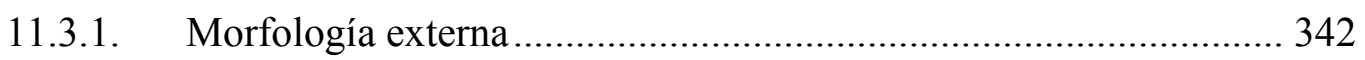

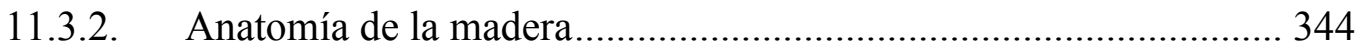




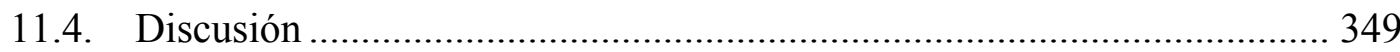

12. Colección de referencia para el análisis de microrrestos ........................ 355

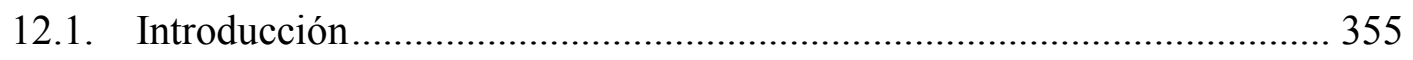

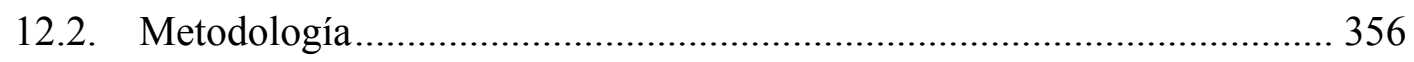

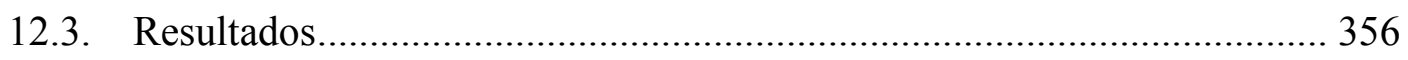

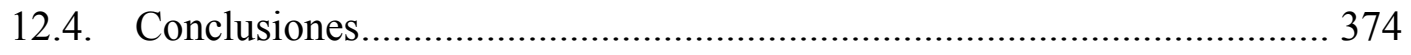

13. El procesamiento post colecta de los vegetales: molienda ....................... 377

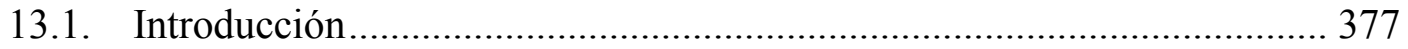

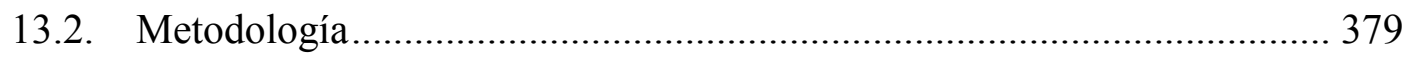

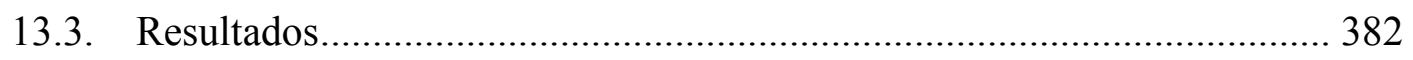

13.3.1. Revisión bibliográfica de sitios arqueológicos de Patagonia con

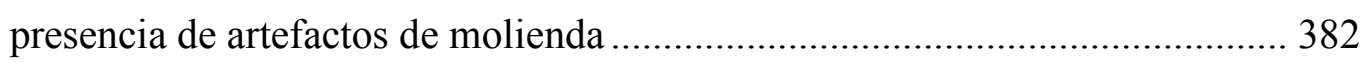

13.3.2. Prospección y registro de artefactos potencialmente utilizados para la molienda en CNSC (sector sur de la Ría Deseado)........................................ 384

13.3.3. Registro y análisis de instrumentos de la colección Museo del Hombre y su Entorno (Caleta Olivia) ........................................................ 387

13.3.4. Recuperación de microrrestos a partir de adherencias de artefactos de

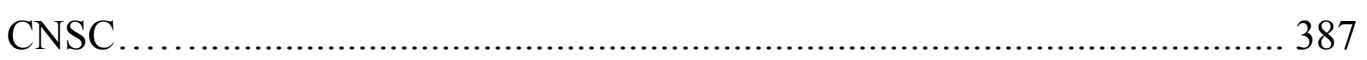

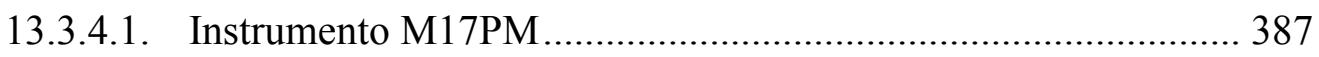

13.3.4.2. Resultados del instrumento M17PM....................................... 390

13.3.4.3. Identificación taxonómica de los microvestigios....................... 396

13.3.4.4. Resultados de los artefactos pertenecientes a la colección Museo

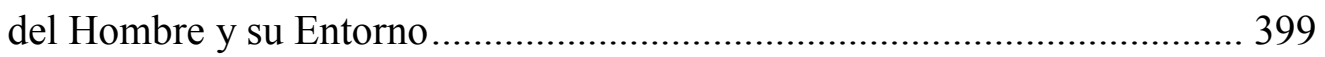

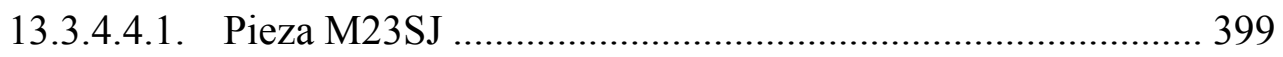

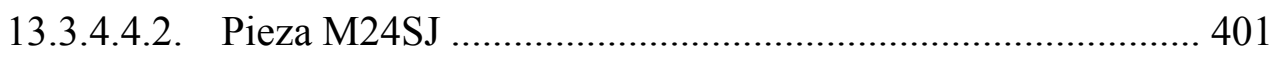

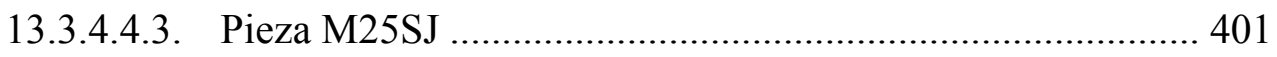

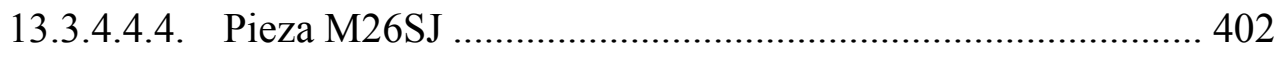

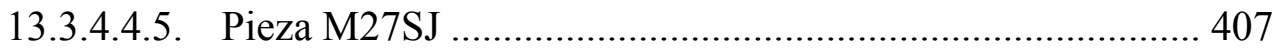

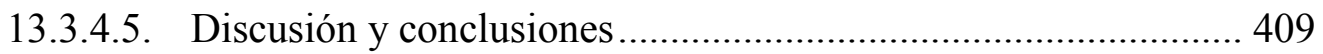

SECCIÓN III: DISCUSIÓN Y CONCLUSIONES.........................417

14. Discusión y Conclusiones ....................................................................... 415

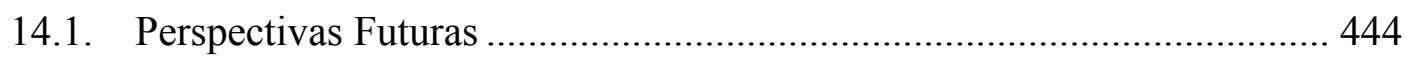




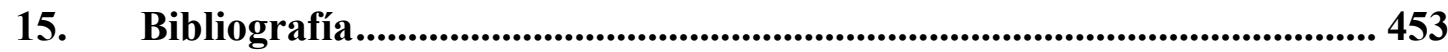




\section{Índice de figuras}

Figura 1.1. Mapa de la Costa Norte de Santa Cruz (franja de puntos) y distribución de los sitio analizados en la presente tesis

Figura 3.1. Distribución de la estepa arbustiva del Golfo San Jorge (rayado) y estepa de arbustos enanos (puntos) según (Oliva et al. 2001). Los triángulos indican los principales puntos de observación de vegetación de la presente tesis. Los números corresponden a los siguientes sitios arqueológicos con información palinológica: 1) Los Toldos; 2) La María; 3) La Martita. 35

Figura 3.2. Costa de Bahía Lángara, Golfo San Jorge (Fotografía de Verónica Trola). 36 Figura 3.3. Unidades geomorfológicas registradas por M. A. Zubimendi para el sector Cabo Blanco (Zubimendi 2010)

Figura 3.4. Estepa arbustiva del Golfo San Jorge, Cañadón León: A, vista general, B, en el cañadón arbustos de Schinus sp. 38

Figura 3.5. Estepa arbustiva del Golfo San Jorge, Cañadón León, en particular fotos de abustos: A, Beberis microphylla, B, Prosopidastrum globosum y C, Colliguaja integerrima.

Figura 3.6. Costa de la Localidad arqueológica de Cabo Blanco (Fotografía de Mikel Zubimendi)

Figura 3.7. Unidades geomorfológicas registradas por M. A. Zubimendi para el sector Cabo Blanco (Zubimendi 2010).

Figura 3.8. Laguna temporaria con aguas hipersalinas al norte de la localidad de Puerto Deseado. Vegetación con adaptación a suelos salobres. 42

Figura 3.9. Sarcocornia magellanica en los bordes de la laguna temporaria con aguas hipersalinas al norte de la ciudad de Puerto Deseado 42

Figura 3.10. Ephedra sp. en los bordes de la laguna temporaria con aguas hipersalinas al norte de la ciudad de Puerto Deseado.

Figura 3.11. Lycium sp. y Lepidophyllum cupressiforme a metros de la laguna temporaria con agua hipersalina al norte de la ciudad de Puerto Deseado.....

Figura 3.12. Margen norte de la ría Deseado, frente a la península Stokes, con suelos salobres: A, Sarcocornia, B Atriplex lampa y C, Berberis sp. 45 
Figura 3.13. Cañadón próximo a la ría Deseado, sobre margen norte en la Reserva Ría Deseado, donde se observa un parche de Mulguraea tridens. 46

Figura 3.14. Cañadón próximo a la ría Deseado, sobre margen norte, en la Reserva Ría

Deseado: A, Prosopis denudans y B, Colliguaja integerrima. 47

Figura 3.15. En las proximidades de la Estancia La Negrita se observan arbustos de Schinus sp. de gran altura atrás y Senecio filaginoides adelante (Fotografía de Aylén Capparelli). 48

Figura 3.16. Prosopis denudans de gran tamaño entre la Estancia La Negrita y la Estancia 8 de Julio (Fotografía de Aylen Capparelli). 48

Figura 3.17. Margen sur de la ría Deseado: A. Vista de la localidad de Puerto Deseado, B, Nardophyllum bryoides sobre sitios concheros, C, "Piedra toba" afloramientos de roca de la formación Bahía Laura con arbustos de Berberis sp. D, Chuquiraga erinaceae, E: Maihueniopsis darwinii y Senecio filaginoides.

Figura 3.18. Unidades geomorfológicas registradas para el sector sur de la ría Deseado por M. A. Zubimendi (Zubimendi 2010). 50

Figura 3.19. Punta Medanosa a $100 \mathrm{~m}$ sobre la línea de costa se observa un arbusto de Schinus sp. y un nido de Spheniscus magellanicus bajo el mismo. 52

Figura 3.20. Punta Medanosa. A. Se observan arbustos de Schinus sp. en la lejanía y adelante otros de menor altura como Senecio sp. B. Senecio $\mathrm{sp}$................................... 52 Figura 3.21. Grupo de guanacos (Lama guanicoe) en la estepa de CNSC..................... 55 Figura 3.22. Lobos marinos de un pelo Otaria flavescens: macho y hembra ................ 56 Figura 3.23. A: Cormorán de cuello negro (Phalacrocorax magellanicus) B: Cormorán

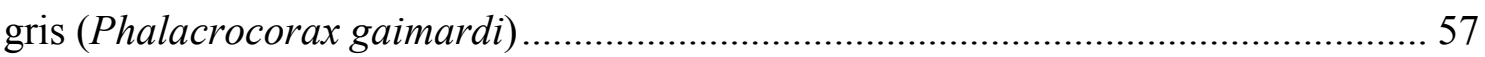

Figura 3.24. Paloma antártica (Chionis alba) y Lobo marino (Otaria flavescens) ........ 57

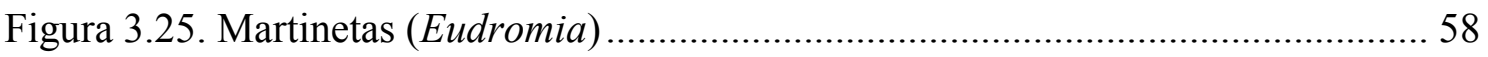

Figura 3.26. A y B: Colonia de pingüinos (Spheniscus magellanicus) en Punta

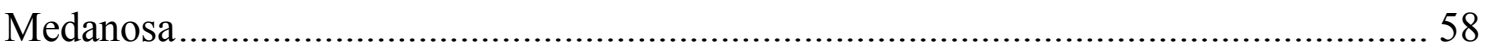

Figura 3.27. Área costa norte de Santa Cruz con los sectores de estudio delimitados: Golfo San Jorge, Cabo Blanco y Sur de la ría Deseado diferenciado en subsectores margen norte de la ría Deseado; Bahía del Oso Marino; Isla Lobos y Punta Medanosa. El triángulo muestra los sitios arqueológicos estudiados en el proyecto CNSC. 68 
Figura 4.1. Rutas seguidas por los autores de las fuentes bibliográficas de primer orden consultadas y ubicación geográfica de las citas extraídas de fuentes de segundo orden. De 15 autores no se pudo precisar el itinerario de viaje completo. 79 Figura 4.2. Gráfico con la frecuencia absoluta de taxa por familia registrados con menciones de uso. 81

Figura 4.3. Gráfico que registra las cateogorías de uso descriptas en las fuentes bibliográficas 82

Figura 5.1. Localidades de Puerto Deseado y Tellier. 114 Figura 5.2. Gráfico en el que se registran la frecuencia abosluta de taxa por familia mencionados por los pobladores locales entrevistados. 117

Figura 5.3. Gráfico donde se registra el porcentaje de taxa mencionados por categorías de uso 118

Figura 5.4. Don Miranda habitante de La Rosita, meseta central de Santa Cruz, mostrando el almacenamiento de leña mogotes (Azorella monantha Clos.) y su uso como combustible en la meseta de Santa Cruz (Foto y registro de Mikel Zubimendi).123 Figura 5.5. Entrevistados identificando y percibiendo las plantas de la zona. A. Pocho G. y su nieto (Puerto Deseado), B., Laura (Puerto Deseado) C. Pocho percibiendo Acantholippia seriphioides, D, José B. con una mata de Clinopodium darwinii (Tellier), E. Fortunato L. con Acantholippia seriphioides y Clinopodium darwnii que traía de su chacra de Tellier. 126

Figura 6.1. Distribución de los sitios arqueológicos con restos arqueobotánicos identificados taxonómicamente. 1 y 5 Lema et al. 2012; 2 Ancibor 1981/1982 y Fernández1981/82; 3 Podestá y Pereda 1979; Ancibor 1988/1990; 6 Crivelli Montero et al. 1996; Rivera 1996, Urrutia y Bogazi 1996 y Palacios 2007; 7 Pérez y Erra 2011; 8 Capparelli y Prates 2010; 9-12 Ortega y Marconetto 2009, 2012; 13 Prates et al. 2011 y Capparelli y Mange 2014; 14 Outes 1915; 15 Casamiquela 1960; 16 Nacuzzi y Pérez de Micou 1983/85, Pérez de Micou et al. 1992; 17 Marconetto 2002; 18 Arrigoni 2002; 19 Gradín 1978; 20 Pérez de Micou et al. 2009; 21 Ciampagna 2012; 22 Capparelli et al. 2009 y Ciampagna et al. 2011; 23 Gradín y Aguerre 1994; 24 Caruso y Capparelli 2013; 25 Aschero 1981/1982; 26 Mehl y Franco 2009.

Figura 6.2. Frecuencia de taxa por familias identificadas en los macro y microvestigios de Patagonia continental. 154 
Figura 7.1. Colecta de especies en el Cañadón León, Golfo San Jorge (foto tomada por Verónica Trola)

Figura 7.2. Tacos de madera cubiertos de arena en crisoles y su carbonización controlada en una mufla.

Figura 7.3. Carbonización controlada de frutos y hojas de Schinus sp. A: fruto y hoja de Schinus sp. en estado fresco, material de herbario; B: Fruto de Schinus sp. sometido a una atomósfera reductora (en un recipiente con arena) y a $300{ }^{\circ} \mathrm{C}$; C: fruto y hoja de Schinus sp. carbonizado.

Figura 7.4. Araucaria araucana: A, CT, Anillos de crecimiento visibles; B, CLtg. Radios uniseriados cortos; C, CLrd. Campo de cruzamiento araucarioide, radio heterogéneo.

Figura 7.5. Schinus sp.: A, CT, Vasos agrupados frecuentes, múltiples cortos y largos en disposición radial; B, CLtg. Espesamiento reticulado de los vasos, placa de perforación oblicua, radios 1-3 seriados homogéneos; C, CLrd. Espesamiento reticulado, placa de perforación simple, células del radio cuadradas y erectas.

Figura 7.6. Baccharis darwinii: A, CT Vasos en banda tangencial, parénquima apotraqueal difuso en agregados. B, CTtg Radios 1-3 seriados, engrosamiento helicoidal de los vasos y placa oblicua; C, CLrd, células erectas y cuadradas 174 Figura 7.7. Chuquiraga avellanedae: A, CT vasos en banda tangencial y exclusivamente solitarios; B, CLTg radios con células elongadas 1-3 seriados C, CLTg placa de perforación simple. 175

Figura 7.8. Lepidophyllum cupressiforme: A, CT, Anillos de crecimiento demarcados, porosidad semicircular, vasos en bandas tangenciales en leño temprano y diagonal en el tardío; B, CLTg. Radios 4-10 (4) seriados, con células elongadas, fibras no septadas presentes.

Figura 7.9. Nardophyllum bryoides: A, CT, Porosidad difusa, vasos exclusivamente solitarios en disposición radial y diagonal, de contorno angular; B, traqueidas vasculares vasicéntricas con punteaduras con reborde conspicuo, radios uniseriados. 176 Figura 7.10. Nassauvia sp.: A, CT, Anillos de crecimiento demarcado, porosidad semicircular, vasos solitarios, paquete de fibras de pared muy gruesa en el leño temprano y de paredes más delgadas en el leño tardío; B, CLTg, fibrotraqueidas con punteaduras con reborde conspicuo. 
Figura 7.11. Senecio sp. A, CT Porosidad difusa, vasos en patrón diagonal y radial, de contorno muy angular; B, CLTg radios con células elongadas, grandes; 178 Figura 7.12. Berberis sp. A, CT, Anillos de crecimiento demarcados, vasos en bandas tangenciales y diagonal; B, CLtg. Radios multiseriados largos, espesamiento reticulado de los vasos y placa de perforación oblicua. C, CLrd., células del radio cuadradas erectas y procumbentes mezcladas. 179 Figura 7.13. Atriplex sp. A, CT: Cámbium anómalo, floema incluso concéntrico inmerso en tejido parenquimático; B, CLtg. Células parenquimáticas fusiformes con dos células por serie parenquimática. 180 Figura 7.14. Colliguaja integerrima: A, CT, anillo de crecimiento demarcado y vasos en banda tangencial en leño temprano; B, CLTg, radios uni y biseriados y engrosamiento helicoidal de los vasos. C, CLrd, células del radio erectas. 181 Figura 7.15. Adesmia boronioides: A, CT vasos en patrón diagonal a dendrítico; B, CLTg radios multiseriados y engrosamiento helicoidal de los vasos; C, CLrd células procumbentes, cuadradas y erectas

Figura 7.16. Prosopidastrum globosum. A, CT. Anillos de crecimiento demarcados por parénquima marginal, Vasos en disposición diagonal y radial. Parénquima axial paratraqueal confluente; B, CLTg. Radios uniseriados homogéneos tipo II; C, CLrd. Células del radio procumbentes.

Figura 7.17. Prosopis denudans: A, CT, Parénquima axial marginal, parénquima paratraqueal confluente, vasos solitarios y múltiples cortos. B, CLTg. Radios 1-3 seriados largos; C, CLrd. Células del radio procumbentes, erectas y cuadradas mezcladas.

Figura 7.18. Fabiana imbricata A: CT: Vasos en disposición diagonal. B: CLT: Radios uniseriados. 185

Figura 7.19. Lycium sp. A, CT, vasos en disposición dendrítica, parénquima apotraqueal difuso en agreados; B, CLTg, radios uniseriados cortos y largos de tipo heterogéneos III; C, CLrd., células cuadradas, erectas y procumbentes mezcladas. 186 Figura 7.20. Mulguraea tridens: A, CT, anillos de crecimiento demarcado por porosidad semicircular; B, CLTg. radios 1-3 seriados, engrosamiento helicoidal de los vasos; C, CLrd, radios con células cuadradas, erectas y procumbentes mezcladas. 
Figura 7.21. Lycium A: $400{ }^{\circ} \mathrm{C}$ y B: $700{ }^{\circ} \mathrm{C}$; Schinus C: $400{ }^{\circ} \mathrm{C}$ y D: $700^{\circ} \mathrm{C}$; Diostea juncea $\mathrm{E}: 400{ }^{\circ} \mathrm{C}$ y F: $700{ }^{\circ} \mathrm{C}$. La flecha señala el rasgo diagnóstico: abertura en anillo 200

Figura 7.22. Berberis sp 8 a $12 \%$ de humedad A: ojos en radios a $400{ }^{\circ} \mathrm{C}$ y B: ojos en radios a $700{ }^{\circ} \mathrm{C}$ 201

Figura 7.23. Colliguaja integerrima 8 a $12 \%$ de humedad A: no se observan modificaciones a $400{ }^{\circ} \mathrm{C} \mathrm{B}$ : Se observan aberturas en en radios a $700{ }^{\circ} \mathrm{C}$. 202 Figura 7.24. Maytenus disthica A: $400{ }^{\circ} \mathrm{C}, 8$ a $12 \%$ de humedad, B: $700{ }^{\circ} \mathrm{C}, 8$ a $12 \%$ de humedad; C: $400{ }^{\circ} \mathrm{C}$ a $0 \%$ de humedad y D $700{ }^{\circ} \mathrm{C}$ a $0 \%$ de humedad. No se observaron aberturas que evidenciaran temperatura o cambios de humedad. .............................. 203

Figura 7.25. Vitrificación en Suaeda sp. a 0\% de humedad y a $400{ }^{\circ} \mathrm{C}$....................... 204 Figura 8.1. Vista del primer escalón del flanco de meseta y sobre el margen izquierdo la

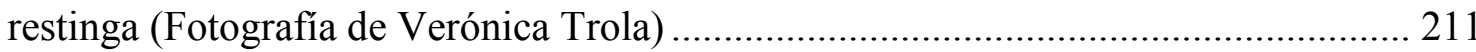

Figura 8.2. Ubicación del Sitio Palo Alto................................................................... 212

Figura 8.3. Vista general del sitio Palo Alto cuadrícula 1,2 y sondeo 1 (Fotografía tomada por Verónica Trola).

Figura 8.4. Esquema de planta de la excavación del sitio Palo Alto. 213

Figura 8.5. Esquema estratigráfico del sitio Palo Alto (cedido por M. A. Zubimendi) 217 Figura 8.6. Carbón identificado del nivel 1, sondeo 1, sitio Palo Alto $(\mathrm{n}=1) \ldots \ldots \ldots \ldots . . .218$ Figura 8.7. Carbones identificados del nivel 2, sondeo 1, sitio Palo Alto (submuestra $\mathrm{n}=$ 40).

Figura 8.8. Carbones identificados del nivel 3, sondeo 1, sitio Palo Alto (submuestra $\mathrm{n}=$ $34)$ 220

Figura 8.9. Carbones identificados del nivel 4, sondeo 1, sitio Palo Alto (submuestra $\mathrm{n}=$ $50)$ 221

Figura 8.10. Carbones identificados del nivel 5, sondeo 1, sitio Palo Alto (submuestra $n$ $=60)$. 222

Figura 8.11. Ubicuidad de los taxa identificados en los 5 niveles analizados 223

Figura 8.12. Correlación entre cantidad y peso de carbón de madera recuperado por nivel arqueológico en el sitio Palo Alto. 224

Figura 9.1. Cormoranera detrás del Tómbolo Cabo Blanco 229

Figura 9.2. Ubicación del sitio Cormorán Quemado. 230 
Figura 9.3. Carbones identificados en el fogón Cormorán Quemado submuestra $(\mathrm{n}=$ 177)

Figura 9.4. Ubicación del sitio Nido del Águila. 235

Figura 9.5. Foto del sitio Nido del Águila (Fotografía tomada por Miguel Ángel Zubimendi). 235

Figura 9.6. Esquema de planta del área excavada del sitio Nidio del Águila (Zubimendi 2006). 236

Figura 9.7. Perfil estratigráfico del sitio Nido del Águila 238

Figura 9.8. Carbones identificados en el fogón Nido del Águila, cuadrícula 1 y 2 ,

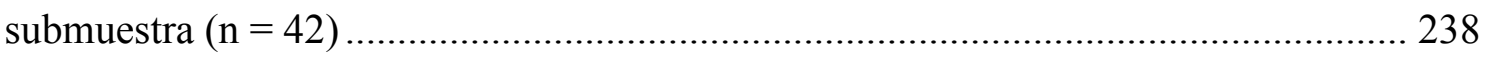

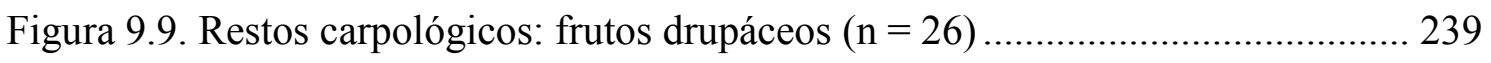

Figura 9.10. Hojas carbonizadas halladas en el fogón ............................................... 240

Figura 9.11. Ubicuidad porcentual de los taxa identificados en los dos fogones analizados del sector Cabo Blanco. 244

Figura 9.12. Ubicación sitio La Estrella 245

Figura 9.13. Distribución espacial y área excavada del sitio La Estrella ( Zubimendi 2006) 245

Figura 9.14. Carbones dispersos identificados en la cuadrícula 1, nivel entre 10-20 cm del sitio La Estrella (submuestra $\mathrm{n}=9$ ).

Figura 9.15. Carbones dispersos identificados en la cuadrícula 2, nivel 10-20 cm (submuestra $\mathrm{n}=28$ ). 248

Figura 9.16. Carbones dispersos de la cuadrícula 3, nivel 10-20 $\mathrm{cm}(\mathrm{n}=4)$. 249

Figura 9.17. Carbones dispersos de la cuadrícula 4, nivel 10-20 cm, (submuestra $\mathrm{n}=14$ ) 249

Figura 9.18. Ubicuidad \% de los taxa identificados en las cuadrículas 1 a 4 del sitio La Estrella 250

Figura 9.19. Correlación entre cantidad y peso de carbón de madera recuperado por cuadrícula Sitio La Estrella 251

Figura 10.1. Cañadón Torcido, margen norte de la Ría Deseado (Foto Lucía Mazzitelli).

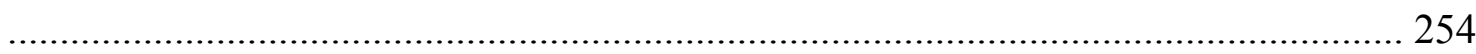

Figura 10.2. Ubicación del sitio Alero 4. 255 
Figura 10.3. Vista panorámica del sitio Alero 4 y en el fondo la Ría Deseado (Fotografía

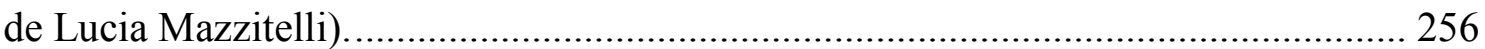

Figura 10.4. Área excavada y distribución espacial del Alero 4 ................................ 256

Figura 10.5. Zaranda de aluminio con riel confeccionada por Hugo E. Ciampagna.... 258 Figura 10.6. Estratigrafía sitio Alero 4, unicomponente (Fotografía de P. Ambrústolo). 259

Figura 10.7. Carbones identificados del Fogón A del sondeo 25 x $50 \mathrm{~cm}$ nivel $2 \mathrm{~d}$ (submuestra $\mathrm{n}=27$ ). 261

Figura 10.8. Carbones identificados del fogón B, cuadrícula 5, nivel 2e, submuestra ( $\mathrm{n}=$ $10)$. 262

Figura 10.9. Carbones identificados del Fogón C, cuadrículas 6 y 7 entre niveles 2 b y c (submuestra $\mathrm{n}=120$ ). 263

Figura 10.10. Ubicuidad de los taxa identificados en los fogones A, B y C del sitio Alero 4 265

Figura 10.11. Correlación entre cantidad y peso de carbón de madera recuperado por cuadrícula Sitio Alero 4. 265

Figura 10.12. Carbones dispersos identificados en las cuadrículas 6 y 7 en la capa 1 (submuestra $\mathrm{n}=29$ carbones). 266

Figura 10.13. Carbones dispersos identificados en las cuadrículas 6 y 7 , nivel 2 a (submuestra $\mathrm{n}=44$ ). 267

Figura 10.14. Carbones dispersos identificados en las cuadrículas 6 y 7, nivel 2 b, sitio Alero 4 (submuestra $\mathrm{n}=39$ ). 268

Figura 10.15. Carbones dispersos identificados en las cuadrículas 6 y 7 , el nivel 2 c submuestra $(n=40)$. 269

Figura 10.16. Carbones dispersos identificados en las cuadrículas 6 y 7, nivel 2 d del sitio Alero 4 (submuestra $n=36$ ). 270

Figura 10.17. Carbones dispersos identificados en las cuadrículas 6 y 7, nivel 2 e, sitio Alero 4 (submuestra $\mathrm{n}=36$ ). 271

Figura 10.18. Carbones dispersos identificados de las cuadrículas 6 y 7 , nivel $2 \mathrm{f}$ del sitio Alero 4 (submuestra $\mathrm{n}=31$ ). 272 Figura 10.19. Ubicuidad \% de los taxa identificados en los carbones dispersos, capa 1, niveles 2 a-f. 
Figura 10.20. Correlación entre el número total de carbones y el peso total de los mismos de carbones dispersos para el sitio Alero 4 .................................................. 274

Figura 10.21. Subsector Bahía del Oso Marino al sur de la ría Deseado ..................... 277

Figura 10.22. Ubicación del sitio Alero El Oriental................................................. 279

Figura 10.23. Afloramiento Bahía Laura donde se encuentra el Alero El Oriental (Foto

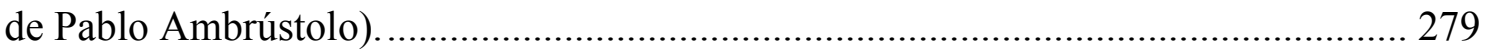

Figura 10.24. . Esquema de planta donde se observan la totalidad de los fogones hallados

Figura 10.25. Vista de la estratigrafía en cuadrícula 1, perfil Oeste, sitio Alero El Oriental 282

Figura 10.26. Fogón C, la flecha señala un resto de Nacella magellanica 287

Figura 10.27. Fogón K, se observa restos de carbones asociados a mitílidos. Los carbones de este fogón fueron utilizados para un fechado radiocarbónico (Fotografía Pablo Ambrústolo). 288

Figura 10.28. Carbones identificados del Fogón A, cuadrícula 1, componente superior, Alero El Oriental (submuestreo $\mathrm{n}=30$ ). 289

Figura 10.29. Carbones identificados del Fogón B, de la cuadrícula1, componente superior del Alero El Oriental (submuestra $n=94)$. 290

Figura 10.30. Carbones identificados del fogón C, cuadrícula 1, del componente superior, Alero El Oriental (submuestra $\mathrm{n}=112$ ). 291 Figura 10.31. Carbones identificados del fogón D, cuadrícula 1, componente superior Alero El Oriental (submuestra $\mathrm{n}=25$ ). 292

Figura 10.32. Carbones identificados en el fogón E, de la cuadrícula 2, componente superior, Alero El Oriental (submuestra $n=19$ ). 293

Figura 10.33. Carbones identificados en el fogón F, cuadrícula 3, componente superior, Alero El Oriental 294

Figura 10.34. Carbones identificados en el fogón L, cuadrícula 6, componente medio Alero El Oriental, (submuestra $\mathrm{n}=23$ ). 295

Figura 10.35. Carbones identificados en el fogón H, cuadrícula 2 componente inferior, Alero El Oriental (submuestra $\mathrm{n}=25$ ). 296

Figura 10.36. Carbones identificados en el fogón J, cuadrícula 3, componente inferior Alero El Oriental (submuestra $n=36$ ). 297 
Figura 10.37. Ubicuidad de los taxa identificados en los carbones de los fogones analizados del Alero El Oriental (componente inferior medio y superior). 298 Figura 10.38. Correlación entre el número de fragmentos de carbones provenientes de fogones y el peso total, Alero El Oriental. 299

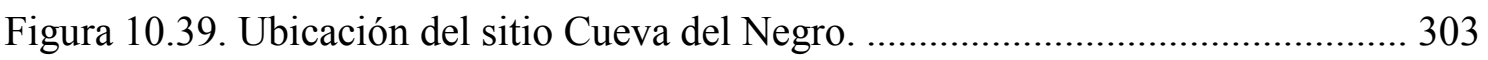

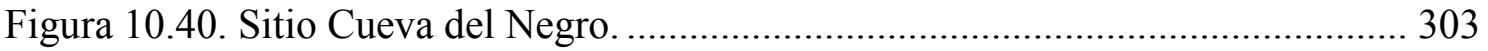

Figura 10.41. Esquema de planta del sitio Cueva del Negro....................................... 304

Figura 10.42. Representación de la secuencia estratigráfica definida en la cuadrícula 1 y columna de muestreo de la Cueva del Negro (Zubimendi et al. 2011). 306 Figura 10.43. Vista de los niveles 1 y 2 excavados de la columna realizada en la cuadrícula 1 (Zubimendi et al. 2011). 307

Figura 10.44. Carbones dispersos identificados de la capa 1 , nivel 1 de la columna estratigráfica de Zubimendi et al. (2011) (submuestra $\mathrm{n}=4$ ). 309

Figura 10.45. Carbones dispersos identificados en la capa 2, nivel 3, de la columna de muestreo de Zubimendi et al. (2011) (submuestra $\mathrm{n}=32$ ). 310 Figura 10.46. Carbones dispersos identificados en la capa 3, nivel 9, de la columna estratigráfica de Zubimendi et al. (2011) (submuestra $\mathrm{n}=31$ ).

Figura 10.47. Carbones dispersos identificados en la capa 4, nivel 17, de la columna de muestreo de Zubimendi et al. (2001) (submuestra $\mathrm{n}=21$ ). 312 Figura 10.48. Carbones dispersos identificados en la capa 5, nivel 23, de la columna de muestreo de Zubimendi et al. (2011) (submuestra $n=20$ ). 313 Figura 10.49. Ubicuidad \% de los carbones dispersos analizados en los niveles dentro de las capas 1 a 5 del sitio Cueva del Negro.

Figura 10.50. Correlación entre número de fragmentos de carbones dispersos y peso total de los mismos, niveles analizados de las capas 1 a 5, sitio Cueva del Negro ...... 314

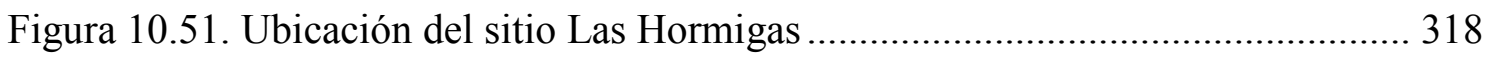

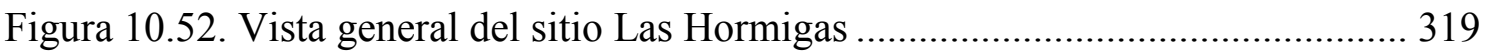
Figura 10.53. Perfil estratigráfico sitio Las Hormigas (Hammond 2014).................... 320 Figura 10.54. Carbones dispersos identificados del cuadrante A, nivel 2, Sitio Las Hormigas (submuestra $\mathrm{n}=25$ ).

Figura 10.55. Carbones dispersos, nivel 2, cuadrante C, sitio Las Hormigas (submuestra $\mathrm{n}=34)$ 322 
Figura 10.56. Ubicuidad \% de los taxa identificados de los carbones dispersos de la

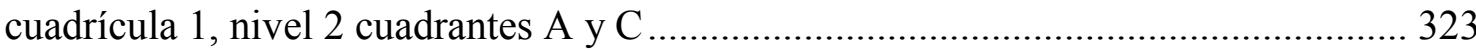

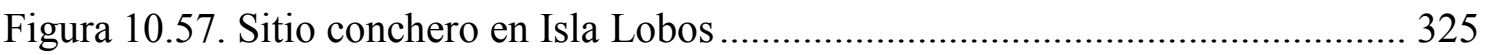

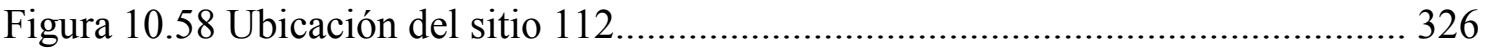

Figura 10.59. Perfil noreste del sitio 112 en Isla Lobos (Fotografía tomada por Heidi

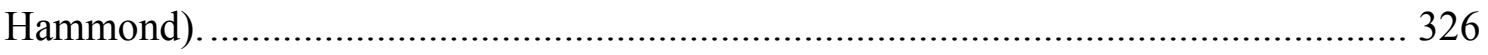

Figura 10.60. Sedimento gris por debajo de la lente de restos malacológicos, sitio 112

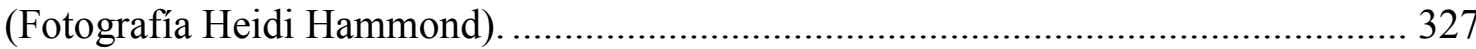

Figura 10.61. Perfil estratigráfico sitio 112 (Hammond 2014)................................... 328

Figura 10.62. Carbones dispersos identificados en el sitio 112 (submuestra $n=17$ ). . 329

Figura 10.63. Colonia de pingüinos de Punta Medanosa y un arbusto de Schinus

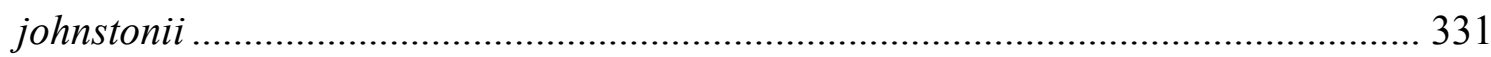

Figura 10.64. Sitios concheros en Punta Medanosa.................................................... 332

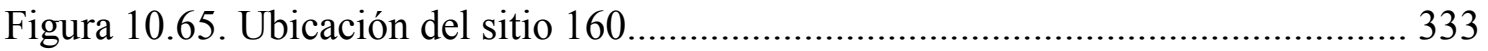

Figura 10.66. Vista del Sondeo 1, perfil sudoeste, sitio 160 (Fotografía de Hedi

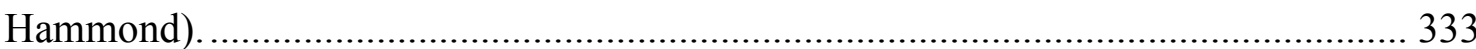

Figura 10.67. Perfil estratigráfico sitio 160 (Hammond 2014). .................................. 335

Figura 10.68. Carbones identificados en nivel 3 superior, sitio conchero 160

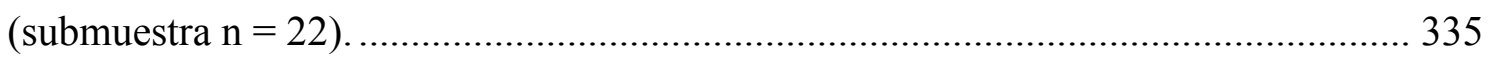

Figura 10.69. Carbones dispersos en el nivel 3 inferior, Sitio 160 (submuestra $n=25$ ). 336

Figura 10.70. Ubicuidad \% de los carbones dispersos de los niveles 3 superior e inferior del sitio 160

Figura 10.71. Ubicuidad de los taxa identificados en todos los fogones registrados en el sector sur de la ría Deseado (Alero El Oriental y Alero 4). 338 Figura 10.72. Ubicuidad de los carbones dispersos de los sitios analizados del sector sur de la ría Deseado. 339

Figura 11.1. A y B fragmento de arpón, se observan líneas paralelas de la manufactura 343

Figura 11.2. Vista de los cabezales de arpón recuperados en el sitio Cueva del Negro. Referencias: a) 344 
Figura 11.3. Madera del arpón en CT mostrando porosidad subcircular, anillos de crecimiento demarcado (corchete), vasos en bandas tangenciales festoneadas (leño temprano), y con ordenamiento diagonal dendrítico (leño tardío) (microscopio de incidencia) 346

Figura 11.4. Vasos agrupados en CT (microscopio de transparencia). A Madera del arpón. B, Material de referencia Berberis sp. 347 Figura 11.5. Radios de dos tamaños distintos, radios 1-3 seriados, radios grandes comúnmente 4-8 seriados (más comúnmente 5 o 6 células de ancho), en CLtg. A. Madera del arpón (microscopio luz de incidencia). B, material de referencia Berberis sp. (microscopio de transparencia). 348 Figura 11.6. Madera del arpón en corte Lg, Rd.: A, mostrando placa de perforación simple (microscopio de transparencia); B, punteaduras intervasculares, opuestas y alternas (microscopio de transparencia); C, engrosamientos helicoidales (microscopio de transparencia) y $\mathrm{D}$, células cuadras o erectas y procumbentes (microscopio de incidencia). 349

Figura 11.7. Células procumbentes (microscopio de transparencia) en corte Lg. Rd. A: madera de arpón. B: material de referencia Berberis sp.

Figura 12.1. Acantholippia seriphioides A. 100X. B.400X. C. 400X. D 400X., Adesmia boronioides E 100X, F 100X, Adesmia volckmanii G 100X, H 400X, Alstroemeria aurea I 100X, J 400X, K 400X, Ameghinoa patagonica L 400X, LL 400X, M 400X, Anarthropyllum rigidum N 100X, N 400X, Apium australe O 100X, P 400X. 369 Figura 12.2. Cyclospermum leptophyllum var. leptophyllum A 100X, Araucaria araucana B 100X, C 400X, D 400X, Arjona patagonica E 100X, F 100X, G 400X, H 400X, Arjona tuberosa I 400X, J 400X, Atriplex lampa K 100X, L 400X, Azorella monantha LL 400X, M 400X, N 400X, Azorella trifurcata N 100X, Benthamiella patagonica $\mathrm{O} 400 \mathrm{X}, \mathrm{P} 400 \mathrm{X}$. Escala $=500 \mu \mathrm{m}$ 370 Figura 12.3. Berberis empetrifolia A 100X, B 400X, C 400X, D 400X, Berberis sp. E 400X, F 400X, Brachyclados caespitosus G 400X, H 400X, I 400X, 400X, Bromus catharticus K 100X, Dysphania oblanceolata L 400X, Dysphania sp. LL 100X, M 400X, N 400X, Chuquiraga avellanedae N 100X, O 100X, P 400X. Escala $=500 \mu \mathrm{m}$ 
Figura 12.4. Colliguaja integerrima A 100X, Condalia microphylla B 100X, C 400X, Descurainia richardsoni D 400X, E 400X, F 400X, Diposis patagonica G 400X, Discaria articulata H 400X, I 400X, Empetrum rubrum J 400X, K 400X, Ephedra ochreata L 400X, LL 400X, Eupatorium M 400X, N 400X, Fabiana imbricata Ñ 400X, O 400X Fabiana peckii P 400X. Escala $=500 \mu \mathrm{m}$ 372

Figura 12.5 Glycyrrhiza astragalina A 100X, Grindelia chiloensis B 400X, Gunnera magellanica C 400X, D 400X, Juncus balticus E 100X, Larrea ameghinoi F 400X, Lycium chilense G 100X, Mimulus glabratus H 400X, Mulguraea tridens I 100X, J 400X, Mulinum sp. K 100X, Nardophyllum sp. L 100X, Oenathera sp. LL 400X, Nassauvia glomerulosa M 400X, Oxalis compacta N 400X, Prosopis sp. N 400X, Sarcocornia sp. O 100X, Senecio filaginoides P 400X. Escala $=500 \mu \mathrm{m}$ 373 Figura 12.6. Schinus sp. A 100X, B 400X, Retanilla patagonica C 100X, Tristagma sp. D $100 X$. Escala $=500 \mu \mathrm{m}$ 374

Figura 13.1. Bolsa con ampolla Biomed, hojas y mango de bisturí y frascos con etiqueta de esterilización 381

Figura 13.2. A: Raspado sobre los poros del artefacto lítico; B: Se observa la succión mediante pipeta sobre los mismos poros.

Figura 13.3. . Mapa de sitios con presencia de artefactos de molienda. En el mapa se muestran también los artefactos de molienda analizados en esta tesis........................... 384 Figura 13.4. Sitio Médano 1, conchero en médano (Foto de H. Hammond) ................ 388 Figura 13.5. Vegetación por detrás de la línea de concheros y costa, en Punta Medanosa 389

Figura 13.6. Instrumento de molienda M17PM 389 Figura 13.7.A, Elementos de vaso; B, tejido xilemático, C, fibras, D, pelo liso, E, elemento de vaso con huellas tecnológicas (roturas) F, fibras, G, corpúsculos de resina, $\mathrm{H}$, pelo verrucoso recuperados en el primer y segundo raspado en laboratorio 391 Figura 13.8. A y B, tejido epidérmico, $\mathrm{C}$, tricomas y corpúsculos de resina y $\mathrm{D}$, grano de almidón 392 Figura 13.9. Microrrestos recuperados con pipeta A, esclereida B, fibra C, pelo unicelular rugoso $\mathrm{D}$, corpúsculo de resina $\mathrm{E}$, pelo unicelular liso $\mathrm{F}$, elemento de vaso degradado G y H grano de almidón con y sin polarizar. 393 
Figura 13.10. A y B: tejido xilemático recuperado en artefacto M17PM con desgarros y fracturas; C: pelo de Maytenus chubutensis con rasgos de corte producto del molido experimental; D: tejido xilemático con desgarros producto de trabajo experimental con denticulado (Cueto et al. 2010). 394

Figura 13.11. Materiales no vegetales recuperados en el raspado del mortero, A, foraminífero; B fragmento de valva 395

Figura 13.12. Cara no activa: A y B elemento de vaso y tricoma recuperados en los raspados; C y D célula pétrea y elemento de vaso recuperado con pipeta 395 Figura 13.13. Sedimento testigo tomado de la superficie que rodeaba y por debajo del artefacto, en la localidad arqueológica Punta Medanosa. 396 Figura 13.14. A: Prosopidastrum globosum (Fotografía tomada en el Laboratorio de Microhistología de INTA Bariloche B: pelos de P. globosum (ídem aclaración), C: tejido epidérmico identificado en M17PM; D: pelo identificado en M17PM. 397 Figura 13.15. Maytenus chubutensis referencia A y B: Tejido epidérmico C: corpúsculos de resina, D, E y F pelos lisos y verrucosos 398 Figura 13.16. A: Tejido epidérmico hoja mortereada de Prosopis alpataco referencia B: Estoma de pedicelo de vaina Prosopis denudans referencia C y D pelos de P. alpataco referencia . 399

Figura 13.17. M23SJ 400

Figura 13.18. A: Muestra general del preparado, B: fibra libriforme y C: polarización del preparado 400

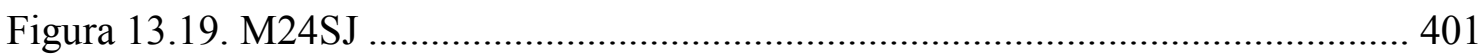

Figura 13.20. A: Vista general del preparado y B: polarización ................................ 401

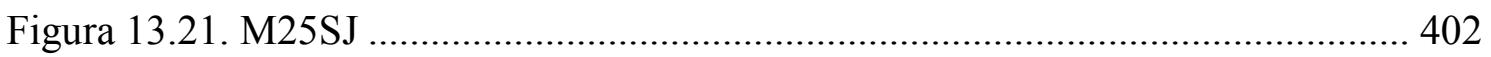

Figura 13.22. A: Vista general del preparado y B: polarización del mismo ................ 402

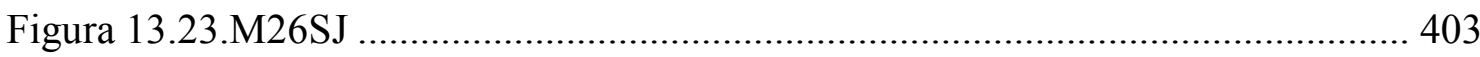

Figura 13.24. P26SJ A: Vista general del preparado, B: fibra deshilachada granos de almidón sin y con polarización, C y D grano de almidón ovoide sin y con polarización; E y F: grano de almidón ovoide sin y con polarización; G y H: grano de almidón de superficies facetadas 404

Figura 13.25. P26SJ A, B y C y D: Granos de almidón ovoides sin y con polarización recuperados en $\mathrm{P} 26 \mathrm{SJ}$ 405 
Figura 13.26. Prosopis sp A y B: grano de almidón esférico, C y D: grano de almidón facetado, E y F grano de almidón ovoide ...................................................................... 406

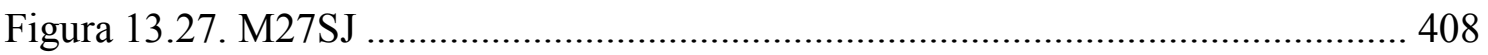

Figura 13.28. A: Visión general del preparado, B: fibra libriforme, C: polarización del

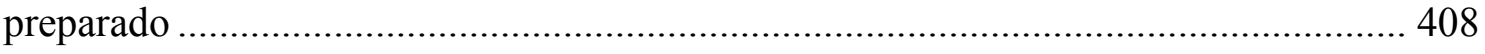

Figura 13.29. Se observa el sedimento testigo sin y con polarizador............................ 409 
XXVI 


\section{Índice de tablas}

Tabla 1.1. Información contextual de los sitios estudiados en esta tesis 8

Tabla 4.1.Denominaciones referidas a los habitantes originarios de Patagonia continental según Harrington, Escalada, Casamiquela y Vignati, resumido en Nacuzzi (1998:107). "Área en estudio" refiere al Fuerte San Carmen ubicado en la desembocadura del río Negro

Tabla 4.2. Base de datos construida a partir de fuentes documentales escritas de primer y segundo orden y trabajos etnográficos de Patagonia continental Argentina. Los taxa con signos de interrogación constituyen interpretación de las autoras. Referencias: [s/e] sin especificar; * también se ha registrado el taxa en el registro arqueobotánico de

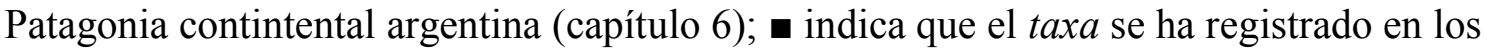
estudios etnobotánicos (capítulo 5) 110

Tabla 5.1. Plantas reportadas como alimenticias en las localidades de Tellier y Puerto Deseado (CNSC). Referencias s/i: sin identificar taxonómicamente.

Tabla 5.2. Plantas reportadas como combustibles en las localidades de Tellier y Puerto Deseado (CNSC). Referencias: s/i: sin identificar. 135

Tabla 5.3. Plantas reportadas como medicinales en las localidades de Tellier y Puerto Deseado (CNSC). Referencias [s/d]: sin datos. 138

Tabla 5.4. Plantas reportadas con otras categorías de uso en las localidades de Tellier y Puerto Deseado (CNSC). 138

Tabla 6.1. Recopilación bibliográfica de los restos arqueológicos vegetales recuperados en el área de estudio seleccionada, y presencia/ausencia de cada taxón en las fuentes documentales escritas.Referencias: [MD] Macrorresto no leñoso desecado; [MLD] Macrorresto leñoso desecado; [MC] Macrorresto no leñoso carbonizado; [m] microrresto; [MLC] Macrorresto leñoso carbonizado; [s/d]: sin datos; [s/i] sin identificar a nivel de género o específico.

Tabla 7.1. Densidad aparente anhidro de las maderas de referencia. Referencias [s/d] sin datos.

Tabla 7.2. Modificaciones de los leños luego de la carbonización controlada a temperaturas de $400{ }^{\circ} \mathrm{C}$ y $700{ }^{\circ} \mathrm{C}$ y a humedades de $8-12 \%$ y $0 \%$. 199 
Tabla 7.3. Reducción (\%) del largo, ancho espesor y peso de las maderas de referencia carbonizadas al 8-12\% de humedad. El asterisco (*) expresa que la madera se fragmentó por lo que no pudo ser medida. El (-) siginifica que la variable en lugar de reducirse aumentó. 205

Tabla 7.4. Reducción (\%) del largo, ancho espesor y peso de las maderas de referencia carbonizadas al $0 \%$ de humedad. El asterisco expresa que la madera se fragmentó por lo que no pudo ser medida. El (-) significa que la variable en lugar de reducirse aumentó. $\mathrm{s} / \mathrm{d}$ hace referencia a sin datos. 206

Tabla 7.5. Porcentajes promedio de la reducción del largo, ancho, espesor y peso luego de la carbonización. 207

Tabla 7.6. Material de referencia (hoja y fruto) de Schinus sp. con sus medidas antes y después de la carbonización experimental. 207

Tabla 9.1. Restos carpológicos arqueológicos (frutos) con sus medidas 240

Tabla 9.2. Restos arqueológicos de hojas carbonizadas 241

Tabla 10.1. Características de los componentes estratigráficos diferenciados. $\left(^{*}\right)$ en las medidas indica que las mismas no corresponden 283

Tabla 12.1. Caracteres cualitativos de las especies analizadas a través de la técnica microhistológica. Referencias: $[\mathrm{X}]$ signfica presencia del rasgo; [s/o] sin observaciones.

Tabla 13.1. Artefactos potencialmente utilizados en la molienda analizados en esta tesis. 386

Tabla 13.2. Artefactos de la Colección Museo del hombre y su Entorno, potencialmente utilizados en la molienda y analizados en esta tesis

Tabla 13.3. Descripción de los granos de almidón recuperados en el artefacto M26SJ407 Tabla 14.1. Información abreviada de de los sitios arqueológicos de CNSC y los resultados del análisis arqueobotánico. 440 


\section{Resumen}

En esta tesis se realiza el estudio de las prácticas de recolección de vegetales silvestres que llevaron a cabo los grupos cazadores recolectores de la costa norte de Santa Cruz (CNSC) entre el Holoceno medio y tardío. El proyecto arqueológico de la CNSC es dirigido por la Dra. Alicia Castro y abarca el estudio arqueológico de las sociedades que habitaron el litoral marino en el norte de esta provincia. La escala espacial comprende de norte a sur, el límite interprovincial de Chubut y Santa Cruz hasta la localidad de bahía Laura. En sentido este-oeste abarca la franja litoral de costa propiamente dicha y hacia el interior un territorio de extensión variable que se ha denominado franja intermedia. Los resultados arqueológicos más relevantes del proyecto CNSC evidencian un aprovechamiento intensivo tanto del litoral marino como de sus recursos faunísticos, desde el Holoceno medio al tardío (Castro et al. 2003, Zubimendi et al. 2011). Se han registrado diferentes estrategias de uso del espacio por parte de estos grupos humanos en relación con los recursos que el sector en particular ofrecía (Zubimendi 2010).

En este contexto, desde un enfoque paleoetnobotánico, se propone en la presente tesis analizar la interacción entre los grupos cazadores recolectores y las plantas a través de las prácticas de recolección. Estas últimas se definen a partir de la selección, obtención, gestión y consumo de plantas silvestres. Las hipótesis que guiaron esta investigación son: que las sociedades cazadoras recolectoras de la CNSC utilizaron y consumieron plantas silvestres. Asimismo, que en la interacción hombre-planta existieron criterios organolépticos, de las propiedades biofísicas de la madera, simbólicos y de disponibilidad que definieron la selección y recolección de plantas dentro de las sociedades cazadoras recolectoras de la CNSC. En este sentido que la recolección de vegetales silvestres se desarrolló en relación a otras estrategias de subsistencia y movilidad de los grupos que habitaron la CNSC. Por último, que estas sociedades desarrollaron procesamientos poscolecta de los vegetales a través de una tecnología adecuada.

Para contrastar estas hipótesis se utilizó una aproximación holística y, por lo tanto se estudiaron distintas líneas de evidencias. En primer lugar, se recopilaron fuentes bibliográficas del siglo XVI al XXI, a partir de las cuales se extrajeron categorías 
referidas a las prácticas de recolección desarrolladas por los distintos grupos que habitaron Patagonia, los usos de las plantas, el procesamiento de las mismas y los agentes de recolección en el contexto histórico en el que se produjo esa información. Se realizaron entrevistas etnobotánicas a pobladores locales de la ciudad de Puerto Deseado y la localidad de Tellier. Dichas entrevistas fueron abiertas, semiestructuradas a través de las cuales se analizaron las dimensiones: prácticas de recolección, categorías de uso de plantas, sistemas de clasificación y transmisión de conocimiento. Se desarrolló la observación participante y colecta de ejemplares en las recorridas con tres informantes por las chacras y la ría Deseado. En tercer lugar, se recopilaron publicaciones científicas sobre el registro arqueobotánico de Patagonia continental argentina y se analizaron los resultados expuestos en ellas. En este sentido, se tuvo en cuenta la identificación taxonómica del resto recuperado, tipo de restos (macro o microvestigio), estado de conservación (i.e. seco, carbonizado), período temporal y ubicación espacial del hallazgo. Esta información permitió desarrollar criterios amplios para la elaboración de la colección de referencia. Esta última se presenta en dos secciones: una conformada por macrorrestos vegetales (tallo, hoja y frutos) en la que se desarrolla además un protocolo experimental de carbonización controlada para la interpretación de los restos antracológicos. La otra sección, presenta el material de referencia de microvestigios (tejidos de frutos, hojas y tallos).

En relación a los macrorrestos vegetales, se identificaron partes leñosas y no leñosas de 10 sitios arqueológicos de tres sectores: Golfo San Jorge, Cabo Blanco y Punta Medanosa. Es importante mencionar que el registro arqueobotánico recuperado proviene de distintos tipos de sitios: alero, cueva, a cielo abierto y conchero.

En relación a los procesamientos poscolecta, específicamente la molienda se analizaron publicaciones científicas de arqueología de Patagonia continental Argentina con menciones sobre estos instrumentos. Se extrajo la siguiente información: sitio, contexto, cronología, materia prima, existencia de análisis de adherencias, presencia /ausencia de microrestos y su identificación. Posteriormente se realizaron prospecciones asistemáticas sobre el sector sur de la ría Deseado donde se tomaron muestras in situ y se recuperó un artefacto de molienda que fue analizado en el laboratorio. De este último se tomaron muestras a través del raspado y pipeteado con agua desmineralizada. De la 
colección Museo del Hombre y su Entorno (Caleta Olivia) se analizaron cinco instrumentos a partir de la toma de muestras in situ.

Los resultados obtenidos permitieron identificar que las familias con mayor cantidad de taxa utilizados y mencionados a través de las distintas líneas de investigación (i.e. fuentes documentales, etnobotánica, registro arqueobotánico de Patagonia y registro arqueobotánico de CNSC) fueron principalmente: Asteraceae y Fabaceae. En las fuentes documentales además de ambas familias se mencionaron con mayor frecuencia taxa de Apiaceae, mientras que en las entrevistas etnobotánicas también predominó Lamiaceae. En el registro arqueobotanico de Patagonia predominó, además de las anteriores, Poaceae y en el caso de CNSC, a través del registro antracológico, además de Asteraceae predominaron Anacardiaceae, Berberidaceae y Solanaceae.

En cuanto a las categorías de uso, en las fuentes documentales el 35,4\% de los taxa mencionados para un único fin correspondió a la categoría de uso alimenticia, el 22,2\% respondió a medicinal y el 19,2\% fueron plantas multipropósito. En relación a las entrevistas etnobotánicas para las localidades de Tellier y Puerto Deseado, el $47 \%$ de los taxa mencionados se clasifican en categorías de uso medicinal, mientras que el $27 \%$ combustible y el 15\% multipropósito. Es notable la disminución de la categoría de uso alimenticia que respondería a la incorporación de dietas basadas en productos industriales y manufacturados. En el caso del registro arqueobotánico de Patagonia analizado desde de las publicaciones científicas existentes, se deduce que no es posible cuantificar la recuperación de taxa por categoría pero sí inferirlas: alimenticias, cestería, combustible, y artefactos en madera. En este caso es significativa la ausencia de la categoría medicinal. Para CNSC los macro y microrrestos recuperados permitieron obtener información acerca de usos relativos a la categorías combustible, alimenticia, artefactos en madera y posiblemente medicinal. La evidencia recuperada para CNSC, a partir de la identificación de 11 familias y 16 taxa: Adesmia, Atriplex/Suaeda, Berberis, Bulnesia, Chuquiraga, cf. Cercidium, cf. Grindelia, Colliguaja, Discaria, Ephedra, Lycium, Pinus, Prosopidastrum, Prosopis contrasta en forma positiva la hipótesis de que los cazadores recolectores utilizaron y consumieron plantas silvestres.

Para el estudio de la interacción de los grupos cazadores recolectores y las plantas silvestres en CNSC, se generó un modelo a partir del cual se registraron criterios de selección de distintos grupos y poblaciones de Patagonia continental argentina (fuentes 
bibliográficas) y las entrevistas etnobotánicas de Tellier y Puerto Deseado. Se discutió el valor de la analogía y de qué manera podía ser utilizada en las inferencias del registro arqueológico. Se registraron los criterios de selección para las plantas silvestres en la esfera de precolecta y colecta que estarían asociados principalmente a las características organolépticas de las plantas (i.e. aroma, sabor, color y textura). En el caso de las plantas combustibles los criterios registrados en las entrevistas a pobladores locales fueron: facilidad para hacer brasa, duración de la brasa, poder calórico, facilidad para el encendido, producción de humo, disponibilidad de la especie. A través de los estudios anatómicos del registro antracológico, se observó que los leños de la estepa arbustiva del Golfo San Jorge presentaron por un lado, una producción de resinas y aceites esenciales que podrían haber funcionado como caracteres organolépticos para los grupos cazadores recolectores. Por otra parte los taxa con mayor densidad de carbones en los fogones y carbones dispersos fueron los de mayor dureza, capacidad de producción de brasa y duración de la misma (i.e. Schinus, Berberis ) así como también de rápido encendido (ricos en resinas) y corta duración (i.e. Senecio/Baccharis, Lycium). En otros casos por el contrario, los taxa seleccionados son característicos por su rápido consumo y producción de ceniza (i.e. Atriplex/Suaeda). Se considera posible inferir la selección de estos taxa a partir de las propiedades de las maderas y criterios organolépticos. También se concluyó que los taxa utilizados en los fuegos no variaban en relación al sitio alero, cueva, conchero o a cielo abierto sino que respondían a actividades específicas para las que fuera elaborado el fogón. Se discutió la funcionalidad de los fogones a partir de la termoalteración de restos malacológicos (i.e. sitio 112, Las Hormigas) y restos líticos (i.e. El Oriental), entre otros.

Se discute a partir de los resultados antracológicos las estrategias de movilidad y subsistencia de los grupos cazadores recolectores del Holoceno medio y tardío, siendo utilizadas en todos los casos leñas disponibles alrededor de los sitios, pero que los taxa fueron seleccionados de acuerdo a la funcionalidad del fogón y de las actividades desarrolladas en los sitios.

Es importante destacar la selección de la madera de Berberis para la confección de un artefacto de madera, fragmento de arpón, que fue recuperado junto a otros seis arpones en hueso. Hallazgos importantes para discutir la tecnología de captura de pinnípedos y 
peces (en el caso del arpón de madera) asociada a rompecráneos para el Holoceno tardío donde la costa fue habitada con mayor intensidad.

También se registraron para CNSC artefactos potencialmente utilizados en el procesamiento poscolecta de recursos vegetales silvestres. La recuperación de microvestigios de dos de los instrumentos permitió la identificación de dos taxa Prosopidastrum globosum y aff. Prosopis, resultados que estimulan a ampliar la muestra analizada. Los resultados obtenidos permiten inferir que los grupos cazadores recolectores que habitaron la CNSC gestionaron los recursos vegetales silvestres durante el Holoceno medio y tardío. 


\section{Abstract}

This thesis analyzes the practices of gathering wild plants that performed huntergatherers on the north coast of Santa Cruz (CNSC) between the middle and late Holocene. The archaeological project of the CNSC is led by Dra. Alicia Castro and covers the archaeological study of societies that inhabited the sea coast in the north of the province. The spatial scale comprises from north to south, the interprovincial boundary of Chubut and Santa Cruz to the town of Laura Bay. In westbound covers the coastal strip of coast itself and through the interior of the continent a region of variable length that has been called middle ground. The most important archaeological findings of the CNSC project show an intensive use both of the seaboard and its wildlife resources, from the middle to late Holocene (Castro et al. 2003, Zubimendi et al. 2011). There have been different approaches to the use of space by these human groups relative to the resources that each sector in particular offered (Zubimendi 2010).

In this context, from a paleoethnobotanical approach, this thesis intends to analyze the interaction between hunter gatherers and plants through harvesting practices. The latter are defined from the selection, acquisition, management and consumption of wild plants. The assumptions that guided this research are that hunter-gatherer societies used the CNSC and ate wild plants. Also, that in the man-plant interaction existed organoleptic, the fuel properties of wood, symbolic, availability which defined the selection and collection of plants in hunter-gatherer societies of the CNSC. In this sense, that the gathering of wild plants was developed in relation to other subsistence and mobility strategies of the groups that inhabited the CNSC. Finally, these societies developed post-harvest processing of vegetables through appropriate technology.

To test these hypotheses a holistic approach was used and therefore different lines of evidence were studied. First, from bibliographic resources from XVI to XIX century, it was extracted categories regarding collection practices developed by different groups that inhabited Patagonia, the uses and processing techniques of plants, and the collection agents in the historical context in which that information was produced. Ethnobotanical interviews with local residents of the town of Puerto Deseado and the locality of Tellier were performed. The interviews were open, semi-structured through which a set of 
dimensions was analyzed: gathering practices and categories usage of plants, classification systems and knowledge transmission. A moderate to severe participant observation was developed in three respondents walking through the orchards and the Deseado sea loch. Third, scientific publications on the archaeobotanical record of continental Patagonia Argentina were compiled and the results presented in them were analyzed. In this respect, consideration was given to taxonomic identification of the remains recovered, type of remains (macro or micro), condition (i.e. dry, charred), temporal and spatial period of discovery. This information was used to develop a broad criterion for developing the reference collection. The latter is organized and presented in two sections: one consisting of plant macroremains (stems, leaves and fruits), in which an experimental carbonization protocol for interpreting anthracological remains is developed. The other section consists of the microremains reference material (fruits, leaves and stems tissues).

Regarding plants macroremains, woody and non-woody parts of 10 archaeological sites were identified in three sectors: Golfo San Jorge, Cabo Blanco and Punta Medanosa. It is noteworthy to mention that the archaeobotanical record came from different types of sites: eaves, cave, and midden open sky.

Regarding the post-harvest prosecutions, specifically grinding, scientific publications with mentions of these instruments, of archeology in continental Argentina Patagonia were analyzed. The following information was extracted: Site, context, chronology, raw material analysis, presence of adhesions, presence or absence of microremains and its identification. Subsequently, unsystematic survey on the south Deseado sea loch was performed where in situ samples were taken and a grinding artifact that was analyzed afterwards in the laboratory. From the latter, it was collected a set of samples through pipetting and scraping with demineralized water. Five instruments were studied coming from the collection "El Hombre y su Entorno" Museum (Caleta Olivia), taking samples in situ.

The results obtained allowed us to identify that the families with the highest number of taxa used and most mentioned through the various research sources (i.e. documentary sources, ethnobotany, archaeobotanical record of Patagonia and archaeobotanical record of CNSC) were mainly: Asteraceae and Fabaceae. In documentary sources, besides both families, it was mentioned more often Apiaceae taxa, whereas in ethnobotanical 
interviews also prevailed Lamiaceae. In the archaeobotanical record of Patagonia, besides the above, Poaceae predominated, and respect to CNSC, through the analysis of the charcoal record, in addition to Anacardiaceae predominated Asteraceae, Solanaceae and Berberidaceae.

Regarding the uses of categories, in the documentary sources, the $35,4 \%$ of the taxa mentioned for a single purpose corresponded to the category of food use, $22,2 \%$ responded to medicine and $19.2 \%$ were multipurpose plants. Regarding the ethnobotanical interviews in localities of Tellier and Puerto Deseado, $47 \%$ of the mentioned taxa were classified into categories of medicinal use, while $27 \%$ corresponded to fuel and $15 \%$ to multipurpose plants. The remarkably decrease of the food category could be explained by the incorporation of industrial and manufactured products into the modern diets. Respect to the Archaeobotanical Patagonia record analyzed from the existing scientific literature, it follows that it is not possible to quantify the recovery of taxa per class, but it can be inferred: food, straw, fuel, and wood artifacts. In this case the absence of the medicine category is significant. In the case of $\mathrm{CNSC}$, the macro and microremains recovered, allowed obtain information about uses related to fuel, food, wood artifacts and possibly medicine categories. The evidence recovered for CNSC supports the hypothesis that hunter-gatherers used and consumed wild plants.

To study the interaction of hunter gatherers and wild plants in CNSC, it was generated model from which selection criteria for different groups and populations of continental Argentinian Patagonia (bibliographic sources) and ethnobotanical interviews were recorded for the localities of Tellier and Puerto Deseado. It was discussed the value of analogy and how it could be used in the archaeological record inferences. The following criteria of selection for wild plants were recorded in the field of precolecta and collection it was evaluated if they would be primarily associated with the organoleptic characteristics of plants (i.e. aroma, flavor, color and texture). In the case of fuels plants the criteria reported by local villagers were: ease of doing grill, grilled duration, calorific value, ease of ignition, smoke production, and availability of the species. Through anatomical studies of the charcoal record, it was observed that the logs of shrub steppe of Golfo San Jorge presented on the one hand, a production of resins and essential oils that may have functioned as organoleptic characteristics for hunter- 
gatherers. On the other hand, the taxa with higher density of charcoal in the stove and scattered coals were the higher hardness, coal production capacity and lifetime (i.e. Schinus, Berberis) and opposed to that, also those of quick start (rich in resins) and short duration (i.e. Senecio/Baccharis, Lycium). In other cases, instead, the selected taxa are characterized by their rapid consumption and production of ash (i.e. Atriplex/Suaeda). It is considered a strong possibility to infer the selection of these taxa from the wood properties and organoleptic criteria. It was also concluded that the taxa used in the fires did not vary in relation to the type of site: rock shelter, cave, shell middens or open air site but responded to specific activities for which the fire was developed. The functionality of the fires was discussed through the thermoalteration of malacologic remains (i.e. site 112, Las Hormigas) and lithic remains (i.e. El Oriental), among others.

From the anthracological results, it is discussed the mobility and subsistence strategies of the middle and late Holocene hunter-gatherer groups, being used in all cases the firewood available around the sites, but the taxa were selected according to the functionality of the fire and activities on the sites.

It is important to highlight the selection of Berberis wood for making wood artifact, a harpoon fragment, which was recovered along with six other bone harpoons. Important findings to discuss the technology of capture of pinnipeds and fish (in the case of the wooden harpoon) associated with skulls-crack for late Holocene where the coast was inhabited more intensely.

It was also registered for CNSC, artifacts potentially used in the poscolecta processing of wild plant resources. The recovery of microremains coming from two instruments allowed the identification of two taxa Prosopidastrum globosum and af. Prosopis, results that encourage expanding the analyzed sample. The results obtained allow inferring that the hunter-gatherers groups who inhabited the CNSC managed wild plant resources during the middle and late Holocene. 


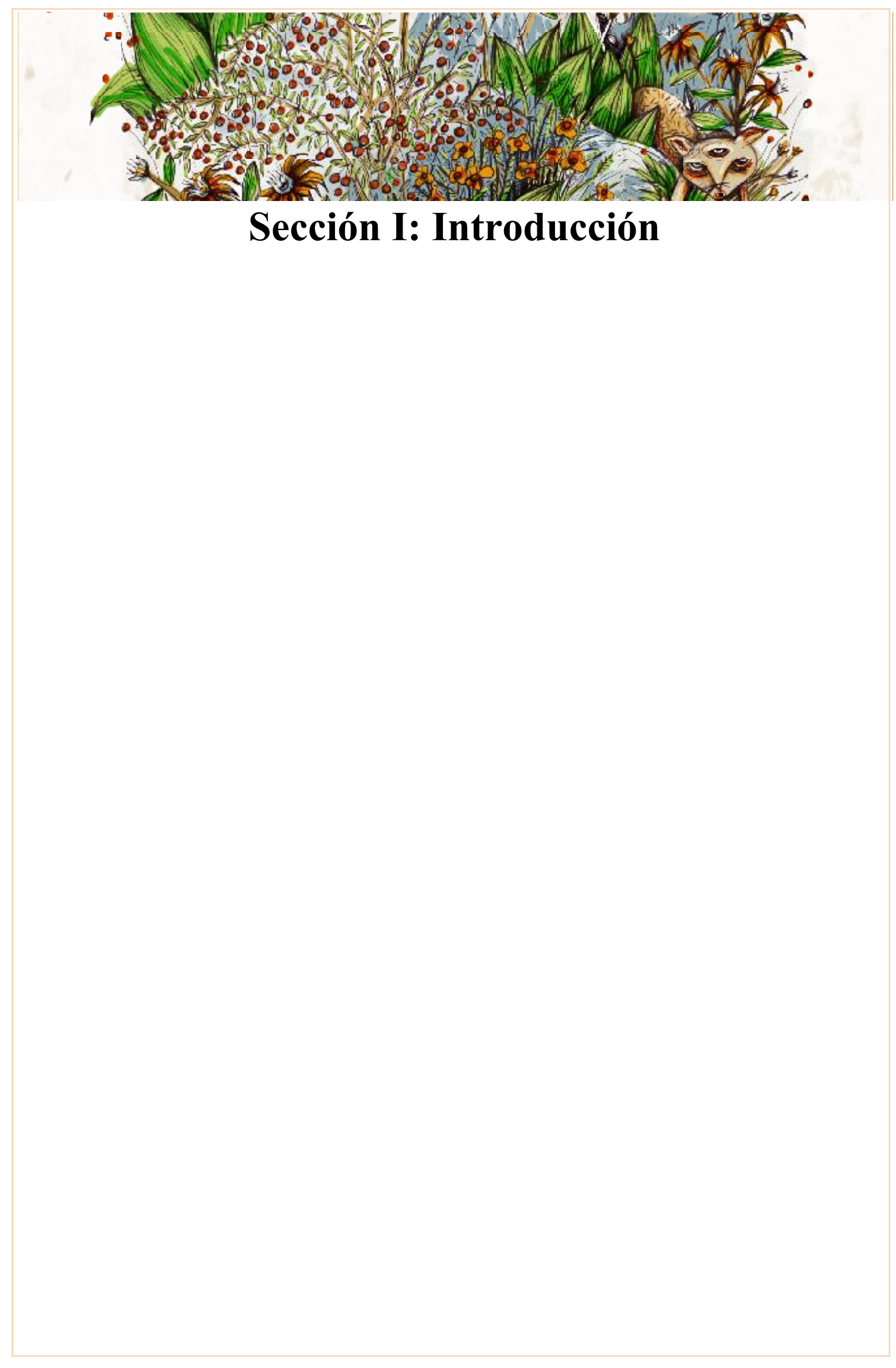




\section{Introducción}

Las investigaciones sobre la interacción entre el ser humano y las plantas en el pasado, en contextos de grupos cazadores recolectores de Argentina son aún escasas. En este sentido, la presente tesis constituye un avance en estos estudios ya que, son los primeros que se llevan adelante específicamente para el área costa norte de Santa Cruz (de ahora en adelante CNSC) dentro del cual se inscribe esta investigación.

El proyecto Arqueológico CNSC, dirigido por la Dra. Alicia Castro, abarca el estudio arqueológico de las sociedades que habitaron el litoral marino en el norte de esta provincia. Específicamente, la escala espacial de análisis se extiende en sentido norte sur, desde el límite interprovincial de Chubut y Santa Cruz hasta bahía Laura, mientras que en sentido este-oeste abarca la franja litoral de costa propiamente dicha y hacia el interior un territorio de extensión variable que se ha denominado franja intermedia. Se ha puesto énfasis hasta el momento en los análisis distribucionales (Zubimendi 2010, 2014), el estudio de los restos líticos (Ambrústolo 2011, Mazzitelli 2014), arqueofaunísticos (Beretta et al. 2011), malacológicos (Hammond 2013), cerámicos (Trola y Ciampagna 2011) y en las prácticas mortuorias de estos grupos humanos (Zilio 2013). Los estudios arqueológicos realizados en el área evidencian un aprovechamiento intensivo tanto del litoral marino como de sus recursos faunísticos, desde el Holoceno medio al tardío (Castro et al. 2003, Zubimendi et al. 2011). Asimismo se han registrado diferentes estrategias de uso del espacio por parte de estos grupos humanos en relación con los recursos que el sector en particular ofrecía (Zubimendi 2010).

Los análisis realizados en esta tesis permiten abrir la discusión sobre los tipos de prácticas de recolección de vegetales que los grupos cazadores recolectores de la CNSC pudieron haber desarrollado. Se entiende a éstas desde un sentido amplio que incluye selección, obtención, gestión y consumo. Se propone analizar, desde un estudio paleoetnobotánico, la relación entre las plantas y los grupos humanos que formaron parte de las sociedades cazadoras recolectoras que habitaron la CNSC, más específicamente se hará hincapié en la recolección de las plantas por parte de estas poblaciones. El enfoque paleoetnobotánico tiene como eje caracterizar y analizar la relación entre sociedades humanas y comunidades vegetales en el pasado, compartiendo 
en este sentido su objeto de estudio relacional con la etnobotánica pero en un período cronológico distinto (Helbaek 1959, Ford 1979 en Lema 2009). Las prácticas de recolección en grupos que explotan recursos vegetales silvestres han sido consideradas, en distintas investigaciones arqueológicas, como marginales dentro de las actividades económicas de grupos cazadores-recolectores. Es posible que esta premisa sea afirmativa, pero es necesario ponerla a prueba y evaluar las dificultades que existen a la hora de estudiar la recolección de plantas desde el registro arqueológico e intentar superarlas a través de una aproximación metodológica adecuada.

Por un lado, se debe tener en cuenta que estas sociedades pueden obtener distintos tipos de recursos a través de estrategias de movilidad, por lo que, cada sitio representará una visión fragmentada de las actividades llevadas a cabo por un mismo grupo, situación que dificulta su caracterización de forma completa (Binford 1980). Por otro lado, la recolección de vegetales posee escasa visibilidad en el registro arqueológico, fundamentalmente debido a la preservación de los restos (Caruso et al 2008), que, en ocasiones, son consumidos en forma directa en el lugar de recolección y sin procesamiento alguno que favorezca su conservación, o aumente su representación en distintas áreas de actividad y/o en artefactos (Capparelli y Prates 2010, en prensa).

Con el fin de contrarrestar las dificultades mencionadas en el reconocimiento de la recolección de vegetales en sociedades cazadoras-recolectoras a partir del registro arqueológico, Mason y Hather (2002), consideran que una investigación paleoetnobotánica que aborde este tema debe ser realizada de forma holística, es decir, debe incluir la mayor cantidad de información posible proveniente de disciplinas complementarias. Dicha información, en lugar de restringirse a poner énfasis en el papel de las plantas dentro de la dieta, debe permitir al investigador preguntarse acerca de los usos amplios de las mismas, abarcando también, por ejemplo, el estudio tanto de artefactos manufacturados con vegetales (objetos musicales, implementos, recipientes, objetos rituales), como de restos de vestimenta, textiles, entre otros. También estos autores proponen un abordaje que incluya tanto la interpretación de datos ambientales y la reconstrucción del paisaje con los datos arqueológicos (polen, análisis de carbones, diatomeas), como la aplicación de modelos etnobotánicos y etnoecológicos; las aproximaciones experimentales; los análisis arqueológicos, bioquímicos $\mathrm{o}$ microscópicos de estructuras o artefactos de procesamiento de plantas; y los análisis de 
fitolitos y coprolitos. Es por ello que en esta tesis se propone un abordaje holístico de las prácticas recolectoras de la Patagonia central a través del análisis tanto de macro como de microrrestos, de restos antracológicos y carpológicos, información que se complementa con datos provenientes del análisis de fuentes escritas y de la etnobotánica. Asimismo, las prácticas de recolección asociadas a restos vegetales son comparadas con aquellas asociadas a otros recursos importantes de la zona, tales como los moluscos. Al igual que los vegetales, los moluscos fueron habitualmente considerados como recursos marginales dentro de las actividades económicas de estos grupos. No obstante, se conoce a través de recientes investigaciones, que su recolección en CNSC fue una práctica de gran importancia en la vida cazadora recolectora (Zubimendi 2012, Zubimendi et al. 2005, Zubimendi y Hammond 2009, Hammond y Zubimendi 2013), ya que procuraba un recurso de alto valor de retorno por el bajo riesgo de captura. La diferencia respecto a las prácticas de recolección de vegetales radica en que la explotación de moluscos tiene alta visibilidad arqueológica debido a las características de las valvas, que constituyen la consecuencia material de la práctica, lo que difícilmente sucede con los restos arqueobotánicos (Zapata Peña 2000). La comparación entre prácticas de este tipo asociadas a distintos recursos permitirá una evaluación más precisa sobre el uso del espacio, el conocimiento y percepción del ambiente, la movilidad y la estacionalidad, entre otros aspectos.

Finalmente, y adscribiendo a las propuestas de Caballero (1987) y Nazarea (1998), se pretende que los resultados obtenidos en esta tesis sobre el conocimiento botánico tradicional (CBT), ligado a recursos que han sido utilizados por la población campesina y originaria durante miles de años, pueda contribuir, a largo plazo y cuando sea necesario, a enfrentar necesidades básicas de la población local. En este sentido se piensa que la construcción de un banco de conocimiento sobre la gestión de plantas silvestres aplicadas a distintos fines (i.e. comestibles, combustibles, medicinales, entre otros), constituirá un punto de partida para el desarrollo futuro de proyectos locales de etnobotánica aplicada.

\subsection{Objetivo general}


Estudiar desde el enfoque paleoetnobotánico la relación entre los grupos humanos y las plantas en las sociedades cazadoras recolectoras que habitaron la CNSC, haciendo énfasis en el análisis de las prácticas de recolección.

\subsection{Objetivos específicos e hipótesis}

Hipótesis 1: Las sociedades cazadores recolectoras de la CNSC utilizaron y consumieron plantas silvestres.

Hipótesis 1.1.: Existió una gestión de los recursos vegetales silvestres: recolección, acarreo, circulación, almacenaje, procesamiento, consumo y descarte ${ }^{1}$.

Objetivo específico 1.1.1.: Analizar la manipulación de las plantas silvestres en el contexto de cazadores recolectores de la CNSC a través del registro arqueobotánico.

Objetivo específico 1.1.2.: Reconocer a través del estado de conservación de los macrorrestos vegetales (i.e. seco, carbonizado) y de las características morfoanatómicas de sus tejidos, distintas etapas de la gestión de los recursos vegetales silvestres (i.e. consumo directo, procesamiento poscolecta, descarte, entre otros).

Hipótesis 2: En la interacción hombre-planta existieron criterios organolépticos, de propiedades combustibles de la madera, simbólicos y de disponibilidad que definieron la selección y recolección de plantas dentro de las sociedades cazadoras recolectoras de la CNSC.

Objetivo específico 2.1.: Determinar a través de caracteres morfo-anatómicos las propiedades organolépticas y combustibles de los taxa identificados en el registro arqueológico de CNSC.

Objetivo específico 2.2.: Generar un modelo para la interpretación de las prácticas de recolección de vegetales en el pasado desde el análisis de fuentes bibliográficas y la etnobotánica.

Hipótesis 3: Las prácticas de recolección de plantas silvestres se desarrollaron en el marco de las estrategias de subsistencia y movilidad de los grupos de CNSC.

\footnotetext{
${ }^{1}$ Estas categorías hacen referencia a las esferas colecta, poscolecta y consumo mencionadas en Capparelli y Lema (2010) y definidas en el capítulo 2. El concepto consumo es entendido en sentido amplio.
} 
Objetivo específico 3.1.: Evaluar la presencia/ausencia y frecuencia relativa de las plantas identificadas taxonómicamente en el registro arqueológico y su ubicuidad a lo largo del tiempo para el área de estudio.

Objetivo específico 3.2.: Establecer relaciones entre las variables mencionadas en el punto 3.1. y otras líneas de evidencia del registro arqueológico (i.e. malacológico, cerámico, óseo) para cada sitio considerado, para los conjuntos de sitios alero, conchero a cielo abierto y conchero en cueva y para cada sector arqueológico de CNSC (Golfo San Jorge, Cabo Blanco y Sur de la Ría Deseado, ver Tabla 1.1.).

Hipótesis 4: Los grupos cazadores recolectores a través de tecnologías específicas desarrollaron procesamientos poscolecta de los vegetales.

Objetivo específico 4.1.: Evaluar la potencial existencia de prácticas de procesamiento poscolecta de plantas silvestres a través del análisis de microrrestos presentes en el instrumental implicado (piedras planas de moler).

El registro arqueológico con el que se pondrá a prueba estas hipótesis y se alcanzarán los objetivos propuestos corresponde tanto a macrorrestos (restos carpológicos, antracológicos y artefactuales) como a microrrestos (almidones, restos de tejidos, entre otros) provenientes de los sitios mencionados en la Tabla 1 y cuya ubicación se observa en la Figura 1. 


\begin{tabular}{|c|c|c|c|c|c|}
\hline $\begin{array}{c}\text { Sector } \\
\text { geográfico }\end{array}$ & Subsector & $\begin{array}{c}\text { Sitio } \\
\text { Arqueológico }\end{array}$ & Tipo de sitio & $\begin{array}{l}\text { Fechados del sitio } \\
\left(\mathrm{C}^{14} \text { años AP }\right)^{2}\end{array}$ & Referencias \\
\hline \multicolumn{2}{|c|}{ Golfo San Jorge } & Palo alto & $\begin{array}{c}\text { Cielo } \\
\text { abierto, } \\
\text { conchero }\end{array}$ & $\begin{array}{c}690 \pm 90 \text { AP (LP } \\
2280, \text { Nacela } \\
\text { magellanica) }\end{array}$ & $\begin{array}{c}\text { Zubimendi et al. } \\
\text { 2010, Trola y } \\
\text { Ciampagna } 2011\end{array}$ \\
\hline \multirow{3}{*}{\multicolumn{2}{|c|}{ Cabo Blanco }} & $\begin{array}{l}\text { Cormorán } \\
\text { Quemado }\end{array}$ & Cielo abierto & $\begin{array}{c}360 \pm 50 \text { AP (LP- } \\
3007)\end{array}$ & Zubimendi 2010 \\
\hline & & $\begin{array}{l}\text { Nido del } \\
\text { Águila }\end{array}$ & Cielo abierto & Sin fechado & $\begin{array}{c}\text { Zubimendi 2010, } \\
\text { Trola y } \\
\text { Ciampagna } 2011\end{array}$ \\
\hline & & La Estrella & $\begin{array}{c}\text { Cielo } \\
\text { abierto, } \\
\text { conchero }\end{array}$ & $690 \pm 70($ LP 2096) & Zubimendi 2010 \\
\hline \multirow{6}{*}{$\begin{array}{l}\text { Sur de la } \\
\text { ría } \\
\text { Deseado }\end{array}$} & $\begin{array}{l}\text { Margen } \\
\text { norte de la } \\
\text { ría } \\
\text { Deseado }\end{array}$ & Alero 4 & Alero & $\begin{array}{c}1690 \pm 90(\text { LP } 2908 \\
\text { carbón vegetal }) \\
2760 \pm 70(\text { LP-2762, } \\
\text { hueso de guanaco })\end{array}$ & $\begin{array}{c}\text { Ambrústolo y } \\
\text { Ciampagna } 2014\end{array}$ \\
\hline & \multirow[t]{3}{*}{$\begin{array}{l}\text { Bahía del } \\
\text { Oso } \\
\text { Marino }\end{array}$} & $\begin{array}{l}\text { Alero El } \\
\text { Oriental }\end{array}$ & Alero & $\begin{array}{l}\text { capa } 1 / 2: 1530 \pm 60 \\
\text { (LP- } 2267, \text { carbón } \\
\text { vegetal), capa } 3: 5150 \\
\pm 80(\text { LP } 2311, \\
\text { carbón vegetal), capa } \\
\text { 4: } 5810 \pm 110 \text { (LP- } \\
2218, \text { carbón vegetal), } \\
5860 \pm 90(\text { LP } 2310, \\
\text { carbón vegetal) y } \\
6930 \pm 100 \text { (LP- } \\
2318, \text { carbón vegetal) }\end{array}$ & $\begin{array}{l}\text { Ambrústolo et } \\
\text { al. } 2011\end{array}$ \\
\hline & & $\begin{array}{l}\text { Cueva del } \\
\text { Negro }\end{array}$ & $\begin{array}{c}\text { Sitio } \\
\text { conchero en } \\
\text { cueva }\end{array}$ & $\begin{array}{c}\text { capa } 2: 1170 \pm 110 \\
\text { (LP- 2290, carbón } \\
\text { vegetal) capa } 3: 1340 \\
\pm 60 \text { (LP- } 2065, \\
\text { carbón vegetal), capa } \\
\text { 4/5:1390 } 70 \text { (LP- } \\
2320, \text { hueso); capa } \\
3: 1220 \pm 80 \text { (LP- } \\
2047, \text { Nacella } \\
\text { magellanica) } 1290 \pm \\
50 \text { (LP-2279, Nacella } \\
\text { magellanica) }\end{array}$ & $\begin{array}{c}\text { Zubimendi } 2010 \\
\text { Zubimendi et al. } \\
\text { 2011, Trola y } \\
\text { Ciampagna } \\
\text { 2011, Capparelli } \\
\text { et al. } 2009\end{array}$ \\
\hline & & Las Hormigas & Conchero & $\begin{array}{l}370 \pm 40(\mathrm{LP}-2504 \\
\text { carbón vegetal) }\end{array}$ & $\begin{array}{c}\text { Hammond y } \\
\text { Zubimendi } 2013\end{array}$ \\
\hline & Isla Lobos & 112 & conchero & $\begin{array}{c}2870 \pm 60(\mathrm{LP}-2141 \\
\text { carbón vegetal) }\end{array}$ & $\begin{array}{c}\text { Hammond y } \\
\text { Zubimendi } 2013\end{array}$ \\
\hline & $\begin{array}{c}\text { Punta } \\
\text { Medanosa }\end{array}$ & 160 & Conchero & $\begin{array}{l}370 \pm 50(\mathrm{LP}-2507 \\
\quad \text { carbón vegetal })\end{array}$ & $\begin{array}{c}\text { Hammond y } \\
\text { Zubimendi 2013, } \\
\text { Trola y } \\
\text { Ciampagna 2011 }\end{array}$ \\
\hline
\end{tabular}

Tabla 1.1. Información contextual de los sitios estudiados en esta tesis

${ }^{2}$ Los fechados realizados sobre valvas marinas han sido corregidos por efecto reservorio restándole 400 años de acuerdo al valor estándar considerado para las muestras de origen marino (Stuiver y Braziunas 1993), ya que el valor local es desconocido. 


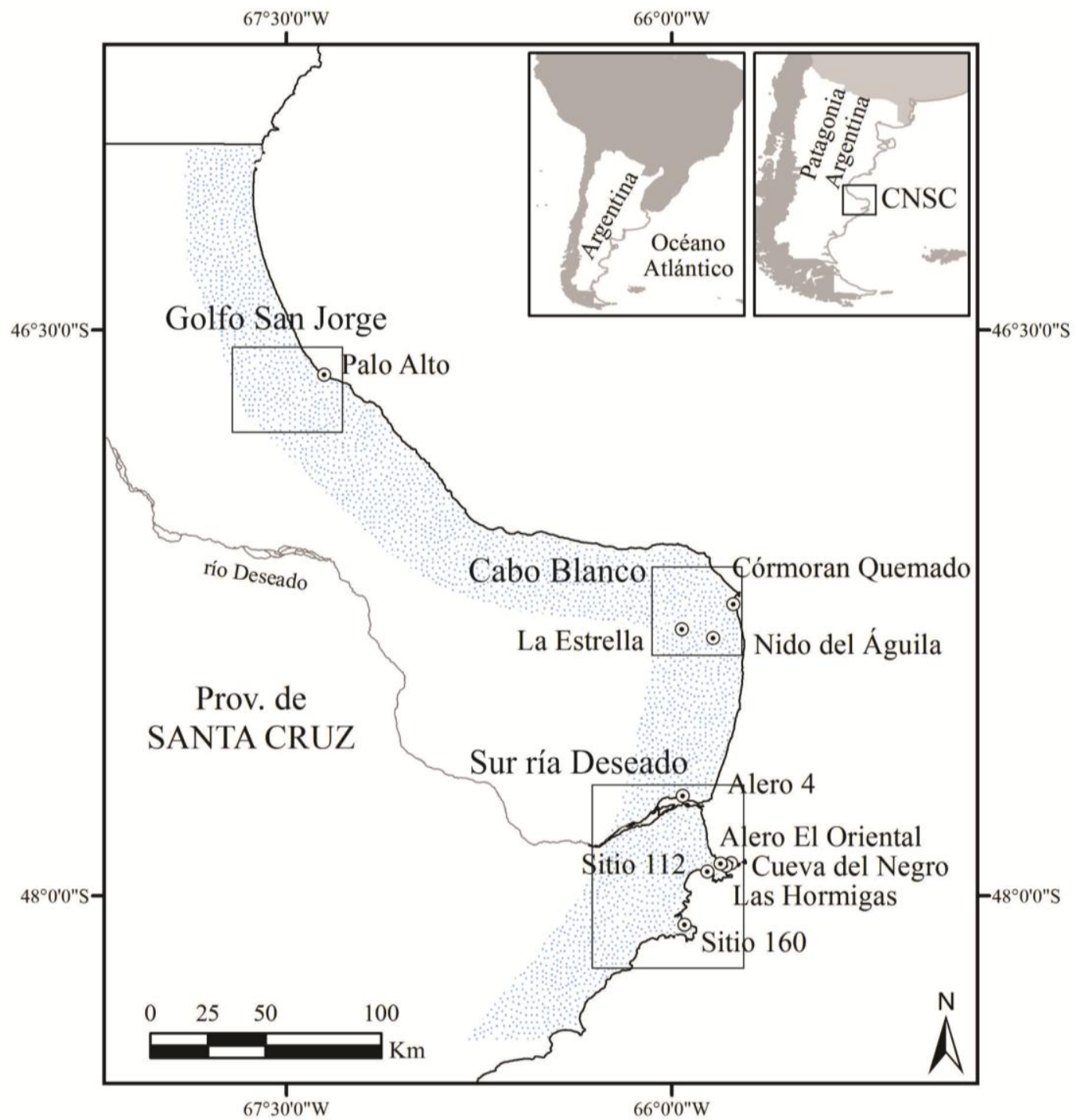

Figura 1.1. Mapa de la Costa Norte de Santa Cruz (franja de puntos) y distribución de los sitio analizados en la presente tesis.

\subsection{Organización de la tesis}

Esta tesis se encuentra conformada por 14 capítulos. La Sección I está constituida por tres capítulos. El primero de ellos es la Introducción, donde se presenta el problema de estudio y el contexto de investigación. También se formulan los objetivos y las hipótesis en relación a los primeros y los sitios arqueológicos analizados para el alcance de ambos. 
En el capítulo 2, se exponen las herramientas conceptuales provenientes de distintos enfoques teóricos que constituyen el Marco teórico desde el cual se abordará el problema de estudio.

El Área de estudio y los Antecedentes arqueológicos se describen en el capítulo 3. Se hace hincapié en la descripción de la vegetación como la variable que mejor describe el ambiente de un área de estudio determinada.

La Sección II presenta el desarrollo de la tesis a través de una Parte I y otra Parte II. En la primera (capítulos 4 y 5), se presentan datos histórico-documentales y etnobotánicos actuales sobre usos de plantas relevantes para el área de estudio; mientras que la segunda (capítulos 4 al 13) hace referencia a aspectos arqueológicos y arqueobotánicos. Dentro de la Parte I, el capítulo 4 en particular, refiere a un análisis bibliográfico de cronistas y viajeros del siglo XVI al XIX, etnografías y primeras investigaciones etnobotánicas del siglo XX de la Patagonia argentina continental. Para ello se utilizaron fuentes editadas de primer y segundo orden de las que se extrajeron datos referidos a las prácticas de recolección desarrolladas por los distintos grupos que habitaron Patagonia, los usos de las plantas, el procesamiento de las mismas y los agentes de recolección en el contexto histórico en el que se produjo esa información. El capítulo 5 presenta los estudios etnobotánicos realizados por la autora en dos localidades del área CNSC (Puerto Deseado y Tellier), a través del raport con pobladores locales vinculados al trabajo rural. Se realizaron entrevistas abiertas y semiestructuradas así como observación participante. Se tienen en cuenta los procesos históricos que se desarrollaron en la región conformando poblaciones con diversas identidades y saberes. Se relevaron tanto prácticas de recolección y categorías de uso de plantas, como datos referentes a sistemas de clasificación y transmisión de conocimiento. A partir de la información obtenida en los capítulos 4 y 5 , y teniendo en cuenta las dificultades y riesgos de extrapolar información entre las diversas poblaciones del área, que han sido atravesadas por distintos procesos históricos, se discute el valor de la analogía para este trabajo y se propone un modelo para interpretar la materialidad de las prácticas de recolección de plantas silvestres en la CNSC en el pasado.

Dentro de la Parte II, el capítulo 6 en particular, refiere a un análisis bibliográfico del registro arqueobotánico recuperado, hasta el momento, en la Patagonia continental argentina. El mismo se basa en una minuciosa recopilación de la información 
disponible, donde se registra, de cada publicación arqueológica, la identificación taxonómica, el estado de preservación (carbonizado o seco) y la parte vegetal de los restos recuperados. Se analizan, discuten y sintetizan los datos obtenidos a fin de delinear expectativas arqueobotánicas y colecciones de referencia necesarias para los sitios de CNSC aquí considerados. El capítulo 7 presenta la colección de referencia de macrorrestos leñosos y su descripción morfo-anatómica, así como un trabajo experimental de carbonización de cada especie recolectada donde se registran las alteraciones producidas en su morfología como consecuencia de la combustión a distintas temperaturas y humedades relativas. Del capítulo 8 al 10 se analiza el registro arqueobotánico de macrorrestos recuperados de cada sitio arqueológico de la CNSC, a excepción de la confección de artefactos que se presenta en el capítulo 11. Los sitios se presentan de norte a sur a lo largo de la CNSC y en relación a su ubicación dentro de los sectores Golfo San Jorge, Cabo Blanco y Sur de la ría Deseado (Zubimendi 2010). El análisis del registro artefactual confeccionado a base de vegetales se describe en el capítulo 11. En este caso, se trata de un único artefacto, un fragmento de arpón manufacturado en madera y recuperado en el Sitio Cueva del Negro. A partir del capítulo 12 al 13 se estudia el registro arqueobotánico de microrrestos. En el capítulo 12 se presenta la colección de referencia utilizada en la presente tesis para el análisis de este tipo de evidencia, cuya implementación contó con la colaboración de la Ing. Agr. Laura Borrelli del INTA Bariloche. Esta colección fue realizada a través de la técnica microhistológica. En el capítulo 13 se presenta, por un lado, una recopilación de las publicaciones arqueológicas con citas de recuperación o registro de artefactos de molienda donde se especifica el contexto cronológico, tipo de sitio donde fueron recuperados, materia prima y si fueron o no analizados con técnicas arqueobotánicas; y por otro, el análisis de los artefactos de CNSC que podrían haber sido potencialmente utilizados en la molienda y los microrrestos recuperados. Por último, se presenta en el capítulo 14 la Discusión final y Conclusiones de esta tesis, donde se vinculan las consideraciones a partir de la información etnobotánica y documental, los distintos registros arqueobotánicos (macro y microrrestos) y el contexto arqueológico desde el análisis de los sitios analizados. Se postulan además las perspectivas futuras derivadas de los resultados de la presente tesis. Al finalizar se presenta un Anexo donde se disponen las fotografías de los carbones arqueológicos identificados en los sitios. 


\section{Marco teórico}

En esta tesis se utilizarán herramientas teóricas para la interpretación de la materialidad de las prácticas desarrolladas por los grupos cazadores recolectores que habitaron la CNSC. Se considerarán además conceptos de la Teoría social que permitan reflejar la complejidad del comportamiento social e históricamente construidos por los grupos humanos. En este sentido se considera que la utilización de varios enfoques y niveles de análisis permite obtener una mayor cantidad de elementos para interpretar prácticas culturales abordando las dimensiones económica, social e ideacional en tanto aspectos interrelacionados (Trigger 1991, Hodder 1986, Ambrústolo 2011).

Como menciona Castro et al. (2003) para describir las elecciones teóricas y metodológicas sobre el estudio de las ocupaciones costeras de CNSC, en el inicio del proyecto arqueológico, el desafío se encontraba en abordar el problema en un área extensa y poco conocida. En este sentido, el estudio de las prácticas de recolección de vegetales por los grupos cazadores recolectores del área, hasta el momento, puede remitirse a esa primera etapa del proyecto CNSC. La mejor estrategia que Castro y colaboradores asumieron para superar este vacío de información, fue la realización de estudios empíricos particularizados para cada ambiente y latitud desde una perspectiva arqueológica. Se considera que para el problema de investigación de esta tesis se retoma esta vía analítica y se suma el análisis holístico de distintas fuentes de información: documental, etnobotánica y arqueobotánica. Esta tesis se enmarca entonces, dentro de una investigación exploratoria debido a que constituye la primera aproximación a las prácticas de recolección de recursos vegetales silvestres por parte de los grupos que habitaron la CNSC.

Las prácticas de recolección de vegetales se encuentran relacionadas con las estrategias de asentamiento y movilidad de los grupos cazadores recolectores. En este sentido, se entiende que la movilidad puede haber sido desarrollada por los grupos humanos en relación a la búsqueda de recursos alimenticios, en el marco de actividades sociales y simbólicas, en relación a vínculos de parentesco o linajes 
exogámicos, motivos artísticos, religiosos o personales (Binford 1980). A su vez, también es posible que estos desplazamientos se hubieran producido en pos de obtener información sobre la estructura de recursos y de esta manera proyectar actividades sobre nuevos espacios (Berón 1994).

Binford (1977) considera que el movimiento de un grupo cazador recolector, en un territorio, se encuentra en relación a la disponibilidad estacional y distribución de recursos. A partir de este contexto, el autor considera dos posibles estrategias para contrarrestar las variaciones en la disponibilidad y distribución de los mismos. Propuso entonces dos tipos hipotéticos de asentamiento: uno de movilidad residencial, donde los grupos explotarían los recursos ubicados a corta distancia de la unidad residencial. Cuando los recursos se agotan el grupo se movilizaría hacia otro lugar. Esta estrategia se encontraría asociada a los emplazamientos denominados bases residenciales, en las que se desarrolla la mayor parte del procesamiento, manufactura $y$ otras actividades de mantenimiento. En este sentido, los grupos desarrollarían tareas en las cercanías de esos campamentos caracterizadas como localizaciones breves y con reocupaciones genéricas de ese espacio. La movilidad logística se desarrollaría en territorios donde la distribución de los recursos es incongruente a nivel espaciotemporal. Los grupos se asentarían en las cercanías de uno o más de un recurso caracterizado como crítico y a través de la implementación de viajes específicos, de corta duración y realizados por pocos individuos, se proveerían de otros recursos. Los tipos de asentamiento que se vincularían con esta estrategia de movilidad son las localizaciones; definidas por Binford como lugares donde se llevan a cabo actividades extractivas: matanza y faenamiento, obtención de recursos vegetales, prueba o acondicionamiento de nódulos, entre otras. Es importante mencionar que estas estrategias de movilidad son complementarias en mayor o menor medida entre sí. Por otra parte, Whallon (2006) menciona dos estrategias más de movilidad: de red social y de información. En la primera, tanto individuos como el grupo en su totalidad se mueven por razones sociales que desde la etnografía fueron descriptas simplemente como "visitas", pero que pueden contener elementos ceremoniales y rituales involucrados. En el segundo caso, que puede estar presente en las otras tres estrategias (residencial, logístico o 
de red social) refiere a aquellos movimientos en los que adquirir o refrescar información ambiental es el principal objetivo. Las evidencias arqueológicas de estas últimas estrategias responderían a sitios en ambientes "no utilitarios" sin patrones de asentamiento residenciales o extractivos.

Se considera que estos modelos de movilidad para los grupos cazadores recolectores y de interacción con el ambiente, permiten un primer nivel de análisis donde se interpreta la materialidad producida por dichos grupos y los datos aqueológicos construidos por el investigador. Sin embargo, si bien se utiliza estos modelos en la presente tesis, se entiende que a pesar de que el medio limita los recursos disponibles en un área, la selección de uno u otro recurso así como, de un lugar de asentamiento, deben ser considerados hechos sociales. Es decir, son producto de una toma de decisiones conscientes por el grupo, en función de la tecnología y las normas sociales del mismo (Barceló et al. 2004 en Berihuete 2009).

En este sentido, además acordamos con la propuesta teórica de Gómez (2008) quien a través de un análisis etnográfico y de investigación participativa con grupos de mujeres recolectoras tobas comprende que la relación con el ambiente se produce a partir de la interacción corporal perceptiva con los lugares que son significativos para el grupo. La autora utiliza como herramientas teóricas los conceptos de interacción comprometida de Ingold (1993:120) en donde refiere que aprender a morar un territorio demanda una participación activa, práctica y perceptiva ya que, se debe adquirir las habilidades necesarias para la percepción directa y comprometida de todos los constituyentes del espacio: humanos, animales, componentes animados y no animados. Así también, se vale del concepto de habitus (Bourdieu 1972,1991) en el que a partir de esquemas prácticos de acción y percepción que se generan históricamente dentro de una cultura, se da un orden práctico al mundo, a las cosas, dejando espacio para la improvisación y la espontaneidad. Consideramos que, como un segundo nivel de análisis estas herramientas teóricas pueden acercarnos a comprender la complejidad del comportamiento humano. 


\subsection{Las prácticas de recolección de plantas silvestres}

En primer lugar, como se definió en el capítulo 1, el presente trabajo de tesis se desarrolla en el marco de la Paleoetnobotánica. Desde este enfoque se analizan e interpretan las interrelaciones directas entre grupos humanos y las plantas que se materializaron en el registro arqueológico (Ford 1979).

A lo largo de la historia, los grupos humanos y las plantas desarrollaron distintos grados de dependencia mutua; Harris (2007) propone un modelo hipotético para describir el proceso, que explica el pasaje a distintos umbrales de incremento de energía humana aplicada por unidad de área de tierra explotada, en el que se produce un continuum de interacción de grupos humanos y plantas. El autor observa niveles de incremento de energía, a partir de un mayor esfuerzo invertido en la elección de áreas de explotación, intervención humana en la ecología y biología reproductiva de determinadas plantas. Se postulan tres umbrales de incremento de energía:

- El primero, se encuentra entre las actividades de baja energía y espacialmente dispersas, éste implica la recolección, protección y distinción entre el sistema de alimento flexible de procuramiento de plantas silvestres o forrajeo de la producción de alimentos silvestres.

- El segundo umbral se encuentra entre actividades espacialmente circunscriptas, de mayor demanda de esfuerzo y actividades ecológicamente más intervencionistas, éstas incluyen desde plantar y sembrar a la irrigación y drenaje, así como las actividades más intensivas en cuanto a energía de limpieza del terreno y cultivo sistemático. En esta etapa se observa una separación entre la producción de alimento de plantas silvestres y el cultivo. Este último se define como la combinación de limpieza sistemática del terreno y labrado con plantación o siembra de cultivos no domesticados.

- El tercer umbral entonces es el pasaje del cultivo a la agricultura, e implica, a partir de la preparación del suelo, el manteniendo de la fertilidad del mismo, el desmalezado, la selección de semillas y almacenamiento, así como la exclusión de predadores potenciales y el cultivo de especies 
domesticadas. En este modelo, una fase no necesariamente implica la sucesión de la otra en sentido progresivo.

En esta tesis se hace foco en el primer umbral de interacción entre hombres y plantas, es decir en el estudio de las prácticas de recolección aplicadas por los grupos cazadores recolectores de la CNSC. La recolección es entendida aquí como una categoría flexible que abarca comportamientos humanos complejos, y que incluye, como se dijo anteriormente, selección, obtención, gestión y consumo de plantas silvestres ${ }^{3}$. Para Harlan y De Wet (1965), Ford (1979), Rindos (1984), la recolección contempla el uso de plantas silvestres sin intención de propiciar un cambio morfológico, fisiológico o de otro tipo en las mismas, pudiendo haber, por lo tanto, sólo modificaciones inconscientes a distinta escala. Chase (1989) en cambio, considera que existe una intencionalidad en los grupos humanos en la articulación y mantenimiento de la producción y distribución de los recursos, por lo que propone el término "domicultura" para el resultado de la acción intencional humana sobre las plantas culturalmente conocidas. Casas (2001) por su parte, a partir de estudios etnobotánicos en comunidades mesoamericanas reconoce distintas técnicas de manipulación de plantas silvestres. Entre ellas, describe la recolección, que está basada en la cosecha de los productos útiles de las poblaciones vegetales silvestres, y observa que generalmente donde no existe un manejo de la vegetación, el impacto sobre los genotipos de las plantas suele ser mínimo. Sin embargo, es posible que en la selección de ciertos fenotipos los grupos humanos puedan establecer formas incipientes de manejo. Por otra parte, se pueden desarrollar prácticas dirigidas a mantener dentro de ambientes antropogénicos, plantas útiles que existían antes de que el ambiente fuera transformado por el hombre, en este caso se habla de tolerancia (Casas 2001). También se han registrado estrategias dirigidas a aumentar la densidad de población de especies útiles en una comunidad vegetal, por ejemplo, mediante quemas y tala de vegetación; en este sentido Casas (2001) habla de fomento. Por

\footnotetext{
${ }^{3}$ Con esta categorización no es nuestra intención acrecentar la dicotomía ya existente entre la estrategia cazadora-recolectora como opuesta y excluyente con respecto a aquella "productora", lo cual podría constituir un preconcepto sesgado de la realidad (ver Mason y Hather 2002), sino definir a la sociedad estudiada en este caso por lo que creemos fue su estrategia de subsistencia dominante.
} 
último, este autor, manifiesta que cuando los grupos humanos desarrollan cuidados, como la eliminación de competidores y depredadores entre otros, a fin de salvaguardar ciertas plantas que tienen un valor especial, se puede denominar a esta interacción como protección. Dentro de los comportamientos de fomento, se encuentran las prácticas observadas por Politis (2007) entre los Nukak, un grupo cazador recolector de la Amazonía Colombiana. Esta práctica favorecería la concentración de plantas útiles silvestres cortando otras que compiten con éstas, como árboles y palmas. Además, cuando las bandas abandonan los campamentos, el piso de la ocupación presenta una gran cantidad de semillas de los frutos consumidos durante la ocupación, con la consecuente concentración de una determinada variedad de especies que por otra parte no tiene otros competidores ya que el piso se encuentra desprovisto de otras plantas. Debido a que los Nukak no construyen campamentos donde hubo uno anterior, estos espacios se desarrollan como huertos silvestres, por lo que la alta movilidad residencial y el uso redundante de algunos sectores del paisaje generarían un sistema de parches de recursos vegetales silvestres (Politis et al. 1997)

Es importante mencionar que muchas plantas silvestres son recursos importantes para los grupos humanos debido a su fisiología. Por ejemplo, Etkin (1994), destaca la alta concentración de aleloquímicos, que son relevantes tanto para la dieta como para la farmacopea de cada sociedad. A su vez, estos compuestos han funcionado como guías para la selección de estas plantas tanto para alimento como para medicina. Por otra parte, también es reconocido el valor de las plantas silvestres en momentos de hambruna, en este caso Etkin (1994) compila estudios etnobotánicos donde se muestra que si bien la práctica de su consumo puede no ser continua, sí lo es la transmisión de la información, que pasa de generación en generación a través de los mitos, el ritual o la historia oral. Asimismo, la autora propone que la búsqueda y el consumo de recursos silvestres en momentos de catástrofes o períodos de escasez, además de ser una estrategia adaptativa en sí misma, permite incorporar nuevos conocimientos. El consumo de plantas silvestres además, aumentaría la respuesta del sistema inmune del organismo humano. En este sentido, se desarrollaron trabajos sobre cómo los grupos humanos conocían las propiedades de estas plantas (Etkin y Ross 1994, Johns 
1994, Logan y Dixon 1994). En ellos se evaluó si primeramente fueron incorporadas a la dieta y luego reconocidas sus propiedades medicinales o si se dio en sentido inverso. Para Etkin y Ross (1994) en sus investigaciones sobre uso de plantas silvestres en las comunidades Hausa es a partir de la experimentación y conocimiento de plantas medicinales que luego incorporan algunas de ellas como alimento. En cambio, Johns (1994) así como Logan y Dixon (1994) sostienen el modelo en que primero las plantas silvestres fueron consumidas como alimento y luego los grupos aprendieron su valor medicinal. Leonti et al. (2003) y Molares (2009) evidencian que las farmacopeas nativas se han construido con la selección de familias y especies a partir de complejas bases quimio-taxonómicas, ecológicas y culturales. Es interesante mencionar que Almeida y colaboradores (2005) han registrado que las plantas leñosas también serían recursos relevantes medicinales en los ambientes áridos, por su contenido de principios activos debido a la adaptación de estas especies al estrés hídrico, a la alta radiación solar y a condiciones térmicas extremas.

Se considera entonces, que, por parte de los grupos humanos existe una selección de los recursos vegetales que son recolectados, y que estas prácticas se basan no sólo en las características anatómicas y fisiológicas de las plantas sino también en las creencias y representaciones simbólicas de los grupos humanos, así como del conocimiento que han construido a lo largo de generaciones (Toledo 1992). Cada sociedad entonces, posee un saber ecológico tradicional conformado por un cuerpo de creencias (cosmos), de conocimientos (corpus) y de prácticas (praxis) que al momento de su aplicación están atravesadas por las dos categorías primeras (Toledo 1992).

Dentro de este saber ecológico se encuentra aquel relacionado específicamente con las plantas, y es denominado conocimiento botánico tradicional (CBT) (Pochettino y Lema 2008). Este concepto refiere a una síntesis de saberes, que se genera tanto a partir del conocimiento producido localmente a través de la práctica y experimentación, así como también, por la incorporación de información de otras fuentes (Pocchettino y Lema 2008: 235). Las autoras consideran que este concepto no necesariamente debe tener un arraigamiento temporal profundo, donde las transformaciones, adquisiciones y puesta en práctica del conocimiento 
sobre el entorno vegetal pueden darse en un lapso breve a partir de la experimentación directa con el entorno (Tengo y Belfrange, 2004). Eyssastier (2011) en su tesis, observa el aprendizaje y la transmisión cultural en pobladores rurales a través de las prácticas hortícolas y de la recolección de plantas silvestres. Esta autora considera al igual que Cavalli-Sforza et al. (1982) que dicha transmisión puede ocurrir entre personas de diferentes generaciones dentro de una genealogía (transmisión vertical), entre individuos de la misma generación (transmisión horizontal) y entre líneas genealógicas (transmisión oblicua).

En esta selección de las plantas se observa a su vez, un ordenamiento del mundo natural, en este sentido Brent Berlin (1992, traducción Pochettino en prensa) considera que los grupos de plantas y animales se presentan como una serie de discontinuidades cuya estructura y contenido pueden ser percibidos por todos los seres humanos. Sin embargo, cualquier sistema folk sólo reconoce ciertas porciones de la realidad biológica presente en un hábitat local. Para Pochettino (en prensa) es posible que dentro de una especie botánica se encuentren diversos cultivares (poblaciones de plantas cultivadas diferentes de las otras por aspectos morfológicos) y que los mismos sean percibidos por los pobladores como entidades vegetales diversas denominadas etnoespecie (Pochettino en prensa). Cada una de estas entidades es una variedad botánica pero es manejada como una especie diferente desde el punto de vista de sus usos y su selección.

En la compilación de trabajos realizados por Etkin (1994), también se considera relevante en el estudio de plantas silvestres los procesamientos que los grupos humanos han realizado sobre las mismas para obtener mayor palatabilidad. La alta concentración de aleloquímicos en dichas plantas pueden resultar tóxicas en consumo directo, además el procesamiento permite obtener mayor bioaccesibilidad de macronutrientes (proteínas, lípidos, carbohidratos y fibras) y/o micronutrientes (minerales y vitaminas) importantes en el consumo y digestión humana (Parada y Aguilera 2007). En este sentido Wollstonecroft (2007), quien estudia sociedades cazadoras recolectoras de British Columbia (Canadá), en relación al consumo de plantas silvestres, construye el concepto de procesamiento poscosecha y lo define en sentido amplio para incluir habilidades, conocimientos, tecnología y coordinación de trabajo que permiten convertir plantas en estado 
bruto en productos comestibles, y/o para preservarlas como productos almacenables, y/o promover la disponibilidad de nutrientes. Capparelli y Lema (2010) a fin de construir un marco teórico que pueda ser aplicado a distintos tipos de sociedades y materialidades arqueológicas en Argentina, y siguiendo el concepto de poscosecha de Wollstonecroft (2007), definen distintas instancias en la relación entre las sociedades humanas y la comunidad vegetal. Proponen así cuatro esferas o ámbitos de acción donde se desarrollan distintas prácticas: la precolecta, colecta, poscolecta y consumo. En la primera, se establece el vínculo del hombre con su medio, sea cual fuere el sistema socioeconómico en el que estuviera inserto. Las prácticas que se lleven a cabo en esta esfera generarán un entorno modificado en distinto grado por la acción antrópica, donde se obtendrá la materia prima vegetal sobre las que se desarrollarán acciones de las otras esferas. A su vez, las autoras expican que la forma en que se colecta la planta producirá un impacto distinto en el sistema precolecta -si se alteran caracteres morfológicos y genéticos a nivel poblacional y modifica la selección cultural aplicada a los mismos (Casas 2001) así como en el sistema poscolecta. En este último, porque es en esta instancia donde se eligen los órganos o parte de órganos a ser utilizados. En esta fase se identifican características de las plantas que favorecen o no a ciertas técnicas como la cocción, molienda o formatización. En cuanto al consumo se observa una influencia sobre las otras esferas puesto que determina qué se produce, qué se elige, y qué se rechaza (precolecta) dentro de la disponibilidad del entorno vegetal, qué órganos o tejidos se emplearán (colecta), cómo serán procesados los mismos, si se los almacenará o dónde se los consumirá -traslado(poscolecta) (Capparelli y Lema 2010:1174). Entonces, las prácticas poscosecha están íntimamente ligadas a los modos de consumo y éstos a los criterios de selección de las plantas (Capparelli y Lema 2010), por lo que resultan importantes para estudiar las prácticas de recolección desde un sentido amplio

En el caso específico de los recursos leñosos, existen otras variables que, junto a las anteriores, deben ser consideradas. Archila (2005) considera que la selección de una madera depende de: características físicas como forma, tamaño; poder calórico; humo producido cuando se quema; razones culturales; disponibilidad local; y facilidad para recolectarla. Asimismo, la madera para combustible es 
seleccionada por su forma y tamaño. En este modelo la autora describe los tipos de combustibles, la localización de los fuegos y los fogones, y los lugares para la disposición de diferentes tipos de fuegos. Picornell (2009) por su parte, realizó un estudio sobre las prácticas cotidianas de aprovisionamiento de leña entre el pueblo Fang de Guinea Ecuatorial, en donde observa que la selección de maderas para combustible sólo se desarrolla en función del tamaño o diámetro adecuado y no por género o especie. Sin embargo, para la manufactura de algún artefacto o instrumento sí se selecciona una madera de un árbol específico. Es interesante remarcar, que en su trabajo etnográfico, observa que entre las prácticas de aprovisionamiento de leña, las mujeres Fang evitan la madera de dos árboles, “ebaiñ” y "ñuará”, debido a que consideran que está asociado a la destrucción. Los fang consideran que se trata de árboles con espíritu violento, demasiado fuerte para ser usado en las cocinas. De este caso se desprende que no siempre las características físicas de las especies taxonómicas determinan su elección o no elección, sino que el sistema de creencias interviene en la misma (Picornell 2009). Cuando no es posible realizar estudios etnográficos para analizar la selección de maderas por distintos grupos humanos, Marston (2009) considera que las variables del modelo de principio de menor esfuerzo son válidas para generar hipótesis a ser contrastadas por el registro arqueológico. De esta manera, el autor compara los ranking de taxa representados en el registro arqueológico de Anatolia Central con el ranking de taxa desarrollado a partir de los datos actuales para cada una de las variables de la ley del principio de menor esfuerzo: disponibilidad, adecuación del material para el objetivo por el cual es seleccionado, y costo de manipulación. La primera variable es medida teniendo en cuenta la frecuencia del recurso en el área; el segundo criterio, en el caso de los recursos combustibles, está en relación al poder calórico, mientras que el costo de manipulación es evaluado en términos de distancia al recurso. Luego evalúa entonces qué criterio prevaleció en el pasado, ya que en los casos por él estudiados, el ránking arqueológico de recursos leñosos utilizados responde más a la disponibilidad de los distintos taxa que al poder calórico de los mismos (Marston 2009).

En esta tesis se considera que la gestión de recursos forestales, tal como la denomina Piqué i Huerta (1999), es el modo históricamente determinado en que 
actúan las sociedades sobre los recursos vegetales del ambiente. Las prácticas de gestión de las especies leñosas, según la autora, se llevan a cabo por el conocimiento de producción y regeneración de las diferentes materias naturales; el conocimiento de las propiedades de los taxa que componen las comunidades forestales explotadas y de los ritmos de producción de madera muerta marcada por ciclos naturales de muerte y regeneración de los bosques. Estos criterios repercutirán en el diseño de las estrategias de aprovisionamiento del combustible, en este sentido socialmente determinadas (Piqué i Huerta 1999). En este sentido esta perspectiva busca trascender los criterios utilizados en los marcos teóricos que tienen como premisa básica del menor esfuerzo. De los recursos forestales utilizados para combustible, en esta tesis se acuerda con Andreoni (2014) en la definición de estos últimos como de buena o mala calidad. Para clasificar las leñas en estos términos debe tenerse en cuenta la resistencia a la combustión e inflamabilidad, que se relaciona con la densidad de la madera, ya que cuanto más densa y más pesada mayor rendimiento tendrá como combustible debido a que tiene una mayor resistencia a la combustión, por lo que se requiere además menos volumen de madera para obtener buenos resultados. Debe considerarse también la resistencia a la transformación mecánica, la cual es importante en el momento de la recolección de los leños, cuanto más flexible más difícil será extraer la planta. Por otra parte, debe considerarse la morfología, aspecto que refiere al calibre del leño, así como la anatomía del mismo teniendo en cuenta la presencia de cristales, resinas y grosor de las fibras. Y por otra parte, el valor que el taxón tiene dentro de la sociedad, variable en la cual intervienen otros factores, como los mencionados por Picornell (2009); o que, por tener mayor valor, por ejemplo por sus frutos no se utilice para combustión.

\subsection{Prácticas de manejo del uso del fuego y el fogón como estructurador del espacio}

Uno de los ejes principales de esta tesis es el análisis de estructuras de combustión en distintos tipos de sitios (cueva, aleros, a cielo abierto y concheros) y esto implica además de la interacción del hombre y las plantas (los recursos leñosos 
combustibles específicamente) las prácticas de manejo del fuego. Como menciona Frank (2011) el fuego está presente en todas las sociedades y es necesario para distintas actividades de los grupos humanos por lo que se asocia a contextos sociales, simbólicos, rituales, tecnológicos y también repercute en los aspectos fisiológicos del hombre. En este sentido, el manejo del fuego puede ser analizado como una tecnología vinculada a la supervivencia y de la vida diaria de las poblaciones (Manzi y Spikins 2008).

Distintos autores clasifican las estructuras de combustión de acuerdo a su morfología y superficie de ocupación (Léroi-Gourhan 1972, Marconetto 2005) en: Estructura en cubeta: la combustión se produce dentro de un área restringida físicamente por un desnivel excavado artificialmente o de origen natural. Se asocia a combustiones de mayor duración siendo que además, deja mayor cantidad de residuos carbonizados.

Estructura en plato: la combustión se produce en una superficie sin desnivel y se asocia a la obtención de fogones de temperaturas más bajas y regulares que las del tipo de fogón anterior.

Estructura sobre-elevada: la combustión se desarrolla en una sobre elevación con respecto al nivel del piso a partir por ejemplo, de una construcción de piedras. Esta estructura al igual que los fogones en plato produce mayor cantidad de ceniza y menos carbón, encontrándose los residuos más expuestos a la dispersión.

Debido a que los fogones en cubeta requieren de mayor trabajo se esperaría que correspondieran a ocupaciones más intensas mientras que, en estructuras en plato las ocupaciones se interpretarían en sentido inverso.

Las prácticas de manejo del fuego entendidas por Pérez de Micou (1991) y Frank (2011), y que dan lugar a las estructuras arriba descriptas, refieren al conjunto de actividades que involucran la apropiación de los recursos leñosos -que en esta tesis se va a denominar de acuerdo a Piqué i Huerta (1999) gestión de recursos leñosos, encendido, mantenimiento, uso y apagado. Pérez de Micou (1991) a través de un estudio etnoarqueológico realizado en el área de Piedra Parada (Chubut, Argentina) desarrolla un modelo sistémico de manejo del fuego y analiza los vestigios que quedarían de las distintas actividades. En el caso de los fuegos desarrollados para calefacción, la obtención de los recursos leñosos se desarrolla o 
bien seleccionando una mata aislada, o bien recolectando tallos leñosos, se encienden (en el caso de la primera opción directamente a la mata y en el segundo amontonando los tallos y luego encendiendo desde la base). En cuanto al mantenimiento de este tipo de fuego, en el primer caso, se controlaría que no se extendiera la llama a otras matas y en el segundo, se pasan los pies y las manos sobre el fuego. Para el apagado se cubre con tierra las matas carbonizadas y en el segundo, se pisotea hasta que se apaga. El resultado de estas actividades produce que la mata esté cubierta de tierra y una estructura amplia plana. En relación al uso del fuego como comunicación la autora describe la selección de un arbusto por pobladores locales, el encendido in situ de la mata aislada, el mantenimiento circunscribiéndolo sin una actividad de apagado. En este caso se observa la base del arbusto quemado.

De esta manera, Pérez de Micou (1991:139) desarrolla las siguientes expectativas arqueológicas: para un fogón cuya función principal haya sido de cocina, iluminación entre otras actividades domésticas, se esperaría en sitios aleros fogones en cubeta por reuso y/o reactivación. En cambio, a cielo abierto en cubeta por cavado y/o plano con borde de piedras. En relación al uso del fuego para señales se esperaría que sólo se registrara en sitios a cielo abierto mediante la acumulación de carbón compactado sobre la superficie. En el caso de calefacción y secado, en sitios alero, se esperaría observar estructuras planas y en sitios a cielo abierto, tanto acumulación de carbón compactado sobre la superficie o estructuras planas.

A través de estudios etnohistóricos y etnográficos, Archila (2005) caracteriza distintos tipos de fogones realizados por grupos cazadores recolectores de la Amazonía colombiana. Entre éstos identifica los fogones domésticos permanentes, que son usados a lo largo del tiempo mientras dure la ocupación de una casa o un campamento. Estos fogones abarcan parte del sitio de habitación siendo su principal función la cocción de alimentos, calentar el ambiente y repeler insectos. Los combustibles usados pueden ser corteza, semillas y leña. En relación a estas últimas son taxa intencionalmente seleccionados como leña. Las maderas secundarias de combustible incluyen leños usados en la construcción y para la manufactura de artefactos domésticos, armas e instrumentos musicales (Archila 
2005:282). Estos fogones pueden localizarse dentro y fuera de las casas, donde los carbones producto de estas estructuras pueden ser dejados in situ o ser removidos y re-depositados en pozos, lugares de descarte o barridos fuera de las casas o de los campamentos. En esta región, los fogones se realizan en el centro de las casas individuales o en un área periférica en una casa comunal. En este último caso el número de estructuras dependerá de la cantidad de familias nucleares que habiten la casa comunal. La autora también identifica en estudios etnográficos entre la gente Yukuna que en el espacio comunal central, los miembros mayores de la comunidad realizan algunos bailes y cantos durante ciertas ceremonias, en las que otras personas de la comunidad se sirven y consumen alimentos comunales (Archila 2005: 286).

En cambio, los fogones domésticos temporales se realizan, según la autora, para cocinar una comida en la noche, repeler insectos y otros animales y calentarse cuando los Nukak se encuentran viajando a través del bosque y se detienen a pernoctar. En este caso los combustibles utilizados provienen de leña muerta y otros vegetales del bosque. Este tipo de fogones podrían ser, para Archila (2005), muy difíciles de localizar debido a la baja visibilidad de los campamentos ocasionales de los cazadores recolectores en esta región.

En su modelo describe otro tipo de fogones, entre los que se encuentran: para ahumar carne y/o pescado, ubicado afuera de la casa o en el área circundante a los campamentos; para quemar cerámica, ubicados en el área que rodea las casas, para elaborar equipos de cacería y pesca cuya localización se puede hallar en los alrededores del campamento y algunas momentos de la cadena operativa en el fogón central; manufactura de artefactos domésticos, cuya ubicación no es específica; asociados a rituales, de difícil visibilidad arqueológica y localizados en las casas ceremoniales, para quemar pelo de pecaríes, en las cercanías de los lagos donde son cazados los animales (Archila 2005).

Sin embargo, Galanidou (2000) postula que a excepción de los hornos cuya función es específica, no es posible asociar morfología de los fogones con su utilización. La autora propone que el resto de los fogones pueden haber sido realizados para múltiples propósitos como cocción, calor e iluminación siendo el eje sobre el cual se desarrollan actividades de interacción social, descanso o 
ceremonias. Por otra parte, Galanidou (2000) no encuentra en sitios de tipo cueva un vínculo significativo en la inversión de energía en acondicionar la estructura de los fogones y la intensidad de ocupación pero sí en cambio, una relación entre el tipo de fogón y el grado de movilidad de los grupos humanos que los produjeron. Los modelos etnográficos para interpretar los contextos arqueológicos de carbones en Patagonia (Pérez de Micou 1991) y en Amazonía (Archila 2005) permiten ampliar las nociones sobre la funcionalidad del fuego en grupos cazadores recolectores así como resaltar la importancia para la vida diaria de estos grupos. En esta tesis se tendrán en consideración los modelos anteriores y la postura de Galanidou (2000), y se intentará a partir de la identificación taxonómica de los carbones y sus propiedades como combustible interpretar la funcionalidad de los fogones e intensidad de las ocupaciones.

En este sentido, es importante remarcar el fogón como eje de organización del espacio intrasitio. Paunero (2004) a través de estudios arqueológicos en Patagonia, afirma que el fuego de los cazadores recolectores organiza el espacio interior, asociado entonces a lo endogámico, la familia, la vivienda, lo cotidiano siendo en cambio, el agua el elemento que organizaría el espacio exterior. Este último se asociaría a lo diferente, cambiante y exogámico.

\subsection{El uso de la analogía para la elaboración de hipótesis arqueológicas}

En el trabajo de Hernando (2006) se presenta distintos enfoques sobre el uso de la analogía en la Etnoarqueología. La autora menciona que esta última tiene su origen en el positivismo procesual como una Teoría de Alcance Medio, donde se buscaba establecer analogías más o menos directas entre ciertos comportamientos del presente antropológico y del pasado arqueológico (Binford 1967, Yellen 1977 en Hernando 2006: 27). Una segunda posición es expuesta por Gándara (1990) desde el materialismo histórico, donde hace visible las dificultades de extrapolar patrones de comportamiento de sociedades atravesadas por el capitalismo a sociedades pre-capitalistas. Sin embargo, el autor defiende la analogía y manifiesta que en todo el proceso de interpretación del registro arqueológico las 
inferencias se establecen a partir de la analogía a través del conocimiento de procesos actuales.

Hernando (2006) presenta también, la corriente postprocesual como otro marco de referencia desde el cual se realizaron trabajos etnoarqueológicos. Sin embargo, esta corriente teórica hizo énfasis en la dimensión subjetiva de la cultura por lo que, la contextualidad de los significados hacía intransferible cualquier conclusión sobre las relaciones observadas en una cultura a otra distinta, ya que, las dimensiones culturales están histórica y coyunturalmente determinadas. La autora propone entonces, una etnoarqueología estructuralista, en la que se busca comprender las pautas estructurales que rigen el orden de racionalidad de una determinada sociedad, que se manifiesta en todas las dimensiones de la cultura incluida la esfera material. Su propuesta considera que existe una relación estructural entre el grado de complejidad socio-económica de un grupo y la estructura de su percepción del mundo.

En esta tesis se considerarán las limitaciones para establecer analogías directas debido a que los pobladores locales del área de estudio se encuentran atravesados por historias e identidades diferentes a las sociedades pre hispánicas. Sin embargo, como manifiestan Founier y Freeman (1991), en términos teóricos si las características estructurales y superestructurales de las sociedades sociales estudiadas no son semejantes es válido teóricamente aislar variables sobre ciertos atributos o procesos que se consideren análogos en cuanto a manifestaciones materiales de la conducta humana (Fournier y Freeman 1991: 111).

En el caso de los estudios etnográficos del siglo XX, Bonomo (2006) advierte que las tradiciones orales transcriptas en estos documentos no deben ser proyectados de forma acrítica y directa al registro arqueológico. Sin embargo, considera que analizados con cautela permiten abordar dimensiones simbólicas e ideacionales en los objetos materiales y que deben ser considerados. En esta tesis se abordan trabajos etnográficos de este período así como crónicas de viajeros que a través de un análisis crítico serán tenidos en cuenta para generar expectativas e hipótesis a contrastar en el registro arqueológico. 


\subsection{Antecedentes Arqueobotánicos en Patagonia Argentina}

En la Patagonia argentina los primeros estudios arqueobotánicos tuvieron como objetivo principal la identificación de macrorrestos ${ }^{4}$. Entre los primeros análisis se encuentran los producidos por Sbriller en el cementerio Las Lajitas en la provincia de Neuquén (Podestá y Pereda 1979) y los trabajos de Pérez de Micou en el valle de Piedra Parada (1979-1982). La Dra. Pérez de Micou fue la primera en abordar el estudio del registro arqueobotánico a partir del análisis de fuentes documentales para el área de la cuenca del Río Chubut (Nacuzzi y Pérez de Micou 1983-1985). Este estudio permitió realizar una base de información sobre el uso de recursos vegetales silvestres por parte de los grupos aborígenes que habitaban el área y la contrastación de dicha base de datos con el registro arqueobotánico de la misma zona (Nacuzzi y Pérez de Micou 1983/1985). Asimismo, desarrolló estudios etnoarqueológicos para la interpretación de fogones arqueológicos (Pérez de Micou 1991), así como, la reconstrucción de áreas de captación de los recursos vegetales por parte de los grupos cazadores recolectores de su área de estudio (Pérez de Micou et al. 1992). Por otra parte, Piqué i Huerta (1999) realizó la primera tesis doctoral sobre antracología en Patagonia haciendo foco en las estrategias de aprovisionamiento de recursos leñosos desarrolladas por los grupos cazadores en los sitios de Tierra del Fuego. Los resultados obtenidos en estos trabajos indicaron la importancia de los recursos vegetales silvestres para las sociedades que habitaron la Patagonia. Con el desarrollo de la disciplina y el aumento de las evidencias arqueobotánicas en el registro, se desarrollaron nuevos problemas a discutir, como la potencial movilidad de los grupos humanos en relación a la obtención de distintos tipos de plantas y el posible diseño de circuitos de recolección, la estacionalidad en el uso de los espacios en relación a la disponibilidad de las plantas en distintos momentos del año, el uso diferencial de leñas según sus condiciones de hallazgo, los artefactos confeccionados con vegetales, el uso medicinal y/o mágico de especies silvestres, y el rol de las plantas en la dieta de los grupos cazadores recolectores (Pérez de Micou 2002).

\footnotetext{
${ }^{4}$ Los antecedentes arqueobotánicos de Patagonia argentina son analizados in extenso en el capítulo 6.
} 
Algunas de estas líneas fueron profundizadas por Berihuete (2006) quien analizó los restos carpológicos recuperados en un contexto doméstico y su comparación con un contexto arqueológico ritual. Llano (2010) analiza restos carpológicos de sitios localizados en distintos ambientes del sur de Mendoza, e indaga sobre el rol de las plantas silvestres para los grupos cazadores recolectores de la zona. Por otra parte, se elaboraron nuevas bases de datos de uso de las especies por las sociedades que habitaron la región patagónica insular a través de las fuentes etnohistóricas (Caruso et al. 2008, Berihuete 2009). También se desarrollaron recientemente estudios experimentales para reconsiderar los usos de la madera tanto para leña como para la manufactura de instrumentos (Caruso e Iriarte 2011, Cueto et al. 2010), el estudio de artefactos en madera provenientes tanto del registro arqueológico como de colecciones (Caruso et al. 2011). Se realizaron estudios sobre prácticas poscolecta (sensu Capparelli y Lema 2011) de recursos vegetales silvestres a través del estudio de artefactos de molienda (Lema et al. 2012) y raspado de cerámica (Pérez y Erra 2011). 


\section{3. Área de Estudio y Antecedentes arqueológicos}

\subsection{Caracterización ambiental del área de estudio}

Como se mencionó en la Introducción, el área de estudio de la presente tesis corresponde a la costa norte de Santa Cruz. Ésta comprende el área de costa atlántica ubicada entre el límite interprovincial Santa Cruz-Chubut por el norte, y la localidad de bahía Laura, ubicada a $\operatorname{los} 48^{\circ} \mathrm{S}$, por el sur. Abarca aproximadamente $420 \mathrm{~km}$ lineales de costa y una franja de territorio hacia el interior de la meseta, de extensión variable (30 km aproximadamente), que se ha denominado franja intermedia (Castro et al. 2003) (Figura 3.1.). La descripción exhaustiva del área de estudio a partir de datos climáticos, topográficos $\mathrm{y}$ biogeográficos fue desarrollada por Zubimendi (2010). A partir de dicho trabajo se sintetiza aquí la información más relevante para los objetivos de la presente tesis y se hace hincapié en la descripción de la vegetación, entre otros componentes, porque se considera que es la variable que mejor describe el ambiente de un área de estudio determinada (Capparelli 1997).

El paisaje del área está caracterizado por mesetas que terminan en la costa y forman parte de la Provincia geológica del Chubut extraandino, que abarca todo el Golfo San Jorge hasta aproximadamente la ciudad de Puerto Deseado y la del Nesocratón del Deseado al sur de la ría Deseado (Codignoto 2000). La Provincia geológica del Chubut extraandino tiene un origen tensional producido durante el movimiento de separación entre el continente sudamericano y africano (Feruglio 1950). La cuenca sedimentaria del Golfo San Jorge comenzó a formarse posiblemente en el Jurásico medio, si bien su relleno se produce en el Cretácico y culmina a finales del Terciario. El relleno de la cuenca durante el Cretácico es principalmente de origen continental (lacustre, deltaico, fluvial). Durante el Terciario se intercalaron varias transgresiones marinas; las del Patagoniano (Eoceno-Mioceno) se realizan sobre una amplia plataforma continental, con suave 
pendiente hacia el este, con comunicación directa con el océano Atlántico. En forma transicional se van depositando capas continentales de la Formación Santa Cruz, las cuales son cubiertas por extensos mantos de gravas de origen fluvioglacial (Terciario-Cuaternario). Sobre dichos mantos se depositaron sedimentos modernos de variados orígenes, tanto continentales como marinos (Giacosa et al. 1998).

La provincia geológica del Nesocratón se extiende desde el río Deseado hasta el río Chico de Santa Cruz. Se caracteriza por la presencia de rocas ignimbríticas cuarcíferas que se desarrollan, en el litoral atlántico a partir de la ría Deseado hacia el sur de forma alternada hasta bahía Laura (Codignotto 2000). Se considera un área estable, no deformada que permaneció como una zona positiva a lo largo de su evolución (Iantanos 2003). La evolución morfológica-estructural del área de estudio comienza a desarrollarse a partir del Jurásico medio, con sedimentos de origen volcánico. Durante el Terciario se produce la depositación de sedimentos marinos. Luego, comienza a producirse una serie de regresiones que quedan evidenciadas a partir de las distintas terrazas marinas, playas con restos de conchillas y planicies mareales inactivas (Codignotto, 1987; Rutter et al. 1989; Codignotto et al. 1992; Gonzáles Bonorino et al. 1999; Rostami et al. 2000; Pedoja et al. 2010; Ponce et al. 2011).

La única cuenca hidrológica en el área de costa norte de Santa Cruz es el río Deseado, que tiene una escasa significación hidrológica actual (Iantanos 2003; Isla et al. 2004). El río Deseado tiene sus nacientes en arroyos cercanos a la ciudad de Perito Moreno. El cauce se interrumpe en partes donde se infiltran las aguas, formando un cauce seco o aflorando en algunos lugares generando pequeños manantiales (Caballero 2000). El curso del río Deseado presenta un diseño meandroso, y se desarrolla en un relieve monótono, horizontal, de pampas o mesetas interrumpidas hacia el este por cañadones y depresiones. El valle propiamente dicho presenta una serie de niveles aterrazados que corresponden a la actividad actual del mismo con un marcado desnivel con respecto a los niveles aterrazados más antiguos. Las planicies aterrazadas corresponden a seis niveles (Feruglio 1950), cuyas altitudes se encuentran entre los 65 a $465 \mathrm{msnm}$, la disección es notoria sobre el valle actual y el Golfo San Jorge donde los niveles 
aterrazados se encuentran aislados porque los atraviesan numerosos cañadones (Oliva et al. 2001:17). La ría Deseado, tiene una longitud aproximada de 40 a 42 km, desde el Paso Gregores o Marsicano hasta la boca del estuario, con un ancho de boca de aproximadamente 1,3 $\mathrm{km}$ entre la isla Chaffers y la margen norte, aproximadamente a la altura de la cueva de los Leones al oeste de la ciudad de Puerto Deseado. En su extremo occidental desemboca el río Deseado que permanece seco gran parte del año. Hacia el este le sucede el cauce principal de la ría, en el cual predominan los fondos rocosos y en los lugares de poca corriente se forman bancos de fango, que pueden estar mezclados con pedregullo a lo largo de aproximadamente $15 \mathrm{~km}$, luego se ensancha el canal durante los último $30 \mathrm{~km}$ hasta su desembocadura en el Océano Atlántico. La margen norte del estuario está caracterizada por una serie de cañadones labrados sobre rocas de la formación bahía Laura de variada longitud, que desembocan en la ría. Por su parte, en la margen sur estos cañadones son escasos y no han alcanzado el nivel de base actual, por lo que en algunos tramos se registran suaves planicies que llegan hasta la costa de la ría (Iantanos 2003, Zubimendi 2010).

Los suelos en el área costa norte de Santa Cruz son Aridisoles someros, pedregosos, pobres en materiales finos y materia orgánica, de $\mathrm{Ph}$ neutro, y con salinidad moderada o alta. En la franja del área más cercana al interior y centro de la provincia de Santa Cruz, los suelos son también Aridisoles pero de textura franco arenosa a franco arcillosa (Oliva et al. 2001:58)

A partir de las variables temperatura y humedad se registran dos tipos de climas en el área de estudio. Desde el límite con la provincia de Chubut y hasta la ría Deseado, abarcando la franja interior del proyecto CNSC, el área presenta un clima templado con temperaturas medias que oscilan entre $12^{\circ}$ y $20{ }^{\circ} \mathrm{C}$ con diferencias estacionales marcadas. En la costa se presentan las mayores temperaturas de las provincias, siendo las precipitaciones menores a los $300 \mathrm{~mm}$. Hacia el sur de la ría Deseado y en el centro de la provincia de Santa Cruz se registra un clima templado frío. En este último las temperaturas medias oscilan entre $0^{\circ}$ y $12{ }^{\circ} \mathrm{C}$, con veranos frescos e inviernos fríos a muy fríos con aporte de nieve y donde predominan los vientos del oeste de gran intensidad. Aquí la zona 
costera se caracteriza por una mayor aridez, donde los registros pluviométricos no superan los $200 \mathrm{~mm}$ (Oliva et al. 2001).

\subsubsection{Descripción fitogeográfica del área de estudio}

En cuanto a la vegetación del área, la costa norte de Santa Cruz se encuentra dentro de la Provincia fitogeográfica Patagónica (Cabrera 1971). Se pueden distinguir en ella dos unidades principales de vegetación según Oliva y colaboradores (2001): una estepa arbustiva con arbustos de $3 \mathrm{~m}$ de altura o más, denominada "estepa arbustiva del Golfo San Jorge" que se extiende de norte a sur por una franja costera de 90 a $25 \mathrm{~km}$ de ancho hasta Punta Medanosa, y una estepa de arbustos enanos o rastreros, que se extiende al sur de Punta Medanosa y sobre la meseta central de Santa Cruz, es decir por fuera del área CNSC (Figura 3.1.).

La estepa arbustiva del Golfo San Jorge se extiende sobre un suelo ondulado surcado por cañadones y valles que desembocan en el mar (Oliva et al. 2001). Entre las especies dominantes se encuentran los arbustos de Retanilla patagónica (malaespina) Speg. Tortosa ${ }^{5}$, Colliguaja integerrima Gillies. \& Hook. (duraznillo), Mulinum spinosum (neneo) (Cav.) Pers, Mulguraea ligustrina (Lag.) N. O'Leary \& P. Peralta var. lorentzii (Niederl. ex Hieron) N. O'Leary \& P. Peralta (mata negra), Ephedra ochreata Miers. (solupe), Lycium chilense Miers. ex Bertero (yaoyín) y Anarthrophyllum rigidum (Gillies ex Hook. \& Arn.) Hieron (mata amarilla). Entre las gramíneas se encuentran Pappostipa humilis (Cav.) Romasch var. humilis (coirón amargo) y Festuca argentina (Speg.) Parodi (huecú). También se registran entre las anuales Lepidium sp. L., Erodium cicutarium (L.) L'Her ex Aiton (alfilerillo) y Vulpia sp. C. C. Gmel.

Es importante mencionar que aunque la provincia fitogeográfica del Monte se extiende hasta unos kilómetros al sur del paralelo $44^{\circ}$, es decir hasta el centro-este de la Provincia de Chubut (Morello 1958), la estepa arbustiva del Golfo San Jorge incluye la distribución más austral de algunos elementos del monte, entre ellos

\footnotetext{
${ }^{5}$ Se mencionan los autores de los géneros y especies descriptos la primera vez que aparecen en la tesis.
} 
Nassella tenuis (Phill.) Barkworth, Prosopis denudans Benth, Larrea Cav. y Lycium ameghinoi Speg. (León et al. 1998).

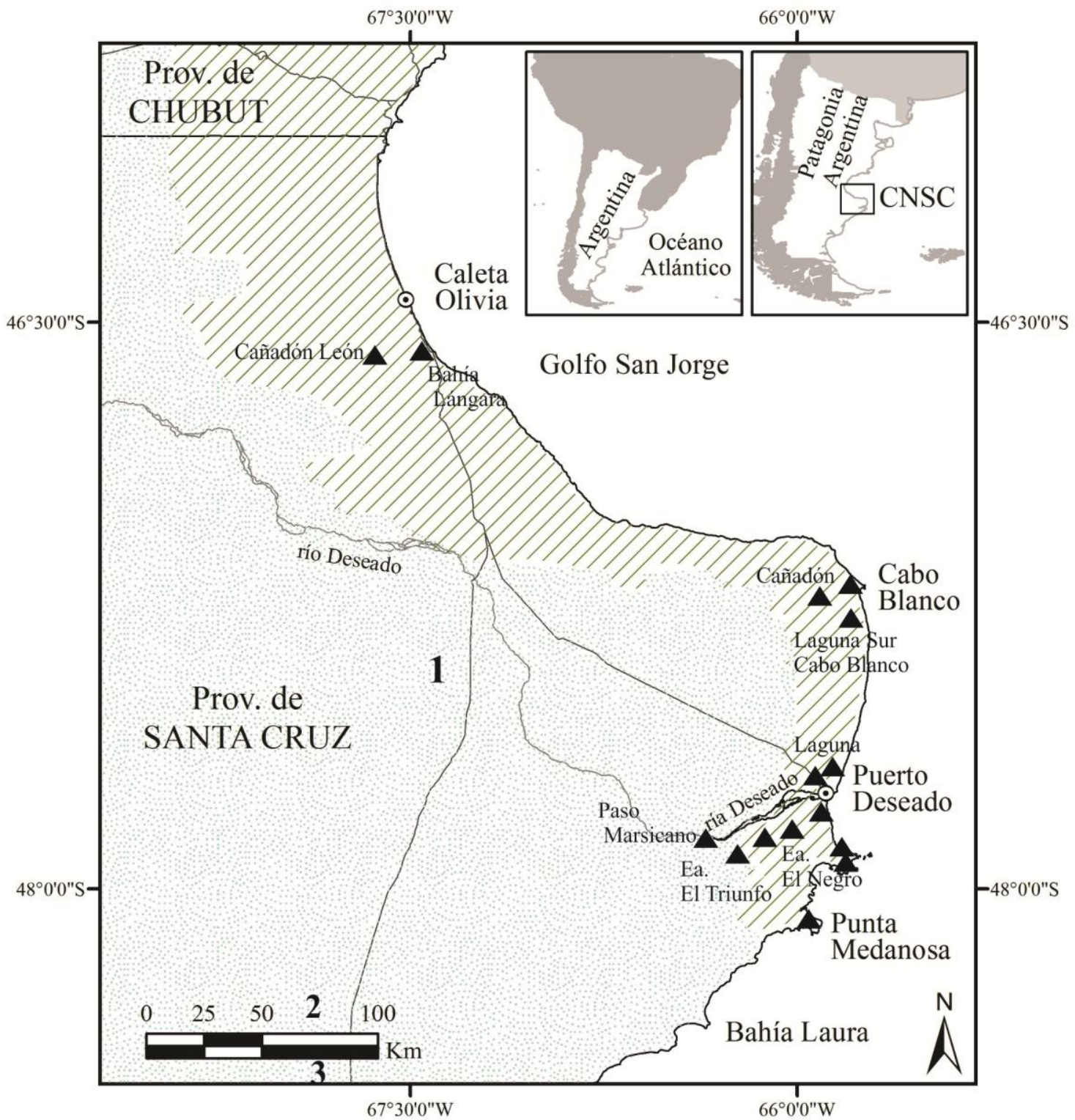

Figura 3.1. Distribución de la estepa arbustiva del Golfo San Jorge (rayado) y estepa de arbustos enanos (puntos) según (Oliva et al. 2001). Los triángulos indican los principales puntos de observación de vegetación de la presente tesis. Los números corresponden a los siguientes sitios arqueológicos con información palinológica: 1) Los Toldos; 2) La María; 3) La Martita.

La franja de esta comunidad vegetal se extiende sobre la unidad geomorfológica definida como costa $\mathrm{y}$ posee variantes en las asociaciones florísticas $\mathrm{y}$ en 
cobertura a lo largo de la misma. Observaciones realizadas en distintas localidades permiten mencionar las características generales de dichas variantes, tal como se describe a continuación. En la costa del centro del Golfo San Jorge se observan unos primeros metros sin cobertura vegetal que paulatinamente aumenta hasta alcanzar una cobertura $\approx 40 \%$, con subarbustos de hasta $50 \mathrm{~cm}$ de altura. Entre ellos predominan, por ejemplo, en Bahía Lángara de acuerdo a observaciones realizadas: Colliguaja integerrima, Atriplex lampa (Moqc.) D. Dietr. y Chuquiraga avellanedae Lorentz. Se registran también arbustos aislados de Schinus sp. L. Estos taxa se encuentran acompañados de gramíneas, fundamentalmente Pappostipa humilis (Cav.) Romasch var. humilis (Figura 3.2. y $3.3)$.

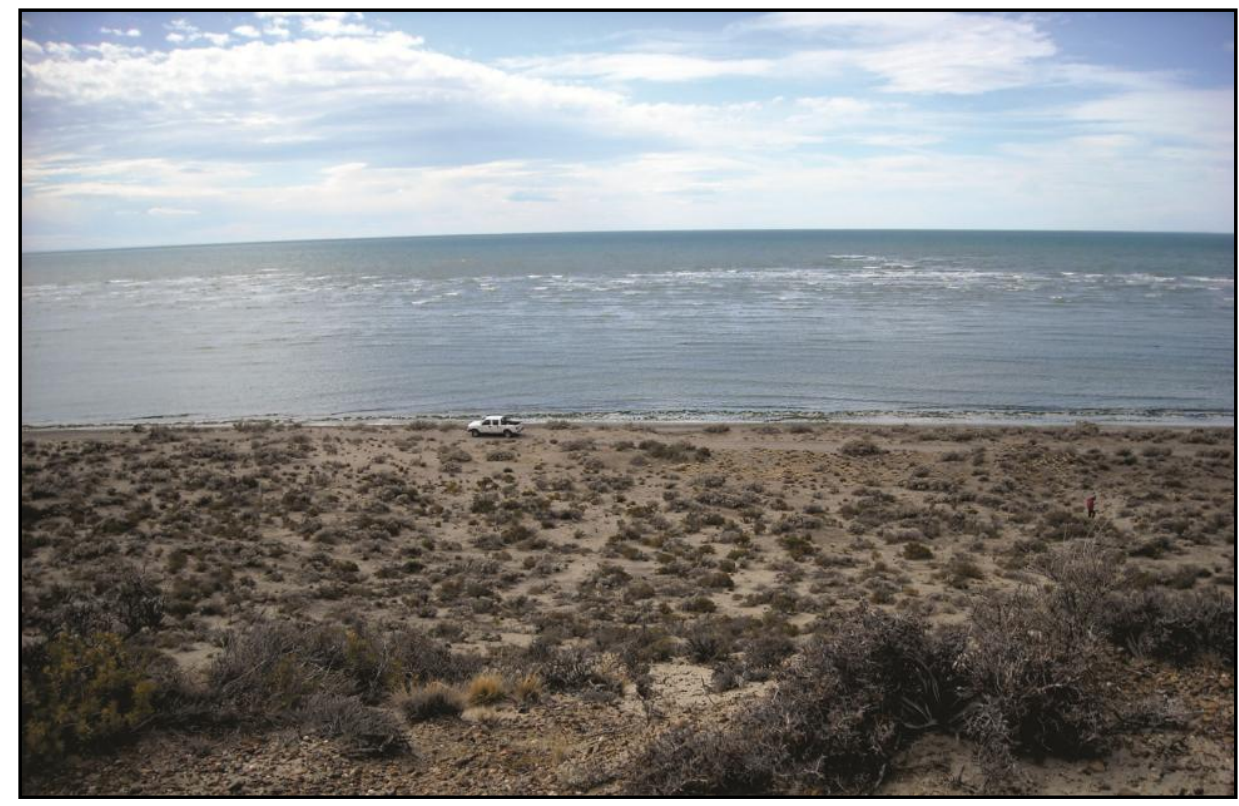

Figura 3.2. Costa de Bahía Lángara, Golfo San Jorge (Fotografía de Verónica Trola). 


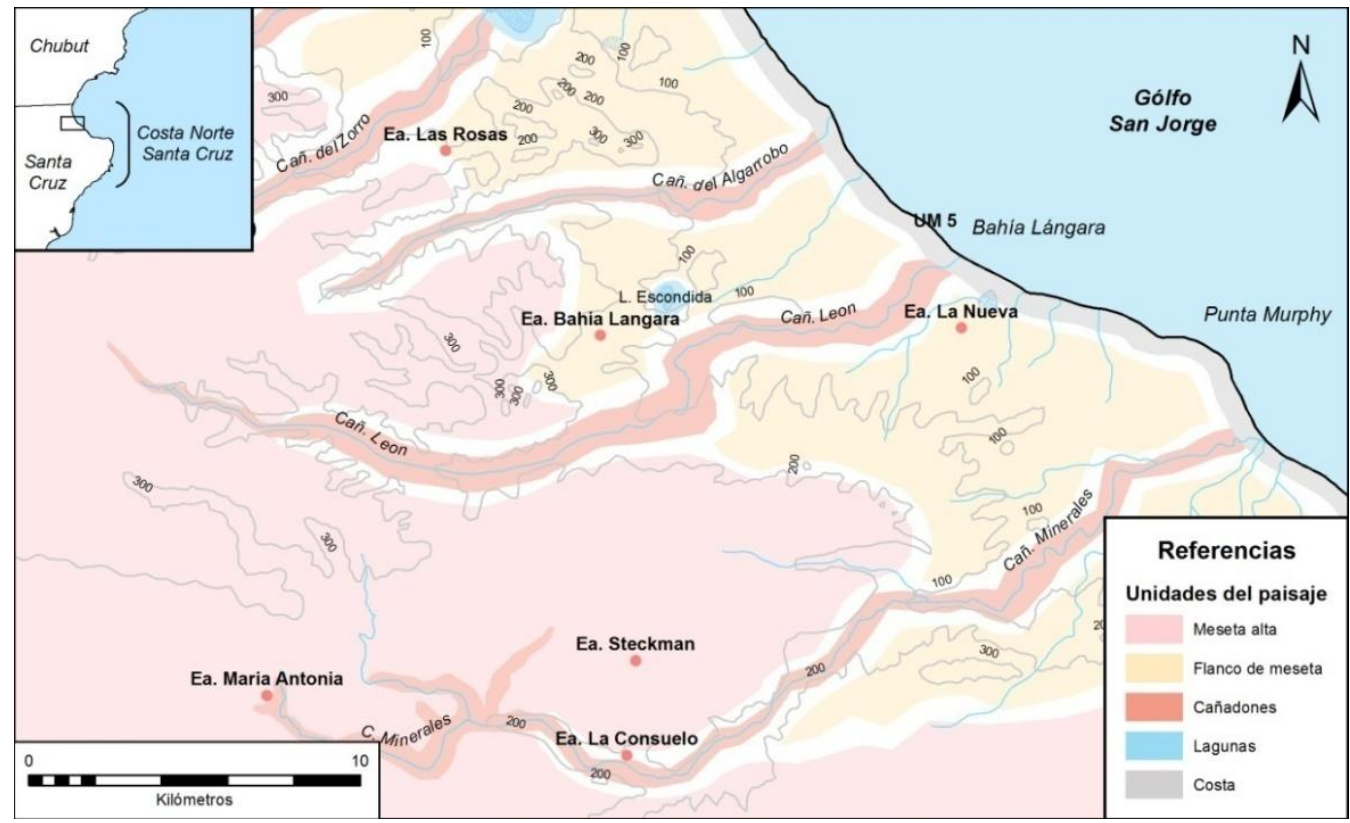

Figura 3.3. Unidades geomorfológicas registradas por M. A. Zubimendi para el sector Cabo Blanco (Zubimendi 2010)

En el cañadón León se observó mayor diversidad de especies que en la costa del Golfo San Jorge, así como una mayor superficie de cobertura vegetal ( $\approx 65 \%$ ) y plantas de mayor altura, tal como describen Paruelo et al. (2005) (Figura 3.4.A). Entre los taxa registrados se pueden mencionar: Schinus sp. (Figura3.4.B), Berberis microphylla G. Forst. (Figura 3.5.A) Prosopidastrum globosum (Gillies. ex Hook. \& Arn.) (Figura 3.5.B), Retanilla patagónica (Speg.) Tortosa, Lycium sp. L., Prosopis denudans, Colliguaja integerrima. (Figura 3.5.C), Chuquiraga erinaceae D. Don. erinaceae, Chuquiraga avellanedae, Atriplex lampa, Grindelia chiloensis (Cornerl.) Cabrera, y Maihueniopsis darwinii (Hensl.) F. Ritter. 


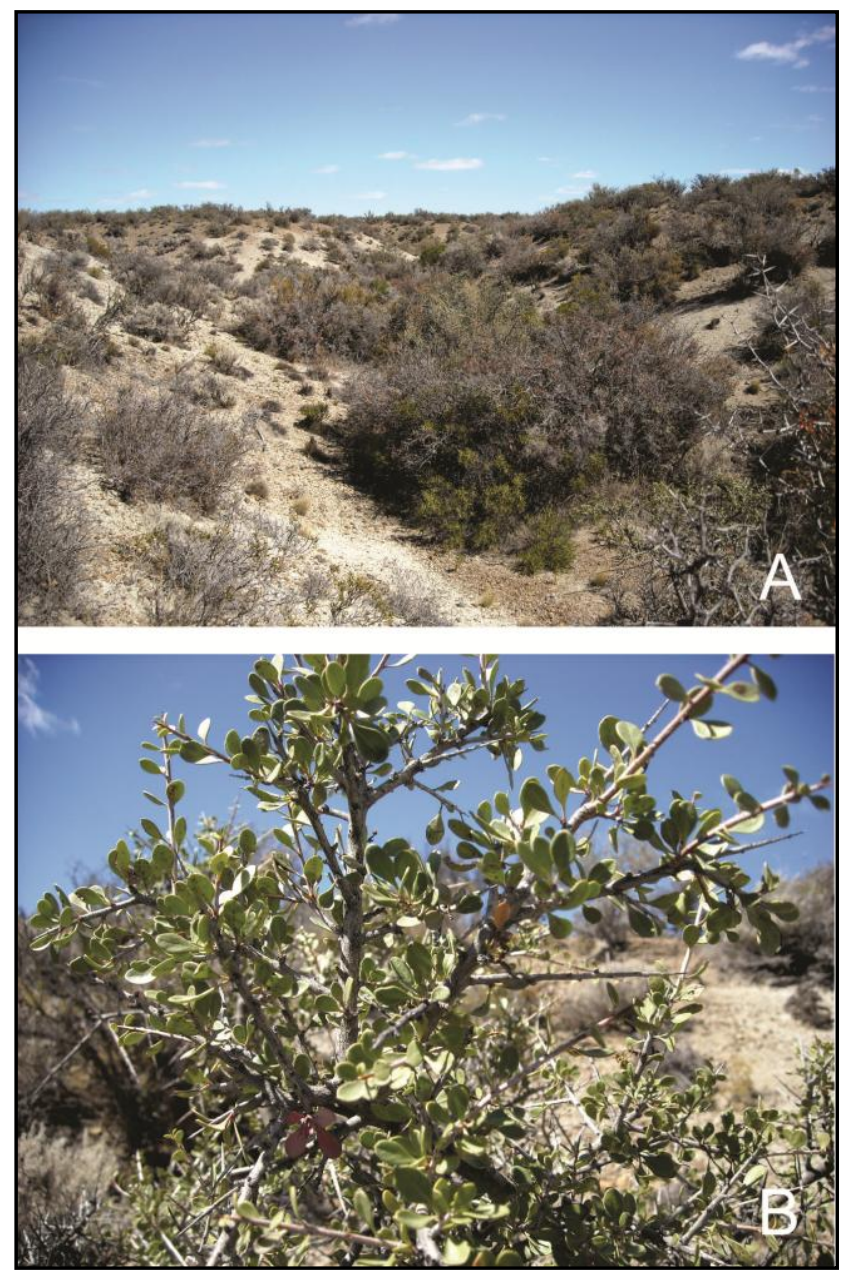

Figura 3.4. Estepa arbustiva del Golfo San Jorge, Cañadón León: A, vista general, B, en el cañadón arbustos de Schinus sp. 


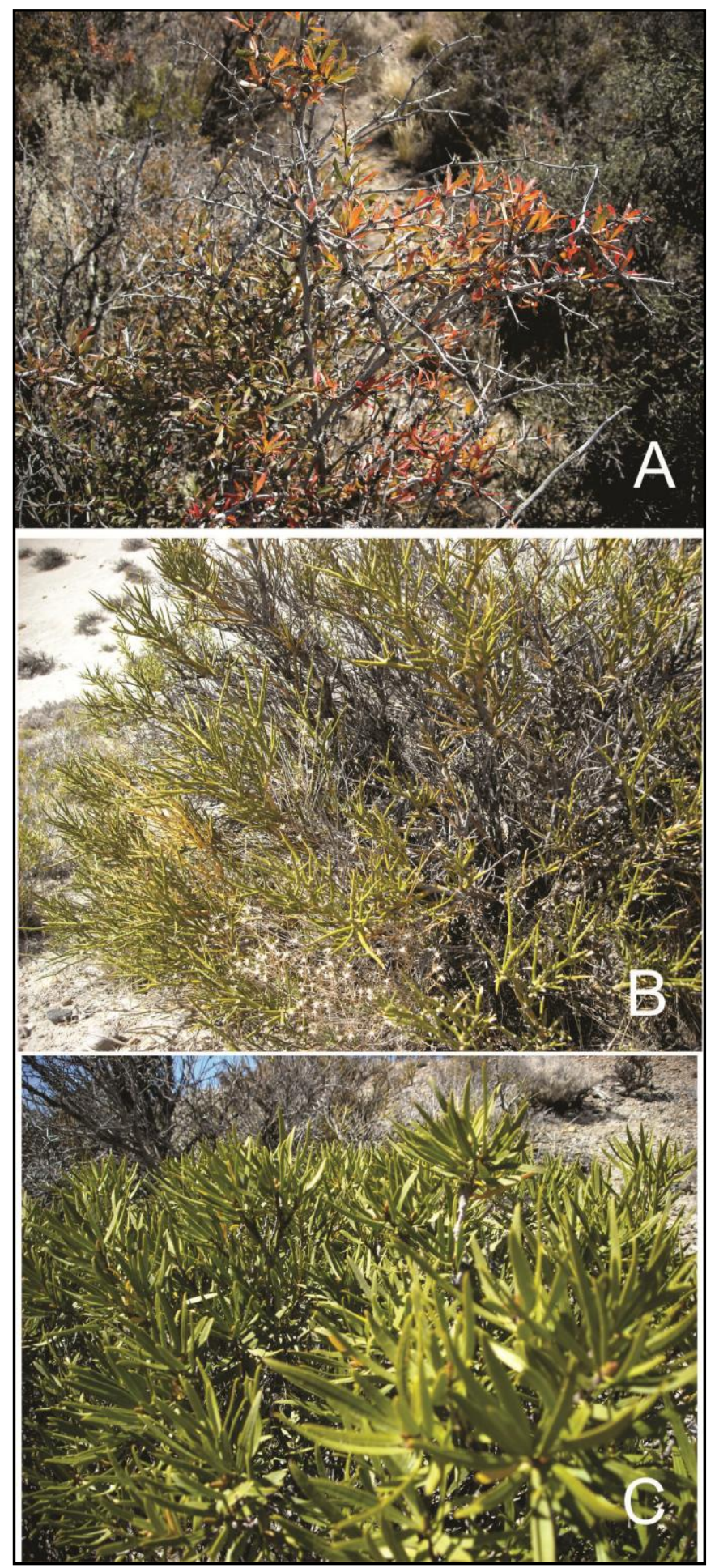

Figura 3.5. Estepa arbustiva del Golfo San Jorge, Cañadón León, en particular fotos de abustos: A, Beberis microphylla, B, Prosopidastrum globosum y C, Colliguaja integerrima.

En el sector de Cabo Blanco, se observa en la costa una baja cobertura vegetal $(\approx$ $20 \%$ ) constituida por una estepa graminosa, con arbustos aislados de poca altura 
de Nassauvia sp. Comm. y plantas en cojín de Chuquiraga erinacea ssp. erinaceae (Figura 3.6).

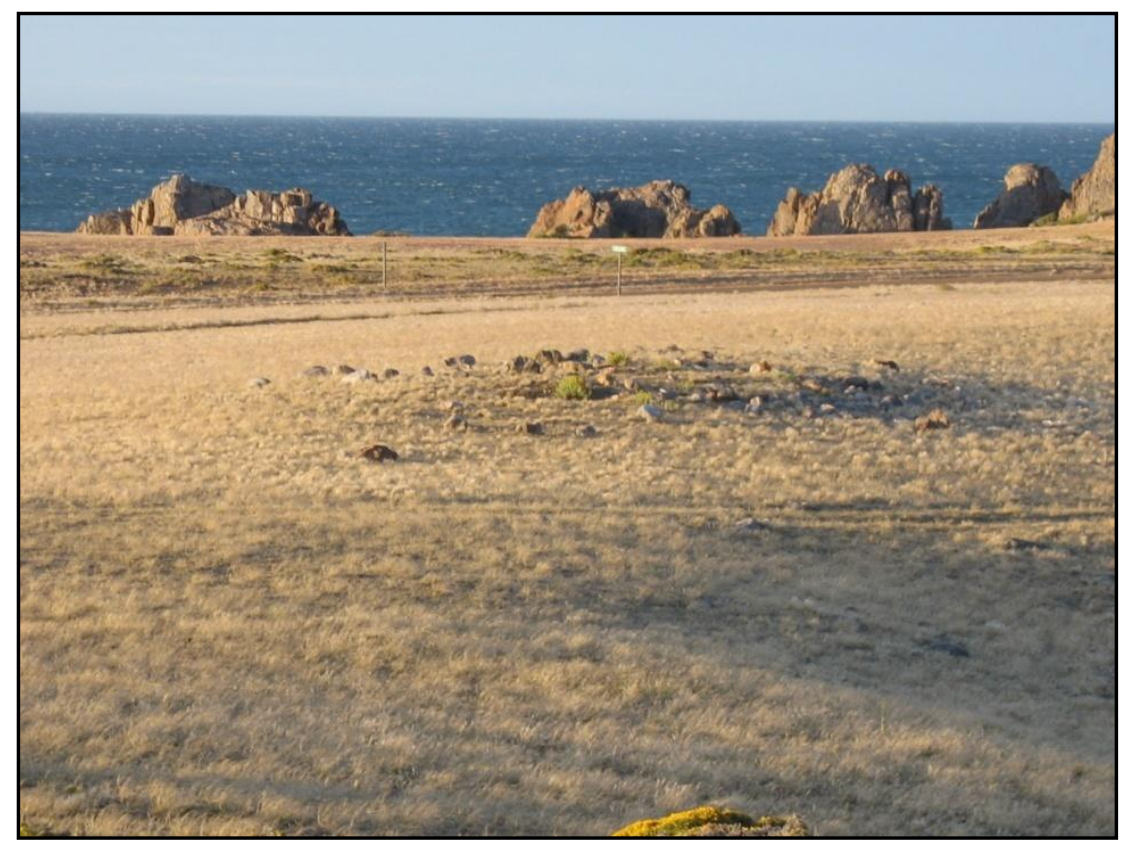

Figura 3.6. Costa de la Localidad arqueológica de Cabo Blanco (Fotografía de Mikel Zubimendi)

Por otro lado, sobre la meseta alta y flanco de meseta (Figura 3.7) se observa una estepa arbustiva graminosa donde predominan Festuca sp. L. y Nacella tenuis, con arbustos de mayor altura (hasta $50 \mathrm{~cm}$ ) con presencia de Berberis sp. L., Nardophyllum bryoides Hook. \& Arn., Lepidophyllum cupressiforme (Lam.) Class., Mulguraeae tridens (Lag.) N.O' Leary \& P. Peralta. En los cañadones se observó, además de las especies mencionadas, Schinus sp. de 1,5 m de altura. En las lagunas se registran plantas halófitas como Atriplex lampa, Suaeda sp. Forssk ex J. F. Gmel, Sarcocornia magellanica (Phil.) M.A. Alonso \& M. B. Crespo. 


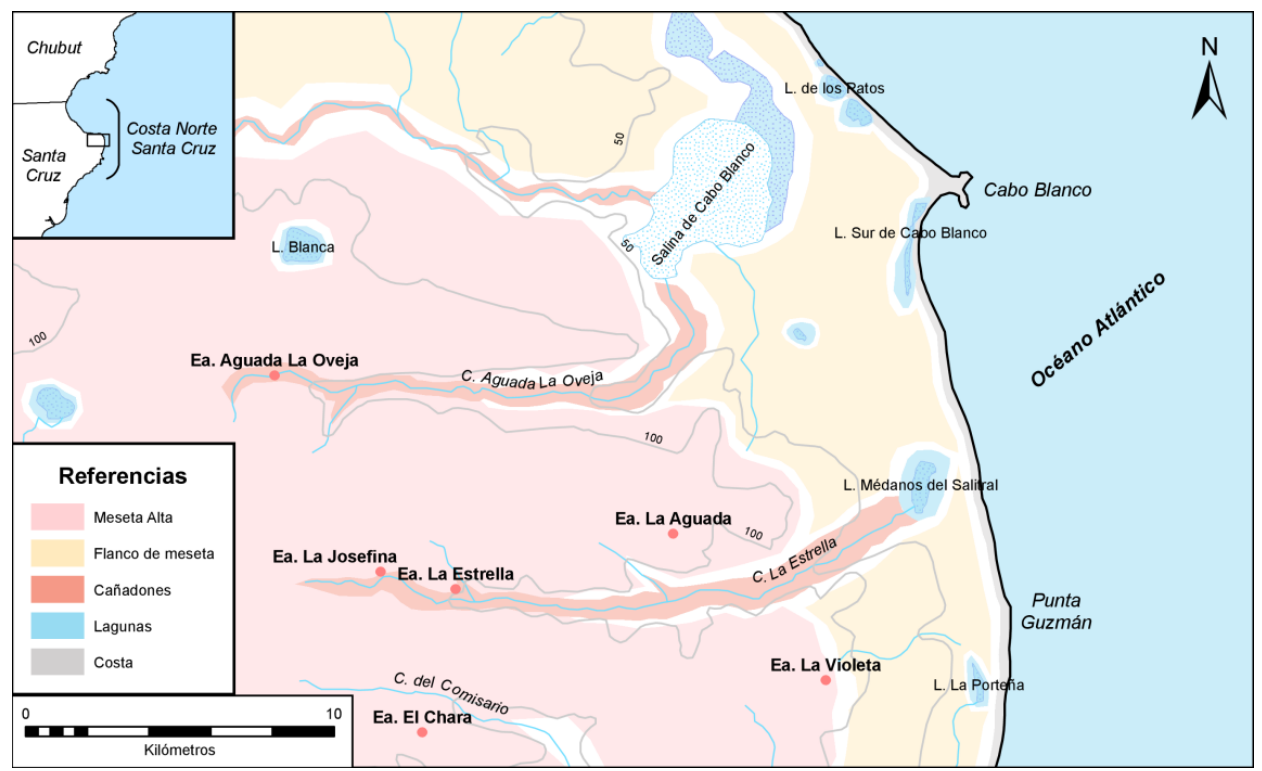

Figura 3.7. Unidades geomorfológicas registradas por M. A. Zubimendi para el sector Cabo Blanco (Zubimendi 2010).

Al norte de la ciudad de Puerto Deseado se registró una laguna temporaria con aguas hipersalinas (Figura 3.8) y se observó que la vegetación que la circundaba estaba compuesta por plantas adaptadas a suelos salobres: Sarcocornia magellanica (Figura 3.9.) y Atriplex lampa. A metros de la laguna se registró gran variedad de arbustos, entre ellos Ephedra sp. L. (Figura 3.10.), Lycium sp. (Figura 3.11), Prosopis denudans, Schinus sp., Lepidophyllum cupresiforme (Figura 3.11), Nassauvia sp, Mulguraea tridens y Nardophyllum bryoides. 


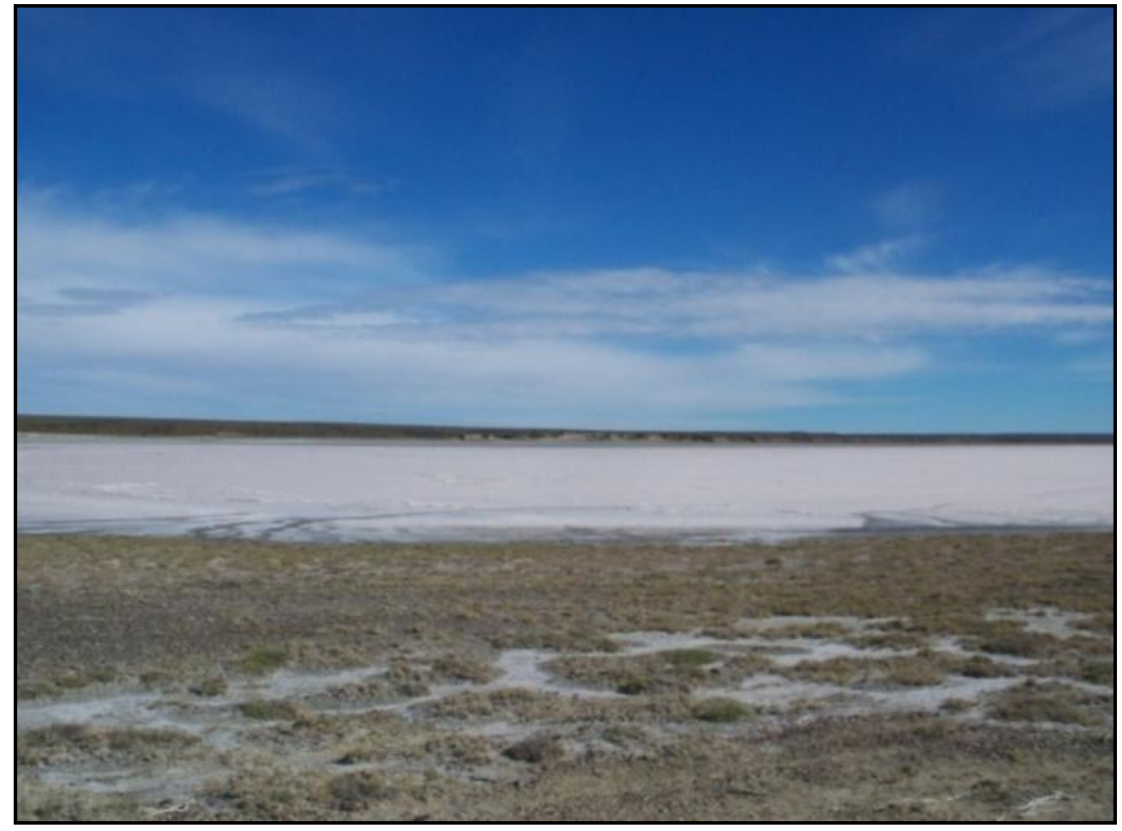

Figura 3.8. Laguna temporaria con aguas hipersalinas al norte de la localidad de Puerto Deseado. Vegetación con adaptación a suelos salobres.

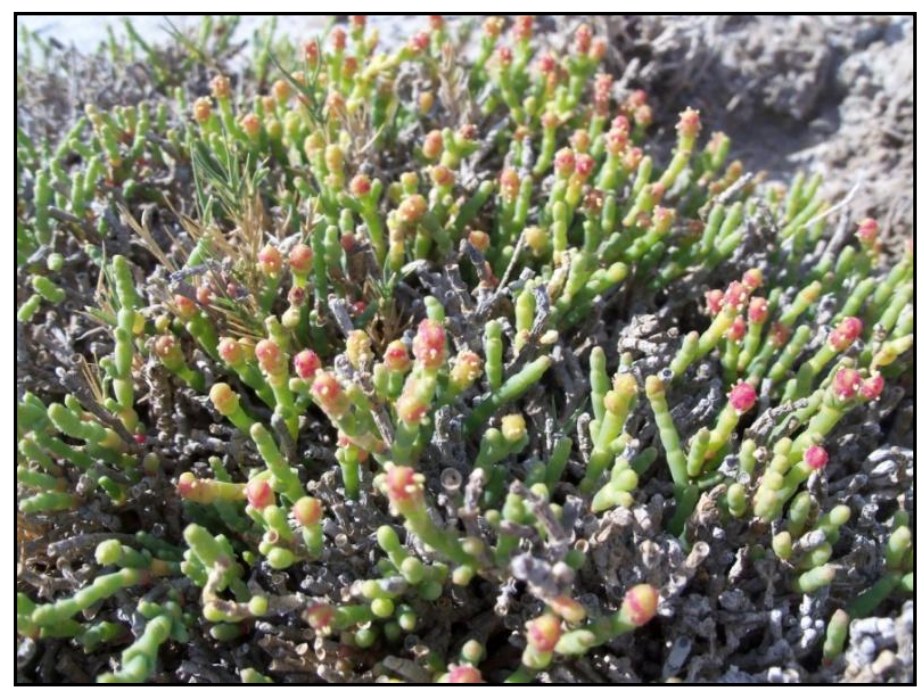

Figura 3.9. Sarcocornia magellanica en los bordes de la laguna temporaria con aguas hipersalinas al norte de la ciudad de Puerto Deseado. 


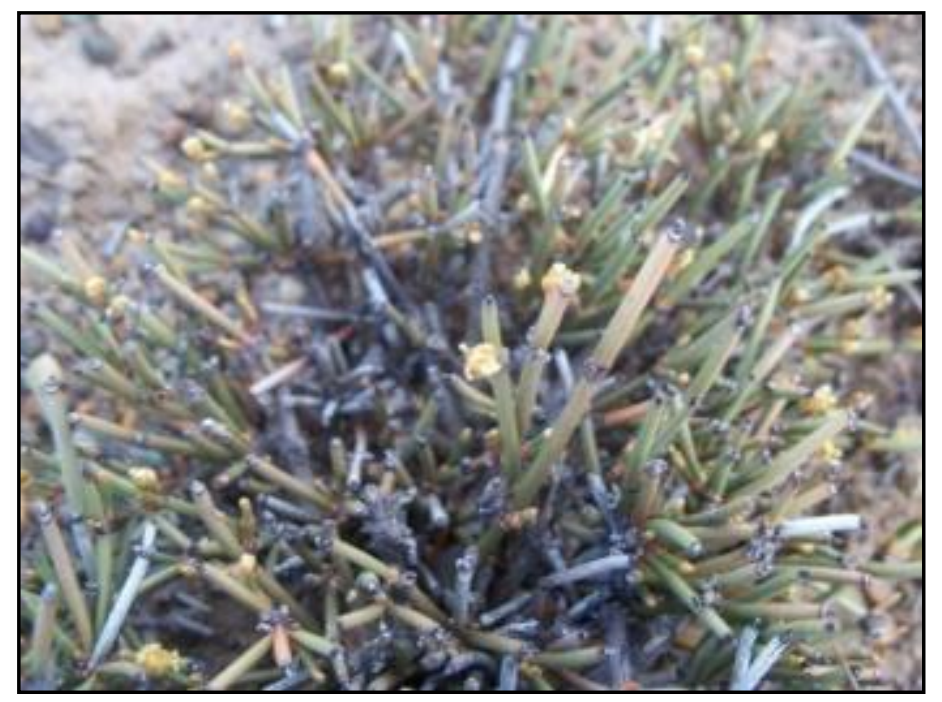

Figura 3.10. Ephedra sp. en los bordes de la laguna temporaria con aguas hipersalinas al norte de la ciudad de Puerto Deseado.

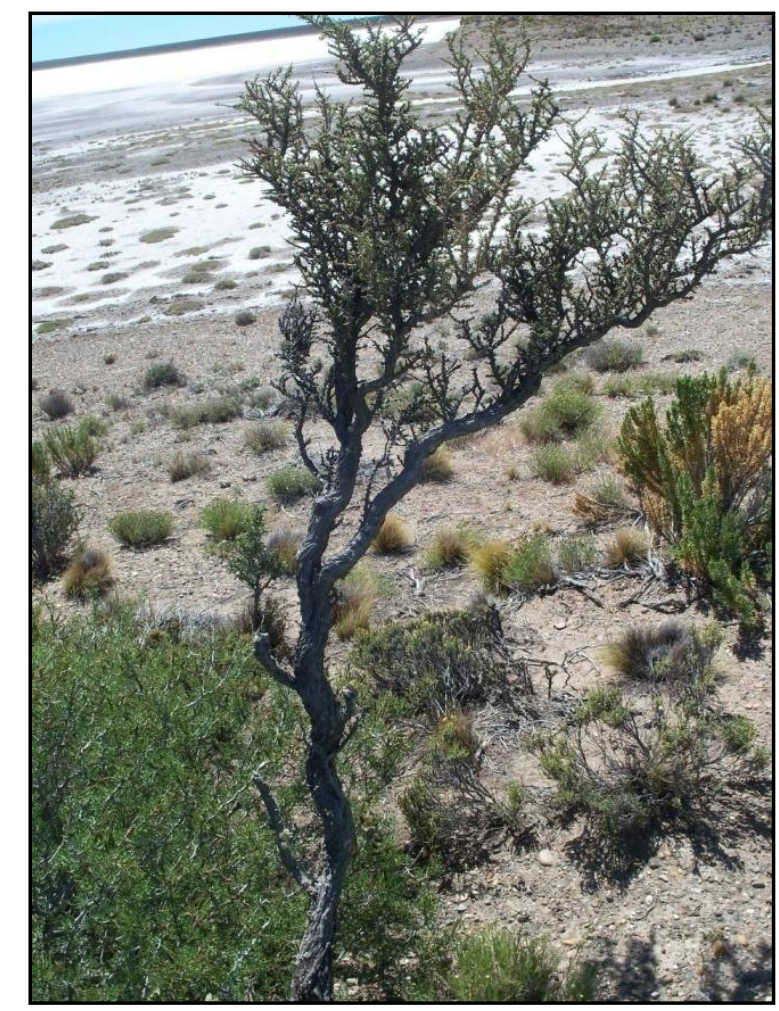

Figura 3.11. Lycium sp. y Lepidophyllum cupressiforme a metros de la laguna temporaria con agua hipersalina al norte de la ciudad de Puerto Deseado.

Sobre el margen norte de la ría Deseado (Figura 3.12), en la zona costera cercana a su desembocadura, se observa vegetación adaptada a suelos salinos como Sarcocornia magellanica (Figura 3.12.A), Atriplex lampa (Figura 3.12B), Suaeda sp., Frankenia sp. L. como se había observado en la laguna temporaria al norte de 
Puerto Deseado. A medida que existe una mayor incorporación de rodados en los suelos, la vegetación cambia a una estepa de gramíneas como Pappostipa humilis, Festuca sp., y arbustos aislados de Schinus sp, Berberis sp. (Figura 3.12C), Lycium sp., y Senecio filaginoides DC, así como Ephedra sp. y Azorella monantha Clos sobre los afloramientos rocosos. 


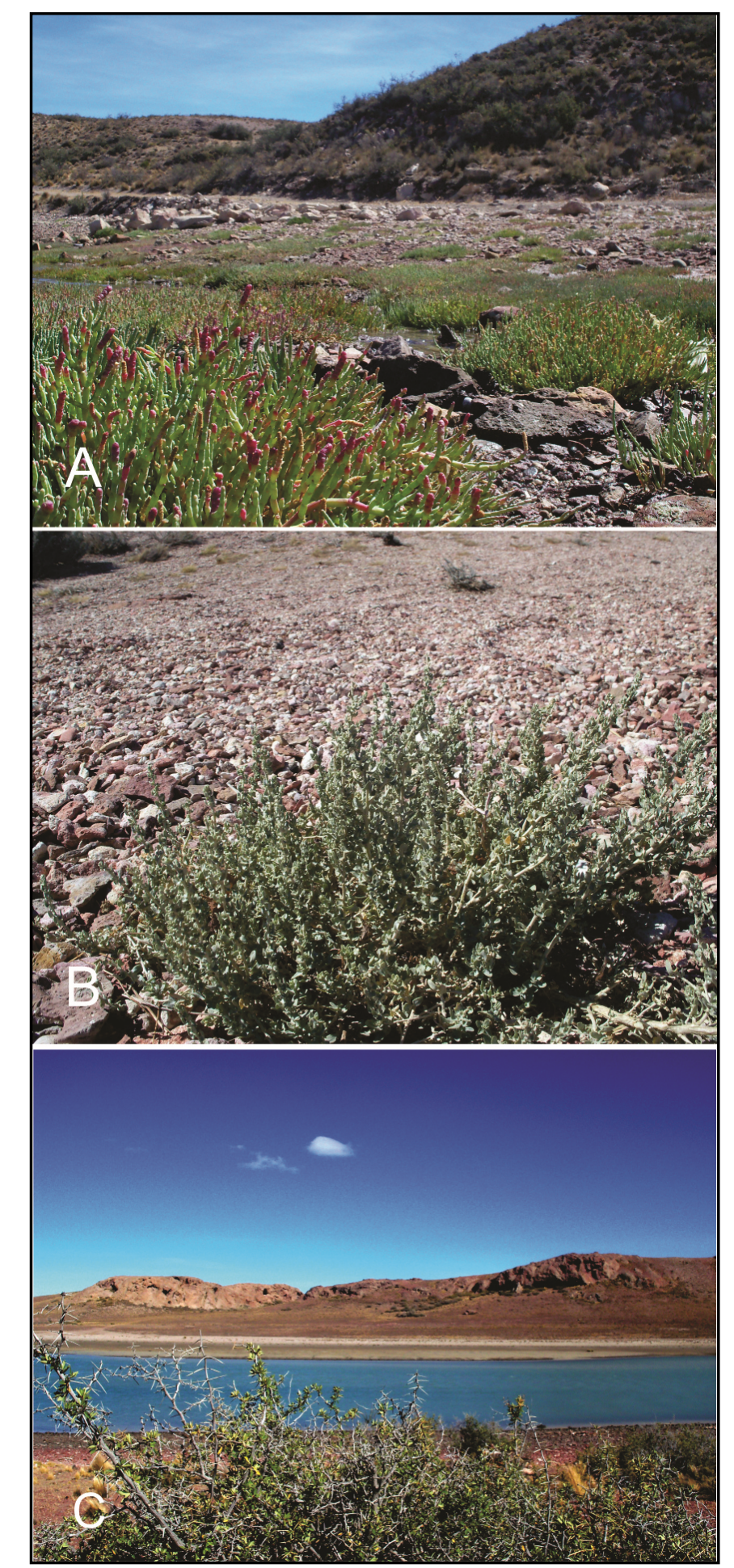

Figura 3.12. Margen norte de la ría Deseado, frente a la península Stokes, con suelos salobres: A, Sarcocornia, B Atriplex lampa y C, Berberis sp.

En el margen norte de la ría, pero hacia el interior del continente, se desarrollan una serie de cañadones y mesetas de mayor altitud (Figura 3.13). En estas últimas se observan parches de Mulguraea tridens y gramíneas alrededor. En los 
cañadones se observan nuevamente mayor diversidad de especies, de mayor altura $(\approx 2 \mathrm{~m})$ y mayor cobertura del suelo $(\approx 65 \%)$. Entre éstas se registran Prosopis denudans (Figura 3.14A), Colliguaja integerrima (Figura 3.14B), Schinus sp, Berberis microphylla, Lycium sp, Senecio sp. L. Baccharis darwinii Hook. \& Arn. Nassauvia sp., Limonium brasiliense (Boiss.) Kuntze, Mulguraea tridens, Chuquiraga erinaceae ssp. erinaceae, Adesmia boroniodes Hook., y entre las herbáceas Erodium cicutarium (L.) L'Hér. ex Aiton, Hoffmanseggia trifoliata Cav., Calceolaria biflora Lam., Chloraea sp. Lindl., Olsynium biflorum (Thunb.) Goldblatt.

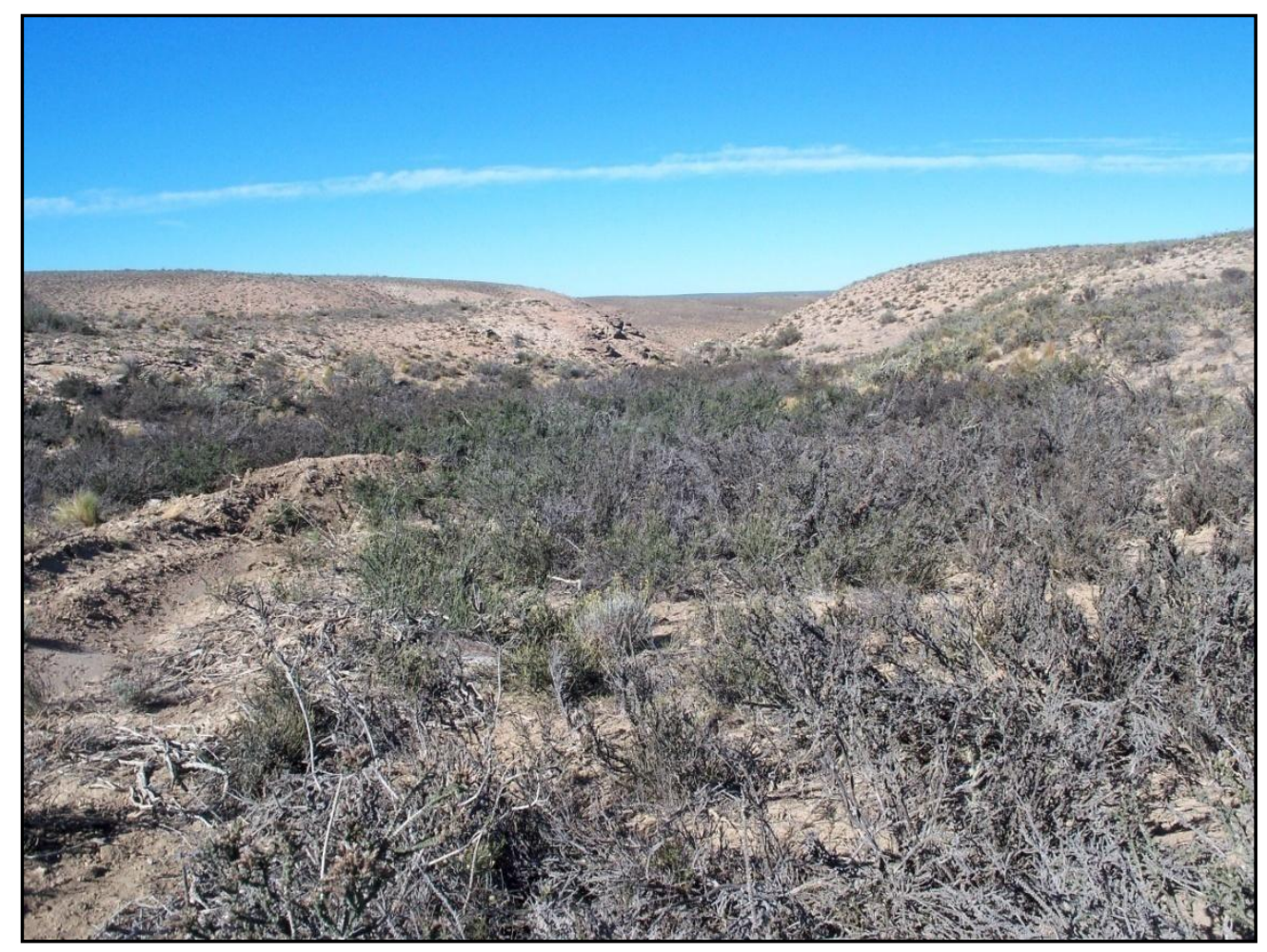

Figura 3.13. Cañadón próximo a la ría Deseado, sobre margen norte en la Reserva Ría Deseado, donde se observa un parche de Mulguraea tridens. 


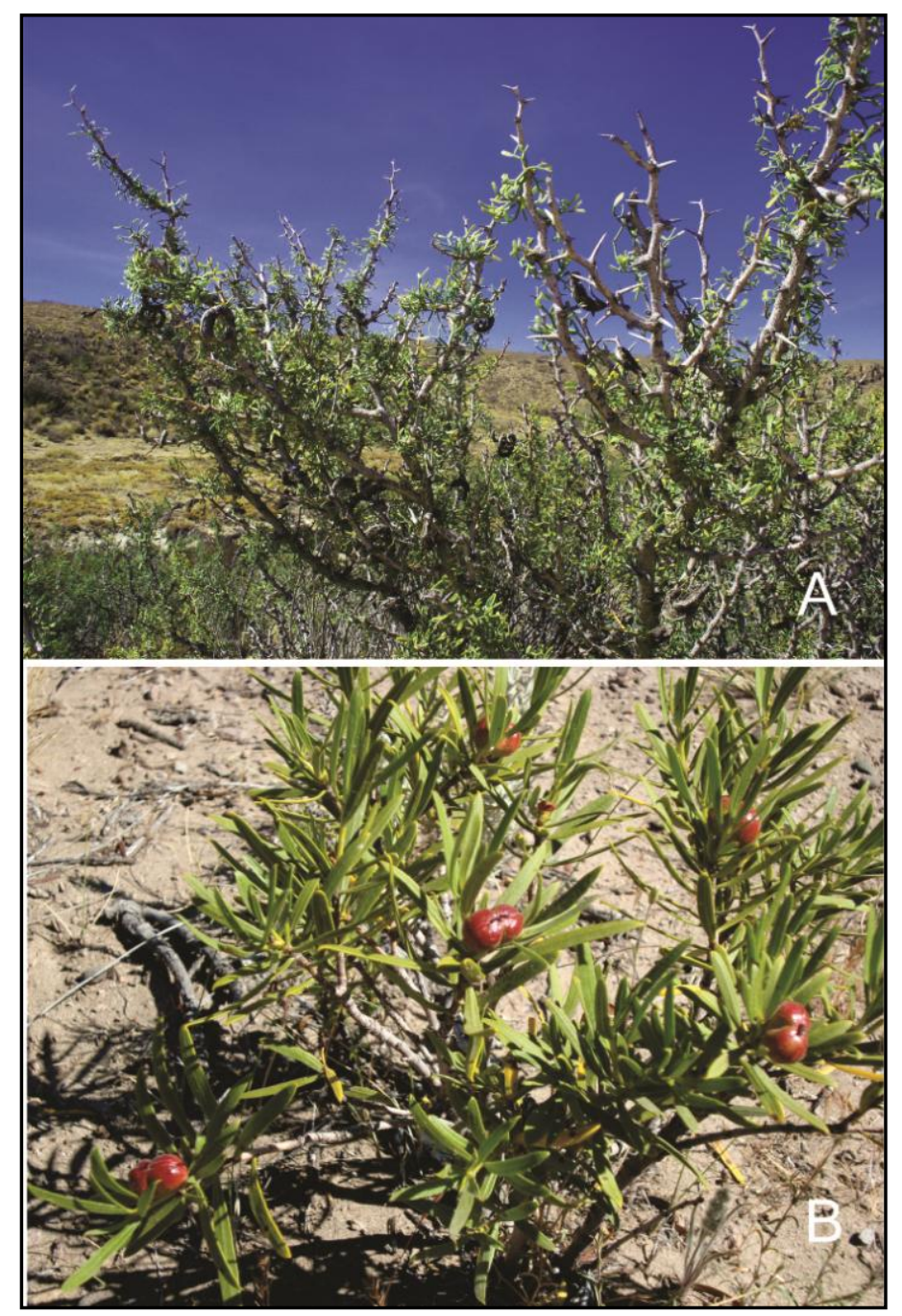

Figura 3.14. Cañadón próximo a la ría Deseado, sobre margen norte, en la Reserva Ría Deseado:

A, Prosopis denudans y B, Colliguaja integerrima.

Siguiendo por la ría Deseado hasta el paso Marsicano, la estepa antes mencionada se hace más baja $(\approx 1 \mathrm{~m})$, y sobre Estancia El Triunfo se observan arbustos de Lyicum sp., Colliguaja integerrima, y Schinus sp. Sobre terrenos de la Estancia La Negrita, siguiendo la ruta 85 , la estepa nuevamente adquiere mayor altura, con Schinus sp. de $\approx 2,5 \mathrm{~m}$ (Figura 3.15). 


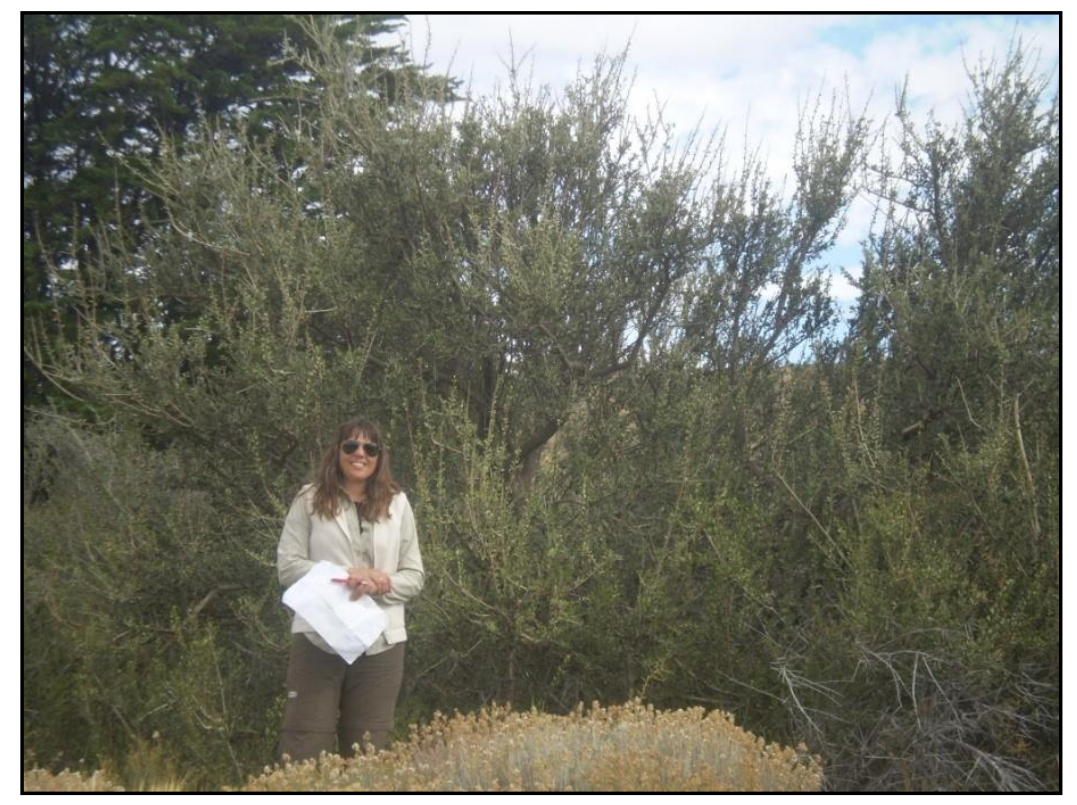

Figura 3.15. En las proximidades de la Estancia La Negrita se observan arbustos de Schinus sp. de gran altura atrás y Senecio filaginoides adelante (Fotografía de Aylén Capparelli).

Entre la Estancia La Negrita y la Ea. 8 de Julio se encuentra un salar donde la vegetación circundante está compuesta por Prosopis denudans (Figura 3.16), Lycium sp., Nassauvia sp, Lepidophyllum cupresiforme, Chuquiraga sp., Berberis sp. y un estrato herbáceo en cojín.

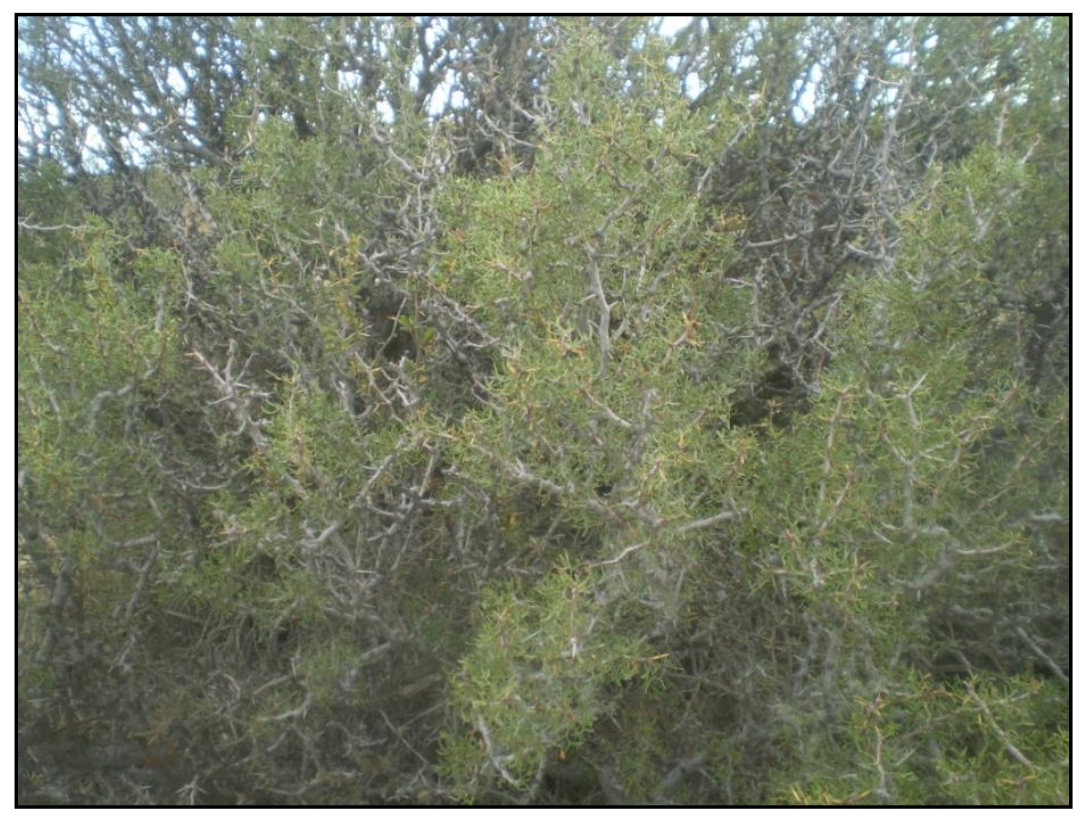

Figura 3.16. Prosopis denudans de gran tamaño entre la Estancia La Negrita y la Estancia 8 de Julio (Fotografía de Aylen Capparelli). 
Sobre la margen sur de la ría Deseado, precisamente frente a la localidad de Puerto Deseado, en la zona denominada Puerto Jenkins (Figura 3.17A, Figura 3.18), se observan arbustos bajos de Nardophyllum bryoides (Figura 3.17.B) y Lepidophyllum cupressiforme sobre sitios conchero. Entre este sitio y el afloramiento de rocas de formación Bahía Laura denominado "Piedra Toba" se registra una estepa graminosa arbustiva compuesta por Lepidophyllum cupressiforme, Festuca sp. y Pappostipa humilis var. humilis. Sobre el afloramiento de rocas denominado "Piedra Toba" se registran gran cantidad de arbustos de Berberis microphylla (Figura 3.17C), cojines de Chuquiraga sp. (Figura 3.17D) y cactáceas rastreras como Maihueniopsis darwinii (Figura 3.17E). También se observaron matas de Nassauvia sp, Senecio filaginoides (Fog. 3.17D), Mulguraeae tridens y Ephedra sp.

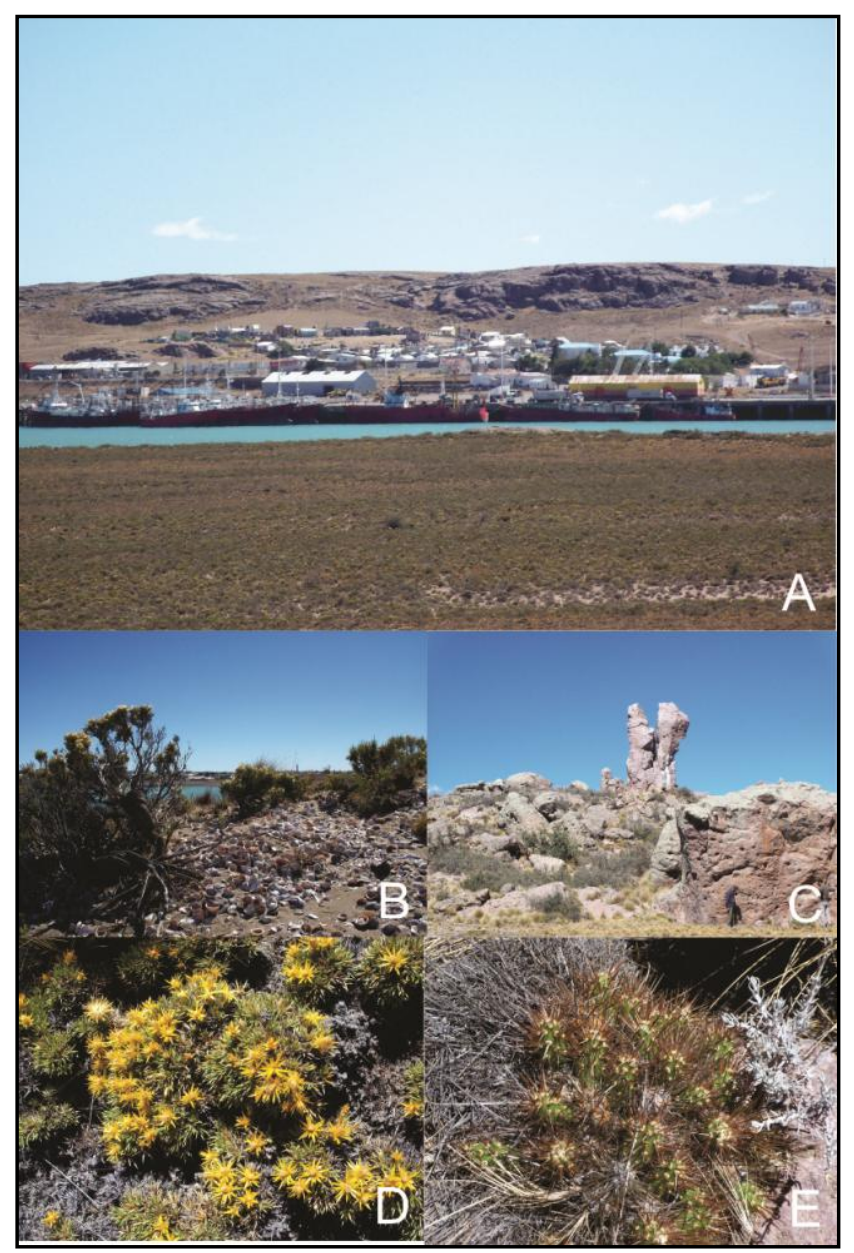

Figura 3.17. Margen sur de la ría Deseado: A. Vista de la localidad de Puerto Deseado, B, Nardophyllum bryoides sobre sitios concheros, C, "Piedra toba" afloramientos de roca de la 


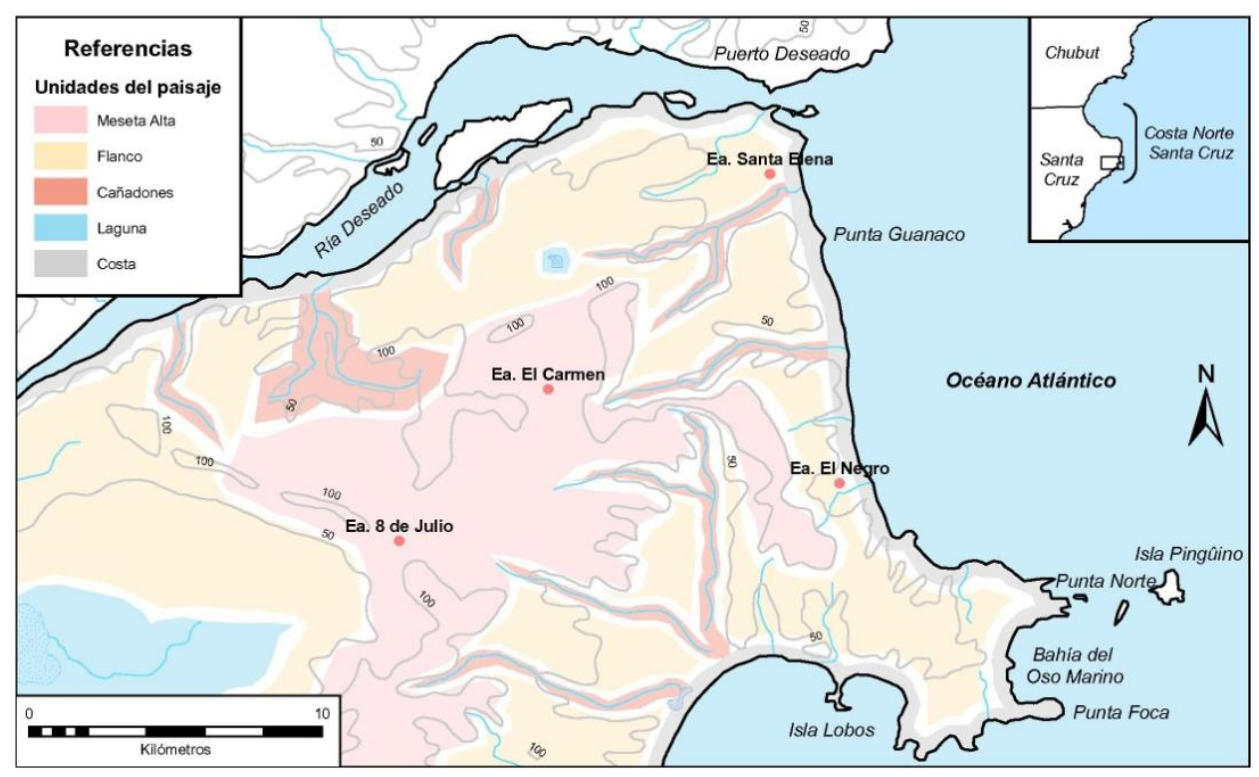

Figura 3.18. Unidades geomorfológicas registradas para el sector sur de la ría Deseado por M. A. Zubimendi (Zubimendi 2010)

En la Estancia El Negro se observan algunos cañadones que desembocan en la costa, entre ellos se encuentra el que finaliza en la playa del Barco Hundido. Allí la vegetación presenta arbustos de Schinus sp. de gran tamaño ( $\approx 2 \mathrm{~m}$ alto), Lycium sp., Berberis microphylla y Senecio sp. que al llegar a la costa se transforma en una estepa graminosa de baja altura.

En la franja costera (Figura 3.18) que abarca la Estancia El Negro se observa una estepa baja $(\approx 1 \mathrm{~m})$ con arbustos de Lepidophyllum cupressiforme, Nardophyllum bryoides, Senecio sp., y Azorella monantha, acompañados de Festuca sp. y Pappostipa humilis var. humilis. Protegidos por los afloramientos rocosos en Punta Norte se encuentran arbustos de Berberis microphylla, Lycium sp., Adesmia boronioides y cactáceas de Maihueniopsis darwinii. Sobre la Bahía del Oso Marino se registraron arbustos de gran tamaño de Schinus sp, Berberis microphylla, Mulinum spinosum, Chuquiraga erinaceae ssp. erinaceae. En la denominada Playa El Castillo se observan subarbustos de Lepidophyllum cupressiforme sobre la arena junto con Azorella monantha y otras plantas en cojín. La bahía Azopardo presenta, sobre los médanos, arbustos de 0,80 m de 
Adesmia boronioides, Chuquiraga erinaceae ssp. erinaceae y Senecio sp. junto con gramíneas de Pappostipa humilis. Sobre la costa de Isla Lobos se observan arbustos de Adesmia boronioides, Senecio sp, y Mulinum spinosum. Hacia el interior, el tamaño de los arbustos aumenta así como su diversidad.

En la localidad de Punta Medanosa se observa una concentración notoria de Schinus sp. de gran tamaño ( $\approx 3 \mathrm{~m}$ alto) (Figura 3.19). Si bien en los otros sectores se observa este género, raramente tienen esta altura y densidad. Esto puede deberse, entre otros factores, a la concentración de abono de pingüinos que producirían suelos más nitrogenados. En sus estudios sobre el pingüino de Magallanes (Spheniscus magellanicus), Pizarro Pinochet (2005) menciona que los lugares de nidificación suelen situarse en áreas de estepas arbustivas, localizándose los nidos en la base de arbustos de Atriplex, Suaeda, Lycium chilense entre otros. También menciona que en el caso de Senecio sp. puede ser colonizadora de espacios abandonados por lo pingüinos debido a la presencia de suelos altamente nitrogenados. En el caso de la pingüinera de Punta Medanosa los nidos se encuentran en cuevas próximas a las raíces o a la base de los troncos de Schinus sp (Figura 3.19). También se observan, sobre los médanos, arbustos de Senecio sp y Adesmia boroniodes, Berberis microphylla, Chuquiraga erinaceae ssp. erinaceae y Lycium sp. junto a gramíneas de Pappostipa humilis, y Poa sp (Figura 3.20A, B). 


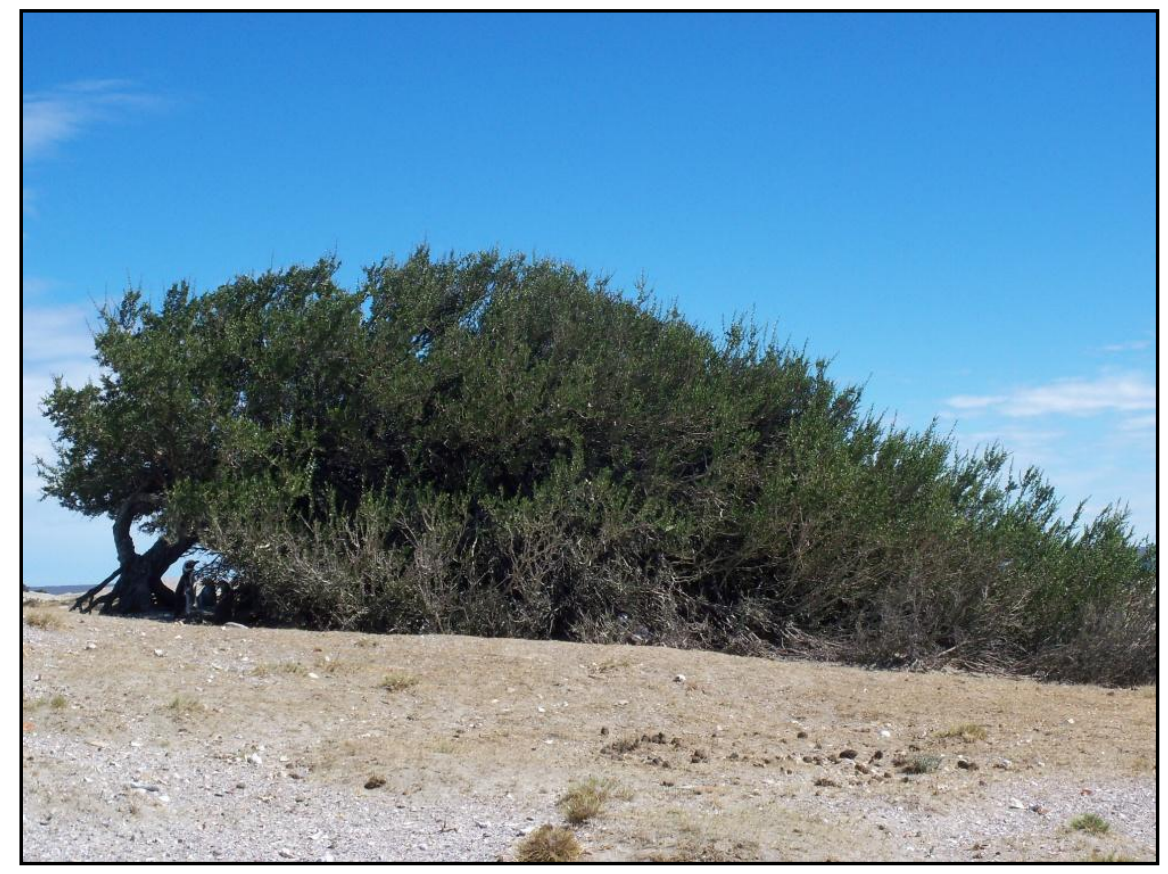

Figura 3.19. Punta Medanosa a 100 m sobre la línea de costa se observa un arbusto de Schinus sp. y un nido de Spheniscus magellanicus bajo el mismo.

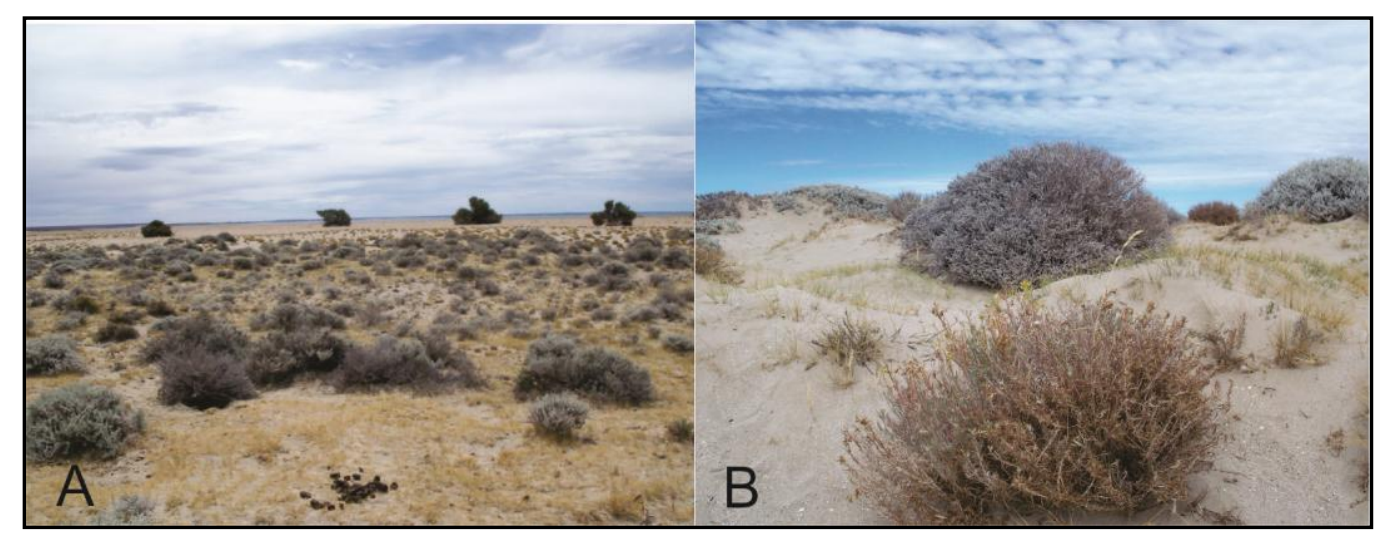

Figura 3.20. Punta Medanosa. A. Se observan arbustos de Schinus sp. en la lejanía y adelante otros de menor altura como Senecio sp. B. Senecio sp.

Se ha descripto anteriormente las variantes de la vegetación de estepa arbustiva del Golfo San Jorge. Se mencionó que hacia el interior del continente se desarrolla otra unidad de vegetación que corresponde a una estepa de arbustos enanos, rastreros, de muy baja cobertura vegetal (entre un 20\% y 30\%), con arbustos de mayor porte solo en las líneas de escorrentía (Oliva et al. 2001). Esta vegetación se extiende en el centro norte de la provincia de Santa Cruz, sobre grandes áreas de pavimento de erosión de relieve plano, conformadas por planicies aluviales de 
rodados patagónicos y mesetas sedimentarias, entre otros paisajes. El clima predominante en esta zona es el frío Árido de Meseta, con promedios anuales de temperatura de $10^{\circ}$ a $8{ }^{\circ} \mathrm{C}$ de noreste a sudoeste respectivamente. Las precipitaciones son menores a los $150 \mathrm{~mm} / \mathrm{año}$, excepto en una delgada franja costera que recibe una cantidad algo mayor a $200 \mathrm{~mm}$ anuales. Los suelos son de textura franco-arenosa a franco-arcillosa. La vegetación predominante está compuesta por Nassauvia glomerulosa (Lag.) N. O'Leary \& Peralta var. Lorentzii, una especie rastrera que es dominante de las estepas subarbustivas que cubren la mayor parte de esta unidad de vegetación. En áreas poco degradadas todavía se pueden encontrar los coirones amargos de Pappostipa speciosa (Trin \& Rupr) Romasch. y el coirón pluma Jarava neaei (Nees ex Steud.) Peñailillo. En las zonas de acumulación de arena se encuentran también otros coirones amargos, indicadores de degradación (i.e. Pappostipa humilis) y el coirón enano [Pappostipa ibarii (Phill.) Romasch]. El coirón blanco subsiste en mesetas sedimentarias y basálticas altas. En los cañadones se encuentran arbustales de Anarthrophyllum rigidum, Schinus polygamus (Cav.) Cabrera var. polygamus, Berberis microphylla, entre otros. Dentro de los subarbustos se identifican Nassauvia ulicina (Hook. f.) Macloskie y Chuquiraga aurea Skotssb. que son comunes en zonas degradadas con suelos arcillosos y abundantes pavimentos de erosión. Mulinum microphyllum (Cav.) Pers. (neneo enano) y Ephedra frustillata Miers. también son arbustos enanos importantes (Oliva et al. 2001:58).

Si bien se describieron estas dos unidades de vegetación por separado (estepa arbustiva del Golfo San Jorge y estepa de arbustos enanos), se desarrollan en el área de estudio situaciones ecotonales entre ambas (i.e. en el comienzo de la ría y fin del río Deseado). Así como se encuentran diferencias entre la vegetación de las mesetas y de los cañadones dentro de estas dos unidades, también presentan los ecosistemas de mallines. Estos últimos se encuentran compuestos principalmente por juncos y pastos asociados a la presencia de agua cerca de la superficie del suelo. Se desarrollan en áreas muy localizadas y asociados con unidades del paisaje que presentan condiciones favorables a la preservación del agua en el suelo. Se encuentran en porciones deprimidas de los pisos de valles, de las planicies de inundación, del fondo de las cuencas endorreicas, o de los bordes las 
lagunas, y, debido a que éstos suelen ser ambientes salinos, es común que su vegetación tenga características halófitas. Los mallines también son frecuentes en las laderas de las mesetas basálticas, donde se localizan manantiales (Mazzoni 2000, Mazzoni y Vazquez 2004).

Un factor importante a tener en cuenta en la descripción de estas unidades de vegetación es el actual proceso de desertificación, puesto que modifica las características del ambiente. Sólo se habla de desertificación cuando los cambios tienen lugar por acción del hombre. La desertificación abarca una serie de procesos asociados al deterioro de ambientes áridos, semiáridos y subhúmedos, provocando la extinción de especies nativas a nivel local, la erosión del suelo, la modificación de la estructura de la vegetación y la disminución de la productividad biológica del ecosistema (Paruelo et al. 2005).

Los estudios desarrollados en la Provincia de Santa Cruz evidencian que la desertificación se debe a una intensificación de los procesos erosivos debida, o bien al sobrepastoreo en áreas naturales propensas, al sobrepastoreo continuo en comunidades frágiles, o a la sobreexplotación de comunidades de arbustos (Andrade 2012), aunque también se puede producir por el desarrollo de actividades mineras (Paruelo et al. 2005).

La colonización de las estepas patagónicas con ganado ovino y vacuno comenzó a fines del siglo XIX (Ibarroule et al. 2011, Barberia 2011). Esta actividad económica tuvo dos fases de evolución: una creciente hasta mediados del siglo XX y otra posterior decreciente asociada a la desertificación (Paruelo et al. 2005). Investigaciones del INTA evidencian que la comunidad de estepa arbustiva del Golfo San Jorge, que se extiende a lo largo del área de estudio del proyecto arqueológico CNSC, presenta niveles de desertificación media, mientras que la comunidad de estepa de arbustos enanos (meseta central) registra un nivel de desertificación grave (Andrade 2012).

\subsubsection{Fauna}

La fauna de la costa norte de Santa Cruz es la misma que la que se observa en toda la Provincia Patagónica (Cabrera y Willink 1973). Muchas de sus especies 
están adaptadas a la vida debajo de plantas achaparradas debido a los fuertes vientos de la región. Entre los mamíferos se pueden encontrar guanacos (Lama guanicoe) (Fig 3.21) lestodelfis (Lestodelphis halli; Zubimendi y Bogan 2006). Entre los carnívoros se encuentran: el zorro gris (Pseudalopex griseus) y el zorro colorado (Pseudalopex culpaeus), el hurón menor (Galictis cuja), el puma (Felis concolor), zorrino (Conepatus humboldtii), el gato montés (Felis geoffroyi), el gato de los pajonales (Felis colocolo). También se observan variedad de roedores como por ejemplo: la mara (Dolichotis patagonum; Manero 2000), el tuco-tuco (Ctenomys magellanicus), el cuis (Microcavia australis). Entre los armadillos, el peludo (Chaetophractus villosus) y el piche (Zaedyus pichiy). También se observa en la costa el lobo marino de un pelo (Otaria flavescens) y de dos pelos (Arctocephalus australis) formando loberías (Bastida et al. 2007) (Figura3.22).

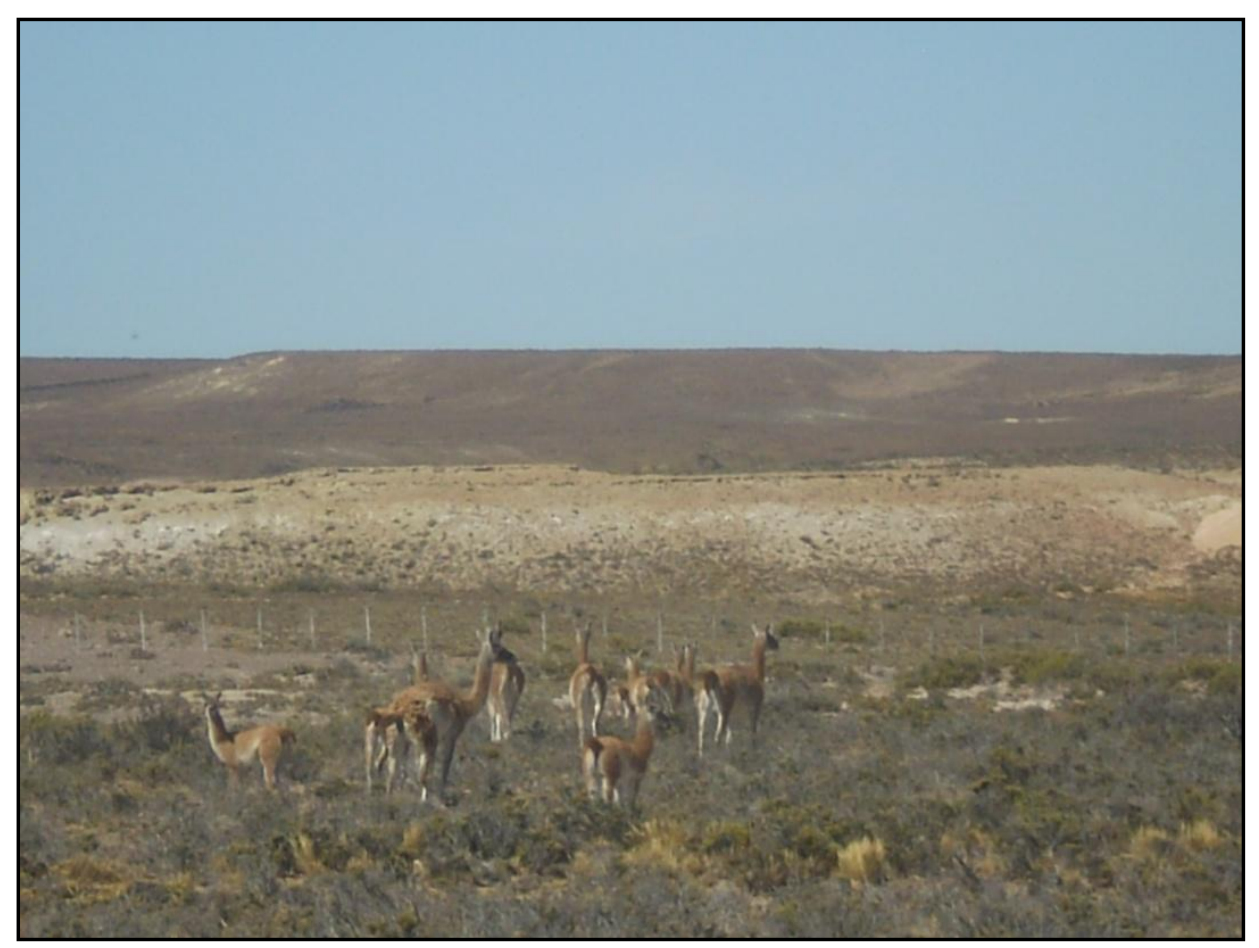

Figura 3.21. Grupo de guanacos (Lama guanicoe) en la estepa de CNSC 


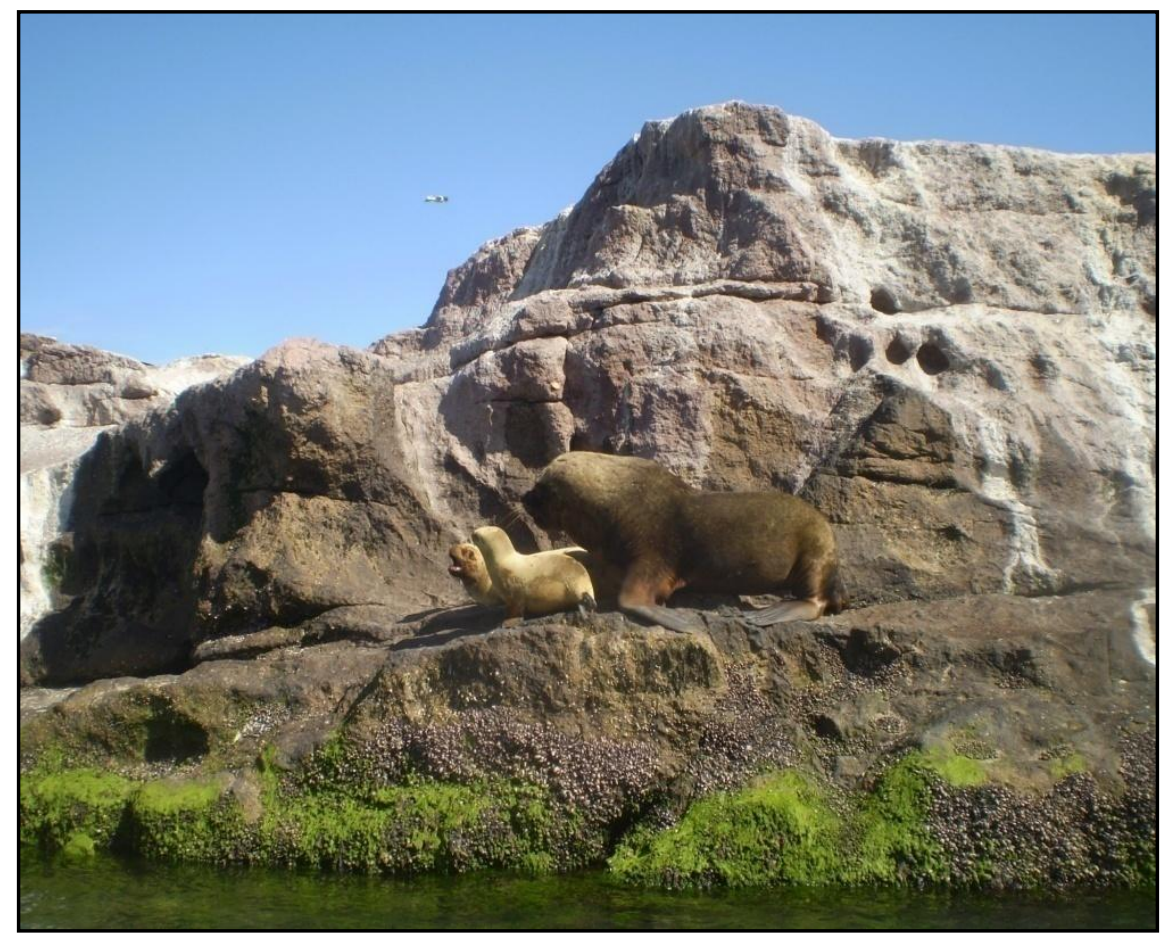

Figura 3.22. Lobos marinos de un pelo Otaria flavescens: macho y hembra

Entre las aves se registra el pato vapor volador (Tachyeres patachonicus), gaviotas cocineras y australes (Laurus dominicanus y Laurus scobesii), cormorán imperial (Phalacrocorax atriceps), cormorán de cuello negro (Phalacrocorax magellanicus) y cormorán gris (Phalacrocorax gaimardi) (Figura 3.23), los albatros (Thalassarche melanophris) y paloma antártica (Chionis alba) (Figura 3.24). También, dentro de los reiformes, se encuentra el ñandú (Pterocnemia pennata), y de los tinamiformes Eudromia elegans (Figura 3.25), entre otros. En la costa se encuentran los pingüinos (Spheniscus magellanicus) formando numerosas colonias (Cruz 2007) (Figura 3.26) y una gran variedad de aves más (Gandini y Frere 2000, Frere et al. 2005, Favero y Silva Rodríguez 2005, Schiavini et al. 2005). 


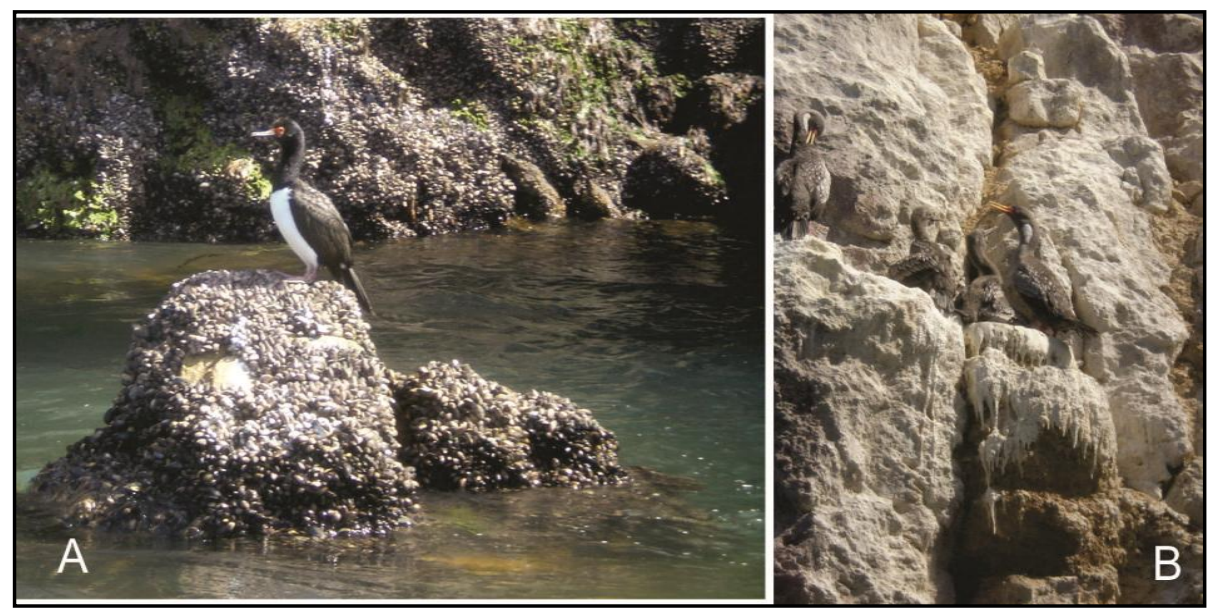

Figura 3.23. A: Cormorán de cuello negro (Phalacrocorax magellanicus) B: Cormorán gris (Phalacrocorax gaimardi)

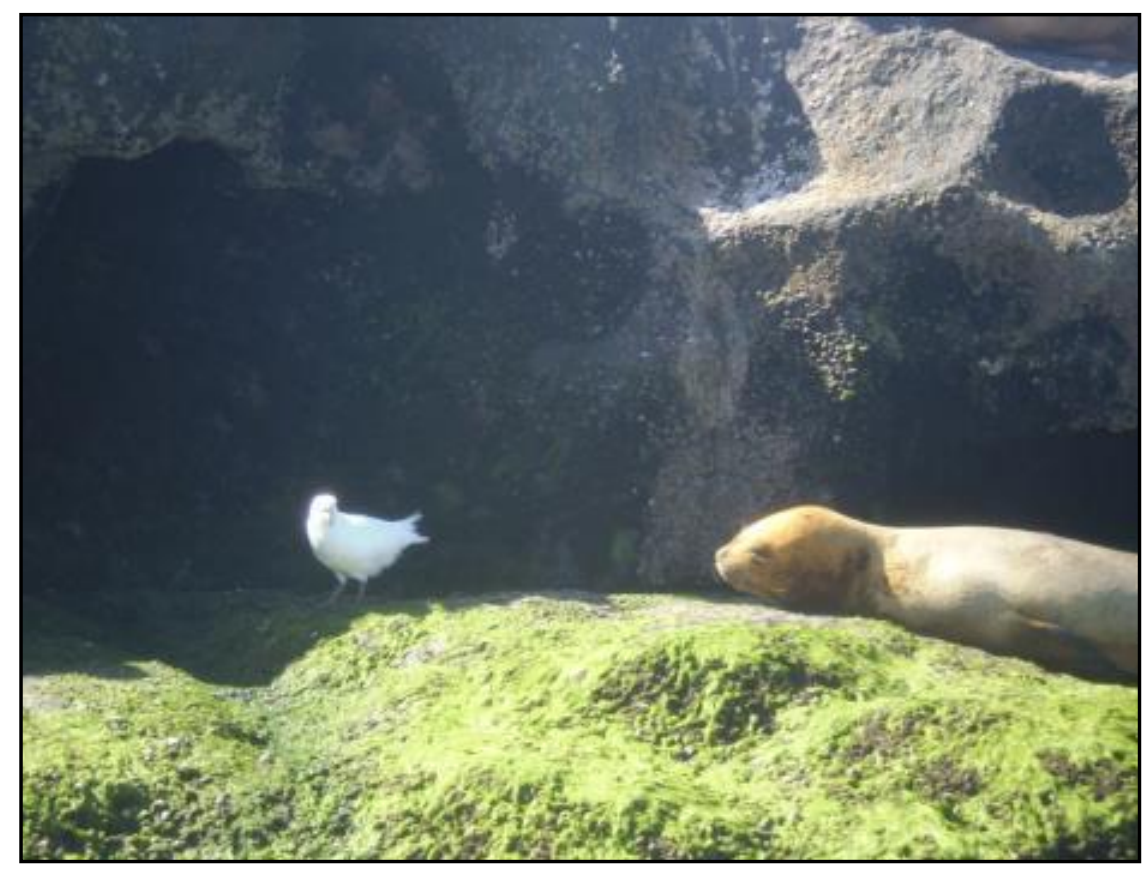

Figura 3.24. Paloma antártica (Chionis alba) y Lobo marino (Otaria flavescens) 


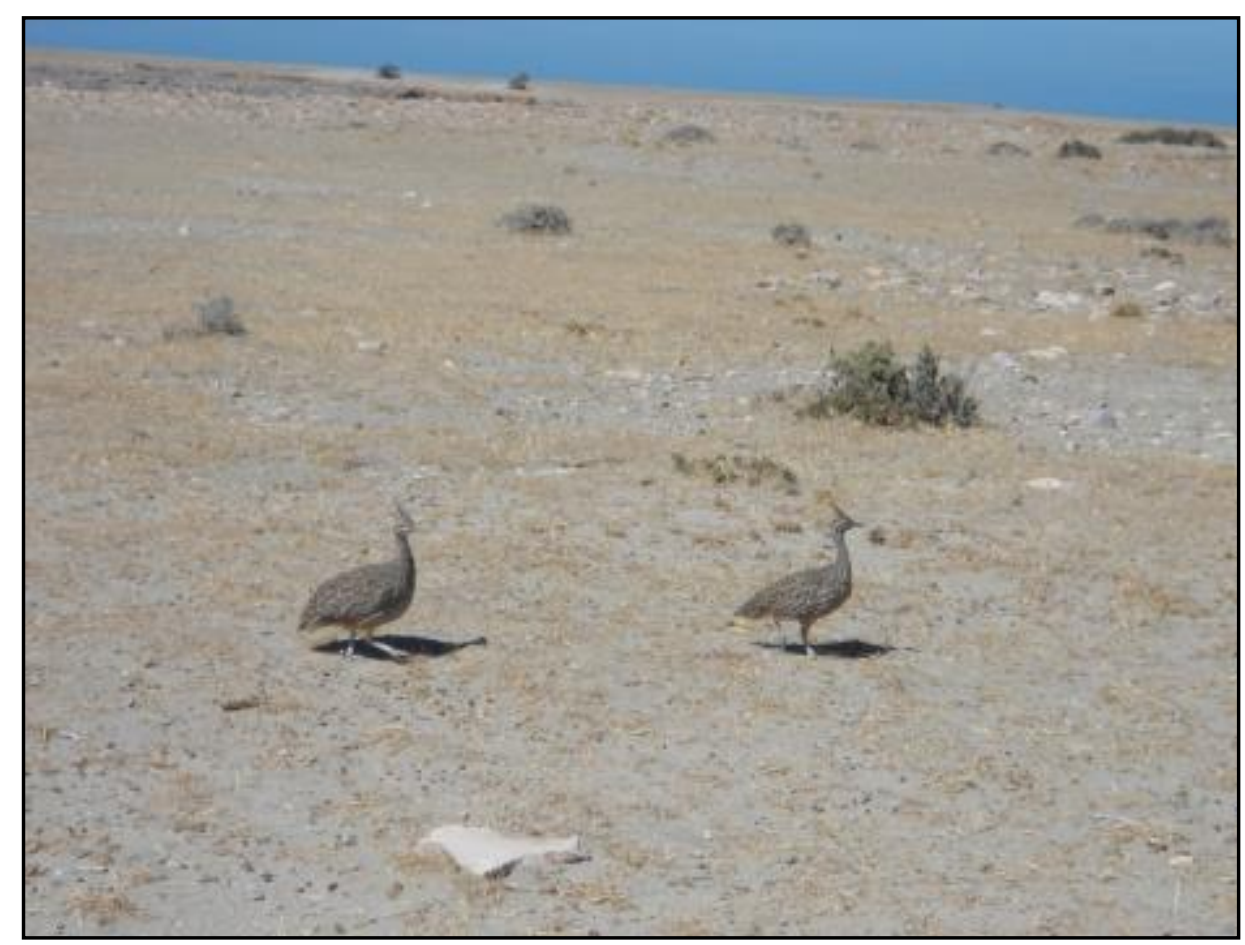

Figura 3.25. Martinetas (Eudromia)

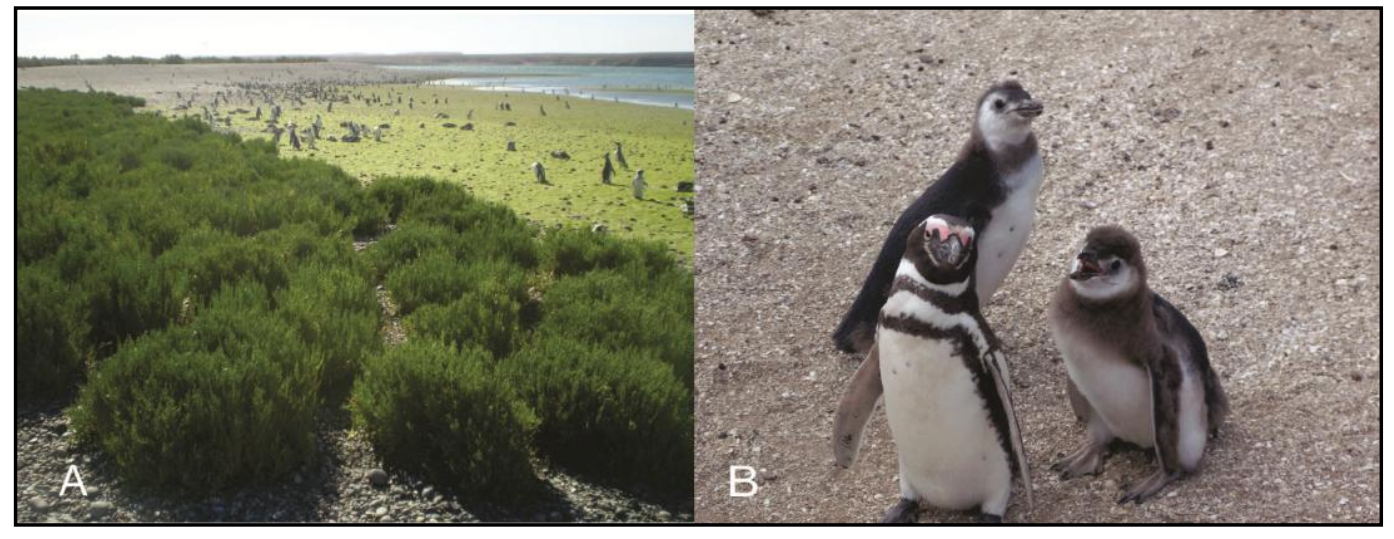

Figura 3.26. A y B: Colonia de pingüinos (Spheniscus magellanicus) en Punta Medanosa

Los peces más comunes son los bagres (Hatcheria spp.), otunos o bagres sapo (Diplomystes spp.), peladillas (Haplochiton spp.), trucha criolla (Percichthys spp.), el pejerrey patagónico (Basilichthys spp.) y los puyenes (Galaxias spp.) (Cabrera y Willink 1973: 96). Entre los moluscos se pueden citar algunos géneros como: lapas (Nacella magellanica) o mitílidos: mejillones (Mytilus edulis), mejillines (Perumytilus purpuratus) y cholgas (Aulacomya atra) (entre otros Aguirre y Farinati 2000, Zubimendi 2007; Zubimendi et al. 2005, 2007, 2004; Zubimendi y Hammond 2009). 


\subsection{Paleoambiente}

En el área costa norte de Santa Cruz no se han desarrollado hasta el momento secuencias polínicas para reconstruir el paleoambiente. Sin embargo, las secuencias polínicas de Los Toldos, La María y La Martita (De Porras 2010, Mancini 1998) son las que se utilizarán en esta tesis debido a que son las más cercanas geográficamente $(c a .150 \mathrm{~km}$ al oeste en línea recta desde Puerto Deseado) y se encuentran dentro de la denominada estepa de arbustos enanos descripta más arriba (Figura 3.1).

Las secuencias polínicas de las cuevas en las localidades arqueológicas de Los Toldos (situada en un cañadón) y La María, fueron analizadas por De Porras (2010). Dichas localidades se encuentran a $100 \mathrm{~km}$ de distancia entre sí dentro de lo que denominamos actualmente como estepa de arbustos enanos (Oliva et al. 2001, De Porras 2010). Entre los 10.500 y ca. 5.000 años AP se registró en Los Toldos una comunidad arbustivo-graminosa de Asteraceae subf. Asteroidea con Nassauvia, Ephedra frustillata y Solanaceae que también se observa en La María antes de los 5.577 AP. Los arbustos enanos y en cojín como Nassauvia y Ephedra frustillata fueron más abundantes con anterioridad a 7.260 AP siendo los arbustos medianos y altos componentes más importantes de la vegetación posteriormente. Este registro sugiere un aumento gradual de la temperatura durante el Holoceno temprano y medio por debajo de la temperatura actual, bajo condiciones de precipitación anual similares a las actuales. Entre los 5.000 y 3.750 AP en Los Toldos se desarrolló una comunidad arbustiva-subarbustiva muy diversa dominada por Asteraceae subf. Asteroidea y otros arbustos medianos y altos como Colliguaja integerrima, Schinus y Lycium y arbustos enanos y en cojín como Nassauvia y Ephedra frustillata. Esta comunidad tiene una analogía parcial con la estepa subarbustiva del noreste de la meseta central (en esta tesis siguiendo a Oliva et al. 2001 "estepa de arbustos enanos") y representa el momento de máxima diversidad entre arbustos medianos y altos del cañadón. No sólo sería similar la diversidad de especies dentro de esta comunidad sino también la distribución, siendo entonces arbustivas en el cañadón y subarbustivas en los alrededores de la estepa. El desarrollo de esta comunidad sugiere un aumento de 
la temperatura y condiciones ambientales similares a las actuales (De Porras 2010:111).

En La María a partir de los 5.190 años AP hasta tiempos recientes se observa el desarrollo de una comunidad arbustiva dominada por Asteraceae subf. Asteroidea similar a la actual. En Los Toldos desde los 3.750 años AP la comunidad arbustiva subarbustiva es reemplazada por una comunidad arbustiva dominada por Colliguaja integerrima acompañada por Asteraceae subf. Asteroidea análoga a la que se desarrolla en algunos cañadones. Este cambio se observa dentro de la capa de ceniza del volcán Hudson siendo que luego de la ceniza aumenta la presencia de Colliguaja integerrima.

Hacia los 4.177 años AP ocurriría en La María el establecimiento de comunidades vegetales similares a las actuales. El registro polínico de Los Toldos en cambio, presenta un pequeño cambio de vegetación con posterioridad a los 1.410 años AP, de una comunidad arbustiva dominada por Colliguaja integerrima a otra dominada por Asteraceae subf. Asteroidea (De Porras 2010:115).

En la Cueva 4 de La Martita, que se encuentra ubicada en el sur de la Altiplanicie central de la provincia de Santa Cruz, a $600 \mathrm{msnm}$, en una zona transicional entre las mesetas altas al norte y la depresión del Bajo San Julián al sur, también se realizaron estudios polínicos (Mancini 1998). Entre el 8.000 y 6.000 años AP en La Martita se registra un incremento de la estepa arbustiva que estaría relacionado con un aumento de la temperatura y precipitaciones de $200 \mathrm{~mm}$, en un clima análogo a las condiciones de la estepa arbustiva moderna. Hacia el 5.000 AP se identifica un cambio ambiental de corto tiempo, en el que se registra una expansión de la estepa dominada por gramíneas similar a la del Holoceno temprano, que indicaría condiciones frías o un incremento de las precipitaciones. Alrededor de los 4.500 AP, la estepa cambió a una estepa arbustiva graminosa con taxa característicos del semidesierto (Poaceae, Nassauvia y Ephedra). Después de los 2.190 años AP la vegetación de estepa arbustiva sería análoga a la que ocupa en el presente el área (Mancini 1998). 


\subsection{Antecedentes arqueológicos generales de la Costa Norte de Santa}

Cruz

En el área de estudio la Dra. Alicia Castro dirige, desde fines de la década 1980, el Proyecto Arqueológico Costa Norte de Santa Cruz cuyo objetivo de investigación fue caracterizar el litoral del norte de dicha provincia y el uso que los grupos humanos hicieron de la costa y de sus recursos. Hasta ese momento la gran cantidad de trabajos desarrollados principalmente en cuevas y aleros de la meseta central y precordillera reforzaban la idea de grupos cazadores de guanaco y consumidores de recursos netamente terrestres. A su vez, el análisis de fuentes documentales del siglo XVIII y XIX registraba descripciones de grupos tehuelches cazadores de grandes animales terrestres sobre todo guanaco y ñandú (ver discusión en Moreno y Castro 1995-1996). Sin embargo los trabajos que se realizaron en el marco del proyecto arqueológico Costa Norte de Santa Cruz revirtieron este modelo a través de las evidencias recuperadas del uso costero.

El desarrollo de las investigaciones en este área dio lugar, a la delimitación de tres sectores arqueológicos de acuerdo a la variabilidad en la distribución y diversidad de los recursos económicos, así como a las unidades geomorfológicas que allí se encontraron: centro del Golfo San Jorge, Cabo Blanco, y margen sur de la Ría Deseado (Zubimendi 2010) (Figura 3.27). Es importante remarcar que dentro de cada uno de estos sectores se pueden reconocer unidades geomorfológicas distintas: meseta alta, flanco de meseta, cañadones, lagunas y litoral o costa propiamente dicha. En los párrafos que siguen se mencionarán los principales resultados obtenidos para cada uno, no obstante, una descripción más profunda de los mismos se presenta en el capítulo 8, 9 y 10 de la presente tesis.

Los primeros trabajos que se llevaron a cabo se desarrollaron en lo que se denominó sector del Golfo San Jorge (Figura 3.27.) a partir de la excavación del sitio Moreno, situado a $32 \mathrm{~km}$ al sur de la localidad de Caleta Olivia. Se identificaron dos componentes, uno de ellos superficial en el que se recuperaron restos malacológicos asociados a carbones, líticos y restos óseos. Entre estos últimos se destaca una cantidad de 2.950 vértebras de peces y 10 fragmentos de huesos de aves. Los artefactos líticos fueron manufacturados con materias primas 
locales. Estos materiales fueron datados en $2720 \pm 50$ años AP (LP 206). En el componente inferior se recuperaron restos malacológicos asociados a un fogón en cubeta y artefactos líticos que en su mayor parte estaban manufacturados en materias primas locales. El fechado de los carbones del fogón fue de $3290 \pm 90$ AP (1063 cSM). Las características de estos dos componentes evidencian un sitio conformado con conjuntos líticos expeditivos, materias primas locales y fauna cuyo origen podría provenir de las restingas próximas al sitio, de fácil obtención (Moreno y Castro 1995, Izeta 1999).

En este mismo sector, en la década de 1990, A. Castro desarrolló tareas de rescate arqueológico a partir del registro de un sitio enterratorio. El sitio Heupel se encuentra a $3 \mathrm{~km}$ al sur de Caleta Olivia y está conformado por un chenque sobre una lomada frente al mar. El contexto del hallazgo evidencia el enterratorio de tres individuos, uno de ellos un individuo adulto masculino, dispuesto a lo largo de la estructura con la cabeza orientada hacia el oeste. Asociado a este individuo se hallaron restos de un párvulo parcialmente calcinado, y sobre las extremidades inferiores del individuo los restos de un niño, articulados y con presencia de ocre. El ajuar de este enterratorio múltiple estaba comprendido por cuatro placas de cobre rectangulares, asociadas al cráneo del párvulo y dos punzones de hueso de aves asociados al cráneo del adulto. La datación de una costilla del individuo adulto arrojó el fechado de $730 \pm 60$ años AP (LP -2393 (Salceda et al. 19992001, Zubimendi et al. 2011, Zilio et al. 2013, 2014).

En la década de 1990 A. Castro y E. Moreno también realizaron prospecciones sobre el sector denominado Cabo Blanco (Fig 3.27). Uno de los sitios identificados y excavados fue el denominado sitio Cabo tres Puntas, ubicado en la Estancia del mismo nombre y sobre la playa. Se encuentra sobre el frente de una terraza de 10 metros de altura, y está conformado por un afloramiento de un conchero sobre la barranca, de unos $10 \mathrm{~cm}$ de espesor y $80 \mathrm{~cm}$ de largo. Los restos malacológicos correspondían a valvas de Mytilus edulis y Nacella sp. en asociación con carbones y fragmentos de líticos, en su mayor parte, lascas. La importancia de este sitio es que es pre-ingresivo, dado que el fechado radiocarbónico arrojó una edad de $6.060 \pm 70$ años AP (AA- 13663) (Castro y Moreno 1996-1998). Con posterioridad se realizaron nuevos fechados sobre lentes 
de valvas expuestas en las cercanías del sitio anterior, cuyos resultados fueron de $5.480 \pm 80$ años AP (LP- 1647) sobre carbón vegetal y $5.020 \pm 80$ años AP (LP1692) edad corregida por efecto reservorio sobre valvas (Castro et al. 2007). Por otra parte, sobre el tómbolo de Cabo Blanco se encuentran los sitios Cabo Blanco I y II. El primero está conformado por una capa con una alta densidad de materiales líticos, óseos y malacológicos. Los artefactos líticos evidencian distintas etapas de la cadena operativa y en asociación con los demás restos arqueológicos permiten definir al sitio como producto de actividades múltiples (Castro et al. 1999). En cuanto al análisis faunístico es relevante mencionar que predomina la fauna marina sobre la terrestre y las aves (pingüinos y cormoranes) sobre los mamíferos en general (Moreno et al. 1998). Para este sitio se realizaron dos fechados radiocarbónicos, uno para el componente inferior que arrojó una edad de $1.700 \pm 30$ años AP (Beta 134598) y otro para el componente superior de $1.420 \pm 50$ años AP (Beta 134597) (Moreno 2008). El sitio Cabo Blanco II, por otra parte, es un sitio también de grandes dimensiones, de planta circular. La composición de este sitio es similar al anterior y presenta los siguientes fechados radiocarbónicos: $3.390 \pm 90$ años AP (LP-992) y la más moderna de $960+60$ años AP (Beta 134599) (Castro et al. 2000, Moreno 2008). A su vez, en este sector se registraron diez estructuras de entierro tipo chenques (Castro y Moreno 2000).

Posteriormente se desarrollan en el equipo trabajos distribucionales a diferentes escalas, de grano grueso (escala regional) y fino (muestreos estratigráficos) (Castro et al. 2003) A una escala regional se observan diferentes patrones de distribución diferencial de sitios según las unidades geomorfológicas. Sobre la franja costera se registra mayor densidad arqueológica mientras que la franja interior podría estar cumpliendo un rol de actividades restringidas con poco descarte de material. Por otra parte, el uso de la costa está determinado por los recursos, la riqueza y la predictibilidad de los recursos marinos, siendo muy importante los bancos de moluscos. A partir de estos estudios se observa que el uso de la costa fue intensivo durante el Holoceno tardío (Castro et al. 2003) y se propone un modelo de uso para dos sectores específicamente: el Golfo San Jorge y el Sur de la Ría Deseado, considerando que entre Cabo Blanco y Puerto 
Deseado no había evidencia de sitios arqueológicos. En el Golfo San Jorge, se observó mayor variedad de tipos de sitios, lo que podría indicar una mayor movilidad en el espacio, cada actividad se habría desarrollado en un lugar diferente del mismo y por lo tanto cada sitio sería un momento dentro de un circuito de movilidad mayor. En el sector sur de la ría Deseado se registró una menor variedad tipológica de sitios, con una estructuración diferente del espacio que refleja un mayor agrupamiento de los sitios. También se registra una mayor densidad de artefactos así como un uso más concentrado de las actividades en el espacio, por lo que se infiere la reocupación de ciertas unidades del paisaje. Esto implicaría un patrón de asentamiento con menor movilidad (Zubimendi et al. 2004 у 2005).

Hacia el año 2000, A. Castro también realizó actividades de rescate, tales como la excavación de una estructura de entierro tipo chenque en la Reserva Natural Cañadón del Duraznillo, al sur del Golfo San Jorge. Se registró un entierro directo de un individuo masculino adulto datado en $c a .640 \pm 50$ (LP 2668) que no presentaba patologías óseas y con rasgos antropométricos similares a los identificados en los grupos nativos de la Patagonia. Los estudios de isótopos realizados en los últimos años sobre los restos de dicho individuo permitieron identificar una dieta mixta con la incorporación de recursos alimenticios marinos y terrestres (Moreno et al. 2011, Zilio et al. 2014, Zubimendi et al. 2014). Hacia el año 2004, a partir también de actividades de rescate, se identificó el sitio Carsa ubicado en el casco urbano de la ciudad de Puerto Deseado. El sitio estaba conformado por el entierro primario de un individuo sin ajuar funerario y con evidencias de una patología infecciosa y alteraciones craneanas (Castro et al. 2009). Estos restos óseos fueron fechados obteniéndose una edad de $1740 \pm 60$ años AP (LP-2088) (Castro et al. 2009).

Castro y E. Moreno también registraron 274 enterratorios y estructuras atribuibles a enterratorios, chenques, en la localidad arqueológica de Punta Medanosa a pocos metros sobre el nivel del mar y sobre la ingresión marina (Castro y Moreno 2000). Como se mencionó más arriba el uso de la costa en este sector no fue homogéneo, registrándose un uso intensivo de la costa para el Holoceno tardío a partir de la identificación de numeroso sitios concheros (Castro et al. 2001, Zubimendi et al. 
2004, 2005; Zubimendi 2012, Hammond et al. 2013). Como se mencionó Zubimendi y colaboradores (2005) postulan que para este sector se habría observado una mayor intensidad de uso, o una menor movilidad, especialmente en Punta Medanosa, que presenta una clara estructuración del espacio. En esta última localidad se registra un área formal de entierro denominada Campo de Chenques donde en una primera instancia se registraron 86 chenques (Castro y Moreno 2000). Nuevos relevamientos en este sitio permitieron a Zilio (2013) contabilizar 217 estructuras.

En la CNSC recientemente se ha enfatizado en la excavación de dos tipos de sitios, concheros y abrigos rocosos. A partir de ambos tipos de registros arqueológicos se identificaron los sitios cuyos componentes más tempranos fueron fechados en ca. 7000 años en el alero El Oriental en la localidad de Bahía del Oso Marino y $6300 \pm 90$ años AP en el sitio conchero Médano Alto en la localidad de Punta Medanosa (Ambrústolo et al. 2011 y Zubimendi et al. 2005). Es importante mencionar también el sitio Cueva del Negro, ubicado cronológicamente en el Holoceno tardío, cuyo registro arqueológico evidencia un sitio conchero en cueva. En este sitio identifica la explotación de recursos marinos, así como de instrumental específico para estas prácticas como arpones en hueso y de madera (Beretta et al. 2011, 2013a y b, Capparelli et al. 2009), evidencias de redundancia ocupacional y temporal en ciertos sectores de la costa (Zubimendi et al. 2011).

E. Moreno desarrolló su tesis doctoral a partir de los estudios distribucionales mencionados anteriormente, así como del análisis de restos faunísticos de los sitios arqueológicos excavados y del análisis de fuentes documentales del siglo XVI a XVII (Moreno 2008). A partir de sus resultados propone un modelo del uso de la costa para el Holoceno tardío hasta momentos preecuestres. En el mismo, se presenta el uso estacional de los sitios costeros, que serían utilizados durante primavera y verano. Durante fines del verano y principios de otoño, los grupos humanos ocuparían la zona más alejada del mar basando su subsistencia en la caza del guanaco y recolección de vegetales. A partir de fines de otoño e inicios del invierno podrían desarrollarse dos alternativas: una, en donde los grupos se acercaron tempranamente a la costa (mayo) y se dedicaron a la caza de aves 
(ñandú y otras) con campamentos cerca del mar o, aproximarse más tarde (junio) y subsistir sobre la base de guanaco y vegetales con uso ocasional de moluscos donde los campamentos se encontrarían a algunos kilómetros del mar. En primavera e inicios del verano los campamentos se dispondrían inmediatos al mar, dependiendo su posición de los recursos marinos presentes, basando su subsistencia en éstos, utilizando tecnología específica y adecuada para explotarlos. Moreno considera que existió un uso intensivo de la costa y de sus recursos para el Holoceno tardío hasta momentos preecuestres donde se abandonaría la costa (Moreno e Izeta 1999).

En los últimos años, M. Zubimendi realizó su tesis doctoral cuyo objetivo fue discutir el uso del espacio costero del área CNSC y del interior inmediato a partir de estudios distribucionales analizando el material arqueológico en superficie y la estructura de los conjuntos artefactuales. Entre sus resultados se observa que el aprovechamiento de la costa no fue homogéneo, estableciéndose distintas estrategias de uso del espacio según la presencia de recursos costeros, tales como los bancos de moluscos y loberías. Respecto al sector de Cabo Blanco manifiesta que existen evidencias de un uso intensivo de un punto específico de la costa: el tómbolo de Cabo Blanco, que ha contado con una alta disponibilidad de recursos marinos, mientras que el resto de la costa habría sido un espacio prácticamente marginal, así también observa que las lagunas y los cañadones habrían sido usados como espacios residenciales (Zubimendi 2009). En un análisis que integra los tres sectores ya mencionados, Cabo Blanco, Golfo San Jorge y Sur de la Ría Deseado, Zubimendi (2010) concluye que la costa ocuparía el primer puesto en la jerarquización del espacio en los tres sectores que ha estudiado, mientras que el segundo lugar habría sido ocupado por los cañadones en el Golfo San Jorge y en el sur de la Ría Deseado, y por las lagunas y los cañadones para el sector de Cabo Blanco. Las diferencias en la intensidad del uso del espacio estarían correlacionadas con los recursos disponibles en cada unidad del paisaje. Así las costas que ofrecieron bancos de moluscos han sido aprovechadas, registrándose extensos loci con restos malacológicos, mientras que las costas con recursos marinos de mayor porte (aves, mamíferos marinos) habrían sostenido ocupaciones residenciales más densas, con redundancia de ocupación y estructuración espacial 
de los asentamientos. Por otro lado, el autor considera que se habría producido una reducción de la movilidad de los grupos humanos que se habrían asentado alrededor de una disponibilidad muy alta de recursos marinos, y que, grupos reducidos podrían haber utilizado el interior inmediato para realizar un rango limitado de actividades, relacionadas con la búsqueda de recursos de interés específico.

Posteriormente P. Ambrústolo en el marco de su tesis doctoral desarrolló el estudio de las estrategias de comportamiento tecnológico implementadas por los grupos cazadores recolectores que ocuparon el sur de la Ría Deseado durante el Holoceno medio y el tardío (Ambrústolo 2011). A partir del análisis de fuentes de aprovisionamiento de materias primas, Ambrústolo (2011) corroboró la existencia de fuentes primarias y secundarias. Asimismo, observó el uso de materias primas que durante momentos de ocupación inicial del sector ingresaron como parte del equipamiento personal de los grupos cazadores recolectores (i.e. rocas silíceas y obsidiana). En momentos de ocupación efectiva, por otra parte, se daría una integración de los espacios a través de circuitos de intercambio de nódulos o núcleos de obsidiana negra de larga distancia entre el interior y la costa. De esta manera, para el Holoceno tardío, Ambrústolo (2011) sugiere que el recurso lítico se habría distribuido socialmente a nivel regional, integrando espacios cercanos y lejanos a través del contacto entre poblaciones.

En los últimos años se desarrollaron nuevas líneas de trabajo en el equipo de CNSC, entre ellas el análisis zooarquelógico (Beretta et al. 2011, Bereretta et al. 2013 a y b), el análisis de tecnología lítica a través del estudio de la organización tecnológica (Castro y Mazzitelli 2011, Mazzitelli 2014), la estructura y composición de sitios concheros (Hammond et al. 2013, Hammond 2014) y el estudio de estructuras de entierro y estudios isotópicos de restos óseos humanos (Zilio 2013, Zilio et al. 2013, Zilio et al. 2014). Algunos resultados de estas investigaciones se describen en el capítulo 8,9 y 10, en los que se emplean las diferentes escalas espaciales definidas en trabajos previos del proyecto CNSC: sectores y subsectores con características homogéneas del registro arqueológico superficial. Sin embargo, hasta el momento de la realización de esta tesis no se 
habían desarrollado estudios sobre el uso de los recursos vegetales para los grupos cazadores recolectores de esta área.

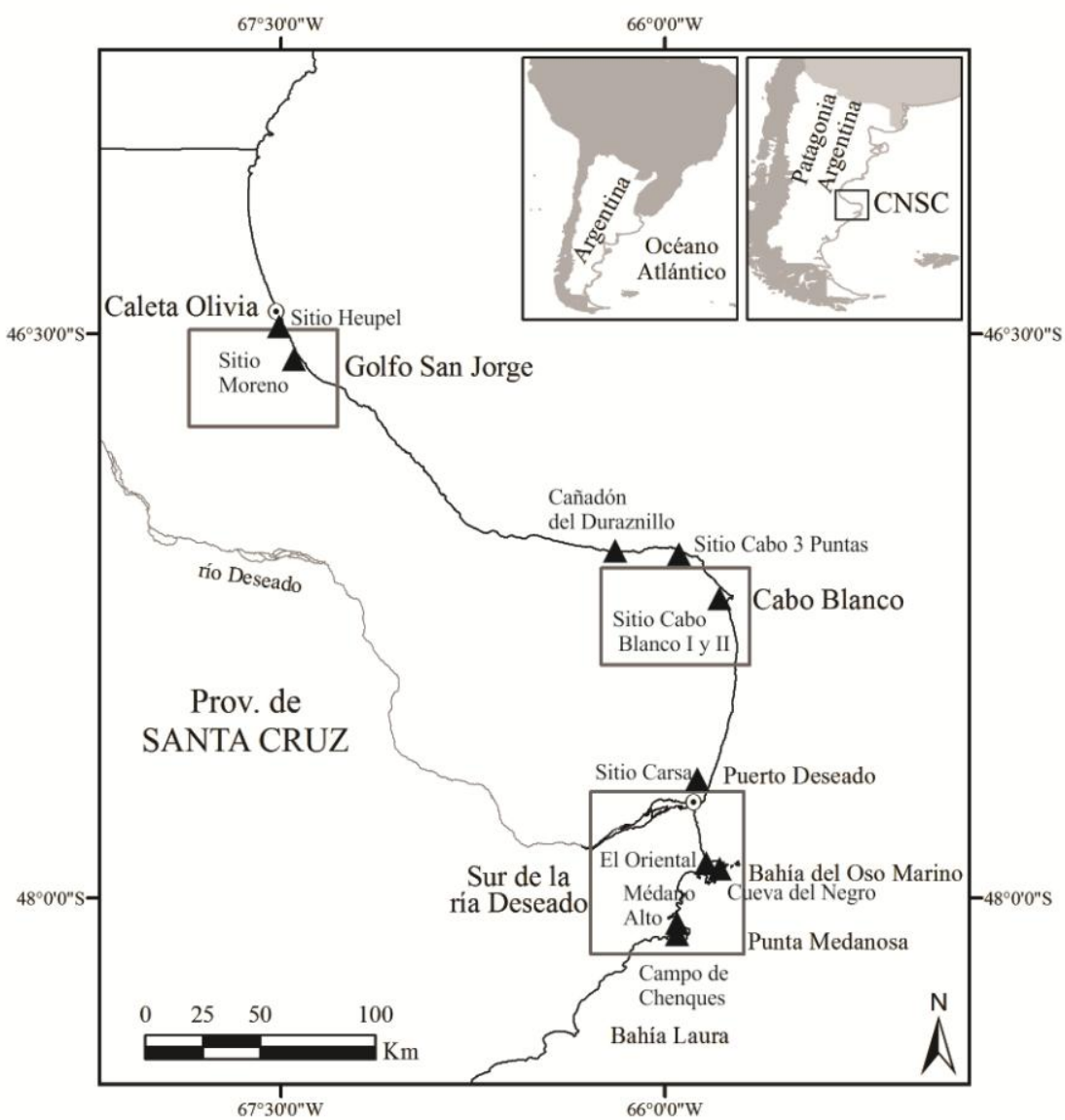

Figura 3.27. Área costa norte de Santa Cruz con los sectores de estudio delimitados: Golfo San Jorge, Cabo Blanco y Sur de la ría Deseado diferenciado en subsectores margen norte de la ría Deseado; Bahía del Oso Marino; Isla Lobos y Punta Medanosa. El triángulo muestra los sitios arqueológicos estudiados en el proyecto CNSC. 
Sección II: Desarrollo 


\section{Parte I: Historia del uso de las plantas por parte de las poblaciones que habitaron la Patagonia}

\section{Argentina}

El objetivo general de los capítulos 4 y 5 es registrar y analizar la información documental escrita sobre usos de plantas y comparar este corpus de datos con la información obtenida a partir de entrevistas etnobotánicas realizadas en esta tesis, para elaborar un modelo para la interpretación arqueobotánica de la Costa Norte de Santa Cruz. Específicamente, se busca indagar sobre el lugar que ocuparon los recursos vegetales dentro de los modos de subsistencia de los habitantes de dicha región. Para ello se construye una exhaustiva base de datos sobre recolección, usos y procesamientos postcolecta a partir de 42 autores del siglo XVI al XXI. Luego se realizan entrevistas etnobotánicas en las localidades de Puerto Deseado y Tellier a 16 informantes. Por último, se comparan ambos corpus de datos. En las fuentes documentales (ver en detalle en capítulo 4) se registraron 222 citas de usos de plantas, correspondientes a 97 taxa pertenecientes a 43 familias, de las que predominan las Asteraceae, Apiaceae y Fabaceae. El 80,8\% de los taxa son mencionadas para un único fin, mientras que el 19,2\% restante presenta más de un uso, los más comunes, el comestible y medicinal. En el caso de las entrevistas etnobotánicas (ver en detalle en capítulo 5) se obtuvo una lista de 59 taxa (género y especie) que pertenecen a 29 familias y cuatro casos sólo con nombre vulgar. Las familias con mayor cantidad de géneros y especies mencionadas son Asteraceae, Lamiaceae, Fabaceae y Apiaceae. En relación a las categorías de uso el $8,6 \%(\mathrm{n}=5)$ de los taxones son utilizados sólo como alimento, 27,6\% $(\mathrm{n}=16)$ sólo como combustible, y el 48,3\% $(\mathrm{n}=28)$ sólo como medicinal, teniendo el resto $(\mathrm{n}=9)$ $15,5 \%$ más de un uso (comestible, combustible, medicinal, tintórea, cosmética y para la confección de cercos). A partir de estos resultados se propone, tal como se dijo anteriormente, un modelo para contribuir a la interpretación del registro arqueobotánico de costa norte de Santa Cruz considerando los alcances y limitaciones de la analogía. 


\section{Las prácticas de recolección de plantas silvestres a través de las fuentes bibliográficas}

\subsection{Introducción}

El objetivo general de este capítulo es registrar y analizar la información documental escrita sobre usos de plantas. Específicamente, se busca indagar sobre el lugar que ocuparon los recursos vegetales dentro de los modos de subsistencia de los habitantes de una región más abarcativa que el área de estudio de la presente tesis: la Patagonia continental Argentina. Esto nos permite discutir un volumen de información mayor, más rico y diverso al que hubiéramos obtenido si nos limitáramos exclusivamente a la CNSC. La selección de este espacio es arbitraria y data del origen del Estado Nación, siendo ésta tomada sólo como corte bibliográfico y no como identitario. Tiene como límites geográficos este-oeste el Océano Atlántico y la Cordillera de los Andes, respectivamente, mientras que se extiende de norte a sur desde la localidad de Sierra de la Ventana ${ }^{6}$ hasta el Estrecho de Magallanes. Se excluye a la Patagonia insular y austral porque para esas áreas ya se han desarrollado trabajos compilatorios con aproximaciones similares a la realizada en la presente tesis (i.e. Berihuet et al. 2009, Caruso et al. 2008), pero que son consideradas en la discusión.

Para lograr el objetivo propuesto se procede, en primer lugar, a construir una exhaustiva base de datos sobre recolección, usos y procesamientos postcolecta (sensu Capparelli y Lema 2010) que los grupos humanos del área mencionada efectuaron sobre las plantas silvestres. Para ello se analizan fuentes de cronistas, viajeros y exploradores del siglo XVI al XIX, así como otras científicas (etnográficas) de los siglos XIX, XX y XXI. Se

\footnotetext{
${ }^{6}$ Se considera a esta localidad como límite norte puesto que a fines del siglo XIX es reconocido un avance de los grupos patagónicos hacia este territorio (ver Nacuzzi 1998). De esta parte septentrional, que corresponde al área arqueológica Pampeana, solo se tiene en cuenta la crónica de Guinnard, que es la que menciona costumbres araucano-pampas en dicha área. Para una recopilación de fuentes relevantes al área Pampeana ver Musaubach y Plos (2010).
} 
puso énfasis en registrar, de cada cita, la parcialidad o grupo étnico a la cual refiere la información, la ubicación geográfica acerca de dónde proviene el dato (espacialidad) y el período histórico en el que se realizó la observación (temporalidad), de manera de poder analizar posibles transformaciones en el registro y/o uso de las plantas a lo largo de los procesos históricos.

La necesidad de trabajos de este tipo fue señalada previamente por Nacuzzi (1998). En este sentido, existen antecedentes (Nacuzzi y Pérez de Micou 1983/1985, Casamiquela 1999, Prates 2009, Frank 2011, Ochoa y Ladio 2011) que constituyen una base importante de información para el presente escrito. De éstos, los cuatro primeros se realizan desde una perspectiva arqueológica, mientras que el último desde un enfoque etnobotánico cuantitativo. En el caso de Nacuzzi y Pérez de Micou (1983/1985), se compilan registros etnohistóricos que son comparados con evidencias arqueobotánicas. Casamiquela (1999) expone datos de uso de plantas desde la lectura de fuentes escritas así como de entrevistas realizadas por Harrington (inédito, en Casamiquela 1999) y por el propio autor.

Por otro lado, Prates (2009) elabora un minucioso cuadro donde figura el uso de especies vegetales mencionadas tanto en documentos concernientes a cronistas y viajeros, como en aquellos referidos a estudios actualísticos. Tanto Casamiquela (1999) como Prates (2009) contemplan una amplia área de estudio (Patagonia Argentina y Patagonia Argentina continental, respectivamente), mientras que Nacuzzi y Pérez de Micou (1983/1985) consideran un área más restringida, la cuenca del río Chubut.

A diferencia de los anteriores, Frank (2011), utiliza la revisión de fuentes etnohistóricas para identificar prácticas de aprovisionamiento de combustible, encendido, mantenimiento, uso y apagado del fuego. Este último trabajo no registra las especies botánicas de los leños utilizados, por lo que no se lo ha incluido en la base de datos aquí presentada, no obstante, brinda información valiosa respecto a las prácticas de recolección y manejo de estos recursos que es considerada en la discusión final. Por último, Ochoa y Ladio (2011), revisan de manera sistemática fuentes y trabajos etnográficos, al tiempo que aportan sus propios datos de campo sobre el uso de plantas con órganos subterráneos comestibles de Patagonia.

Si bien este capítulo posee algunas características que comparte con las publicaciones antes mencionadas, se diferencia porque parte de un enfoque paleoetnobotánico para 
interpretar los datos provenientes de fuentes escritas etnohistóricas y etnobotánicas de un amplio espacio geográfico (Patagonia continental). Este enfoque permite investigar la relación entre las sociedades humanas y las plantas en el pasado desde una concepción bidireccional que contemple los registros arqueobotánicos, históricos y/o lingüísticos, entre otros, de forma complementaria para evaluar los atributos, transformaciones y evolución de cada parte componente de dicha relación (Giovanetti et al. 2008, Lema 2009).

\subsection{Material y Métodos}

La recopilación de fuentes documentales fue realizada a partir de crónicas de viajeros y exploradores del siglo XVI y XVIII (cuatro y siete autores respectivamente) y publicaciones de naturalistas del siglo XIX (19 autores); entre las que se cuentan fuentes editadas de primer y segundo orden. También se consultaron investigaciones botánicas específicas publicadas durante el siglo $\mathrm{XX}^{\prime}$ y etnográficas (11 autores $\left.{ }^{7}\right)$, mientras que del siglo XXI se consultó un solo trabajo, el de Ancibor y Pérez de Micou (2002). Este último es el único de ese período en el área de estudio que hace referencia explícita a que los datos extraídos de entrevistas a pobladores de la localidad de Piedra Parada serían potencialmente aplicables a trabajos experimentales etnoarqueológicos. En cambio, no se incorporaron a la tabla aquí presentada los registros de vegetales mencionados en trabajos recientes de etnobotánica cuantitativa (Ladio 2006b, Ladio 2011, Ladio et al. 2007, Molares 2010, Cardoso et al. 2009, entre otros). Estos últimos son trabajos donde la recopilación del dato etnobotánico es dirigida, sistemática y está suficientemente descripta y detallada en las publicaciones originales. Por lo tanto, no se repiten en esta tesis aunque los datos sí son considerados en la discusión final.

Cada cita se desdobló en varias categorías de análisis: especie botánica, nombre vulgar, lugar donde es citada la especie, procedencia (nativa o introducida), práctica de recolección, uso, órgano utilizado, procesamiento y agente (edad y/o sexo de la persona que procesa, en caso de ser mencionados). A partir de esta información se elaboró una

\footnotetext{
${ }^{7}$ La publicación de Martínez Crovetto (1968), si bien refiere a grupos patagónicos, no se incorporó a la base de datos debido a que las entrevistas realizadas por el autor se desarrollaron en General Viamonte (provincia de Bs. As.), fuera del espaciogeográfico delimitado para este trabajo.
} 
base de datos en una planilla de cálculo que permitió analizar tanto los registros de cada variable en particular, como establecer semejanzas y diferencias entre más de una variable.

\subsection{Resultados y discusión}

\subsubsection{Las fuentes documentales escritas: en torno a las denominaciones $y$ distribución de los grupos humanos que habitaron el área.}

A lo largo del análisis de las fuentes etnohistóricas se observa que los grupos humanos a los que se hace referencia en ellas fueron denominados de manera diversa. Es necesario conocer a qué grupos se están refiriendo los autores con cada una de esas denominaciones para poder interpretar fehacientemente la procedencia de cada registro de uso de plantas. Sin embargo, Nacuzzi (1998) advierte, que los nombres utilizados por viajeros o cronistas (i.e. "pampas", "tehuelches", "aucas") son poco confiables por varios motivos. Por ejemplo, porque en el momento de mencionarlos en el texto no se aclara si la denominación es la que la etnia reconoce como propia, si ésta fue proporcionada por terceros externos al autor de la obra, o por éste último a partir de su observación personal. Según Nacuzzi (1998), incluso muchos de los nombres provenientes de los estudios etnográficos realizados hasta el siglo XX estarían basados en las denominaciones de los exploradores y cronistas que los precedieron. A esta complejidad de nombres se suman los gentilicios usados a nivel gubernamental durante los siglos XVIII y XIX, que sirvieron para facilitar la operatividad administrativa y el entendimiento de los gobernantes al momento de estipular fronteras.

A fin de mejorar la comprensión de las fuentes documentales y de entender la complejidad étnica de Patagonia, Nacuzzi (1998) resume las distintas denominaciones utilizadas por los investigadores que estudiaron hasta ese momento la problemática, las que ordena según el área geográfica de procedencia de los datos en relación a su área propia de estudio (Tabla 4.1)

\begin{tabular}{|l|l|l|l|l|}
\hline $\begin{array}{l}\text { Grupo } \\
\text { étnico }\end{array}$ & Harrington & Escalada & Casamiquela & Vignati \\
\hline
\end{tabular}




\begin{tabular}{|l|l|l|l|l|}
\hline $\begin{array}{l}\text { Vecinos del } \\
\text { norte }\end{array}$ & mapuches & $\begin{array}{l}\text { gününa këna o tehuelches } \\
\text { septentrionales (boreales) }\end{array}$ & $\begin{array}{l}\text { pampas } \\
\text { allentiac }\end{array}$ \\
\hline $\begin{array}{l}\text { Área de } \\
\text { estudio }\end{array}$ & $\begin{array}{l}\text { günuna küne o tehuelches } \\
\text { del norte o pampas }\end{array}$ & guénena- kéne & $\begin{array}{l}\text { gününa këna o tehuelches } \\
\text { septentrionales (australes) }\end{array}$ & $\begin{array}{l}\text { pampas } \\
\text { millcayac yüna küne o } \\
\text { gün } \\
\text { tuelche }\end{array}$ \\
\hline $\begin{array}{l}\text { Vecinos del } \\
\text { sur }\end{array}$ & $\begin{array}{l}\text { Superposición de günuna } \\
\text { küne y aóni kenk }\end{array}$ & aóni- kénk & $\begin{array}{l}\text { aónik'enk o tehuelches } \\
\text { meridionales (boreales) }\end{array}$ & $\begin{array}{l}\text { aonükün'k o } \\
\text { patagones }\end{array}$ \\
\hline $\begin{array}{l}\text { Vecinos del } \\
\text { oeste }\end{array}$ & $\begin{array}{l}\text { chulila küne } \\
\text { pehuenches } \\
\text { chehuache- } \\
\text { kénk }\end{array}$ & $\begin{array}{l}\text { pehuenches mäwach a këna } \\
\text { chëwaneros }\end{array}$ & pehuenche \\
\hline
\end{tabular}

Tabla 4.1.Denominaciones referidas a los habitantes originarios de Patagonia continental según Harrington, Escalada, Casamiquela y Vignati, resumido en Nacuzzi (1998:107). “Área en estudio” refiere al Fuerte San Carmen ubicado en la desembocadura del río Negro

El ordenamiento de Nacuzzi (1998) fue tenido en cuenta en este trabajo al momento de leer e interpretar lo más acertadamente las fuentes escritas, y de sortear, en la medida de lo posible, el obstáculo que representa la complejidad de términos con los que se denomina a estos grupos. Es por ello que, siguiendo las recomendaciones de dicha autora, se puso énfasis en registrar, para cada cita en particular, el nombre del grupo mencionado en la fuente, el siglo y área geográfica de colección del dato (Tabla 4.1), así como también aquellos fragmentos de texto en los que se encontró alusión directa a caciques de los distintos grupos y a las áreas de dispersión de los mismos.

Con respecto a las áreas de dispersión de los distintos grupos cabe menionar que se encontraron varias citas que aportan información al respecto, las que se transcriben a continuación. Por ejemplo, Viedma y Villarino ([1780-1783] 2006) menciona a los caciques Julián Grande y Julián Gordo en el Puerto San Julián, presentándose con ellos 200 hombres y mujeres (no describe si había niños) en la playa. Dice que a 1 y 1/4 legua de la playa se encontraba su toldería. A su vez, deja asentado que el 30 y 31 de diciembre de 1780 el cacique Julián manifiesta: “... que por la banda del S, a dos días de camino, hay un arroyo y junto a él se halla un establecimiento de indios, cuyo cacique se llama Onos, que es amigo. A otro día más de camino se encuentra el río de Santa Cruz, a cuya ribera viven otros, cuyo cacique también es amigo y se llama Cohopan (...) A 25 días de camino al $N$ hay otro arroyo, entre el cual y la mar viven indios con un cacique amigo suyo, llamado Ayzo (...) Que más tierra adentro sobre el 
mismo arroyo hay más indios y que su cacique llamado Coconoros es su amigo igualmente. A otros dos días más de camino hay otro arroyo y mucho indios junto a él cuyo cacique se llama Carmen, que también es su amigo (...) Que a otros 20 días más de camino está el río Negro cuyos indios eran malos y enemigos suyos y que el cacique se llama Chanel, y Julián también Camelo..." (Viedma y Villarino [1780-1783] 2006: 81). En relación a la movilidad e interacción de estos caciques el 3 de julio de 1781 se registra que el cacique Julián se fue con su gente al río de Santa Cruz (Viedma y Villarino [1780-1783] 2006:86). Para el siglo XIX, Claraz ([1865-66] 2008) describe que es acompañado en su viaje por Hernández, hijo de un comandante y la hija del cacique Maciel-hermana ésta de Sinchel. El autor menciona que Hernández hablaba "pampa", pero también algo de "araucano" y "tehuelche". El suegro de Hernández, también lo acompañó y era "pampa" pero también hablaba "tehuelche" y casi siempre había recorrido el campo con los "tehuelches". También aporta el dato de la ubicación del cacique Antonio, a dos leguas y media de Yaulal, luego del yamnagoo, donde se encuentra con él y su toldería, compuesta por 8 toldos. Moreno ([1876-1877] 2007) manifiesta que en el Limay había vivido con "araucanos" y en Santa Cruz compartiría el toldo con "patagones". Describe que, siguiendo el Limay, encuentran las tolderías del cacique Saihueque y que en un valle distante del Collon-Curá, los toldos del cacique Ñancucheuque.

\subsubsection{Plantas utilizadas por los grupos humanos}

De los 42 autores consultados, a excepción de Darwin (2006), Fontana ([18851886]:2006) y Villarino ([1781] en Viedma y Villarino [1780-1783] 2006), 39 presentaron referencias de uso de plantas por parte de grupos aborígenes y sus descendientes. Se obtuvieron 222 citas, la mayor parte de ellas provenientes de fuentes de cronistas, exploradores y naturalistas del siglo XIX. Para el siglo XX, las citas corresponden a trabajos que aplicaron diferentes metodologías de campo con respecto a períodos anteriores, ya que los datos se extrajeron a partir de entrevistas a descendientes de distintas etnias, las cuales constituyeron, en algunos casos, los primeros trabajos de etnobotánica de Patagonia (i.e. Martínez Crovetto 1982). Las citas provienen geográficamente de dos franjas de dirección norte-sur, aledañas a la cordillera de los 
Andes y al Océano Atlántico, al oeste y al este respectivamente. Transversalmente a ambas franjas las citas se extienden a lo largo de los ríos Negro, Chubut, Deseado y Santa Cruz (Figura 4.1).

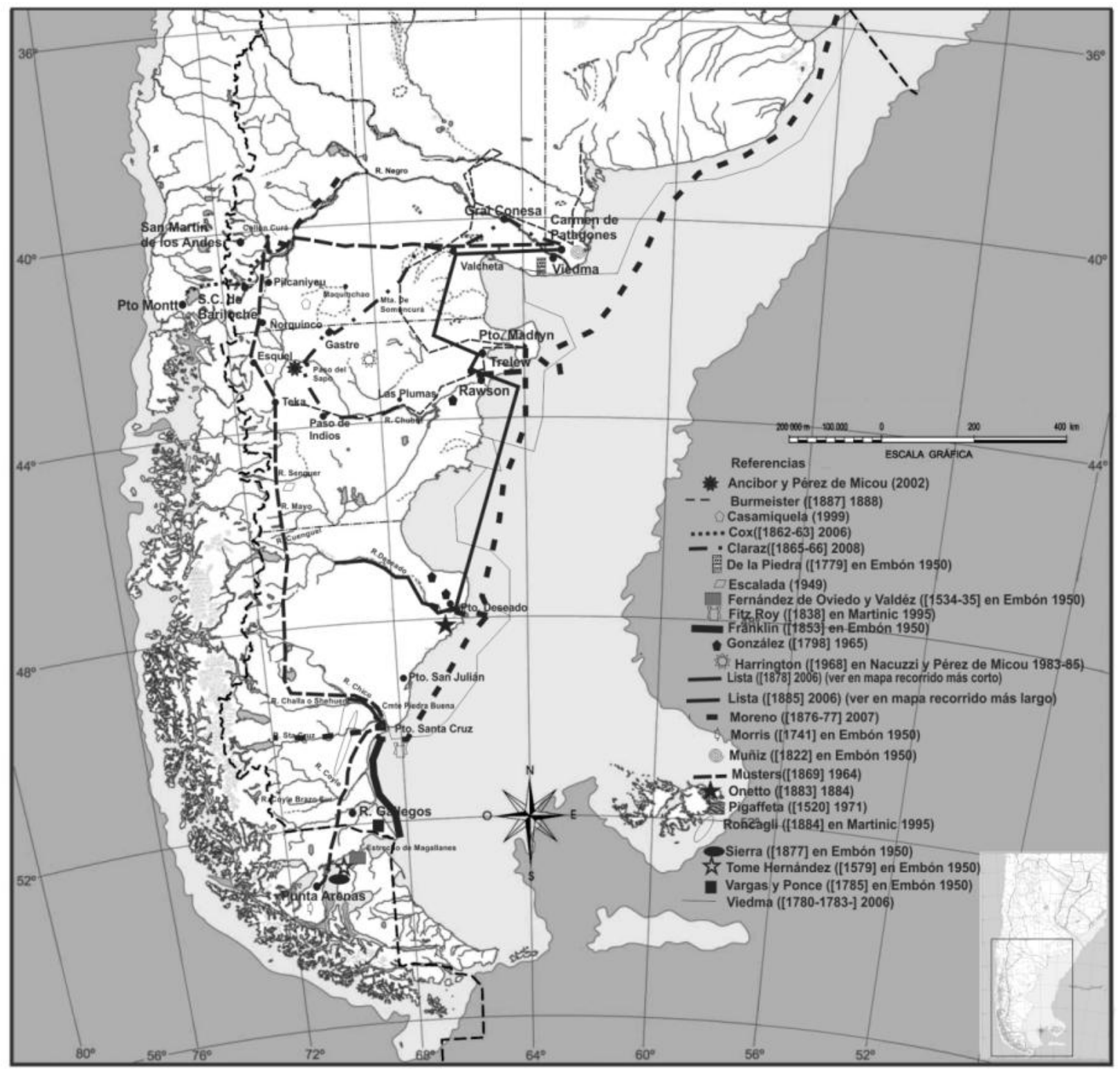

Figura 4.1. Rutas seguidas por los autores de las fuentes bibliográficas de primer orden consultadas y ubicación geográfica de las citas extraídas de fuentes de segundo orden. De 15 autores no se pudo precisar el itinerario de viaje completo.

En relación a los recursos vegetales, se registraron 96 taxa (género o especie), un taxa que pertenece al Reino Fungi $^{8}$ y otros 2 que no presentan sinonimias con la nomenclatura actual (Zuloaga y Morrone 1999) (Figura 4.2); por otra parte, 64 citas

\footnotetext{
${ }^{8}$ Nótese que dos citas hacen referencia al Reino Fungi, una de ellas asignada al género Cyttaria spp.
} 
carecen de referencia al nombre científico de la planta en cuestión, aunque 33 de ellas poseen nombre vulgar (Tabla 4.2). Los taxa pertenecen a 43 familias, predominando las Asteraceae, Apiaceae y Fabaceae (Figura 4.2). En cuanto a las Apiaceae y Asteraceae son familias con aromas, con propiedades medicinales en su gran mayoría, así también muchas especies son comestibles (ver Molares 2010). Las Fabaceae poseen también una importancia especial, ya que representan especies a partir de las cuales se pueden elaborar harinas, o consumir frutos frescos (i.e. Prosopis denudans, Capparelli 2007, Molares y Ladio 2012a). El 92,5\% de los taxa son nativos (se incluyeron aquí aquellos que no tienen sinonimia actual pero se asumió que eran nativos), siendo los restantes introducidos. 


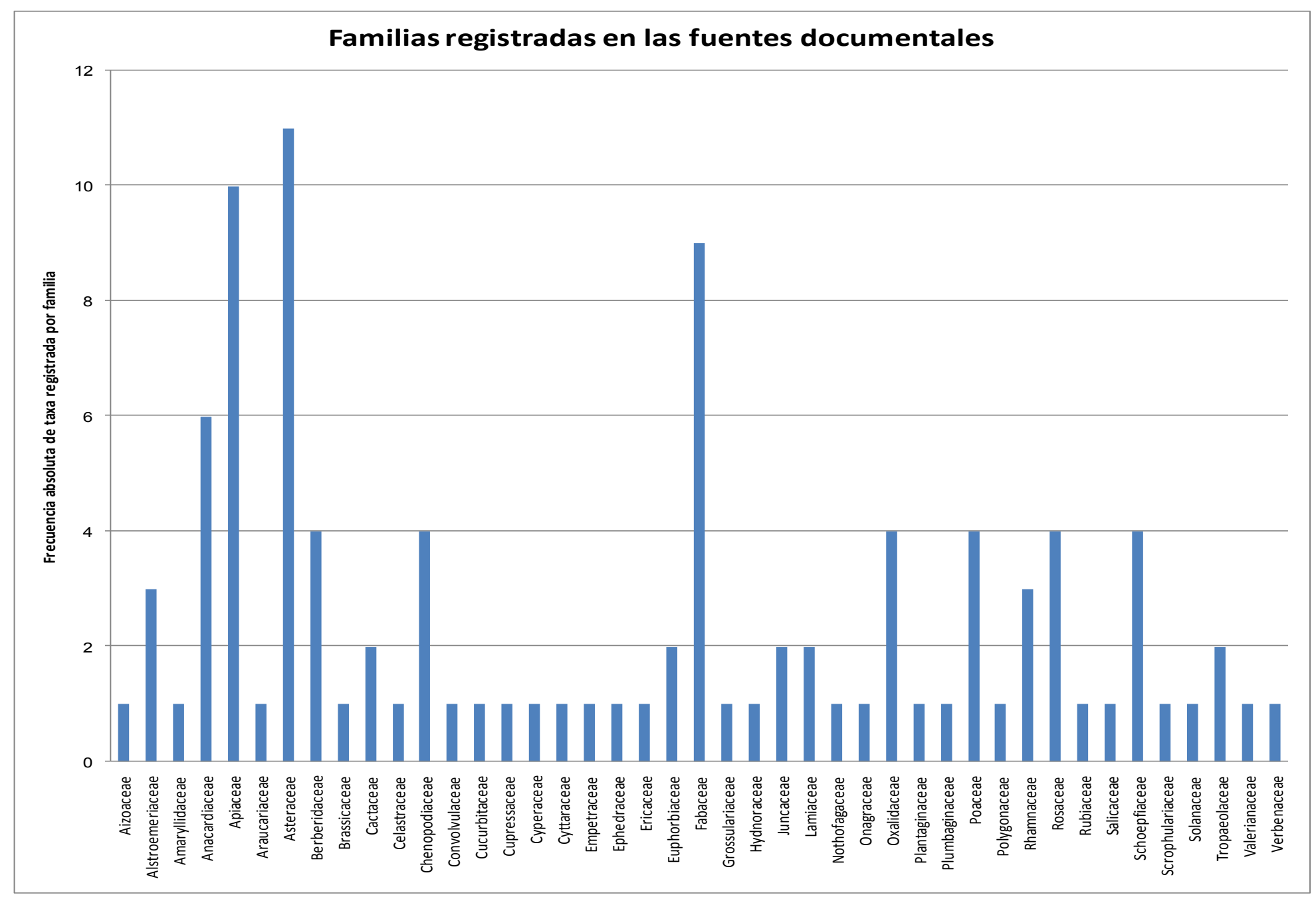

Figura 4.2. Gráfico con la frecuencia absoluta de taxa por familia registrados con menciones de uso 
El 80,8\% de los taxa son mencionados para un único fin, mientras que el 19,2\% restante presenta más de un uso. Entre los primeros, el 35,3\% tiene uso comestible, el 22,2\% medicinal, el 9,1\% combustible, el 5,1\% bebible, el 3\% tintóreo, el 2\% es usado como veneno, y el 1\% para la construcción de viviendas, empaste de pinturas, pegamento e instrumentos musicales.

Del total de las 222 citas, $73(33 \%)$ son las que simultáneamente hacen referencia al nombre científico de la planta y al modo de consumo de la misma -se consideran aquí todas las categorías de uso- (Figura 4.3). En estas citas se da cuenta de 56 taxa, que equivalen al 56,6\% del total de los taxa. De esas 73 menciones, el 12,3\% registra solo consumos en fresco sin procesamiento, el 79,5\% registra consumos que siempre incluyen algún tipo de procesamiento, mientras que el 8,32\% registra ambos tipos de consumo. Dentro de la segunda categoría mencionada, el 43,1\% incluye solo procesamientos sin cocción (i.e. extracción, maceración, molienda, dilución en agua, destilado, emplastos), mientras que el 56,9\% incluye algún tipo de procesamiento por cocción (i.e. asado al rescoldo, tostado, quemado o hervido).

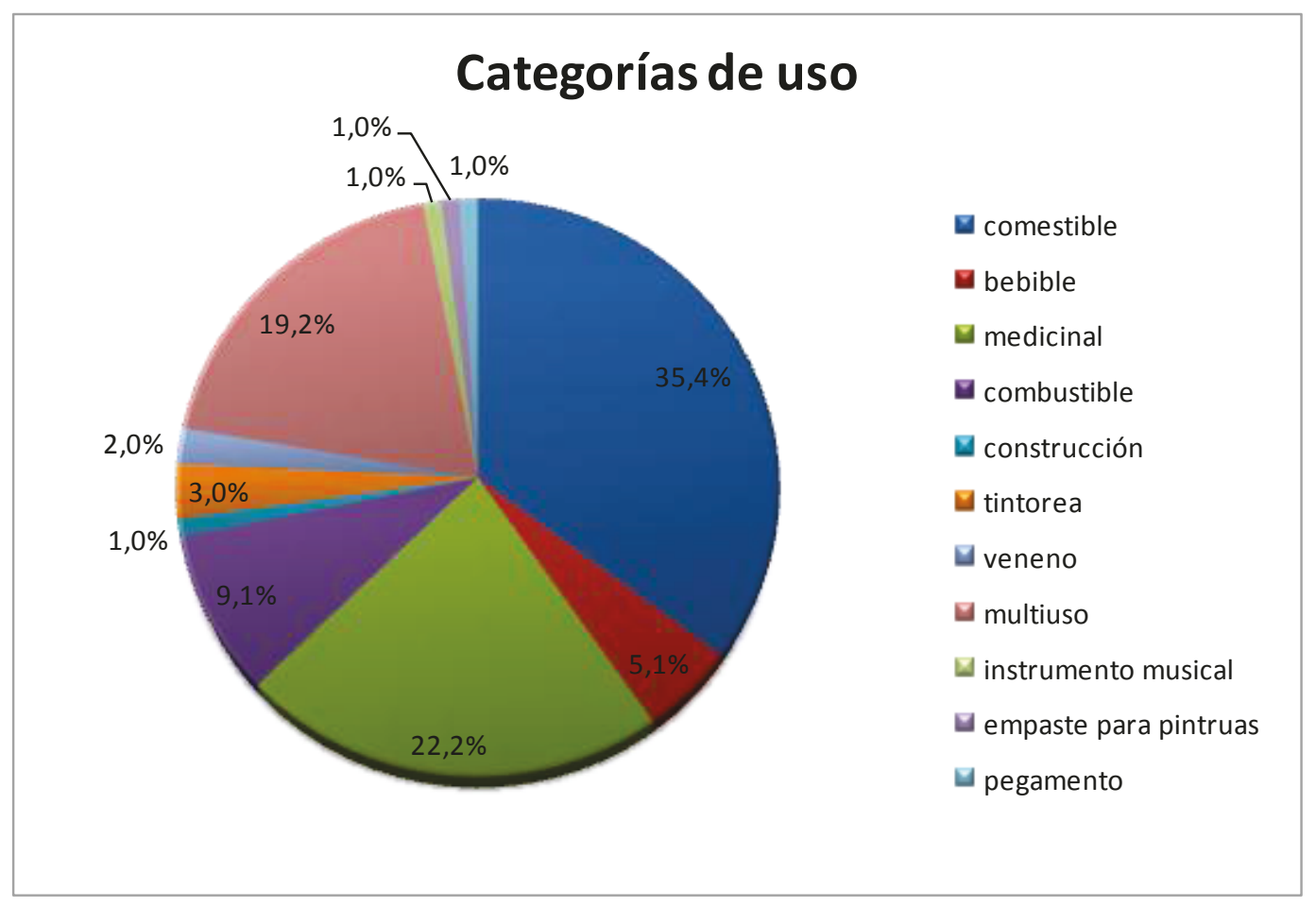

Figura 4.3. Gráfico que registra las cateogorías de uso descriptas en las fuentes bibliográficas 
Algunas prácticas de procesamiento y consumo se transforman a lo largo de los períodos temporales analizados. Esto último, tiene que ver en parte, con el hecho de que, a partir de finales del siglo XVII y principios del siglo XVIII, los grupos aborígenes habrían comenzado a utilizar el caballo para movilizarse, siendo éste incorporado plenamente para mediados del siglo XVIII. Para los grupos que habitaron la costa de Chubut y norte de Santa Cruz, la incorporación del caballo se encuentra asociada a una disminución del consumo de recursos faunísticos marinos (Moreno y Videla 2008). Así también para este período se registra la introducción de productos industrializados (i.e. harinas y yerba) en la dieta de los grupos patagónicos a partir de circuitos de intercambio (Nacuzzi 1998). Sin embargo, aún no se ha establecido qué grado de influencia pudieron haber tenido la introducción del caballo y el acceso a los bienes manufacturados en la utilización y colecta de vegetales silvestres locales. En este caso, se observa también que hay prácticas de procesamiento y modos de consumo que persisten y otros que se transforman a lo largo del tiempo.

Entre las prácticas que persisten, vale la pena destacar el consumo de raíces. Por ejemplo, para el siglo XVI, Pigafetta ([1520] 1971) menciona que las raíces eran lo único que tenían para comer estos grupos y que tenían guardado el polvo blanco proveniente de la raíz de un "yuyo" en cazuelas de terracota. Otros autores también observan este uso: -..traen muy hermosos penachos en las cabecas y en los pies, y comen la carne cruda y el pescado asado y muy caliente. No tienen pan, o sí lo tienen estos cristianos no lo vieron, sino unas rayces que comen asadas y también crudas, y muchos mariscos de lapas y muxillones que comen asadas, y hostias mucho grandes..." (Fernández de Oviedo y Valdez [1526] en Embon 1950:12). Para el siglo XIX se sigue registrando el consumo de raíces, aún con las transformaciones acontecidas durante la conquista y el comercio de bienes manufacturados, por ejemplo: -...En La Subida se presenta una planta que llaman khet-héla. Parece que reemplaza las saxifragas; crece donde hay pantanos y tiene un lindo aspecto verde. Los indios dicen que allí la raíz no es todavía muy buena, pero sí más al sud. La ponen a secar, la muelen y hacen de ella harina como los araucanos (ranqueles nota de Casamiquela) del algarrobo. Tiene un gusto parecido y es dulce..." (Claraz [1865-1866] 2008:78). Para el siglo XX Casamiquela (1999) y Harrington (en Casamiquela 1999) registran también la práctica 
del uso de raíces como comestibles. Se observa entonces, más allá de las especies en sí, que esta práctica persiste en el tiempo y en distintos grupos étnicos.

En cambio, las prácticas de macerado de frutos para la realización de bebidas varían a lo largo del tiempo. Por ejemplo, en los primeros registros se describe la incorporación de agua al macerado de frutos (González [1798] 1965, no se especifica la especie vegetal), mientras que para el siglo XIX se observa la misma práctica pero con el reemplazo del agua por aguardiente (Moreno [1876-1877] 2007, mencionado para Prunus, Ribes y Schinus).

En cuanto a los agentes que llevan a cabo las tareas de recolección (generalmente de raíces y de leña), por lo general la práctica se asocia a mujeres. Por ejemplo, Claraz ([1865-1866] 2008:128) menciona -...Encontramos rastros de caballo y mucha bosta, y en un lugar, los restos de algunos toldos. Las mujeres habían estado buscando macachinas; la tierra estaba algo revuelta y había huesos machacados...". Incluso esta asociación se refleja en las leyendas: -... dicen que como es una vieja que ya no puede juntar leña (entre los indios, el juntar leña es tarea de las mujeres; sólo cuando son viejas no salen más a juntar), éste es el regalo que más aprecia..." (Leyenda de yamnago, ver Claraz [1865-1866] 2008:84). Sin embargo, existen algunas referencias aisladas a que los hombres podían intervenir, también, en la búsqueda de tubérculos: -...En las lagunas secas de la parte occidental del valle, las mujeres y los hombres también a veces se ocupaban con frecuencia en desenterrar una raíz comestible que crecía en grandes cantidades (...) los dos últimos días de nuestra estancia alli no tomamos sino ese alimento y pescado sacado del río porque no se conseguía carne..." (Musters [1869] 1964:278). Queda evidenciada en esta cita, además de los agentes de recolección, la importancia de los recursos vegetales silvestres en la dieta y su papel complementario al consumo de carne.

En este sentido, Etkin (1994) menciona que aunque el uso de muchas plantas de "emergencia" se practique durante episodios de extrema necesidad y se abandone cuando las condiciones mejoran, en este último caso sigue vivo el recuerdo de estas plantas a través de las leyendas, rituales o la historia oral para transmisión intergeneracional de conocimientos. Esto se observó en el caso de las fuentes documentales de Patagonia, en la relevancia de las raíces, por ejemplo, que es destacada en las leyendas referidas a una cueva situada al sur del río Limay, de la cual Claraz 
expresa: “...Los indios cuentan sobre ella una larga historia. Los antiguos, dicen, abandonaron en esta cueva a una vieja que no podía caminar más. Vivía allí de las raíces que llaman peya, y de ahí el nombre. Un día encontró una raíz grande y profunda; no tenía suficiente fuerza para arrancarla. Entonces, orinó sobre la tierra para ablandarla y joh milagro! La raiz se había transformado en un niño, un muchacho, que al día siguiente ya era grande y quiso salir al campo... " (Claraz [18651866] 2008:159). Asimismo el autor también menciona los tubérculos de una planta denominada "yahtsch" que "presenta el aspecto de un capuchino cultivado. Tiene flores amarillas; parece pertenecer a la familia Tropaeolae [sic] y al género Tropaeolum. Tiene tubérculos que alcanzan hasta el largo de $1 / 2$ y casi los 2 dm de diámetro (...) los indios aseguran que según una tradición fueron sus ancestros quienes las plantaron y la trajeron de lejos, que de lejos viene muy multiplicada sobre las márgenes arenosas del río" (Claraz [1865-1866] 2008:199).

Con respecto a las distancias de recolección, si bien no se especifican en las citas, la mayor parte de ellas reflejan una recolección cercana a los toldos en el momento en que se encuentran permaneciendo en un lugar. Sin embargo Musters en una ocasión menciona el uso del caballo para las salidas a recolectar: "cerca de ese lugar había una cantidad de plantas de papa silvestre, y las mujeres acostumbraban salir por la mañana temprano para volver a la tarde con sus caballos cargados. Los tubérculos eran los más grandes que había visto yo entonces, y se parecían mucho, por su aroma a la batata. La manera corriente era hervirlos en una olla, colocándose encima de todo un terrón de arcilla para que el vapor no saliera" (Musters [1869] 1964:275).

Respecto al uso de las plantas como combustible, es importante aclarar que los autores consultados hacen mención en mayor medida a la acción de prender el fuego o hacer señales, pero en escasas ocasiones aclaran qué especies son utilizadas para ello (ver Tabla 4.1), por lo tanto éstas se encuentran subestimadas en las citas. Se registraron 15 taxa combustibles, de los cuales se utilizan sus órganos aéreos, subterráneos y resinas, según el caso. Asimismo, se registraron distintos usos de los fuegos, tales como comunicación, iluminación y combustión propiamente dicha. Sin embargo, la mayor cantidad de acciones se registran en relación a los fuegos para señales (por ejemplo, prender fuego a partes de un campo a través de la combustión de las plantas in situ (Claraz [1865-1866] 2008, González [1798]: 1965), y a la producción de los fuegos. 
Frank (2011) también observa estas acciones, y describe en detalle las prácticas de mantenimiento y apagado del fuego, de las cuales registra que intervienen principalmente mujeres, niños y cautivos. Si bien el trabajo de Aguerre (2000) es contemplado por Frank (2011), se considera relevante para esta tesis citar algunos fragmentos de la descripción de los fuegos en el discurso de la informante Paty Chapalala quien pasó su niñez en una toldería en el Río Pinturas. "En invierno las dos mediaslunas se juntaban (toldos) y el fogón iba al medio, adentro con piedras para que no se corrieran las brasas puesto con piedras... así lajas... para que no corrieran... los fogones se limpiaban (...) todo el tiempo estaba prendido el fogón, se limpiaba, adentro de los toldos se dormía, trabajaba los cueros, lápices, cremas, ollas y jarros, afuera los telares. La ceniza se tiraba afuera en los basurales. (...) Cada familia tenía su fogón (...) en invierno el fógon estaba adentro, en verano el fogón se sacaba afuera" (Aguerre 2000:31).

En cuanto al estado de la leña al momento de la combustión no se registraron numerosas citas pero una de ellas hacía mención a que la madera de un árbol era blanda y de poco mérito (no menciona nombre vulgar ni da sus características) pero que cuando está seca arde bien (Musters [1869] 1964: 189). En relación a la recolección del material leñoso, no hay referencias si cortaban o juntaban leña muerta, sin embargo, se observó una mención en la que se describe que para la elaboración de toldos nuevos se cortaron troncos con hachas melladas (Musters [1869] 1964:279).

Respecto al uso medicinal de las plantas, que junto al uso comestible y combustible, es de los más citados, no se tiene registro del mismo para los siglos XVI al XVIII. Una posibilidad de explicar esta carencia, que posiblemente no se corresponda con una falta de uso de esta categoría de plantas, sino a que los contactos entre los autores y los habitantes del lugar en estos primeros siglos son cortos y esporádicos, y/o por otro lado, que los exploradores tenían como principales preocupaciones los recursos comestibles y la búsqueda de agua. Para el siglo XIX se registra por primera vez la utilización de plantas con fines medicinales, práctica que continúa siendo registrada hacia los siglos XX y XXI a la vez que aumenta el interés por el conocimiento tradicional de los grupos humanos a partir del surgimiento de la etnobotánica (i.e. Martínez Crovetto 1982, Casamiquela 1999, Molares 2010). 
Tal como se mencionó en la introducción, en la presente base de datos no se tuvieron en cuenta los trabajos etnobotánicos más recientes realizados en comunidades mapuches de Neuquén, Río Negro y Chubut. Éstos, por desarrollarse de una manera sistemática y acordes al progreso último de la disciplina, cuentan con resultados propios $\mathrm{y}$ provenientes de información recopilada de otros trabajos etnobotánicos de Patagonia, que han sido ordenados ya, por los mismos investigadores que los llevaron a cabo, en tablas y bases de datos que facilitan al lector la búsqueda de información específica. Nos referimos a los trabajos de Rapoport et al. (1999 y 2001), Ladio y Lozada (2000, 2003, 2004, 2009), Ladio (2001, 2006 a y b, 2011), Ladio et al. (2007), Estomba et al. (2005, 2006), Molares y Ladio (2008, 2009), Molares (2010), Gonzáles y Molares (2004), Cardoso et al. (2009), Ochoa y Ladio (2011). Las publicaciones de Rapoport et al. (1999 y 2001) describen las plantas comestibles silvestres nativas y exóticas de la Patagonia Andina, indicando cuáles son los órganos comestibles, cómo fueron utilizadas por comunidades originarias en el pasado según datos bibliográficos, y la forma de preparación para su consumo según pobladores de la comunidad mapuche Rams (Neuquén) y de la comunidad Cayulef. Ladio y colaboradores (Ladio 2001, 2006a y b, 2011, Ladio y Lozada 2000, 2003, 2004, Ladio et al. 2007), asimismo, estudian el uso actual de plantas silvestres comestibles en comunidades Mapuches de Neuquén y Río Negro, recuperando el conocimiento tradicional de sus pobladores. Realizan estudios sobre el aprovechamiento de recursos vegetales silvestres medicinales y alimenticios en poblaciones mapuches de la estepa y el bosque. De manera similar, Estomba et al. (2005, 2006) registran el conocimiento de plantas medicinales y su patrón de recolección en la comunidad de Currhuinca, Neuquén. El trabajo de Ochoa y Ladio (2011), tal como se menciona anteriormente (ver Introducción de este capítulo), analiza de manera sistemática el uso de plantas con órganos subterráneos comestibles de Patagonia.

De la comparación entre los resultados obtenidos por las publicaciones antes mencionadas y los resultados propios presentados en la Tabla 4.2, se observan algunas diferencias y similitudes. Por ejemplo, hay especies que no están presentes en la base de datos de la Tabla 4.2 (i. e. Diposis patagónica, Tristagma patagonicum), mientras que otras coinciden en ambos set de datos (i. e. Araucaria araucana, Schinus johnstonii). Por otra parte, Cardoso et al. (2009), quien evalúa la importancia de la recolección de 
especies leñateras en las comunidades de Pilcaniyeu del Limay, Laguna Blanca y Comallo de la provincia de Río Negro, en la estepa de Patagonia, registra 27 especies utilizadas como combustibles por persona entrevistada, mientras que en la base de datos del Tabla 4.2 sólo se mencionan 15 especies. Sin embargo, en la Tabla 4.2 se mencionan especies que no registra Cardoso et al. (i.e. Azorella monantha), y viceversa (i.e. Adesmia volckmannii). A su vez, Molares (2010), en su tesis doctoral, además de entrevistas etnobotánicas en comunidades mapuches, realiza la revisión de 16 artículos de etnobotánica de la Patagonia argentino-chilena, revelando que a nivel regional los recursos utilizados con fines medicinales ascienden a un número de 504 especies vegetales. Se observan coincidencias en la mención de algunas especies y sus usos entre el set de datos de Molares y el de la Tabla 4.2 (i.e. Adesmia boronioides, Fabiana imbricata, entre otros), pero se advierte una gran cantidad de taxa de uso medicinal que registra Molares y que no están presentes en dicha Tabla.

\subsection{Conclusiones}

El análisis de las fuentes documentales sugiere un rol importante de las plantas en los modos de subsistencia de los grupos cazadores recolectores de la Patagonia continental argentina, en concordancia con lo explicitado por Nacuzzi y Pérez de Micou (1983/85), Casamiquela (1999), Prates (2009), Ochoa y Ladio (2011), y Frank (2011). Es notable la gran diversidad de taxa vegetales registrados, así como las categorías de uso de las mismas: comestibles, medicinales, bebibles, fumitorios, combustibles, para la elaboración de armas (i.e. lanzas, mangos), de aseo, tintóreos, para extraer veneno o pegamentos y elementos de montura. Las categorías más representadas son las comestibles, medicinales y combustibles siendo llamativa la ausencia de referencias a la manufactura de cestería. Esto último puede deberse a un sesgo en la observación de los autores posiblemente porque no estaban dentro de sus objetivos (los primeros viajeros buscaban fuentes de agua y recursos alimenticios). Por otra parte las actividades de cestería podrían estar asociadas al trabajo femenino y muchas de las prácticas desarrolladas por las mujeres no fueron descriptas por viajeros y cronistas, debido a que era difícil acceder al ámbito femenino y/o por un sesgo de género (Berihuete 2006). 
En las fuentes documentales se registró una gran cantidad de prácticas de procesamiento que evidencian un conocimiento botánico tradicional y una profundidad temporal que permitirían pensar en su potencial representación en el registro arqueobotánico.

En definitiva, la confección de una base de datos documentales escritos de usos de plantas, órganos utilizados y técnicas de procesamiento, además de ser una fuente de información en sí misma, constituye un recurso interesante para la interpretación del registro arqueológico ya que, permite reformular metodologías de recuperación de restos y diseñar nuevos abordajes de estudios actualísticos en pos de un análisis que vaya más allá de la identificación taxonómica de especies. 


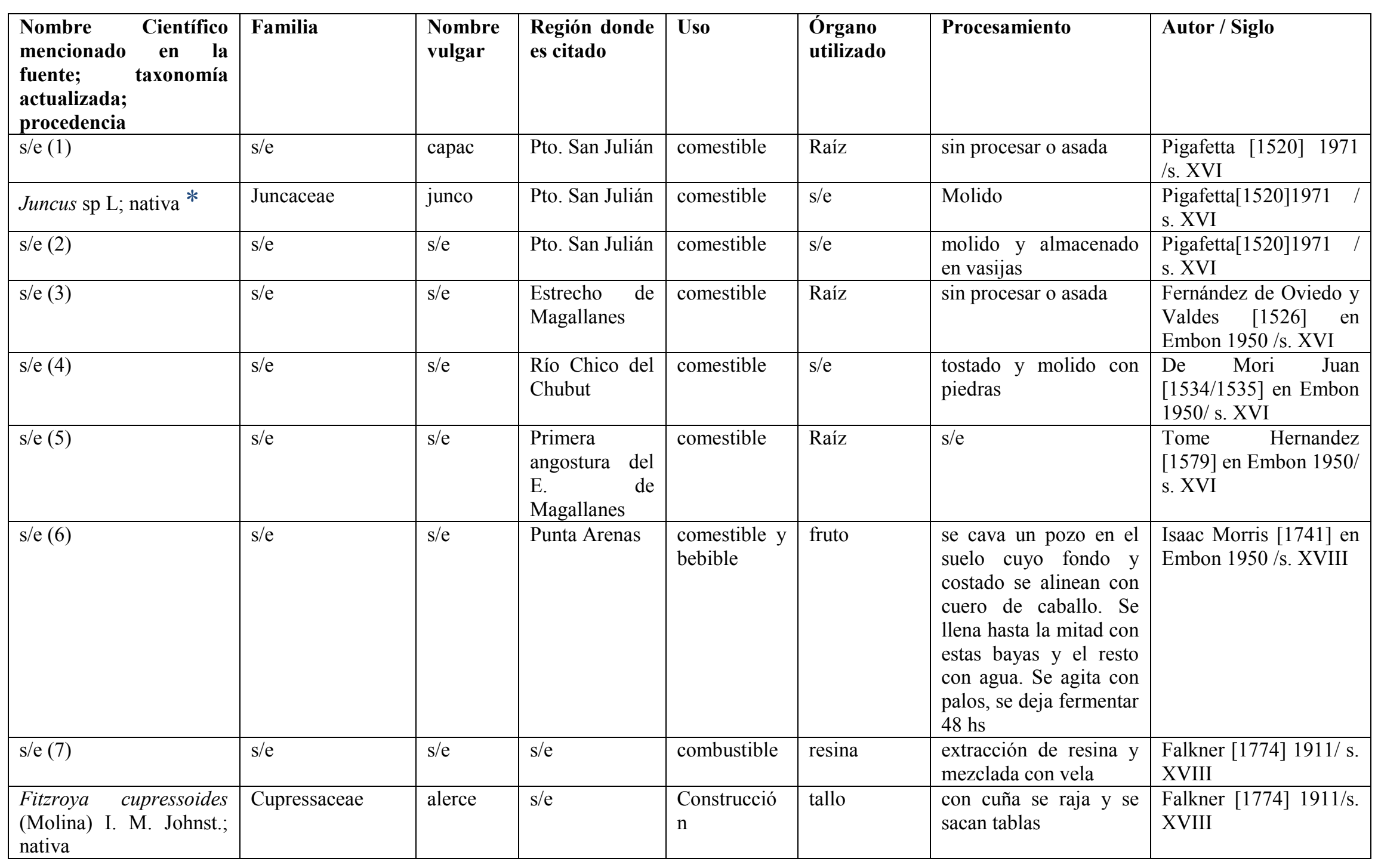




\begin{tabular}{|c|c|c|c|c|c|c|c|}
\hline $\mathrm{s} / \mathrm{e}(8)$ & $\mathrm{s} / \mathrm{e}$ & $\mathrm{s} / \mathrm{e}$ & & fumable & $\mathrm{s} / \mathrm{e}$ & $\begin{array}{l}\text { se enrollan, se hacen } \\
\text { gruesos y se machacan }\end{array}$ & $\begin{array}{l}\text { Falkner [1774] 1911/s } \\
\text { XVIII }\end{array}$ \\
\hline Potentilla sp L.? nativa & Rosaceae & frutillas & $\begin{array}{l}\text { En el país de } \\
\text { los Telhuet }\end{array}$ & comestible & fruto & Crudo & $\begin{array}{l}\text { Falkner [1774] 1911/s } \\
\text { XVIII }\end{array}$ \\
\hline s/e (9) & $\mathrm{s} / \mathrm{e}$ & caña & $\begin{array}{l}\text { Cerca de la } \\
\text { cordillera }\end{array}$ & armas & Tallo & $\mathrm{s} / \mathrm{e}$ & $\begin{array}{l}\text { Falkner [1774] 1911/s } \\
\text { XVIII }\end{array}$ \\
\hline $\mathrm{s} / \mathrm{e}(10)$ & $\mathrm{s} / \mathrm{e}$ & $\mathrm{s} / \mathrm{e}$ & $\begin{array}{l}\text { Entrada al Río } \\
\text { Negro, } \\
\text { Viedma }\end{array}$ & comestible & tubérculo & sin procesar o asada & $\begin{array}{l}\text { De la Piedra Juan } \\
\text { [1779] en Embon 1950/ } \\
\text { s. XVIII }\end{array}$ \\
\hline $\mathrm{s} / \mathrm{e}(12)$ & $\mathrm{s} / \mathrm{e}$ & $\mathrm{s} / \mathrm{e}$ & $\begin{array}{l}\text { Entrada al Río } \\
\text { Negro, } \\
\text { Viedma }\end{array}$ & comestible & semilla & molido con piedras & $\begin{array}{l}\text { De la Piedra Juan } \\
\text { [1779] ]en } \\
\text { 1950/s. XVIII }\end{array}$ \\
\hline s/e (13) & $\mathrm{s} / \mathrm{e}$ & $\mathrm{s} / \mathrm{e}$ & $\begin{array}{l}\text { Puerto } \\
\text { Deseado y San } \\
\text { Julián }\end{array}$ & combustible & tronco & $\mathrm{s} / \mathrm{e}$ & $\begin{array}{l}\text { Viedma y Villarino } \\
\text { [1783] 2006/ s. XVIII }\end{array}$ \\
\hline $\mathrm{s} / \mathrm{e}(15)$ & $\mathrm{s} / \mathrm{e}$ & $\mathrm{s} / \mathrm{e}$ & $\begin{array}{l}\text { Puerto } \\
\text { Deseado y San } \\
\text { Julián }\end{array}$ & construcción & Tallo & $\mathrm{s} / \mathrm{e}$ & $\begin{array}{l}\text { Viedma y Villarino } \\
\text { [1783] 2006/ s. XVIII }\end{array}$ \\
\hline s/e (16) & $\mathrm{s} / \mathrm{e}$ & $\mathrm{s} / \mathrm{e}$ & $\begin{array}{l}\text { Puerto } \\
\text { Deseado y San } \\
\text { Julián }\end{array}$ & $\begin{array}{l}\text { construcción } \\
\text { toldos }\end{array}$ & Tallo & $\mathrm{s} / \mathrm{e}$ & $\begin{array}{l}\text { Viedma y } \text { Villarino } \\
\text { [1783] 2006/ s. XVIII }\end{array}$ \\
\hline s/e (17) & $\mathrm{s} / \mathrm{e}$ & $\mathrm{s} / \mathrm{e}$ & $\begin{array}{l}\text { Norte de Cabo } \\
\text { Vírgenes }\end{array}$ & comestible & $\mathrm{s} / \mathrm{e}$ & $\mathrm{s} / \mathrm{e}$ & $\begin{array}{l}\text { José de Vargas y Ponce } \\
{[1785] \text { en Embón }} \\
1950 / \text { s. XVIII }\end{array}$ \\
\hline $\mathrm{s} / \mathrm{e}(18)$ & $\mathrm{s} / \mathrm{e}$ & murtilla & $\begin{array}{l}\text { Norte de Cabo } \\
\text { Vírgenes }\end{array}$ & comestible & fruto & $\mathrm{s} / \mathrm{e}$ & $\begin{array}{l}\text { José de Vargas y Ponce } \\
\text { [1785] en Embón } \\
1950 / \text { s. XVIII }\end{array}$ \\
\hline
\end{tabular}




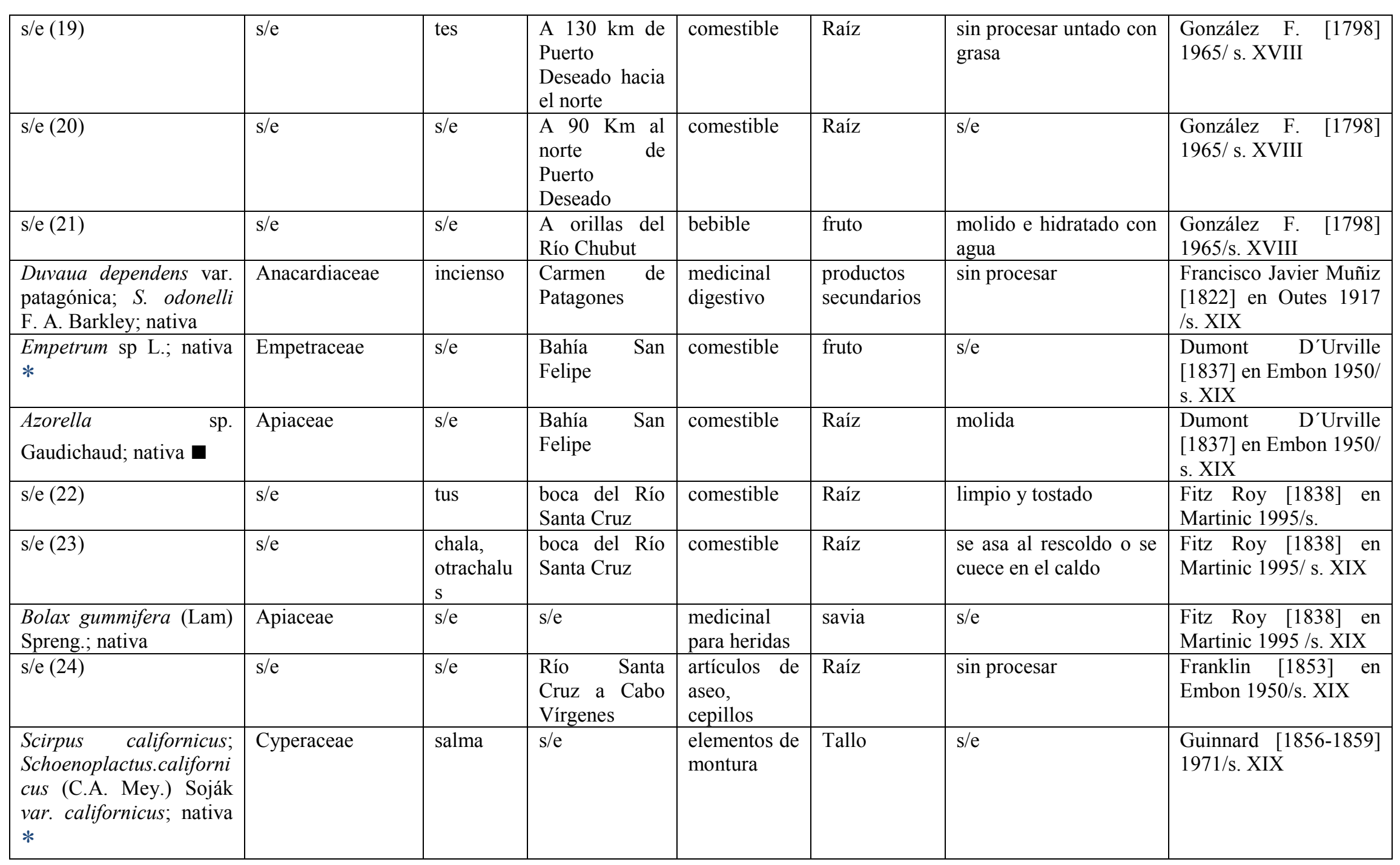




\begin{tabular}{|c|c|c|c|c|c|c|c|}
\hline $\begin{array}{l}\text { Cortaderia selloana } \\
\text { (Schult. \& Schult. F.) } \\
\text { Asch. \& Graebn.; nativa } \\
*\end{array}$ & Poaceae & köeni & $\mathrm{s} / \mathrm{e}$ & $\begin{array}{l}\text { instrumento } \\
\text { musical }\end{array}$ & tallo & $\mathrm{s} / \mathrm{e}$ & $\begin{array}{l}\text { Guinnard [1856-1859] } \\
\text { 1971/s. XIX }\end{array}$ \\
\hline $\begin{array}{l}\text { Atriplex undulata (Moq.) } \\
\text { D. Dietr. Nativa }\end{array}$ & Chenopodiaceae & chilpe & $\mathrm{s} / \mathrm{e}$ & medicinal & Hoja & $\begin{array}{lr}\text { se usan las } & \text { hojas } \\
\text { quemadas y mezcladas } \\
\text { con raíz de } & \text { ñim ñim } \\
\text { para curar } & \text { heridas } \\
\text { agusanadas } & \text { de } \\
\text { animales } & \\
\end{array}$ & $\begin{array}{l}\text { Guinnard [1856-1859] } \\
\text { 1971/s.XIX }\end{array}$ \\
\hline $\begin{array}{l}\text { Prosopis alba Griseb.; } \\
\text { nativa }\end{array}$ & Fabaceae & soé & $\mathrm{s} / \mathrm{e}$ & bebible & fruto & $\begin{array}{l}\text { se recogen las vainas, } \\
\text { las colocan entre dos } \\
\text { piedras, y meten en } \\
\text { bolsos de cuero llenos } \\
\text { de agua, dejan } \\
\text { fermentar y quitan } \\
\text { espuma; le agregan } \\
\text { porción de algarrobas } \\
\text { hervidas y mezclan y } \\
\text { agitan }\end{array}$ & $\begin{array}{l}\text { Guinnard [1856-1859] } \\
\text { 1971/s.XIX }\end{array}$ \\
\hline $\begin{array}{l}\text { Schinus patagonicus } \\
\text { (Phill.) I. M. Johnst ex } \\
\text { Cabrera; nativa }\end{array}$ & Anacardiaceae & $\mathrm{s} / \mathrm{e}$ & $\mathrm{s} / \mathrm{e}$ & comestible & $\begin{array}{l}\text { productos } \\
\text { secundarios }\end{array}$ & $\mathrm{s} / \mathrm{e}$ & $\begin{array}{l}\text { Guinnard [1856-1859] } \\
\text { 1971/s.XIX }\end{array}$ \\
\hline $\begin{array}{l}\text { Condalia microphylla } \\
\text { Cav.; nativa } *\end{array}$ & Rhamnaceae & $\mathrm{s} / \mathrm{e}$ & $\mathrm{s} / \mathrm{e}$ & comestible & fruto & macerado & $\begin{array}{l}\text { Guinnard [1856-1859] } \\
\text { 1971/s.XIX }\end{array}$ \\
\hline
\end{tabular}




\begin{tabular}{|c|c|c|c|c|c|c|c|}
\hline $\begin{array}{l}\text { Eryngium paniculatum; } \\
\text { Eryngium } \\
\text { Malme nativa }\end{array}$ & Apiaceae & $\mathrm{s} / \mathrm{e}$ & $\mathrm{s} / \mathrm{e}$ & Comestible & Tallo & $\begin{array}{l}\text { se mezclan los trozos } \\
\text { del tallo con leche y se } \\
\text { dejan fermentar o se } \\
\text { cuece sobre la ceniza, } \\
\text { mezclado con carne } \\
\text { cocida }\end{array}$ & $\begin{array}{l}\text { Guinnard [1856-1859] } \\
\text { 1971/s.XIX }\end{array}$ \\
\hline $\begin{array}{l}\text { Spilanthes decumbens; } \\
\text { Acmella decumbens } \\
\text { (Sm.) R.K. Jansen var. } \\
\text { affinis (Hook \& Arn) R. } \\
\text { K. Jansen. Nativa }\end{array}$ & Asteraceae & $\mathrm{s} / \mathrm{e}$ & $\mathrm{s} / \mathrm{e}$ & $\begin{array}{l}\text { medicinal } \\
\text { resfríos }\end{array}$ & Raíz & $\mathrm{s} / \mathrm{e}$ & $\begin{array}{l}\text { Guinnard [1856-1859] } \\
\text { 1971/s.XIX }\end{array}$ \\
\hline $\begin{array}{l}\text { Duvaua dependens; } \\
\text { Schinus odonelli F. A. } \\
\text { Barkley; nativa }\end{array}$ & Anacardiaceae & muchi & $\begin{array}{l}\text { Este } \quad \text { del } \\
\text { Nahuel Huapi }\end{array}$ & $\begin{array}{l}\text { comestible y } \\
\text { bebible }\end{array}$ & fruto & $\begin{array}{l}\text { se refriega con las } \\
\text { manos, cae la cáscara } \\
\text { en un plato donde hay } \\
\text { agua y se mezcla }\end{array}$ & $\begin{array}{l}\text { Cox }[1862-1863] \\
\text { 2006/s.XIX }\end{array}$ \\
\hline $\begin{array}{l}\text { Arjona appressa; } A . \\
\text { tuberosa var tuberosa } \\
\text { Cav.?; nativa } *\end{array}$ & Schoepfiaceae & $\begin{array}{l}\text { yahu- } \\
\text { yahuines }\end{array}$ & $\begin{array}{l}\text { Este del } \\
\text { Nahuel Huapi }\end{array}$ & comestible & tubérculo & $\mathrm{s} / \mathrm{e}$ & $\begin{array}{l}\text { Cox }[1862-1863] \\
\text { 2006/s.XIX }\end{array}$ \\
\hline $\begin{array}{l}\text { Muhlenbeckia } \\
\text { sagittaefolia; } \\
\text { Muehlenbeckia } \\
\text { sagittifolia (Ortega) } \\
\text { Meisn.; nativa }\end{array}$ & Polygonaceae & queneu & $\begin{array}{l}\text { cerca del } \\
\text { Limay }\end{array}$ & bebible & semilla & $\mathrm{s} / \mathrm{e}$ & $\begin{array}{l}\text { Cox }[1862-1863] \\
\text { 2006/s.XIX }\end{array}$ \\
\hline s/e (26) & $\mathrm{s} / \mathrm{e}$ & gitscha & $\begin{array}{l}\text { Viaje al río } \\
\text { Chubut }\end{array}$ & comestible & resina & $\begin{array}{l}\text { se queman las ramas, } \\
\text { se coloca un recipiente } \\
\text { con agua debajo y se } \\
\text { juntan las gotas de cera } \\
\text { que caen dentro }\end{array}$ & $\begin{array}{l}\text { Claraz } \\
\text { 2008/s.XIX }\end{array}$ \\
\hline $\mathrm{s} / \mathrm{e}(27)$ & $\mathrm{s} / \mathrm{e}$ & $\begin{array}{l}\text { chakaipa, } \\
\text { keneo }\end{array}$ & $\begin{array}{l}\text { Viaje al rio } \\
\text { Chubut, a } \\
\text { orillas del rio }\end{array}$ & $\begin{array}{l}\text { medicinal } \\
\text { antipirético }\end{array}$ & rama & hervido & $\begin{array}{l}\text { Claraz } \\
\text { 2008/s.XIX }\end{array}$ \\
\hline s/e (28) & $\mathrm{s} / \mathrm{e}$ & $\begin{array}{l}\text { lengua de } \\
\text { vaca, } \\
\text { lefó }\end{array}$ & $\begin{array}{l}\text { Viaje al río } \\
\text { Chubut, cerca } \\
\text { de un arroyito }\end{array}$ & comestible & Tallo & crudo & $\begin{array}{l}\text { Claraz } \\
\text { 2008/s.XIX }\end{array}$ \\
\hline
\end{tabular}




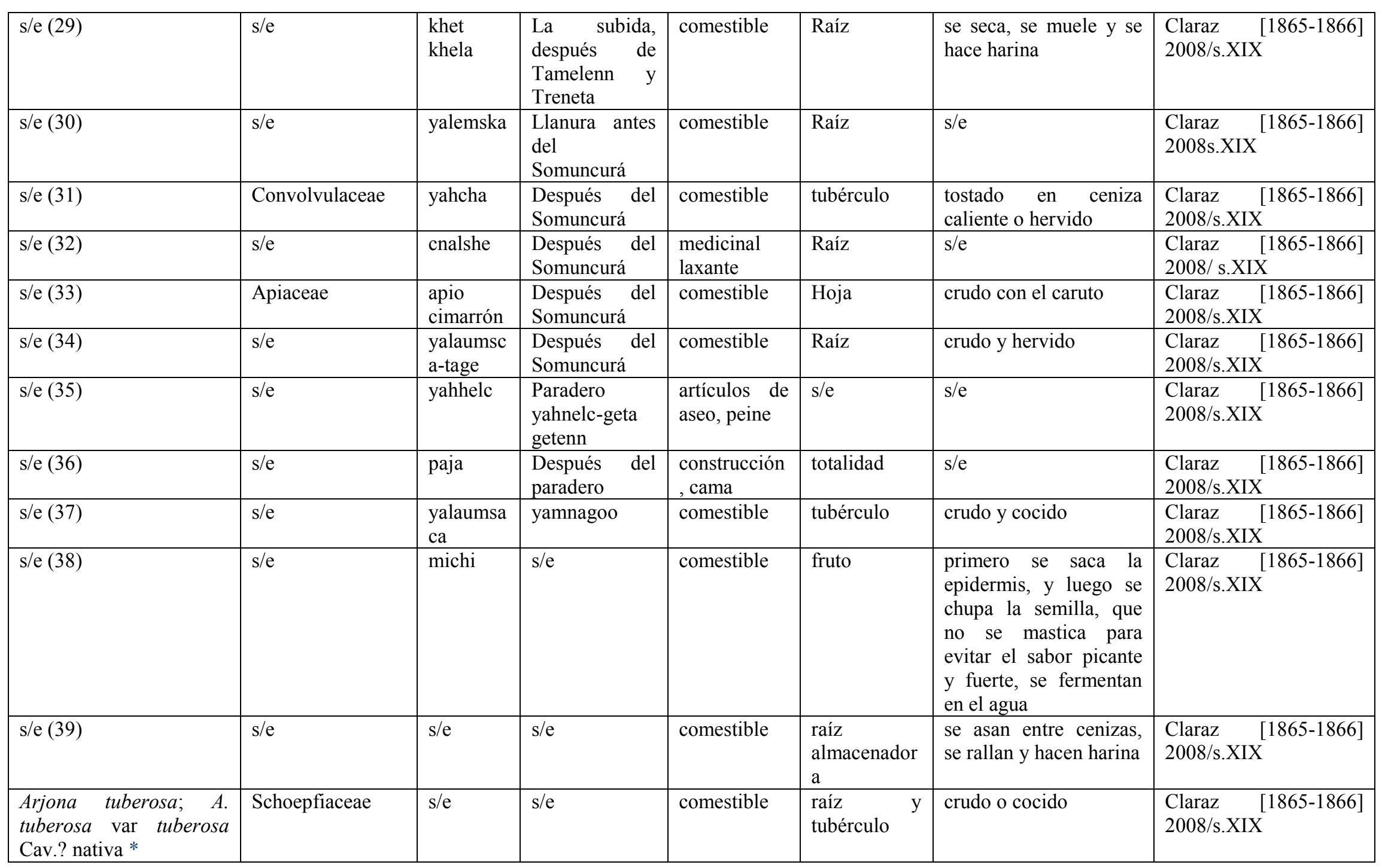




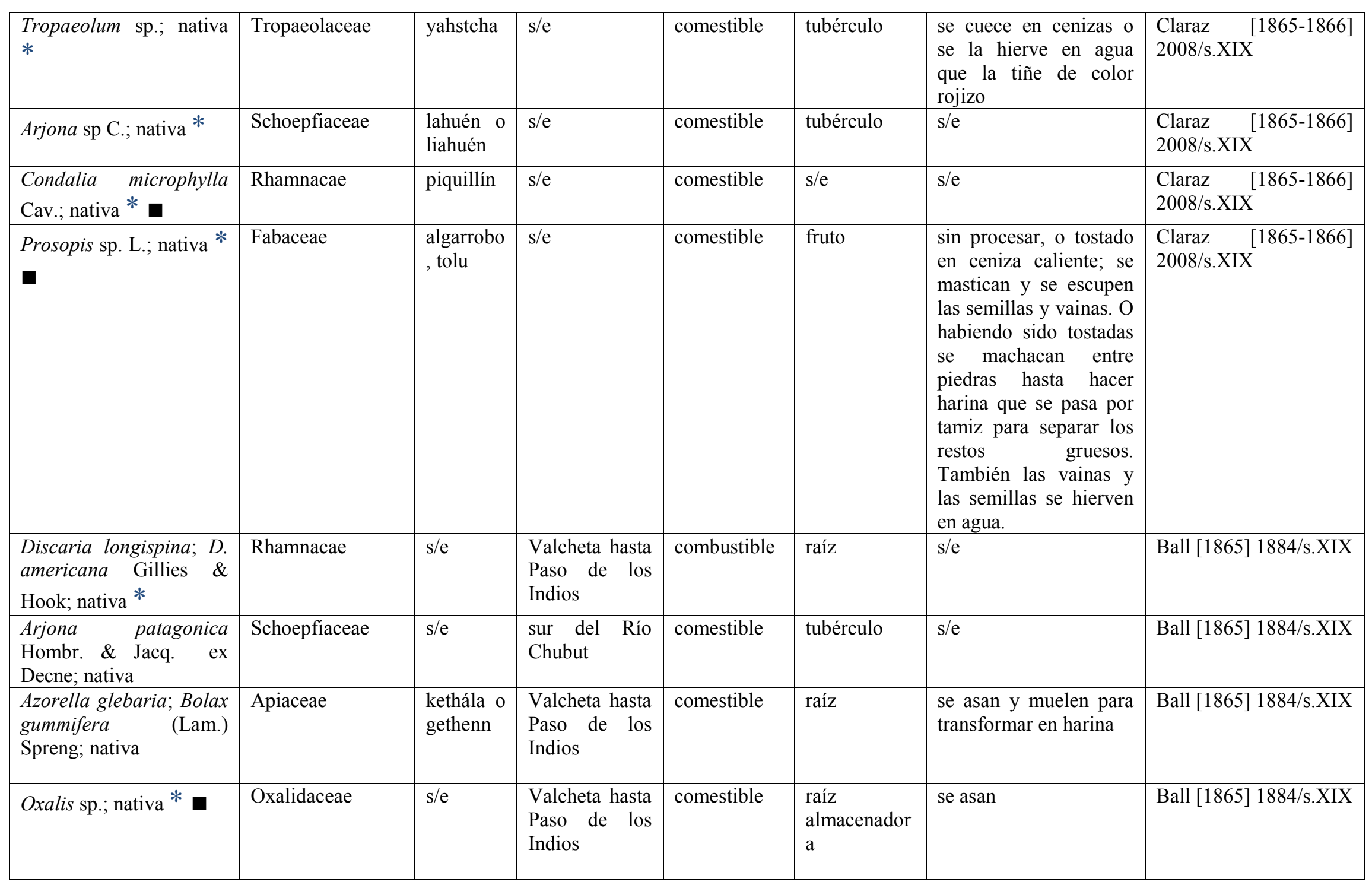




\begin{tabular}{|c|c|c|c|c|c|c|c|}
\hline $\begin{array}{l}\text { Nassauvia glomerulosa } \\
\text { (Lag. Ex Lindl.) D. Don; } \\
\text { nativa } *\end{array}$ & Asteraceae & yahnëlk & $\begin{array}{l}\text { Valcheta hasta } \\
\text { Paso de los } \\
\text { Indios }\end{array}$ & $\begin{array}{l}\text { elementos de } \\
\text { montura }\end{array}$ & raíz & $\mathrm{s} / \mathrm{e}$ & Ball [1865] 1884/s.XIX \\
\hline $\begin{array}{l}\text { Sesuvium } \\
\text { portulacastrum (L.) L.; } \\
\text { nativa }\end{array}$ & Aizoaceae & jume & $\begin{array}{l}\text { Valcheta hasta } \\
\text { Paso de los } \\
\text { Indios }\end{array}$ & bebible & $\mathrm{s} / \mathrm{e}$ & $\mathrm{s} / \mathrm{e}$ & Ball [1865] 1884/s.XIX \\
\hline $\begin{array}{l}\text { Schinus polygamus; S. } \\
\text { poligamus } \quad \text { (Cav.) } \\
\text { Cabrera; nativa }\end{array}$ & Anacardiaceae & molle & $\begin{array}{l}\text { Valcheta hasta } \\
\text { Paso de los } \\
\text { Indios }\end{array}$ & bebible & fruto & $\mathrm{s} / \mathrm{e}$ & Ball [1865] 1884/s.XIX \\
\hline $\begin{array}{l}\text { Duvaua sp.; Schinus sp. } \\
\text { L.; nativa * }\end{array}$ & Anacardiaceae & $\mathrm{s} / \mathrm{e}$ & $\begin{array}{l}\text { Valcheta hasta } \\
\text { Paso de los } \\
\text { Indios }\end{array}$ & bebible & fruto & macerado con agua & Ball [1865] 1884/s.XIX \\
\hline $\begin{array}{l}\text { Spilanthes helenioides; } \\
\text { Acmela decumbens (Sm) } \\
\text { R. K. Jansen }\end{array}$ & Asteraceae & $\mathrm{s} / \mathrm{e}$ & $\begin{array}{l}\text { Valcheta hasta } \\
\text { Paso de los } \\
\text { Indios }\end{array}$ & bebible & raíz & sin procesar & Ball [1865] 1884/s.XIX \\
\hline $\begin{array}{l}\text { Bromus unioloides; } B . \\
\text { catharticus Vahl; nativa } \\
*\end{array}$ & Poaceae & $\mathrm{s} / \mathrm{e}$ & $\begin{array}{l}\text { Valcheta hasta } \\
\text { Paso de los } \\
\text { Indios }\end{array}$ & comestible & semilla & tostado y molido & Ball [1865] 1884/s.XIX \\
\hline $\begin{array}{l}\text { Spilanthes helenioides; } \\
\text { Acmela decumbens (Sm) } \\
\text { R. K. Jansen }\end{array}$ & Asteraceae & ñim ñim & $\begin{array}{l}\text { Valcheta hasta } \\
\text { Paso de los } \\
\text { Indios }\end{array}$ & $\begin{array}{l}\text { medicinal, } \\
\text { para calmar } \\
\text { migrañas }\end{array}$ & $\mathrm{s} / \mathrm{e}$ & compresas & Ball [1865] 1884/s.XIX \\
\hline $\begin{array}{l}\text { E. tanacetifolium; Gyptis } \\
\text { tanacetifolia (Gillies ex } \\
\text { Hook. Et Arn.) D. J. N. } \\
\text { Hind Et Flann; nativa }\end{array}$ & Asteraceae & menuéke & $\begin{array}{l}\text { Valcheta hasta } \\
\text { Paso de los } \\
\text { Indios }\end{array}$ & $\begin{array}{l}\text { medicinal, } \\
\text { sudorífico }\end{array}$ & $\mathrm{s} / \mathrm{e}$ & decocciones & Ball [1865] 1884/s.XIX \\
\hline $\begin{array}{l}\text { Oenothera } \\
\text { mendocinensis Gilies ex } \\
\text { Hook. \& Arn; nativa }\end{array}$ & Onagraceae & inulei & $\begin{array}{l}\text { Valcheta hasta } \\
\text { Paso de los } \\
\text { Indios }\end{array}$ & medicinal & $\mathrm{s} / \mathrm{e}$ & $\mathrm{s} / \mathrm{e}$ & Ball [1865] 1884/s.XIX \\
\hline
\end{tabular}




\begin{tabular}{|c|c|c|c|c|c|c|c|}
\hline $\begin{array}{l}\text { Glychirriza astragalina; } \\
\text { Glycyrrhiza astragalina } \\
\text { Gilies ex Hook. \& Arn; } \\
\text { nativa } *\end{array}$ & Fabaceae & $\mathrm{s} / \mathrm{e}$ & $\begin{array}{l}\text { Valcheta hasta } \\
\text { Paso de los } \\
\text { Indios }\end{array}$ & $\begin{array}{l}\text { medicinal, } \\
\text { post parto }\end{array}$ & $\mathrm{s} / \mathrm{e}$ & $\mathrm{s} / \mathrm{e}$ & Ball [1865] 1884/s.XIX \\
\hline $\begin{array}{l}\text { Solidago linearifolia; } S \text {. } \\
\text { chilensis Meyen var } \\
\text { chilensis; nativa }\end{array}$ & Asteraceae & felel & $\begin{array}{ll}\text { norte } & \text { de } \\
\text { Patagonia } & \end{array}$ & tintórea & $\mathrm{s} / \mathrm{e}$ & $\mathrm{s} / \mathrm{e}$ & Ball [1865] 1884/s.XIX \\
\hline 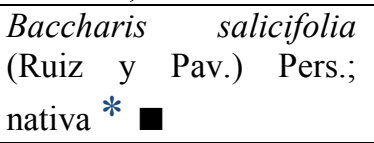 & Asteraceae & $\mathrm{s} / \mathrm{e}$ & $\mathrm{s} / \mathrm{e}$ & combustible & tallo & $\mathrm{s} / \mathrm{e}$ & Ball [1865] 1884/s.XIX \\
\hline $\mathrm{s} / \mathrm{e}(40)$ & $\mathrm{s} / \mathrm{e}$ & espadaña & $\begin{array}{l}\text { paradero Golf, } \\
\text { Gobernardor } \\
\text { Gregores }\end{array}$ & comestible & tallo & $\mathrm{s} / \mathrm{e}$ & $\begin{array}{l}\text { Musters } \\
{[1869] 1964 / \text { s.XIX }}\end{array}$ \\
\hline $\begin{array}{l}\text { Bolax gummifera (Lam.) } \\
\text { Spreng.; nativa }\end{array}$ & Apiaceae & $\mathrm{s} / \mathrm{e}$ & Río Chico & comestible & $\begin{array}{l}\text { raíz } \\
\text { almacenador } \\
\text { a }\end{array}$ & se asan al rescoldo & $\begin{array}{l}\text { Musters } \\
{[1869] 1964 / \text { s.XIX }}\end{array}$ \\
\hline $\mathrm{s} / \mathrm{e}(41)$ & $\mathrm{s} / \mathrm{e}$ & papa & Río Chico & comestible & Raíz & $\mathrm{s} / \mathrm{e}$ & $\begin{array}{l}\text { Musters } \\
{[1869] 1964 / \text { s.XIX }}\end{array}$ \\
\hline Beta vulgaris L.; exótica & Chenopodiaceae & espinaca & $\begin{array}{l}\text { De Hennokaik } \\
\text { a Teckel }\end{array}$ & comestible & hoja & $\begin{array}{l}\sin \text { procesar } \\
\text { acompañada con grasa } \\
\text { y huevo de avestruz }\end{array}$ & $\begin{array}{l}\text { Musters } \\
{[1869] 1964 / \text { s.XIX }}\end{array}$ \\
\hline $\begin{array}{lll}\begin{array}{l}\text { Pastinaca sativa? } \\
\text { exótica }\end{array} & \text { L.; } \\
\end{array}$ & Apiaceae & $\mathrm{s} / \mathrm{e}$ & $\begin{array}{l}\text { De Hennokaik } \\
\text { a Teckel }\end{array}$ & comestible & hoja & se asan al rescoldo & $\begin{array}{l}\text { Musters } \\
\text { [1869]1964/s.XIX }\end{array}$ \\
\hline Opuntia sp?; nativa $\square$ & Cactaceae & tuna & $\begin{array}{l}\text { después del } \\
\text { Río Senguel }\end{array}$ & comestible & fruto & $\mathrm{s} / \mathrm{e}$ & $\begin{array}{l}\text { Musters } \\
{[1869] 1964 / \text { s.XIX }}\end{array}$ \\
\hline s/e (42) & $\mathrm{s} / \mathrm{e}$ & hongo & $\begin{array}{l}\text { de Hennokaik } \\
\text { a Teckel }\end{array}$ & comestible & totalidad & $\mathrm{s} / \mathrm{e}$ & $\begin{array}{l}\text { Musters } \\
{[1869] 1964 / \text { s.XIX }}\end{array}$ \\
\hline $\mathrm{s} / \mathrm{e}(43)$ & $\mathrm{s} / \mathrm{e}$ & $\mathrm{s} / \mathrm{e}$ & $\begin{array}{l}\text { paradero } \\
\text { Pelwecken } \\
\text { estancia la } \\
\text { Ofelia Chubut } \\
\end{array}$ & $\begin{array}{l}\text { construcción } \\
\text {, toldos }\end{array}$ & tallo & $\mathrm{s} / \mathrm{e}$ & $\begin{array}{l}\text { Musters } \\
{[1869] 1964 / \text { s.XIX }}\end{array}$ \\
\hline
\end{tabular}




\begin{tabular}{|c|c|c|c|c|c|c|c|}
\hline s/e (44) & $\mathrm{s} / \mathrm{e}$ & $\mathrm{s} / \mathrm{e}$ & $\begin{array}{l}\text { al pie } \\
\text { suroccidental } \\
\text { de la sierra de } \\
\text { Putrachoique } \\
43^{\circ} 50^{\prime} \text { Sur }\end{array}$ & medicinal & hoja & $\mathrm{s} / \mathrm{e}$ & $\begin{array}{l}\text { Musters } \\
{[1869] 1964 / \text { s.XIX }}\end{array}$ \\
\hline $\mathrm{s} / \mathrm{e}(45)$ & $\mathrm{s} / \mathrm{e}$ & incienso & $\mathrm{s} / \mathrm{e}$ & $\begin{array}{l}\text { artículos de } \\
\text { aseo, higiene } \\
\text { bucal }\end{array}$ & $\begin{array}{l}\text { productos } \\
\text { secundarios }\end{array}$ & $\mathrm{s} / \mathrm{e}$ & $\begin{array}{l}\text { Musters } \\
{[1869] 1964 / \text { s.XIX }}\end{array}$ \\
\hline s/e (46) & $\mathrm{s} / \mathrm{e}$ & $\mathrm{s} / \mathrm{e}$ & $\begin{array}{lr}\text { después } & \text { de } \\
\text { Gisk } & \text { zona } \\
\text { donde } & \\
\text { acamparon } & \end{array}$ & $\begin{array}{l}\text { construcción } \\
\text { toldos }\end{array}$ & tallo & $\mathrm{s} / \mathrm{e}$ & $\begin{array}{l}\text { Musters } \\
{[1869] 1964 / \text { s.XIX }}\end{array}$ \\
\hline s/e (47) & $\mathrm{s} / \mathrm{e}$ & hongo & $\begin{array}{lr}\text { despues } & \text { de } \\
\text { Gisk } & \text { zona } \\
\text { donde } & \\
\text { acamparon } & \end{array}$ & $\begin{array}{l}\text { combustible, } \\
\text { yesca }\end{array}$ & totalidad & $\mathrm{s} / \mathrm{e}$ & $\begin{array}{l}\text { Musters } \\
{[1869] 1964 / \text { s.XIX }}\end{array}$ \\
\hline $\begin{array}{l}\text { Berberis buxifolia; } B . \\
\text { microphylla } \text { G. Forst; } \\
\text { nativa }\end{array}$ & Berberidaceae & calafate & $\begin{array}{l}\text { a orillas de un } \\
\text { río }\end{array}$ & comestible & fruto & $\mathrm{s} / \mathrm{e}$ & $\begin{array}{l}\text { Musters } \\
{[1869] 1964 / \text { s.XIX }}\end{array}$ \\
\hline s/e (48) & $\mathrm{s} / \mathrm{e}$ & $\mathrm{s} / \mathrm{e}$ & $\begin{array}{l}\text { lagunas secas } \\
\text { en la parte } \\
\text { occidental del } \\
\text { valle }\end{array}$ & comestible & raíz & se cuece y bebe el agua & $\begin{array}{l}\text { Musters } \\
{[1869] 1964 / \text { s.XIX }}\end{array}$ \\
\hline s/e (49) & $\mathrm{s} / \mathrm{e}$ & $\mathrm{s} / \mathrm{e}$ & $\begin{array}{l}\text { de teckel a } \\
\text { geylum }\end{array}$ & comestible & tubérculo & $\begin{array}{l}\text { hervido en una olla } \\
\text { tapada para utilizar el } \\
\text { vapor }\end{array}$ & $\begin{array}{l}\text { Musters } \\
{[1869] 1964 / . s . X I X}\end{array}$ \\
\hline 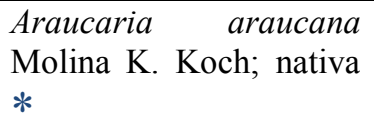 & Araucariaceae & piñones & $\begin{array}{l}\text { en las } \\
\text { Manzanas, en } \\
\text { la cordillera }\end{array}$ & comestible & semilla & $\begin{array}{l}\text { sin procesar o crudo } \\
\text { pelado o asado en su } \\
\text { cáscara }\end{array}$ & $\begin{array}{l}\text { Musters } \\
{[1869] 1964 / \text { s.XIX }}\end{array}$ \\
\hline Prunus sp L.; exótica & Rosaceae & manzana & $\begin{array}{l}\text { en las } \\
\text { Manzanas, en } \\
\text { la cordillera } \\
\end{array}$ & $\begin{array}{l}\text { comestible y } \\
\text { bebible }\end{array}$ & fruto & $\begin{array}{l}\text { sin procesar } 0 \\
\text { fermentado }\end{array}$ & $\begin{array}{l}\text { Musters } \\
{[1869] 1964 / \text { s.XIX }}\end{array}$ \\
\hline $\begin{array}{l}\text { Prosopis sp L.; nativa } \\
*\end{array}$ & Fabaceae & algarrobo & $\begin{array}{l}\text { en las } \\
\text { Manzanas, en } \\
\text { la cordillera } \\
\end{array}$ & bebible & fruto & destilado & $\begin{array}{l}\text { Musters } \\
{[1869] 1964 / \text { s.XIX }}\end{array}$ \\
\hline
\end{tabular}




\begin{tabular}{|c|c|c|c|c|c|c|c|}
\hline $\begin{array}{l}\text { Chusquea culeou E. } \\
\text { Desv.; nativa } *\end{array}$ & Poaceae & $\begin{array}{l}\text { caña } \\
\text { coligue }\end{array}$ & $\begin{array}{l}\text { en las } \\
\text { Manzanas, en } \\
\text { la cordillera }\end{array}$ & $\begin{array}{l}\text { armas, } \\
\text { lanzas }\end{array}$ & tallo & $\mathrm{s} / \mathrm{e}$ & $\begin{array}{l}\text { Musters } \\
{[1869] 1964 / \text { s.XIX }}\end{array}$ \\
\hline $\begin{array}{l}\text { Chuquiraga } \\
\text { avellanedae? Lorentz; } \\
\text { nativa } *\end{array}$ & Asteraceae & $\mathrm{s} / \mathrm{e}$ & $\begin{array}{l}\text { de Geylum a } \\
\text { Patagones }\end{array}$ & medicinal & Hoja & machacado y hervido & $\begin{array}{l}\text { Musters } \\
{[1869] 1964 / \text { s.XIX }}\end{array}$ \\
\hline Schinus sp L.; nativa * & Anacardiaceae & incienso & $\begin{array}{l}\text { de Geylum a } \\
\text { Patagones }\end{array}$ & bebible & fruto & macerado con agua & $\begin{array}{l}\text { Musters } \\
{[1869] 1964 / \text { s.XIX }}\end{array}$ \\
\hline $\mathrm{s} / \mathrm{e}(50)$ & $\mathrm{s} / \mathrm{e}$ & tomillo & $\begin{array}{l}\text { de Geylum a } \\
\text { Patagones }\end{array}$ & $\begin{array}{l}\text { comestible, } \\
\text { condimento }\end{array}$ & hoja & $\mathrm{s} / \mathrm{e}$ & $\begin{array}{l}\text { Musters } \\
{[1869] 1964 / \text { s.XIX }}\end{array}$ \\
\hline Prosopis sp. L.; nativa * & Fabaceae & algarrobo & $\begin{array}{l}\text { de Geylum a } \\
\text { Patagones }\end{array}$ & comestible & fruto & $\mathrm{s} / \mathrm{e}$ & $\begin{array}{l}\text { Musters } \\
{[1869] 1964 / \text { s.XIX }}\end{array}$ \\
\hline Prosopis sp. L.; nativa * & Fabaceae & algarrobo & $\begin{array}{l}\text { de Geylum a } \\
\text { Patagones }\end{array}$ & comestible & fruto & $\begin{array}{l}\text { molido e hidratado con } \\
\text { agua }\end{array}$ & $\begin{array}{l}\text { Musters } \\
{[1869] 1964 / \text { s.XIX }}\end{array}$ \\
\hline $\begin{array}{l}\text { Condalia microphyla; } C \text {. } \\
\text { microphylla Cav.; nativa } \\
*\end{array}$ & Rhamnacae & picayún & $\begin{array}{l}\text { de Geylum a } \\
\text { Patagones }\end{array}$ & combustible & tallo & $\mathrm{s} / \mathrm{e}$ & $\begin{array}{l}\text { Musters } \\
{[1869] 1964 / \text { s.XIX }}\end{array}$ \\
\hline Ribes sp? L.; nativa & Grossulariaceae & $\begin{array}{l}\text { zarzaparr } \\
\text { illa }\end{array}$ & $\begin{array}{l}\text { Limay, Nahuel } \\
\text { Huapi }\end{array}$ & bebible & fruto & $\begin{array}{l}\text { maceración, } \\
\text { aguardiente }\end{array}$ & $\begin{array}{l}\text { Moreno F. [1876-1877] } \\
\text { 2007/s.XIX }\end{array}$ \\
\hline Prunus sp. L.; exótica & Rosaceae & $\begin{array}{l}\text { manzana } \\
\mathrm{s}\end{array}$ & $\begin{array}{l}\text { Limay, Nahuel } \\
\text { Huapi }\end{array}$ & bebible & fruto & $\begin{array}{l}\text { maceración, } \\
\text { aguardiente }\end{array}$ & $\begin{array}{l}\text { Moreno F. [1876-1877] } \\
\text { 2007/s.XIX }\end{array}$ \\
\hline $\begin{array}{l}\text { Duvaua sp.; Schinus sp } \\
\text { L.; nativa * }\end{array}$ & Anacardiaceae & michi & $\begin{array}{l}\text { Limay, Nahuel } \\
\text { Huapi }\end{array}$ & bebible & fruto & $\begin{array}{l}\text { maceración, } \\
\text { aguardiente }\end{array}$ & $\begin{array}{l}\text { Moreno F. [1876-1877] } \\
\text { 2007/s.XIX }\end{array}$ \\
\hline Potentilla sp.? L.; nativa & Rosaceae & frutillas & $\begin{array}{l}\text { Limay, Nahuel } \\
\text { Huapi }\end{array}$ & comestible & fruto & crudo & $\begin{array}{l}\text { Moreno F. [1876-1877] } \\
\text { 2007/s.XIX }\end{array}$ \\
\hline Prunus sp L.; exótica & Rosaceae & $\begin{array}{l}\text { manzana } \\
\mathrm{s}\end{array}$ & $\begin{array}{l}\text { Limay, Nahuel } \\
\text { Huapi }\end{array}$ & comestible & fruto & crudo & $\begin{array}{l}\text { Moreno F. [1876-1877] } \\
\text { 2007/s.XIX }\end{array}$ \\
\hline
\end{tabular}




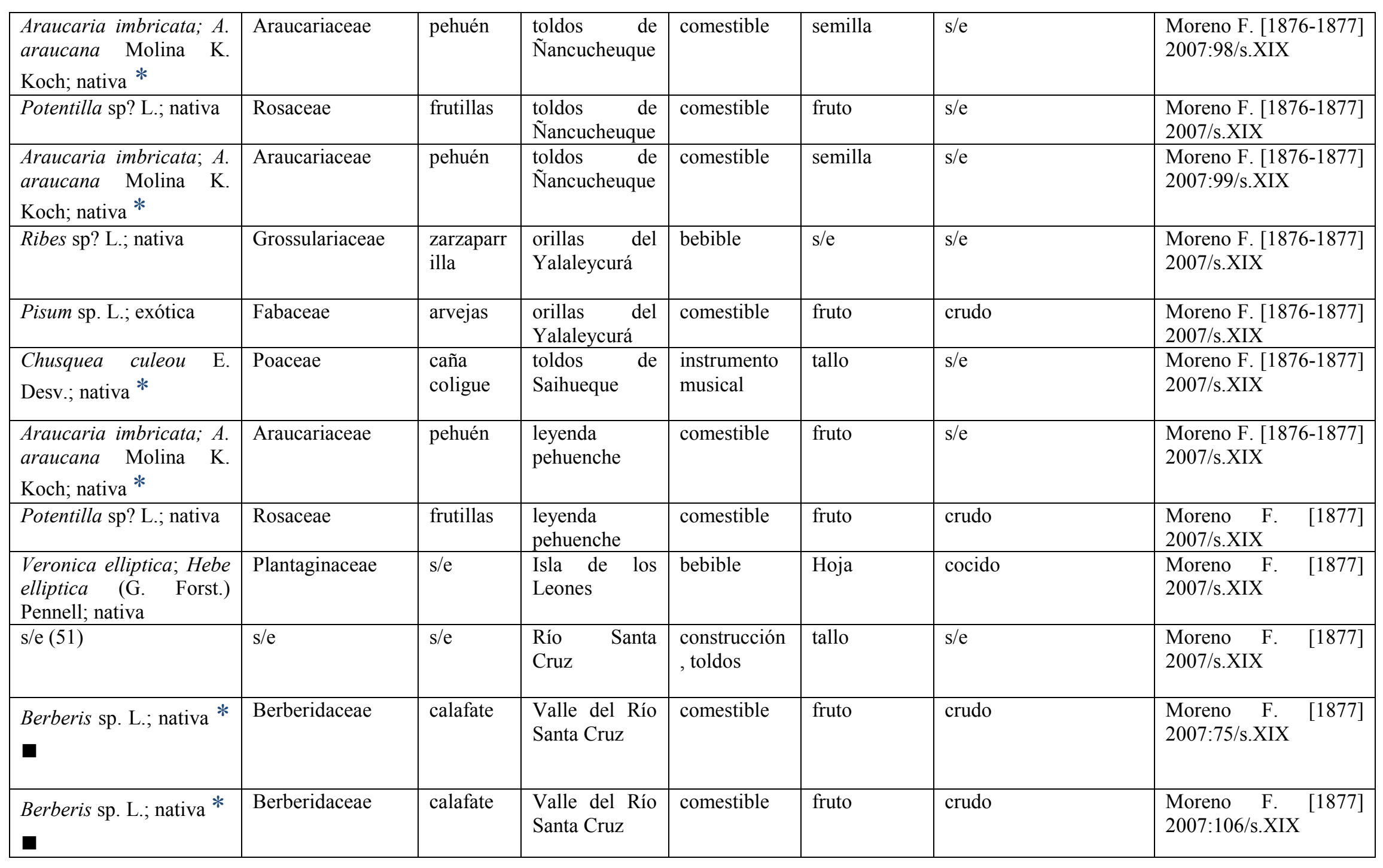




\begin{tabular}{|c|c|c|c|c|c|c|c|}
\hline $\begin{array}{l}\text { Berberis sp. L.; nativa } \\
*\end{array}$ & Berberidaceae & calafate & $\begin{array}{l}\text { Lago } \\
\text { Argentino }\end{array}$ & comestible & fruto & crudo & $\begin{array}{l}\text { Moreno F. [1877] } \\
\text { 2007/s.XIX }\end{array}$ \\
\hline $\mathrm{s} / \mathrm{e}(52)$ & $\mathrm{s} / \mathrm{e}$ & $\mathrm{s} / \mathrm{e}$ & $\begin{array}{l}\text { Lago } \\
\text { Argentino }\end{array}$ & construcción & Tallo & $\mathrm{s} / \mathrm{e}$ & $\begin{array}{l}\text { Moreno F. [1877] } \\
\text { 2007/s.XIX }\end{array}$ \\
\hline $\begin{array}{l}\text { Alstroemeria patagonica } \\
\text { Phil.; nativa }\end{array}$ & Alstroemeriaceae & $\mathrm{s} / \mathrm{e}$ & $\begin{array}{l}\text { Estrecho de } \\
\text { Magallanes }\end{array}$ & comestible & tubérculo & asado & $\begin{array}{l}\text { Ibar Sierra [1877] en } \\
\text { Embon 1950/s.XIX }\end{array}$ \\
\hline $\begin{array}{l}\text { Alstroemeria ligtu (L.) } \\
\text { Curtis; nativa }\end{array}$ & Alstroemeriaceae & $\begin{array}{l}\text { chuño de } \\
\text { Concepci } \\
\text { ón }\end{array}$ & $\begin{array}{l}\text { Estrecho de } \\
\text { Magallanes }\end{array}$ & comestible & tubérculo & $\mathrm{s} / \mathrm{e}$ & $\begin{array}{l}\text { Ibar Sierra [1877] en } \\
\text { Embon 1950/s.XIX }\end{array}$ \\
\hline $\begin{array}{l}\text { Berberis sp. L.; nativa } \\
*\end{array}$ & Berberidaceae & calafate & $\mathrm{s} / \mathrm{e}$ & bebible & fruto & $\mathrm{s} / \mathrm{e}$ & Lista [1879-1894]2006 \\
\hline s/e (53) & $\mathrm{s} / \mathrm{e}$ & $\begin{array}{l}\text { endibia } \\
\text { silvestre }\end{array}$ & $\begin{array}{l}\text { Puerto } \\
\text { Deseado }\end{array}$ & comestible & hoja & crudo & $\begin{array}{l}\text { Oneto } \quad[1883] 1884- \\
\text { 1885/s.XIX }\end{array}$ \\
\hline s/e (54) & $\mathrm{s} / \mathrm{e}$ & guaycurú & $\begin{array}{l}\text { de Punta } \\
\text { Arenas a Santa } \\
\text { Cruz } \\
\end{array}$ & $\begin{array}{l}\text { medicinal, } \\
\text { laxante }\end{array}$ & $\mathrm{s} / \mathrm{e}$ & $\mathrm{s} / \mathrm{e}$ & Roncagli 1884 /XIX \\
\hline $\begin{array}{l}\text { Berberis sp. L.; nativa } \\
\text { * }\end{array}$ & Berberidaceae & calafate & $\begin{array}{l}\text { entre los ríos } \\
\text { Coyle y Chico }\end{array}$ & $\begin{array}{l}\text { construcción } \\
\text {, pipas }\end{array}$ & tallo & $\mathrm{s} / \mathrm{e}$ & Roncagli 1884 /s.XIX \\
\hline $\begin{array}{lr}\text { Margyricarpus } & \text { setosus; } \\
\text { M. pinnatus } & \text { (Lam.) } \\
\text { Kuntze; nativa } & \\
\end{array}$ & Rosaceae & $\begin{array}{l}\text { yerba de } \\
\text { la perdiz }\end{array}$ & $\begin{array}{ll}\text { después } & \text { del } \\
\text { Cañadón } & \text { del } \\
\text { Gualicho } & \\
\end{array}$ & $\begin{array}{l}\text { medicinal, } \\
\text { astringente }\end{array}$ & $\mathrm{s} / \mathrm{e}$ & infusión & $\begin{array}{l}\text { Burmeister } \\
{[1887] 1888 / \text { s. XIX }}\end{array}$ \\
\hline $\begin{array}{l}\text { Duvava magellanica; } \\
\text { Schinus? Kunth; nativa } \\
\text { * }\end{array}$ & Anacardiaceae & $\mathrm{s} / \mathrm{e}$ & Chubut & pegamento & $\begin{array}{l}\text { productos } \\
\text { secundarios }\end{array}$ & extracción & $\begin{array}{l}\text { Burmeister } \\
{[1887] 1888 / \mathrm{s} . \text { XIX }}\end{array}$ \\
\hline $\begin{array}{lll}\text { Chuquiraga } & \text { sp. } & \text { Juss.; } \\
\text { nativa * } & & \\
\end{array}$ & Asteraceae & $\mathrm{s} / \mathrm{e}$ & Chubut & $\begin{array}{l}\text { combustible, } \\
\text { señales }\end{array}$ & totalidad & $\mathrm{s} / \mathrm{e}$ & Burmeister [1887]1888 \\
\hline
\end{tabular}




\begin{tabular}{|c|c|c|c|c|c|c|c|}
\hline Zea mays $\mathrm{L} *$ & Poaceae & maíz & Valcheta & comestible & fruto & $\mathrm{s} / \mathrm{e}$ & Burmeister [1877]1888 \\
\hline Allium sp L. & Amaryllidaceae & cebolla & Valcheta & comestible & bulbo & $\mathrm{s} / \mathrm{e}$ & Burmeister [1877]1888 \\
\hline Cucurbita sp? L. * & Ccucurbitaceae & zapallo & Valcheta & comestible & fruto & $\mathrm{s} / \mathrm{e}$ & Burmeister [1877]1888 \\
\hline $\begin{array}{l}\text { Taraxacum sp.; } \\
\text { nativa }\end{array}$ & Asteraceae & $\begin{array}{l}\text { achicoria } \\
\text { silvestre }\end{array}$ & $\mathrm{s} / \mathrm{e}$ & comestible & hoja & $\mathrm{s} / \mathrm{e}$ & $\begin{array}{l}\text { Lista }[1879- \\
1894] 2006 / \text { s.XIX }\end{array}$ \\
\hline $\mathrm{s} / \mathrm{e}(55)$ & $\mathrm{s} / \mathrm{e}$ & $\begin{array}{l}\text { jaye } 0 \\
\text { péchoro }\end{array}$ & $\mathrm{s} / \mathrm{e}$ & comestible & tubérculo & $\begin{array}{l}\text { sin procesar } \\
\text { o asado al rescoldo }\end{array}$ & $\begin{array}{l}\text { Lista } \\
1894] 2006 / \text { s.XIX }\end{array}$ \\
\hline 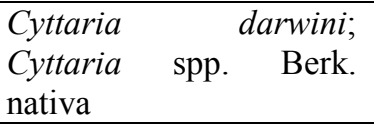 & Cyttareaceae & llao llao & Payne & comestible & totalidad & sin procesar & Siewert 1896/s.XIX \\
\hline Berberis sp. nativa ${ }^{*} \boldsymbol{\square}$ & Berberidaceae & calafate & $\mathrm{s} / \mathrm{e}$ & fumable & hoja & se quema y se fuma & $\begin{array}{l}\text { Hesketh Prichard } 1902 \\
\text { en Embon } 1950 / \text { s.XX }\end{array}$ \\
\hline $\begin{array}{l}\text { Juncus lesueurii; no } \\
\text { tiene sinonimia actual }\end{array}$ & Juncaceae & $\mathrm{s} / \mathrm{e}$ & $\begin{array}{ll}\text { cañadones en } \\
\text { el oeste de } \\
\text { Chubut }\end{array}$ & combustible & rizoma & $\mathrm{s} / \mathrm{e}$ & $\begin{array}{lcl}\text { Hauman } & 1926 & \text { en } \\
\text { Nacuzzi y } & \text { Perez } & \text { de } \\
\text { Micou 1983-85 } & \end{array}$ \\
\hline $\begin{array}{l}\text { Azorella cespitosa; } A . \\
\text { trifurcata } \quad \text { (Gaertn.) } \\
\text { Pers.; nativa }\end{array}$ & Apiaceae & $\mathrm{s} / \mathrm{e}$ & $\mathrm{s} / \mathrm{e}$ & comestible & raíz & molido & Vignati 1941/s. XX \\
\hline $\begin{array}{l}\text { Valeriana carnosa Sm.; } \\
\text { nativa }\end{array}$ & Valerianaceae & $\begin{array}{l}\text { ñanku } \\
\text { lawem }\end{array}$ & Chubut & $\begin{array}{l}\text { medicinal, } \\
\text { digestivo }\end{array}$ & $\mathrm{s} / \mathrm{e}$ & hervido & $\begin{array}{l}\text { Harrington inédito en } \\
\text { Casamiquela 1999/s. } \\
\text { XX }\end{array}$ \\
\hline $\begin{array}{l}\text { Buddleja globosa Hope; } \\
\text { nativa }\end{array}$ & Scrophulariaceae & pañil & Chubut & medicinal & $\mathrm{s} / \mathrm{e}$ & hervido & $\begin{array}{l}\text { Harrington inédito en } \\
\text { Casamiquela 1999/s. } \\
\text { XX }\end{array}$ \\
\hline $\begin{array}{l}\text { Mulinum espinosum; } M . \\
\text { spinosum (Cav.) Pers.; } \\
\text { native * }\end{array}$ & Apiaceae & neneo & Chubut & $\begin{array}{l}\text { medicinal, } \\
\text { analgésico }\end{array}$ & raíz & hervido & $\begin{array}{l}\text { Harrington inédito en } \\
\text { Casamiquela 1999/s. } \\
\text { XX }\end{array}$ \\
\hline Dysphania sp. L.; nativa & Chenopodiaceae & $\mathrm{s} / \mathrm{e}$ & Chubut & $\begin{array}{l}\text { medicinal, } \\
\text { digestivo }\end{array}$ & raíz & hervido & $\begin{array}{l}\text { Harrington inédito en } \\
\text { Casamiquela 1999/s. } \\
\text { XX }\end{array}$ \\
\hline $\begin{array}{l}\text { Adesmia boronioides } \\
\text { Hook.; nativa } \mathbf{\square}\end{array}$ & Fabaceae & $\begin{array}{l}\text { paramela } \\
\text {, yaken }\end{array}$ & Chubut & $\begin{array}{l}\text { medicinal, } \\
\text { analgésico }\end{array}$ & tallo & hervido & $\begin{array}{l}\text { Harrington inédito en } \\
\text { Casamiquela 1999/s. } \\
\text { XX }\end{array}$ \\
\hline
\end{tabular}




\begin{tabular}{|c|c|c|c|c|c|c|c|}
\hline $\begin{array}{l}\text { Statice antartica; no } \\
\text { tiene sinonimia actual } \\
\text { nativa }\end{array}$ & Plumbaginaceae & $\mathrm{s} / \mathrm{e}$ & Chubut & $\begin{array}{l}\text { medicinal, } \\
\text { analgésico }\end{array}$ & raíz & $\mathrm{s} / \mathrm{e}$ & $\begin{array}{l}\text { Harrington inédito en } \\
\text { Casamiquela 1999/s. } \\
\text { XX }\end{array}$ \\
\hline $\mathrm{s} / \mathrm{e}(56)$ & $\mathrm{s} / \mathrm{e}$ & $\begin{array}{l}\text { barba de } \\
\text { piedra }\end{array}$ & Chubut & $\begin{array}{l}\text { medicinal, } \\
\text { analgésico }\end{array}$ & totalidad & $\mathrm{s} / \mathrm{e}$ & $\begin{array}{l}\text { Harrington inédito en } \\
\text { Casamiquela 1999/s. } \\
\text { XX }\end{array}$ \\
\hline $\begin{array}{l}\text { Fabiana imbricata? } \\
\text { Ruiz \& Pav.; nativa }\end{array}$ & Solanaceae & $\begin{array}{l}\text { palo } \\
\text { piche }\end{array}$ & Chubut & $\begin{array}{l}\text { medicinal, } \\
\text { digestivo }\end{array}$ & tallo & $\mathrm{s} / \mathrm{e}$ & $\begin{array}{l}\text { Harrington (inédito) en } \\
\text { Casamiquela 1999/s. } \\
\text { XX }\end{array}$ \\
\hline $\mathrm{s} / \mathrm{e}(58)$ & Apiaceae & $\begin{array}{l}\text { apio } \\
\text { cimarrón }\end{array}$ & Chubut & medicinal & $\mathrm{s} / \mathrm{e}$ & $\mathrm{s} / \mathrm{e}$ & $\begin{array}{l}\text { Harrington (inédito) en } \\
\text { Casamiquela 1999/s. } \\
\text { XX }\end{array}$ \\
\hline s/e (59) & $\mathrm{s} / \mathrm{e}$ & ktápeli & $\begin{array}{ll}\text { oeste del río } \\
\text { Senguerr }\end{array}$ & comestible & tubérculo & $\mathrm{s} / \mathrm{e}$ & Escalada 1949/s. XX \\
\hline $\begin{array}{l}\text { Chenopodium } \\
\text { ambrosioides; } \\
\text { Dysphania ambrosioides } \\
\text { (L.) Mosyakin \& } \\
\text { Clemants; nativa }\end{array}$ & Chenopodiaceae & paico & $\mathrm{s} / \mathrm{e}$ & $\begin{array}{l}\text { medicinal, } \\
\text { diurético, } \\
\text { hepático, } \\
\text { digestivo }\end{array}$ & $\mathrm{s} / \mathrm{e}$ & $\mathrm{s} / \mathrm{e}$ & $\begin{array}{l}\text { Chayep (1950) en } \\
\text { Casamiquela 1999/s. } \\
\text { XX }\end{array}$ \\
\hline s/e (60) & $\mathrm{s} / \mathrm{e}$ & dawala & $\begin{array}{l}\text { Gan Gan, } \\
\text { Chubut }\end{array}$ & comestible & tubérculo & $\mathrm{s} / \mathrm{e}$ & $\begin{array}{ll}\text { Harrington } & 1943 \text { en } \\
\text { Casamiquela } & 1999 / \mathrm{s} . \\
\text { XX } & \end{array}$ \\
\hline $\begin{array}{l}\text { Schinus sp. L.; nativa } * \\
\square\end{array}$ & Anacardiaceae & molle & $\begin{array}{l}\text { Río Negro, } \\
\text { Chubut y } \\
\text { Pampa }\end{array}$ & $\begin{array}{l}\text { construcción } \\
\text {, cuna }\end{array}$ & tallo & $\mathrm{s} / \mathrm{e}$ & $\begin{array}{lr}\text { Bórmida } & \text { y } \\
\text { Casamiquela } & 1958- \\
\text { 59/s. XX } & \end{array}$ \\
\hline $\begin{array}{l}\text { Colliguaja integerrima } \\
\text { Gilies \& Hook.; nativa * } \\
\end{array}$ & Euphorbiaceae & $\begin{array}{l}\text { duraznill } \\
\text { o }\end{array}$ & $\mathrm{s} / \mathrm{e}$ & $\begin{array}{l}\text { medicinal, } \\
\text { analgésico, } \\
\text { veneno }\end{array}$ & $\begin{array}{l}\text { productos } \\
\text { secundarios }\end{array}$ & diluido en agua & $\begin{array}{llr}\text { Erize } 1960 & \text { en } \\
\text { Casamiquela } & 1999 / \mathrm{s} . \\
\text { XX } & & \end{array}$ \\
\hline
\end{tabular}




\begin{tabular}{|c|c|c|c|c|c|c|c|}
\hline Schinus sp. L.; nativa * & Anacardiaceae & $\begin{array}{l}\text { molle de } \\
\text { madera } \\
\text { roja }\end{array}$ & $\begin{array}{l}\text { cerca de Gan } \\
\text { Gan }\end{array}$ & combustible & tallo & $\mathrm{s} / \mathrm{e}$ & $\begin{array}{l}\text { Harrington }[1911- \\
\text { 1936] 1968/s. XX }\end{array}$ \\
\hline Juncus sp. L.; native * & Juncaceae & yájitch & Gan Gan & comestible & $\mathrm{s} / \mathrm{e}$ & $\mathrm{s} / \mathrm{e}$ & $\begin{array}{l}\text { Harrington }[1911- \\
\text { 1936] 1968/s. XX }\end{array}$ \\
\hline $\begin{array}{l}\text { Ephedra ochreata } \\
\text { Miers.; nativa } *\end{array}$ & Ephedraceae & sulupe & $\mathrm{s} / \mathrm{e}$ & $\begin{array}{l}\text { medicinal } \\
\text { antidiarreico }\end{array}$ & Raíz & hervido & $\begin{array}{l}\text { Harrington } \quad[1911- \\
\text { 1936] 1968/s. XX }\end{array}$ \\
\hline 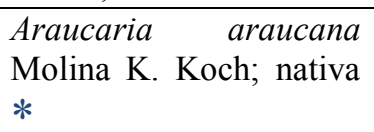 & Araucariaceae & $\mathrm{s} / \mathrm{e}$ & $\mathrm{s} / \mathrm{e}$ & comestible & semillas & $\mathrm{s} / \mathrm{e}$ & $\begin{array}{ll}\text { Martínez } & \text { Crovetto } \\
\text { 1982/s. XX } & \end{array}$ \\
\hline $\begin{array}{l}\text { Berberis darwinii Hook.; } \\
\text { nativa }\end{array}$ & Berberidaceae & $\begin{array}{l}\text { calafates } \\
\text { y michay }\end{array}$ & $\mathrm{s} / \mathrm{e}$ & comestible & frutos & $\mathrm{s} / \mathrm{e}$ & $\begin{array}{ll}\text { Martínez } & \text { Crovetto } \\
\text { 1982/s. XX } & \\
\end{array}$ \\
\hline $\begin{array}{l}\text { Berberis empetrifolia } \\
\text { Lam.; nativa }\end{array}$ & Berberidaceae & $\begin{array}{l}\text { calafates } \\
\text { y michay }\end{array}$ & $\mathrm{s} / \mathrm{e}$ & comestible & frutos & $\mathrm{s} / \mathrm{e}$ & $\begin{array}{ll}\text { Martínez } & \text { Crovetto } \\
\text { 1982/s. XX } & \\
\end{array}$ \\
\hline $\begin{array}{l}\text { Berberis microphylla } \mathrm{G} . \\
\text { Forst.; nativa }\end{array}$ & Berberidaceae & $\begin{array}{l}\text { calafates } \\
\text { y michay }\end{array}$ & $\mathrm{s} / \mathrm{e}$ & comestible & frutos & $\mathrm{s} / \mathrm{e}$ & $\begin{array}{ll}\text { Martínez } & \text { Crovetto } \\
\text { 1982/s. XX } & \end{array}$ \\
\hline $\begin{array}{l}\text { Pernettya mucronata; } \\
\text { Gaultheria mucronata } \\
\text { (L. f.) Hook. \& Arn.; } \\
\text { nativa }\end{array}$ & Ericaceae & chaura & $\mathrm{s} / \mathrm{e}$ & comestible & frutos & $\mathrm{s} / \mathrm{e}$ & $\begin{array}{ll}\text { Martínez } & \text { Crovetto } \\
\text { 1982/s. XX } & \end{array}$ \\
\hline $\begin{array}{l}\text { Potentilla chiloensis (L.) } \\
\text { Mabb. exótica }\end{array}$ & Rosaceae & frutilla & $\mathrm{s} / \mathrm{e}$ & comestible & frutos & $\mathrm{s} / \mathrm{e}$ & $\begin{array}{ll}\text { Martínez } & \text { Crovetto } \\
\text { 1982/s. XX } & \end{array}$ \\
\hline $\begin{array}{l}\text { Prosopanche bonacinae } \\
\text { Speg.; nativa }\end{array}$ & Hydnoraceae & guaycurú & $\mathrm{s} / \mathrm{e}$ & comestible & fruto & $\mathrm{s} / \mathrm{e}$ & $\begin{array}{ll}\text { Martínez } & \text { Crovetto } \\
\text { 1982/s. XX } & \end{array}$ \\
\hline $\begin{array}{l}\text { Taraxacum sp. Class.; } \\
\text { nativa }\end{array}$ & Asteraceae & $\begin{array}{l}\text { diente de } \\
\text { león }\end{array}$ & $\mathrm{s} / \mathrm{e}$ & comestible & $\mathrm{s} / \mathrm{e}$ & $\mathrm{s} / \mathrm{e}$ & $\begin{array}{ll}\text { Martínez } & \text { Crovetto } \\
\text { 1982/s. XX } & \end{array}$ \\
\hline $\begin{array}{l}\text { Tropaeolum } \\
\text { patagonicum } \\
\text { nativa } *\end{array}$ & Tropaeolaceae & $\mathrm{s} / \mathrm{e}$ & $\mathrm{s} / \mathrm{e}$ & comestible & tubérculo & $\mathrm{s} / \mathrm{e}$ & $\begin{array}{ll}\text { Martínez } & \text { Crovetto } \\
\text { 1982/s. XX } & \end{array}$ \\
\hline $\begin{array}{l}\text { Oxalis mallobolba; O. } \\
\text { perdicaria (Molina) } \\
\text { Bertero; nativa }\end{array}$ & Oxalidaceae & macachín & $\mathrm{s} / \mathrm{e}$ & comestible & tubérculo & $\mathrm{s} / \mathrm{e}$ & $\begin{array}{ll}\text { Martínez } & \text { Crovetto } \\
\text { 1982/s. XX } & \end{array}$ \\
\hline
\end{tabular}




\begin{tabular}{|c|c|c|c|c|c|c|c|c|}
\hline $\begin{array}{l}\text { Oxalis patagonica; O. } \\
\text { enneaphylla Cav. Ibari } \\
\text { Ssp. (Phil) Lourteig; } \\
\text { nativa }\end{array}$ & Oxalidaceae & macachín & $\mathrm{s} / \mathrm{e}$ & comestible & tubérculo & $\mathrm{s} / \mathrm{e}$ & $\begin{array}{l}\text { Martínez } \\
\text { 1982/s. XX }\end{array}$ & Crovetto \\
\hline $\begin{array}{lr}\text { Oxalis macachín; } O . \\
\text { brasiliensis } & \text { Lodd.; } \\
\text { nativa, pero } & \text { no } \\
\text { patagónica } & \end{array}$ & Oxalidaceae & macachín & $\mathrm{s} / \mathrm{e}$ & comestible & tubérculo & $\mathrm{s} / \mathrm{e}$ & $\begin{array}{l}\text { Martínez } \\
\text { 1982/s. XX }\end{array}$ & Crovetto \\
\hline $\begin{array}{l}\text { Alstroemeria } \\
\text { aurantiaca; A. aurea } \\
\text { Graham; nativa }\end{array}$ & Alstroemeriaceae & liuto & $\mathrm{s} / \mathrm{e}$ & comestible & rizomas & $\begin{array}{l}\text { asados y luego } \\
\text { reducidos a harina }\end{array}$ & $\begin{array}{l}\text { Martínez } \\
\text { 1982/s. XX }\end{array}$ & Crovetto \\
\hline $\begin{array}{l}\text { Alstroemeria ligtu (L.) } \\
\text { ssp. ligtu Curtis; nativa }\end{array}$ & Alstroemeriaceae & liuto & $\mathrm{s} / \mathrm{e}$ & comestible & rizomas & $\begin{array}{l}\text { asados y luego } \\
\text { reducidos a harina }\end{array}$ & $\begin{array}{l}\text { Martínez } \\
\text { 1982/s. XX }\end{array}$ & Crovetto \\
\hline $\begin{array}{l}\text { Scirpus californicus; } \\
\text { Schoenoplectus } \\
\text { californicus (C.A. Mey) } \\
\text { Soják var. californicus; } \\
\text { nativa } *\end{array}$ & Cyperaceae & junco & $\mathrm{s} / \mathrm{e}$ & comestible & rizomas & $\begin{array}{l}\text { asados y luego } \\
\text { reducidos a harina }\end{array}$ & $\begin{array}{l}\text { Martínez } \\
\text { 1982/s. XX }\end{array}$ & Crovetto \\
\hline $\begin{array}{l}\text { Berberis sp. L.; nativa } * \\
\text { a }\end{array}$ & Berberidaceae & calafate & $\mathrm{s} / \mathrm{e}$ & bebible & frutos & $\begin{array}{ll}\text { restregados } & y \\
\text { macerados en agua } & \end{array}$ & $\begin{array}{l}\text { Martínez } \\
\text { 1982/s. XX }\end{array}$ & Crovetto \\
\hline $\begin{array}{l}\text { Azorella sp. } \\
\text { Gaudichaud; nativa }\end{array}$ & Umbeliferae & yareta & $\mathrm{s} / \mathrm{e}$ & $\begin{array}{l}\text { empastes } \\
\text { para pinturas }\end{array}$ & $\begin{array}{l}\text { productos } \\
\text { secundarios }\end{array}$ & $\begin{array}{l}\text { fundida y mezclada con } \\
\text { grasa }\end{array}$ & $\begin{array}{l}\text { Martínez } \\
\text { 1982/s. XX }\end{array}$ & Crovetto \\
\hline $\begin{array}{l}\text { Bolax sp. Commers. ex } \\
\text { Juss; native }\end{array}$ & Apiaceae & yareta & $\mathrm{s} / \mathrm{e}$ & $\begin{array}{l}\text { empastes } \\
\text { para pinturas }\end{array}$ & $\begin{array}{l}\text { productos } \\
\text { secundarios }\end{array}$ & $\begin{array}{l}\text { fundida y mezclada con } \\
\text { grasa }\end{array}$ & $\begin{array}{l}\text { Martínez } \\
\text { 1982/s. XX }\end{array}$ & Crovetto \\
\hline $\begin{array}{l}\text { Chuquiraga erinaceae } \\
\text { D. Don ssp. erinaceae; } \\
\text { nativa }\end{array}$ & Asteraceae & $\begin{array}{l}\text { chillador } \\
\text { a }\end{array}$ & $\mathrm{s} / \mathrm{e}$ & $\begin{array}{l}\text { medicinal, } \\
\text { estimulante }\end{array}$ & hoja & sin procesar & $\begin{array}{l}\text { Martínez } \\
\text { 1982/s. XX }\end{array}$ & Crovetto \\
\hline $\begin{array}{l}\text { Schinus patagonicus } \\
\text { (Phill.) I. M. Johnst ex } \\
\text { Cabrera; nativa }\end{array}$ & Anacardiaceae & laura & $\mathrm{s} / \mathrm{e}$ & $\begin{array}{l}\text { artículos de } \\
\text { aseo, higiene } \\
\text { bucal }\end{array}$ & $\begin{array}{l}\text { productos } \\
\text { secundarios }\end{array}$ & $\mathrm{s} / \mathrm{e}$ & $\begin{array}{l}\text { Martínez } \\
\text { 1982/s. XX }\end{array}$ & Crovetto \\
\hline
\end{tabular}




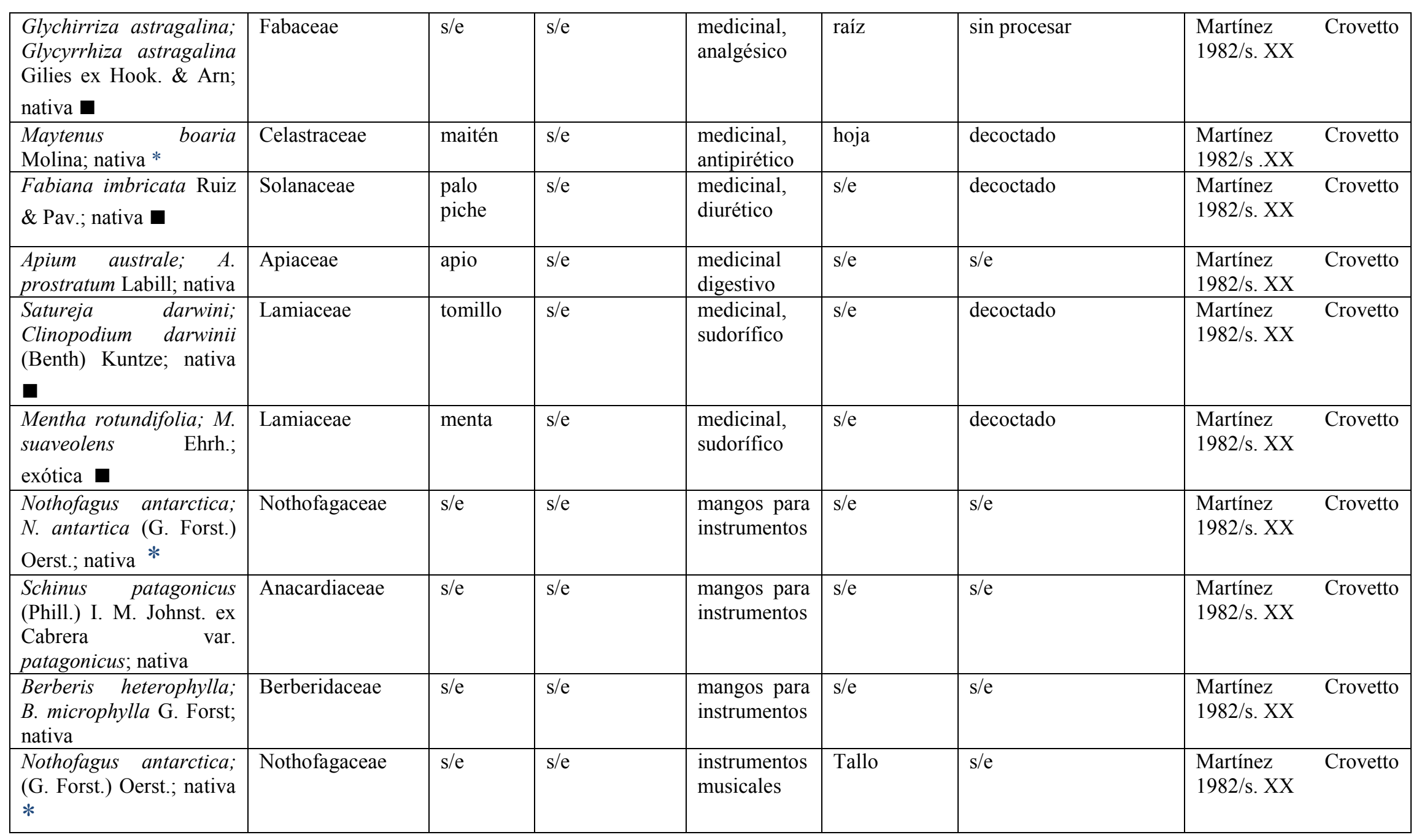




\begin{tabular}{|c|c|c|c|c|c|c|c|}
\hline Berberis sp.; nativa ${ }^{*} \boldsymbol{\square}$ & Berberidaceae & calafate & $\mathrm{s} / \mathrm{e}$ & bebible & fruto & $\begin{array}{l}\text { macerado } \\
\text { dejándose } \\
\text { Luego sermentar. } \\
\text { alcohol }\end{array}$ & Martinic 1995/s. XX \\
\hline s/e (61) & $\mathrm{s} / \mathrm{e}$ & $\begin{array}{l}\text { barba de } \\
\text { piedra }\end{array}$ & $\begin{array}{l}\text { Río Negro, } \\
\text { Ingeniero } \\
\text { Jacobacci }\end{array}$ & $\begin{array}{l}\text { medicinal, } \\
\text { venéreas }\end{array}$ & totalidad & sin procesar & $\begin{array}{l}\text { Casamiquela } 1999 / \mathrm{s} \\
\text { XX }\end{array}$ \\
\hline $\begin{array}{l}\text { Lippia foliolosa; } \\
\text { Acantholippia } \\
\text { seriphioides (A. Gray) } \\
\text { Moldenke nativa }\end{array}$ & Verbenacae & tomillo & Río Negro & $\begin{array}{l}\text { medicinal, } \\
\text { analgésico }\end{array}$ & $\mathrm{s} / \mathrm{e}$ & $\mathrm{s} / \mathrm{e}$ & $\begin{array}{l}\text { Casamiquela } 1999 / \mathrm{s} \\
\text { XX }\end{array}$ \\
\hline Dysphania sp. L.; nativa & Chenopodiaceae & paico & Río Negro & $\begin{array}{l}\text { medicinal, } \\
\text { digestivo }\end{array}$ & $\mathrm{s} / \mathrm{e}$ & $\mathrm{s} / \mathrm{e}$ & $\begin{array}{ll}\text { Casamiquela } 1999 / \mathrm{s} \\
\text { XX }\end{array}$ \\
\hline $\begin{array}{l}\text { Berberis buxifolia; } B . \\
\text { microphylla } \text { G. Forst; } \\
\text { nativa }\end{array}$ & Berberidaceae & calafate & Río Negro & $\begin{array}{l}\text { medicinal, } \\
\text { oftálmico }\end{array}$ & fruto & $\begin{array}{l}\text { se reventaba y colaba, } \\
\text { sin semillas ni ollejos, } \\
\text { se guardaba el jugo } \\
\text { para colar y se ponían } \\
\text { unas gotitas en los ojos. } \\
\text { Emplastos }\end{array}$ & $\begin{array}{l}\text { Casamiquela } 1999 / \mathrm{s} \\
\text { XX }\end{array}$ \\
\hline $\begin{array}{l}\text { Grindelia chiloensis } \\
\text { (Cornel.) Cabrera; nativa } \\
*\end{array}$ & Asteraceae & $\begin{array}{l}\text { botón de } \\
\text { oro }\end{array}$ & Río Negro & $\begin{array}{l}\text { medicinal, } \\
\text { antimigraña }\end{array}$ & Flor & emplastos & $\begin{array}{ll}\text { Casamiquela } & 1999 / \mathrm{s} \\
\text { XX } & \end{array}$ \\
\hline $\begin{array}{l}\text { Azorella sp. } \\
\text { Gaudichaud; nativa }\end{array}$ & Umbeliferae & $\begin{array}{l}\text { leña de } \\
\text { piedra }\end{array}$ & Río Negro & $\begin{array}{l}\text { empaste } \\
\text { pinturas }\end{array}$ & $\begin{array}{l}\text { productos } \\
\text { secundarios }\end{array}$ & $\mathrm{s} / \mathrm{e}$ & $\begin{array}{l}\text { Casamiquela } 1999 / \mathrm{s} \\
\text { XX }\end{array}$ \\
\hline s/e (62) & $\mathrm{s} / \mathrm{e}$ & alfilerillo & Río Negro & $\begin{array}{l}\begin{array}{l}\text { medicinal, } \\
\text { cicatrizante }\end{array} \\
\end{array}$ & totalidad & $\begin{array}{l}\text { decocción y lavado de } \\
\text { la herida }\end{array}$ & $\begin{array}{ll}\text { Casamiquela } 1999 / \mathrm{s} \\
\text { XX }\end{array}$ \\
\hline
\end{tabular}




\begin{tabular}{|c|c|c|c|c|c|c|c|}
\hline $\begin{array}{lll}\text { Chuquiraga } & \text { sp. } & \text { Juss.; } \\
\text { nativa * } & & \end{array}$ & Asteraceae & trayao & Río Negro & $\begin{array}{l}\text { medicinal, } \\
\text { antipirético }\end{array}$ & Hoja & $\begin{array}{l}\text { sin procesar o hervido } \\
\text { con azúcar quemada }\end{array}$ & $\begin{array}{l}\text { Casamiquela 1999/s. } \\
\text { XX }\end{array}$ \\
\hline $\begin{array}{l}\text { Nassavia glomerulosa; } \\
\text { Nassauvia glomerulosa } \\
\text { (Lag. Ex Lindl.) D. Don } \\
\text { nativa * }\end{array}$ & Asteraceae & $\begin{array}{l}\text { cola de } \\
\text { piche }\end{array}$ & Río Negro & $\begin{array}{l}\text { artículos de } \\
\text { aseo, peine }\end{array}$ & Raíz & $\mathrm{s} / \mathrm{e}$ & $\begin{array}{ll}\text { Casamiquela } & 1999 / \mathrm{s} . \\
\text { XX } & \end{array}$ \\
\hline $\mathrm{s} / \mathrm{e}(63)$ & Cactaceae & $\begin{array}{l}\text { tuna } \\
\text { grande }\end{array}$ & Río Negro & comestible & fruto & se asa al rescoldo & $\begin{array}{l}\text { Casamiquela 1999/s. } \\
\text { XX }\end{array}$ \\
\hline $\begin{array}{l}\text { Tropaeolum } \\
\text { patagonicum } \\
\text { nativa }\end{array}$ & Tropaeolaceae & chalía & $\begin{array}{l}\text { Río Negro, } \\
\text { Chubut }\end{array}$ & comestible & tubérculo & $\mathrm{s} / \mathrm{e}$ & $\begin{array}{l}\text { Casamiquela 1999/s. } \\
\text { XX }\end{array}$ \\
\hline $\begin{array}{l}\text { Alstroemeria ligtu (L.) } \\
\text { ssp. ligtu; nativa }\end{array}$ & Alstroemeriaceae & $\begin{array}{l}\text { chuño de } \\
\text { Concepci } \\
\text { ón }\end{array}$ & Río Negro & comestible & rizoma & $\mathrm{s} / \mathrm{e}$ & $\begin{array}{ll}\text { Casamiquela } & 1999 / \mathrm{s} . \\
\text { XX } & \end{array}$ \\
\hline s/e (64) & $\mathrm{s} / \mathrm{e}$ & $\begin{array}{l}\text { sing-é } \\
\text { poñe }\end{array}$ & $\begin{array}{l}\text { Reserva } \\
\text { Nahuelpán, } \\
\text { Esquel, } \\
\text { Chubut }\end{array}$ & comestible & tubérculo & $\mathrm{s} / \mathrm{e}$ & $\begin{array}{l}\text { Casamiquela 1999/s. } \\
\text { XX }\end{array}$ \\
\hline 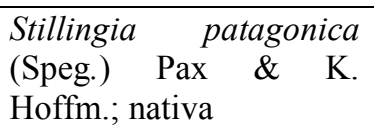 & Euphorbiaceae & $\begin{array}{l}\text { yuyo } \\
\text { crespo }\end{array}$ & Río Negro & veneno & $\mathrm{s} / \mathrm{e}$ & $\mathrm{s} / \mathrm{e}$ & $\begin{array}{ll}\text { Casamiquela } & 1999 / \mathrm{s} . \\
\text { XX } & \end{array}$ \\
\hline $\begin{array}{l}\text { Astragalus sp. L.; nativa } \\
*\end{array}$ & Fabaceae & $\mathrm{s} / \mathrm{e}$ & Río Negro & veneno & $\mathrm{s} / \mathrm{e}$ & $\mathrm{s} / \mathrm{e}$ & $\begin{array}{l}\text { Casamiquela 1999/s. } \\
\text { XX }\end{array}$ \\
\hline $\begin{array}{l}\text { Berberis buxifolia; } B . \\
\begin{array}{l}\text { microphylla } \\
\text { nativa }\end{array} \\
\begin{array}{l}\text { G. Forst; } \\
\end{array}\end{array}$ & Berberidaceae & calafate & $\begin{array}{lr}\text { Valle } r \\
\text { Piedra } \\
\text { Chubut } \\
\end{array}$ & combustible & $\mathrm{s} / \mathrm{e}$ & $\mathrm{s} / \mathrm{e}$ & $\begin{array}{l}\text { Ancibor y Pérez de } \\
\text { Micou 2002/s.XXI }\end{array}$ \\
\hline $\begin{array}{l}\text { Prosopis denundans } \\
\text { Bentham; nativa } * \square\end{array}$ & Fabaceae & $\begin{array}{l}\text { algarrobi } \\
\text { llo }\end{array}$ & $\begin{array}{lr}\text { Valle } & \text { de } \\
\text { Piedra } & \text { Parada } \\
\text { Chubut } & \end{array}$ & combustible & $\begin{array}{l}\text { tallo } \\
\text { subterráneo }\end{array}$ & $\mathrm{s} / \mathrm{e}$ & $\begin{array}{l}\text { Ancibor y Pérez de } \\
\text { Micou 2002/s.XXI }\end{array}$ \\
\hline $\begin{array}{l}\text { Salix humboldtiana } \\
\text { Wild.; nativa } \mathbf{\square}\end{array}$ & Salicaceae & sauce & $\begin{array}{l}\text { Valle } \quad \text { de } \\
\text { Piedra Parada } \\
\text { Chubut } \\
\end{array}$ & combustible & tallo & $\mathrm{s} / \mathrm{e}$ & $\begin{array}{l}\text { Ancibor y Pérez de } \\
\text { Micou 2002/s.XXI }\end{array}$ \\
\hline
\end{tabular}




\begin{tabular}{|c|c|c|c|c|c|c|c|}
\hline $\begin{array}{l}\text { Schinus marchandii (F. } \\
\text { A. Barkley); nativa }\end{array}$ & Anacardiaceae & molle & $\begin{array}{l}\text { Valle } \quad \text { de } \\
\text { Piedra Parada } \\
\text { Chubut }\end{array}$ & combustible & tallo & $\mathrm{s} / \mathrm{e}$ & $\begin{array}{l}\text { Ancibor y Pérez de } \\
\text { Micou 2002/s.XXI }\end{array}$ \\
\hline $\begin{array}{l}\text { Anarthrophyllum } \\
\text { rigidum (Gillies ex Hook } \\
\text { \& Arn.) Hieron; nativa }\end{array}$ & Fabaceae & $\begin{array}{l}\text { monte } \\
\text { guanaco }\end{array}$ & $\begin{array}{l}\text { Valle de } \\
\text { Piedra Parada } \\
\text { Chubut } \\
\end{array}$ & combustible & tallo & $\mathrm{s} / \mathrm{e}$ & $\begin{array}{l}\text { Ancibor y Pérez de } \\
\text { Micou 2002/s.XXI }\end{array}$ \\
\hline $\begin{array}{l}\text { Schinus polygamus; } S . \\
\text { polygamus } \quad \text { (Cav.) } \\
\text { Cabrera var. polygamus; } \\
\text { nativa }\end{array}$ & Anacardiaceae & $\begin{array}{l}\text { monte } \\
\text { blanco }\end{array}$ & $\begin{array}{l}\text { Valle de } \\
\text { Piedra Parada } \\
\text { Chubut }\end{array}$ & combustible & Tallo & $\mathrm{s} / \mathrm{e}$ & $\begin{array}{l}\text { Ancibor y Pérez de } \\
\text { Micou 2002/s.XXI }\end{array}$ \\
\hline $\begin{array}{l}\text { Discaria sp.; nativa } \\
*\end{array}$ & Rhamnacae & $\begin{array}{l}\text { monte } \\
\text { laguna }\end{array}$ & $\begin{array}{l}\text { Valle re } \\
\text { Piedra Parada } \\
\text { Chubut } \\
\end{array}$ & combustible & Tallo & $\mathrm{s} / \mathrm{e}$ & $\begin{array}{l}\text { Ancibor y Pérez de } \\
\text { Micou 2002/s.XXI }\end{array}$ \\
\hline $\begin{array}{l}\text { Azorella monantha Clos; } \\
\text { nativa }\end{array}$ & Apiaceae & $\begin{array}{l}\text { leña de } \\
\text { piedra }\end{array}$ & $\begin{array}{l}\text { Valle } \quad \text { de } \\
\text { Piedra Parada } \\
\text { Chubut } \\
\end{array}$ & combustible & totalidad & $\mathrm{s} / \mathrm{e}$ & $\begin{array}{l}\text { Ancibor y Pérez de } \\
\text { Micou 2002/s.XXI }\end{array}$ \\
\hline $\begin{array}{ll}\text { Caesalpinia } & \text { gilliesii } \\
\text { (Wall. ex Hook) D. } \\
\text { Dietr.; nativa }\end{array}$ & Fabaceae & $\begin{array}{l}\text { barba de } \\
\text { chivo }\end{array}$ & $\begin{array}{l}\text { Valle } \quad \text { de } \\
\text { Piedra Parada } \\
\text { Chubut } \\
\end{array}$ & combustible & Tallo & $\mathrm{s} / \mathrm{e}$ & $\begin{array}{l}\text { Ancibor y Pérez de } \\
\text { Micou 2002/s.XXI }\end{array}$ \\
\hline
\end{tabular}

Tabla 4.2. Base de datos construida a partir de fuentes documentales escritas de primer y segundo orden y trabajos etnográficos de Patagonia continental Argentina.

Los taxa con signos de interrogación constituyen interpretación de las autoras. Referencias: [s/e] sin especificar; $*$ también se ha registrado el taxa en el registro arqueobotánico de Patagonia contintental argentina (capítulo 6); $\mathbf{\square}$ indica que el taxa se ha registrado en los estudios etnobotánicos (capítulo 5) 


\section{Las prácticas de recolección a través de la etnobotánica: de}

\section{percepciones y saberes}

\subsection{Introducción}

El análisis de prácticas de recolección desde la Etnobotánica permite observar y abordar su complejidad, así como aprehender todas las esferas de interacción entre hombres y plantas (creencias, conocimientos y práctica). Por otra parte es una vía de aproximación a los momentos previos a la colecta donde intervienen la percepción del ambiente, los criterios de selección, los sistemas de clasificación (Berlin 1992), la adaptación de las plantas a ese ambiente, entre otros factores, de los que no se obtienen vestigios materiales. Es por lo tanto una vía de análisis relevante para repensar e interpretar el registro arqueobotánico teniendo en cuenta todos los recaudos necesarios de no extrapolar directamente la información obtenida (ver discusión al final de esta Parte de la tesis).

A través de entrevistas a pobladores de la localidad de Puerto Deseado y Tellier se abordarán la percepción organoléptica de las plantas, las categorías de uso y la transmisión de conocimientos (Eyssastier 2011), conceptos que fueron definidos en el capítulo 2. A partir de estos datos se reconstruye el conocimiento botánico tradicional de una muestra de la población de estas dos comunidades.

\subsection{Localidades donde se realizaron las entrevistas etnobotánicas dentro del área de costa norte de Santa Cruz}

El estudio etnobotánico aquí presentado se desarrolló en dos localidades próximas entre sí dentro del área de costa norte de Santa Cruz: Puerto Deseado y Tellier. Se realizaron entrevistas a una muestra de la población que estuviera en relación con las actividades rurales y a la que se accedió a través de un referente local (ver más abajo). 
Se seleccionaron la ciudad de Puerto Deseado y la localidad de Tellier (Figura 5.1) para realizar este estudio porque, si bien actualmente las principales actividades económicas de las mismas no están estrictamente relacionadas con la explotación de plantas silvestres, sus orígenes se encuentran asociados a la explotación de la tierra para el ganado y un sector de los pobladores está estrechamente vinculado a las actividades rurales (Dos Santos Lopes 2012). Puerto Deseado, por un lado, se encuentra sobre la margen norte del río Deseado y tiene actualmente una población de 14.183 habitantes (INDEC 2010). Las principales actividades económicas en la localidad de Puerto Deseado son la industria pesquera, la ganadería ovina y recientemente la minería. La localidad de Tellier, por otro lado, se encuentra ubicada a $20 \mathrm{~km}$ de Puerto Deseado y tiene 58 habitantes: 40 hombres (68,9\%) y 18 mujeres (INDEC 2010). Esta localidad surge como una estación del Ferrocarril que unía Puerto Deseado con Las Heras, en el año 1914, Ferrocarril que luego es abandonado. Si bien actualmente su actividad más importante proviene del matadero de ovinos, es reconocida históricamente como el lugar de chacras donde hace unos 40 años atrás se abastecía de verduras y hortalizas a la ciudad de Puerto Deseado.

Es importante mencionar que la población actual de estos dos lugares está conformada por diversas identidades y orígenes. Para comprender la complejidad de esta población es relevante relatar cómo se conformó a lo largo del tiempo. En 1880, a través de un decreto nacional, se creó una colonia pastoril en el territorio santacruceño, de manera que en 1884 arribaron 14 personas a Puerto Deseado (Cuadra 2000). En el censo de 1895 la localidad tenía 44 habitantes. De éstos, 25 (57\%) eran extranjeros, 11 (43\%) de ellos provenían de países no limítrofes (Francia, Inglaterra, Alemania, España, Italia, Austria y Suiza) y 14 (57\%) de países limítrofes (principalmente de Chile y Uruguay) y 19 eran argentinos (solo 3,18\%, de los cuales eran nacidos en Santa Cruz). Cabe destacar que la mayoría de la población estaba constituida, en ese momento, por varones entre los 20 y 39 años (Cuadra 2000). En 1990, la población de Puerto Deseado alcanzaba un total de 7.089 habitantes, entre los que 6.026 (85\%) eran argentinos y $1.063(15 \%)$ eran extranjeros. De estos últimos, predominaban los chilenos, uruguayos y en menor medida los europeos (españoles, italianos y yugoslavos) y asiáticos (Cuadra 2000). En el último censo, del año 2010, como ya dijimos, la población de Puerto Deseado estaba constituída por 14.183 habitantes, de los cuales 7.291 son hombres y 
6.892 son mujeres. Los datos se encuentran en procesamiento por lo que no es posible hasta el momento conocer las diversas nacionalidades de la población deseadense. En el caso de Tellier, en el año 1991 la localidad tenía 40 habitantes, mientras que para el año 2001 había ascendido a 56 personas y en el último censo a 58 (INDEC 1991, 2001 y 2010).

En cuanto a la estimación del porcentaje de población aborigen en momentos históricos tempranos no es exacta y de difícil acceso, y esto se debe a varios motivos. En primer lugar, a finales del siglo XIX se desarrolló la "conquista del desierto", proceso en el que se proponía ganar territorio a los grupos aborígenes a fin de instalar colonias con población inmigrante proveniente de países europeos. Por tal motivo, los registros de población aborigen de ese período histórico se encuentran en documentos militares (jefes de los fortines), cronistas y viajeros (Nacuzzi 1998). Así en el censo de 1895 se omitió censar a los habitantes originarios (INDEC 2010) Los sobrevivientes de este proceso desarrollaron diversas estrategias para integrarse al nuevo Estado Nación, que en algunos casos implicó ocultar su identidad. Con la reforma de la Constitución Nacional del año 1994 se plantea el reconocimiento a las poblaciones indígenas y, a partir de la misma, la necesitad del Estado de contabilizar el número de habitantes de diferentes etnias. En la actualidad hay un proceso de reivindicación de los habitantes originarios y de restitución de su identidad. En el último censo se registró que 955.032 personas se reconocen a sí mismas como originarias o descendientes de pueblos aborígenes en toda Argentina (el 2,4\% de la población total), mientras que en la provincia de Santa Cruz habitan 9.552 (1\%) aborígenes o descendientes de poblaciones aborígenes (INDEC 2010). 


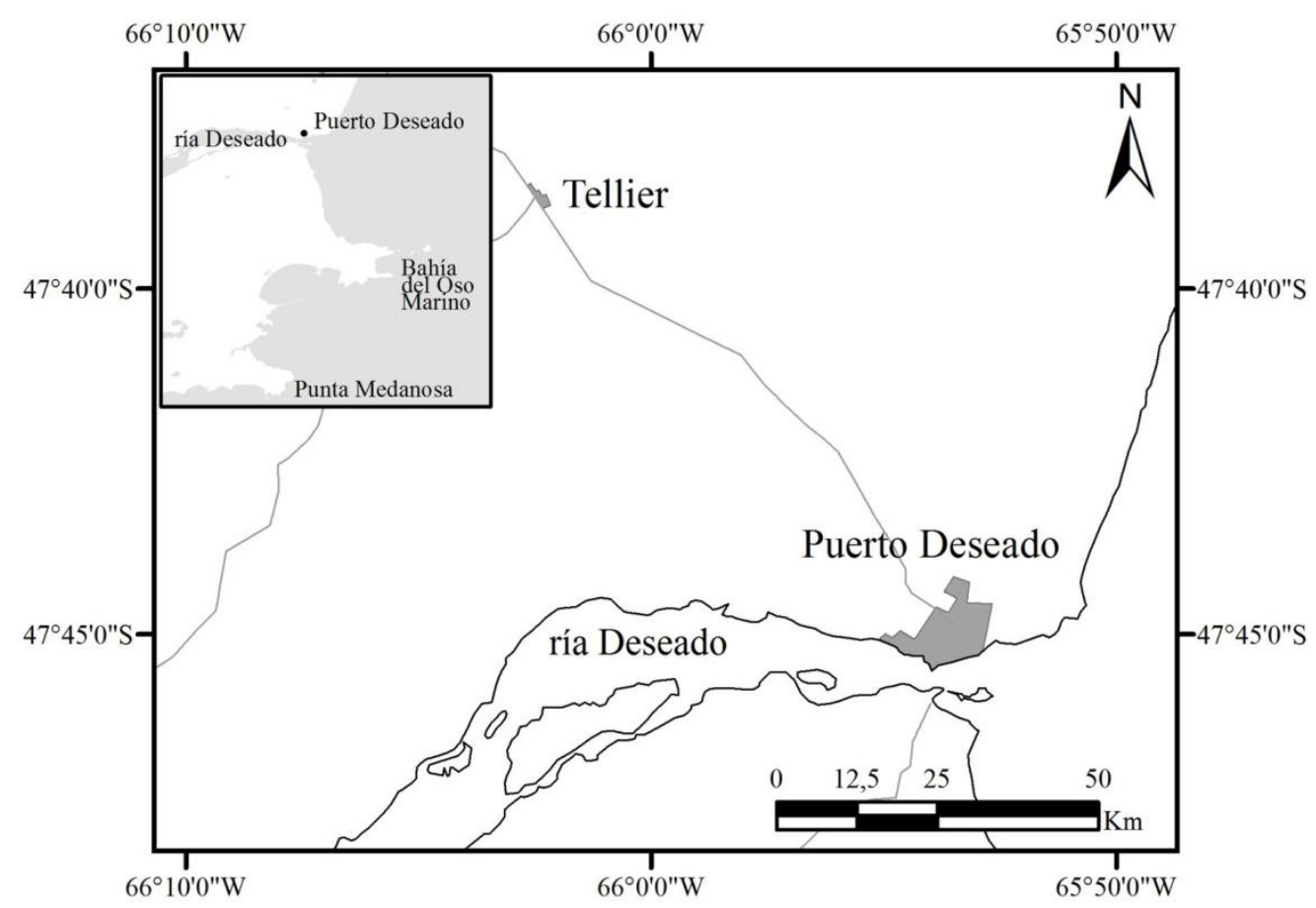

Figura 5.1. Localidades de Puerto Deseado y Tellier

\subsection{Metodología}

En este estudio se desarrolló una metodología cualitativa, de diseño flexible (Valles 1997, Guber 2001) propia de la Etnobotánica de tipo etnográfica. Se aplicaron técnicas de observación y entrevistas, éstas últimas de carácter semiestructurado. Para su elaboración se tuvieron en cuenta las siguientes dimensiones: categorías de usos que las personas hacen de las plantas silvestres nativas, criterios de selección de las plantas silvestres, percepción de la planta, práctica de recolección, procesamientos poscolecta y transmisión del conocimiento sobre las plantas. A partir de éstas se elaboró un guión de 16 preguntas que, según los conocimientos de los informantes se pudieron desarrollar en su totalidad o no. Algunas de ellas se referían, por ejemplo, al uso de recursos leñosos: ¿qué plantas son buenas para hacer fuego? ¿cuáles son buenas para encender el fuego? ¿cuáles lo mantienen y duran más? ¿qué leñan usan seca o verde? ¿dónde encuentran esta leña? ¿dónde van a buscarla? ¿es abundante la leña? ¿o perciben que falta leña?, cuándo tenían que cocinar ¿cuánta leña necesitaban antes de que haya gas? Otras preguntas, por otra parte, hacían foco en las plantas alimenticias y medicinales: ¿qué plantas del campo se pueden comer? ¿en qué momento del año se encuentran? ¿quién le 
enseñó que estas plantas se comían? ¿qué utilizan para remedio? ¿para qué se usan? ¿cómo se procesan? ¿en dónde se encuentran? ¿con quién aprendió esto? ¿cómo reconoce la planta?, ¿cómo sabe que es no es tóxica?

Para la elección de los informantes se estableció contacto con un referente de la historia local (Carlos Santos) quien nos guió hacia dos informantes. A partir de allí se estableció la técnica bola de nieve (Valles 1997). Se realizaron 19 entrevistas a 16 informantes, cuyas edades oscilaron entre los 45 a 90 años. De cada uno de ellos se obtuvo el consentimiento oral previo para realizar las mismas. Cuatro de los informantes son mujeres, una de ellas nacida en Albares, España, que desde adolescente vive en la localidad de Puerto Deseado teniendo hoy unos 80 años, mientras que las demás son nacidas y criadas en Puerto Deseado (dos con ascendencia europea y otra con ascendencia europea y aborigen mapuche). De los hombres en cambio, cuatro provenían del oeste de Santa Cruz, de Chubut y centro de Río Negro y los demás eran nativos de Puerto Deseado. El mayor número de hombres se debe a que en las estancias de Patagonia se contratan hombres "solos" para los trabajos duros del campo, los llamados "puesteros" quienes debido a su aislamiento por las distancias y a veces la falta de vehículos, son los que más regularmente recurren a las plantas locales en busca de medicina así como de leña. Entre los entrevistados varones existen diversas ascendencias. En su gran mayoría, son hijos o nietos de inmigrantes europeos que llegaron a Puerto Deseado a principio de siglo, pero en otros casos, han mencionado tener ascendencia mapuche. En el marco de estas entrevistas también se realizaron caminatas con tres informantes en las cuales se hizo un registro escrito y visual, por medio de fotografías, de los criterios de reconocimiento, selección y colecta de plantas. Estas observaciones se realizaron en las chacras de algunos de los informantes y en espacios abiertos de la margen norte de la Reserva ría Deseado.

Es importante mencionar que el acceso a todos los puestos de estancias fue dificultoso ya que son muy distantes entre sí, e impidió obtener un mayor número de informantes. Por este motivo, además, se realizaron entrevistas en la ciudad (cuando los puesteros "bajaban" de la estancia) y en algunos casos en las chacras de la zona rural. Cuando los entrevistados se encontraban en la ciudad se les llevó plantas para corregir la identificación de especies así como "disparadores" de la memoria. En los casos en que se visitaron las chacras, se confeccionó un herbario a partir de las plantas mencionadas 
y señaladas por los informantes. Se considera que los resultados obtenidos son aún preliminares pero es valiosa la información obtenida a través de la metodología cualitativa.

Para el análisis de los datos cualitativos, se tiene como marco de referencia, al igual que en el capítulo 2, a la Etnoecología (Toledo 1992), donde la naturaleza es vista por los grupos humanos a través de un tamiz de creencias, conocimientos que se cristalizan en las prácticas. Si bien esta separación entre cosmos y praxis es interpretada por el investigador a fin de interpelar el problema de estudio, este proceso ocurre como una totalidad y es analizado a través de esferas o dimensiones sólo a fin dilucidar procesos de interacción. En este sentido también se tiene en cuenta el concepto de "interacción comprometida" de Ingold (1993), en el que, como se mencionó en el capítulo 2, aprender a morar un territorio implica tener una participación activa, práctica $\mathrm{y}$ perceptiva para adquirir las habilidades necesarias para la percepción directa y comprometida de todos los constituyentes del espacio: humanos, animales, componentes animados y no animados (traducción de Gómez 2008). Dentro de esta concepción, el ser está inmerso en un entorno ambiental a través de la experiencia y la atención en el mismo.

El registro se realizó con grabador digital, cámara fotográfica y libreta de campo, en los casos que el entrevistado prefirió que no se utilizara el grabador sólo se registró la información por escrito. Los datos se procesaron en el programa Microsoft Excel. Se consideró como de origen exótico a los taxa que provienen del Viejo Mundo y como de origen nativo a todos taxa que crecen en Argentina, no obstante, aquellos que no crecen en Patagonia fueron catalogados como "nativo no local". Se calculó el índice de consenso para cada taxón (número de entrevistados que remiten a la misma aplicación de la planta) según Ladio et al. (2007).

\subsection{Resultados y discusión}

A partir de las entrevistas realizadas se obtuvo una lista de 59 taxa (género y especie) de plantas utilizadas, que pertenecen a 29 familias, otros cuatro casos no pudieron ser identificados, por lo que se cuenta, hasta el momento, sólo con el nombre vulgar (Figura 5.2). El 50,8\% de los taxa registrados son nativos locales, es decir disponibles en la 
zona actualmente, el 15,2\% son nativos no locales (i.e. Prosopis sp. "algarrobo" de la provincia fitogeográfica Chaqueña [sensu Cabrera 1971], que se adquiere a través de su compra), por último, el $33,9 \%$ de los taxa son exóticos y un caso que al no saber la especie no es posible determinar si era exótica o nativa 1,7\%. Las familias con mayor cantidad de géneros y especies mencionadas son Asteraceae, Lamiaceae, Fabaceae y Apiaceae.

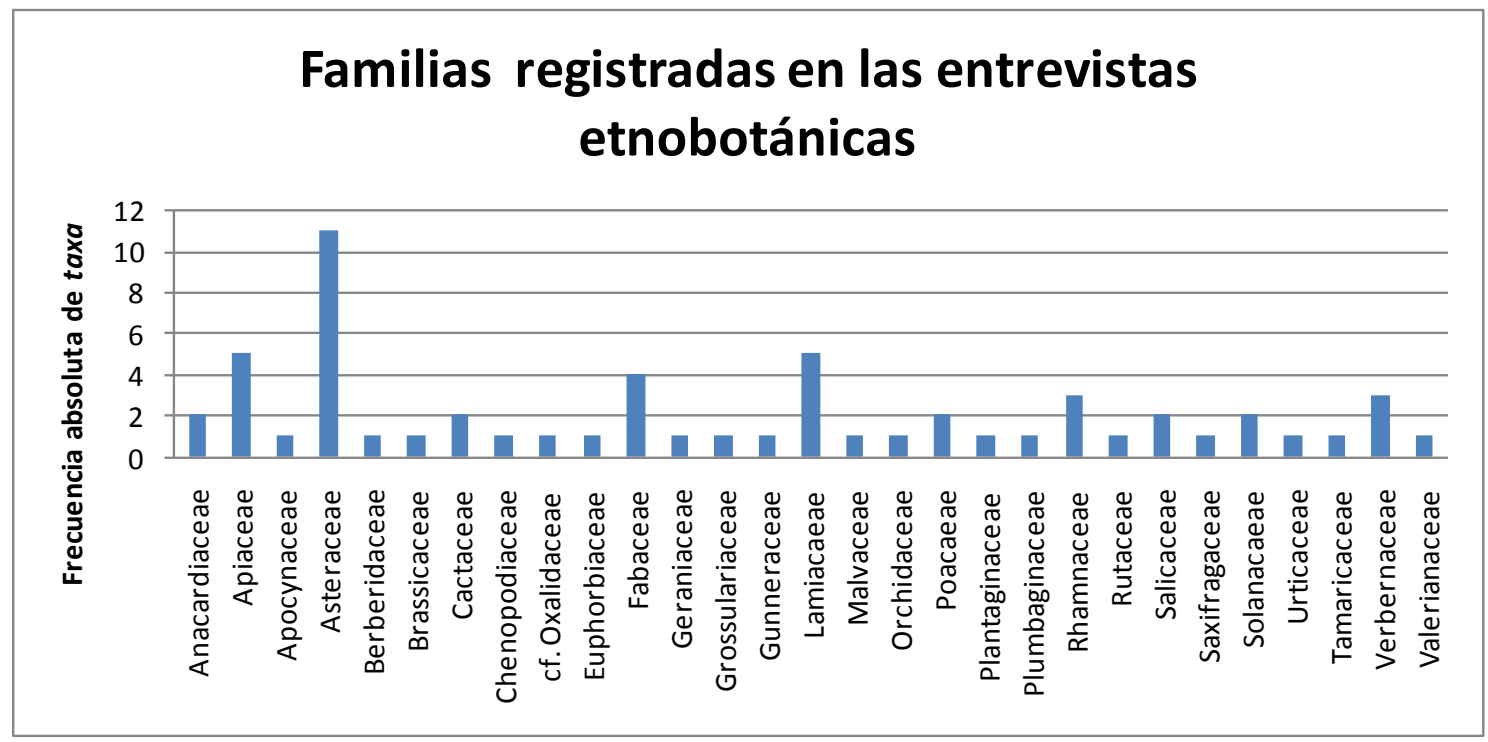

Figura 5.2. Gráfico en el que se registran la frecuencia abosluta de taxa por familia mencionados por los pobladores locales entrevistados.

En relación a las categorías de uso el 8,6\% $(\mathrm{n}=5)$ de los taxa son utilizados sólo como alimento, el $27,6 \%(\mathrm{n}=16)$ sólo como combustible y el 48,3\% $(\mathrm{n}=28)$ sólo como medicinales, $(n=1)$ ornamental, teniendo el resto $(n=9) 15,5 \%$ más de un uso (comestible, combustible, medicinal, tintórea y para cercos vivos) (Figura 5.3). De las especies que sólo se obtuvo el nombre vulgar: dos son comestibles y dos medicinales. En líneas generales los taxa más nombrados en estas categorías son Berberis sp. (comestible o tintóreo), Schinus sp. (combustible) y Dysphania sp. "paico" (medicinal). El promedio de taxa mencionados por informante es de 14, con un rango de 3 a 27. 


\section{Categorías de uso}

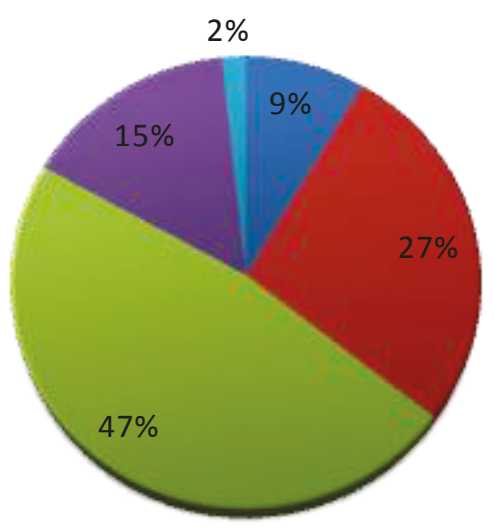

Alimenticias

- Combustible

$\square$ Medicinales

Multiuso

$\square$ Ornamental

Figura 5.3. Gráfico donde se registra el porcentaje de taxa mencionados por categorías de uso

\subsubsection{Recursos comestibles}

Se registraron once géneros y especies de plantas silvestres utilizadas como alimento y una de las que sólo se obtuvo el nombre vulgar (Tabla 5.1). En su mayoría se recolectan en primavera-verano y, dependiendo de la planta, se observó que se consume la flor, el fruto y los órganos subterráneos, siendo una sola la especie que se consume la hoja como especia. Diez de estas plantas se consumen directamente en fresco, una luego de ser tostada y otra se consume tanto en fresco como a través de la cocción (dulce) o preparación en licor (i.e. Berberis sp.). Seis de las especies son nativas locales (50\%), cinco exóticas $(41,6 \%)$ y una no ha podido ser identificada aún (8,3\%) (Tabla 5.1).

Las especies que han tenido mayor índice de consenso (Eyssastier 2011) fueron Berberis sp. (37,5\%), las papitas patagónicas (31,2\%), entre ellas puede ser identificada cf. Oxalis sp, y "la flor de vino" (25\%). Las prácticas de recolección asociadas a éstos últimos taxa responden a distintas motivaciones, por un lado, la saciedad del hambre y la sed mientras se realizan actividades del campo (es el caso de la flor de vino), y por otro lado, la elaboración de dulces y licores (es el caso de los frutos de Berberis sp.). En el discurso de algunos informantes también la recolección de plantas se encuentra relacionada con la reproducción de prácticas tradicionales de sus lugares de origen $\rightarrow m i$ mamá aprendió de mi abuela que era Española y era también del estilo de ella (se refiere a Josefa la entrevistada Española que reside en Puerto Deseado desde hace 62 
años) que todo sembraba, todo usaba y todo se aprovechaba, prácticamente nada se compraba porque antes era todo distinto" (Laura). La recolección también se realizaba durante momentos recreativos y de aprendizaje "Era salir los sábados a tomar la leche a la rural que quedaba lejísimo de la casa, porque no había nada, así que era juntar flores: los pastores, los jazmines, los zapatitos, a comer las flores de vino a hacer con el calafate dulce. Era aprovechar todas las plantas del campo. Traíamos el té de paico para tomar, té pampa para tomar, te dolía el estómago, te caía mal una comida te decían té de paico. O un té pampa si estabas resfriado y era todo del campo lo que se traía. Comer las manzanitas, había unas plantas que dan como unas manzanitas muy chiquititas y mamá nos enseñaba a comer eso. Ir al campo era volver con las botellas de calafate llenas y haber comido las manzanitas, las flores de vino todo por las vías del tren" (Laura).

En cuanto al procesamiento poscosecha de las plantas alimenticias se registró limpieza y/o pelado en dos casos (macachín y Azorella monantha), cortado (tuna), tostado (Malva sp.) y, en el caso de Berberis sp., la elaboración de dulces y licores. Un solo informante (Laura) mencionó la molienda como técnica de procesamiento para uso cosmético de los frutos de una Cactaceae que luego de su trituración eran hervidos (cf. Opuntia/cf. Maihuenopsis) y fue sólo una, la mención que refiere que las vainas de Prosopis denudans son comestibles utilizadas para la elaboración de harina (Capparelli y Prates 2010, Capparelli y Lema 2011).

\subsubsection{Recursos leñosos}

Entre los recursos leñosos se registraron 16 plantas locales, $(72,7 \%$, de las especies mencionadas), 4 nativas no locales $(18,2 \%)$ y dos especies exóticas $(9,1 \%)$ (Tabla 5.2). Para presentar los resultados de las especies clasificadas como combustibles se toman dos criterios: uno, a través del índice de consenso; y otro, en relación a la calificación del combustible en función del fuego que se quiera obtener.

El género que tuvo mayor consenso de uso y que fue clasificado como muy buena leña fue Schinus sp. "molle" $(81,2 \%)$ porque da buena brasa, dura mucho y brinda más calor. La segunda especie siguiendo el índice de consenso es Mulguraea tridens (ex Junellia tridens, conocida como mata negra) (75\%) sin embargo, fue considerada como una 
buena leña sólo para encender y dar calor. Para otro poblador no obstante, se hace ceniza y se consume enseguida por lo que, se utiliza solo cuando no hay otras leñas disponibles.

Con un alto índice de consenso y clasificadas como buenas leñas se registraron Prosopis denudans, algarrobilllo, (62,5\%) que también deja brasa, dura y da calor y Beberis sp., calafate $(50 \%)$, aunque un entrevistado manifestó que se utiliza, pero que no desprende tanto calor como Schinus y Prosopis.

Respecto a Lycium ameghinoi, mata laguna (50\%), se registraron distintas opiniones a partir de las cuales se evidenciaron las siguientes características: que produce más llama que el molle, que se enciende rápidamente, que se obtiene fácilmente pero que no deja brasa.

Otra especie que se registró como una buena leña fue la Discaria sp. Hook., (chacay) pero con un bajo índice de consenso $(6,2 \%)$.

Uno de los entrevistados, manifestó que Anarthrophyllum rigidum Benth., mata guanaco $(12,5 \%)$ se enciende con facilidad pero se hace ceniza rápidamente sin dejar brasa. En el caso de leña Azorella monantha (leño de piedra) (37,5\%) se observó un alto índice de consenso pero los pobladores expresaron que usan esta leña si no hay otra de mejor calidad disponible y que entre sus propiedades se observa que mantiene la brasa, pero produce mucho humo. Esta última característica se registró también para Chuquiraga avellanedae, quilimbay (6,2\%). En un caso un iformante mencionó que el humo se utilizaba para señales en la fiesta de doma del "Makamenke".

Para encender, además de la mata negra se mencionaron Mulinum spinosum, neneo, $(12,5 \%)$ que se quema rápidamente y también produce mucho humo; Nardophyllum bryoides, mata torcida (6,2\%) y Chuquiraga erinaceae, uña de gato, $(6,2 \%)$ que arde fácilmente. Estas especies sin embargo, son consideradas leñas regulares o malas porque de usarse solas constantemente habría que estar reponiendo para mantener el fuego. Asimismo, aunque no se trate de una especie arbustiva se utiliza también Pappostipa sp., coirón, (18,7\%) para encender el fuego, y se mencionó el uso de bosta de animales para iniciar la combustión.

Otras especies que fueron registradas son: la malaespina (12,5\%) [dos leños se adscriben a este nombre vulgar Retanilla patagonica (Speg.) Tortosa, en este caso no se pudo contrastar el discurso con la práctica] y el duraznillo, Colliguaja integerrima 
$(6,2 \%)$. Por otra parte, también hicieron referencia a que en ocasiones utilizan leñas compradas provenientes del norte, como las nativas Condalia microphylla Cav. (piquillín) (12,5\%), Schinopsis sp. Engl., quebracho, (6,2\%), y Prosopis sp. L., algarrobo, (12,5\%) o leñas de especies introducidas, que en primer lugar se usan en la región como cortinas de viento pero que pueden luego utilizarse como combustibles, tales como Tamarix ramosissima Ledeb., tamarisco (25\%), Salix sp. L., sauce, (12,5\%) y Populus sp. L., álamo, (12,5\%) (Tabla 5.2). En los últimos años los recursos combustibles vegetales se han ido reemplazando paulatinamente por la utilización de querosén y de gas envasado y en red.

En cuanto a la recolección de las leñosas, la mayoría de los entrevistados coincide en que, si bien se puede realizar en cualquier momento del año, es principalmente durante el verano cuando se recolecta entre dos y tres camiones llenos de troncos y ramas secas para abastecer el invierno. Es importante destacar el consenso de los informantes en que la leña siempre debía estar seca ya que de esta manera se evita, no solo el exceso de humo (en el caso de que no estuvieran buscando humo adrede) sino también, un manejo perjudicial para la supervivencia de los arbustos de la zona. En este sentido, Laura expresó: “lo que pasa que nosotros somos muy cuidadosos de las plantas del campo, un molle verde no se saca, eso de sacar el molle verde para dejarlo que se seque para el año siguiente no se pasa por la cabeza”

La recolección de leña consiste en la búsqueda de ramas y troncos secos, y en algunos casos, si no hay leña de buena calidad, se extrae de la leña disponible la base de los troncos por ser más gruesos, o la mata entera excepcionalmente (i.e. Mulguraea tridens, Azorella monantha respectivamente). En cuanto a las distancias de recolección de los arbustos no se pudo cuantificar pero sí se registró que la mayoría de los entrevistados describió el uso del camión para la recolección de leña "últimamente íbamos con el camión a buscar leña, en otros campos... y después se usaba lo de la casa, tamarisco, sauce, álamo" (Walter) También un informante ampliaba esta información "y para encontrar leña en la chacra hay que recorrer (...) después con el camión íbamos a buscar leña al campo ipero lejos!’ (Juan). Ambos informantes vivían en una chacra en la localidad de Tellier.

En cuanto a la percepción de los pobladores locales sobre la abundancia o escasez de leña se registraron discursos contrapuestos. Por un lado, que existe buena 
disponibilidad: hasta el día de hoy hay muchísima leña gracias a Dios, en la estancia no ha faltado" (Laura) y por otro lado, que hay escasez: "hay poca leña ahora en los campos, se consume leña y no crece, van cortando y el molle y el algarrobo tardan mucho para crecer" (Juan) Respecto al cuidado de los arbustos, al menos en lo que respecta al discurso, aparecen las expresiones de cuidado de las especies a través de prácticas de recolección de madera muerta, y de protección de algunas especies en particular (i.e. Schinus sp. y Berberis sp.). Beatriz S.J. expresó sobre Berberis sp. para usarla como leña sacaba los palitos secos, pero no ibas a cortar una mata de calafate para usar, sacabas las varillitas que estaban quebradas, yo pienso que se cuidaban por la frutita"; y sobre esta especie y Schinus sp. Laura mencionó -no se sacaban las matas de calafate, no se sacan para que se mantenga, y el molle la mata verde no se saca, sino está seco no se saca”.

En cuanto a la cantidad de leña necesaria para cocinar y mantener el calor de una casa en el campo los informantes (Josefa y Laura) consideraron, a partir de su experiencia y sin discriminar la estación del año, unos $25 \mathrm{~kg} /$ día aproximadamente de buena leña y que con $4 \mathrm{~kg}$ se podía hacer una comida en la cocina económica al mismo tiempo que brinda calor al ambiente. Mientras que la mayor parte de los entrevistados hicieron mención que para abastecer todo un invierno hacía falta entre 2 y 3 camiones de leña?

\footnotetext{
${ }^{9}$ Podemos destacar que esta unidad de volumen fue empleada por la mayor parte de los entrevistados, por lo que constituiría una unidad de medida emic. Hasta el momento no se ha podido establecer el volumen en $\mathrm{m}^{3}$ aproximado.
} 


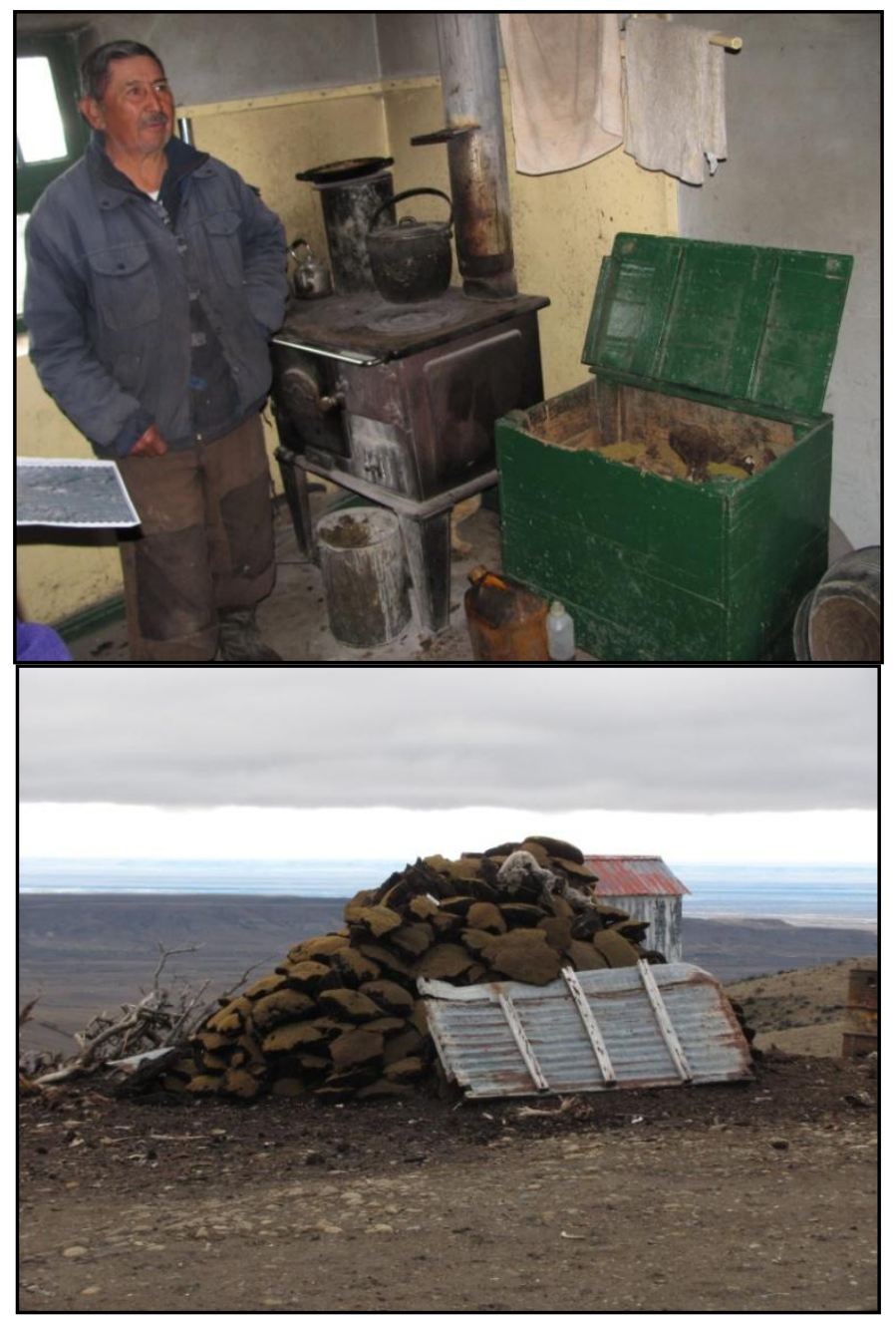

Figura 5.4. Don Miranda habitante de La Rosita, meseta central de Santa Cruz, mostrando el almacenamiento de leña mogotes (Azorella monantha Clos.) y su uso como combustible en la meseta de Santa Cruz (Foto y registro de Mikel Zubimendi).

\subsubsection{Recursos medicinales}

En la categoría de uso medicinal se registró un total de 35 taxa que poseen alguna aplicación de este tipo (Tabla 5.3). Más de la mitad de éstos $(\mathrm{n}=18)$ son empleados para una acción terapéutica específica (categorías éticas de uso). Entre ellos, Adesmia boronioides Hook. F. (paramela), aplicada como antigripal, fue la que tuvo un mayor índice de consenso (56,2\%), a la cual le sigue Matricaria chamomilla (37,5\%), digestiva. Otros 16 taxa se utilizan para más de una acción terapéutica. Entre éstos los de mayor índice de consenso son Dysphania ambrosioides. ("paico") (87,5\%), que se emplea como digestivo, analgésico y laxante; Clinopodium darwinii (Benth.) Kuntze (té 
pampa) (75\%), antipirético y digestivo; Valeriana carnosa S.M. (ñamculawén) (62,5\%), analgésica, antipirética y digestiva; Erodium cicutarium (alfilerillo) (56,2\%), desinfectante, diurético y anticoagulante; y Acantholippia seriphioides (50\%), antigripal y para la sangre (ver Tabla 3). Con menores valores de consenso le siguen a éstas últimas Mentha sp. (37,5\%), Plantago cf. patagonica (25\%) y Schinus sp. (18,7\%), siendo el resto mencionadas solo por uno o dos entrevistados. Es interesante destacar, por un lado, que pese a existir un gran porcentaje de especies exóticas entre las medicinales utilizadas (40\%), aún predominan las nativas de Patagonia (49\%), y, por otro, que el uso de las nativas no locales (11\%) nos demuestra la existencia de circuitos actuales de circulación interna de plantas, que incluyen tanto vías de comercialización como de intercambio.

El momento de la recolección según la mayoría de los informantes es durante todo el año, cada vez que se necesita, sin embargo para Clinopodium darwinii uno de los entrevistados mencionó que se recolecta de primavera a mediados de marzo. Respecto a si tenían alguna de estas plantas en la casa como cultivo a excepción de las introducidas o de algunas nativas no locales (cedrón, bálsamo, anís, menta, malva) los pobladores consultados manifestaron que no era necesario porque estaban en el campo, siendo que se las recolectaba según se necesitaran. En el caso de las especies nativas no locales o introducidas se encontraban en los jardines y huertas (i.e. anís, bálsmao, menta entre otras).

En relación al reconocimiento de las especies, tanto en las salidas con Enrique, Laura y Pocho, como a través del discurso, se registraron percepciones organolépticas (i.e. aroma, sabor, color y textura) que guiaban la identificación de las plantas, tal como registran Molares (2010) y Molares y Ladio (2014) al oeste de Patagonia. En CNSC se registró que para describir el aroma las variantes fueron: "lindo", “dulzón”, "feo" y "a anís" (i.e. Marrubium vulgare L., Acantholippia seriphioides, Senecio filaginoides, Clinopodium darwinii respectivamente); en el caso del sabor: "amargo", "feo", "rico", y "a menta" (i.e. Senecio filaginoides, Adesmia boronioides, Dysphania ambrosioides, y Clinopodium darwinii respectivamente), en el caso del color: el color azulado del tinte del agua después de hervir (i.e. Valeriana carnosa); y en el caso de la textura: "pegajosa", "espinosa" (i.e. Adesmia boronioides, Opuntia/Maihueniopsis sp. Speg. respectivamente) (Tabla 5.3). Como se registra en la Figura 5.5 los informantes se 
llevaban la planta a la nariz, para percibir el aroma y luego indicaban si era la planta buscada. Este gesto puede interpretarse como una práctica corporificada, tal como menciona Gómez (2008) en su trabajo sobre la recolección en el monte de las mujeres tobas, al describir posturas o lenguajes corporales que producen sentido y comunican información antes que el discurso mismo.

En cuanto a los órganos de las plantas utilizadas, principalmente se colectan las hojas (i.e. Schinus sp.), y en menor medida las raíces o rizomas (i.e. Valeriana carnosa, Berberis sp.), el tallo o las flores (i.e. Senecio filaginoides, Matricaria chamomilla (L.) Rydb respectivamente), el fruto (i.e. Opuntia/Maihueniopsis sp. Speg.) o toda la planta (i.e. Erodium cicutarium [L.] K'Herit). Para una especie se mencionó la extracción del látex del tallo para uso analgésico (Colliguaja integerrima) y de la hoja (Chuquiraga avellanedae). Respecto al procesamiento postcolecta, se describió el emplasto (Chuquiraga avellanedae, Saxifraga geranioides L., Urtica L.) la molienda y hervido de los frutos (cf. Opuntia/Maihueniopsis) el resto de los taxa se someten a hervor bebiéndose como decocción. En el caso de Erodium cicutarium se utiliza en emplasto y también se puede consumir en una infusión. En relación a otras percepciones organolépticas Fortunato L. explicó: “El 7 coyunturas (Plantago cf. patagonica) también se usa, bien verde. Se hierve el agua, se vuelve azul que es bueno para los riñones. Se hace hervir, el agua azul se toma a la madrugada antes que nada".

También se observó en el discurso de uno de los entrevistados la noción de dosis según la planta y el efecto que se quisiera obtener: El tomillo [Acantholippia seriphioides] lo que tiene es que debilita mucho si lo toma muy seguido. Debilita la sangre, es para tomarlo una semana, cortar y así ¿viste? Y bueno después la dejas, tomas de vez en cuando, poco pero no mucho tampoco. Y bueno el ñamcolawén [Valeriana carnosa] es lo mismo porque fortalece la sangre pero al tomarlo mucho también lo debilita" (Fortunato L.)

En cuanto a los taxa mencionadas por los entrevistados, la mayoría corresponden a especies silvestres nativas y exóticas, de las cuales las primeras crecen en el campo $(65,7 \%)$ y las segundas son cultivadas en el jardín $(31,4 \%)$, y un porcentaje menor $(2,8 \%)$ son domesticadas, entre las que se encuentran aquellas cultivadas en los huertos (i.e. Zea mays, la chala de la infrutescencia), y en el jardín (i.e. Pimpinella anisum L.). 


\subsubsection{Otros usos}

Se identificaron en las entrevistas el uso de plantas tintóreas (i.e. Berberis sp.), del uso de arbustos para la construcción de cercos (Chuquiraga avellanedae) y ornamentales (i.e. Chloraea sp.) (Tabla 5.4).

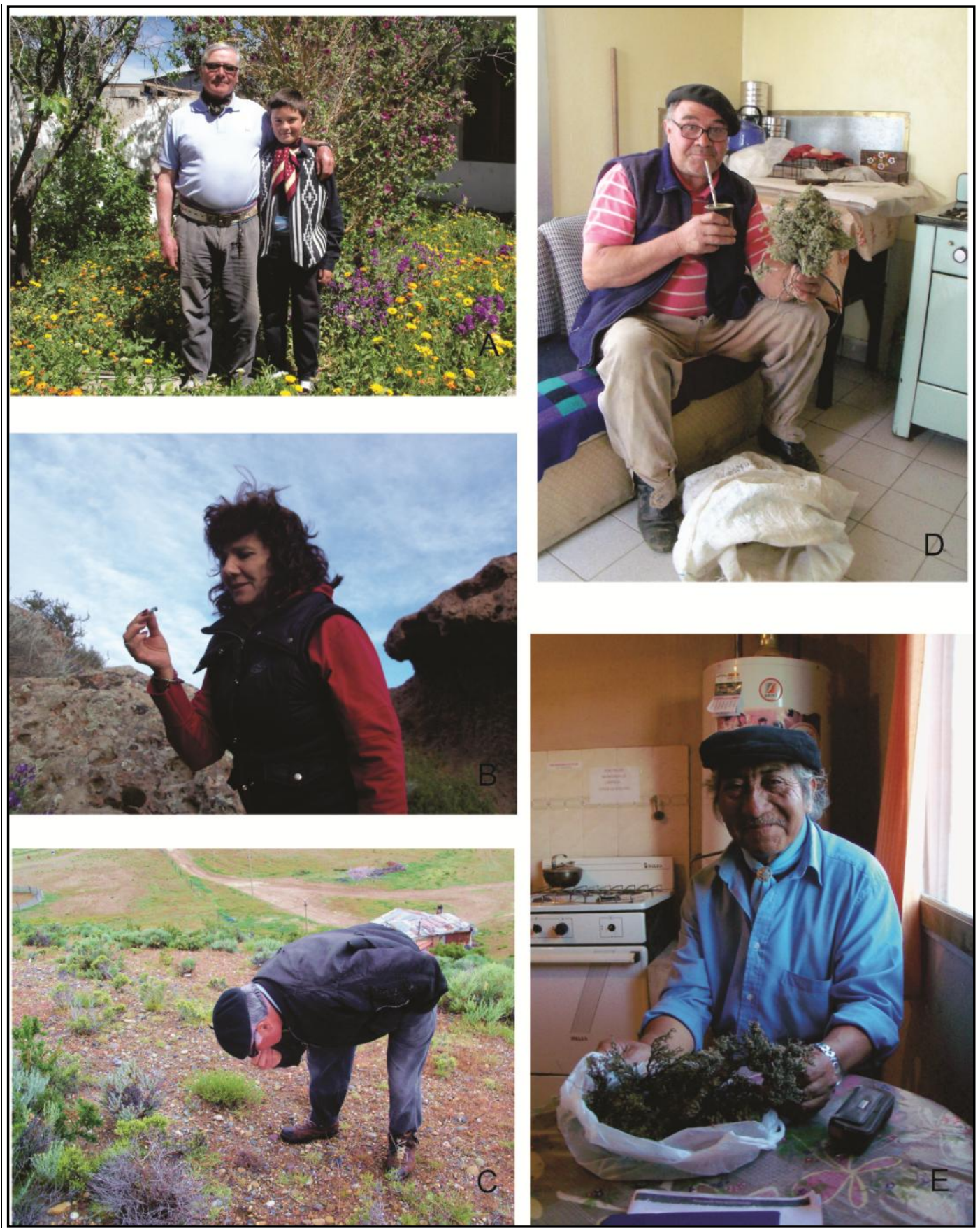

Figura 5.5. Entrevistados identificando y percibiendo las plantas de la zona. A. Pocho G. y su nieto (Puerto Deseado), B., Laura (Puerto Deseado) C. Pocho percibiendo Acantholippia seriphioides, D, José 
B. con una mata de Clinopodium darwinii (Tellier), E. Fortunato L. con Acantholippia seriphioides y Clinopodium darwnii que traía de su chacra de Tellier.

\subsubsection{Conocimiento botánico tradicional}

El conocimiento sobre las plantas locales e introducidas en la zona así como las prácticas de recolección se registraron tanto en informantes mujeres como en hombres. En cuanto a la esfera práctica del conocimiento botánico tradicional, a través de la observación participante se pudo registrar la recolección de especies comestibles, leñosas, medicinales y ornamentales (i.e. Chloraea sp.), y el almacenamiento de recursos leñosos y algunas especies medicinales (Acantholippia seriphioides). Las prácticas de combustión, curaciones y/o consumo de especies medicinales y comestibles se registraron a través del discurso.

También se registraron casos de transmisión vertical y horizontal del conocimiento, tanto a través del discurso como de la observación de la práctica. Dentro del primer tipo observamos, por ejemplo, en el caso de uno de los informantes (60 años) que se encontraba con su nieto (9 años) en el momento de la entrevista, que a medida que el abuelo contestaba sobre las plantas el niño apoyaba con datos la información del abuelo. El nieto afirmó que eran sus padres y su abuelo quienes le habían enseñado sobre las plantas y sus usos. En cuanto a la forma en que el abuelo transmitía esa información describió que le mostraba la planta, le decía su nombre y usos y que, de tanto andar en el campo con una o dos veces que la veía la reconocía. En relación a esta última noción del discurso "de tanto andar en el campo" se observa el aprendizaje a través de la experiencia, la percepción y exploración del entorno como menciona Ingold (1993). Por otro lado, otra informante (50 años) recordó: "nosotros íbamos al campo algo que yo siempre les cuento a las chicas (a sus hijas) que después nos reímos, nos íbamos con la canasta con el chocolate, los scones, a tomar la leche al campo, ibamos de picnic entonces después había que salir porque mamá era como que nos daba una clase: bueno hoy hay que juntar pastores, no se equivoquen eh, entonces te enseñaba cuál era el pastor, el pastor tiene un bulbito abajo, hojitas finitas y la flor como una estrellita. Mañana juntamos jazmines, el jazmín también tiene como un bulbito pero tiene la hoja más ancha y es una varita como con tres o cuatro flores y nos iba enseñando así, nos enseñaba a conocer cada planta" (Laura). En relación con la única informante 
extranjera (española) asentada hace unos 62 años en la zona expresó: “aprendimos de que los padres dijeran esta es la planta, en España ya naces con los nombres de las plantas" (Josefa). Dentro de lo que se incluye como transmisión horizontal del conocimiento también observamos varios casos. Por ejemplo, la entrevistada antes mencionada (Josefa) dijo que al llegar a Puerto Deseado fue su esposo, también español pero que trabajaba en el campo con otros puesteros nativos, quién le transmitió el conocimiento sobre el uso de determinadas plantas. Asimismo, otros dos hermanos descendientes de padres alemanes manifestaron $\rightarrow$ siempre habia de la gente antigua sobre todo los nativos de acá que te enseñaba, porque esa gente se curaba con los remedios del campo nomás" (Walter y Juan P.).

A través del discurso se pudo reconocer casos de pensamiento crítico sobre lo que se aprende. Por ejemplo, en relación a la hoja de Schinus sp. Walter afirma: "los viejos decían que era venenoso, pero resulta que una vuelta fuimos a buscar leña y un hombre estaba resfriado e hirvió agua y puso hoja de molle y se tomó el agua, así que se ve que veneno no era ¿pero veneno sabes por qué no puede ser? Porque los animales lo comen". Es importante destacar que los informantes si tenían dudas respecto del reconocimiento de una planta o de su potencial toxicidad manifestaron observar detenidamente el comportamiento de los animales frente al consumo de la misma. En otros casos, el nombre común de las plantas describe alguna característica de la misma que se asemeja a particularidades de los animales de la zona. Por ejemplo, Fortunato dice: está el palo piche que le dicen que acá no hay. Ese es medicina, mucha gente lo pide, allá tenía un muchacho conocido que le había pedido si me podía conseguir pero no, me habían dado palitos pero no era palo piche. El palo piche es conocido porque la cascarita, porque tiene una cascarita que es bien como la cascarita del piche por eso le dicen palo piche".

En cuanto a la esfera de las creencias no se registraron en el discurso plantas asociadas a festividades o rituales. Sin embargo, en las categorías de uso de plantas medicinales subyace la concepción de que las plantas son parte de la naturaleza y, por lo tanto, consumirlas es más sano que tomar otro remedio de laboratorio: -Uh sí es la gente del campo, la gente de antes que sabía un montón y si hay mucha gente del norte que sabe. Ellos se curan con eso, por eso viven tantos años. Era todo natural” (Fortunato). Así mismo este informante menciona las prácticas de curación de su mamá de la siguiente 
manera Ahora por qué no sé, si ya tendrían ese don no sé, pero se fueron con muchos secretos, como para curar verrugas, para curar el empacho, todo eso lo curaban ellos con secretos pero cómo lo hacían no sé. Ellos capaz que curaban con palabras y al otro día andabas re bien" (Fortunato). Sin embargo, a excepción de este entrevistado (de ascendencia mapuche) es menos evidente en el discurso la dimensión simbólica.

Tanto hombres como mujeres mencionaron y se observó que recolectaban plantas silvestres. Sin embargo, debido al mayor acceso a trabajadores rurales esta práctica se asoció más a los hombres quienes en los recorridos por las estancias recurrían las plantas silvestres, entre otras cosas para saciar la sed, o para obtener aplicaciones medicinales. Estas prácticas también ha sido observada por Cardoso (2013) para la comunidad de Pilcaniyeu del Limay, donde en el recorrido de pastoreo con el ganado pueden desarrollarse distintas actividades como recolectar plantas comestibles, buscar leña, entre otras.

En relación a las categorías de uso las plantas comestibles fueron las que menor frecuencia de uso tuvo y las que presentaron un índice de consenso más bajo (Tabla 5.1). Si a esto se suma el impacto de las prácticas actuales de alimentación basada en productos manufacturados, compra de verduras y hortalizas de las provincias del norte, este contexto podría explicar las escasas menciones para esta categoría.

Dentro de las plantas alimenticias se mencionó el consumo de órganos subterráneos, éstos fueron registrados a través de su nombre vulgar y, debido a que aún estaban en la estación de reposo al momento de las entrevistas, no se pudo colectar la parte aérea, por lo cual carecemos de su identificación específica hasta el momento. Por otro lado, Tristagma patagónica (Baker) Traub. fue identificada por un informante en una recorrida, sin embargo si bien esta planta tiene registro de consumo de la parte subterránea para otras áreas de Patagonia (Ladio 2004:31), el informante no utilizaba la planta para comer sino que utilizaba la flor como ornamental. Tampoco se mencionó el consumo de los frutos de Schinus sp., que otros autores lo registran para las comunidades mapuches de Neuquén (Ladio 2001:246).

En relación a las plantas leñosas, es llamativo que, los pobladores mencionaran el uso de la parte aérea de la planta, y no de la base o la raíz del tronco para proteger las especies y no quedarse sin el arbusto. Esta situación no parece ser la misma que la sí registrada para algunas de las especies mencionadas en el acápite 5.3.2. en otras áreas 
de Patagonia (Valle de Piedra Parada) donde el uso de las partes subterráneas es una práctica frecuente (Ancibor y Pérez de Micou 2002:17). De la misma manera es importante destacar el cuidado expresado por los informantes sobre las matas de calafate Berberis sp. debido a que sus frutos son comestibles. Este cuidado sobre determinadas especies también fue registrado en Chubut por Marconetto (2002) y para frutales en general (Dufraisse 2012) lo que sugiere el desarrollo de prácticas de tolerancia y protección en términos de Casas (2001). Se deberán realizar en el futuro más trabajos de observación participante y aumentar el número de informantes para corroborar con la práctica este tipo de relación entre los pobladores y las plantas.

Los principales criterios locales de selección de leña fueron: facilidad para hacer brasa, duración de la brasa, poder calórico, facilidad para el encendido, producción de humo y disponibilidad de la especie. Picornell (2009) en un trabajo con los pueblos Fang de África observa que los diámetros de las leñas en función de la actividad para la que se necesitara el fuego era un criterio de clasificación y selección cuya jerarquía era mayor que el de diferenciación de etnoespecies. Esto no se observó en este estudio, donde los pobladores diferencian cada especie lineana por sus características propias que por lo general se reflejan en el nombre vulgar de cada una (i.e. mata negra, leño de piedra, mata guanaco, entre otros). Sin embargo, sí es notable que las leñas más calificadas según los informantes para hacer calor son las que mayor grosor tienen (i. e. Schinus sp., Berberis sp., Prosopis denudans), y que las calificadas como "buenas" para iniciar el fuego son las de diámetros chicos, siendo el resto homogéneas en su medida y, de diámetros chicos. Entre estas últimas, hay algunas especies que son consideradas como "buenas" para iniciar el fuego, por lo que, según la disponibilidad de leña, se están conjugando los dos criterios: especie y diámetro.

En la categoría de uso medicinal, el conocimiento es dispar entre los informantes, uno de ellos (Fortunato), a quien se le realizó más de una entrevista debido a sus conocimientos, es quien estableció con mayor precisión las dosis y una mayor diversidad de especies utilizadas. Por otro lado, si bien en esta tesis no se desarrollaron estudios específicos de verificación de principios activos de todas las especies relevadas, se discuten, aquellos trabajos realizados por otros investigadores sobre aceites esenciales, pigmentos y estructuras morfológicas que confirmen la presencia de los mismos, así como su implicancia en las características organolépticas de las plantas 
en el caso que existan para las especies aquí tratadas (i.e. Molares 2010, González et al. 2011, Guerra et al. 2012, entre otros). Estos estudios, así como el de Almeida et al. (2005), evidencian el valor de las plantas leñosas de zonas áridas como recursos medicinales debido a su alto contenido en principios activos producto de su adaptación al estrés hídrico, a la alta radiación solar y a condiciones térmicas extremas (Tabla 5.3). Esto también se observa en la valoración de estas especies en su uso como combustible debido a que son plantas resinosas valoradas positivamente por los informantes como buenas para encender o mantener el fuego.

Por otro lado, es interesante el trabajo de Picornell (2009) quien alerta sobre la importancia de no pensar en las plantas medicinales para un pueblo como un listado de especies y principios activos sino también en el marco de una cosmovisión donde actúan las creencias

Se considera que si bien la población entrevistada presenta una diversidad en cuanto a sus orígenes, permanencia en la localidad, la interacción de los informantes con el ambiente, su percepción de los animales y las plantas y sus experiencias de vida han dado forma a un conocimiento botánico tradicional (CBT) (Pocchettino y Lema 2008). En este sentido se acuerda con Pochettino y Lema (2008) al entender el factor temporal como una variable no exclusiva en la caracterización del CBT, y que, el conocimiento que las comunidades tuvieron de su entorno no necesariamente debe tener un arraigamiento temporal profundo. No obstante, es posible inferir que los primeros inmigrantes en llegar a Puerto Deseado en el siglo XIX, se hayan vinculado con grupos aborígenes que aún permanecían habitando los alrededores (como mencionaron Josefa, Juan y Walter P.).

\subsection{Conclusiones}

De las categorías de uso registradas en las entrevistas, las especies comestibles y ornamentales fueron las que menor cantidad de menciones y especies registradas tuvieron, siendo entonces las categorías medicinal y combustibles las predominantes. Se registró que si bien tanto hombres como mujeres recolectaban plantas silvestres, los hombres, durante las recorridas por la estancia consumen las plantas silvestres para saciar el hambre y recurren a ellas en caso de aplicaciones terapéuticas. 
En cuanto a los recursos leñosos se destaca una variedad importante de especies nombradas para el ambiente de estepa. Los informantes a excepción de uno, mencionaron que solo usaban leña seca y que no colectaban las partes subterráneas para la combustión ya que, eran "muy cuidadosos de las plantas del campo". En cuanto a la selección de leñas como combustible se observó que existen preferencias entre las mismas según la necesidad: calor, humo, luminosidad, cocina. Respecto a la recolección, se observó que tanto mujeres como hombres seleccionan, utilizan y encienden el fuego, sin embargo, en las estancias es más común que haya hombres solos y por lo tanto, son ellos quienes se proveen de dichos recursos. Se registra una recolección más marcada durante el verano para abastecer el invierno. No se pudieron cuantificar las distancias que recorrían en la búsqueda de leña, pero algunos informantes señalaron que, cuando se carecía de ella en los alrededores, debían ir a otros campos para recolectarla y se registró en la mayoría de los casos el uso de camiones, por lo que inferimos que las distancias podían variar desde algunos metros a varios kilómetros.

En relación a las plantas medicinales, se infirió que existe confianza en que las plantas proveen un "remedio natural" por lo tanto "más sano". Para Fortunato, el acto de curar no sólo con la planta sino también con el "secreto", es decir, lo que su mamá sabía y no decía estaba ligado a prácticas simbólicas de curación. Así mismo, Pocho G. narra que si había una herida en el pie se debía marcar el mismo en la corteza de un álamo y sacar la corteza, a medida que el árbol cicatriza se va cerrando la herida del pie. Sin dudas, la utilización de las plantas y su efecto sobre el organismo no sería igual si no estuviera enmarcada por la esfera simbólica.

Si bien se observó una diversidad identitaria de la población entrevistada en cuanto a sus orígenes y permanencia en la localidad se considera que sus experiencias en la interacción con el entorno y experimentación permitieron construir este CBT. Asimismo, se observa que la transmisión de este conocimiento tiene su relevancia particular en CNSC ya que los informantes han profundizado conscientemente su relación con las plantas poniendo énfasis en la realización de diferentes prácticas dentro de una interacción fuertemente comprometida con el entorno y que transmiten a las siguientes generaciones. 


\begin{tabular}{|c|c|c|c|c|c|c|c|c|}
\hline Familia & Sp & Nombre vulgar & Origen & $\begin{array}{l}\text { Modo de } \\
\text { consumo }\end{array}$ & $\begin{array}{c}\text { Órgano } \\
\text { utilizado }\end{array}$ & Procesamiento & $\begin{array}{c}\text { Percepción } \\
\text { organoléptica }\end{array}$ & $\begin{array}{c}\text { Índice de } \\
\text { consenso de } \\
\text { uso }\end{array}$ \\
\hline Verbenaceae & $\begin{array}{l}\text { Acantholippia } \\
\text { seriphioides }\end{array}$ & tomillo & nativo & $\begin{array}{l}\text { directo en } \\
\text { fresco }\end{array}$ & hojas & no requiere & no expresa & $6,25 \%(n=1)$ \\
\hline Apiaceae & $\begin{array}{l}\text { Azorella } \\
\text { monantha }\end{array}$ & leño de piedra & nativo & $\begin{array}{l}\text { directo en } \\
\text { fresco }\end{array}$ & $\begin{array}{l}\text { órgano } \\
\text { subterráneo }\end{array}$ & $\begin{array}{l}\text { se le saca la } \\
\text { cáscara }\end{array}$ & no expresa & $6,25 \%(n=1)$ \\
\hline Berberidaceae & Berberis sp. & calafate & nativo & $\begin{array}{l}\text { directo en } \\
\text { fresco }\end{array}$ & fruto & no requiere & no expresa & $37,5 \%(n=6)$ \\
\hline Berberidaceae & Berberis sp. & calafate & nativo & $\begin{array}{l}\text { en dulces o } \\
\text { mermeladas }\end{array}$ & fruto & $\begin{array}{lr}\text { cocción } & \text { con } \\
\text { agua y azúcar, } \\
\text { filtrado }\end{array}$ & no expresa & $18,75 \%(\mathrm{n}=3)$ \\
\hline Berberidaceae & Berberis sp. & calafate & nativo & licor & fruto & & no expresa & $12,5 \%(n=2)$ \\
\hline Brassicaceae & $\begin{array}{ll}\text { cf. } & \text { Lepidium } \\
\text { sp. } & \end{array}$ & berros silvestres & exótico & $\begin{array}{ll}\text { directo } & \text { en } \\
\text { fresco } & \text { en } \\
\text { ensalada } & \end{array}$ & el brote & no requiere & gusto riquísimo & $6,25 \%(\mathrm{n}=1)$ \\
\hline Cactaceae & $\begin{array}{lr}\text { cf. } & \text { Opuntia } \\
\text { sp/ } & \text { cf. } \\
\text { Maihueinopsis } \\
\text { sp }\end{array}$ & tuna & nativo & $\begin{array}{l}\text { directo en } \\
\text { fresco }\end{array}$ & fruto & $\begin{array}{l}\text { se corta a la } \\
\text { mitad }\end{array}$ & fea, pegajosa, sin sabor & $12,5 \%(n=2)$ \\
\hline Asteraceae & $\begin{array}{l}\text { Cichorium sp. } \\
\text { L. }\end{array}$ & salsifí & exótico & $\begin{array}{l}\text { directo en } \\
\text { fresco }\end{array}$ & $\mathrm{s} / \mathrm{i}$ & no requiere & gusto rico & $6,25 \%(n=1)$ \\
\hline Malvaceae & Malva sp. L. & malva & exótico & tostado & fruto & $\begin{array}{l}\text { tostado al horno } \\
\text { con sal }\end{array}$ & gusto rico & $12,5 \%(n=2)$ \\
\hline Grossulariaceae & $\begin{array}{l}\text { Ribes rubrum } \\
\text { L. }\end{array}$ & corinto & exótico & $\begin{array}{l}\text { directo en } \\
\text { fresco, } \\
\text { condimento }\end{array}$ & fruto & no requiere & no expresa & $6,25 \%(n=1)$ \\
\hline Fabaceae & $\begin{array}{l}\text { Prosopis } \\
\text { denudans }\end{array}$ & algarrobillo & nativo & $\begin{array}{l}\text { directo en } \\
\text { fresco }\end{array}$ & fruto & no requiere & no expresa & $6,25 \%(\mathrm{n}=1)$ \\
\hline $\mathrm{s} / \mathrm{i}$ & $\begin{array}{l}\text { s/i (podría ser } \\
\text { Oxalis spp.) }\end{array}$ & $\begin{array}{l}\text { macachín/papita } \\
\text { de piche/papita }\end{array}$ & nativo & $\begin{array}{l}\text { directo en } \\
\text { fresco }\end{array}$ & $\begin{array}{l}\text { órgano } \\
\text { subterráneo }\end{array}$ & $\begin{array}{l}\text { se limpiaban y } \\
\text { se comían }\end{array}$ & dulce, riquísimo & $31,25 \%(\mathrm{n}=5)$ \\
\hline
\end{tabular}




\begin{tabular}{|l|l|l|l|l|l|l|l|}
\hline & & blanca & & & & \\
\hline s/i & s/i & flor de vino & $\mathrm{s} / \mathrm{i}$ & $\begin{array}{l}\text { directo en } \\
\text { fresco }\end{array}$ & $\begin{array}{l}\text { flor } \\
\text { completa }\end{array}$ & no requiere & gusto a vino, agrias \\
\hline Asteraceae & $\begin{array}{l}\text { Taraxacum } \\
\text { sp. F. H. H. } \\
\text { Wigg. }\end{array}$ & achicoria & exótico & en $=4)$ & no requiere & no expresa \\
\hline
\end{tabular}

Tabla 5.1. Plantas reportadas como alimenticias en las localidades de Tellier y Puerto Deseado (CNSC). Referencias s/i: sin identificar taxonómicamente.

\begin{tabular}{|c|c|c|c|c|c|}
\hline Familia & Sp & Nombre vulgar & Origen & Etapa de combustión & $\begin{array}{c}\text { Índice de } \\
\text { consenso de } \\
\text { uso }\end{array}$ \\
\hline Fabaceae & Anarthrophyllum rigidum & mata guanaco & nativo & todas las etapas & $12,5 \%(\mathrm{n}=2)$ \\
\hline Apiaceae & Azorella monantha & leño de piedra & nativo & todas las etapas & $37,5 \%(n=6)$ \\
\hline Berberidaceae & Berberis sp. & calafate & nativo & todas las etapas & $50 \%(n=8)$ \\
\hline Asteraceae & cf. Nardophyllum bryioides & mata torcida & nativo & para encender & $6,25 \%(n=1)$ \\
\hline Fabaceae & cf. Prosopis denudans & algarrobillo, algarrobo & nativo & todas las etapas & $62,5 \%(n=10)$ \\
\hline Asteraceae & Chuquiraga avellanedae & quilinbay & nativo & $\mathrm{s} / \mathrm{i}$ & $6,25 \%(n=1)$ \\
\hline Asteraceae & Chuquiraga erinaceae & uña de gato & nativo & encendido & $6,25 \%(n=1)$ \\
\hline Euphorbiaceae & Colliguaja integerrima & duraznillo & nativo & todas las etapas & $6,25 \%(\mathrm{n}=1)$ \\
\hline Rhamnaceae & Condalia microphylla & piquillín & $\begin{array}{l}\text { nativo no local, de } \\
\text { más al norte }\end{array}$ & todas las etapas & $12,5 \%(n=2)$ \\
\hline Rhamnaceae & Discaria sp. & chacay & nativo & todas las etapas & $6,25 \%(n=1)$ \\
\hline Solanaceae & Lycium ameghinoi & mata laguna & nativo & todas las etapas & $50 \%(\mathrm{n}=8)$ \\
\hline Verbenaceae & Mulguraea tridens & mata negra & nativo & $\begin{array}{l}\text { para encender y para todas las } \\
\text { etapas }\end{array}$ & $75 \%(n=12)$ \\
\hline Apiaceae & Mulinum spinosum & neneo & nativo & encendido y todas las etapas & $12,5 \%(n=2)$ \\
\hline Salicaceae & Populus sp & álamo & exótico & todas las etapas & $12,5 \%(n=2)$ \\
\hline Fabaceae & Prosopis sp. & algarrobo & $\begin{array}{l}\text { nativo no local, de } \\
\text { más al norte }\end{array}$ & todas las etapas & $12,5 \%(n=2)$ \\
\hline Rhamnaceae & Retanilla patagonica & malaespina & nativo & $\mathrm{s} / \mathrm{i}$ & $18,75 \%(\mathrm{n}=3)$ \\
\hline Salicaceae & Salix sp. & sauce & exótico & todas las etapas & $12,5 \%(n=2)$ \\
\hline Anacardiaceae & Schinopsis sp. & quebracho & $\begin{array}{l}\text { nativo no local, } \\
\text { bosque chaqueño }\end{array}$ & todas las etapas & $6,25 \%(n=1)$ \\
\hline
\end{tabular}




\begin{tabular}{|l|l|l|l|l|l|}
\hline Anacardiaceae & Schinus sp. & molle & Nativo & todas las etapas \\
\hline Tamaricaceae & Tamarix gallica & tamarisco & Exótico & todas las etapas & $(\mathrm{n}=13)$ \\
\hline
\end{tabular}

Tabla 5.2. Plantas reportadas como combustibles en las localidades de Tellier y Puerto Deseado (CNSC). Referencias: s/i: sin identificar.

\begin{tabular}{|c|c|c|c|c|c|c|c|c|}
\hline Familia & Sp & $\begin{array}{c}\text { Nombre } \\
\text { vulgar }\end{array}$ & Origen & Uso & $\begin{array}{c}\text { Percepción } \\
\text { organolépti } \\
\text { ca } \\
\end{array}$ & $\begin{array}{l}\text { Modo de } \\
\text { consumo }\end{array}$ & Productos secundarios & $\begin{array}{c}\text { Índice de } \\
\text { consenso de } \\
\text { uso } \\
\end{array}$ \\
\hline Verbenaceae & $\begin{array}{l}\text { Acantholippia } \\
\text { seriphioides }\end{array}$ & tomillo & nativo & $\begin{array}{l}\text { antigripal, } \\
\text { para la sangre }\end{array}$ & $\begin{array}{l}\text { aroma } \\
\text { "lindo" } \\
\text { dulzón }\end{array}$ & infusión & 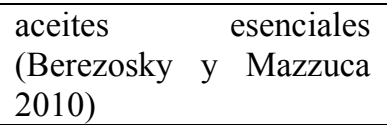 & $50 \%(n=8)$ \\
\hline Fabaceae & $\begin{array}{l}\text { Adesmia } \\
\text { boronioides }\end{array}$ & paramela & nativo & antigripal & $\begin{array}{l}\text { amarga, fea, } \\
\text { pegajosa, } \\
\text { aroma lindo }\end{array}$ & Infusión & $\begin{array}{l}\text { gran cantidad de aceites } \\
\text { esenciales (González et } \\
\text { al. 2004, Guerra et al. } \\
\text { 2012) }\end{array}$ & $56,25 \%(n=9)$ \\
\hline Verbenaceae & $\begin{array}{l}\text { Aloysia triphylla } \\
\text { Palau }\end{array}$ & cedrón & $\begin{array}{ll}\text { nativo no } \\
\text { local }\end{array}$ & digestivo & $\mathrm{s} / \mathrm{i}$ & infusión & $\begin{array}{l}\text { aceites esenciales (Rojas } \\
\text { et al. 2012) }\end{array}$ & $6,25 \%(n=1)$ \\
\hline Asteraceae & $\begin{array}{l}\text { Artemisia } \\
\text { absinthium } \mathrm{L} .\end{array}$ & ajenjo & exótico & digestivo & gusto feo & infusión & $\begin{array}{l}\text { aceites esenciales Lopes } \\
\text { Lutz et al. } 2008\end{array}$ & $6,25 \%(n=1)$ \\
\hline Asteraceae & $\begin{array}{l}\text { Baccharis obovata } \\
\text { Hook et. Arn. }\end{array}$ & carqueja & $\begin{array}{l}\text { nativo no } \\
\text { local }\end{array}$ & $\begin{array}{l}\text { digestivo } \\
\text { hepático }\end{array}$ & $\mathrm{s} / \mathrm{i}$ & infusión & $\begin{array}{l}\text { se registraron aceites } \\
\text { esenciales y estructuras } \\
\text { secretoras (i.e. Malizia et } \\
\text { al. 2005, Molares 2010, } \\
\text { Molares et al. 2009, } \\
\text { Guerra et al. 2012) } \\
\end{array}$ & $6,25 \%(n=1)$ \\
\hline Berberidaceae & Berberis sp. & calafate & nativo & $\begin{array}{l}\text { antitusivo/resp } \\
\text { iratorio }\end{array}$ & $\mathrm{s} / \mathrm{i}$ & infusión & $\begin{array}{l}\text { alcaloides (Manosalva et } \\
\text { al. 2014) }\end{array}$ & $6,25 \%(n=1)$ \\
\hline Cactaceae & $\begin{array}{l}\text { cf. Opuntia } \mathrm{sp} / \mathrm{cf} . \\
\text { Maihuenopsis } \mathrm{sp}\end{array}$ & tuna & nativo & $\begin{array}{l}\text { purgante para } \\
\text { animales, } \\
\text { cosmético }\end{array}$ & $\mathrm{s} / \mathrm{i}$ & $\begin{array}{lr}\text { consumo } \\
\text { directo, el } \\
\text { agua del fruto } \\
\text { hervido para } \\
\text { enjuagar } \\
\text { cabello. }\end{array}$ & $\mathrm{s} / \mathrm{d}$ & $18,75 \%(\mathrm{n}=3)$ \\
\hline Asteraceae & $\begin{array}{l}\text { Chuquiraga } \\
\text { avellanedae }\end{array}$ & quilinbay & nativo & analgésico & $\mathrm{s} / \mathrm{i}$ & $\begin{array}{l}\text { aplicación del } \\
\text { látex como } \\
\text { emplasto }\end{array}$ & $\begin{array}{l}\text { flavonoides (Mendiondo } \\
\text { et al. 2000) }\end{array}$ & $6,25 \%(n=1)$ \\
\hline
\end{tabular}




\begin{tabular}{|c|c|c|c|c|c|c|c|c|}
\hline Lamiaceae & $\begin{array}{l}\text { Clinopodium } \\
\text { darwinii }\end{array}$ & té pampa & nativo & $\begin{array}{l}\text { antipirético, } \\
\text { digestivo }\end{array}$ & $\begin{array}{l}\text { aroma lindo } \\
\text { tipo "anís", } \\
\text { gusto } \\
\text { amargo, a } \\
\text { menta }\end{array}$ & infusión & $\begin{array}{l}\text { se registraron aceites } \\
\text { esenciales (Guerra et al. } \\
\text { 2012) }\end{array}$ & $75 \%(n=12)$ \\
\hline Euphorbiaceae & $\begin{array}{l}\text { Colliguaja } \\
\text { integerrima }\end{array}$ & $\begin{array}{l}\text { duraznill } \\
\text { o }\end{array}$ & nativo & $\begin{array}{l}\text { analgésico, } \\
\text { también tóxico }\end{array}$ & $\mathrm{s} / \mathrm{i}$ & $\begin{array}{l}\text { aplicación del } \\
\text { látex como } \\
\text { emplasto }\end{array}$ & $\begin{array}{l}\text { flavonoides, ácidos } \\
\text { mirísticos, palmítico, } \\
\text { palmitoleico, } \\
\text { ricinoleico (Alcalde et al. } \\
2010 \text { ) }\end{array}$ & $6,25 \%(n=1)$ \\
\hline Chenopodiaceae & $\begin{array}{l}\text { Dysphania } \\
\text { ambrosioides }\end{array}$ & paico & $\begin{array}{l}\text { nativo no } \\
\text { local }\end{array}$ & $\begin{array}{l}\text { digestivo, } \\
\text { analgésico, } \\
\text { laxante }\end{array}$ & $\begin{array}{lr}\text { gusto } & a \\
\text { menta, feo, } \\
\text { rico }\end{array}$ & infusión & $\begin{array}{l}\text { aceite esencial (Gómez } \\
\text { Castellanos 2008) }\end{array}$ & $87,5 \%(n=14)$ \\
\hline Geraniaceae & Erodium cicutarium & alfilerillo & exótico & $\begin{array}{l}\text { desinfectante, } \\
\text { diurético, } \\
\text { anticoagulante }\end{array}$ & $\begin{array}{ll}\text { no } & \text { tiene } \\
\text { aroma } & \end{array}$ & $\begin{array}{l}\text { infusión, } \\
\text { emplasto }\end{array}$ & $\begin{array}{l}\text { taninos, aminoáciso, } \\
\text { entre otros (Sroka et } \\
\text { al.1994) }\end{array}$ & $56,25 \%(\mathrm{n}=9)$ \\
\hline Solanaceae & Fabiana imbricata & $\begin{array}{l}\text { palo } \\
\text { piche }\end{array}$ & $\begin{array}{l}\text { nativo } \\
\text { (crece al } \\
\text { oeste de } \\
\text { Patagonia) }\end{array}$ & $\begin{array}{l}\text { digestivo, } \\
\text { hepático renal }\end{array}$ & $\mathrm{s} / \mathrm{i}$ & infusión & $\begin{array}{l}\text { aceites } \\
\text { (Guerra et al. 2012) }\end{array}$ & $12,5 \%(n=2)$ \\
\hline Apiaceae & $\begin{array}{l}\text { Foeniculum vulgare } \\
\text { Mill. }\end{array}$ & hinojo & exótico & antigripal & $\mathrm{s} / \mathrm{i}$ & $\mathrm{s} / \mathrm{i}$ & $\begin{array}{l}\text { fenoles, aceites } \\
\text { esenciales (Rather et al. } \\
\text { 2012) }\end{array}$ & $12,5 \%(n=2)$ \\
\hline Asteraceae & $\begin{array}{l}\text { Grindelia } \\
\text { chiloensis }\end{array}$ & $\begin{array}{l}\text { botón de } \\
\text { oro }\end{array}$ & nativo & $\begin{array}{ll}\text { para } & \text { el } \\
\text { corazón } & \\
\end{array}$ & $\mathrm{s} / \mathrm{i}$ & infusión & $\begin{array}{lll}\text { terpenos (Ravetta } & \mathrm{y} \\
\text { Soriano 1998) } & \\
\end{array}$ & $6,25 \%(n=1)$ \\
\hline Gunneraceae & $\begin{array}{lr}\text { Gunnera } & \text { tinctoria } \\
\text { var. } & \text { tinctoria } \\
\text { (Molina) Mirb. }\end{array}$ & nalca & $\begin{array}{l}\text { nativo pero } \\
\text { no local }\end{array}$ & anticoagulante & $\mathrm{s} / \mathrm{i}$ & infusión & $\begin{array}{l}\text { flavonoides (Ojeda Rojas } \\
\text { 2013) }\end{array}$ & $6,25 \%(n=1)$ \\
\hline Plumbaginaceae & $\begin{array}{l}\text { Limonium } \\
\text { brasiliense (Boiss.) } \\
\text { Kuntze }\end{array}$ & guaycurú & nativo & antigripal & $\mathrm{s} / \mathrm{i}$ & infusión & $\mathrm{s} / \mathrm{d}$ & $12,5 \%(n=2)$ \\
\hline Malvaceae & Malva sp. & malva & exótico & $\mathrm{s} / \mathrm{i}$ & $\mathrm{s} / \mathrm{i}$ & infusión & $\begin{array}{l}\text { aceites esenciales Knaak } \\
\text { et al. (2013) }\end{array}$ & $6,25 \%(n=1)$ \\
\hline Lamiaceae & Marrubium vulgare & $\begin{array}{l}\text { malva } \\
\text { rubia }\end{array}$ & exótico & $\begin{array}{l}\text { antigripal, } \\
\text { analgésico }\end{array}$ & $\begin{array}{l}\text { aroma } \\
\text { "lindo", } \\
\text { sabor más }\end{array}$ & infusión & $\begin{array}{l}\text { flavonoides entre otros } \\
\text { (Nawwar et al. 1989) }\end{array}$ & $12,5 \%(n=2)$ \\
\hline
\end{tabular}




\begin{tabular}{|c|c|c|c|c|c|c|c|c|}
\hline & & & & & $\begin{array}{l}\text { amargo que } \\
\text { la paramela }\end{array}$ & & & \\
\hline Asteraceae & $\begin{array}{l}\text { Matricaria } \\
\text { chamomilla } \\
\text { Rydb) }\end{array}$ & $\begin{array}{l}\text { manzanil } \\
\text { la }\end{array}$ & exótico & digestiva & $\mathrm{s} / \mathrm{i}$ & infusión & $\begin{array}{l}\text { aceites esenciales (Ríos } \\
\text { et al. 2008) }\end{array}$ & $37,5 \%(n=6)$ \\
\hline Lamiacaea & $\begin{array}{l}\text { Melissa officinalis } \\
\text { L. }\end{array}$ & toronjil & exótico & $\mathrm{s} / \mathrm{i}$ & $\mathrm{s} / \mathrm{i}$ & infusión & $\begin{array}{l}\text { aceites esenciales } \\
\text { (Acevedo et al. 2013) }\end{array}$ & $6,25 \%(\mathrm{n}=1)$ \\
\hline Lamiaceae & Mentha x piperita & peperina & exótico & hepática & $\mathrm{s} / \mathrm{i}$ & infusión & $\begin{array}{l}\text { aceites esenciales } \\
\text { (Sujana et al. 2013) }\end{array}$ & $6,25 \%(n=1)$ \\
\hline Lamiaceae & Mentha sp. L. & menta & exótico & $\begin{array}{l}\text { digestivo, } \\
\text { analgésico }\end{array}$ & $\mathrm{s} / \mathrm{i}$ & infusión & $\begin{array}{ll}\text { aceites } & \text { esenciales } \\
\text { (Prasad 2014) } & \\
\end{array}$ & $37,5 \%(n=6)$ \\
\hline Asteraceae & $\begin{array}{l}\text { Nassauvia } \quad \mathrm{sp} \\
\text { Comm. }\end{array}$ & colapiche & nativo & digestivo & $\mathrm{s} / \mathrm{i}$ & infusión & $\begin{array}{l}\text { lupeol y taraxasterol, 5- } \\
\text { methyl coumarins } 1[2], 2 \\
\text { y } 3 \text { (Bittner } \text { et al. } 1988)\end{array}$ & $6,25 \%(n=1)$ \\
\hline Apocynaceae & Nerium olander L. & $\begin{array}{l}\text { laurel de } \\
\text { jardín }\end{array}$ & exótico & $\begin{array}{l}\text { antitusívo, } \\
\text { respiratorio }\end{array}$ & $\mathrm{s} / \mathrm{i}$ & $\mathrm{s} / \mathrm{i}$ & $\begin{array}{l}\text { alcaloides, terpenoides, } \\
\text { saponinas, taninos } \\
\text { (Bhuvaneshwari et al. } \\
\text { 2007) }\end{array}$ & $6,25 \%(n=1)$ \\
\hline Apiaceae & $\begin{array}{l}\text { Pimpinella anisum } \\
\text { L. }\end{array}$ & anís & exótico & digestivo & $\mathrm{s} / \mathrm{i}$ & infusión & $\begin{array}{l}\text { aceites esenciales } \\
\text { (Shojaii y Fard 2012) }\end{array}$ & $12,5 \%(n=2)$ \\
\hline Plantaginaceae & $\begin{array}{l}\text { Plantago cf. } \\
\text { patagónica Jacq. }\end{array}$ & $\begin{array}{l}\text { siete } \\
\text { coyuntur } \\
\text { as }\end{array}$ & $\mathrm{s} / \mathrm{i}$ & $\begin{array}{l}\text { digestivo, } \\
\text { hepático } \\
\text { analgésico, }\end{array}$ & $\begin{array}{l}\text { agua azulada } \\
\text { luego de } \\
\text { hervir }\end{array}$ & infusión & $\mathrm{s} / \mathrm{d}$ & $25 \%(n=4)$ \\
\hline Rutaceae & Ruta sp L. & ruda & exótico & digestivo & $\mathrm{s} / \mathrm{i}$ & infusión & $\begin{array}{l}\text { aceites esenciales } \\
\text { (Asgarpanah } \\
\text { Khoskham 2012) }\end{array}$ & $12,5 \%(n=2)$ \\
\hline Saxifragaceae & $\begin{array}{l}\text { Saxifraga } \\
\text { geranioides L. }\end{array}$ & bálsamo & exótico & para heridas & $\mathrm{s} / \mathrm{i}$ & emplasto & $\mathrm{s} / \mathrm{d}$ & $6,25 \%(n=1)$ \\
\hline Anacardiaceae & Schinus sp. L. & molle & nativo & $\begin{array}{l}\text { analgésico, } \\
\text { antitusivo }\end{array}$ & $\mathrm{s} / \mathrm{i}$ & infusión & $\begin{array}{l}\text { se registraron aceites } \\
\text { esenciales (González et } \\
\text { al. 2011) (Guerra et al. } \\
\text { 2012) }\end{array}$ & $18,75 \%(\mathrm{n}=3)$ \\
\hline Asteraceae & $\begin{array}{l}\text { Senecio filaginoides } \\
\text { D.C. }\end{array}$ & charcao & nativo & $\begin{array}{l}\text { digestivo } \\
\text { hepático }\end{array}$ & amargo, feo & infusión & $\begin{array}{l}\text { furanoeremofilano } \\
\text { (Arancibia } \text { et al. 2013) }\end{array}$ & $6,25 \%(n=1)$ \\
\hline Urticaceae & Urtica sp. L. & ortiga & exótico & antireumático & $\mathrm{s} / \mathrm{i}$ & emplasto & $\begin{array}{l}\text { flavonoides, } \begin{array}{r}\text { taninos } \\
\text { entre otros (Asgarpanah }\end{array} \\
\end{array}$ & $6,25 \%(n=1)$ \\
\hline
\end{tabular}




\begin{tabular}{|c|c|c|c|c|c|c|c|c|}
\hline & & & & & & & y Mohajerani 2012) & \\
\hline Valerianaceae & $\begin{array}{l}\text { Valeriana carnosa } \\
\text { S.M }\end{array}$ & $\begin{array}{l}\text { ñamcula } \\
\text { wén }\end{array}$ & nativo & $\begin{array}{l}\text { para las siete } \\
\text { enfermedades, } \\
\text { antifebril, } \\
\text { hepática, } \\
\text { anticoagulante } \\
\end{array}$ & $\begin{array}{l}\text { agua azulada } \\
\text { luego de } \\
\text { hervir }\end{array}$ & infusión & $\begin{array}{l}\text { valepotriatos, lignanos, } \\
\text { flavonoides, taninos, } \\
\text { ácidos fenólicos y aceites } \\
\text { esenciales (Kutschker et } \\
\text { al. } 2010 \text { en Molares y } \\
\text { Ladio 2012b) }\end{array}$ & $62,5 \%(\mathrm{n}=10)$ \\
\hline $\mathrm{s} / \mathrm{i}$ & $\begin{array}{l}\text { cf. Xanthium/cf. } \\
\text { Acaena splendens }\end{array}$ & $\begin{array}{l}\text { cepa de } \\
\text { caballo }\end{array}$ & nativo & $\begin{array}{l}\text { antitusivo, } \\
\text { respiratorio }\end{array}$ & $\mathrm{s} / \mathrm{i}$ & $\mathrm{s} / \mathrm{i}$ & $\mathrm{s} / \mathrm{d}$ & $6,25 \%(\mathrm{n}=1)$ \\
\hline Poaceae & Zea mays & choclo & $\begin{array}{l}\text { nativo no } \\
\text { local }\end{array}$ & $\begin{array}{l}\text { digestivo } \\
\text { hepático }\end{array}$ & $\mathrm{s} / \mathrm{i}$ & infusión & $\mathrm{s} / \mathrm{d}$ & $6,25 \%(\mathrm{n}=1)$ \\
\hline
\end{tabular}

Tabla 5.3. Plantas reportadas como medicinales en las localidades de Tellier y Puerto Deseado (CNSC). Referencias [s/d]: sin datos.

\begin{tabular}{|c|c|c|c|c|c|c|}
\hline Familia & Sp & Nombre vulgar & Origen & $\begin{array}{c}\text { Categoría de } \\
\text { uso }\end{array}$ & Parte de la planta & $\begin{array}{c}\text { Índice de } \\
\text { consenso de } \\
\text { uso }\end{array}$ \\
\hline Fabaceae & Berberis & Calafate & Nativo & tintóreo & raíz & $25 \%(n=4)$ \\
\hline Orchidaceae & Chloraea sp & Orquídea & Nativo & Ornamental & Flor & $6,25 \%(n=1)$ \\
\hline Asteraceae & Chuquiraga avellanedae & Quilimbay & Nativo & Cerco & Tronco & $12,5 \%(n=2)$ \\
\hline Euphorbiaceae & Colliguaja integerrima & Duraznillo & Nativo & Cerco & Tronco & $12,5 \%(n=2)$ \\
\hline Anacardiaceae & Schinus & Molle & Nativo & tintóreo & raíz & $6,25 \%(n=1)$ \\
\hline
\end{tabular}

Tabla 5.4. Plantas reportadas con otras categorías de uso en las localidades de Tellier y Puerto Deseado (CNSC). 


\subsection{Construcción de un modelo de prácticas de recolección para contribuir a la interpretación del registro arqueobotánico de Costa Norte de Santa Cruz}

\subsubsection{Componentes del modelo y qué datos pueden utilizarse en la analogía}

A partir del corpus de información obtenida en las fuentes bibliográficas y el estudio etnobotánico realizado en dos localidades (Puerto Deseado y Tellier), se propone construir un modelo de explicación de la interacción hombre-planta en la estepa patagónica a lo largo de la historia y de distintas sociedades. En este sentido, se busca comprender los criterios de selección de las plantas para distintas categorías de uso y la existencia de prácticas poscolecta. Se discute qué aspectos de las prácticas, entendidas éstas como una dimensión atravesada por el corpus y el cosmos en sentido de Toledo (1992), y desde el concepto de hábitus en sentido de Bourdieu $(1972,1991)$ pueden ser utilizados para la formulación de modelos explicativos y su contrastación con el registro arqueológico de la CNSC.

\subsubsection{Las fuentes bibliográficas y la formulación de modelos para la interpretación del registro aqueobotánico}

La base de datos elaborada a partir de la recopilación bibliográfica (capítulo 4) ofrece una fuente de información potencialmente utilizable para interpretar y explicar el registro arqueobotánico. Sin embargo, y en el marco de la aproximación paleoetnobotánica aquí elegida, cabe preguntarse ¿qué parte del saber, asociado a la relación bidireccional ser humano-planta, se registra en cada cita?

Cada sociedad posee un saber ecológico tradicional (Toledo 1992) y en el mismo se encuentra aquel relacionado específicamente con las plantas, y denominado conocimiento botánico tradicional (CBT) (Pochettino y Lema 2008). En este sentido, cada cita aquí compilada es interpretada como una elección al utilizar tal o cual planta, que un grupo particular de personas llevó a cabo, en un momento dado. Esa elección se tradujo en acciones particulares o prácticas que fueron registradas por un sujeto externo a esa cultura, que convierte al estudio del sistema ser humano-planta en el estudio de un sistema cibernético de segundo orden (Hurrell 1987).

A partir de esta aclaración, es necesario remarcar algunas cuestiones importantes a tener en cuenta al momento de utilizar esta información en el estudio de las prácticas ser 
humano-plantas en el pasado. En primer lugar, que las citas aquí presentadas permiten distinguir cambios en la forma en que cada sujeto externo, que visitó la Patagonia, colectó y registró la información. Estos cambios se observan a partir del ordenamiento de las citas a lo largo de una línea histórica de contactos entre exploradores e investigadores con los grupos aborígenes, y tuvieron que ver con distintos puntos de vista, intereses y objetivos de los mismos. Por ejemplo, los autores que durante los siglos XVI al XVIII describían los nuevos territorios conquistados o por conquistar a partir de crónicas de viaje (i.e. Pigafetta [1520] 1971) mantienen encuentros esporádicos con los grupos aborígenes y registran distinto tipo de información. En el siglo XIX los que registraron con mayor asiduidad el uso de plantas fueron aquellos que presentaban formación "naturalista", los cuales entre sus objetivos tenían el de describir los espacios geográficos potencialmente útiles para asentar poblaciones colonas (i.e. Claraz [18651866] 2008, Viedma y Villarino [1780-1783] 2006). En cambio, durante los siglos XX y XXI los trabajos ya presentan caracteres más sistemáticos, donde los objetivos principales estaban centrados en el registro de los recursos vegetales en términos de su explotación, y donde el método científico es aplicado en cada caso de estudio (i.e. Martínez Crovetto 1968).

En segundo lugar, se debe tener en cuenta que, así como cada cita representa una elección que un grupo particular de personas llevó a cabo en un momento dado, no podemos saber qué otras elecciones se descartaron, ni la totalidad de gestos que acompañaron las acciones realizadas, ni la forma de aprendizaje de las mismas. Por lo tanto, se puede decir que lo que se visualiza a través de cada cita es una porción del CBT de la sociedad en cuestión, que se evidencia a través de las prácticas registradas en el relato. El CBT ha sido caracterizado como comunal -es decir gestado, reproducido y transformado en el seno de una comunidad-, acumulativo, dinámico y transformable (Pochettino y Lema 2008). Respecto a estas dos últimas cualidades, se pueden establecer continuidades y rupturas de las prácticas aquí registradas, entendiendo que cada una de ellas representa una "fotografía" congelada en las descripciones de 39 autores. Tal como se mencionó anteriormente, algunas prácticas perduraron por varios siglos según el registro de citas de distintas épocas históricas (i.e. la continuidad en la práctica del uso de raíces comestibles), mientras que otras se transformaron (las modificaciones en la elaboración de bebidas).

En tercer lugar, se considera que las creencias están indisolublemente asociadas a cada práctica registrada. No obstante ello, son difícilmente visualizadas en la materialidad de 
la acción, a menos que se haga explícita mención a éstas, o que el sujeto externo registre prácticas en contextos específicamente ceremoniales. En el caso de los datos presentados en el capítulo 4, las únicas alusiones claras a los dimensiones simbólicas que vinculan a los hombres y las plantas se observan en las citas de la leyenda de yamnago (en Claraz [1865-1866] 2008:84) y en la de la cueva al sur del Limay (en Claraz [1865-1866] 2008:159).

Por último, resulta útil considerar que el estudio de las prácticas ser humano-plantas en el pasado se ve enriquecido si se lo enmarca dentro de las siguientes cuatro posibles esferas o ámbitos de acción: precolecta, colecta, poscolecta y consumo (Capparelli y Lema 2010). Esta delimitación responde a que cada una de estas esferas involucra por lo general prácticas distintas entre sí, por lo que llevan a la generación de un registro arqueológico (y por ende arqueobotánico) diferente (Capparelli y Lema 2010). En el caso de las citas recopiladas en el capítulo 4, se observa que hay escasas menciones de prácticas que representen la esfera precolecta (i.e. cultivo de tubérculos según una tradición en Claraz [1865-1866] 2008: 199) pero sí se registraron mayor cantidad de menciones de aquellas correspondientes a las otras tres esferas. Por ejemplo, en la colecta se pueden incluir menciones a la obtención de tubérculos, de madera para postes de toldos, así como de leña (i. e. Musters [1869] 1964; Ancibor y Pérez de Micou 2002); en el caso de la poscolecta, se mencionan procesamientos de vainas de algarrobo (i.e. molienda, tostado), de raíz de la Azorella sp. (molienda), de frutos de zarzaparrilla (macerado), de calafate (macerado, quemado en el caso de las pipas) y de molle (extracción de resina); por último, en la de consumo, se observa la ingesta de frutos frescos de calafate, manzanas, frutillas, de hojas de apio cimarrón, de raíces, rizomas y tubérculos, entre otros. La mayor cantidad de citas, sin discriminar por especie, se encuentra en las esferas de la poscolecta/consumo.

Las prácticas poscolecta, en particular, se caracterizan porque pueden tener gran impacto en los sistemas productivos de una sociedad. Esto es debido a que los cambios acontecidos dentro de esta esfera requieren necesariamente de un reajuste en las actividades de subsistencia, en la organización social, en el manejo de la tierra, en la dieta, en la toma de decisiones productivas y en la organización del trabajo, entre otras (Wollstonecroft 2007, 2011; Capparelli y Lema 2010). Es importante tener esto en consideración al momento de evaluar las citas que hacen referencia a ellas y de estimar el valor de las plantas en la vida de estas sociedades. El sistema postcolecta, en términos de Yen (1980), incluye todas las habilidades, conocimiento, tecnología y coordinación 
de trabajo para convertir las plantas en productos comestibles. Si dicho sistema se ve sometido a un proceso de intensificación, pueden surgir prácticas que permitan aumentar la bioaccesibilidad de energía de macro y micro nutrientes contenidos en las plantas, y/o aumentar la vida útil de las mismas a través del almacenamiento. Considerar la interacción entre los grupos originarios patagónicos y las plantas en el contexto prehispánico y post-conquista bajo este marco teórico, permite redimensionar la complejidad de estas sociedades.

\subsubsection{La etnobotánica y la formulación de modelos para la interpretación del registro aqueobotánico}

En el caso del estudio etnobotánico realizado en la localidad de Puerto Deseado y Tellier (capítulo 5 de la presente tesis), los informantes tienen distintos orígenes y se encuentran atravesados por distintos procesos sociales. Sin embargo, la interacción con el entorno a partir del trabajo rural y de insertarse en territorios nuevos, permiten esa vinculación comprometida a través de la percepción y la participación activa y práctica (i.e. Ingold 1993). Por tal motivo, es posible identificar, por ejemplo, qué características organolépticas de las plantas son percibidas por los informantes, qué criterios permiten reconocer las plantas útiles de las que pueden ser tóxicas, y cómo se llevan a cabo las prácticas de recolección en todas sus dimensiones. Estas categorías escasamente producen en la CNSC una materialidad factible de ser interpretada en el registro arqueobotánico, sin embargo, considerar la complejidad del proceso de recolección de plantas silvestres permite otro tipo de aproximación e interpretación del registro arqueológico.

Es importante destacar las propiedades atribuidas por los informantes a los recursos leñosos utilizados como combustible, puesto que permite comprender, junto con trabajos experimentales y anatómicos de las maderas, los posibles usos de los fuegos en el pasado.

En cuanto a los recursos medicinales y alimenticios se observa que la población actual (capítulo 5) en comparación con lo expuesto a través de los datos correspondientes a períodos previos recopilados para Patagonia en general (capítulo 4), mantiene en mayor medida saberes respecto a la primera categoría de uso y una disminución de conocimiento respecto a la segunda. Por un lado, esto puede deberse a que la población está inmersa en los patrones alimenticios actuales basados en la industrialización de los 
productos. Mientras que, las grandes distancias del campo a los centros de atención primaria de salud, influyen en la permanencia de los cuidados a través de emplastos o infusiones basados en las plantas del lugar.

También se observó actualmente una menor cantidad de categorías de uso de las plantas con respecto a los datos de la recopilación bibliográfica. Esto puede deberse a que estas poblaciones están insertas en el mercado, por lo que la distintas necesidades básicas pueden ser satisfechas a través del mismo.

La construcción del dato a partir de entrevistas etnobotánicas en el área de estudio evidencian procesos históricos y sociales que impiden una extrapolación directa a la interpretación del registro arqueobotánico (Gándara 2006). Sin embargo, como manifiestan Founier y Freeman (1991), se considera válido teóricamente aislar variables sobre ciertos atributos o procesos que se consideren análogos en cuanto a manifestaciones materiales de la conducta humana. Tanto el análisis de fuentes bibliográficas como el de los estudios etnográficos y etnobotánicos, son fundamentales para ampliar el entendimiento de la relación que los hombres y las plantas tuvieron en el pasado. Permiten la observación de la variabilidad y complejidad del comportamiento humano, así como de su contraparte, la respuesta fisiológica y evolutiva de las plantas. En este sentido, por ejemplo, el estudio etnográfico de los grupos Nukak (en la amazonía colombiana) permitió considerar otras formas de manipulación de los recursos vegetales silvestres y a su vez, observar la complejidad de los sistemas de movilidad en estos grupos (Politis et al. 1997). Se considera entonces que aún con sus limitaciones y recaudos es válido el uso de fuentes bibliográficas y etnográficas para la interpretación del registro arqueológico.

\subsubsection{Cuestiones a tener en cuenta en la interpretación de las prácticas de recolección de plantas silvestres a partir del registro arqueobotánico de Costa Norte de Santa Cruz}

A partir de la base de datos construida a través de la información bibliográfica y de las entrevistas etnobotánicas, las plantas mayormente recolectadas por distintas poblaciones en Patagonia continental han sido aquellas pertenecientes a las familias Asteraceae, Apiaceae, Fabaceae y Lamiaceae. Estas familias presentan, por su adaptación a ambientes semidesérticos una gran producción de metabolitos secundarios que dan lugar a aromas, aceites esenciales y texturas que son percibidos por las poblaciones humanas 
(Almeida et al. 2005, Molares 2010) y que han permitido que éstas las reconozcan, consuman y memoricen (Etkin 1994). En este sentido se identificaron, para Patagonia, distintas leyendas que actuarían como disparadores de la memoria del grupo, por ejemplo, para el consumo de órganos subterráneos como fuente de alimento en casos de hambruna (Claraz [1865-18866] 2008:159; Etkin 1994), o que resaltarían la importancia de la leña para los grupos cazadores recolectores (Leyenda de yamnago, ver Claraz [1865-1866] 2008:84). También la observación de los animales en cuanto a los efectos del consumo de determinados vegetales ha sido una fuente de aprendizaje sobre la toxicidad o no de las plantas silvestres. Si bien acciones como la percepción, la memoria o la transmisión de conocimiento son difícilmente asequibles a través de los restos arqueobotánicos, su recuperación e identificación taxonómica precisa permite acceder a datos sobre uso y no uso en el pasado de plantas con caracteres específicos que deben ser tenidos en cuenta para su interpretación.

En relación a las categorías de uso de las plantas se observa que tanto en las fuentes escritas como etnobotánicas predominan las alimenticias, medicinales y combustibles. Es importante mencionar que las plantas leñosas además de ser utilizadas como combustible son también, por su adaptación al ambiente, recursos de la flora medicinal. Así entonces, una misma planta puede contener varias categorías de uso simultáneamente (i.e. Berberis sp. cuyo leño es combustible, es apreciada también por sus frutos para elaborar bebidas y alimento, sus frutos y hojas son medicina y las raíces recursos tintóreos). Otras categorías de uso identificadas pero con menor redundancia son los de recursos empleados como bebibles, tintóreos, venenosos, para la construcción de toldos e instrumentos musicales, para el empaste de pinturas, como pegamento y aquellos que pueden servir a modo de tabaco. En cuanto a las partes de las plantas utilizadas se registraron en algunos casos la totalidad, en otros el uso de órganos subterráneos, así como el de leño, frutos y hojas. La recolección de las plantas es referida principalmente a las mujeres y niños en períodos históricos (cronistas y viajeros), pero también se hacen menciones a los hombres por lo que el conocimiento sería compartido. En el caso de las entrevistas etnobotánicas también se registraron prácticas de colecta tanto en mujeres, niños y hombres. Respecto a las plantas comestibles, en contraposición a las anteriores se relevó más información de las fuentes escritas que de las etnobotánicas. En el caso de los órganos subterráneos, las fuentes bibliográficas evidenciaron que se iba a buscar la planta y se removía la tierra hasta encontrarlos. Los frutos eran recolectados y en algunos casos consumidos directamente. 
Se observa también a partir de cronistas y viajeros, la recolección de plantas en algunos casos planificada para la obtención de recursos que complementaran la carne y en otros casos asociadas a otras actividades (i.e. el traslado de un campamento; Musters [1869] 1964: 221).

Los criterios de selección registrados en las entrevistas etnobotánicas para los recursos leñosos estuvieron guiados por las siguientes variables: si la madera era de rápido encendido, si daba buena llama, si hacía brasa y la duración de la misma, si producía calor y si producía mucho humo. En función de estas propiedades, las que podrían ser desfavorables para un tipo de fuego podían ser ventajosas para otro. En el caso de humo para señales, por ejemplo, que la madera provocara mucho humo es un criterio valorado positivamente (i.e. Mulinum spinosum. neneo, Nardophyllum bryoides, mata torcida y Chuquiraga erinaceae, uña de gato). Sin embargo, en el caso de los fogones para cocinar, la leña más elegida por los entrevistados fue Schinus sp. Cuando no había disponibilidad de leña para elegir, se usaba la que estaba disponible en el entorno. Se utilizó la parte aérea de la planta y en las entrevistas se mencionó siempre el uso de leña seca para la combustión. Sin embargo, dada la cantidad de leña consumida es probable que cortaran leña y se dejara estacionar. Los informantes manifestaron colectar grandes cantidades de leña a fines del verano para abastecerse durante el invierno. En relación a los usos de los fuegos principalmente se registraron los de cocción y calor. En cuanto al encendido en las entrevistas etnobotánicas se mencionó el uso de bosta animal, así como matas de Pappostipa sp. y algunas especies como Verbena tridens, Mulinum spinosum, Nardophyllum bryoides y Chuquiraga erinaceae aunque estas últimas tres producían mucho humo.

Con respecto a la frecuencia de la recolección de leña, en las crónicas se hace referencia a una búsqueda continua en el tiempo: cada mañana las mujeres iban a recolectar leña y encendían el fogón (Claraz [1865-1866] 2008:93). En el caso del grupo tehuelche con el que compartió Musters gran parte de su recorrido, cuando se acercaban al bosque describe la recolección de madera para postes. El autor describe el corte de los troncos con herramientas de metal como las hachas melladas (Musters [1869] 1964:279). Se identificaron en las fuentes bibliográficas distintos usos del fuego: encendido de campos para obtener luz, calor y en otras ocasiones para señales, fogones domésticos alrededor de los cuales se trabajaba el cuero, se comía, se asaban los órganos subterráneos y la carne (Aguerre 2000, Cox [1862-1862]: 2006). De acuerdo a la información de Patty Chapalala, informante de Aguerre (2000) quien vivió en la toldería en el Río Pinturas, el 
fogón se ubicaba en el medio del toldo, adentro, durante el invierno, quedaba prendido todo el tiempo, y cuando se apagaba se limpiaba. Alrededor del fogón se ponían piedras para que no se corrieran las brasas, se dormía, se trabajaba los cueros, se disponían los lápices, cremas, ollas, y jarros. La ceniza se tiraba afuera en los basurales, lejos del toldo. En relación al encendido del fuego en las fuentes bibliográficas se registraron hongos, cera y fricción de Baccharis salicifolia.

En el caso de las plantas medicinales, como se dijo anteriormente, se relevó mas información a través de las entrevistas etnobotánicas que del análisis de las fuentes escritas. Se registraron dos prácticas de recolección: una en la que a partir de la aparición de la dolencia se buscaba la planta cuyas características la apaciguaran, porque "para qué se iba a almacenar si estaba en el campo". Otra, en la que se recolectaba la planta y se dejaba secar en la casa para usar en infusión aunque no apareciera la dolencia previamente. Es importante destacar que no se observó ni se registró en el discurso la mezcla de plantas medicinales, sino que cada una se consumía por separado a diferencia de lo registrado en trabajos etnobotanicos actuales en el oeste de Chubut y Río Negro, donde habitualmente los preparados medicinales se componen de más una sp. (Molares 2010).

Como se mencionó más arriba, luego de la recolección de plantas silvestres, se registraron prácticas de procesamiento. Sthal (1989) describe distintas técnicas de procesamiento poscosecha como maceración, tostado, molido entre otras, a fin de eliminar la toxicidad de la planta. Estas prácticas permiten obtener sustancias más digeribles y alimentos con formas y texturas diferentes (Parada y Aguilera 2007). En este sentido se registraron en las fuentes bibliográficas el tostado o hervido de órganos subterráneos, el tostado y la molienda de vainas de algarrobo, macerado de calafate entre otros. En el caso de las plantas medicinales la mayoría eran hervidas y consumidas como infusión, aunque también se registró la elaboración de emplastos. Las prácticas poscosecha fueron menos evidentes a partir de las fuentes etnobotánicas pero sí se registró el pelado, cortado, tostado, elaboración de bebidas y dulces, y un solo caso de molienda.

\subsubsection{Expectativas sobre las evidencias materiales de prácticas de recolección} que podrían encontrase en el registro arqueológico de Costa Norte de Santa

\section{Cruz}


El modelo se construyó a partir de datos tomados en momentos de contacto hispano indígena siglos XVI a XIX- y fuentes bibliográficas provenientes de los siglos, XX y XXI así como entrevistas etnobotánicas, a partir de lo cual se propone considerar qué evidencias de estas prácticas se pueden encontrar en el registro arqueológico.

En primer lugar, las familias que predominaron en ambas fuentes de datos tienen que tener un correlato con la información paleoambiental. En este sentido, si se considera la información palinológica obtenida para La María y Los Toldos (De Porras 2010) y se la extrapola a la estepa arbustiva del Golfo San Jorge hacia ca. de 4.100 año AP la vegetación sería similar a la actual.

Para corroborar la interacción de los hombres y las plantas a través de percepciones organolépticas, deberían reconocerse por un lado, en la flora local estructuras anatómicas de las plantas productoras de aceites esenciales y otros aleloquímicos como pelos glandulares, tricomas, cavidades y conductos secretores entre otros (Molares 2010). También que en la anatomía del leño se deberían identificar caracteres diagnósticos relacionados con la adaptación al ambiente (traqueidas vasculares, punteaduras areoladas, engrosamiento espiralado, entre otros).

En relación a las prácticas de recolección de los grupos cazadores recolectores la información obtenida refiere, en gran parte, a los grupos que habitaron el interior de la Patagonia continental argentina. De acuerdo a los antecedentes arqueológicos del proyecto CNSC, debería esperarse una mayor vinculación entre la recolección de vegetales y moluscos, u otras prácticas asociadas a los recursos costeros.

Deberían reconocerse estructuras de fogón con diversidad de taxa, con distintas propiedades de combustión que dieran cuenta de diferentes tipos de fogón (iluminación, calor, señales, doméstico). Se podría esperar recuperar en contextos arqueológicos de aleros y sitios a cielo abierto órganos subterráneos carbonizados asociados a fogones, que dieran cuenta de procesamientos poscolecta. También fragmentos de cerámica y artefactos de molienda que evidenciaran técnicas de molienda y hervido de vegetales. Se esperaría recuperar también artefactos manufacturados con vegetales como cestería, o instrumentos y material lítico que fuera potencialmente utilizado para cortar y procesar vegetales. 


\section{Parte II: El registro Arqueobotánico}




\section{El registro arqueobotánico de Patagonia continental: análisis bibliográfico}

\subsection{Introducción}

En este capítulo se realiza un análisis bibliográfico del registro arqueobotánico (macro y microrrestos) recuperado hasta el momento en la Patagonia continental Argentina. El mismo se basa en una minuciosa recopilación de la información disponible, donde se registra, de cada publicación: la identificación taxonómica, el estado de preservación (carbonizado o seco), la parte vegetal de los restos recuperados y la cronología del hallazgo. El objetivo general del análisis es caracterizar el registro arqueobotánico disponible macro-regionalmente y comparar este conjunto de datos con aquel derivado del análisis de los documentos escritos presentado en el Capítulo 4. De esta manera, se evaluarán las correspondencias entre uno y otro corpus de información, así como las continuidades y discontinuidades en las prácticas de uso de los vegetales. Se pretende que el desarrollo de este objetivo permita, al final de esta tesis, evaluar los resultados arqueobotánicos del área de estudio (CNSC) con respecto al uso de plantas registrado para la Patagonia continental a lo largo del tiempo y en función de las diferencias espaciales de la región.

\subsection{Metodología}

En primer lugar se realizó una búsqueda bibliográfica de aquellas publicaciones que mencionaran la presencia de restos arqueobotánicos que estuvieran identificados taxonómicamente. Una vez realizada la compilación se registró: tipo de restos recuperados (taxa y parte vegetal), período temporal y estado de preservación (seco o carbonizado). Asimismo, se dispuso en un mapa la localización de los sitios donde fueron recuperados para observar la distribución espacial de aquellos con restos vegetales identificados. 


\subsection{Resultados y Discusión}

Se registraron 31 publicaciones que describen e identifican taxonómicamente restos arqueobotánicos para la Patagonia continental argentina (ver Figura 6.1).

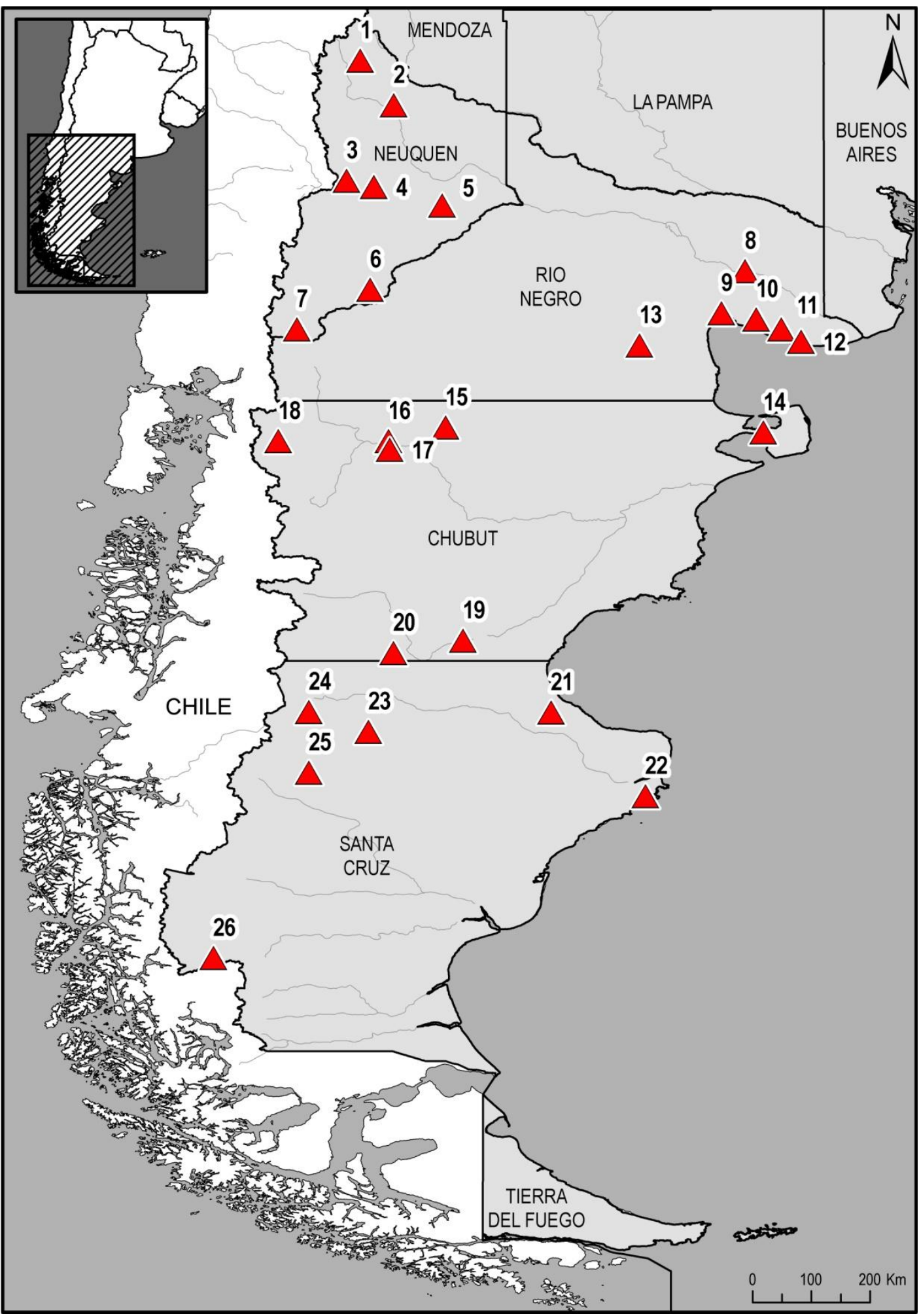

Figura 6.1. Distribución de los sitios arqueológicos con restos arqueobotánicos identificados taxonómicamente. 1 y 5 Lema et al. 2012; 2 Ancibor 1981/1982 y Fernández1981/82; 3 Podestá y Pereda 
1979; Ancibor 1988/1990; 6 Crivelli Montero et al. 1996; Rivera 1996, Urrutia y Bogazi 1996 y Palacios 2007; 7 Pérez y Erra 2011; 8 Capparelli y Prates 2010; 9-12 Ortega y Marconetto 2009, 2012; 13 Prates et al. 2011 y Capparelli y Mange 2014; 14 Outes 1915; 15 Casamiquela 1960; 16 Nacuzzi y Pérez de Micou 1983/85, Pérez de Micou et al. 1992; 17 Marconetto 2002; 18 Arrigoni 2002; 19 Gradín 1978; 20 Pérez de Micou et al. 2009; 21 Ciampagna 2012; 22 Capparelli et al. 2009 y Ciampagna et al. 2011; 23 Gradín y Aguerre 1994; 24 Caruso y Capparelli 2013; 25 Aschero 1981/1982; 26 Mehl y Franco 2009.

Se observó que solo en cuatro trabajos (Pérez y Erra 2011, Ciampagna et al. 2011, Ciampagna 2012 y Lema et al. 2012) se registraron microrrestos (fitolitos en el primer caso, restos de tejido epidérmico y almidones en el segundo, almidones en el tercero y almidones y fitolitos en el último). En las 27 publicaciones restantes se identificaron macrorrestos desecados y carbonizados, tales como: palitos de caña decorados, leños, instrumentos manufacturados a partir de vegetales, cestería, acumulaciones de vegetales utilizados como relleno, ovillos de fibras, órganos reservantes y carporrestos, entre otros. Se identificaron 70 taxa (clase, familia, género, especie) pertenecientes a 30 familias (Figura 6.2), de las que predominan Poaceae, Asteraceae y Fabaceae. Estas dos últimas también predominan en las fuentes documentales escritas (ver Capítulo 4). Es llamativo que 7 familias presentes en el registro arqueobotánico no están mencionadas en la base de datos de las fuentes documentales (Capítulo 4). No obstante, es importante aclarar que se registraron 64 citas de la base de datos documental que aluden al uso de plantas pero carecen del nombre científico de las mismas, por lo que cabe la posibilidad de que algunas de estas familias estén comprendidas dentro de dichas citas, aunque hasta el momento no se han registrado correspondencia entre el uso inferido en el registro arqueobotánico y las citas de las fuentes documentales. Asimismo, existen numerosas familias mencionadas en la base de datos documental que no están representadas en el registro arqueobotánico. Esto puede deberse a un efectivo "no uso" de la planta, aunque así también a lo fragmentario del registro, a la escasez de sitios arqueológicos analizados, y/o a falencias metodológicas en la búsqueda de restos botánicos, tales como una falta de sistematicidad en la disciplina hasta la segunda mitad del siglo XX, procesos tafonómicos entre otros (Capparelli et al. 2007). No obstante estas consideraciones, se pueden establecer algunas comparaciones, tal como se describe a continuación. 


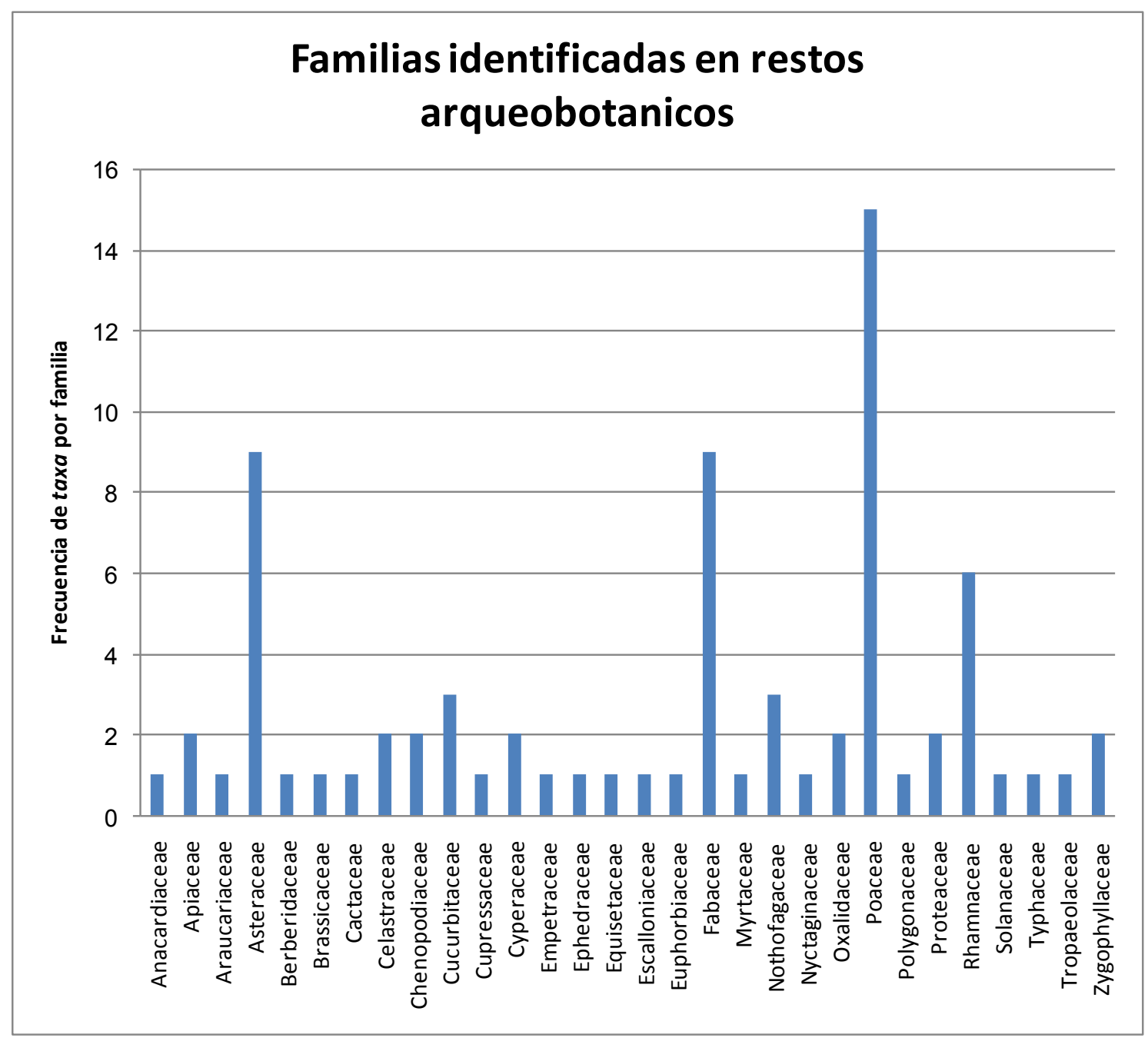

Figura 6.2. Frecuencia de taxa por familias identificadas en los macro y microvestigios de Patagonia continental.

En relación al procesamiento y a las partes de las plantas utilizadas, dentro de los restos arqueológicos se evidencian tallos (secos y carbonizados), órganos subterráneos almacenadores (secos), frutos y semillas (carbonizados), fibras (secas), entre otros. Éstos han sido interpretados como derivados del consumo de partes de plantas cocidas (i.e. rizomas carbonizados asociados al fogón de Oxalis articulata; vainas carbonizadas de Prosopis alpataco, Prosopis denudans, Capparelli y Prates 2009), de la recolección y procesamiento de fibras para la realización de cestería (i.e. Ephedra sp., Podestá y Pereda 1979), de la carbonización de leños utilizados como combustible (i.e. Chuquiraga avellanedae, Anarthrophyllum rigidum, Nacuzzi y Pérez de Micou 1983/1985, Pérez de Micou et al. 1992) y de la manufactura y decoración de cañas (i.e. cañas decoradas de Chusquea culeou, Crivelli Montero et al. 1996). Todos estos tipos 
de prácticas están representadas en las fuentes etnohistóricas que en este trabajo se relevaron.

Dentro del registro de macrorrestos cabe remarcar la presencia de cuatro especies que no son propias de la región: Zea mays, cf. Lagenaria siceraria, Cucurbita maxima y Ziziphus mistol, siendo las tres primeras cultivadas y la última una especie que crece en el chaco y en el monte, en el noreste de la República Argentina. La presencia de estos taxa podría estar evidenciando o bien el cultivo/recolección, según el caso, de los mismos, o bien el intercambio de bienes y recursos entre grupos originarios y entre éstos y los colonos y/o gobernantes; así como también la ampliación de las áreas de dispersión de los grupos patagónicos. En las fuentes documentales escritas se encontraron alusiones a las dos últimas posibilidades, pero no a la primera. Por ejemplo, Viedma y Villarino ([1780-1783] 2006) manifiestan el pedido de manufacturas y recursos, de los caciques a los gobernadores de los asentamientos cercanos a los asentamientos aborigenes; mientras que Musters ([1869]1964) menciona que la gran movilidad de los grupos posibilitaba el contacto con otras parcialidades, lo que permitía la obtención de otro tipo de recursos distintos a los de las colonias.

En cuanto a los recursos leñosos utilizados como combustible, en el registro arqueobotánico, no sólo se encuentran aquellos que son vestigios de la combustión (macrorrestos leñosos carbonizados), sino también aquellos utilizados para el encendido del fuego (palos de caña con ápices aguzados descriptos en Ancibor 1988/1990), lo cual coincide con las aplicaciones más frecuentes mencionadas en las fuentes etnohistóricas. En estas últimas se registró el uso de 16 especies leñosas, mientras que dentro del registro arqueobotánico se identificaron hasta el momento 17 especies. A través de un mayor énfasis en la identificación taxonómica del registro antracológico se podrá ampliar el conocimiento de los taxa utilizados como leña en momentos prehispánicos.

Por otra parte, en cuanto a la distribución de los sitios arqueológicos donde se recuperaron macro y/o microrrestos vegetales, los que poseen mayor densidad y diversidad de hallazgos se encuentran en la provincia de Neuquén (Ancibor 1981/1982; Ancibor 1988/1990; Crivelli Montero et al. 1996; Rivera 1996, Urrutia y Bogazzi 1996; Podestá y Pereda 1979; Lema et. al 2012; Pérez y Erra 2011). En el caso de Río Negro, se encontraron restos arqueobotánicos en los sitios La Angostura I y Cueva Galpón, a 150 y $80 \mathrm{~km}$ de la costa respectivamente (Capparelli y Prates 2009, Capparelli y Mange 2014) y en los sitios costeros de Bajo de la Quinta y Promontorio Belén (Ortega y Marconetto 2009, 2012). En cuanto a Chubut, la mayor cantidad de hallazgos se registra 
en el valle de Piedra Parada, centro oeste de la provincia (Nacuzzi y Pérez de Micou 1983/1985, Pérez de Micou et al. 1992, Marconetto 2002), no obstante también se han recuperado restos vegetales en Colonia Sarmiento (Gradín 1978), Gastre (Casamiquela 1960) y en el Parque Nacional Los Alerces (Arrigoni 2002). En Santa Cruz, se encuentran hallazgos en la costa (Capparelli et al. 2009, Ciampagna et al. 2011 y la presente tesis) y en el área del Río Pinturas (Aschero 1981-1982; Gradín et al. 1987, Gradín y Aguerre 1994). Entonces, Neuquén y en general en el oeste antes que el este, sobresale por la densidad de su registro arqueobotánico, así como también Chubut; mientras que Santa Cruz es la provincia donde se observa menor diversidad de vestigios vegetales.

\subsection{Conclusiones}

El análisis bibliográfico del registro arqueobotánico de Patagonia continental argentina, y su comparación con la base de datos de las fuentes documentales, sugieren un papel importante de las prácticas de recolección de plantas silvestres en los modos de vida de los grupos cazadores recolectores en concordancia con lo explicitado por Nacuzzi y Pérez de Micou (1983/1985), Casamiquela (1999), Prates (2009), Ochoa et al. (2011), y Frank (2011).

Es relevante la gran diversidad de taxa vegetales registrados, tanto en las fuentes documentales como en el registro arqueobotánico, a pesar de que este último es aún escaso. Predominan en ambos tipos de registros, las familias Asteraceae y Fabaceae, pero en los restos arqueobotánicos predomina también Poaceae, mientras que en las fuentes documentales lo hace Apiaceae.

No obstante, existen diferencias en las categorías de usos que se presentan en las fuentes históricas (comestibles, medicinales, bebibles, fumitorios, combustibles, para la elaboración de armas, de aseo, tintóreos, para extraer veneno o pegamentos y elementos de montura), con respecto a las del registro arqueobotánico (comestible, combustible, activadores de fuego, materia prima para la confección de recipientes, cestas, palas e instrumentos de caza, y fardos de almacenamiento o inhumaciones). Por ejemplo, en las fuentes escritas, es llamativa la ausencia de referencias a la manufactura de cestería, en tanto que en el registro arqueobotánico están ausentes las dos categorías más representadas en las fuentes documentales: medicinales y bebibles. 
En las fuentes documentales se registró una gran cantidad de prácticas de procesamiento que evidencian un conocimiento botánico tradicional y una profundidad temporal que permitirían pensar en su potencial representación en el registro arqueobotánico. Por ello, se considera pertinente poner más énfasis, en el futuro, en la recuperación de restos botánicos a partir de artefactos susceptibles de haber sido utilizados para el procesamiento de vegetales en el pasado, tales como, molinos y/o morteros, vasijas cerámicas, pipas, que permitan evaluar no sólo tipos de uso de las plantas sino las prácticas involucradas en su transformación para hacerlas aptas para el consumo, en un sentido amplio (i.e. Cueto et al. 2010, Ciampagna et al. 2011 y Ciampagna 2012).

Se observa una disminución en la cantidad absoluta de macro y microrrestos recuperados en sentido nornoroeste-sur de la Patagonia continental Argentina. Como se menciona más arriba, en el registro arqueobotánico se observa mayor cantidad de restos recuperados, categorías de uso y prácticas en Neuquén, Río Negro y Chubut, mientras que, Santa Cruz presenta una menor cantidad y variabilidad. Esto puede deberse a varios motivos, en primer lugar, porque en Patagonia en términos generales la diversidad y altura de la vegetación disminuye en sentido NO- SE. En segundo lugar, y en el caso específico de la provincia de Santa Cruz, se observa una disminución en diversidad y altura de las plantas desde el NO y NE de la provincia hacia la meseta central, donde se distribuye la estepa de arbustos enanos. En el NO de Santa Cruz, se registra la zona del complejo Andino (Oliva et al. 2001) conformado por un mosaico de bosques de Nothofagus. Es en el ecotono entre estos bosques y la estepa, en el Parque Nacional Perito Moreno, en el que se recuperan restos carbonizados de cf. Astragalus, frutos carbonizados de Empetrum rubrum, dos frutos de Carex desecados, entre otros aún no identificados del sitio Cerro Casa de Piedra 7 (Caruso y Capparelli 2013). Estos macrorrestos se hallaron asociados a un fogón cuyos carbones vegetales también fueron identificados. La relevancia de estos restos vegetales se encuentra en su fechado: 9.390 \pm 40 años AP (Caruso y Capparelli 2013), ya que es el más antiguo para un contexto de este tipo de toda Patagonia continental Argentina. Por otra parte, estudios microhistológicos de coprolitos humanos recuperados en el mismo sitio habrían identificado tejidos de frutos de Empetrum rubrum en dichos restos para un fechado posterior (ca. 6.150 años AP, Martinez y Yagueddú 2012) lo que evidenciaría y reforzaría la premisa del consumo humanos de estos frutos.

Entonces, la menor cantidad de restos arqueobotánicos en Santa Cruz puede deberse a que hay una menor diversidad de taxa en la meseta central (Oliva et al. 2001), pero 
también a que el desarrollo arqueobotánico en esta provincia de forma sistemática y articulada con los proyectos arqueológicos comenzó a desarrollarse en los últimos años. Si bien el oeste de Patagonia continental argentina presenta mayor diversidad de especies con respecto al este, se han recuperado macro y microrrestos vegetales tanto en la zona de bosques y en el oeste patagónico (Ancibor 1988/1990, Rivera 1996, Crivelli Montero et al. 1996, Lema et al. 2012), en la estepa (Nacuzzi y Pérez de Micou 1983/1985, Marconetto 2002, Pérez de Micou et al. 1992) a 150 y $80 \mathrm{~km}$ de la costa (Capparelli y Prates 2009, Capparelli y Mange 2014), como en la costa propiamente dicha (Capparelli et al. 2009, Ciampagna et al. 2011, Ciampagna 2012). Por otra parte, más allá de la distribución de las especies, es importante remarcar la importancia de los recursos vegetales en la inferencia sobre la circulación de materias primas, artefactos o contactos entre los grupos nativos. En este sentido, es relevante mencionar los hallazgos de fragmentos de caña, intermediarios de astiles entre otros confeccionados con Chusquea spp. cuya distribución abarca el distrito del Pehuén, en el centro-oeste de Neuquén y el distrito del Bosque caducifolio ambos pertenecientes a la provincia fitogeográfica Subantártica o Bosque Andino Patagónico en el que esta especie tiene una distribución desde Neuquén hasta Chubut (Cabrera 1971, Zuloaga y Morrone 1999). En Neuquén, en el sitio Cueva Chenque Haichol, se recuperó una caña decorada manufacturada con esta especie con una datación de 1.390 años AP (Ancibor 1988/1990). Asimismo, en Piedra del Águila, sobre la cuenca del Río Limay se recuperó un astil confeccionado con dicha materia prima vegetal en un contexto de entre $2.180 \mathrm{y}$ 1.080 años AP (Palacios 2007). Si bien, estos sitios se encuentran en áreas próximas a la distribución de la especie, se recuperaron artefactos manufacturados sobre Chusquea en áreas más distantes tales como los del sitio El Mallín y un fragmento carbonizado en el sur de Mendoza, en la parte media del valle del Río Atuel en el sitio Aroyo Malo 3 (Andreoni 2014), ambos a aproximadamente $300 \mathrm{~km}$ de la distribución actual de Chusquea. El hallazgo de un artefacto manufacturado, tipo intermediario, con esta materia prima vegetal en el sitio Cueva Galpón en Río Negro (datado en $3350 \pm 50$ años AP), a $80 \mathrm{~km}$ de la costa Atlántica y a $400 \mathrm{~km}$ de la distribución de Chusquea (Prates et al. 2011, Capparelli y Mange 2014) evidencia aún más la circulación de artefactos, de la materia prima o el intercambio entre los grupos aborígenes.

En la provincia de Chubut, en la estepa sobre el Valle de Piedra Parada, en el sitio Piedra Parada I, a aproximadamente $100 \mathrm{~km}$ del Bosque Caducifolio, se recuperó una pinza de caña con extremos carbonizados de Chusquea culeou cuyo contexto fue 
fechado en $1330 \pm 50$ años AP (Nacuzzi y Pérez de Micou 1983/1985). En la localidad de Gastre, en la Estancia Moré Niyeo, a $150 \mathrm{~km}$ de la distribución de la especie, Casamiquela (1960) registró fragmentos de caña asociados a un enterratorio. Más distante aún del área de distribución de esta especie, a ca. $550 \mathrm{~km}$, Outes (1915) menciona el hallazgo de un astil de caña asociado a un enterratorio en el sitio Cerrito de las Calaveras en Península Valdez. Hacia el sur de la Provincia de Chubut a una distancia entre 100 y $150 \mathrm{~km}$ del Bosque Caducifolio, se recuperaron un fragmento de Chusquea culeou asociado a un contexto de enterratorio ca. 200 años AP en el Alero Mazquiarán, situado en un cañadón antecedente del Río Guenguel (Pérez de Micou et al. 2009); mientras que en Colonia Sarmiento, se identificaron también fragmentos de caña de esta especie en el Cerro Shequen (Gradín 1978:80).

Para Santa Cruz no se han registrado hasta el momento artefactos confeccionadas con esta especie, sin embargo, en el sitio Casa de Piedra 5 se registró un intermediario de astil confeccionado con Nothofagus pumilio (Aschero 1981-1982), y en el sitio Cueva del Negro un fragmento de arpón manufacturado con madera de Berberis sp. (Capparelli et al. 2009). Es posible que se haya reemplazado el uso de caña por maderas de mayor densidad para la confección de artefactos hacia el sur de Chubut, o bien que debido a la disparidad del registro arqueobotánico aún no se han recuperado instrumentos manufacturados con esta especie.

Este registro particular de los hallazgos de Chusquea spp. fue analizado en esta discusión para remarcar el valor de los recursos vegetales silvestres como evidencias para discutir la circulación de bienes y materias primas, así como posibles intercambios entre los grupos cazadores recolectores de Patagonia.

Las diferentes técnicas de recuperación de los restos arqueobotánicos, así como los distintos contextos de hallazgos dificultan pensar en la ubicuidad de especies a lo largo del tiempo, teniendo en cuenta los sesgos que se pueden producir por lo fragmentario del registro. Sin embargo, es importante mencionar que desde el Holoceno temprano (Caruso y Capparelli 2013) al Holoceno tardío final (i.e. Fernández 1981-1982, Ciampagna et al 2011) se registra la utilización de recursos vegetales silvestres. Los fechados más tempranos para la incorporación de especies domesticadas (i.e. Zea mays) provienen del análisis de microrrestos en Neuquén para 1750 años AP en combinación con el consumo de plantas silvestres (i.e. Prosopis sp.).

Se considera que los resultados obtenidos al analizar el registro arqueobotánico de Patagonia continental argentina permiten no sólo formular nuevas hipótesis sino realizar 
una aproximación a comprender distintos procesos que sólo pueden ser vistos ampliando la escala (i.e. circulación de bienes e intercambio).

\begin{tabular}{|c|c|c|c|}
\hline Nombre científico & Familia & Cronología & $\begin{array}{l}\text { Publicación } \\
\text { arqueobotánica/Uso } \\
\text { registrado en las fuentes } \\
\text { documentales }\end{array}$ \\
\hline Agrostis sp. L. [MD] & Poaceae & $\begin{array}{l}5000 \text { a comienzos del } \\
\text { s. XX }\end{array}$ & $\begin{array}{l}\text { Crivelli Montero et } a l . \\
(1996) / \mathrm{No}\end{array}$ \\
\hline $\begin{array}{l}\text { Agrostis leptotricha } \\
\text { E. Desv. [MD] }\end{array}$ & Poaceae & 5000 a 1000 años AP & $\begin{array}{l}\text { Crivelli Montero et al. } \\
(1996) / \mathrm{No}\end{array}$ \\
\hline $\begin{array}{l}\text { Anarthrophyllum } \\
\text { rigidum (Gilies ex } \\
\text { Hook) \& Arn. } \\
{[\mathrm{MLC}]}\end{array}$ & Fabaceae & $\mathrm{s} / \mathrm{d} / 9.390 \pm 40$ años AP & $\begin{array}{l}\text { Pérez de Micou et al. (1992) } \\
\text { Caruso y Capparelli 2013/Si. }\end{array}$ \\
\hline $\begin{array}{lr}\text { cf. } & \text { Araucaria } \\
\text { araucana } & \text { (Molina) } \\
\text { K. Koch } & \text { [MLD] } \\
\end{array}$ & Araucariaceae & $\mathrm{s} / \mathrm{d}$ & Ancibor (1988/1990)/ Si \\
\hline $\begin{array}{l}\text { Araucaria araucana } \\
\text { (Molina) K. Koch } \\
{[\mathrm{MC}]}\end{array}$ & Araucariaceae & $\mathrm{s} / \mathrm{d}$ & $\begin{array}{l}\text { Crivelli Montero et al. } \\
(1996) / \mathrm{Si}\end{array}$ \\
\hline $\begin{array}{l}\text { Araucaria araucana } \\
\text { (Molina) K. Koch } \\
{[\mathrm{MC}]}\end{array}$ & Araucariaceae & $\begin{array}{lrr}630 \pm 80 & \text { años } & \text { AP } \\
585 \pm 75 \text { años } & \text { AP } & \text { y } \\
350 \pm 70 \text { AP } & & \\
\end{array}$ & Fernández 1981-1982/si \\
\hline $\begin{array}{l}\text { cf. Arjona tuberosa } \\
\text { Cav. [MD] }\end{array}$ & Santalaceae & $\begin{array}{l}780 \pm 80 \quad \text { años } \\
\mathrm{AP} / 860 \pm 80 \text { años AP }\end{array}$ & $\begin{array}{l}\text { Pérez de Micou et al. 1992/ } \\
\text { si }\end{array}$ \\
\hline cf. Astragalus [MC] & Fabaceae & $9.390 \pm 40$ años AP & Caruso y Capparelli 2013/ si \\
\hline Atriplex sp L [MLC] & Chenopodiaceae & $\begin{array}{l}1380 \pm 90 \text { años AP, y } \\
800 \pm 90 \text { años AP; s/d }\end{array}$ & $\begin{array}{l}\text { Ortega y Marconetto (2009 y } \\
2012) \text {; Marconetto (2002)/Si }\end{array}$ \\
\hline Atriplex sp L [MD] & Chenopodiaceae & $\begin{array}{l}(780 \pm 80 \text { años } \\
/ 860 \pm 80 \text { años } \\
/ 5080 \pm 100 \text { años } \\
4885 \pm 135 \text { AP } \\
4 \text { APos AP }\end{array}$ & $\begin{array}{l}\text { Pérez de Micou et al } \\
(1992) / \mathrm{si}\end{array}$ \\
\hline $\begin{array}{lr}\text { Austrocactus } & \text { aff. } \\
\text { bertinii } & \text { (Cels) } \\
\text { Britton \& Rose [MD] }\end{array}$ & Cactaceae & $\begin{array}{l}7000 \quad \text { años } \text { AP } \\
\text { comienzos del s. XX }\end{array}$ & $\begin{array}{l}\text { Crivelli Montero et al. } \\
(1996) / \text { No }\end{array}$ \\
\hline $\begin{array}{l}\text { Austrocedrus } \\
\text { chilensis (D. Don) } \\
\text { Pic. Serm.\& Bizarri } \\
\text { [MD] }\end{array}$ & Cupressaceae & $\mathrm{s} / \mathrm{d}$ & Ancibor $(1988 / 1990) / \mathrm{No}$ \\
\hline Baccharis sp & Asteraceae & $\begin{array}{l}780 \pm 80 \quad \text { años } \\
\mathrm{AP} / 860 \pm 80 \text { años AP }\end{array}$ & $\begin{array}{l}\text { Pérez de Micou et al (1992) } \\
\text { /si }\end{array}$ \\
\hline $\mathrm{s} / \mathrm{i}[\mathrm{MC}]$ & Brassicaceae & $1330 \pm 50$ años AP & $\begin{array}{l}\text { Nacuzzi y Perez de Micou } \\
(1983 / 1985) \\
\text { Brassicaceae }\end{array}$ \\
\hline Berberis sp [MD] & Berberidaceae & $\begin{array}{l}5080 \pm 100 \text { años AP a } \\
780 \pm 80 \text { años AP }\end{array}$ & $\begin{array}{l}\text { Pérez de Micou et al (1992) } \\
\text { /si }\end{array}$ \\
\hline Berberis sp. [MLC] & Berberidaceae & $\begin{array}{l}\text { s/d; } 9.390 \pm 40 \text { años } \\
\text { AP }\end{array}$ & $\begin{array}{l}\text { Marconetto (2002) Caruso y } \\
\text { Capparelli (2013)/Si }\end{array}$ \\
\hline Berberis sp. [MC] & Berberidaceae & $1340 \pm 60$ años AP & Capparelli et al. (2009)/si \\
\hline Berberis sp. [MC] & Berberidaceae & $\begin{array}{l}\text { ca. } 6270 \text { y } 5400 \text { años } \\
\text { AP. }\end{array}$ & Mhel y Franco (2009)/si \\
\hline 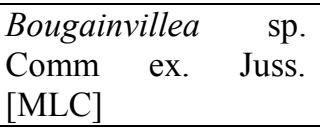 & Nyctaginaceae & $\begin{array}{l}2777 \pm 54 \text { años } \mathrm{AP} / 800 \\
\pm 90 \text { años } \mathrm{AP}\end{array}$ & $\begin{array}{l}\text { Ortega y Marconetto (2009 } \\
\text { y 2012)/no }\end{array}$ \\
\hline $\begin{array}{l}\text { Bromus catharticus } \\
\text { Vahl. [MD] }\end{array}$ & Poaceae & $\begin{array}{l}5000 \text { años AP a } 1000 \\
\text { años AP }\end{array}$ & 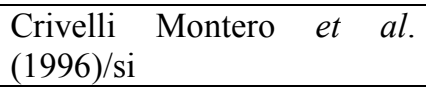 \\
\hline
\end{tabular}




\begin{tabular}{|c|c|c|c|}
\hline $\begin{array}{l}\text { Bromus catharticus } \\
\text { Vahl. [MD] }\end{array}$ & Poaceae & $\begin{array}{l}480 \pm 75 \text { años } \mathrm{AP} / \\
1330 \pm 50 \text { años AP }\end{array}$ & $\begin{array}{l}\text { Nacuzzi y Perez de Micou } \\
(1983 / 1985) \text { Pérez de Micou } \\
(1979 / 1982) / \text { si }\end{array}$ \\
\hline $\begin{array}{l}\text { Bromus setifolius } \mathrm{J} . \\
\text { Pressl [MD] }\end{array}$ & Poaceae & $\begin{array}{l}5000 \quad \text { años AP } \quad \text { a } \\
\text { comienzos del s. XX }\end{array}$ & $\begin{array}{l}\text { Crivelli Montero et al. } \\
\text { (1996); /Bromus catharticus }\end{array}$ \\
\hline $\mathrm{s} / \mathrm{i}[\mathrm{MD}]$ & Cactaceae & $1750 \pm 80$ años AP & $\begin{array}{l}\text { Pérez de Micou et al. (1992) } \\
\text { /si Cactaceae }\end{array}$ \\
\hline Carex sp. L. [MD] & Poaceae & $\mathrm{s} / \mathrm{d} / 9.390 \pm 40$ años AP & $\begin{array}{l}\text { Ancibor (1988/1990) Pérez } \\
\text { de Micou } \\
\begin{array}{l}(1979 / 1982), \\
\text { Caruso y } \\
(2013) / \text { no }\end{array}\end{array}$ \\
\hline $\begin{array}{l}\text { Chuquiraga } \\
\text { avellanedae Lorentz } \\
{[\mathrm{MLC}]}\end{array}$ & Asteraceae & $1330 \pm 50$ años AP & $\begin{array}{l}\text { Nacuzzi y Perez de Micou } \\
(1983 / 1985) / \mathrm{Si}\end{array}$ \\
\hline $\begin{array}{l}\text { Chuquiraga } \\
\text { avellandedae Lorentz } \\
\text { [MD] }\end{array}$ & Asteraceae & $\begin{array}{l}780 \pm 80 \quad \text { años } \\
\mathrm{AP} / 860 \pm 80 \text { años AP }\end{array}$ & Pérez de Micou et al. (1992) \\
\hline Chuquiraga sp [MD] & Asteraceae & $\begin{array}{l}5080 \pm 100 \text { años } \mathrm{AP} / \\
4885 \pm 135 \text { años } \\
\mathrm{AP} / 4770 \pm 90 \mathrm{AP} \\
3350 \pm 90 \mathrm{AP} / 1750 \pm 80 \\
\mathrm{AP}\end{array}$ & $\begin{array}{l}\text { Pérez de Micou et al. } \\
(1992) / \mathrm{si}\end{array}$ \\
\hline $\begin{array}{l}\text { Chuquiraga sp. Juss } \\
\text { [MLC] }\end{array}$ & Asteraceae & $\begin{array}{l}2100 \pm 35 \text { años AP/ } \\
1380 \pm 90 \text { años AP }\end{array}$ & $\begin{array}{l}\text { Ortega y Marconetto (2009 } \\
\text { y 2012) / si }\end{array}$ \\
\hline $\begin{array}{l}\text { Chuquiraga sp. Juss } \\
\text { [MLC] }\end{array}$ & Asteraceae & $\begin{array}{l}1100 \text { años AP a } \\
\text { comienzos del s. XX }\end{array}$ & Rivera (1996)/si \\
\hline $\begin{array}{l}\text { Chusquea culeou E. } \\
\text { Desv. [MLD] }\end{array}$ & Poaceae & $\mathrm{s} / \mathrm{d}$ & Outes $(1915) / \mathrm{si}$ \\
\hline $\begin{array}{l}\text { Chusquea culeou E. } \\
\text { Desv. [MLD] }\end{array}$ & Poaceae & $\mathrm{s} / \mathrm{d}$ & Casamiquela (1960)/si \\
\hline $\begin{array}{l}\text { Chusquea culeou E. } \\
\text { Desv. [MLD] }\end{array}$ & Poaceae & $\mathrm{s} / \mathrm{d}$ & Gradín (1978)/si \\
\hline $\begin{array}{l}\text { Chusquea culeou E. } \\
\text { Desv. [MLD] }\end{array}$ & Poaceae & $\begin{array}{l}630 \pm 80 \quad \text { años } \\
585 \pm 75 \text { años AP }\end{array}$ & Fernández 1981-1982 /si \\
\hline $\begin{array}{l}\text { Chusquea culeou E. } \\
\text { Desv. [MLD pero } \\
\text { con extemo } \\
\text { carbonizado] }\end{array}$ & Poaceae & $1330 \pm 50$ años AP & $\begin{array}{l}\text { Nacuzzi y Perez de Micou } \\
(1983 / 1985) / \mathrm{si}\end{array}$ \\
\hline $\begin{array}{l}\text { Chusquea culeou E. } \\
\text { Desv. [MLD] }\end{array}$ & Poaceae & $\begin{array}{l}5000 \quad \text { años } \quad \text { AP } \\
\text { comienzos del s. XX }\end{array}$ & $\begin{array}{l}\text { Crivelli Montero et al. } \\
(1996) / \mathrm{si}\end{array}$ \\
\hline $\begin{array}{l}\text { Chusquea culeou E. } \\
\text { Desv. [MLD] }\end{array}$ & Poaceae & $2190 \pm 60$ años AP. & Palacios (2007)/si \\
\hline $\begin{array}{l}\text { Chusquea culeou E. } \\
\text { Desv. [MLD] }\end{array}$ & Poaceae & ca. 200 años AP & Pérez de Micou et al. 2009 \\
\hline $\begin{array}{l}\text { Chusquea sp. Kunth } \\
\text { [MLD] }\end{array}$ & Poaceae & $\mathrm{s} / \mathrm{d}$ & Ancibor (1988/1990)/ si \\
\hline $\begin{array}{l}\text { Chusquea sp. Kunth } \\
\text { [MLD] }\end{array}$ & Poaceae & 3300 años AP & $\begin{array}{lll}\text { Prates et } & \text { al. } & (2011) / \\
\text { Capparelli } & \text { y } & \text { Mange } \\
(2014) / \mathrm{si} & & \end{array}$ \\
\hline $\begin{array}{l}\text { Chusquea sp. Kunth } \\
\text { [MLD] }\end{array}$ & Poaceae & $210 \pm 70$ años AP & $\begin{array}{l}\text { Pérez de Micou et al. } \\
(1992) / \mathrm{si}\end{array}$ \\
\hline $\begin{array}{l}\text { Colletia sp. Comm } \\
\text { ex Juss. }\end{array}$ & Rhamnaceae & $\begin{array}{l}780 \pm 80 \quad \text { años } \\
\mathrm{AP} / 860 \pm 80 \text { años AP }\end{array}$ & $\begin{array}{l}\text { Pérez de Micou et al. } \\
(1992) / \text { no }\end{array}$ \\
\hline Colliguaja $s p$ & Euphorbiaceae & 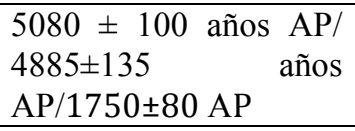 & $\begin{array}{l}\text { Pérez de Micou et al. } \\
(1992) / \mathrm{si}\end{array}$ \\
\hline Colliguaja & Euphorbiaceae & 5000 años AP $\quad$ a & Crivelli Montero et $a l$. \\
\hline
\end{tabular}




\begin{tabular}{|c|c|c|c|}
\hline $\begin{array}{l}\text { integerrima Gilies \& } \\
\text { Hook [MD] }\end{array}$ & & comienzos del s. XX & $(1996) / \mathrm{si}$ \\
\hline $\begin{array}{l}\text { Colliguaja } \\
\text { integerrima Gilies \& } \\
\text { Hook [MD] } \\
\end{array}$ & Euphorbiaceae & $780 \pm 80 \mathrm{BP} / 860 \pm 80 \mathrm{BP}$ & $\begin{array}{l}\text { Pérez de Micou et al. } \\
(1992) / \mathrm{si}\end{array}$ \\
\hline $\begin{array}{l}\text { Colliguaja } \\
\text { integerrima Gilies \& } \\
\text { Hook [MLC] }\end{array}$ & Euphorbiaceae & $\mathrm{s} / \mathrm{d}$ & Marconetto (2002)/Si \\
\hline Condalia sp. [MLC] & Rhamnaceae & $\begin{array}{l}1380 \pm 90 \text { años } \mathrm{AP} / \\
800 \pm 90 \text { años AP }\end{array}$ & $\begin{array}{l}\text { Ortega y Marconetto (2009 y } \\
\text { 2012)/Si }\end{array}$ \\
\hline Cortaderia sp. [MD] & Poaceae & $\mathrm{s} / \mathrm{d}$ & $\begin{array}{l}\text { Pérez de Micou (1979- } \\
\text { 1982)/Si }\end{array}$ \\
\hline $\begin{array}{ll}\text { Cucurbita maxima } \\
\text { Dutch [MD] }\end{array}$ & Cucurbitaceae & $\begin{array}{l}1000 \quad \text { años } \quad \text { AP } \\
\text { comienzos del s. XX }\end{array}$ & $\begin{array}{l}\text { Urrutia y Bogazzi (1996)/ Si } \\
\text { cf. Cucurbita }\end{array}$ \\
\hline $\mathrm{s} / \mathrm{i}[\mathrm{MC}]$ & Cyperaceae & $1330 \pm 50$ años $\mathrm{AP}$ & $\begin{array}{l}\text { Nacuzzi y Pérez de Micou } \\
(1983 / 1985) / \text { si Cyperaceae }\end{array}$ \\
\hline $\mathrm{s} / \mathrm{i}[\mathrm{m}]$ & Cucurbitaceae & & Lema et al. (2012)/Si \\
\hline $\begin{array}{l}\text { Dasyphyllum } \\
\text { diacanthoides (Less.) } \\
\text { Cabrera [MD] }\end{array}$ & Asteraceae & $\mathrm{s} / \mathrm{d}$ & Ancibor (1988/1990)/No \\
\hline $\begin{array}{l}\text { Discaria chacaye (G. } \\
\text { Don) Tortosa [MD] }\end{array}$ & Rhamnaceae & 1000 años AP & $\begin{array}{l}\text { Gradin y Aguerre (1994)/si } \\
\text { Discaria americana Gilies } \\
\text { \& Hook. }\end{array}$ \\
\hline Discaria sp. [MLC] & Rhamnaceae & $\mathrm{s} / \mathrm{d}$ & $\begin{array}{l}\text { Marconetto }(2002) / \mathrm{si} \\
\text { Discaria americana Gilies } \\
\text { \& Hook }\end{array}$ \\
\hline \begin{tabular}{lllr} 
cf. & \multicolumn{3}{c}{ Embothrium } \\
coccineum & J. & R. \\
Forst. \& & g. & Forst. \\
[MD] & & &
\end{tabular} & Proteaceae & $\mathrm{s} / \mathrm{d}$ & Ancibor (1988/1990)/No \\
\hline $\begin{array}{l}\text { Empetrum rubrum } \\
{[\mathrm{MC}] \mathrm{y}[\mathrm{MLC}]}\end{array}$ & Empetracaeae & $9.390 \pm 40$ años AP & $\begin{array}{lll}\begin{array}{l}\text { Caruso } \\
(2013) / \mathrm{si}\end{array} & \text { y } & \text { Capparelli } \\
\end{array}$ \\
\hline Ephedra sp. L. [MD] & Ephedraceae & Período Colonial tardío & Podestá y Pereda (1979)/no \\
\hline $\begin{array}{l}\text { Equisetum } \quad \text { sp. } \\
\text { L.[MD] }\end{array}$ & Equisetaceae & $\begin{array}{l}1440 \pm 90 \text { años } \mathrm{AP} \\
\text { period histórico }\end{array}$ & Arrigoni (2002)/no \\
\hline $\begin{array}{l}\text { Escallonia rubra } \\
{[\mathrm{MLC}]}\end{array}$ & Escalloniaceae & $9.390 \pm 40$ años AP & $\begin{array}{lll}\begin{array}{l}\text { Caruso } \\
(2013) / \text { no }\end{array} & \text { y } & \text { Capparelli } \\
\end{array}$ \\
\hline Festuca sp L [MD] & Poaceae & $\begin{array}{l}7000 \text { años AP a } 1000 \\
\text { años AP }\end{array}$ & $\begin{array}{l}\text { Crivelli Montero et al. } \\
(1996) / \text { no }\end{array}$ \\
\hline Geoffroea sp. [MLC] & Fabaceae & $\mathrm{s} / \mathrm{d}$ & $\begin{array}{l}\text { Ortega y Marconetto } \\
\text { 2012)/no }\end{array}$ \\
\hline $\begin{array}{l}\text { Glycyrrhiza } \\
\text { astragalina Gilies ex } \\
\text { Hook \& Arn. [MD] }\end{array}$ & Fabaceae & $480 \pm 75$ años AP. & $\begin{array}{l}\text { Nacuzzi y Pérez de Micou } \\
(1983 / 1985) / \mathrm{si}\end{array}$ \\
\hline Grindelia sp. [MLC] & Aste & $\begin{array}{l}1380 \pm 90 \text { años Ap } \\
/ 800 \pm 90 \text { años AP }\end{array}$ & $\begin{array}{l}\text { Ortega y Marconetto (2009 y } \\
2012) / \quad \text { si Grindelia } \\
\text { chiloensis }\end{array}$ \\
\hline $\begin{array}{l}\text { Guadua trinii } \\
\text { (Nees) Nees ex Rupr. } \\
{[\mathrm{MC}]}\end{array}$ & Poaceae & $\begin{array}{l}1000 \text { AP a comienzos } \\
\text { del siglo XX }\end{array}$ & $\begin{array}{l}\text { Crivelli Montero et al. } \\
(1996) / \text { no }\end{array}$ \\
\hline $\begin{array}{l}\text { Hordeum comosum } \\
\text { J. Presl [MD] }\end{array}$ & Poaceae & $\begin{array}{l}5000 \text { años AP a } 1000 \\
\text { años AP }\end{array}$ & $\begin{array}{l}\text { Crivelli Montero et al. } \\
(1996) / \text { no }\end{array}$ \\
\hline Juncus sp. [MD] & Poaceae & $780 \pm 80 \mathrm{AP} / 860 \pm 80 \mathrm{AP}$ & $\begin{array}{l}\text { Nacuzzi y Perez de Micou } \\
(1983 / 1985) \text { Pérez de Micou } \\
\text { et al. }(1992) / \mathrm{si}\end{array}$ \\
\hline $\begin{array}{lr}\text { cf. } & \text { Lagenaria } \\
\text { siceraria } & \text { (Molina) } \\
\text { Standl. [MD] }\end{array}$ & Cucurbitaceae & 400 años AP & Ancibor (1988/1990)/no \\
\hline Larrea nitida Cav. & Zygophyllaceae & 7000 a 1000años AP & Crivelli Montero et al. \\
\hline
\end{tabular}




\begin{tabular}{|c|c|c|c|}
\hline [MD] & & & $(1996) /$ no \\
\hline Larrea sp. [MLC] & Zygophyllaceae & $\begin{array}{l}2700 \pm 90 \text { años } \mathrm{AP} / 800 \\
\pm 90 \text { años AP }\end{array}$ & $\begin{array}{l}\text { Ortega y Marconetto (2009 y } \\
2012) / \text { no }\end{array}$ \\
\hline Larrea sp. [MLC] & Zygophyllaceae & $\begin{array}{l}1100 \text { años AP a } \\
\text { comienzos del s. XX }\end{array}$ & Rivera (1996)/no \\
\hline $\begin{array}{l}\text { Lepidophyllum } \\
\text { cupressiforme (Lam.) } \\
\text { Class [MD] }\end{array}$ & Asteraceae & 1000 años AP & Gradin y Aguerre (1994)/no \\
\hline $\begin{array}{l}\text { Lomatia hirsuta } \\
\text { (Lam.) Diels. [MLD] }\end{array}$ & Proteaceae & $\begin{array}{l}630 \pm 80 \text { años AP } \quad \text { y } \\
585 \pm 75 \text { años AP }\end{array}$ & Ancibor (1981/1982)/no \\
\hline Lycium sp. [MLC] & Solanaceae & $800 \pm 90$ años AP & $\begin{array}{l}\text { Ortega y Marconetto (2009 y } \\
2012) / \text { no }\end{array}$ \\
\hline Lycium sp. [MLC] & Solanaceae & $\begin{array}{l}1000 \text { años AP a } \\
\text { comienzos del s. XX }\end{array}$ & Rivera (1996) /no \\
\hline $\begin{array}{l}\text { Maytenus sp. nov. A. } \\
\text { [MLD] }\end{array}$ & Celastraceae & & $\begin{array}{l}\text { Ancibor } \quad(1988 / 1990) / \mathrm{si} \\
\text { Maytenus boaria Molina }\end{array}$ \\
\hline $\begin{array}{l}\text { Maytenus boaria } \\
\text { Molina [MD] }\end{array}$ & Celastraceae & 1000 años AP & Gradin y Aguerre (1994)/si \\
\hline $\begin{array}{l}\text { Monocotiledóneas y } \\
\text { Dicotiledóneas [MD] }\end{array}$ & & $\mathrm{s} / \mathrm{d}$ & Podestá y Pereda (1979)/si \\
\hline Mulinum sp. [MD] & Apiaceae & $\begin{array}{l}1000 \quad \text { años AP a } \\
\text { comienzos del s. XX }\end{array}$ & $\begin{array}{lcc}\text { Crivelli } & \text { Montero } & \text { et } a l \\
(1996) / & \text { si } & \text { Mulinum } \\
\text { spinosum } & & \end{array}$ \\
\hline $\begin{array}{l}\text { Mulinum spinosum } \\
\text { (Cav). Pers. [MD] }\end{array}$ & Apiaceae & $\begin{array}{l}5000 \text { años AP a } \\
\text { comienzos del s. XX }\end{array}$ & $\begin{array}{l}\text { Crivelli Montero et } a l \\
(1996) / \mathrm{si}\end{array}$ \\
\hline $\begin{array}{l}\text { Mulinum spinosum } \\
(\mathrm{Cav}) . \text { Pers. }[\mathrm{MD}]\end{array}$ & Apiaceae & $780 \pm 80 \mathrm{AP} / 860 \pm 80 \mathrm{AP}$ & $\begin{array}{l}\text { Pérez de Micou et al. (1992) } \\
\text { /si }\end{array}$ \\
\hline $\begin{array}{l}\text { Nassauvia } \\
\text { glomerulosa (Lag. } \\
\text { ex Lindl.) D. Don } \\
{[\mathrm{MD}]}\end{array}$ & Asteraceae & $\mathrm{s} / \mathrm{d}$ & $\begin{array}{l}\text { Nacuzzi y Perez de Micou } \\
(1983 / 1985) / \mathrm{si}\end{array}$ \\
\hline $\begin{array}{l}\text { Nassauvia } \\
\text { glomerulosa } \\
\text { ex Lindl.) D. Dog. } \\
{[\mathrm{MD}]}\end{array}$ & Asteraceae & $\begin{array}{l}1000 \quad \text { años } \quad \text { AP } \\
\text { comienzos del s. XX }\end{array}$ & $\begin{array}{l}\text { Crivelli Montero et al } \\
(1996) ; \text { Pérez de } \\
(1979 / 1982) / \mathrm{si}\end{array}$ \\
\hline $\begin{array}{l}\text { Nothofagus } \quad \mathrm{sp} . \\
\text { [MLC] }\end{array}$ & Nothofagaceae & $\mathrm{s} / \mathrm{d}$ & Marconetto (2002)/no \\
\hline $\begin{array}{l}\text { Nothofagus } \\
\text { antarctica }\end{array}$ & Nothofagaceae & $9.390 \pm 40$ años AP & $\begin{array}{lll}\begin{array}{l}\text { Caruso } \\
(2013) / s i\end{array} & y & \text { Capparelli } \\
\end{array}$ \\
\hline $\begin{array}{lr}\text { Nothofagus } & \text { pumilio } \\
\text { (Poepp. \& } & \text { Endl.) } \\
\text { Krasser [MD] } & \\
\end{array}$ & Nothofagaceae & $\mathrm{s} / \mathrm{d}$ & $\begin{array}{l}\text { Aschero } \quad(1981 / 1982) / \mathrm{si} \\
\text { Nothofagus antárctica }\end{array}$ \\
\hline $\begin{array}{lcc}\text { cf. Oxalis } & \text { sp. } \\
\text { Crucíferas }[\mathrm{MD}] & \\
\end{array}$ & $\begin{array}{l}\text { cf.Oxalidaceae cf. } \\
\text { Brassicaceae }\end{array}$ & $\mathrm{s} / \mathrm{d}$ & $\begin{array}{l}\text { Ancibor }(1988 / 1990) / \text { Oxalis } \\
\text { sp }\end{array}$ \\
\hline $\begin{array}{l}\text { Oxalis articulata } \\
\text { Savigny [MC] }\end{array}$ & Oxalidaceae & $\begin{array}{l}1440 \pm 90 \text { años } \mathrm{AP} \\
\text { período histórico }\end{array}$ & Arrigoni (2002)/ Oxalis $\mathrm{sp}$ \\
\hline Phragmites sp & Poaceae & $\begin{array}{l}3350 \pm 90 \quad \text { años } \\
\text { AP/4770 } \pm 90 \text { años AP }\end{array}$ & $\begin{array}{l}\text { Pérez de Micou et al. (1992) } \\
\text { /no }\end{array}$ \\
\hline Prosopis sp. L. [m] & Fabaceae & 4.200 años AP & $\begin{array}{l}\text { Lema et al. }(2012) / \\
\text { Ciampagna } 2012 / \mathrm{si}\end{array}$ \\
\hline Prosopis sp. L.[MD] & Fabaceae & $\begin{array}{l}780 \pm 80 \quad \text { años } \\
\text { AP/860 } \pm 80 \text { años AP }\end{array}$ & P. de Micou et al. (1992)/si \\
\hline $\begin{array}{lll}\text { Prosopis } & \text { sp. } & \text { L. } \\
\text { [MLC] } & & \end{array}$ & Fabaceae & $\begin{array}{l}2700 \pm 90 \text { años } \mathrm{AP} / 800 \\
\pm 90 \text { años AP }\end{array}$ & $\begin{array}{l}\text { Ortega y Marconetto (2009 } \\
\text { y 2012), Marconetto } \\
(2002) / s i\end{array}$ \\
\hline $\begin{array}{l}\text { Prosopis alpataco } \\
\text { Phill [MC] }\end{array}$ & Fabaceae & $983 \pm 45$ años AP & $\begin{array}{l}\text { Capparelli y Prates (2009)/si } \\
\text { Prosopis sp. y P. denudans }\end{array}$ \\
\hline $\begin{array}{l}\text { Prosopis alpataco } \\
\text { Phill [MLC] }\end{array}$ & Fabaceae & $983 \pm 45$ años AP & $\begin{array}{l}\text { Marconetto (2002)/si } \\
\text { Prosopis sp. y P. denudans }\end{array}$ \\
\hline
\end{tabular}




\begin{tabular}{|c|c|c|c|}
\hline $\begin{array}{l}\text { Prosopis denudans } \\
\text { Bentham [MC] }\end{array}$ & Fabaceae & $983 \pm 45$ años AP & Capparelli y Prates (2009)/si \\
\hline $\begin{array}{l}\text { Prosopis denudans } \\
\text { Bentham [MLC] }\end{array}$ & Fabaceae & $\mathrm{S} / \mathrm{d}$ & $\begin{array}{l}\text { Marconetto (2002) Rivera } \\
(1996) / s i\end{array}$ \\
\hline $\begin{array}{l}\text { Prospidastrum } \\
\text { globosum (Gilies ex } \\
\text { Hook \& Arn.) } \\
\text { Burkart [m] }\end{array}$ & Fabaceae & Holoceno tardío & Ciampagna et al. (2011)/no \\
\hline Rumex sp. L. [s/d] & Polygonaceae & $\begin{array}{lcr}3350 \quad \pm 90 \quad \text { años } \\
\mathrm{AP} / 4770 \pm 90 \text { años AP }\end{array}$ & P. de Micou et al. (1992)/no \\
\hline $\mathrm{s} / \mathrm{i}[\mathrm{MD}]$ & Myrtaceae & $\mathrm{s} / \mathrm{d}$ & Ancibor (1988/1990)/no \\
\hline Schinus sp. L. [MC] & Anacardiaceae & $\mathrm{s} / \mathrm{d}$ & $\begin{array}{l}\text { Nacuzzi y Perez de Micou } \\
(1983 / 1985) / \mathrm{si}\end{array}$ \\
\hline Schinus sp. L. [MC] & Anacardiaceae & $\begin{array}{l}3350 \pm 90 \quad \text { años } \\
\mathrm{AP} / 4770 \pm 90 \text { años AP }\end{array}$ & $\begin{array}{l}\text { Perez de Micou et al. } \\
(1992) / \mathrm{si}\end{array}$ \\
\hline $\begin{array}{lll}\text { Schinus } & \text { sp. } & \text { L. } \\
{[\text { MLC }]} & & \end{array}$ & Anacardiaceae & $\begin{array}{l}2100 \pm 35 \text { años } \mathrm{AP} / 800 \\
\pm 90 \text { años AP }\end{array}$ & $\begin{array}{l}\text { Ortega y Marconetto (2009 y } \\
2012) / \mathrm{si}\end{array}$ \\
\hline $\begin{array}{lll}\text { Schinus } & \text { sp. } & \text { L. } \\
\text { [MLC] } & & \\
\end{array}$ & Anacardiaceae & $\begin{array}{l}5000 \text { a comienzos del } \\
\text { s. XX }\end{array}$ & Rivera (1996)/si \\
\hline Scirpus sp L. [MD] & Poaceae & $\begin{array}{l}780 \pm 80 \quad \mathrm{AP} / 860 \pm 80 \\
\mathrm{AP} / 1750 \pm 80 \mathrm{AP}\end{array}$ & $\begin{array}{l}\text { Perez de Micou et al. } \\
(1992) / \text { si }\end{array}$ \\
\hline Senecio sp. L.[MLC] & Asteraceae & & $\begin{array}{l}\text { Ortega y Marconetto (2009 y } \\
2012) \quad / \quad \text { si Senecio } \\
\text { filaginoides DC. }\end{array}$ \\
\hline Senecio sp L. [MD] & Asteraceae & $780 \pm 80 \mathrm{AP} / 860 \pm 80 \mathrm{AP}$ & $\begin{array}{l}\text { Perez de Micou et al. } \\
(1992) / \mathrm{si}\end{array}$ \\
\hline $\begin{array}{l}\text { Senecio patagonicus } \\
\text { sinónimo de Senecio } \\
\text { sericeonitens Speg. } \\
{[\mathrm{MD}]}\end{array}$ & Asteraceae & 1000 años AP & $\begin{array}{l}\text { Gradín y Aguerre (1994)/ si } \\
\text { Senecio filaginoides DC }\end{array}$ \\
\hline $\begin{array}{l}\text { Stipa speciosa Trin. } \\
\text { \& Rupr. [M] }\end{array}$ & Poaceae & $\mathrm{s} / \mathrm{d}$ & Aschero (1981-1982)/ no \\
\hline Suaeda sp. [MLC] & Chenopodiaceae & $1380 \pm 90$ AP & $\begin{array}{l}\text { Ortega y Marconetto (2009 y } \\
\text { 2012)/no }\end{array}$ \\
\hline Typha sp L. [MD] & Poaceae & $\begin{array}{ll}780 \pm 80 \text { años } & \text { AP/ } \\
860 \pm 80 \text { años } & \text { AP/ } \\
3350 \pm 90 & \text { BP/ } \\
4770 \pm 90 \text { años AP } & \end{array}$ & $\begin{array}{l}\text { Perez de Micou et al. } \\
(1992) / \text { no }\end{array}$ \\
\hline Tropaeolum sp [MD] & Tropaeolaceae & $\begin{array}{l}780 \pm 80 \quad \text { años } \\
\mathrm{AP} / 860 \pm 80 \text { años AP }\end{array}$ & $\begin{array}{l}\text { Perez de Micou et al. } \\
(1992) / \mathrm{si}\end{array}$ \\
\hline Zea mays L. [MD] & Poaceae & 400 años AP & Ancibor (1988/1990)/si \\
\hline Zea mays L. [m] & Poaceae & $\begin{array}{l}730 \pm 80 \text { AP y } 920 \pm \\
60 \mathrm{AP} / 1750 \text { años } \mathrm{AP}\end{array}$ & $\begin{array}{l}\text { Perez y Erra (2011)/ Lema et } \\
\text { al. }(2012) / \mathrm{si}\end{array}$ \\
\hline $\begin{array}{ll}\text { Ziziphus } & \text { mistol } \\
\text { Griseb [MC] } & \\
\end{array}$ & Rhamnaceae & $983 \pm 45$ años AP & $\begin{array}{lll}\begin{array}{l}\text { Capparelli } \\
(2009) / \text { no }\end{array} & \text { y } & \text { Prates } \\
\end{array}$ \\
\hline
\end{tabular}

Tabla 6.1. Recopilación bibliográfica de los restos arqueológicos vegetales recuperados en el área de estudio seleccionada, y presencia/ausencia de cada taxón en las fuentes documentales escritas.

Referencias: [MD] Macrorresto no leñoso desecado; [MLD] Macrorresto leñoso desecado; [MC] Macrorresto no leñoso carbonizado; [m] microrresto; [MLC] Macrorresto leñoso carbonizado; [s/d]: sin datos; [s/i] sin identificar a nivel de género o específico. 


\section{Colección de referencia de macrorrestos y Experimentación}

\subsection{Introducción}

Para la determinación taxonómica de los macrorrestos vegetales arqueológicos se requiere de una colección de referencia amplia, que represente la vegetación actual del área de estudio y que esté conformada tanto por material herborizado como carbonizado (Capparelli 1997, Solari 2000, Marconetto 2005, Andreoni 2014). En el caso del presente estudio se colectaron partes de plantas que puedan potencialmente haber sido utilizadas por los grupos humanos en el pasado para diferentes fines (alimentos, medicina, combustible, artefactos, entre otros), a partir de la información relevada en los capítulos 4 y 5, aunque el énfasis estuvo puesto en el material leñoso.

En primer lugar, se define como macrorrestos vegetales a aquellos restos visibles a ojo desnudo, e identificables con bajo poder de magnificación (Ford 1979:301) si bien, en numerosas ocasiones se debe recurrir a distintas técnicas para su determinación (Capparelli 1997). Se pueden recuperar distintas categorías de órganos dentro de este tipo de restos (raíces, tallos, órganos subterráneos almacenadores, hojas e inflorescencias, frutos y semillas entre otros, Capparelli 1997). En CNSC se recuperaron macrorrestos leñosos (carbón de madera) y en un solo caso (i.e. sitio Nido del Águila) restos de frutos y hojas carbonizados.

En cuanto al carbón de madera es considerado como un material inerte, negro con propiedades morfológicas similares a la madera actual pero, para Braadbaart y Poole (2008), esta definición no alcanza para reflejar el proceso completo de la carbonización. La formación del carbón se produce tanto si se calienta madera en un ambiente con limitada presencia de oxígeno (quemar o “chamuscar") o en ausencia de oxígeno (carbonización). Estos autores diferencian ambos procesos ya que, en presencia de oxígeno las sustancias volátiles se encienden y queman produciendo la llama característica y la apariencia de madera quemada. Con el contacto de abundante oxígeno se desarrolla la combustión de la madera hasta producir como elemento final la ceniza. Bajo condiciones de oxígeno limitado o ausencia del mismo, se forma el carbón (Baadbaart y Poole 2008: 2435). 
La combustión desencadena procesos fisicoquímicos en las maderas como emanación de gases, pérdida de agua, de masa entre otros, que repercuten en la morfología de la madera aunque no en su microestructura (Pique i Huerta 1999). Los carbones son producto de una combustión incompleta, porque si esta se completara el producto final obtenido serían cenizas. De acuerdo a Piqué i Huerta (1999) las causas de la interrupción de este proceso pueden ser variadas:

- las combustiones continuas pueden dejar más carbones, entonces, una mayor concentración de residuos no combustibles interrumpiría de manera natural la combustión de las brasas. En cambio, una limpieza periódica facilitaría una combustión completa.

- el tamaño de la madera que se quemará, debido a que es más fácil lograr la combustión completa para las ramas finas que para las gruesas.

- el tipo de uso del fuego puede producir más carbones, por ejemplo, los yámanas de Tierra del Fuego abrían los mejillones sobre las brasas, por lo que el líquido que estos desprendían apagaba las brasas.

Los trabajos experimentales realizados por distintos especialistas en antracología han permitido avanzar en el conocimiento del proceso de combustión y las distintas variables que se desprenden del mismo (MacParland et al. 2009, Braadbaart et al. 2012, Théry-Parisot y Henry 2011, Andreoni 2014,).

En este capítulo, entonces se presenta la colección de referencia y la carbonización controlada de los leños, frutos y hojas que pertenecen a dicha colección. Esta última se encuentra conformada a partir de la colecta de plantas del área de estudio y regiones adyacentes, la herborización e identificación de los ejemplares, los cortes diagnósticos de los leños a través del micrótomo y por último su carbonización.

\subsection{Material y Métodos}

El material de referencia (todas las categorías de órganos de las plantas) se colectaron principalmente en la CNSC, en todas aquellas áreas que representaran la biodiversidad actual de vegetación de la zona. No obstante, y en pos de evaluar en el registro arqueológico posibles introducciones de taxa del oeste patagónico, se colectó también material leñoso en otras dos localidades: Villa Pehuenia (provincia de Neuquén) y el Parque Nacional Los Alerces (provincia de Chubut), las que corresponderían al Distrito del Pehuén y al Distrito Valdividiano de la provincia fitogeográfica Subantártica 
respectivamente (Cabrera 1971). Como se dijo anteriormente, se colectaron además otras partes de plantas que puedan haber sido utilizadas por los grupos humanos en el pasado para alimentos, medicina, entre otros. Se realizó la colecta de los ejemplares en los meses de noviembre, enero y febrero, con el objetivo de hallar todos los órganos vegetativos y sexuales presentes, se realizaron transectas cubriendo distintos espacios ecológicos (mallines, meseta, costa) y se dispusieron los ejemplares en diarios (según Katinas 2001).

Se utilizó material bibliográfico de referencia como la flora patagónica y claves de determinación (Correa 1969, 1999) textos de morfología de distintas plantas útiles (Winton y Winton 1935).

De las especies leñosas se seleccionaron los tallos y se cortaron en cinco cubos de $1,5 \mathrm{x}$ $1,5 \mathrm{~cm}$ y se realizaron cortes histológicos, carbonización experimental y cálculos de densidad, siguiendo la metodología de Capparelli et al. (2003) y Andreoni (2010).

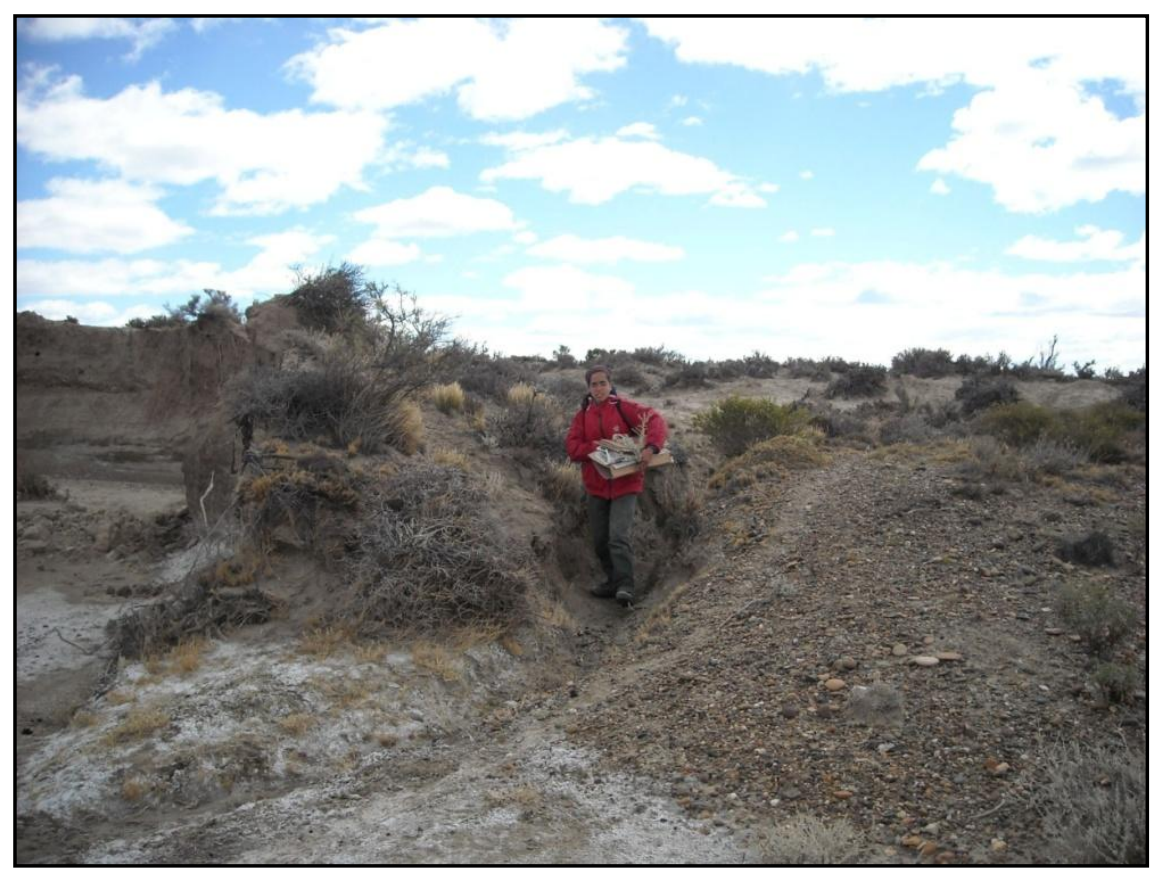

Figura 7.1. Colecta de especies en el Cañadón León, Golfo San Jorge (foto tomada por Verónica Trola)

\subsubsection{Cortes histológicos}

Los tacos de madera se hidrataron y se hirvieron en agua y detergente industrial durante dos a cinco horas. Se realizaron luego los tres cortes histológicos diagnósticos 
(transversal, longitudinal tangencial y $\operatorname{radial}^{10}$ ) con micrótomo a un espesor de $30 \mu \mathrm{m}$. Se decoloraron con hipoclorito de sodio al 50\% durante cinco a diez minutos, luego, se lavaron diez minutos aproximadamente sumergiéndolos en agua destilada. Posteriormente, se deshidrataron y tiñeron con safranina en una batería de alcoholes (alcohol $50^{\circ}$ con safranina al $1 \%$, alcohol 70, alcohol $80^{\circ}$, alcohol $96^{\circ}$, alcohol $100^{\circ}$, alcohol y xilol en partes iguales y xilol 100\%). Se montaron los cortes en bálsamo de Canadá artificial y se describieron los caracteres cualitativos por medio de la observación al microscopio óptico de luz reflejada y siguiendo los criterios de IAWA (1989 y 2004). El material bibliográfico de referencia que se usó de soporte para esta descripción figura entre paréntesis al lado de cada especie tratada. A partir de esta caracterización se elaboró una clave dicotómica con los caracteres diagnósticos que fueron reconocibles en el material carbonizado, la que fue utilizada para la identificación del material antracológico recuperado (ver capítulo siguiente).

\subsubsection{Densidad}

Se considera que la densidad de la madera es una de las propiedades físicas que influye en las decisiones en torno a la selección de leña, de modo que las maderas densas pueden haber contribuido al mantenimiento del fuego (Piqué i Huerta 1999, Andreoni 2014). Por tal motivo, se obtuvo la densidad de las maderas recolectadas para el área de estudio.

Se sumergieron los tacos en agua durante siete días hasta lograr su saturación. Luego fueron pesados en un recipiente con agua sin que el taco tocara alguno de los bordes o el fondo, para calcular el volumen de agua desplazado. Se secaron a estufa hasta eliminar todo el contenido de agua y se pesaron hasta que el peso fue constante. Luego, se calculó el cociente entre el peso anhidro y el volumen de agua desplazada, cuyo resultado es la densidad aparente anhidro (Andreoni 2010 y 2014). Los valores obtenidos corresponden a una medida por taxa y se pueden observar en la Tabla 7.1. Se consideró como referencia los criterios de Barroso (1987) para la clasificación de las maderas por su densidad, pero se siguió una clasificación propia para obtener un ranking de las maderas del área de estudio según sus valores de densidad. De esta

\footnotetext{
${ }^{10}$ En algunos taxa no se presenta vista del corte longitudinal radial por no observarse con claridad en la foto El corte transversal será abreviado de ahora en más CT, el longitudinal tangencial CLTg y el radial CLrd.
} 
manera se estableció que de $0,65 \mathrm{gr} / \mathrm{cm}^{3}$ a $0,53 \mathrm{gr} / \mathrm{cm}^{3}$ son maderas de alta densidad, de $0,52 \mathrm{gr} / \mathrm{cm}^{3}$ a $0,45 \mathrm{gr} / \mathrm{cm}^{3}$ intermedias; de $0,44 \mathrm{gr} / \mathrm{cm}^{3}$ a $0,36 \mathrm{gr} / \mathrm{cm}^{3}$ bajas y muy bajas inferior a $0,35 \mathrm{gr} / \mathrm{cm}^{3}$.

\subsubsection{Protocolo experimental de carbonización controlada}

El protocolo experimental replica dentro del laboratorio las condiciones ambientales bajo las que se pudo producir tanto la colecta y el secado de la madera antes de su utilización como leña (distintos contenidos de humedad) como las condiciones en las que se pudo producir la combustión (distintas temperaturas de carbonización). Se seleccionaron los siguientes géneros para carbonizar en forma experimental: Araucaria, Aristotelia, Atriplex, Berberis, Buddleja, Chuquiraga, Colliguaja, Diostea, Escallonia, Fabiana, Mulguraea, Luma, Lepidophyllum, Lycium, Maytenus, Nassauvia, Nothofagus, Nardophyllum, Senecio, Schinus, Prosopis, Baccharis y Prosopidastrum. Cuatro de los tacos que se habían obtenido a partir del material leñoso de cada taxa se utilizaron para la carbonización controlada. Ésta se realizó en una mufla con termocupla digital perteneciente al LATYR (Laboratorio de Tritio y Radiocarbono del Museo de Ciencias Naturales de La Plata). Se carbonizaron a $400{ }^{\circ} \mathrm{C}$ y $700{ }^{\circ} \mathrm{C}$ en atmósfera reductora (crisoles cubiertos de arena) dos tacos de un mismo taxón, uno conteniendo un $8 \%$ a $12 \%$ de humedad y otro luego de haber sido desecado hasta alcanzar el $0 \%$ de humedad. Este nivel de deshidratación máxima se obtuvo secando los tacos en estufa a $80{ }^{\circ} \mathrm{C}$ hasta peso constante (en este caso durante 36 horas), en el INFIVE (Instituto de Fisiología Vegetal). Las muestras con un 8 a 12\% de humedad representan a los leños secados "al aire", es decir, con su humedad natural en relación al ambiente. En cambio las maderas con $0 \%$ de humedad sirvieron a modo comparativo para identificar rasgos morfológicos diagnósticos contrastantes con respecto al grado de deshidratación de las muestras al momento de su carbonización.

Tanto para la deshidratación como para cada caso de carbonización controlada los tacos fueron medidos y pesados, antes y después de cada proceso, a fin de constatar porcentajes de reducción de la madera. La pérdida de peso relativa de cada taxa podría implicar diferencias a nivel de preservación en los restos arqueológicos. Se podría sugerir que aquellos taxa que hayan presentado los porcentajes de pérdida de peso más elevado podrían tener menor resistencia a los procesos postdepositacionales y de esta manera una mayor fragmentación o pulverización en el registro. 
La aplicación de dicho protocolo permite observar la presencia y ausencia de rasgos de combustión a diferentes temperaturas y porcentaje de humedad. Como describe Andreoni (2014), se registró la presencia/ausencia de split u “ojos” (aberturas pequeñas) y "aberturas" (de mayor tamaño que las anteriores y alargadas) en radios y en anillos luego de cada set experimental. Como "grieta" se denominó a aquellas aberturas de tipo irregular y cobertura amplia que no precisamente siguen el curso de anillos o radios de la madera (ver Tabla 7.2). Estos resultados se encuentran aún en un estado preliminar y serán replicados en el futuro. En el caso de Atriplex lampa, Baccharis darwinii, Mulguraea tridens, Lepidophyllum cupressiforme y Nassauvia sp, no pudo realizarse la experimentación debido a que fueron recolectados tallos muy pequeños, sin embargo, en próximos trabajos se someterán al protocolo experimental.
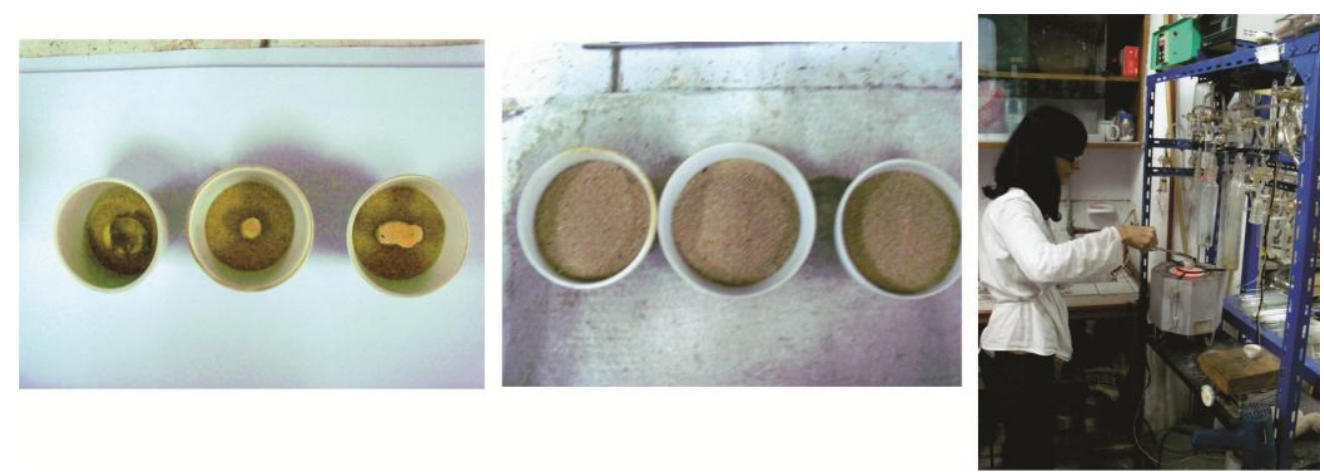

Figura 7.2. Tacos de madera cubiertos de arena en crisoles y su carbonización controlada en una mufla.

\subsubsection{Identificación de los carporrestos}

La carbonización controlada también se aplicó para la identificación de los frutos y hojas carbonizados arqueológicos.

Para la identificación de los restos vegetales no leñosos se carbonizaron, en atmósfera reductora durante 30 minutos a una temperatura de $300{ }^{\circ} \mathrm{C}$, frutos y hojas de la colección de referencia de Schinus sp. y se compararon tanto sus caracteres morfológicos como sus medidas (largo, diámetro y peso) antes y después de la carbonización. Esta última se realizó sobre frutos y hojas de Schinus y no de otras especies de la colección de referencia debido a que se compararon previamente los restos arqueológicos con los frutos herborizados de otros taxa de la colección de referencia mediante lupa. Los frutos de Schinus aún sin carbonizar eran los que presentaban mayores similitudes anatómicas. 


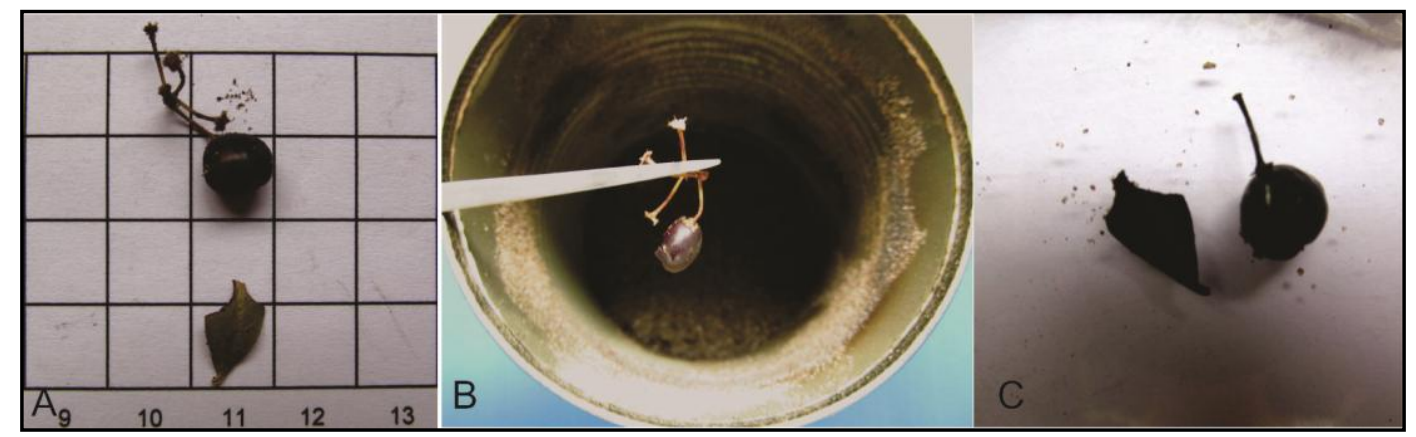

Figura 7.3. Carbonización controlada de frutos y hojas de Schinus sp. A: fruto y hoja de Schinus sp. en estado fresco, material de herbario; B: Fruto de Schinus sp. sometido a una atomósfera reductora (en un recipiente con arena) y a $300^{\circ} \mathrm{C}$; C: fruto y hoja de Schinus sp. carbonizado.

\subsection{Resultados}

\subsubsection{Registro de Flora}

Se recolectaron e identificaron taxonómicamente 89 taxa (incluyendo niveles de género y especie) utilizando la Flora de Patagonia de Correa (1999) que pertenecen a 37 familias botánicas: Adoxaceae, Amaryllidaceae, Anacardiaceae, Apiaceae, Asteraceae,

Berberidaceae, Brassicaceae, Cactaceae, Celastraceae, Chenopodiaceae, Cupressaceae, Elaeocarpaceae, Empetraceae, Ephedraceae, Equisetaceae, Ericaceae, Escalloniaceae, Euphorbiaceae, Fabaceae, Geraniaceae, Grossulariaceae, Lamiaceae, Myrtaceae, Nothofagaceae, Onagraceae, Plantaginaceae, Plumbaginaceae, Poaceae, Poligonaceae, Proteaceae, Rhamnaceae, Santalaceae, Scrophulariaceae, Solanaceae, Tropaeolaceae, Valerianaceae y Zygophyllaceae. Estos ejemplares se encuentran en el Laboratorio 1 del Departamento Científico de Arqueología del Museo de Ciencias Naturales de La Plata y serán ingresados al finalizar la tesis en el Herbario de Plantas Vasculares (LP) de dicho Museo.

\subsubsection{Cortes histológicos}

\section{Gimnospermas}

- Araucariaceae

Araucaria araucana Molina K. Koch "pehuén" (Material bibliográfico de referencia consultado: Guerra et al. 1994, Tortorelli 2009). 
Corte transversal. Anillos de crecimiento visibles, trayecto rectilíneo de los radios. Parénquima axial ausente y canales resiníferos axiales ausentes (Figura 7.4A).

Corte longitudinal tangencial. Radios leñosos uniseriados de una a cuatro células de alto (Figura 8.4B). Traqueidas con puntuaciones areoladas uniseriadas.

Corte longitudinal radial. Campo de cruzamiento araucarioide, radio heterogéneo con traqueidas radiales presentes de paredes internas lisas (Figura 7.4C).

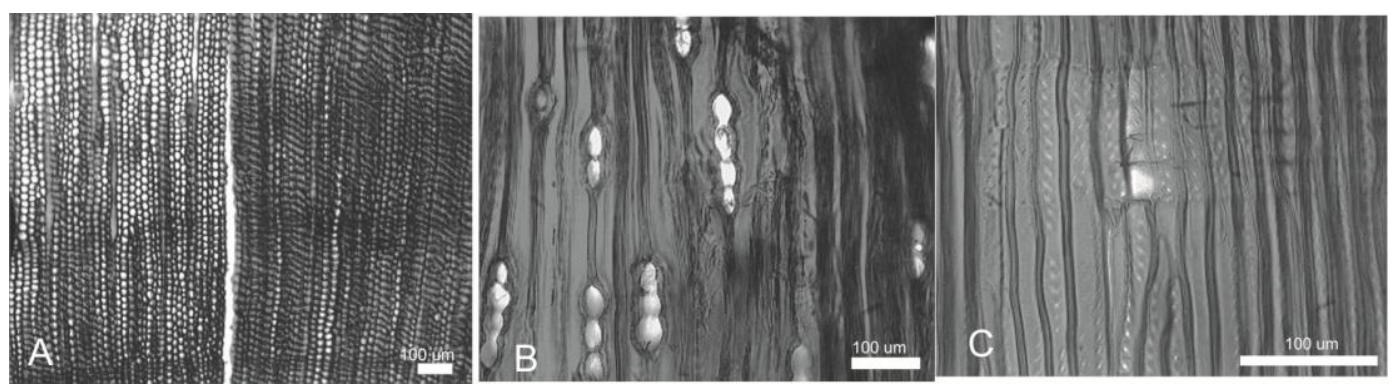

Figura 7.4. Araucaria araucana: A, CT, Anillos de crecimiento visibles; B, CLtg. Radios uniseriados cortos; C, CLrd. Campo de cruzamiento araucarioide, radio heterogéneo.

\section{Angiospermas}

- Anacardiaceae

Schinus sp. "molle" (Material bibliográfico de referencia consultado: Ancibor y Pérez de Micou 1995, Garibotti 1998, Ancibor y Pérez de Micou 2002, Marconetto 2002, Roig y Videla 2006-2010, Andreoni 2010, Ortega y Marconetto 2009, Andreoni 2014).

Corte transversal. Anillos de crecimiento demarcados por la porosidad semicircular y una hilera de fibras achatadas. Vasos en bandas tangenciales en el leño temprano, en patrón diagonal y radial (múltiples de 4,5 y 6) en el leño tardío (Figura 7.5A). Vasos solitarios y agrupados frecuentes en el leño tardío. Fibras de pared delgada a gruesa y parénquima axial ausente o extremadamente escaso.

Corte longitudinal tangencial. Placa de perforación simple, oblicua. Punteaduras intervasculares alternas poligonales. Espesamiento reticulado a lo largo del elemento de vaso. Fibras con punteaduras simples a punteadoras con rebordes diminutos. Espesamientos espiralados en tejido básico, fibras septadas presentes. Radios 1-3 seriados heterogéneos con extremos uniseriados de hasta cuatro células (Figura 7.5B). 
En promedio 11 células de alto de los radios (de 3 a 28) y presencia de canales radiales. Cristales prismáticos presentes.

Corte longitudinal radial. Punteaduras vasoradiales con rebordes muy reducidos hasta con apariencia simples. Células del radio procumbentes con una hilera de células erectas y/o cuadradas, también se registraron radios con células cuadradas, erectas y procumbentes mezcladas. Se observaron cristales prismáticos en células radiales, cuadradas y erectas (Figura 7.5C).
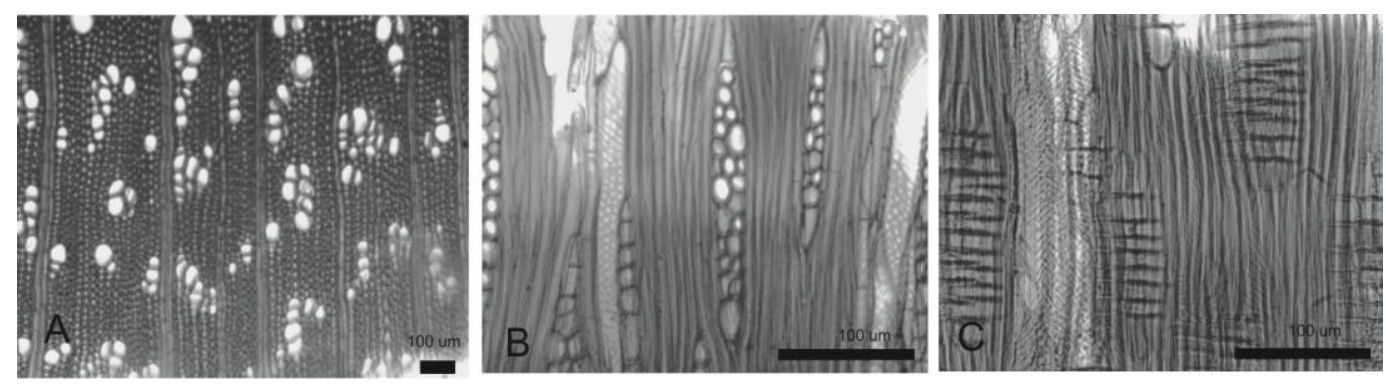

Figura 7.5. Schinus sp.: A, CT, Vasos agrupados frecuentes, múltiples cortos y largos en disposición radial; B, CLtg. Espesamiento reticulado de los vasos, placa de perforación oblicua, radios 1-3 seriados homogéneos; C, CLrd. Espesamiento reticulado, placa de perforación simple, células del radio cuadradas $\mathrm{y}$ erectas.

- Asteraceae

Baccharis darwinii (Material bibliográfico de referencia consultado: Garibotti 1998, Andreoni 2010, Guerra et al. 2012)

Corte transversal. Anillos de crecimiento demarcados por parénquima marginal y vasos en banda tangencial (Figura 7.6A). Porosidad difusa, con vasos en disposición radial y diagonal, dendríticos, múltiples radiales, agrupados y solitarios. Parénquima paratraqueal confluente. Parénquima apotraqueal difuso en agregados.

Cabe aclarar que Guerra et al. (2012) describen los cortes histológicos de Baccharis linearis, B. obovata y B. salicifolia del ecotono bosque estepa de Chubut e identifican porosidad circular a semicircular en las dos primeras y semicircular en la última. Además de parénquima paratraqueal confluente observan parénquima vasicéntrico. 
Corte longitudinal tangencial. Placa de perforación simple, oblicua. Punteaduras intervascularas alternas, espesamiento reticulado (Figura 7.6B). Radios de 1 a 3 células presentes así como de 4 a 10 de ancho, células elongadas. Algunos radios fusionados. Tipo de radios homogéneos pero con células elongadas. Estratificación parcial (solo en fibras).

Guerra et al. (2012) observan radios heterogéneos.

Corte longitudinal radial: Células erectas y cuadradas (Figura 7.6C).

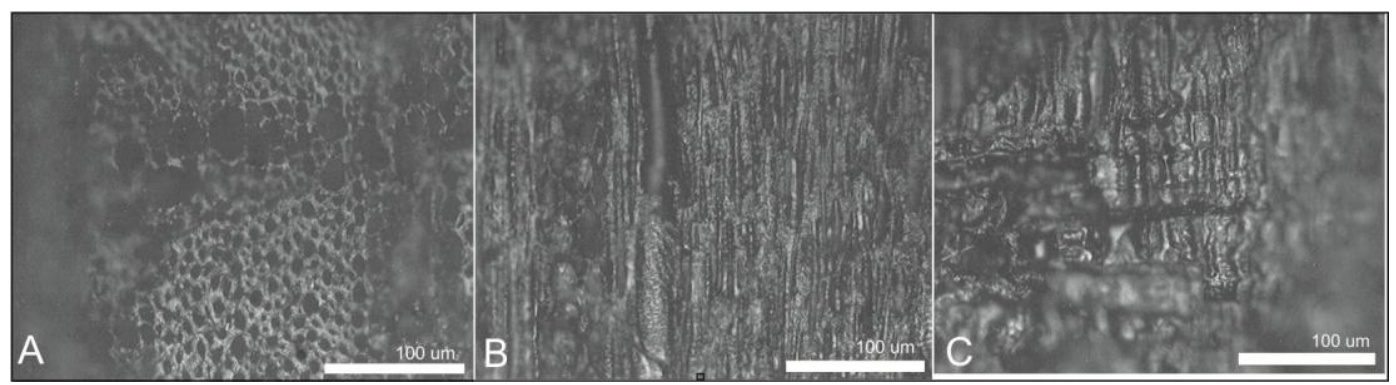

Figura 7.6. Baccharis darwinii: A, CT Vasos en banda tangencial, parénquima apotraqueal difuso en agregados. B, CTtg Radios 1-3 seriados, engrosamiento helicoidal de los vasos y placa oblicua; C, CLrd, células erectas y cuadradas

Chuquiraga avellanedae "quilembay" (Material bibliográfico de referencia consultado: Andreoni 2010, Ortega y Marconetto 2009, Andreoni 2014)

Corte transversal. Anillo de crecimiento demarcado por la porosidad semicircular y el achatamiento de las fibras. Vasos en bandas tangenciales y exclusivamente solitarios (Figura 7.7A). Fibras de pared delgada a gruesa. Parénquima axial ausente o extremadamente escaso.

Andreoni (2010) observa para Chuquiraga oppositifolia algunos caracteres distintos como porosidad difusa, vasos en patrón dendrítico, de contorno angular.

Corte longitudinal tangencial. Placa de perforación simple, oblicua (Figura 7.7C). Punteaduras intervasculares alternas poligonales. Engrosamiento helicoidal tenue en los elementos de vaso, siendo los elementos de vasos muy finos. Traqueidas vasicéntricas presentes. Fibras con reborde conspicuo (fibrotraqueidas). Espesamiento espiralado en fibras del tejido básico. Fibras no septadas presentes. Radios 1 a 3 seriados y grandes 4 a 7 seriados. La forma de las células de los radios es elongada (Figura 7.7B), pero son radios homogéneos. Son de dos tamaños distintos, con células radiales perforadas. 
Andreoni (2010) registra punteaduras intervasculares escalariformes y opuestas. No observa engrosamiento helicoidal. Registra sólo radios uni a tri-seriados.

Corte longitudinal radial. Punteaduras vaso-radiales con rebordes visibles, similares a punteaduras intervasculares en tamaño y forma. Radios con células procumbentes, cuadradas y erectas mezcladas.

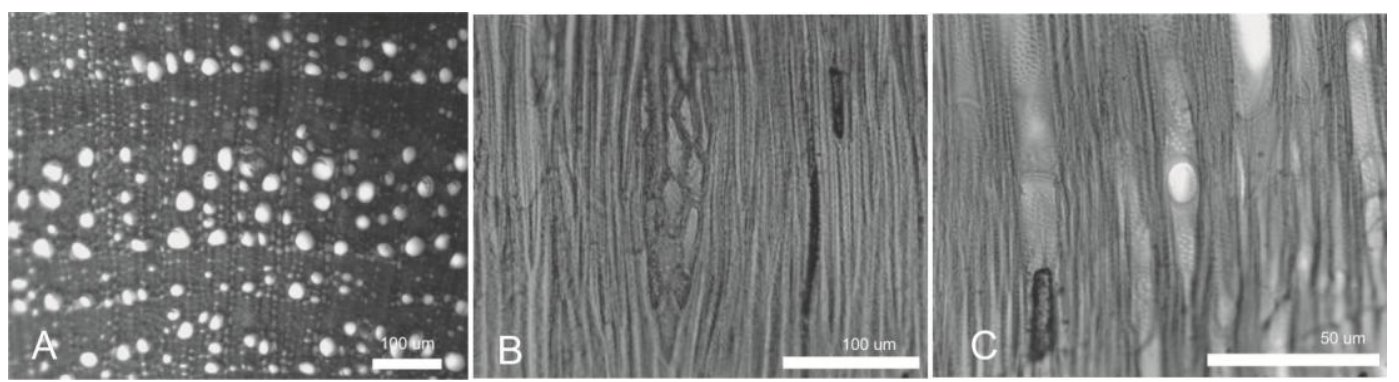

Figura 7.7. Chuquiraga avellanedae: A, CT vasos en banda tangencial y exclusivamente solitarios; B, CLTg radios con células elongadas 1-3 seriados C, CLTg placa de perforación simple.

Lepidophyllum cupressiforme "mata verde" (Material bibliográfico de referencia consultado: Caruso 2013)

Corte transversal. Anillo de crecimiento demarcado por fibras achatadas, porosidad semicircular. Vasos en bandas tangenciales en leño temprano y en patrón diagonal en el tardío. Vasos exclusivamente solitarios (Figura 7.8A). Fibras de pared delgada a gruesa. Parénquima apotraqueal axial difuso y difuso en agregados.

Caruso (2013) observa porosidad difusa.

Corte longitudinal tangencial. Placa de perforación simple, oblicua. Punteaduras intervasculares alternas. Engrosamientos helicoidales presentes en los elementos de vaso. Traqueidas vasculares vasicéntricas presentes. Fibras con punteaduras simples a punteaduras con rebordes diminutos y fibras con reborde conspicuo (fibrotraqueidas). Espesamiento espiralado en fibras del tejido básico. Fibras no septadas presentes. Radios 1 a 3 seriados (generalmente bi y tri-seriados) y 4 a 10 seriados (generalmente 4 a 8), homogéneos pero de células alargadas (Figura 7.8B). Se observó una baja densidad de $\operatorname{radios}(\approx 10 \mathrm{radios} / \mathrm{mm})$. Células del radio perforadas. 

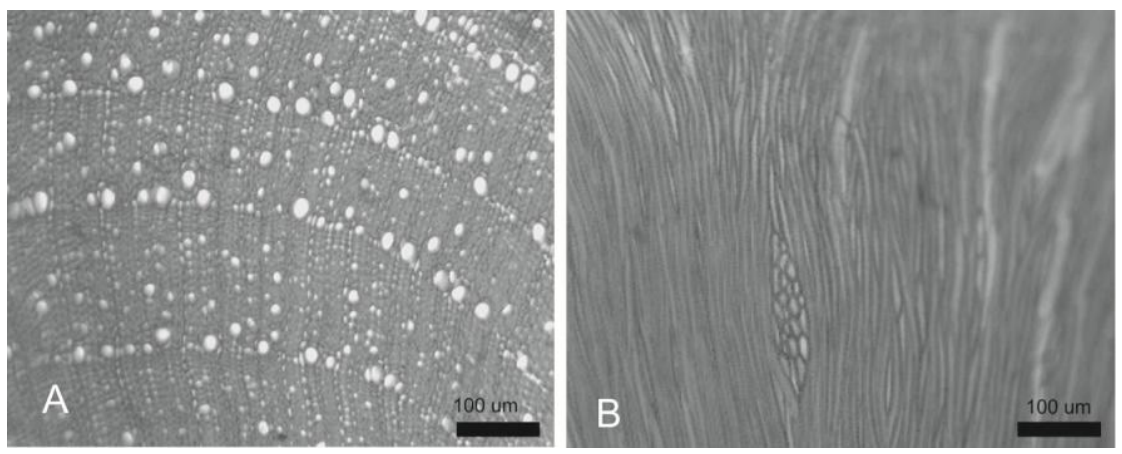

Figura 7.8. Lepidophyllum cupressiforme: A, CT, Anillos de crecimiento demarcados, porosidad semicircular, vasos en bandas tangenciales en leño temprano y diagonal en el tardío; B, CLTg. Radios 410 (4) seriados, con células elongadas, fibras no septadas presentes.

Nardophyllum bryoides "siete camisas" (Material bibliográfico de referencia consultado: no se encontró bibliografía para comparar la presente descripción)

Corte transversal. Anillos de crecimiento demarcado por fibras achatadas, porosidad difusa (Figura 7.9A). Vasos en patrón diagonal y radial. Vasos exclusivamente solitarios (escasos radiales cortos de dos), todos de contorno angular. Fibras de pared delgada a gruesa. Parénquima axial ausente o extremadamente escaso.

Corte longitudinal tangencial. Se observaron placas de perforación escalariforme de 12 barras pero predominan las placas simples. Elementos de vaso con apéndice en los extremos. Punteaduras intervasculares alternas. Traqueidas vasculares vasicéntricas presentes. Fibras con punteaduras con reborde conspicuo (Figura 7.9B). Fibras no septadas presentes. Radios 1 a 3 seriados, con células alargadas, homogéneos.
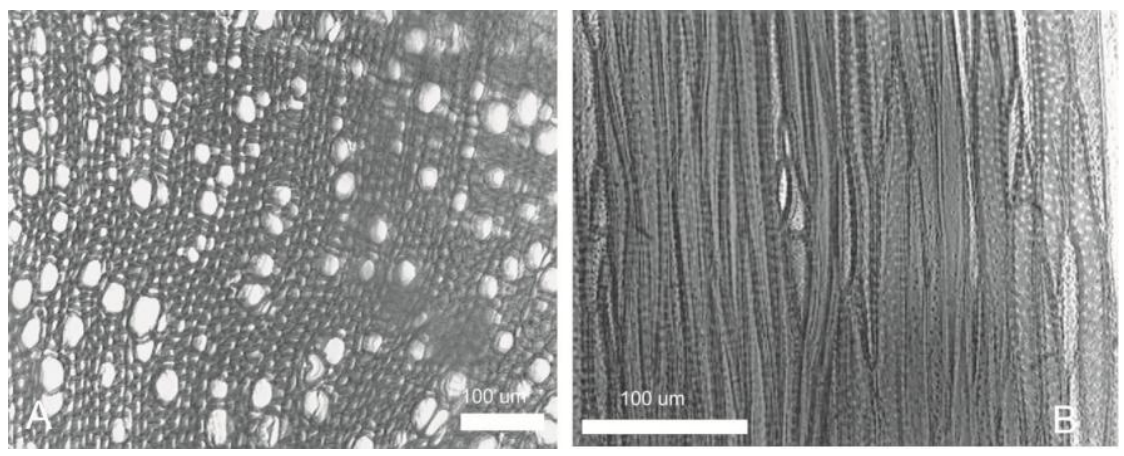

Figura 7.9. Nardophyllum bryoides: A, CT, Porosidad difusa, vasos exclusivamente solitarios en disposición radial y diagonal, de contorno angular; B, traqueidas vasculares vasicéntricas con punteaduras con reborde conspicuo, radios uniseriados. 
Nassauvia sp. "cola piche" (Material bibliográfico de referencia consultado: no se encontró bibliografía para comparar la presente descripción)

Corte transversal. Anillos de crecimiento demarcados, con porosidad semicircular. Vasos en bandas tangeciales en el leño temprano y radiales en el tardío. Vasos exclusivamente solitarios, fibras de pared delgada a gruesa y fibras de pared muy gruesa en el leño temprano (Figura 7.10A). Parénquima axial en bandas mayor a tres células de ancho, y parénquima marginal en el leño temprano.

Corte longitudinal tangencial. Placa de perforación simple, con apéndices. Engrosamientos helicoidales en los elementos de vaso. Traqueidas vasculares vasicéntricas presentes, fibras con punteaduras con reborde conspicuo (Figura 7.10B). Espesamiento espiralado en tejido básico. Parénquima axial estratificado y fibras estratificadas. No se observaron radios.

Corte longitudinal radial. Punteaduras vaso-radiales con reborde visible similares a punteaduras intervasculares en tamaño y forma a lo largo.

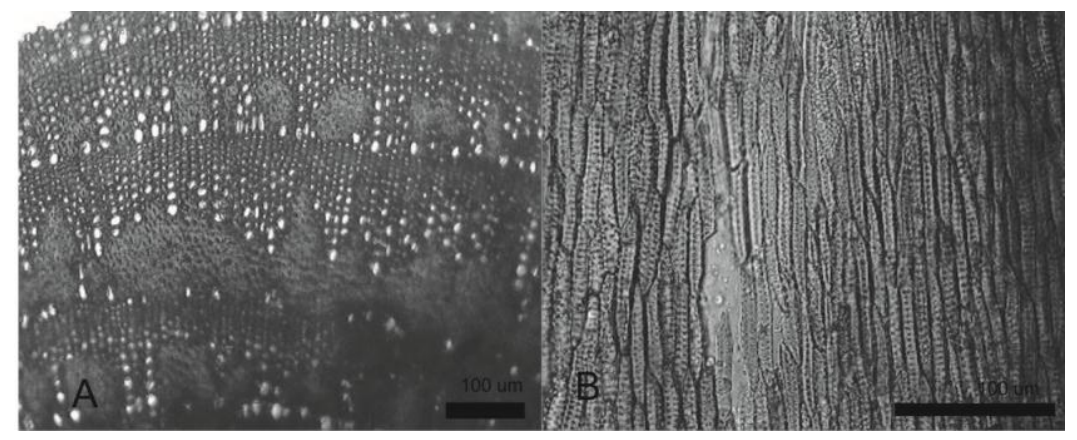

Figura 7.10. Nassauvia sp.: A, CT, Anillos de crecimiento demarcado, porosidad semicircular, vasos solitarios, paquete de fibras de pared muy gruesa en el leño temprano y de paredes más delgadas en el leño tardío; B, CLTg, fibrotraqueidas con punteaduras con reborde conspicuo.

Senecio sp. (Material bibliográfico de referencia consultado: Roig y Videla 2006-2010, Andreoni 2014)

Corte transversal. Anillos de crecimiento demarcado por líneas de fibras achatadas. Porosidad difusa (Figura 7.11A). Vasos en patrón diagonal y radial, solitarios y radiales múltiples de dos, tres y cuatro. Vasos de contorno angular. Fibras de pared muy delgada. Parénquima apotraqueal axial difuso en agregado. 
Corte longitudinal tangencial. Placa de perforación simple, oblicua, vasos con apéndice. Punteaduras intervasculares alternas y opuestas. Traqueidas vasculares vasicéntricas presentes. Fibras con punteaduras simples a punteaduras con reborde diminuto. Fibras no septadas presentes. Radios 1 a 3 seriados y grandes hasta 10 seriados homogéneos con células elongadas (Figura 7.11B).

Corte longitudinal radial. Punteaduras vaso-radiales con rebordes muy reducidos hasta con apariencia de simples. Radios de células procumbentes, erectas y cuadradas mezcladas.

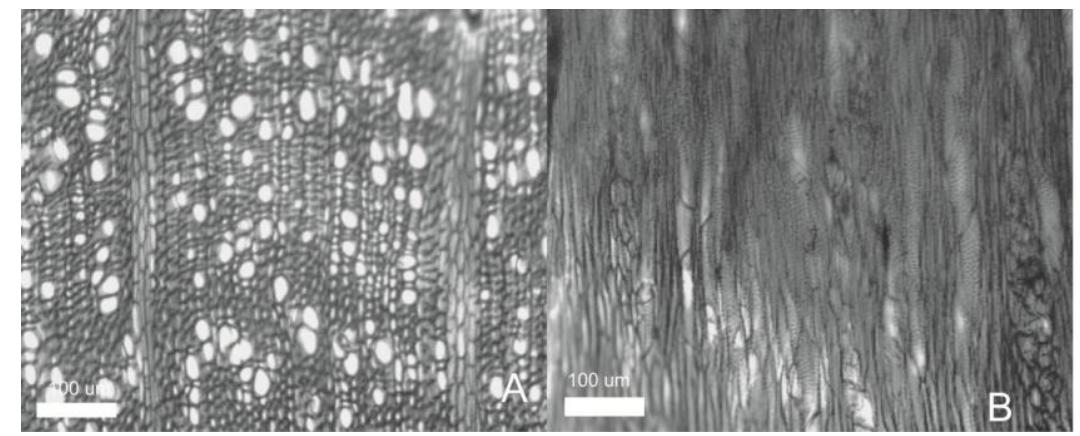

Figura 7.11. Senecio sp. A, CT Porosidad difusa, vasos en patrón diagonal y radial, de contorno muy angular; B, CLTg radios con células elongadas, grandes;

- Berberidaceae

Berberis sp. "calafate" (Material bibliográfico de referencia consultado: Ancibor y Pérez de Micou 1995, Ancibor y Pérez de Micou 2002, Piqué i Huerta 1999, Andreoni 2010, Caruso 2013)

Corte transversal. Anillos de crecimiento demarcado, porosidad semicircular. Vasos en bandas tangenciales en el leño temprano, diagonal y dendrítico en el leño tardío (Figura 7.12A). Vasos exclusivamente solitarios con mucho contenido, de contorno angular. Fibras de pared muy gruesa. Parénquima axial ausente o extremadamente escaso.

Ancibor y Pérez de Micou (1995) registran para esta especie algunos caracteres diferentes tales como, porosidad circular y parénquima axial paratraqueal vasicéntrico. En la base de datos de la IAWA (consultado 2014) se registra para Berberis chilensis 
anillo de crecimiento no demarcado, porosidad difusa, vasos radiales múltiples de $4 \mathrm{o}$ más. Fibras de pared delgada a gruesa. Parénquima apotraqueal difuso.

Corte longitudinal tangencial. Placa de perforación simple, oblicua. Punteaduras intervasculares alternas poligonales principalmente, y raramente opuestas. Engrosamiento helicoidal a lo largo de los elementos de vasos. Fibras con punteaduras con rebordes diminutos y conspicuos (fibrotraqueidas). Fibras con punteaduras generalmente en las paredes radiales y tangenciales. Tejido básico, fibrotraqueidas, con espesamiento espiralado. Radios 1 a 3 seriados (comúnmente biseriados) y radios grandes 4 a 10 seriados (comúnmente 8 seriados), homogéneos (Figura 7.12B). Radios de altura mayor a $1 \mathrm{~mm}$, de dos tamaños distintos. Cristales prismáticos presentes.

Corte longitudinal radial. Punteaduras vaso-radiales con rebordes visibles, similares a las punteaduras intervasculares en tamaño y forma a lo largo. Radios con células cuadradas, erectas y procumbentes mezcladas. Cristales prismáticos en células radiales procumbentes (Figura 7.12C).

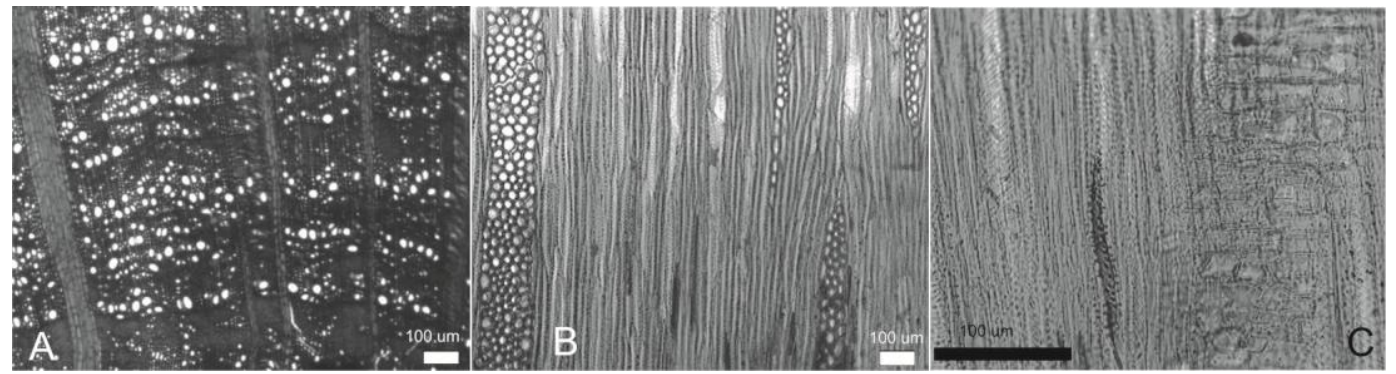

Figura 7.12. Berberis sp. A, CT, Anillos de crecimiento demarcados, vasos en bandas tangenciales y diagonal; B, CLtg. Radios multiseriados largos, espesamiento reticulado de los vasos y placa de perforación oblicua. C, CLrd., células del radio cuadradas erectas y procumbentes mezcladas.

- Chenopodiaceae

Atriplex lampa "zampa" (Material bibliográfico de referencia consultado: Marconetto 2002, Roig y Videla 2006-2010, Ortega y Marconetto 2009, Andreoni 2014)

Corte transversal. Anillos de crecimiento demarcado por hileras de parénquima. Cámbium anómalo, floema incluso, concéntrico, inmerso en tejido parenquimático (Figura 7.13A)(Roig y Vidal 2006-2009). Vasos en patrón diagonal y radial por detrás 
de las inclusiones de floema. Vasos exclusivamente solitarios. Fibras de pared muy gruesa. Parénquima axial en bandas angostas de hasta tres células de ancho.

Andreoni (2014) no registró anillos de crecimiento demarcados, incluso observó que podían estar ausentes.

Corte longitudinal tangencial. Placa de perforación simple. Punteaduras intervasculares alternas. Engrosamientos helicoidales presentes a lo largo de los elementos de vasos de espiras anchas. Células parenquimáticas fusiformes con dos células por serie parenquimática (Figura 7.13B). Parénquima axial y/o elementos de vaso estratificados.
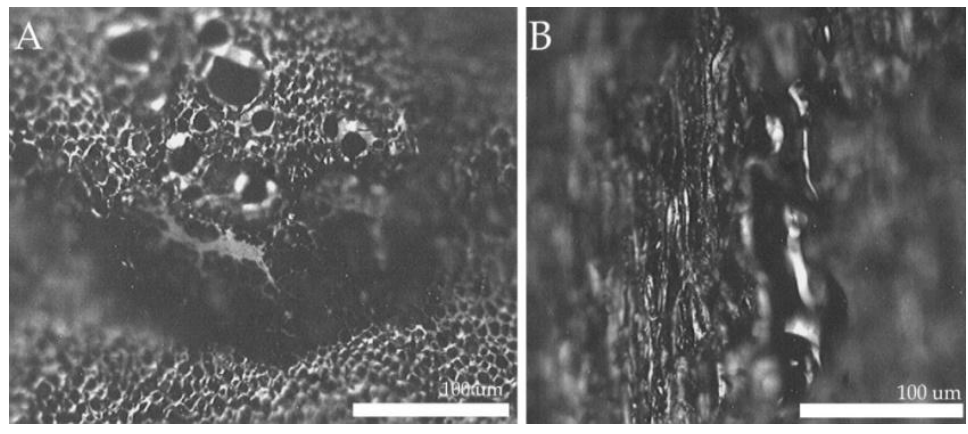

Figura 7.13. Atriplex sp. A, CT: Cámbium anómalo, floema incluso concéntrico inmerso en tejido parenquimático; B, CLtg. Células parenquimáticas fusiformes con dos células por serie parenquimática.

- Euphorbiaceae

Colliguaja integerrima "duraznillo" (Material bibliográfico de referencia consultado: Ancibor y Pérez de Micou 1995, Marconetto 2002, Andreoni y Capparelli 2012)

Corte transversal. Anillos de crecimiento demarcados, porosidad semicircular. Vasos en bandas tangenciales en el leño temprano, en patrón diagonal y radial en leño tardío. Vasos solitarios y radiales múltiples de cuatro o más (en los que uno es grande y luego los demás son de menor tamaño). Son de contorno angular (Figura 7.14A). Fibras de pared muy delgada. Parénquima axial ausente o extremadamente escaso.

Corte longitudinal tangencial. Placa de perforación simple, oblicua. Punteaduras intervasculares alternas. Engrosamientos helicoidales en los elementos de vaso; fibras con punteaduras simples a punteaduras con rebordes diminutos. Espesamientos espiralados en fibras del tejido básico (más visibles que en Chuquiraga avellanedae). 
Radios mayormente uniseriados, aunque también parcialmente biseriados, heterogéneos III (Figura 7.14B). Células radiales perforadas.

Corte longitudinal radial. Punteaduras vaso-radiales con reborde visibles, similares a punteaduras intervasculares en tamaño y forma a lo largo de las células radiales. Todas las células del radio erectas y/o cuadradas (Figura 7.14C).

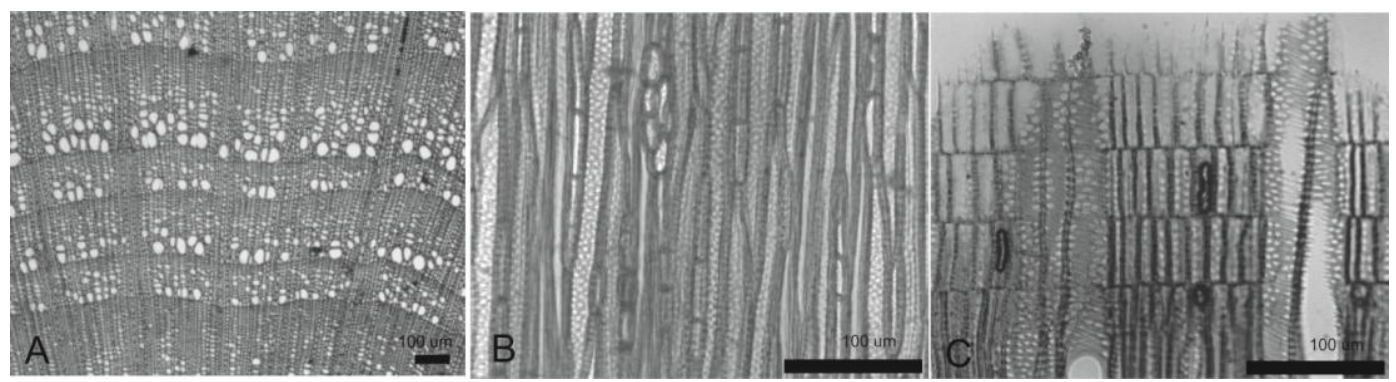

Figura 7.14. Colliguaja integerrima: A, CT, anillo de crecimiento demarcado y vasos en banda tangencial en leño temprano; B, CLTg, radios uni y biseriados y engrosamiento helicoidal de los vasos. C, CLrd, células del radio erectas. .

- Fabaceae

Adesmia boronioides "paramela" (Material bibliográfico de referencia consultado: Garibotti 1998, Andreoni 2010, Roig y Varela 2006-2010, Andreoni y Capparelli 2012)

Corte transversal. Anillos de crecimiento demarcado por vasos en bandas tangenciales en leño temprano, porosidad semicircular y vasos en patrón diagonal a dendrítico en leño tardío. Vasos exclusivamente solitarios angulares. Fibras de pared muy gruesa. Parénquima apotraqueal difuso. Parénquima axial paratraqueal confluente acompañando en el leño tardío a los vasos en disposición dendrítica y diagonal (Figura 7.15A). Parénquima axial en bandas marginales en el leño temprano asociado a los vasos de cinco células de espesor.

Andreoni (2010) observa para Adesmia obovata en la región de Mendoza, vasos de contorno angular, pero no describe parénquima apotraqueal difuso. Guerra et al. (2012) para la región de ecotono bosque-estepa de Chubut observa en Adesmia boronioides porosidad circular al inicio de cada anillo de crecimiento, poros solitarios y agrupados, múltiples cortos de 2 y 3 , y largos, en disposición ulmoide y agrupados en racimos. 
Además de los tipos de parénquima descriptos en la presente tesis Guerra et al. (2012) observa parénquima vasicéntrico incompleto y completo.

Corte longitudinal tangencial. Placas de perforación simple horizontales y oblicuas, punteaduras intervasculares escalariformes y opuestas. Engrosamiento helicoidal a lo largo de los vasos dispuestos en espiras apretadas y horizontales. Fibras con punteaduras simples a fibras con punteaduras de rebordes diminutos. Fibras no septadas presentes. Células parenquimáticas fusiformes, dos por serie parenquimática. Radios 1 a 3 seriados (predominantemente biseriados) y radios grandes 4 a 10 seriados (comúnmente 7 seriados) de tipo Heterogéneos II (Figura 7.15B).

Andreoni (2010) no observa para Adesmia obovata engrosamiento espiralado en el cuerpo de los vasos. También parénquima axial y/o elementos de vaso estratificados.

Corte longitudinal radial. Punteaduras vaso-radiales con rebordes muy reducidos hasta con apariencia de simples. Radios con células procumbentes, cuadradas y erectas mezcladas (Figura 7.15C).

Andreoni (2010) identifica punteaduras vaso-radiales con rebordes visibles similares a punteaduras intervasculares en tamaño y forma a lo largo de las células radiales.
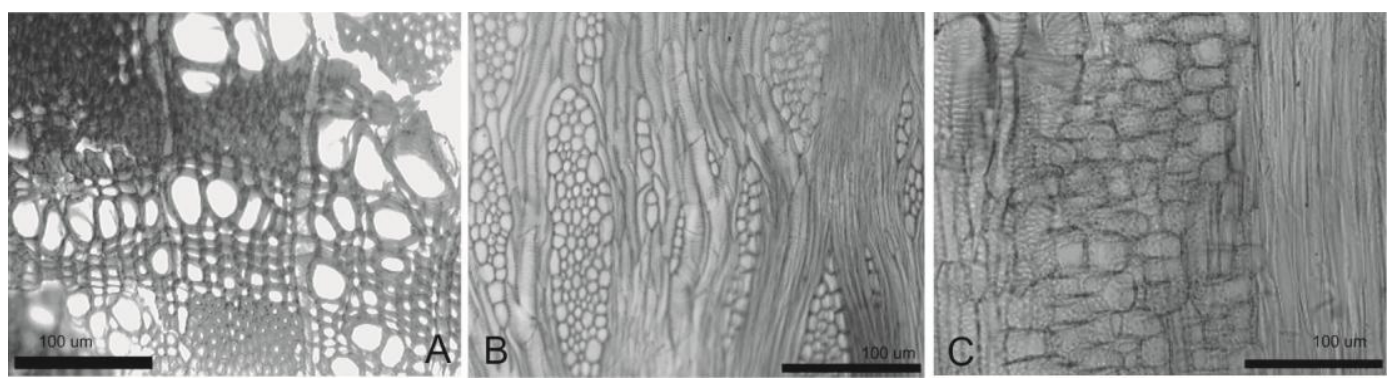

Figura 7.15. Adesmia boronioides: A, CT vasos en patrón diagonal a dendrítico; B, CLTg radios multiseriados y engrosamiento helicoidal de los vasos; C, CLrd células procumbentes, cuadradas y erectas.

Prosopidastrum globosum "manca caballo" (Material bibliográfico de referencia consultado: Roig y Videla 2006-2010, Andreoni 2014)

Corte transversal. Anillos de crecimiento demarcados por parénquima marginal, por porosidad semicircular y una hilera de vasos en disposición tangencial y una banda de fibras achatadas. Vasos en disposición tangencial, radial y diagonal a dendrítica. Vasos 
solitarios, vasos múltiples cortos y largos en el leño tardío. Vasos agrupados frecuentes. Fibras de pared muy gruesa. Parénquima apotraqueal difuso en agregados, paratraqueal axial confluente, axial en bandas mayor de tres células de ancho, angostas de hasta tres células de ancho y marginal o aparentemente en bandas (Figura 7.16A).

Corte longitudinal tangencial. Placa de perforación simple, oblicua. Punteaduras intervasculares alternas. Engrosamiento helicoidal y reticulado presente a lo largo del elemento de vaso. Fibras septadas presentes. Células parenquimáticas fusiformes, dos por serie parenquimáticas. Radios uni a triseriados de tipo homogéneos II (Figura 7.16B). Cristales prismáticos presentes en fibras.

Corte longitudinal radial. Todas las células radiales procumbentes (Figura 7.16C).

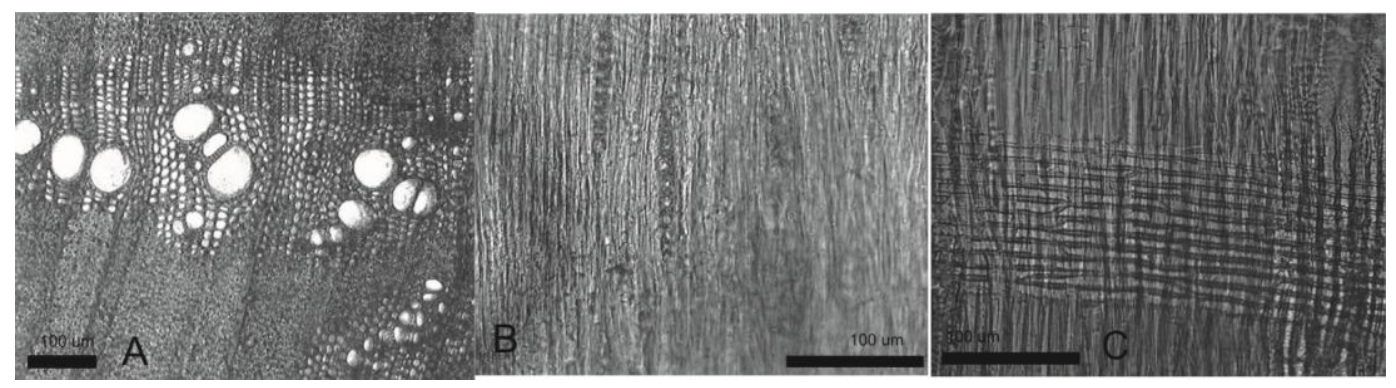

Figura 7.16. Prosopidastrum globosum. A, CT. Anillos de crecimiento demarcados por parénquima marginal, Vasos en disposición diagonal y radial. Parénquima axial paratraqueal confluente; B, CLTg. Radios uniseriados homogéneos tipo II; C, CLrd. Células del radio procumbentes

Prosopis denudans "algarrobillo" (Material bibliográfico de referencia consultado: Ancibor y Pérez de Micou 1995, 2002, Marconetto 2002, Ortega y Marconetto 2009, Roig y Videla 2006-2010, Andreoni y Capparelli 2012)

Corte transversal. Anillos de crecimiento demarcados por parénquima marginal del leño tardío y por porosidad semicircular. Vasos en disposición tangencial en leño temprano y diagonal en el tardío. Vasos solitarios, múltiples cortos de dos, tres y cuatro, con contenido y agrupados en el leño tardío. Fibras de pared muy gruesa. Parénquima axial paratraqueal confluente, parénquima axial marginal o aparentemente en bandas marginales (Figura 7.17A).

Corte longitudinal tangencial. Placa de perforación simple, oblicua y horizontal. Punteaduras intervasculares alternas, fibras con punteaduras simples con rebordes 
diminutos. Células parenquimáticas fusiformes, dos por serie. Radios 1 a 3 seriados (en gran proporción uniseriados y parcialmente biseriados y en menor medida triseriados) y radios grandes de 4 a 10 seriados (4 seriados escasos). Radios de tipo homogéneo (Figura 7.17B). Cristales prismáticos en fibras y radios.

Corte longitudinal radial. Punteaduras vaso-radiales con rebordes muy reducidos hasta con apariencia de simples. Todas las células del radio procumbentes y también células del radio procumbentes, erectas y cuadradas mezcladas (Figura 7.17C).

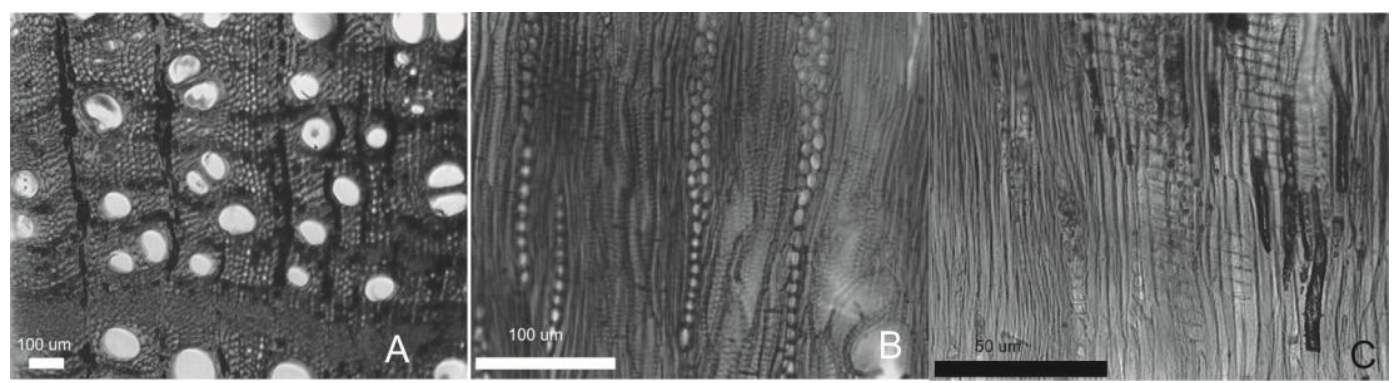

Figura 7.17. Prosopis denudans: A, CT, Parénquima axial marginal, parénquima paratraqueal confluente, vasos solitarios y múltiples cortos. B, CLTg. Radios 1-3 seriados largos; C, CLrd. Células del radio procumbentes, erectas y cuadradas mezcladas.

- Solanaceae

Fabiana imbricata "palo piche" (Material bibliográfico de referencia consultado: (Rodríguez 2008)

Corte transversal. Anillos de crecimiento demarcados por fibras achatadas y disposición tangencial de los vasos del leño temprano. Porosidad semicircular, vasos también en disposición diagonal en leño tardío (Figura 7.18A). Vasos exclusivamente solitarios. Fibras de pared delgada a gruesa. Parénquima axial ausente o extremadamente escaso. Parénquima apotraqueal axial difuso.

La base de datos IAWA (consultado 2014) describe para esta especie anillos no demarcados

Corte longitudinal tangencial. Placa de perforación simple, oblicua. Punteaduras intervasculares alternas. Traqueidas vasculares vasicéntricas presentes. Fibras con punteaduras simples a punteaduras con reborde diminuto. Fibras no septadas presentes. Radios exclusivamente uniseriados de tipo homogéneo III (Figura 7.18B). 
En la base de la IAWA (consultado en 2014) se describen fibras con punteaduras con reborde conspicuo, fibras con punteaduras generalmente en las paredes radiales y tangenciales. Tres a cuatro células por serie parenquimática

Corte longitudinal radial. Punteaduras vaso-radiales con rebordes muy reducidos hasta con apariencia simples. Células del cuerpo del radio procumbentes con una hilera de células marginales erectas y/o cuadradas. También, radios con células cuadradas, erectas y procumbentes mezcladas. Cristales prismáticos en células radiales cuadradas y erectas.

En la IAWA (consultado en 2014) se observa todas las células del radio erectas y/o cuadradas.
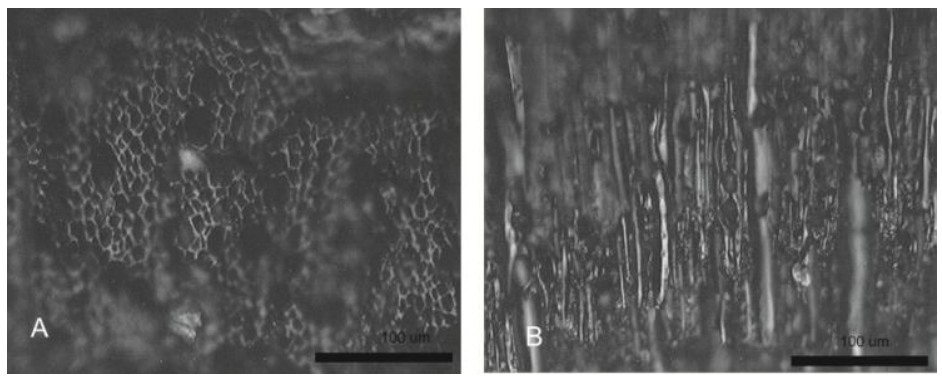

Figura 7.18. Fabiana imbricata A: CT: Vasos en disposición diagonal. B: CLT: Radios uniseriados.

Lycium sp. según la especie: "mata laguna, yaoyín"(Material bibliográfico de referencia consultado: Roig y Videla 2006-2010, Ortega y Marconetto 2009, Andreoni y Capparelli 2012)

Corte transversal. Anillo de crecimiento demarcado por fibras achatadas. Porosidad semicircular, vasos en bandas tangenciales en leño temprano, diagonal a dendrítico en el tardío (Figura 7.19A). Vasos exclusivamente solitarios. Fibras de pared delgada a gruesa. Paréquima apotraqueal difuso en agregados, y paratraqueal escaso. Parénquima axial marginal o aparentemente en bandas marginales de una hilera de células.

Corte longitudinal tangencial. Placa de perforación simple, oblicua. Punteaduras intervasculares alternas. Engrosamiento helicoidal presente en elementos de vaso. Fibras con punteaduras simples a punteaduras con rebordes diminutos. Espesamiento espiralado en fibras del tejido básico. Fibras no septadas presentes. Dos, tres y cuatro 
células por serie parenquimática. Radios mayormente uniseriados, algunos parcialmente biseriados, de tipo heterogéneos III (Figura 7.19B).

Corte longitudinal radial. Punteaduras vaso-radiales con rebordes visibles, similares a punteaduras intervasculares en tamaño y forma a lo largo de las células radiales. Células procumbentes, cuadradas y erectas mezcladas (Figura 7.19C).

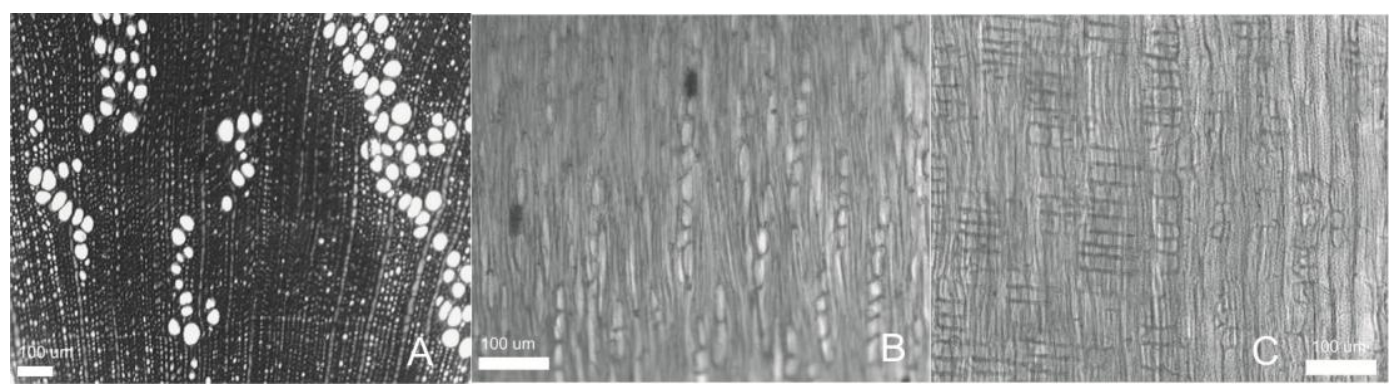

Figura 7.19. Lycium sp. A, CT, vasos en disposición dendrítica, parénquima apotraqueal difuso en agreados; B, CLTg, radios uniseriados cortos y largos de tipo heterogéneos III; C, CLrd., células cuadradas, erectas y procumbentes mezcladas

- Verbernaceae

Mulguraea tridens "mata negra" (Material bibliográfico de referencia consultado: Andreoni y Capparelli 2012, Caruso 2013).

Corte transversal. Anillos de crecimiento demarcados por porosidad semicircular. Disposición de los vasos en bandas tangenciales en leño temprano y tardío (Figura 7.20A). Disposición de los vasos en diagonal y dendrítico en leño tardío. Vasos exclusivamente solitarios y de contorno angular. Fibra de pared delgada a gruesa. Parénquima apotraqueal axial difuso y difuso en agregados. Parénquima axial paratraqueal vasicéntrico escaso. Parénquima axial paratraqueal confluente en diagonal en bandas finas. Parénquima axial marginal o aparentemente en bandas marginales de 3 a 4 células al final del leño tardío no asociado a la banda tangencial de vasos del leño temprano.

Corte longitudinal tangencial. Placa de perforación simple, punteaduras intervasculares alternas, poligonales. Engrosamientos helicoidales a lo largo de los elementos de vaso. Traqueidas vasicéntricas presentes. Fibras con punteaduras simples a punteaduras con rebordes diminutos. Espesamientos espiralados en fibras del tejido básico (en 
firbrotraqueidas). Fibras no septadas presentes. Radios 1 a 3 seriados (principalmente 12) de tipo heterogéneo Iib (Figura 7.20B).

Corte longitudinal radial. Punteaduras vaso-radiales con rebordes visibles, similares a punteaduras intervasculares en tamaño y forma a lo largo de las células radiales. Radios con células procumbentes, cuadradas y erectas mezcladas (Figura 7.20C).

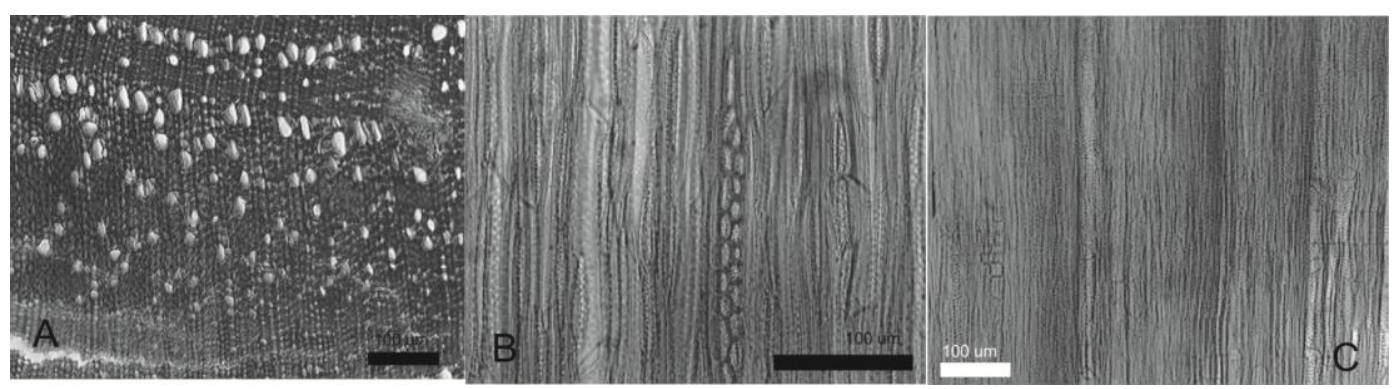

Figura 7.20. Mulguraea tridens: A, CT, anillos de crecimiento demarcado por porosidad semicircular; B, CLTg. radios 1-3 seriados, engrosamiento helicoidal de los vasos; C, CLrd, radios con células cuadradas, erectas y procumbentes mezcladas. 


\subsubsection{Clave dicotómica}

A) CT: Madera con variaciones cambiales. CLTg: vasos con engrosamiento espiralado

B) CT: Maderas con crecimiento secundario anómalo con paquetes separados de xilema- floema (distribuidos en una matriz de fibras o parenquima) CLTg: anillos no demarcados, placas de perforación y punteaduras escalariformes, maderas sin radios

C) Vasos exclusivamente solitarios

Mulinum

$C^{\prime}$ ) Vasos solitarios y radiales múltiples

B') CT: Maderas con floema incluso, anillos demarcados o no demarcados, con o sin radios, vasos solitarios, múltiples cortos en disposición radial y diagonal a tangencial. CLTg: placas simples, con estratificación parcial o total

D) Madera sin radios o extremadamente escasos

E) CT: anillos demarcados por parénquima en bandas de 2 a 3 células. Floema incluso tipo difuso, dentro del parénquima paratraqueal y por "debajo" de cada conjunto de vasos. CLTg: estratificación de vasos y parénquima

Atriplex

E') CT: anillos no demarcados, floema incluso tipo difuso concéntrico dentro de bandas de parénquima de más de 4 células de ancho. CLTg: estratificación de vasos, parénquima y fibras.

Suaeda

D') Madera con radios.

Bougainvillea 
$\left.\mathrm{A}^{\prime}\right) \mathrm{CT}$ : Madera sin variantes cambiales

F) CT: vasos exclusivamente solitarios de contorno angular bien marcados, porosidad difusa, anillos demarcados, parénquima escaso a ausente. CLTg: Traqueidas con placas de perforación foraminada, fibrotraqueidas, campos de cruzamiento cupresoides, radios con células alargadas y redondeadas comúnmente de 4 a 5 células de ancho (madera de Gimnosperma)

Ephedra

$\mathrm{F}^{\prime}$ ) Otras combinaciones de caracteres (maderas de Angiospermas, sin traqueas)

G) CT: porosidad difusa a semicircular. Vasos solitarios abundantes y de contorno angular, también vasos múltiples radiales cortos y a veces largos agrupados. Disposición de los vasos radial/diagonal al menos en leño tardío (a veces algo dendrítico). CLTg: Fibras con punteaduras conspicuas y punteaduras vaso-radio con rebordes conspicuos en vista tangencial, se observan punteaduras en todos los tipos de células (incluso en el CLR). Cuerpo del radio predominantemente con células elongadas dispuestas en varias direcciones, aunque también puede haber algunas células redondeadas. Radios 1 a 6 seriados, nunca exclusivamente uniseriados

(H) (Asteraceae)

H) Maderas con anillos no demarcados

I) Radios comúnmente 1-3 seriados (a veces parcialmente 4 seriados) Grindelia

I') Radios con más de 4 células de ancho frecuentes...... 
$\left.\mathrm{H}^{\prime}\right)$ Maderas con anillos demarcados

K) Radios extremadamente escasos o no visibles

L) Parénq. axial difuso y difuso en agregados, poros solitarios

L') Parénquima axial ausente o escaso

LL) Placas escalariformes y simples, poros múltiples cortos .Nardophyllum

LL') Placas simples, poros solitarios Nassauvia

$\mathrm{K}^{\prime}$ ) Radios conspicuos o visibles

M) Parénquima axial ausente o escaso, radios agregados Chuquiraga

M') Parénquima axial evidente

N) Parénquima axial vasicéntrico y confluente. CLrd: células radiales, erectas y procumbentes, engrosamiento espiralado Neosparton $\mathrm{N}^{\prime}$ ) Parénquima axial paratraqueal escaso. CLrd: todas las células del radio procumbentes sin engrosamiento espiralado

Baccharis 
G') Otras combinaciones de caracteres. CT: Generalmente porosidad difusa o semicircular, vasos solitarios, múltiples cortos y a veces también múltiples largos y agrupados, disposición de los vasos por lo general tangencial en leño temprano y diagonal/radial a dendrítica en leño tardío. CLTg: no se presentan células elongadas en distintas direcciones en los cuerpos de los radios multiseriados. Si bien puede haber fibrotraqueidas o fibras con punteaduras visibles, las punteaduras en CLTg y CLrd no son tan abundantes como se aprecia en Asteraceae, ni se dan en todos los tipos de células

.(O) (No Asteraceae)

O) Parénquima en bandas y/o parénquima paratraqueal presente

P) Radios exclusivamente uniseriados

Q) Parénquima en bandas de 1 a 3 células, poros solitarios, múltiples cortos y agregados

Stillingia

Q') Parénquima marginal de 1 célula, poros solitarios y radios uniseriados heterogéneos

Lycium

$\left.\mathrm{P}^{\prime}\right)$ Radios no exclusivamente uniseriados

R) Radios mayor a $1 \mathrm{~mm}$ presentes, radios 1-3 seriados y 4-10 seriados, con células envolventes

S) Células por parénquima strand: fusiformes, 2 predominan poros solitarios ..Adesmia

$\left.\mathrm{S}^{\prime}\right)$ Células por parénquima strand: fusiformes, 3 a 4,5 a 8

Caesalpinia 
$\mathrm{R}^{\prime}$ ) Radios mayor a $1 \mathrm{~mm}$ ausentes, radios 1 a 4 seriados, sin células envolventes

T) Radios heterogéneos con colas uniseriadas y cuerpo multiseriado presentes

Mulguraea

$\mathrm{T}^{\prime}$ ) Todos los radios homogéneos de células redondeadas

U) Sin parénquima en bandas

V) Con radios agregados parénquima aliforme.

Prosopis alpataco

V') Sin radios agregados, parénquima confluente

Condalia

$\left.\mathrm{U}^{\prime}\right)$ Con parénquima en bandas

W) Con engrosamiento helicoidal en vasos, placa de perforación solo oblicuas

Prosopidastrum

W') Sin engrosamiento helicoidal en vasos, placas de perforación horizontales y oblicuas...

Prosopis denudans

O') Sin parénquima en bandas ni parénquima paratraqueal. El parénquima es ausente, escaso o apotraqueal difuso/difuso en agregados

$\mathrm{X}$ ) Con estructura estratificada en vasos, parénquima y fibras Larrea

$\left.\mathrm{X}^{\prime}\right)$ Sin estructura estratificada 
(Y) R.adios exclusivamente uniseriados

(Z) Vasos solitarios angulares y vasos múltiples radiales, porosidad semicircular, radios uniseriados heterogéneos, vasos con engrosamiento espiralado

Colliguaja

(Z') Vasos mayormente solitarios, porosidad difusa, radios uniseriados homogénos, vasos sin engrosamiento espiralado

Fabiana

$\left.\mathrm{Y}^{\prime}\right)$ Radios no exclusivamente uniseriados

(1) radios mayor a $1 \mathrm{~mm}$ presentes, radios de 2 tamaños, 1-3 seriados y 4-10 seriados

Berberis

(1') radios mayor a $1 \mathrm{~mm}$ ausentes, radios de 1 tamaño, 1-3 seriados. Schinus 


\subsubsection{Valores de densidad}

A partir de los resultados obtenidos del cálculo de densidad de las maderas analizadas (Tabla 7.1.), se pueden establecer como maderas de alta densidad de CNSC a los siguientes taxa: Prosopis denudans, Suaeda, Berberis, Schinus, Chuquiraga avellanedae. Dentro de las maderas de densidad intermedia se encuentran: Nardophyllum bryoides y Lycium. Las madera de baja densidad es Colliguaja integerrima y de muy baja densidad Senecio y Adesmia boronioides. De las especies provenientes de la Provincia Subantártica (oeste de Neuquén y Chubut) las maderas de alta densidad son: Lycium ameghinoi y Nothofagus antarctica. Dentro de las maderas de densidad intermedia se encuentran: Maytenus disticha, Fabiana imbricata, Diostea juncea, Aristotelia chilensis, Myoschilos oblongum. Leños de densidad baja se registraron Escallonia rubra, Escallonia virgata, Nothofagus dombeyi, Austrocedrus chilensis, Araucaria araucana y Luma apiculata. Las maderas de muy baja densidad son Ribes magellanicum, Maytenus boaria, Berberis microphylla, Buddleja globosa y Sambucus.

\begin{tabular}{|c|c|c|}
\hline Familia & Especie & $\begin{array}{c}\text { Densidad aparente } \\
\text { anhidro (peso anhidro/ } \\
\text { volumen de agua } \\
\text { desplazada) }\end{array}$ \\
\hline Fabaceae & Adesmia boronioides & 0,32 \\
\hline Araucariaceae & Araucaria araucana & 0,37 \\
\hline Elaeocarpaceae & Aristotelia chilensis & 0,45 \\
\hline Cupressaceae & Austrocedrus chilensis & 0,42 \\
\hline Chenopodiaceae & Atriplex lampa & $\mathrm{s} / \mathrm{d}$ \\
\hline Asteraceae & Baccharis darwinii & $\mathrm{s} / \mathrm{d}$ \\
\hline Berberidaceae & Berberis sp. & 0,55 \\
\hline Berberidaceae & Berberis microphylla & 0,31 \\
\hline Scrophulariaceae & Buddleja globosa & 0,26 \\
\hline Asteraceae & $\begin{array}{l}\text { Chuquiraga } \\
\text { avellanedae }\end{array}$ & 0,53 \\
\hline Euphorbiaceae & Colliguaja integerrima & 0,41 \\
\hline Verbenaceae & Diostea juncea & 0,49 \\
\hline Escalloniaceae & Escallonia rubra & 0,43 \\
\hline Escalloniaceae & Escallonia virgata & 0,4 \\
\hline
\end{tabular}




\begin{tabular}{|c|c|c|}
\hline Solanaceae & Fabiana imbricata & 0,51 \\
\hline Verbenaceae & Mulguraeae tridens & $\mathrm{s} / \mathrm{d}$ \\
\hline Asteraceae & $\begin{array}{l}\text { Lepidophyllum } \\
\text { curessiforme }\end{array}$ & $\mathrm{s} / \mathrm{d}$ \\
\hline Myrtaceae & Luma apiculata & 0,36 \\
\hline Solanaceae & Lycium ameghinoi & 0,66 \\
\hline Solanaceae & Lycium sp. & 0,5 \\
\hline Celastraceae & Maytenus boaria & 0,33 \\
\hline Celastraceae & Maytenus disticha & 0,52 \\
\hline Santalaceae & Myoschilos oblongum & 0,45 \\
\hline Asteraceae & Nardophyllum bryoides & 0,52 \\
\hline Asteraceae & Nassauvia sp & $\mathrm{s} / \mathrm{d}$ \\
\hline Nothofagaceae & Nothofagus antarctica & 0,53 \\
\hline Nothofagaceae & Nothofagus dombeyi & 0,43 \\
\hline Fabaceae & $\begin{array}{c}\text { Prosopidastrum } \\
\text { globosum }\end{array}$ & $\mathrm{s} / \mathrm{d}$ \\
\hline Fabaceae & Prosopis denudans & 0,56 \\
\hline Grossulariaceae & Ribes magellanicum & 0,38 \\
\hline Adoxaceae & Sambucus sp & 0,23 \\
\hline Anacardiaceae & Schinus sp. & 0,53 \\
\hline Asteraceae & Senecio sp. & 0,31 \\
\hline Chenopodiaceae & Suaeda sp. & 0,56 \\
\hline
\end{tabular}

Tabla 7.1. Densidad aparente anhidro de las maderas de referencia. Referencias [s/d] sin datos. 


\subsubsection{Experimentación}

A continuación se presenta una tabla con los rasgos de carbonización a distintas temperaturas producto de la carbonización experimental del material de referencia (Tabla 7.2). Como se dijo anteriormente, se debe considerar a estos resultados como preliminares hasta tanto se realicen las réplicas necesarias en el futuro cercano. En primer lugar, se pueden observar diferencias en las grietas de contracción en la cara A y B (cara superior e inferior, respectivamente, de acuerdo a su localización en el crisol), siendo la primera la que presentó más cantidad de ellas. Es difícil relacionar estas diferencias con una causa específica, debido a que todas las variables se mantuvieron constantes para cada cara y cada taco de madera se encuentra tapado en su totalidad por arena, lo que hace homogénea la temperatura alcanzada por el taco en todos sus lados. Una posibilidad es que la cara más próxima al exterior fuera más afectada por la presencia de oxígeno que la interior, pero esto será corroborado en futuros trabajos experimentales.

Los taxa que potencialmente podrían ser diagnósticos de altas temperaturas de combustión son Schinus, Diostea juncea y Lycium sp. (Tabla 7.2.), tal como se desprende de los párrafos siguientes.

\begin{tabular}{|c|c|c|c|c|}
\hline \multirow{2}{*}{ Taxa } & \multicolumn{2}{|c|}{$400{ }^{\circ} \mathrm{C}$} & \multicolumn{2}{c|}{$700{ }^{\circ} \mathrm{C}$} \\
\cline { 2 - 5 } & $0 \%$ de humedad & $\begin{array}{c}8 \text { al 12\% de } \\
\text { humedad }\end{array}$ & $0 \%$ de humedad & al $\%$ de \\
humedad
\end{tabular}




\begin{tabular}{|c|c|c|c|c|}
\hline $\begin{array}{c}\text { Austrocedrus } \\
\text { chilensis }\end{array}$ & $\begin{array}{c}\text { Lado A y B: no } \\
\text { presentan cambios }\end{array}$ & $\begin{array}{l}\text { Lado A y B: no } \\
\text { presenta cambios }\end{array}$ & $\begin{array}{l}\text { Lado A: abertura por } \\
\text { radios } \\
\text { Lado B: no presenta } \\
\text { cambios }\end{array}$ & $\begin{array}{l}\text { Lado A y B: no } \\
\text { presentan cambios }\end{array}$ \\
\hline $\begin{array}{l}\text { Berberis sp. } \\
\text { (colectado en } \\
\text { CNSC) }\end{array}$ & $\begin{array}{l}\text { Lado A: ojos en } \\
\text { radios y vasos } \\
\text { Lado B: Aberturas } \\
\text { en anillos y ojos en } \\
\text { los radios }\end{array}$ & $\begin{array}{c}\text { Lado A: ojos en los } \\
\text { radios } \\
\text { Lado B: ojos y } \\
\text { aberturas en radios }\end{array}$ & $\begin{array}{l}\text { Lado A y B: abertura } \\
\text { en anillo y ojos en los } \\
\text { radios }\end{array}$ & $\begin{array}{l}\text { Lado A y B: } \\
\text { aberturas en los } \\
\text { radios }\end{array}$ \\
\hline $\begin{array}{c}\text { Berberis } \\
\text { microphylla } \\
\text { (colectado en el } \\
\text { oeste de Chubut) }\end{array}$ & $\begin{array}{l}\text { Lado A: no presenta } \\
\text { cambios Lado B: } \\
\text { pequeñas aberturas } \\
\text { ojos en los radios }\end{array}$ & $\begin{array}{l}\text { Lado A y B: } \\
\text { abertura en el anillo }\end{array}$ & $\begin{array}{l}\text { Lado A: ojos en los } \\
\text { radios y abertura en los } \\
\text { radios. Lado B: } \\
\text { abertura en los radios }\end{array}$ & $\begin{array}{l}\text { Lado A: abertura en } \\
\text { el anillo Lado B: } \\
\text { ojos en radios y } \\
\text { abertura en el anillo }\end{array}$ \\
\hline $\begin{array}{l}\text { Buddleja } \\
\text { globosa }\end{array}$ & $\begin{array}{l}\text { Lado A: no presenta } \\
\text { cambios Lado B: } \\
\text { aberturas en la } \\
\text { médula, anillos y } \\
\text { radios }\end{array}$ & $\begin{array}{l}\text { Lado A: abertura en } \\
\text { la médula Lado B: } \\
\text { no presenta cambios }\end{array}$ & $\begin{array}{l}\text { Lado A: no presenta } \\
\text { cambios } \\
\text { Lado B: abertura por } \\
\text { médula }\end{array}$ & $\begin{array}{c}\text { Lado A: no } \\
\text { presenta cambios, } \\
\text { Lado B: ojos en los } \\
\text { radios }\end{array}$ \\
\hline $\begin{array}{l}\text { Chuquiraga } \\
\text { avellanedae }\end{array}$ & $\begin{array}{l}\text { Lado A y B: no } \\
\text { presenta cambios }\end{array}$ & $\begin{array}{l}\text { Lado A: pequeñas } \\
\text { grietas en anillos } \\
\text { Lado B: no presenta } \\
\text { cambios }\end{array}$ & $\begin{array}{c}\text { Lado A y B: ojos en los } \\
\text { radios }\end{array}$ & $\begin{array}{l}\text { Lado A: aberturas } \\
\text { en los radios } \\
\text { Lado B: ojos en los } \\
\text { radios }\end{array}$ \\
\hline $\begin{array}{l}\text { Colliguaja } \\
\text { integerrima }\end{array}$ & $\begin{array}{l}\text { Lado A: no presenta } \\
\text { cambios } \\
\text { Lado B: pequeña } \\
\text { grietas por los radios }\end{array}$ & $\begin{array}{l}\text { Lado Ay B: pequeña } \\
\text { grieta por los radios }\end{array}$ & $\begin{array}{l}\text { Lado A: pequeñas } \\
\text { grietas en radios y } \\
\text { anillos Lado B: no } \\
\text { presenta cambios }\end{array}$ & $\begin{array}{c}\text { Lado A: no } \\
\text { presenta cambios } \\
\text { Lado B: abertura en } \\
\text { radios y a través de } \\
\text { los vasos }\end{array}$ \\
\hline Diostea juncea & $\begin{array}{c}\text { Lado A y B: no } \\
\text { presentan cambios }\end{array}$ & $\begin{array}{l}\text { Lado A y B: no } \\
\text { presenta cambios }\end{array}$ & $\begin{array}{l}\text { Lado A: no presentan } \\
\text { cambios } \\
\text { Lado B: abertura en } \\
\text { anillo y en radio }\end{array}$ & $\begin{array}{l}\text { Lado A: ojos en } \\
\text { anillos Lado B: } \\
\text { ojos y aberturas en } \\
\text { anillos y radios }\end{array}$ \\
\hline Escallonia rubra & $\begin{array}{l}\text { Lado A: abertura en } \\
\text { anillo y radio Lado } \\
\text { B: no presenta } \\
\text { cambios }\end{array}$ & $\begin{array}{l}\text { Lado A: no presenta } \\
\text { cambios Lado B: } \\
\text { abertura en radios, } \\
\text { poros y anillos }\end{array}$ & $\begin{array}{c}\text { Lado A: ojos en radio y } \\
\text { Lado B: abertura en } \\
\text { anillos }\end{array}$ & $\begin{array}{l}\text { Lado A: abertura en } \\
\text { radios Lado B: } \\
\text { abertura y ojos en } \\
\text { radios }\end{array}$ \\
\hline $\begin{array}{c}\text { Escallonia } \\
\text { virgata }\end{array}$ & $\begin{array}{l}\text { Lado A: abertura en } \\
\text { radio } \\
\text { Lado B: no presenta }\end{array}$ & $\begin{array}{l}\text { Lado A y B: no } \\
\text { presentan cambios }\end{array}$ & $\begin{array}{c}\text { Lado A y B: no } \\
\text { presentan cambios }\end{array}$ & $\begin{array}{c}\text { Lado A: no } \\
\text { presenta cambios } \\
\text { Lado B: no }\end{array}$ \\
\hline
\end{tabular}




\begin{tabular}{|c|c|c|c|c|}
\hline & cambios & & & presenta cambios \\
\hline $\begin{array}{l}\text { Fabiana } \\
\text { imbricata }\end{array}$ & $\begin{array}{l}\text { Lado A y B: no } \\
\text { presenta cambios }\end{array}$ & $\begin{array}{l}\text { Lado A: abertura en } \\
\text { anillo y radio Lado } \\
\text { B: no presenta } \\
\text { cambios }\end{array}$ & $\begin{array}{l}\text { Lado A y B: no } \\
\text { presenta cambios }\end{array}$ & $\begin{array}{c}\text { Lado A: no } \\
\text { presenta cambios } \\
\text { Lado B: abertura en } \\
\text { radio }\end{array}$ \\
\hline Luma apiculata & $\begin{array}{l}\text { Lado A y B: no } \\
\text { presenta cambios }\end{array}$ & $\begin{array}{l}\text { Lado A y B: no } \\
\text { presenta cambios }\end{array}$ & $\begin{array}{l}\text { Lado A: no presenta } \\
\text { cambios } \\
\text { Lado B: ojos en radios }\end{array}$ & $\begin{array}{l}\text { Lado A: ojos poco } \\
\text { profundos en radios } \\
\text { Lado B: no } \\
\text { presenta }\end{array}$ \\
\hline $\begin{array}{l}\text { Lycium } \\
\text { ameghinoi }\end{array}$ & $\begin{array}{l}\text { Lado A: aberturas } \\
\text { profundas en los } \\
\text { radios } \\
\text { Lado B: no presenta } \\
\text { cambios }\end{array}$ & $\begin{array}{l}\text { Lado A: abertura por } \\
\text { radios Lado B: } \\
\text { abertura en radio y } \\
\text { anillo }\end{array}$ & $\begin{array}{c}\text { Lado A: ojos en anillos } \\
\text { y ojos profundos en } \\
\text { radios } \\
\text { Lado B: aberturas en } \\
\text { radios }\end{array}$ & $\begin{array}{l}\text { Lado A: abertura en } \\
\text { radio, ojos en } \\
\text { anillos } \\
\text { Lado B: abertura y } \\
\text { ojos en radios y } \\
\text { anillos }\end{array}$ \\
\hline Lycium $\mathrm{sp}$ & $\begin{array}{l}\text { Lado A y B: no } \\
\text { presenta cambios }\end{array}$ & $\begin{array}{l}\text { Lado A: abertura en } \\
\text { radios } \\
\text { Lado B: no presenta } \\
\text { cambios }\end{array}$ & $\begin{array}{l}\text { Lado A: abertura en } \\
\text { radios } \\
\text { Lado B: abertura en } \\
\text { radio y ojos en anillos }\end{array}$ & $\begin{array}{c}\text { Lado A: abertura en } \\
\text { los radios } \\
\text { Lado B: ojos y } \\
\text { abertura en los } \\
\text { radios }\end{array}$ \\
\hline Maytenus boaria & $\begin{array}{l}\text { Lado A: no presenta } \\
\text { cambios } \\
\text { Lado B: abertura en } \\
\text { anillos }\end{array}$ & $\begin{array}{l}\text { Lado A: abertura en } \\
\text { radio Lado B: no } \\
\text { presenta cambios }\end{array}$ & $\begin{array}{l}\text { Lado A y B: no } \\
\text { presenta cambios }\end{array}$ & $\begin{array}{c}\text { Lado A: ojos y } \\
\text { abertura en radios } \\
\text { Lado B: abertura en } \\
\text { radios }\end{array}$ \\
\hline $\begin{array}{c}\text { Maytenus } \\
\text { disticha }\end{array}$ & $\begin{array}{c}\text { Lado A y B: no } \\
\text { presentan cambios }\end{array}$ & $\begin{array}{l}\text { Lado A: abertura en } \\
\text { radios Lado B: no } \\
\text { presenta cambios }\end{array}$ & $\begin{array}{l}\text { Lado A: no presenta } \\
\text { cambios } \\
\text { Lado B: ojos en anillo }\end{array}$ & $\begin{array}{l}\text { Lado A: ojos en } \\
\text { radio. Lado B: no } \\
\text { hay cambios }\end{array}$ \\
\hline $\begin{array}{l}\text { Myoschilos } \\
\text { oblongum }\end{array}$ & $\begin{array}{l}\text { Lado A y B: no } \\
\text { presenta cambios }\end{array}$ & $\begin{array}{l}\text { Lado A: abertura en } \\
\text { radios } \\
\text { Lado B: no presenta } \\
\text { cambios }\end{array}$ & $\begin{array}{l}\text { Lado A y B: no } \\
\text { presenta cambios }\end{array}$ & $\begin{array}{l}\text { Lado A: ojos en los } \\
\text { radios } \\
\text { Lado B: no } \\
\text { presenta cambios }\end{array}$ \\
\hline $\begin{array}{c}\text { Nardophyllum } \\
\text { bryoides }\end{array}$ & $\begin{array}{l}\text { Lado A: no presenta } \\
\text { cambios } \\
\text { Lado B: abertura en } \\
\text { anillos y radios }\end{array}$ & $\begin{array}{l}\text { Lado A y B: no } \\
\text { presenta cambios }\end{array}$ & $\begin{array}{c}\text { Lado A: no presenta } \\
\text { cambios } \\
\text { Lado B: abertura en los } \\
\text { radios }\end{array}$ & $\begin{array}{l}\text { Lado A y B: no } \\
\text { presenta cambios }\end{array}$ \\
\hline $\begin{array}{l}\text { Nothofagus } \\
\text { antarctica }\end{array}$ & $\begin{array}{l}\text { Lado A: abertura } \\
\text { por anillo y radio }\end{array}$ & $\begin{array}{c}\text { Lado A:abertura en } \\
\text { anillo y ojos en }\end{array}$ & $\begin{array}{c}\text { Lado A: no presenta } \\
\text { cambios }\end{array}$ & $\begin{array}{c}\text { Lado A y B: no } \\
\text { presentan cambios }\end{array}$ \\
\hline
\end{tabular}




\begin{tabular}{|c|c|c|c|c|}
\hline & $\begin{array}{c}\text { Lado B: no presenta } \\
\text { cambios }\end{array}$ & $\begin{array}{c}\text { radios Lado B: } \\
\text { abertura y ojos en } \\
\text { radio }\end{array}$ & $\begin{array}{l}\text { Lado B: fractura por } \\
\text { radio }\end{array}$ & \\
\hline $\begin{array}{c}\text { Nothofagus } \\
\text { dombeyi }\end{array}$ & $\begin{array}{l}\text { Lado A: abertura en } \\
\text { anillo Lado B: no } \\
\text { presenta cambios }\end{array}$ & $\begin{array}{l}\text { Lado A y B: no } \\
\text { presenta cambios }\end{array}$ & $\begin{array}{l}\text { Lado A y B: no } \\
\text { presenta cambios }\end{array}$ & $\begin{array}{l}\text { Lado A y B: no } \\
\text { presenta cambios }\end{array}$ \\
\hline $\begin{array}{c}\text { Prosopidastrum } \\
\text { globosum }^{11}\end{array}$ & $\mathrm{~s} / \mathrm{d}$ & $\begin{array}{c}\text { Lado A: no presenta } \\
\text { cambios Lado B: } \\
\text { ojos en radios }\end{array}$ & $\mathrm{s} / \mathrm{d}$ & $\begin{array}{l}\text { Lado A: aberturas } \\
\text { en radios Lado B: } \\
\text { ojos en radios y } \\
\text { poros }\end{array}$ \\
\hline $\begin{array}{l}\text { Prosopis } \\
\text { denudans }\end{array}$ & $\begin{array}{l}\text { Lado A y B: no } \\
\text { presenta cambios }\end{array}$ & $\begin{array}{l}\text { Lado A y B: no } \\
\text { presenta cambios }\end{array}$ & $\begin{array}{l}\text { Lado A y B: no } \\
\text { presenta cambios }\end{array}$ & $\begin{array}{l}\text { Lado A y B: no } \\
\text { presenta cambios }\end{array}$ \\
\hline $\begin{array}{c}\text { Ribes } \\
\text { magellanicum }\end{array}$ & $\begin{array}{l}\text { Lado A y B: no } \\
\text { presenta cambios }\end{array}$ & $\begin{array}{l}\text { Lado A: no presenta } \\
\text { cambios Lado B: } \\
\text { ojos en radios }\end{array}$ & $\begin{array}{l}\text { Lado A y B. no } \\
\text { presenta cambios }\end{array}$ & $\begin{array}{c}\text { Lado A: no } \\
\text { presenta cambios } \\
\text { Lado B:abertura en } \\
\text { radios }\end{array}$ \\
\hline Sambucus sp. & $\begin{array}{l}\text { Lado A y B: no } \\
\text { presenta cambios }\end{array}$ & $\begin{array}{l}\text { Lado A y B: no } \\
\text { presenta cambios }\end{array}$ & $\begin{array}{l}\text { Lado A: abertura en } \\
\text { radios Lado B. no } \\
\text { presenta cambios }\end{array}$ & $\begin{array}{l}\text { Lado A y B: no } \\
\text { presenta cambios }\end{array}$ \\
\hline Senecio sp. & $\begin{array}{l}\text { Lado A y B: no } \\
\text { presenta cambios }\end{array}$ & $\begin{array}{l}\text { Lado A: aberturas en } \\
\text { radios y ojos en } \\
\text { anillos Lado B: no } \\
\text { presenta cambios }\end{array}$ & $\begin{array}{c}\text { Lado A : no presenta } \\
\text { cambios Lado B: } \\
\text { abertura en anillo }\end{array}$ & $\begin{array}{c}\text { Lado A y } \\
\text { B: no presentan } \\
\text { cambios }\end{array}$ \\
\hline Schinus sp & $\begin{array}{c}\text { Lado A: no se } \\
\text { observan cambios } \\
\text { Lado B: aberturas en } \\
\text { radios y en anillo }\end{array}$ & $\begin{array}{c}\text { Lado A: no se } \\
\text { observan cambios. } \\
\text { Lado B: se } \\
\text { desprende la corteza, } \\
\text { no hay cambios en } \\
\text { leño. }\end{array}$ & $\begin{array}{l}\text { Lado A: aberturas en } \\
\text { anillo, grietas en radio. } \\
\text { Lado B: ojos y grietas } \\
\text { en el radio, abertura en } \\
\text { anillo }\end{array}$ & $\begin{array}{l}\text { Lado A: aberturas } \\
\text { en anillo y en radio. } \\
\text { Lado B: aberturas } \\
\text { en radios. }\end{array}$ \\
\hline Suaeda sp. & $\begin{array}{l}\text { Lado A: aberturas } \\
\text { en radios Lado B: } \\
\text { ojos en radios }\end{array}$ & $\begin{array}{l}\text { Lado A: no presenta } \\
\text { cambios Lado B: } \\
\text { ojos y aberturas en } \\
\text { radios }\end{array}$ & $\begin{array}{l}\text { Lado A: ojos en radios } \\
\text { Lado B: ojos en radios } \\
\text { y anillos }\end{array}$ & $\begin{array}{l}\text { Lado A: ojos en } \\
\text { radios Lado B: ojos } \\
\text { en radios }\end{array}$ \\
\hline
\end{tabular}

Tabla 7.2. Modificaciones de los leños luego de la carbonización controlada a temperaturas de $400{ }^{\circ} \mathrm{C}$ y $700{ }^{\circ} \mathrm{C}$ y a humedades de $8-12 \%$ y $0 \%$.

\footnotetext{
${ }^{11}$ Se realizará la replicación del experimento en Prospidastrum globosum para los tacos que deben ser sometidos a estufa.
} 
Los resultados expuestos en la Tabla 7.2 demuestran que algunas maderas presentaron abundantes aberturas en vasos, radios y en anillos a $700{ }^{\circ} \mathrm{C}$ independientemente del contenido de humedad. Se considera que las aberturas en anillo en las tres especies podrían ser diagnósticas de altas temperaturas de combustión (i.e. Diostea juncea, Schinus y Lycium, Figura 7.21).

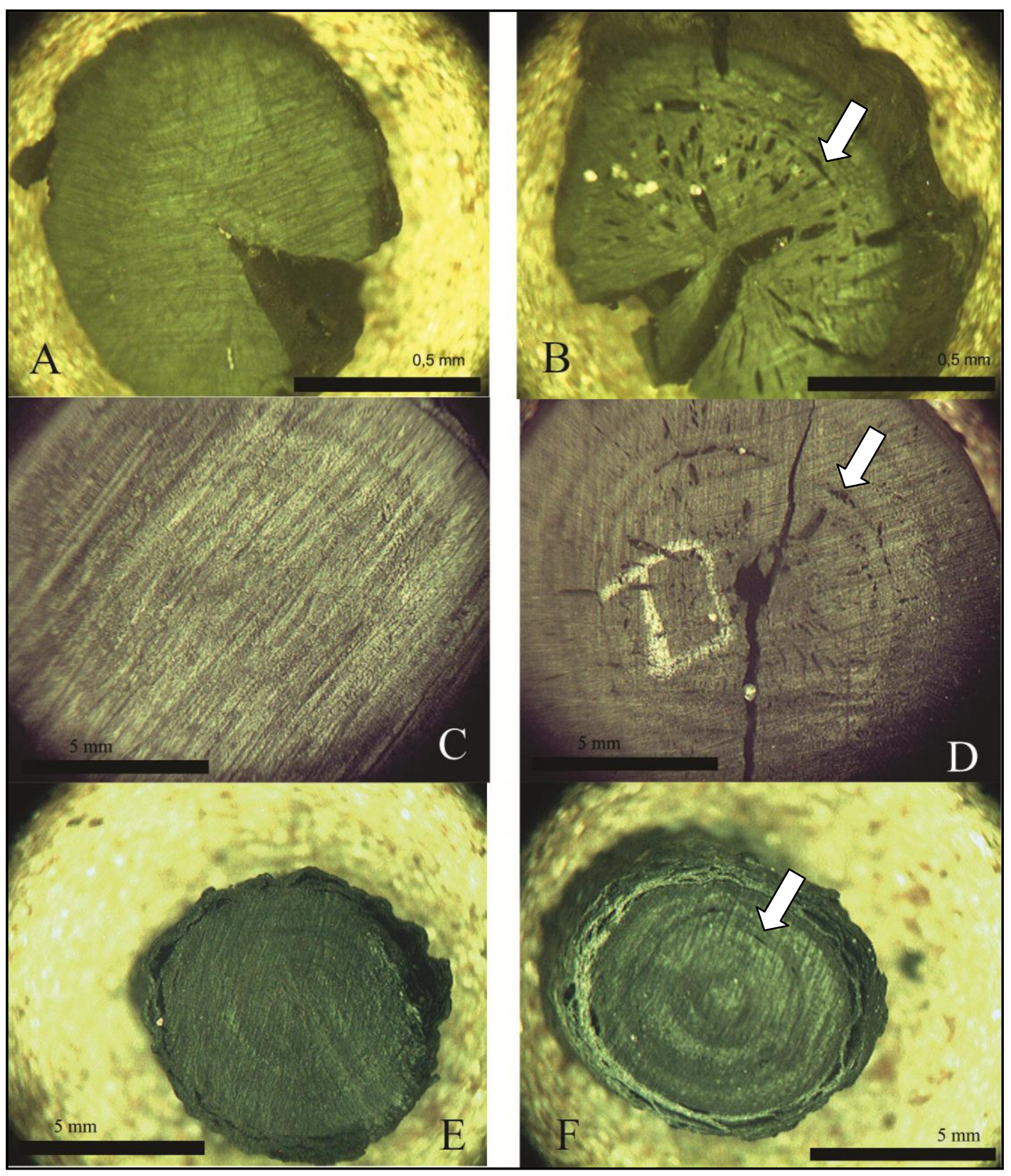

Figura 7.21. Lycium A: $400{ }^{\circ} \mathrm{C}$ y B: $700{ }^{\circ} \mathrm{C}$; Schinus C: $400^{\circ} \mathrm{C}$ y D: $700^{\circ} \mathrm{C}$; Diostea juncea $\mathrm{E}: 400{ }^{\circ} \mathrm{C}$ y F: $700{ }^{\circ} \mathrm{C}$. La flecha señala el rasgo diagnóstico: abertura en anillo 
Otras presentaron cambios tanto en bajas como altas temperaturas con y sin contenidos de humedad (i.e Berberis sp. Lycium ameghinoi, Nothofagus antarctica, Escallonia rubra, Aristotelia chilensis, Suaeda divaricata) que no responden a un patrón definido, por lo que no resultan diagnósticas para uno u otro carácter (Figura 7.22). Se observaron maderas que no presentaron cambios tanto a distinta temperatura como a distintos porcentajes de humedad (i.e. Adesmia boronioides, Berberis microphylla, Prosopis denudans, Escallonia virgata, Myoschilos oblongum, Luma apiculata, Sambucus, Nothofagus dombeyi), por lo que tampoco tendrían carácter diagnóstico.

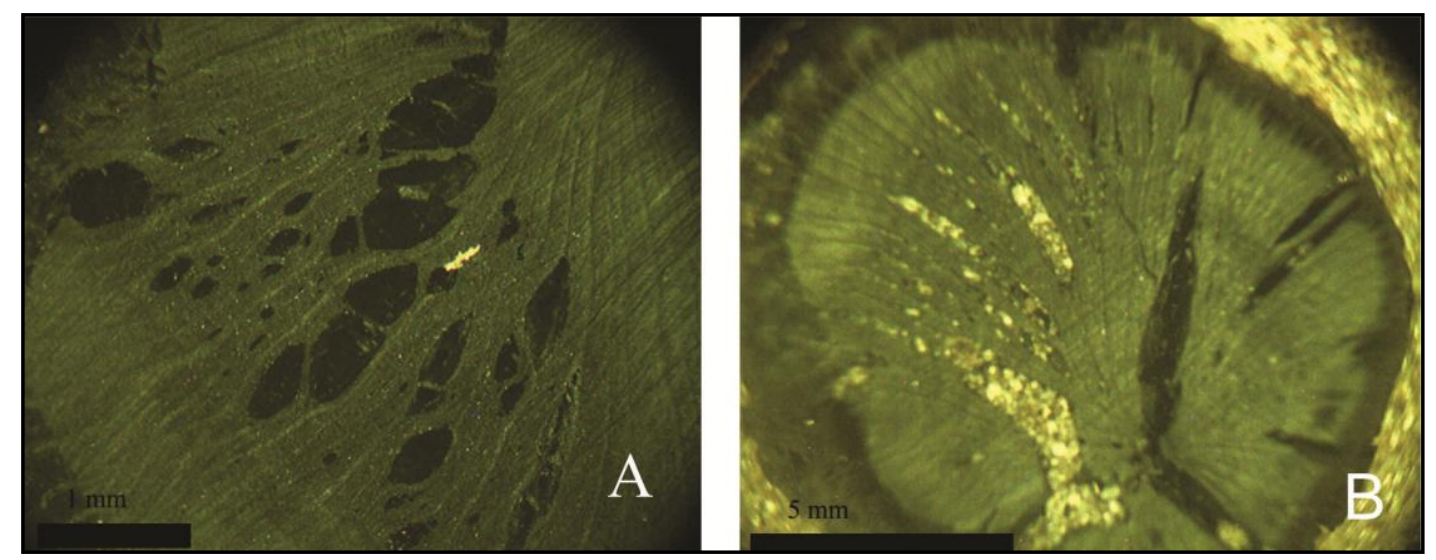

Figura 7.22. Berberis sp 8 a $12 \%$ de humedad A: ojos en radios a $400{ }^{\circ} \mathrm{C}$ y B: ojos en radios a $700{ }^{\circ} \mathrm{C}$

Otras maderas presentaron cambios relacionados tanto con la temperatura como con el contenido de humedad, en este caso se observó que Chuquiraga avellanedae y Colliguaja integerrima presentan más aberturas en radio y anillos en maderas con mayor contenido de humedad ( 8 al $12 \%$ ) y a $700{ }^{\circ} \mathrm{C}$ (Figura 7.23). En cambio, en Ribes magellanicum y Maytenus boaria las aberturas de los radios aparecen en las madera con 8 a $12 \%$ de humedad pero son independientes de la temperatura. En el caso de Nardophyllum brioydes ocurrió lo opuesto, las aberturas en los radios se encontraron en las maderas con $0 \%$ de contenido de humedad y a $700{ }^{\circ} \mathrm{C}$. 


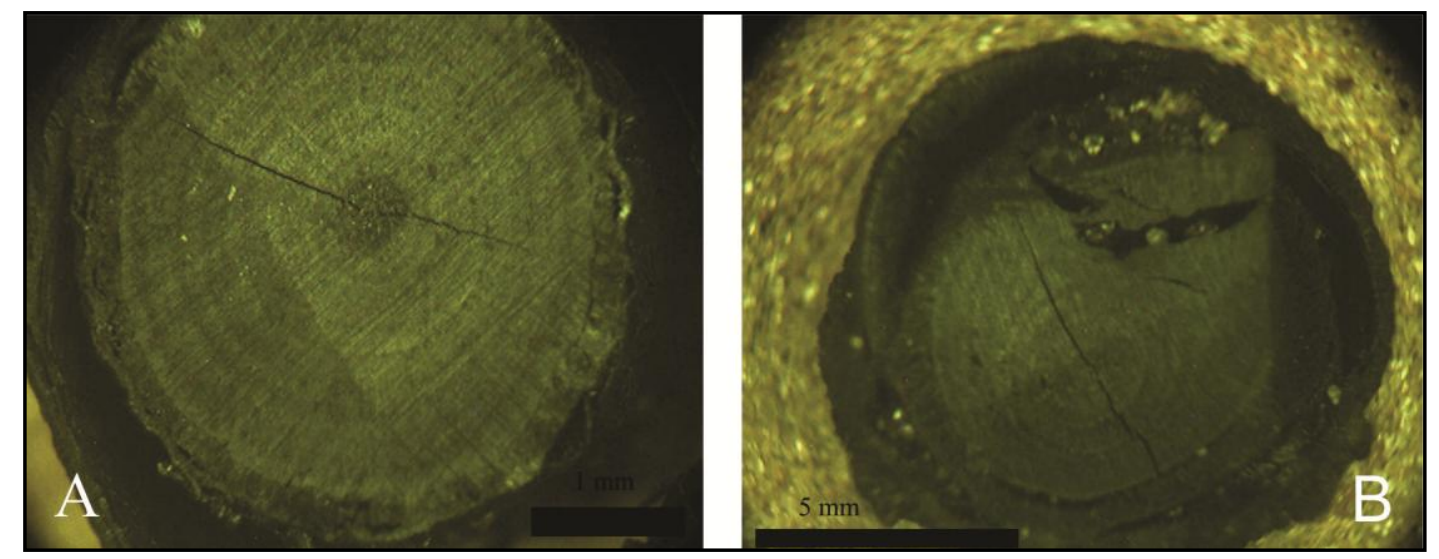

Figura 7.23. Colliguaja integerrima 8 a $12 \%$ de humedad A: no se observan modificaciones a $400{ }^{\circ} \mathrm{C} \mathrm{B}$ : Se observan aberturas en en radios a $700{ }^{\circ} \mathrm{C}$.

Por otro lado, en el caso de la madera de Fabiana imbricata presentó cambios significativos a $\operatorname{los} 400{ }^{\circ} \mathrm{C}$ con alto contenido de humedad, aunque no a los $700{ }^{\circ} \mathrm{C}$. Las maderas de esta misma especie sin contenido de humedad no registraron modificaciones con las distintas temperaturas. No fue diagnóstico el comportamiento de las maderas luego de la carbonización en el caso de Maytenus disticha, Senecio y Budleja globosa (Figura 7.24). 


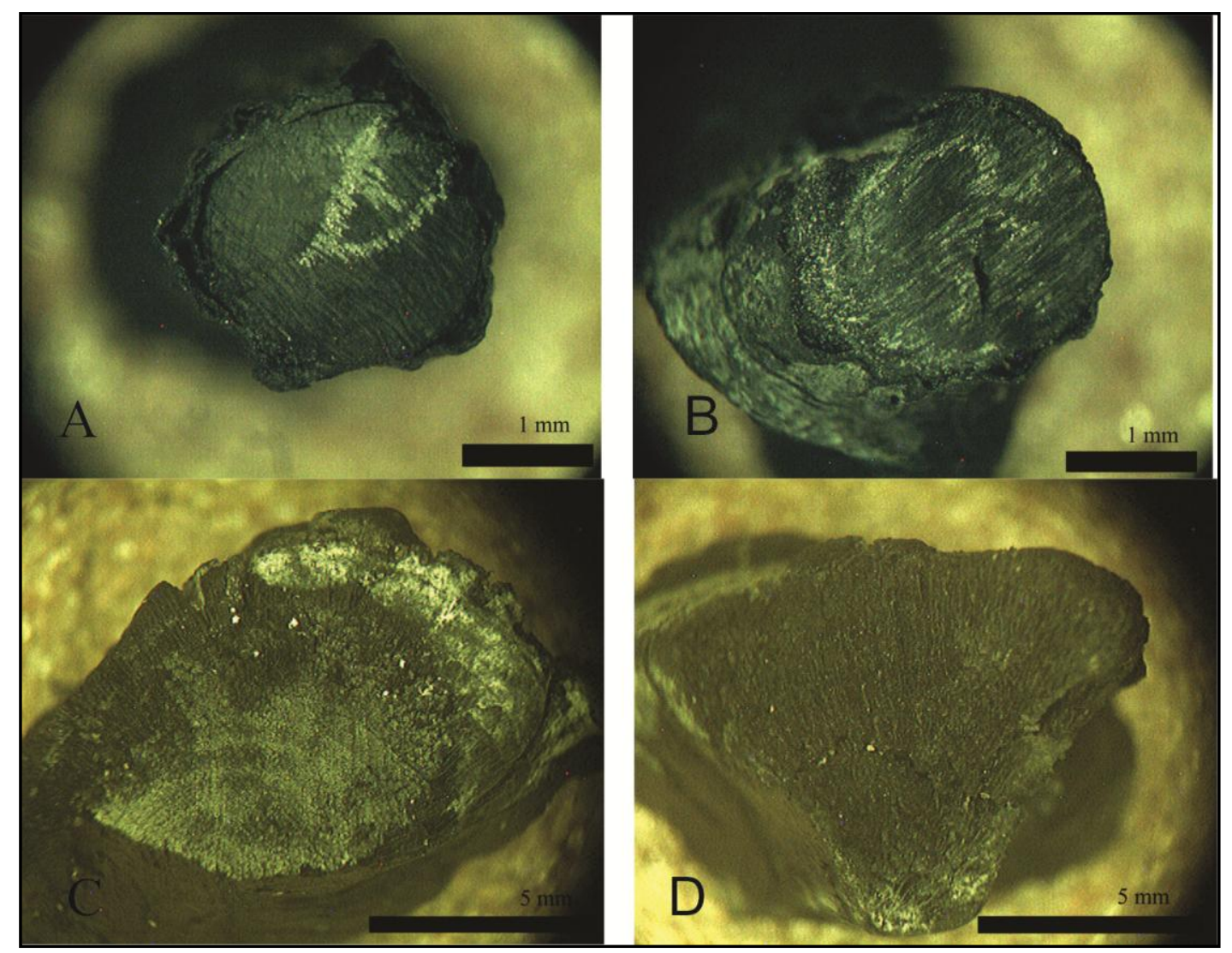

Figura 7.24. Maytenus disthica A: $400{ }^{\circ} \mathrm{C}, 8$ a $12 \%$ de humedad, B: $700{ }^{\circ} \mathrm{C}, 8$ a $12 \%$ de humedad; C: 400

${ }^{\circ} \mathrm{C}$ a $0 \%$ de humedad y D $700{ }^{\circ} \mathrm{C}$ a $0 \%$ de humedad. No se observaron aberturas que evidenciaran temperatura o cambios de humedad.

Además se registró la formación de vitrificación en algunos taxa. En los siguientes éste no respondió a patrones de humedad o a temperatura determinados: Berberis sp., Lycium sp, Suaeda, Sambucus, Maytenus boaria, Escallonia rubra, Aristotelia chilensis (Figura 7.25). Sin embargo, en otros taxa, la vitrificación se produjo solo a los $700{ }^{\circ} \mathrm{C}$ independientemente del contenido de humedad (i.e. Berberis microphylla, Araucaria araucana, Austrocedrus chilensis). En un caso, además de producirse vitrificación a 700 ${ }^{\circ} \mathrm{C}$ se registró solo en la madera con contenido del 8 a 12\% de humedad (i.e. Buddleja globosa) y en otro, opuesto, se produjo con $0 \%$ de humedad (i.e. Colliguaja integerrima). Un caso llamativo fue el de Diostea juncea en donde la vitrificación ocurrió a los $400{ }^{\circ} \mathrm{C}$ en la madera con $0 \%$ de humedad y a $700{ }^{\circ} \mathrm{C}$ en la madera con 8 a $12 \%$ de humedad no registrándose en las otras dos posibilidades. 


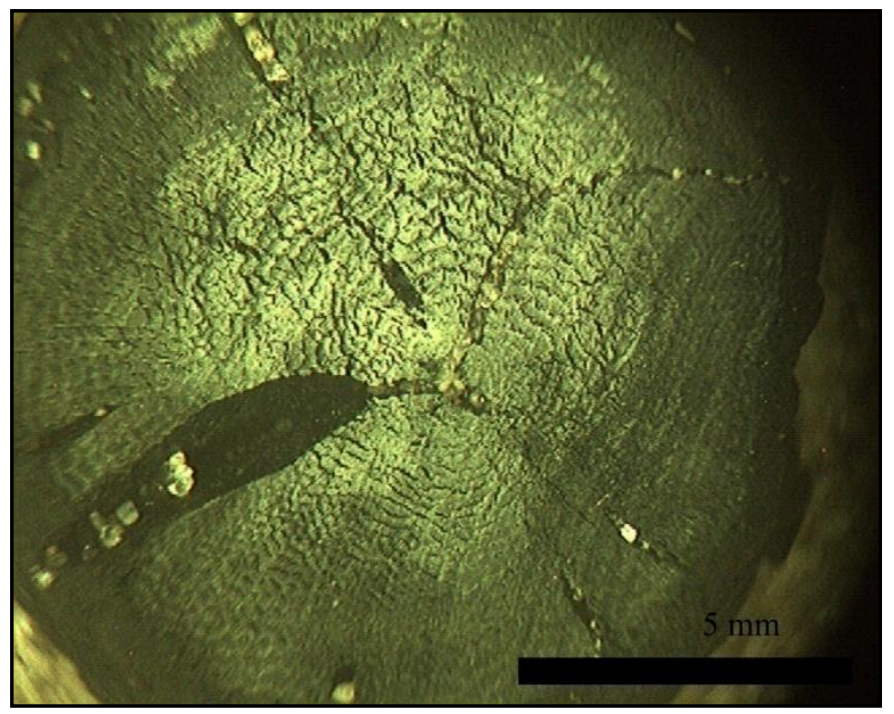

Figura 7.25. Vitrificación en Suaeda sp. a $0 \%$ de humedad y a $400{ }^{\circ} \mathrm{C}$.

Se calculó el porcentaje de reducción de la madera en largo, ancho, espesor y peso de todas las especies tratadas, según el porcentaje de humedad y la temperatura (Tablas 7.3. y 7.4.). Para facilitar la lectura global de estos datos se presentan en la Tabla 7.5 los porcentajes promedios de reducción en tamaño y peso. Se observa que a $400{ }^{\circ} \mathrm{C}$ las maderas con $0 \%$ de contenido de humedad tuvieron una pérdida de peso mayor que las maderas con el 8 a $12 \%$ de humedad. A $700{ }^{\circ} \mathrm{C}$ sin embargo no sucede lo mismo, hay una mayor reducción porcentual del largo y del espesor en las maderas con el 8 a 12\% de humedad y mayor reducción del ancho y del peso en las maderas con $0 \%$ de humedad. En cuanto al tamaño se observa que las maderas con $0 \%$ de humedad disminuyeron su tamaño en mayor medida que las que tenían el 8 a 12\% de humedad, tanto a $400{ }^{\circ} \mathrm{C}$ como a $700{ }^{\circ} \mathrm{C}$. Existe una excepción a esta última observación, en el porcentaje de reducción del largo a $700{ }^{\circ} \mathrm{C}$ ya que las maderas con 8 a $12 \%$ de humedad tienen mayor reducción del tamaño que la de $0 \%$ de humedad.

\begin{tabular}{|l|l|l|l|l|l|l|l|l|}
\hline $\begin{array}{l}8 \text { a } 12 \% \text { de } \\
\text { Humedad }\end{array}$ & \multicolumn{3}{|l|}{$40{ }^{\circ} \mathrm{C}$} & \multicolumn{3}{l|}{$700{ }^{\circ} \mathrm{C}$} \\
\hline Taxa & $\begin{array}{l}\% \text { red. } \\
\text { largo }\end{array}$ & $\begin{array}{l}\% \text { red. } \\
\text { ancho }\end{array}$ & $\begin{array}{l}\text { \%red. } \\
\text { espesor }\end{array}$ & $\begin{array}{l}\text { \%red. } \\
\text { peso }\end{array}$ & $\begin{array}{l}\% \text { red. } \\
\text { Largo }\end{array}$ & $\begin{array}{l}\% \text { red. } \\
\text { Ancho }\end{array}$ & $\begin{array}{l}\text { \%red. } \\
\text { espesor }\end{array}$ & $\begin{array}{l}\text { \%red. } \\
\text { Peso }\end{array}$ \\
\hline $\begin{array}{l}\text { Adesmia } \\
\text { boronioides }\end{array}$ & 11,52 & 14,69 & 17,2 & 61,71 & 11,21 & 2,14 & 16,61 & 49,42 \\
\hline $\begin{array}{l}\text { Araucaria } \\
\text { araucana }\end{array}$ & 11,44 & 14,18 & 15,78 & 65,39 & 21,49 & 18,51 & 24,73 & 73,22 \\
\hline $\begin{array}{l}\text { Aristotelia } \\
\text { chilensis }\end{array}$ & 13,59 & 5 & 9,18 & $(-) 45,9$ & 3,67 & 4,01 & 2,3 & $(-) 54$ \\
\hline Austrocedrus & 10,9 & 7,35 & 9 & 57,15 & 11,95 & 2,02 & 10,48 & 71,55 \\
\hline
\end{tabular}




\begin{tabular}{|c|c|c|c|c|c|c|c|c|}
\hline chilense & & & & & & & & \\
\hline Berberis & 14,92 & 9,52 & 17,5 & 38,36 & 6,6 & 2,73 & 5,64 & 57,89 \\
\hline $\begin{array}{l}\text { Berberis } \\
\text { microphylla }\end{array}$ & 10,74 & 27,7 & 18,28 & 66,7 & 7,75 & 25,11 & 15,37 & 72,5 \\
\hline $\begin{array}{l}\text { Buddleja } \\
\text { globosa }\end{array}$ & 11,62 & 14,63 & 14,71 & 94,03 & 13,76 & 8,08 & 79,61 & 96,69 \\
\hline $\begin{array}{l}\text { Nothofagus } \\
\text { pumilio }\end{array}$ & 12,54 & 20,18 & 2,77 & 94,96 & 15,14 & 10,7 & 19,15 & * \\
\hline $\begin{array}{l}\text { Chuquiraga } \\
\text { avellanedae }\end{array}$ & 12,38 & 8,45 & 19,59 & 63,71 & 10,24 & 8,92 & 12,73 & 59,23 \\
\hline $\begin{array}{l}\text { Colliguaja } \\
\text { integerrima }\end{array}$ & 5,04 & 5,44 & $(-) 4,80$ & 59,38 & 4,60 & $(-) 0,76$ & 6,03 & 41,34 \\
\hline Diostea juncea & 4,47 & 12,39 & 19,22 & 62,5 & 17,1 & 18,15 & 21,98 & 76,85 \\
\hline $\begin{array}{l}\text { Escallonia } \\
\text { rubra }\end{array}$ & 8,22 & 12,27 & 18,06 & 88,15 & 11,68 & 8,77 & 9,83 & 91,47 \\
\hline $\begin{array}{l}\text { Escallonia } \\
\text { virgata }\end{array}$ & 3,88 & 8,69 & 14,44 & 60,47 & 18,02 & 14,71 & 16,5 & 78,1 \\
\hline $\begin{array}{l}\text { Fabiana } \\
\text { imbricata }\end{array}$ & $(-) 1,49$ & 1,6 & 11,17 & 37,5 & 10,92 & $(-) 8,41$ & 15,58 & 32 \\
\hline Luma apiculata & 13,96 & 10,85 & 13,72 & 63,23 & 13,39 & 8,34 & $(-) 31,79$ & 30,73 \\
\hline Lycium & 9,67 & 17,45 & 20,56 & 65,17 & 9,45 & 4,5 & 13,08 & 58,73 \\
\hline $\begin{array}{l}\text { Lycium } \\
\text { ameghinoi }\end{array}$ & 11,82 & 7,86 & 21,29 & 66,46 & 3,58 & 1,22 & 5,42 & 57,26 \\
\hline Maytenus & 9,87 & 20,18 & 17,04 & 65,44 & 10,72 & 2,98 & 5,96 & 51,59 \\
\hline $\begin{array}{l}\text { Maytenus } \\
\text { disticha }\end{array}$ & 9,89 & 12,45 & $(-) 3$ & 37,5 & 18,77 & 0,54 & $-3,36$ & 75 \\
\hline $\begin{array}{l}\text { Myoschilos } \\
\text { oblongum }\end{array}$ & 7,1 & 18,12 & 15,39 & 59,56 & 3,41 & 4,25 & 29,9 & 55,85 \\
\hline $\begin{array}{l}\text { Nardophyllum } \\
\text { bryoides }\end{array}$ & 13,66 & 11,96 & 11,93 & 62,17 & 3,09 & 4,2 & $(-) 6,73$ & 39,29 \\
\hline $\begin{array}{l}\text { Nothofagus } \\
\text { antarctica }\end{array}$ & 19,15 & 11,46 & 14,24 & 65,54 & $*$ & * & $*$ & $*$ \\
\hline $\begin{array}{l}\text { Nothofagus } \\
\text { dombeyi }\end{array}$ & 2,25 & 8,2 & 7,49 & 57,26 & 7,85 & $(-) 15,8$ & 21,53 & 66,15 \\
\hline $\begin{array}{l}\text { Prosopidastrum } \\
\text { globosum }\end{array}$ & 8,96 & 15,88 & 14,08 & 74,62 & $\mathrm{~s} / \mathrm{d}$ & $\mathrm{s} / \mathrm{d}$ & $\mathrm{s} / \mathrm{d}$ & $\mathrm{s} / \mathrm{d}$ \\
\hline $\begin{array}{l}\text { Prosopis } \\
\text { denudans }\end{array}$ & 2,33 & 4,64 & 0,31 & 53,6 & $-0,4$ & 8,75 & 17,37 & 27,27 \\
\hline $\begin{array}{l}\text { Ribes } \\
\text { magellanicum }\end{array}$ & 20,28 & 18,65 & 17,42 & 68,66 & 23,78 & 10,24 & 14,87 & 67,57 \\
\hline Sambucus & 7,85 & 8,77 & 6,62 & 61,67 & 10,74 & 5,75 & 7,7 & 66,7 \\
\hline Schinus & 4,5 & 2,14 & 8,44 & 59,63 & 1,79 & 1,41 & $(-) 2,43$ & 63,16 \\
\hline Senecio & 9,27 & 13,2 & 19,33 & 62,91 & 20,8 & 16,66 & 25,48 & 77,47 \\
\hline Suaeda & 4,51 & 2,44 & 1,82 & 62,09 & 6,14 & 6,39 & $(-) 11,8$ & 46,27 \\
\hline
\end{tabular}

Tabla 7.3. Reducción (\%) del largo, ancho espesor y peso de las maderas de referencia carbonizadas al 8-

$12 \%$ de humedad. El asterisco $(*)$ expresa que la madera se fragmentó por lo que no pudo ser medida. El

(-) siginifica que la variable en lugar de reducirse aumentó.

\begin{tabular}{|l|l|l|l|l|l|l|l|l|}
\hline 0 \% de Humedad & \multicolumn{4}{|l|}{$400{ }^{\circ} \mathrm{C}$} & \multicolumn{4}{l|}{$700{ }^{\circ} \mathrm{C}$} \\
\hline Taxa & $\begin{array}{l}\% \text { red. } \\
\text { largo }\end{array}$ & $\begin{array}{l}\% \text { red. } \\
\text { ancho }\end{array}$ & $\begin{array}{l}\text { \%red. } \\
\text { Espesor }\end{array}$ & $\begin{array}{l}\text { \%red. } \\
\text { peso }\end{array}$ & $\begin{array}{l}\% \text { red. } \\
\text { largo }\end{array}$ & $\begin{array}{l}\text { \% red. } \\
\text { Ancho }\end{array}$ & $\begin{array}{l}\text { \%red. } \\
\text { Espesor }\end{array}$ & $\begin{array}{l}\text { \%red. } \\
\text { Peso }\end{array}$ \\
\hline $\begin{array}{l}\text { Adesmia } \\
\text { boronioides }\end{array}$ & 12,06 & 7,35 & $(-) 0,63$ & 56,76 & 19,2 & 9,64 & 9,49 & 64,14 \\
\hline Araucaria & 14,94 & 25,46 & 18,64 & 64,95 & $*$ & $*$ & $*$ & $*$ \\
\hline
\end{tabular}




\begin{tabular}{|c|c|c|c|c|c|c|c|c|}
\hline araucana & & & & & & & & \\
\hline $\begin{array}{l}\text { Aristotelia } \\
\text { chilensis }\end{array}$ & 12,25 & 10,39 & 12,05 & 60,22 & 13,04 & 11,15 & 12,98 & 69,54 \\
\hline $\begin{array}{l}\text { Austrocedrus } \\
\text { chilense }\end{array}$ & 3,71 & 10,74 & 12,02 & 53,10 & 10,02 & 3,37 & $(-) 11,64$ & 69,23 \\
\hline Berberis & 3,52 & 3,4 & 10,2 & 57,2 & 1,94 & 5,25 & $(-) 0,07$ & 54,59 \\
\hline $\begin{array}{l}\text { Berberis } \\
\text { microphylla }\end{array}$ & 26,18 & 18,54 & 14,48 & 63,94 & 16,89 & 5,18 & 19,85 & 68,37 \\
\hline Buddleja globosa & 9,17 & 20,55 & 16,42 & 65 & 18,04 & 11,27 & 14,84 & 75 \\
\hline $\begin{array}{l}\text { Nothofagus } \\
\text { pumilio }\end{array}$ & 19,92 & 7,7 & 18,68 & 66,97 & 14,79 & 11,88 & 39,52 & 79,91 \\
\hline $\begin{array}{l}\text { Chuquiraga } \\
\text { avellanedae }\end{array}$ & 2,86 & 14,09 & 19,83 & 57,5 & 1,02 & 5,8 & 14,13 & 42,57 \\
\hline $\begin{array}{l}\text { Colliguaja } \\
\text { integerrima }\end{array}$ & 6,48 & $(-) 7,80$ & $(-) 1,07$ & 54,5 & 0,85 & $(-) 11,27$ & 1,11 & 56 \\
\hline Diostea juncea & 12,35 & 10,51 & 11,54 & 56,32 & 14,84 & 4,11 & 7,48 & 68,35 \\
\hline Escallonia rubra & 6,88 & 7,48 & 9,65 & 55,38 & 10,79 & 9,78 & 19,41 & 65 \\
\hline $\begin{array}{l}\text { Escallonia } \\
\text { virgata }\end{array}$ & 7,70 & 9,66 & 5,62 & 58,90 & 10,50 & 5,69 & 2,41 & 63 \\
\hline $\begin{array}{l}\text { Fabiana } \\
\text { imbricata }\end{array}$ & 13,24 & 21,34 & 19,3 & 65,96 & $(-) 1,14$ & 7,16 & 9,34 & 60,53 \\
\hline Luma apiculata & 13,22 & 7,85 & 14,68 & 67,98 & 8,25 & 13,71 & 0,87 & 65,96 \\
\hline Lycium & 9,42 & 28,57 & $(-) 2,73$ & 61,22 & 3,44 & 5,28 & 17,49 & 25,51 \\
\hline $\begin{array}{l}\text { Lycium } \\
\text { ameghinoi }\end{array}$ & 22,38 & 9,3 & 20,82 & 65,82 & 10,5 & 7,2 & 5,3 & 67,2 \\
\hline Maytenus & 11,96 & 13,14 & 22,30 & 67,07 & 10,05 & 23,42 & 20,83 & 72,34 \\
\hline $\begin{array}{l}\text { Maytenus } \\
\text { disticha }\end{array}$ & 10,67 & 66,42 & 20,63 & 70,83 & 16,88 & 20,73 & 9,51 & 73,08 \\
\hline $\begin{array}{l}\text { Myoschilos } \\
\text { oblongum }\end{array}$ & 8,30 & 14,64 & 13,26 & 55,91 & 6,18 & 2,78 & 7,49 & 45,74 \\
\hline $\begin{array}{l}\text { Nardophyllum } \\
\text { bryoides }\end{array}$ & 15,16 & 24,58 & 25,17 & 65,72 & 13,15 & $(-) 5,49$ & 12,8 & 49,34 \\
\hline $\begin{array}{l}\text { Nothofagus } \\
\text { antarctica }\end{array}$ & 14,90 & 9,14 & 8,43 & 59,83 & 6,92 & 10,55 & 14,98 & 63,53 \\
\hline $\begin{array}{l}\text { Nothofagus } \\
\text { dombeyi }\end{array}$ & 8,43 & 11,50 & 9,27 & 54,38 & 21,53 & 16,06 & 8,16 & 75,26 \\
\hline $\begin{array}{l}\text { Prosopidastrum } \\
\text { globosum }\end{array}$ & $\mathrm{s} / \mathrm{d}$ & $\mathrm{s} / \mathrm{d}$ & $\mathrm{s} / \mathrm{d}$ & $\mathrm{s} / \mathrm{d}$ & $\mathrm{s} / \mathrm{d}$ & $\mathrm{s} / \mathrm{d}$ & $\mathrm{s} / \mathrm{d}$ & $\mathrm{s} / \mathrm{d}$ \\
\hline $\begin{array}{l}\text { Prosopis } \\
\text { denudans }\end{array}$ & 2,55 & 2,8 & $(-) 2,2$ & 51,06 & 4,75 & 7,4 & 1,58 & 61,6 \\
\hline $\begin{array}{l}\text { Ribes } \\
\text { magellanicum }\end{array}$ & 10,47 & 1,7 & 17,21 & 63,74 & 15,69 & 1,05 & 7,54 & 42,75 \\
\hline Sambucus & 2,19 & 13,18 & 9,93 & 60,71 & 14,31 & 10,85 & 8,43 & 71,15 \\
\hline Schinus & 4,9 & 0,42 & 6,02 & 73,88 & 8,79 & $(-) 3,62$ & 4,32 & 59,75 \\
\hline Senecio & 10,04 & $(-) 5,79$ & 25,49 & 61,76 & 13,95 & 18,28 & 22,95 & 67,92 \\
\hline Suaeda & 6,54 & 8,8 & 4,88 & 59,17 & 2,94 & $(-) 0,19$ & $(-) 3,56$ & 71,31 \\
\hline
\end{tabular}

Tabla 7.4. Reducción (\%) del largo, ancho espesor y peso de las maderas de referencia carbonizadas al 0 $\%$ de humedad. El asterisco expresa que la madera se fragmentó por lo que no pudo ser medida. El (-) significa que la variable en lugar de reducirse aumentó. s/d hace referencia a sin datos.

\begin{tabular}{|l|l|l|l|l|lr|}
\hline Temperatura & Humedad & $\begin{array}{l}\% \\
\text { largo }\end{array}$ & $\begin{array}{l}\% \text { red. } \\
\text { Ancho }\end{array}$ & $\begin{array}{l}\% \text { red. } \\
\text { Espesor }\end{array}$ & $\begin{array}{l}\% \text { red. } \\
\text { Peso }\end{array}$ \\
\hline $400^{\circ} \mathrm{C}$ & $0 \%$ & 10,42 & 12,61 & 12,43 & 61,23 \\
\hline $400^{\circ} \mathrm{C}$ & $8 \mathrm{al} 12 \%$ & 9,50 & 11,54 & 12,29 & 59,65 \\
\hline
\end{tabular}




\begin{tabular}{|l|l|l|l|l|l|}
\hline $700^{\circ} \mathrm{C}$ & $0 \%$ & 10,29 & 7,39 & 9,60 & 62,45 \\
\hline $700{ }^{\circ} \mathrm{C}$ & $8 \mathrm{al} 12 \%$ & 11,20 & 6,44 & 14 & 57,86 \\
\hline
\end{tabular}

Tabla 7.5. Porcentajes promedio de la reducción del largo, ancho, espesor y peso luego de la carbonización.

\subsubsection{Carbonización experimental de los carporrestos}

Como se mencionó en el acápite 7.2.3.1 las hojas y los frutos de Schinus sp. fueron carbonizados de forma experimental. A partir de los resultados obtenidos se observó que el porcentaje de reducción del largo de los frutos fue de 13,8\% mientras que el porcentaje de reducción para el diámetro fue de 11,3\%. El porcentaje de reducción del largo de las hojas de Schinus sp. luego de la carbonización fue de 8,6\% siendo, el del ancho de $9,2 \%$ (Tabla 7.6).

\begin{tabular}{|l|l|l|l|l|l|l|l|l|}
\hline \multirow{2}{*}{$\begin{array}{c}\text { Parte de la } \\
\text { Planta }\end{array}$} & \multicolumn{4}{|l|}{ Previo a la carbonización } & \multicolumn{3}{l|}{ Posterior a la carbonización } \\
\cline { 2 - 9 } & $\begin{array}{l}\text { Largo } \\
\mathrm{mm}\end{array}$ & $\begin{array}{l}\text { Ancho } \\
\mathrm{mm}\end{array}$ & $\begin{array}{l}\text { Diámetro } \\
\mathrm{mm}\end{array}$ & $T$ & ${ }^{\circ} \mathrm{C}$ & $\begin{array}{l}\text { Largo } \\
\mathrm{mm}\end{array}$ & $\begin{array}{l}\text { Ancho } \\
\mathrm{mm}\end{array}$ & $\begin{array}{l}\text { Diámetro } \\
\text { mm }\end{array}$ \\
\hline Hoja & 12,83 & 7,2 & - & $20^{\prime}$ & 300 & 11,72 & 6,54 & - \\
\hline Fruto & 7,87 & - & 7,39 & $30^{\prime}$ & 300 & 6,98 & - & 6,37 \\
\hline
\end{tabular}

Tabla 7.6. Material de referencia (hoja y fruto) de Schinus sp. con sus medidas antes y después de la carbonización experimental

\subsection{Discusión y Conclusiones}

El estudio de las aberturas radiales de las maderas correspondientes a los taxa de la colección de referencia evidenció que ante la diversidad de resultados este tipo de alteración de la madera no sería atribuible al contenido inicial de humedad o a la temperatura de exposición en todas las especies por igual. Sí en algunos casos a mayor temperatura se observó una mayor incidencia en el desarrollo de ojos o grietas radiales y aberturas en anillo (i.e. Lycium), pero también se registraron aberturas en otros taxa ante la exposición a las dos temperaturas a las que fueron expuestas (i.e. Berberis sp, Lycium ameghinoi) $\mathrm{y}$, otros taxa donde ante las mismas variables controladas no sufrieron modificaciones durante la carbonización (i.e. Adesmia boronioides, Prosopis 
denudans). Estos resultados concuerdan con lo propuesto por Théry Parisot y Herny (2011), Braadbaart y Poole (2008), Andreoni (2014), entre otros autores, donde se plantea que cada taxón reacciona diferencialmente al proceso de carbonización y esto se debe a múltiples factores como la estructura anatómica, las propiedades físicas de la madera, las temperaturas de combustión, el contenido de humedad, el tamaño de la madera y el contenido de resinas.

La vitrificación en los taxa estudiados no respondería tampoco al contenido inicial de humedad, es decir si la madera se encontraba seca (estacionada) o con algún porcentaje de humedad (recién recolectada). Este resultado coincide con los trabajos de Mc Parland et al. (2010) y Andreoni (2014). También se observó una relación entre maderas de taxa resinosos y la vitrificación como en el trabajo de Andreoni (2014).

Respecto a la pérdida de peso de las maderas expuestas experimentalmente a la carbonización se registró que aquellas que tenían $0 \%$ de contenido de humedad redujeron más su peso en relación a las maderas con el 8 al 12\% de humedad. Por otra parte, no hubo una variación significativa de la reducción de peso entre los $400{ }^{\circ} \mathrm{C} y$ $700^{\circ} \mathrm{C}$. 


\section{Registro arqueobotánico del sector del centro del Golfo San Jorge}

\subsection{Introducción}

En este capítulo se presenta en primer lugar, los antecedentes recientes generados en el marco del proyecto CNSC por otros investigadores del equipo desde el inicio de esta tesis en el sector centro del Golfo San Jorge. Luego, se describen los sitios y las excavaciones realizadas en cada caso, a partir de las cuales se han recuperado los materiales arqueobotánicos analizados en la presente tesis. En la excavación que se presenta en este sector no se desarrolló un diseño de muestreo con un objetivo arqueobotánico puesto que el análisis de estos materiales se realizó con posterioridad a la misma. Por último, se presentan los resultados de los estudios arqueobotánicos ralizados.

\subsection{Antecedentes recientes}

El sector comprende el centro del Golfo San Jorge (Zubimendi 2010), ubicado dentro de la Provincia Geológica del Chubut Extraandino (Feruglio 1950). Como se mencionó en el capítulo 3, la vegetación característica es la estepa arbustiva del Golfo San Jorge (Oliva et al. 2001).

La costa de este sector es recta, se encuentra erosionada y se puede caracterizar por la presencia de acantilados, playas de rodados e intermareales de restinga. En estos últimos se suelen registrar gran cantidad de algas y bancos de moluscos (Codignoto 2000). Hacia el interior se observan cañadones que comunican la costa con la meseta alta ubicada hacia el centro de la provincia. La meseta alta continúa hasta el valle del río Deseado (Zubimendi 2010).

Este sector presenta actualmente una distribución homogénea de recursos faunísticos entre los que se encuentran el guanaco y extensos bancos de moluscos disponibles anualmente. En el pasado se han registrado también apostaderos de pinnípedos y aves marinas (Zubimendi 2010). 
Los antecedentes arqueológicos del equipo Costa Norte de Santa Cruz en este sector fueron mencionados en el capítulo Área de estudio, sin embargo, se describirán a continuación los fechados radiocarbónicos y los últimos resultados de las investigaciones realizadas.

Como se mencionó en el capítulo 3, en el sitio Moreno, multicomponente en médano, se obtuvieron las dataciones más antiguas para el sector: $2720 \pm 50$ AP (LP-206) y $3290 \pm$ 90 AP (1063cSM) (Moreno y Castro 1995). Por otra parte, el fechado más reciente se obtuvo sobre restos óseos humanos del sitio Bahía Lángara 1 siendo de $320 \pm 50$ años AP (LP-2713) (Zilio et al. 2014).

Se realizaron también estudios isotópicos sobre restos humanos recuperados a partir de rescates arqueológicos y de otros provenientes de la colección del Museo del Hombre y su Entorno, de Caleta Olivia (Zilio et al. 2014, Moreno et al. 2011). Los resultados evidencian, según Zilio et al. (2014), que para un primer período (2300-1500 AP) se habrían identificado diversos tipos de dietas. Tanto mixtas, con aportes de recursos marinos y terrestres, como predominantemente marinas y/o terrestres. Para el segundo período (1100-300 AP) en cambio, los valores isotópicos evidencian solo dietas mixtas. 


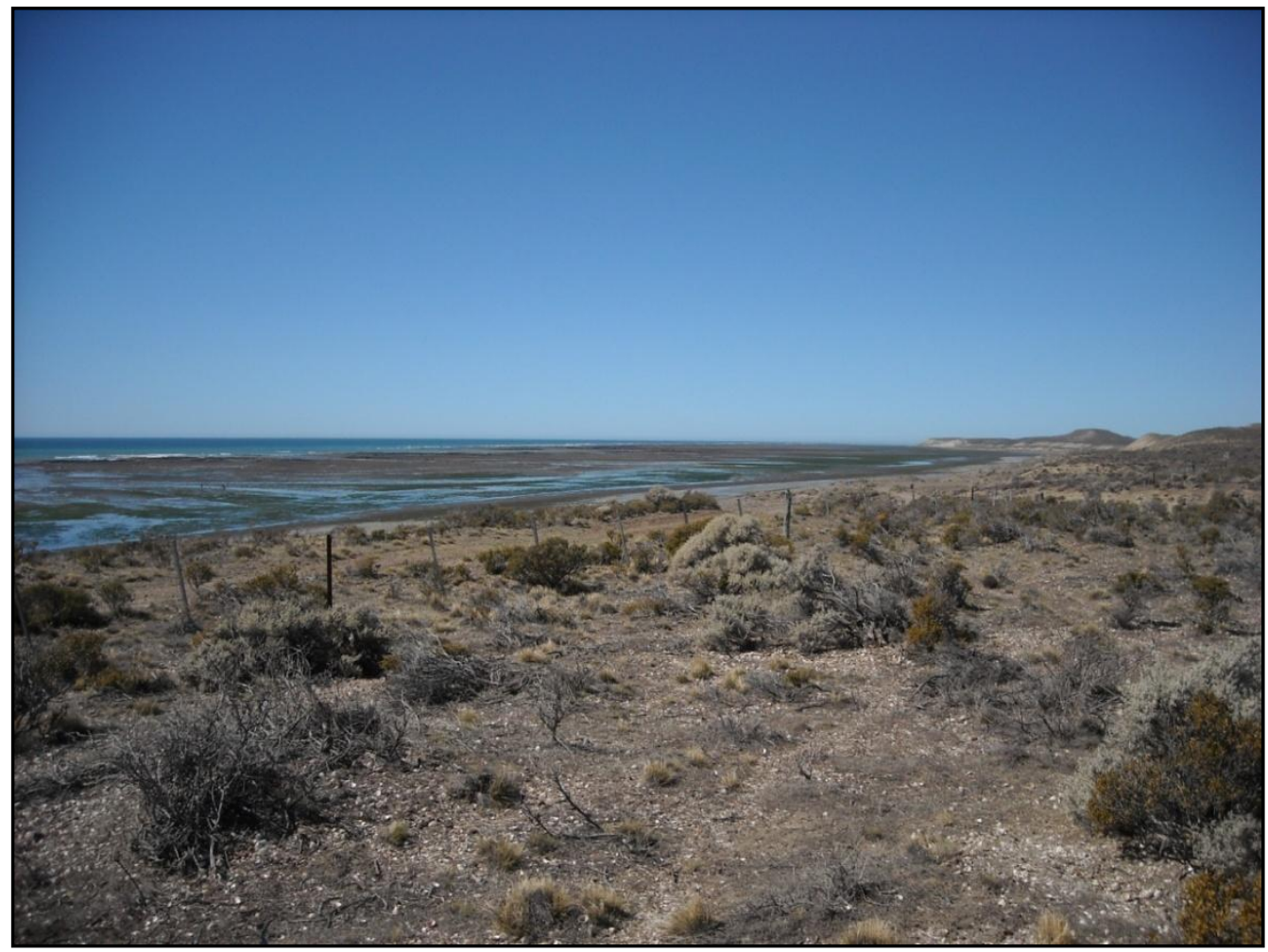

Figura 8.1. Vista del primer escalón del flanco de meseta y sobre el margen izquierdo la restinga (Fotografía de Verónica Trola)

\subsection{Sitio Palo Alto}

\subsubsection{Introducción}

El sitio Palo Alto se encuentra en la localidad arqueológica de Bahía Lángara, sobre el primer escalón del flanco de meseta a $60 \mathrm{~m}$ de la línea de costa actual (Figura 8.2). Es un sitio a cielo abierto, de aproximadamente 50 × $25 \mathrm{~m}$ de extensión de forma oval con uno de sus lados paralelos al borde de la barranca y la línea de costa. Uno de los extremos del sitio se encuentra afectado por la presencia de un camino y una alambrada (Figura 8.3). En los alrededores del sitio, se observan arbustos y subarbustos de Chuquiraga avellanedae, Atriplex lampa, Senecio filaginoides, Colliguaja integerrima, Grindelia chiloensis y gramíneas como Pappostipa sp. y Poa sp. 


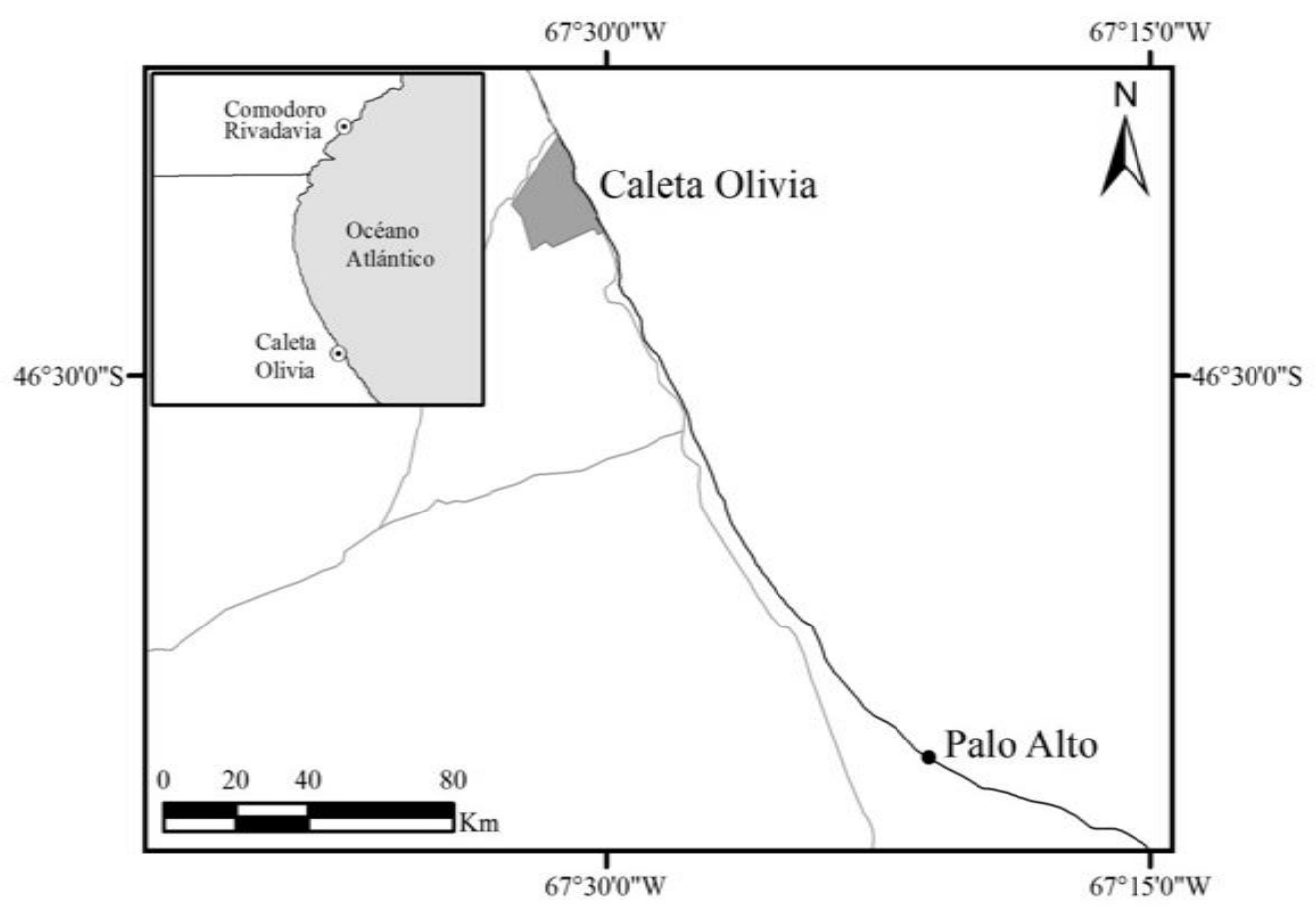

Figura 8.2. Ubicación del Sitio Palo Alto.

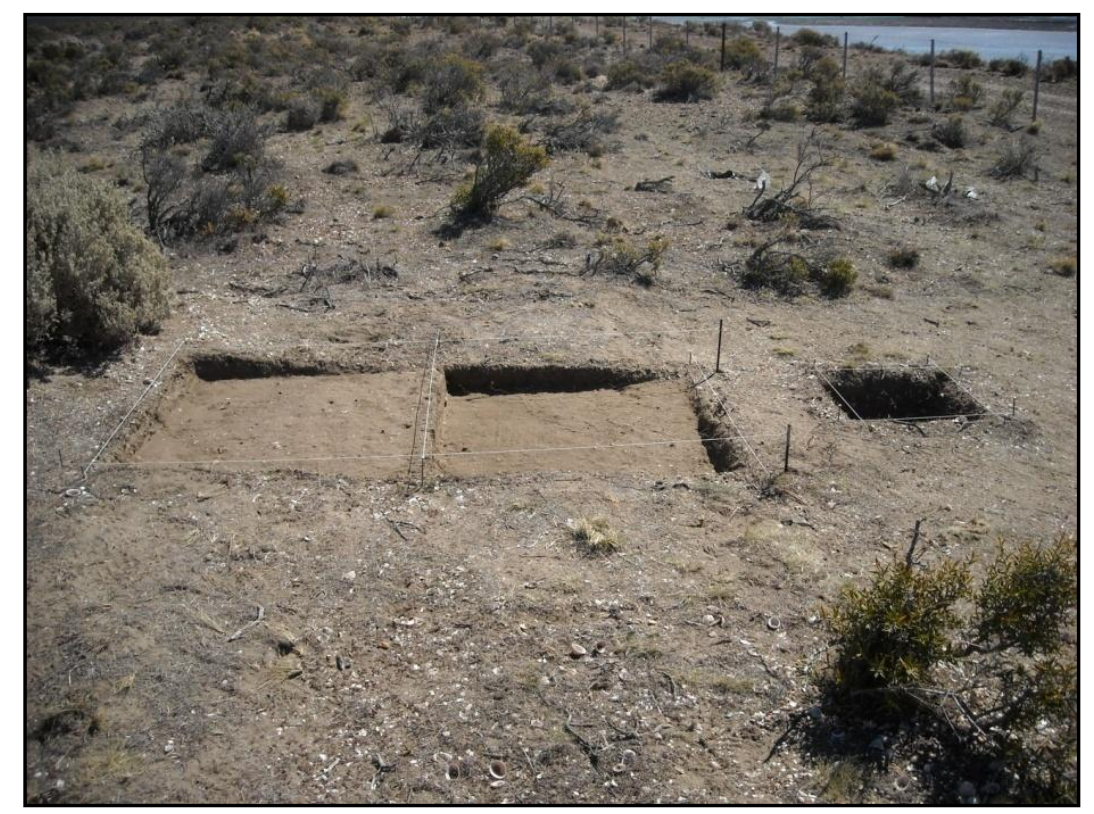

Figura 8.3. Vista general del sitio Palo Alto cuadrícula 1,2 y sondeo 1 (Fotografía tomada por Verónica Trola). 


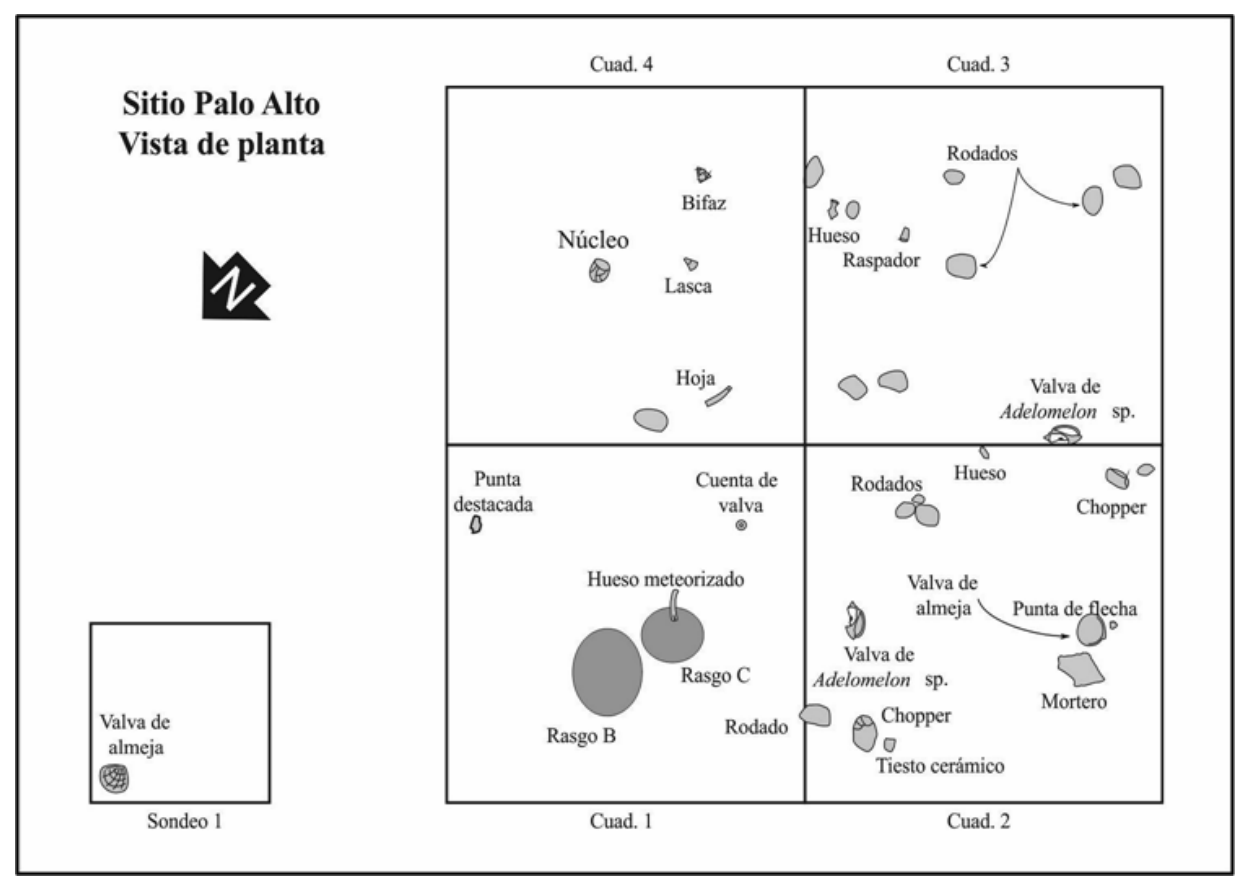

Figura 8.4. Esquema de planta de la excavación del sitio Palo Alto.

La dirección de excavación del sitio estuvo a cargo del Dr. Zubimendi, en la que se realizaron cuatro cuadrículas de $1 \mathrm{~m}^{2}$ y dos sondeos de 0,50 x 0,50 m (Figura 8.4). Se realizó un fechado radiocarbónico sobre valvas de Nacella magellanica cuyo resultado fue de $690 \pm 90$ años AP (LP-2280). En superficie se registraron fragmentos de morteros, cerámica (Trola y Ciampagna 2011) y artefactos líticos (Zubimendi et al. 2010).

\subsubsection{Metodología}

\subsubsection{Excavación}

En primer lugar, se realizó un sondeo de $0,5 \times 0,5 \mathrm{~m}$ en un sector de media a alta densidad, en superficie, de restos malacológicos por medio de niveles artificiales de 5 $\mathrm{cm}$ de potencia a excepción de identificar cambios sedimentológicos significativos. Al comprobar que se registraba material arqueológico en estratigrafía se realizaron cuatro cuadrículas de $1 \mathrm{~m}^{2}$ cada una al sudeste del primer sondeo. En esta tesis se analizarán 
los carbones dispersos correspondientes al sondeo 1, debido a que presenta un mejor control estratigráfico.

\subsubsection{Recuperación de restos antracológicos}

Debido a las características de los sitios analizados en esta tesis (cielo abierto, abrigos rocosos y concheros), la metodología de excavación y el diseño de muestreo aplicado fueron diferentes adecuándose a las particularidades de los mismos. Por este motivo, la recuperación de muestras antracológicas, carpológicas y de otros macrorrestos (i.e. fragmento de arpón de madera) no fue homogénea en todos los casos.

En el sitio a cielo abierto Palo Alto, del sector Golfo San Jorge, no se registraron estructuras de combustión o fogones. Se recuperaron a través de zaranda de $2 \mathrm{~mm}$ los carbones dispersos de todos los niveles del sitio, pero en esta tesis, se analizaron los materiales antracológicos sólo del sondeo 1. Por otra parte el denominado fondo de zaranda del sondeo 1 se analizó en el laboratorio recuperando carbones y registrando la presencia/ausencia de otros restos arqueobotánicos (ver Zubimendi 2012, Zubimendi y Hammond 2009, Hammond 2013, entre otros).

En pos de registrar la potencialidad de uso y eficacia de la técnica de flotación en el área de estudio se procedió en el sitio Cueva del Negro a realizar por vez primera una flotación manual en agua salada (Pearsall 2000), debido a la escasez de agua dulce. Se tomó una muestra de 5 litros de sedimento del sitio, que poseía restos zooarqueológicos, líticos y antracológicos y se flotó en un balde cuyo fondo fue reemplazado por una malla de $2 \mathrm{~mm}$. El resultado fue positivo en cuanto a que los distintos tipos de materiales se separaron rápidamente. Sin embargo, dos factores fueron negativos con este método, por un lado los carbones se deterioraron sustancialmente al mojarse, y, por otro lado existen varios problemas de orden logístico: el proceso de secado de los materiales fue de difícil resolución dado los fuertes vientos patagónicos, y en especial porque no se pudo contar con una habitación o depósito que los protegiera de éstos sin que se volaran. Por otro lado, los sitios más alejados de la costa también representaban un problema a la hora de tener que trasladar agua de mar para la flotación, y en cuanto a la posibilidad de poder realizar la misma en el laboratorio o el Museo Municipal Mario 
Brozosky de la localidad de Puerto Deseado, resultó muy difícil trasladar la cantidad de volumen de sedimento necesario, debido a la falta de transporte adecuado para ello.

Dados estos inconvenientes, de allí en adelante y en este caso en particular, en el sitio Palo Alto, se optó por emplear la técnica de zarandeo con una malla fina (2 $\mathrm{mm}$ ) y el análisis de la totalidad de los denominados fondos de zaranda (ver Zubimendi y Hammond 2009, Zubimendi 2012, Hammond 2013), la cual permite la separación en el laboratorio de los restos arqueológicos más pequeños, y en espacial una cuidadosa recuperación de carbones (Martínez et al. 2000, Solari 2000). Esta metodología entonces, es la que se empleó en el sitio Palo Alto. De esta manera, en dicho sitio se procesaron 11 litros por nivel con este método.

Para la identificación taxonómica de los carbones de madera se tomó una submuestra de los mismos siguiendo una curva de riqueza específica (Piqué i Huerta 1999, Solari 2000, Marconetto 2005). Se clasificó en categorías de tamaño los restos antracológicos y se analizó de forma alternada cada uno de ellos de modo de no sesgar la muestra (Miller 1988, Thièbault 1989, Andreoni y Capparelli 2010). Por otra parte, se calculó la frecuencia relativa de los taxa identificados sobre la base de los valores de densidad. Esto último se realizó de igual manera en todos los sitios analizados. En términos descriptivos y comparativos se consideró una densidad baja entre 0 y 100 n/l; media entre 100 y 1000 n/l; y alta más de 1000 n/l. En los sitios donde se recuperaron carbones dispersos en más de un nivel se realizaron análisis de ubicuidad, para identificar cambios en el uso de taxa a lo largo de la ocupación. Al finalizar el capítulo con los resultados de todos los sitios por sector se realizaron nuevos análisis de ubicuidad porcentual (Capparelli 1997, Marconetto 2005, Andreoni 2014). En el caso de los carbones provenientes de fogones se realizaron análisis de ubicuidad en el sitio Alero El Oriental (que tiene fogones en los tres componentes) y al finalizar el capítulo de casa sector considerando fogones de distintos sitios.

Por último, en todos los sitios con más de un nivel, o más de una cuadrícula analizada se calculó el índice de correlación entre el número total de fragmentos y el peso total. Este análisis permitió identificar si algún nivel sufrió algún proceso postdepositacional distinto al resto, cambios a lo largo de la secuencia estratigráfica o en áreas de actividad a nivel espacial (Andreoni 2014). 


\subsubsection{Contexto estratigráfico}

En el sondeo se excavó una capa que presentaba restos arqueológicos hasta una profundidad de $27 \mathrm{~cm}$ con respecto al nivel 0 (Figura 8.5). Este sedimento fértil es eólico arenoso, de color pardo, con poca cohesión y gran cantidad de rodados de pequeño tamaño. Las valvas se disponen al azar sin estructura, no se observó ninguna lente de carbones o presencia de fogón. Por debajo de éste, se registró un sedimento muy duro, compactado de granulometría muy fina y color gris, sin restos arqueológicos, que pertenece al estrato terciario del Patagoniano y que actuó como roca de base (Zubimendi et al. 2010). Posteriormente, se excavaron cuatro cuadrículas de $1 \mathrm{~m}^{2}$. Las características sedimentológicas y de estructura del sitio en su totalidad permiten analizar todo el registro arqueológico como un conjunto, ya que formarían parte de una sola capa arqueológica que puede ser producto de una o más ocupaciones que no se diferencian debido a que no es posible observar distintos eventos depositacionales (Zubimendi et al. 2010). Si bien las características sedimentológicas y de estructura del sitio permiten considerar todo el registro como un conjunto, se analizan los restos arqueobotánicos recuperados por niveles artificiales. Esto permitirá entre otras vairiables obtener un mejor control tafonómico e información de la acción de los procesos postdepositacionales. 


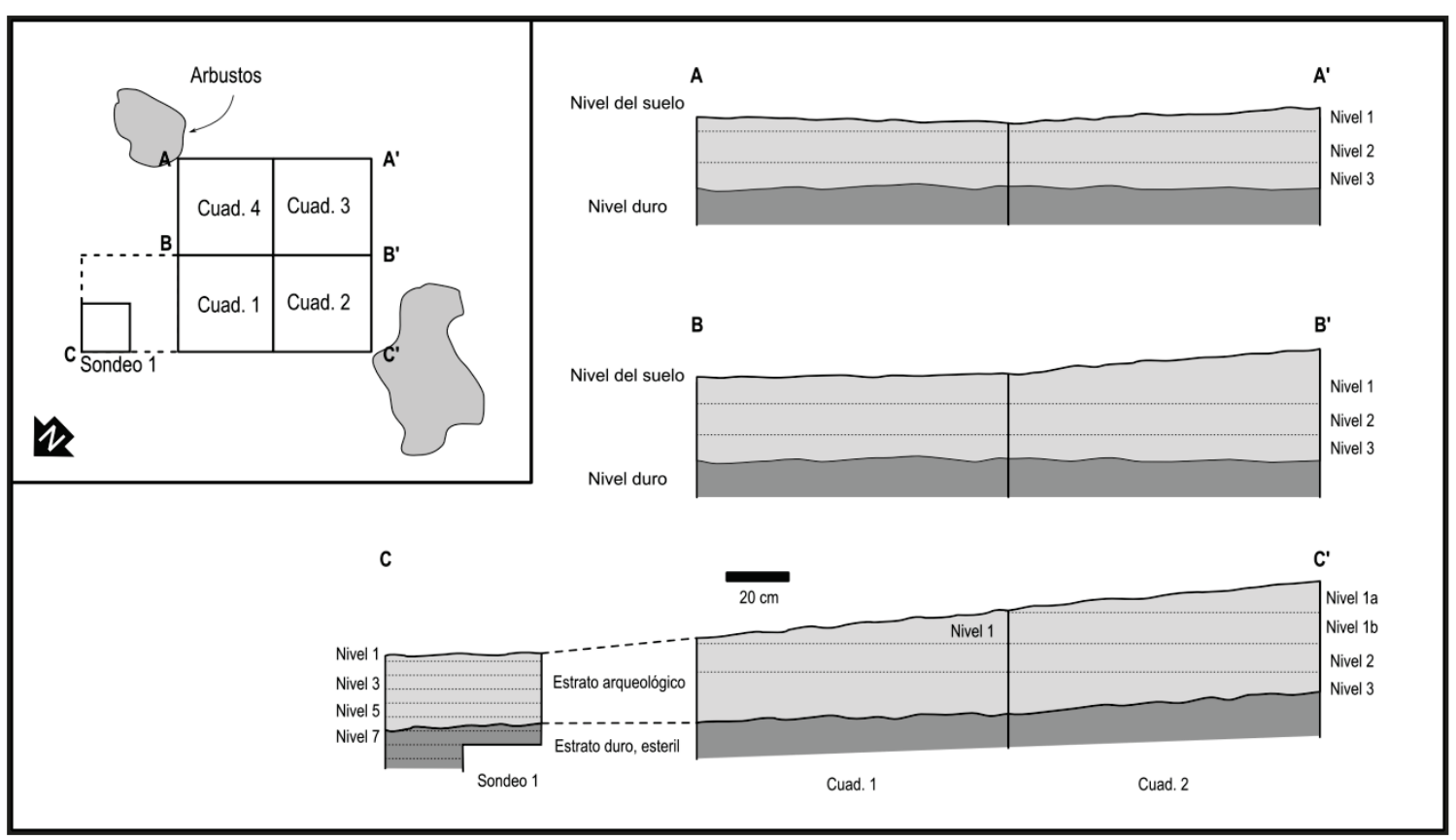

Figura 8.5. Esquema estratigráfico del sitio Palo Alto (cedido por M. A. Zubimendi)

\subsubsection{Estudios arqueológicos}

En estratigrafía se recuperaron restos líticos, óseos y malacológicos, así como se observaron posibles huellas de poste. Se analizaron los artefactos líticos que provenían de las cuadrículas 1 y 2 con un total de 915 artefactos. En este conjunto predominan los desechos, y en una baja proporción las formas base potenciales (Zubimendi et al. 2010). La materia prima sobre la que fueron confeccionados dichos artefactos es mayormente calcedonia, en gran parte de disponibilidad local. El análisis realizado sobre el conjunto artefactual sugiere que representaría actividades de talla muy específicas relacionadas con la confección y mantenimiento del instrumental lítico. Se evidencian las últimas etapas de talla, formatización y reactivación de filos principalmente en materias primas locales, mientras que las primeras etapas de talla no estarían representadas.

Respecto a los restos óseos se recuperaron 577 especímenes correspondientes al sondeo y a las cuadrículas excavadas. Asimismo se han hallado 407 fragmentos de cáscara de huevo de ñandú, algunos con evidencias de exposición al fuego. Estos fragmentos permitirían considerar la ocupación del sitio en primavera verano (Zubimendi et al. 2010, Moreno 2008). De los especímenes óseos se identificaron 21 taxones pertenecientes tanto a fauna marina como terrestre, entre ellos los más abundantes en 
cuanto al \% NISP son los mamíferos indeterminados, los peces, los guanacos y por último los pinnípedos. La proporción de restos óseos con diferentes grados de combustión es alta, ya que el $40 \%$ presenta evidencias de este tipo (Zubimendi et al. 2010).

En cuanto a los restos malacológicos sólo se analizaron aquellos que se recuperaron en la cuadrícula 2. Se observó un predominio de lapas, seguido por los mitílidos: los mejillones, mejillines y cholgas. El análisis de estos restos sugiere el consumo orientado a una única especie del intermareal, siendo las restantes producto del acarreo no intencional (Zubimendi 2010; Zubimendi 2012).

\subsubsection{Resultados antracológicos}

En el primer nivel del sondeo se recuperó solamente un carbón vegetal en un volumen de sedimento total de 11,25 1, siendo entonces la densidad calculada de 0,09 $\mathrm{n} / 1$ y por ende baja. La categoría de tamaño de este carbón era de 2 a 4,9 mm. Se identificó un solo género, Lycium, que no presentó grietas de contracción ni vitrificación, así como tampoco ataque de microorganismos o hifas (Figura 8.6).

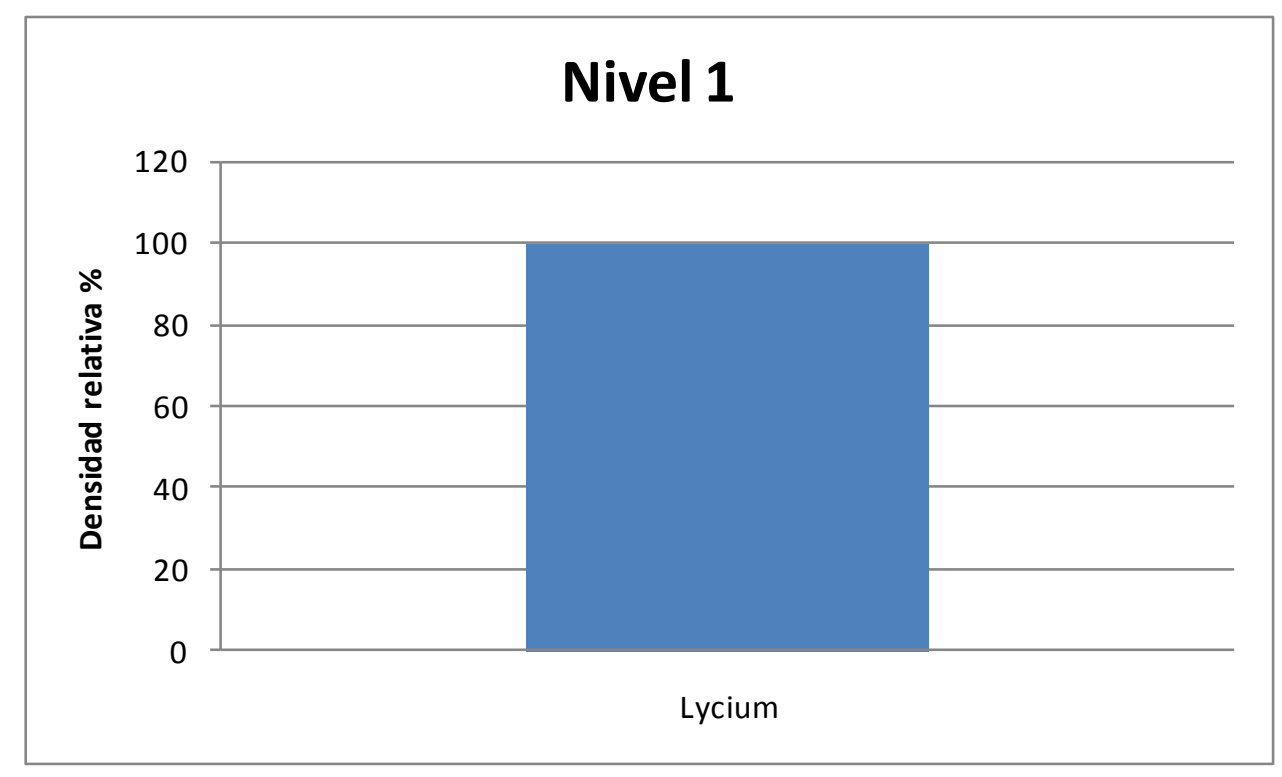

Figura 8.6. Carbón identificado del nivel 1, sondeo 1, sitio Palo Alto $(\mathrm{n}=1)$. 
La madera de Lycium como se registró en el capítulo 7 es una madera de densidad intermedia, de rápido encendido que deja poca brasa. La densidad calculada de carbones para el volumen de sedimento es baja y se incrementa en los siguientes niveles.

En el nivel 2 del sondeo 1, se recuperaron un total de 90 carbones sobre un volumen de 11,25 1 siendo entonces la densidad calculada de $8 \mathrm{n} / 1$ y por lo tanto baja. Las categorías de tamaño registradas son de 5-9 $\mathrm{mm}$ a 2-4,9 $\mathrm{mm}$ encontrándose la mayor cantidad de carbones en la última. La submuestra analizada es de 40 carbones siendo identificados 5 taxa entre los que predominan Lycium y Atriplex/Suaeda (Figura 8.7).

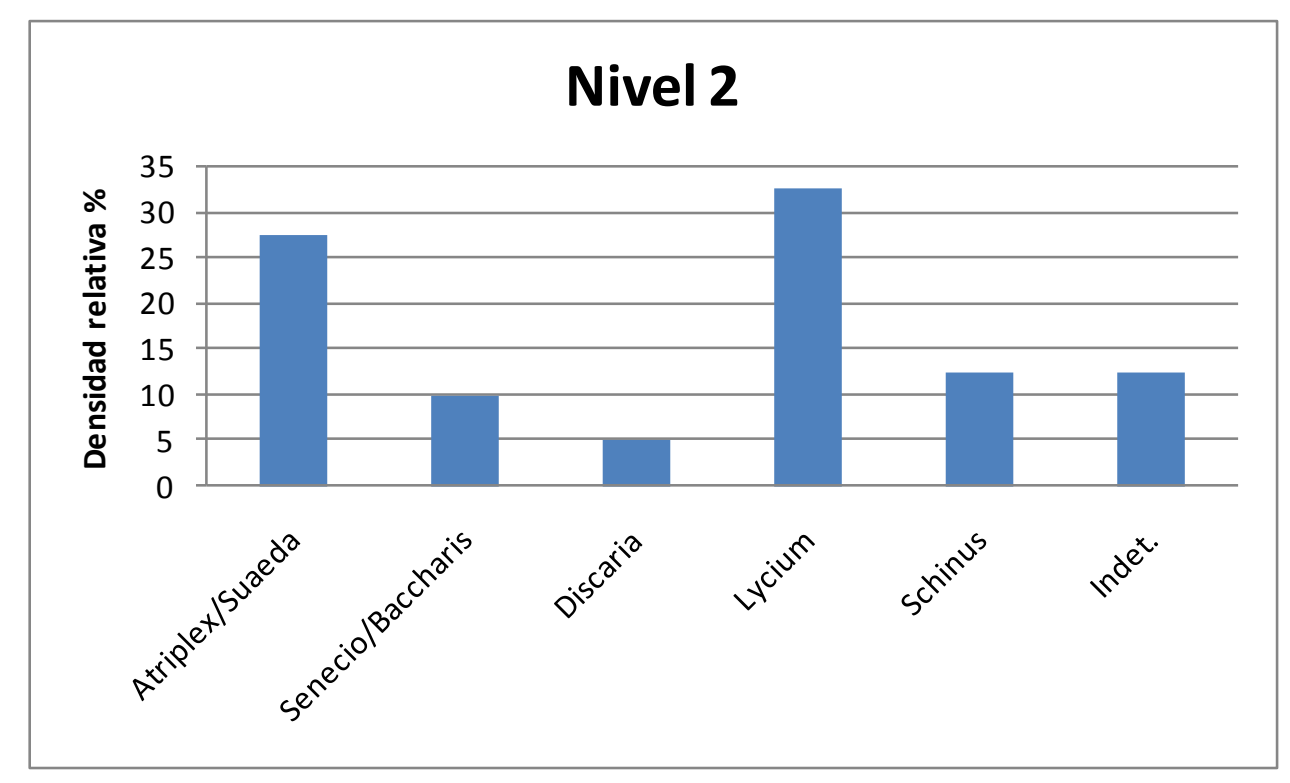

Figura 8.7. Carbones identificados del nivel 2, sondeo 1, sitio Palo Alto (submuestra $n=40$ ).

De esta submuestra, se registró vitrificación en Atriplex/Suaeda $(\mathrm{n}=2)$, Senecio/Baccharis $(\mathrm{n}=1)$, Discaria $(\mathrm{n}=2)$, Lycium $(\mathrm{n}=3)$, Schinus $(\mathrm{n}=1)$ y un carbón indeterminable $(n=1)$. Es decir, en el 25\% de los carbones se observó vitrificación. La presencia de médula se identificó en el $2,5 \%$ de los carbones en los géneros Senecio/Baccharis $(\mathrm{n}=1)$.

Respecto a las contracciones de la madera se observaron aberturas en el parénquima y floema incluso de Atriplex/Suaeda $(\mathrm{n}=7)$, en radios de Senecio/Baccharis $(\mathrm{n}=2)$, Discaria $(\mathrm{n}=1)$, Lycium $(\mathrm{n}=1)$ y en radios y vasos de Schinus $(\mathrm{n}=1)$. Por lo tanto el $30 \%$ de los carbones sufrió aberturas y ojos.

En el nivel 3 se recuperó un total de 116 carbones en un volumen de 11,25 1, siendo la densidad calculada de $10,31 \mathrm{n} / 1$, considerada baja. Las categorías de tamaño registradas 
abarcan los 10-14,9 $\mathrm{mm}$ a 2-4,9 $\mathrm{mm}$. La mayor parte de los carbones se encuentra en la última categoría. La submuestra analizada es de 34 carbones habiéndose identificado 6 taxa, entre los que predominan Lycium, Atriplex/Suaeda y Schinus (Figura 8.8).

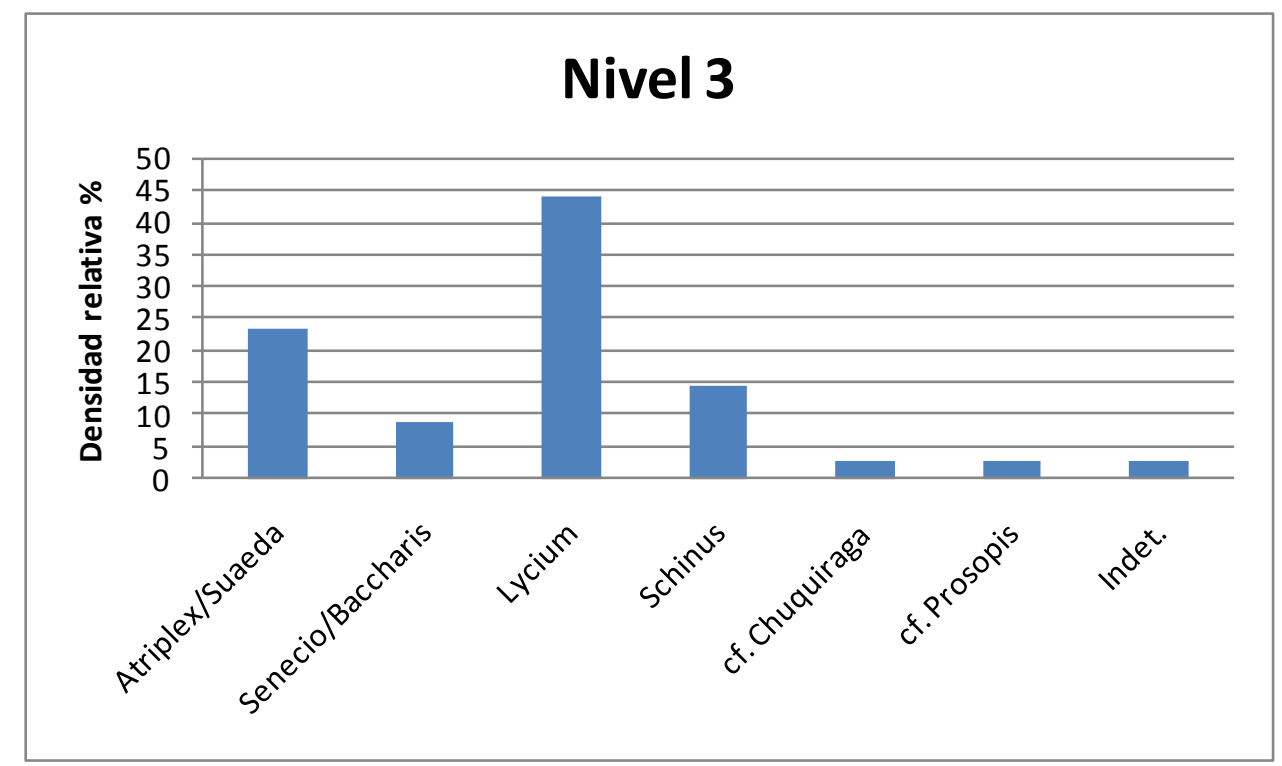

Figura 8.8. Carbones identificados del nivel 3, sondeo 1, sitio Palo Alto (submuestra n = 34)

Se registró vitrificación en el 30\% de los carbones entre los que se identificaron Lycium $(\mathrm{n}=10)$, Schinus $(\mathrm{n}=1)$, Atriplex/Suaeda $(\mathrm{n}=1)$. En Atriplex/Suaeda $(\mathrm{n}=2)$ se observó médula así como para este taxa se registraron también aberturas en parénquima y floema incluso $(n=6)$. La presencia de ojos en vasos se registró en Lycium $(n=4)$, en radios en Senecio/Baccharis $(\mathrm{n}=1)$, cf. Chuquiraga $(\mathrm{n}=1)$ y en radios y vasos en Schinus $(\mathrm{n}=3)$. Por lo tanto, el 44,1\% de los carbones sufrió aberturas.

En el nivel 4 se obtuvo un total de 135 carbones en un volumen de 11,25 1, siendo entonces la densidad calculada de $12 \mathrm{n} / 1$ considerada baja. Las categorías de tamaño registradas abarcaron los rangos de 10-14,9 $\mathrm{mm}$ a 2-4,9 $\mathrm{mm}$ encontrándose mayor cantidad de carbones en la última categoría. La submuestra analizada es de 50 carbones donde se identificaron 7 taxa, entre los que predominan Atriplex/Suaeda y Lycium (Figura 8.9). 


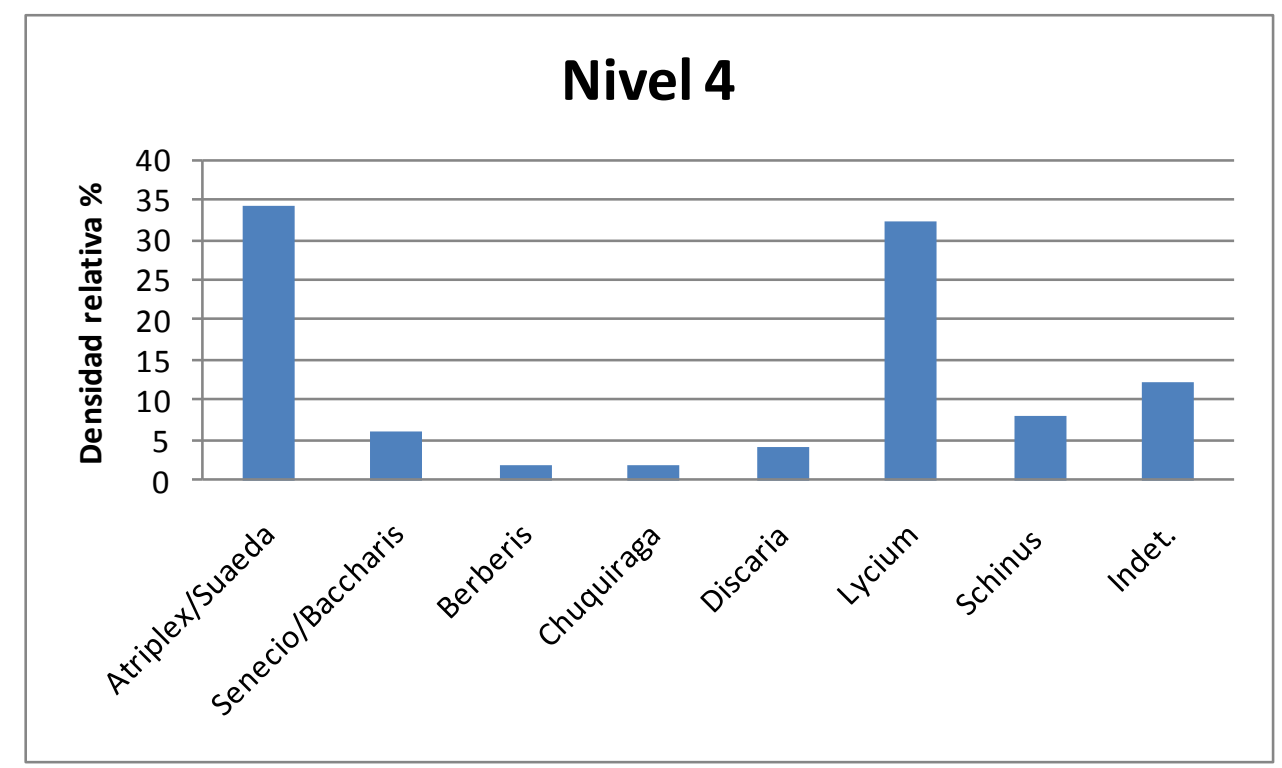

Figura 8.9. Carbones identificados del nivel 4, sondeo 1, sitio Palo Alto (submuestra $\mathrm{n}=50$ )

Se observó vitrificación en el 18\% de los carbones siendo identificados como Lycium (n =5), Senecio/Baccharis $(\mathrm{n}=1)$, Discaria $(\mathrm{n}=1)$ e indeterminable $(\mathrm{n}=2)$. Un solo caso, identificado como Atriplex /Suaeda, registró presencia de médula. En relación a las contracciones de combustión se contabilizaron abundantes aberturas en el floema incluso y parénquima de Atriplex/Suaeda $(\mathrm{n}=13)$, sobre los radios en Schinus $(\mathrm{n}=1)$, Lycium $(\mathrm{n}=1)$, Discaria $(\mathrm{n}=1)$, indeterminable $(\mathrm{n}=2)$. En radios y vasos en Discaria $(\mathrm{n}=2)$ y Senecio/Baccharis $(\mathrm{n}=2)$. Y solo sobre vasos en Schinus $(\mathrm{n}=2)$. Es decir, que el 48\% registró contracciones por la combustión.

En el nivel 5 se recuperó un total de 184 carbones en un volumen de 11,25 1, siendo la densidad calculada de $16,36 \mathrm{n} / 1$, clasificada como baja. Las categorías de tamaño consideradas abarcan el 10-14,9 $\mathrm{mm}$ a 2-4,9 $\mathrm{mm}$, siendo esta última la categoría con mayor cantidad de especímenes. La submuestra analizada es de 60 carbones y se identificaron 7 taxa entre las que predominan Lycium y Atriplex/Suaeda (Figura 8.10). 


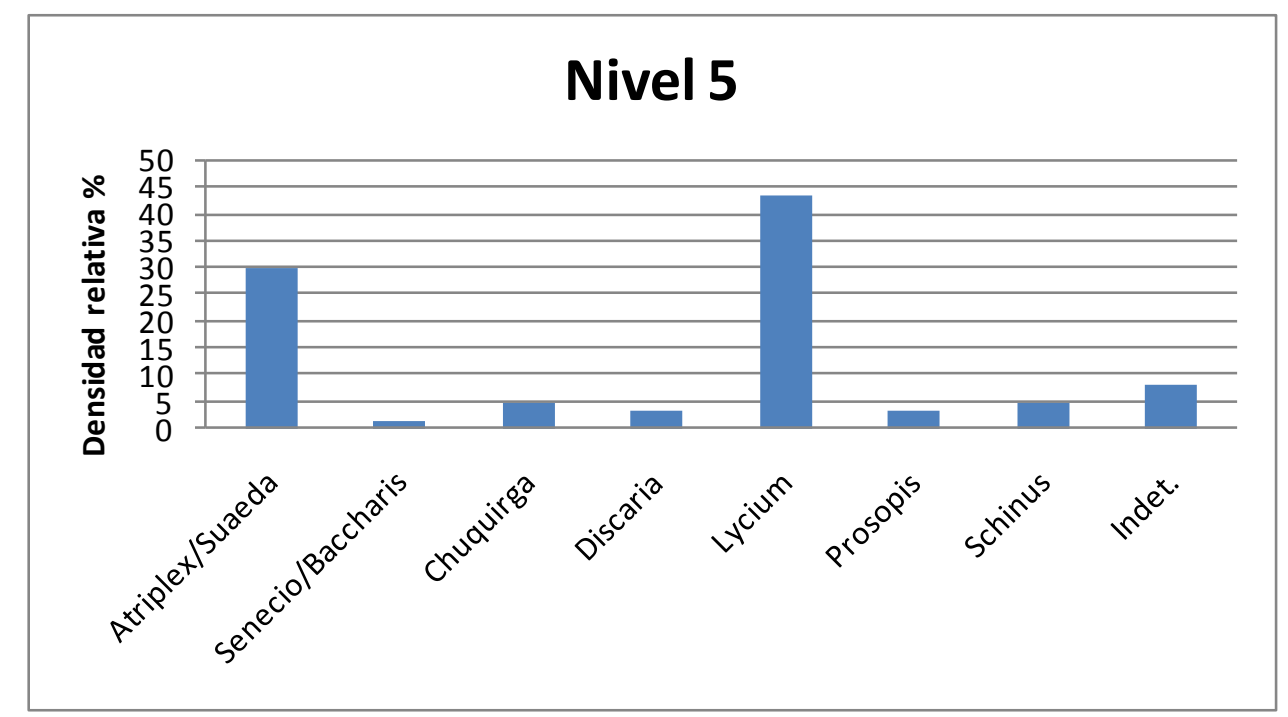

Figura 8.10. Carbones identificados del nivel 5, sondeo 1, sitio Palo Alto (submuestra n=60).

Se observó vitrificación en el $28,3 \%$ de la submuestra en los carbones de Atriplex/Sueada $(\mathrm{n}=2)$; Chuquiraga $(\mathrm{n}=1)$, Discaria $(\mathrm{n}=1)$, Lycium $(\mathrm{n}=8)$, Prosopis $(\mathrm{n}=2)$, Schinus $(\mathrm{n}=1)$ e indeterminable $(\mathrm{n}=2)$. Sólo se registró médula en Atriplex/Suaeda $(\mathrm{n}=1)$.

En cuanto a las aberturas la mayor parte se hallaron en el floema incluso en Atriplex/Suaeda $(\mathrm{n}=16)$, y en radios y vasos en Lycium $(\mathrm{n}=7)$, Schinus $(\mathrm{n}=3)$, e indeterminable $(\mathrm{n}=2)$. Entonces, el $46,6 \%$ de la submuestra presentó grietas de contracción producto de la combustión.

Si se analizan los cinco niveles en conjunto, se puede observar que Lycium fue la especie que presentó el $100 \%$ de ubicuidad, seguida por Atriplex/Suaeda, Senecio/Baccharis y Schinus con el 80\% (Figura 8.11). 


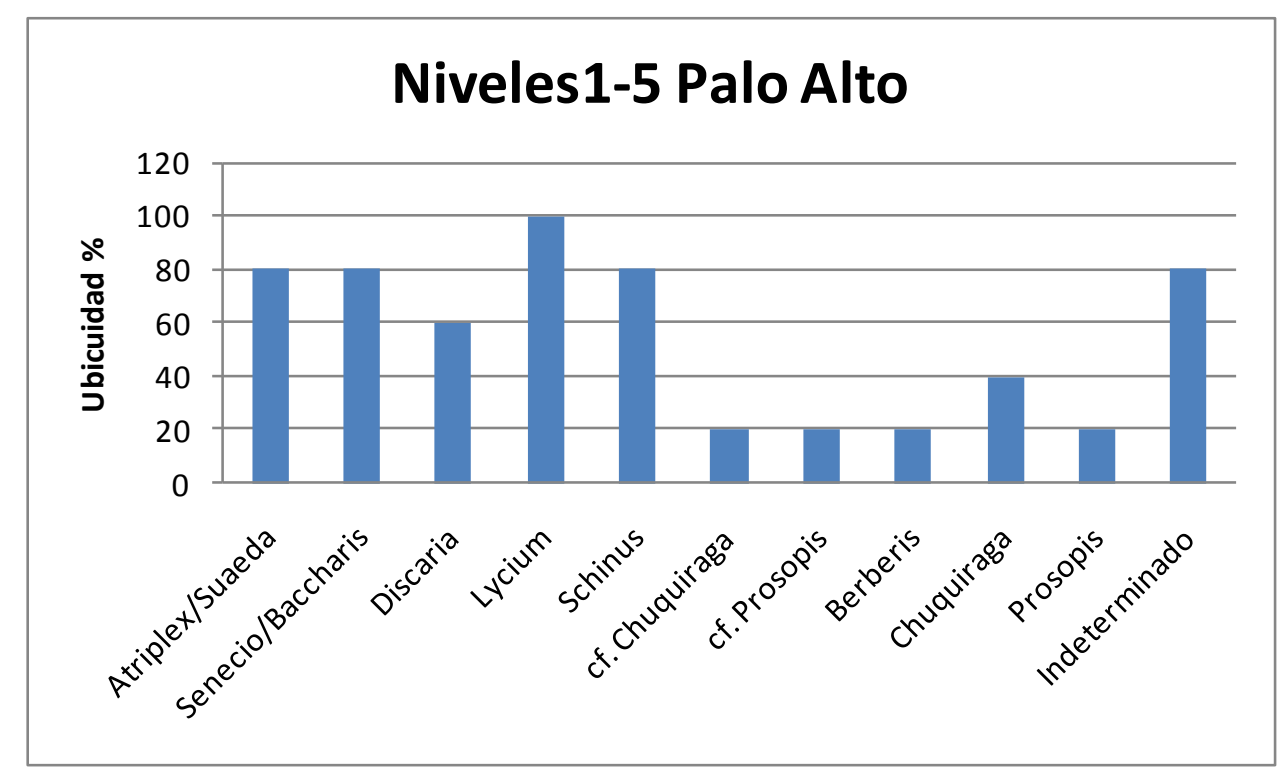

Figura 8.11. Ubicuidad de los taxa identificados en los 5 niveles analizados

Se realizó el análisis de correlación entre el número de fragmentos de carbones dispersos recuperados por nivel arqueológico y el peso de los mismos (Figura 8.12). Este análisis dio como resultado $\mathrm{R}^{2}=0,90$ con un nivel de significancia de $\mathrm{p}<0.01$ para 5 niveles. La asociación positiva entre el número de fragmentos recuperados por nivel arqueológico y el peso total de los restos de cada nivel permite inferir que ningún nivel arqueológico atravesó procesos postdepostacionales significativamente diferentes al resto. Es decir, no se observaron para cada uno de ellos un número de fragmentos elevado con bajo peso total lo que podría indicar una fragmentación muy intensa. Tampoco se registraron un número escaso de restos por nivel para un peso total elevado, en este caso se trataría de un evento con muy poca fragmentación. 


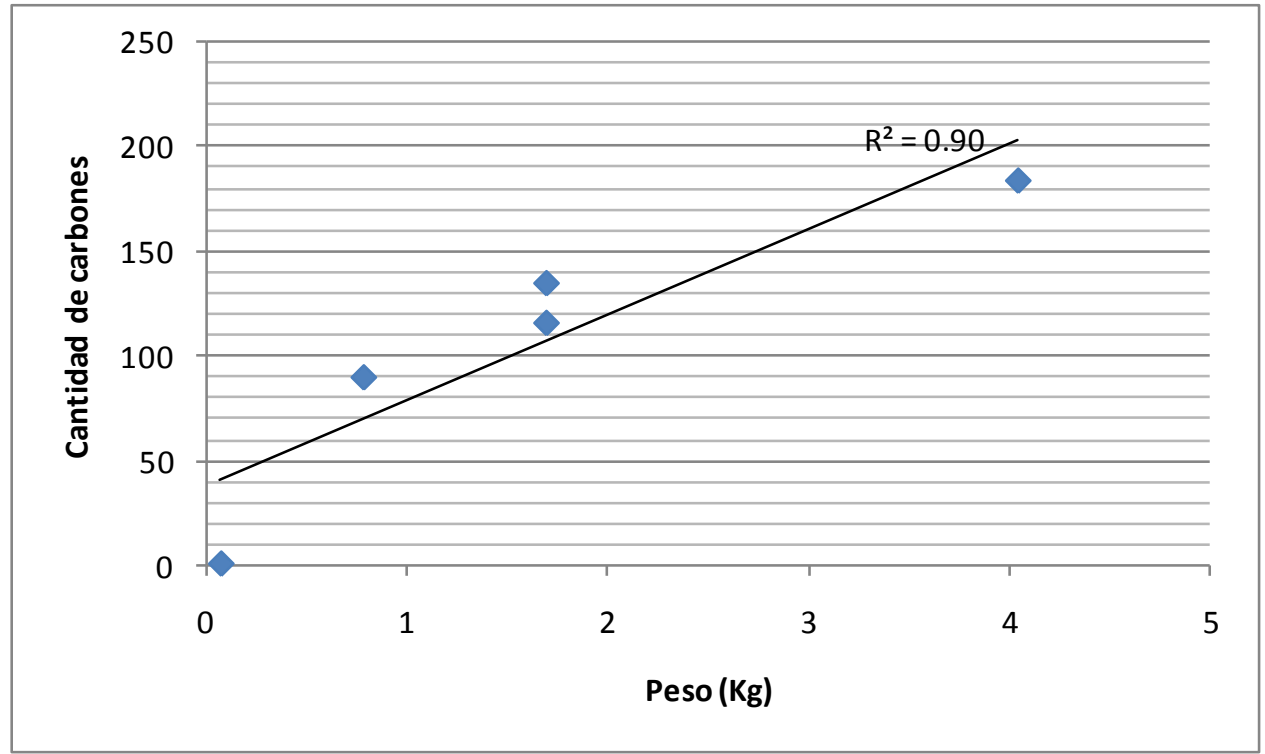

Figura 8.12. Correlación entre cantidad y peso de carbón de madera recuperado por nivel arqueológico en el sitio Palo Alto.

\subsubsection{Discusión y conclusiones}

En primer lugar, es importante mencionar que para el período cronológico del sitio Palo Alto, el Holoceno tardío final, la vegetación sería análoga a la actual (De Porras 2010). Se considera además que los procesos de desertificación producto de acciones antrópicas para ese momento todavía no habrían comenzado a actuar (i.e. introducción de la oveja). Actualmente las especies identificadas taxonómicamente se encuentran próximas al sitio, hacia la costa Atriplex/Suaeda, Senecio/Baccharis, Schinus, Chuquiraga y Lycium, y más distante, hacia el flanco de meseta y cañadones, Prosopis denudans.

La densidad calculada de los carbones respecto al volumen de sedimento de cada nivel permite observar un incremento de la misma a mayor profundidad, especialmente a partir del nivel 2. La riqueza de taxa también aumenta a partir del segundo nivel y se mantiene constante en los niveles 4 y 5 . Entre los taxa que predominan en todos los niveles se encuentran Lycium y Atriplex/Suaeda, seguidos en menor medida, por Schinus y Senecio/Baccharis. Además, Lycium presenta el 100\% de ubicuidad en los niveles analizados, seguidos por Atriplex/Suaeda, Sencio/Baccharis y Lcyium que presentan el $80 \%$ de ubicuidad (Figura 8.11) 
Tal como se expresó en los capítulos 5 y 7 de esta tesis, las maderas de las especies determinadas en el sondeo 1 evidencian una combinación de maderas de rápido encendido (i.e. Atriplex/Suaeda, Lycium, Senecio/Baccharis, Chuquiraga) con otras de mayor duración (i.e. Schinus, Prosopis).

En cuanto al registro arqueológico no se observaron concentraciones de carbones así como tampoco estructuras de fogón. Sin embargo, los restos de cáscara de huevo de ñandú registran evidencias de exposición al fuego, así como algunos de los restos óseos recuperados.

La ausencia de fogones y la baja densidad de restos antracológicos podrían explicarse $a$ priori por procesos tafonómicos y de remoción como los que se observan en el conjunto óseo, altamente meteorizado. Zubimendi y colaboradores (2010, y también en Zubimendi 2012) sugieren que los restos arqueológicos habrían quedado expuestos a la intemperie durante un periodo prolongado de tiempo antes de quedar enterrados, y luego podrían haber sido sometidos intensamente a agentes de alteración postdepositacional, como animales fosoriales, y recientemente también a procesos antrópicos (i.e. presencia de caminos, explotación de canteras de arena, entre otras). Sin embargo, los análisis de correlación positiva entre la cantidad total de fragmentos de carbón por nivel y el peso de los mismos permite inferir que ningún nivel arqueológico atravesó procesos postdepostacionales significativamente diferentes al resto. En este sentido, este análisis no permite a través de los carbones arqueológicos recuperados profundizar en los procesos tafonómicos que habría afectado el registro arqueológico. La ausencia de fogones debería ser explicada por otro tipo de procesos, como la limpieza de los mismos, o los fuertes vientos que podrían haber dispersado los carbones antes de su entierro. 


\section{Registro arqueobotánico sector Cabo Blanco}

\subsection{Introducción}

En este capítulo se presenta en primer lugar, los antecedentes recientes generados en el marco del proyecto CNSC por otros investigadores del equipo para este sector. Luego, se describen los sitios y las excavaciones realizadas en cada caso, a partir de las cuales se han recuperado los materiales arqueobotánicos analizados en la presente tesis. Las excavaciones realizadas en Cabo Blanco no se realizaron con un diseño de muestreo que contara con un objetivo arqueobotánico debido a que el análisis de estos materiales se realizó con posterioridad. Después, se presentan los resultados de los estudios arqueobotánicos ralizados así como, los resultados de ubicuidad de taxa de los fogones de los sitios Cormorán Quemado y Nido del Águila de este sector.

\subsection{Antecedentes recientes}

El sector Cabo Blanco comienza a $20 \mathrm{~km}$ al sur del Cabo Tres Puntas, límite sur del Golfo San Jorge. Este sector también pertenece a la Provincia geológica del Chubut extraandino y la vegetación predominante es la estepa arbustiva del Golfo San Jorge, aunque hacia el interior existen áreas de ecotono entre ésta y la estepa de arbustos enanos, rastreros de muy baja cobertura vegetal (entre un 20 y 30\%), y vegetación zonal con arbustos de mayor porte en las líneas de escorrentía (Oliva et al. 2001).

Este sector presenta un tómbolo, de origen Holocénico, que se proyecta desde el continente hacia el mar (Iantanos et al. 2009, Castro et al. 2011) y posee dos promontorios que reciben la denominación de Cabo Blanco. A principios del siglo XX se construyó sobre uno de los promontorios un faro que aún hoy funciona y un poblado que se fundó con el desarrollo del telégrafo y la explotación de las salinas cercanas, pero que en la década de 1970 fue abandonado. Esta zona presenta un fuerte impacto antrópico debido a su atractivo turístico, lo que repercute en los sitios más cercanos al tómbolo (Zubimendi et al. 2014). Hacia el interior se encuentra la meseta patagónica y 
entre ambos espacios geográficos se registran, como se mencionó anteriormente, cañadones y algunas lagunas (Zubimendi 2010).

La costa cercana a Cabo Blanco, y hasta Punta Guzmán, presenta cordones litorales de rodados gruesos y salinas. Allí el acantilado se retira de la costa y forma un paleoacantilado que reaparece en Cabo Guzmán. Al oeste del paleoacantilado se ubica la meseta alta (Zubimendi 2010).

En cuanto a los recursos faunísticos marinos se hallan concentrados en la región del peñón y el tómbolo de Cabo Blanco. Se registran en este espacio colonias de nidificación de gaviotas cocineras y australes (Laurus dominicanus y L. scoresbii) cormoranes imperial (Phalacrocorax atriceps), de cuello negro (P. magellanicus) y cormorán gris (P. gaimardi). También es en este sector donde se registra una colonia permanente de lobos marinos de dos pelos (Carrara 1952, Schiavini et al. 1999; Zubimendi 2010).

Como se mencionó en el capítulo 3, en este sector se realizaron estudios arqueológicos enfocados desde el análisis distribucional y las excavaciones sistemáticas de los sitios Cabo Blanco 1 y 2, entre otros. El fechado más antiguo del sector se obtuvo en el sitio Cabo Blanco 2 y fue de $3390 \pm 60$ años AP (LP-992; Castro et al. 2000), mientras que el más reciente fue de $360 \pm 50$ AP (LP- 3007) en el sitio Cormorán quemado, que se describe más abajo.

Considerando las distintas unidades del paisaje, Zubimendi (2010) registró para las mesetas altas y los flancos de meseta distintas formas de uso del espacio por parte de los grupos que habitaron el sector, aunque éstas comparten un uso esporádico, de baja intensidad y ocupaciones cortas. En los cañadones al contrario, se registró un uso intensivo y repetido en el tiempo, con bases residenciales y campamentos de corta duración, lo cual se piensa que es debido a que estas geoformas serían parte del circuito de movilidad costa interior-inmediato. En las lagunas y el tómbolo se registraron los sitios con mayor riqueza artefactual, ocupaciones muy densas, repetidas en el tiempo por medio de bases residenciales, con equipamiento del espacio (Zubimendi 2010, Castro et al. 2011) A través del último concepto se hace referencia a la planificación de los grupos cazadores recolectores que al reutilizar esos espacios, los artefactos de difícil traslado (i.e. instrumentos de molienda, cerámica) se dejaban en los sitios (Nelson y Lippmeier 1993, Cassiodoro 2008). 


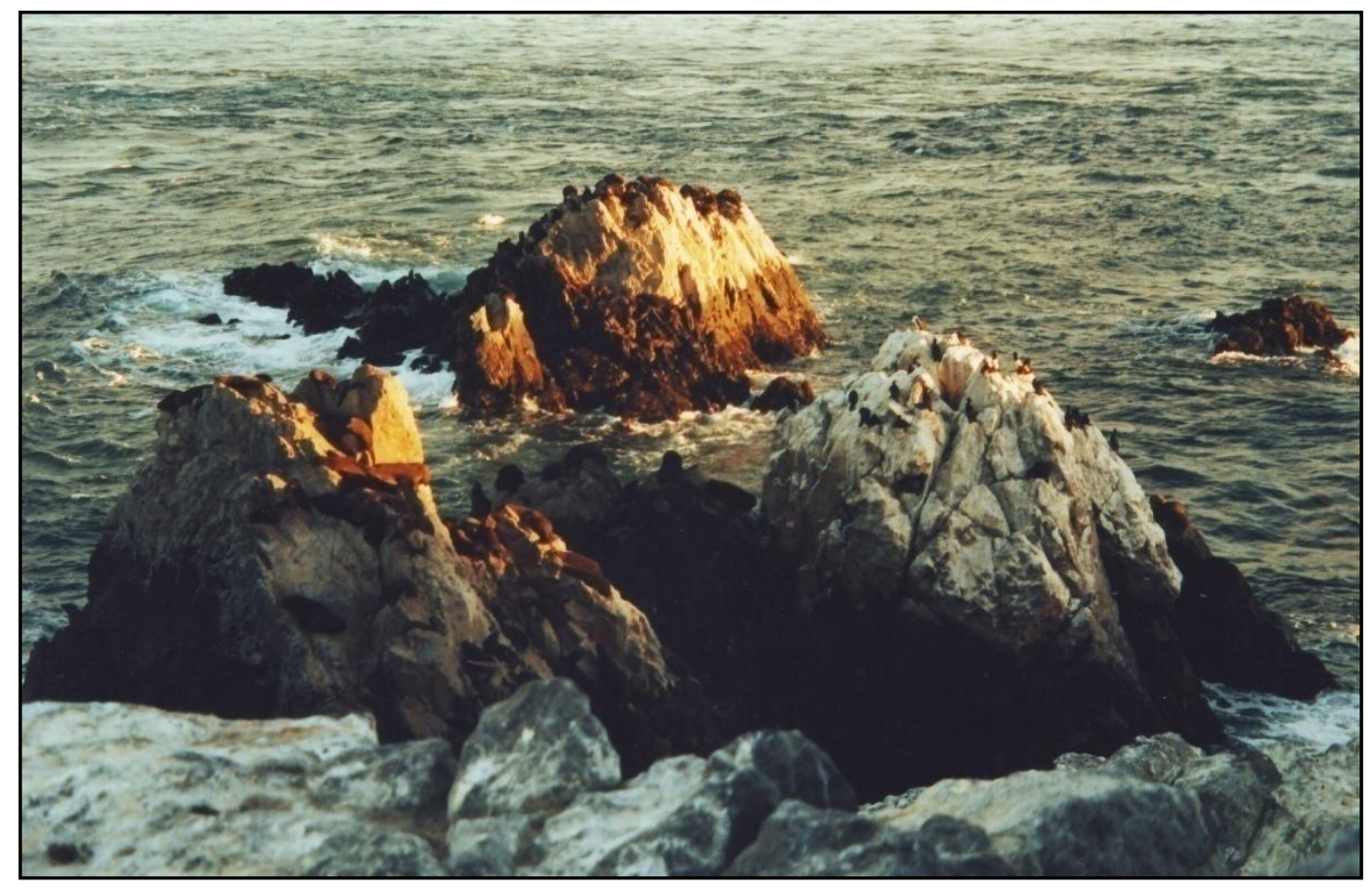

Figura 9.1. Cormoranera detrás del Tómbolo Cabo Blanco

\subsection{Sitio Cormorán Quemado}

\subsubsection{Introducción}

El sitio Cormorán Quemado se encuentra ubicado al sur del Cabo Blanco, en el borde de una laguna (Figura 9.2). Es un sitio a cielo abierto, de gran tamaño, sobre sedimento arcilloso, con alta densidad de material lítico en superficie, en el cual se registraron puntas de proyectil de pequeño tamaño, puntas destacadas, dos perforadores, veintitrés productos de talla y varias conanas; también se recuperaron cinco fragmentos de cerámica, un fragmento de cobre pequeño y restos óseos de cormorán con alteración térmica asociados a valvas de mejillón y cholga (Zubimendi 2006). En la superficie del sitio se observa vegetación halófita como Atriplex lampa, Suaeda, entre otras.

A partir de este registro, Zubimendi (2006) realizó una excavación de $2 \mathrm{~m}^{2}$ en la que se recuperaron carbones provenientes de un fogón en cubeta subsuperficial en un sector concentrado con una potencia de $10 \mathrm{~cm}$. En este último se registraron algunos restos malacológicos (fragmento de valvas de mejillín, mejillón, cholga y lapa) (ver más abajo). El fechado radiocarbónico efectuado sobre los carbones de ese fogón tuvo como 
resultado $360 \pm 50$ años AP (LP- 3007). Es importante mencionar que tanto Cormorán Quemado como los restantes sitios del sector Cabo Blanco se excavaron en el año 2006, cuando el estudio arqueobotánico de los materiales no estaba aún contemplado para ser realizado de modo sistemático. Por tal motivo, en algunos casos se obtuvieron muestreos sesgados (i.e. Nido del Águila).

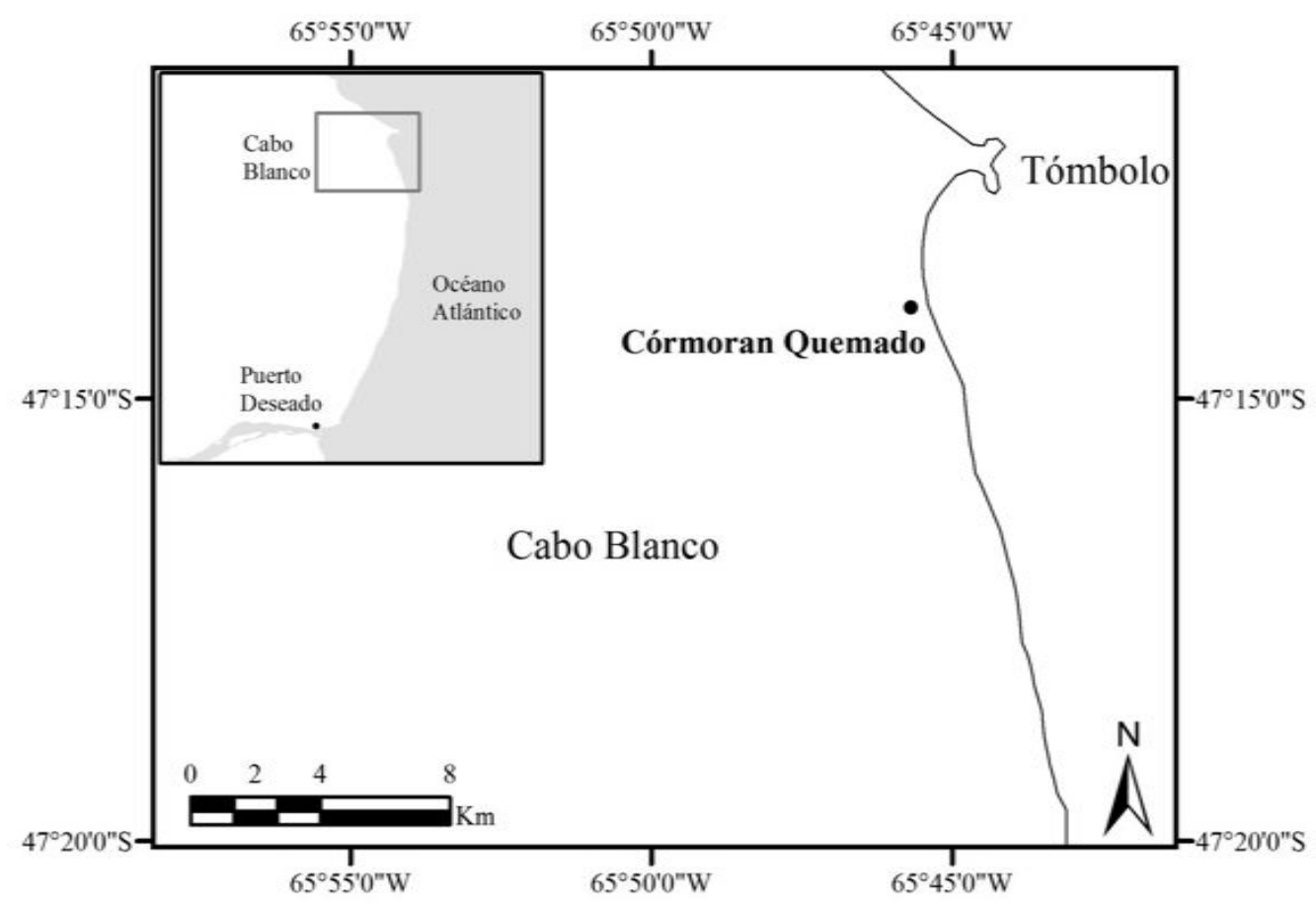

Figura 9.2. Ubicación del sitio Cormorán Quemado

\subsubsection{Metodología}

\subsubsection{Excavación}

Se realizaron dos cuadrículas de 1 x $1 \mathrm{~m}$, contiguas, en las que se excavó siguiendo capas naturales estratigráficas en combinación con niveles artificiales cada $20 \mathrm{~cm}$. Se seleccionó una muestra de carbones provenientes del fogón para datar en el INGEIS, sin embargo, no se obtuvieron resultados por lo que posteriormente luego de identificar taxonómicamente los carbones se extrajo una segunda muestra (cuadrícula 1, nivel 1) que fue datada en el Laboratorio de Tritio y Radiocarbono (LATYR) del Museo de Ciencias Naturales de La Plata y dio como resultado el fechado arriba mencionado. 


\subsubsection{Recuperación de restos antracológicos}

Se extrajo el material antracológico proveniente del fogón en cubeta mencionado, por medio de recuperación manual in situ y del tamizado del sedimento de excavación a través de una malla de $2 \mathrm{~mm}$. Estos fueron los únicos restos con los que se contó para analizar en esta tesis.

\subsubsection{Contexto estratigráfico}

En la cuadrícula 1 se observaron escasos artefactos líticos y restos óseos en la capa arqueológica fértil. Se recuperaron gran cantidad de carbones provenientes de un fogón en cubeta de una potencia de $5 \mathrm{~cm}$. En la cuadrícula 2 en un sector de $30 \times 30 \mathrm{~cm}$ se detectó una capa arqueológica fértil con valvas, artefactos líticos y restos óseos con una potencia de $10 \mathrm{~cm}$.

\subsubsection{Resultados antracológicos}

Del fogón registrado en la cuadrícula 1, se recuperaron un total de 1785 carbones en un volumen de sedimento de 1,8 1. La densidad calculada entonces, es de 991,67 n/1, clasificada como baja. En cuanto a las categorías de tamaño, se observó un rango amplio de 40-44,9 $\mathrm{mm}$ a 2-4,9 $\mathrm{mm}$, sin embargo, la mayor cantidad de carbones se encontró en las categorías 10-14,9 mm; 5-9,9 mm y 2-4,9 mm.

La submuestra analizada fue de 177 carbones, cuya identificación taxonómica permitió registrar tres taxa (Figura 9.3). 


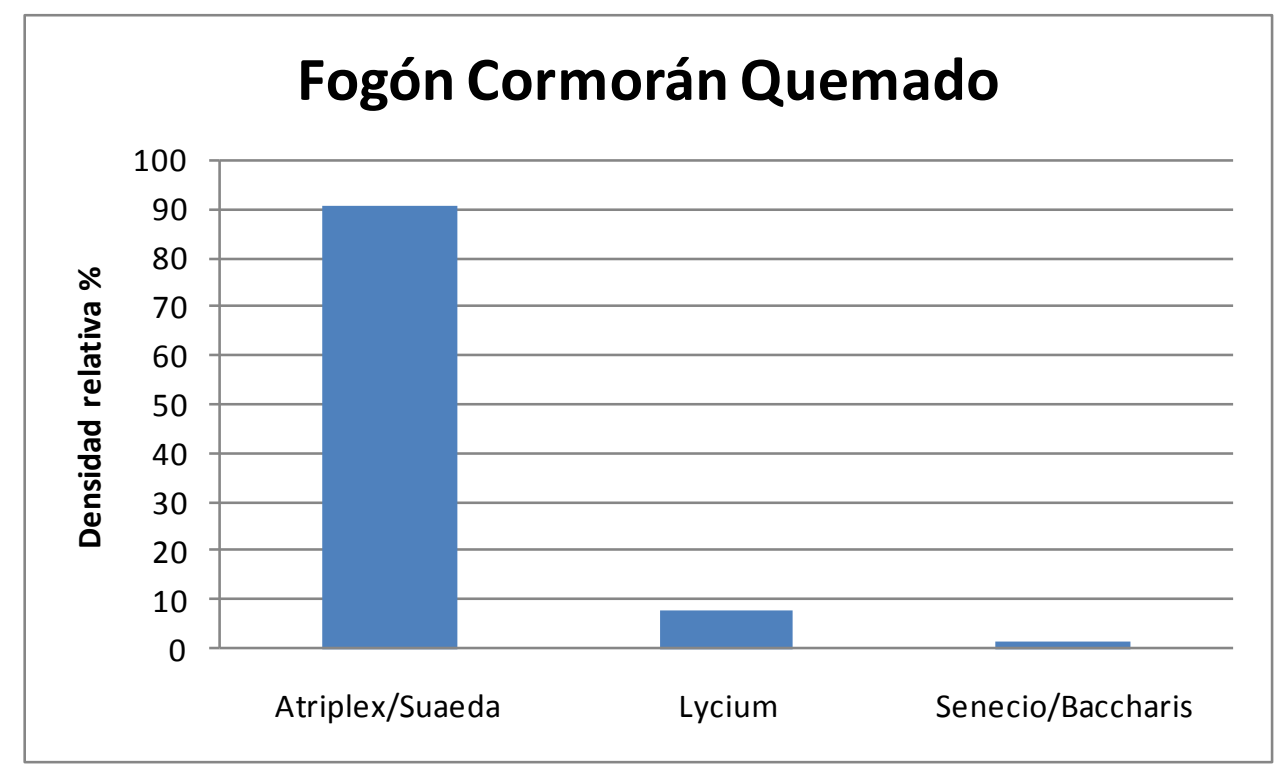

Figura 9.3. Carbones identificados en el fogón Cormorán Quemado submuestra $(n=177)$

La Figura 9.3 evidencia la predominancia de Atriplex/Suaeda en la conformación de este fogón. Sólo en el $0,1 \%$ de los carbones $(n=2)$ correspondientes a los géneros Lycium y Atriplex/Suaeda se registró vitrificación. De la submuestra analizada, el 26,5\% de los carbones $(\mathrm{n}=47)$ tenían médula. El 69,5\% $(\mathrm{n}=123)$ de los carbones presentaron aberturas como producto de la combustión. Se identificaron aberturas sobre el floema incluso de Atriplex/Suaeda $(\mathrm{n}=120)$ y sobre parénquima en Lycium $(\mathrm{n}=1)$. Las aberturas en los radios se observaron en Senecio/Baccharis $(\mathrm{n}=1)$ y sobre radios y vasos en Lycium $(\mathrm{n}=1)$.

En este caso no se pudo aplicar la correlación para observar si la fragmentación de los carbones es alta/baja y su relación con los procesos postdepositacionales, dado que se registró un solo fogón y no hay otros en el mismo sitio para comparar.

\subsubsection{Discusión y conclusiones}

En primer lugar, la ubicación cronológica del sitio en el Holoceno tardío final, permite sugerir que la vegetación de ese momento era similar a la actual, teniendo en cuenta los resultados de De Porras (2010) expuestos en el capítulo 3. Es importante mencionar que la vegetación asociada a las lagunas del sector Cabo Blanco presenta actualmente especies adaptadas a suelos salinos (i.e. Atriplex lampa). 
En relación a los taxa identificados en el conjunto de carbones se observan maderas de alta densidad como Atriplex/Suaeda (Andreoni 2014) e intermedia como Lycium. Estas maderas se combinaron con Senecio/Baccharis que por el contrario, según su densidad, se clasifican dentro de las muy bajas.

Respecto a las características mencionadas por los informantes en el capítulo 5, sobre la madera de Lycium expresaron: que produce mucha llama, es de rápido encendido pero produce poca brasa. En el caso de Atriplex lampa los informantes en Campo Moncada, Chubut, le comunicaron a Marconetto (2002) que era buena leña para encender el fuego. De acuerdo a las fuentes etnohistóricas recopiladas por Andreoni (2014), las cenizas de esta especie eran utilizadas por los ranqueles para hacer lejía. En cuanto a Baccharis, en el registro de fuentes documentales realizado en el capítulo 5, Ball (1884) quien analiza el herbario de Claraz ([1865-1866] 2008) de su viaje por Chubut, menciona que esta planta era utilizada por los aborígenes para hacer fuego mediante fricción (Ball [1865] 1884:221).

Los resultados obtenidos, la densidad de las maderas y las propiedades de combustión identificadas a través de entrevistas a informantes y del registro bibliográfico permiten sugerir que se produjeron aquí fuegos de corta duración, con leños que permitieron un encendido rápido (los tres taxa tendrían esta propiedad), y que habría producido abundante ceniza de completarse la combustión. Si bien la morfología de estos fogones (en cubeta) ha sido asociada a duraciones largas de los fuegos (Pérez de Micou 1991) en este caso, a pesar de tratarse de un fogón de esta morfología la identificación taxonómica de las especies, su densidad y características sugerirían un fuego de leñas que se consumirían rápidamente. En este sentido (Galanidou 2000) también advierte que no siempre la morfología de los fuegos puede dar información directa de la duración de los mismos. Es posible como plantea Pérez de Micou (1991) en su modelo etnoarqueológico, que aquellos que son en cubeta en sitios a cielo abierto pueden desarrollarse por cavado. Esto podría haberse realizado, dada la ubicación del sitio, para obtener reparo del viento.

Las modificaciones de estos carbones arqueológicos no serían diagnósticas de temperatura en el caso de Atriplex, ya que, según Andreoni (2014), presenta aberturas tanto en bajas como altas temperaturas. Al no registrarse aberturas diagnósticas en Lycium se sugiere que el fogón habría alcanzado temperaturas bajas. 
El registro de médula en el $26,5 \%$ de los carbones evidencia la utilización de tallos juveniles para alimentar el fogón así como la ausencia del ataque de microorganismos indican el buen estado de la madera para su utilización en la combustión.

Es importante destacar el uso de la ceniza de Atriplex y Suaeda para la elaboración de jabón (Andreoni 2014) pero también para el trabajo sobre cuero (Marchioni y Belleli 2013). Según estas últimas autoras, en la cadena operativa de la fabricación de quillangos, reconstruida a partir de fuentes etnohistóricas y entrevistas actuales a informantes, la técnica para extraer el pelo del cuero estaba basado en el untado de ceniza sobre el mismo, del lado de la carne, enrollado el pelo hacia afuera y reposando durante tres días cerca de la fuente de calor (fogón), luego el pelo se retira con la mano o con un artefacto. Este podría ser la funcionalidad que tuvo este fogón considerando que la cantidad de restos malacológicos es baja en relación al tamaño del fogón. También considerado que Atriplex/Suaeda es un taxa halófito puede haber sido seleccionado para la obtención de sal y la producción de carne salada.

\subsection{Sitio Nido del Águila}

\subsubsection{Introducción}

El sitio Nido del Águila se encuentra ubicado próximo al cauce principal del cañadón que atraviesa las Estancias El Chara, La Estrella y La Aguada, específicamente en terrenos de esta última, a $9 \mathrm{~km}$ de la costa actual (Figura 9.4). 


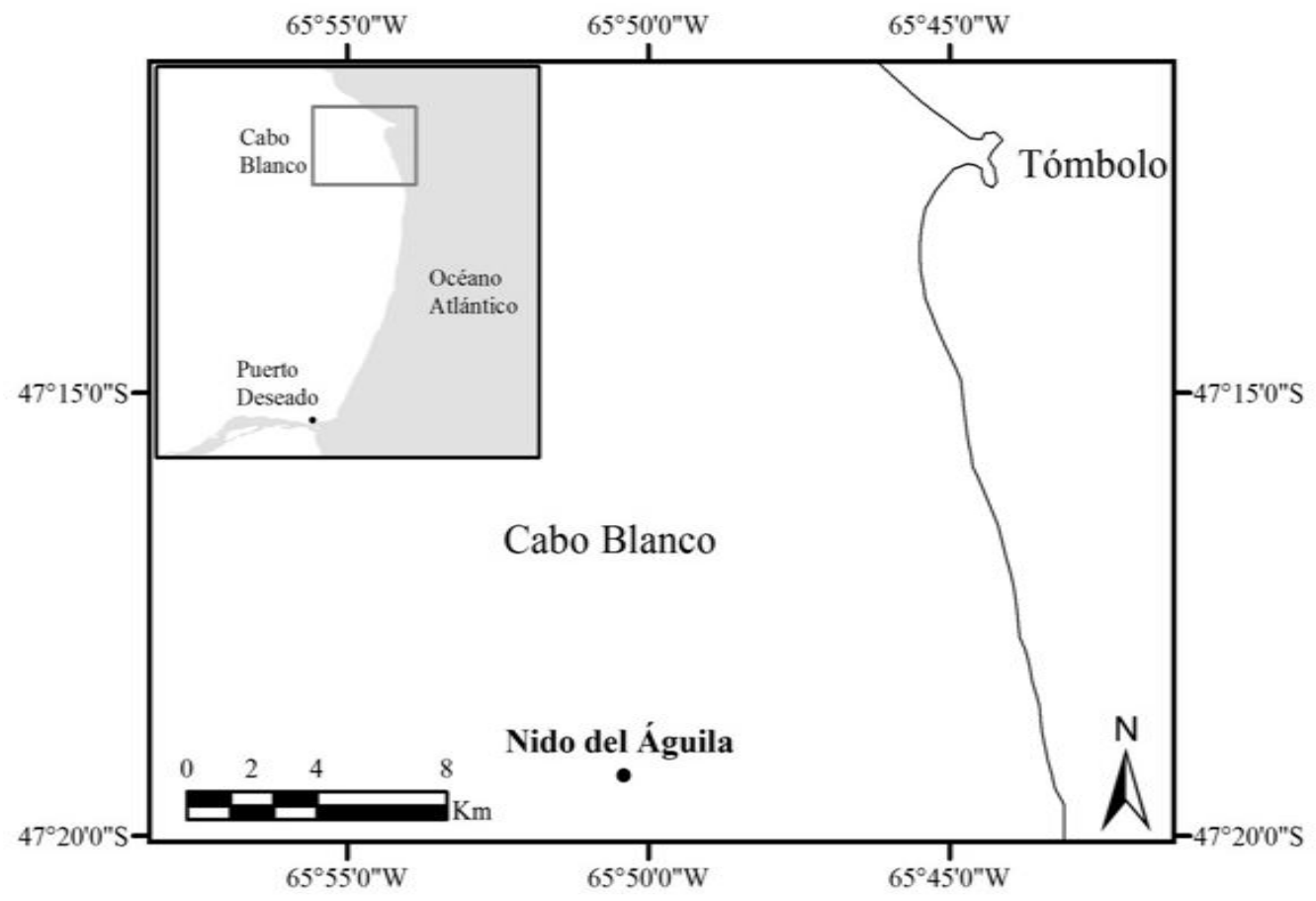

Figura 9.4. Ubicación del sitio Nido del Águila.

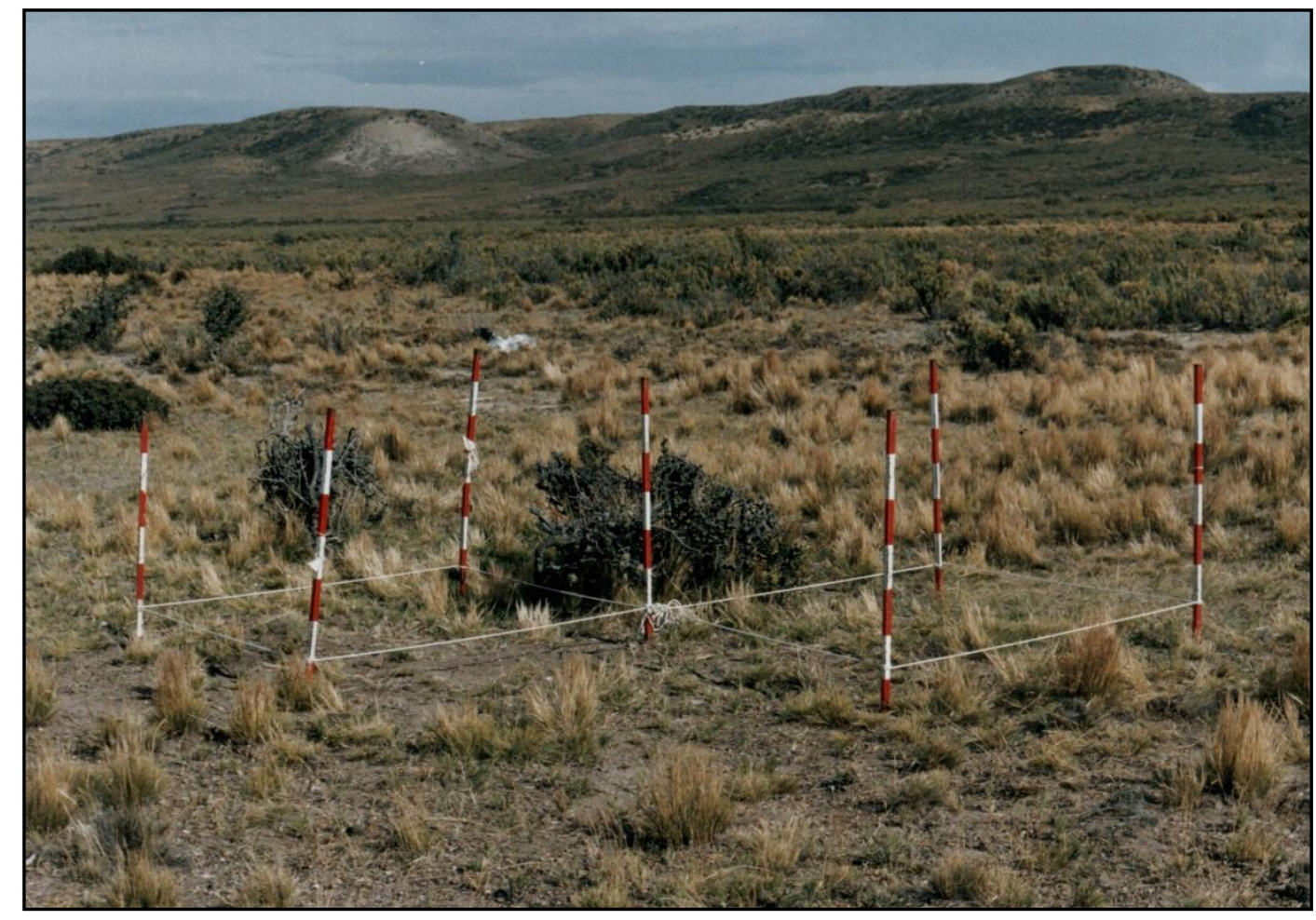

Figura 9.5. Foto del sitio Nido del Águila (Fotografía tomada por Miguel Ángel Zubimendi). 


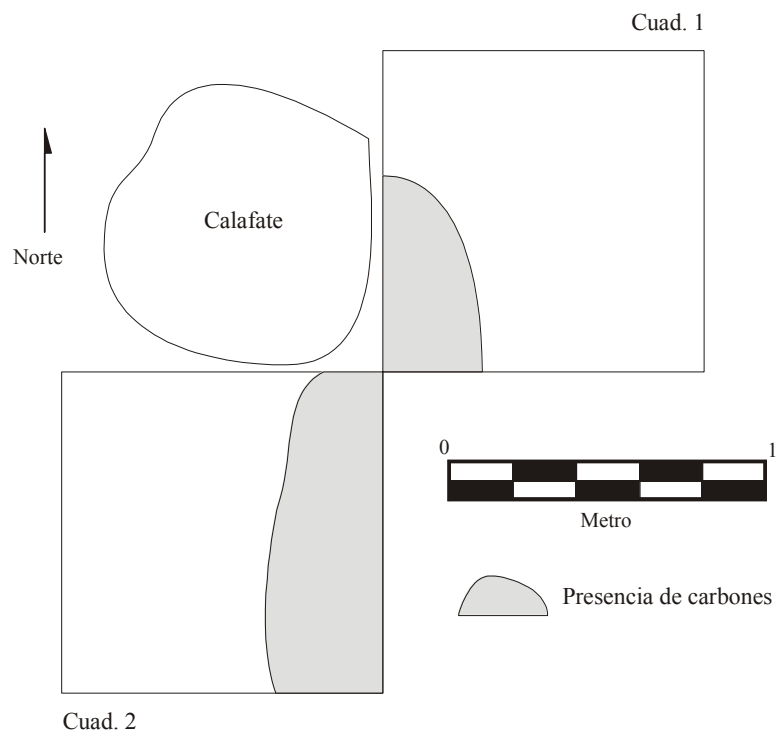

Figura 9.6. Esquema de planta del área excavada del sitio Nidio del Águila (Zubimendi 2006).

Es un sitio a cielo abierto, en el que se registró un nido bajo un arbusto de molle (Schinus sp.) y en superficie la dispersión de huesos producto de la actividad de aves rapaces que lo habitaron. El sitio se encuentra sobre un sedimento terroso rodeado por matas de coirones (Pappostipa sp.) y de calafate (Berberis microphylla). En superficie se observaron materiales arqueológicos varios, próximos al nido y en el sedimento terroso, entre ellos dos puntas de proyectil, un ápice, tiestos cerámicos, una cuenta de vidrio europea y un caracol de gran tamaño de Adelomelon sp. (Zubimendi 2006). La recolección superficial mediante unidades de muestreo, así como la excavación del sitio, se realizó bajo la dirección de Zubimendi (2006). Si bien no se cuenta con un fechado radiocarbónico (ver Conclusión y discusiones de este sitio) la asociación de cuentas de vidrio (Zubimendi 2010), cerámica y puntas de flecha tardías sugieren que este sitio se ubicaría cronológicamente en el Holoceno tardío final (Zubimendi com. pers.).

\subsubsection{Metodología}

\subsubsection{Excavación}

Se realizaron dos cuadrículas de 1 x $1 \mathrm{~m}$ a dos costados de una arbusto de Berberis sp. y se realizó la excavación siguiendo las capas naturales de la estratigrafía en combinación 
con niveles artificiales de $20 \mathrm{~cm}$ (Figura 9.6). Se utilizó una malla de $2 \mathrm{~mm}$ para la recuperación de todos los restos.

\subsubsection{Recuperación de restos antracológicos}

Se extrajo el material antracológico proveniente de un fogón en cubeta que abarcaba las cuadrículas 1 y 2 (ver párrafos siguientes) por medio de recuperación manual in situ y del tamizado del sedimento de excavación a través de una malla de $2 \mathrm{~mm}$. Se registraron también carporrestos (frutos drupáceos) y hojas carbonizadas que fueron recuperados a partir del tamizado del sedimento. Estos fueron los únicos materiales que pudieron analizarse en la presente tesis.

\subsubsection{Contexto estratigráfico}

El sedimento superficial es terroso con rodados de pequeño y mediano tamaño, con gran cantidad de raíces. Se registraron restos líticos y fragmentos óseos hasta los $20 \mathrm{~cm}$ de profundidad donde se identificó una lente de carbones y frutos quemados ubicada entre los 20 y $30 \mathrm{~cm}$ de profundidad. Se definió como un fogón en cubeta con unas dimensiones de $0,50 \times 0,20 \mathrm{~m}$ y una potencia de $10 \mathrm{~cm}$ en la cuadrícula 1 , que se continuaba en la cuadrícula 2 con 0,30 x $1 \mathrm{~m}$ y $10 \mathrm{~cm}$ de potencia (Figura 9.7). Un gran número de los carbones provenientes de este fogón fueron enviados al INGEIS para la datación radiocarbónica, sin embargo, hasta el momento no se obtuvieron los resultados. Los escasos carbones que quedaron son los que se analizan a continuación. Por debajo de esta lente se recuperaron restos óseos enteros de guanaco (vértebras y falanges), aunque no fue posible confirmar su asociación con el fogón. A los $40 \mathrm{~cm}$ de profundidad se identificó un nivel arcilloso duro y se cerró la excavación (Zubimendi 2006). 


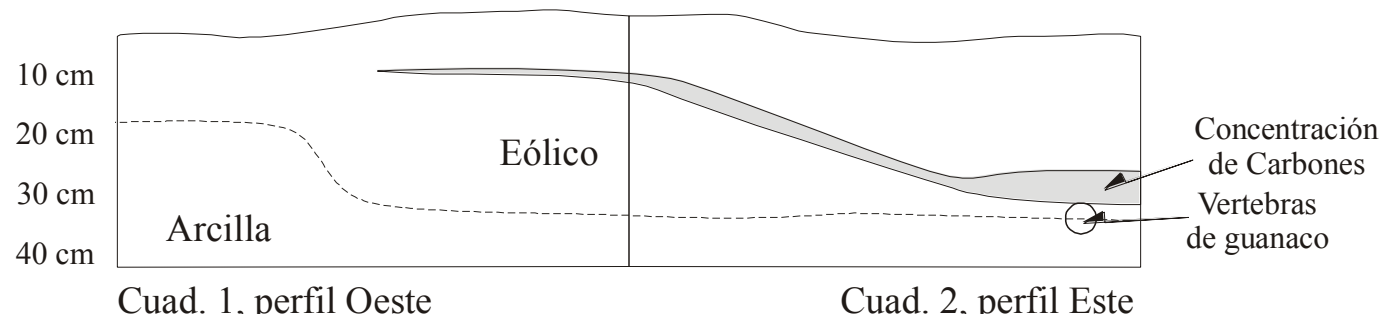

Figura 9.7. Perfil estratigráfico del sitio Nido del Águila

\subsubsection{Resultados}

\subsubsection{Material antracológico}

Se contabilizaron en total 73 carbones provenientes de las cuadrículas 1 y 2 , considerando entonces una densidad de 2,03 n/l, clasificada como baja. Esta densidad calculada se encuentra sesgada debido a la muestra que se envió a datar al INGEIS, por lo que debe ser considerada como un valor mínimo. Las categorías de tamaño tienen un rango de $15-19,9 \mathrm{~mm}$ a 24,49 $\mathrm{mm}$, pero la mayor parte de los carbones se encuentran en 5 a 9,9 mm y 2 a 4,9 mm. La submuestra analizada contó con un total de 42 carbones de la que se identificaron cuatro taxa (Figura 9.8)

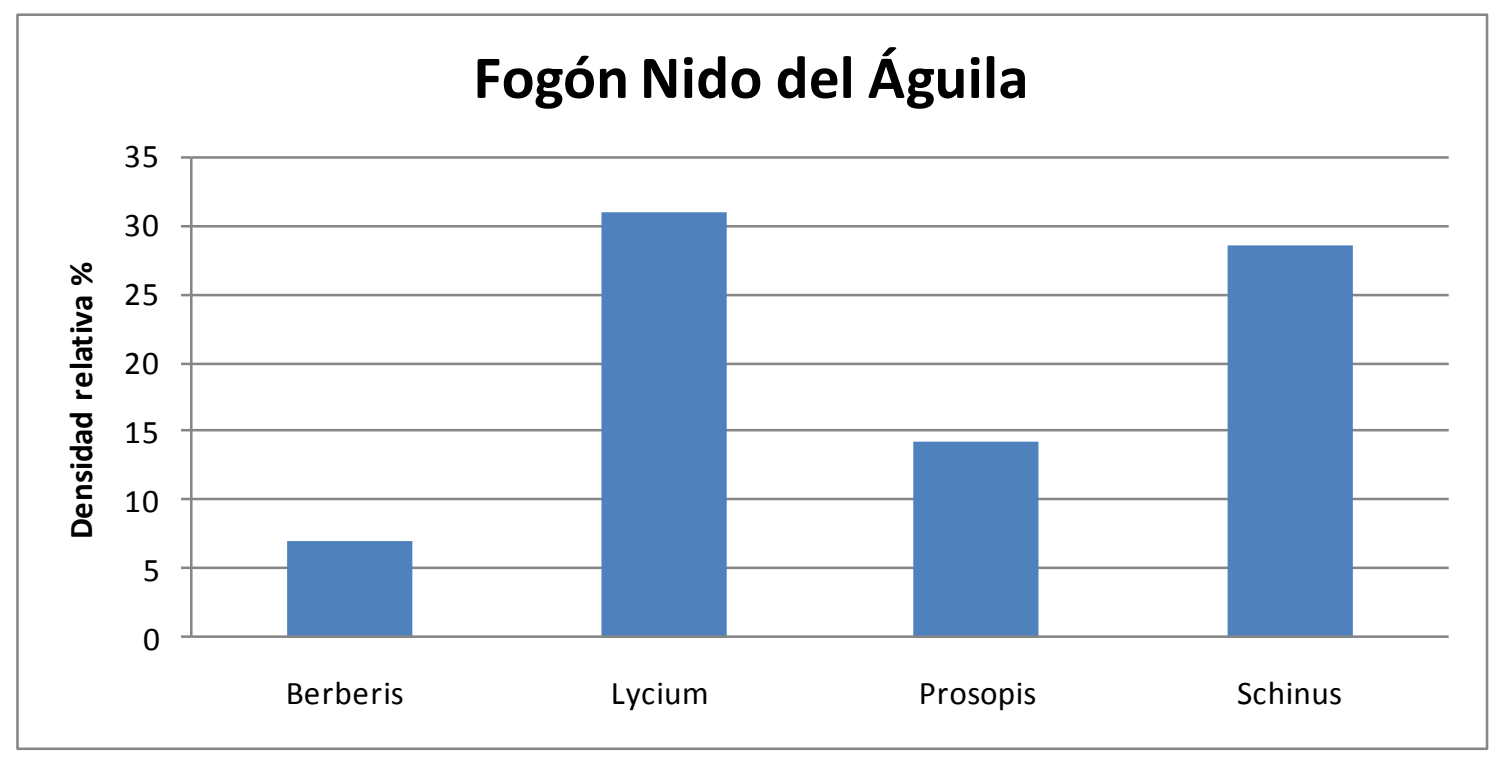

Figura 9.8. Carbones identificados en el fogón Nido del Águila, cuadrícula 1 y 2, submuestra $(\mathrm{n}=42)$ 
De esta submuestra analizada, 8 carbones $(10,95 \%)$ presentaron vitrificación siendo identificados como Schinus $(\mathrm{n}=2)$, Prosopis $(\mathrm{n}=1)$ y Lycium $(\mathrm{n}=4)$. Debido al grado 3 de vitrificación un carbón no pudo ser determinado (Marguerie y Hunot 2007).

Respecto a la presencia de médula se registró en 10 carbones (13,69\%), identificados como Schinus $(\mathrm{n}=4)$, y Lycium $(\mathrm{n}=3)$ y 3 indeterminables. En cuanto a los rasgos de combustión, 10 carbones $(13,69 \%)$ presentan aberturas (en radios y vasos) identificados como Schinus $(\mathrm{n}=7)$, Lycium $(\mathrm{n}=4)$, y Berberis $(\mathrm{n}=1)$.

\subsubsection{Restos carpológicos}

Se registraron 26 restos carpológicos carbonizados entre la cuadrícula 1 y 2 asociados al fogón (Figura 9.9). El peso total de los mismos fue de 0,34 g. Las dimensiones de los mismos se registran en la Tabla 9.1.

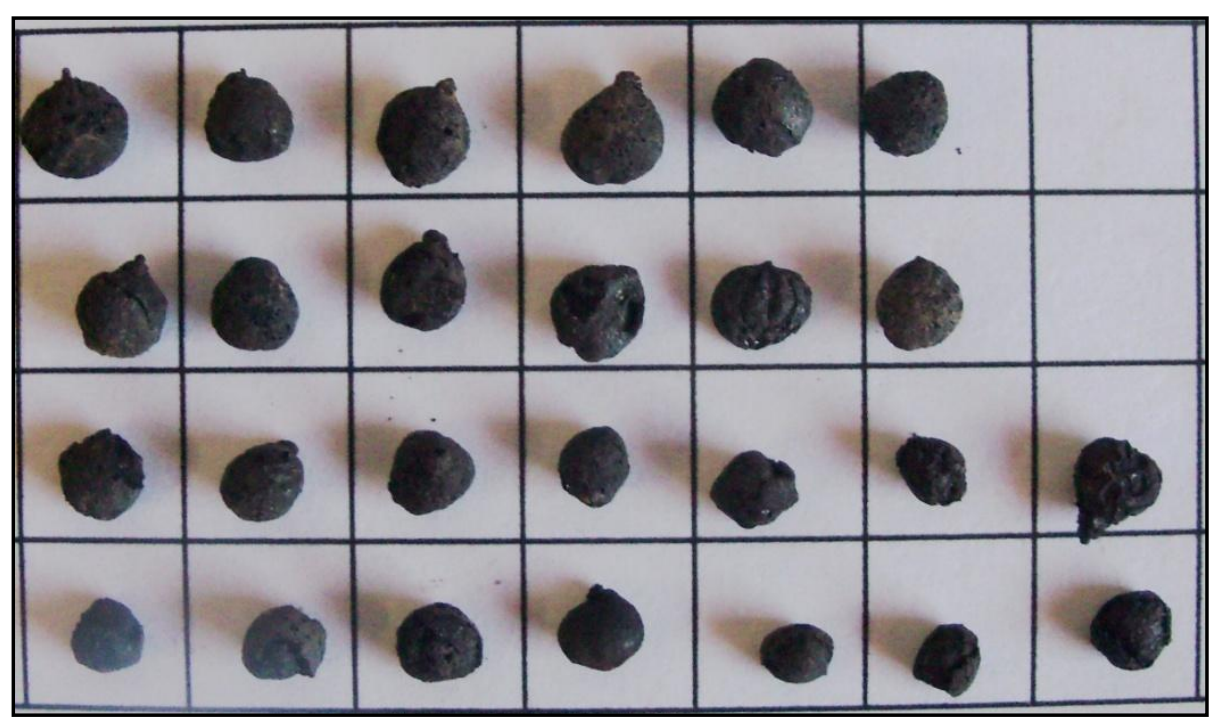

Figura 9.9. Restos carpológicos: frutos drupáceos $(\mathrm{n}=26)$

\begin{tabular}{|l|l|l|l|}
\hline Frutos & Largo $\mathrm{mm}$ & Diámetro $\mathrm{mm}$ & Sector de Excavación \\
\hline 1 & 4,77 & 4,45 & Cuad. 1 Fogón \\
\hline 2 & 3,85 & 3,55 & Cuad. 1 Fogón \\
\hline 3 & 4,59 & 3,8 & Cuad. 1 Fogón \\
\hline 4 & 4,82 & 4,81 & Cuad. 1 Fogón \\
\hline 5 & 4,55 & 4,44 & Cuad. 1 Fogón \\
\hline 6 & 4,16 & 3,18 & Cuad. 1 Fogón \\
\hline
\end{tabular}




\begin{tabular}{|l|l|l|l|}
7 & 4,11 & 3,02 & Cuad. 2 Fogón \\
\hline 8 & 4,09 & 3,58 & Cuad. 2 Fogón \\
\hline 9 & 5,43 & 3,83 & Cuad. 2 Fogón \\
\hline 10 & 4,61 & 4,41 & Cuad. 2 Fogón \\
\hline 11 & 5,75 & 5,04 & Cuad. 2 Fogón \\
\hline 12 & 5,29 & 4,87 & Cuad. 2 Fogón \\
\hline 13 & 5,18 & 4,68 & Cuad. 2 Fogón \\
\hline 14 & 5,15 & 4,67 & Cuad. 2 Fogón \\
\hline 15 & 5,1 & 5,19 & Cuad. 2 Fogón \\
\hline 16 & 5,56 & 5,91 & Cuad. 2 Fogón \\
\hline 17 & 5,85 & 4,92 & Cuad. 2 Fogón \\
\hline 18 & 5,14 & 5,39 & Cuad. 2 Fogón \\
\hline 19 & 5,78 & 5,08 & Cuad. 2 Fogón \\
\hline 20 & 6 & 5,86 & Cuad. 2 Fogón \\
\hline 21 & 6,05 & 5,29 & Cuad. 2 Fogón \\
\hline 22 & 6,37 & 5,35 & Cuad. 2 Fogón \\
\hline 23 & 6,7 & 5,46 & Cuad. 2 Fogón \\
\hline 24 & 5,44 & 5,62 & Cuad. 2 Fogón \\
\hline 25 & 6,81 & 5,83 & Cuad. 2 Fogón \\
\hline 26 & 6,42 & 5,84 & Cuad. 2 Fogón \\
\hline
\end{tabular}

Tabla 9.1. Restos carpológicos arqueológicos (frutos) con sus medidas

Además de los restos carpológicos se observaron 6 hojas de borde entero también carbonizadas, algunas de ellas fragmentadas, también se tomaron sus medidas (Figura 9.10 y Tabla 9.2.). El peso de las hojas no pudo ser relevado debido a que era demasiado bajo, si bien se pesaron en una balanza de precisión digital de 0,01 g.

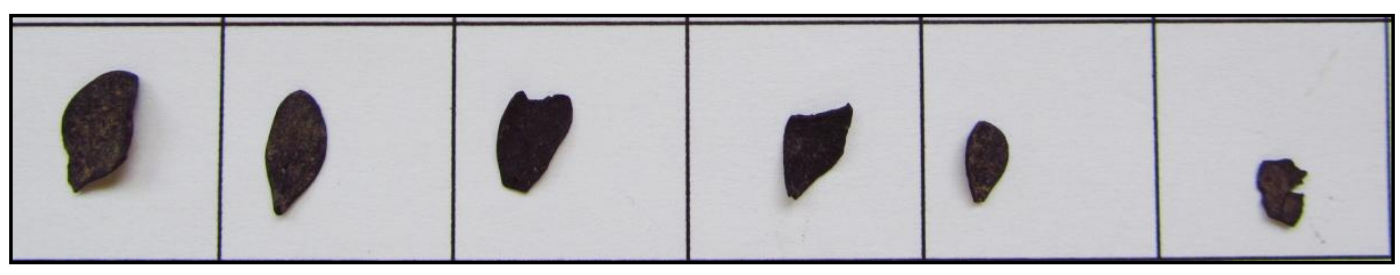

Figura 9.10. Hojas carbonizadas halladas en el fogón

\begin{tabular}{|l|l|l|l|}
\hline Hojas & Largo $\mathrm{mm}$ & Ancho $\mathrm{mm}$ & Observaciones \\
\hline 1 & 11,01 & 7,55 & Entera \\
\hline 2 & 10,59 & 5,15 & Entera \\
\hline
\end{tabular}




\begin{tabular}{|l|l|l|l|}
\hline 3 & 8,74 & 5,28 & Fragmentada \\
\hline 4 & 9,16 & 5,43 & Fragmentada \\
\hline 5 & 6,72 & 3,92 & Entera \\
\hline 6 & 5,34 & 4,22 & Fragmentada \\
\hline
\end{tabular}

Tabla 9.2. Restos arqueológicos de hojas carbonizadas

Para la identificación taxonómica se compararon los restos encontrados con hojas y frutos de Schinus sp. por ser éstos los que morfológicamente presentaban mayores similitudes con los arqueológicos. Dentro de estos últimos las hojas se caracterizan por ser hojas simples, oblongo lanceoladas, glabras. En cuanto a los frutos son drupas globosas con el ápice deprimido con una sola semilla. Se compararon los tamaños (largo y ancho, diámetro) del material arqueológico y de referencia carbonizado (Tabla 7.6, capítulo 7). Considerando la reducción producto de la carbonización se observa que tanto las características morfológicas cualitativas como las dimensiones coinciden entre el material arqueológico y el material de referencia utilizado.

Como se mencionó en el sitio anterior, los datos obtenidos de un solo fogón no permiten realizar un análisis de correlación entre el número total de fragmentos de carbón y el peso total. En este sentido, entonces no es posible a través de las herramientas estadísticas interpretar procesos postdepositacionales.

\subsubsection{Discusión y conclusiones}

En primer lugar es importante mencionar el sesgo que presenta la muestra analizada tanto de carbones como de restos carpológicos. Esto se debe a que una muestra grande de estos restos fue enviada para realizar una datación radiocarbónica al INGEIS, aunque la misma no se efectuó, sin que se pudiera recuperar la muestra antracológica y carpológica (Zubimendi com. pers.). Como se mencionó más arriba la cuenta de vidrio, los fragmentos de cerámica y las puntas de flechas tardías asignan una cronología relativa de Holoceno tardío final.

Es significativa la recuperación de restos carpológicos y antracológicos en este sitio, ya que es el único hasta el momento en el área de estudio en el que se recuperaron frutos carbonizados. 
Como se mencionó anteriormente la cronología tentativa del sitio permite considerar que la vegetación sería análoga a la actual, considerando los resultados palinológicos desarrollados para la estepa de arbustos enanos (De Porras 2010). Las especies identificadas taxonómicamente se encuentran en los alrededores del sitio $y$, específicamente en la geoforma en la que se encuentra el sitio (cañadón), se registran en mayor concentración y altura.

La densidad de la madera de la mayoría de los taxa identificados en el fogón es alta (i.e. Prosospis, Berberis, Schinus) y se registra el uso de Lycium, que es una madera intermedia. A su vez, es importante mencionar que Schinus, el taxa que prevalece en el fogón es además resinosa característica que podría ser beneficiosa para el encendido y mantenimiento del fuego. En relación a las modificaciones de las maderas por la carbonización se observaron aberturas en radios y vasos en dos géneros Lycium y Schinus. Estos géneros, como se mencionó en el sitio anterior y se registró en el capítulo 7 presenta más aberturas en radios, vasos y/o anillos a temperaturas más altas $\left(700{ }^{\circ} \mathrm{C}\right.$ siendo caracteres diagnósticos de temperatura). El 55,5\% de los carbones identificados como Schinus presentaron abundantes aberturas en radios y vasos. En cuanto a la vitrificación, también se presentó en estos dos géneros. Si bien no se observaron las aberturas en anillo, el carácter diagnóstico de temperaturas próximas a $700{ }^{\circ} \mathrm{C}$, se considera que el fogón podría haber alcanzado temperaturas mayores a los $400{ }^{\circ} \mathrm{C}$ por la abundancia de aberturas en vasos y radios. Según los informantes entrevistados en esta tesis (capítulo 5), el molle (Schinus) es la leña que mayor consenso de uso tiene y entre sus propiedades se mencionan: que produce buena brasa, dura mucho y es la que más calor brinda. Con menor consenso en cuanto a la preferencia, los informantes se refirieron a Prosopis y Berberis, aunque se refieren a ellas como buenas leñas en cuanto a su capacidad de dar brasa y duración. En el caso de Lycium ya expuesto en el sitio anterior, se dice que produce poca brasa pero que se enciende rápidamente.

Entonces, en este fogón se observa la combinación de una leña de fácil encendido (i.e. Lycium) con otras de mayor densidad, duración, y poder calórico. Este contexto estaría evidenciando un fogón de mayor intensidad que el del sitio anterior. En este caso, la asociación de maderas con altas densidades identificadas evidenciaría en un fogón en cubeta con un evento de mayor duración (Pérez de Micou 1991). 
Por otra parte, en cuanto a los restos carpológicos carbonizados de Schinus, se puede decir que el período de ocupación estacional del sitio incluyó al menos verano-otoño, puesto que los frutos maduran entre febrero y mayo (Ferro et al. 2004). Es posible que las hojas y frutos de Schinus hayan podido ingresar al fogón en conjunto con la leña, considerando además que este taxón presenta la mayor densidad porcentual en el fogón. Archila (2005) menciona, en su modelo para caracterizar los carbones arqueológicos de la Amazonía colombiana, el aporte de hojas secas, semillas de árboles y palmas, cortezas de árboles así como restos de artefactos o instrumentos musicales al fogón. Sin embargo, llama la atención el hecho de que el extremo de las ramas con sus frutos no es la parte que mejor propiedades combustibles posee, ya que implica poco leño y material aún verde cuando los frutos no se han desprendieron del pedicelo (ver discusión en Capparelli y Prates 2014). Incluso, es sugerente que, como se verá más adelante en muchos otros fogones donde se identificó madera de Schinus (i.e. sitio 160, 112, El Oriental, entre otros) no se recuperaron hojas y frutos de éste. Por este motivo, y dadas las propiedades medicinales y/o comestibles de esta planta (ver por ejemplo Ciampagna y Capparelli 2012), no se puede descartar el ingreso de frutos y hojas al fogón producto de alguna otra aplicación de los mismos.

Finalmente, la asociación del fogón a restos líticos y óseos indicaría que se trataría de un fogón doméstico, de larga duración y producción de calor. También, la presencia de fragmentos de cerámica y una cuenta de vidrio podrían ser indicadores de un sitio de actividades múltiples.

\subsubsection{Análisis comparativo entre los taxa identificados en los sitios Cormorán Quemado y Nido del Águila}

El análisis de ubicuidad porcentual entre los dos fogones permite identificar la presencia de Lycium en ambos fogones con una ubicuidad del 100\% (Figura 9.11). Los taxa que acompañan a este género presentan todos $50 \%$ de ubicuidad. Es importante remarcar, que esta madera es blanda y no tienen tanta duración (en relación a capacidad de producir brasa) que otras maderas que han tenido menor ubicuidad. Esto puede deberse la funcionalidad de los fogones que en la sección de arriba han sido discutidos. 


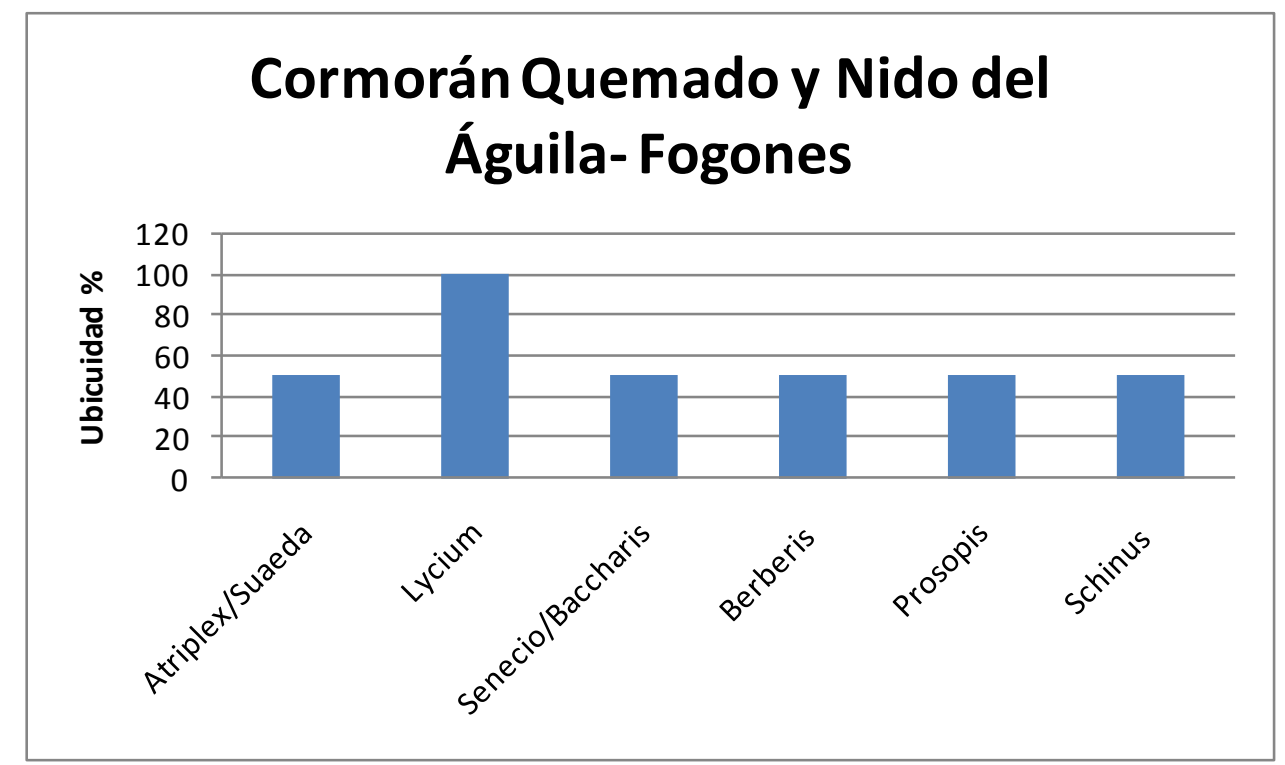

Figura 9.11. Ubicuidad porcentual de los taxa identificados en los dos fogones analizados del sector Cabo Blanco.

\subsection{La Estrella}

\subsubsection{Introducción}

El sitio La Estrella se encuentra en un pequeño cañadón tributario del cañadón principal que atraviesa las estancias El Chara, La Estrella y La Aguada, a 2,5 km al norte del casco de la Estancia La Estrella (Fig 9.12). Está localizado en una zona de transición entre la meseta alta y el cañadón La Estrella, a $17 \mathrm{Km}$ de distancia a la costa. Es un sitio a cielo abierto rodeado por matas de "coirones" (Pappostipa sp.) y "leño de piedra" (Azorella monantha) sobre un sedimento eólico.

El estudio de este sitio, al igual que los anteriores fue llevado a cabo por Zubimendi (2006), quien realizó cuatro cuadrículas de 1 x $1 \mathrm{~m},\left(4 \mathrm{~m}^{2}\right)$. Se recuperaron artefactos líticos, restos óseos fragmentados, con marcas de corte y alteración térmica, y carbones dispersos. A partir de estos últimos se obtuvo un fechado de $690 \pm 70$ años AP (Zubimendi 2010). 


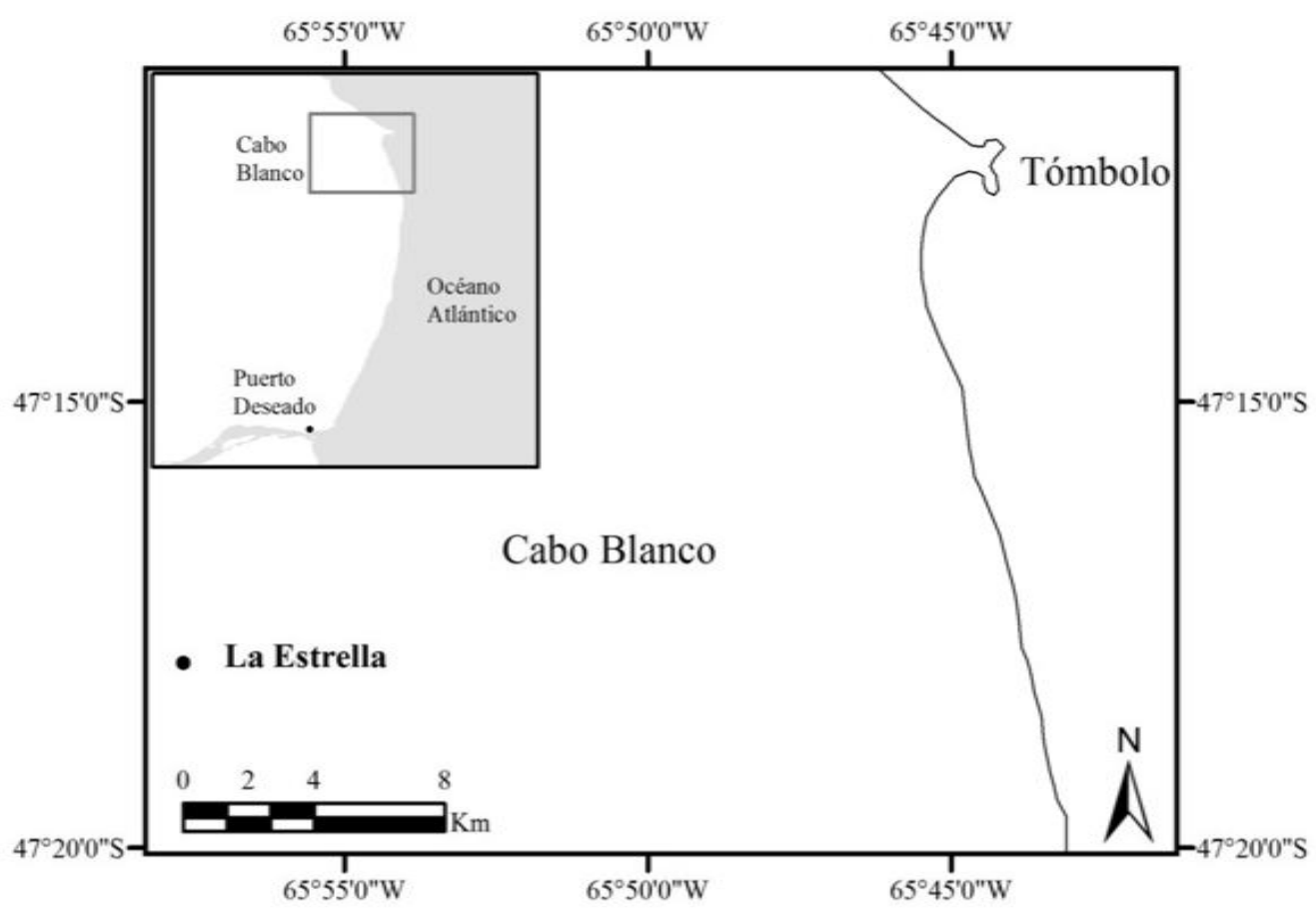

Figura 9.12. Ubicación sitio La Estrella

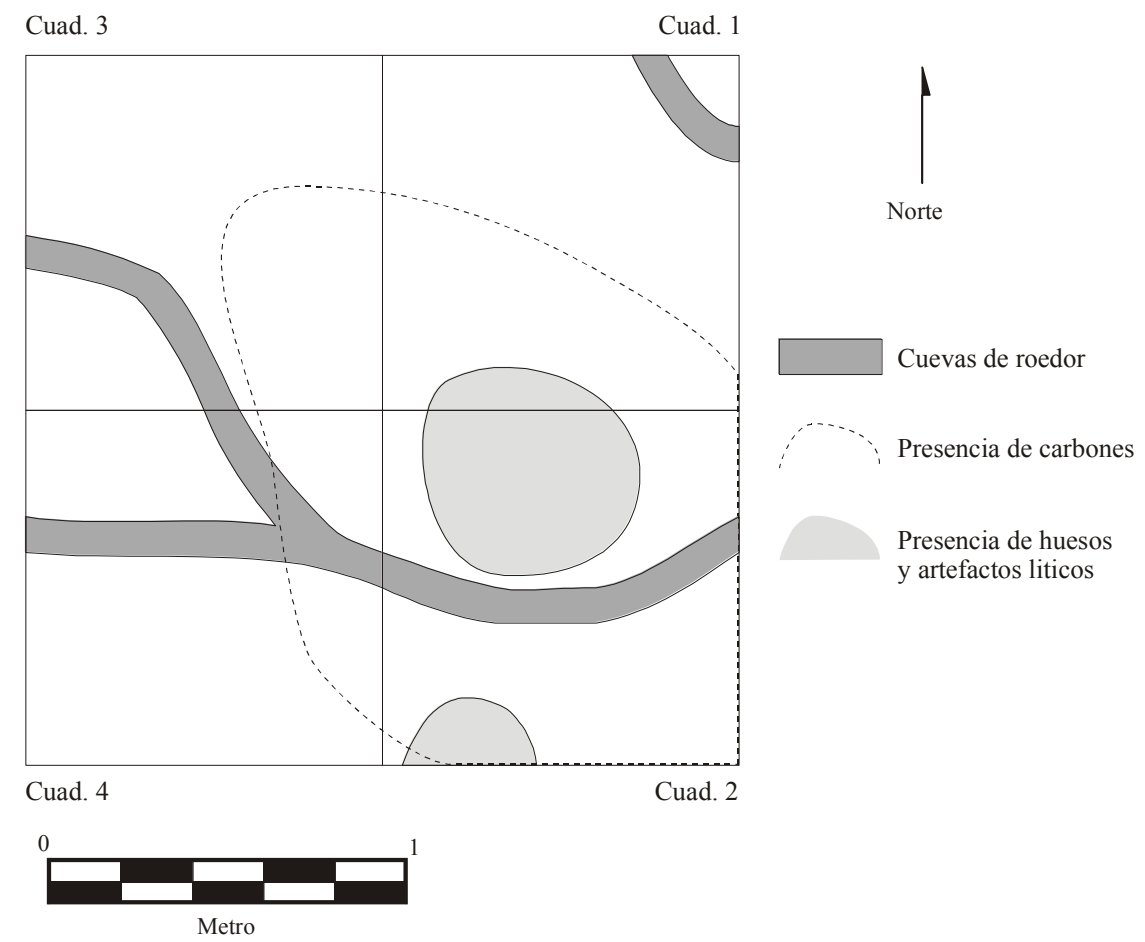

Figura 9.13. Distribución espacial y área excavada del sitio La Estrella ( Zubimendi 2006) 


\subsubsection{Metodología}

\subsubsection{Excavación}

Se recuperaron los materiales arqueológicos en superficie y se realizaron cuatro cuadrículas de 1 x $1 \mathrm{~m}$ (Figura 9.13). Se excavó siguiendo niveles artificiales de $20 \mathrm{~cm}$ y se realizó el tamizado de todo el sedimento con una malla fina de $2 \mathrm{~mm}$. A los $35 \mathrm{~cm}$ de profundidad se cerraron las cuadrículas a excepción de una subcuadrícula de 50 x 50 $\mathrm{cm}$ en la que se excavó hasta $115 \mathrm{~cm}$ para corroborar la existencia de otro nivel arqueológico fértil, sin resultados positivos.

\subsubsection{Recuperación de restos antracológicos}

En el sitio La Estrella ante la ausencia de una estructura de fogón definida, se recuperaron carbones dispersos provenientes del nivel entre $10-20 \mathrm{~cm}$ de profundidad para las cuatro cuadrículas excavadas.

\subsubsection{Resultados antracológicos}

En la cuadrícula 1 en el nivel fértil arqueológico $(10-20 \mathrm{~cm})$ se recuperó un total de 9 carbones para un volumen de sedimento de 90 l. La densidad calculada es de $0,10 \mathrm{n} / 1$ lo que evidencia una densidad baja en esta cuadrícula. Las categorías de tamaño registradas se ubican en el rango de 15-19,9 $\mathrm{mm}$ a 5-9,9 $\mathrm{mm}$, observándose una mayor cantidad de especímenes en las categorías mayores. Se analizó la totalidad de la muestra y se evidenció la predominancia de Berberis en los taxa identificados (Figura 9.14). 


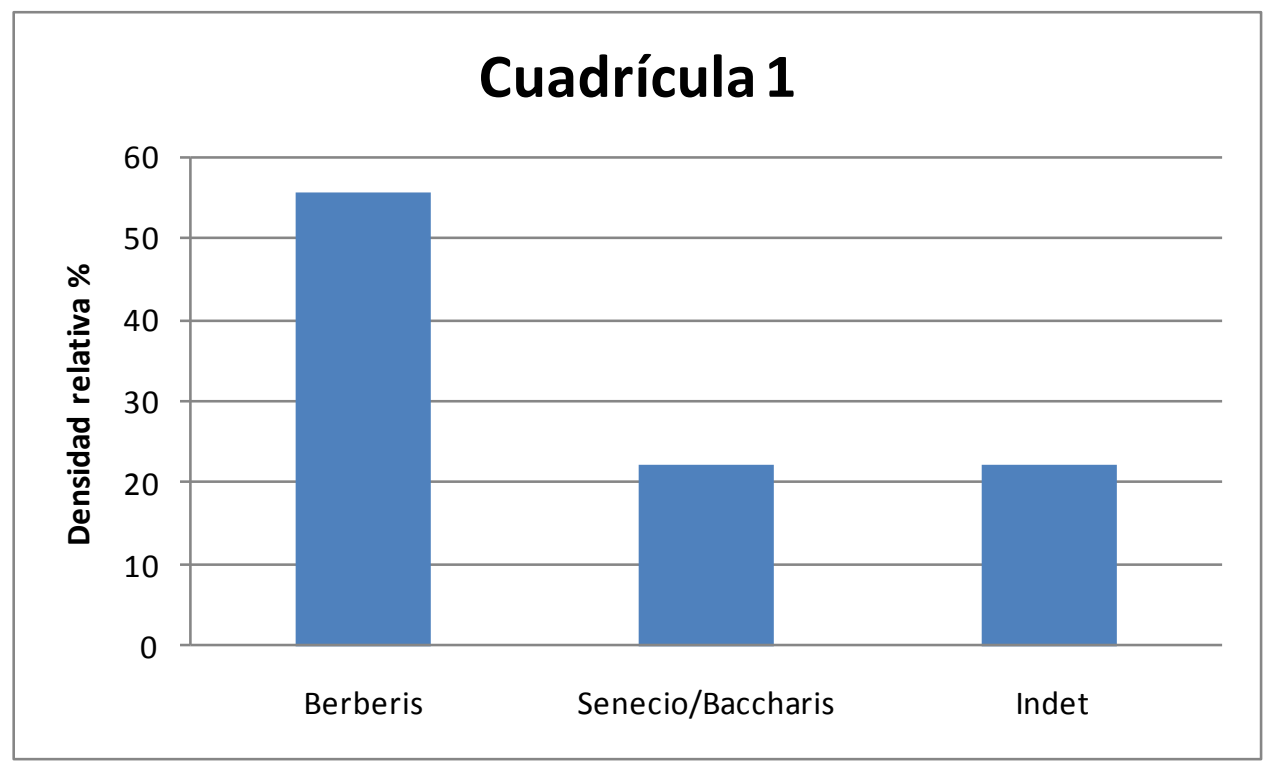

Figura 9.14. Carbones dispersos identificados en la cuadrícula 1, nivel entre 10-20 cm del sitio La Estrella ( submuestra $\mathrm{n}=9$ ).

Se registró vitrificación en el $44,4 \%$ de los carbones identificados como Senecio/Baccharis $(\mathrm{n}=3)$, y uno indeterminable. La presencia de hifas se observó en Senecio/Baccharis $(\mathrm{n}=1)$.

En relación a las aberturas se observaron en vasos, radios y anillos en Senecio/Baccharis $(\mathrm{n}=3)$ y en vasos en un carbón indeterminable $(\mathrm{n}=1)$.

En la cuadrícula 2 se recuperó un total de 75 carbones en un volumen de 901 . Se obtiene entonces, una densidad de $0,83 \mathrm{n} / 1$, que sigue siendo baja para esta cuadrícula. Las categorías de tamaño representadas abarcan los rangos de 20-24,9 $\mathrm{mm}$ a 2-4,9 mm, encontrándose la mayor parte de los carbones en la categoría 5-9,9 $\mathrm{mm}$. Se analizó una submuestra de 28 carbones entre los que predominó Senecio/Baccharis entre los taxa identificados (Figura 9.15). 


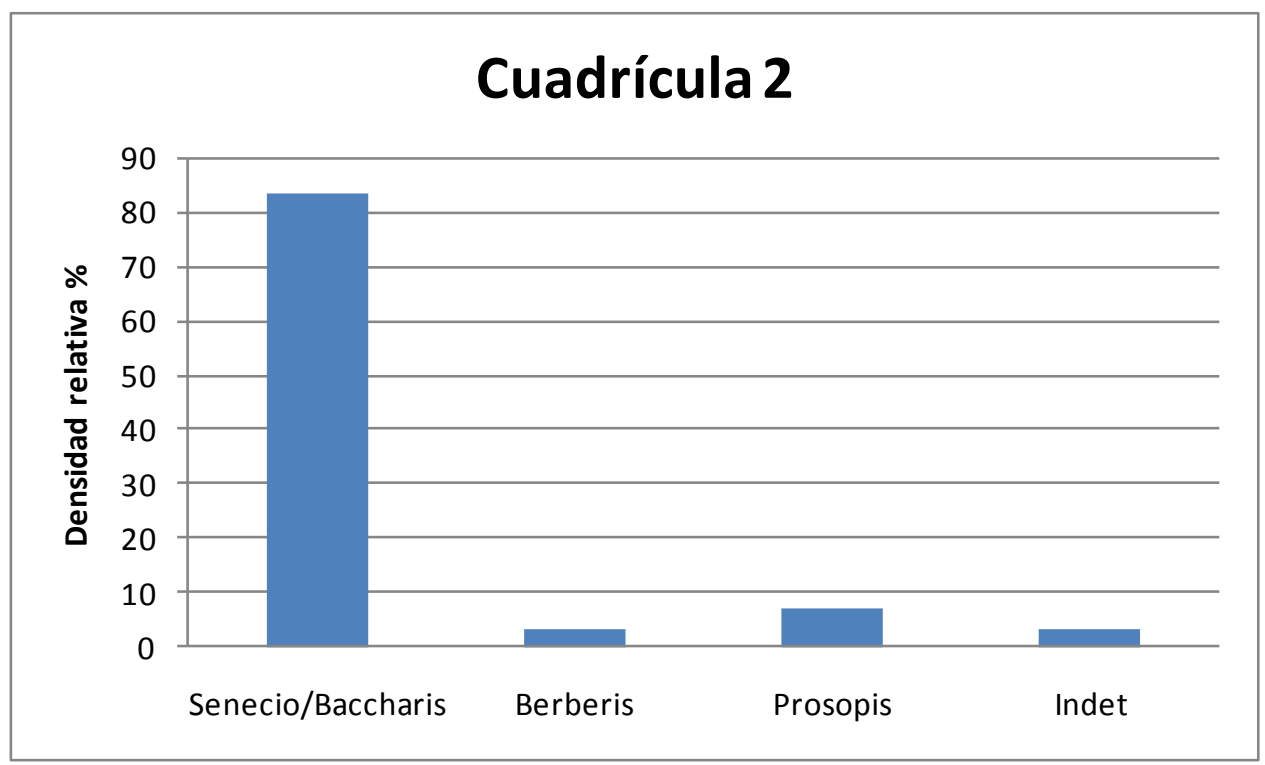

Figura 9.15. Carbones dispersos identificados en la cuadrícula 2, nivel 10-20 $\mathrm{cm}($ submuestra $\mathrm{n}=28)$.

Se registró vitrificación en Senecio/Baccharis $(\mathrm{n}=9)$, y Prosopis $(\mathrm{n}=2)$, es decir para un 39,28\%. Se observó presencia de hifas en Prosopis $(\mathrm{n}=1)$, Senecio/Baccharis $(\mathrm{n}=$ 1) y un indeterminable.

Se identificó médula en Senecio/Baccharis $(\mathrm{n}=3)$ y Prosopis $(\mathrm{n}=1)$, por lo tanto, en un $14,28 \%$ de la submuestra.

Las aberturas se observaron en vasos, radios y anillos de Senecio/Baccharis $(\mathrm{n}=11)$ y en un carbón indeterminable.

En la cuadrícula 3 se recuperó un total de 4 carbones para el volumen de 90 1, por lo que la densidad calculada es de $0,04 \mathrm{n} / 1$ y baja. Las categorías de tamaño representadas son de 10-14,9 mm a 2-4,9 mm, hallándose la mayor cantidad en la categoría 5-9,9 $\mathrm{mm}$. Se analizó la totalidad de carbones y se identificó un único taxa Senecio/ Baccharis (Figura 9.16). 


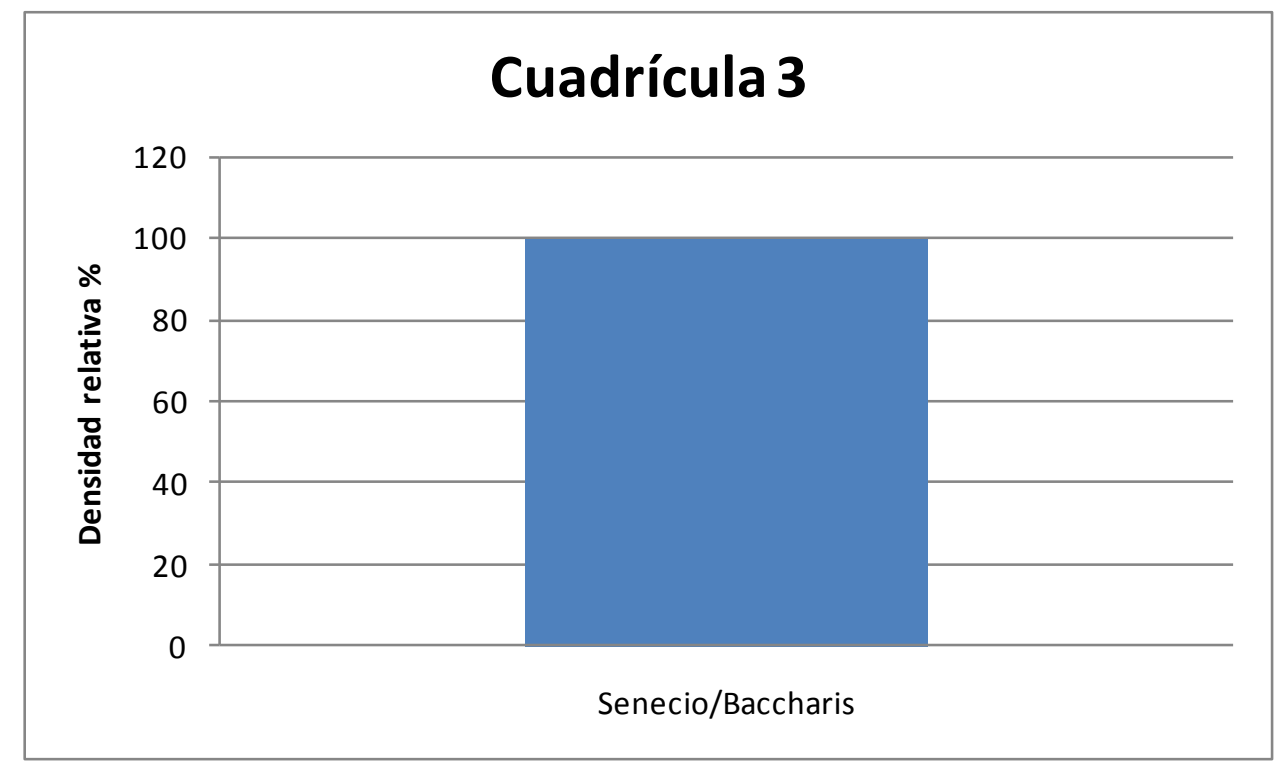

Figura 9.16. Carbones dispersos de la cuadrícula 3, nivel 10-20 cm $(\mathrm{n}=4)$.

Sólo se registraron ojos en vasos en un carbón de Senecio/Baccharis.

En la cuadrícula 4 se registró un total de 17 carbones en un volumen de 90 1, por lo que la densidad calculada es de 0,19 n/l, también baja. Las categorías de tamaño observadas abarcan el rango de 10-14,9 $\mathrm{mm}$ a 2-4,9 $\mathrm{mm}$, siendo 5-9,9 $\mathrm{mm}$ la categoría con más carbones.

La submuestra analizada es de 14 carbones entre los que se identificaron tres taxa y el predominio de Senecio/Baccharis (Figura 9.17).

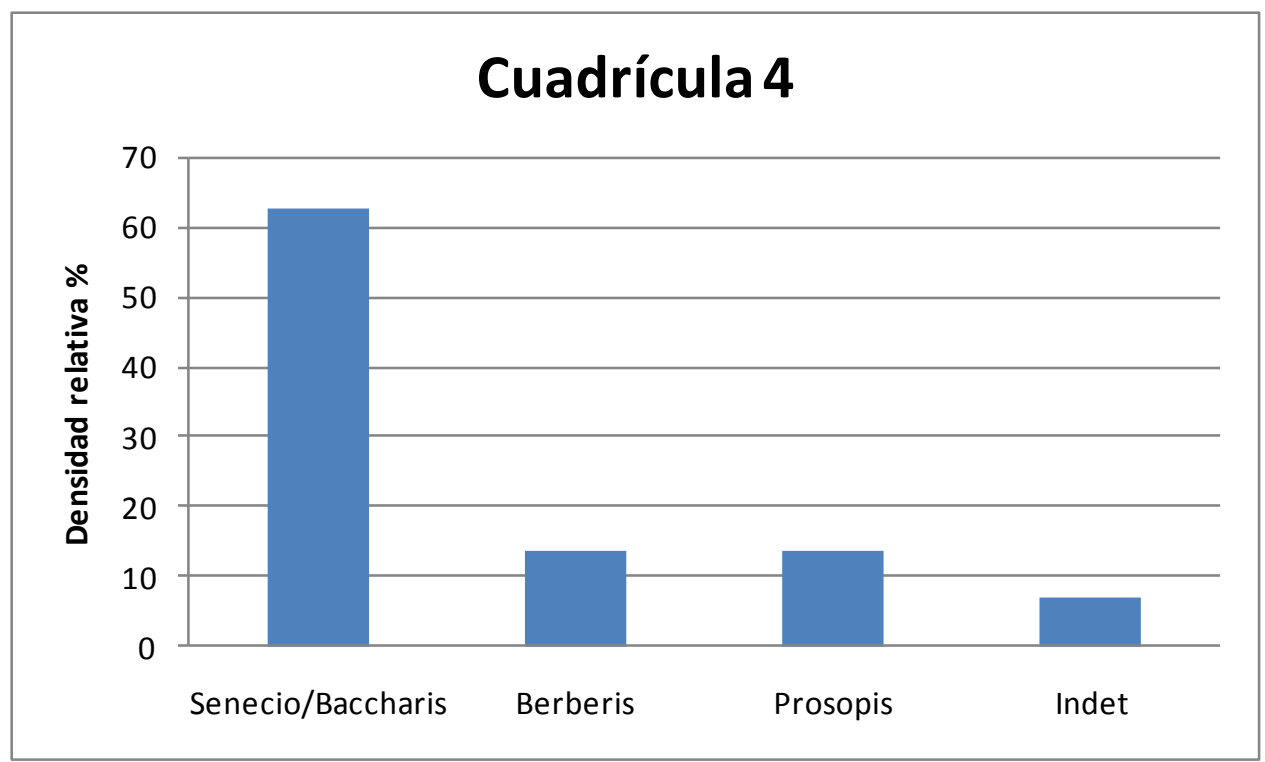

Figura 9.17. Carbones dispersos de la cuadrícula 4, nivel 10-20 cm, (submuestra $\mathrm{n}=14$ ) 
La vitrificación se encontró en el $28,5 \%$ de los carbones, específicamente en Senecio/Baccharis $(\mathrm{n}=2)$, Prosopis $(\mathrm{n}=1)$ y un indeterminable. Las hifas se observaron en Senecio/Baccharis $(\mathrm{n}=1)$ mientras que las contracciones por combustión se registraron en Senecio/Baccharis $(n=2)$ es decir en el $14,28 \%$.

A través del análisis de ubicuidad se registró presencia/ausencia de taxa en cuanto a su distribución espacial y áreas de actividad. Se observó la presencia de Senecio/Baccharis en las cuatro cuadrículas (100\%) del sitio La Estrella. En segundo lugar, Berberis alcanzó el 75 \% de ubicuidad seguido por Prosopis (Figura 9.18).

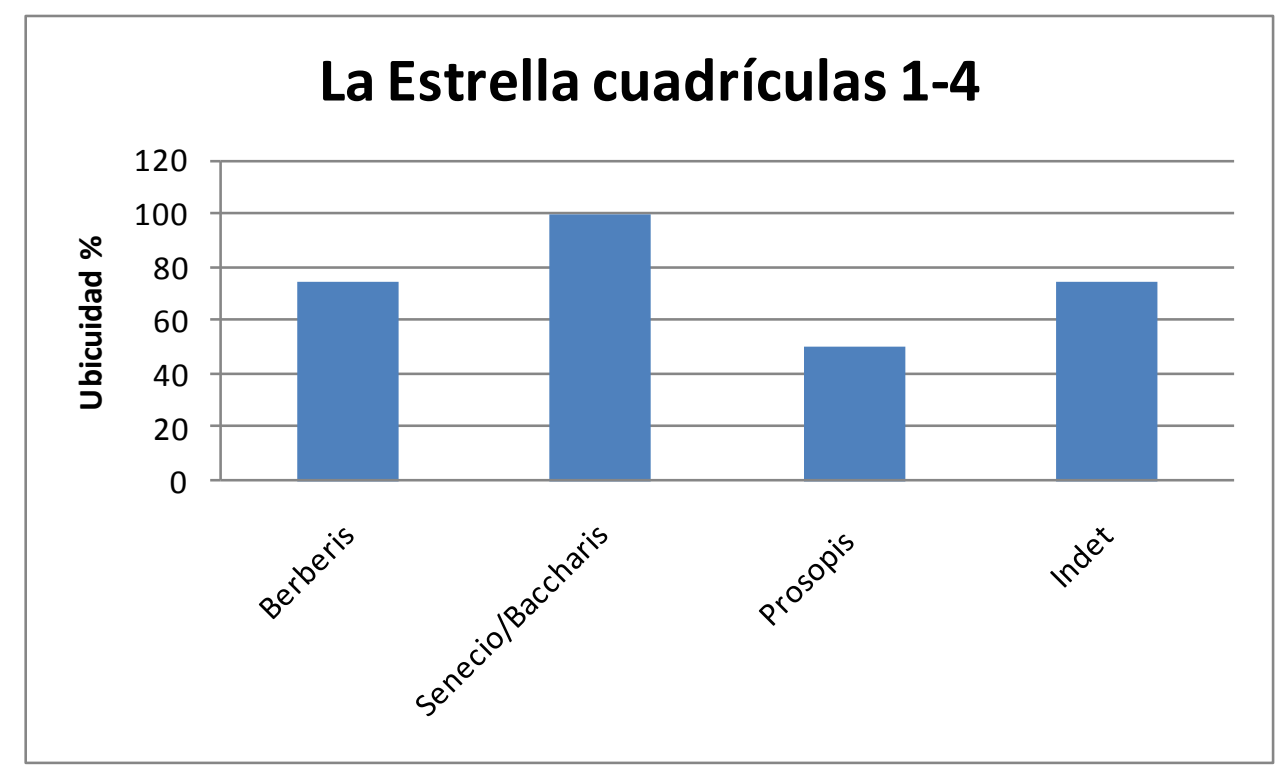

Figura 9.18. Ubicuidad \% de los taxa identificados en las cuadrículas 1 a 4 del sitio La Estrella

El análisis de correlación entre el número de fragmentos de carbones dispersos recuperados por nivel arqueológico y el peso de los mismos (Figura 9.19) tuvo como resultado un $\mathrm{R}^{2}=0,99$ con un nivel de significancia de $\mathrm{p}<0.01$ para 4 cuadrículas. Este resultado permite concluir que ninguno de los niveles atravesó procesos postdepositacionales distintos del resto. 


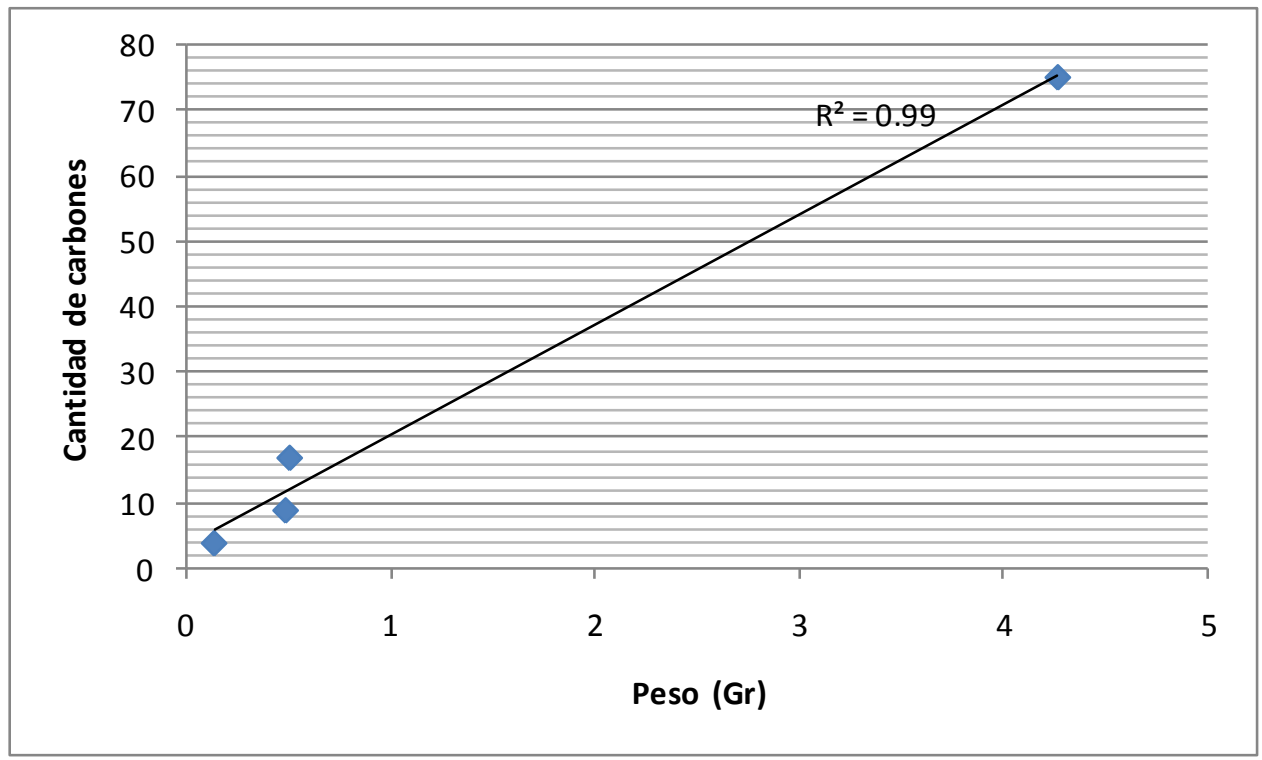

Figura 9.19. Correlación entre cantidad y peso de carbón de madera recuperado por cuadrícula Sitio La Estrella.

\subsubsection{Discusión y conclusiones}

En relación a la cronología del sitio, perteneciente al Holoceno tardío final, es posible considerar que la vegetación para este período sería análoga a la actual (De Porras 2010). En este sentido los taxones identificados se encuentran en las proximidades del sitio, teniendo en cuenta, además, que este último se ubica en un cañadón. Estas especies (i.e. Berberis, Prosopis), si bien se encuentran a lo largo de todo el área de estudio, es en lo cañadones donde tienen mayor concentración y altura.

La densidad calculada, es decir los individuos por litros de sedimento, evidencia una baja presencia de carbones vegetales en las cuatro cuadrículas del sitio para el nivel arqueológico fértil, aunque la cuadrícula 2 fue la que presentó la densidad más alta. También se observó que las cuadrículas 2, 3 y 4, presentan un predominio de Senecio/Baccharis y presencia de Prosopis, mientras que la 1 se diferencia por tener un predominio de Berberis y ausencia de Prosopis. Asimismo, la cuadrícula 3 es monoespecífica habiéndose identificado solo Senecio/Baccharis, mientras que las cuadrículas 2 y 4 poseen una riqueza específica de los mismos 3 taxa en una y otra. En términos de ubicuidad fue Senecio/Baccharis los que presentaron el 100\% de ubicuidad, mientras que Berberis obtuvo el 75\% y Prosopis el 50\% (Figura 9.18). Los artefactos líticos recuperados en el sitio presentaron alteración térmica, sin embargo no se 
observaron estructuras de combustión. La limpieza del sitio o los procesos tafonómicos así como las actividades de roedores, pueden haber producido la dispersión de los carbones que antes habrían estado presentes en dichas estructuras. Si observa el esquema de planta 9.13 se puede decir que la concentración de carbones se distribuye en una superficie continua que abarca la totalidad de la cuadrícula 2 y una escasa porción de las cuadrículas 1, 3 y 4 . Esto es coincidente con los valores de densidad y de riqueza específica de taxa de los carbones recuperados. En este sentido, se observa que la cuadrícula 2 (porción sudeste de la planta) presenta los valores más altos de estas variables, los cuales disminuyen hacia las cuadrículas 1 y 3 (nornoroeste). Estos resultados permiten inferir que el viento, que en toda CNSC corre predominantemente oeste-este no habría sido un factor tafonómico preponderante. Los carbones de mayor densidad de madera se encuentran en un arco que comprende las porciones noreste, sudeste y sudoeste del conjunto excavado y disminuyen hacia el noroeste. Esto es coincidente con todo lo demás.

Los taxa identificados presentan una combinación de maderas de rápido encendido (i.e. Senecio/Baccharis) que son predominantes en algunas cuadrículas (i.e. 2, 3 y 4) con maderas de mayor duración y producción de brasa (i.e. Berberis, Prosopis). Lamentablemente, los taxones identificados no son diagnósticos de altas temperaturas a través del registro de ojos y aperturas de la madera, por lo que no es posible estimar la temperatura alcanzada en las combustiones que produjeron estos carbones dispersos.

Si bien en el sitio La Estrella no es posible estimar si los carbones refieren a uno o más eventos, podría inferirse que se habrían desarrollado actividades diversas a juzgar por las diferencias encontradas en los resultados antracológicos de cada cuadrícula (monopluriespecíficas, predominio de Senecio/Baccharis o Berberis).

Es importante mencionar que para todas las cuadrículas se observa una correlación positiva entre el número de carbones totales y el peso total de los mismos, lo que permite inferir que ninguna cuadrícula atravesó procesos postdepostacionales significativamente diferentes al resto. Si bien es necesario profundizar el análisis de los restos arqueológicos e identificar diferencias en las actividades realizadas por cuadrículas, el registro sugeriría un sitio logístico de consumo de animales y retalla lítica. 


\section{Registro arqueobotánico sector sur de la ría Deseado}

En este capítulo se presenta en primer lugar, los antecedentes recientes generados en el marco del proyecto CNSC por otros investigadores del equipo para cada uno de los subsectores que comprenden el sector sur de la ría Deseado. Luego, se describen los sitios y las excavaciones realizadas en cada caso, a partir de las cuales se han recuperado los materiales arqueobotánicos analizados en la presente tesis. El diseño de muestreo desarrollado en cada sitio permitió la recuperación del material arqueobotánico. Posteriormente se presentan para cada sitio los resultados de los estudios arqueobotánicos realizados. Al finalizar el capítulo se presentan dos gráficos de ubicuidad de taxa para fogones y otro para carbones dispersos considerando todo el fogón.

\subsection{Subsector Margen norte de la ría Deseado}

\subsubsection{Antecedentes recientes}

Este subsector abarca desde la desembocadura del río Deseado, aproximadamente a la altura del Paso Marsicano, hasta la boca del estuario, formado por la Punta Guanaco y Península Foca (Iantanos 2003). Si bien este subsector se encuentra en la margen norte de la ría Deseado, en las investigaciones realizadas en el proyecto arqueológico CNSC forma parte del denominado sector sur de la ría Deseado (Zubimendi 2010, Ambrústolo 2011). Comprende la unidad de paisaje del tipo valle del río Deseado y terrazas adyacentes (Oliva et al. 2001). El río Deseado presenta un relieve horizontal con mesetas interrumpidas hacia el este por cañadones y depresiones. El valle presenta seis niveles aterrazados cuyas altitudes oscilan entre los $45 \mathrm{msnm}$ y los $450 \mathrm{msnm}$ en la costa del Golfo San Jorge (Feruglio 1933). Como se mencionó en el capítulo 3 la vegetación del sector es la estepa arbustiva del Golfo San Jorge, aunque hacia el interior 
se observa una zona ecotonal entre ésta y la estepa de arbustos enanos (Oliva et al.2001).

Los estudios realizados por el equipo en este sector han sido en un primer momento prospectivos, luego se realizaron excavaciones en los sitios Cañadón Giménez, para contribuir a la discusión del modelo del abandono de la costa en tiempos ecuestres (Moreno y Videla 2008) y en los últimos años han tenido el objetivo de identificar reparos rocosos potencialmente utilizados por los grupos humanos que habitaron este sector (Ambrústolo et al. 2011, Ambrústolo y Ciampagna 2014).

En relación a los datos cronológicos, el fechado más antiguo se obtuvo en el sitio Alero 4 y fue de $2760 \pm 70$ años AP (LP-2762; Zubimendi et al. 2014; Ambrústolo y Ciampagna 2014). A partir de actividades de rescate arqueológico en el sitio Carsa, se recuperaron restos humanos cuya antigüedad es de $1740 \pm 60$ años AP (Castro et al. 2009). Por otra parte, en el sitio Cañadón Giménez, Moreno y Videla (2008), obtuvieron un fechado corregido de $1070 \pm 70$ años AP (LP- 1800) sobre una muestra de valvas.

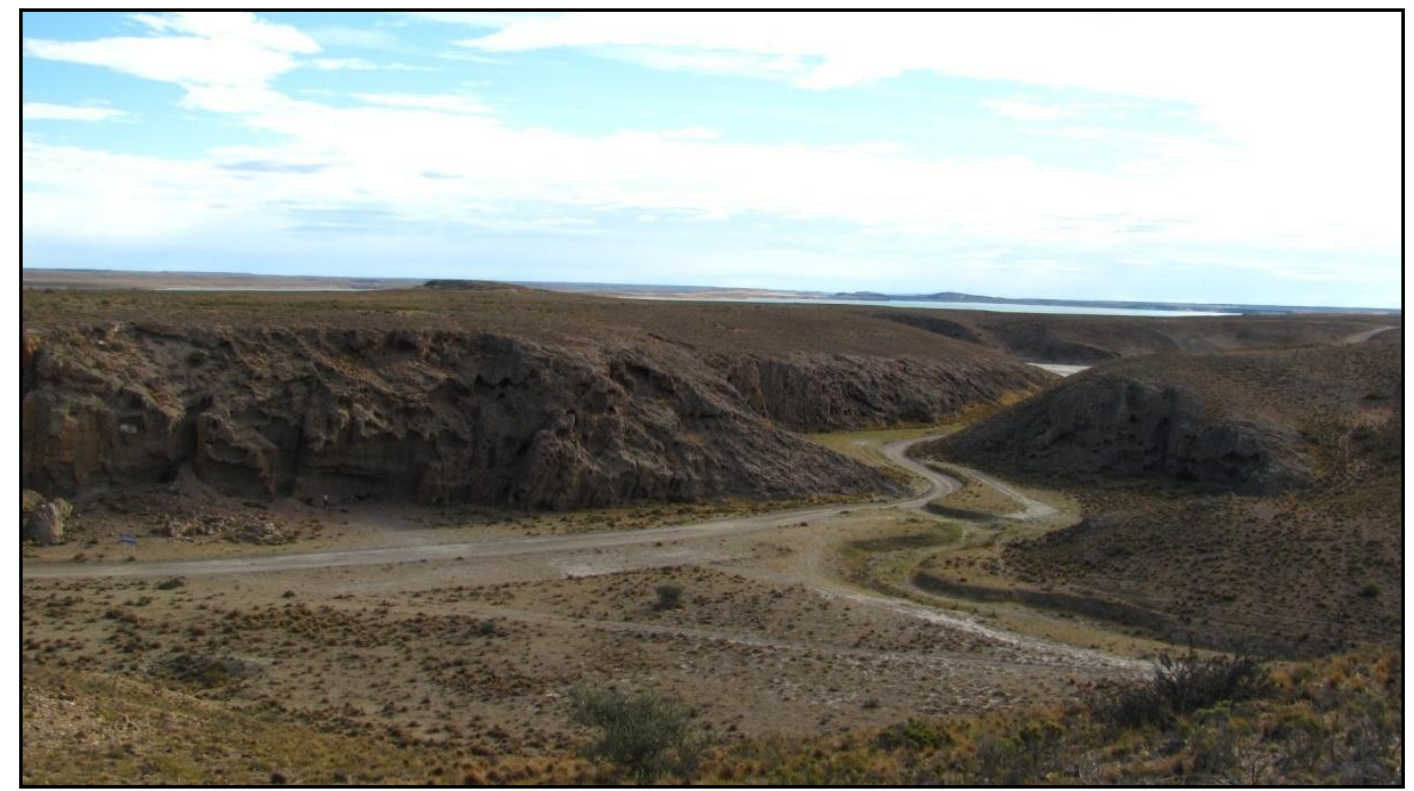

Figura 10.1. Cañadón Torcido, margen norte de la Ría Deseado (Foto Lucía Mazzitelli).

\subsubsection{Sitio Alero 4}

\subsubsection{Introducción}


El sitio Alero 4 es un abrigo rocoso ubicado en el Cañadón Torcido, a $3 \mathrm{~km}$ del ingreso a la Ciudad de Puerto Deseado, a 700 m de la Ría Deseado en línea recta y a $8 \mathrm{~km}$ de la costa Atlántica. Está conformado en el frente de un afloramiento de rocas porfíricas, de la formación Bahía Laura (Giacosa et al. 1998), con orientación norte (ver Figura 10.2). El estudio de los abrigos rocosos en la CNSC ha sido desarrollado por Ambrústolo (2010, Ambrústolo et al. 2011) entendiendo a los mismos como recursos del paisaje (Goñi 1995, Paunero 2003) utilizados por los grupos humanos que habitaron dicha área. En este sentido, Goñi (1995) plantea que los aleros constituyen un recurso más de los disponibles dentro del paisaje y que posiblemente en muchos casos haya sido un recurso de primer orden para protección y/o abrigo. Pero una opción más dentro de la amplia gama de recursos y no la única disponible. Como se observa por la descripción de los sitios anteriores, el registro arqueológico de la CNSC se presenta en gran medida en superficie, a cielo abierto y en los denominados concheros sobre médanos. Sin embargo, el estudio de la ocupación en abrigos rocosos permite obtener secuencias estratigráficas con delimitaciones espaciales y temporales más definidas. La información resultante de los distintos tipos de sitios permite ampliar la discusión sobre estrategias planificadas en el marco de rangos de acción amplios (Zubimendi 2010).

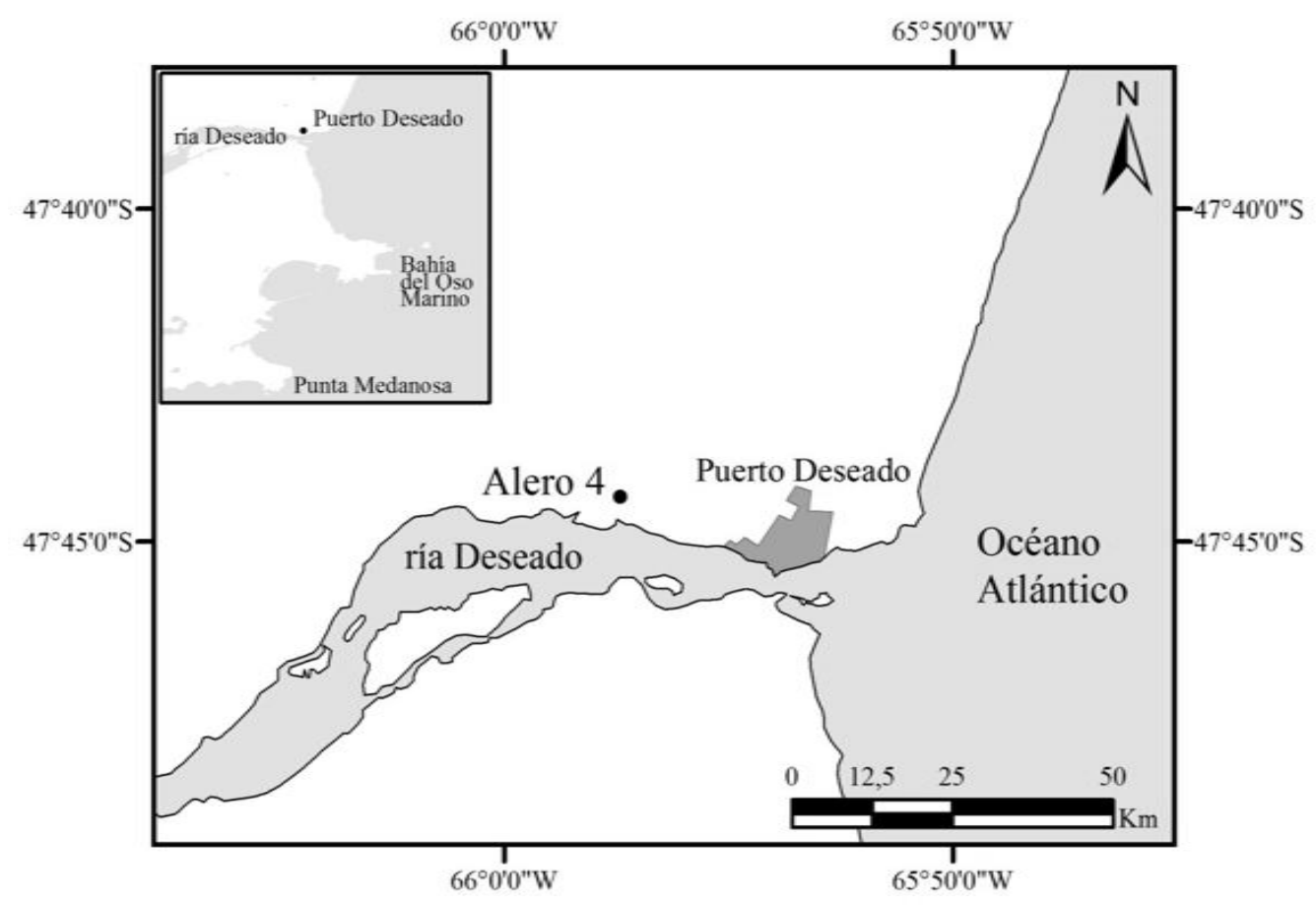

Figura 10.2. Ubicación del sitio Alero 4. 


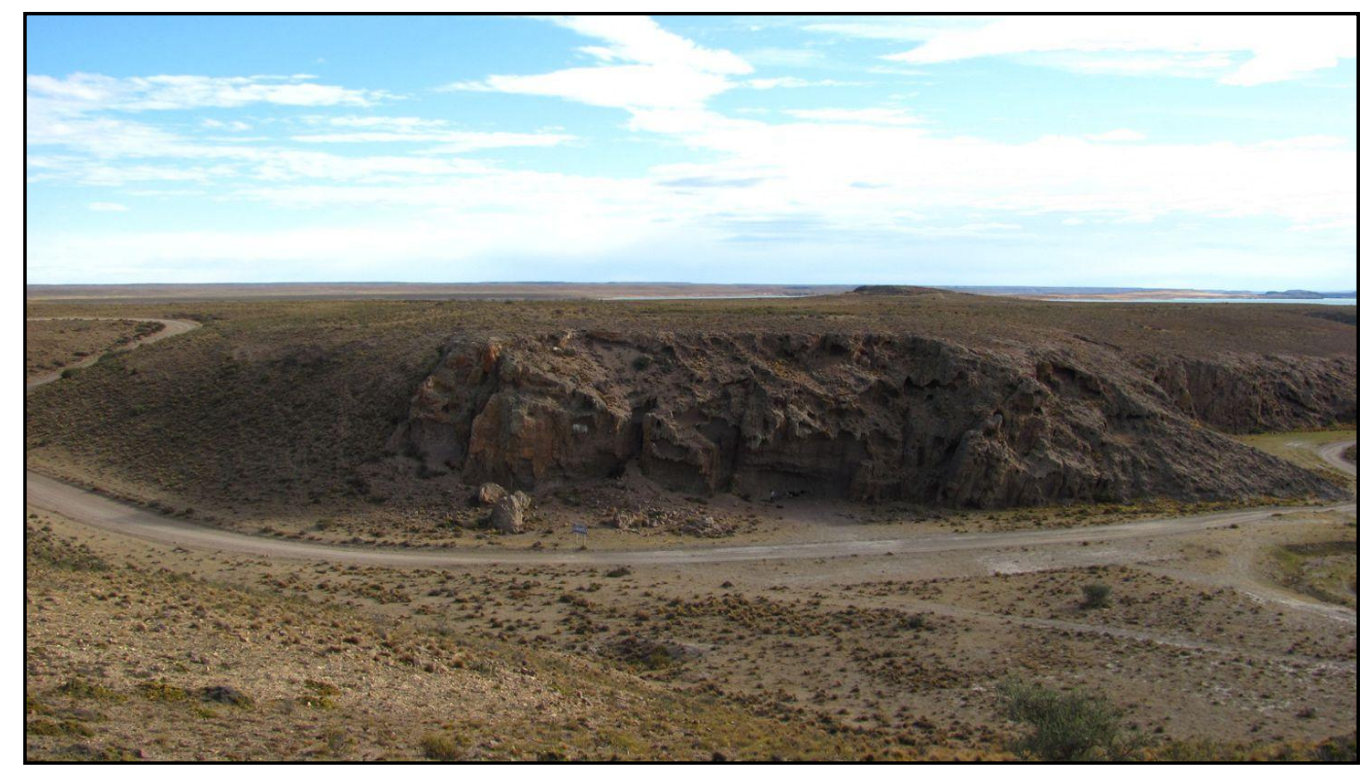

Figura 10.3. Vista panorámica del sitio Alero 4 y en el fondo la Ría Deseado (Fotografía de Lucia Mazzitelli).

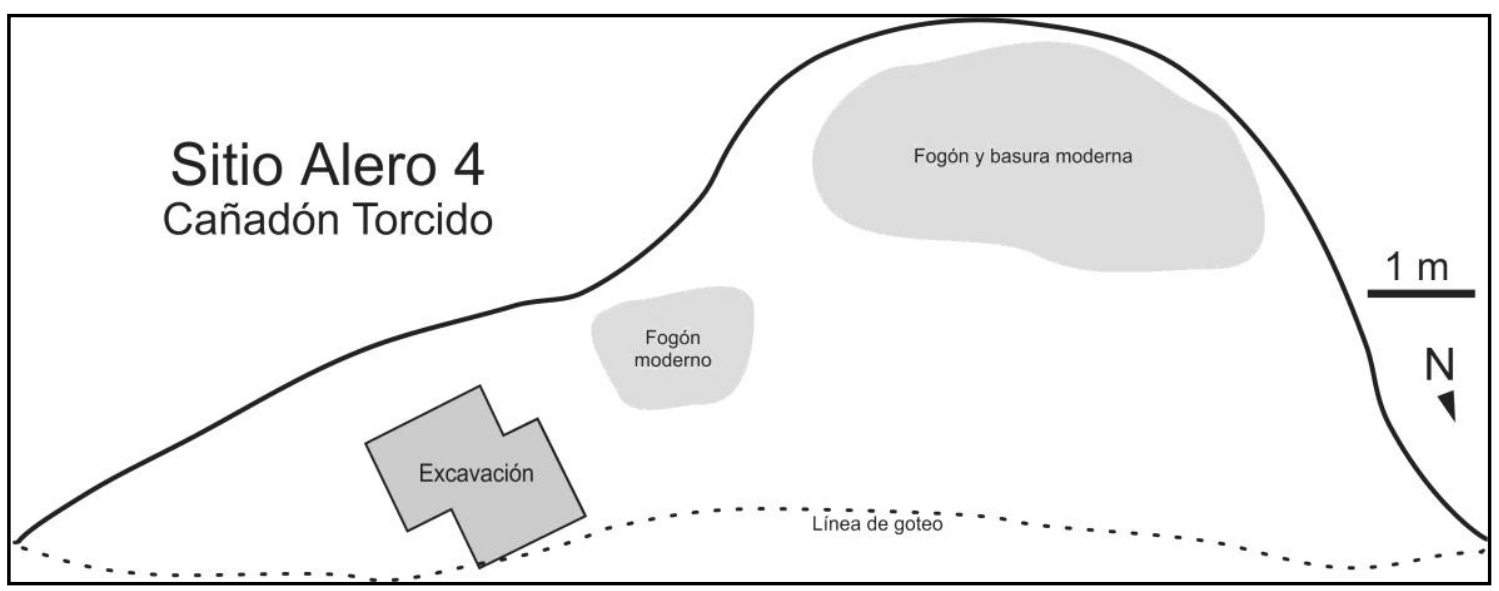

Figura 10.4. Área excavada y distribución espacial del Alero 4

En la superficie del alero se registró material arqueológico (lítico) y alteraciones antrópicas (fogones actuales y basura). Sobre el frente del alero se observaron matas de calafate (Berberis microphylla), coirones (Pappostipa sp. y Poa sp.), malva rubia (Marrubium vulgare), alfilerillo (Erodium cicutarium) y unos metros hacia el norte se observó molle (Schinus sp), así como un cañadón con mayor diversidad de plantas (Lycium sp, Senecio sp, Mulguraea tridens, Chuquiraga erinaceae, entre otras.) A partir de excavaciones estratigráficas se registraron tres fogones arqueológicos y se obtuvieron dos fechados radiocarbónicos, uno sobre hueso de guanaco con marcas de corte de la 
capa 2 d datado en $2760 \pm 70$ años AP (LP-2762) y otro sobre carbón del fogón C cuya cronología es $1690 \pm 90$ años AP (LP-2908).

\subsubsection{Metodología}

\subsection{Excavación}

Se realizó, bajo la dirección del Dr. Ambrústolo, un sondeo de 0,50 x 0,50 m, en el que se excavó siguiendo las capas naturales del terreno de acuerdo a las características del sedimento. Posteriormente, una vez que se había llegado a la capa 1, se definió que para tener un mayor control estratigráfico era necesario definir arbitrariamente niveles de 5 cm si bien la composición estructural de sitio no había cambiado. Se excavaron luego, siete cuadrículas siendo en total $2 \mathrm{~m}^{2}$ el área excavada con una potencia de $40 \mathrm{~cm}$ (Figura 10.4).

\subsection{Recuperación de restos antracológicos}

En el sitio Alero 4 se recuperaron en su totalidad los fogones arqueológicos registrados (carbones y sedimento) encontrados en estratigrafía, siendo tamizados con mallas de 2 mm, 800 y $400 \mu \mathrm{m}$ en laboratorio. En dos cuadrículas además se recuperaron los carbones dispersos con malla de $2 \mathrm{~mm}$ a través de una zaranda especialmente construida de mayor tamaño, fácil traslado y mallas intercambiables (ver figura 10.5). La fracción menor se tamizó con mallas de 800 y $400 \mu \mathrm{m}$. Debido a que la estratigrafía en estos sitios permite un mayor control de los eventos culturales, la implementación de zarandeo por mallas más finas a $2 \mathrm{~mm}$ en este sitio estuvo justificada por la búsqueda de recuperación de restos carpológicos en sitios aleros. 

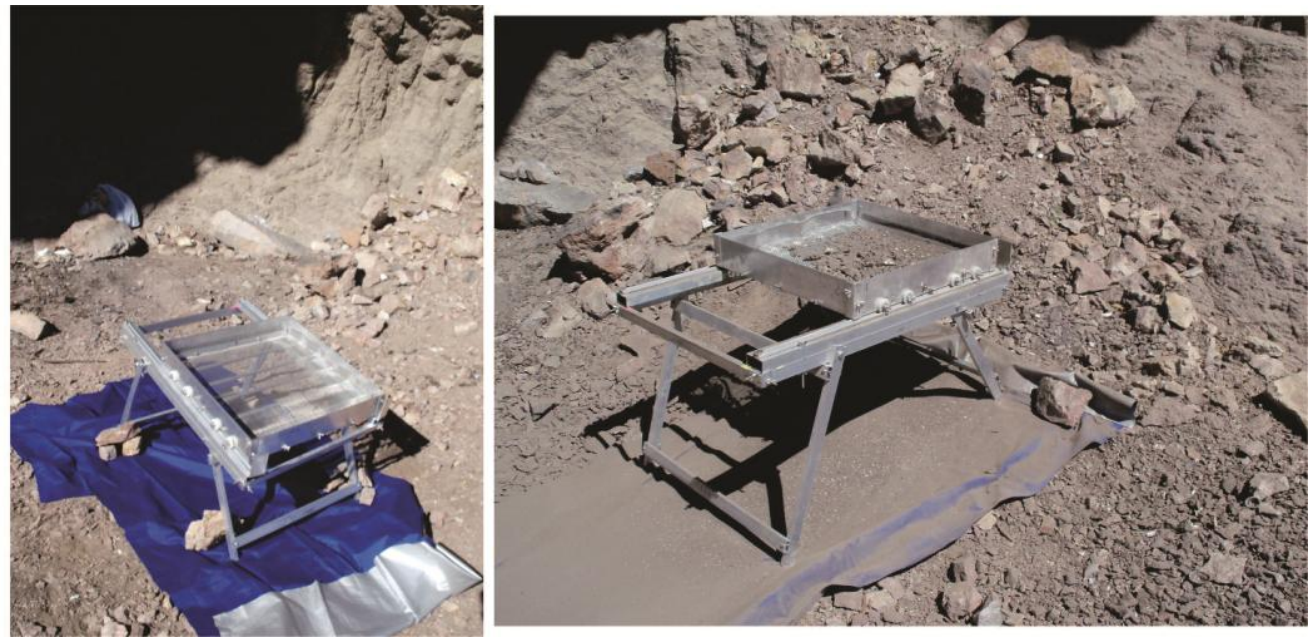

Figura 10.5. Zaranda de aluminio con riel confeccionada por Hugo E. Ciampagna

\subsubsection{Contexto estratigráfico}

La capa superficial está compuesta por guano y cascajo proveniente de la roca que constituye el alero, es de color rosado debido al color del cascajo y tuvo $1 \mathrm{~cm}$ de espesor e inclinación hacia el Norte. La capa 1 se definió al registrar un cambio en el sedimento que pasó a caracterizarse como areno-limoso de color castaño, con algunos cascajos pero en menor cantidad, restos malacológicos y artefactos líticos. Esta capa tuvo un espesor de $5 \mathrm{~cm} \mathrm{y}$, si bien no se presentaron cambios en la estructura del sitio, se procedió a cambiar de nivel como se mencionó más arriba (Figura 10.6). El nivel 2a, entonces, contenía lapas y mejillones asociados a artefactos líticos. En el siguiente nivel (2b), se recuperaron restos malacológicos y artefactos aislados. El 2c presenta la misma composición que las anteriores así como el nivel $2 \mathrm{~d}$ a excepción de que en esta última se recuperaron mayor cantidad de artefactos líticos, uno de ellos de obsidiana negra y otro, un raspador frontal doble de sílice y restos de valvas. Sobre el perfil sur se identificaron restos óseos, uno de ellos, una escápula de lobo marino. El nivel 2e es similar a las anteriores pero con menor cantidad de restos óseos y el sedimento es de color gris oscuro. En el $2 \mathrm{f}$ se observaron raíces actuales y carbones arqueológicos dispersos y se registraron dos raspadores y otros artefactos líticos asociados con hueso posiblemente de guanaco. Este nivel se encuentra sobre sedimentos con cascajos (Ambrústolo 2010:20). 


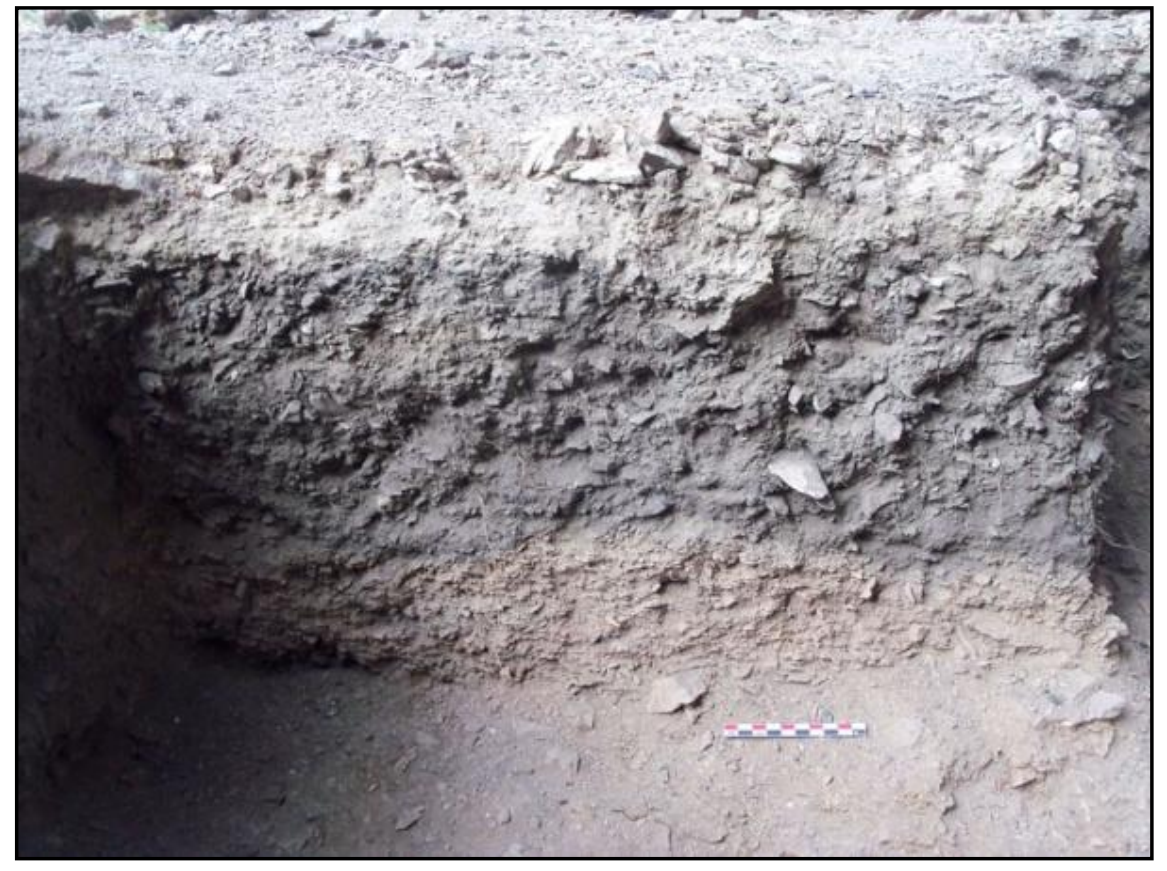

Figura 10.6. Estratigrafía sitio Alero 4, unicomponente (Fotografía de P. Ambrústolo).

\subsubsection{Estudios arqueológicos}

El sitio presenta en estratigrafía un componente cultural en el que se recuperaron restos malacológicos, óseos y líticos, y se registraron áreas de combustión (Ambrústolo y Ciampagna 2014). El registro zooarqueológico está constituido en su mayor parte por restos de valvas de mejillones, vértebras y costillas de lobo marino y guanaco. En cuanto al material lítico, se registraron 1.946 artefactos, entre los que se identificaron productos de talla, artefactos formatizados y núcleos. Entre los artefactos formatizados, los raspadores son el grupo tipológico que predomina, sugiriendo entonces, el uso de artefactos para la realización de actividades de procesamiento. Los núcleos, por otra parte, son escasos, por lo que se evidencia actividades de talla de baja inversión, tiempo y energía (Ambrústolo y Ciampagna 2014). El registro arqueológico del Alero 4 sugiere un sitio donde se realizaron actividades múltiples.

\subsubsection{Resultados antracológicos}




\subsection{Estructuras de combustión}

Se identificaron tres fogones de tipo plano o extendido (Pérez de Micou 1991, Marconetto 2005), denominados A, B y C, con una potencia de $c a$. 1,5 a $2 \mathrm{~cm}$. Las dimensiones del fogón $\mathrm{A}$, de la cuadrícula 3 (nivel 2d), son de 15 x $7 \mathrm{~cm}$ y se registraron artefactos líticos, óseos y malacológicos asociados. El fogón $\mathrm{B}$ de la cuadrícula 5 (nivel 2e) es una lente de carbones de 14 x $13 \mathrm{~cm}$, al mismo nivel y a $7 \mathrm{~cm}$ al este de la lente sobre el mismo perfil se halló un hueso de guanaco y a $6 \mathrm{~cm}$ hacia el norte de la lente un filo frontal de raspador. Y, por otra parte, el fogón C, ubicado entre las cuadrículas 6 y 7 (nivel 2 b y 2c), es el de mayor tamaño de $42 \times 23 \mathrm{~cm}$ asociado a una valva de lapa (Nacella magellanica).

Antes de describir las identificaciones taxonómicas de los tres fogones es importante mencionar que para la fechados que se obtuvieron en este sitio, los registros palinológicos interpretados para la estepa de arbustos enanos estarían indicando condiciones climáticas similares a las actuales, por lo que ante la inexistencia de registros palinológicos de CNSC consideramos posible extrapolar estos datos a la estepa del Golfo San Jorge (De Porras 2010).

El total de carbones recuperados en el fogón A fue de 257 para un volumen de 4,25 1 y la densidad calculada en términos del número de individuos por litro de sedimento fue 60,47 n/1, clasificada como baja. Las clases diamétricas registradas tienen un rango de 10-14,9 mm a 2-4,9 mm pero la mayoría de los carbones se encuentran en las clases 24,9 $\mathrm{mm}$ y 5-9,9 $\mathrm{mm}$. El número de carbones de la submuestra analizada fue de 27 carbones a partir de los cuales se identificaron 5 taxa. Los resultados evidencian un mayor porcentaje de Schinus (con 29,7\%; Figura 10.7). 


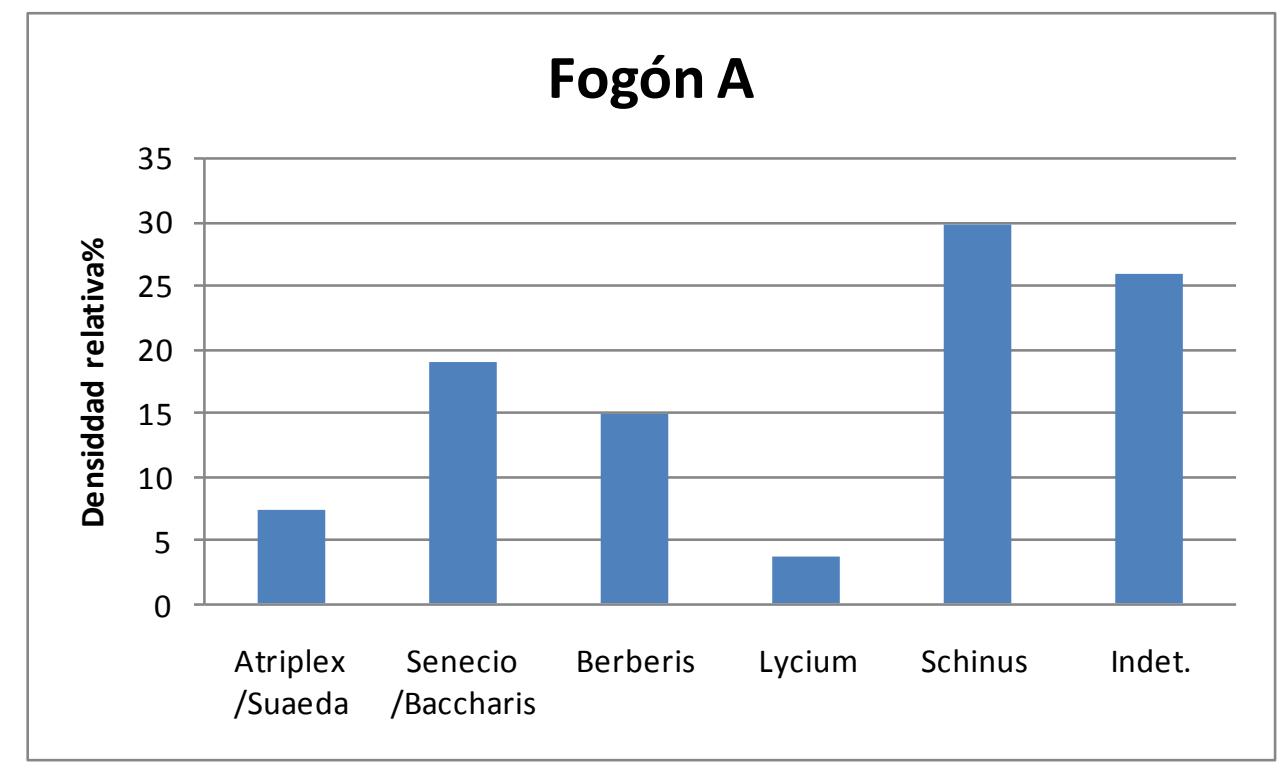

Figura 10.7. Carbones identificados del Fogón A del sondeo 25 x $50 \mathrm{~cm}$ nivel 2 d (

De la submuestra analizada 2 carbones $(7,4 \%)$ no identificables tenían médula, uno de ellos estaba compuesto en su mayor parte por este tejido por lo que no podían reconocerse sus caracteres diagnósticos. Se identificaron 3 carbones $(11,11 \%)$ con presencia de hifas, identificados como Senecio/Baccharis $(\mathrm{n}=2)$ y el otro como Lycium $(\mathrm{n}=1)$. En cuanto al registro de aberturas 6 carbones $(22,22 \%)$ presentaron ojos $\mathrm{y}$ aberturas en radios y vasos, estos correspondían a Berberis $(\mathrm{n}=2)$, Schinus $(\mathrm{n}=3)$ y uno indeterminable. Solo 2 carbones $(7,4 \%)$ tuvieron evidencias de vitrificación, uno de ellos identificado como Berberis y otro indeterminable.

Como se mencionó en los sitios anteriores las maderas utilizadas en este fogón tuvieron predominio de alta densidad (i.e. Berberis, Schinus, Atriplex) (51,8\%), aunque también estuvieron presentes maderas de densidad intermedia (i.e. Lycium) y muy baja densidad (Senecio/Baccharis), en conjunto 22,61\%. Estos taxa según referencia de informantes, producen calor y brasa duraderos (i.e. Berberis, Schinus). Por otra parte, se encuentran combinados con maderas de fácil encendido, que producen llama pero que no dejan brasa de rápida combustión y producción de ceniza (Lycium, Senecio/Baccharis y Atriplex/Suaeda).

Dentro de las modificaciones de la madera es llamativa la presencia de hifas en los carbones mencionados anteriormente. El ataque de hongos en las maderas disminuye el poder calórico de la misma debido a que agrede los tejidos del leño. No se puede determinar el momento de la contaminación de la madera para establecer si fue 
recolectada en pie o como madera muerta (Caruso 2012). En el caso de las aberturas identificadas en Schinus se registró que 37,5\% $(\mathrm{n}=3)$ del total de carbones de este género presentaba ojos y aberturas en radios y vasos.

Considerando las variables expuestas, la asociación del fogón a material lítico con alteración térmica, restos malacológicos y óseos es posible sugerir que su funcionalidad está relacionada con actividades domésticas: consumo de recursos marinos y terrestres, actividades de procesamiento (considerando el tipo de artefactos líticos del sitio, en su mayoría raspadores).

En el fogón B se recuperaron un total de 61 carbones para un volumen de 0,25 1 y la densidad calculada por cantidad de individuos por litro de sedimento es de $305 \mathrm{n} / 1$, de tipo media. Se observaron sólo dos clases diamétricas: 5-9,9 mm $(49,2 \%)$ a 2-4,9 $\mathrm{mm}$ (50,8\%). La submuestra fue de 10 carbones en los que se pudo identificar solo Senecio/Baccharis (Figura10.8). Los especímenes indeterminables alcanzaron un total $40 \%$ de la muestra debido a la preponderancia de carbones de tamaño pequeño que dificultó la visualización de caracteres diagnósticos. En este fogón no se observan rasgos de vitrificación, aberturas ni presencia de médula.

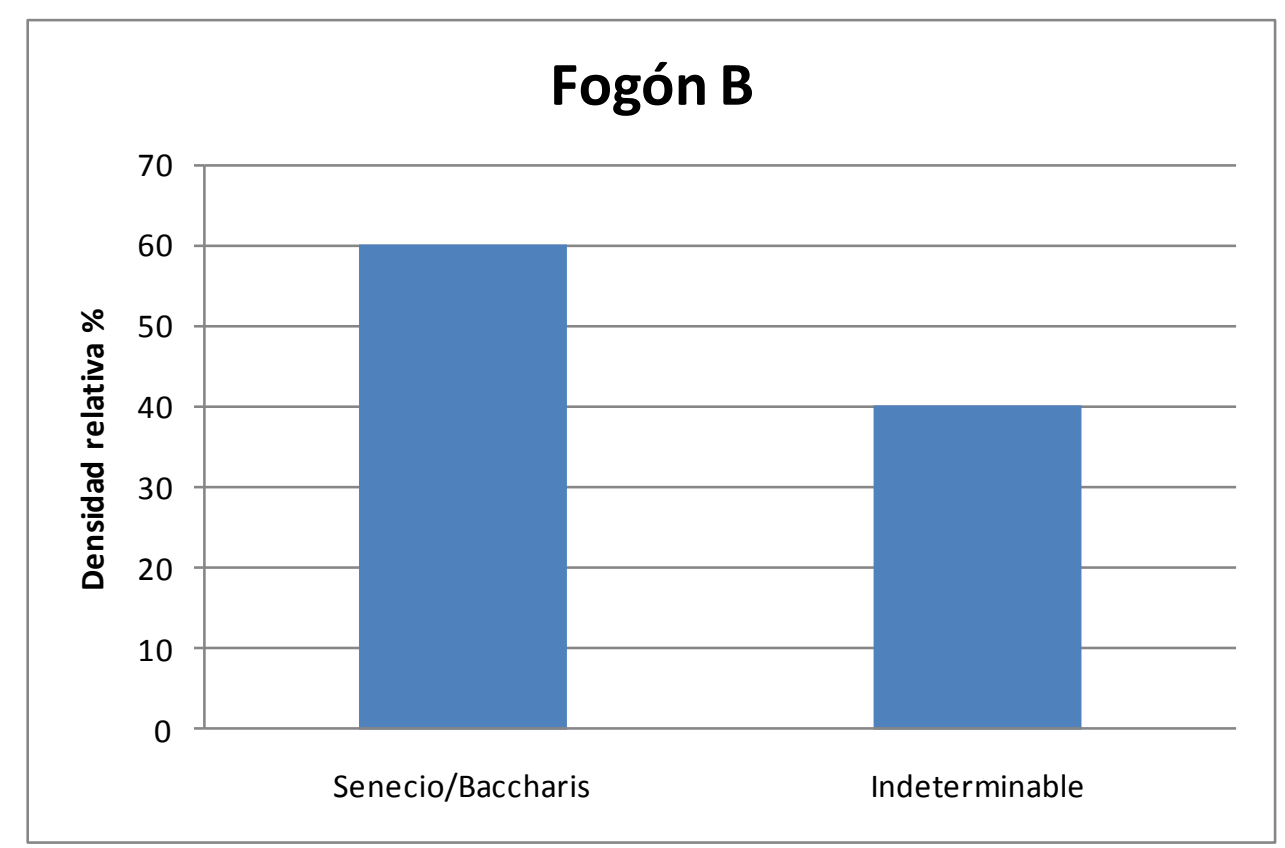

Figura 10.8. Carbones identificados del fogón B, cuadrícula 5, nivel 2e, submuestra $(\mathrm{n}=10)$. 
En cuanto a Senecio/Baccharis, ambos taxones son maderas de muy baja densidad. Son entonces, maderas que producen más llama que brasa. Se registraron asociados al fogón un hueso de guanaco sin evidencias de alteración térmica y un filo frontal de raspador. Por la alta densidad de carbones en relación al volumen de sedimento, este fogón parece haber constituido un evento de mayor intensidad que los demás (o varios menos intensos repetidos reiteradamente) y dado que no se lo puede vincular a evidencias de termoalteración en los elementos arqueológicos asociados (hueso de guanaco y un raspador) su función no parece haber estado relacionada al consumo de alimentos, aunque parece haber sido específica dada la reducida cantidad de taxa utilizados (si bien es posible que entre los indeterminables se esté invisibilizando una mayor diversidad de taxa). Es posible que su función estuviera asociada a brindar luz en el alero, pero no se obtuvieron más evidencias del contexto arqueológico como para afirmar o inferir una funcionalidad más específica.

En el fogón C se recuperaron 1194 carbones para un volumen de 2,5 1 con 478 n/l, una densidad media. Se registraron las siguientes clases diamétricas: 20-24,9 mm a 2-4,9 $\mathrm{mm}$. Pero la mayor parte de los carbones se encuentran en la clase 2-4,9 mm (64,5\%). La submuestra analizada es de 120 carbones. Es el fogón que mayor diversidad taxa presenta, siendo identificados siete taxa. El género que predomina por sobre el resto teniendo en cuenta la densidad relativa es Schinus (55,8\%; Figura 10.9).

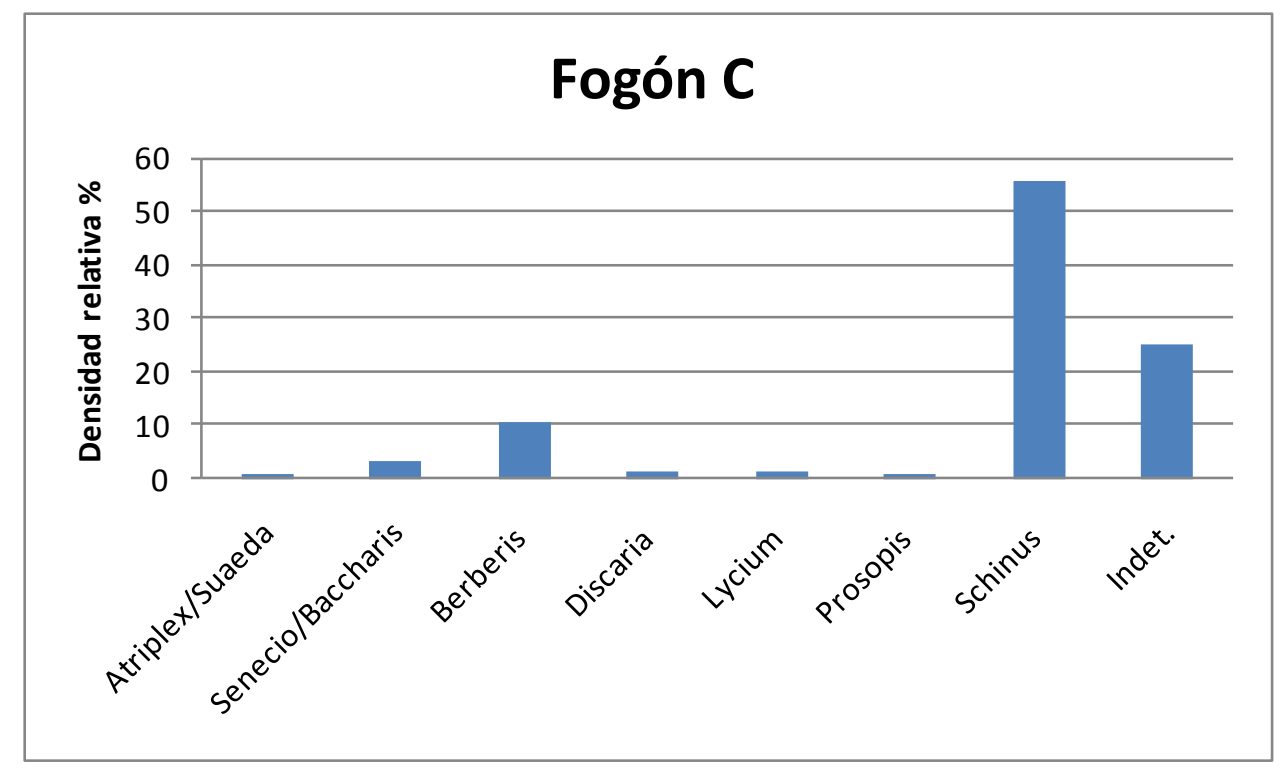

Figura 10.9. Carbones identificados del Fogón C, cuadrículas 6 y 7 entre niveles 2 b y c (submuestra $\mathrm{n}=$ 120). 
De la submuestra se registraron 5 carbones (4,16\%) con vitrificación, de ellos 2 fueron identificados como Schinus y 3 fueron indeterminables. En cuanto a la presencia de médula, se registró en un solo carbón identificado como Discaria. Respecto al registro de aberturas, 37 carbones (30,83\%) presentaron evidencias de aberturas u ojos. Se identificaron en radios, vasos y anillos en Berberis $(\mathrm{n}=5)$ y Schinus $(\mathrm{n}=24)$, y aberturas en radios en los carbones indeterminables $(n=8)$.

En relación a la densidad de las maderas utilizadas en este fogón, se encuentran combinadas maderas de alta densidad (i.e. Prosopis denudans, Schinus, Berberis y Atriplex) con otros leños que se habrían utilizado para encender el fuego, siendo maderas de densidad intermedia (Discaria y Lycium) o de muy baja densidad (Senecio/Baccharis). Predominan las maderas de mayor densidad por sobre las más livianas. Como se dijo anteriormente, se registra una gran cantidad de aberturas en Schinus, especialmente en anillo, alcanzando el 37,5\% del total de carbones de este género, lo cual es diagnóstico de altas temperaturas. Este fogón habría por lo menos alcanzado los $700{ }^{\circ} \mathrm{C}$.

El Fogón C, de mayor tamaño que los fogones A y B, presenta las mayores densidades de carbones y está compuesto por elevados porcentajes de leños con alta densidad, lo que podría estar reflejando un evento aún más intensivo o repetitivo que el fogón B. La alta frecuencia de raspadores y el registro de un instrumento en hueso (punzón) podrían sugerir que el fogón $\mathrm{C}$ se asociaría a la producción de calor para actividades tecnológicas (aunque no tenemos certeza de ello, un ejemplo podría ser la fuente de calor que necesita el cuero para ser procesado según lo planteado por Marchioni y Belleli 2013).

Se registró la ubicuidad de los taxa identificados en los tres fogones, a partir de dicho análisis se observó que Senecio/Baccharis alcanzó el 100\% de ubicuidad. Con el 66,6\% le siguieron Berberis, Schinus, Atriplex/Suaeda y Lycium (Figura 10.10) 


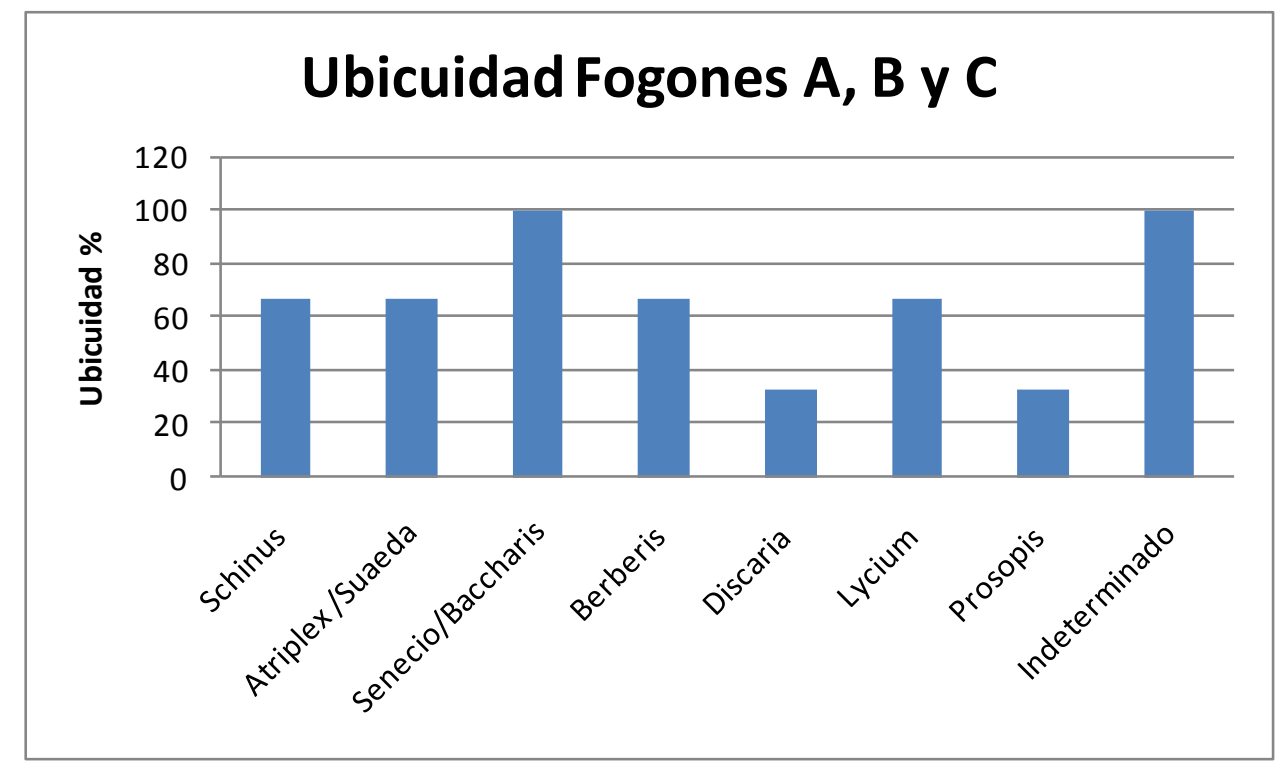

Figura 10.10. Ubicuidad de los taxa identificados en los fogones A, B y C del sitio Alero 4

El análisis de correlación entre el número de fragmentos de carbones dispersos recuperados por nivel arqueológico y el peso de los mismos (Figura 10.11) tuvo como resultado un $\mathrm{R}^{2}=0,99$ con un nivel de significancia de $\mathrm{p}<0.01$. Este resultado permite concluir que ninguno de los eventos de combustión atravesó procesos postdepositacionales distintos del resto.

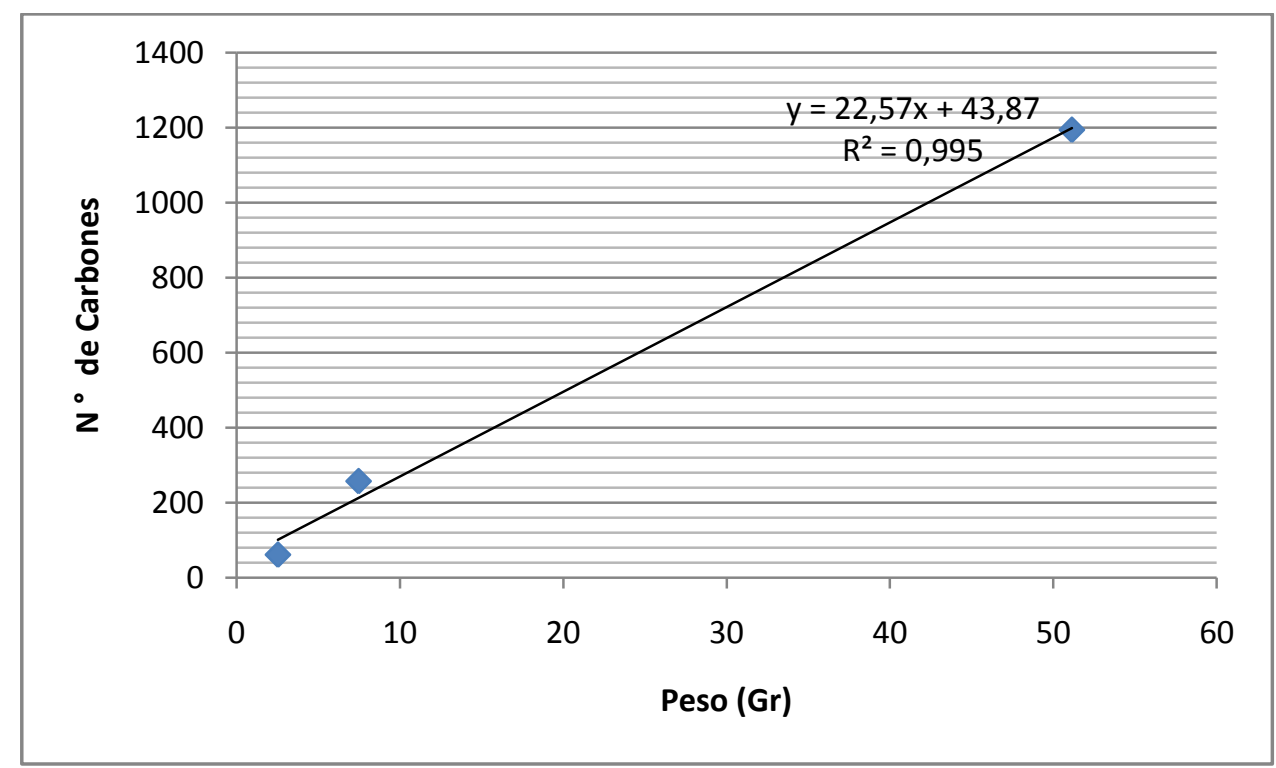

Figura 10.11. Correlación entre cantidad y peso de carbón de madera recuperado por cuadrícula Sitio Alero 4. 


\subsection{Carbones dispersos}

En la capa 1 de las cuadrículas 6 y 7 se recuperó un total de 142 carbones para 33,5 1, con una densidad baja de 4,21 n/l. Las clases diamétricas se encuentran en el rango de tamaño entre 10-14,9 mm a 2-4,9 mm pero la concentración está en 5-9,9 mm y 2-4,9 mm $(57,7 \%)$. La submuestra analizada fue de 29 carbones donde se identificaron siete taxa. De la submuestra analizada, Berberis es el género predominante $(58,6 \%)$ frente al resto de los taxa, de los cuales Schinus tiene un 10,34\% y el resto no pasa del $10 \%$ (Figura 10.12).

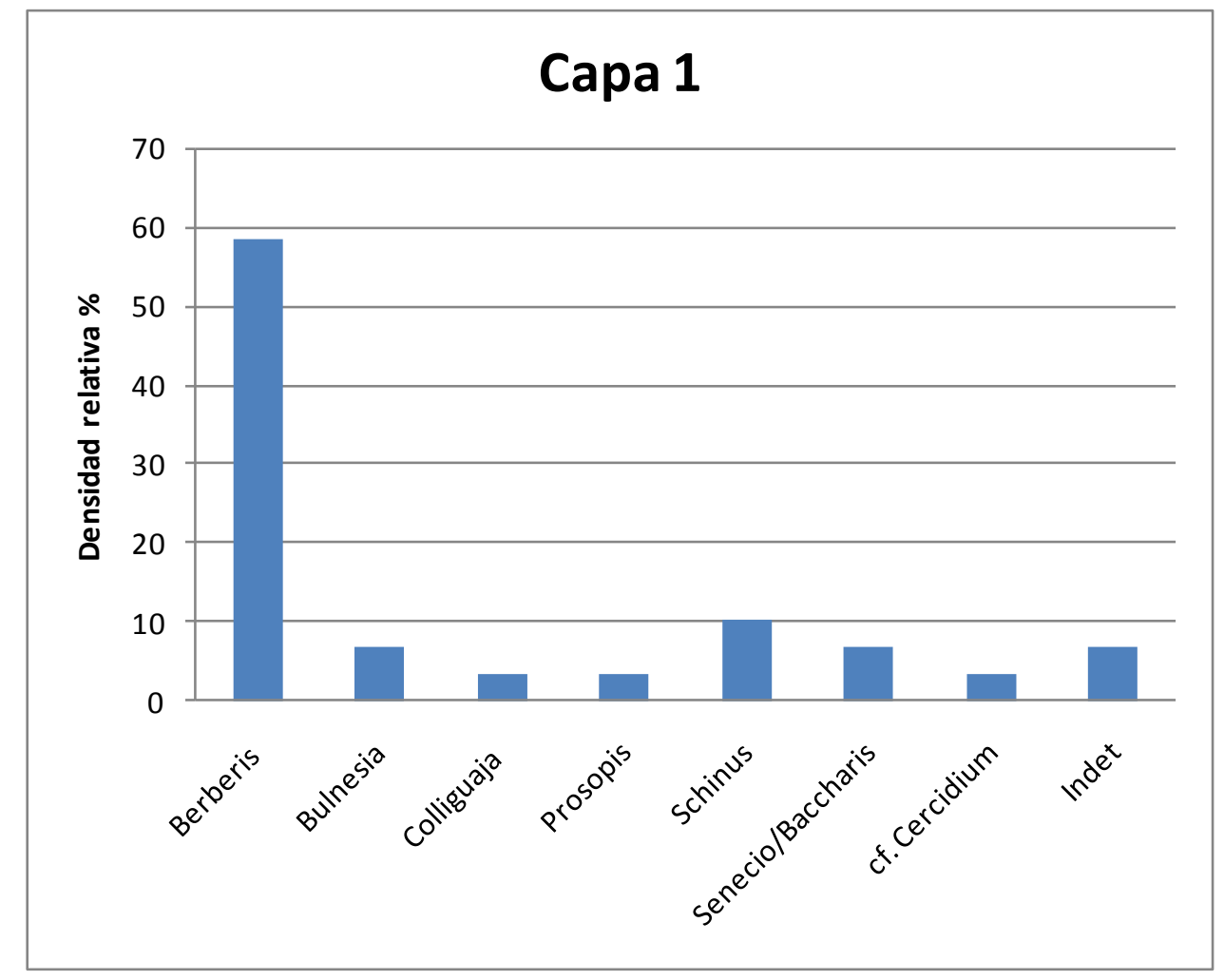

Figura 10.12. Carbones dispersos identificados en las cuadrículas 6 y 7 en la capa 1 ( carbones).

Se observaron sólo dos carbones $(6,89 \%)$ con rasgos de vitrificación identificados, uno corresponde a Bulnesia y otro es indeterminable. En el 6,89\% $(\mathrm{n}=2)$ de los carbones de Berberis se observó la presencia de médula. Respecto al registro de aberturas se identificaron radios y vasos en Berberis $(\mathrm{n}=4)$ y en Colliguaja $(\mathrm{n}=1)$, es decir, el 13,79\%. En suma, los carbones dispersos de la capa 1 registran una marcada presencia de maderas duras y semiduras (Prosopis, Bulnesia, Schinus, y principalmente Berberis) 
$\mathrm{y}$, en menor escala, muy blandas y livianas (Senecio/Baccharis); las aberturas observadas en un ejemplar de Colliguaja indican altas temperaturas y maderas con contenido de humedad (ver capítulo 7).

En nivel 2a se recuperaron un total de 176 carbones para 33,5 1 con una densidad calculada de 5,21 $\mathrm{n} / 1$ y baja. Las clases diamétricas registradas tienen un rango de 1014,9 a 2-4,9 mm, siendo las más abundantes 5-9,9 mm y 2-4,9 mm. La submuestra tuvo un total de 44 carbones donde se identificaron los siguientes ocho taxa. El género que prevalece es Schinus (36,5\%) (aunque su prevalencia es menor que la de Berberis en la capa anterior), seguido por Senecio/Baccharis (18,2\%) y Berberis (16\%) (Figura 10.13), lo cual es coincidente con el porcentaje relativo del Fogón $\mathrm{C}$, pero no con el $\mathrm{B}$ del mismo nivel, cuya riqueza específica es restringida.

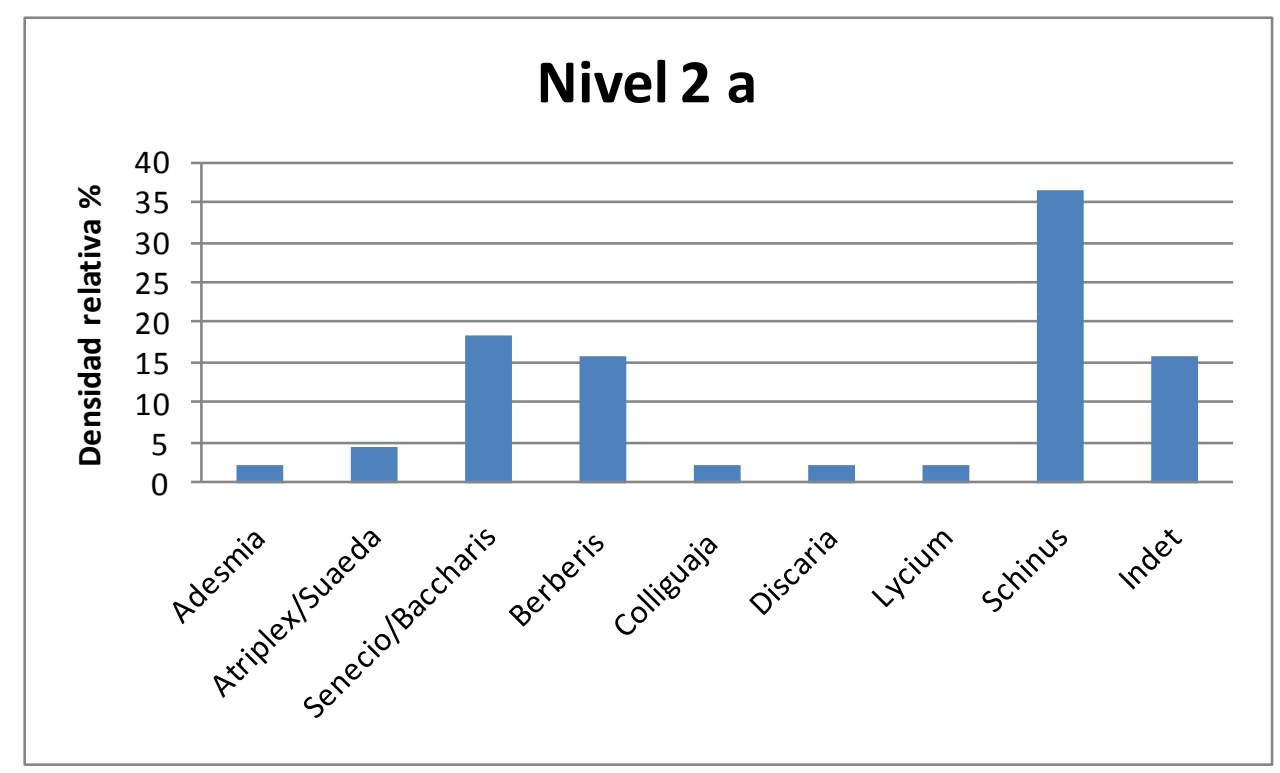

Figura 10.13. Carbones dispersos identificados en las cuadrículas 6 y 7 , nivel 2 a (

En este nivel, y en la submuestra analizada, se observaron vitrificación en seis carbones $(13,63 \%)$, identificados como Adesmia $(\mathrm{n}=1)$, Schinus $(\mathrm{n}=4)$ y Berberis $(\mathrm{n}=1)$. Respecto a la presencia de médula, se registró tan sólo para Berberis en un carbón. En relación a la presencia de aberturas, y ojos se identificaron en radios y vasos en Schinus $(\mathrm{n}=5)$, Berberis $(\mathrm{n}=2)$, Senecio/Baccharis $(\mathrm{n}=1)$ y Atriplex/Suaeda $(\mathrm{n}=1)$. En total se observaron aberturas para el $20,5 \%$ de los carbones. Se observa en este caso la combinación de maderas de muy baja densidad que encienden rápidamente (i.e. Senecio/Baccharis, Adesmia); de maderas bajas e intermedias (i.e. Colliguaja, Discaria, 
Lycium) y maderas de alta densidad, de brasa y de mayor duración (i.e. Schinus, Berberis, Atriplex/Suaeda).

En nivel 2b se recuperó un total de 269 carbones para 33,5 1 con una densidad calculada de 7,97 n/l y clasificada como baja. Las categorías de tamaño tuvieron un rango de 2024,9 $\mathrm{mm}$ a 2-4,9 $\mathrm{mm}$ siendo que la mayoría de los carbones se concentraron en las categorías 5-9,9, 2-4,9 $\mathrm{mm}$ y 10-14,9 $\mathrm{mm}$. La submuestra analizada fue de 39 carbones donde se identificaron siete taxa. Los porcentajes más altos se encuentran entre Berberis, Schinus y Senecio/Baccharis (Figura 10.14), lo cual también es coincidente con los porcentajes relativos del fogón C, aunque en dicho fogón Schinus posee un porcentaje mayor a Berberis y en los carbones dispersos del mismo nivel ocurre lo inverso.

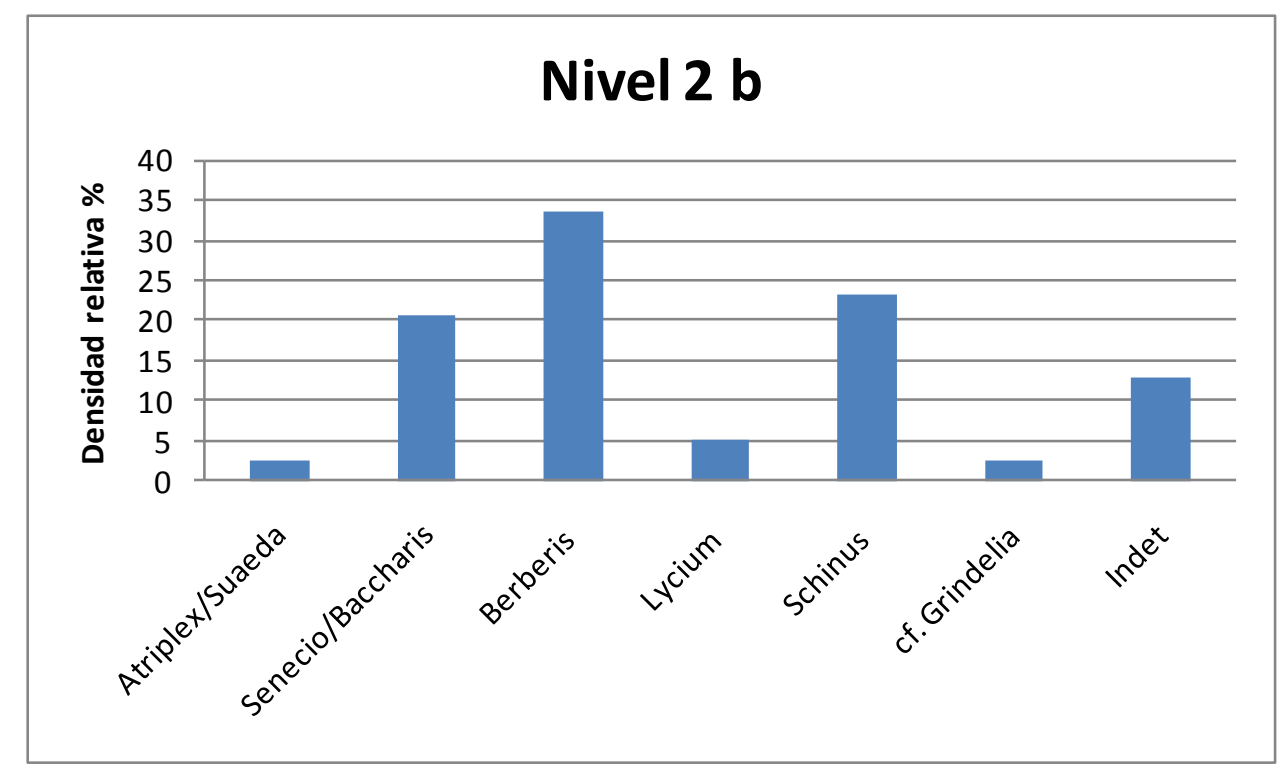

Figura 10.14. Carbones dispersos identificados en las cuadrículas 6 y 7, nivel 2 b, sitio Alero 4 (submuestra $\mathrm{n}=39$ ).

En este nivel, los carbones dispersos que presentaron vitrificación fueron seis $(15,38 \%)$ identificados como Schinus $(\mathrm{n}=2)$, Senecio/Baccharis $(\mathrm{n}=1)$ e identificables $(\mathrm{n}=3)$. Con presencia de médula se registraron cuatro carbones $(10,25 \%)$ pertenecientes a Berberis $(n=2)$, Senecio/Baccharis $(n=2)$. En relación a las aberturas se observaron aberturas en radios, vasos y anillos: Berberis $(\mathrm{n}=3)$, radios y vasos en Senecio/Baccharis $(\mathrm{n}=1)$ y Schinus $(\mathrm{n}=3)$, en total 7 carbones $(17,94 \%)$. 
Como en la capa anterior, se observa aquí la combinación de maderas de rápido encendido y llama (i.e. Senecio/Baccharis, cf. Grindelia) con aquellas de mayor duración y producción de brasa (i.e. Schinus, Berberis, Atriplex/Suaeda).

En el nivel 2c se recuperó un total de 335 carbones para un volumen de 33,5 1 con 9,93 n/l, clasificada como baja. En cuanto a las categorías de tamaño abarcan el rango de 20$24,9 \mathrm{~mm}$ a 2-4,9 $\mathrm{mm}$ donde la mayor abundancia se da en las de 5-9,9 $\mathrm{mm}$ y 2-4,9 $\mathrm{mm}$. La submuestra analizada es de 40 carbones donde se identificaron siete taxa. El género que más densidad porcentual tiene es Schinus (37,5\%) pero le siguen en porcentaje Senecio/Baccharis (24,9\%) y Berberis (19,9\%) (Figura 10.15).

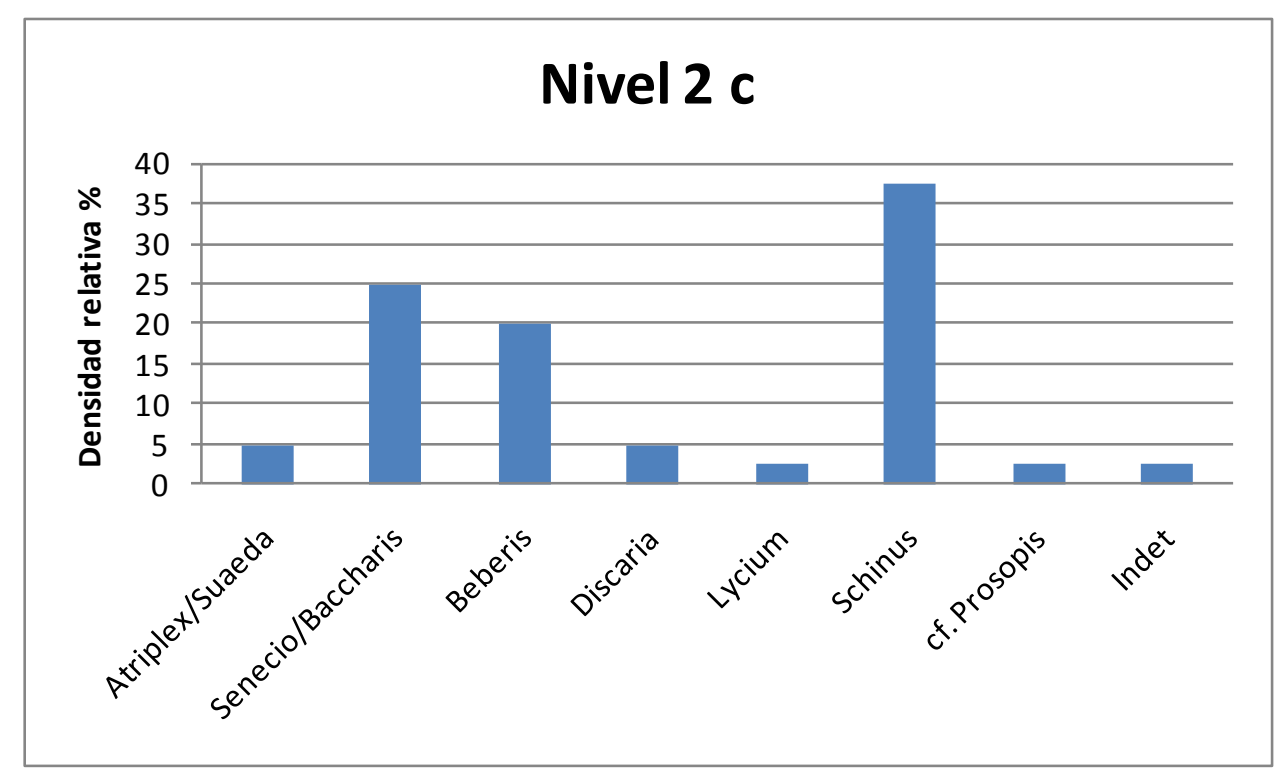

Figura 10.15. Carbones dispersos identificados en las cuadrículas 6 y 7 , el nivel 2 c submuestra $(n=40)$.

En este nivel se observa vitrificación en cinco carbones (12,5\%) pertenecientes a Schinus $(\mathrm{n}=5)$, Berberis $(\mathrm{n}=1)$, Senecio/Baccharis $(\mathrm{n}=1)$, y sin identificar $(\mathrm{n}=2)$. Se registró médula en cuatro carbones de Berberis $(n=1)$, Senecio/Baccharis $(n=2)$, Discaria $(\mathrm{n}=1)$. Respecto a las aberturas se observaron en radios y vasos en carbones de Berberis $(\mathrm{n}=3)$, Discaria $(\mathrm{n}=1), \operatorname{Lycium}(\mathrm{n}=1)$, Schinus $(\mathrm{n}=4)$, y en anillos y radios en Senecio/Baccharis $(\mathrm{n}=1)$. Como en las capas anteriores se observa el uso de leños de rápido encendido con otros de mayor densidad y poder de combustión.

En nivel 2 d se recuperó un total de 288 carbones para un volumen de 33,5 1 con una densidad calculada de $8,53 \mathrm{n} / 1$ de tipo baja. Respecto a las clases de tamaño se encuentran en un rango de 10-14,9 $\mathrm{mm}$ a 2-4,9 $\mathrm{mm}$, siendo que la mayoría de los 
carbones están representados en las clases diamétricas de 5-9,9 mm y 2-4,9 $\mathrm{mm}$. La submuestra analizada fue de 36 carbones donde se identificaron seis taxa, que incluyen el primer registro de Ephedra entre los carbones analizados (Figura 10.16)

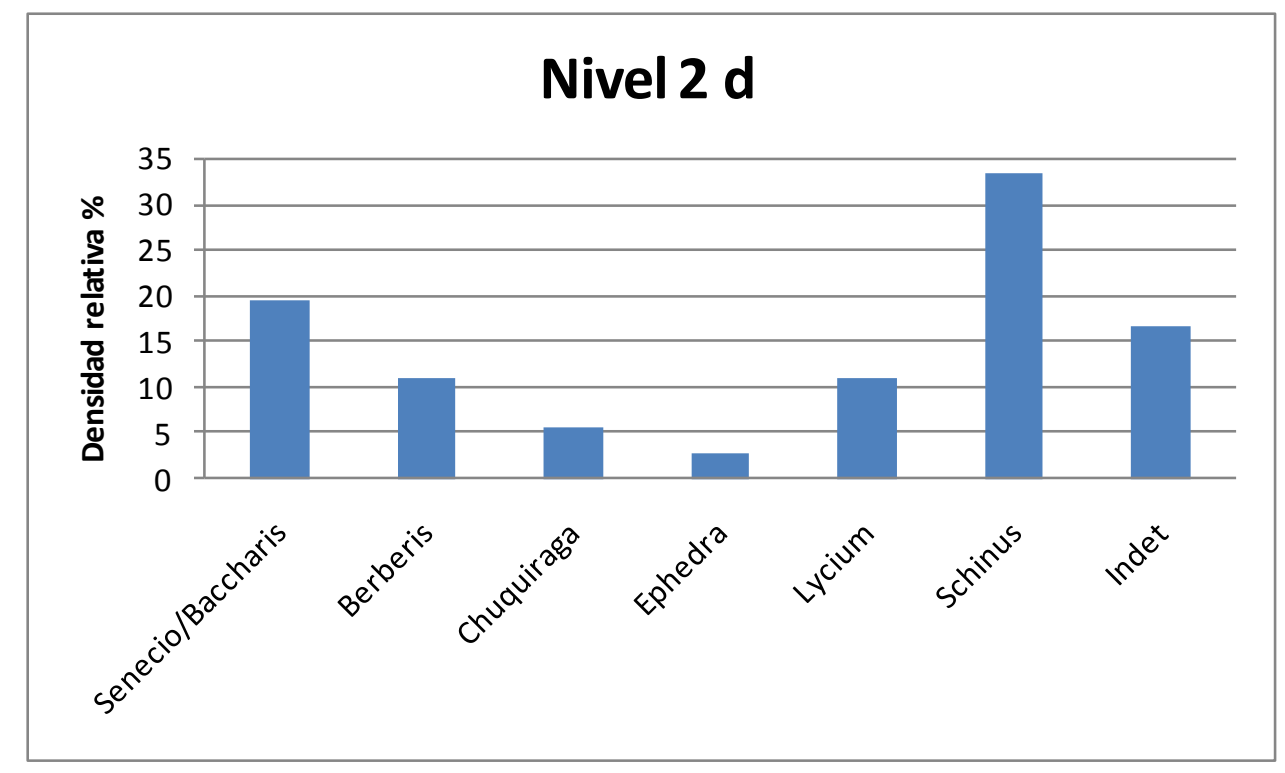

Figura 10.16. Carbones dispersos identificados en las cuadrículas 6 y 7, nivel $2 \mathrm{~d}$ del sitio Alero 4 (submuestra $\mathrm{n}=36$ ).

En los carbones dispersos de la submuestra de este nivel se observó la presencia de xilófagos en Berberis $(\mathrm{n}=1,2,77 \%)$, rasgos de vitrificación en 7 carbones $(17,44 \%)$, identificados como Schinus $(\mathrm{n}=2)$, Berberis $(\mathrm{n}=1)$, Lycium $(\mathrm{n}=1)$ e indeterminables $(\mathrm{n}=3)$. Se observó la médula en 3 carbones $(8,3 \%)$, en Lycium $(\mathrm{n}=2) \mathrm{y}$ Senecio/Baccharis $(\mathrm{n}=1)$. En cuanto a las aberturas producto de la carbonización se observaron en radios y vasos en 6 carbones $(16,6 \%)$ correspondientes a Schinus $(\mathrm{n}=3)$, Nardophyllum $(\mathrm{n}=1)$, Berberis $(\mathrm{n}=1)$ y $\operatorname{Lycium}(\mathrm{n}=1)$.

Es interesante la presencia del género Ephedra ya que en el registro palinológico de la estepa de arbustos enanos es interpretado como un género relacionado a condiciones de aridez y clima frío (De Porras 2010).

En nivel 2e se recuperaron un total de 316 carbones para un volumen de 33,5 1, con una densdad calculada de 9,36 n/l, baja. Las clases diamétricas se ajustaron a un rango de 15-19,9 mm a 2-4,9 mm, registrándose la mayor cantidad de carbones en el intervalo 59,9 mm. La submuestra analizada es de 36 carbones y se identificaron 6 taxa. En esta capa no hay un predominio marcado de un taxa por sobre otro, aunque Schinus y 
Berberis siguen teniendo los porcentajes relativos mayores $(19,4 \%)$, seguidos por Atriplex/Suaeda y Senecio/Baccharis con un 11\% (Figura 10.17).

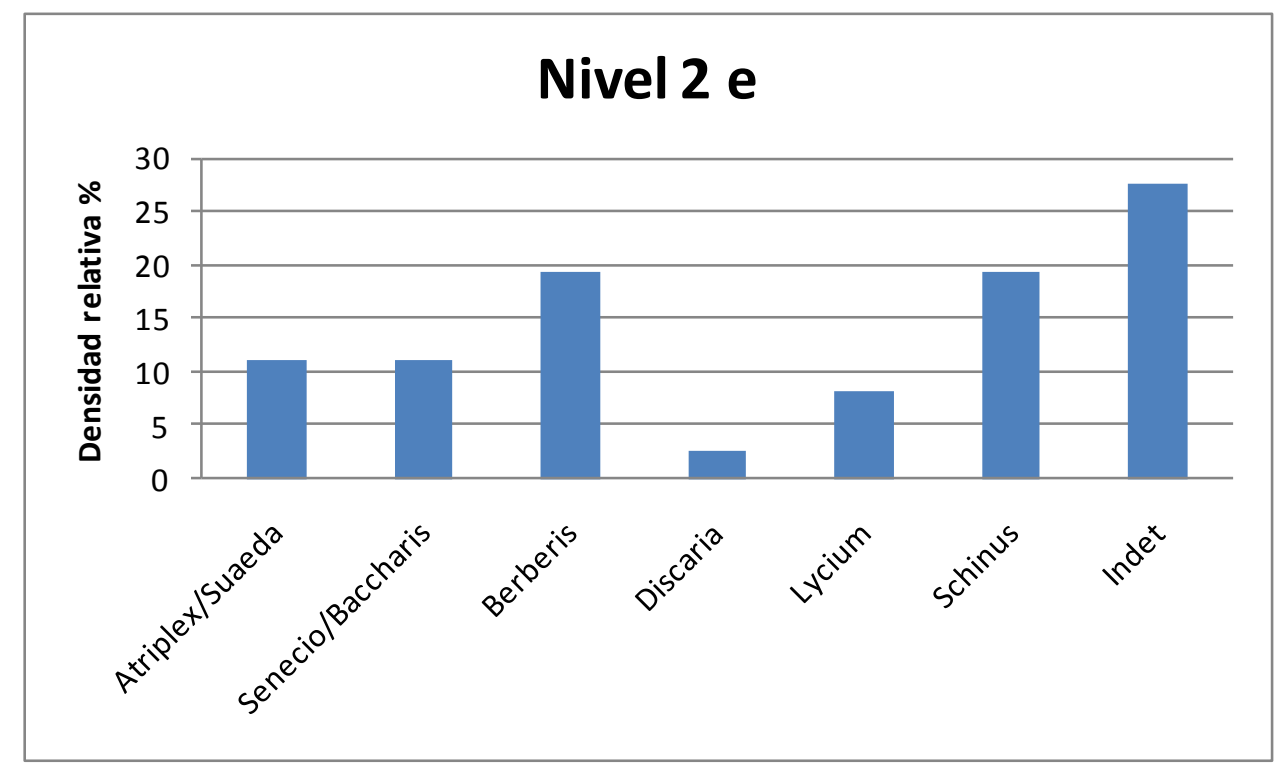

Figura 10.17. Carbones dispersos identificados en las cuadrículas 6 y 7, nivel 2 e, sitio Alero 4 (submuestra $\mathrm{n}=36$ ).

En cuanto a los rasgos de alteración por combustión se observaron 7 carbones $(19,44 \%)$ que presentaron vitrificación, entre ellos, Schinus $(n=3)$, e indeterminables $(n=4)$. En relación a la presencia de médula se observó en 2 carbones $(5,5 \%)$ en Berberis $(\mathrm{n}=1)$ y el otro indeterminable. Se registraron aberturas en radios y vasos en 3 carbones $(8,3 \%)$, en Schinus $(\mathrm{n}=3)$ e indeterminable $(\mathrm{n}=1)$. Continúa observándose la combinación de maderas de distintas densidades y propiedades de combustión, de rápido y fácil encendido con otras de mayor capacidad de brasa y poder calórico.

En el nivel $2 \mathrm{f}$ se recuperó un total de 207 carbones para un volumen de 33,5 1 con 6,13 $\mathrm{n} / 1$, una densidad baja. Las clases diamétricas variaron entre $10-14,9 \mathrm{~mm}$ y 2-4,9 $\mathrm{mm}$ siendo la última la clase la más abundante. En la submuestra analizada se destaca la preponderancia (11 a 16\%) de varios géneros (Schinus, Lycium, Berberis, Senecio/Baccharis y Atriplex/Suaeda), encontrándose en menor escala Discaria y Pinus (3\%) (Figura 10.18). 


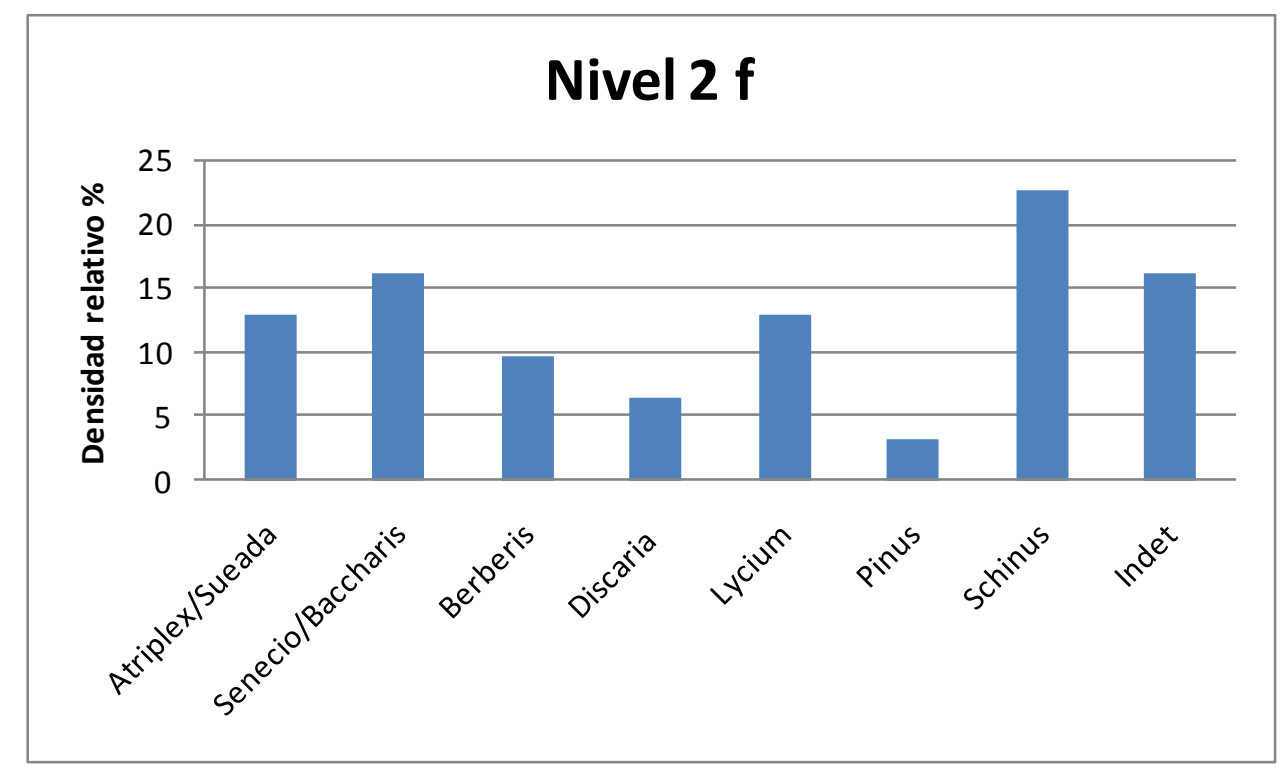

Figura 10.18. Carbones dispersos identificados de las cuadrículas 6 y 7, nivel $2 \mathrm{f}$ del sitio Alero 4 (submuestra $\mathrm{n}=31$ ).

Se observó la presencia de xilófagos en un carbón $(3,2 \%)$ identificado como Senecio/Baccharis. Se registró la presencia de hifas en tres carbones $(9,7 \%)$ pertenecientes a Atriplex/Suaeda, Senecio/Baccharis e indeterminable. En cuanto a los rasgos de alteración de la madera por la combustión se registró vitrificación en 1 carbón $(3,22 \%)$ de Lycium. De este taxón también se observó un carbón con presencia de médula. En cuanto a los rasgos de abertura se registraron en radios, vasos y anillos de 4 carbones $(12,9 \%)$ pertenecientes a Senecio/Baccharis $(\mathrm{n}=3)$, Atriplex/Suaeda $(\mathrm{n}=1)$ y Schinus $(\mathrm{n}=1)$.

Se presenta a continuación (Figura 10.19) los resultados de ubicuidad \% de los carbones dispersos. Los taxa que tuvieron el 100\% de ubicuidad fueron Schinus, Berberis y Senecio/Baccharis, seguidos por Lycium con el 85,7\% y Atriplex/Suaeda con el 71,4\%. 


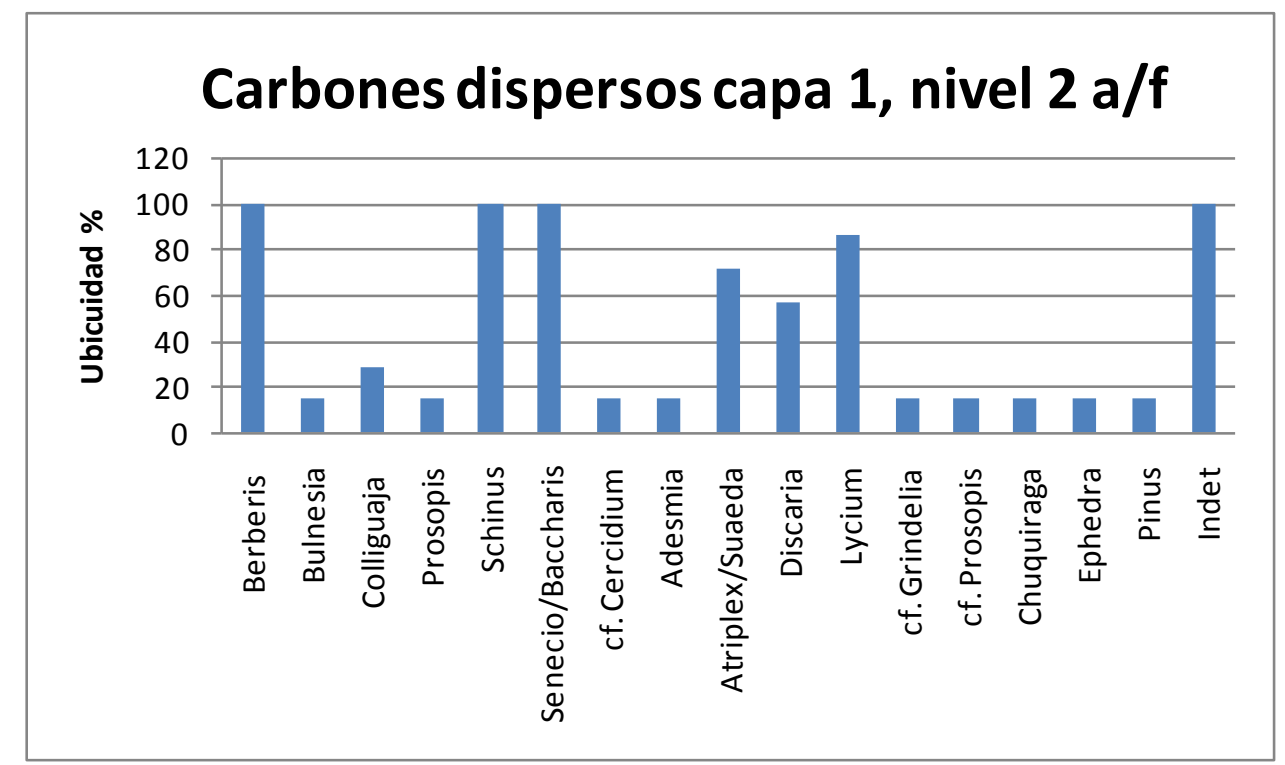

Figura 10.19. Ubicuidad \% de los taxa identificados en los carbones dispersos, capa 1, niveles 2 a-f.

Se realizó el análisis de correlación entre el número de fragmentos de carbones dispersos recuperados por nivel arqueológico y el peso de los mismos (Figura 10.20). Este análisis dio como resultado un $\mathrm{R}^{2}=0,98$ con un nivel de significancia de $\mathrm{p}<0.01$. La asociación positiva entre el número de fragmentos recuperados por nivel arqueológico y el peso total de los restos de cada nivel permite inferir que ningún nivel arqueológico atravesó procesos postdepostacionales significativamente diferentes al resto. 


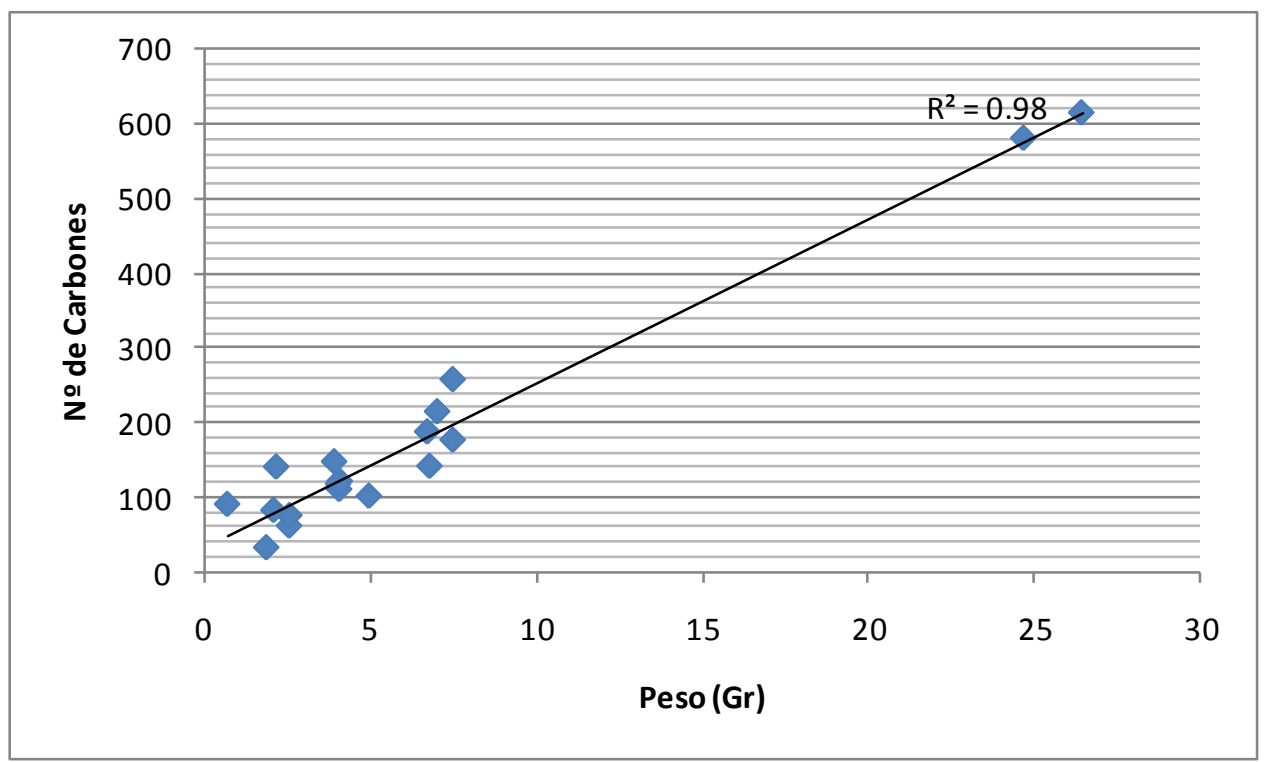

Figura 10.20. Correlación entre el número total de carbones y el peso total de los mismos de carbones dispersos para el sitio Alero 4.

\subsubsection{Discusión y Conclusiones}

En cuanto a la distribución espacial de los fogones en cuevas, Henry (2012) sugiere que los fogones suelen estar más cerca a la pared del abrigo que en la entrada. Sin embargo, el fogón $\mathrm{C}$-que es el que presenta la mayor densidad de carbones- se encuentra próximo a la línea de goteo. Esta ubicación expone a este fogón al viento en mayor medida que los demás fogones analizados, lo que podría haber afectado su tamaño y forma original (reduciéndolo en su estructura). Esto podría explicar la gran cantidad de carbones dispersos registrados en las cuadrículas 6 y 7 donde se encontraba el fogón C. El análisis taxonómico de los carbones de cada fogón sugiere que existió una selección de las maderas utilizadas como combustible por los grupos cazadores recolectores que ocuparon el sitio. Estos taxa presentan diferentes propiedades de valor calórico y funciones dentro del proceso de combustión siendo las de mayor densidad las más utilizadas. Las proporciones y combinaciones entre maderas de baja densidad, intermedias y altas varía de fogón a fogón. Estas diferencias podrían estar respondiendo a la variedad de actividades múltiples a las que estarían asociados dichos fogones según el registro arqueológico del Alero 4.

El fogón $\mathrm{C}$ representaría un evento de mayor duración donde las maderas de alta densidad predominan y podría estar relacionado con la manufactura de herramientas y otras actividades tecnológicas (i.e. trabajo del cuero). El registro de una alta frecuencia 
de raspadores y un punzón de hueso podría estar sugiriendo el desarrollo de estas actividades. En cambio, las características del fogón A sugieren un evento de menor intensidad, asociado al consumo de alimentos (Ambrústolo y Ciampagna 2014). Tanto el fogón A como el C presentan alta riqueza de taxa, mientras que el B presenta solo un taxa, por lo cual se lo asocia a alguna actividad más específica, como por ejemplo la de brindar luz. Se identificó que Senecio/Baccharis presentó el 100\% de ubicuidad para los tres fogones analizados, seguidos por Berberis, Schinus, Lycium y Atriplex/Suaeda con el $66,6 \%$ de ubicuidad.

Es importante mencionar que para el período cronológico del sitio (Holoceno tardío) la vegetación sería análoga a la actual. Los taxones identificados, a excepción de Bulnesia, Pinus y cf. Cercidium, se encuentran hoy en día en el cañadón Torcido donde se sitúa el Alero 4.

Es importante discutir la presencia de Bulnesia y cf. Cercidium entre los carbones dispersos de la capa 1, así como de Pinus en el nivel 2f. Estos taxa no son maderas locales y en el caso de Pinus no es un género nativo. El ingreso de estos carbones a las cuadrículas de excavación sería producto de contaminación, muy probablemente provenientes de un fogón actual observado sobre la pared del alero (ver Figura 10.4), que dados los fuertes vientos de la región, pueden haber caído a la capa 1 y el nivel $2 \mathrm{f}$ de la cuadrícula 6 y 7 durante la excavación. La identificacón del resto de los taxa se considera válida debido a cada uno de los otros eventos se encuentra avalado por un contexto de asociación con una cronología absoluta y relativa. Este es el único caso, el sitio Alero 4, en el que había un fogón expuesto actual cerca de la cuadrícula de excavación y que durante las actividades de trabajo el viento podría haber introducido algún carbón.

Es importante mencionar que la correlación positiva entre el número de fragmentos de los carbones dispersos y el peso total de los mismos permite corroborar que ninguno de los niveles tuvo un proceso postdepositacional diferente. Los carbones dispersos presentaron una ubicuidad del 100\% para Senecio/Baccharis, Berberis y Schinus (estos dos últimos taxa se encontraban en un segundo lugar en el caso de los fogones).

El registro antracológico, especialmente aquellos restos provenientes de los fogones A y $\mathrm{C}$, así como las otras evidencias materiales del sitio (i.e. restos óseos, líticos) reflejan actividades de procesamiento y consumo de recursos marinos y terrestres. Entre los 
restos óseos se identificaron un número mínimo de individuos de dos juveniles y un adulto de Otaria flavescens, y un juvenil y un adulto de Lama guanicoe, así como restos de aves marinas (Ambrústolo y Ciampagna 2014). Los fragmentos óseos presentaban marcas de corte por lo que se infieren actividades de consumo y procesamiento en el sitio. Esta proporción bastante similar de fauna marina y terrestre es novedosa en la CNSC (ver Moreno 2008, Beretta et al. 2011).

En cuanto a los restos malacológicos se identificaron siete especies, donde los mitílidos fueron predominantes. Los más representados son Mytilus edulis y Aulacomya atra, y en menor proporción Perumytilus purpuratus y el gasterópodo Nacella magellanica. Estas especies se encuentran disponibles en la costa de la ría Deseado (Ringuelet et al. 1962; Otaegui y Zaixso, 1974).

Este contexto arqueológico, sumado a la gran cantidad de raspadores, sugiere que la ocupación de este sitio alero, para el Holoceno tardío, no habrían sido de corta duración, sino que habrían estado relacionadas con la explotación de recursos marinos y terrestres y un uso estratégico del espacio (Ambrútolo y Ciampagna 2014). La evidencia de varios fogones con densidades medias de carbón, uno con un solo taxa presente y otros dos con alta riqueza específica (5 a 8 taxa), la abundancia y gran riqueza de taxa representada en los carbones dispersos del sitio, sumado a una preponderancia de maderas densas, aunque también la representación de maderas más livianas, permite pensar en una multiplicidad de actividades relacionadas con el fuego.

\subsection{Subsector Bahía del Oso Marino}

\subsubsection{Antecedentes recientes}

El subsector Bahía del Oso marino se encuentra al sur de la playa Barco Hundido y se extiende hasta Punta Foca (Zubimendi 2010). En cuanto a la provincia geológica, pertenece al Nesocratón del Deseado donde se observan rocas ingimbríticas cuarcíferas (Codignoto 2000). Este sector presenta diferencias con los anteriores, ya que tiene costas irregulares con paredones o acantilados sedimentarios y playas extensas de arena. $\mathrm{Su}$ interior inmediato tiene mayor diversidad de ambientes que los sectores anteriores, principalmente producto de los extensos mantos rocosos existentes, que conforman 
estrechos cañadones, y paredones rocosos. En cuanto a la vegetación, el subsector se encuentra dentro del área de distribución de la estepa arbustiva del golfo San Jorge, no obstante hacia el interior domina la estepa de arbustos enanos (Oliva et al. 2001).

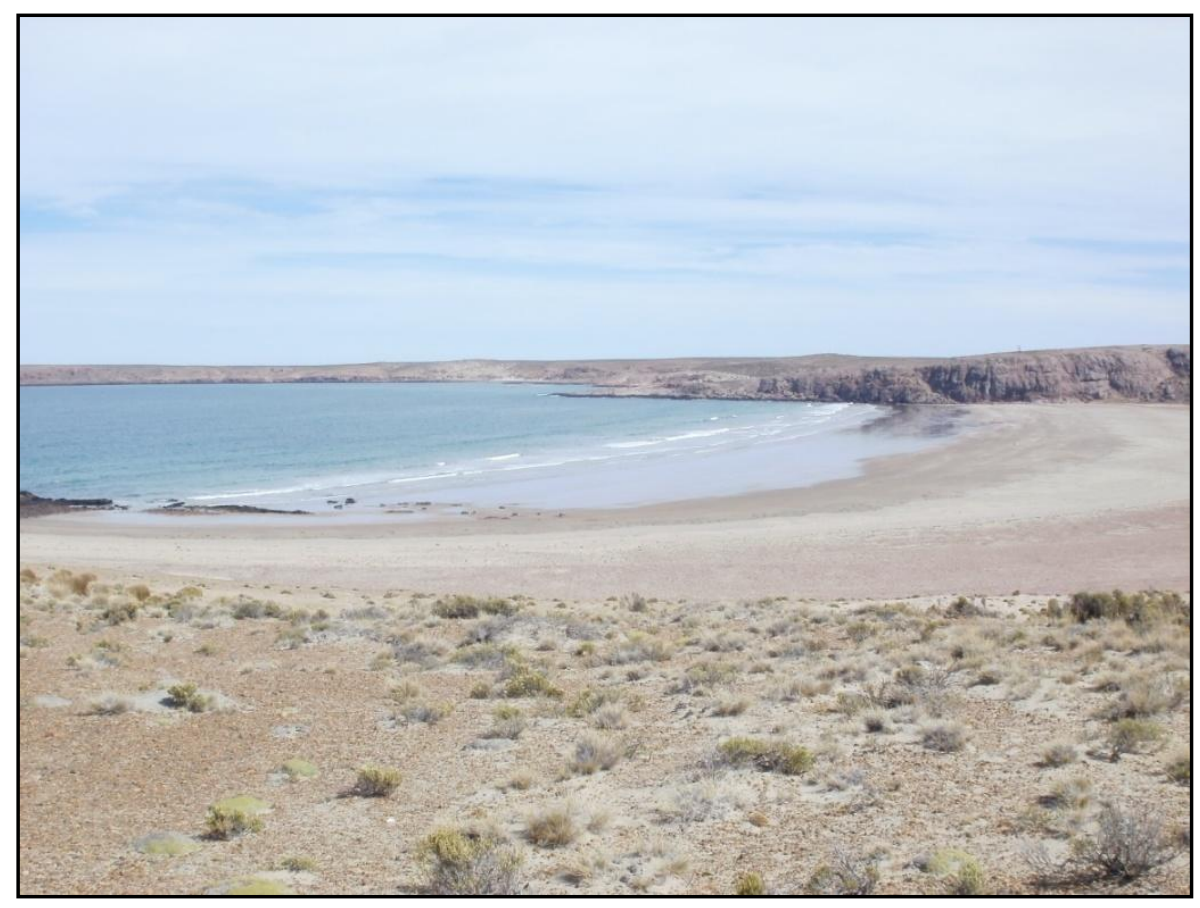

Figura 10.21. Subsector Bahía del Oso Marino al sur de la ría Deseado

Los recursos faunísticos se encuentran dispersos en forma heterogénea en el sector, existen espacios de costa con una alta concentración de fauna y otros sectores con baja densidad. Los recursos faunísticos que presenta este sector son: bancos de moluscos, pinnípedos, aves marinas y guanaco hacia el interior (Zubimendi 2010).

Los estudios arqueológicos de este sector se realizaron a partir de análisis distribucionales de artefactos líticos (Zubimendi 2010; Zubimendi y Zilio 2013), fuentes de materias primas (Ambrústolo 2011), estudios tecnológicos líticos (Castro y Mazzitelli 2011) análisis arqueofaunísticos (Beretta et al. 2011), estudio de sitios enterratorios (Zilio 2013) y excavaciones sistemáticas, tanto en aleros como en concheros (Hammond 2013). En el primer caso, Zubimendi (2010) y Zubimendi y Zilio (2013) registra para este sector diferencias en el uso de las distintas unidades del paisaje. La meseta alta, el flanco de meseta, y las lagunas habrían tenido un uso marginal y distanciado en el espacio, con partidas logísticas específicas para actividades acotadas o producto de actividades de grupos poco numerosos. La costa por el contrario, 
habría tenido distintos patrones de uso, en aquellas donde se registran una gran riqueza de recursos faunísticos, se observa una alta frecuencia artefactual, que habría tenido una alta redundancia ocupacional de bases residenciales de grupos numerosos o con una permanencia larga de la costa y en otros tramos costeros se observarían eventos puntuales de ocupación. Para este sector el fechado más antiguo es de $6930 \pm 100$ (LP2218) correspondiente al último estrato del alero El Oriental (Ambrústolo et al. 2011) y el más reciente $370 \pm 40$ años AP (LP- 2504) del sitio conchero Las Hormigas (Hammond 2013).

\subsubsection{Alero El Oriental}

\subsubsection{Introducción}

El Alero El Oriental es un abrigo rocoso que forma parte de un afloramiento de rocas porfíricas del Grupo Bahía Laura (Giacosa 1998), situado en el subsector Bahía del Oso Marino, en la cabecera del cañadón del Barco (Ambrústolo et al. 2011), que desemboca en la costa norte de la punta homónima (Figura 10.22). En relación a la línea de costa actual, el sitio se ubica a 1,2 km hacia el sur y a 1,6 km hacia el oeste del frente atlántico. El frente del sitio se orienta hacia el sudoeste, con una profundidad de la línea de goteo hacia la pared del abrigo de $c a .2 \mathrm{~m}$ y el largo del paredón alcanza los 9,5 m. Afuera del sitio y en sus alrededores se observan matas de coirones (Pappostipa sp.), calafate (Berberis sp.) y malva rubia (Marrubium vulgare). 


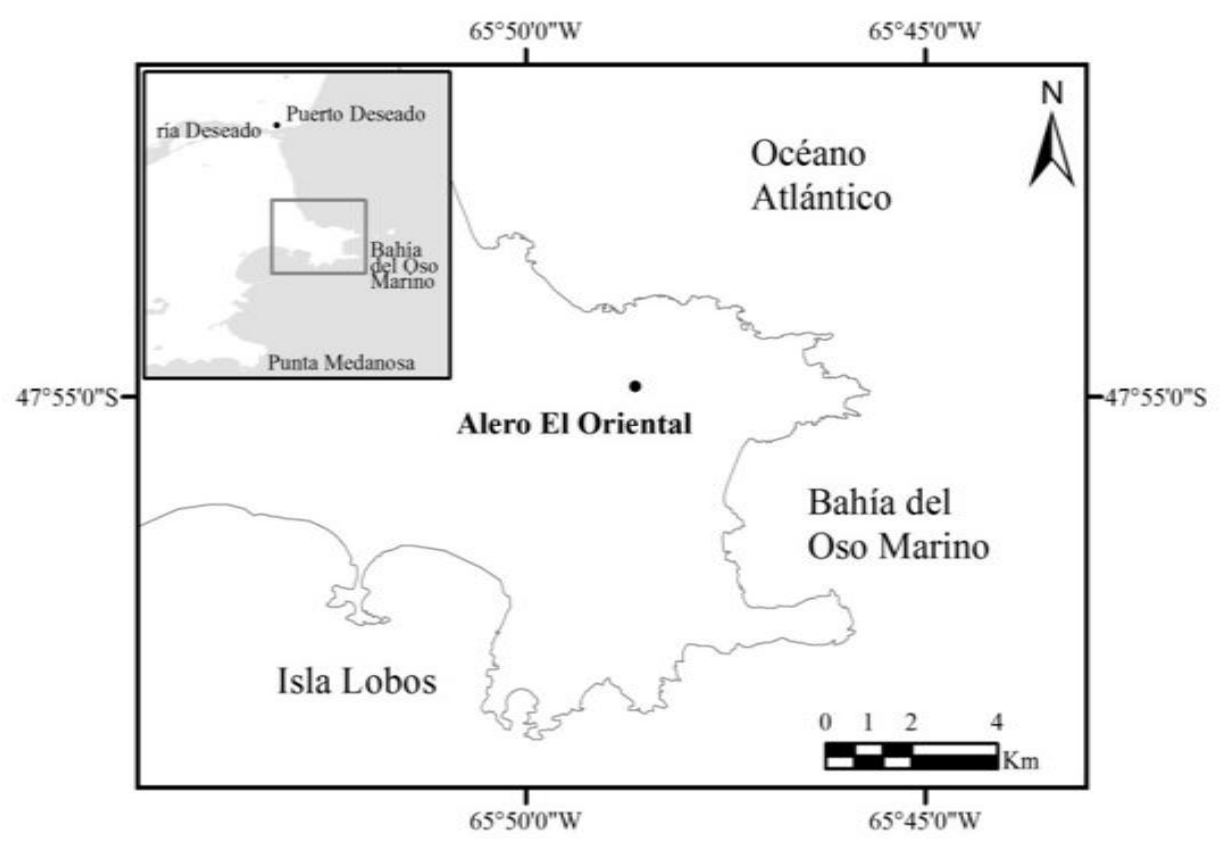

Figura 10.22. Ubicación del sitio Alero El Oriental.

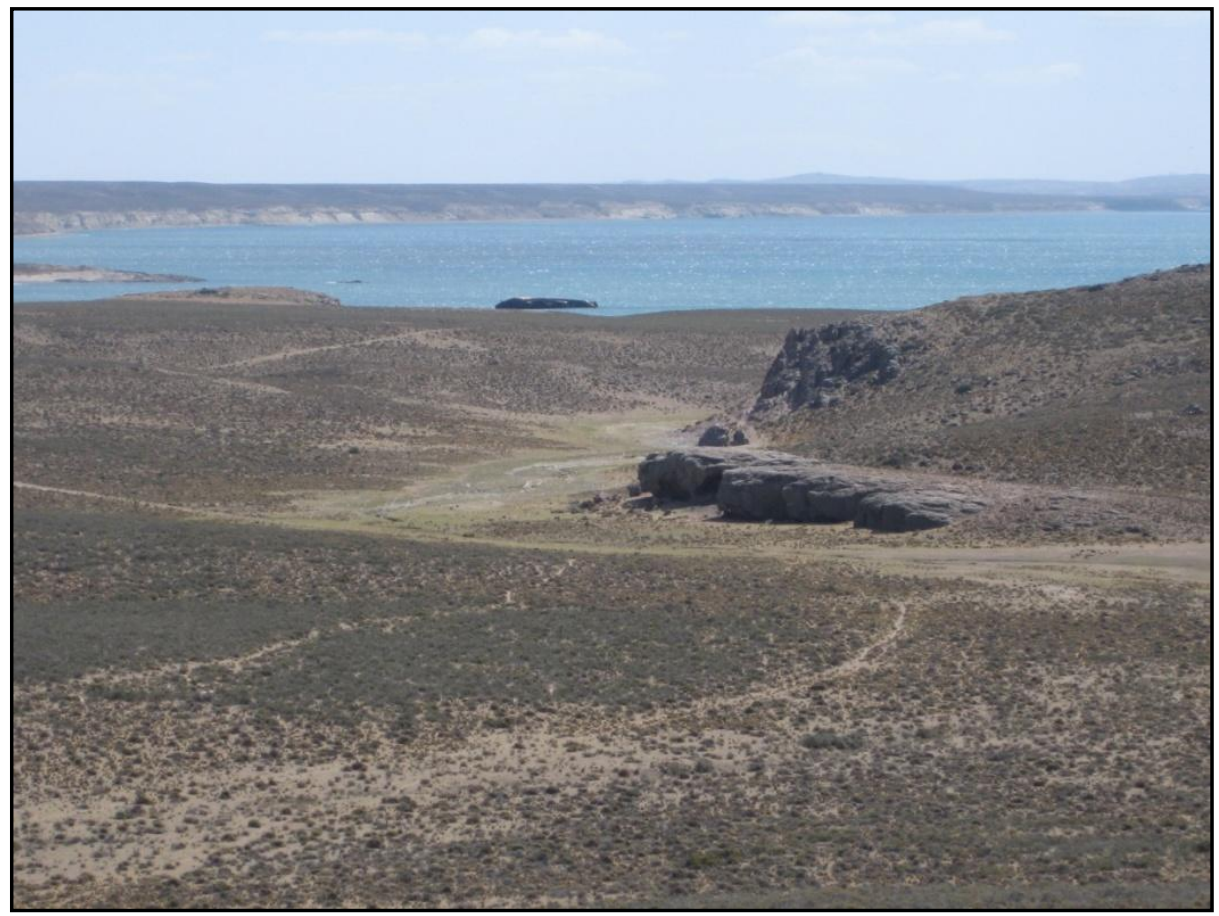

Figura 10.23. Afloramiento Bahía Laura donde se encuentra el Alero El Oriental (Foto de Pablo Ambrústolo). 


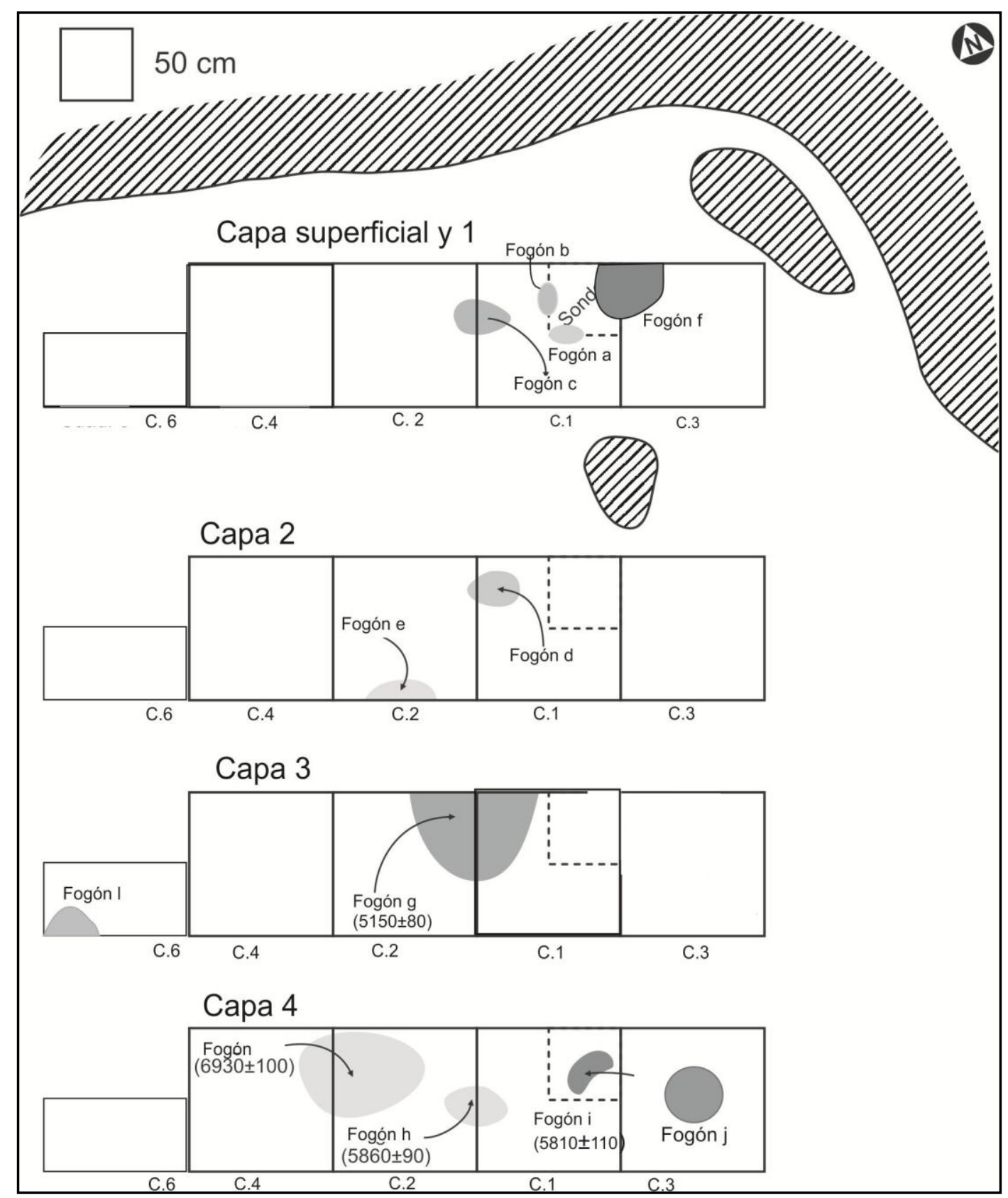

Figura 10.24. . Esquema de planta donde se observan la totalidad de los fogones hallados

El estudio del sitio fue dirigido por el Dr. Ambrústolo, quien excavó ca. 30\% de la superficie total de alero, hasta una profundidad máxima de $30 \mathrm{~cm}$. Para este sitio se realizaron cinco fechados provenientes de estructuras de combustión (Tabla 10.1) entre los que se registra la datación más antigua para el registro arqueológico de la CNSC (6930 \pm 100 LP-2218) y una secuencia de ocupación desde el Holoceno medio al tardío (Ambrústolo et al. 2011). El registro arqueológico del sitio presenta restos 
malacológicos, óseos, líticos y antracológicos que serán presentados luego de describir el contexto estratigráfico.

\subsubsection{Metodología}

\subsection{Excavación}

En primer lugar se realizó un sondeo estratigráfico de 0,50 x 0,50 m en el que se excavó teniendo en cuenta los cambios en la composición y la estructura del sedimento, es decir por capas naturales, y se identificaron cinco estratos. A partir de los fechados radiocarbónicos que se realizaron con carbón vegetal de las estructuras de combustión se definieron tres componentes (inferior, medio y superior).

\subsection{Recuperación de macrorrestos}

Se delimitaron las estructuras de combustión y se mapearon a fin de registrar e interpretar el uso del espacio en el interior del abrigo rocoso (sensu Frank 2011). A excepción de los carbones provenientes de los fogones que se enviaron a fechar, cada estructura de combustión fue recuperada en su totalidad y dispuesta en bolsas para ser tamizada en laboratorio con mallas de 2000,800 y $400 \mu \mathrm{m}$.

\subsubsection{Contexto estratigráfico}

Las capas se identificaron por la composición, color y estructura del sedimento. La capa superficial está conformada por una capa de guano suelto en el sector superior y guano compactado en la base. Asimismo, se registraron algunos pequeños bloques de rocas porfíricas que serían producto de la meteorización de la roca que conforma el abrigo. La capa 1 presenta un sedimento arenoso fino de color castaño (Figura 10.25). Debido al grado de selección y homogeneidad que presenta el depósito estaría indicando una posible génesis vinculada con procesos de acción eólica. La siguiente, capa 2 , está conformada por un sedimento arenoso de color castaño claro, poco consolidado. Se registran pequeños litos producto de la meteorización de la roca que conforma el abrigo. 
Se identificó un gran fogón en cubeta en el sector noreste de la cuadrícula 1 y una lente de carbón asociada al perfil sur. En la capa 3 se registra un sedimento arenoso grueso de coloración castaño rojizo, que se presenta muy desagregado y con gran cantidad de pequeños clastos de pórfido. Hacia el centro de la cuadrícula 1 se registró una pequeña lente de carbón. La capa 4 presenta un sedimento arenoso castaño oscuro. Está más consolidada que la capa anterior, tiene mayor humedad y presenta menor cantidad de litos. Se identificaron dos lentes de carbón asociadas al perfil Sur de la cuadrícula 1 (Ambrústolo 2011). Las capas superficiales, 1 y 2 conforman el componente superior, mientras que la capa 3 el medio y la capa 4 , el inferior.

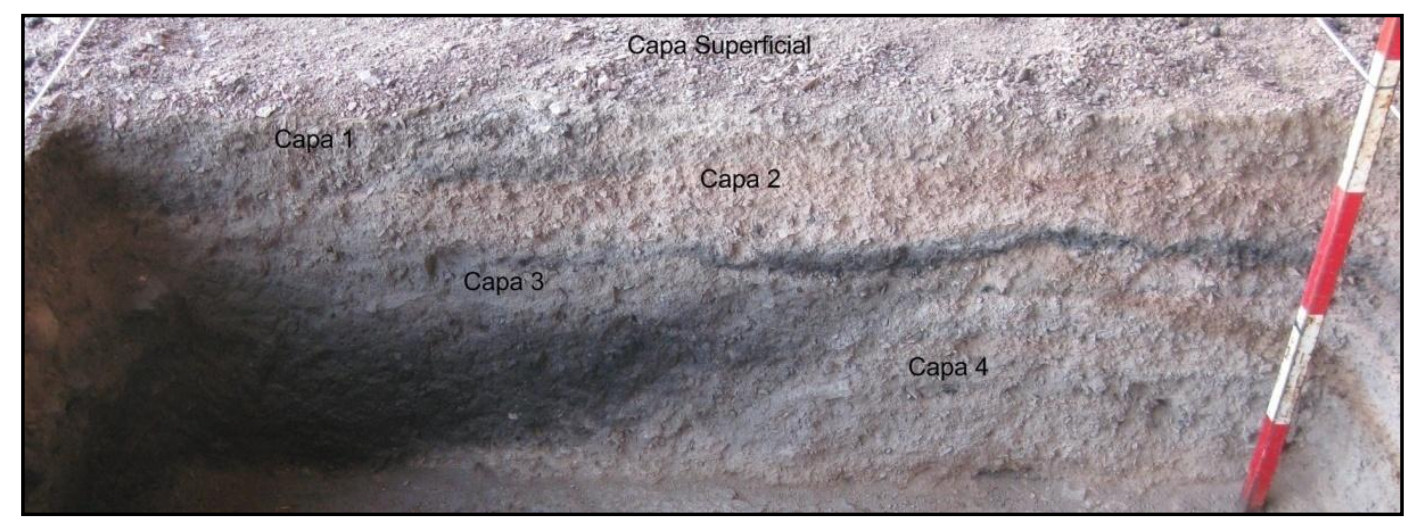

Figura 10.25. Vista de la estratigrafía en cuadrícula 1, perfil Oeste, sitio Alero El Oriental 


\begin{tabular}{|c|c|c|c|c|c|c|c|c|c|c|}
\hline $\begin{array}{l}\text { Componente } \\
\text { estratigráfico }\end{array}$ & Lítico & Huesos & Valvas & $\begin{array}{l}\text { Fogó } \\
\mathrm{n}\end{array}$ & Tipo & Cuad. & $\begin{array}{l}\text { Medidas } \\
(\mathrm{cm})\end{array}$ & $\begin{array}{l}\text { Potencia } \\
(\mathrm{cm})\end{array}$ & $\begin{array}{l}\text { Fechado } \\
\left(\text { años } \mathrm{AP}{ }^{14} \mathrm{C}\right)\end{array}$ & $\begin{array}{l}\text { Fechado } \\
\text { (años AP } \\
\text { calib.)** }\end{array}$ \\
\hline \multirow{6}{*}{ Superior } & \multirow{6}{*}{$47(8,9 \%)$} & \multirow{6}{*}{$18(23,3 \%)$} & \multirow{6}{*}{$1(2 \%)$} & $\mathbf{A}$ & Plano & 1 & $10 \times 20$ & 2 & - & - \\
\hline & & & & B & Plano & 1 & $10 \times 20$ & 2 & - & - \\
\hline & & & & $\mathrm{C}$ & Plano & $1-2$ & $40 \times 25$ & 2 & - & - \\
\hline & & & & D & Plano & $1-2$ & $25 \times 30$ & 2,5 & - & - \\
\hline & & & & $\mathbf{E}$ & Plano & 2 & $10 \times 30 *$ & 2 & - & - \\
\hline & & & & $\mathbf{F}$ & Cubeta & $1-3$ & $45 \times 40 *$ & 6 & $1530 \pm 60(\mathrm{LP}-2267)$ & $1535-1310$ \\
\hline \multirow{2}{*}{ Medio } & \multirow{2}{*}{$247(47,3 \%)$} & \multirow{2}{*}{$43(55,8 \%)$} & \multirow{2}{*}{-} & $\mathrm{G}$ & Plano & $1-2$ & $70 \times 60 *$ & 3 & $5150 \pm 80($ LP-2311) & $6178-5668$ \\
\hline & & & & $\mathbf{L}$ & Plano & 6 & $20 \times 20$ & 1 & - & - \\
\hline \multirow{4}{*}{ Inferior } & \multirow{4}{*}{$229(43,7 \%)$} & \multirow{4}{*}{$16(20,7 \%)$} & \multirow{4}{*}{$48(98 \%)$} & $\mathbf{H}$ & Plano & $1-2$ & $35 \times 25$ & 3,5 & $5860 \pm 90(\mathrm{LP}-2310)$ & $6893-6452$ \\
\hline & & & & $\mathrm{I}$ & Plano & 1 & $20 \times 15$ & 3 & $5810 \pm 110(\mathrm{LP}-2218)$ & $6893-6351$ \\
\hline & & & & $\mathbf{J}$ & Plano & 3 & $60 \times 20$ & 2 & - & - \\
\hline & & & & $\mathrm{K}$ & Plano & $2-4$ & $70 \times 60$ & 3,5 & $6930 \pm 100(\mathrm{LP}-2318)$ & $7948-7595$ \\
\hline
\end{tabular}

Tabla 10.1. Características de los componentes estratigráficos diferenciados. $(*)$ en las medidas indica que las mismas no corresponden

a la totalidad de la estructura de combustión debido a que se interceptaron por los perfiles de excavación. (**) fechas calendáricas calibradas con 2 desviaciones estándar OxCalv.4. i, Bronk Ramsey (2009); r:5 ShCal04 Suthern hemisphere atmospheric curve (McCormac et al. 2004). 
10.2.4. Estudio arqueológico

Se recuperó un total de 523 artefactos líticos, siendo el componente medio donde se registró la mayor frecuencia artefactual $(n=247)$. En los tres componentes se observa un predominio de los productos de talla en relación a los artefactos formatizados y los núcleos. Las materias primas utilizadas son las silíceas de buena a muy buena calidad para la talla. Dentro de éstas son las calcedonias opacas las más abundantes y le siguen las calcedonias translúcidas. En porcentajes menores se identificaron la riolita, el basalto, el ópalo, el vidrio riolítico, la toba y la obsidiana negra.

En los tres conjuntos se evidencia una alta proporción de artefactos con evidencias relacionadas con actividades de talla intermedia dentro de la secuencia de reducción lítica (entre el 70 y el 90\%). No se encontraron núcleos en el componente medio, pero sí en los otros dos (superior e inferior) en bajas frecuencias. Se identificaron artefactos formatizados en los tres componentes estratigráficos, entre los que se han recuperado artefactos con filo denticulados confeccionados sobre calcedonias opacas. Mayoritariamente estos ejemplares se registraron en el componente medio, junto con raspadores frontales y un cuchillo. En el componente superior se obtuvieron dos lascas de calcedonia para la talla y un denticulado confeccionados sobre una lasca angular de calcedonia. En el componente inferior se identificaron cinco artefactos formatizados, dos denticulados, dos fragmentos de raedera, y un raspador doble. La causa de abandono de los mismos se relaciona con la presencia de fracturas o el embotamiento de los filos. Se observaron evidencias diagnósticas de alteración térmica en la superficie de los artefactos (hoyuelos y craquelados), siendo el $12,1 \%$ del total de los ejemplares en los que se registraron dichos rasgos.

Por otra parte los tres componentes estratigráficos presentaron especímenes óseos $(\mathrm{n}=77)$. La mayoría se identificaron en la cuadrícula $2(73,9 \%)$ y en menor medida en la 1 y la 4 (17,8\% y 6,8\% respectivamente), mientras que en la cuadrícula 3 se identificó sólo un fragmento óseo (1,4\%). Es en el componente medio donde se registraron la mayor cantidad de restos óseos $(55,8 \%)$ mientras 
que en el componente inferior y en el superior, el porcentaje de éstos es considerablemente menor (23,4\% y 20,8\%) (Ambrústolo et al. 2011).

El $80 \%$ de los restos óseos corresponde a mamíferos, mientras que las aves son el 20\%. Los análisis zooarqueológicos determinaron la presencia de otáridos (familia Otariidae), guanaco (Lama guanicoe), tucu tucu (Chtenomys sp.), mara (Dolichotis patagonum), y piche patagónico (Zaedyus pichy). Entre las aves se registraron albatros de ceja negra (Thalassarche melanophys), pingüinos de Magallanes (Spheniscus magellanicus), gaviotas (Larus sp.), chorlito (Calidris sp.) y ostrero (Haematopus sp.).

El componente medio es el que presenta mayor riqueza de especies, aunque casi todas en muy bajas frecuencias de restos esqueletales. La relación entre aves y mamíferos es diferente según los componentes, las primeras se encuentran en porcentajes más altos en el componente inferior y medio y, disminuyen en el superior.

Si se agrupan las especies en terrestres (Lama guanicoe, Ctenomys sp., Dolichotis patagonum, y Zaedyus pichy) y marinas (Thalassarche melanophys, Spheniscus magellanicus, Larus sp, Calidris sp y Haematopus sp.), las primeras tienen una mayor representación en el componente superior, mientras que las segundas lo tienen en el componente medio e inferior.

Por otra parte se recuperaron restos malacológicos, siendo 49 el total de valvas enteras o fragmentadas cuantificables como valvas individuales. Se identificaron tres especies de gasterópodos y tres de bivalvos mitílidos. Los restos malacológicos se hallan espacialmente asociados a las estructuras de combustión, la mayor parte al fogón $\mathrm{K}$ y un único resto asociado al fogón $\mathrm{C}$ (Ambrústolo et al. 2011).

Los mejillones (Mytilus edulis) y las cholgas (Aulacomya ater) son las especies más numerosas, seguidas por mejillines (Perumytilus purpuratus) y caracoles (Trophon sp.). El resto de las especies (Nacela magellanica y Iotia coppingeri) se presenta en muy bajas frecuencias. Se evidencia un alto porcentaje de los mitílidos (70\%), aunque no se registra un predominio de una especie por sobre otra. De las especies recuperadas sólo los mitílidos y Nacela magellanica se asocian al consumo antrópico (Zubimendi et al. 2005, Zubimendi 2012, Hammond 2013), 
siendo el resto acompañantes de las seleccionadas. Todas estas especies tienen su hábitat en el intertidal de intermareales duros o rocosos, como las playas rocosas existentes en las costas cercanas.

\subsubsection{Resultados antracológicos}

A lo largo de la secuencia estratigráfica se identificaron once estructuras de combustión en los tres componentes estratigráficos diferenciados (inferior, medio y superior) (Figura 10.24). En el componente superior se registra la mayor cantidad de fogones, denominados A, B, C, D, E y F, este último posee un fechado de $c a$. 1500 años AP. Los dos primeros son pequeños, de forma circular y se identificaron en la cuadrícula 1; las estructuras C y D se registraron entre las cuadrículas 1 y 2, el E en la cuadrícula 2 y el F entre la 1 y la 3 (Figura 10.24). En el fogón $\mathrm{C}$ se recuperó un resto de valva perteneciente a la especie Nacella magellanica (Figura 10.25) y en la estructura D se hallaron artefactos líticos con alteración térmica (microlascas y lascas de adelgazamiento). El fogón E corresponde a una lente de dimensiones acotadas que se continúa sobre el perfil sur de la cuadrícula 2 (Figura 10.24). En el fogón F se registraron artefactos líticos, entre ellos una lasca secundaria de obsidiana negra. En cuanto a la forma de las estructuras, cabe mencionar que los cinco primeros fogones son planos con una potencia de 2 a 2,5 cm, mientras que el fogón F se presenta "en cubeta" con una potencia aproximada de $6 \mathrm{~cm}$. Las estructuras A, B, C y D han sido medidas en su totalidad mientras que, las $\mathrm{E}$ y $\mathrm{F}$ son interceptadas por perfiles estratigráficos por lo que solo se cuenta con medidas parciales. 


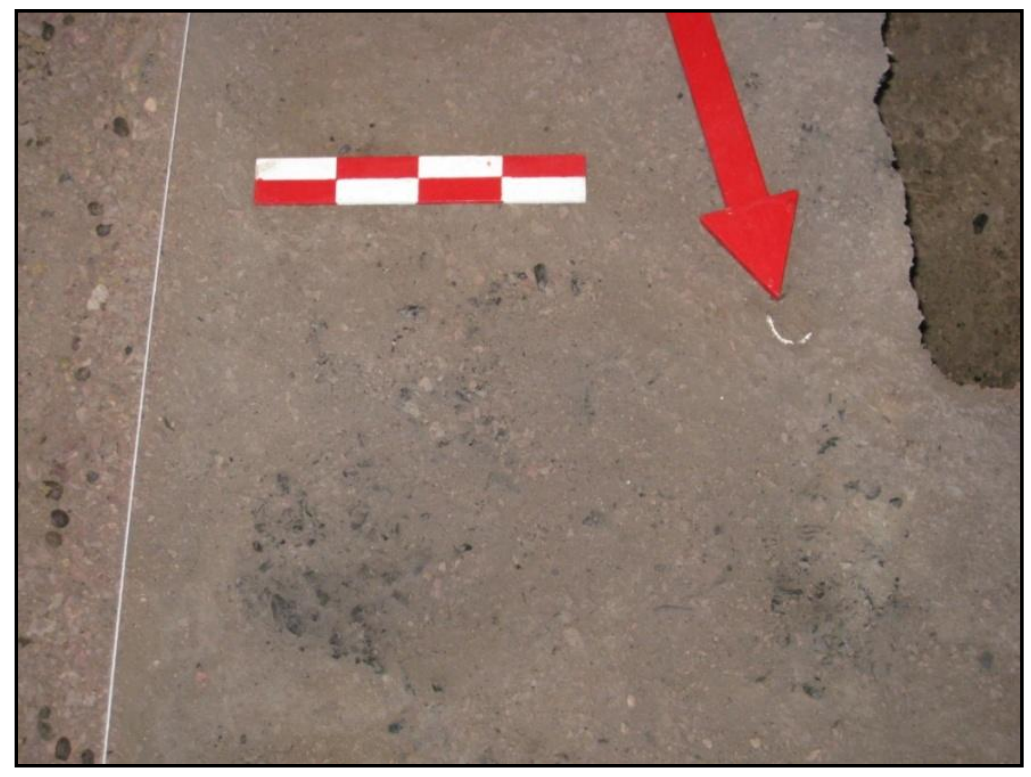

Figura 10.26. Fogón C, la flecha señala un resto de Nacella magellanica

El componente medio presenta la estructura de combustión G datada en $c a .5100$ años AP. La misma abarca parte de las cuadrículas 1 y 2 , y es atravesada por el perfil norte de la excavación (Figura 10.24), por lo que sus medidas no refieren a su totalidad. Dentro del fogón se recuperaron restos óseos de guanaco (Lama guanicoe) y artefactos líticos. Su morfología corresponde a un fogón plano con una potencia de $3 \mathrm{~cm}$. En la cuadrícula 6, para este componente, se observó una estructura de combustión de menor dimensión (L), si bien en las capas superiores se recuperaron artefactos líticos no se encontraron asociados directamente al fogón.

En el componente inferior se registraron cuatro fogones (H, I, J y K), de los cuales tres han sido datados arrojando antigüedades entre $c a .7000$ y 5800 años AP (Ambrústolo et al. 2011). Los fogones de este componente son de tipo plano y extendido denominados también "en plato" con potencias comprendidas de 2 a 3,5 cm (Tabla 10.1). El fogón $\mathrm{K}$ presenta una mayor dimensión respecto de los superiores (H, I y J) abarcando la mitad de la cuadrícula 2 y extendiéndose hacia la 4 (Figura 10.24 y 10.27). En esta lente de carbones se hallaron valvas tiznadas y artefactos líticos (ver más arriba). La estructura de combustión J se registró en la cuadrícula 3, la I en la 1 y la H se identificó en el sector central de la excavación entre las cuadrículas 1 y 2 . 


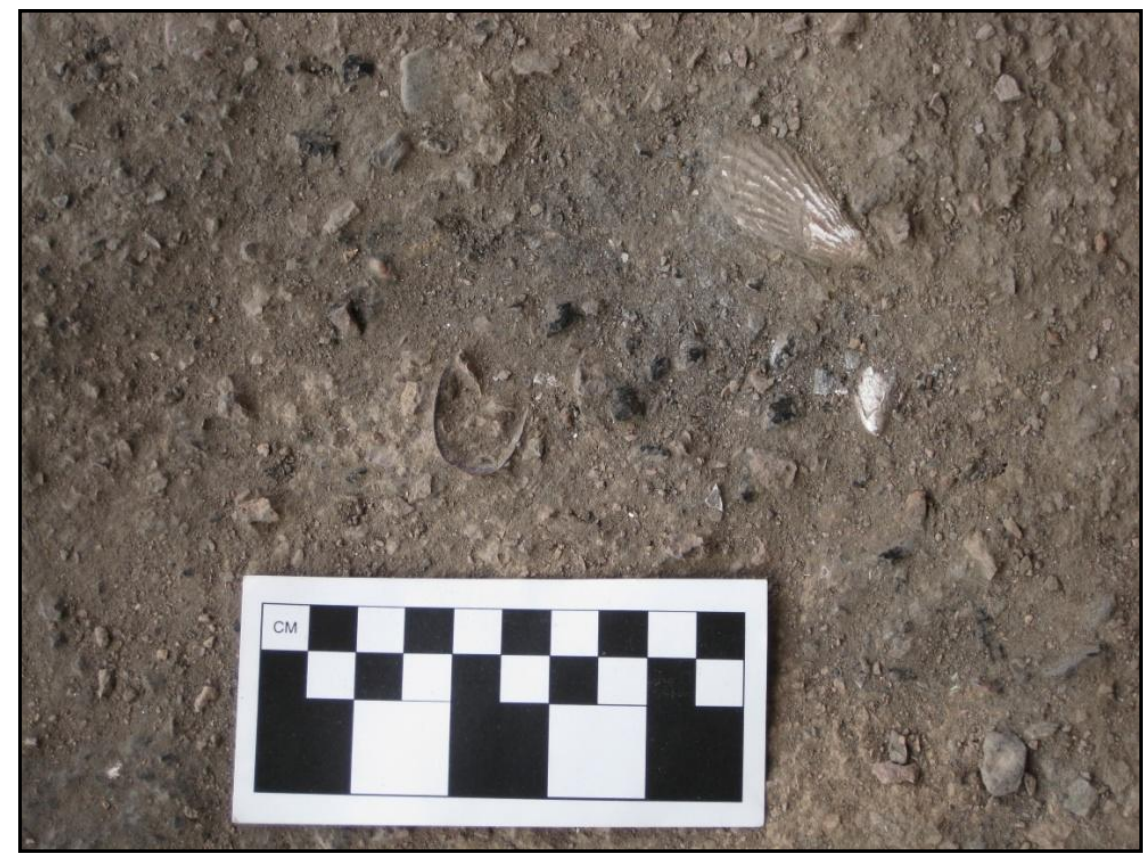

Figura 10.27. Fogón K, se observa restos de carbones asociados a mitílidos. Los carbones de este fogón fueron utilizados para un fechado radiocarbónico (Fotografía Pablo Ambrústolo).

A continuación se presentan los resultados antracológicos de los fogones estudiados, el fogón $\mathrm{J}$ y $\mathrm{H}$ del componente inferior, el fogón $\mathrm{L}$ del componente medio y todos los fogones del componente superior. Aquellos que no han sido analizados en esta tesis son los que han sido enviados para obtener fechados radiocarbónicos.

Del Fogón A se recuperó un total de 226 carbones en un volumen de 0,18 1 y una densidad calculada de $1256 \mathrm{n} / \mathrm{l}$, clasificada como alta. Se observaron las clases diamétricas de 20-24,9 $\mathrm{mm}$ a 2-4,9 $\mathrm{mm}$ siendo la clase de 5-9,9 $\mathrm{mm}$ la que registró mayor cantidad de carbones. La submuestra analizada fue de 30 carbones y se identificaron dos taxa: Lycium y Senecio /Baccharis. La densidad relativa porcentual evidencia el predominio de Senecio/Baccharis $(86,7 \%)$ por sobre el restante taxa (Figura 10.28). 


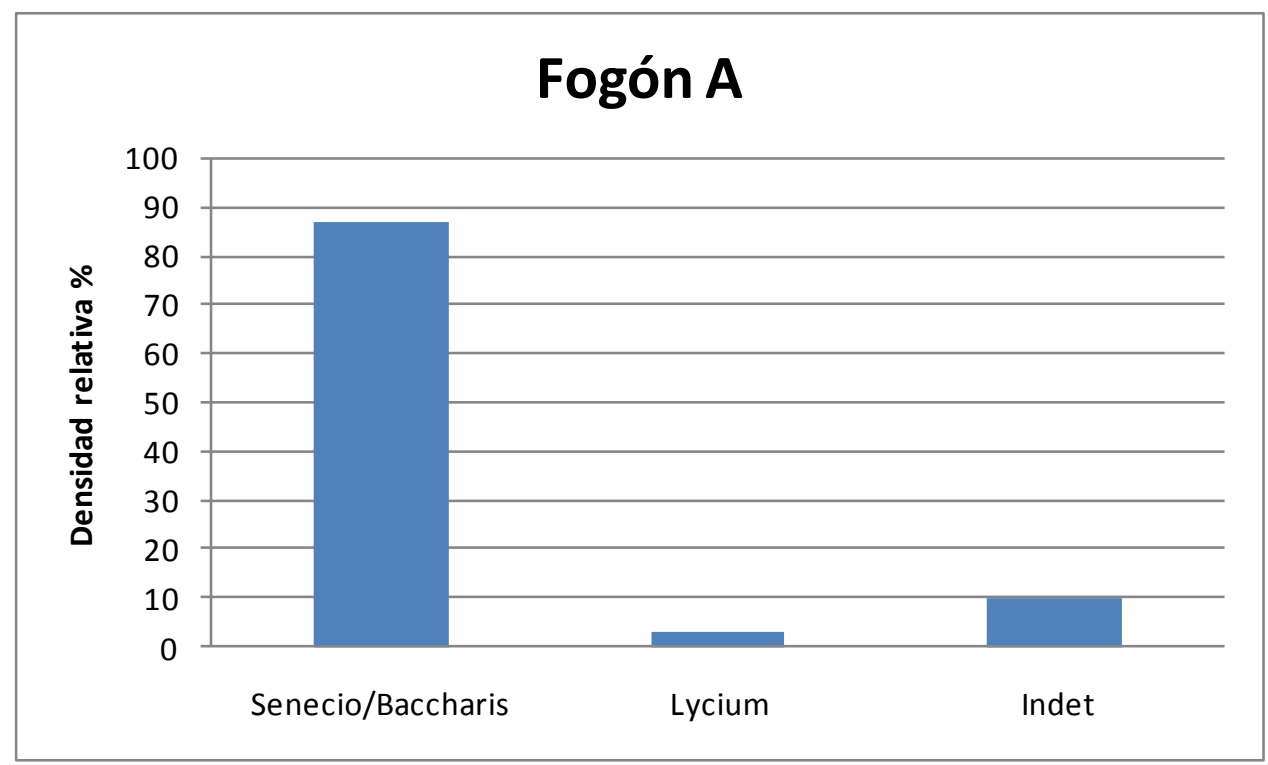

Figura 10.28. Carbones identificados del Fogón A, cuadrícula 1, componente superior, Alero El Oriental (submuestreo $\mathrm{n}=30$ ).

Se registraron rasgos de vitrificación en 2 carbones $(6,6 \%)$ identificados como Senecio/Baccharis $(\mathrm{n}=1)$ y Lycium $(\mathrm{n}=1)$. En cuanto a la presencia de médula se registró en 6 carbones (20\%) pertenecientes a Senecio/Baccharis $(\mathrm{n}=5)$, Lycium $(\mathrm{n}=1)$. En cuanto a los rasgos de aberturas debido a la combustión se observaron en radios en $3(10 \%)$ carbones de Senecio/ Baccharis.

Del fogón B se recuperaron 890 carbones de 0,3 1, habiéndose calculado entonces una densidad de 2966 n/l, determinada como alta. Las clases diamétricas son de 20-24,9 mm a 2-4,9 mm siendo el intervalo de 5-9,9 $\mathrm{mm}$ el de mayor cantidad de carbones. La submuestra analizada es de 94 carbones y se identificaron 6 taxa (Figura 10.29). 


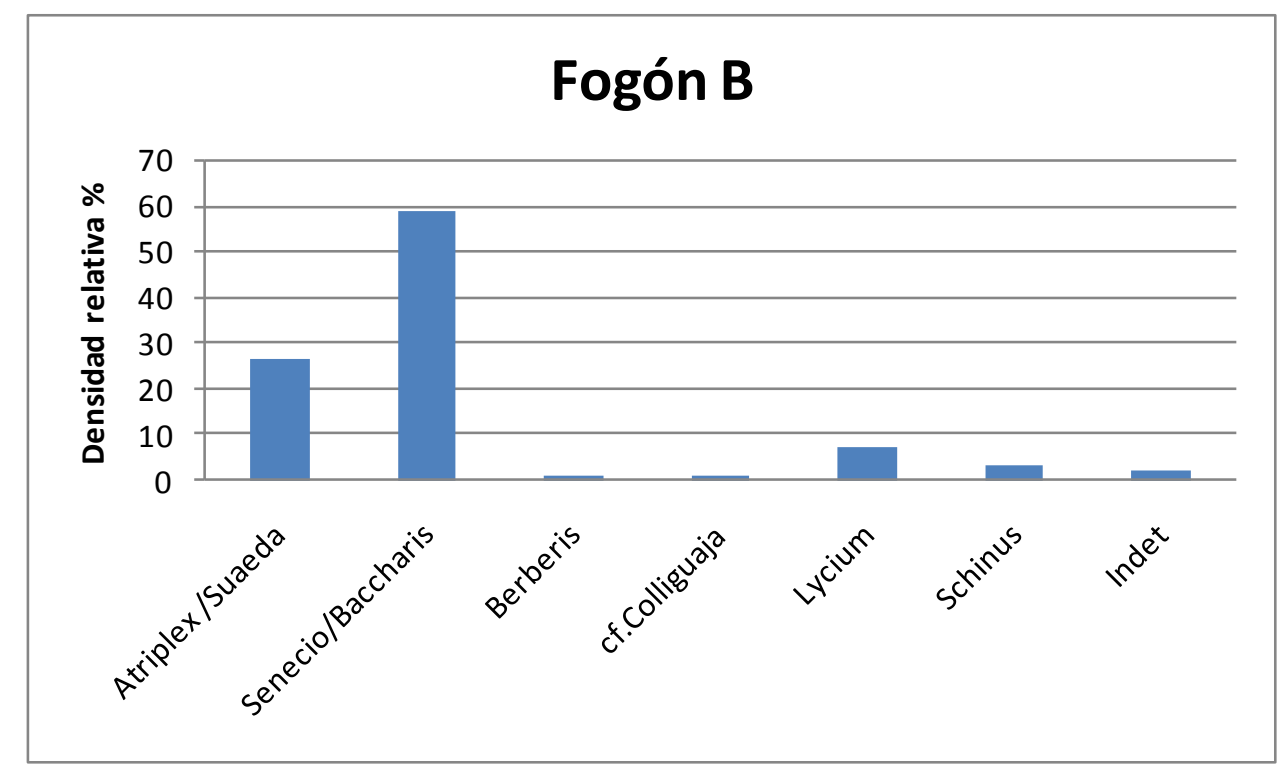

Figura 10.29. Carbones identificados del Fogón B, de la cuadrícula1, componente superior del Alero El Oriental (submuestra $\mathrm{n}=94$ ).

En este fogón no se observaron rasgos de vitrificación, se registró la presencia de médula en un carbón (1,06\%) de Atriplex/Suaeda y sí se identificaron aberturas producto de la combustión. Estas últimas se reconocieron en floema incluso y parénquima de Atriplex/Suaeda $(\mathrm{n}=9)$ y en radios y vasos en Senecio /Baccharis $(\mathrm{n}=1)$, Schinus $(\mathrm{n}=2)$, Lycium $(\mathrm{n}=1)$ y Berberis $(\mathrm{n}=1)$. Es decir, se observaron aberturas en el $14,89 \%$ de la submuestra $(n=14)$.

En el fogón C se registraron 1036 carbones de 1,6 1 de sedimento, por lo que la densidad calculada es de 0,64 n/l, clasificada como baja. Las clases diamétricas tienen un rango de 20-24,9 $\mathrm{mm}$ a 2-4,9 $\mathrm{mm}$ siendo 5-9,9 $\mathrm{mm}$ la clase con mayor cantidad de carbones. La submuestra analizada es de 114 carbones y se identificaron dos taxa donde Senecio/Baccharis (83\%) predomina (Figura 10.30). 


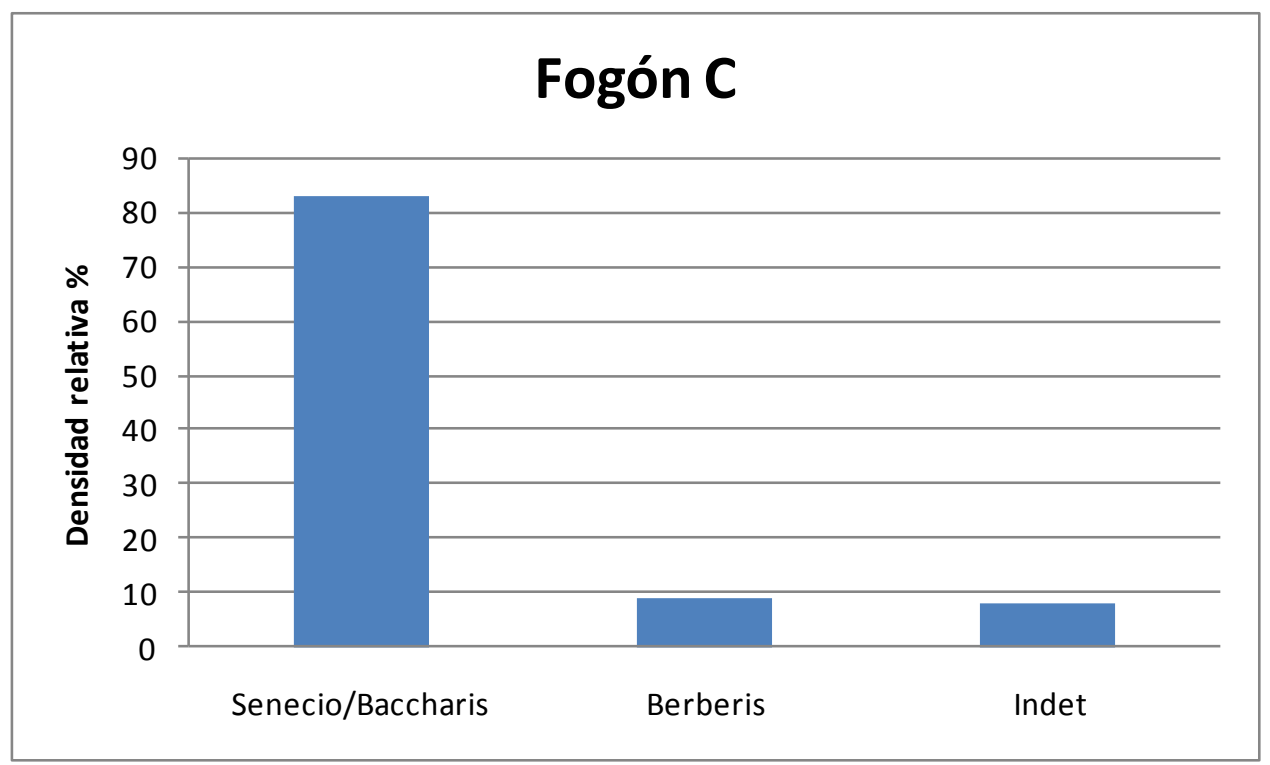

Figura 10.30. Carbones identificados del fogón C, cuadrícula 1, del componente superior, Alero El Oriental (submuestra $\mathrm{n}=112$ ).

En esta submuestra se registraron rasgos de vitrificación en 1 carbón $(0,89 \%)$ de Senecio/Baccharis, la presencia de médula en 4 carbones $(3,57 \%)$ : Berberis $(\mathrm{n}=$ 2) y Senecio/Baccharis $(\mathrm{n}=2)$. En cuanto a las aberturas se registraron en vasos, radios y anillos en 16 carbones (14,28\%), identificados como Senecio/Baccharis $(\mathrm{n}=14)$ y los restantes como Berberis $(\mathrm{n}=2)$.

En el fogón D se recuperó un total de 689 carbones para volumen de 1,7 1 y una densidad calculada de 405,29 n/l, clasificada como media. Las categorías de tamaño registradas abarcan el rango de 10-14,9 $\mathrm{mm}$ a 2-4,9 $\mathrm{mm}$, siendo esta última la que mayor cantidad de carbones presentó. La submuestra analizada es de 25 carbones entre los que se identificaron tres taxa (Berberis, Schinus y cf. Lycium). Se observó un predominio marcado de Schinus (71,98\%) (Figura10.31). 


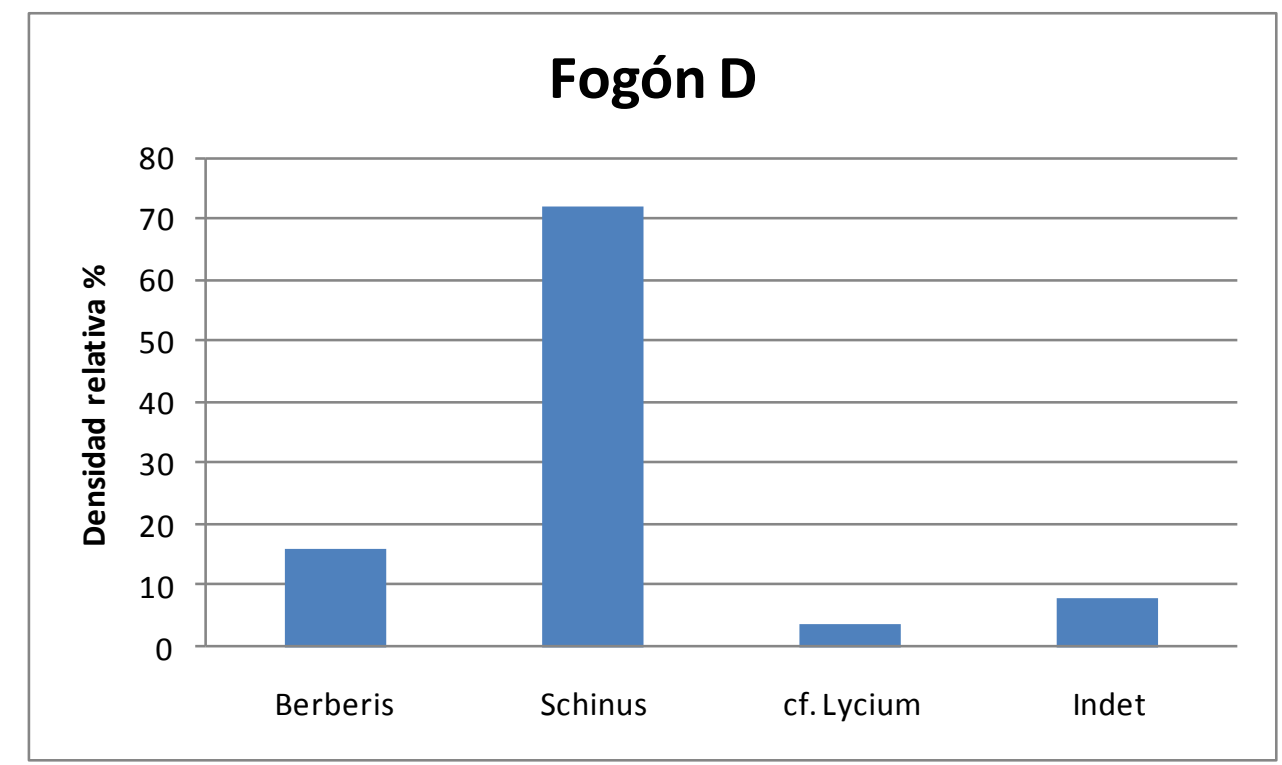

Figura 10.31. Carbones identificados del fogón D, cuadrícula 1, componente superior Alero El Oriental (submuestra $n=25$ ).

Se observó vitrificación en Schinus $(\mathrm{n}=1)$ y en un carbón indeterminable $(\mathrm{n}=1)$. La presencia de médula se identificó en Schinus $(\mathrm{n}=1)$ y aberturas en radios y vasos de Schinus $(\mathrm{n}=5)$, e indeterminable $(\mathrm{n}=2)$.

En el fogón E se halló un total de 474 carbones en 1,4 1 siendo la densidad calculada de $338,57 \mathrm{n} / 1$, considerada media. Las categorías de tamaño abarcan el rango de 15-19,9 $\mathrm{mm}$ a 2-4,9 $\mathrm{mm}$, estando la mayor cantidad de carbones en la última categoría. La submuestra analizada es de 19 carbones donde se identificaron dos taxa siendo dominante Senecio/Baccharis (94,7\%) (Figura 10.32). 


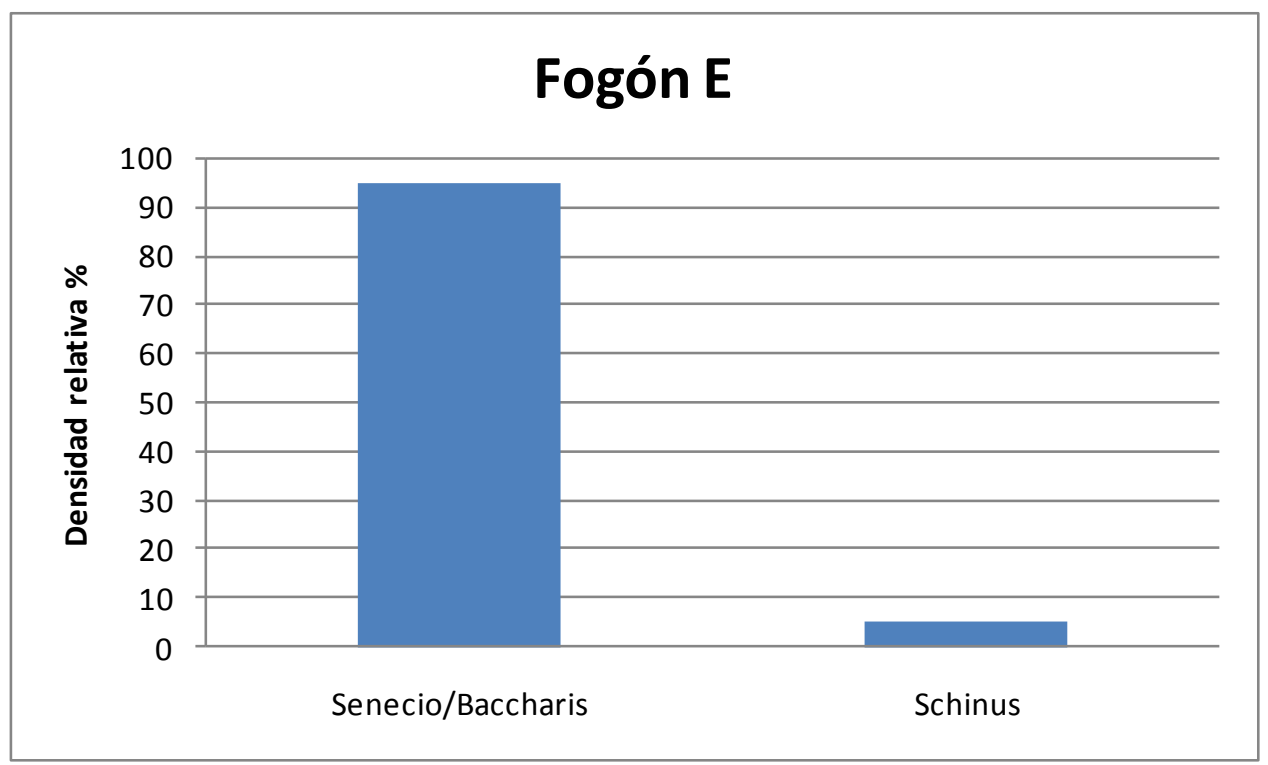

Figura 10.32. Carbones identificados en el fogón E, de la cuadrícula 2, componente superior, Alero El Oriental (submuestra $\mathrm{n}=19$ ).

Se registró vitrificación sólo en Senecio/Baccharis $(\mathrm{n}=4)$ y aberturas en Senecio/Baccharis $(\mathrm{n}=6)$ y Schinus $(\mathrm{n}=1)$ es decir, en el 36,84\%.

En el fogón $\mathrm{F}$ el total de carbones es de 3464 siendo la densidad calculada de 949,04 n/1, clasificada como media. Las categorías de tamaño registradas abarcan los rangos 15-19,9 mm a 2-4,9 mm, encontrándose en la última categoría la mayor cantidad de carbones. La submuestra analizada es de 52 carbones entre los que se identificaron tres taxa siendo predominante Senecio/Baccharis (Figura 10.33). 


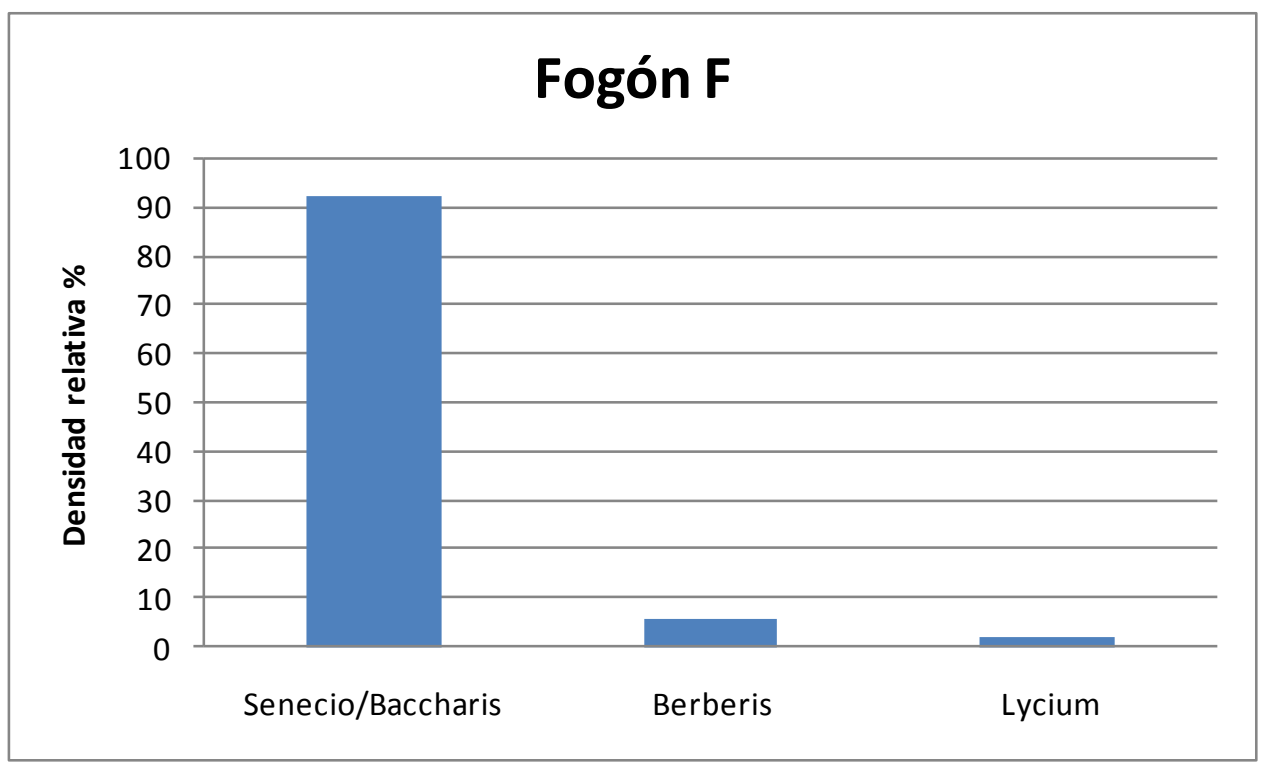

Figura 10.33. Carbones identificados en el fogón F, cuadrícula 3, componente superior, Alero El Oriental

La vitrificación se observó en Senecio/Baccharis $(\mathrm{n}=1)$ y es llamativo el alto número de carbones con presencia de médula en estos mismos géneros $(n=11)$. Las aberturas grietas y ojos se identificaron en Senecio/Baccharis $(\mathrm{n}=10)$ en vasos, radios y anillos y Lycium $(\mathrm{n}=1)$ en vasos.

En el fogón L se hallaron 134 carbones en un volumen de 0,6 1, siendo la densidad calculada de 223,33 n/l y media. Las categorías de tamaño abarcan el rango de 1519,9 $\mathrm{mm}$ a 2-4,9 $\mathrm{mm}$, entre los cuales la categoría 5-9,9 $\mathrm{mm}$ es la que mayor número de carbones tiene. La submuestra es de 23 carbones entre los que se identificaron tres taxa siendo predominante Schinus (Figura 10.34). 


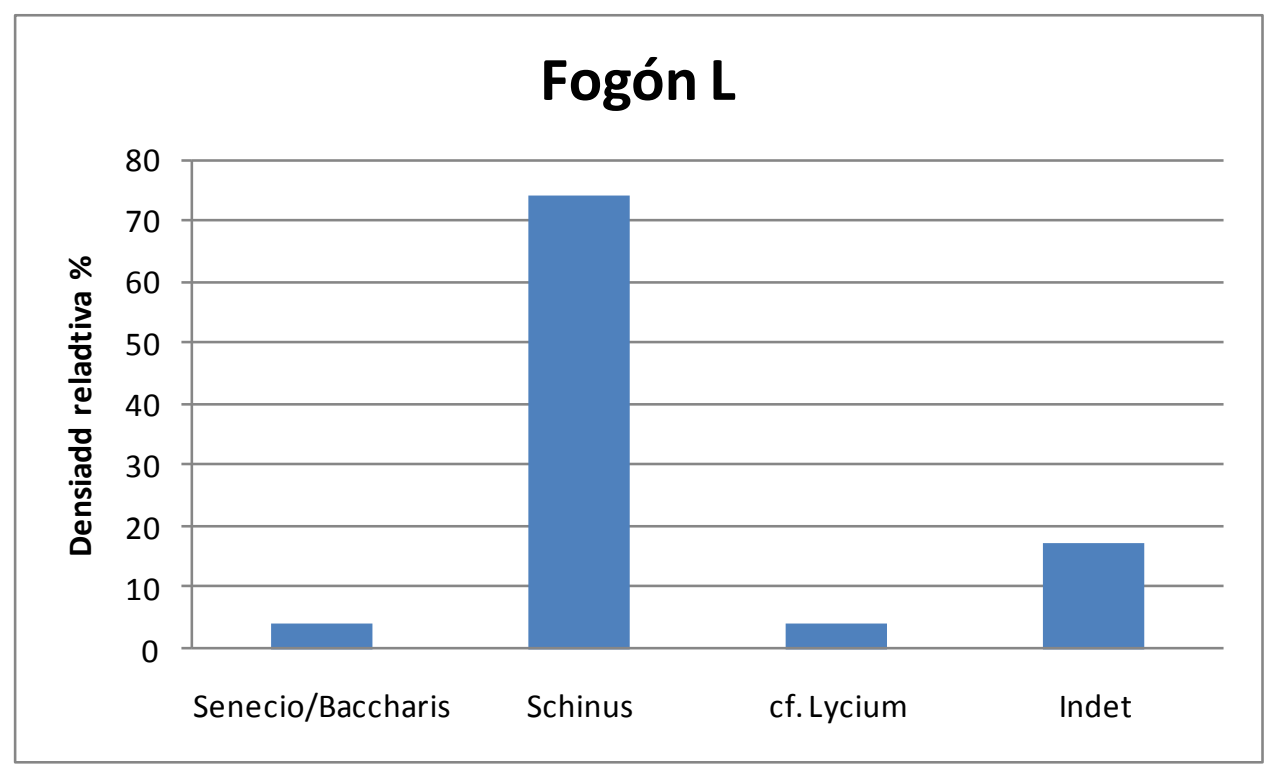

Figura 10.34. Carbones identificados en el fogón L, cuadrícula 6, componente medio Alero El Oriental, (submuestra $n=23$ ).

La vitrificación se observó en Schinus $(\mathrm{n}=7)$, cf. Lycium $(\mathrm{n}=1)$ e indeterminables $(\mathrm{n}=2)$, es decir en el $43,5 \%$ de la submuestra. Se identificó hifas en un carbón indeterminable $(\mathrm{n}=1)$ y médula en cf. Lycium $(\mathrm{n}=1)$.

Las aberturas se identificaron en vasos, radios y anillos en un carbón de Schinus $(\mathrm{n}=1)$ en vasos y radios en carbones del mismo género $(\mathrm{n}=9)$, cf. Lycium $(\mathrm{n}=$ $1)$, e indeterminable $(n=3)$.

El fogón H presentó un total de 125 carbones en un volumen de 3,5 1, siendo la densidad calculada 35,71 n/1 clasificada como baja. Las categorías de tamaño abarcan 15-19,9 mm a 2-4,9 mm encontrándose la mayor cantidad de carbones en la categoría 5-9,9 $\mathrm{mm}$. La submuestra analizada es de 25 carbones entre los que identificaron cuatro taxa. En este fogón predominan Schinus, Senecio/Baccharis y Berberis (44,28, 28 y 12\% respectivamente), siendo Lycium el de menor porcentaje relativo (4\%) (Figura 10.35). 


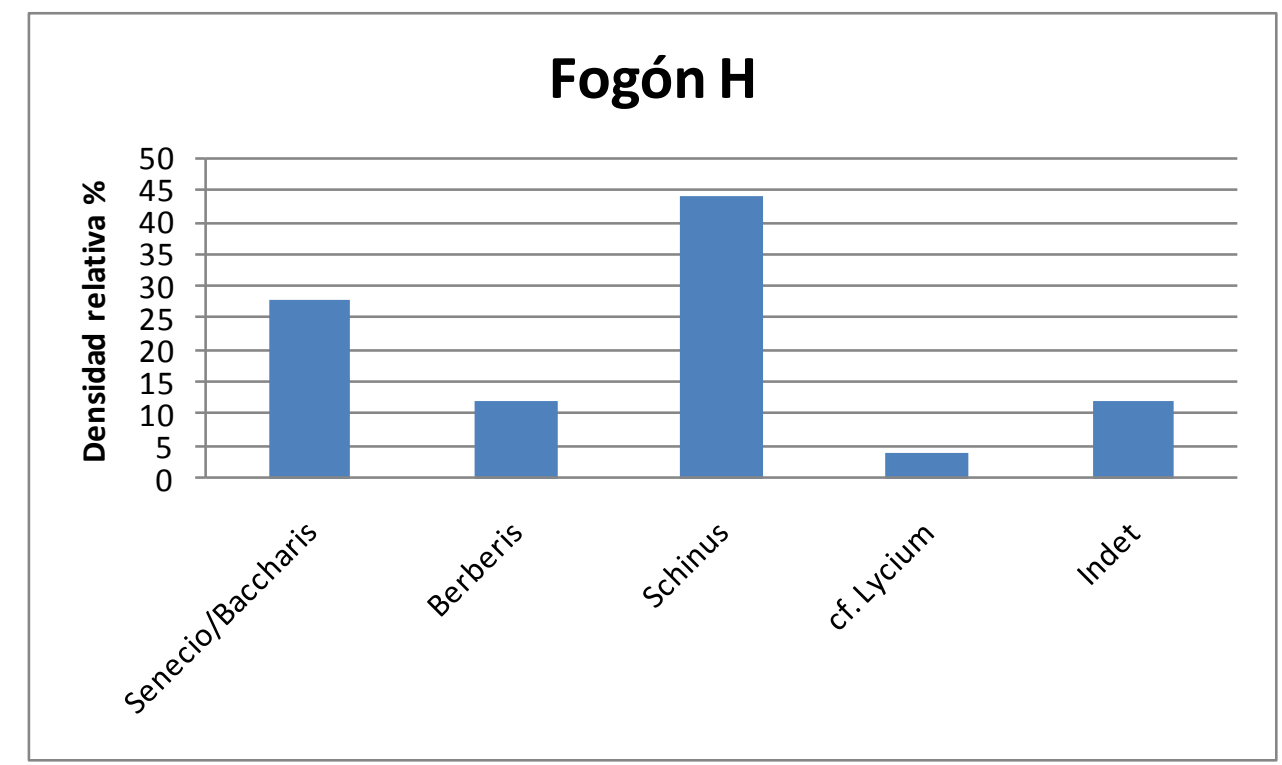

Figura 10.35. Carbones identificados en el fogón H, cuadrícula 2 componente inferior, Alero El Oriental (submuestra $n=25$ ).

Se observó vitrificación en los siguientes taxa: Schinus $(\mathrm{n}=3)$, Senecio/Baccharis $(\mathrm{n}=1)$, indeterminable $(\mathrm{n}=3)$ es decir, en el $28 \%$ de la submuestra. Se registraron hifas en un carbón de cf. Lycium $(\mathrm{n}=1)$, para el mismo género se observó presencia de médula en cf. Lycium $(\mathrm{n}=1)$, y en el caso de Senecio/Baccharis $(\mathrm{n}=1)$ corteza.

Las aberturas en la madera se identificaron en Senecio/Baccharis $(\mathrm{n}=1)$, Schinus $(n=4)$ en radios y vasos, cf. Lycium $(n=1)$ e indeterminable $(n=2)$, es decir en el $32 \%$ de la submuestra.

En el fogón $\mathrm{J}$ se recuperaron un total de 515 carbones para un volumen de 1,6 1, calculándose una densidad de 321,18 n/l, determinada como media. Las categorías de tamaño registradas abarcan 10-14,9 $\mathrm{mm}$ a 2-4,9 $\mathrm{mm}$, siendo esta última la que mayor carbones contuvo. La submuestra analizada es de 36 carbones entre los que se identificaron cuatro taxa siendo predominante Schinus (Figura 10.36). 


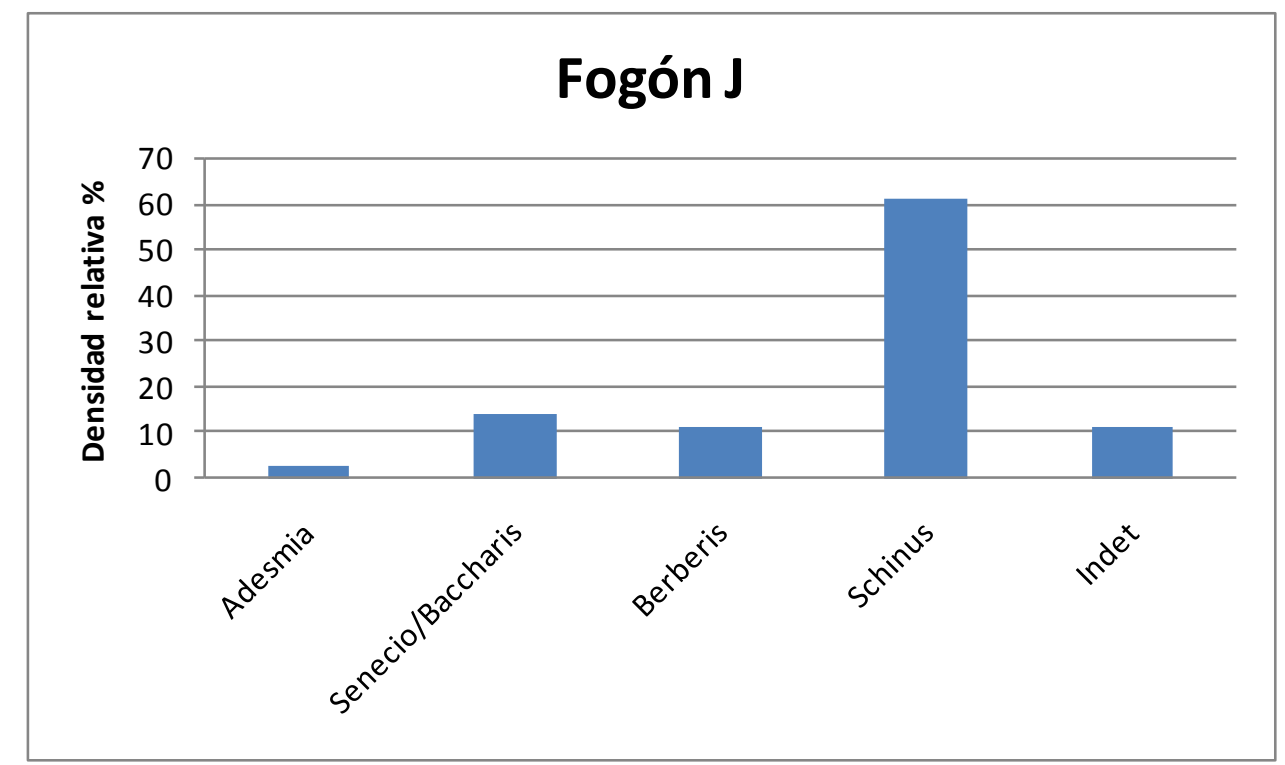

Figura 10.36. Carbones identificados en el fogón J, cuadrícula 3, componente inferior Alero El Oriental (submuestra $n=36$ ).

La vitrificación se observó en Schinus $(\mathrm{n}=7)$, Adesmia $(\mathrm{n}=1)$, y en los indeterminables $(\mathrm{n}=4)$, por lo tanto en el $33,3 \%$ de la submuestra. Se identificó médula en Schinus $(\mathrm{n}=5)$ y en Berberis $(\mathrm{n}=1)$.

En cuanto a las aberturas, se registraron en radios y vasos en Adesmia ( $\mathrm{n}=1)$, Berberis $(\mathrm{n}=1)$, Schinus $(\mathrm{n}=13)$ e indeterminable $(\mathrm{n}=3)$, es importante mencionar que el 50\% de la submuestra registró aberturas.

El análisis de ubicuidad para todos los fogones, componentes inferior, medio y superior permitió registrar que el taxa con mayor ubicuidad fue Senecio/Baccharis (90\%) seguido por Schinus y Berberis (con un 66\%) y considerando en conjunto Lycium y cf. Lycium (66\%) (Figura 10.37). 


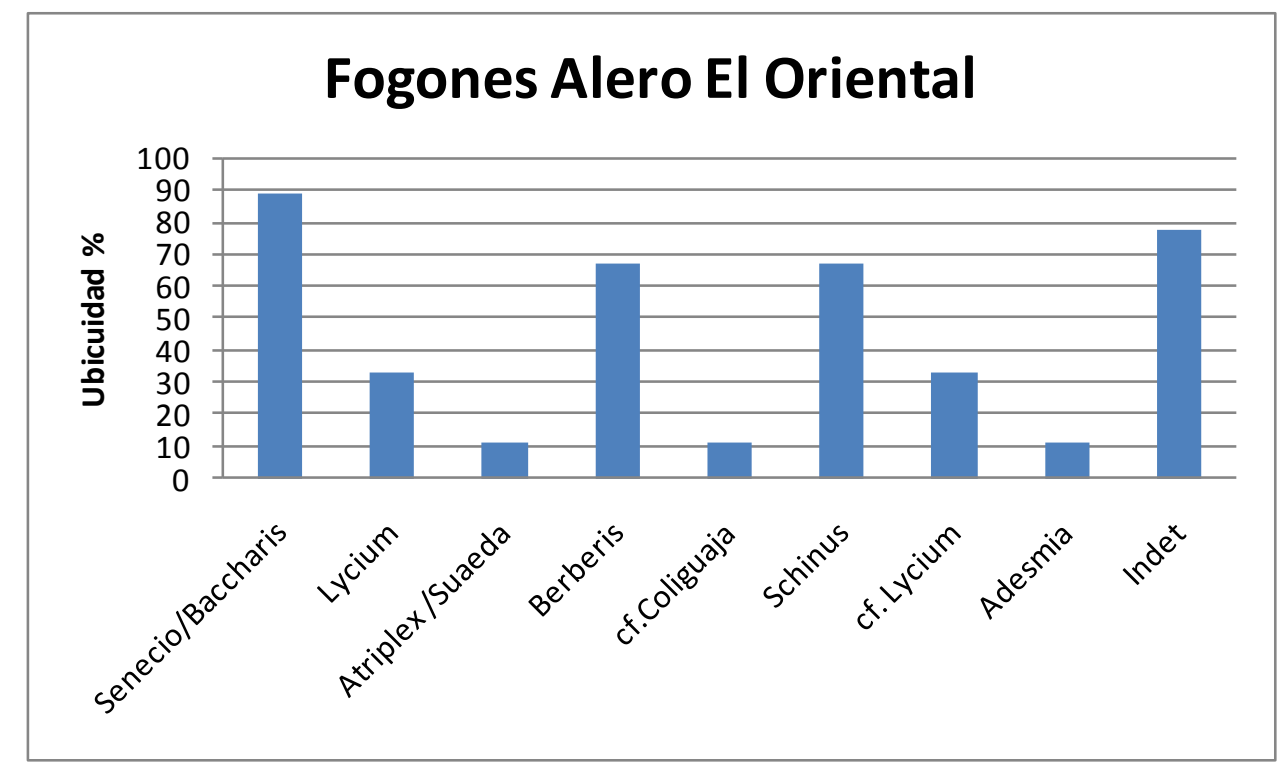

Figura 10.37. Ubicuidad de los taxa identificados en los carbones de los fogones analizados del Alero El Oriental (componente inferior medio y superior).

Se realizó el análisis de correlación entre el número total de fragmentos de todos los carbones provenientes de los fogones del Alero El Oriental y el peso total de cada uno de los mismos (Figura 10.38). El resultado obtenido es una correlación positiva con un valor de $\mathrm{R}^{2}=0,98$ con un nivel de significancia de $\mathrm{p}<0.01$ para un $\mathrm{n}=9$ fogones. La asociación entre el número de fragmentos recuperados en los fogones y el peso total de los mismos permite inferir que ningún fogón arqueológico atravesó procesos postdepositacionales significativamente diferentes al resto. 


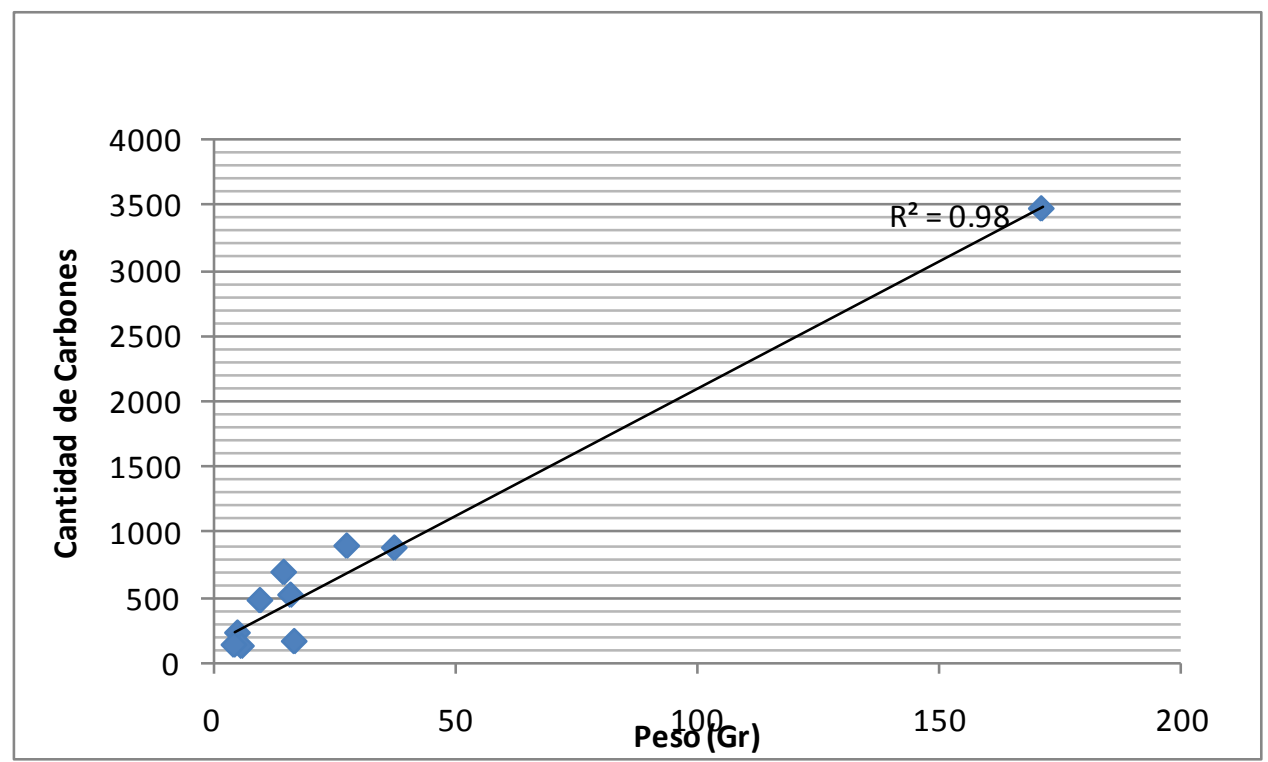

Figura 10.38. Correlación entre el número de fragmentos de carbones provenientes de fogones y el peso total, Alero El Oriental.

\subsubsection{Discusión y conclusiones}

Para el componente del Holoceno tardío final la vegetación sería análoga a la actual teniendo en cuenta los resultados de De Porras (2010). El sitio El Oriental se encuentra próximo a dos cañadones en los que es posible recolectar las especies identificadas en los fogones.

En el fogón A se identificó el uso de maderas de muy baja densidad (i.e. Senecio/Baccharis) e intermedia (i.e. Lycium), con un porcentaje alto (20\%) de tallos juveniles, en este sentido, se trataría de un evento poco intenso, de llama y rápido encendido y poca duración.

En el caso de los fogones B, C, E y F la estrategia de uso de leños sería levemente distinta, se observa que predomina el uso de maderas de muy baja densidad de rápido encendido (i.e. Senecio/Baccharis) pero con el aporte de maderas más densas que Lycium, de mayor duración, poder calórico y brasa (i.e. Berberis, Schinus). Si bien parecerían ser eventos poco intensos serían de mayor duración que en el caso del fogón A, debido a que éste sólo presenta un $87 \%$ de maderas muy livianas (i.e.Senecio/Baccharis) de rápido consumo. Es importante mencionar que se encontraron asociados en el fogón $\mathrm{C}$ una valva de Nacella magellanica y en el fogón $\mathrm{F}$ artefactos líticos. Estos restos materiales estarían 
dando cuenta de las actividades domésticas asociadas a estos fogones, aunque probablemente en baja intensidad. No se observaron en ninguno de los anteriores fogones rasgos diagnósticos de altas temperaturas.

Por otra parte, el fogón D registra leños de maderas de alta densidad, combinadas con Lycium que podría haber funcionado para encender. Se trataría de un fogón diferente a los anteriores teniendo en cuenta que predomina Schinus que tiene una madera que produce brasa, sin embargo no se observaron aberturas diagnósticas en anillos de Schinus ni de Lycium como para identificar altas temperaturas alcanzadas. La presencia de líticos con alteración térmica también sería una evidencia de que se realizaron actividades de talla alrededor del mismo cuando éste se encontraba encendido (Frank 2011). Cabría la posibilidad de que al predominar una madera dura, el fogón podría haber tenido mayor intensidad tanto en términos de duración como de temperatura alcanzada.

A excepción de este último fogón, los anteriores reforzarían la premisa de eventos de reocupación poco intensivos propuesto por Ambrústolo et al. (2011) para el Holoceno tardío final. En este sentido, el alero habría funcionado como refugio de corta duración en el marco de rangos de acción diarios de los grupos cazadores recolectores que ocupaban el sector costero.

En el Holoceno medio de acuerdo a los resultados polínicos de Los Toldos y La María, hacia el 10.500 y ca. 5.000 años AP se registró en el primero una comunidad arbustivo-graminosa de Asteraceae subf. Asteroidea con Nassauvia, Ephedra frustillata y Solanaceae que también se observa en La María antes de los 5577 AP. Los arbustos enanos y en cojín como Nassauvia y Ephedra frustillata fueron más abundantes con anterioridad a 7.260 AP, mientras que en momentos posteriores predominan los arbustos medianos y altos. Entre los 5.000 y 3.750 AP en Los Toldos (cañadón) se desarrolló una comunidad arbustiva-subarbustiva muy diversa dominada por Asteraceae subf. Asteroidea y otros arbustos medianos y altos como Colliguaja integerrima, Schinus y Lycium y arbustos enanos y en cojín como Nassauvia y Ephedra frustillata.

Sin embargo, los resultados de los fogones L, H y J del componente medio e inferior correspondientes al Holoceno medio presentan leños que se asemejan más a la vegetación que se desarrolló posteriormente a los 5000 AP. Siendo que, 
en los tres fogones predominan los leños de Schinus, género arbustivo, acompañado de otras arbustivas como Berberis y Lycium y de otros de la familia Asteraceae como Senecio/Baccharis, sería importante establecer secuencias polínicas en el área de estudio para poder identificar de manera más precisa la vegetación de este período. Las diferencias observadas permiten suponer o bien que la vegetación de arbustos altos se estableció con anterioridad a lo conocido en el presente o bien que dichos leños están siendo colectados de manera dirigida en áreas más lejanas al sitio.

Es importante destacar que a diferencia del componente superior, los fogones de este período presentan una combinación de maderas de Schinus y Berberis, maderas de mayor densidad, poder calórico y brasa permiten fuegos de mayor intensidad. Así también se observaron abundantes aberturas en vasos y radios de Schinus en los tres fogones y en un carbón del fogón L además se observaron aberturas en anillo diagnósticas de temperaturas próximas a los $700{ }^{\circ} \mathrm{C}$.

Si bien no se analizaron los carbones provenientes de los fogones $\mathrm{G}$ y K debido a que se enviaron a fechar es importante mencionar que ambos se encontraban asociados a restos de valvas de mitílidos que presentaban manchas de carbón en las caras internas y externas, así como alto contenido de restos carbonosos. Del fogón $\mathrm{G}$ se recuperaron restos óseos de guanaco (Lama guanicoe) y artefactos líticos. Si se tiene en cuenta este contexto sumado a las leñas seleccionadas en los fogones $\mathrm{L}, \mathrm{H}$ y $\mathrm{J}$ se podría mencionar que los mismos estarían asociados a actividades domésticas de mayor duración que el componente superior. Si bien para este período se había propuesto la utilización del alero en el marco de la exploración de los espacios costeros, en el que se habrían aprovechado recursos marinos y terrestres, con artefactos de obsidiana cuya fuente sería de Pampa del Asador en el centro oeste de la provincia de Santa Cruz (Ambrústolo et al. 2011), las estrategias de selección de leña dan cuenta del conocimiento de las maderas locales, siendo que para este período el interior tendría una vegetación más baja y no tan arbustiva.

Si se considera la totalidad de los fogones como un conjunto, los taxa que tuvieron un $90 \%$ de ubicuidad fueron Senecio/Baccharis, seguidos por Berberis, Schinus y Licium con un 66\%, es decir combinaciones de madera de alta densidad 
con maderas más blandas. Es importante mencionar que para la totalidad de los contextos de fogones analizados evidencia la asociación entre el número de fragmentos recuperados en los fogones y el peso total de los mismos permite inferir que ningún fogón arqueológico atravesó procesos postdepostacionales significativamente diferentes al resto.

\subsubsection{Sitio Cueva del Negro}

\subsubsection{Introducción}

El sitio Cueva del Negro se encuentra ubicado en la Estancia El Negro, en un afloramiento de rocas porfíricas de la formación Bahía Laura, en el extremo sur de la denominada bahía del Puesto, en la Punta Norte del subsector Bahía del Oso Marino (Figura 10.39). Se encuentra a $21 \mathrm{~m}$ sobre la línea de costa actual y en una cota de $4 \mathrm{~m}$, por lo que se sugiere que el acceso al mismo haya sido posterior al máximo transgresivo del Holoceno medio (Zubimendi et al. 2011).

Este sitio presenta la característica única de ser un sitio conchero en cueva. Presenta un recinto oscuro de dimensiones pequeñas y subcircular, un alero en la entrada y un amplio talud de media pendiente por el que se accede a la cueva. La vegetación que rodea a la cueva está compuesta por Chuquiraga erinaceae, Berberis microphylla, Senecio sp., Urtica sp., Lepidophyllum cupressiforme y Pappostipa sp. 


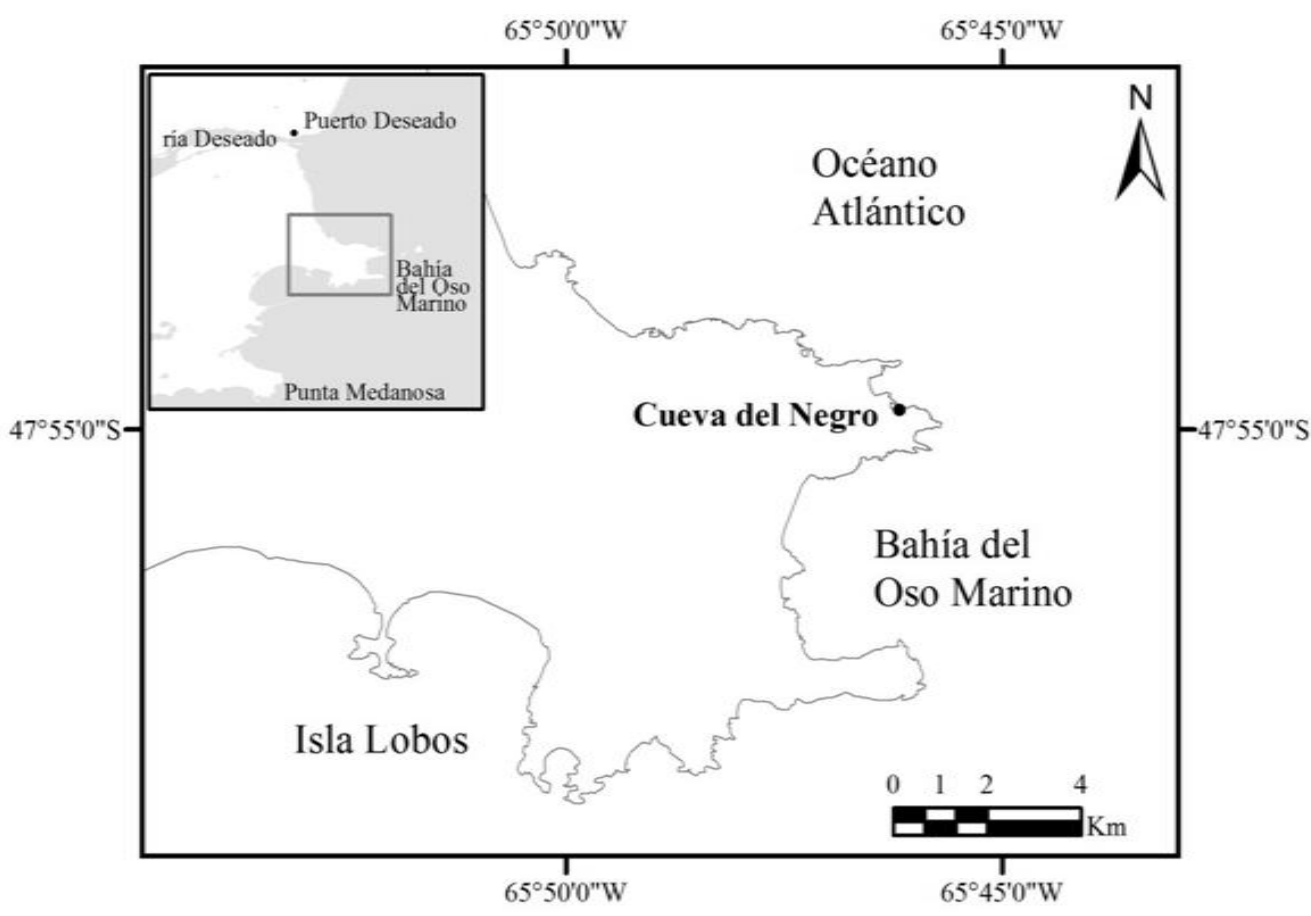

Figura 10.39. Ubicación del sitio Cueva del Negro.

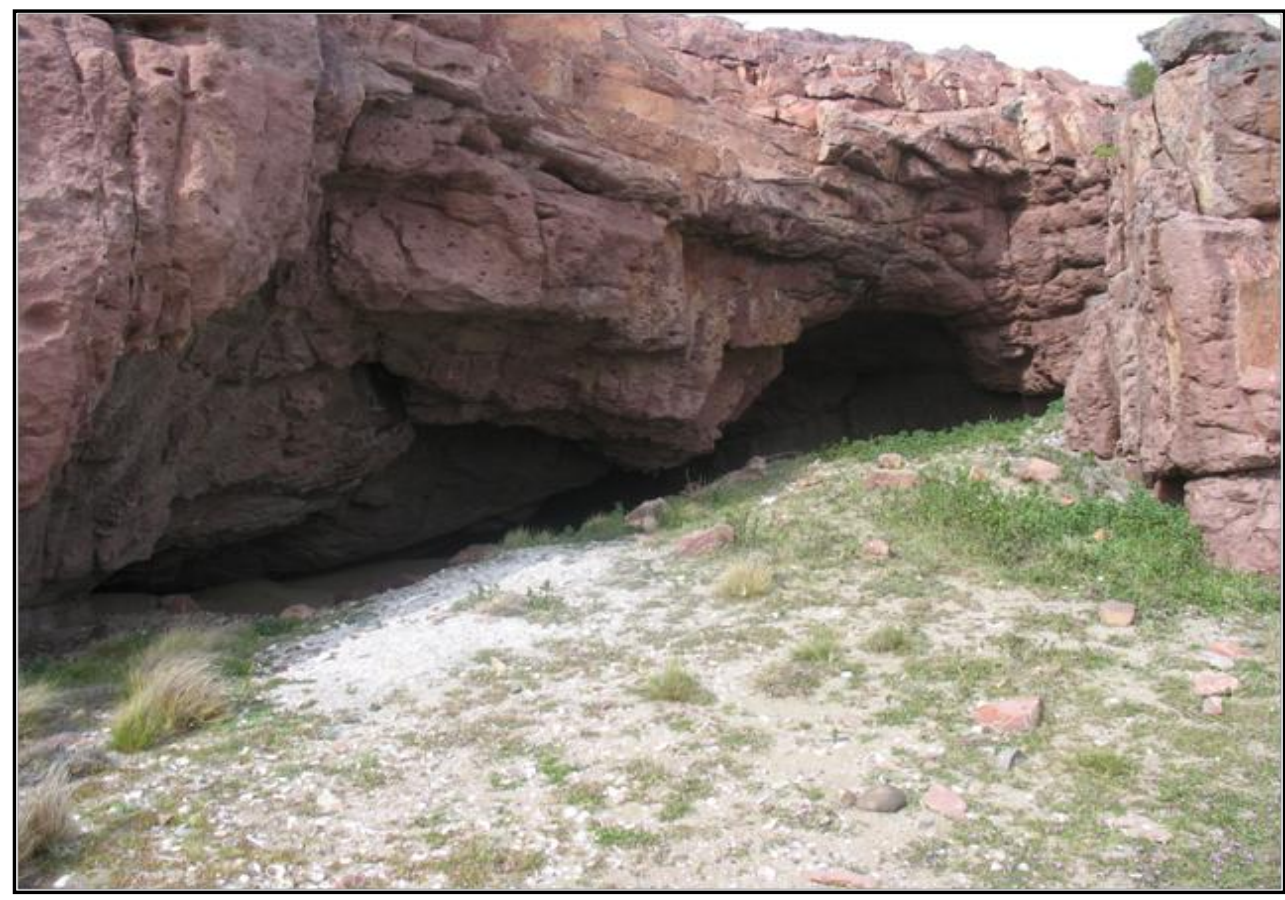

Figura 10.40. Sitio Cueva del Negro. 


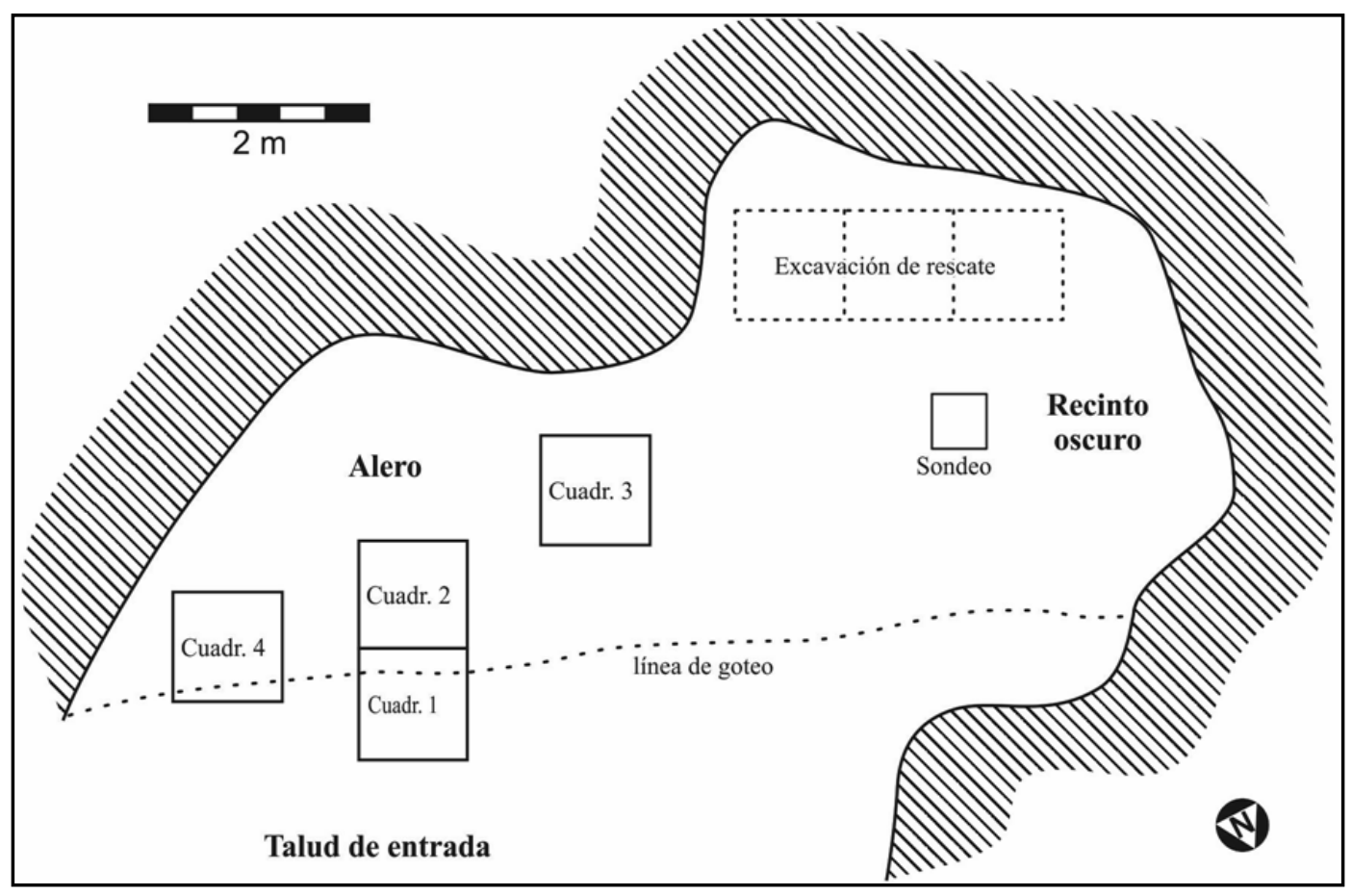

Figura 10.41. Esquema de planta del sitio Cueva del Negro.

\subsubsection{Metodología.}

\subsection{Excavación}

Se realizaron tres cuadrículas en el recinto oscuro, en las que se observó una estratigrafía invertida producto de las actividades de saqueo. En el mismo sector se realizó un sondeo en una zona que se encontraba intacta. En el sector del alero como en el talud se realizaron las restantes cuadrículas. Las número 1 y 2 se excavaron hasta alcanzar una profundidad de $2 \mathrm{~m}$ desde la superficie del terreno. Las cuadrículas 2 y 3 se realizaron a fin de registrar material arqueológico en estratigrafía en un sector intermedio entre el recinto oscuro y las cuadrículas 1 y 2 . La cuadrícula 5 fue la más externa de la cueva a fin de constatar los límites de extensión de las capas arqueológicas (Figura 10.41).

\subsection{Recuperación de los restos antracológicos}

M. Zubimendi realizó adyacente a la cuadrícula 1 una columna de muestreo de 20 x $20 \mathrm{~cm}$ y $5 \mathrm{~cm}$ de espesor que fue tamizada con malla de $2 \mathrm{~mm}$. El fondo de 
zaranda es decir, lo que no fue seleccionado manualmente de la zaranda fue flotado en el laboratorio con agua corriente. De ambos procedimientos se recuperaron los carbones vegetales dispersos de un nivel de la columna de muestreo correspondiente a cada capa estratigráfica. Los materiales antracológicos analizados de esta tesis corresponden a los provenientes a esta columna dado que cuenta con un mejor control estratigráfico que los provenientes de las excavaciones de las cuadrículas 1 a 5 .

\subsubsection{Contexto estratigráfico}

Se definieron cinco capas, la primera de ellas se caracteriza por presentar sedimentos eólicos arenosos junto con fragmentos de roca proveniente de la cueva. Tiene un espesor que abarca entre los 20 y $30 \mathrm{~cm}$. La segunda capa, se encuentra más compactada, con gran cantidad de restos malacológicos fragmentados, material óseo y lítico. La potencia de esta última es de $c a .40 \mathrm{~cm}$ y se realizaron dos fechados radiocarbónicos, uno sobre hueso de choique (Pterocnemia pennata) datado en $1170 \pm 110$ años AP y otro sobre un fragmento de pinnípedo cuyo resultado fue de $1730 \pm 80$ AP. La capa tres presenta un gran volumen de moluscos asociado a huesos de pinnípedos, aves marinas, material lítico, y otros restos óseos. Se han identificado arpones sobre hueso y estructuras de combustión. El sedimento que contiene estos restos se encontraba desagregado. Los fechados realizados sobre pinnípedos tuvieron un resultado de $1120 \pm 80 \mathrm{y}$ $1290 \pm 50$ años AP. En la capa cuatro se observaron valvas muy fragmentadas y huesos de pinnípedos alterados por la humedad sobre sedimento húmico oscuro, en una potencia de $c a .30 \mathrm{~cm}$. La quinta y última capa se encuentra conformada por sedimento húmico y conchillas muy fragmentadas, con mayor grado de compactación que la capa anterior. Se identificó una estructura de fogón asociada a restos óseos y líticos. Los carbones de dicha estructura fueron datados en $1390 \pm$ 70 años AP, por lo tanto no pudieron ser analizados en esta tesis (Figura 10.42). 


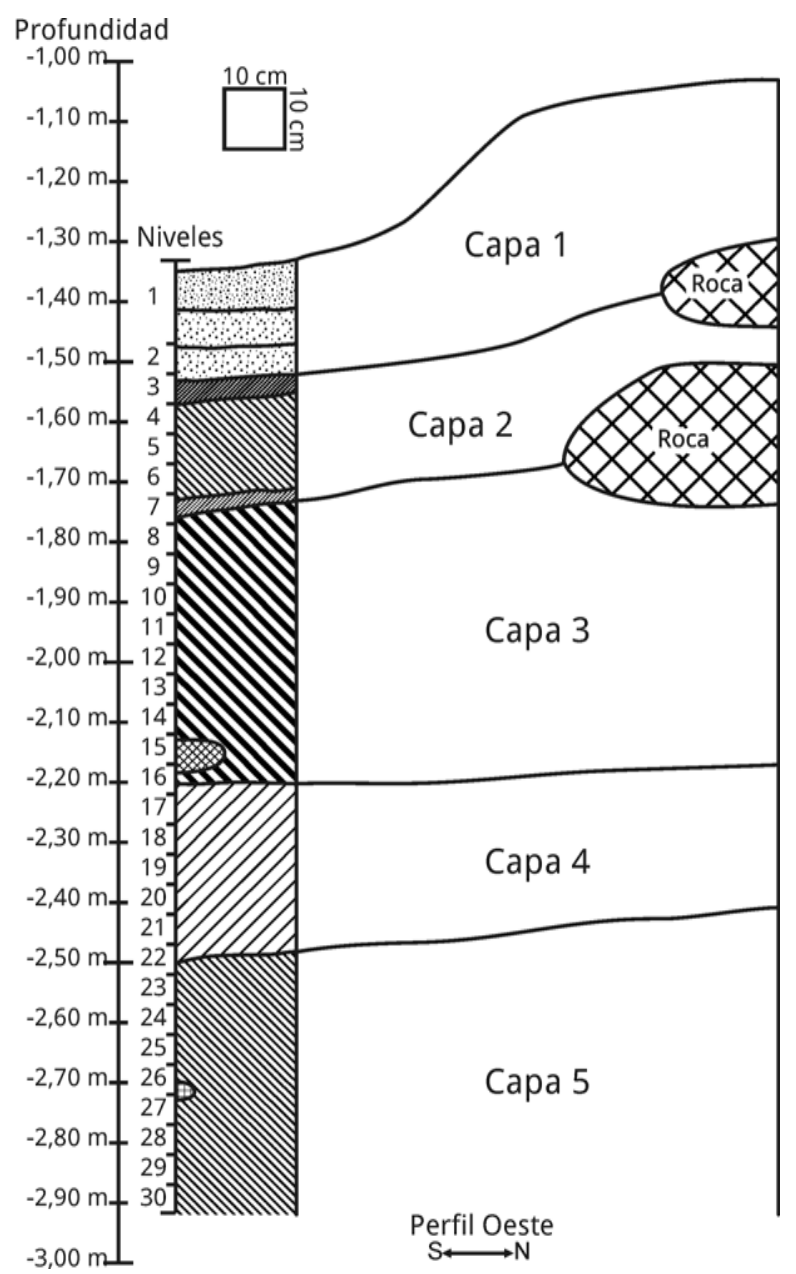

Figura 10.42. Representación de la secuencia estratigráfica definida en la cuadrícula 1 y columna de muestreo de la Cueva del Negro (Zubimendi et al. 2011).

Para el análisis de los carbones dispersos se analizaron de a capa 1 el nivel 1; de la capa 2 el correspondiente nivel 3; de la capa 3 el nivel 9; de la capa 4, el nivel 17 y de la capa 5 el nivel 23 (Figura 10.43) 


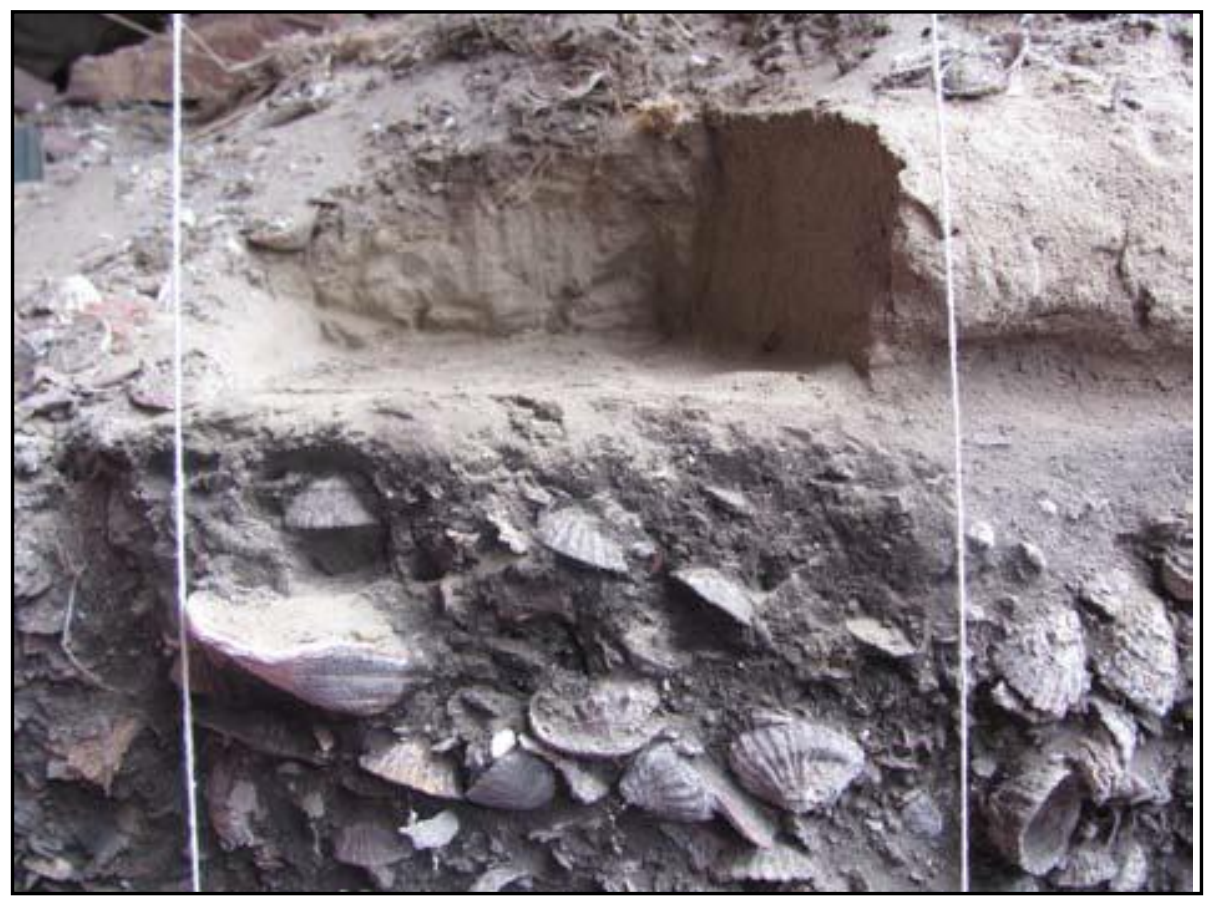

Figura 10.43. Vista de los niveles 1 y 2 excavados de la columna realizada en la cuadrícula 1 (Zubimendi et al. 2011).

\subsubsection{Estudio Arqueológico}

La excavación de todo el sitio Cueva del Negro se llevó a cabo por todo el equipo dirigido por la Dra. Alicia Castro y el Dr. M.A. Zubimendi. La columna estratigráfica de la cual se analizaron los carbones dispersos fue realizada por el Dr. Zubimendi (Zubimendi et al. 2011). Se realizaron en primer lugar, tres cuadrículas en el recinto oscuro como parte de una excavación de rescate ante el impacto de saqueadores. Luego, en la parte más profunda del recinto se realizó un sondeo en un sector intacto, donde se obtuvo un fechado de $1340 \pm 60$ años AP (LP-2261). De este sondeo se recuperaron gran cantidad de restos óseos (Beretta et al. 2011), líticos, malacológicos, cuentas de collar de valva y un fragmento de arpón de madera (Capparelli et al. 2009, ver capítulo 11). En el sector del alero y en el talud se realizaron cinco cuadrículas de 1 x $1 \mathrm{~m}$ (Zubimendi et al. 2011).

En cuanto al registro arqueológico de estas últimas cuadrículas se estudiaron con mayor profundidad la uno y la dos. Dentro de los artefactos líticos, el grupo tipológico más representativo fue el de productos de talla, en menor medida el de artefactos formatizados y en muy baja frecuencia el de los núcleos. Se recuperó un 
total de 693 artefactos manufacturados principalmente con calcedonia (73\%), riolita $(23,4 \%)$, calcedonia translúcida $(19,6 \%)$. Se identificaron eventos de talla intermedios en casi todas las materias primas y se reconocieron en bajas proporciones evidencias de actividades de retoque que sugieren la realización de etapas finales de talla y formatización de filos. Respecto a los núcleos la mayor parte se registraron agotados y sin corteza. En relación a los instrumentos se sugiere que no habrían sido manufacturados en el sitio ya que no se registraron evidencias de su formatización. Entre otros instrumentos se recuperaron rompecráneos y fragmentos de artefactos bifaciales (Ambrústolo 2011; Zubimendi et al. 2011).

El análisis de restos zooarqueológicos contabilizó un total de 11.681 especímenes óseos determinables anatómica y taxonómicamente. Se identificaron 31 taxones de los cuales la mayor parte correspondió al grupo de los mamíferos siguiendo en menor medida las aves y los peces. Entre los primeros se identificaron especies tanto marinas como terrestres. El 93\% pertenece a los otáridos y los especímenes restantes pertenecen a una gran diversidad de taxones. En cuanto a las aves no hay taxa que predominen sobre otros, siendo identificados: cormorán (Phalacrocorax sp), pingüino magellánico (Spheniscus magellanicus), pingüino rey (Aptenodytes patagónica), albatros ceja negra (Thalassarche melanophyris), ñandú (Pterocnemia pennata) entre otros. Se registraron en los tres grupos numerosas marcas de corte y de raspado, hoyos y hoyuelos de percusión, diferentes tipo de fractura y distintos tipos de combustión (quemados, carbonizados y calcinados). Del total de los restos óseos, el $63 \%$ presenta evidencias de procesamiento y consumo humano mientras que el $37 \%$ restante no lo demuestra o es imposible determinarlo (Zubimendi et al. 2011).

También se analizaron los restos malacológicos provenientes de una columna de muestreo en la cuadrícula 1 . Se contabilizaron 2.833 restos malacológicos cuya identificación taxonómica tuvo como resultado 18 géneros de moluscos y crustáceos. Predominan las lapas y en proporciones más bajas se registran los mitílidos, entre los cuales los mejillones son los más abundantes, seguidos por las cholgas y en menor proporción mejillines. 
Es importante destacar que se recuperaron seis arpones en las cuadrículas 1 y 2 manufacturados sobre hueso (Beretta et al. 2013a) así como también, 2 posibles ganchos de propulsor (Beretta et al. 2013b). En la primera cuadrícula se registró también una cuenta de collar de molusco de forma campaniforme, sobre el recinto oscuro también se hallaron varios artefactos de este tipo sobre valva (Zubimendi 2013). Por otra parte en las cuadrículas 3 y 5, así como en el recinto oscuro se registraron tres restos óseos humanos (dos hemimandíbulas y una falange) uno de ellos con trazos de pintura de color negro.

El registro de la Cueva del Negro, entonces, evidencia la explotación intensiva de los recursos marinos, la reocupación de determinados sitios, el desarrollo de industrias artefactuales específicas para la caza y el procesamiento de recursos costeros (Zubimendi et al. 2011).

\subsubsection{Resultados antracológicos}

En la capa 1 se recuperó un total de 4 carbones dispersos en un volumen de 1,8 1 y una densidad calculada de 2,22 n/l, clasificada como baja. La categoría de tamaño registrada es de 5-9,9 $\mathrm{mm}$. Se analizó el total de carbones identificándose dos taxa y predominando Schinus (75\%) (Figura 10.44).

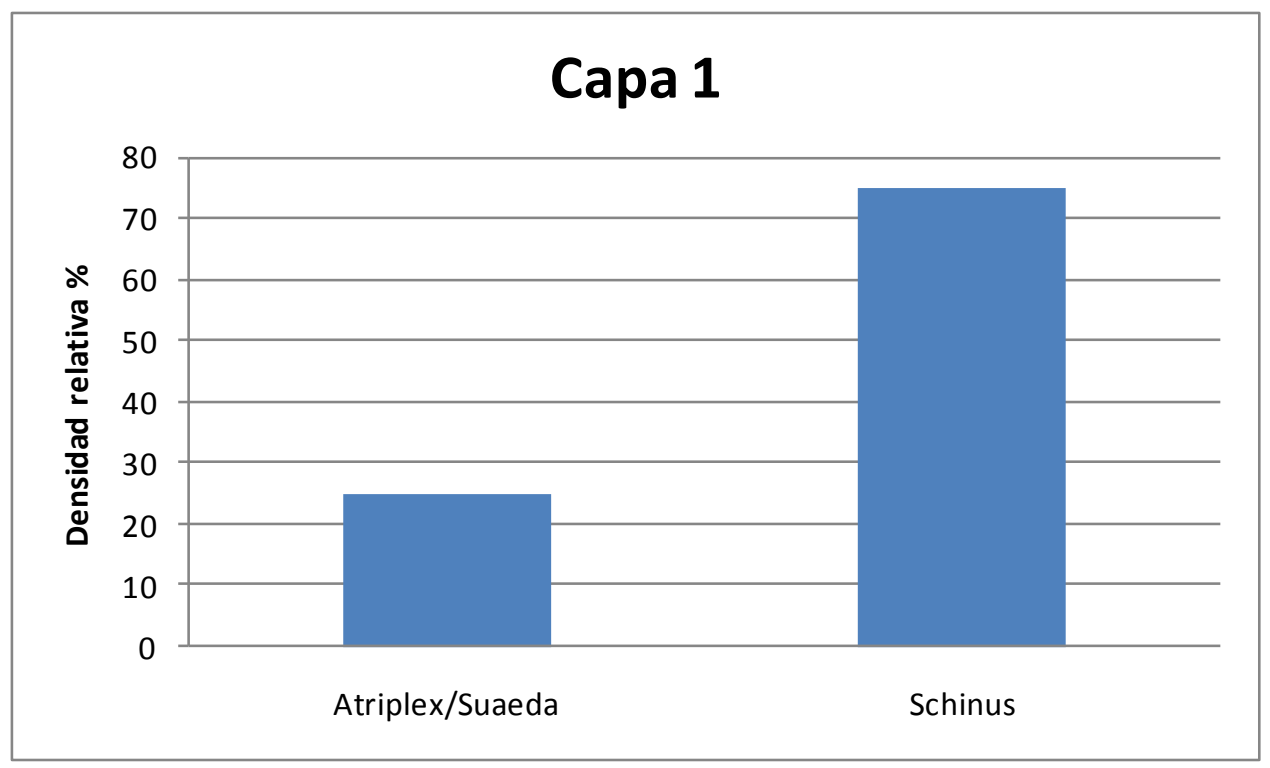

Figura 10.44. Carbones dispersos identificados de la capa 1, nivel 1 de la columna estratigráfica de Zubimendi et al. (2011) (submuestra $\mathrm{n}=4$ ). 
Se identificaron aberturas en Atriplex/Suaeda $(\mathrm{n}=1)$ en floema incluso y parénquima y en Schinus $(\mathrm{n}=2)$ en vasos y radios.

En la capa 2 se incrementa el número de carbones siendo el total 440 para un volumen de 1,8 1 y una densidad calculada que alcanza los 244,4 n/1 y es clasificada como media. Las categorías de tamaño abarcan 10-14,9 mm a 2-4,9 $\mathrm{mm}$ siendo esta última la que mayor cantidad de carbones registra. El subtotal analizado es de 32 carbones siendo identificados tres taxa siendo predominantes Schinus (43,7\%) y Senecio/Baccharis (37,5\%) (Figura 10.45).

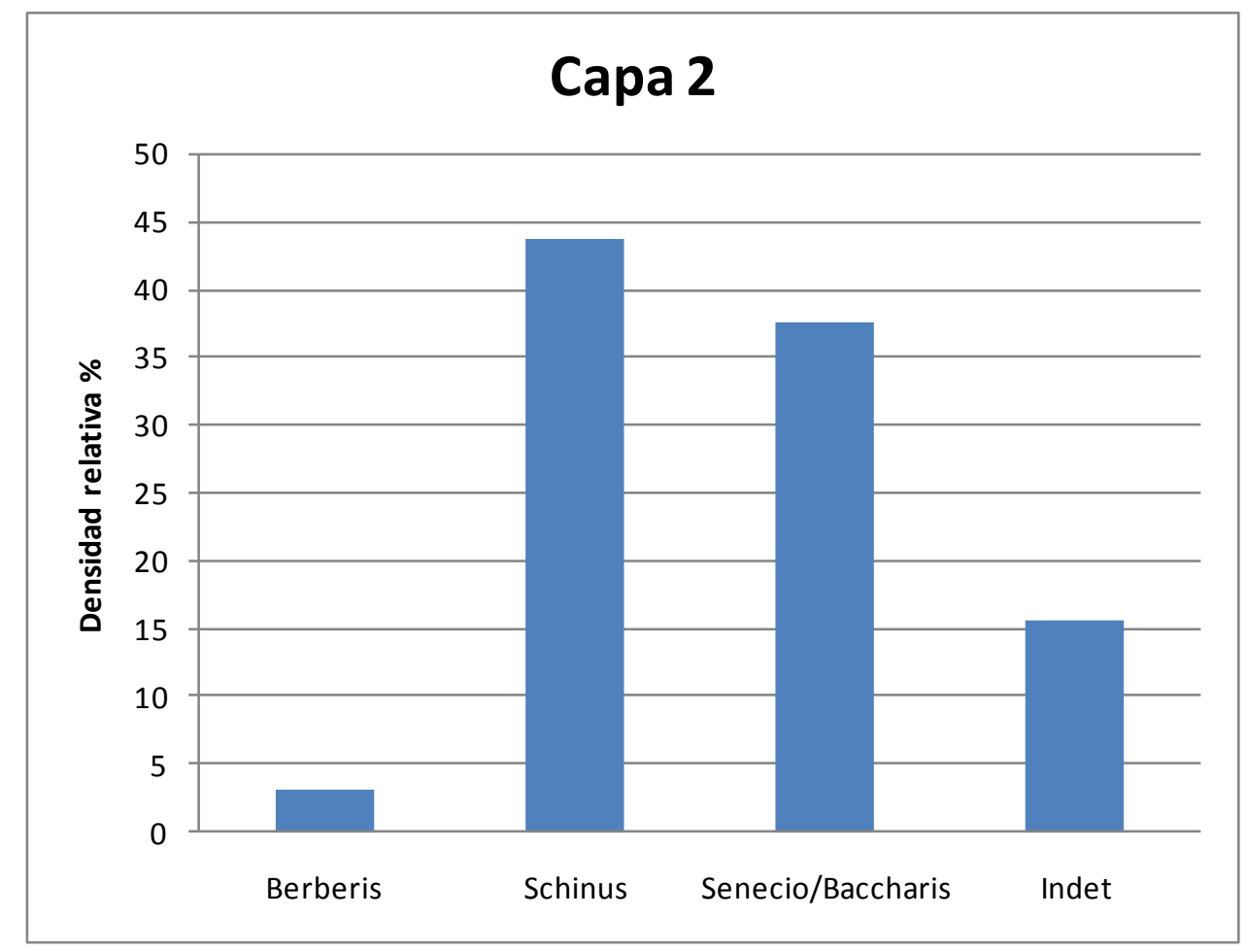

Figura 10.45. Carbones dispersos identificados en la capa 2, nivel 3, de la columna de muestreo de Zubimendi et al. (2011) (submuestra $\mathrm{n}=32$ ).

Se observó vitrificación en Schinus $(\mathrm{n}=4)$, e indeterminable $(\mathrm{n}=1)$ es decir el $15,62 \%$ de la submuestra. Se registró la presencia de médula en Senecio/Baccharis $(\mathrm{n}=1)$, Schinus $(\mathrm{n}=1)$ e indeterminable $(\mathrm{n}=1)$. Las aberturas producto de la combustión se registraron en anillos, vasos y radios en Schinus $(\mathrm{n}=$ 1) y sólo en vasos y radios en Schinus $(\mathrm{n}=4)$, y Senecio/Baccharis $(\mathrm{n}=3)$, es decir se observaron en el $25 \%$ de la submuestra. 
En la capa 3 se recuperó un total de 130 carbones para un volumen de 1,8 1 y una densidad calculada de 72,22 n/l, baja. Las categorías de tamaño abarcan un rango de 10-14,9 mm a 2-4,9 mm siendo esta última la que mayor cantidad de carbones presenta. La submuestra analizada es de 31 carbones entre los que se identificaron cuatro taxa siendo predominantes Schinus y Senecio/Baccharis (45,2\% al 38,7\%) y, en menor medida, Berberis y Atriplex/Suaeda (menos del 7\%) (Figura 10.46).

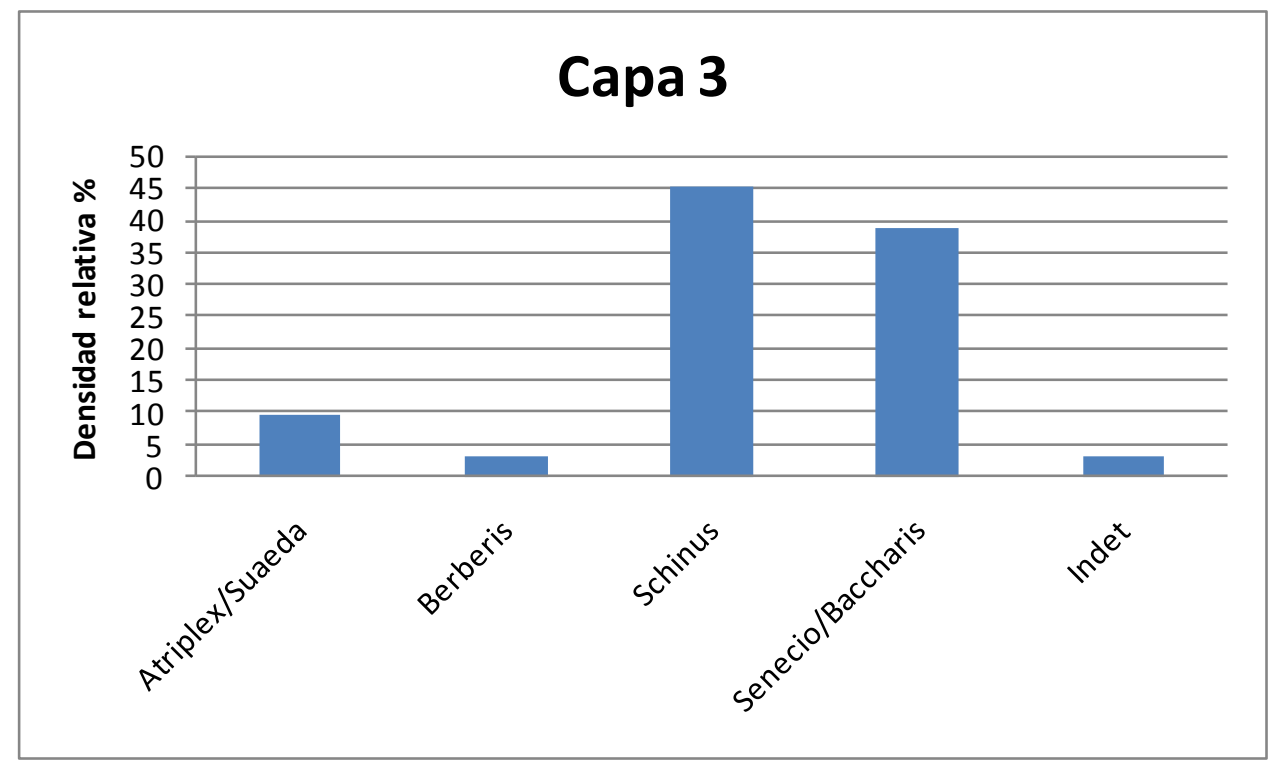

Figura 10.46. Carbones dispersos identificados en la capa 3, nivel 9, de la columna estratigráfica de Zubimendi et al. (2011) (submuestra $\mathrm{n}=31$ ).

Se identificó vitrificación en los siguientes géneros: Schinus $(\mathrm{n}=1)$, Atriplex/Suaeda $(\mathrm{n}=1)$ y en Senecio/Baccharis $(\mathrm{n}=1)$ por lo tanto en el $9,67 \%$ de la submuestra. Las aberturas en radios y vasos se observaron en Schinus $(\mathrm{n}=$ 6), en radios y vasos, es decir en el 19,35\% de la submuestra.

La capa 4 presenta un total de carbones de 89 para un volumen de 1,81 y una densidad calculada de 49,44 n/l, determinada como baja. Las categorías de tamaño abarcan el rango de 15-19,9 $\mathrm{mm}$ a 2-4,9 $\mathrm{mm}$ siendo la categoría 5-9,9 $\mathrm{mm}$ la que más carbones presenta. Se analizó una submuestra de 21 carbones entre los que se identificaron dos taxa, siendo predominante Senecio/Baccharis $(71,4 \%)$ y en menor medida Schinus (23,8\%) (Figura 10.47). 


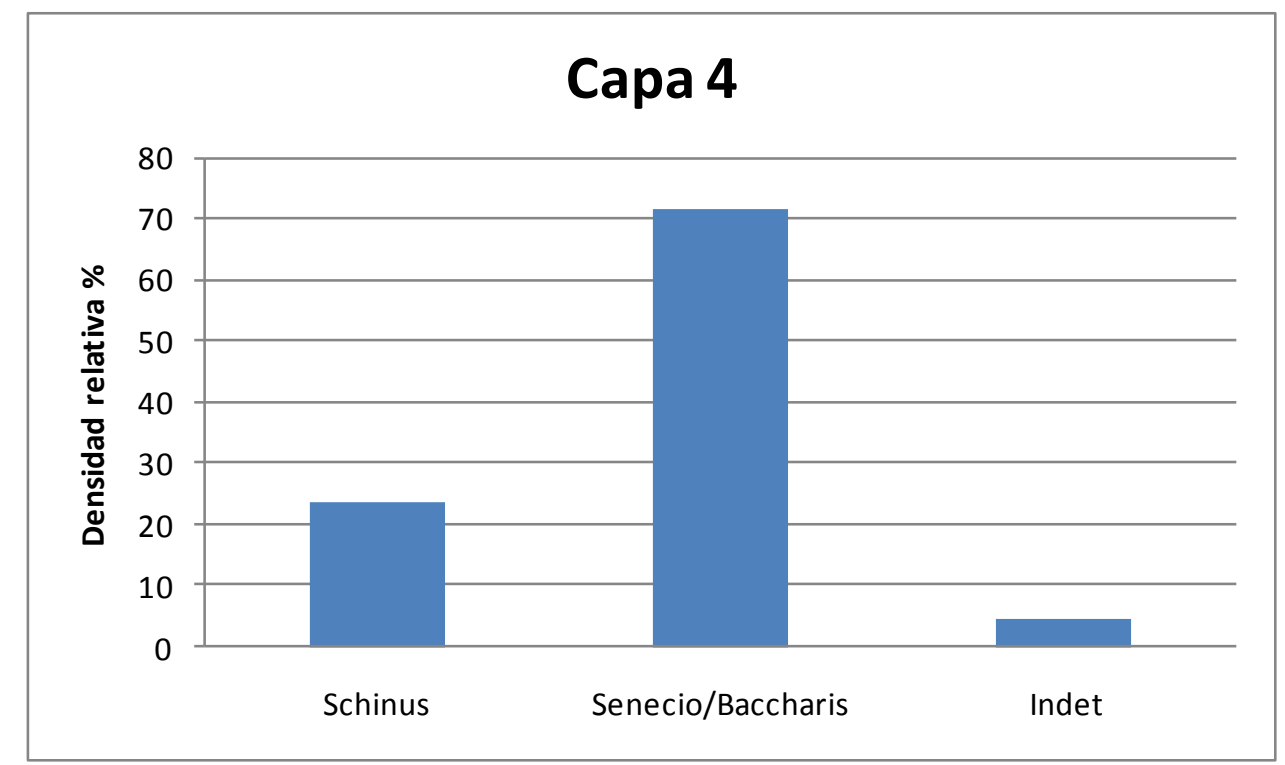

Figura 10.47. Carbones dispersos identificados en la capa 4, nivel 17, de la columna de muestreo de Zubimendi et al. (2001) (submuestra $\mathrm{n}=21$ ).

Se observó vitrificación en Schinus $(\mathrm{n}=4)$, Senecio /Baccharis $(\mathrm{n}=3) \mathrm{y}$, es decir en el $33,3 \%$ de la submuestra. La presencia de médula se registra en Senecio/Baccharis $(\mathrm{n}=1)$ y las aberturas post-combustión en radios de Schinus ( $\mathrm{n}$ =2) y en radios y vasos de Senecio/Baccharis $(n=5)$. Las aberturas se registraron para el 33,3\% de la submuestra.

La capa 5 tiene un total de 86 carbones para un volumen de 1,8 1 siendo la densidad calculada de 47,78 n/l clasificada como baja. Las categorías de tamaño registradas son de 15-19,9 $\mathrm{mm}$ a 2-4,9 $\mathrm{mm}$ siendo la categoría 5-9,9 $\mathrm{mm}$ la que más carbones presenta. La submuestra analizada es de 20 carbones entre los que se identificaron tres taxa. Tanto Schinus (45\%) como Senecio/Baccharis (30\%) presentan una densidad relativa alta (Figura 10.48). 


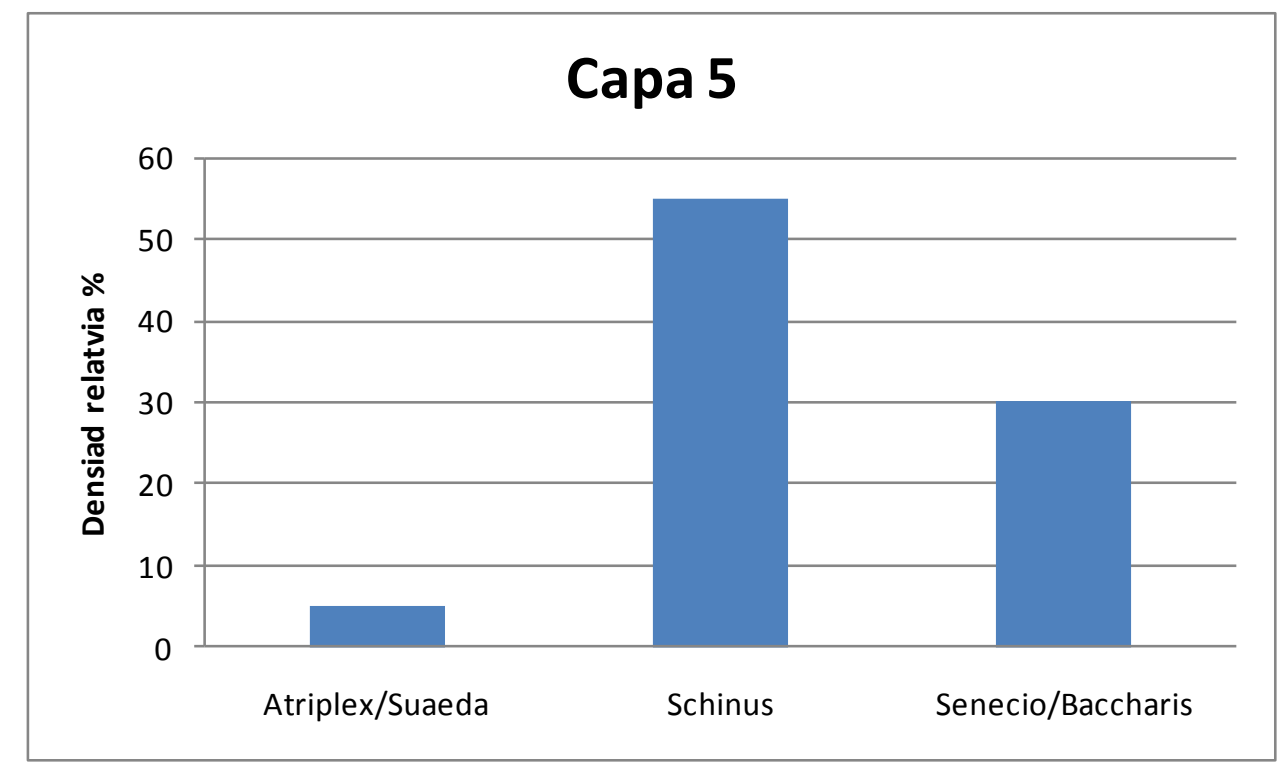

Figura 10.48. Carbones dispersos identificados en la capa 5, nivel 23, de la columna de muestreo de Zubimendi et al. (2011) (submuestra $\mathrm{n}=20$ ).

La vitrificación se observa en Schinus $(\mathrm{n}=4)$ es decir, en un $20 \%$ de la submuestra. En cuanto a las aberturas se identificaron sobre el floema incluso y el parénquima de Atriplex/Suaeda $(\mathrm{n}=1)$, en radios y vasos de Schinus $(\mathrm{n}=7)$, Senecio/Baccharis $(\mathrm{n}=1)$ e indeterminable $(\mathrm{n}=1)$, por lo tanto en el $45 \%$ de la submuestra.

El análisis de ubicuidad \% realizado para los niveles pertenecientes a las capas 1 a 5 de este sitio evidencian que los taxa con mayor ubicuidad fueron los siguientes: Schinus (100\%) y Senecio/Baccharis (80\%) (Figura 10.49). 


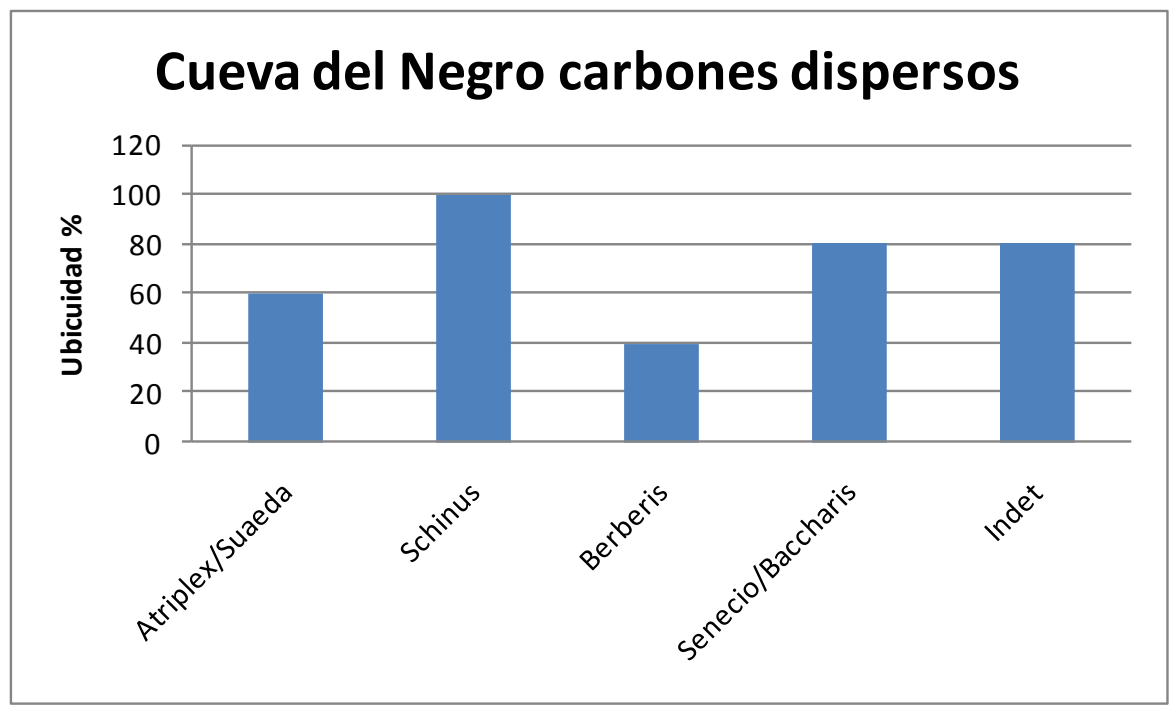

Figura 10.49. Ubicuidad \% de los carbones dispersos analizados en los niveles dentro de las capas 1 a 5 del sitio Cueva del Negro.

En cuanto al análisis de asociación entre las variables número de fragmentos de los carbones dispersos y peso se obtuvo correlación $\mathrm{R}^{2}=0,023$, es decir baja o nula (Figura 10.50). Esto se debería a que en el evento de la capa 2, nivel 3, se observó un número elevado de restos pero con bajo peso total, lo podría indicar una fragmentación muy intensa.

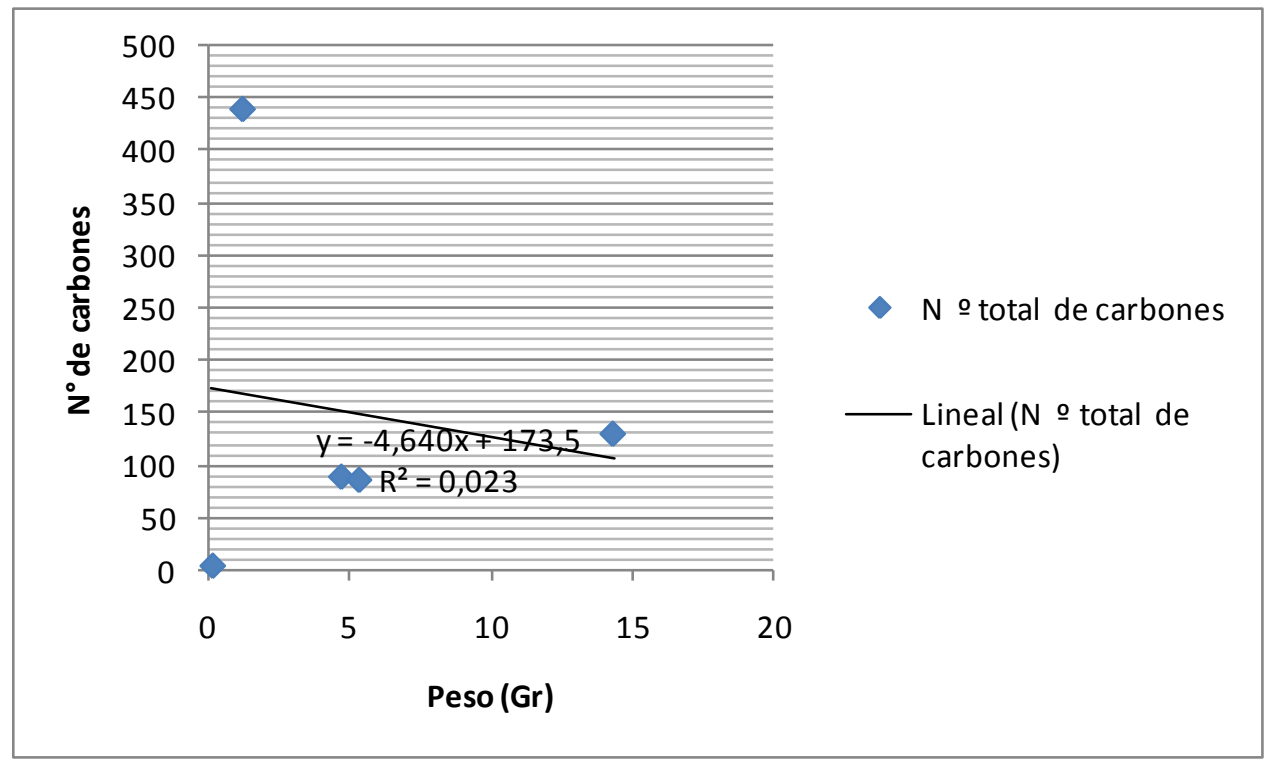

Figura 10.50. Correlación entre número de fragmentos de carbones dispersos y peso total de los mismos, niveles analizados de las capas 1 a 5, sitio Cueva del Negro 


\subsubsection{Discusión y conclusiones}

El sitio Cueva del Negro presenta fechados radiocarbónicos que lo ubican cronológicamente en el Holocento tardío. Para este período la vegetación sería análoga a la actual (De Porras 2010).

En las capas 1, 2, 3 y 4 se identificaron los mismos taxa, pero la densidad relativa de los carbones de cada uno de ellos varió en relación a la capa. En la primera predomina Schinus y es acompañado por Atriplex/Suaeda. Los leños de estos taxa son de densidad alta siendo maderas semipesadas y semiduras, y como se mencionó para otros sitios Atriplex/Suaeda es buena leña para encender y produce ceniza, mientras que Schinus es más duradera porque produce brasa y tiene mayor densidad. Sin embargo, no se registraron para esta capa rasgos diagnósticos de altas temperaturas. En relación al contexto, se observó una baja densidad de restos malacológicos para el nivel 1, se recuperaron artefactos formatizados y productos de talla, así como también restos óseos de mamíferos y aves (Zubimendi et al. 2011).

En la capa 2 en cambio, Schinus presenta mayor densidad relativa pero Senecio/Baccharis muy próximo a éste. En tercer y cuarto lugar se encuentran Atriplex/Suaeda y Berberis. Se registraron caracteres diagnósticos de altas temperaturas próximas a $\operatorname{los} 700{ }^{\circ} \mathrm{C}$ en un carbón de Schinus así como se observaron abundantes aberturas $(25 \%)$ y vitrificación $(15,62 \%)$. En este caso se registra una gran cantidad de restos malacológicos muy fragmentados, restos óseos y líticos. Es en esta capa donde aumenta la densidad de materiales arqueomalacológicos. Es importante mencionar, en relación a la fragmentación de restos malacológicos, que el análisis de correlación entre el número de fragmentos de carbones dispersos y el peso total evidenció en esta capa y para el nivel 3, una fragmentación intensa de los carbones arqueológicos. Esta alta fragmentación de los restos malacológicos y antracológicos, junto con una alta compactación registrada durante la excavación (Zubimendi et al. 2011) podría estar relacionada con procesos postdepositacionales y de alteración moderna. Por encima de este nivel se encontraba la capa 1 que corresponde a sedimentos eólicos con restos arqueológicos redepositados, formada luego de una intensa alteración producto 
del saqueo que sufrió parate de este sitio. En este sentido, el nivel 3 estaría reflejando el pisoteo y compactación anterior a la acumulación de este depósito eólico.

Si bien se recuperaron carbones dispersos que pueden responder a más de un evento de combustión se considera relevante que se siguen manteniendo la combinación de maderas de rápido encendido con otras de mayor duración para todas las capas.

En la capa 3 se observa densidades relativas altas de carbones por volumen de sedimento tanto para Schinus como para Senecio/Baccharis acompañadas de densidades más bajas de Berberis y Atriplex/Suaeda. Si bien se observaron gran cantidad de aberturas en los carbones producto de la combustión $(19,35 \%)$, y no se registraron caracteres diagnósticos de altas temperaturas $\left(700^{\circ} \mathrm{C}\right)$. En esta capa se registra la mayor densidad de restos malacológicos (lapas y mitílidos), se recuperó la mayor cantidad de restos óseos (mamíferos, aves y peces) en esta capa y artefactos líticos (artefactos formatizados, núcleos y productos de talla). Es relevante la alta densidad de Schinus en asociación a este contexto, si bien, se analizaron carbones dispersos, los fuegos de los cuales provienen debieron haber estado asociado al procesamiento de estos recursos.

En la capa 4 se observa una mayor densidad relativa de carbones por volumen de sedimento de Senecio/Baccharis y en menor medida Schinus, en este caso se trataría de fuegos de menor duración y poder calórico que el anterior. No se registraron aberturas diagnósticas de altas temperaturas en los carbones, aunque sí se registra un porcentaje alto en radios y vasos. En cuanto a los restos malacológicos se observa un detrimento en relación a la capa anterior con mayor presencia de lapas que de mitílidos. En cuanto a los restos zooarqueológicos también hay una disminución en la cantidad, pero igualmente sigue siendo alta la densidad de material óseo en esta capa.

En la capa 5 se registró una alta densidad relativa de carbones por volumen de sedimento para Schinus y Senecio/Baccharis seguida por Atriplex/Suaeda. Se observaron rasgos de vitrificación y aberturas post carbonización, pero no rasgos diagnósticos de altas temperaturas. En esta capa tiene un aumento la densidad de restos malacológicos, en cambio los restos óseos disminuyeron en relación a la 
capa anterior. En cuanto a los artefactos líticos es bajo el número de artefactos formatizados $\mathrm{y}$ productos de talla. La densidad calculada de los carbones disminuyó respecto a la capa anterior pero aún es alta.

El análisis de ubicuidad \% de todas las capas permitió identificar que el taxa que se registró en todas las capas, y por ende, obtuvo el 100\% de ubicuidad fue Schinus, seguido con el $80 \%$ por Senecio/Baccharis y un $60 \%$ por Atriplex/Suaeda.

Es importante mencionar que no se registró en todas las capas el ataque de microorganismos e hifas, por lo que el estado de las maderas antes de carbonizar fue bueno, lo que habría favorecido a mantener el poder calórico de los leños (Caruso 2012). Por otra parte, si bien los restos zooarqueológicos se analizaron como un conjunto sin discriminar por capa, se observó que el 63\% de la muestra presentaba huellas antrópicas entre ellas, distintos grados de combustión (quemados, carbonizados, y calcinados).

En este sitio se produjeron múltiples actividades, con una ocupación redundante e intensiva del sitio, evidenciado en la gran abundancia de recursos faunísiticos y malacológicos con características de su explotación y consumo. También la presencia de restos líticos. Es llamativo entonces, que el uso de las leñas haya sido similar a otros sitios del sur de la ría Deseado, con maderas cercanas al sitio, e incluso como se verá en el capítulo 11 a partir de una de ellas (i.e. Berberis) su utilización para la manufactura de artefactos. Este último podría estar asociado a la captura de peces en pozos de agua, actividad que tiene su correlato en la cantidad de restos de peces hallados en el sitio. Este fragmento de arpón en madera asociado a otros seis arpones de hueso evidencia una tecnología de captura de pinnípedos. En este sentido la explotación y consumo de pinnípedos entre otras especies marinas y en menor medida terrestres, habrían sido intensivas durante los 300 años, aproximadamente, de ocupación de la cueva, teniendo en cuenta los fechados radiocarbónicos (Zubimendi et al. 2011). Este contexto podría sugerir un impacto en la vegetación de la zona siendo que todas las maderas seleccionadas para la combustión estaban disponibles en los alrededores. 


\subsubsection{Sitio Las Hormigas}

\subsubsection{Introducción}

El sitio Las Hormigas se encuentra ubicado en Bahía del Oso Marino sobre el primer escalón de la playa a $16 \mathrm{msnm}$, y a $80 \mathrm{~m}$ de la línea de costa (Figura 10.51). Es un sitio de los denominados "conchero" conformado por una lente de valvas asociadas entre sí (fábrica de tipo bioclasto-sostenida) emplazado sobre un manto eólico (Hammond 2013). La vegetación circundante al sitio está compuesta por Nardophyllum bryoides, Senecio sp, Pappostipa sp. y Poa sp.

El sitio fue excavado bajo la dirección de la Lic. Hammond y se realizó una cuadrícula de 1 x $1 \mathrm{~m}$. Se realizó un fechado radiocarbónico sobre carbón vegetal, cuyo resultado es de $370 \pm 40$ años AP (LP 2504).

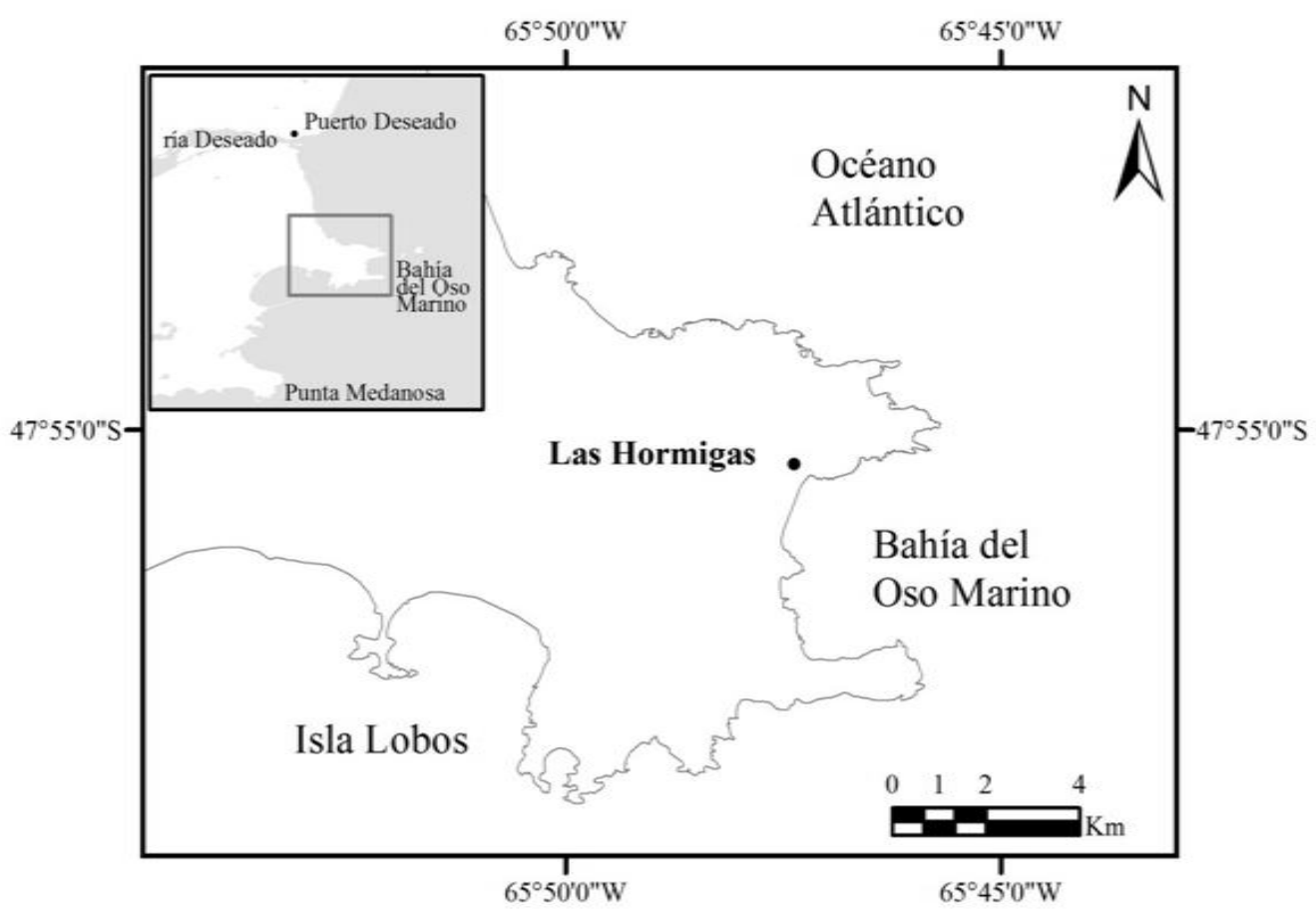

Figura 10.51. Ubicación del sitio Las Hormigas 


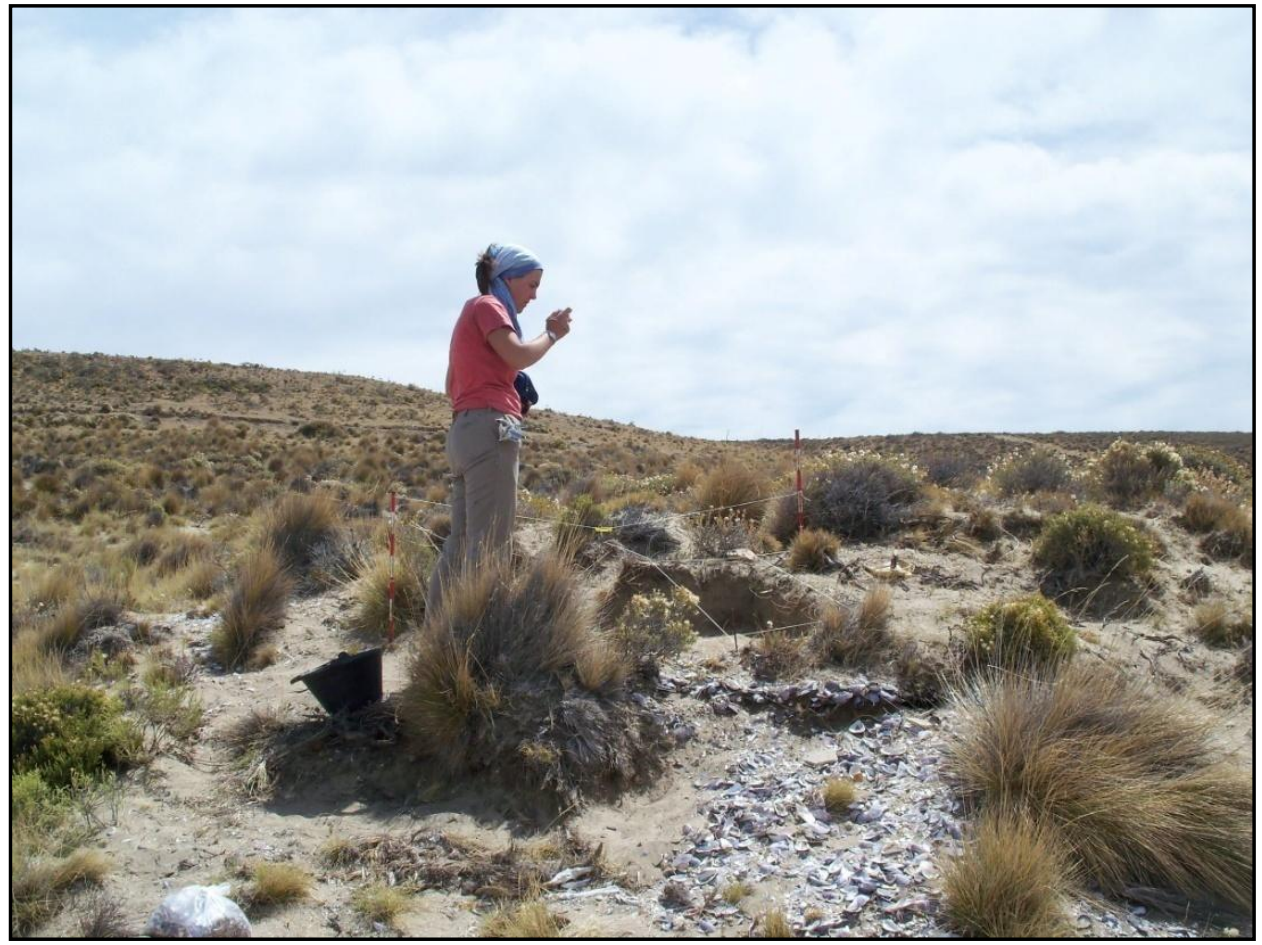

Figura 10.52. Vista general del sitio Las Hormigas

\subsubsection{Metodología}

\subsection{Excavación}

Se realizó una cuadrícula de 1 x $1 \mathrm{~m}$ sobre la que se desarrollaron cuatro cuadrantes y se excavó siguiendo los niveles naturales observando cambios en la estructura o color de los sedimentos. Se utilizó una malla de zaranda de $2 \mathrm{~mm}$ y se guardó el fondo de zaranda para su posterior análisis en el laboratorio (Hammond 2013).

\subsection{Recuperación de restos antracológicos}

En el sitio conchero Las Hormigas se recuperaron carbones dispersos con malla de $2 \mathrm{~mm}$ de cada nivel y del fondo de zaranda de la misma malla. Sólo se realizó el análisis antracológico del nivel 2 cuadrantes A y $\mathrm{C}$ debido a que los carbones provenientes de los otros cuadrantes se utilizaron para obtener el fechado radiocarbónico. 


\subsubsection{Contexto estratigráfico}

Se identificaron cuatro niveles estratigráficos, el primero denominado superficial tiene $10 \mathrm{~cm}$ de potencia y se encuentra conformado por sedimento eólico arenoso (Figura 10.53). En el nivel 1 se registra una lente de valvas junto con restos óseos y líticos y carbones dispersos sobre un sedimento eólico arenoso, con una potencia de $8 \mathrm{~cm}$. El nivel 2 se caracteriza por un sedimento eólico arenoso de color gris sobre el que se registran valvas dispersas y carbones. El nivel 3 se conforma por sedimento eólico arenoso sobre el cual se estableció el conchero, se registraron escasos materiales arqueológicos (Hammond 2013).

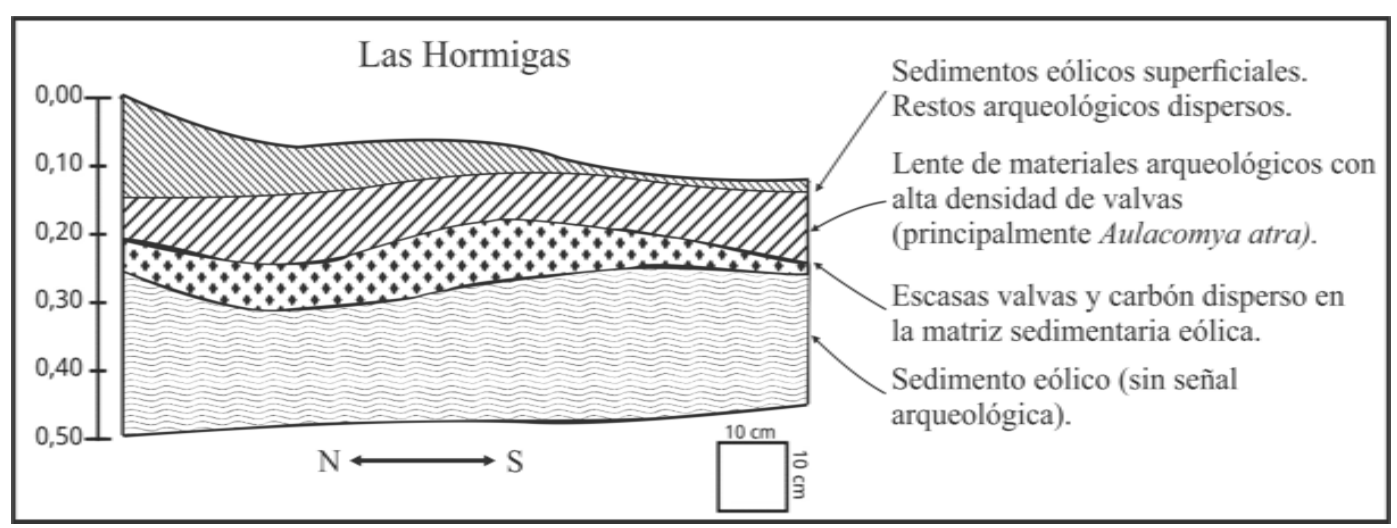

Figura 10.53. Perfil estratigráfico sitio Las Hormigas (Hammond 2014).

\subsubsection{Estudios arqueológicos}

Sobre la superficie del sitio se observan valvas de moluscos, restos de pinnípedos y material lítico. El análisis malacológico del sitio tuvo como resultado el registro de 20 especies de moluscos y un número mínimo de 2.698 individuos entre los que predominaron los mitílidos y en menor medida lapas. En cuanto a los restos óseos, una alta proporción del conjunto presentaba fragmentación y ausencia de rasgos diagnósticos, sin embargo se identificaron un total de 1777 especímenes óseos, entre los que predominaron los pinnípedos (Hammond 2013). En cuanto a los restos líticos, se recuperaron 380 artefactos manufacturados, de diversas materias primas, entre las que predominan las de calcedonia. Los productos de 
talla son el grupo tipológico que predomina, registrándose además, instrumentos y dos núcleos agotados. Se recuperaron fragmentos de huevos de ñandú, y restos de hierro.

\subsubsection{Resultados antracológicos}

En el nivel 2, cuadrante A, se recuperaron 175 carbones dispersos en un volumen de 181 para una densidad calculada de 9,72 n/l clasificada como baja. Las categorías de tamaño se encuentran en el rango de 15-19,9 mm a 2-4,9 mm, siendo la última categoría donde se encuentran mayor cantidad de carbones. La submuestra analizada es de 25 carbones entre los que se identificaron tres taxa siendo predominante Schinus (71,8\%), seguido por Senecio /Baccharis y Adesmia (con valores menores al 20\% para cada uno) (Figura 10.54).

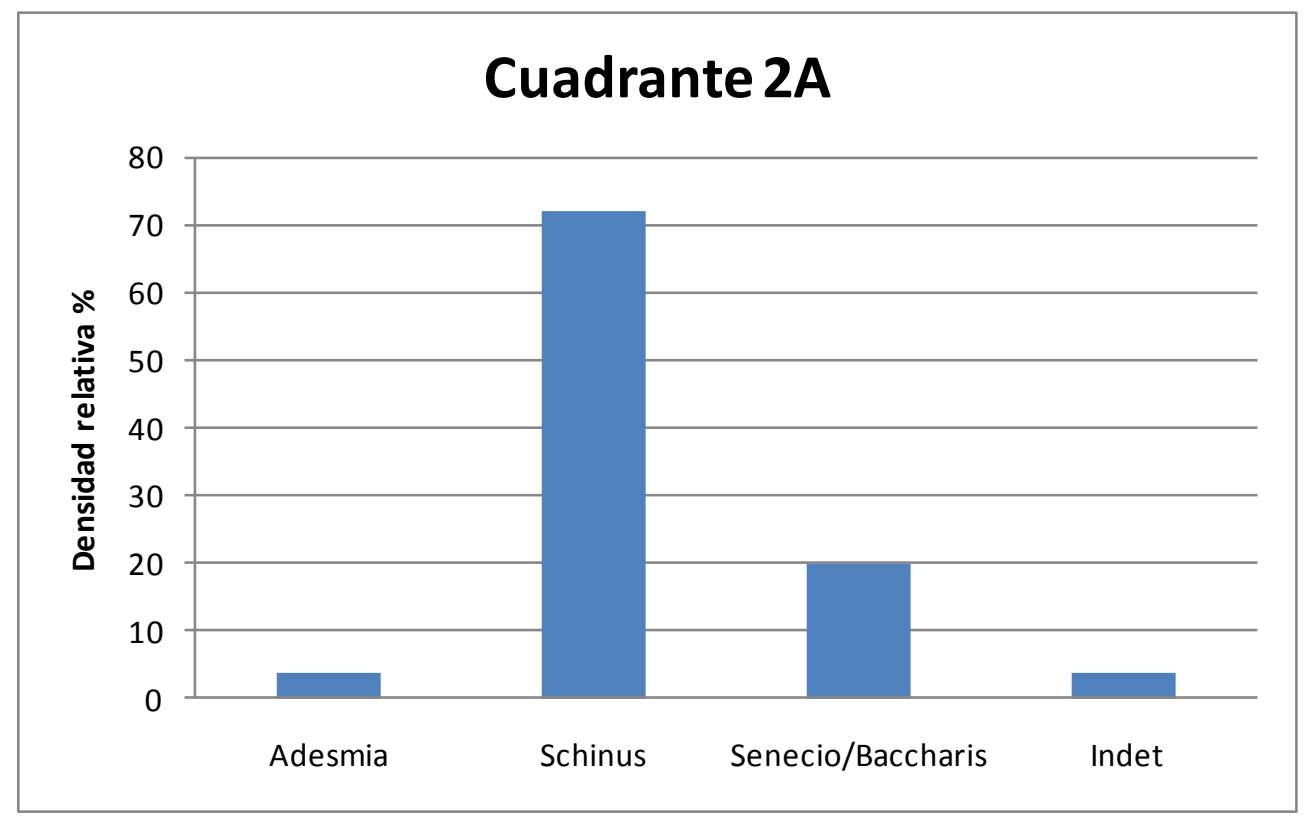

Figura 10.54. Carbones dispersos identificados del cuadrante A, nivel 2, Sitio Las Hormigas ( submuestra $\mathrm{n}=25$ ).

La vitrificación se registró en los carbones de Schinus $(\mathrm{n}=3)$ y un carbón indeterminable $(\mathrm{n}=1)$, es decir el $16 \%$ de la submuestra. Se observó médula en Schinus $(\mathrm{n}=2)$ y Senecio/Baccharis $(\mathrm{n}=1)$. Es importante mencionar que se observó en todos los carbones una depositación de carbonato que fue 
característico de este sitio, si bien se observa en el sitio 112 (Isla Lobos) y en menor medida en el sitio 160 (Punta Medanosa, ver Hammond y Zubimendi 2013). Es en Las Hormigas donde se presenta como una capa sobre los carbones tapando incluso, los poros de los vasos. Las aberturas se observaron en radios y vasos de Schinus $(\mathrm{n}=15)$, y Senecio/Baccharis $(\mathrm{n}=1)$, es decir en el $65 \%$ de la submuestra.

En el nivel 2, cuadrante C, se recuperaron 679 carbones en un volumen de 181 en una densidad calculada de 37,72 n/l determinada como baja. Las categorías de tamaño abarcaron un rango de 20-24,9 $\mathrm{mm}$ a 2-4,9 $\mathrm{mm}$ siendo esta última donde se encuentran mayor cantidad de carbones. La submuestra analizada es de 34 carbones entre los que se identificaron tres taxa donde predomina Schinus (44\%) y le siguen en cuanto a menor densidad relativa del 26,4\%, 20,6\% al 2,94\% Senecio/Baccharis, Atriplex/Suaeda y cf. Lycium respectivamente (Figura 10.55).

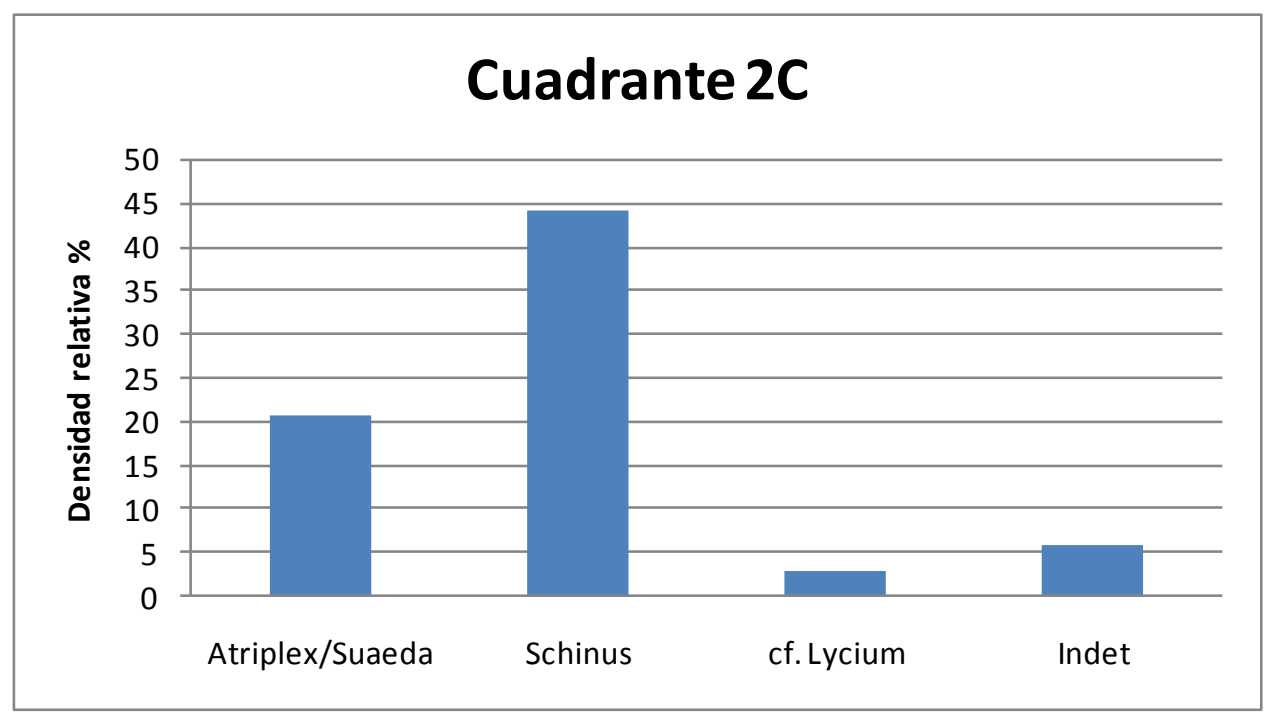

Figura 10.55. Carbones dispersos, nivel 2, cuadrante C, sitio Las Hormigas (submuestra n $=34$ ).

Se observó vitrificación en Schinus $(\mathrm{n}=5)$, y carbones indeterminados $(\mathrm{n}=2)$. Los carbones que presentaron una depositación de carbonato son los siguientes Schinus $(\mathrm{n}=3)$, Senecio/Baccharis $(\mathrm{n}=2)$, cf. Lycium $(\mathrm{n}=1)$ e indeterminable $(\mathrm{n}$ $=1)$. Se registró presencia de médula en Atriplex/Suaeda $(\mathrm{n}=4)$, Senecio/Baccharis $(\mathrm{n}=2)$, Schinus $(\mathrm{n}=1)$. Las aberturas sobre parénquima y floema incluso se identificaron en Atriplex/Suaeda $(\mathrm{n}=4)$, sobre radios y vasos en 
Senecio/Baccharis $(\mathrm{n}=1)$, Schinus $(\mathrm{n}=9)$ e indeterminables $(\mathrm{n}=2)$, es decir el $47,5 \%$ de la submuestra presenta aberturas.

Se realizó el análisis de ubicuidad de ambos cuadrantes A y C de la cuadrícula 1, nivel 2. Se observó el $100 \%$ de ubicuidad para Schinus y Senecio/Baccharis y el resto de los taxa con el 50\% de ubicuidad (Figura 10.56).

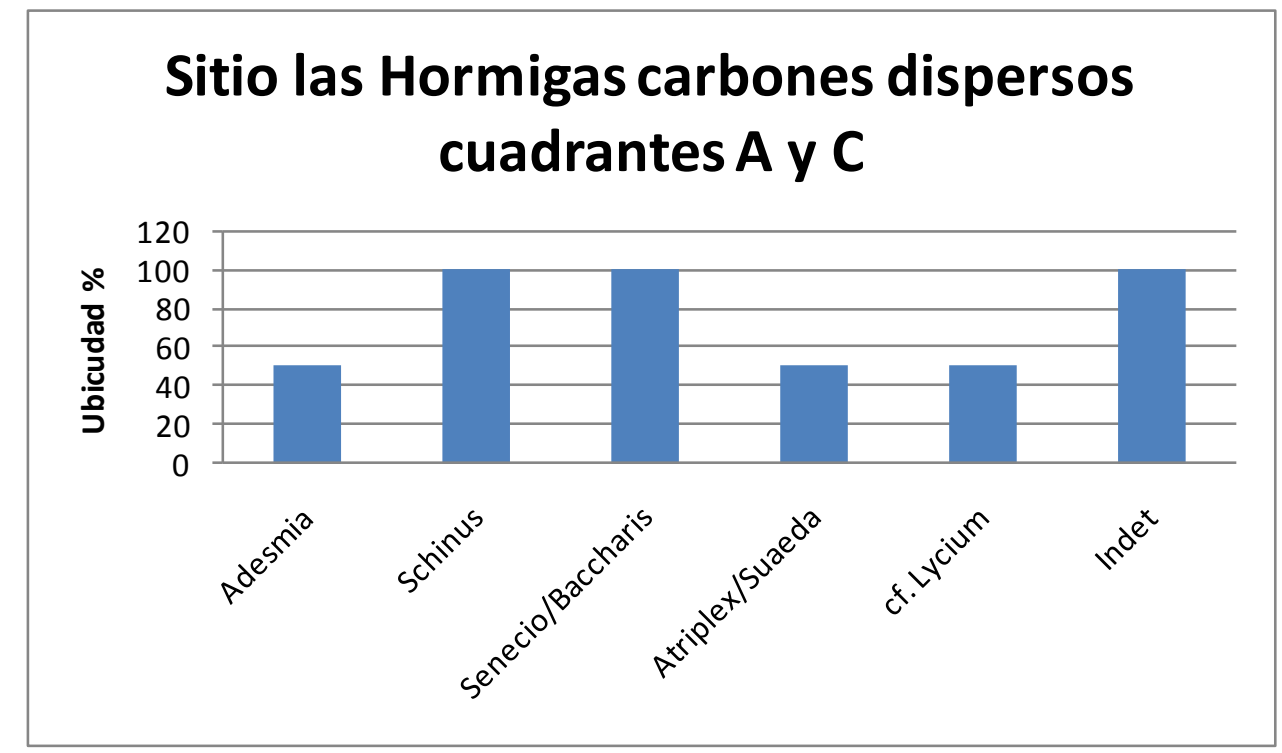

Figura 10.56. Ubicuidad \% de los taxa identificados de los carbones dispersos de la cuadrícula 1, nivel 2 cuadrantes A y C

En cuanto al análisis de correlación entre el número de fragmentos de carbones dispersos y el peso total de los mismos no pudo realizarse debido a que la muestra es muy pequeña.

\subsubsection{Discusión y conclusiones}

En primer lugar, como se mencionó para otros sitios de cronología similar, para el Holoceno tardío la vegetación sería análoga a la actual (De Porras 2010).

En el nivel 2 del sitio Las Hormigas se observa una mayor densidad relativa de las maderas semiduras como Schinus, acompañada de leños de menor densidad que son buenos iniciadores del fuego (i.e. Senecio/Baccharis, Atriplex). Los carbones dispersos darían cuenta de uno o más eventos intensos, con producción de brasa debido al predominio de Schinus. En relación a las temperaturas que pudo 
alcanzar la combustión de estas maderas, no se observan los caracteres diagnósticos de altas temperaturas, pero sí en el cuadrante $2 \mathrm{~A}$ se registra el 65\% de aberturas siendo su mayor parte en radios y vasos de Schinus.

El registro arqueomalacológico, por otro lado, evidencia una alteración térmica del 36\% (Hammond 2013). A su vez, Hammond considera que una porción del conjunto estuvo expuesta al calor pero que la exposición habría sido de corta duración o a temperaturas relativamente bajas, debido a que las valvas presentan una buena conservación de su estructura.

Entonces, los eventos de combustión que dieron lugar a estos carbones dispersos estarían asociados a las actividades de apertura de valvas, y por esta razón los mitílidos presentan una coloración diferencial respecto a las lapas debido a un mayor contacto con el calor.

\subsection{Subsector Isla Lobos}

\subsubsection{Antecendentes recientes}

Este subsector de la costa se encuentra sobre una pequeña bahía al norte de la Bahía de los Nodales, frente a la Isla Lobos. Presenta afloramientos rocosos de la Formación Bahía Laura, pero, sin embargo, no desarrolla puntas. Se observan playas de arena de extensión variable y presenta un extenso intermareal arenoso, sin presencia de restingas. Sobre este sector se identificaron 21 estructuras de enterratorios de tipo chenque ubicados cronológicamente para el Holoceno tardío, abiertos por saqueos (Castro y Moreno 2000). Posteriormente, estudios distribucionales realizados por Castro et al. (2003) registran seis sitios concheros de gran extensión y densidad sobre médanos. El fechado más antiguo que se obtuvo en este subsector corresponde al sitio conchero Médano Alto de $5790 \pm 80$ años AP (LP- 1579) (Zubimendi et al. 2005). Se realizaron estudios sobre los conjuntos líticos de este sitio así como del sitio Denticulados, a $500 \mathrm{~m}$ hacia el sur del anterior (Hammond et al. 2009, Mazzitelli 2013). Por otro lado, el fechado más reciente para este sector es de $2870 \pm 60$ AP (LP-2141) y se obtuvo del sitio 112 que se estudiará a continuación. 


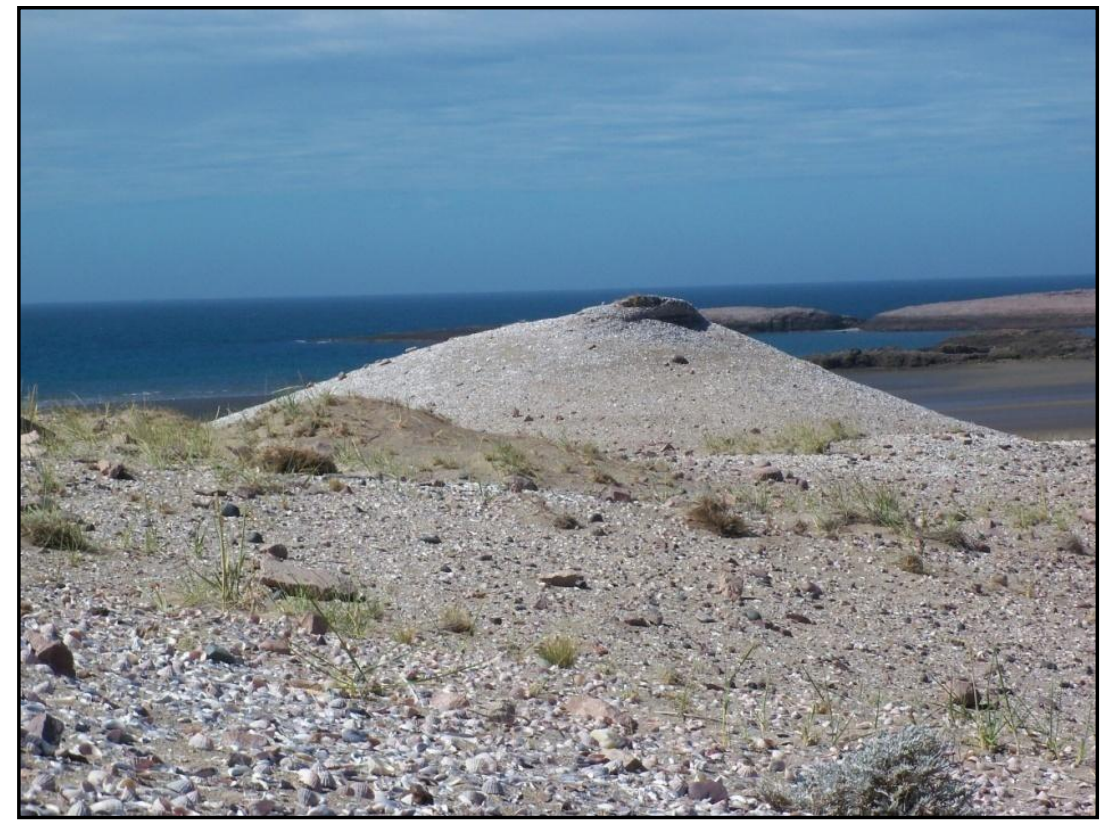

Figura 10.57. Sitio conchero en Isla Lobos

\subsubsection{Sitio 112}

El sitio 112 se encuentra en la localidad arqueológica Isla Lobos, sobre la Bahía Nodales frente a la Isla Lobos a $100 \mathrm{~m}$ de la línea actual de mareas (Figura 10.58). Se registra una lente de valvas donde predominan los mejillones y en menor medida las lapas. En superficie se registra además un sedimento de coloración gris, restos líticos, entre ellos tres boleadoras, y restos óseos, entre los que se destacan tres vértebras articuladas de cetáceos y una mandíbula humana muy meteorizada con cinco piezas dentales (Hammond 2013). La lente se encuentra sobre un manto eólico, siendo lenticular, con escasa vegetación alrededor del sitio. 


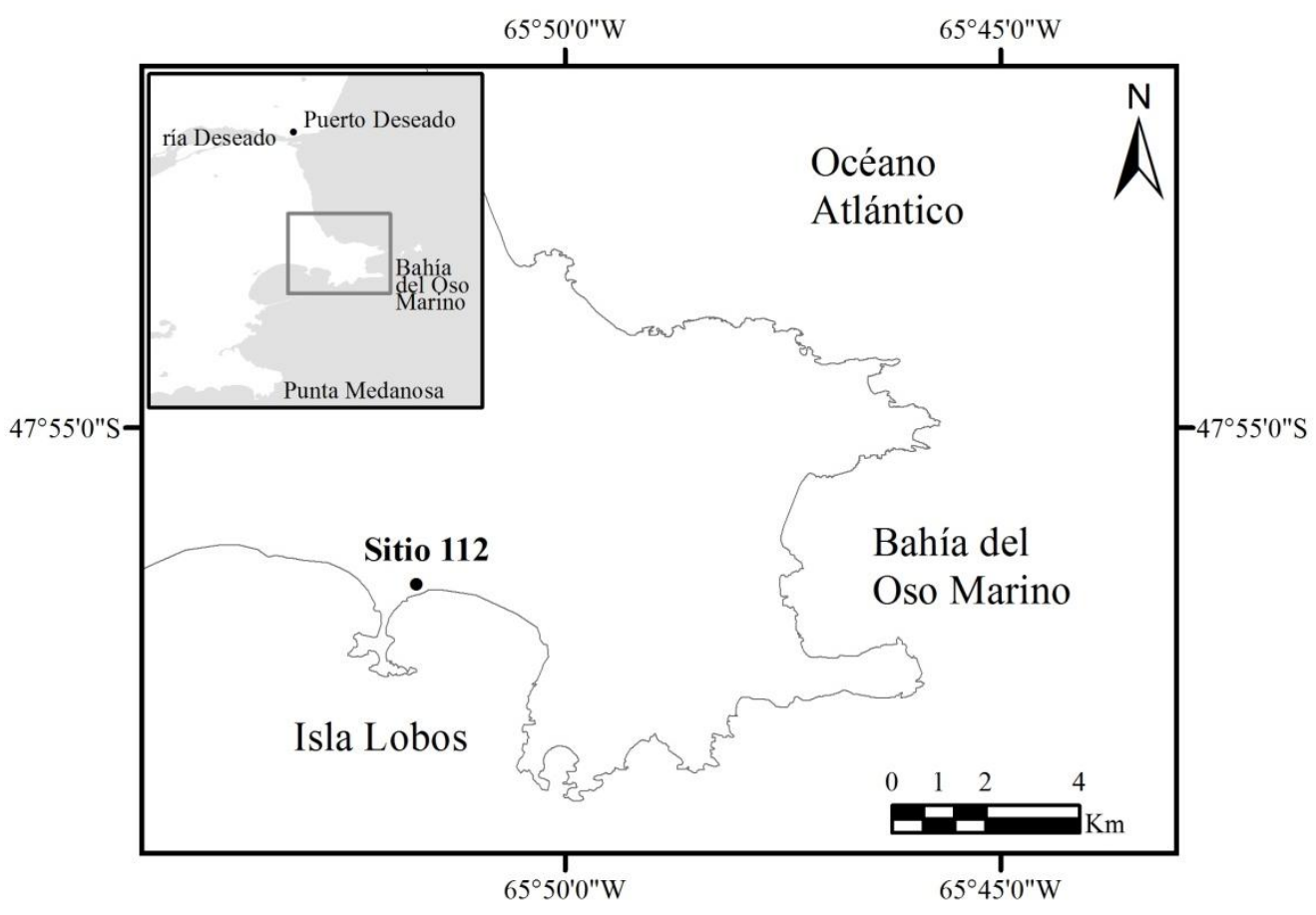

Figura 10.58 Ubicación del sitio 112

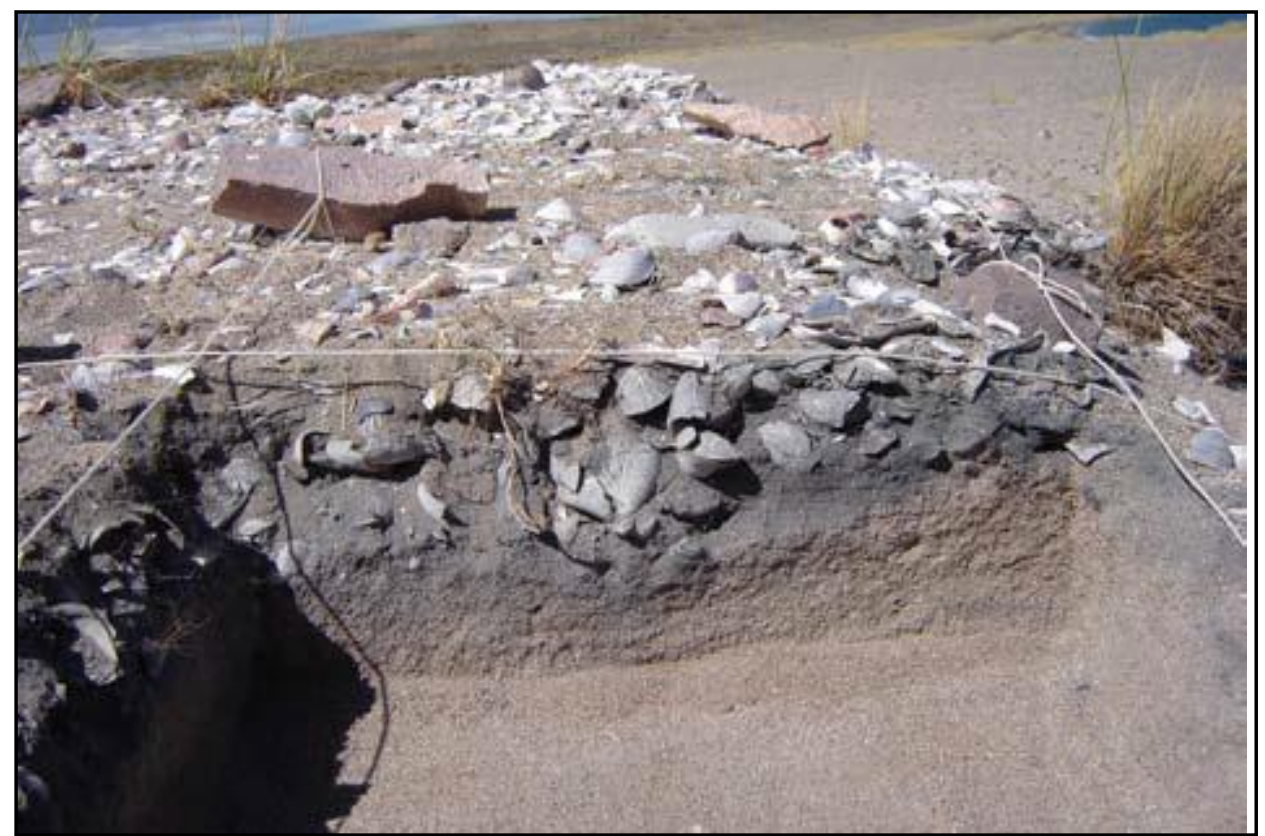

Figura 10.59. Perfil noreste del sitio 112 en Isla Lobos (Fotografía tomada por Heidi Hammond). 


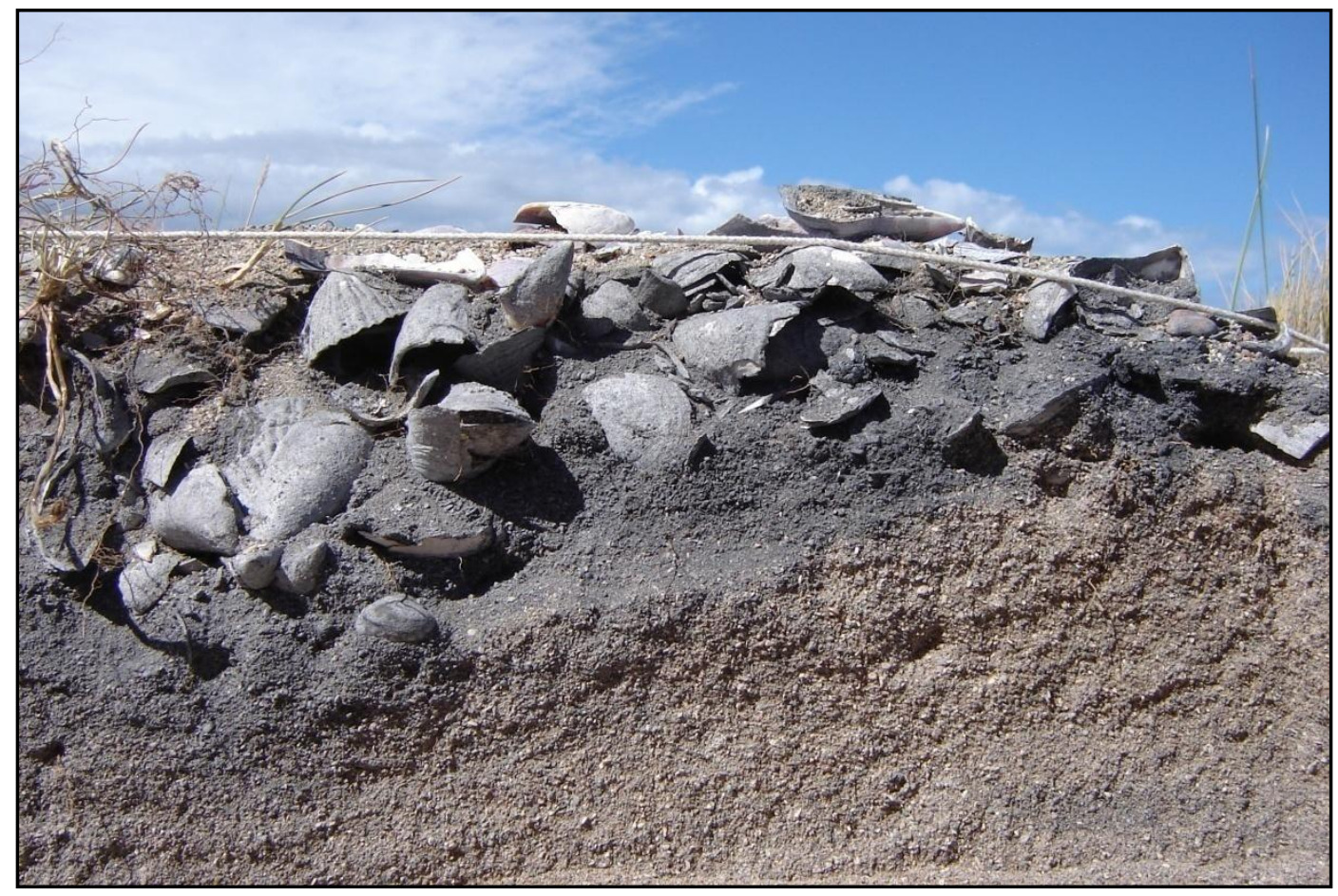

Figura 10.60. Sedimento gris por debajo de la lente de restos malacológicos, sitio 112 (Fotografía Heidi Hammond).

\subsubsection{Metodología}

\subsection{Excavación}

Se realizó una cuadrícula de 0,50 x 0,50 m y se siguieron las capas naturales de la estratigrafía siguiendo los cambios en la estructura y color del sedimento. Se utilizó una malla de $2 \mathrm{~mm}$ y se guardó el fondo de zaranda para su posterior análisis en el laboratorio.

\subsection{Recuperación de restos antracológicos}

Se recuperaron carbones dispersos con malla de $2 \mathrm{~mm}$ y del fondo de zaranda de la misma malla. Sólo se analizaron antracológicamente los carbones provenientes del nivel 1. 


\subsubsection{Contexto estratigráfico}

En el nivel superficial se observa sedimento de color gris oscuro sobre el que se hallan valvas de moluscos, restos líticos y algunos fragmentos de hueso (Figura 10.61). Este nivel tiene una potencia máxima de $3 \mathrm{~cm}$. El nivel 1 comienza con una lente de valvas donde predominan los mejillones, algunas de ellas quemadas, y en menor medida, lapas. Sobre uno de los sectores se observa el sedimento de color negro, muy oscuro y la lente de valvas muy densa. En la base eólica se halló un instrumento lítico. La potencia de este nivel es de $6 \mathrm{~cm}$.

Sobre el nivel 2 se observa una la lente de carbones siendo algunos de gran tamaño. El sedimento es arenoso de color marrón claro y las valvas se encuentran dispersas (Hammond y Zubimendi 2013).

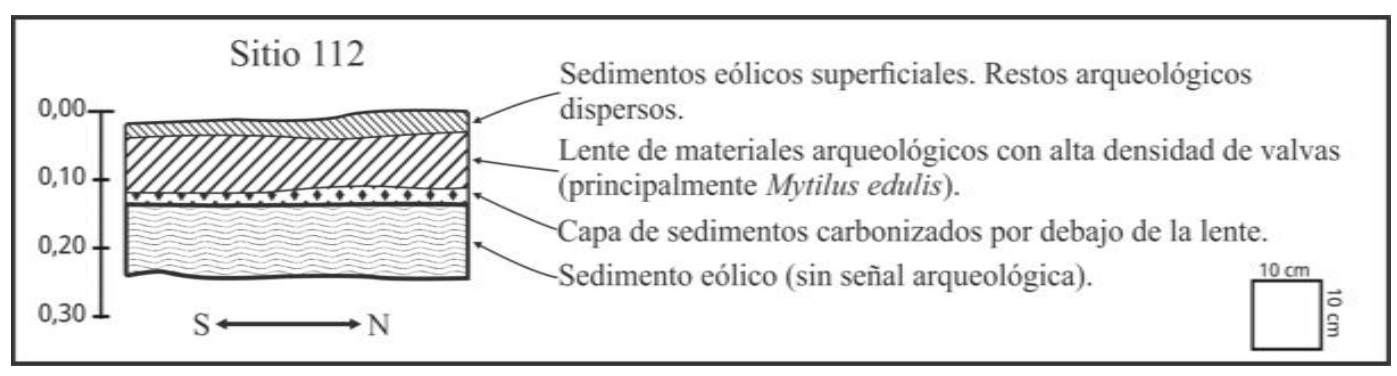

Figura 10.61. Perfil estratigráfico sitio 112 (Hammond 2014).

\subsubsection{Resultados antracológicos}

En el nivel 1 se recuperaron un total de 155 carbones en un volumen de 13,5 1 siendo una densidad calculada de 11,48 n/l clasificada como baja. Las categorías de tamaño abarcan el rango de 15-19,9 $\mathrm{mm}$ a 2-4,9 $\mathrm{mm}$ siendo esta última la categoría que mayor cantidad de carbones presenta. La submuestra analizada es de 17 carbones, siendo predominante Schinus (88\%) seguido muy en menor escala por Senecio/Baccharis (menos del 5\%) (Figura 10.62). 


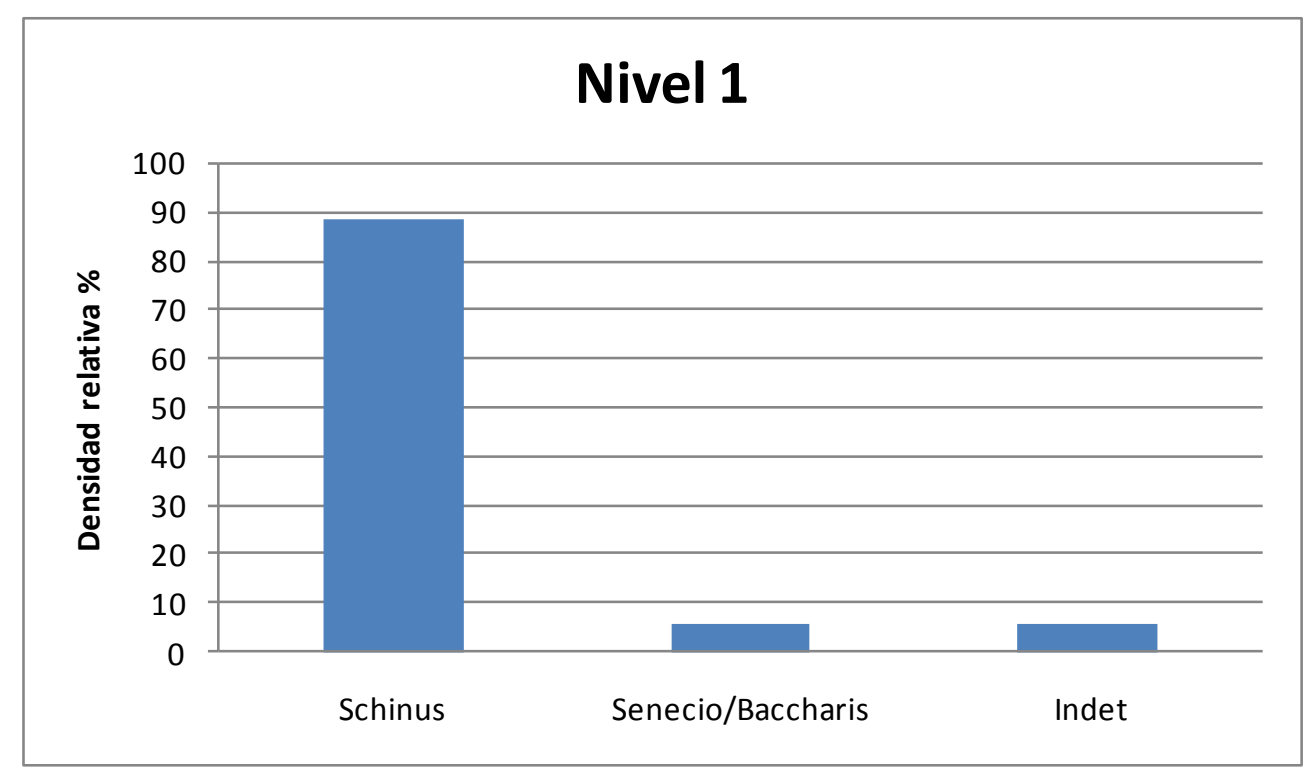

Figura 10.62. Carbones dispersos identificados en el sitio 112 (

Se observó una depositación de carbonato, al igual que en el sitio Las Hormigas, en el $88,3 \%$ de la submuestra $(n=15)$. En relación a las aberturas de la madera post carbonización se registraron en radios y vasos de Schinus $(\mathrm{n}=4)$ y un carbón indeterminable $(n=1)$ es decir el $29,4 \%$ de la submuestra.

En este sitio no se puede realizar análisis de ubicuidad debido a que se analizó un solo nivel, tampoco, entonces es posible desarrollar el test de correlación.

\subsubsection{Discusión y conclusiones}

El sitio 112 se ubica cronológicamente para el Holoceno tardío, período en el que ya se había formado la comunidad diversa arbustiva y subarbustiva de Lycium, Colliguaja, Schinus y Asteraceas análoga a la actual (De Porras 2010).

Los carbones dispersos del nivel 1 evidencian una mayor densidad relativa de carbones de Schinus, lo que evidencia que los eventos de combustión habrían tenido poder calórico y duración ya que, los leños de este género producen brasa y alcanzan temperaturas altas. Sin embargo, no se observaron grietas de combustión que evidencien una combustión por encima de los $400{ }^{\circ} \mathrm{C}$.

Es importante mencionar que Hammond $(2013$, 2014) registra para lapas y mitílidos una alteración térmica del 100\%. Hammond (2013) describe que las valvas se hallaban en su mayoría calcinadas y su estructura se encontraba muy 
debilitada. Así también la lente de valvas se encontraba sobre una capa de sedimentos quemados y las valvas presentaban adherido un sedimento muy fino de color gris. Este mismo precipitado se observó en los carbones dificultando en algunos casos su identificación. Si bien los carbones no parecerían indicar temperaturas tan altas, es probable que el jugo desprendido de la misma cocción de las valvas haya disminuido las temperaturas de combustión. La presencia de un sedimento muy fino de color gris sobre los carbones así como, otros materiales arqueológicos del sitio (lítico, valvas) además del sedimento quemado sobre el que se encontraban las valvas y su estado de calcinación podría sugerir que las valvas fueron cocidas directamente al fuego dando lugar a un proceso de carbonificación (Gutiérrez Zugasti 2008). Si esto efectivamente es así explicaría por qué se registró ese sedimento gris cubriendo distintos elementos del registro arqueológico (i.e. carbones, valvas y lítico) que en otros sitios concheros se observa en menor medida.

\subsection{Subsector Punta Medanosa}

\subsubsection{Antecendentes recientes}

La Punta Medanosa se extiende desde el sur de Isla Lobos hasta el final de la Punta en el litoral Atlántico. La punta mide $12 \mathrm{~km}$ de largo por $6 \mathrm{~km}$ de ancho y se encuentra separada del continente por un sistema de marismas (Ensenada Ferrer). El sector norte de la Punta está conformado por la terraza marina cubierta por dunas y depósitos de arena. En las costas este y sur se observa el afloramiento de rocas ignimbríticas del grupo Bahía Laura (Constante 2001, Castro et al. 2011 y Hammond 2013).

En cuanto al clima se observan las mismas condiciones que el sector anterior (templado frío, árido de meseta) sin embargo, en cuanto a la vegetación se registra el límite sur de la estepa arbustiva del Golfo San Jorge para pasar a predominar la estepa de arbustos enanos (Oliva et al 2001). Es notoria la presencia de molles (Schinus johnstonii) de gran tamaño, en especial en el sector norte, vinculados con pingüineras. 
En relación a los recursos faunísticos actualmente se encuentra una colonia de reproducción de pingüinos de Magallanes (Spheniscus magallanicus), amplios bancos de moluscos y en el pasado se registraron grandes loberías en la punta e islotes adyacentes a la playa (Castro et al. 2001; Schiavini et al 2005; Hammond et al. 2013).

En cuanto a los estudios arqueológicos realizados en este sector abarcan tanto el análisis distribucional, de aprovisionamiento de fuentes de materias primas, organización tecnológica, estructura y composición de los sitios concheros como de sitios enterratorios (Castro et al. 2001, Ambrústolo 2011, Mazzitelli 2014, Hammond et al. 2013, Zilio et al. 2013). En cuanto a la antigüedad de los sitios arqueológicos de este sector, el fechado más antiguo se registró en el sitio Médano 1, de $6300 \pm 90$ AP (LP-1544) (Castro et al. 2007) y el más moderno es el sitio 160 de $370 \pm 50$ AP (LP-2507), ambos sobre carbón vegetal (Hammond et al. 2013).

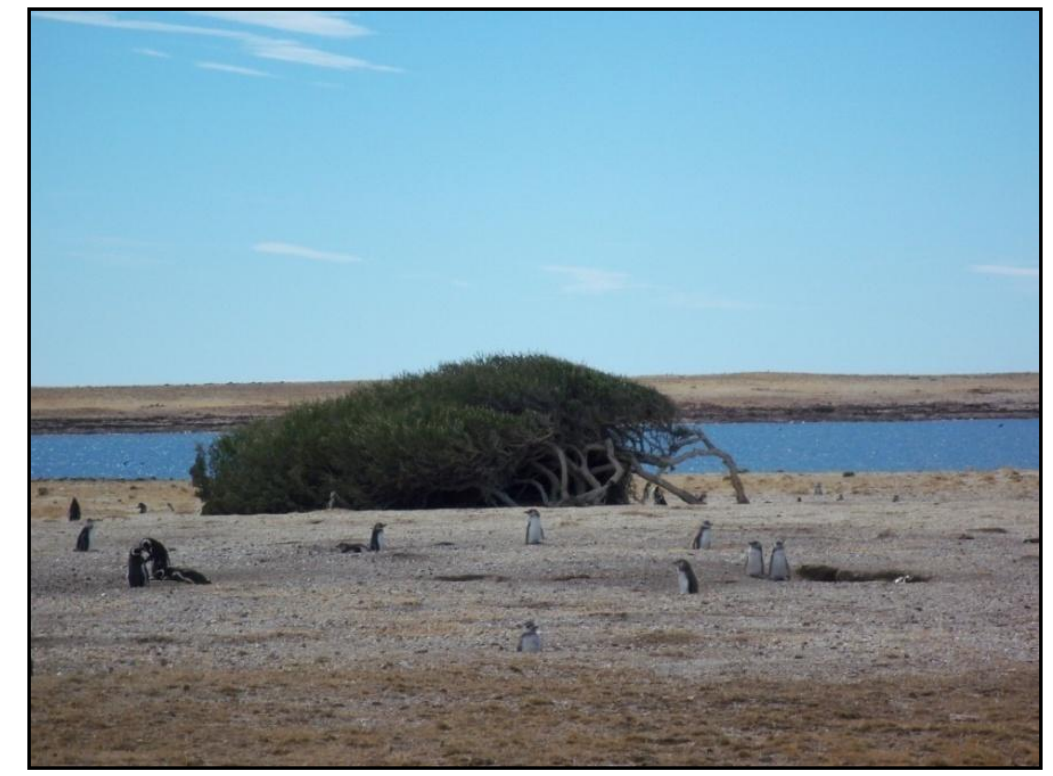

Figura 10.63. Colonia de pingüinos de Punta Medanosa y un arbusto de Schinus johnstonii 


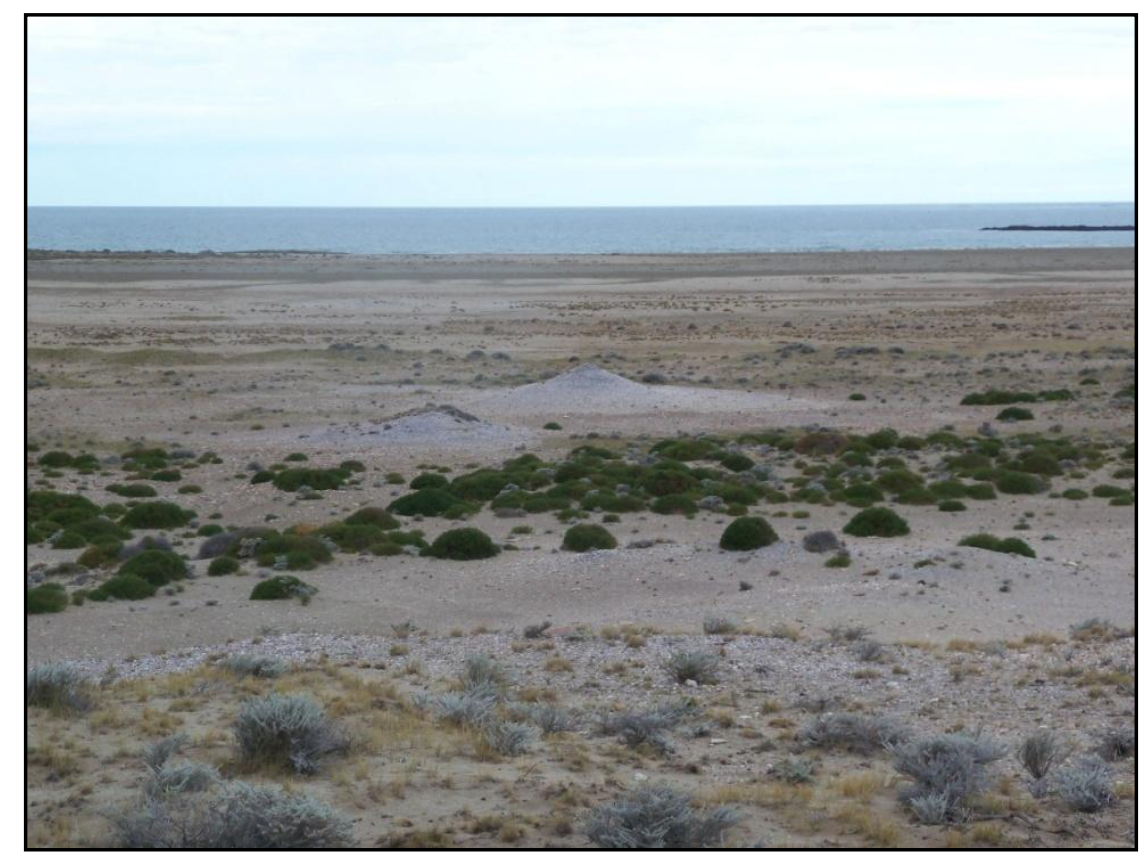

Figura 10.64. Sitios concheros en Punta Medanosa.

\subsubsection{Sitio 160}

El sitio 160 se encuentra próximo a la Ensenada Ferrer (Figura 1.65), siendo una lente densa de valvas y carbón con una extensión de 4,5 m. En superficie se recuperó cerámica con decoración, cáscaras de huevo de ñandú, huesos de cetáceo, de pinnípedos y guanaco, valvas, lítico. La excavación estuvo dirigida por la Lic. Hammond y se realizaron dos sondeos de 0,50 x 0,50 m. Como se mencionó más arriba el fechado de este sitio permite ubicarlo en el Holoceno tardío final más específicamente en momentos posteriores al contacto hispanoindígena (Hammond et al. 2013). 


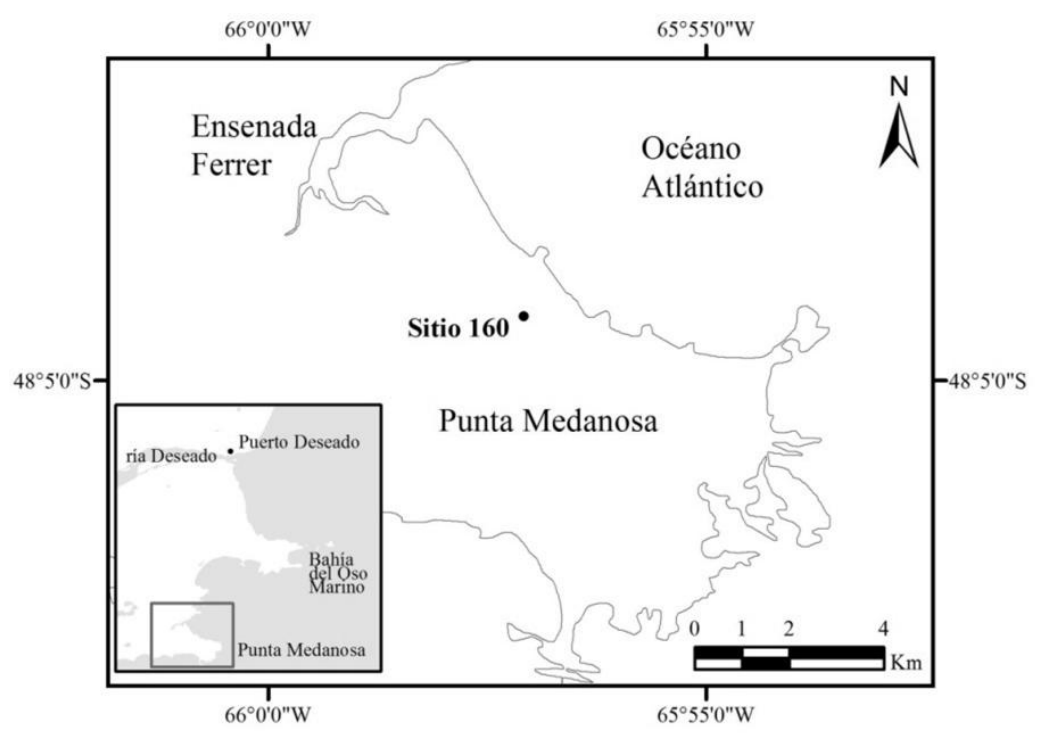

Figura 10.65. Ubicación del sitio 160.

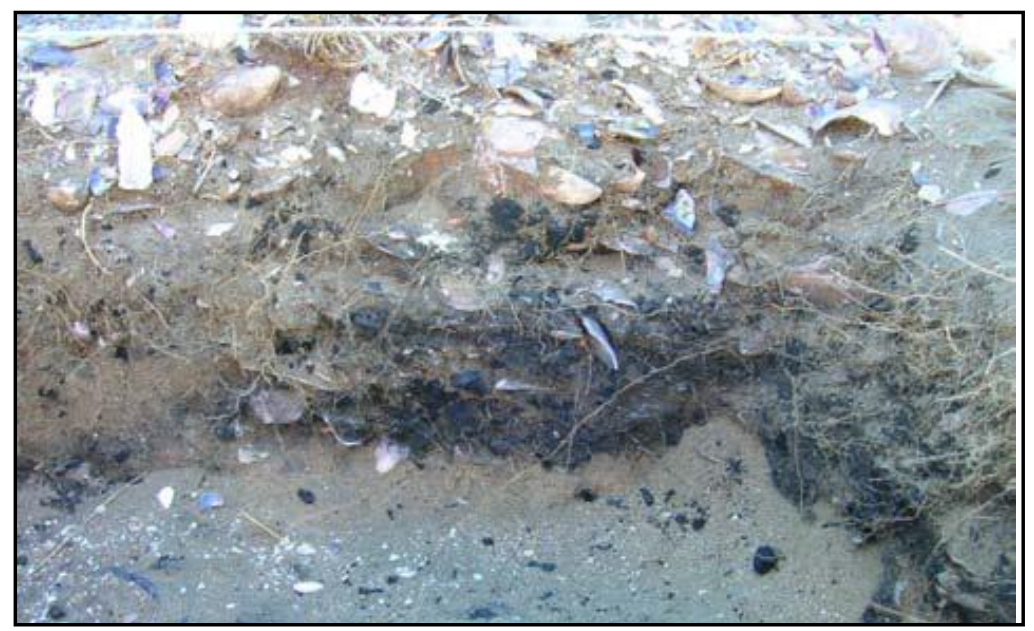

Figura 10.66. Vista del Sondeo 1, perfil sudoeste, sitio 160 (Fotografía de Hedi Hammond).

\subsubsection{Metodología}

\subsection{Excavación}

En el sondeo 1 se realizó una cuadrícula de 0,50 x 0,50 m siguiendo las capas naturales al observar los cambios de sedimento. Se recuperaron los materiales arqueológicos con una malla de $2 \mathrm{~mm}$.

\subsection{Recuperación de restos antracológicos}


Se recuperaron carbones concentrados en una lente a través de una malla de 2 mm, así como del fondo de zaranda de la misma malla. Sólo se analizaron los carbones del nivel 3 superior e inferior.

\subsubsection{Contexto estratigráfico}

Se realizó una cuadrícula de 0,50 x $0,50 \mathrm{~m}$, donde en el nivel superficial se registraron valvas, restos óseos, y carbón, con una potencia de $2 \mathrm{~cm}$ (Hammond et al. 2013). El nivel 1, con una potencia de $2 \mathrm{~cm}$, presentó un sedimento limoso marrón oscuro donde predominan los mejillones y en menor medida lapas (Figura 10.67). Se observó en este nivel gran cantidad de carbón y restos pequeños de hueso.

El nivel 2 presentó un sedimento color marrón oscuro, con carbones y valvas entre las que predominan los mejillones. Sobre la base del nivel se observó un sedimento color marrón claro, y la totalidad del nivel tiene $2 \mathrm{~cm}$ de potencia.

En el nivel 3 se registró un sedimento color marrón oscuro con restos de valvas dispersas y carbón. Es importante destacar para el análisis y discusión de los restos antracológicos que las valvas se encontraban termoalteradas. Se observó una lente compuesta sólo por carbón. El nivel 3 inferior presentó mayor cantidad de valvas, dispersas y carbón. Se realizó un subcuadrante de 20 x $20 \mathrm{~cm}$ para observar la potencia de la lente de fogón. Sobre la base del mismo se registra un sedimento arenoso. Esta lente tiene unos $10 \mathrm{~cm}$ de potencia. El nivel 3 y el 3 inferior juntos tienen $13 \mathrm{~cm}$ de potencia. El nivel 4, por debajo de la lente de carbones concentrados, tiene un sedimento marrón color claro con carbones y valvas dispersas de $4 \mathrm{~cm}$ de potencia. El nivel 5, presenta un sedimento arenoso con carbones dispersos en poca cantidad. Se registraron huesos pequeños. En la base del mismo aparece una lente de mejillón.

En el nivel 6 se registró una pequeña lente de mejillón con carbones sobre un sedimento eólico. Sobre el noreste de la cuadrícula se identificó una cueva de roedor de $15 \mathrm{~cm}$ de potencia. En el nivel 7 se registra la cueva de roedor en la esquina noreste. El sedimento es arenoso de color marrón claro. Se excavó $15 \mathrm{~cm}$ más y ante la ausencia de material arqueológico se cerró la excavación. 


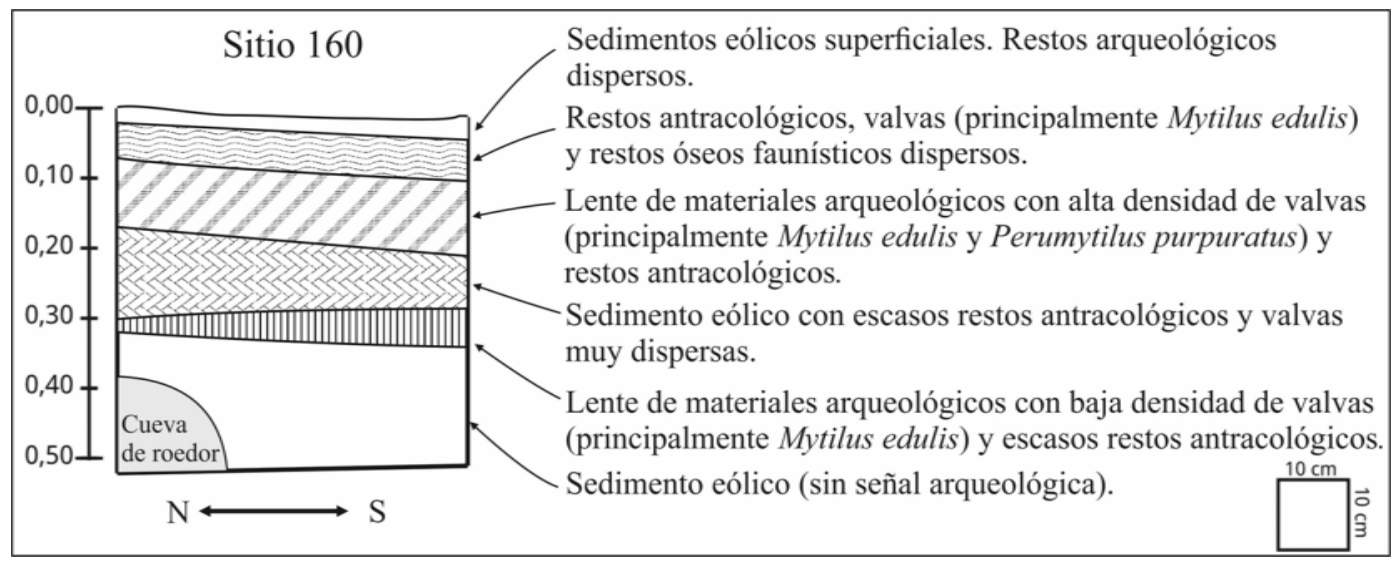

Figura 10.67. Perfil estratigráfico sitio 160 (Hammond 2014).

\subsubsection{Resultados antracológicos}

En el nivel 3 superior se recuperó un total de 885 carbones en un volumen de 22,5 1 de sedimento, y una densidad calculada 39,3 n/l clasificada como baja. Las categorías de tamaño registradas abarcan el rango de 20-24,9 mm a 2-4,9 mm, siendo esta última categoría la que mayor cantidad de carbones presenta. La submuestra analizada tiene un total de 22 carbones entre los que se identificó un solo taxa: Schinus (95\%) (Figura 10.68).

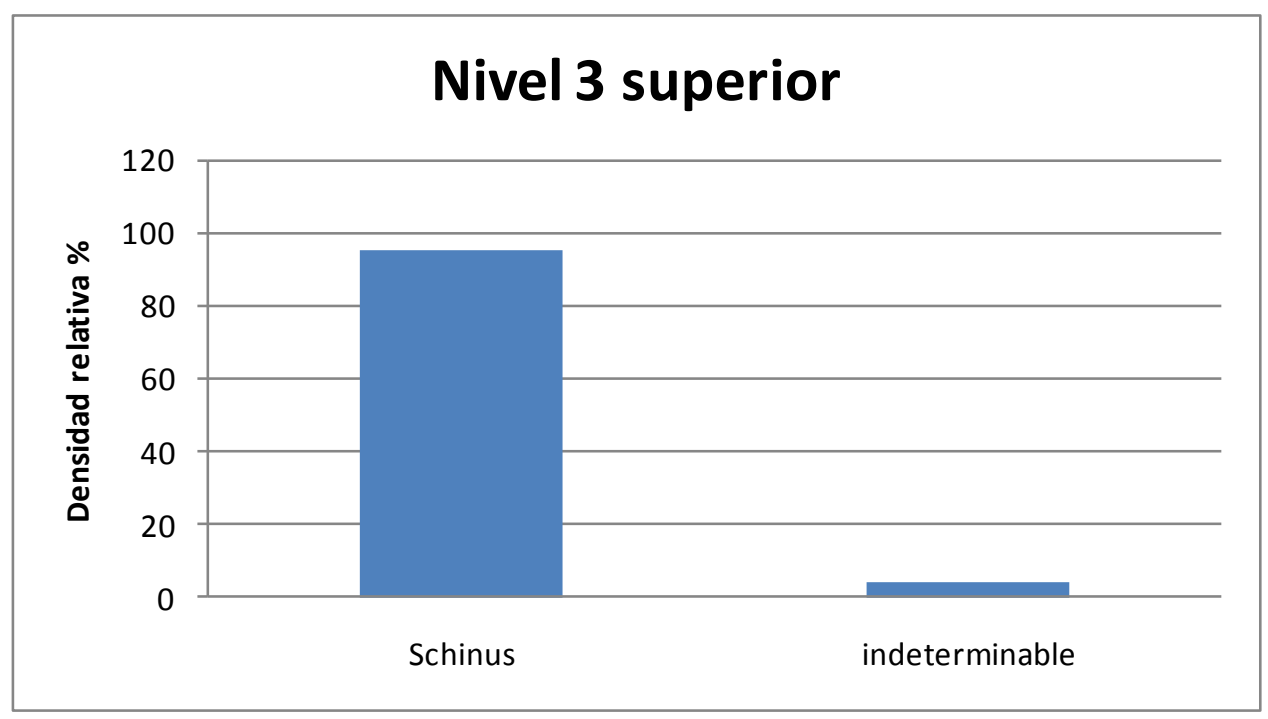

Figura 10.68. Carbones identificados en nivel 3 superior, sitio conchero 160 (submuestra $n=22$ ). 
Se observó vitrificación en Schinus $(\mathrm{n}=9)$ e indeterminable $(\mathrm{n}=1)$, es decir un $45,4 \%$ de la submuestra. Se identificó la presencia de médula en Schinus $(\mathrm{n}=3)$. En relación a las aberturas en anillo, radios y vasos se registraron en carbones de Schinus $(\mathrm{n}=4)$, sólo en radios y vasos de Schinus $(\mathrm{n}=12)$, e indeterminable $(\mathrm{n}=$ $1)$.

El nivel 3 Inferior presentó un total de 850 carbones en un volumen de 6,75 1, siendo la densidad calculada de 125,93 n/l determinada como media. Las categorías de tamaño abarcan el rango de 20-24,9 $\mathrm{mm}$ a 2-4,9 $\mathrm{mm}$, siendo la categoría 5 a 9,9 mm la que mayor cantidad de carbones presenta. La submuestra es de 25 carbones entre los que se identificaron dos taxa, entre los que predomina Schinus (96\%) (Figura 10.69).

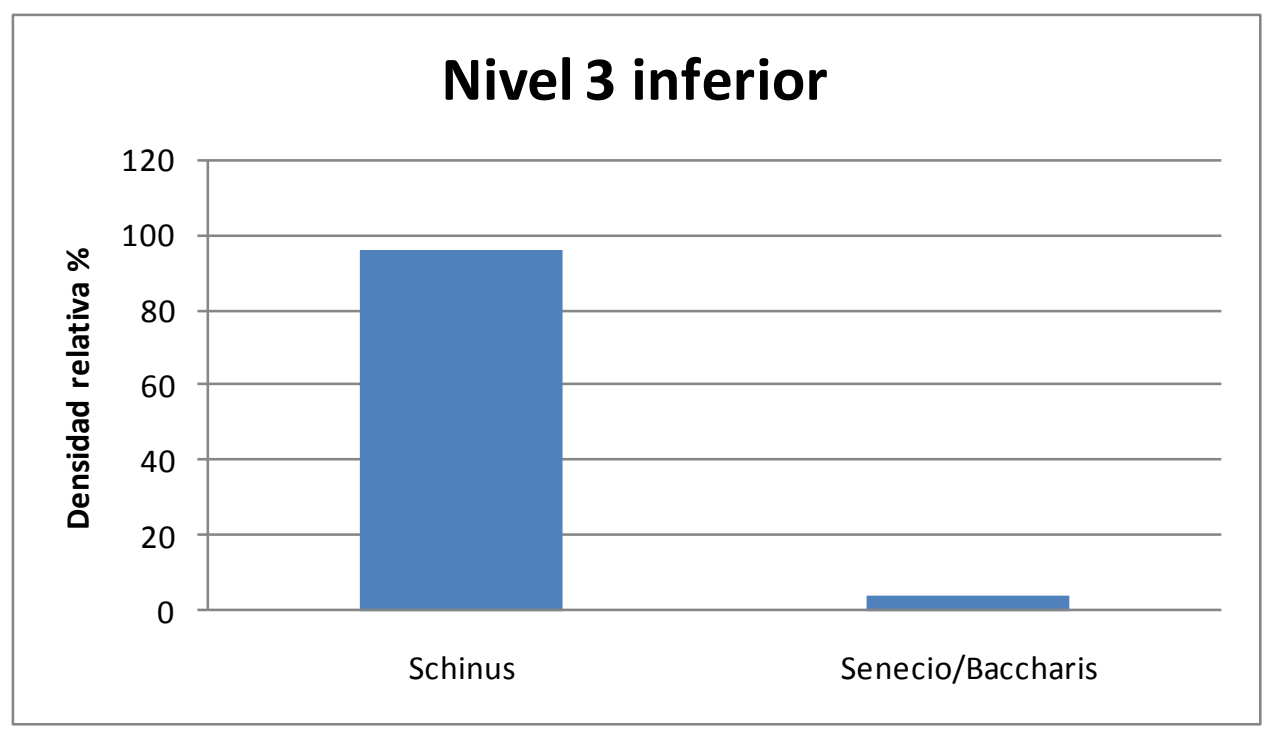

Figura 10.69. Carbones dispersos en el nivel 3 inferior, Sitio 160 (submuestra $n=25$ ).

Se observó vitrificación en Schinus $(\mathrm{n}=3)$ y presencia de médula en el mismo género $(n=2)$ y en Senecio/Baccharis $(n=1)$. Las aberturas se registraron en anillo, radios y vasos en Schinus $(\mathrm{n}=2)$ y en radios y vasos en carbones del mismo género $(n=20)$, por lo que se identificaron en el $88 \%$ de la submuestra.

El análisis de ubicuidad permite definir que Schinus presenta el 100\% de ubicuidad mientras que Sencio/Baccharis el 50\% (Figura 10.70). Debido a que la muestra es pequeña no pudo realizarse el test de correlación para identificar estados de fragmentación por procesos postdepositacionales. 


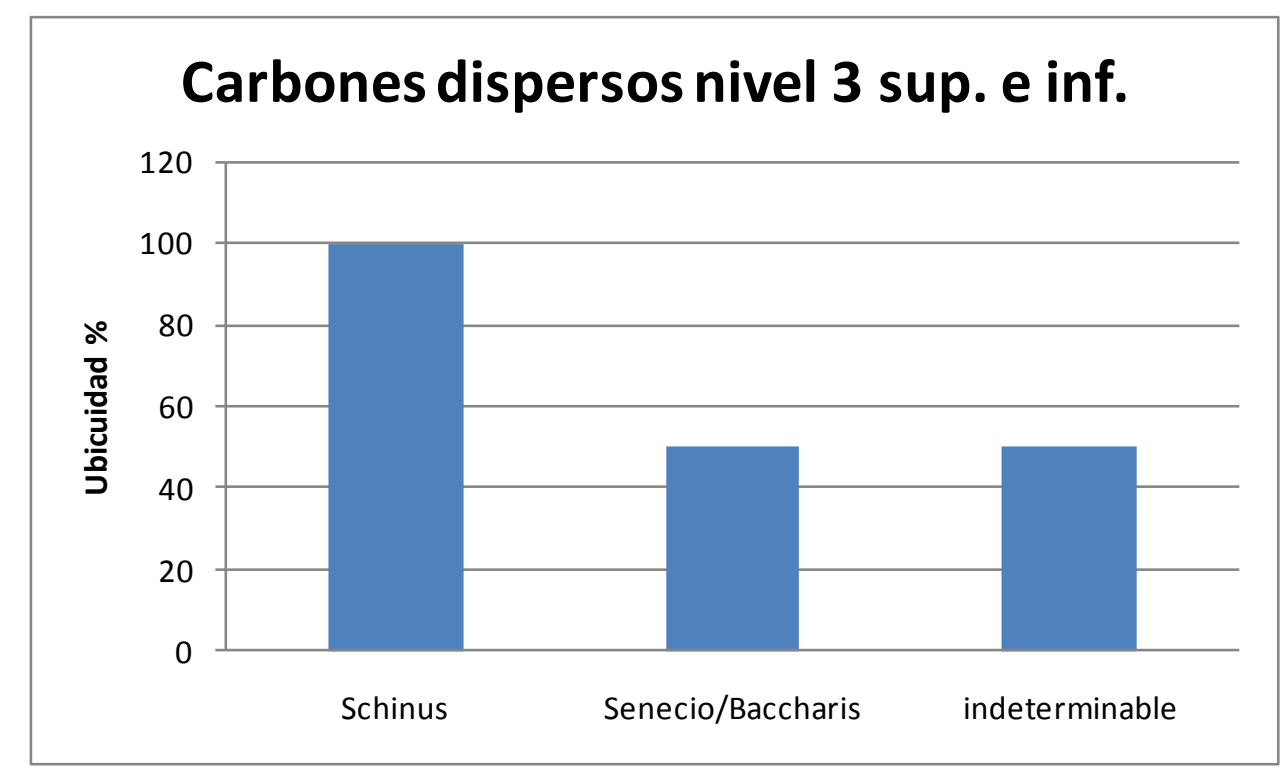

Figura 10.70. Ubicuidad \% de los carbones dispersos de los niveles 3 superior e inferior del sitio 160

\subsubsection{Discusión y conclusiones}

El sitio 160 se ubica cronológicamente en el Holoceno tardío final, por lo que la vegetación sería análoga a la actual. Cabe remarcar que la localidad arqueológica de Punta Medanosa se destaca por la densidad de Schinus y el tamaño y altura de los arbustos. Considerando que, en la actualidad, se han talado gran cantidad de "molles" el paisaje entonces habría sido aún más denso.

El conchero 160 es relevante en cuanto al estudio antracológico de este tipo de sitios porque presentaba una lente de carbones densa por debajo de la lente de valvas. Si bien en los sitios concheros no es posible delimitar una estructura de fogón esta concentración será considerada como un área de combustión (Pique i Huerta 1999:126).

La identificación taxonómica de esta concentración en el nivel 3 superior y en el inferior evidencia que Schinus es el género con mayor densidad relativa (95\%) de carbones por volumen de sedimento. En el caso del nivel 3 inferior, Schinus está acompañado de leños de muy baja densidad buenos para encender el fuego como Senecio/Bacharis. Es importante mencionar que el 88\% de la submuestra presentó aberturas en vasos y radios, así como anillo. Este último carácter serían 
diagnóstico de que el fuego alcanzó alturas próximas a los $700^{\circ} \mathrm{C}$. En este caso la alteración térmica de las valvas alcanzó el $80 \%$, y no se observó como en el sitio 112 un sedimento gris cubriendo las mismas. Es posible que en este sitio, la cocción de moluscos no haya sido directamente sobre el fuego, sino sobre las brasas o cenizas y en menor tiempo de exposición. Sin embargo, debería ampliarse la muestra a fin de observar si se mantiene el patrón de elección de Schinus sobre otros taxa así como profundizar sobre el registro de diversas técnicas de cocción de moluscos.

\subsection{Ubicuidad de taxa en fogones y carbones dispersos del sector margen sur de la ría Deseado}

A continuación se describe la ubicuidad de los taxa identificados en el sector sur de la ría Deseado diferenciando carbones provenientes de fogones (i.e. Alero El Oriental y Alero 4, Figura 10.71) de aquellos que son dispersos (i.e. Cueva del Negro, Alero 4, 112, Las Hormigas y 160, Figura 10.72)

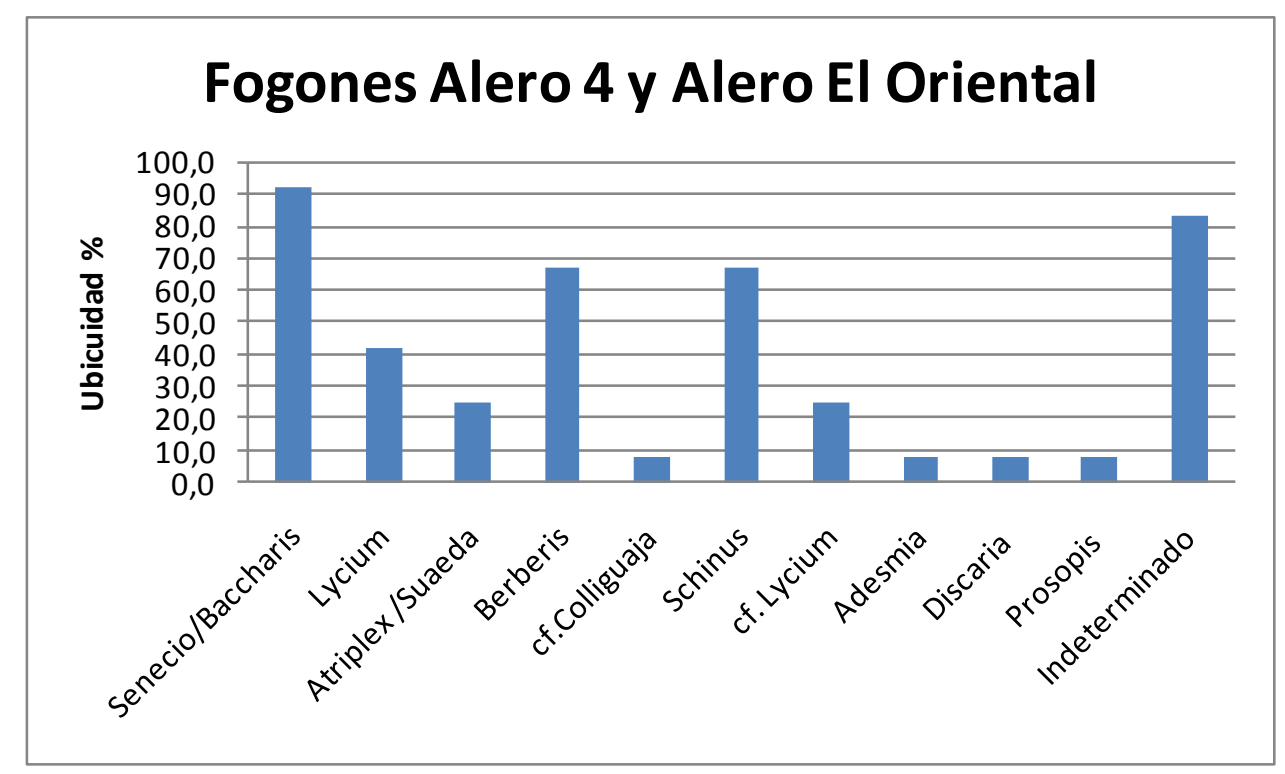

Figura 10.71. Ubicuidad de los taxa identificados en todos los fogones registrados en el sector sur de la ría Deseado (Alero El Oriental y Alero 4). 


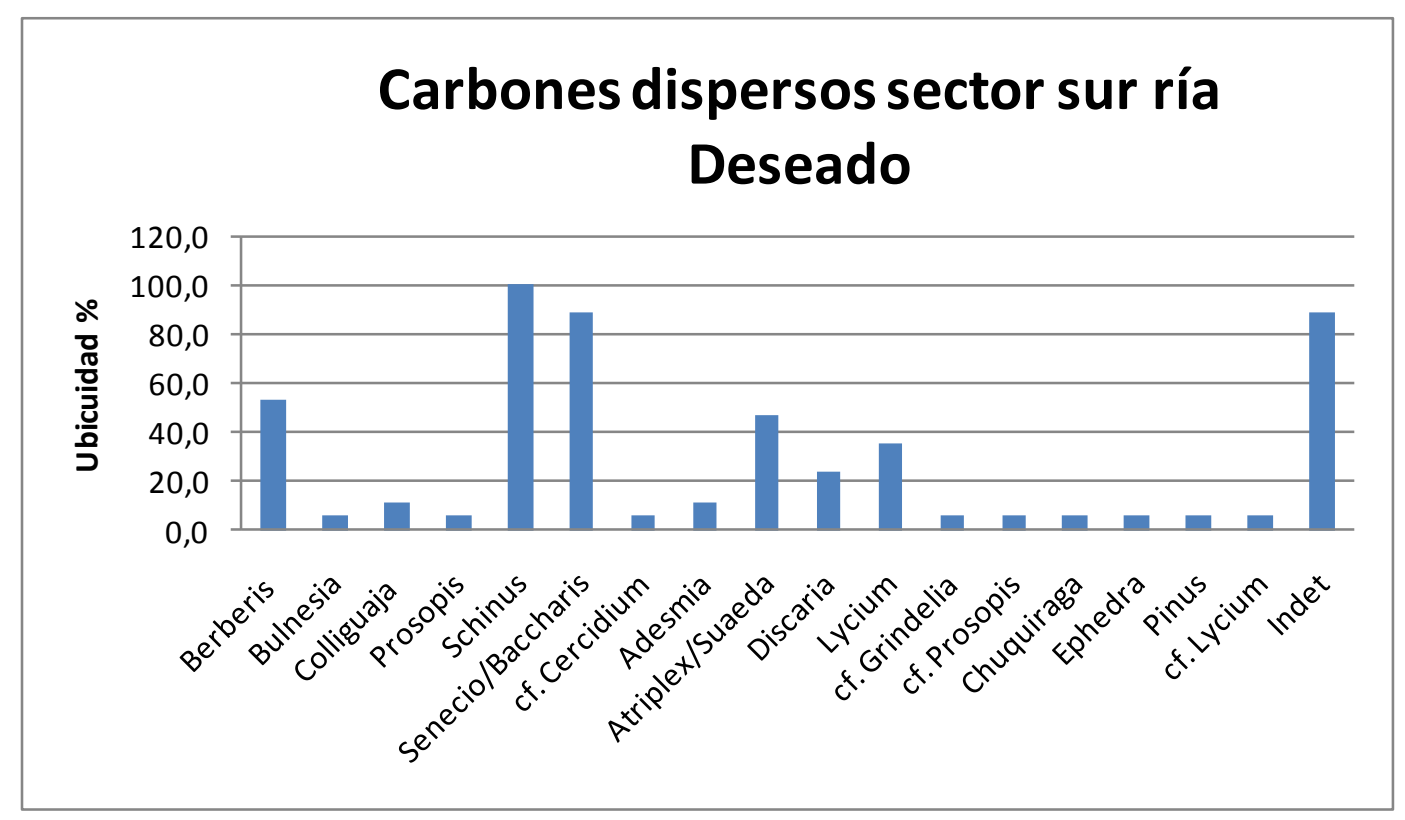

Figura 10.72. Ubicuidad de los carbones dispersos de los sitios analizados del sector sur de la ría Deseado

Se observan diferencias en la prevalencia de algunos taxa en relación a los carbones de los fogones y los carbones dispersos. Entre los primeros predomina Senecio/Baccharis (92\%) seguido por Berberis y Schinus (66,8\%). En cambio en los carbones dispersos, se observa mayor diversidad de taxa con predominio de Schinus (100\%), seguido por Senecio/Baccharis (88,2\%) y Berberis $(55,9 \%)$. Sin embargo, a pesar de las diferencias de prevalencia de un taxa sobre otro, la estrategia parecería ser similar: la combinación de maderas más densas de mayor brasa (Schinus, Berberis) con otras más livianas y de rápido encendido (Senecio/Baccharis). Es relevante considerar que se analizaron carbones provenientes tanto de sitios alero, cueva como concheros en este sector y sin embargo la gestión de recursos leños es similar.

Como se puede observar, el porcentaje de ubicuidad de los carbones indeterminables es alto. Se realizó un análisis teniendo en cuenta todos los sitios presentados y analizados en esta tesis (capítulo 8, 9 y 10). El 17,5\% de los casos los carbones arqueológicos se determinaron en su totalidad, mientras que el 82,5\% restante tuvo algún indeterminable. En los casos en que se determinaron la totalidad de los carbones, las especies presentes fueron Senecio/Baccharis, Lycium, Schinus, Berberis, Atriplex y estuvieron representadas todas las clases 
diamétricas, por lo que se deduce que en estos casos el tamaño de los carbones más pequeños no limitó la identificación. Por otro lado, si bien dentro del 82,5\% que posee carbones indeterminables el valor de los mismos se extiende entre el $0 \%$ y $40 \%$, un $70 \%$ de estos casos posee valores de entre 0,1 a $20 \%$. La mayor proporción de indeterminados $(78 \%$ de los casos) se encuentran en las tres primeras clases diamétricas de 2-4,9 mm, 5 a 9,9 $\mathrm{mm}$ y de 10 a $14,9 \mathrm{~mm}$, mientras que el $12 \%$ restante en carbones de 15 a 29,9 mm. Las limitantes más comunes de la identificación en estos casos fueron el pequeño tamaño del carbón, la fragilidad de los mismos al momento de realizar los cortes de identificación, las vitrificaciones, y la laminación de los carbones por fracturas de los carbones en el corte transversal a nivel de los radios y por pátinas grises por precipitación de sales. 


\section{Análisis de instrumentos de}

\section{madera}

\subsection{Introducción}

En el sitio Cueva del Negro, tal como se describió en el capítulo anterior, se recuperaron siete puntas o cabezales de arpón manufacturados en hueso y una realizada sobre madera (Capparrelli et al. 2009; Beretta et al. 2013a). El objetivo de este capítulo es describir la morfología externa de esta última, identificar anatómicamente su madera y discutir su contexto de hallazgo en relación al sitio y a las otras puntas realizadas sobre hueso. Como se ha mencionado antes Cueva del Negro es un sitio conchero en cueva. Como describe Beretta y colaboradores (2013a), los cabezales de arpón provienen del recinto oscuro y las cuadrículas 1 y 3 del alero. En la cuadrícula 1 se recuperaron cuatro puntas asociadas a tres fechados radiocarbónicos: uno sobre un húmero de pinnípedo (antigüedad corregida de $1220 \pm 80$ años AP), otro sobre una hemimandíbula de pinnípedo (antigüedad corregida de $1290 \pm 50$ años AP) y un tercer fechado sobre carbones provenientes de una estructura de combustión $(1340 \pm 60$ años AP). En la cuadrícula 3 se recuperaron dos puntas de arpón que no poseen fechados asociados, sin embargo, por las características contextuales de depositación se infiere su contemporaneidad. En el recinto oscuro, en contextos alterados por saqueo se recuperó otra punta de arpón confeccionada en madera (Capparelli et al. 2009) (Figuras $11.1 \mathrm{y}$ 11.2).

\subsection{Metodología}

Para el análisis morfológico del instrumento se tuvo en cuenta su forma y dimensiones (ancho, largo y espesor), así como la presencia o ausencia de caracteres específicos, tales como cantidad de dientes y tipo de espaldón (ver por ejemplo Orquera y Piana 1999a,b). En una primera instancia, el estudio anatómico de la madera se realizó a través de un microscopio de luz incidente Leica DM/LM. Mediante éste se observaron 
tanto el sector de fractura del extremo distal carbonizado del artefacto, como un fragmento de 3 x $3 \mathrm{~mm}$ que se desprendió naturalmente del mismo. Se registraron la mayor cantidad posible de caracteres diagnósticos de las tres secciones de corte del material leñoso: transversal (CT), longitudinal tangencial ( $\mathrm{LgTg}$ ) y longitudinal radial (LgRd). En una segunda instancia se realizaron cortes delgados a mano alzada y en las tres secciones mencionadas del extremo proximal del mismo, para ser visualizados a través de microscopio de transparencia (Leica DM/LM). Los caracteres cualitativos microscópicos de diagnóstico se registraron usando la IAWA, List of Microscope Features for Hardware Identification (IAWA 1989).

Finalmente, la especie identificada se comparó con cortes delgados de material de referencia moderno de CNSC (ver capítulo 7), depositado en el Laboratorio de Arqueobotánica del Departamento Científico de Arqueología (Museo de Ciencias Naturales de La Plata).

\subsection{Resultados}

\subsubsection{Morfología externa}

La forma alargada y aplanada del instrumento, sumada a la presencia de un extremo adelgazado que, a pesar de estar fracturado, se podría asimilar a un extremo en punta, y a la presencia de un diente prominente y corto en su parte superior (Figura 11.1, A-B), permite sugerir que el fragmento de artefacto es parte de un arpón. Aunque ambos extremos del instrumento se hallan fragmentados, es posible inferir que lo que se observa es parte del fuste y la primera porción de la aguja (cuerpo principal: 4,7 $\mathrm{cm}$ de largo x 2,5 cm de ancho y 0,67 de espesor), y que se trata de un artefacto que, aún completo, podemos estimar que ha sido de pequeñas dimensiones. Esta estimación se realiza a partir de su comparación con los restantes arpones de hueso hallados en el sitio (Figura 11.1 A-B, Figura 11.2). Presenta rastros de alteración térmica, encontrándose mayormente alterada la punta y en menor medida la porción distal de la pieza. Aunque su tamaño inicial debe haber sido reducido, dicha carbonización parcial pudo haber producido una mayor reducción ulterior. Sobre la cara lateral izquierda del fuste se observan marcas de corte tipo $\mathrm{V}$ poco profundas, cortas y oblicuas a las fibras de la 
madera. También posee estrías poco profundas paralelas a las fibras, que se desarrollan de un extremo al otro del fragmento de arpón (Figura 11.1 B).

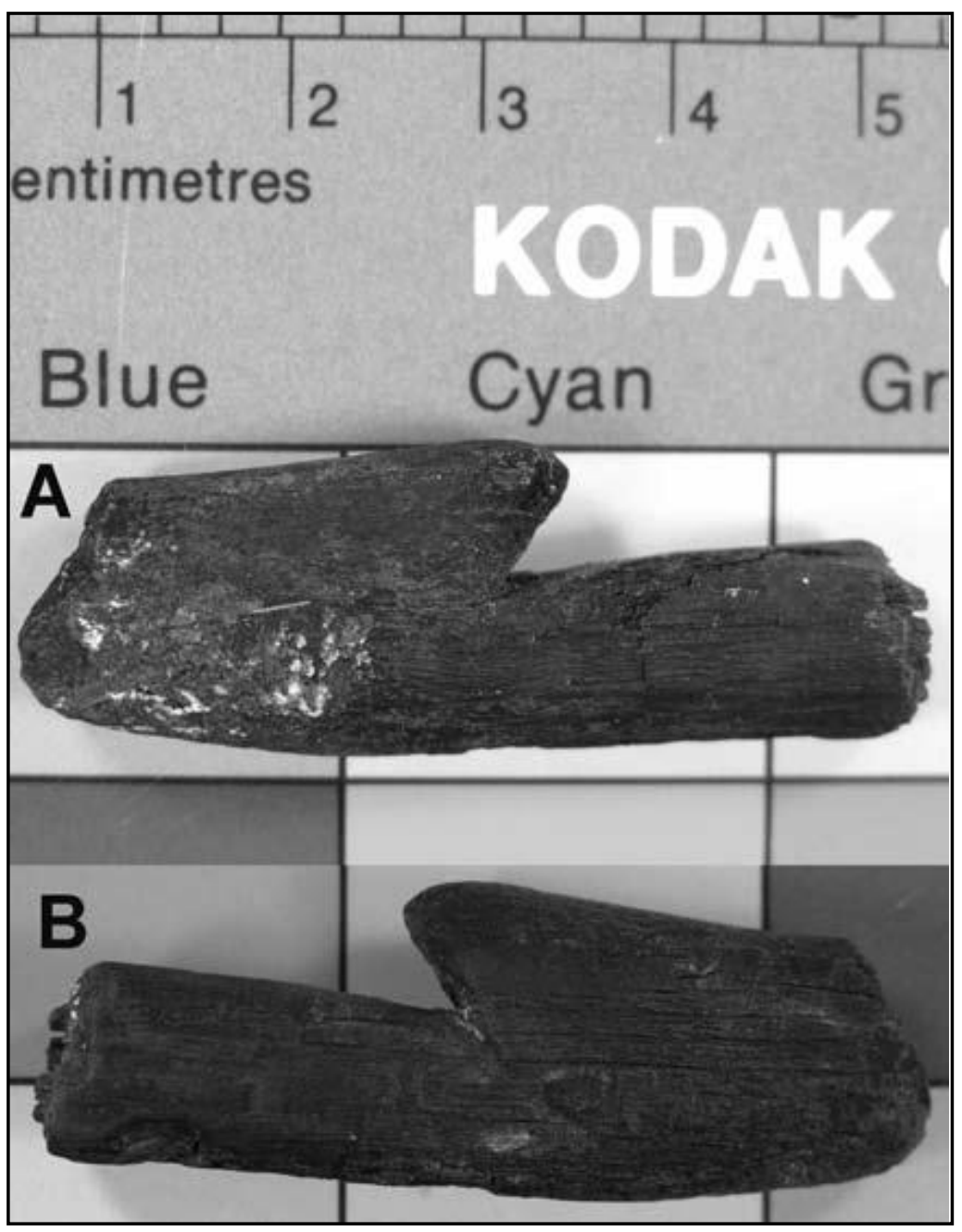

Figura 11.1. A y B fragmento de arpón, se observan líneas paralelas de la manufactura 


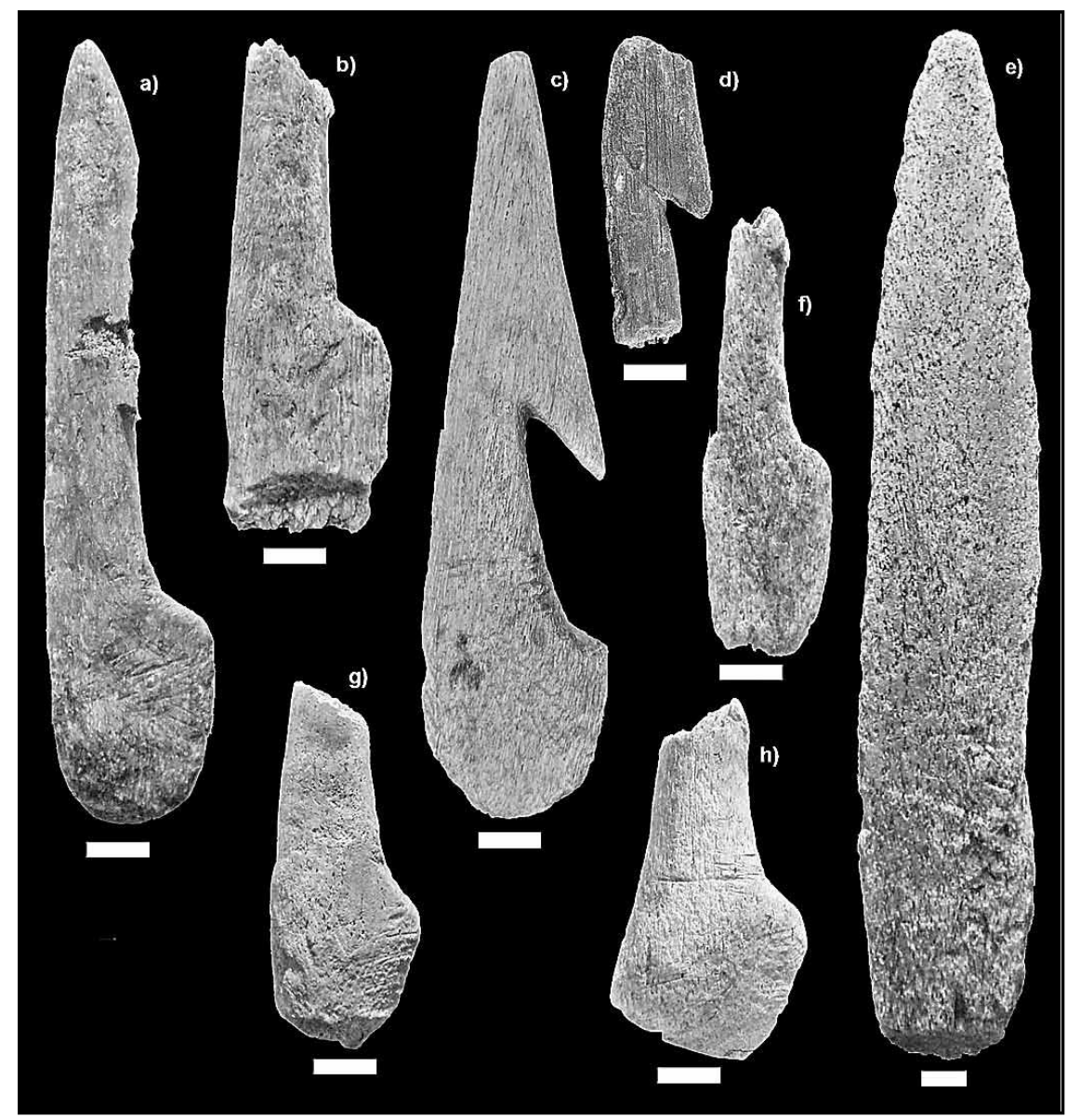

Figura 11.2. Vista de los cabezales de arpón recuperados en el sitio Cueva del Negro. Referencias: a) arpón que presenta espolón y punta, pero con ausencia del diente producto de una fractura (pieza 2); b) espaldón, fragmento central y posterior de arpón (pieza 6); c) arpón monodentado entero (pieza 1); d) fragmento central de arpón de madera de calafate (Berberis sp.; pieza 7); e) probable preforma de arpón (Pieza 8); f) espaldón, fragmento central y posterior de arpón (pieza 4); g) espaldón, fragmento posterior de arpón (pieza 5); y h) espaldón, fragmento posterior de arpón (pieza 3). En todos los casos la barra blanca equivale a $1 \mathrm{~cm}$ (Beretta et al. 2013a)

\subsubsection{Anatomía de la madera}

Identificación: Berberis sp. (Fam. Berberidaceae).

Material de referencia: material de herbario de Berberis microphylla G. Forst. y $B$. buxifolia Lam.var. buxifolia (Ciampagna 41, 56 y 57), colectado de diversas localidades de la provincia de Santa Cruz, como Bahía del Oso Marino y material leñoso de Berberis sp. (colectado por S. Bogan de la localidad Bahía del Oso Marino, Santa Cruz). Literatura de referencia: descripciones anatómicas parciales de la madera de plantas nativas del sur Argentino del género Berberis se encuentran en Piqué i Huerta 
(1999:112-113), de B. microphylla en Ancíbor y Pérez de Micou (2002:26), y de $B$. buxifolia var buxifolia en Marconetto (2002:42-43). Otras especies de Berberis son descriptas en Inside Wood (2004-en adelante). Características generales de la anatomía del xilema de tallo y raíz del género son descriptas en Cutler et al. (1987).

Descripción de la madera del arpón: en la sección transversal (Figura 11.3) se observó porosidad semicircular, anillos de crecimiento demarcados, vasos en bandas tangenciales festoneadas (mayormente en leño temprano) y con ordenamiento diagonal a dendrítico (mayormente en leño tardío), contorno angular de la pared de los vasos solitarios; vasos agrupados frecuentes (Figura 11.4 A), pared de las fibras mediana a gruesa, parénquima axial raro o extremadamente raro.

Con relación a la sección longitudinal tangencial se observaron los siguientes caracteres: traqueidas vasculares/vasicéntricas presentes; fibras con punteadura con reborde conspicuo; radios 1-3 seriados; radios grandes comúnmente 4-8 seriados (más comúnmente 5 ó 6 células de ancho); altura de los radios mayor a $1 \mathrm{~mm}$ (88 células de promedio) en radios 2-8 seriados; radios de dos tamaños distintos (Figura 11.5 A).

Finalmente, en la sección longitudinal radial se observaron: placas de perforación oblicua, simples, punteaduras intervasculares opuestas y alternas, en ocasiones con forma poligonal; vasos con engrosamientos helicoidales; secciones parciales de los radios, compuestas algunas de ellas por células erectas o cuadradas y otras por células procumbentes (Figura 11.6). 


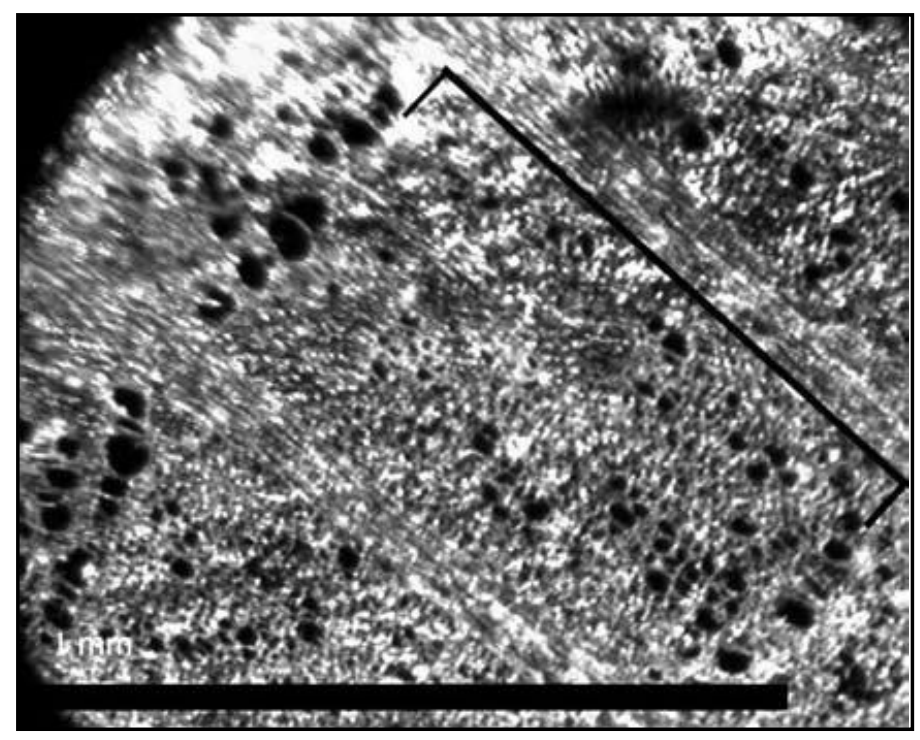

Figura 11.3. Madera del arpón en CT mostrando porosidad subcircular, anillos de crecimiento demarcado (corchete), vasos en bandas tangenciales festoneadas (leño temprano), y con ordenamiento diagonal dendrítico (leño tardío) (microscopio de incidencia). 

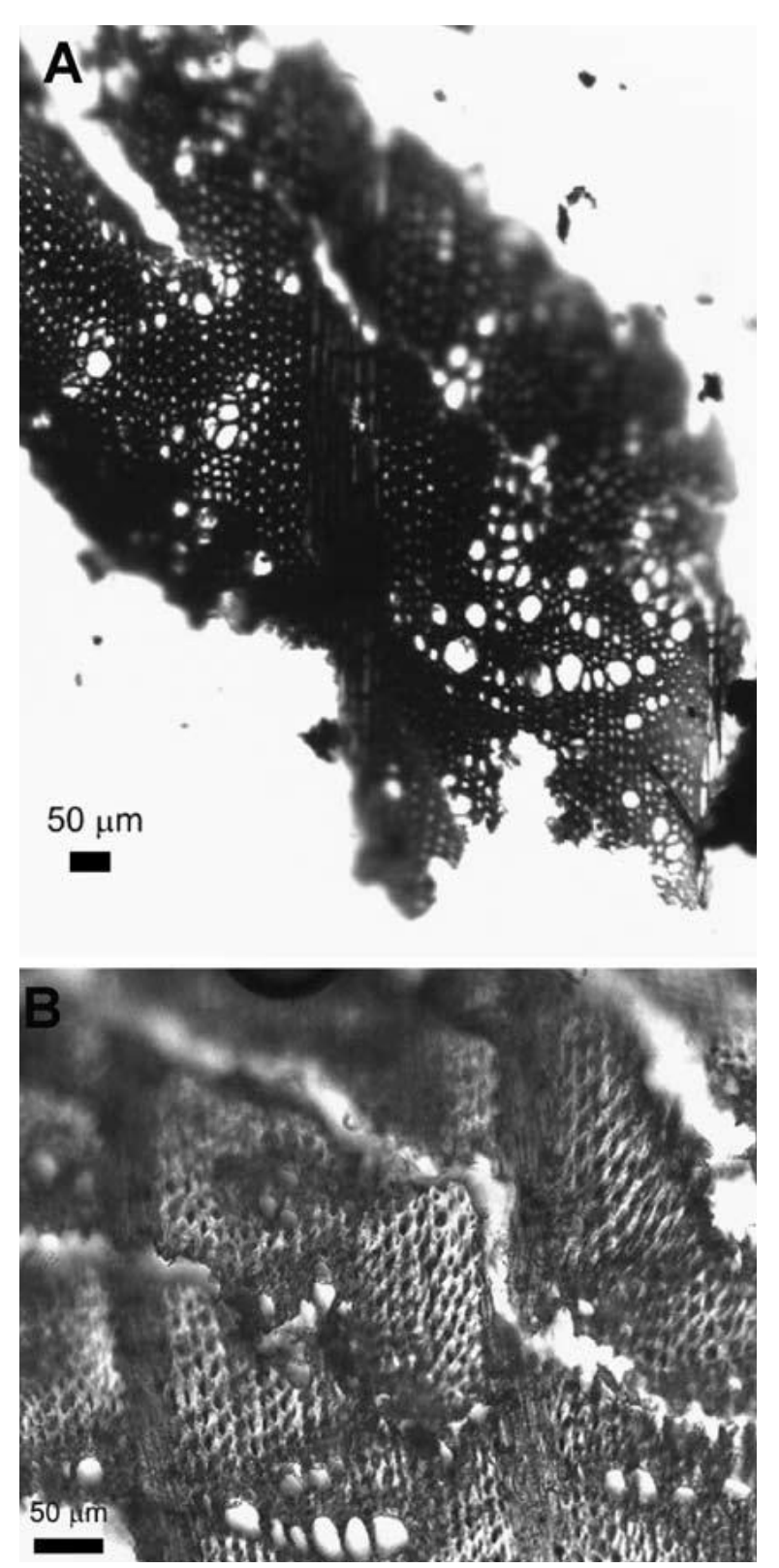

Figura 11.4. Vasos agrupados en CT (microscopio de transparencia). A Madera del arpón. B, Material de referencia Berberis sp. 


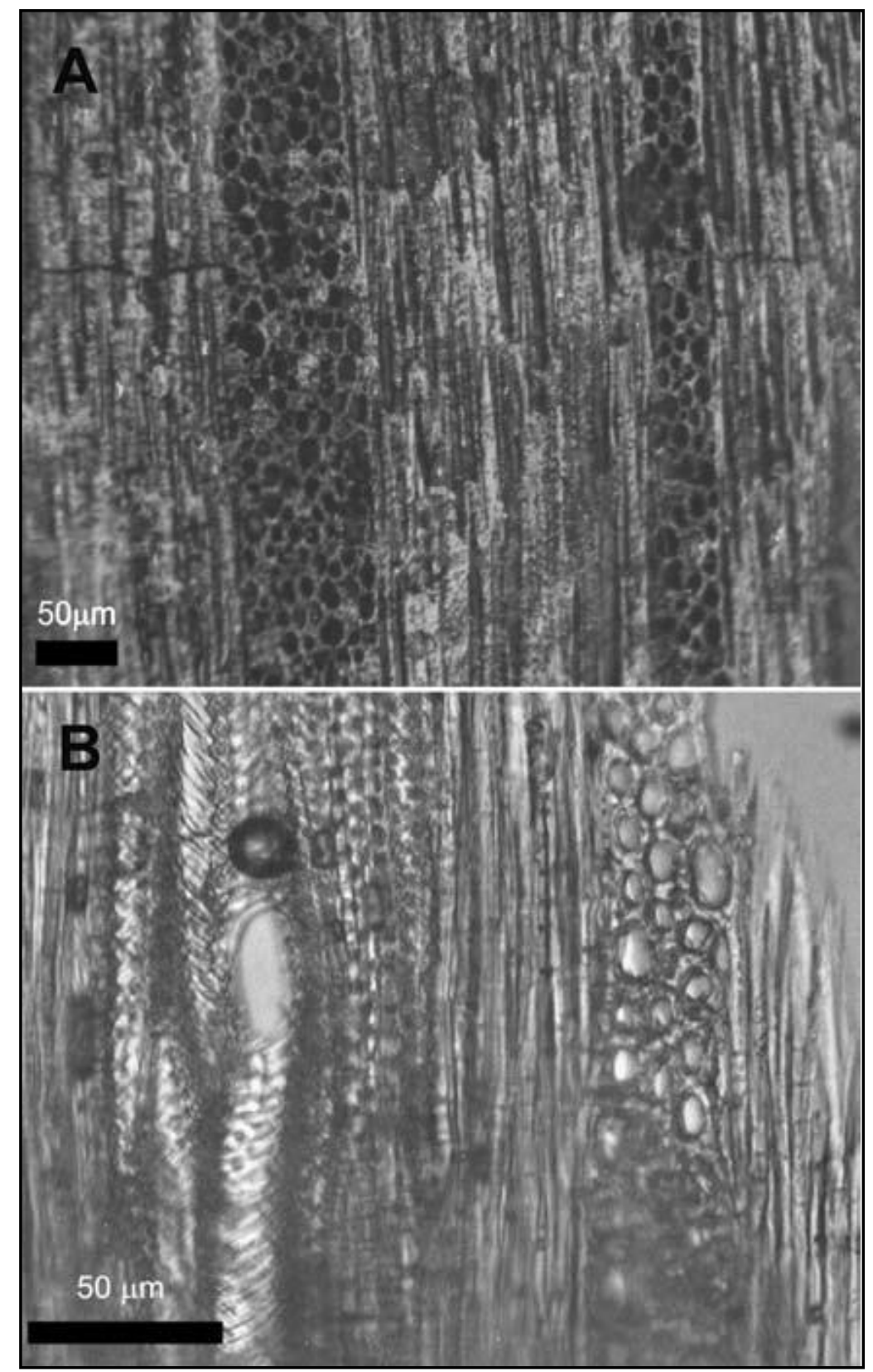

Figura 11.5. Radios de dos tamaños distintos, radios 1-3 seriados, radios grandes comúnmente 4-8 seriados (más comúnmente 5 o 6 células de ancho), en CLtg. A. Madera del arpón (microscopio luz de incidencia). B, material de referencia Berberis sp. (microscopio de transparencia). 


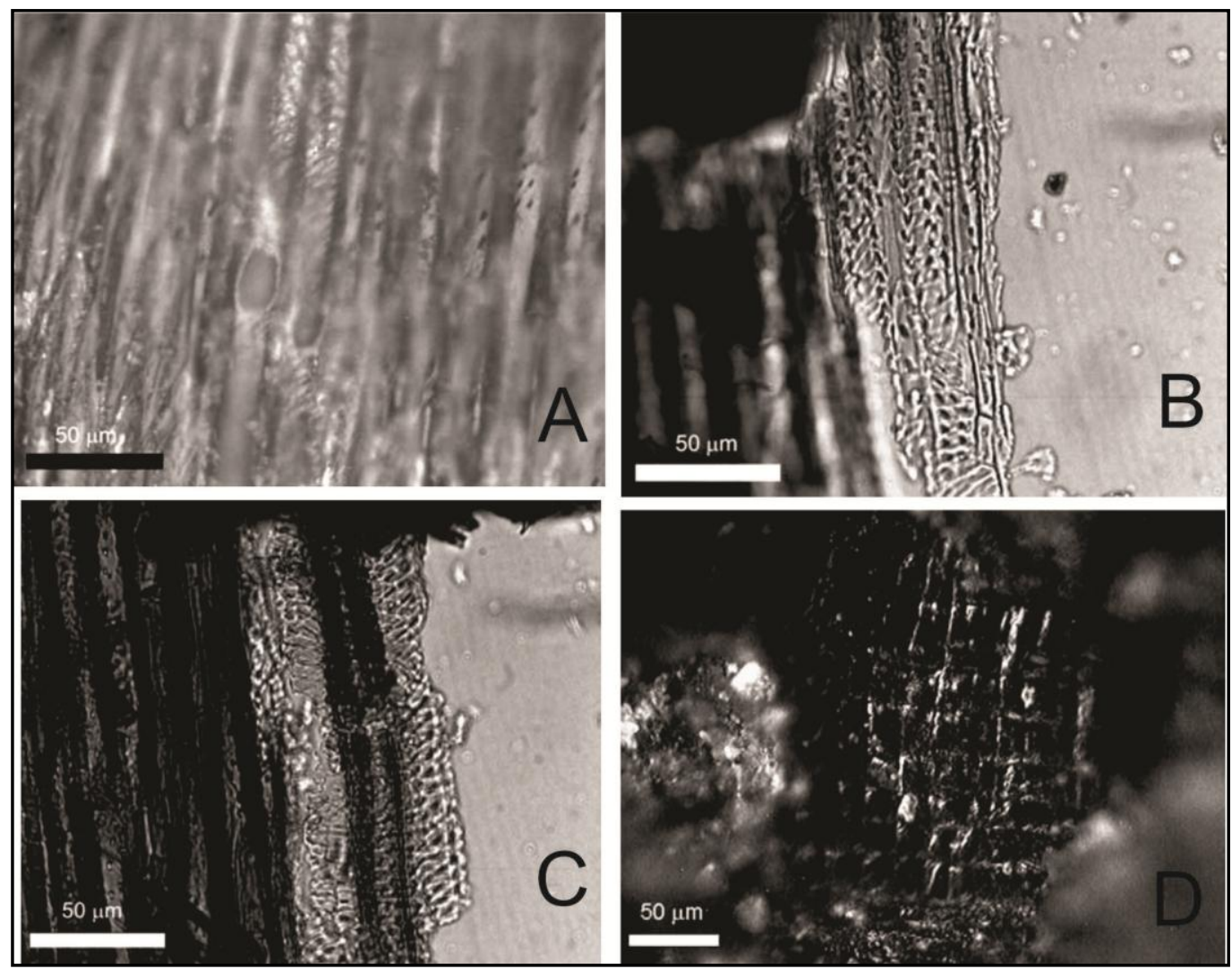

Figura 11.6. Madera del arpón en corte Lg, Rd.: A, mostrando placa de perforación simple (microscopio de transparencia); B, punteaduras intervasculares, opuestas y alternas (microscopio de transparencia); C, engrosamientos helicoidales (microscopio de transparencia) y D, células cuadras o erectas y procumbentes (microscopio de incidencia).

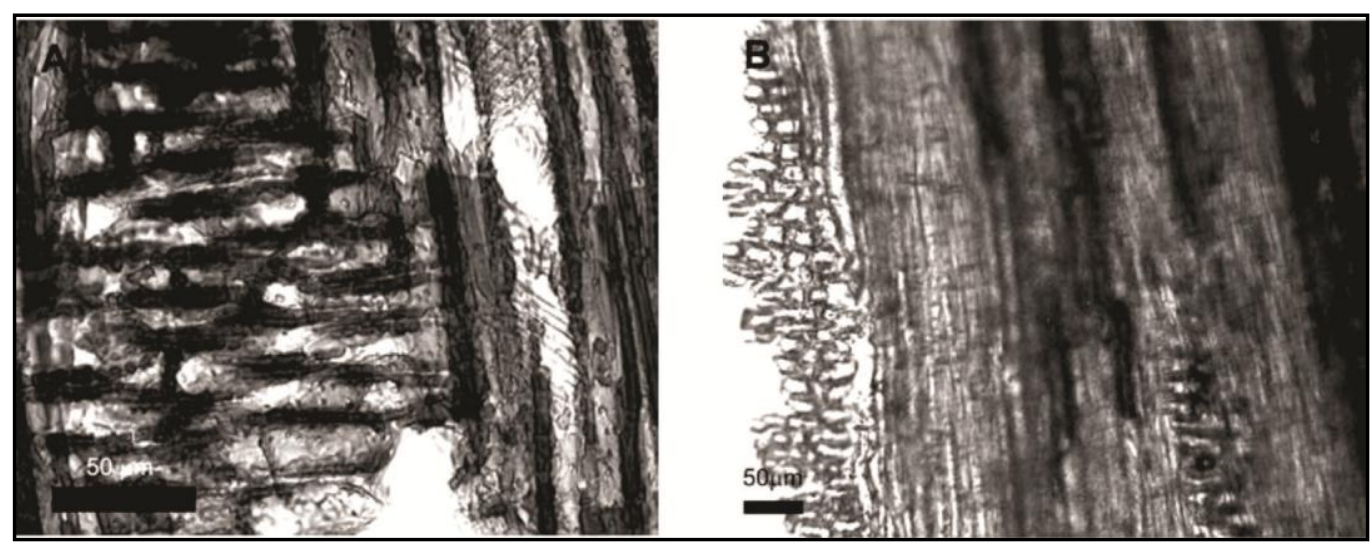

Figura 11.7. Células procumbentes (microscopio de transparencia) en corte Lg. Rd. A: madera de arpón. B: material de referencia Berberis sp.

\subsection{Discusión}


Debido a las características morfométricas del instrumento -fundamentalmente sus reducidas medidas- se considera que éste podría haberse empleado para la extracción de recursos económicos acuáticos (posiblemente peces o piezas de bajo peso y tamaño). No existen menciones sobre arpones de madera recuperados en el registro arqueológico de la Patagonia, Tierra del Fuego o los canales septentrionales chilenos (Zubimendi y Beretta 2014). Sí existen referencias en el registro etnohistórico, entre las poblaciones canoeras de Tierra del Fuego. En este sentido, Molina (1967-1970:178) menciona un dato aportado por E. Chapoala, un informante indígena de la provincia de Santa Cruz, el cual hace referencia a que antiguamente se empleaban arpones de madera para la pesca en pozones. Esto sugiere que el arpón de madera podría haber sido utilizado para la captura de otros tipos de recursos como los peces (Emperaire 2002, Beretta et al. 2013a). Es relevante mencionar la presencia en el registro arqueológico de la cueva de peces, entre otros restos zooarqueológicos (Zubimendi et al. 2011).

Se encuentran en Patagonia artefactos similares realizados a partir de material óseo a los que se les ha asignado dicha función (Piqué i Huerta 1999). Si bien se ha registrado en fuentes etnográficas el uso de arpones de madera por grupos canoeros (Orquera y Piana 1999a), hasta el momento el arpón de madera aquí descripto es el único recuperado arqueológicamente. Asimismo, se halló también un único anzuelo de madera, proveniente de la región costera central de la Patagonia (costa centro de Chubut) (Gómez Otero 1996). Los arpones conocidos hasta el momento, tanto aquellos recuperados a partir de trabajos de excavación arqueológicos sistemáticos, como aquellos que forman parte de colecciones privadas, son más grandes, de tipo mono dentado de base ancha y están realizados en hueso (Beretta et al. 2013a). Se piensa, por lo tanto, que un hallazgo de este tipo indica, entre otras cuestiones, que el espectro de materiales utilizados en la confección de utensilios ha sido más amplio del que se tenía hasta hoy conocimiento por parte de cazadores recolectores costeros.

En relación a los otros seis arpones recuperados en estratigrafía en este sitio, están manufacturados sobre huesos de cetáceo, específicamente con las costillas y mandíbulas de dichos animales. Uno de los cabezales y una preforma, en cambio se elaboraron sobre costillas de pinnípedo. En este sentido la presencia de un artefacto de hueso que por sus características morfológicas y modificaciones antrópicas probablemente corresponda a una preforma de arpón recuperado en la capa 3, cuadrícula 3 y asociada a 
otras puntas de arpón, podría reforzar la hipótesis de manufactura local de los cabezales de arpón (Beretta et al. 2013a).

Con relación al taxón identificado en el artefacto de madera, el género Berberis posee 26 especies nativas de Argentina, de las cuales sólo tres son mencionadas para la provincia de Santa Cruz en la base más actualizada de datos de la Flora Argentina (Zuloaga y Morrone 1999, Instituto de Botánica Darwinion) B. microphylla., y B. empetrifolia., B. ilicifolia. La especie B. darwinii (michai) podría estar presente también, dado que se halla mencionada para Chubut, Neuquén, Río Negro y Tierra del Fuego. Por tales motivos pueden considerarse especies características del área de estudio en la actualidad y su presencia allí fue confirmada por las observaciones y colecta de especies realizadas para la confección del material de referencia. Otras varias especies de Berberis están citadas para los Bosques Andino Patagónicos y para las provincias vecinas (Cabrera 1971; Kofalt y Mascó 2000; Giménez Gowland 2001). Los estudios paleoambientales desarrollados en La María evidencian que hacia los 4177 años AP se habrían desarrollado comunidades vegetales similares a las actuales (De Porras 2010), por lo que la presencia efectiva de Berberis se podría remontar a esa época. Hasta el momento no es posible discernir a cuál de las especies puede corresponder a la madera del arpón, por lo que sería osado aventurar si se trata de un recurso local o no local. Si bien la materia prima del artefacto realizado en madera no es determinante para la corroboración de la manufactura de estos artefactos en el sitio sí es importante considerar que tanto las materias primas faunísticas como vegetales se encuentran en el área.

Con relación a las propiedades de la madera de Berberis, Martinez Crovetto (1968) menciona que se trata de una madera liviana que flota con facilidad y que por lo tanto, los grupos cazadores recolectores Selknam la empleaban para la confección de astiles de flechas para "flechear" aves sobre el agua. Sin embargo, según Piqué i Huerta (1999) la madera de Berberis es dura y flexible, fue utilizada en la Patagonia para confeccionar varios útiles, como por ejemplo mangos de flechas (Gusinde 1937 en Piqué i Huerta 1999). Los análisis arqueobotánicos desarrollados en astiles y arcos de madera etnográficos de grupos Selknam de la colección del Museo del Fin del Mundo (Ushuaia), tuvieron como resultado la identificación anatómica de Berberis como madera preponderante para la confección de los astiles (Caruso et al. 2011). Asimismo, 
Ratto y Marconetto (2011), realizaron estudios sobre las maderas de arpones y astiles fueguinos de la colección del Museo Etnográfico Juan B. Ambrosetti, y sostienen que la madera seleccionada para la confección de astiles en dicha colección también fue Berberis. Para reconocer las propiedades físicas de esta madera Ratto y Marconetto (2011) relevaron caracteres cuantitativos diagnósticos a través de disociados del tejido leñoso. Los valores del largo de las fibras presentaron medias de entre 361 a $505 \mu \mathrm{m}$, son por lo tanto, elementos cortos, característica asociada a la resistencia de las maderas. También, las autoras registraron que la pared celular de este género es espesa lo que produce densidad y dureza (Ratto y Marconetto 2011:145).

Un aspecto relevante en el arpón de Cueva del Negro es la alteración térmica que se observa en la pieza objeto de este estudio. Esto se podría interpretar, por un lado, como resultado de la aplicación del fuego como un recurso tecnológico para la manufactura de equipos de cacería y pesca (ver por ej. Archila Montañez 2005:326). Lira San Martín y Lavier (2014) a través del estudio de canoas monóxilas de los lagos andinos de la Patagonia septentrional (Argentina y Chile) y de un trabajo etnográfico con artesanos locales registró el uso del fuego de las maderas nativas para obtener mayor flexibilidad en la construcción de las canoas. Por otro lado, se podría interpretar también como producto de una acción accidental del fuego ejercida durante o posteriormente al proceso de descarte. Si fuera éste el caso, como no todo el arpón sino los dos tercios distales son los que se hallan carbonizados, se podría decir que o bien dicho fogón no tuvo las características necesarias como para lograr una carbonización completa de la madera, o bien el arpón no estaba lo suficientemente próximo al fuego. Es sabido que las propiedades de carbonización de un vegetal dependen de varios factores: a) la tasa de humedad que contenga el mismo; b) la densidad de la especie vegetal de la que procede; c) el estado de conservación de la madera; d) el calibre; e) el tipo de fogón; f) la temperatura de combustión; y g) la duración del fuego (Badal et al. 2013; Archila Montañez 2005). En el caso del presente arpón, tanto las buenas condiciones de preservación, como la especie vegetal de la que procede (considerada como una leña dura y buen combustible, Marconetto 2002:46-47), y que cunde al fuego mejor que el Nothofagus (March 1992 en Piqué i Huerta 1999:113), podrían estar retardando su combustión. En contraposición, el tamaño chico del mismo la aceleraría. 
Es importante mencionar también las evidencias del procesamiento de la madera para la manufactura del artefacto. Como se mencionó en la sección Morfología externa, el fuste del arpón presenta estrías paralelas que podrían producirse por la acción de artefactos líticos utilizados en la manufactura del mismo. La información brindada por Patty Chapalala a Ana M. Aguerre, mujer tehuelche que vivió en las últimas tolderías del siglo XX, apoyaría esta idea, ya que describe el uso del cepillo para trabajar el palo de molle para los telares o los palos de calafate para los toldos (Aguerre 2000). Ella dice: "para alisarlo bien y dejarlo bien pulido, le ponían ceniza del fogón para que la madera quedara bien y lo iban raspando" (Aguerre A. 2000:99). En un trabajo experimental realizado por la autora de esta tesis en colaboración con otros autores, se procesó madera de Berberis y Prosopis utilizando artefactos líticos (raspadores y denticulados) procedentes de una colección experimental de referencia elaborada por $\mathrm{M}$. Cueto. Se recuperaron y diagnosticaron los residuos vegetales que quedaron adheridos a los filos de dichos artefactos. Asimismo, se observaron las microhuellas de pulido en los líticos, producto del procesamiento de la madera. Entre los resultados de la experimentación se observó que los denticulados producían estrías en ambas maderas según el descortezado y el trabajo del xilema, tantas como dientes tuviera (Cueto et al. 2010).

Por último, cabe mencionar la importancia del hallazgo de este tipo de instrumento en los sitios de CNSC, por un lado, por su conservación en estratigrafía, y por otro porque amplía la discusión de la presencia de instrumental asociado a la captura de recursos marinos hacia el Holoceno tardío (Beretta et al. 2013a). En este sentido, la presencia de arpones, rompecráneos y pinnípedos (ver sección sitio Cueva del Negro, capítulo 10) evidencia un sistema tecnológico de captura. Estos dos elementos son los únicos que se diferencian del conjunto tecnológico conocido para el Holoceno tardío en la región patagónica argentina (Beretta et al. 2013a, Orquera 1987). Si bien el fragmento medial de arpón de madera habría tenido otro uso (presas más chicas) también representa el primer tipo de artefacto hallado en dicha región. En este sentido el diseño de este tipo de instrumentos como sugieren Beretta y colaboradores (2013a) evidencian el conocimiento de los grupos cazadores recolectores costeros tenían de su ambiente, las materias primas y las técnicas de captura. 


\section{Colección de referencia para el análisis de microrrestos}

\subsection{Introducción}

La construcción de la colección de referencia para el análisis de microrrestos provenientes de instrumental lítico se realizó a través de la técnica microhistológica a partir de un entrenamiento de quien suscribe con la Ing. Agrónoma Laura Borrelli del INTA Bariloche. Borrelli participó, junto con Pelliza Sbriller en la realización de estudios de microhistología, los cuales estuvieron principalmente enfocados al análisis de composiciones botánicas de dieta de herbívoros patagónicos (Pelliza Sbriller et al. 2001, Bonino y Borrelli 2006). A partir del desarrollo de los estudios microhistológicos, la técnica fue aplicada en otras disciplinas como la paleobotánica y la arqueobotánica (Figuerero Torres et al. 1982, Martínez y Yagueddú 2012).

Es significativo el aporte de la identificación taxonómica a través de la histología vegetal, porque permite determinar mezclas de vegetales que han sufrido algún procesamiento, que han sido sometidas a distinto grado de digestión (i.e. muestras de fístula esofágica o rumial, contenidos estomacales, Pelliza Sbriller 1993).

En el caso de Argentina los primeros vestigios arqueobotánicos analizados a través de esta técnica fueron realizados por Alicia Pelliza Sbriller en el INTA Bariloche. La autora realizó la determinación de tallos, hojas y raíces de gramíneas y restos de varias maderas que se encontraban asociados e enterratorios en un cementerio indígena en Neuquén (Podestá y Pereda 1979).

En esta tesis se propone confeccionar una base de datos fotográfica con aquellas plantas que, según los registros de las fuentes bibliográficas consultadas y las entrevistas etnobotánicas realizadas (ver Parte I de esta tesis, capítulos 4 y 5), podrían haber sido procesadas a través de la molienda en instrumental lítico, luego de su colecta y previo a su consumo.

Para confeccionar dicha base de datos se procesaron previamente las plantas en el Laboratorio de Microhistología del INTA EE Bariloche, donde se encuentran 
depositados los preparados. A partir de dicha base de datos se describen los rasgos anatomo-histológicos de distintas partes de la planta de cada especie y se registran los caracteres diagnósticos para diferenciar unas de otras.

\subsection{Metodología}

Junto a la Ing. Agrónoma Borrelli se procesaron las plantas antes mencionadas aplicando la técnica descripta por Williams (1969) y modificada por Latour y Pelliza Sbriller (1981). En el Laboratorio de Microhistología del INTA EE Bariloche, en primer lugar, se secó el material vegetal de herbario o de campo en estufa a $60{ }^{\circ} \mathrm{C}$ hasta peso seco constante (48-72 hs), luego se molió con un molino eléctrico de choque logrando partículas de $1 \mathrm{~mm}$. El material molido se sometió luego a un tratamiento de fijación (alcohol $70^{\circ}$ ), hervido y lavado con agua caliente, aclaración (hipoclorito de sodio sin diluir), coloración (safranina alcohólica) y montaje sobre portaobjetos utilizando como medio de montaje gelatina glicerinada. Se observaron al microscopio (Olympus BX 41) a 100x, características histológicas de la epidermis de las plantas tales como: forma, dimensión y arreglo de las células, tipo y ubicación de estomas, diferentes tipos de tricomas, glándulas, papilas, aguijones. Se elaboraron tablas de presencia/ausencia de dichas características. Estas características fueron también microfotografiadas utilizando cámara Olympus E330.

\subsection{Resultados}

Se registraron 56 especies pertenecientes a 29 familias (Tabla 12.1). Los caracteres corresponden a plantas enteras molidas [i.e Cyclospermum leptophyllum (Pers.) Sprague var. leptophyllum, Adesmia boronioides, Azorella monantha], a hojas (i.e Arjona patagónica, Lycium chilense), frutos (i.e Mulguraea tridens, Empetrum rubrum) molidas. Entre las características diagnósticas más importantes se pueden mencionar la presencia de papilas, drusas y el tipo de aparato estomático. A continuación se describen los caracteres cualitativos registrados en las distintas especies, es importante mencionar siguiendo a Pelliza Sbriller (1993) que se adoptan criterios más simples de clasificación y descripción de los resultados por ser más prácticos para el análisis microhistológico. 
Se observa en la tabla la diferenciación de pelos glandulares y glándulas. De acuerdo a Pelliza Sbriller (1993) los pelos multiseriados no ramificados, comprenden estructuras glandulares o pelos secretores sólo diferenciables de las glándulas propiamente dichas porque estas son sésiles. La autora identifica una serie de características para cada familia de plantas estudiadas de Patagonia. En el caso de Gramineae el tejido epidérmico se caracteriza por un ordenamiento de células largas y células cortas en hileras longitudinales y la diferenciación entre venas y entrevenas, siendo éstas los rasgos que más la definen (Pelliza Sbriller 1993:23)

En el caso de Compositae, la autora identifica mayor variedad de estructuras entre las que se encuentran pelos multiseriados acumidados, multiseriados glandulares, bicelulares con la célula apical lanuginosa, multicelulares uniseriados acuminados y malpighiáceos En el caso de Leguminoseae no registra caracteres diagnósticos que identifiquen a la familia (Pelliza Sbriller 1993:23). 


\begin{tabular}{|c|c|c|c|c|c|c|c|c|c|c|c|}
\hline Especie & Órgano & Drusas & Papilas & Pelos & Cristales & Rafidios & Contenidos & Glándulas & $\begin{array}{l}\text { Aparato } \\
\text { estomático }\end{array}$ & $\begin{array}{l}\text { Células } \\
\text { epidérmicas }\end{array}$ & Estrías \\
\hline $\begin{array}{l}\text { Acantholippia } \\
\text { seriphioides }\end{array}$ & $\begin{array}{l}\text { Planta } \\
\text { molida c/ } \\
\text { flor }\end{array}$ & - & - & $\begin{array}{l}\text { Pelos lisos } \\
\text { unicelulares } \\
\text { (Fig.12.1A) } \\
\text { pelos } \\
\text { glandulares } \\
\text { (Fig. 12.1B) } \\
\text { base } \\
\text { engrosada } \\
\text { del pelo } \\
\text { (Fig. 12.1C) }\end{array}$ & - & - & - & - & (Figura 12.1D) & $\mathrm{s} / \mathrm{o}$ & - \\
\hline $\begin{array}{l}\text { Adesmia } \\
\text { boronioides }\end{array}$ & $\begin{array}{l}\text { Planta } \\
\text { molida }\end{array}$ & - & - & $\begin{array}{l}\text { Pelos } \\
\text { glandulares } \\
\text { lisos, } \\
\text { unicelulares, } \\
\text { paredes } \\
\text { gruesas Fig. } \\
12.1 \mathrm{E}\end{array}$ & $\begin{array}{l}\text { X cúbicos } \\
\text { sobre las } \\
\text { nervaduras } \\
\text { (caracterísi } \\
\text { tico de las } \\
\text { Fabaceae) }\end{array}$ & - & $\begin{array}{l}\text { Aceites } \\
\text { color verde }\end{array}$ & - & $\begin{array}{l}\text { Engrosamientos } \\
\text { encima de los estomas. } \\
\text { Estomas hundidos. El } \\
\text { tejido es más grueso } \\
\text { que las otras Adesmias. } \\
\text { (Figura } 12.1 \mathrm{~F} \text { ) }\end{array}$ & $\mathrm{s} / \mathrm{o}$ & - \\
\hline $\begin{array}{l}\text { Adesmia } \\
\text { volckmannii } \\
\text { Phil. }\end{array}$ & $\begin{array}{l}\text { Flor } \quad y \\
\text { fruto }\end{array}$ & - & - & 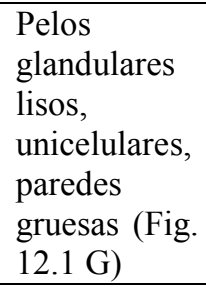 & $\begin{array}{l}\text { X cúbicos } \\
\text { sobre las } \\
\text { nervaduras } \\
\text { (Fig. } 12.1 \\
\text { H) }\end{array}$ & - & - & - & $\mathrm{s} / \mathrm{o}$ & $\mathrm{s} / \mathrm{o}$ & - \\
\hline $\begin{array}{l}\text { Alstroemeria } \\
\text { aurea Graham }\end{array}$ & Hoja & - & - & - & - & $\begin{array}{l}\text { X lo más } \\
\text { caracterís } \\
\text { tico (Fig. } \\
12.1 \text { I) }\end{array}$ & - & - & $\begin{array}{l}\text { Engrosamiento en las } \\
\text { paredes de células } \\
\text { oclusivas, estomas algo } \\
\text { hundidos (Fig. 12.1J). } \\
\text { Estomas longitudinales } \\
\text { siguen la orientación de } \\
\text { las células (Fig. 12.1K) }\end{array}$ & $\begin{array}{l}\text { longitudinales } \\
\text { (Fig. } 12.1 \mathrm{~K} \text { ) }\end{array}$ & - \\
\hline $\begin{array}{l}\text { Ameghinoa } \\
\text { patagonica }\end{array}$ & Hoja & - & - & $\begin{array}{l}\text { Característic } \\
\text { os } \\
\text { multicelulare } \\
\mathrm{s} \text {, de bases } \\
\text { engrosadas y } \\
\text { más grandes }\end{array}$ & - & - & - & - & $\begin{array}{l}\text { Estomas pequeños en } \\
\text { relación a las células } \\
\text { epidérmicas (Fig. 12.1 } \\
\text { M) }\end{array}$ & $\begin{array}{l}\text { Pared anticlinal } \\
\text { irregular }\end{array}$ & - \\
\hline
\end{tabular}




\begin{tabular}{|c|c|c|c|c|c|c|c|c|c|c|c|}
\hline & & & & $\begin{array}{l}\text { que los } \\
\text { estomas } \\
\text { (Fig. 12.1L y } \\
\text { LL) }\end{array}$ & & & & & & & \\
\hline $\begin{array}{l}\text { Anartrophyllum } \\
\text { rigidum }\end{array}$ & $\begin{array}{l}\text { Planta } \\
\text { molida }\end{array}$ & - & - & $\begin{array}{l}\text { Pelos muy } \\
\text { largos } \\
\text { unicelulares } \\
\text { y lisos } \\
\text { (Fig.12.1 N } \\
\text { y } \tilde{N})\end{array}$ & - & - & - & - & $\mathrm{s} / \mathrm{o}$ & $\mathrm{s} / \mathrm{o}$ & - \\
\hline Apium australe & $\begin{array}{l}\text { Planta } \\
\text { molida } \\
\text { con flor }\end{array}$ & - & $\begin{array}{l}\mathrm{X} \quad(\text { Fig. } \\
12.1 \mathrm{P})\end{array}$ & - & - & - & - & - & $\begin{array}{ll}\text { Células } & \text { oclusivas } \\
\text { engrosadas. } & \end{array}$ & $\begin{array}{l}\text { Células } \\
\text { lobuladas }\end{array}$ & $\begin{array}{l}\mathrm{X}(\text { Fig. } 1 \\
2.1 \mathrm{O})\end{array}$ \\
\hline $\begin{array}{l}\text { Cyclospermum } \\
\text { leptophyllum } \\
\text { var. } \\
\text { leptophyllum }\end{array}$ & $\begin{array}{l}\text { Planta } \\
\text { molida } \\
\text { con flor }\end{array}$ & - & $\begin{array}{l}\mathrm{X} \\
\text { (Fig.12.2 } \\
\text { A) }\end{array}$ & - & - & - & - & - & $\begin{array}{l}\text { Engrosadas las paredes } \\
\text { de las células oclusivas }\end{array}$ & $\begin{array}{l}\text { Células } \\
\text { lobuladas }\end{array}$ & $\mathrm{X}$ \\
\hline $\begin{array}{l}\text { Araucaria } \\
\text { araucana }\end{array}$ & $\begin{array}{l}\text { Tegumen } \\
\text { tos de } \\
\text { semillas }\end{array}$ & - & - & - & - & - & - & - & 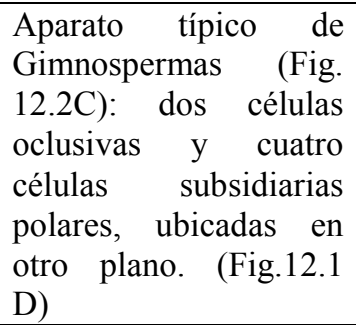 & $\mathrm{s} / \mathrm{o}$ & $\mathrm{X}$ \\
\hline $\begin{array}{l}\text { Arjona } \\
\text { patagonica }\end{array}$ & $\begin{array}{ll}\text { Hoja } & y \\
\text { planta } & \\
\text { molida } & \\
\end{array}$ & - & $\begin{array}{l}\text { Brillantes } \\
\text { (Fig.12.2 } \\
\text { E, F y H) } \\
\end{array}$ & - & - & - & - & - & Fig. (12.2.G) & $\mathrm{s} / \mathrm{O}$ & - \\
\hline Arjona tuberosa & $\begin{array}{l}\text { Hoja } \quad y \\
\text { tallo }\end{array}$ & - & $\begin{array}{l}X \text { en el } \\
\text { margen de } \\
\text { la } \\
\text { epidermis } \\
\text { (Fig. } \\
12.2 \mathrm{~J})\end{array}$ & - & - & - & - & - & $\mathrm{s} / \mathrm{o}$ & $\mathrm{s} / \mathrm{o}$ & - \\
\hline Atriplex lampa & $\begin{array}{l}\text { Hoja } \\
\text { molida }\end{array}$ & $\begin{array}{l}\mathrm{X} \\
\text { (Fig.12 }\end{array}$ & - & $\begin{array}{l}\text { Pelos } \\
\text { vesiculosos }\end{array}$ & - & - & - & $\begin{array}{l}\mathrm{X} \text { glándu- } \\
\text { las de sal }\end{array}$ & $\mathrm{s} / \mathrm{o}$ & $\begin{array}{l}\text { colapsadas } \\
\text { (Fig.12.2 K) }\end{array}$ & - \\
\hline
\end{tabular}




\begin{tabular}{|c|c|c|c|c|c|c|c|c|c|c|c|}
\hline & & $.2 \mathrm{~L})$ & & colapsados & & & & & & & \\
\hline $\begin{array}{l}\text { Azorella } \\
\text { monantha }\end{array}$ & $\begin{array}{l}\text { Planta } \\
\text { molida }\end{array}$ & $\begin{array}{l}\mathrm{X} \\
\text { (Fig.12 } \\
.2 \mathrm{LL})\end{array}$ & - & - & - & - & $\begin{array}{l}\text { Aceites } \\
\text { (Fig.12.2 } \\
\mathrm{N})\end{array}$ & - & (Fig. 12.2M) & $\mathrm{s} / \mathrm{o}$ & - \\
\hline $\begin{array}{l}\text { Azorella } \\
\text { trifurcata } \\
\text { (Gaertn.) Pers. }\end{array}$ & $\begin{array}{l}\text { Planta } \\
\text { molida }\end{array}$ & $\mathrm{X}$ & - & - & - & - & - & & $\mathrm{s} / \mathrm{o}$ & $\begin{array}{l}\text { Paredes de las } \\
\text { células } \\
\text { segmentadas en } \\
\text { fruto (Fig.12.2 } \\
\tilde{N})\end{array}$ & - \\
\hline $\begin{array}{l}\text { Benthamiella } \\
\text { patagónica } \\
\text { Speg. }\end{array}$ & $\begin{array}{l}\text { Planta } \\
\text { molida }\end{array}$ & - & $\mathrm{X}$ & Secretores & - & - & - & - & $\begin{array}{ll}\text { Estomas } & \text { hundidos } \\
\text { (Fig.12.2P) } & \end{array}$ & $\begin{array}{l}\text { Células } \\
\text { lobuladas } \\
(\text { Fig.12.2 O) } \\
\end{array}$ & - \\
\hline $\begin{array}{l}\text { Berberis } \\
\text { empetrifolia }\end{array}$ & $\begin{array}{l}\text { Hoja } \\
\text { molida }\end{array}$ & - & $\begin{array}{l}\mathrm{X} \quad \text { (Fig. } \\
12.3 \mathrm{~B})\end{array}$ & $\begin{array}{l}\text { Pelos } \\
\text { unicelulares } \\
\text { (Fig.12.3 A) }\end{array}$ & - & - & - & - & $\mathrm{s} / \mathrm{o}$ & $\begin{array}{l}\text { Con paredes } \\
\text { segmentadas y } \\
\text { fibras } \\
\text { subepidérmicas } \\
\text { paralelas entre } \\
\text { sí (Fig.12.3C) }\end{array}$ & - \\
\hline Berberis $s p$ & $\begin{array}{l}\text { Fruto } \\
\text { molido }\end{array}$ & - & $\mathrm{X}$ & - & - & - & - & - & $\mathrm{s} / \mathrm{o}$ & (Fig.12.3 E y F) & - \\
\hline $\begin{array}{l}\text { Brachyclados } \\
\text { caespitosus } \\
\text { (Phil.) Speg. }\end{array}$ & $\begin{array}{l}\text { Planta } \\
\text { molida }\end{array}$ & - & - & $\begin{array}{l}\text { Pelos } \\
\text { lanuginosos } \\
\text { (Pelliza } \\
\text { Sbriller } \\
\text { 1993:30, } \\
\text { Fig.12.3 G) } \\
\text { de dos o más } \\
\text { células (Fig. } \\
\text { 12.3 I, J) }\end{array}$ & - & . & . & $\mathrm{X}$ & $\begin{array}{l}\text { Se ven blanquecinos } \\
\text { los estomas }\end{array}$ & $\mathrm{s} / \mathrm{o}$ & - \\
\hline $\begin{array}{l}\text { Bromus } \\
\text { catharticus } \\
\text { Vahl var. } \\
\text { catharticus }\end{array}$ & $\begin{array}{l}\text { Planta } \\
\text { molida }\end{array}$ & - & - & $\begin{array}{l}\text { Aguijones } \\
\text { (Fig.12.3K) }\end{array}$ & - & - & - & - & $\begin{array}{l}\text { Típico de monocot- } \\
\text { iledónea: } \\
\text { ubicados en hileras } \\
\text { longitudinales, que } \\
\text { alternan con zonas de } \\
\text { tejido sin estomas. } \\
\text { Estoma más largo y }\end{array}$ & $\begin{array}{l}\text { Largas } \\
\text { intercaladas con } \\
\text { células cortas } \\
\text { cuadradas }\end{array}$ & - \\
\hline
\end{tabular}




\begin{tabular}{|c|c|c|c|c|c|c|c|c|c|c|c|}
\hline & & & & & & & & & finos que en Poa. & & \\
\hline $\begin{array}{l}\text { Dysphania } \\
\text { oblanceolata } \\
\text { (Speg.) } \\
\text { Mosyakin et } \\
\text { Clemants }\end{array}$ & $\begin{array}{l}\text { Planta } \\
\text { entera sin } \\
\text { flor } \\
\text { molida }\end{array}$ & $\mathrm{X}$ & - & 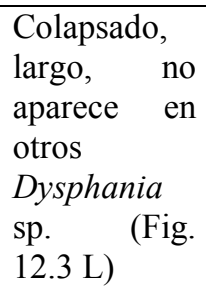 & - & - & Aceites & $\mathrm{X}$ & $\begin{array}{l}\text { Estomas pequeños en } \\
\text { relación a las células } \\
\text { epidérmicas }\end{array}$ & s/o & - \\
\hline Dysphania sp. & $\begin{array}{l}\text { Planta } \\
\text { molida } \\
\text { con flor }\end{array}$ & $\begin{array}{l}\mathrm{X} \\
\text { (Fig.12 } \\
.3 \mathrm{LL}) \\
\end{array}$ & - & $\begin{array}{l}\text { Pelo peltado } \\
\text { o escama } \\
(\text { Fig. } 12.3 \mathrm{M})\end{array}$ & - & - & & $\mathrm{X}$ & (Fig.12.3N) & s/o & - \\
\hline Dysphania sp & $\begin{array}{l}\text { Infloresce } \\
\text { ncia con } \\
\text { hoja } \\
\text { molidas }\end{array}$ & - & - & $\mathrm{X}$ & - & - & Aceites & - & - & $\mathrm{s} / \mathrm{o}$ & - \\
\hline $\begin{array}{l}\text { Chuquiraga } \\
\text { avellanedae }\end{array}$ & $\begin{array}{l}\text { Hoja } \quad \mathrm{y} \\
\text { tallo }\end{array}$ & - & - & $\begin{array}{l}\text { Pelos } \\
\text { transparentes } \\
\text { cortos } \\
\text { (Fig.12.3 O), } \\
\text { la base está } \\
\text { sobreelevada } \\
\text { Pelos } \\
\text { malpighiace } \\
\text { os. }\end{array}$ & - & - & - & - & $\begin{array}{l}\text { Estomas blanquecinos, } \\
\text { el ostíolo se ve blanco } \\
\text { (Fig.12.3 N) }\end{array}$ & $\begin{array}{l}\text { Poligonales muy } \\
\text { gruesas Fibras } \\
\text { suepidérmicas } \\
\text { paralelas entre } \\
\text { sí } \\
\text { (Fig.12.3 P) }\end{array}$ & - \\
\hline $\begin{array}{l}\text { Colliguaja } \\
\text { integerrima }\end{array}$ & $\begin{array}{l}\text { Hoja } \\
\text { molida }\end{array}$ & - & - & $\mathrm{X}$ & $\mathrm{X}$ & - & - & - & Estomas algo hundidos & $\mathrm{s} / \mathrm{o}$ & - \\
\hline $\begin{array}{l}\text { Condalia } \\
\text { microphylla }\end{array}$ & $\begin{array}{l}\text { Planta } \\
\text { molida }\end{array}$ & $\mathrm{X}$ & - & $\begin{array}{l}\text { Muchos } \\
\text { pelos. Tiene } \\
\text { orificios en } \\
\text { el tejido } \\
\text { cubierto por } \\
\text { pelos }\end{array}$ & - & - & - & - & $\begin{array}{lr}\text { Estomas } & \text { ecriptas } \\
\text { estomáticas ubicadas } \\
\text { en epidermis foliar } \\
\text { abaxial. }\end{array}$ & $\begin{array}{l}\text { Poligonales } \\
\text { marrones or }\end{array}$ & - \\
\hline $\begin{array}{l}\text { Descurainia } \\
\text { richardsoni }\end{array}$ & $\begin{array}{l}\text { Planta } \\
\text { con flor y } \\
\text { fruto }\end{array}$ & - & - & $\begin{array}{l}\text { Pelos } \\
\text { malpighiáce } \\
\text { os } \\
\text { (Fig.12.4D) }\end{array}$ & - & - & - & - & $\mathrm{s} / \mathrm{o}$ & $\begin{array}{l}\text { Con paredes } \\
\text { segmentadas } \\
\text { (Fig.12.4E) }\end{array}$ & - \\
\hline
\end{tabular}




\begin{tabular}{|c|c|c|c|c|c|c|c|c|c|c|c|}
\hline $\begin{array}{l}\text { Diposis } \\
\text { patagonica }\end{array}$ & $\begin{array}{l}\text { Planta } \\
\text { molida } \\
\text { con flor y } \\
\text { fruto }\end{array}$ & $\mathrm{X}$ & - & - & - & - & - & - & $\mathrm{s} / \mathrm{o}$ & $\begin{array}{lr}\text { Poligonales } & \text { y } \\
\text { lobuladas } & \text { en } \\
\text { fruto } & \end{array}$ & $\begin{array}{l}\mathrm{X} \\
\text { (Fig. } 12 . \\
4 \mathrm{G})\end{array}$ \\
\hline $\begin{array}{l}\text { Discaria } \\
\text { articulata } \\
\text { (Phil.) Miers. }\end{array}$ & $\begin{array}{l}\text { Planta } \\
\text { molida }\end{array}$ & $\mathrm{X}$ & - & $\begin{array}{l}\mathrm{X} \text { pelo } \\
\text { malpighiáce } \\
\text { os (con dos } \\
\text { brazos) y } \\
\text { dendroides } \\
\text { (Fig.12.4I) }\end{array}$ & $\mathrm{X}$ & - & - & - & (Fig.12.4 H) & $\mathrm{s} / \mathrm{o}$ & - \\
\hline $\begin{array}{l}\text { Empetrum } \\
\text { rubrum }\end{array}$ & Fruto & - & - & - & - & - & - & - & $\mathrm{s} / \mathrm{o}$ & $\begin{array}{l}\text { Fibras, paredes } \\
\text { engrosadas, } \\
\text { tejido grueso } \\
\text { (Fig.12.4J) }\end{array}$ & - \\
\hline $\begin{array}{l}\text { Empetrum } \\
\text { rubrum }\end{array}$ & $\begin{array}{l}\text { Planta } \\
\text { molida } \\
\text { con fruto }\end{array}$ & $\mathrm{X}$ & - & $\begin{array}{l}\text { Lanuginosos } \\
\mathrm{y} \quad \text { otros } \\
\text { secretores } \\
\text { (Fig. } 12.4 \mathrm{~K})\end{array}$ & - & - & aceites & - & $\mathrm{s} / \mathrm{o}$ & $\begin{array}{l}\text { Cuadradas, } \\
\text { paredes } \\
\text { segmentadas en } \\
\text { fruto }\end{array}$ & - \\
\hline $\begin{array}{l}\text { Ephedra } \\
\text { ochreata }\end{array}$ & Tallo & - & $\begin{array}{l}\mathrm{X} \\
\text { (Fig.12.4 } \\
\text { L) }\end{array}$ & $\mathrm{s} / \mathrm{o}$ & - & - & resinas & - & $\begin{array}{l}\text { Típico } \\
\text { Gimnospermas, } \\
\text { engrosamiento de las } \\
\text { paredes de células } \\
\text { oclusivas en el mismo } \\
\text { nivel del tejido } \\
\text { (Fig.12.4 LL) }\end{array}$ & $\mathrm{s} / \mathrm{o}$ & - \\
\hline Eupatorium $\mathrm{sp}$ & $\begin{array}{l}\text { Planta } \\
\text { molida } \\
\text { con flor }\end{array}$ & - & & $\begin{array}{l}\text { Secretores y } \\
\text { glandulares } \\
\text { (Fig.12.4 M) }\end{array}$ & - & - & $\mathrm{X}$ & $\mathrm{X}$ & $\mathrm{s} / \mathrm{o}$ & $\begin{array}{l}\text { Tejido grueso } \\
\text { (Fig.12.4 M) }\end{array}$ & $\mathrm{X}$ \\
\hline $\begin{array}{l}\text { Fabiana } \\
\text { imbricata }\end{array}$ & $\begin{array}{l}\text { Planta } \\
\text { molida } \\
\text { sin flor }\end{array}$ & - & - & $\begin{array}{l}\text { Glandulares } \\
\text { (Fig.12.4 O) }\end{array}$ & - & - & aceites & - & $\begin{array}{l}\text { Estomas hundidos con } \\
\text { marcado reborde de las } \\
\text { células (Fig. } 12.4 \tilde{\mathrm{N}} \text { ) }\end{array}$ & $\mathrm{s} / \mathrm{o}$ & - \\
\hline $\begin{array}{l}\text { Fabiana peckii } \\
\text { Niederl. }\end{array}$ & $\begin{array}{l}\text { Planta } \\
\text { molida } \\
\text { con cáliz } \\
\text { de flor }\end{array}$ & - & - & $\begin{array}{l}\text { Pelos } \\
\text { glandulares }\end{array}$ & $\mathrm{X}$ & - & - & - & $\begin{array}{l}\text { Estomas hundidos con } \\
\text { marcado reborde de las } \\
\text { células (Fig.12.4 P) }\end{array}$ & $\mathrm{s} / \mathrm{o}$ & - \\
\hline Glycyrrhiza & Hoja $\quad \mathrm{y}$ & - & - & - & - & - & - & $\mathrm{X}$ & $\mathrm{s} / \mathrm{o}$ & Tejido grueso & - \\
\hline
\end{tabular}




\begin{tabular}{|c|c|c|c|c|c|c|c|c|c|c|c|}
\hline astragalina & flor & & & & & & & $\begin{array}{l}\text { (Fig.12.5 } \\
\text { A) }\end{array}$ & & en fruto & \\
\hline $\begin{array}{l}\text { Grindelia } \\
\text { chiloensis }\end{array}$ & $\begin{array}{l}\text { Planta } \\
\text { molida }\end{array}$ & - & - & $\begin{array}{l}\text { Pelos } \\
\text { globosos } \\
\text { (Fig.12.4B) } \\
\end{array}$ & - & - & - & $\mathrm{X}$ & $\mathrm{s} / \mathrm{o}$ & $\mathrm{s} / \mathrm{o}$ & $\mathrm{X}$ \\
\hline $\begin{array}{l}\text { Gunnera } \\
\text { magellanica } \\
\text { Lam. }\end{array}$ & $\begin{array}{l}\text { Planta } \\
\text { molida } \\
\text { con flor }\end{array}$ & $\mathrm{X}$ & - & \begin{tabular}{|l} 
Pelos \\
transparentes \\
con algunas \\
estrías, \\
inserción \\
base ancha \\
de dos \\
células \\
(Fig.12.4C)
\end{tabular} & - & - & - & - & $\begin{array}{l}\text { Estomas un poco } \\
\text { hundidos }\end{array}$ & $\begin{array}{l}\text { Células } \\
\text { lobuladas pared } \\
\text { gruesa (Fig. } 12.5 \\
\text { D) }\end{array}$ & \\
\hline Juncus balticus & $\begin{array}{l}\text { Planta } \\
\text { molida }\end{array}$ & - & - & - & - & - & - & - & $\begin{array}{l}\text { Estomas paracíticos, } \\
\text { similares a los de } \\
\text { Gimnospermas } \\
\text { (Fig.12.5 E) }\end{array}$ & $\begin{array}{l}\text { Células } \\
\text { alargadas, sin, } \\
\text { células cortas }\end{array}$ & - \\
\hline $\begin{array}{l}\text { Mulguraea } \\
\text { tridens }\end{array}$ & $\begin{array}{l}\text { Brotes } \\
\text { molidos } \\
\text { (Hojas) }\end{array}$ & - & - & $\begin{array}{l}\text { Pelos con } \\
\text { ornamentaci } \\
\text { ón, } \\
\text { engrosamien } \\
\text { to de la base } \\
\text { a lo largo de } \\
\text { las células, } \\
\text { base del pelo } \\
\text { (Fig.12.5 I) } \\
\end{array}$ & - & - & - & $\mathrm{X}$ & Estomas algo hundidos & $\begin{array}{l}\text { Células más } \\
\text { largas que } \\
\text { anchas, } \\
\text { longitudinales }\end{array}$ & \\
\hline $\begin{array}{l}\text { Mulguraeae } \\
\text { tridens }\end{array}$ & Fruto & - & $\mathrm{X}$ & \begin{tabular}{|l|} 
Pelos \\
secretores \\
\end{tabular} & - & - & - & - & $\mathrm{s} / \mathrm{o}$ & $\mathrm{s} / \mathrm{o}$ & - \\
\hline $\begin{array}{l}\text { Larrea } \\
\text { ameghinoi }\end{array}$ & $\mathrm{s} / \mathrm{d}$ & $\mathrm{X}$ & - & \begin{tabular}{|l|} 
Pelos \\
transparentes \\
algunos \\
achatados, \\
flexibles \\
(Pelliza \\
Sbriler \\
\end{tabular} & - & - & - & - & $\mathrm{s} / \mathrm{o}$ & $\mathrm{s} / \mathrm{o}$ & - \\
\hline
\end{tabular}




\begin{tabular}{|c|c|c|c|c|c|c|c|c|c|c|c|}
\hline & & & & $\begin{array}{l}\text { 1993:30, } \\
\text { Fig.12.5 } \\
\text { F))con } \\
\text { estrías }\end{array}$ & & & & & & & \\
\hline Lycium chilense & Hoja & $\mathrm{X}$ & $X$ & $\begin{array}{l}\text { Pelos de } \\
\text { cutícula } \\
\text { dibujada } \\
\text { uniseriados, } \\
\text { simples o } \\
\text { ramificados } \\
\text { y } \\
\text { unicelulares. } \\
\text { Además } \\
\text { pequeños } \\
\text { pelos } \\
\text { secretores. }\end{array}$ & $\mathrm{X}$ & - & - & $\mathrm{X}$ & $\mathrm{s} / \mathrm{o}$ & $\mathrm{s} / \mathrm{o}$ & - \\
\hline $\begin{array}{l}\text { Mimulus } \\
\text { glabratus } \\
\text { Kunth } \\
\end{array}$ & $\begin{array}{l}\text { Planta } \\
\text { entera } \\
\text { con flor }\end{array}$ & - & - & $\begin{array}{l}\text { Tricomas } \\
\text { unicelulares }\end{array}$ & - & - & - & $\mathrm{X}$ & $\mathrm{s} / \mathrm{o}$ & lobuladas & - \\
\hline $\begin{array}{l}\text { Mimulus } \\
\text { glabratus }\end{array}$ & $\begin{array}{l}\text { Planta } \\
\text { molida }\end{array}$ & - & - & $\begin{array}{l}\text { Pelos } \\
\text { glandulares } \\
\text { largos } \\
\text { (Fig.12.5 H) }\end{array}$ & - & - & - & - & $\mathrm{s} / \mathrm{o}$ & $\mathrm{s} / \mathrm{o}$ & - \\
\hline Mulinum sp & $\begin{array}{l}\text { Infloresce } \\
\text { ncias }\end{array}$ & $\begin{array}{l}\mathrm{X} \\
\text { (Fig.12 } \\
.5 \mathrm{~K})\end{array}$ & - & $\begin{array}{l}\text { Pelos } \\
\text { achatados } \\
\text { transparentes }\end{array}$ & - & - & - & - & - & - & $\mathrm{X}$ \\
\hline $\begin{array}{l}\text { Nardophyllum } \\
\text { sp }\end{array}$ & Fruto & - & - & $\begin{array}{l}\text { Pelos } \\
\text { bicelulares } \\
\text { con una } \\
\text { célula apical } \\
\text { larga tipo } \\
\text { lanuginosa y } \\
\text { pelos } \\
\text { secretores } \\
\text { uni o } \\
\text { multiseriado }\end{array}$ & - & - & - & - & $\mathrm{s} / \mathrm{o}$ & esclereidas & - \\
\hline
\end{tabular}




\begin{tabular}{|c|c|c|c|c|c|c|c|c|c|c|c|}
\hline & & & & $\begin{array}{l}\text { s. (ver } \\
\text { lanuginosos } \\
\text { Pelliza } \\
\text { Sbriller } \\
\text { 1993:30) } \\
\text { (Fig.12.5 L) }\end{array}$ & & & & & & & \\
\hline $\begin{array}{l}\text { Nassauvia } \\
\text { glomerulosa }\end{array}$ & Hoja & - & - & $\begin{array}{l}\text { Pelos } \\
\text { bicelulares } \\
\text { con célula } \\
\text { apical larga } \\
\text { con pelos } \\
\text { secretores } \\
\text { uni o } \\
\text { multiseriado } \\
\text { s en gran } \\
\text { cantidad }\end{array}$ & - & - & - & - & $\begin{array}{l}\text { Estomas pequeños en } \\
\text { relación a las células } \\
\text { epidérmicas (Fig. } 12.5 \\
\text { M) }\end{array}$ & - & - \\
\hline Oenothera sp & $\begin{array}{l}\text { Planta } \\
\text { molida }\end{array}$ & - & - & $\begin{array}{l}\text { Pelos lisos y } \\
\text { pelos con } \\
\text { rugosidad } \\
\text { (Fig. } 12.5 \\
\text { LL) }\end{array}$ & - & - & - & - & $\mathrm{s} / \mathrm{o}$ & $\mathrm{a} / \mathrm{o}$ & - \\
\hline $\begin{array}{l}\text { Oxalis } \\
\text { compacta }\end{array}$ & $\begin{array}{l}\text { Planta } \\
\text { entera } \\
\text { con flor }\end{array}$ & - & - & $\begin{array}{l}\text { Pelo con } \\
\text { ornamentaci } \\
\text { ón (Fig.12.5 } \\
\mathrm{N} \text { ) }\end{array}$ & - & - & - & - & Estomas pequeños & $\begin{array}{l}\text { Células grandes } \\
\text { con almidones }\end{array}$ & - \\
\hline Prosopis sp & Vainas & - & - & - & - & - & - & - & s/o & $\begin{array}{l}\text { Células pétreas, } \\
\text { esclereidas (Fig. } \\
12.5 \tilde{\mathrm{N}} \text { ) }\end{array}$ & - \\
\hline Prosopis sp & $\begin{array}{l}\text { Tallos } \\
\text { tiernos } \\
\end{array}$ & - & - & $\begin{array}{l}\text { Pelos tipo } \\
\text { aguijones }\end{array}$ & - & - & - & - & Estomas diacíticos & $\mathrm{s} / \mathrm{O}$ & - \\
\hline $\begin{array}{l}\text { Prosopis } \\
\text { alpataco }\end{array}$ & $\mathrm{s} / \mathrm{d}$ & - & - & $\begin{array}{l}\text { Pelos con } \\
\text { pared más } \\
\text { gruesa, se } \\
\text { nota aún más } \\
\text { la } \\
\text { ornamentaci }\end{array}$ & - & - & - & taninos & $\begin{array}{l}\text { Estomas más pequeños } \\
\text { que Prosopis denudans }\end{array}$ & $\mathrm{s} / \mathrm{o}$ & - \\
\hline
\end{tabular}




\begin{tabular}{|c|c|c|c|c|c|c|c|c|c|c|c|}
\hline & & & & ón & & & & & & & \\
\hline $\begin{array}{l}\text { Prosopis } \\
\text { denudans }\end{array}$ & $\mathrm{s} / \mathrm{d}$ & - & - & $\begin{array}{l}\text { Pelos con } \\
\text { ornamentaci } \\
\text { ón }\end{array}$ & - & - & - & taninos & $\begin{array}{l}\text { Estomas más grandes } \\
\text { que Prosopis alpataco }\end{array}$ & $\mathrm{s} / \mathrm{o}$ & - \\
\hline Sarcocornia $\mathrm{sp}$ & $\begin{array}{l}\text { Planta } \\
\text { entera } \\
\text { molida }\end{array}$ & - & $\mathrm{X}$ & - & - & - & - & - & $\mathrm{s} / \mathrm{o}$ & $\begin{array}{l}\text { Con } \\
\text { engrosamiento, } \\
\text { células } \\
\text { papilosas en } \\
\text { fruto y flor, } \\
\text { esclereidas(Fig. } \\
12.5 \mathrm{O} \text { ) }\end{array}$ & - \\
\hline $\begin{array}{l}\text { Schinus } \\
\text { jhonstonii }\end{array}$ & $\begin{array}{l}\text { Hoja } \\
\text { molida }\end{array}$ & $\mathrm{X}$ & - & $\begin{array}{l}\text { Pelos tipo } \\
\text { aguijón, no } \\
\text { muy largos, } \\
\text { ornamentado } \\
\text { s, rígidos en } \\
\text { los bordes de } \\
\text { la epidermis, } \\
\text { unicelulares, } \\
\text { pared gruesa } \\
\text { (Fig. 12.6 A } \\
\text { y B) }\end{array}$ & $\mathrm{X}$ & - & - & - & $\begin{array}{l}\text { Estomas hundidos, se } \\
\text { ven } \\
\text { blanquecinos }\end{array}$ & $\begin{array}{l}\text { Poligonales } \\
\text { apretadas, de } \\
\text { paredes gruesas }\end{array}$ & - \\
\hline $\begin{array}{l}\text { Senecio } \\
\text { filaginoides }\end{array}$ & $\begin{array}{l}\text { Tallo } \quad \mathrm{y} \\
\text { hoja }\end{array}$ & - & - & $\begin{array}{l}\text { Pelos de } \\
\text { aspecto } \\
\text { lanuginosos } \\
\text { (Pelliza } \\
\text { Sbriller } \\
\text { 1993:30) } \\
\text { con base de } \\
\text { dos células } \\
\text { (Fig. 12.5 P) }\end{array}$ & - & - & - & - & $\mathrm{s} / \mathrm{o}$ & $\mathrm{s} / \mathrm{o}$ & - \\
\hline $\begin{array}{l}\text { Taraxacum } \\
\text { officinale }\end{array}$ & $\begin{array}{l}\text { Planta } \\
\text { molida } \\
\text { con flor }\end{array}$ & - & - & $\begin{array}{l}\text { Pelos } \\
\text { glandulares } \\
\text { pluricelulare } \\
\text { S }\end{array}$ & - & - & - & - & $\mathrm{s} / \mathrm{o}$ & $\mathrm{s} / \mathrm{o}$ & - \\
\hline Retanilla & Flores & $\mathrm{X}$ & $X$ & Gran & - & - & - & - & $\mathrm{s} / \mathrm{o}$ & Papilosas & $\mathrm{X}$ \\
\hline
\end{tabular}




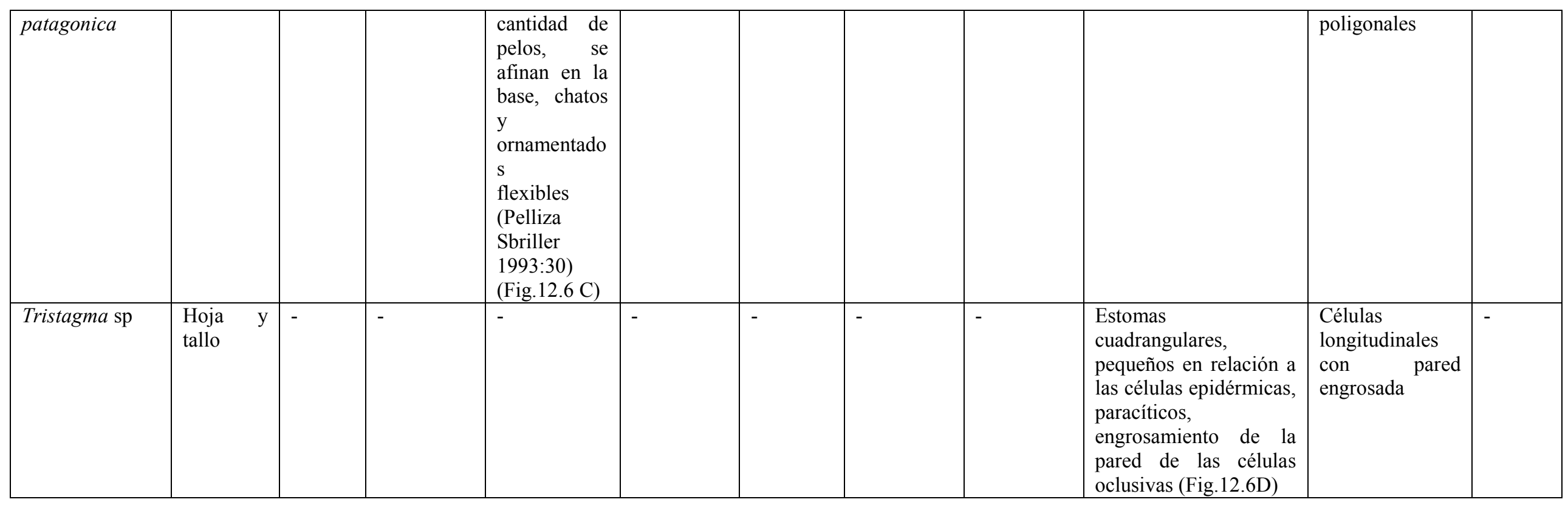

Tabla 12.1. Caracteres cualitativos de las especies analizadas a través de la técnica microhistológica. Referencias: [X] signfica presencia del rasgo; [s/o] sin observaciones. 


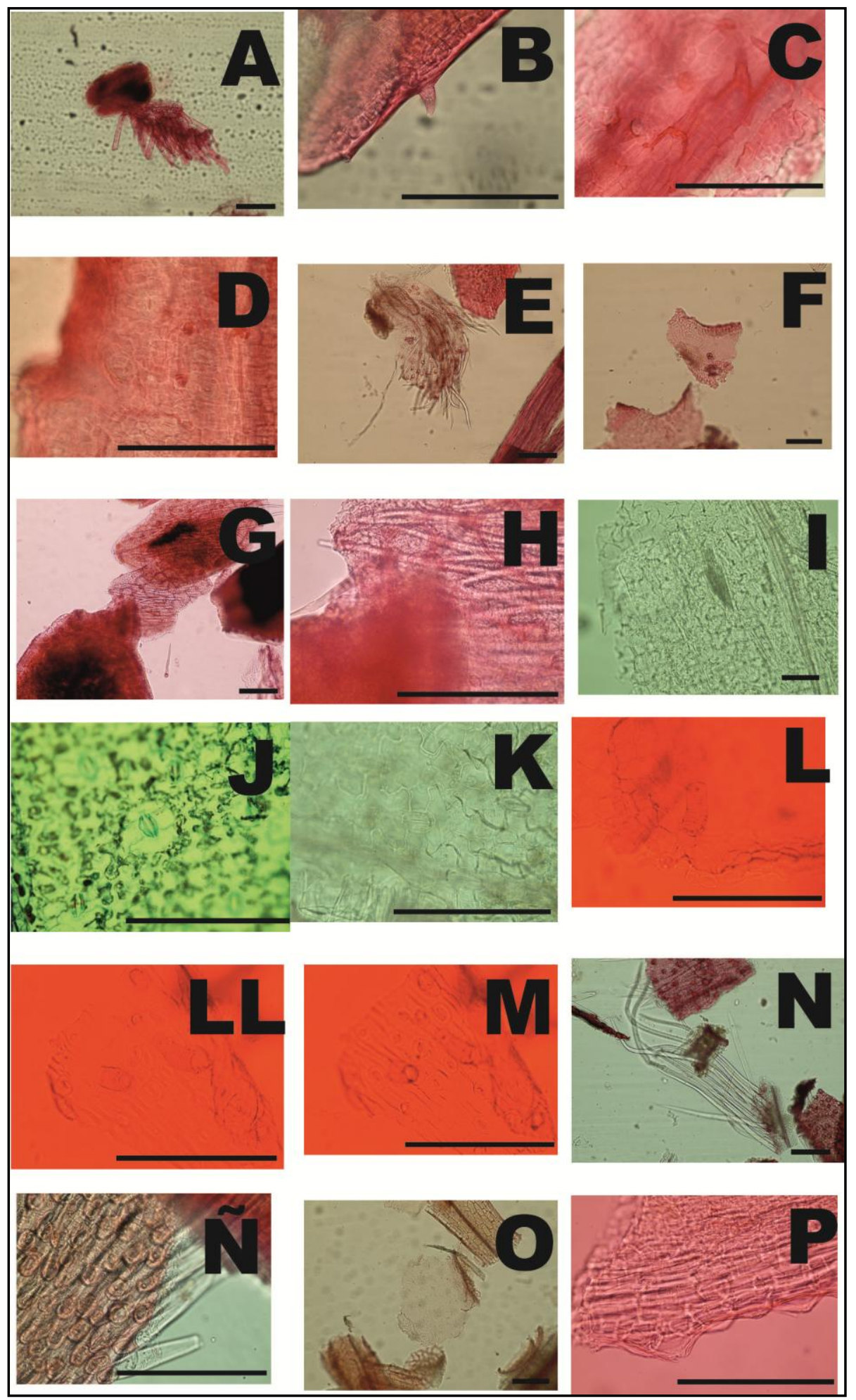

Figura 12.1. Acantholippia seriphioides A. 100X. B.400X. C. 400X. D 400X., Adesmia boronioides E 100X, F 100X, Adesmia volckmanii G 100X, H 400X, Alstroemeria aurea I 100X, J 400X, K 400X, Ameghinoa patagonica L 400X, LL 400X, M 400X, Anarthropyllum rigidum N 100X, Ñ 400X, Apium australe O 100X, P 400X. 


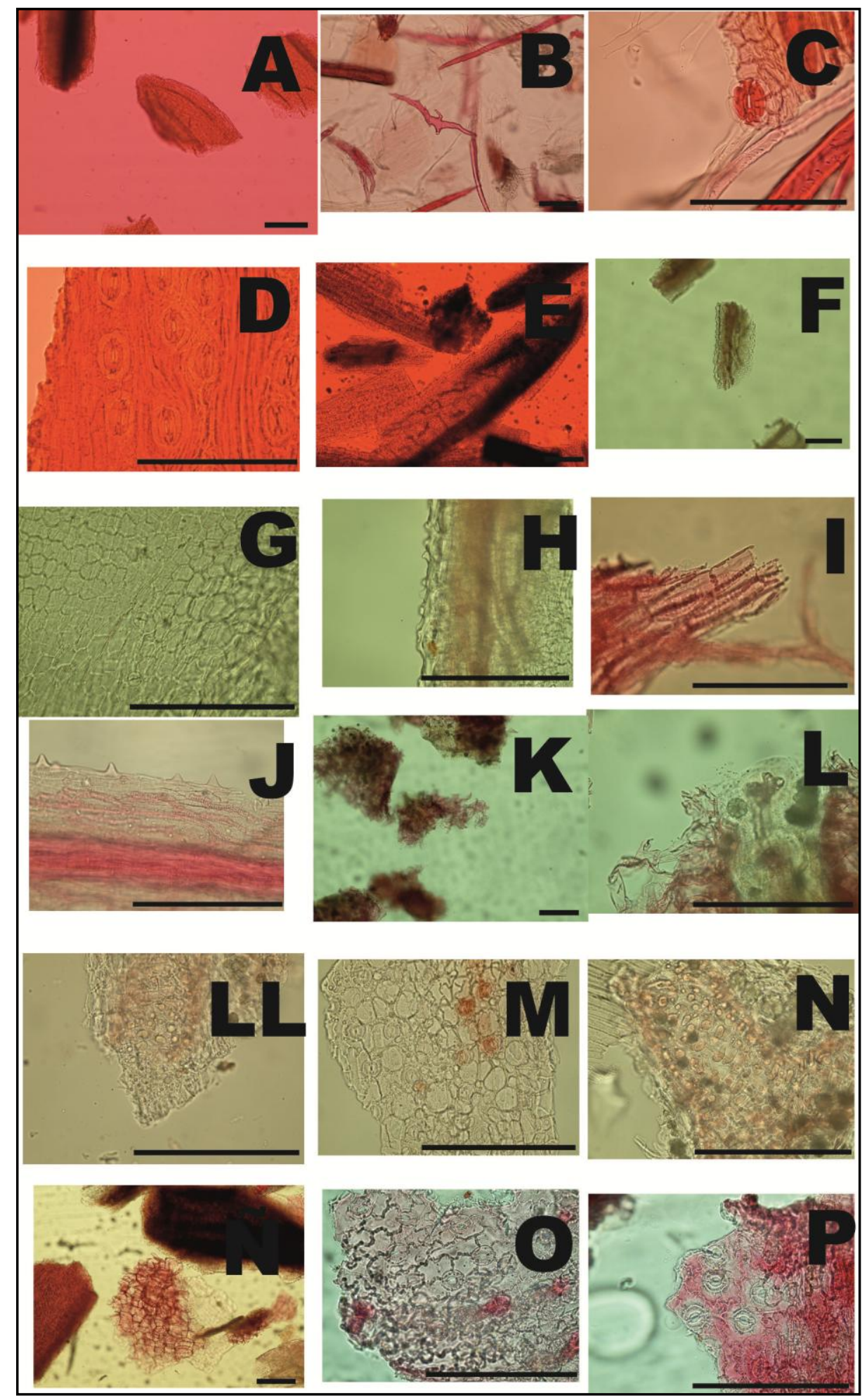

Figura 12.2. Cyclospermum leptophyllum var. leptophyllum A 100X, Araucaria araucana B 100X, C 400X, D 400X, Arjona patagonica E 100X, F 100X, G 400X, H 400X, Arjona tuberosa I 400X, J 400X, Atriplex lampa K 100X, L 400X, Azorella monantha LL 400X, M 400X, N 400X, Azorella trifurcata Ñ 100X, Benthamiella patagonica O 400X, P 400X. Escala $=500 \mu \mathrm{m}$ 


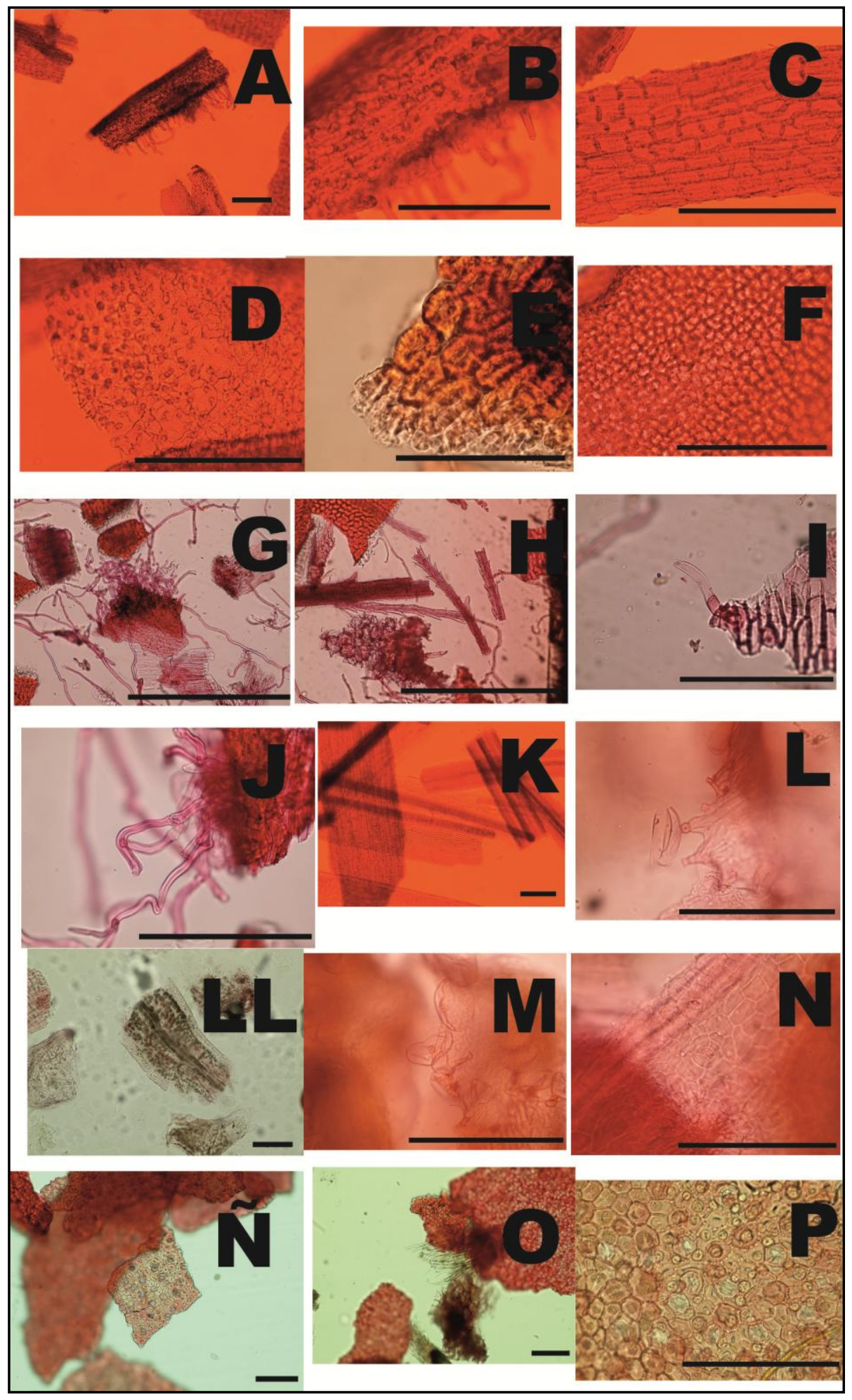

Figura 12.3. Berberis empetrifolia A 100X, B 400X, C 400X, D 400X, Berberis sp. E 400X, F 400X, Brachyclados caespitosus G 400X, H 400X, I 400X, 400X, Bromus catharticus K 100X, Dysphania oblanceolata L 400X, Dysphania sp. LL 100X, M 400X, N 400X, Chuquiraga avellanedae Ñ 100X, O 100X, P 400X. Escala $=500 \mu \mathrm{m}$ 


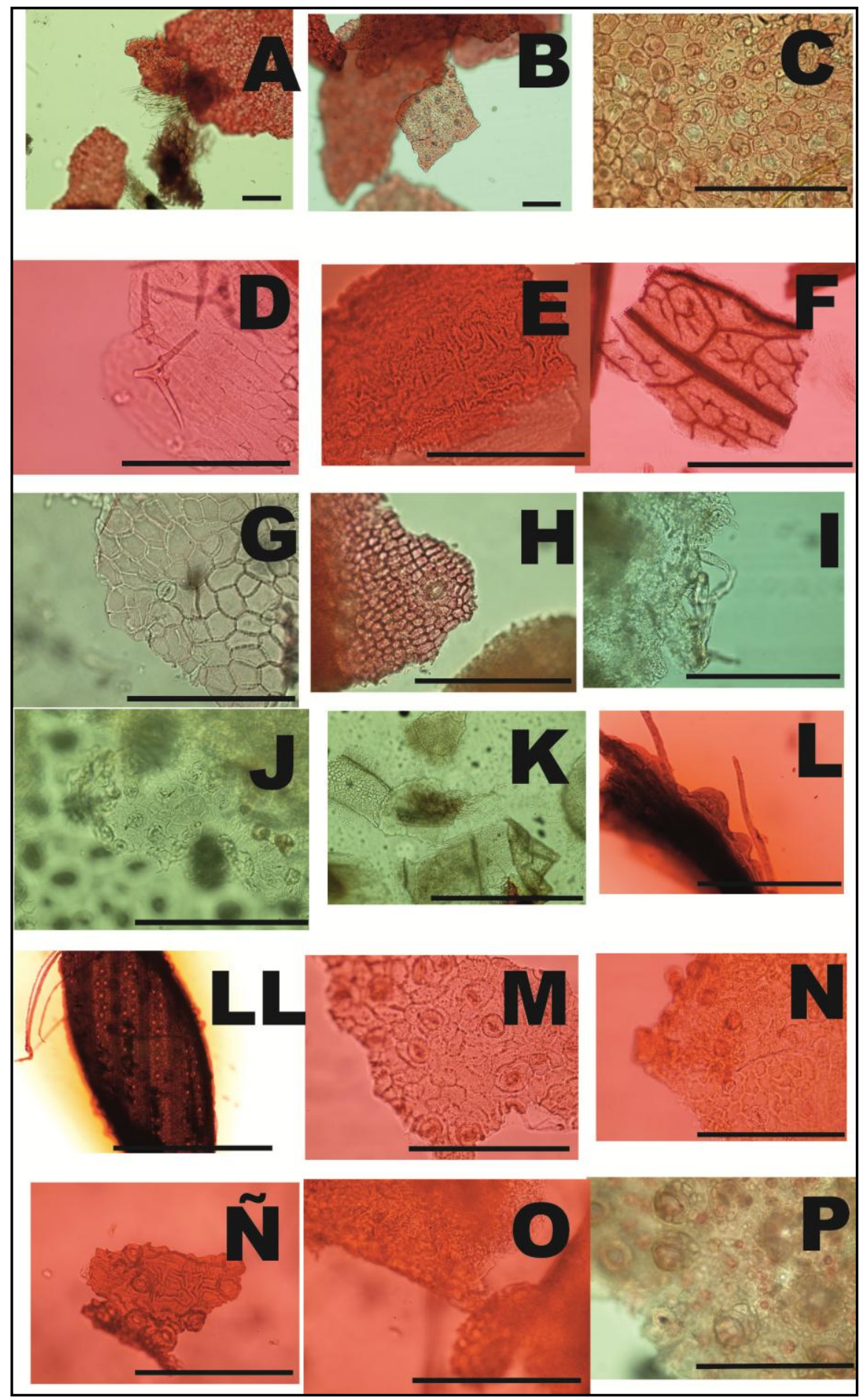

Figura 12.4. Colliguaja integerrima A 100X, Condalia microphylla B 100X, C 400X, Descurainia richardsoni D 400X, E 400X, F 400X, Diposis patagonica G 400X, Discaria articulata H 400X, I 400X, Empetrum rubrum J 400X, K 400X, Ephedra ochreata L 400X, LL 400X, Eupatorium M 400X, N 400X, Fabiana imbricata Ñ 400X, O 400X Fabiana peckii P 400X. Escala $=500 \mu \mathrm{m}$ 


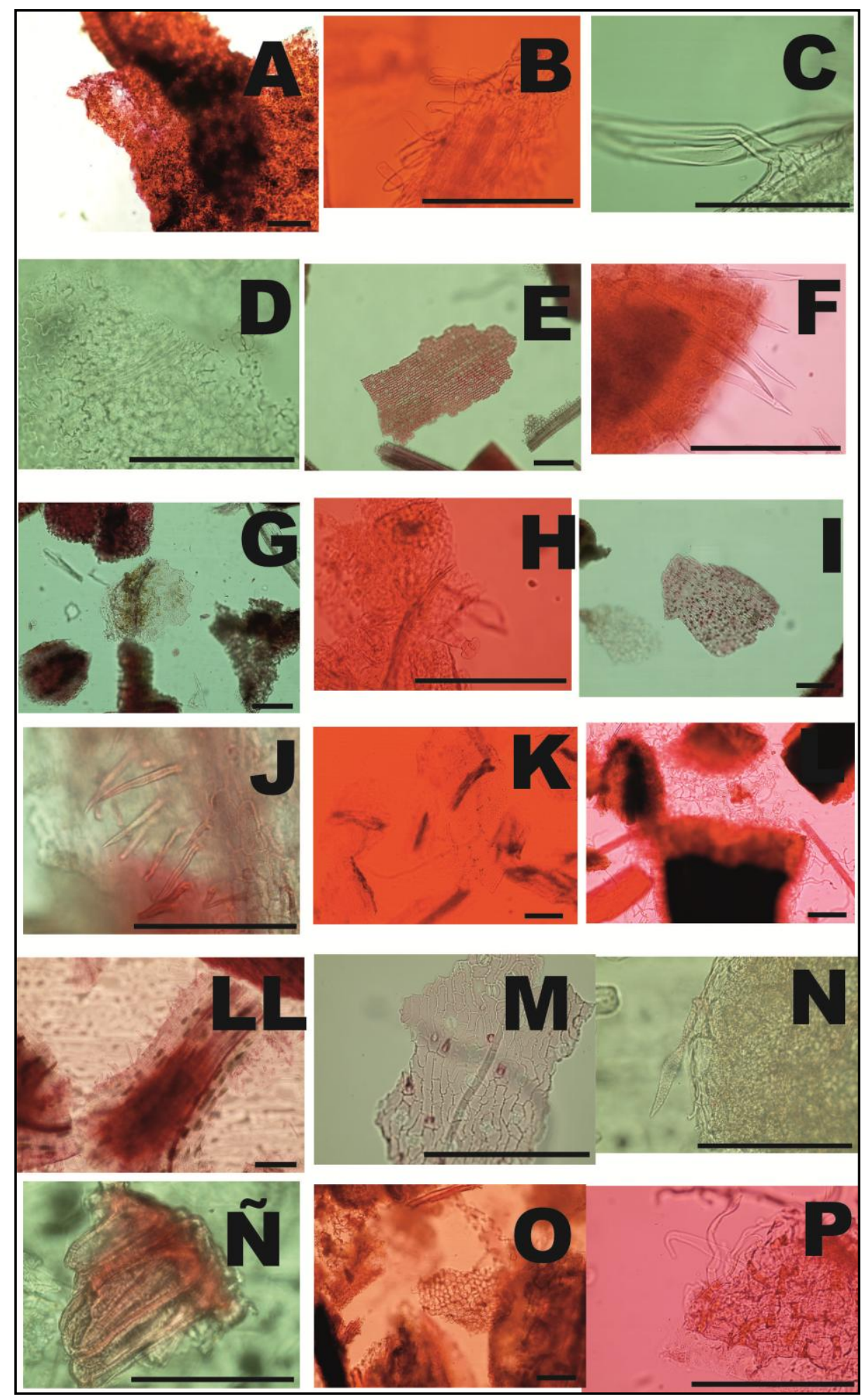

Figura 12.5 Glycyrrhiza astragalina A 100X, Grindelia chiloensis B 400X, Gunnera magellanica C 400X, D 400X, Juncus balticus E 100X, Larrea ameghinoi F 400X, Lycium chilense G 100X, Mimulus glabratus H 400X, Mulguraea tridens I 100X, J 400X, Mulinum sp. K 100X, Nardophyllum sp. L 100X, Oenathera sp. LL 400X, Nassauvia glomerulosa M 400X, Oxalis compacta N 400X, Prosopis sp. N 400X, Sarcocornia sp. O 100X, Senecio filaginoides P 400X. Escala $=500 \mu \mathrm{m}$ 

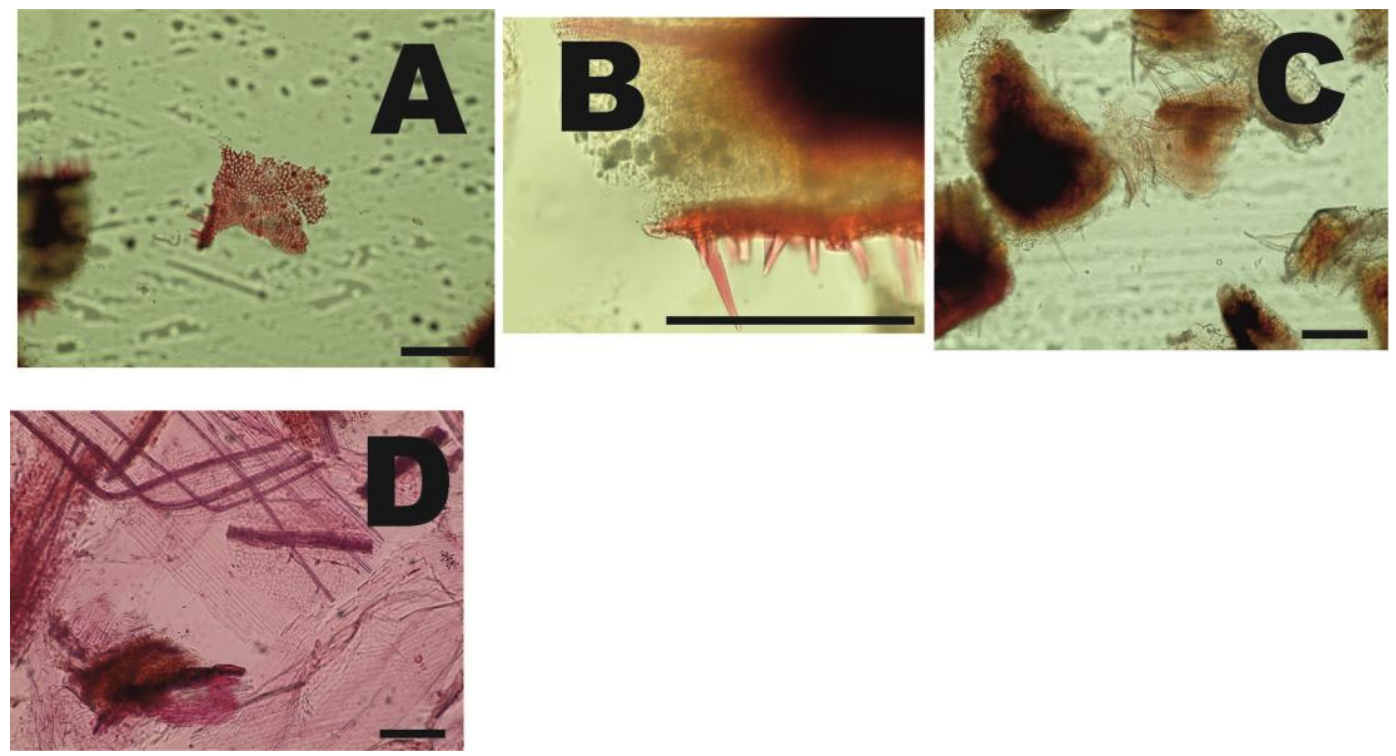

Figura 12.6. Schinus sp. A 100X, B 400X, Retanilla patagonica C 100X, Tristagma sp. D 100X. Escala= $500 \mu \mathrm{m}$

\subsection{Conclusiones}

La técnica microhistológica se desarrolló con el objetivo de identificar la dieta de herbívoros y por lo tanto de microvestigos de plantas silvestres. Por lo tanto, los restos analizados se encuentran sometidos a distinto grado de digestión: muestras de fístula esofágica o ruminal, contenidos estomacales o intestinales y heces (Pelliza Sbriller 1993. Debido a esto, a través de este tipo de análisis es posible identificar mezclas de vegetales a partir de distintos caracteres. Sin embargo, como se observó en la Tabla 12.1, es la combinación de caracteres lo que permite la identificación de un género de otro. En el caso de Adesmia boronioides, por ejemplo, se registra en primer lugar cristales sobre las nervaduras (característica compartida con otras Fabaceae), pelos glandulares lisos, y se diferencia de Adesmia lotoides porque esta última presenta pelos malpighiáceos. A su vez, presenta un aparato estomático con estomas levemente hundidos, con tejido epidérmico más grueso que las otras Adesmias. En el caso de Alstromeria aurea, de la familia Poaceae, lo que la diferencia de otros géneros de la familia es la presencia de rafidios, que si bien también están presentes en las Ranunculaceas la epidermis característica de las Poaceae con células longitudinales y los estomas en el mismo sentido que las células epidérmicas. A su vez, presenta engrosamiento de las células oclusivas y estomas levemente hundidos. 
En el caso de Apium australe, las características diagnósticas son las células lobuladas de la epidermis, la presencia de estrías en este tejido así como de papilas. Si bien son caracteres que se pueden encontrar en otros géneros es la combinación de ellos en el tejido lo que permite diferenciarlos.

En el caso de Descurainia richardsonii de la familia Brassicaceae, presenta pelos tectores dendroides.

Se considera relevante la descripción de los tejidos de las especies patagónicas y en futuros trabajos se profundizará en observar aquellas características que permitan diferenciar aún más cada especie. Se profundizará en la descripción de los pelos tectores que son más confiables en la identificación y en la diferenciación de estructuras secretoras por especie. 


\section{El procesamiento post colecta de los vegetales: molienda}

\subsection{Introducción}

Como se mencionó en el capítulo 2 (Marco Teórico) el término procesamiento poscolecta hace referencia a las prácticas realizadas luego de la colecta de las plantas silvestres o cultivadas (Capparelli y Lema 2010). Si bien este concepto fue desarrollado originalmente para el análisis de plantas cultivadas, distintos autores consideraron su uso para plantas silvestres también. Entre ellos es importante mencionar a Wollstonecroft, quien amplía el término incluyendo: "todas las habilidades, conocimientos, tecnología y coordinación de trabajo que son necesarios para convertir plantas en estado bruto en productos comestibles y/o para preservarlas como productos almacenables y/o promover la disponibilidad de nutrientes" (Wollstonecroft 2007). Las prácticas poscosecha están íntimamente ligadas a los modos de consumo y éstos a los criterios de selección de las plantas (Capparelli y Lema 2010), por lo que resultan importantes para estudiar las prácticas de recolección desde un sentido amplio.

La recopilación bibliográfica sobre usos y prácticas de procesamiento luego de la recolección descripta en el capítulo 4 evidencian que las técnicas de procesamiento más frecuentes en Patagonia son: maceración, remojo, tostado, molido, hervido y asado, y, por último, que las partes de las plantas implicadas son comúnmente frutos y órganos subterráneos. En el caso de estos últimos, varios autores han destacado el rol de las prácticas de procesamiento poscosecha para transformarlos en sustancias más digeribles y sin toxicidad (Stahl 1989). En particular, las prácticas de molienda, fermentación o calor, pueden promover la bioaccesibilidad de nutrientes porque transforman la microestructura del tejido vegetal, rompiendo las paredes celulares, cambiando el complejo matriz de nutrientes y/o transformando las sustancias de los tejidos en estructuras moleculares más activas (Parada y Aguilera 2007). En el registro arqueobotánico de Patagonia continental se infirieron prácticas de molienda de frutos para su consumo (i.e. Zea mays, Prosopis) (Lema et al. 2012). Es relevante entonces 
indagar e identificar prácticas de procesamiento poscolecta de grupos humanos que habitaron la CNSC, entendiendo que este conocimiento podría haber permitido ampliar su dieta u obtener medicina a través de la manipulación de plantas con principios activos, entre otros aspectos. Los resultados de los análisis efectuados para abordar este problema de investigación se exponen en el presente capítulo y se hizo énfasis en las prácticas de molienda. Se propuso como objetivos específicos en primer lugar, recopilar a partir de las publicaciones arqueológicas de Patagonia continental Argentina, las menciones de artefactos que según criterios morfológicos correspondan a instrumentos de molienda (Babot 2004). Esto permitió establecer las áreas donde fueron recuperados dichos instrumentos, los tipos de sitios y las materias primas con las que fueron confeccionados. Los artefactos de molienda pueden definirse como aquellos utensilios usados de a pares para quebrantar o reducir sustancias intermedias, no artefactuales, a un tamaño más pequeños que el actual (Babot 2004:83). Es importante destacar que la autora advierte que pueden presentarse como artefactos manufacturados o como litos modificados por el uso. En este último caso se definen como artefactos de molienda no manufacturados con rastros complementarios. Dentro del sistema de artefactos de molienda, se requiere de un elemento pasivo y otro activo, en este sentido se definen como artefactos de molienda pasivo inferior y artefactos de molienda activo superior (Babot 2004:85). Para la identificación de uno u otro la autora considera las siguientes variables: a) portabilidad, b) presencia/ausencia de oquedades, c) curvaturas longitudinal y transversal de las caras activas y d) presencia/ausencia y tipo de rasgos morfológicos complementarios.

También se registra la categoría de artefactos indefinidos debido a su fragmentación o porque algunos de las características antes mencionadas están ausentes. Entonces dentro de los grupos tipológicos (Aschero 1975, Babot 2004) los morteros y manos de morteros tienen como función primaria: machacar, triturar, moler o pulverizar. El modo de acción, es decir los movimientos del instrumento durante su uso, en el caso de los morteros es el de percusión, en presión hacia abajo, en vaivén, por rotación o alternativa semirotativa. En el caso de los molinos y manos de molino, la función primaria es moler, pulverizar o triturar siendo la función primaria triturar y moler. El modo de acción de este último tipo de artefactos es por percusión y por presión las acciones de 
vaivén, rotación, hacia abajo, semirotativa pero también por deslizamiento en sentido de traslación circular y alternativa (curvilínea o rectilínea) (Babot 2004:89).

En esta tesis no se va a desarrollar un análisis tecnológico (sensu Aschero 1975, Babot 2004) de los artefactos de molienda pero sí se consideran los criterios más importantes para distinguir estos artefactos, y poder realizar la extracción de muestras de adherencias in situ.

En segundo lugar, se registraron y analizaron de acuerdo a criterios morfo-funcionales los artefactos recuperados hasta el momento en CNSC teniendo en cuenta las definiciones anteriormente expuestas, que puedan haber sido potencialmente utilizados en el procesamiento post colecta de vegetales. En tercer lugar, se recuperararon muestras de adherencias de algunos de estos artefactos en pos de confirmar o no el procesamiento de vegetales y de determinar cuáles pudieron haber sido procesados y para qué tipo de aplicación. Para este último objetivo se analizaron hasta el momento seis artefactos: uno es el M17PM, recuperado superficialmente en Punta Medanosa, y los otros 5 artefactos pertenecen a una colección del Museo del Hombre y su Entorno de la ciudad de Caleta Olivia, que fueron depositados allí, a partir de recolecciones superficiales realizadas por gente de la zona, a lo largo de los últimos 25 años (Gribaudo com. pers.).

\subsection{Metodología}

Con respecto al primer objetivo, se recopilaron citas de morteros, molinos y manos de Patagonia continental a partir de las siguientes publicaciones de arqueología: Jornadas de Patagonia desde el año 1996; Actas de los Congresos Nacional de Arqueología Argentina del 2007, 2010 y 2013; así como, 14 tesis de doctorado realizadas en Patagonia continental (Moreno 2008, Gómez Otero 2006, Carden 2007, Cassiodoro 2008, Hermo 2008, Prates 2008, Cardillo 2009, Skarbun 2009, Castro 2010, Cordero 2010, Magnin 2010, Zubimendi 2010, Frank 2011, Ambrústolo 2011). Se incluyó en la muestra de análisis además, dos trabajos cuyos resultados son relevantes para el objetivo propuesto. Uno de ellos, desarrolla el análisis arqueobotánico de microrrestos vegetales en artefactos de molienda (Lema et al. 2012) y el otro, brinda el fechado más 
antiguo para Patagonia de este tipo de artefactos (Sanguinetti de Bórmida y Curzio 1996).

De la muestra total consultada se registraron menciones de artefactos de molienda en 15 trabajos publicados en las Jornadas de Patagonia y Congresos de Arqueología en los años mencionados, así como en 6 tesis y en los dos trabajos seleccionados $(n=23)$. De estas publicaciones se registró la siguiente información: sitio, contexto, cronología, materia prima, existencia de análisis de adherencias, presencia /ausencia de microrrestos y su identificación.

En cuanto al segundo objetivo, se realizaron prospecciones asistemáticas al sur de la Ría Deseado en las localidades arqueológicas Bahía del Oso Marino y Punta Medanosa. Se relevaron posibles artefactos de morfología morteros o molinos (Babot 2004) a partir de una ficha en la que se tomaron los siguientes datos: posición geográfica, localidad arqueológica, nombre y tipo de sitio arqueológico, posición en el sitio (superficie o estratigrafia), descripción (alteraciones naturales de la pieza, presencia/ausencia de rastros de uso, materia prima, medidas y cuadrante de extracción. Se tomaron sólo estas variables en primer lugar, como una primera aproximación al registro de artefactos de molienda. En segundo lugar, porque además de registrar estos datos se tomaron muestras in situ, entonces las fichas debían ser prácticas y expeditivas para recabar los datos.

En relación al tercer objetivo, es importante destacar que varias de las muestras de adherencias analizadas se recuperaron in situ. Para el raspado se usaron hojas de bisturí descartables y estériles $n^{\circ} 15$, marca Troge medical GmbH, D-20148 Hamburg, una por cada artefacto. Para la esterilización de los frascos donde se depositaron las muestras se realizaron los pasos mencionados a continuación. Los tubos de plástico, de $4 \mathrm{~cm}$ de altura por $2 \mathrm{~cm}$ de diámetro con tapa a presión, se lavaron con agua y detergente, dejándolos secar al aire en una habitación cerrada. Luego se agruparon 5 frascos por cada bolsa de ampolla de óxido de etileno. Se sometieron a dicho óxido (marca Biolene) durante 24 hs (Figura 13.1). 


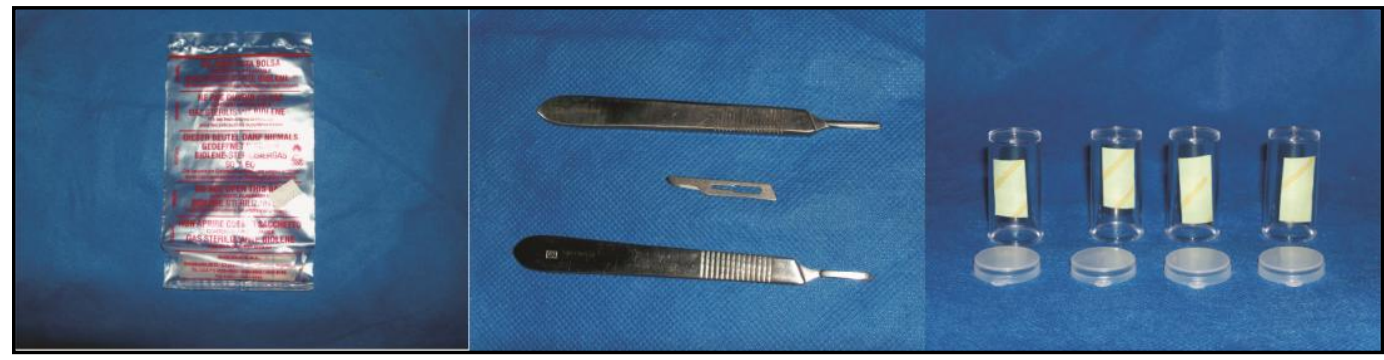

Figura 13.1. Bolsa con ampolla Biomed, hojas y mango de bisturí y frascos con etiqueta de esterilización

Se realizó el raspado in situ del $25 \%$ de la cara activa de cada artefacto analizado. Se tomaron dos muestras separadas, una del sedimento superficial más suelto y otra del más profundo, así como muestras del sedimento asociado a los artefactos. Del artefacto M17PM se obtuvo una muestra in situ mediante el procedimiento antes mencionado, no obstante luego, como pudo ser transportado al laboratorio para su análisis, se realizaron dos raspados (uno en mayor profundidad que otro) sobre cada una de las cinco oquedades de la cara activa. Con una pipeta y agua desmineralizada se depositaron gotas de agua sobre los raspados de dichas oquedades y se succionaron (Figura 13.2). Se repitió el procedimiento para cinco oquedades de la cara no activa del mortero. Se seleccionó la misma cantidad de oquedades a fin de poder comparar cuantitativamente la cantidad de especímenes recuperados y se analizó el sedimento testigo. En los resultados se presenta el análisis sólo del instrumento M17PM que además de haber recuperado una muestra in situ se analizó el instrumento en el laboratorio. Las muestras de los artefactos restantes aún deben ser procesadas en futuros trabajos.

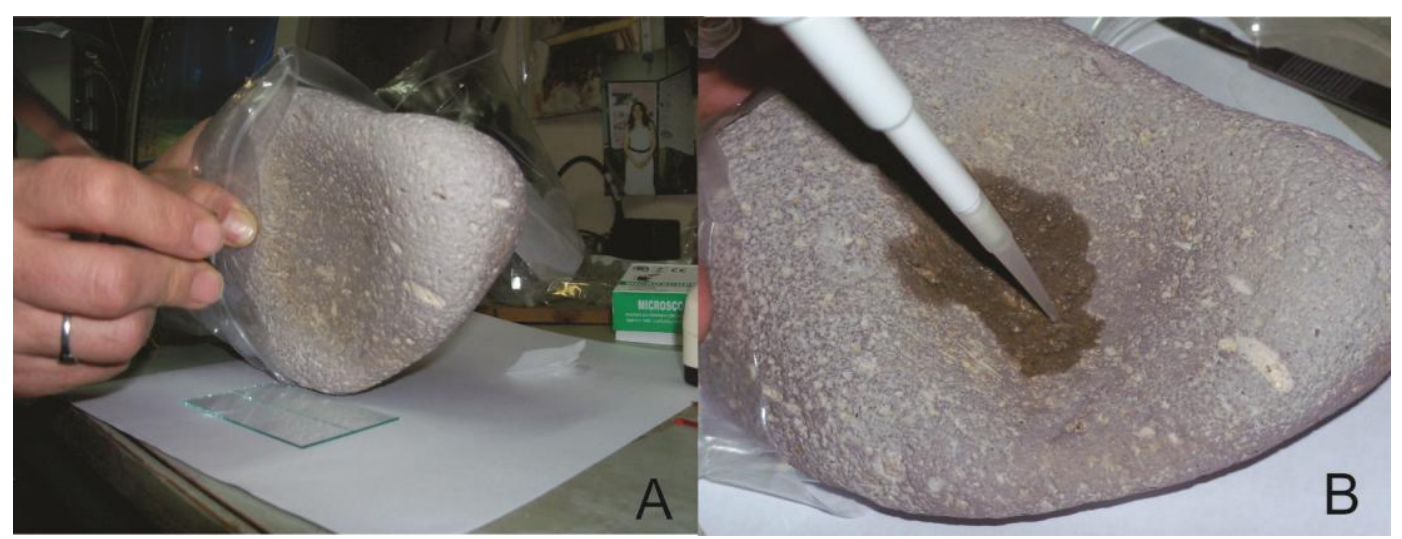

Figura 13.2. A: Raspado sobre los poros del artefacto lítico; B: Se observa la succión mediante pipeta sobre los mismos poros. 
De la colección del Museo del Hombre y su Entorno (Caleta Olivia) se seleccionaron 5 artefactos para su análisis. Como no podían ser trasladados al laboratorio se realizaron solo raspados in situ, en seco como se describió más arriba. Debido a que estos instrumentos provenían de una colección, no había sedimento asociado de control por lo que se colectó sedimento de Monte Loayza para tener una referencia siendo que algunos de ellos provenían de esa localidad. En el laboratorio se montaron las muestras en glicerina-gelatina y se observaron a microscopio óptico de luz incidente. Para la identificación taxonómica de los residuos se utilizó material de referencia depositado en el Laboratorio 1 del Departamento Científico del Museo de La Plata y las muestras histológicas del mismo (capítulo 12).

\subsection{Resultados}

\subsubsection{Revisión bibliográfica de sitios arqueológicos de Patagonia con presencia de artefactos de molienda}

En las 23 publicaciones se registraron los hallazgos de 243 artefactos de molienda, no obstante cabe aclarar que en 29 citas no se especifica la cantidad de los mismos, sólo presencia. Las 23 publicaciones remiten: a 91 sitios arqueológicos, tres colecciones de la Estancia San Román (Castro 2010:257) y una prospección entre Punta Pórfido y Odriozola -donde no se especifica cuantos artefactos de molienda se hallaron- (Borella et al. 2013), todos distribuidos en la Patagonia continental Argentina (Figura 13.3). La mayor cantidad de menciones de artefactos se registró en la zona costera de Chubut, sin embargo, esta frecuencia más alta puede deberse a estudios específicos sobre artefactos de molienda realizados en esta área (i.e. Orlando 2009). Los artefactos se recuperaron en sitios aleros, cuevas, a cielo abierto, concheros, sobre médanos, y en sitios enterratorios, tanto en superficie como en estratigrafía. El fechado más antiguo de esta recopilación es $4880 \pm 130$ AP (Sanguinetti de Bórmida y Curzio 1996) y el más moderno entre el siglo XVI y el año 1891 (Silveira 1996).

En cuanto a la distribución de los artefactos de molienda, la figura 13.3 sugiere una disminución hacia el centro de la Patagonia continental Argentina así como de norte a sur. Sin embargo, como menciona Babot (2004) el análisis de este tipo de artefactos aún 
se encuentra disperso de acuerdo a las áreas de estudio, de modo que es difícil comparar la presencia/ausencia de este instrumental. En el recorte bibliográfico realizado hasta el momento la presencia más al sur de artefactos de molienda se encuentra en la costa del Lago Guitarra (Goñi et al. 2010). Es similar en este sentido a la distribución del registro arqueobotánico cuyo punto más al sur es el sitio Chorrillo Malo 2 al sudeste del Lago Roca (Mehl y Franco 2009). En el 86\% $(n=209)$ de los artefactos registrados no se identificó su materia prima, mientras que el 24\% $(\mathrm{n}=34)$ restante, estuvo manufacturado sobre arenisca el 44,1\% $(\mathrm{n}=15)$, sobre traqueandesita el $29,41 \%(\mathrm{n}=$ $10)$, sobre pórfido el $11,76 \%(\mathrm{n}=4)$, sobre andesita e ignimbrita el 5,9\% $(\mathrm{n}=2), \mathrm{y}$ sobre costilla de cetáceo fósil el 2,9\% $(\mathrm{n}=1)$. De estos instrumentos tres presentaron pigmentos adheridos a la cara activa (Hajduk y Albornoz 1999, Gómez Otero 2006). Sólo siete artefactos fueron analizados desde un enfoque arqueobotánico, en el que los taxones identificados fueron Prosopis sp. L., Zea mays L. y Cucurbitaceae (Lema et al. 2012). 


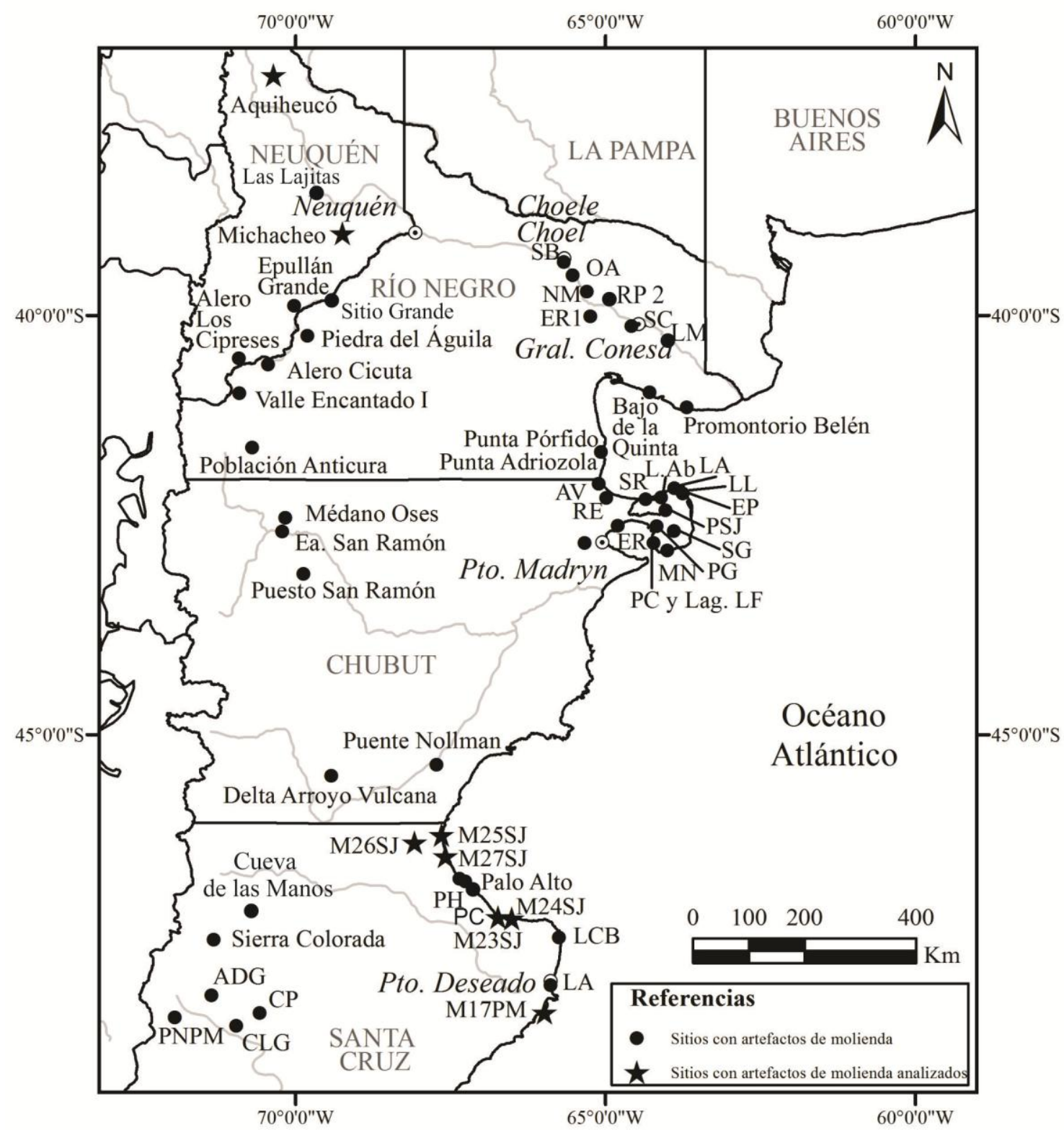

Figura 13.3. . Mapa de sitios con presencia de artefactos de molienda. En el mapa se muestran también los artefactos de molienda analizados en esta tesis.

\subsubsection{Prospección y registro de artefactos potencialmente utilizados para la molienda en CNSC (sector sur de la Ría Deseado).}

A continuación se describen en la Tabla 13.1 los resultados de las prospecciones asistemáticas realizadas en CNSC. Hasta el momento se recorrió el margen sur de la Ría Deseado. Se registraron veinte artefactos potencialmente utilizados para la molienda en 
su mayoría molinos planos (Babot 2004). Todos se recuperaron en superficie y se encontraron asociados a sitios de tipo conchero. Sin embargo, estudios posteriores a dicha prospección por miembros del equipo de CNSC registraron una mayor cantidad de artefactos de molienda para la localidad de Punta Medanosa (Hammond et al. 2013) En esta localidad se encontraron además fragmentos de cerámica, lo que podría sugerir el equipamiento del espacio (Zubimendi 2010).

\begin{tabular}{|c|c|c|c|c|c|c|}
\hline Denominación & $\begin{array}{l}\text { Posición } \\
\text { Geográfica }\end{array}$ & $\begin{array}{l}\text { Localidad } \\
\text { Arqueológica }\end{array}$ & $\begin{array}{l}\text { Tipo de } \\
\text { sitio }\end{array}$ & $\begin{array}{l}\text { Descripción } \\
\text { del artefacto }\end{array}$ & Medidas & $\begin{array}{l}\text { Materia } \\
\text { Prima }\end{array}$ \\
\hline M9PJ & 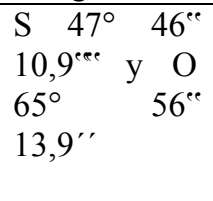 & Puerto Jenkins & $\begin{array}{l}\text { Sitio } \\
\text { Laguna de } \\
\text { los } \\
\text { Chenques. } \\
\text { Superficie }\end{array}$ & $\begin{array}{l}\text { Tipo } \\
\text { mortero con } \\
\text { una pequeña } \\
\text { oquedad. }\end{array}$ & $\begin{array}{lll}25 & \mathrm{x} & 29 \\
\mathrm{~cm} & & \\
\end{array}$ & Ignimbrita \\
\hline M1BA & $\begin{array}{lr}\mathrm{S} \quad 47^{\circ} & 56^{\text {ce }} \\
04,7^{\text {cee }} \text { y } \mathrm{O} & \mathrm{O} \\
65^{\circ} & 47^{\text {ce }} \\
35,5^{\text {ceee }} & \end{array}$ & $\begin{array}{l}\text { Bahía } \\
\text { Azopardo }\end{array}$ & $\begin{array}{l}\text { Sitio } \\
\text { conchero } \\
\text { Los } \\
\text { Albatros. } \\
\text { Superficie }\end{array}$ & $\begin{array}{l}\text { Presenta } \\
\text { estrías de } \\
\text { pulimento } \\
\text { Tipo } \\
\text { morfológico } \\
\text { molino. }\end{array}$ & $\begin{array}{l}29 \times 9 \mathrm{~cm} \\
\text { y } 4 \mathrm{~cm} \mathrm{de} \\
\text { espesor }\end{array}$ & $\begin{array}{l}\text { Pórfido de } \\
\text { color } \\
\text { grisáceo }\end{array}$ \\
\hline M2BA & $\begin{array}{l}\mathrm{S} 47{ }^{\circ} 56^{\text {ee }} \\
03,2^{\text {ecee }} \text { y } \mathrm{O} \\
65^{\circ} 47^{\text {ee }} 33 \text {, } \\
3^{\text {eere }}\end{array}$ & $\begin{array}{l}\text { Bahía } \\
\text { Azopardo }\end{array}$ & $\begin{array}{l}\text { Sitio } \\
\text { conchero } \\
\text { Los } \\
\text { Albatros. } \\
\text { Superficie }\end{array}$ & $\begin{array}{l}\text { Presenta } \\
\text { tiznes de } \\
\text { carbón y una } \\
\text { superficie de } \\
\text { mayor } \\
\text { pulido. Tipo } \\
\text { morfológico } \\
\text { mano }\end{array}$ & $\begin{array}{l}9 \times 9 \mathrm{~cm} \\
\text { y } 3 \mathrm{~cm} \mathrm{de} \\
\text { espesor }\end{array}$ & Pórfido \\
\hline M3BA & $\begin{array}{l}\mathrm{S} 47^{\circ} 56^{\text {ee }} \\
04,8^{\text {eee }} \text { y } O \\
65^{\circ} 47^{\text {ee }} 35, \\
7^{\text {eree }}\end{array}$ & $\begin{array}{l}\text { Bahía } \\
\text { Azopardo }\end{array}$ & $\begin{array}{l}\text { Sitio } \\
\text { conchero } \\
\text { Los } \\
\text { Albatros. } \\
\text { Superficie }\end{array}$ & $\begin{array}{l}\text { Presenta un } \\
\text { precipitado } \\
\text { blanco como } \\
\text { de carbonato } \\
\text { de calcio. } \\
\text { Mano }\end{array}$ & $\begin{array}{l}12 \times 9 \mathrm{~cm} \\
\text { y } 3 \mathrm{~cm} \mathrm{de} \\
\text { espesor }\end{array}$ & $\begin{array}{l}\text { Pórfido } \\
\text { rosado }\end{array}$ \\
\hline M4BA & 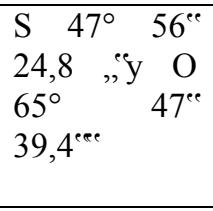 & $\begin{array}{l}\text { Costa sur de la } \\
\text { Punta } \\
\text { Azopardo }\end{array}$ & $\begin{array}{l}\text { Sitio } \\
\text { conchero } \\
\text { de gran } \\
\text { extensión. } \\
\text { Superficie }\end{array}$ & $\begin{array}{l}\text { Tipo } \\
\text { morfológico } \\
\text { molino } \\
\text { plano }\end{array}$ & $\begin{array}{l}9 \times 7 \text { y } 2 \\
\mathrm{~cm} \text { de } \\
\text { espesor. }\end{array}$ & $\begin{array}{l}\text { Pórfido de } \\
\text { coloración } \\
\text { rojiza }\end{array}$ \\
\hline M5BA & $\begin{array}{lr}\mathrm{S} \quad 47^{\circ} & 56^{\text {ee }} \\
25,7^{\text {ere }} \text { y } \mathrm{O} \\
65^{\circ} & 47^{\text {cee }} \\
38,7^{\text {ere }} & \end{array}$ & $\begin{array}{l}\text { Costa sur de la } \\
\text { Punta } \\
\text { Azopardo }\end{array}$ & $\begin{array}{l}\text { Sitio } \\
\text { conchero. } \\
\text { Superficie }\end{array}$ & Tipo molino & $\begin{array}{l}12 \times 6 \mathrm{~cm} \\
\text { y } 2 \mathrm{~cm} \mathrm{de} \\
\text { espesor }\end{array}$ & $\begin{array}{l}\text { Toba- } \\
\text { pizarra }\end{array}$ \\
\hline M8IL & $\begin{array}{l}\mathrm{S} \quad 47^{\circ} 56^{\text {ce }} \\
16,09^{\text {ere }} \text { y O } \\
65^{\circ} 52^{\text {ce }} 02^{\text {ceee }}\end{array}$ & Isla Lobos & $\begin{array}{l}\text { Sitio } \\
\text { conchero. } \\
\text { Superficie }\end{array}$ & $\begin{array}{l}\text { Tipo molino, } \\
\text { con estrías } \\
\text { de } \\
\text { coloración } \\
\text { claras }\end{array}$ & $\begin{array}{l}30 \text { x } \\
15 \mathrm{~cm} \text { y } 3 \\
\mathrm{~cm} \text { de } \\
\text { espesor }\end{array}$ & $\begin{array}{l}\text { Toba- } \\
\text { Pizarra gris } \\
\text { oscura }\end{array}$ \\
\hline M10PM & $\begin{array}{l}\mathrm{S} 48^{\circ} \quad 05^{\text {ce }} \\
32,8 \text { ״e } \mathrm{y} 0 \\
65^{\circ} 54^{\text {ee }} 35,8 \\
\text { „e. }\end{array}$ & $\begin{array}{l}\text { Punta } \\
\text { Medanosa }\end{array}$ & $\begin{array}{l}\text { Sitio } \\
\text { conchero } \\
\text { extenso. } \\
\text { Superficie }\end{array}$ & $\begin{array}{l}\text { Presenta } \\
\text { tiznes } \\
\text { oscuros. } \\
\text { Tipo molino }\end{array}$ & $\begin{array}{lrr}16 & \mathrm{x} & 10 \\
\mathrm{~cm} & \mathrm{y} & 2 \\
\mathrm{~cm} & & \mathrm{de} \\
\text { espesor } & \end{array}$ & Pórfido \\
\hline
\end{tabular}




\begin{tabular}{|c|c|c|c|c|c|c|}
\hline M11PM & $\begin{array}{l}\mathrm{S} 48^{\circ} 05^{\text {ce }} \\
29^{\text {eree }} \text { y } \mathrm{O} 65^{\circ} \\
54^{\text {ee }} 37,9^{\text {eree }}\end{array}$ & $\begin{array}{l}\text { Punta } \\
\text { Medanosa }\end{array}$ & $\begin{array}{l}\text { Sitio } \\
\text { conchero. } \\
\text { Superifice }\end{array}$ & $\begin{array}{l}\text { Presenta } \\
\text { estrías y } \\
\text { poros sobre } \\
\text { una de sus } \\
\text { caras. Mano }\end{array}$ & $\begin{array}{lrr}12,5 & \mathrm{x} & 10 \\
\mathrm{~cm} & \mathrm{x} & 4 \\
\mathrm{~cm} & \mathrm{de} \\
\text { espesor. }\end{array}$ & Riolita \\
\hline M12PM & $\begin{array}{l}\mathrm{S} 48^{\circ} 05^{\text {ce }} \\
16^{\text {ere }} \text { y } \mathrm{O} 65^{\circ} \\
54^{\text {ee }} 45,5^{\text {ece }}\end{array}$ & $\begin{array}{l}\text { Punta } \\
\text { Medanosa }\end{array}$ & $\begin{array}{l}\text { Sitio } \\
\text { conchero. } \\
\text { Superficie }\end{array}$ & $\begin{array}{l}\text { Un lado muy } \\
\text { pulido }\end{array}$ & $\begin{array}{lrr}21 & \mathrm{x} & 14 \\
\mathrm{~cm} & \mathrm{y} & 1 \\
\mathrm{~cm} & \mathrm{de} \\
\text { espesor } & \end{array}$ & Toba \\
\hline M13 PM & $\begin{array}{l}\mathrm{S} 48^{\circ} 05^{\text {ce }} \\
13^{\text {ece }} \text { y } \mathrm{O} 65^{\circ} \\
54^{\text {ee }} 53,5^{\text {cee }}\end{array}$ & $\begin{array}{l}\text { Punta } \\
\text { Medanosa }\end{array}$ & $\begin{array}{l}\text { Sitio } \\
\text { conchero. } \\
\text { Superficie }\end{array}$ & $\begin{array}{l}\text { También } \\
\text { posible } \\
\text { yunque. } \\
\text { Estrías. } \\
\text { Molino }\end{array}$ & $\begin{array}{l}17,5 \mathrm{x} 17 \\
\text { y } 2 \mathrm{~cm} \mathrm{de} \\
\text { espesor }\end{array}$ & Riolita \\
\hline M14PM & 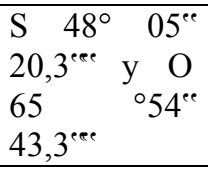 & $\begin{array}{l}\text { Punta } \\
\text { Medanosa }\end{array}$ & $\begin{array}{l}\text { Sitio } \\
\text { conchero, } \\
\text { superficie. }\end{array}$ & $\begin{array}{l}\text { Porosa. } \\
\text { Molino }\end{array}$ & $\begin{array}{lrr}13,5 & \mathrm{x} & 11 \\
\mathrm{~cm} & \mathrm{y} & 3 \\
\mathrm{~cm} & \mathrm{de} \\
\text { espesor } & \end{array}$ & Riolita \\
\hline M15PM & $\begin{array}{l}\mathrm{S} 48^{\circ} \quad 05^{\text {ce }} \\
01,2^{\text {cere }} \text { y } \mathrm{O} \\
65 \quad \circ 5^{\text {ce }} \\
17,5^{\text {ere }}\end{array}$ & $\begin{array}{l}\text { Punta } \\
\text { Medanosa }\end{array}$ & $\begin{array}{l}\text { Sitio } \\
\text { conchero, } \\
\text { superficie }\end{array}$ & $\begin{array}{l}\text { Estrías, } \\
\text { negativos en } \\
\text { el borde de } \\
\text { la pieza. } \\
\text { Molino }\end{array}$ & 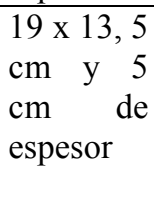 & Riolita \\
\hline M16PM & $\begin{array}{l}\mathrm{S} 48^{\circ} 04^{\text {ce }} \\
52^{\text {ece }} \text { y } 05^{\circ} \\
55^{\text {ee }} 40,6^{\text {ece }}\end{array}$ & $\begin{array}{l}\text { Punta } \\
\text { Medanosa }\end{array}$ & $\begin{array}{l}\text { Sitio } \\
\text { conchero. } \\
\text { Superficie }\end{array}$ & $\begin{array}{l}\text { Tiene un } \\
\text { precipitado } \\
\text { como de } \\
\text { carbonato de } \\
\text { calcio. Mano }\end{array}$ & 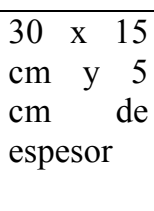 & Ignimbrita \\
\hline M17PM & $\begin{array}{lr}\mathrm{S} \quad 48^{\circ} & 04^{\text {ce }} \\
52,6^{\text {ere }} & \text { y } \mathrm{O} \\
65^{\circ} & 55^{\text {ce }} \\
47,7^{\text {cere }} & \end{array}$ & $\begin{array}{l}\text { Punta } \\
\text { Medanosa }\end{array}$ & $\begin{array}{l}\text { Sitio } \\
\text { conchero. } \\
\text { Superficie }\end{array}$ & $\begin{array}{l}\text { Tiene una } \\
\text { depresión } \\
\text { con una } \\
\text { coloración } \\
\text { activa. } \\
\text { Mortero }\end{array}$ & $\begin{array}{lrr}19 & \text { x } & 15 \\
\mathrm{~cm} & \mathrm{y} & 5 \\
\mathrm{~cm} & & \mathrm{de} \\
\text { espesor } & \end{array}$ & $\begin{array}{l}\text { Pórfido } \\
\text { color gris } \\
\text { verdoso }\end{array}$ \\
\hline M18PM & $\begin{array}{lr}\mathrm{S} \quad 48^{\circ} & 04^{\text {ee }} \\
30,6^{\text {cere }} & \text { y } \mathrm{O} \\
65^{\circ} & 57^{\text {ce }} \\
00,0^{\text {cere }} & \end{array}$ & $\begin{array}{l}\text { Punta } \\
\text { Medanosa }\end{array}$ & $\begin{array}{l}\text { Sitio } \\
\text { conchero. } \\
\text { Superficie }\end{array}$ & $\begin{array}{l}\text { Manchas } \\
\text { blancas } \\
\text { como de } \\
\text { carbonato y } \\
\text { rojizas. } \\
\text { Molino } \\
\end{array}$ & \begin{tabular}{lrr}
22 & $\mathrm{x}$ & 12 \\
$\mathrm{~cm}$ & $\mathrm{y}$ & 2 \\
$\mathrm{~cm}$ & & $\mathrm{de}$ \\
\multicolumn{2}{l}{ espesor }
\end{tabular} & Pórfido. \\
\hline M19PM & $\begin{array}{lr}\mathrm{S} \quad 48^{\circ} & 04^{\text {ee }} \\
38,9^{\text {cere }} & \text { y } \mathrm{O} \\
65^{\circ} & 57^{\text {ce }} \\
01,9^{\text {cere }} & \end{array}$ & $\begin{array}{l}\text { Punta } \\
\text { Medanosa }\end{array}$ & $\begin{array}{l}\text { Sitio } \\
\text { conchero } \\
\text { Superficie }\end{array}$ & $\begin{array}{l}\text { Mancha } \\
\text { blanca de } \\
\text { carbonato. } \\
\text { Molino }\end{array}$ & $\begin{array}{lrr}16 & \mathrm{x} & 12 \\
\mathrm{~cm} & \mathrm{y} & 1 \\
\mathrm{~cm} & \mathrm{de} \\
\text { espesor }\end{array}$ & Pórfido \\
\hline M20PM & $\begin{array}{lr}\mathrm{S} \quad 48^{\circ} & 04^{\text {ce }} \\
51,8^{\text {cere }} \text { y } \mathrm{O} \\
65^{\circ} & 55^{\text {ce }} \\
42,8^{\text {eree }} & \end{array}$ & $\begin{array}{l}\text { Punta } \\
\text { Medanosa }\end{array}$ & $\begin{array}{l}\text { Sitio } \\
\text { conchero } \\
\text { Médano 1 }\end{array}$ & $\begin{array}{ll}\text { Poroso } & \text { con } \\
\text { una leve } & \text { lepresión. } \\
\text { Molino }\end{array}$ & $\begin{array}{lrr}18 & \text { x } & 15 \\
\mathrm{~cm} & \mathrm{y} & 5 \\
\mathrm{~cm} & & \mathrm{de} \\
\text { espesor } & \end{array}$ & $\begin{array}{l}\text { Pórfido } \\
\text { blanco. }\end{array}$ \\
\hline M21PM & $\begin{array}{l}\mathrm{S} 48 \quad 04^{\text {ee }} \\
59^{\text {ece }} \text { y } \mathrm{O} 65^{\circ} \\
55^{\text {ee }} 29,7^{\text {eree }}\end{array}$ & $\begin{array}{l}\text { Punta } \\
\text { Medanosa }\end{array}$ & $\begin{array}{l}\text { Sitio } \\
\text { conchero } \\
\text { Superficie }\end{array}$ & $\begin{array}{l}\text { Molino } \\
\text { plano }\end{array}$ & $\begin{array}{l}10 \times 8 \mathrm{~cm} \\
\text { y } 3 \mathrm{~cm} \mathrm{de} \\
\text { espesor }\end{array}$ & Pórfido \\
\hline M22PM & $\begin{array}{lr}\mathrm{S} \quad 48^{\circ} & 04^{\text {ce }} \\
50,1^{\text {cere }} & \text { y } \mathrm{O} \\
65^{\circ} & 55^{\text {ce }} \\
41,3^{\text {ere }} & \end{array}$ & $\begin{array}{l}\text { Punta } \\
\text { Medanosa }\end{array}$ & $\begin{array}{l}\text { Sitio } \\
\text { conchero }\end{array}$ & $\begin{array}{l}\text { Mano o } \\
\text { sobador, } \\
\text { muy pulido } \\
\text { sobre una de } \\
\text { sus caras }\end{array}$ & $\begin{array}{l}11,6 \quad \mathrm{x} \\
11,6 \mathrm{~cm} \mathrm{y} \\
6 \mathrm{~cm} \mathrm{de} \\
\text { espesor }\end{array}$ & Pórfido \\
\hline
\end{tabular}

Tabla 13.1. Artefactos potencialmente utilizados en la molienda analizados en esta tesis. 


\subsubsection{Registro y análisis de instrumentos de la colección Museo del Hombre y su Entorno (Caleta Olivia)}

Se registraron cinco artefactos de molienda donados al Museo por particulares durante los últimos 25 años (Gribaudo com. pers.), se tomaron las muestras y se registró su procedencia en los casos en que fue posible (Tabla 13.2). Si bien es importante mencionar la posibilidad de contaminación de estos artefactos, la observación del lugar de depósito y los controles metodológicos justificaron la realización del estudio.

\begin{tabular}{|c|c|c|c|c|c|c|}
\hline Denominación & $\begin{array}{l}\text { Posición } \\
\text { Geográfica }\end{array}$ & $\begin{array}{l}\text { Localidad } \\
\text { Arqueológica }\end{array}$ & $\begin{array}{l}\text { Tipo } \\
\text { de sitio }\end{array}$ & $\begin{array}{l}\text { Descripción } \\
\text { del artefacto }\end{array}$ & Medidas & $\begin{array}{l}\text { Materia } \\
\text { Prima }\end{array}$ \\
\hline M23SJ & $\begin{array}{l}\text { Colección } \\
\text { MHT }\end{array}$ & Monte Loayza & $\begin{array}{l}\text { No hay } \\
\text { datos }\end{array}$ & $\begin{array}{l}\text { Molino, una } \\
\text { cara pulida }\end{array}$ & $\begin{array}{l}25 \text { x } 18 \\
\mathrm{~cm} \text { y } 3 \mathrm{~cm} \\
\text { de espesor }\end{array}$ & Arenisca \\
\hline M24SJ & $\begin{array}{l}\text { Colección } \\
\text { MHT }\end{array}$ & Monte Loayza & $\begin{array}{l}\text { No hay } \\
\text { datos }\end{array}$ & Mano & $\begin{array}{l}14 \times 9 \mathrm{~cm} \\
\text { y } 4 \mathrm{~cm} \mathrm{de} \\
\text { espesor }\end{array}$ & $\begin{array}{l}\text { Pórfido } \\
\text { blanco }\end{array}$ \\
\hline M25SJ & $\begin{array}{l}\text { Colección } \\
\text { MHT }\end{array}$ & Bahía Lángara & $\begin{array}{l}\text { No hay } \\
\text { datos }\end{array}$ & $\begin{array}{l}\text { Molino, pulido } \\
\text { en una cara } \\
\text { con marcas } \\
\text { transversales. }\end{array}$ & $\begin{array}{l}14,5 \text { x } 10 \\
\text { y } 3 \mathrm{~cm} \mathrm{de} \\
\text { espesor }\end{array}$ & Arenisca \\
\hline M26SJ & $\begin{array}{l}\text { Colección } \\
\text { MHT }\end{array}$ & Bahía Lángara & $\begin{array}{l}\text { No hay } \\
\text { datos }\end{array}$ & $\begin{array}{ll}\text { Mano } & \text { de } \\
\text { molino. } & \\
\text { Asociado } & \text { a } \\
\text { base de } 60 & \mathrm{x} \\
30 \mathrm{~cm} & \\
\end{array}$ & $\begin{array}{l}17 \text { x } 12 \\
\mathrm{~cm} \text { y } 3 \mathrm{~cm} \\
\text { de espesor }\end{array}$ & Arenisca \\
\hline M27SJ & $\begin{array}{l}\text { Colección } \\
\text { MHT }\end{array}$ & Bahía Lángara & $\begin{array}{l}\text { No hay } \\
\text { datos }\end{array}$ & $\begin{array}{l}\text { Molino plano, } \\
\text { muy pulido en } \\
\text { una de sus } \\
\text { caras }\end{array}$ & $\begin{array}{l}19 \text { x } 15 \\
\mathrm{~cm} \text { y } 4 \mathrm{~cm} \\
\text { de espesor }\end{array}$ & Arenisca \\
\hline
\end{tabular}

Tabla 13.2. Artefactos de la Colección Museo del hombre y su Entorno, potencialmente utilizados en la molienda y analizados en esta tesis

\subsubsection{Recuperación de microrrestos a partir de adherencias de artefactos de CNSC}

\subsubsection{Instrumento M17PM}


Como se mencionó más arriba (Tabla 13.1) este instrumento se hallaba próximo al sitio conchero Médano 1, si bien se encontraba en superficie es relevante mencionar que dicho sitio presenta tres fechados radiocarbónicos: uno sobre carbón vegetal proveniente del fogón 1 de $6300 \pm 90$ AP (LP-1544), otro sobre carbones del fogón 2, $2390 \pm 90$ AP (LP 1536), y el último del sondeo 167 también realizado sobre carbón vegetal que tuvo como resultado $2140 \pm 60$ años AP (Zubimendi et al. 2009, Castro et al. 2011; Hammond y Zubimendi 2013).

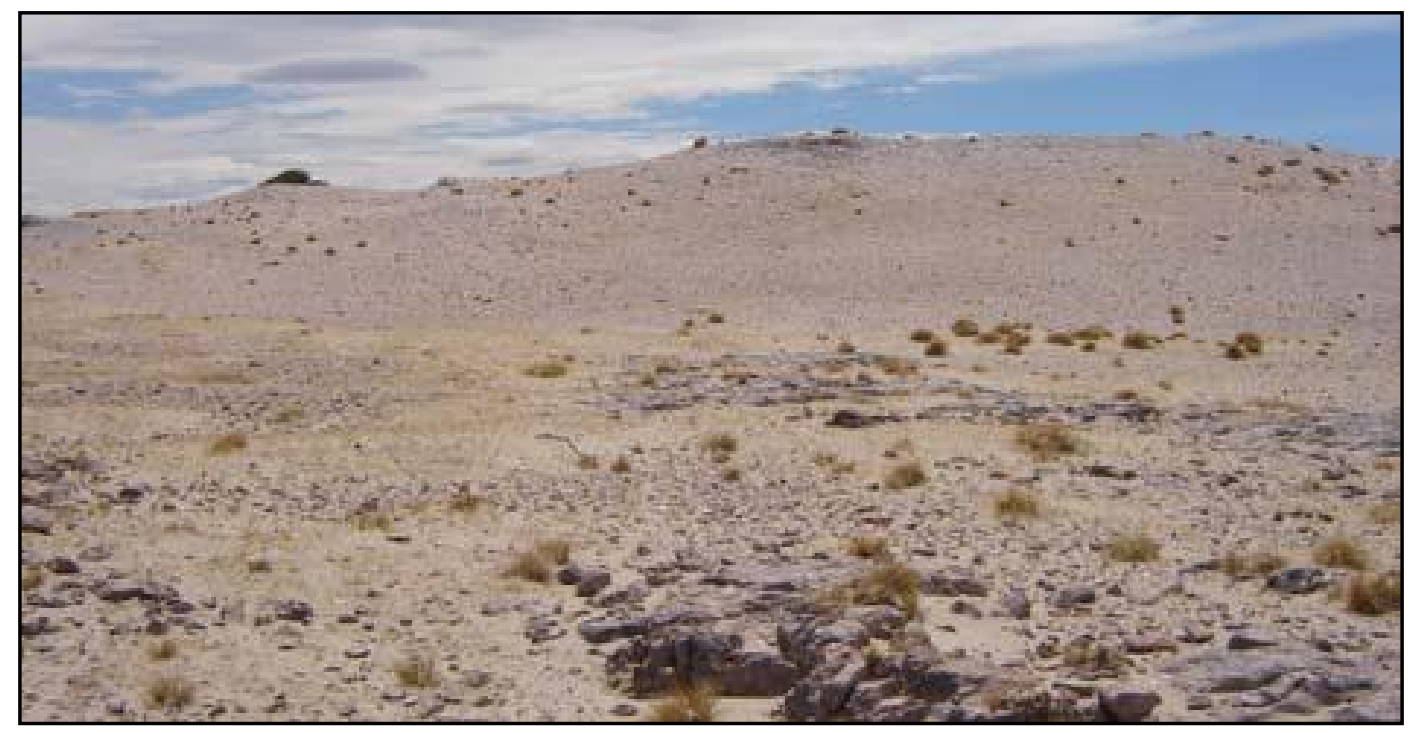

Figura 13.4. Sitio Médano 1, conchero en médano (Foto de H. Hammond)

En el sector por fuera de la paleoplaya, hacia el interior, se observan arbustos de Schinus sp, subarbustos de Senecio sp, Adesmia boronioides, entre otros. Como se mencionó en el capítulo Área de Estudio, este es el punto más austral donde, de acuerdo a Oliva y colaboradores (2001) llega la estepa arbustiva del Golfo San Jorge. Es importante reiterar las condiciones climáticas del sector, porque se retomará en la discusión, que presenta precipitaciones anuales que no llegan a los $200 \mathrm{~mm}$. 


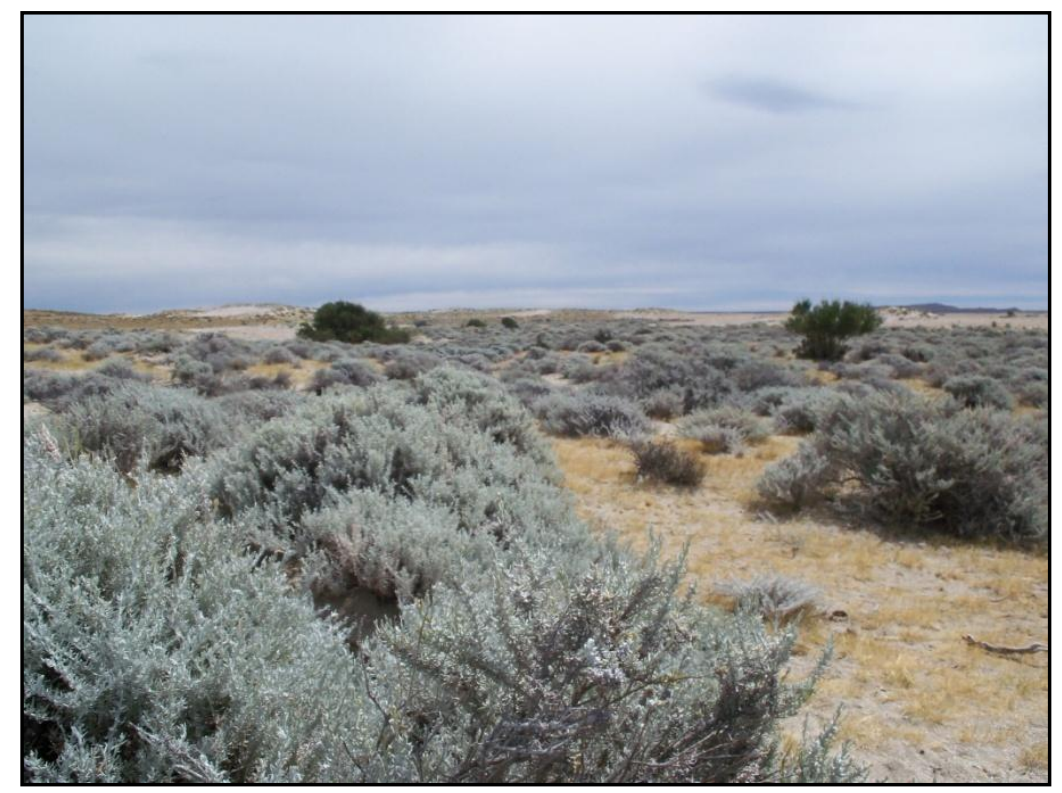

Figura 13.5. Vegetación por detrás de la línea de concheros y costa, en Punta Medanosa

El artefacto de morfología molino está manufacturado a partir de un pórfiro verdoso y poroso. Tiene una cara activa con una oquedad, pulida con manchas de coloración marrón. En la Figura 13.6 se observa que se encuentra en superficie y alrededor tiene una Poaceae.

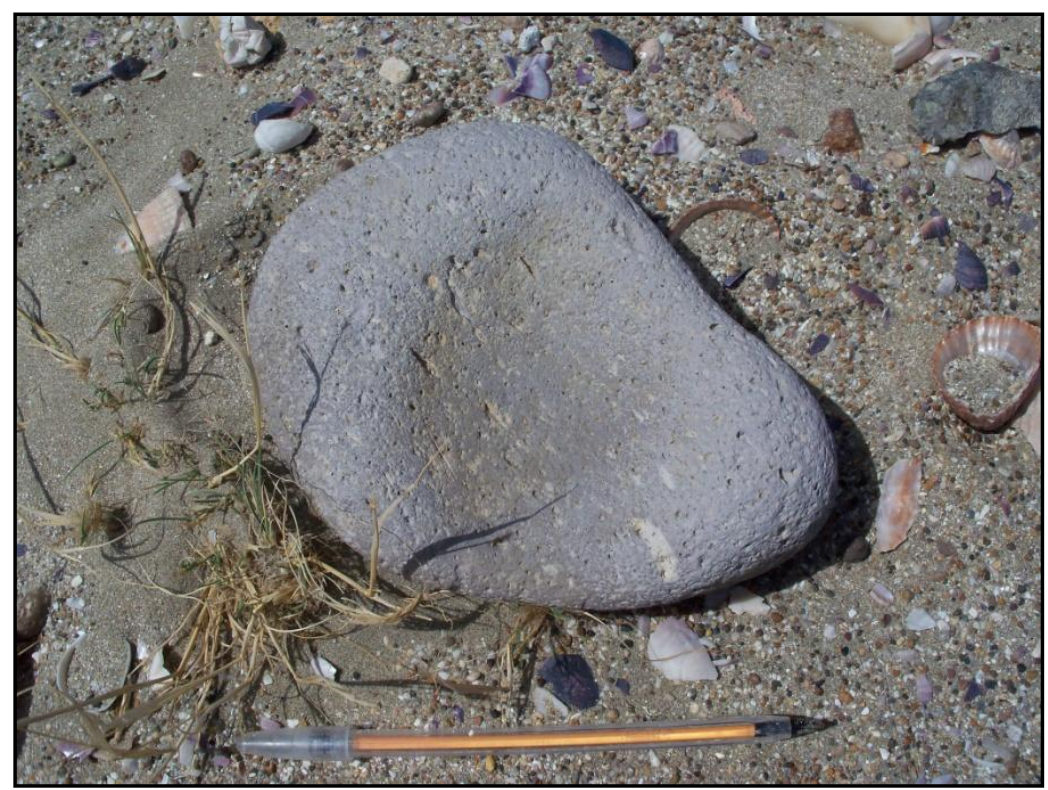

Figura 13.6. Instrumento de molienda M17PM 


\subsubsection{Resultados del instrumento M17PM}

En el raspado realizado in situ no se registraron residuos vegetales. Sin embargo, en los dos raspados por cada una de las cinco oquedades, uno en mayor profundidad que el otro, sí se recuperaron restos de tejido y células vegetales. Como se observa en la Figura 13.7 se registraron elementos de vaso, uno de ellos con las paredes celulares rotas y desgarrado. También se observaron fibras libriformes con los extremos rotos, tejido xilemático compuesto de parénquima, fibras y un elemento de vaso. Por otra parte, se recuperó un fragmento de tejido epidérmico con un aparato estomático anomocítico, en el que los estomas se encuentran al mismo nivel que las células epidérmicas (Figura 13.8 A y B). Se observó una alta densidad de estomas por superficie. A su vez, se identificaron tricomas: pelos unicelulares de cutícula verrucosa, desprendidos del tejido epidérmico por lo que no se pudo registrar la forma de la base y corpúsculos de resina. Por último, un grano de almidón esférico con cruz de polarización central (Figura 13.8). 


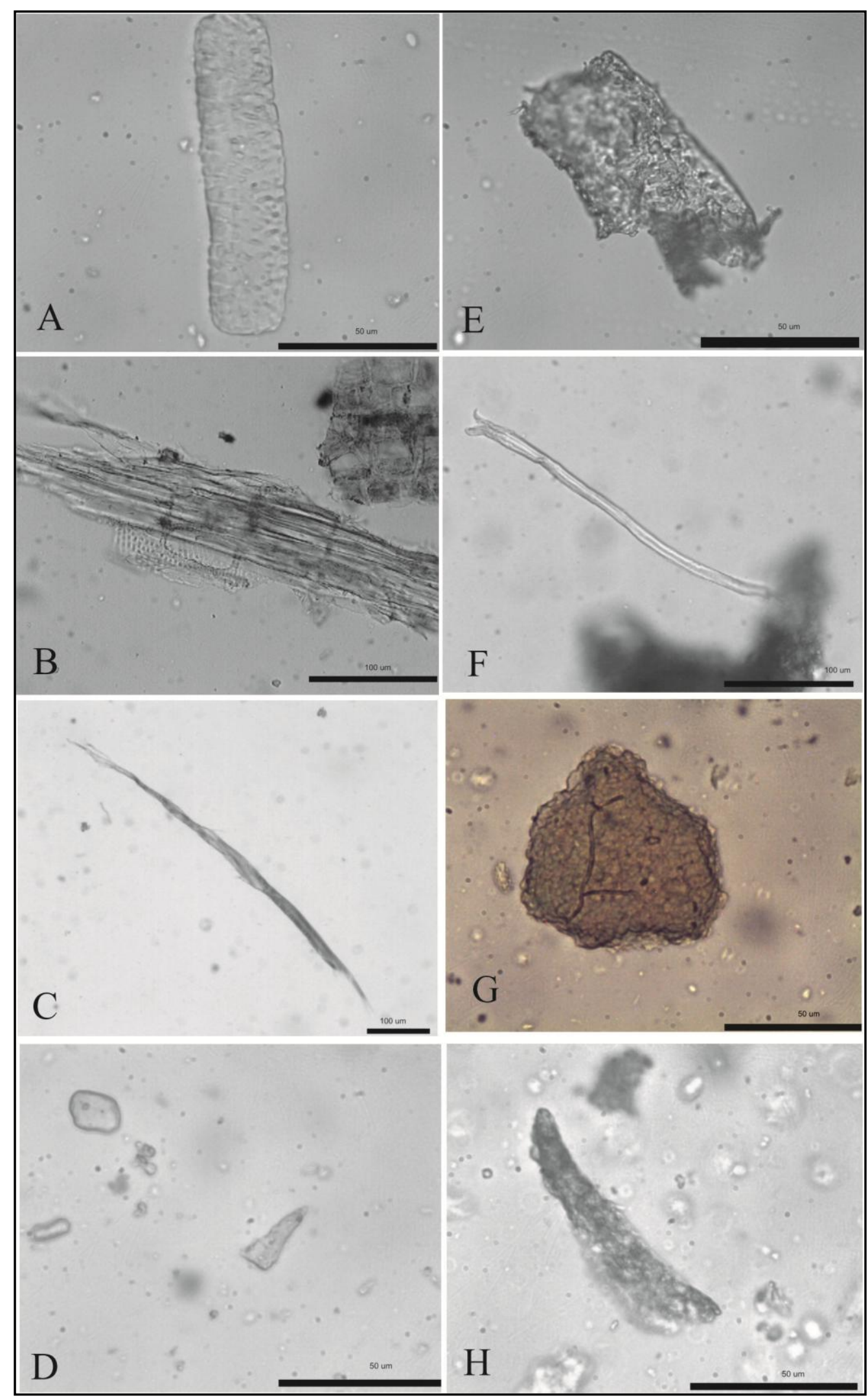

Figura 13.7.A, Elementos de vaso; B, tejido xilemático, C, fibras, D, pelo liso, E, elemento de vaso con huellas tecnológicas (roturas) F, fibras, $\mathrm{G}$, corpúsculos de resina, $\mathrm{H}$, pelo verrucoso recuperados en el primer y segundo raspado en laboratorio 


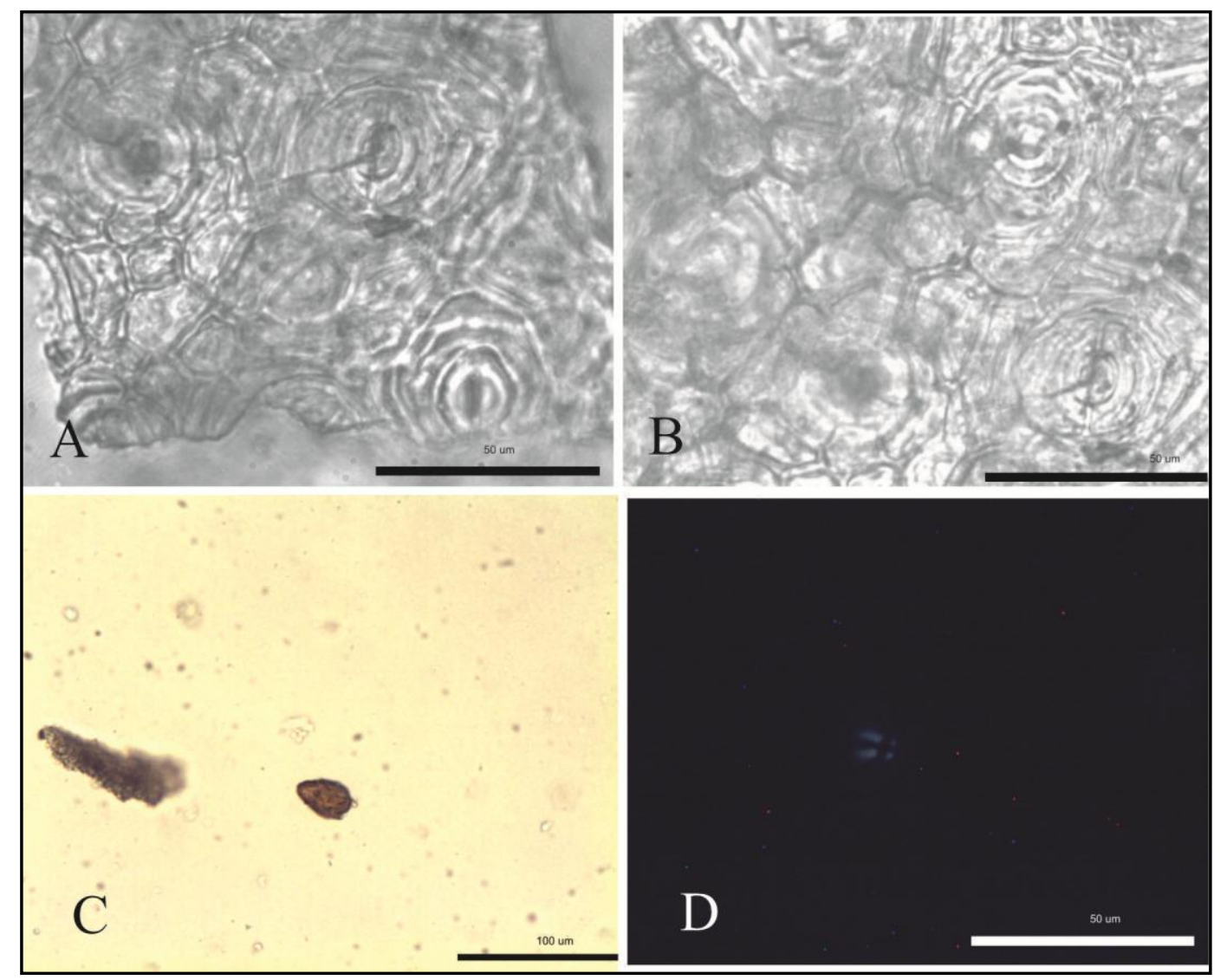

Figura 13.8. A y B, tejido epidérmico, C, tricomas y corpúsculos de resina y D, grano de almidón

En la muestra extraída mediante pipeta se recuperó tejido parénquimático y un elemento de vaso, fibrotraqueidas y fibras libriformes, un pelo epidérmico de cutícula lisa, unicelular y corpúsculos de resina (Figura13.9). También se registró un grano de almidón regular con hilium central. Es importante mencionar que las fibras y elementos de vasos recuperados en el raspado presentaron características de deterioro de las paredes celulares y fracturas que podrían atribuirse al procesamiento tecnológico (Cueto et al. 2010, Figura 13.10). 


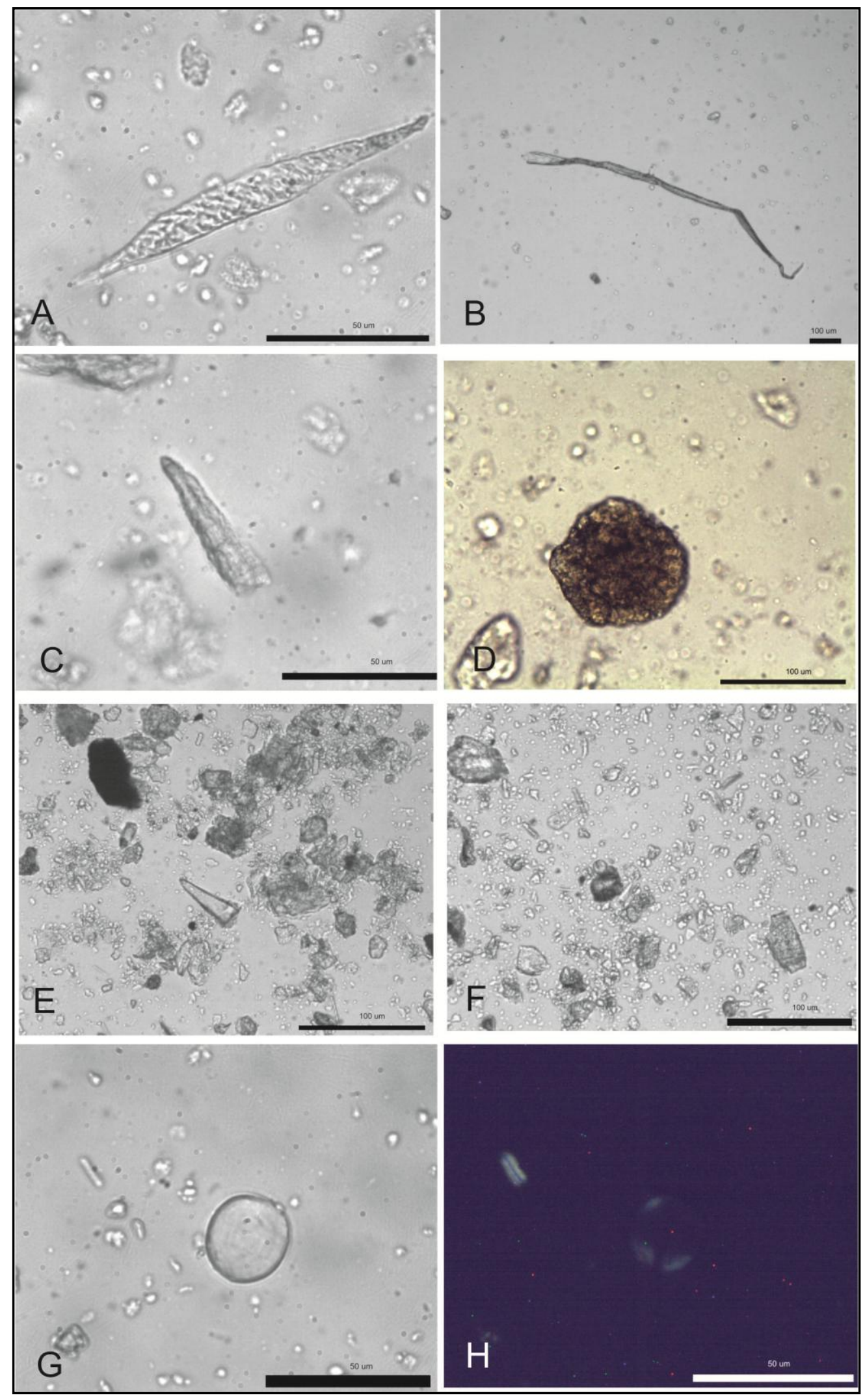

Figura 13.9. Microrrestos recuperados con pipeta A, esclereida B, fibra C, pelo unicelular rugoso D, corpúsculo de resina $\mathrm{E}$, pelo unicelular liso $\mathrm{F}$, elemento de vaso degradado $\mathrm{G}$ y $\mathrm{H}$ grano de almidón con y sin polarizar. 


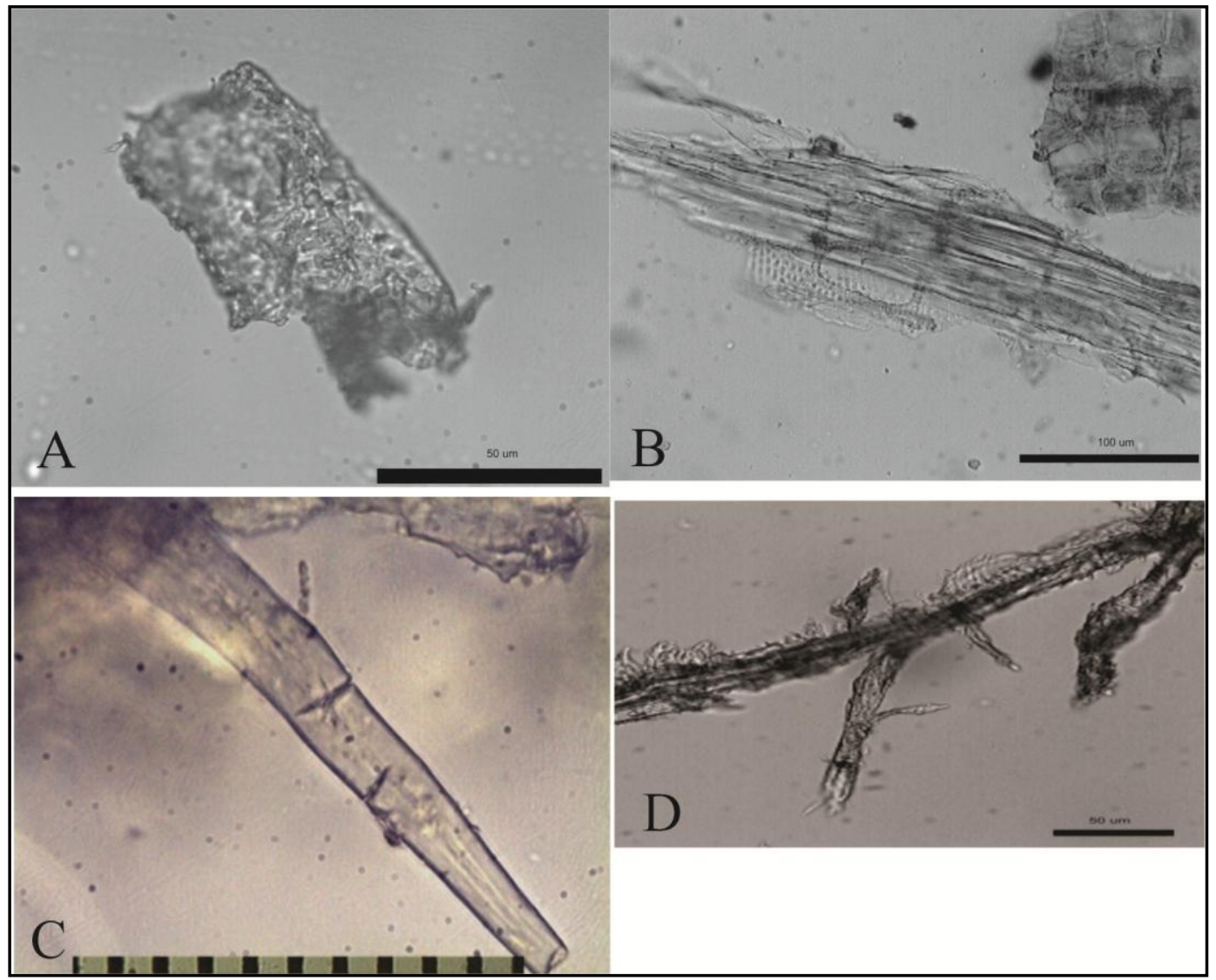

Figura 13.10. A y B: tejido xilemático recuperado en artefacto M17PM con desgarros y fracturas; C: pelo de Maytenus chubutensis con rasgos de corte producto del molido experimental; D: tejido xilemático con desgarros producto de trabajo experimental con denticulado (Cueto et al. 2010).

Dentro de los elementos de origen no vegetal que se recuperaron se observó un fragmento de valva pequeño, y un foraminífero del género Elphidium sp (Melina Márquez com. personal, Figura 13.11) 


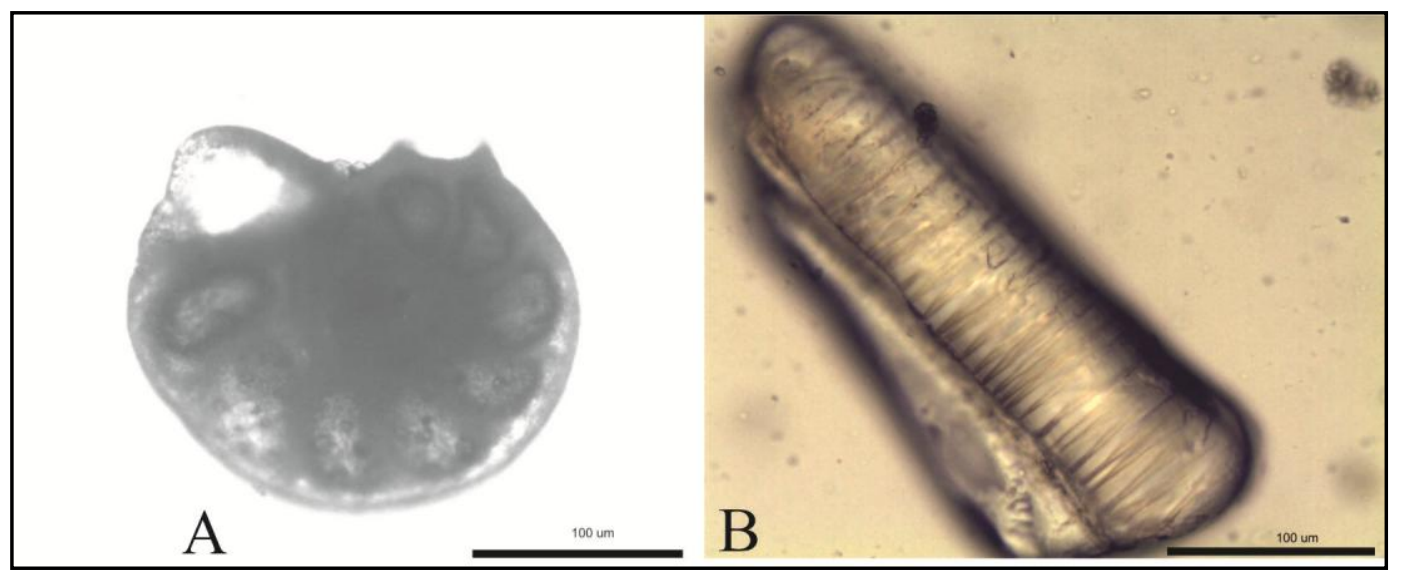

Figura 13.11. Materiales no vegetales recuperados en el raspado del mortero, A, foraminífero; B fragmento de valva

De la extracción mediante raspado en el laboratorio de las cinco oquedades de la cara no activa se recuperó un pelo vegetal de cutícula lisa, no se observa la base, una célula pétrea y un elemento de vaso. De la muestra extraída mediante pipeta sólo se obtuvo un elemento de vasos (Figura13.12). Del sedimento testigo, es decir, ubicado alrededor del mortero no se recuperaron restos vegetales (Figura 13.13).

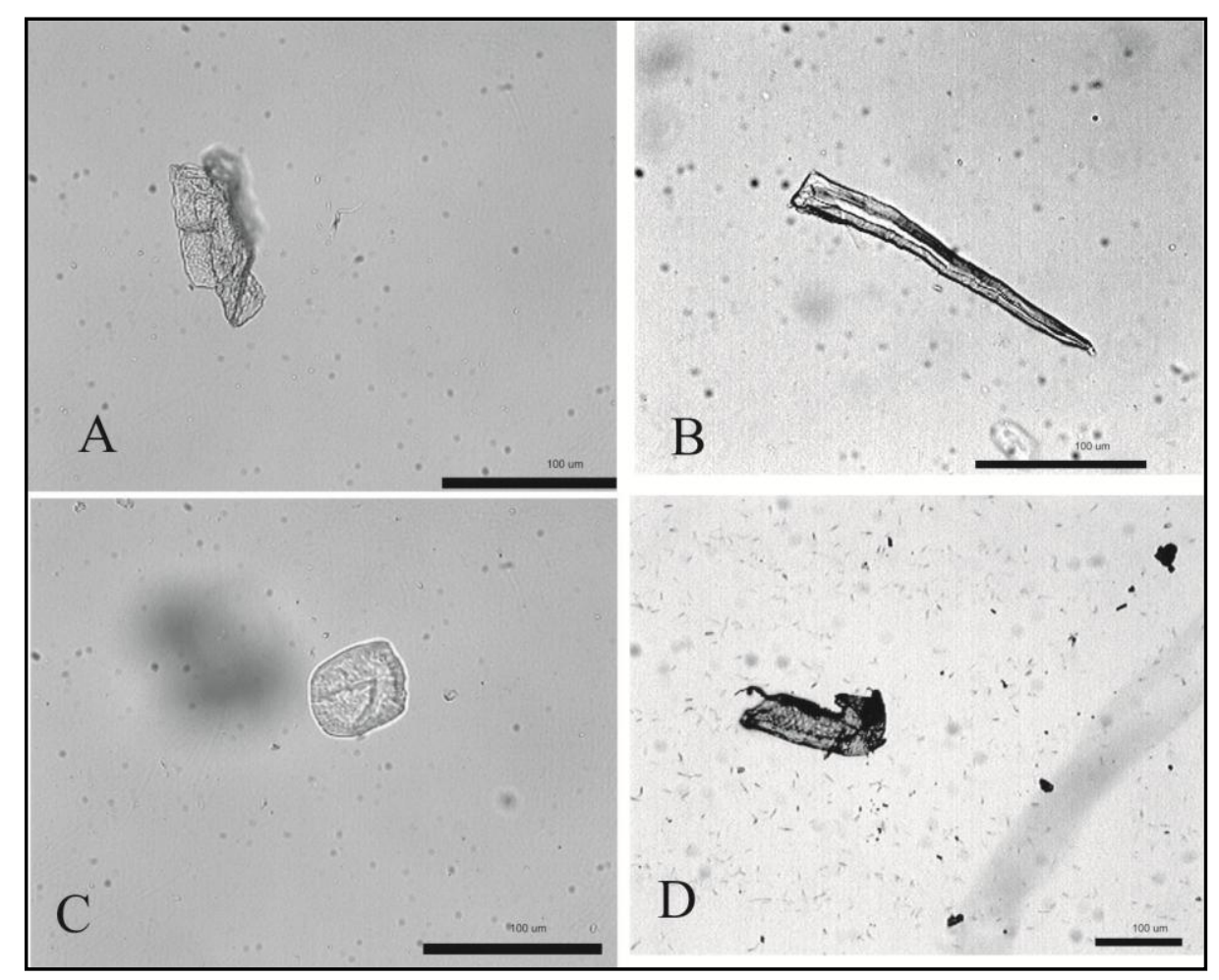

Figura 13.12. Cara no activa: A y B elemento de vaso y tricoma recuperados en los raspados; C y D célula pétrea y elemento de vaso recuperado con pipeta 


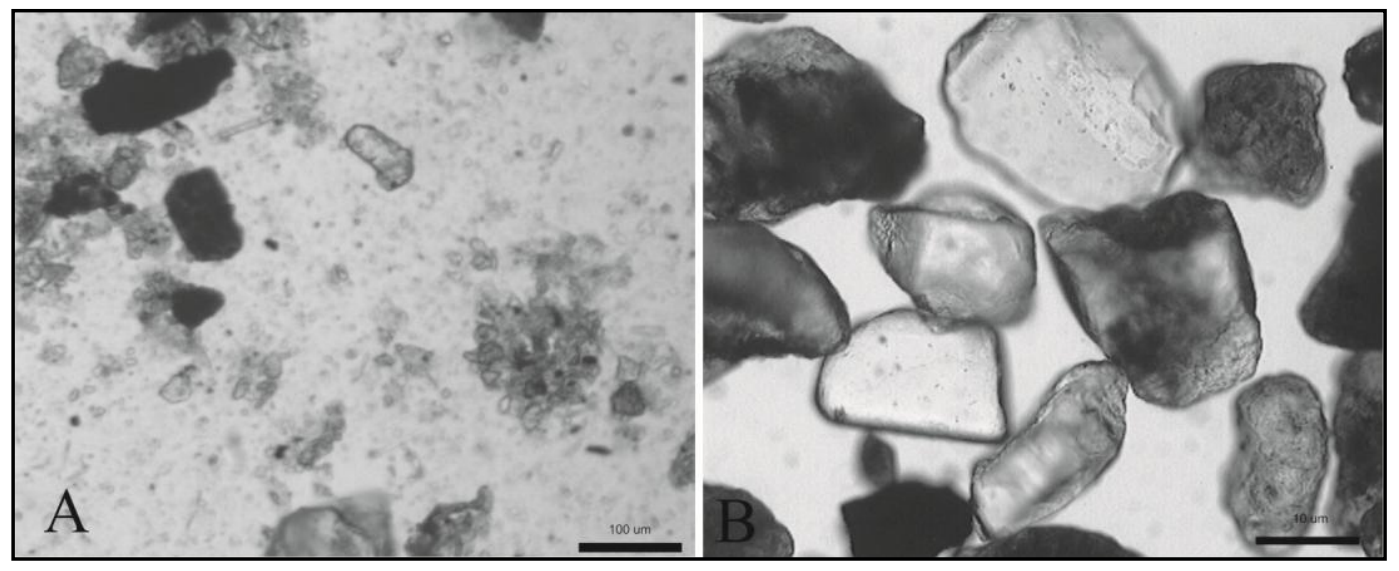

Figura 13.13. Sedimento testigo tomado de la superficie que rodeaba y por debajo del artefacto, en la localidad arqueológica Punta Medanosa.

\subsubsection{Identificación taxonómica de los microvestigios}

El fragmento de tejido epidérmico presenta una integridad que permite su identificación anatómica. Por el patrón epidérmico y siendo comparado con las plantas de uso y procesamiento mencionadas en fuentes documentales (ver capítulo 4) la especie más afín es Prosopidastrum globosum (Gillies ex Hook. \& Arn.) Bukart (Figura 13.14) 


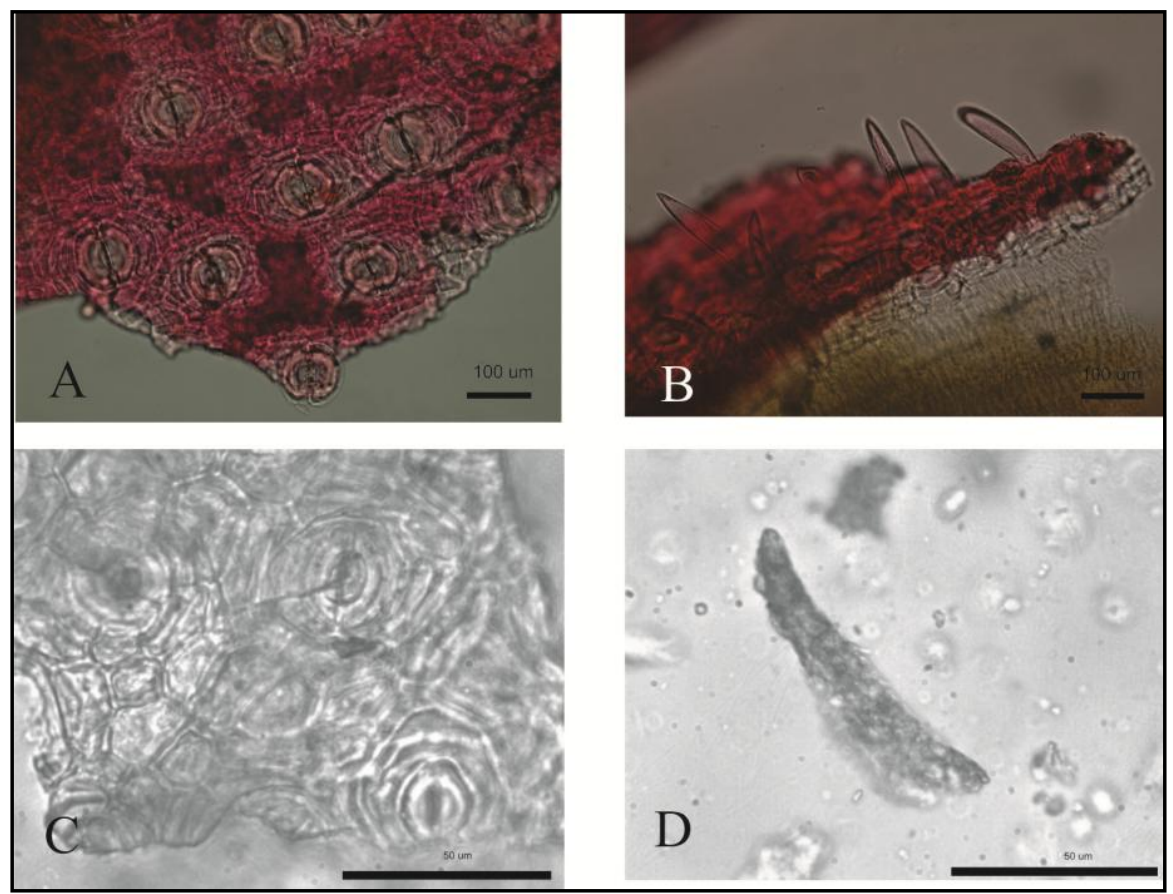

Figura 13.14. A: Prosopidastrum globosum (Fotografía tomada en el Laboratorio de Microhistología de

INTA Bariloche B: pelos de P. globosum (ídem aclaración), C: tejido epidérmico identificado en M17PM; D: pelo identificado en M17PM

La descripción del fragmento epidérmico recuperado en el artefacto de molienda fue comparada con el material de referencia y con bibliografía, coincidiendo con los rasgos descriptos por Balmaceda y Porro de Digiuni (1979). Estos autores mencionan que los estomas son abundantes, generalmente mayores que las células no diferenciadas, los estomas son anomocíticos y están orientados al azar. Las células oclusivas aparecen con los contornos muy definidos. Es importante mencionar que respecto a los pelos los autores los caracterizan como simples, unicelulares, de superficie verrugosa, muy similares a $P$. strombulifera pero más largos, que son poco frecuentes y aparecen en la zona nerval (Balmaceda y Porro de Digiuni 1979:11). Los pelos recuperados en el artefacto arqueológico son similares a las especies de Prosopis más que a los de Prosopidastrum.

Otra especie que es similar en cuanto al patrón de células epidérmicas, pero no así respecto al aparato estomático fue Maytenus chubutensis (Speg.) Lourt., O'Don. et. Sleum (Figura 13.15). Se evidencia esto último también para Prosopis denudans (Figura 13.16). Sin embargo, los pelos de cutícula verrucosa y los corpúsculos de resina sí son similares tanto a Maytenus chubutensis como a Prosopis denudans y P. alpataco. El 
resto de las plantas con registro de uso y del área de estudio fueron descartadas por no compartir elementos de coincidencia con el material arqueológico.

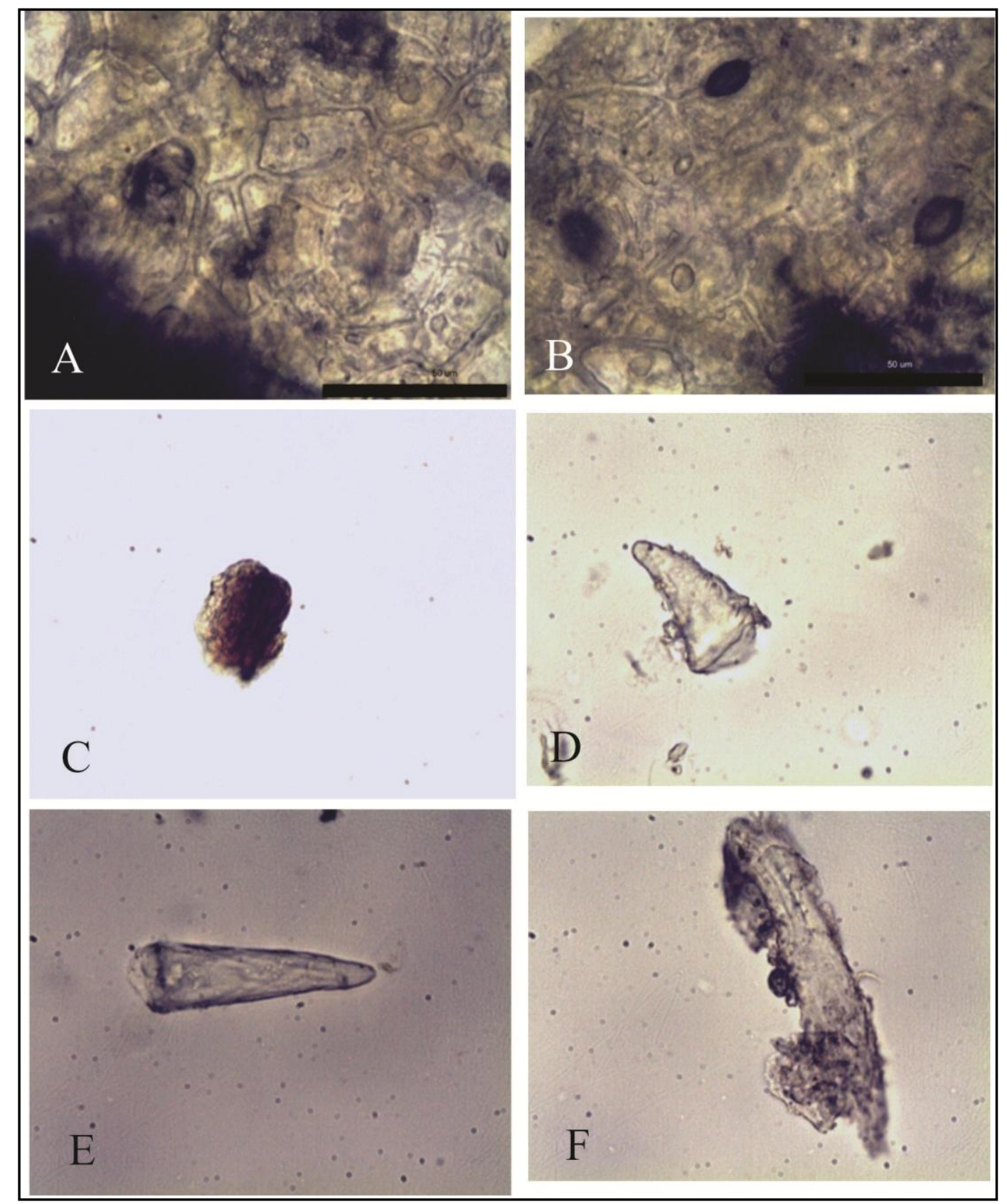

Figura 13.15. Maytenus chubutensis referencia A y B: Tejido epidérmico C: corpúsculos de resina, D, E y F pelos lisos y verrucosos 


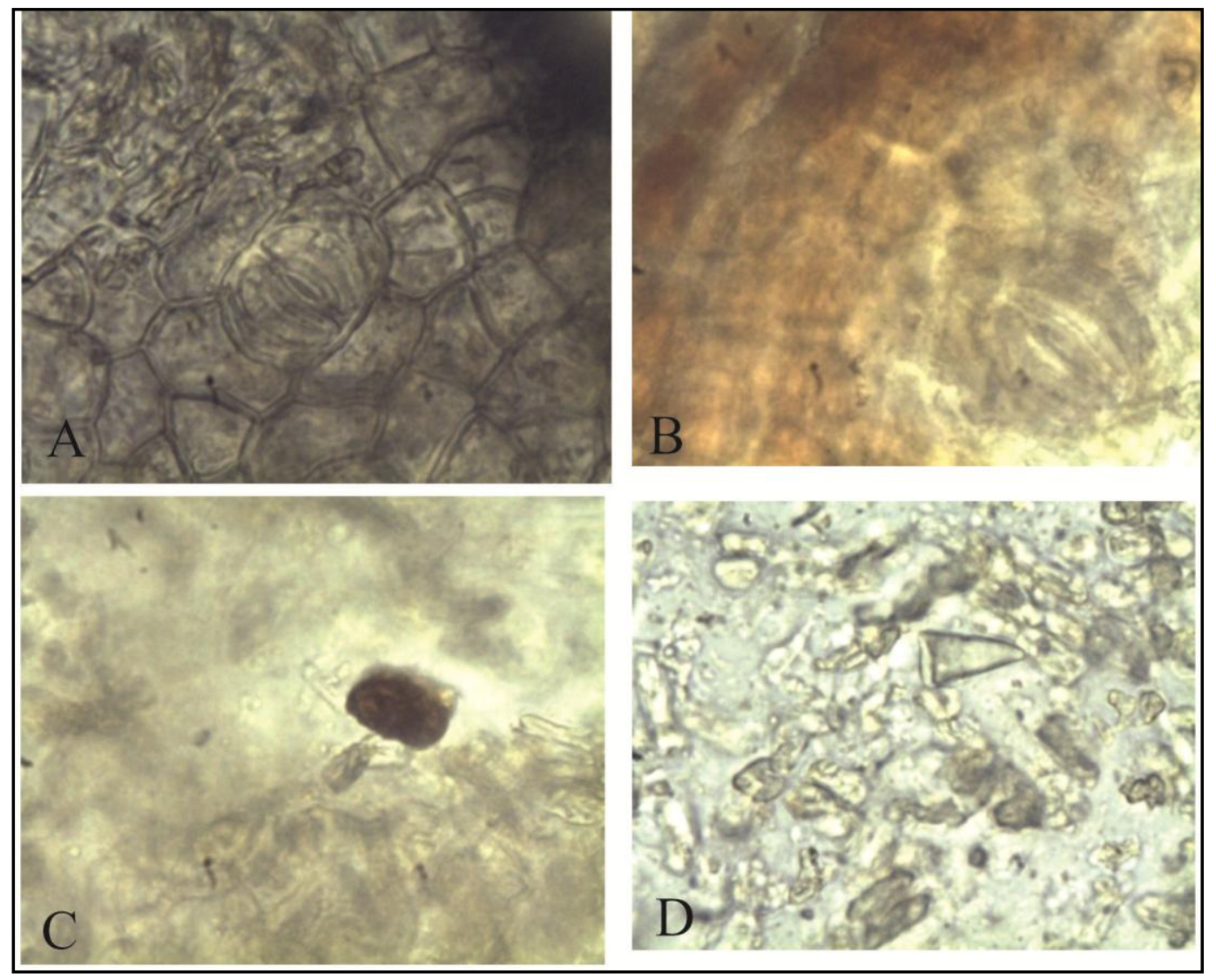

Figura 13.16. A: Tejido epidérmico hoja mortereada de Prosopis alpataco referencia B: Estoma de pedicelo de vaina Prosopis denudans referencia C y D pelos de P. alpataco referencia

\subsubsection{Resultados de los artefactos pertenecientes a la colección Museo del Hombre y su Entorno}

\subsection{Pieza M23SJ}

El artefacto fue colectado por el Dir. César Gribaudo (Museo del Hombre y su Entorno) en la Localidad Arqueológica de Monte Loayza, más propiamente en Cañadón del Duraznillo (ver Castro et al. 2000), en superficie y a metros de un sitio conchero. El molino es de arenisca, porosa, de color gris claro, presenta sobre una de sus caras, una superficie pulida (Figura13.17). Se observaron cristales de sílice de la adherencia analizada, pero no se encontró material vegetal a excepción de fibras libriformes largas. Tampoco se hallaron almidones (Figura 13.18). No se puede afirmar en este caso el uso del artefacto para la molienda de recursos vegetales. 
El sedimento sobrante se guardó en ependorf y puede ser utilizado para un nuevo análisis.

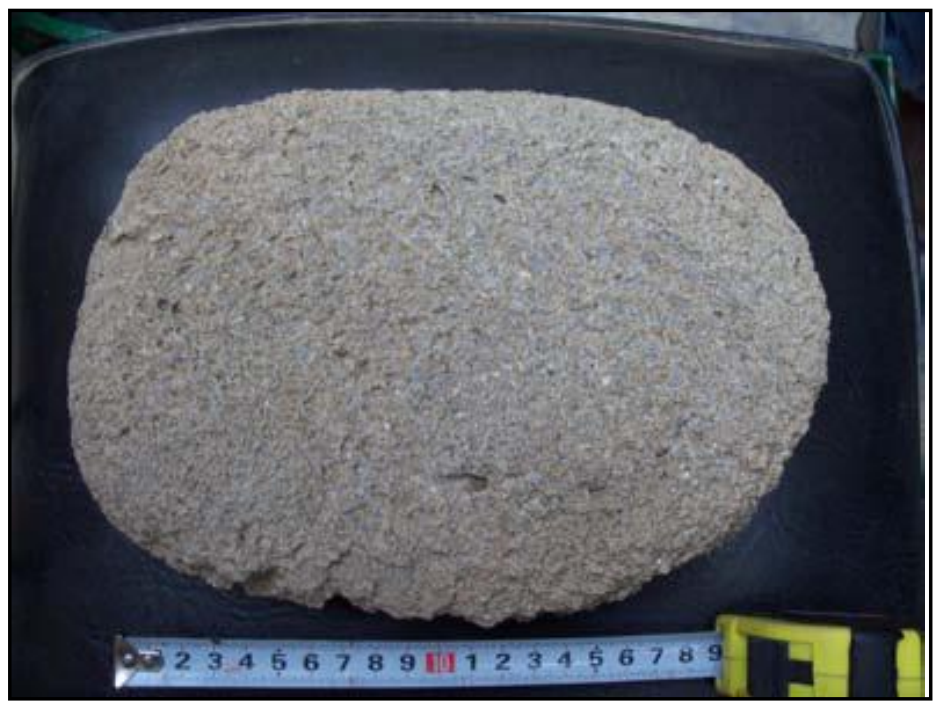

Figura 13.17. M23SJ

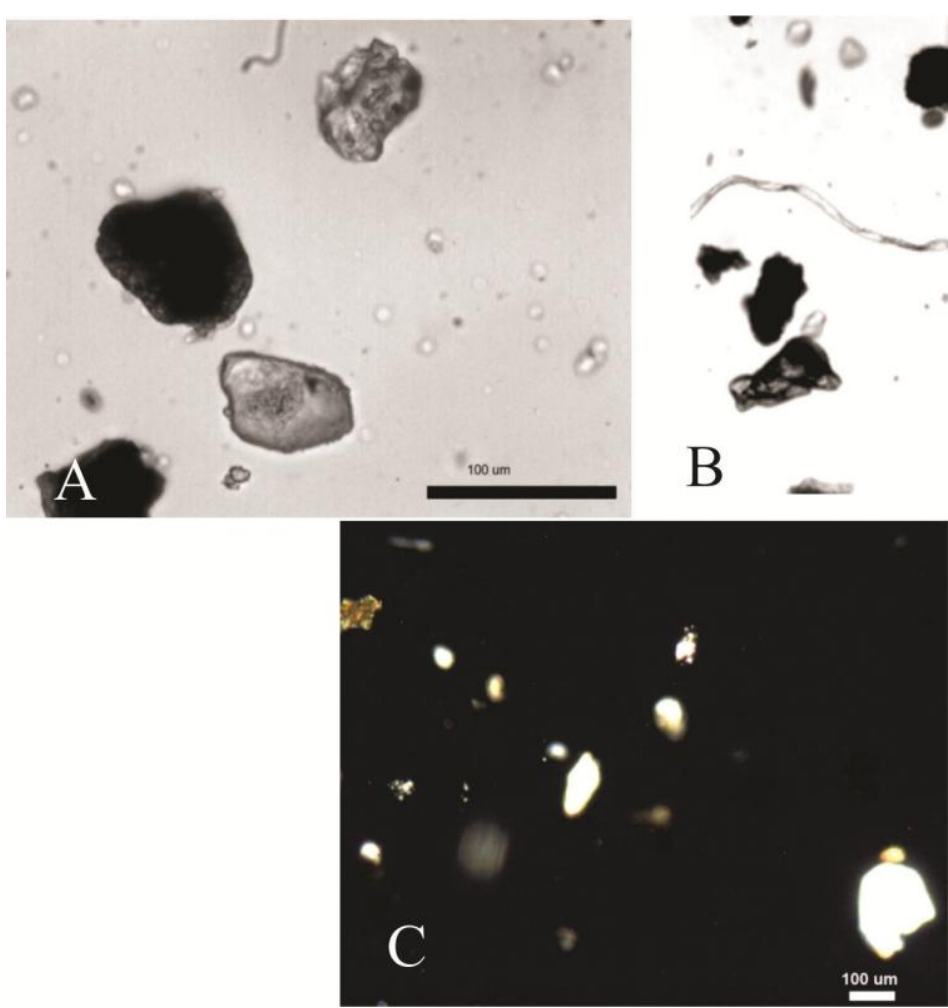

Figura 13.18. A: Muestra general del preparado, B: fibra libriforme y C: polarización del preparado 


\subsection{Pieza M24SJ}

A $50 \mathrm{~cm}$ de la pieza anterior (M23SJ) se halló una mano de molino en superficie, en Monte Loayza. Es un pórfido blanco, menos porosa que el anterior (Figura 13.19). Se recuperó muy poco sedimento en el proceso de raspado. Se observan solo cristales de arena. No se hallaron almidones (Figura 13.20). No hay en esta extracción evidencia de uso de molienda para recursos vegetales.

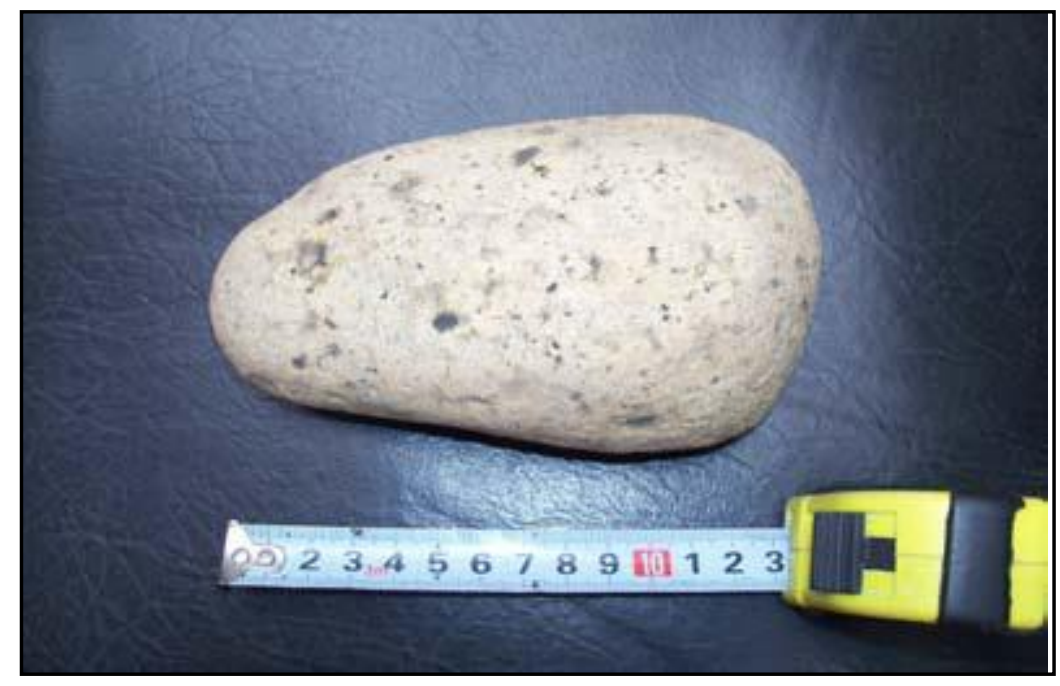

Figura 13.19. M24SJ

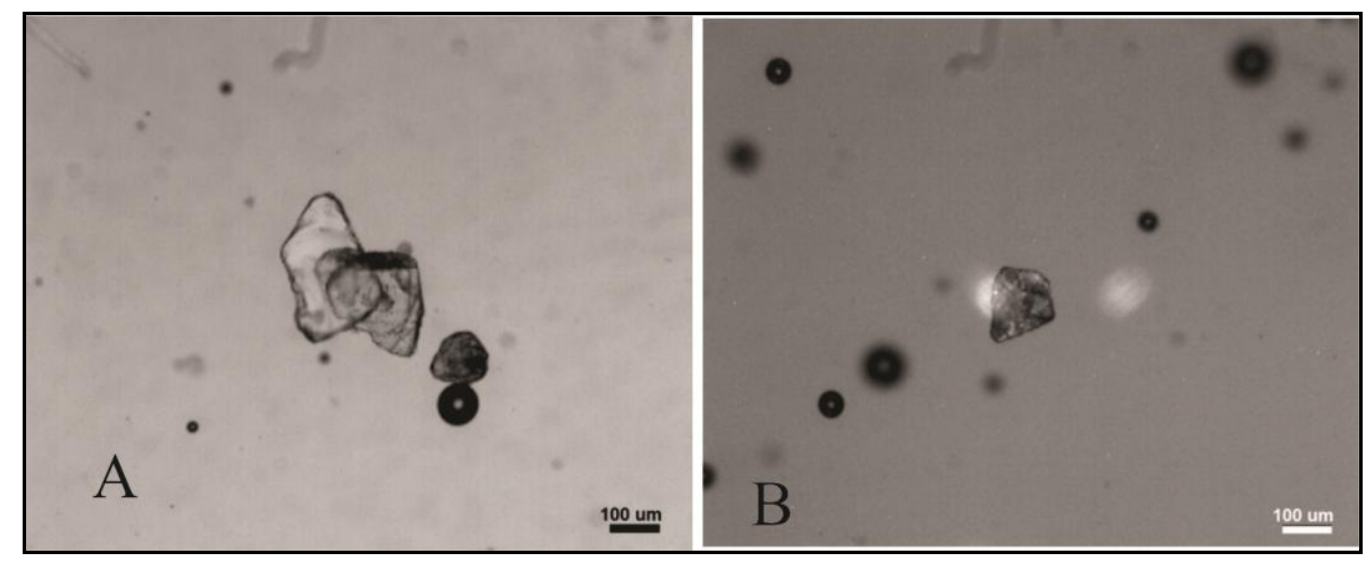

Figura 13.20. A: Vista general del preparado y B: polarización

\subsection{Pieza M25SJ}


Se realizaron raspados sobre la pieza rotulada con el número 901 de la Colección Museo del Hombre y su entorno, proveniente de Bahía Lángara. Este instrumento tiene como materia prima-fuente una arenisca gris, pulida sobre una de sus caras, con marcas transversales a los granos de rocas (Figura 13.21). Se observaron fibras de paredes medias a finas muy largas. No se observó otro tipo de células vegetales. Al colocar el polarizador no se encontraron almidones (Figura 13.22). No se encontraron evidencias que respalden el procesamiento de vegetales.

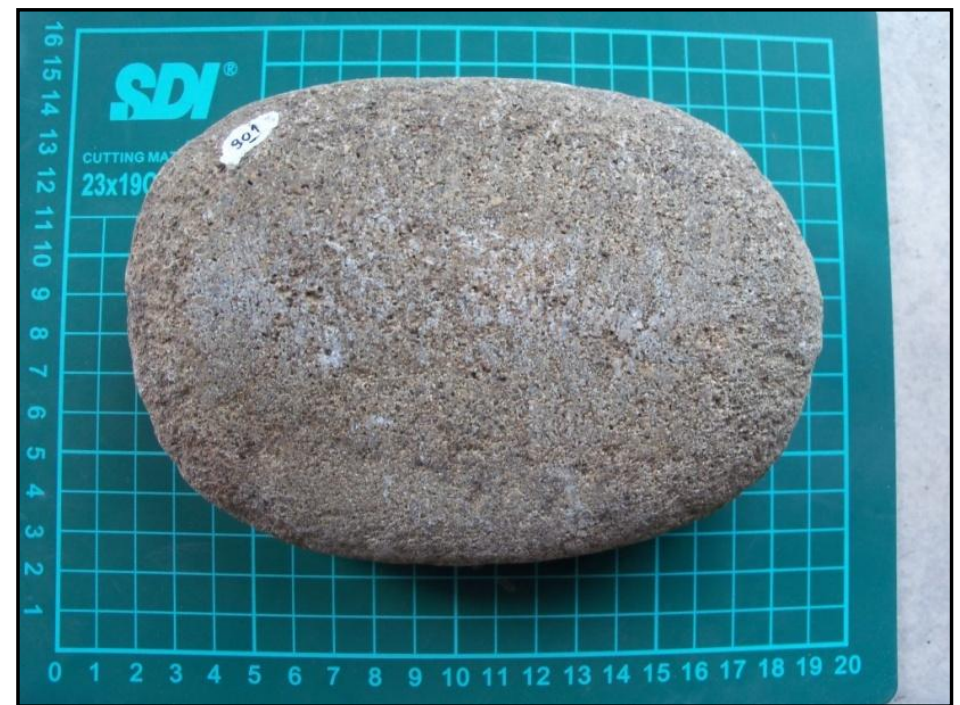

Figura 13.21. M25SJ

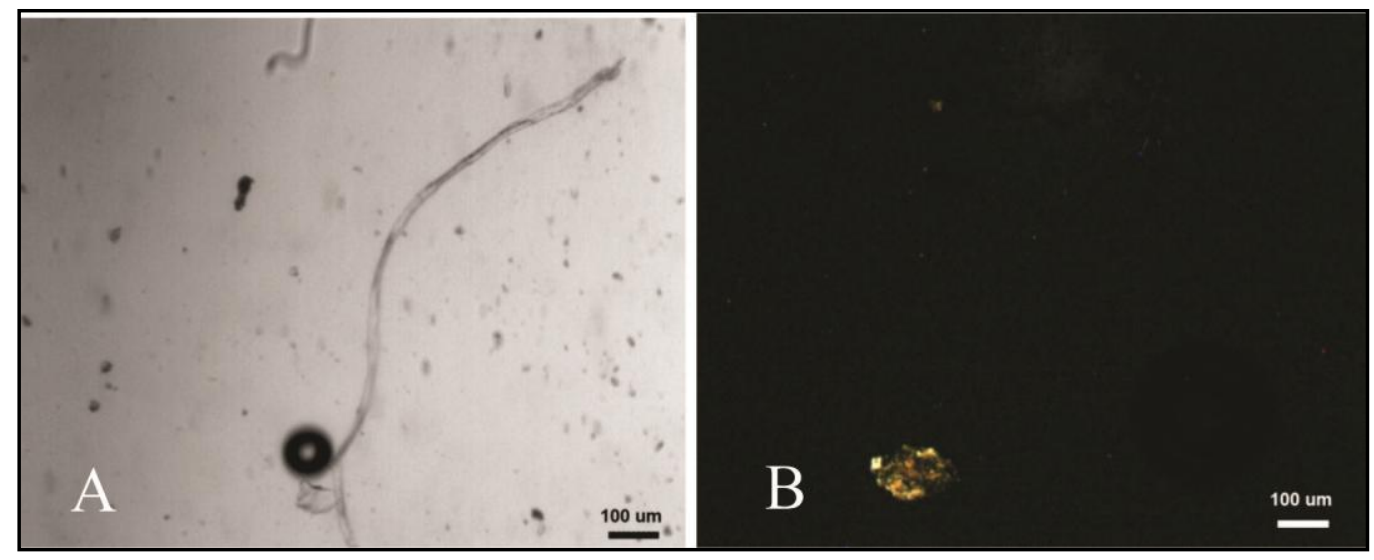

Figura 13.22. A: Vista general del preparado y B: polarización del mismo

\subsection{Pieza M26SJ}


La pieza M26SJ tiene un rótulo previo conteniendo la sigla 5b (correspondiente a la colección del Museo del Hombre y su Entorno). Proviene de un sitio arqueológico ubicado sobre la ruta que comunica las localidades de Fitz Roy y Pico Truncado. Este instrumento sería de morfología molino o mano de molino sobre una materia prima de arenisca y estaría asociado a un molino de 60 x $30 \mathrm{~cm}$ (Figura 13.23). Se halló la pieza en superficie y se encuentra muy pulida sobre una de sus caras.

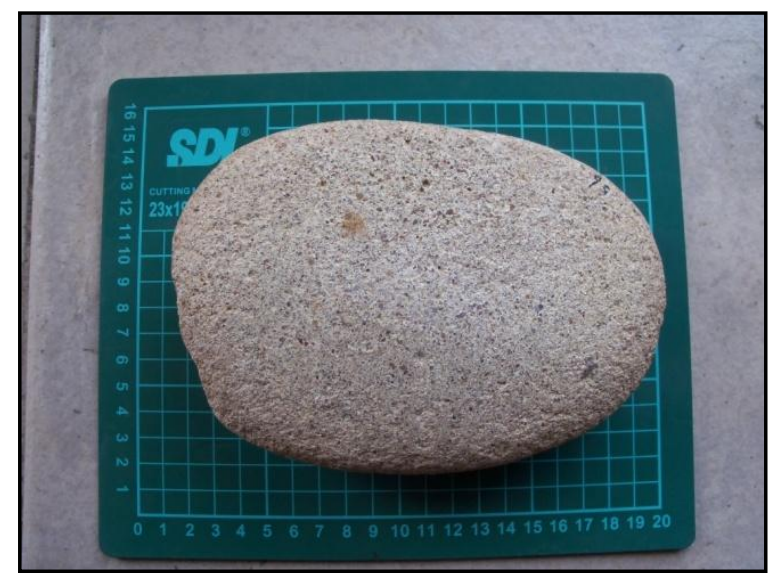

Figura 13.23.M26SJ

Se observaron cristales de arena propios del sedimento extraído y residuos vegetales: fibras con las puntas rotas, corpúsculos de resina y almidones. Las fibras se encontraban rotas, desgarradas a diferencia de las fibras que se encontraron en los restantes artefactos. Estas roturas son identificadas como huellas tecnológicas (Cueto et al 2010). En cuanto a los granos de almidón se registraron 13 donde la mayor parte son esféricos, oblongos y ovoides. Sin embargo un grano de almidón es facetado, de cruz de polarización excéntrica que correspondería a un grano de leguminosas posiblemente de Prosopis sp (Figura 13.24, Tabla 13.3). Entre los granos de almidón esféricos, oblongos y ovoides se registraron cuatro que también serían afines a los granos de Prosopis sp (Figura 13.24 y 13.25, Tabla 13.3).

Los resultados son alentadores para replicar la extracción con técnica de pipeteado con agua destilada. 

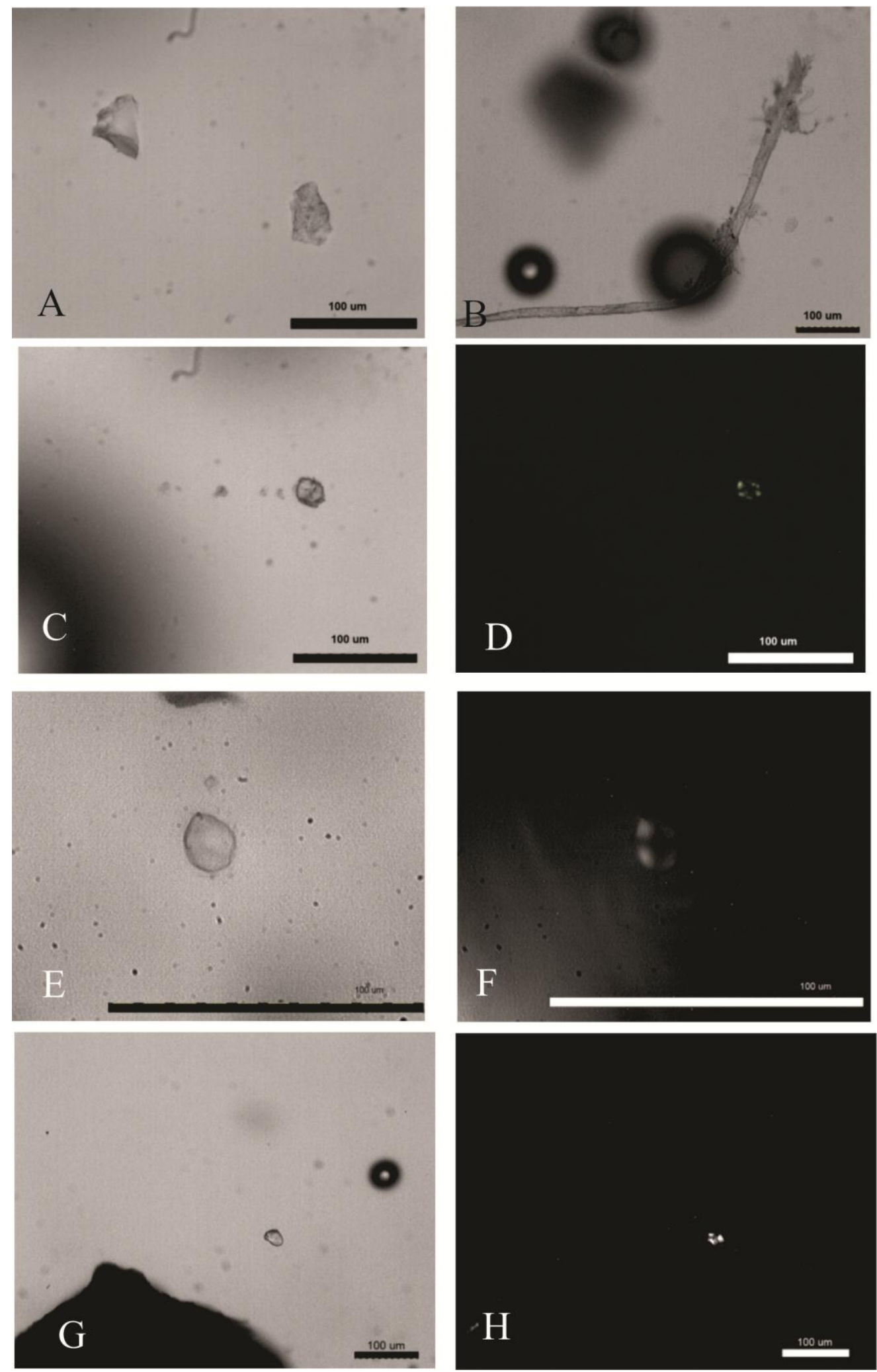

Figura 13.24. P26SJ A: Vista general del preparado, B: fibra deshilachada granos de almidón sin y con polarización, C y D grano de almidón ovoide sin y con polarización; E y F: grano de almidón ovoide sin y con polarización; G y H: grano de almidón de superficies facetadas 

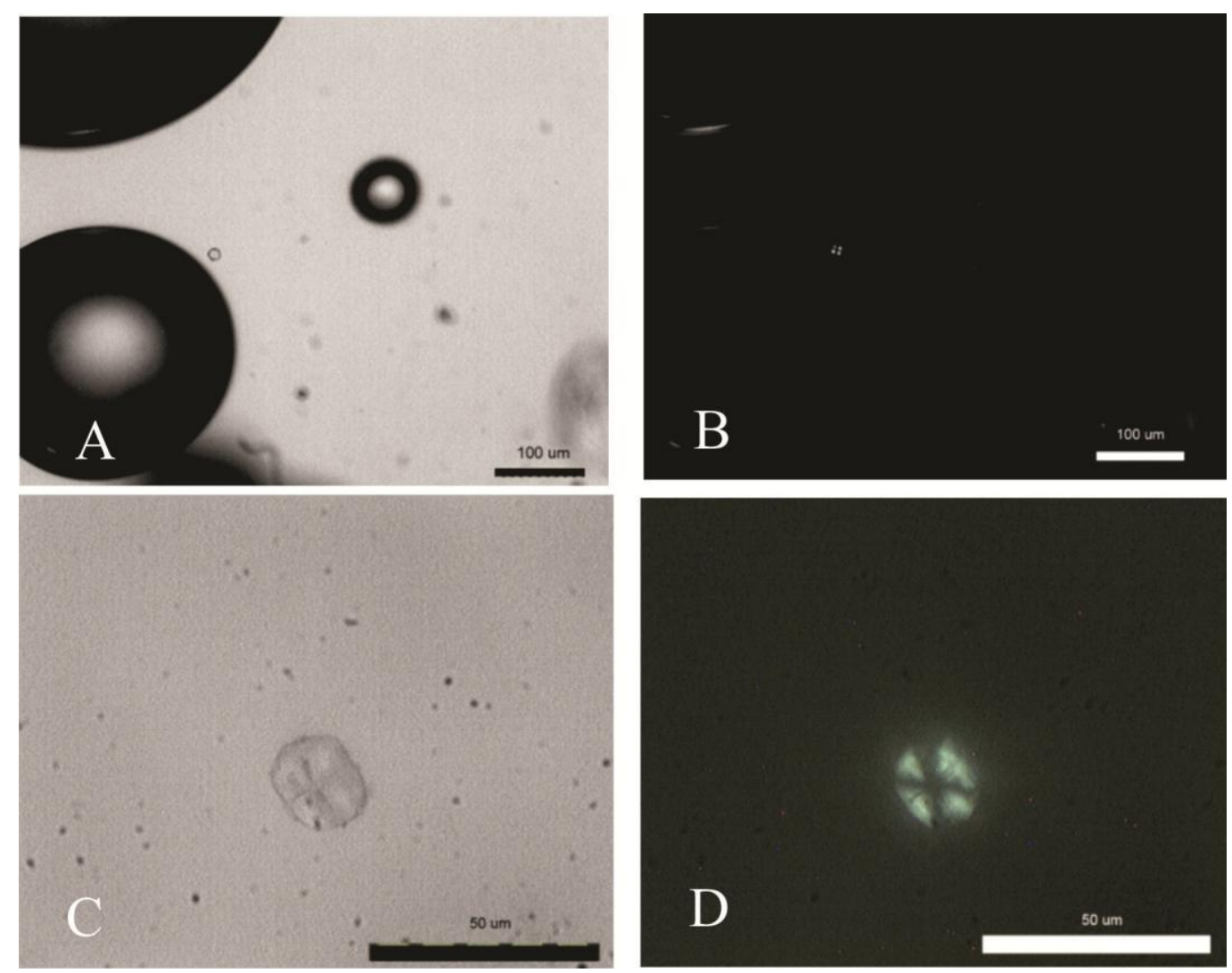

Figura 13.25. P26SJ A, B y C y D: Granos de almidón ovoides sin y con polarización recuperados en P26SJ

Los granos de almidón arriba identificados fueron comparados con las fotos de referencia de la publicación de Giovanetti et al. (2008), a partir de las cuales, y como se mencionó más arriba, se reconocen que los granos de almidón de Prosopis sp. tipo A1b y A2 son similares a los identificados en el artefacto P26SJ (Figura 13.26 ). 


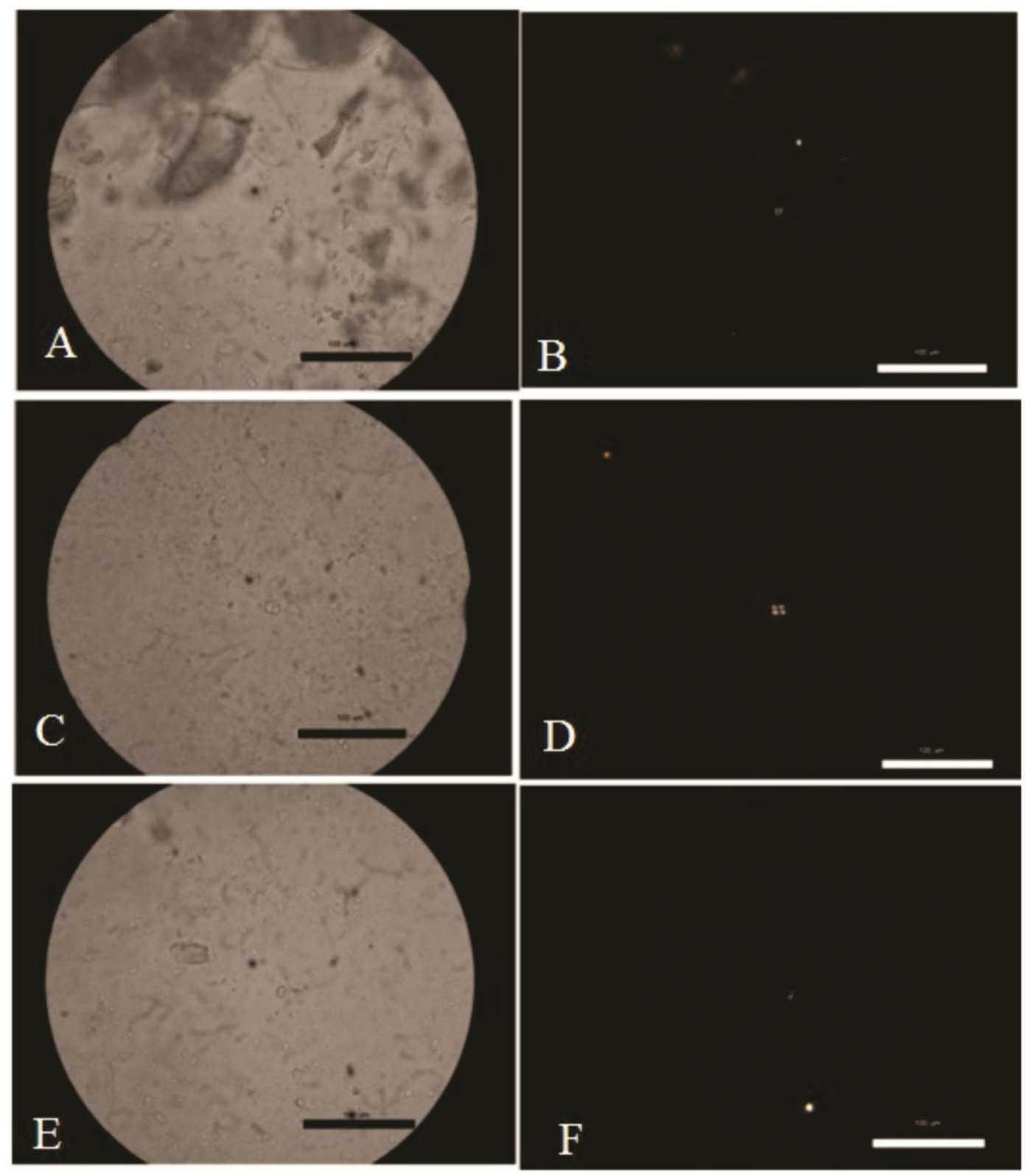

Figura 13.26. Prosopis sp A y B: grano de almidón esférico, C y D: grano de almidón facetado, E y F grano de almidón ovoide

\begin{tabular}{|c|c|c|c|c|c|c|c|c|}
\hline $\begin{array}{l}\text { Posición } \\
\text { en el } \\
\text { campo } \\
\text { del } \\
\text { preparado }\end{array}$ & Forma & $\begin{array}{l}\text { Larg } \\
\mathrm{o} \mu \mathrm{m}\end{array}$ & $\begin{array}{l}\text { Ancho } \\
\mu \mathrm{m}\end{array}$ & $\begin{array}{l}\text { Índice de } \\
\text { forma } \\
\text { (largo/ancho) }\end{array}$ & $\begin{array}{l}\text { Simple } \\
\text { /compuesto }\end{array}$ & Hilio & $\begin{array}{l}\text { Cruz de } \\
\text { Polari- } \\
\text { zación }\end{array}$ & $\begin{array}{l}\text { Afín a } \\
\text { Prosopis } \\
\text { sp. }\end{array}$ \\
\hline $103-40,5$ & $\begin{array}{l}\text { esférico } \\
\text { pero } \\
\text { roto }\end{array}$ & 12,69 & 9.52 & 1.33 & Simple & $\begin{array}{l}\text { Punti- } \\
\text { forme }\end{array}$ & Central & \\
\hline $103-40 a$ & oblongo & 14,28 & 12.69 & 1.12 & Simple & no se ve & Central & \\
\hline $103-40 b$ & esférico & 12,69 & 11.69 & 1.08 & Simple & no se ve & $\begin{array}{l}\text { Excén- } \\
\text { trico }\end{array}$ & \\
\hline
\end{tabular}




\begin{tabular}{|c|c|c|c|c|c|c|c|c|}
\hline $103-43$ & ovoide & 31,3 & 26.6 & 4.7 & Simple & no se ve & Central & $\begin{array}{l}\text { Tipo A1b } \\
\text { (Giovanet } \\
\text { ti et al. } \\
2008 \text { ) }\end{array}$ \\
\hline $114-63$ & ovoide & 22,22 & 17,46 & 1,27 & Simple & filiforme & Central & $\begin{array}{l}\text { Tipo A1a } \\
\text { (Giovanet } \\
\text { ti et al. } \\
2008 \text { ) }\end{array}$ \\
\hline $103-39,5$ & ovoide & 11,8 & 10,9 & 1,08 & Simple & $\begin{array}{l}\text { Punti- } \\
\text { forme }\end{array}$ & Central & \\
\hline $105-49$ & esférico & 4,3 & 4,2 & 1,02 & Simple & no se ve & Central & $\begin{array}{l}\text { Tipo A1b } \\
\text { (Giovanet } \\
\text { ti et al. } \\
2008 \text { ) }\end{array}$ \\
\hline $109-49$ & esférico & 7,7 & 5,3 & 1,45 & Simple & $\begin{array}{l}\text { Punti- } \\
\text { forme }\end{array}$ & Central & \\
\hline $111-40$ & $\begin{array}{l}\text { esférico } \\
\text { a } \\
\text { oblongo }\end{array}$ & 5,9 & 5,7 & 1,04 & Simple & $\begin{array}{l}\text { Punti- } \\
\text { forme }\end{array}$ & Central & \\
\hline $113-49$ & $\begin{array}{l}\text { esférico } \\
\text { a } \\
\text { oblongo }\end{array}$ & 4,8 & 4,3 & 1,12 & Simple & no se ve & Central & \\
\hline $115-55$ & facetado & 10,5 & 6,9 & 1,52 & Simple & no se ve & $\begin{array}{l}\text { Excén- } \\
\text { trico }\end{array}$ & $\begin{array}{l}\text { Tipo A2 } \\
\text { (Giovanet } \\
\text { ti et al. } \\
2008 \text { ) }\end{array}$ \\
\hline $120-48$ & esférico & 5 & 3,7 & 1,35 & simple & no se ve & Central & \\
\hline $\mathrm{s} / \mathrm{c}$ & ovoide & 16,4 & 12,3 & 1,33 & simple & filiforme & Central & $\begin{array}{l}\text { Tipo A1b } \\
\text { (Giovanet } \\
\text { ti et al. } \\
2008 \text { ) }\end{array}$ \\
\hline
\end{tabular}

Tabla 13.3. Descripción de los granos de almidón recuperados en el artefacto M26SJ

\subsection{Pieza M27SJ}

Se analizó la pieza rotulada con la sigla 583J de la colección del Museo del Hombre y su Entorno de Caleta Olivia, y se realizaron los raspados correspondientes. Este instrumento proviene de la Localidad Arqueológica Bahía Lángara, se encontró en la superficie del sitio y constituye un molino plano. La materia prima es una arenisca, porosa, aunque muy pulida sobre una de sus caras. Posee manchas más blancas y tiznes oscuros (Figura 13.27). 


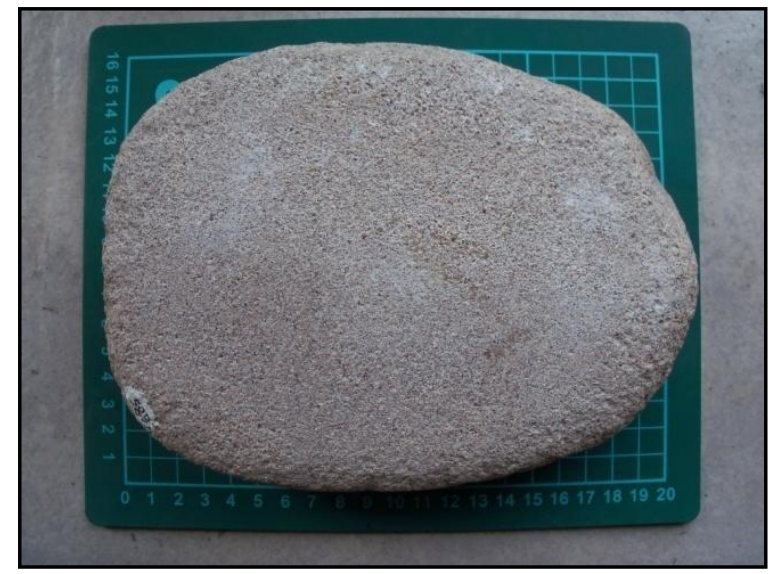

Figura 13.27. M27SJ

Se observaron cristales de arena pero no habría material vegetal a excepción de dos fibras libriformes. No se hallaron almidones (Figura 13.28). No hay en esta extracción evidencia de uso de molienda para recursos vegetales.

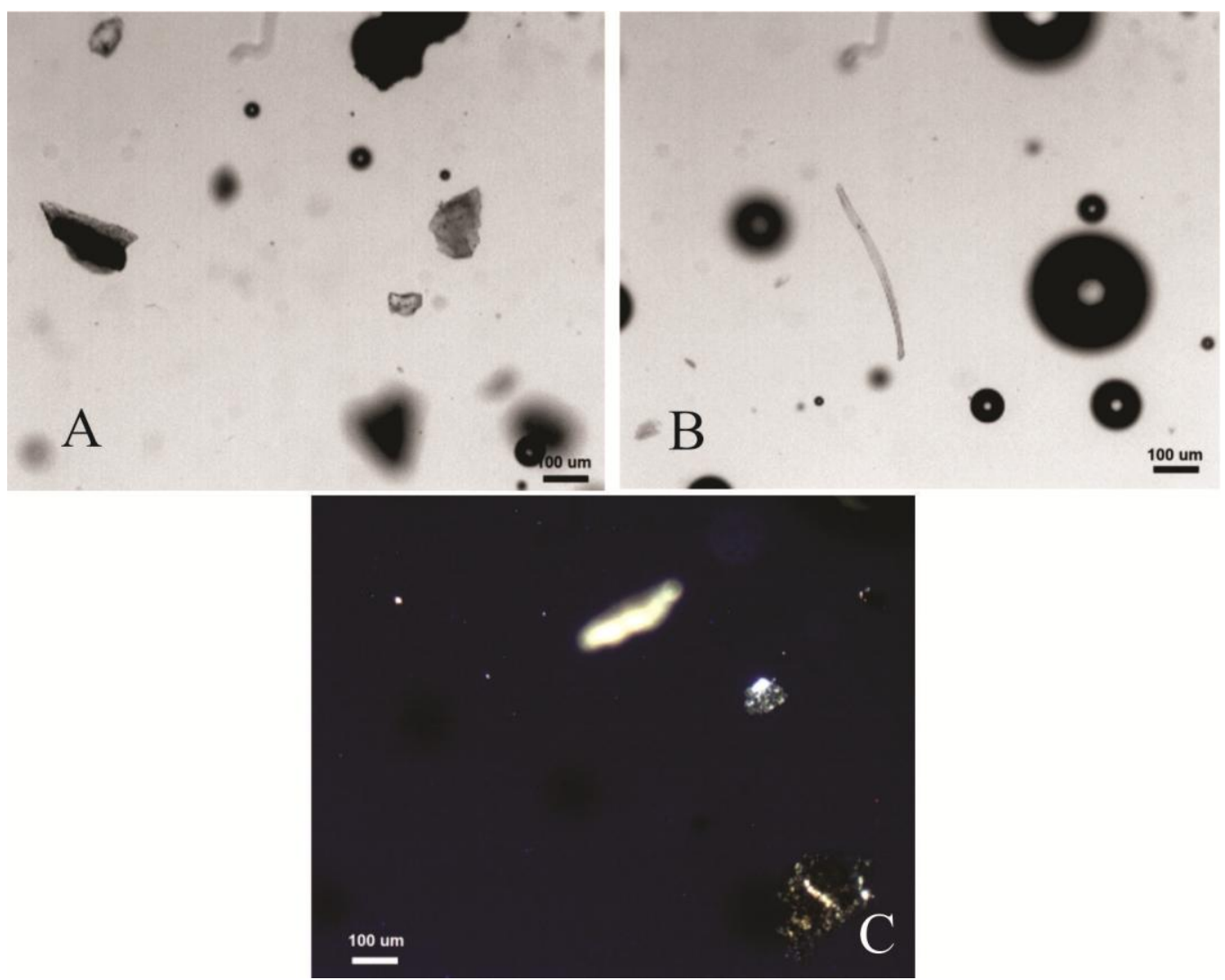

Figura 13.28. A: Visión general del preparado, B: fibra libriforme, C: polarización del preparado 
Debido a que los artefactos de la colección del Museo del Hombre y su Entorno han sido donados por pobladores locales, no se tenía una muestra de sedimento control. Por lo tanto, se recuperó con la ubicación estimada de uno de los artefactos, sedimento para ser analizado a través de un escaneo con lupa y microscopio. No se registraron microrrestos vegetales así como tampoco granos de almidón en la muestra analizada.

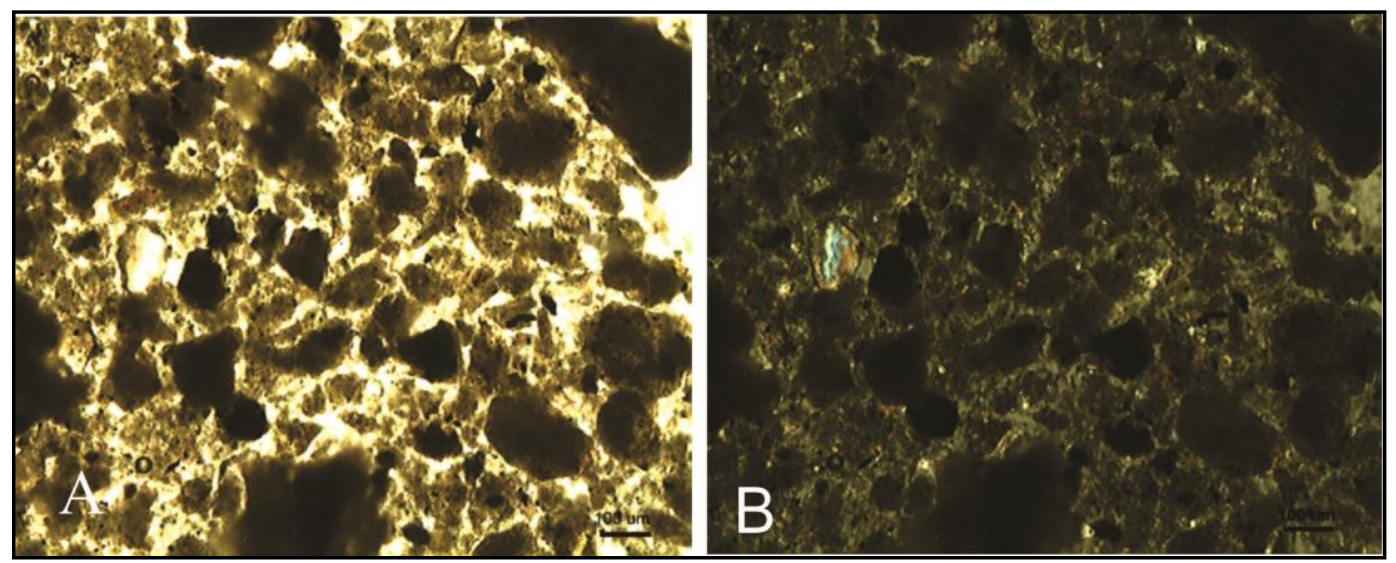

Figura 13.29. Se observa el sedimento testigo sin y con polarizador

\subsubsection{Discusión y conclusiones}

En este capítulo se realizaron distintos análisis para abordar las prácticas de procesamiento poscolecta a partir de la molienda. En el primer estudio, se realizó una recopilación bibliográfica en la que se registraron los fechados más tempranos y más tardíos para el registro arqueológico de Patagonia continental Argentina: $4880 \pm 130$ AP (Sanguinetti de Bórmida y Curzio 1996) y el más moderno entre el siglo XVI y el año 1891 (Silveira 1996). Ambas cronologías se registraron para artefactos de molienda de sitios de Neuquén. Sin embargo, la distribución de dichos instrumentos continúa hasta la provincia de Santa Cruz, siendo el sitio Costa del Lago Guitarra (Goñi et al. 2010) el más al sur registrado hasta el momento y para el recorte bibliográfico realizado. Sólo el $24 \%(n=34)$ de los artefactos mencionados en las publicaciones arqueológicas fue identificada la materia prima fuente, así como sólo siete instrumentos fueron analizados desde un enfoque arqueobotánico (Lema et al. 2012). Esto refuerza la necesidad de realizar estudios sistemáticos tecno-morfológicos y tecno-funcionales de los instrumentos de molienda (Babot 2004) para profundizar en el conocimiento de estas 
prácticas, no sólo sobre vegetales sino también de pigmentos destacando la multifuncionalidad de dichos artefactos. Por otra parte, para evitar el uso de analogías directas, el análisis químico y arqueobotánico de los mismos permite realizar nuevas preguntas al registro arqueológico.

Es importante destacar que a partir de los resultados de Lema et al. (2012) se registraron prácticas de molienda de recursos vegetales silvestres y domesticados (Prosopis sp y Zea mays) hacia ca. 1750 años AP.

A partir de este contexto es importante la discusión y análisis de los artefactos potencialmente utilizados en la molienda para la CNSC. En primer lugar, las prospecciones realizadas al sur de la Ría Deseado, así como los artefactos provenientes de la colección del Museo del Hombre y su Entorno, permiten una discusión acerca del desarrollo de estas prácticas en el área de estudio. Se relevaron 20 artefactos y 5 provenientes de la colección antes mencionada, sumado a nuevos trabajos en el área de estudio que han registrados nuevos artefactos (Hammond et al. 2013).

De los 20 artefactos identificados al sur de la ría el 55\% $(\mathrm{n}=11)$ fueron manufacturados sobre pórfido, el 20\% $(n=4)$ sobre riolita, el 15\% $(n=3)$ sobre toba y el $10 \%(n=2)$ a partir de ignimbrita. En cuanto a la materia prima fuente de los instrumentos de la colección del Museo del Hombre y su Entorno el $80 \%(\mathrm{n}=4)$ fue arenisca y $20 \%(\mathrm{n}=$ 1) fue pórfido. Se recuperaron tanto morteros (i.e. M17PM), manos de molino (i.e. P24SJ) como molino (i.e. P26SJ).

El análisis arqueobotánico de los instrumentos M17PM como de los cinco provenientes de la colección del Museo de la localidad de Caleta Olivia permiten sugerir en dos casos procesamiento de recursos vegetales silvestres. En el artefacto M17PM esta inferencia se sustenta en la presencia de abundantes y diversos residuos vegetales así como por la escasa evidencia de restos vegetales en las muestras testigo. Las especies compatibles con el fragmento de epidermis recuperado en la cara activa no están inmediatamente presentes actualmente en el área donde se halló el instrumento por lo que se descartaría contaminación actual. La preservación de los tejidos vegetales en las oquedades del artefacto se debe al grado de sequedad del ambiente de la zona (menos de $200 \mathrm{~mm}$ de precipitaciones al año) y a la salinidad del sustrato. Los restos vegetales recuperados del instrumento M17PM evidencian prácticas de procesamiento postcolecta. 
De las tres especies, Prosopidastrum globosum es la identificada en el fragmento de epidermis, respecto a los pelos y corpúsculos de resina las especies más afines son Prosopis denudans y Maytenus chubutensis. Respecto a Prosopidastrum globosum "manca caballo" es mencionado por cronistas de la siguiente manera: Claraz ([18651866] 2008) hace referencia a raíces que se comen, luego habla especies que tienen raíces grandes y entre ellas menciona a Prosopidastrum globosum. Steibel (1997) menciona a la especie registrando su nombre en el idioma "chedungun" a través de su estudio con descendientes ranqueles. No menciona usos por parte de la población de Colonia Mitre pero registra el consumo de los brotes tiernos por animales. Sin embargo estudios sobre productos secundarios sobre esta especie tuvieron como resultado la identificación de flavonoides de la parte aérea de la planta y de las semillas (Agnese et al. 1986). Trabajos recientes sobre estos metabolitos en la nutrición humana evidencian la acción de los mismos como antioxidantes, antiinflamatorios, antivirales o antialérgicos siendo compuestos que no son sintetizados por el hombre y sólo los incorpora a través del consumo de vegetales (Martínez Flores et al. 2002). Además Richeri y colaboradores (2013) registraron su uso medicinal para el tracto urinario en localidades rurales de la meseta central de Chubut.

La especie Prosopis denudans tiene referencias de uso alimenticio, mientras que Maytenus chubutensis y Maytenus boaria presentan numerosas aplicaciones medicinales (Molares 2010). En cuanto a la distribución de Prosopidastrum globosum, éste se registra en la costa norte de Santa Cruz, por ejemplo en Puerto Deseado. No se observó en las inmediaciones del sitio donde se recuperó el artefacto M17PM. Como se mencionó en el capítulo Área de estudio y antecedentes arqueológicos, Prosopis denudans tiene en los límites de la estepa arbustiva del Golfo San Jorge, es decir, Punta Medanosa su distribución más austral (Leon et al. 1998). En cuanto a Maytenus boaria se encuentra en el Distrito del Bosque Caducifolio desde Neuquén a Tierra del Fuego, ocupando todo el borde oriental de la Provincia Subantártica (Cabrera et al. 1971). Si bien los informantes de CNSC mencionaron no mezclar plantas, los microvestigios recuperados indicarían que se procesó más de una planta.

Las fibras con huellas tecnológicas (tipo de roturas), corpúsculo de resina y los granos de almidón hallados en el instrumento M26SJ (5b) evidencian el procesamiento poscolecta de vegetales a partir de la técnica de molienda. Cinco de los granos de 
almidón han sido identificados como aff. Prosopis sp. El sedimento testigo no se recuperó en el momento de la recolección del instrumento, por lo que no se pudo analizar, sin embargo, sí se ha procesado sedimento de la región como en el caso de Punta Medanosa (Ciampagna et al. 2011). Este resultado es relevante para el estudio de las prácticas de los grupos cazadores recolectores de la Costa Norte de Santa Cruz en relación al uso y procesamiento de las plantas, considerando que en esta pequeña muestra de 5 artefactos, uno de ellos evidenció efectivamente huellas tecnológicas de molienda.

A través de entrevistas etnobotánicas y observación participante en el noroeste del país Capparelli (2007) registró el uso de las vainas de Prosopis. En el pasado y el presente, en Catamarca se utilizaron para la preparación de cinco subproductos: arrope (líquido viscoso muy dulce), patay (una clase de pan), añapa (bebida fresca no fermentada), ulpo (una bebida que se tomaba durante el desayuno o mientras se pastaban los rebaños y aloja (una bebida fermentada). Para la preparación de cada uno de estos subproductos es necesaria la molienda de las vainas de los distintos algarrobos (Capparelli 2007:112). En el sitio arqueológico Angostura I, en el norte de Patagonia, se recuperaron un total de 77 de fragmentos determinados como vainas de Prosopis denudans y P. alpataco asociados a otros restos vegetales, líticos, artefactos sobre valvas de moluscos, animales fluviales y terrestres con una cronología de $938 \pm 45$ años AP (Capparelli y Prates 2010: 14 y en prensa). Como se mencionó en la sección 15.3.1, Lema et al. (2012) registró la molienda de Prosopis sp. en artefactos provenientes del sitio Aquihuecó (Neuquén) asociados a entierros de una antigüedad de $4172 \pm 52$ años AP y $3817 \pm 59$ años AP. Estos antecedentes contribuyen a continuar el análisis de artefactos de molienda en la CNSC, sumado al registro de este tipo de instrumentos en el área y los análisis arqueobotánicos aquí presentados.

Si bien la muestra analizada en pos de la recuperación de microrrestos en este capítulo es pequeña los resultados son positivos en relación al procesamiento de plantas a través de la molienda. Se debería aumentar la muestra de instrumentos analizados bajo esta metodología, sumando además análisis químicos de tipo ácidos grasos y azúcares. 


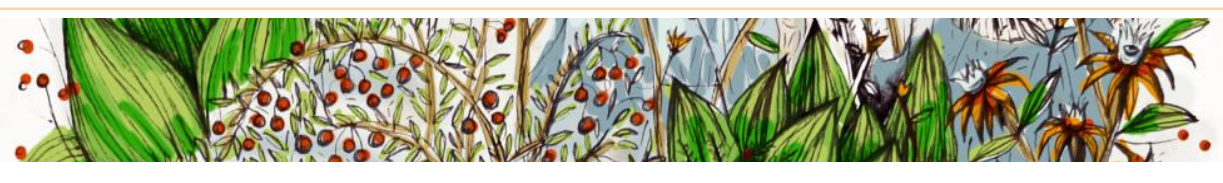

Sección III: Discusión y conclusiones 


\section{Discusión y Conclusiones}

Como se mencionó en la Introducción (capítulo 1), el objetivo general de la presente tesis fue estudiar la interacción entre los grupos humanos y las plantas en las sociedades cazadoras recolectoras que habitaron la CNSC. En este sentido, los resultados permitieron abordar las prácticas de recolección y los criterios de selección de las plantas silvestres, la gestión de recursos leñosos y no leñosos y algunas de las prácticas poscolecta que llevaron a cabo estos grupos humanos. Para la realización de un modelo de interpretación que permitiera elaborar hipótesis y contrastarlas con el registro arqueobotánico, se utilizaron líneas de investigación como la lectura crítica de las fuentes documentales y la etnobotánica. En el caso de esta última, se pudo observar y analizar a través del discurso y la corporalidad, el habitus (Bourdieu 1972, 1991) así como desde la perspectiva teórica (Toledo 1992) donde se considera la conjunción del cosmos, corpus y praxis dimensiones de la complejidad del comportamiento humano y de las prácticas de recolección en particular. En ese sentido, se considera que la aproximación holística del estudio de la recolección de vegetales silvestres ha permitido obtener mayor información y nuevas líneas de investigación que estudios más acotados, para el desarrollo de la investigación en CNSC en el que la tesis se enmarcó como exploratoria.

Para la contrastación de la Hipótesis 1 "Las sociedades cazadores recolectoras de la CNSC utilizaron y consumieron plantas silvestres" es necesario vincular los resultados de las distintas líneas de investigación desarrolladas en esta tesis. En todos los registros de información (Capítulo 4: fuentes bibliográficas del siglo XVI al XXI; Capítulo 5: registro etnobotánico; Capítulo 6: registro arqueobotánico de Patagonia continental exceptuando el área de estudio de la presente tesis; y Capítulos 7 al 12 estudios arqueobotánicos de CNSC en particular) se observó que: las familias botánicas que predominaron en el consumo y utilización por los grupos humanos, en distintos

períodos cronológicos fueron: Asteraceae y Fabaceae. En el análisis de fuentes bibliográficas (capítulo 4) y del registro arqueobotánico de Patagonia continental (capítulo 6) también predominó la familia Apiaceae. En este último se destaca también la prevalencia de Poaceae, que en los otros registros presenta menor frecuencia de 
menciones o no está presente (i.e. etno y arqueobotánico de CNSC). En el caso de CNSC, las familias que prevalecieron a través del registro antracológico, carpológico y de microrrestos son, además de Asteraceae y Fabaceae: Anacardiaceae, Berberidaceae, Chenopodiaceae y Solanaceae. Si bien éstas últimas también están presentes en la base de datos realizada en el capítulo 4, en la información brindada por los entrevistados en el capítulo 5 y en el registro arqueobotánico de Patagonia continental del capítulo 6, no son predominantes como sucede en el registro arqueobotánico de CNSC.

En el registro arqueobotánico (macrorrestos leñosos, no leñosos y microrrestos) del área de estudio, CNSC, se identificaron 11 familias y 16 taxa: Adesmia, Atriplex/Suaeda, Berberis, Bulnesia, Chuquiraga, cf. Cercidium, cf. Grindelia, Colliguaja, Discaria, Ephedra, Lycium, Pinus, Prosopidastrum, Prosopis. El 87,5\% (n $=14)$ de los géneros son nativos locales, el $12,5 \%$ son nativos no locales $(n=2)$ y se ha discutido en el capítulo 10 su posible ingreso al sitio Alero 4 como contaminación, al igual que el $6,25 \%$ de los taxa, que son exóticos y muy probablemente constituyan una intrusión de fogones actuales (i.e. Pinus). Dentro de estos resultados se destaca una riqueza de 15 géneros utilizados como combustibles, los que fueron identificados en los macrorrestos leñosos arqueológicos. Si se comparan estos resultados con los de los capítulos 4, 5 y 6 podemos decir que dicha riqueza de géneros es similar a la registrada para la misma categoría en las fuentes bibliográficas $(n=16)$ y en la recopilación bibliográfica del registro arqueobotánico de patagonia continental $(\mathrm{n}=17)$. Sin embargo, para otras categorías de uso (i.e. comestible, medicinal, tecnológica, entre otras), la riqueza específica de los taxa seleccionados es mayor en las líneas de evidencia presentadas en los capítulos 4, 5 y 6 que en el registro arqueobotánico de CNSC.

A su vez, se observan diferencias entre las categorías de uso alimenticio y medicinal entre el registro de fuentes documental y el etnobotánico actual de CNSC. En el primero predomina la categoría de uso alimenticia, mientras que en las entrevistas etnobotánicas esta categoría desciende abruptamente, predominando las categorías medicinal y combustible. Se considera que la incorporación al consumo de productos manufacturados e industrializados explicaría este descenso. En el registro arqueobotánico de Patagonia continental y de CNSC en particular es difícil cuantificar 
las categorías de uso, aunque, como se menciona más arriba hay menor diversidad en general a excepción del uso combustible.

Es importante mencionar aquí que algunos géneros estuvieron presentes como representantes de más de una categoría de uso. Por ejemplo, Berberis y Schinus no sólo fueron identificados en los macrorrestos vegetales leñosos como combustibles. En el caso del primero, además de leña para combustible, como se mencionó en el capítulo 5, este género es apreciado también por sus frutos para elaborar bebidas y alimento, sus frutos y hojas son medicinales y las raíces recursos tintóreos. Aunque en el registro etnobotánico no se haya registrado, su madera es además un recurso tecnológico, ya que, también se identificó en el registro arqueológico de CNSC en un fragmento de arpón manufacturado con Berberis. Como se mencionó en el capítulo 11, la madera de este género ha sido utilizada por grupos Selknam para la confección de astiles y arcos (Caruso et al. 2011). Ratto y Marconetto (2011) en su identificación de maderas de astiles fueguinos también registran la utilización de este género para la manufactura de estos instrumentos. Los resultados de Cueto y colaboradores permiten sugerir que Berberis es una madera dura a semidura (capítulo 7 de la presente tesis) que puede ser trabajada tanto con raspadores como con denticulados, dos tipos de instrumentos presentes en los sitios del área de estudio (Cueto et al. 2010; Ambrústolo et al. 2011).

En el caso de Schinus se identificaron frutos y hojas carbonizadas en el sitio Nido del Águila (capítulo 9). La presencia de estos restos en el sitio es discutida en el capítulo antes mencionado, sin embargo, se considera un ejemplo en el que las categorías de uso pueden estar solapándose en el registro arqueológico. Si bien es posible que, tanto frutos como hojas puedan haber ingresado al sitio junto con el resto de ramas y troncos de Schinus, no puede descartarse que ambos órganos de dicha planta puedan haber tenido otros usos (i.e. comestible, medicinal). Entonces, es importante en las inferencias de este tipo de registro tener en cuenta que estos taxa pueden ser considerados como plantas multipropósito. En este sentido, Etkin y Ross (1994), por ejemplo, observan en el caso de plantas silvestres que funcionan simultáneamente como alimenticias y medicinales, cómo algunas veces se advierte su uso primero a través de su empleo como "remedio", y otras, por el contrario, a través de su empleo en la alimentación, en tanto que habitualmente un uso queda solapado por el otro. 
A excepción del caso anterior, no se recuperaron hasta el momento otros macrorrestos vegetales que puedan indicar el consumo alimenticio de estas plantas silvestres en CNSC. En el análisis de microrrestos del instrumento M26SJ, de la colección del Museo del Hombre y su Entorno (capítulo 13), potencialmente utilizado en la molienda se identificaron 5 granos de almidón aff. Prosopis. En el caso del instrumento M17PM, potencialmente utilizado en la molienda, se recuperaron numerosos restos de tejido vegetal, entre ellos, un fragmento de epidermis identificado como Prosopidastrum globosum. Si bien, es escasa la cantidad de granos de almidón recuperada y provienen de un instrumento de colección, es positivo el hallazgo de estos microrrestos que podrían estar dando cuenta del uso alimenticio de este taxa que ya ha sido recuperado en otras áreas de Patagonia (Capparelli y Prates 2010, Lema et al. 2012) y es muy común en sitios arqueológicos de toda la Argentina (Cappareli 2007, Giovannetti et al. 2008). En el caso de Prospidastrum globosum, la identificación a través de la epidermis de hoja, así como los componentes químicos que presenta la planta en la actualidad pueden estar sugiriendo un uso alimenticio (Steibel 1997) y medicinal de la especie (Martínez Flores et al. 2002) (ver Discusión y Conclusiones 13.3.4.2).

De lo discutido anteriormente se considera que es posible corroborar la Hipótesis 1, entendiendo que los grupos cazadores recolectores que habitaron CNSC utilizaron recursos vegetales silvestres: como combustible para la realización de distintos tipos de fuego, como recurso tecnológico, como alimento, y posiblemente como medicina. La primera categoría es la más abundante, y la riqueza de taxa utilizados fue amplia.

Es posible que el consumo de recursos vegetales silvestres como alimento se encuentre subestimado en el área de estudio, debido a que muchas de las especies de esta categoría (capítulo 4) no requieren de procesamiento alguno que permita visibilizar evidencias en el registro arqueobotánico. Es llamativo que los resultados del análisis de fuentes documentales en el capítulo 4, reflejen que un 35,4\% de las menciones sobre uso de plantas silvestres sean utilizadas como alimento. En el capítulo 5, los resultados de las entrevistas etnobotánicas actuales marcaban un descenso en la utilización de recursos vegetales silvestres con respecto a los documentos históricos: solo se registra el $9 \%$ de las menciones totales en referencia a este uso. En el capítulo 6, a través de la recopilación de trabajos arqueobotánicos de Patagonia continental, y sin poder establecer una cuantificación por la disparidad de las metodologías de recuperación y 
análisis de los registros, se puede mencionar la presencia de evidencias de procesamiento de plantas silvestres que sugerirían su consumo como alimento (i.e. rizomas carbonizados de Oxalis articulata asociados al fogón, Arrigoni 2002, Zea mays Pérez y Erra 2011 y Lema et al. 2012). De esta manera, las evidencias de microrrestos af. Prosopis de CNSC permiten una primera aproximación al registro de este tipo de uso en el área que tendrá que ser explorada en el futuro con mayor intensidad.

Se considera importante comenzar a incluir en próximos trabajos otras líneas de evidencias indirectas que permitan recuperar evidencias del consumo de recursos vegetales silvestres como alimento. Por ejemplo, es importante mencionar el trabajo de Gómez Otero et al. (2000) quienes realizan estudios de isótopos estables de colágeno y apatita aplicados sobre 11 esqueletos humanos de la costa norte de Chubut. Los resultados sugieren para esta muestra una dieta terrestre basada en el consumo de guanaco, de otros tipos de animales y de plantas, aunque en algunos individuos un porcentaje de la dieta (35\%) estuvo compuesta por alimentos marinos. En este trabajo los autores mencionan el análisis de isótopos estables sobre un tiesto cerámico, cuyo resultado habría sugerido el procesamiento de plantas en el interior de la vasija (Gómez Otero et al. 2000). En el valle del río Neuquén, Lema et al. (2012) a través de análisis de microrrestos identificaron almidones de Prosopis en manos y molinos del sitio Aquihuecó (4.200 años AP) y Prosopis y Zea mays en artefactos de molienda recuperados en el sitio Michacheo (1750 años AP). En el sitio Parque Nacional Lanín (Neuquén), Pérez y Erra (2011) realizan estudios de microrrestos en una cerámica donde identificaron fitolitos de Zea mays (730 \pm 80 AP y $920 \pm 60$ AP). Estudios sobre patologías bucales en cráneos humanos del noreste de Patagonia (valle inferior del Río Negro) también evidenciaron la incorporación progresiva en la dieta de elementos cariogénicos donde los recursos vegetales del espinal como el algarrobo, chañar, caldén entre otros, habrían tenido una importancia mayor a partir del 1000 AP (Menéndez 2010).

En la CNSC se realizaron estudios isotópicos sobre restos humanos recuperados a partir de rescates arqueológicos y de otros provenientes de la colección del Museo del Hombre y su Entorno, de Caleta Olivia (Moreno et al. 2011, Zilio et al. 2014). Los resultados evidencian, según Zilio et al. (2014), que para un primer período (2300-1500 AP) se habrían identificado diversos tipos de dietas. Tanto mixtas, con aportes de 
recursos marinos y terrestres, como predominantemente marinas y/o terrestres. Para el segundo período (1100-300 AP) en cambio, los valores isotópicos evidencian solo dietas mixtas. Este trabajo compara, además, sus resultados con los desarrollados por Tessone (2010) en la zona de Sierras Coloradas (centro oeste de Santa Cruz), cuyas muestras sugieren dietas basadas en consumo de recursos terrestres con vía fotosintética $\mathrm{C}_{3}$ a diferencia de los resultados de dietas marinas de CNSC. Es importante, entonces, en CNSC desarrollar estudios de ácidos grasos y microrestos en fragmentos de cerámica y continuar el análisis de artefactos potencialmente utilizados en la molienda para profundizar en el consumo de recursos silvestres como aporte a la dieta marina y mixta. Se considera importante continuar con la búsqueda de evidencias indirectas que puedan visibilizar las prácticas de consumo de recursos vegetales silvestres, no sólo para la dieta sino también, para medicina, bebidas fermentas (categorías que se registraron en las fuentes documentales, ver capítulo 4) pero de las cuales aún no se posee su correlato arqueológico. Es importante mencionar que en las fuentes documentales del capítulo 4 la categoría de uso medicinal tuvo un $22,2 \%$ de las menciones totales, mientras que actualmente, para las localidades de Puerto Deseado y Tellier, los pobladores locales entrevistados refieren en un $47 \%$ a esta categoría, más que el doble que en las fuentes documentales. Es notable que, de la recopilación de trabajos arqueobotánicos de Patagonia continental Argentina, no se infiere esta categoría de uso para ningún sitio arqueológico, y que, en CNSC, sólo una especie puede ser interpretada por sus propiedades como terapéutica, la epidermis de Prospidastrum globosum antes mencionada.

En relación a otras categorías de uso, se considera que la riqueza de taxa utilizados en la gestión de recursos leñosos, da cuenta de un conocimiento y experimentación sobre los mismos, que se profundizarán más adelante. Es llamativo, en relación a otras categorías la ausencia de cestería, órganos reservantes expuestos al fuego, material constructivo (toldos), tintóreos, fibras, bases o leños utilizados en el encendido del fuego tal como aparece en otros sitios de Patagonia continental (ver capítulo 4 y 6). También es posible que la ausencia de estas categorías se deban a la escasa preservación de los mismos y por lo tanto su ausencia en el registro arqueológico de CNSC. 
En relación a la contrastación de la Hipótesis 1.1.: "Existió una gestión de los recursos vegetales silvestres: recolección, acarreo, circulación, almacenaje, procesamiento, consumo y descarte" es necesario caracterizar el estado de los restos vegetales recuperados en la CNSC. La mayor parte de los restos recuperados en los sitios del área de estudio se encuentran carbonizados (a excepción de los microrrestos). Puesto que la mayor parte de los vestigios fueron recolectados y utilizados como leña (ver discusiones de cada contexto arqueológico en el que fueron hallados, Capítulos 8 a 10), se puede decir que la etapa de la gestión de los recursos que se observa es la final.

En el caso de los frutos y hojas carbonizadas de Schinus del sitio Nido del Águila, es posible inferir su recolección, debido al contexto arqueológico en el que se encontraba y que, por lo tanto, su ubicuidad en el sitio no se debe a causas naturales (capítulo 9). Se recuperaron de un fogón en cubeta asociados a restos líticos y óseos lo que evidenciaría un fuego antrópico. En este sentido, los frutos y hojas podrían haber sido arrojadas al fuego junto con las ramas combustibles (Archila 2005) aunque no se puede dejar de considerar que pueden haber sido objeto de descarte de algún procesamiento del cual no se obtuvieron evidencias.

Por otro lado, es importante también para contrastar esta hipótesis 1.1 considerar el fragmento de arpón de madera confeccionado con madera de Berberis del sitio Cueva del Negro. La asociación de este fragmento medial de arpón con seis arpones de hueso recuperados en estratigrafía en el sitio Cueva del Negro (capítulo 11) puede evidenciar más de una etapa en la gestión de los recursos silvestres. En primer lugar, se puede considerar que, si bien por la identificación taxonómica no se puede confirmar la manufactura local de dicho artefacto (ver Discusión en capítulo 11) la presencia de un artefacto de hueso que, por sus características morfológicas y modificaciones antrópicas probablemente corresponda a una preforma de arpón recuperado en la capa 3 , cuadrícula 3, asociada a otras puntas de arpón, podría reforzar la hipótesis de manufactura local de todos los cabezales de arpón incluido el de madera (Beretta et al. 2013a). En segundo lugar, dicho instrumento presenta sobre la cara lateral izquierda del fuste marcas de corte tipo V poco profundas, cortas y oblicuas a las fibras de la madera (Capparelli et al. 2009 y Beretta et al. 2013a). También posee estrías poco profundas paralelas a las fibras, que se desarrollan de un extremo al otro del fragmento de arpón. En el trabajo experimental de Cueto y colaboradores (2010) estas líneas se producían al 
trabajar madera de Berberis y Prosopis con artefactos líticos de tipo raspador y denticulados. Por otra parte, el fragmento de arpón presenta rastros de alteración térmica, encontrándose mayormente alterada la punta y en menor medida la porción distal de la pieza. Aunque su tamaño inicial debe haber sido reducido, dicha carbonización parcial pudo haber producido una mayor reducción ulterior. La alteración térmica se podría interpretar, por un lado, como resultado de la aplicación del fuego como un recurso tecnológico para la manufactura de equipos de cacería y pesca (ver por ej. Archila Montañez 2005:326). Por otro lado, se podría considerar como producto de una acción accidental del fuego ejercida durante o posteriormente al proceso de descarte. Si fuera éste el caso, como no todo el arpón sino los dos tercios distales son los que se hallan carbonizados, se podría decir que o bien dicho fogón no tuvo las características necesarias como para lograr una carbonización completa de la madera, o bien el arpón no estaba lo suficientemente próximo al fuego.

A través de los resultados obtenidos podemos apoyar la hipótesis aunque no fue posible encontrar todas las etapas de la gestión de los recursos vegetales silvestres en el registro arqueobotánico de CNSC.

En cuanto a la Hipótesis 2: “En la interacción hombre-planta existieron criterios organolépticos, de propiedades combustibles de la madera, simbólicos, de disponibilidad que definieron la selección y recolección de plantas dentro de las sociedades cazadoras recolectoras de la CNSC", la contrastación se realiza en dos etapas de análisis. La primera a través del modelo realizado con la conjunción de los resultados de las fuentes documentales (Capítulo 4) y la información que brindaron los pobladores locales de CNSC (Capítulo 5). La segunda etapa se realiza a través del registro arqueobotánico de CNSC.

A partir del modelo desarrollado con la información arriba detallada (capítulo 5), los criterios de selección que actuarían en la esfera de precolecta y colecta estarían asociados principalmente a las características organolépticas de las plantas (i.e. aroma, sabor, color y textura) tal como observó Molares (2010) para las comunidades mapuches del oeste de Chubut. En el caso de las maderas para combustible, los criterios de selección registrados en los pobladores locales de Tellier y Puerto Deseado fueron: facilidad para hacer brasa, duración de la brasa, poder calórico, facilidad para el encendido, producción de humo, disponibilidad de la especie y calibre de la leña 
(troncos más grandes para mantener el fuego, y de calibres más chicos para iniciarlos). Estos criterios organolépticos así como las propiedades combustibles de las maderas se encuentran asociados a las características de la vegetación de la estepa patagónica. A continuación se describen qué propiedades químicas presentan las plantas para tener aroma, sabor o resinas.

Por otra parte, se registró que las plantas de la estepa arbustiva del Golfo San Jorge (Oliva et al. 2001), presentan una alta producción de metabolitos secundarios, entre ellos aceites esenciales, resinas, taninos, flavonoides, alcaloides, entre otros (i.e. Guerra et al. 2012, Berezosky y Mazzuca 2010, Molares 2010, Molares y Ladio 2012b entre otros, ver capítulo 5). Guerra y colaboradores (2012) realizaron estudios anatómicos y de composición química sobre 15 plantas (arbustos y subarbustos) de la estepa de Chubut. En este trabajo se analiza el vínculo entre la composición química de las plantas y su adpatación a los ambientes áridos. En este sentido esta vegetación presenta un alto contenido de alcaloides y aceites esenciales. Estos últimos, según los autores, parecerían haber tenido un rol importante en la protección contra la sequía ya que evitan la evaporación del agua y actúan por difracción de la luz. Se considera entonces que la alta producción de aceites esenciales es una propiedad xerofítica dada su abundancia en ambientes áridos (Chopra et al. 1960, Bezic et al. 2003, Paris y Dillema 1960 en Guerra et al. 2012). También, Gershenzon (1994) menciona que en zonas semiáridas las resinas pueden constituir hasta el 30\% del peso seco de la hoja.

Por otra parte, la descripción anatómica de las maderas de los arbustos y subarbustos de la colección de referencia (capítulo 7) evidenciaron que la mayor parte de las especies descriptas presentan: distribución de los poros en bandas tangenciales en el leño temprano y dendrítica en el leño tardío (sobre todo en las Asteraceae). Este carácter se asocia a la adaptación a la aridez (Carlquist 1987, Giménez 1988 en Guerra et al. 2012). En cuanto a los elementos de vasos, varios taxa (i.e. Chuquiraga, Colliguaja, Lepidophyllum, entre otros) registraron elementos cortos y finos. Estas características son observadas por Guerra et al. (2012) para las especies que él analiza, vinculándolas además con la adaptación a ambientes xerófitos puesto que, los elementos vasculares más cortos son más fuertes y resisten grandes presiones y embolias que los vasos largos no toleran (Moglia y Giménez 1988). Por otra parte, a excepción de Prosopis denudans, y de Fabiana imbricata, las demás especies analizadas presentan espesamientos 
reticulados y espiralados en los elementos de vasos, especialmente las Asteraceae. De acuerdo a Carlquist (1966) y a Guerra et al. (2012), el espesamiento otorga más resistencia a las paredes y es un carácter de adaptación ecológica. Como mencionan también estos últimos autores, el parénquima confluente paratraqueal, permite la comunicación entre el parénquima axial y radial. Este tejido tiene un rol importante para la acumulación de sustancias de reserva y la translocación de azúcares. Este carácter se observó en varias de las especies descriptas en el capítulo 7 (i.e. Baccharis darwinii, Adesmia boronioides, Prosopis denudans, Mulguraeae tridens, Prospidastrum globosum).

En este sentido, las percepciones organolépticas y los criterios de selección de las maderas que mencionan los informantes de CNSC tienen su fundamento empírico, y además se encuentra vinculado a las características anatómicas y fisiológicas de las plantas de la estepa arbustiva del Golfo San Jorge.

En el registro arqueobotánico de CNSC, es importante mencionar que las maderas que predominaron en gran parte en los sitios arqueológicos estudiados corresponden a Schinus, Berberis, Lycium, Senecio/Baccharis y Atriplex/Suaeda (Tabla 14.1). La frecuencia de aparición de estas maderas y sus combinaciones en los sitios de CNSC presenta similitudes a las maderas elegidas por los pobladores del área de estudio en la actualidad, si bien no es posible extrapolar directamente la analogía. Es importante mencionar que desde el Holoceno medio al tardío, estos géneros fueron utilizados en altas densidades porcentuales, tanto en sitios concheros, aleros, cueva, y al aire libre. Los géneros seleccionados por distintos grupos cazadores recolectores de CNSC a lo largo del tiempo presentan las siguientes características: Atriplex/Suaeda una madera dura y pesada, Schinus y Berberis, son maderas semiduras y semipesadas, Lycium una madera blanda y liviana y Senecio/Baccharis maderas muy blandas y muy livianas. Estos leños tienen distinto calibre de modo que Schinus y Berberis brindan brasa y fuego duradero, Lycium se encuentra en una posición intermedia y Atriplex/Suaeda y Senecio /Baccharis tienen calibres pequeños que podrían facilitar un rápido encendido y/o colaborar en la producción de cenizas con sales (Atriplex/Suaeda).

Es importante mencionar la combinación de maderas resinosas como Schinus y Senecio/Baccharis que también estimulan la llama del fuego. En este sentido, se considera que a partir de las propiedades de las maderas, si bien se recolectaron otros 
géneros más, el predominio de estos taxa evidencia su selección para la realización de distintos tipos de fuegos.

En el caso del fragmento de arpón confeccionado con madera de Berberis recuperado en el sitio Cueva del Negro (capítulo 11), los estudios experimentales realizados por Cueto y colaboradores (2010), Ratto y Marconetto (2011), Caruso et al. (2011) reafirman las cualidades de la madera de este género para la confección de artefactos. Su identificación taxonómica permitió considerarla una madera preponderante para la confección de los astiles (Caruso et al. 2011). Asimismo, Ratto y Marconetto (2011), también identificaron esta madera en astiles de arpones fueguinos de la colección del Museo Etnográfico Juan B. Ambrosetti. Para reconocer las propiedades físicas de esta madera Ratto y Marconetto (2011) relevaron caracteres cualitativos y cuantitativos que permitieran definir las propiedades de la madera para la confección de artefactos. Los valores del largo de las fibras presentaron medidas de entre 361 a $505 \mu \mathrm{m}$, por lo que se consideran elementos cortos, característica asociada a la resistencia de las maderas. También, las autoras registraron que la pared celular de este género es espesa, lo que produce densidad y dureza (Ratto y Marconetto 2011:145).

Estos estudios, realizados sobre otros artefactos de colecciones etnográficas refuerzan la hipótesis de que existió una selección de la madera, en este caso sólo hemos podido confirmar la manufactura del fragmento de arpón.

En cuanto a los resultados de microrrestos la presencia de almidones aff. Prosopis y tejido parenquimático de Prosopidastrum globosum, puede estar indicando la selección de especies alimenticias y medicinales. En el primer caso los estudios de Capparelli (2007) registran las percepciones de los pobladores del Valle de Hualfín sobre Prosopis flexuosa y $P$. chilensis destacándose el sabor, el aroma y la textura (suavidad) en la selección de una u otra especie. También registra no sólo el consumo de estas especies como alimento (i.e. arrope, patay, añapa, ulpo) sino también el consumo de vainas frescas $\mathrm{o}$ en forma de arrope por sus propiedades medicinales (antitusivas $\mathrm{y}$ antiasmáticas) (Capparelli 2007:115). En el registro arqueobotánico de Patagonia, en el sitio Angostura I, esta autora identifica vainas carbonizadas de Prosopis alpataco y $P$. denudans para el Holoceno tardío, interpretando su consumo como alimento (Capparelli y Prates en prensa). Sobre Prosopidastrum globosum existen trabajos sobre su composición química donde se registra la presencia de flavonoides en la parte aérea de 
la planta y las semillas (Agnese et al. 1986), lo que podría sugerir su utilización como medicina.

A partir del registro arqueobotánico de CNSC, se considera que los grupos cazadores recolectores seleccionaron las plantas para distintos fines. No es suficiente aún el tipo de registro recuperado como para evaluar en qué medida se aplicaron en el pasado criterios de selección organolépticos similares a aquellos que en la actualidad perciben los pobladores locales.

Es importante mencionar que, vincular información de las fuentes documentales (capítulo 4) con la recopilación de trabajos arqueobotánicos de Patagónia continental (capítulo 7), puede ser una vía para inferir criterios de selección a través de las percepciones organolépticas. En este sentido un comentario de Claraz ([1865-1866] 2008) describe su propia percepción de una planta con órganos subterráneos: “La planta más valiosa del río es una trepadora, una convolvulácea con flores amarillas. Los indios la llaman yahcha. Sus raíces se parecen a la de mandioca dulce. Crudas tienen un sabor algo amargo: comidas así, se dice que causan dolores de vientre. Pero tostadas en ceniza caliente tienen el mismo gusto que las papas dulces y casi el de las castañas. Hervidas en agua, igualmente. El agua de la cocción adquiere un color pardo rojizo” (Claraz [1865-66] 2008: 112). En la recopilación bibliográfica del registro arqueobotánico de Patagonia continental se recuperaron en el Alero Sendero de Interpretación (Parque Nacional Los Alerces, Chubut) rizomas carbonizados asociados a un fogón de Oxalis articulata (Arrigoni 2002). Si bien no se puede asociar directamente que la técnica de cocción de rizomas esté vinculada a la palatabilidad de esta especie sería interesante realizar estudios experimentales para corroborar desde la percepción etic dichas referencias y proponer nuevas hipótesis en relación a los criterios que están guiando la utilización de determinadas especies y no otras.

Por último, en el caso de las leñas y teniendo en cuenta el registro palinológico como referente de los cambios de vegetación de las condiciones climáticas a lo largo del tiempo, sí se considera que las propiedades intrínsecas de las maderas han sido una guía para su selección. En cuanto a otros criterios como los tabús o preferencias simbólicas no pudieron ser inferidas hasta el momento con la evidencia arqueobotánica disponible en CNSC. No se descarta que en un futuro con mayor superficie excavada y otros tipos de contextos arqueológicos sea posible profundizar sobre estas variables 
Para contrastar la Hipótesis 3: "Las prácticas de recolección de plantas silvestres se desarrollan en el marco de las estrategias de subsistencia y movilidad de los grupos de CNSC" se va a hacer énfasis en los resultados del análisis antracológico (Capítulos 8, 9 y 10, ver Tabla 14.1). En este sentido se analizarán en primer lugar los resultados de los sitios con componentes más tempranos. Para el Holoceno medio, el sitio Alero El Oriental, ubicado en el sector sur de la Ría Deseado en el subsector Bahía del Oso Marino (Zubimendi 2010) y a 1,2 km de la costa, presenta el fechado más antiguo para la CNSC ( $c a .7000$ años AP). En este período se registraron cinco fogones planos (sensu Ancibor y Pérez de Micou 2002, Marconetto 2005), de los cuales se analizaron los carbones vegetales de tres de ellos ( $\mathrm{L}, \mathrm{H}$ y J), donde el taxa que prevaleció en todos fue Schinus con el 40 y el $60 \%$ de densidad de carbones, acompañado por Berberis $(26 \%$, fogón H) y Senecio/Baccharis (14\%, fogón J). Estos fogones, a excepción del L, se encontraron asociados a restos malacológicos, líticos y óseos (guanaco y lobo marino). Es importante mencionar que en el fogón L se registraron aberturas en anillo en un carbón de Schinus diagnósticas de temperaturas próximas a los $700{ }^{\circ} \mathrm{C}$. Este contexto sugeriría fogones con capacidad de producir brasa y por lo tanto de cierta duración. Para este período y, a partir del registro lítico (i.e. artefactos bifaciales que ingresaron al sitio, obsidiana que proviene de Pampa del Asador), Ambrústolo y colaboradores (2011) sugieren una fase de exploración inicial del sector de la costa y peri-costero (sensu Borrero 1994-1995). Sin embargo, la leña utilizada en forma predominante en los sitios abre interrogantes en relación a esta premisa. Para los $c a .7000$ años AP los estudios palinológicos realizados en la Estancia La María y Los Toldos reflejan una vegetación con predominio de una comunidad arbustiva graminosa de Asteraceae subf. Asteroidea con Nassauvia, Ephedra frustillata y Solanaceae (De Porras 2010). No habría en el registro polínico de la meseta central polen de Schinus para ese período (Oliva et al. 2001). Es llamativo entonces, que predominen Schinus en los fogones del Holoceno medio del Alero El Oriental. En respuesta a este interrogante pueden considerarse dos situaciones: la primera, que habría que realizar estudios palinológicos para el área de CNSC y comparar estos resultados con los obtenidos del análisis antracológico. Segundo, si Schinus no estaba en el interior (meseta central) y sí se encontraba en la franja costera, entonces, es posible decir que los grupos cazadores recolectores conocían 
las propiedades de este taxa por lo cual se podría sugerir que no se trataría de una fase de exploración inicial.

Para el Holoceno tardío, donde el registro palinológico evidencia una comunidad vegetal análoga a la actual, en el sitio Alero El Oriental se registraron seis fogones. En cuanto a la morfología de los mismos, cinco fogones eran planos y uno en cubeta, uno de ellos (F) fue fechado en $1530 \pm 60$ años AP (LP-2267). A excepción de la estructura de combustión D, en los fogones A, B, C, E y F predominó Senecio/Baccharis con una densidad porcentual de carbones de entre 58,5\% (B) a 94,7\% (E). En este sentido, se tratan de fogones de maderas muy blandas, de baja densidad, de rápido encendido que no producen brasa. Estas estructuras de combustión reforzarían la premisa de que para este período cronológico el alero habría sido utilizado de forma redundante, efímera y poco intensiva. Es decir, este tipo de fogones serían de corta duración debido al rápido tiempo en que se consumen estos taxa. Esta ocupación efímera y redundante podría estar relacionada con el consumo de recursos terrestres en circuitos logísticos mientras que para este período se registra un aprovechamiento intensivo de la costa. El único caso en que podría tratarse de un fogón de mayor intensidad es el $\mathrm{D}$, que tiene un predominio de Schinus (67\%) y en segundo lugar de Berberis (26\%), maderas de alta densidad, con capacidad de producir brasa y calor. Asociado a este fogón se recuperaron artefactos con alteración térmica (microlascas y lascas de adelgazamiento), lo que permite discutir su funcionalidad en relación a actividades de talla alrededor del fogón. Este caso sería un ejemplo de la interpretación que propone Paunero (2004) para considerar al fogón como estructurador del espacio en sitios aleros. También se observa en la estratigrafía y el área excavada de este sitio la estructuración del espacio, donde la ubicación de los fogones es similar en los dos períodos temporales registrados. Para el Holoceno tardío, los taxa identificados como combustible se encuentran en los alrededores del sitio.

Para este último período cronológico, el Alero 4, ubicado sobre el margen norte de la ría Deseado pero en el mismo sector definido por Zubimendi (2010), evidencia otro tipo contexto arqueológico. Este sitio ubicado en el cañadón Torcido, se encuentra a $700 \mathrm{~m}$ de la ría Deseado y a $8 \mathrm{~km}$ de la costa atlántica. A través del fechado de un hueso de guanaco con marcas de corte se obtuvo un fechado de $2760 \pm 60$ años AP (LP-2762) en tanto que sobre carbones vegetales del fogón C se obtuvo otro fechado de $1690 \pm 90$ AP 
años AP (LP-2908). Este alero es un sitio unicomponente donde se recuperaron restos malacológicos, líticos y óseos. Entre estos últimos se identificó un NMI (número mínimo de individuos) de un guanaco (Lama guanicoe) y un NMI de tres lobos (Otaria flavescens): un adulto y dos juveniles. También es importante mencionar la alta frecuencia de raspadores dentro del conjunto lítico del sitio. Este contexto permite sugerir que se trata de un sitio de actividades múltiples. En este alero se recuperaron tres fogones planos (A, B y C). En el primero de ellos tres taxa alcanzan el 60\% de la densidad de los carbones: Schinus, Senecio/Baccharis y Berberis, y reflejan la combinación de maderas de rápido encendido (Senecio/Baccharis) con otras de producción de brasa y calor. Este fogón se encuentra asociado a material lítico termoalterado, restos malacológicos y óseos por lo que se sugiere una funcionalidad relacionada al procesamiento de recursos marinos y terrestres. En el fogón $\mathrm{B}$, en cambio, sólo Senecio/Baccharis alcanza el 60\% de la densidad porcentual de carbones, siendo una madera muy blanda y liviana. Se registraron asociados al fogón un hueso de guanaco sin evidencias de alteración térmica y un filo frontal de raspador. No puede asignarse una funcionalidad específica a este fogón, sin embargo, es importante destacar la gran densidad de individuos por litro de sedimento. El fogón C, por el contrario, presenta un predominio de Schinus del 50\% acompañado por Berberis con el 10\%. Este último podría estar asociado a actividades tecnológicas, dada la alta frecuencia de raspadores en el sitio en general y la presencia de un punzón en hueso. Entonces, estos tres casos son contextos distintos de los presentados para el Holoceno tardío en el Alero El Oriental. Mientras en este último los fogones estaban constituidos en su mayoría por maderas muy blandas y de muy baja densidad, de poca duración, en el Alero 4 se observan maderas de alta densidad (fogón A y C) y en el caso del B, a pesar de presentar madera muy blanda si se considera la alta densidad de carbones por litro de sedimento, se trata de ocupaciones más duraderas vinculadas a actividades de procesamiento de animales, tecnológicas, entre otras (Ambrústolo y Ciampagna 2014). En este sitio también fueron recuperados carbones dispersos provenientes de las cuadrículas 6 y 7, capa 1 y niveles $2 \mathrm{a}, \mathrm{b}, \mathrm{c}$, d, e y f. A partir de su identificación se observó que Schinus, Berberis, Senecio/ Baccharis presentaron el 100\% de ubicuidad, seguidos por Lycium (85\%) y Atriplex/Suaeada (71,4\%). Se observa, entonces, la combinación de maderas duras, de alta densidad (Atriplex/Suaeda, Berberis, Schinus), 
densidad intermedia (Lycium) y muy baja intensidad (Senecio/Baccharis). Todas las especies identificadas en este sitio, a excepción de aquellas que ingresaron al sitio por contaminación, se encuentran disponibles en el cañadón donde se ubica el sitio.

Siguiendo el período del Holoceno tardío y para el mismo sector sur de la ría Deseado, subsector Isla Lobos (Zubimendi 2010), es importante incorporar a la discusión al sitio conchero 112, debido a su cronología: $2870 \pm 60$ años AP (LP 2141). Como se mencionó más arriba, para este momento debido a la alta densidad de sitios y la redundancia de los espacios sobre la franja costera se considera que hay un uso intensivo de la costa y de sus recursos naturales. El sitio 112 es una lente de valvas donde predominan los mejillones y en menor medida las lapas, que se encuentra ubicado a $100 \mathrm{~m}$ de la línea de costa actual emplazado sobre el manto eólico (Hammond 2013). En superficie se registra además, un sedimento de coloración gris, restos líticos, entre ellos tres boleadoras, y restos óseos, entre los que se destacan tres vértebras articuladas de cetáceos y una mandíbula humana muy meteorizada con cinco piezas dentales. Es importante mencionar que las valvas se hallaban en su mayoría calcinadas y su estructura muy debilitada, siendo que la lente se encontraba sobre una capa de sedimentos quemados y los moluscos tenían un sedimento muy fino de color gris que los cubría (Hammond 2013). Los carbones dispersos del nivel 1 también presentaron la misma capa de sedimento. Su identificación taxonómica permitió registrar la prevalencia de Schinus con un $88 \%$ de densidad. La presencia de valvas calcinadas, el sedimento gris sobre las valvas y carbones $\mathrm{y}$, dado que no se observaron caracteres diagnósticos de altas temperaturas (aberturas en anillos, $700^{\circ} \mathrm{C}$ ) la calcinación podría sugerir la cocción de las valvas en fuego directo o muy próximo a las brasas. Teniendo en cuenta que la vegetación sería análoga a la actual (De Porras 2010) la madera de Schinus se encontraría disponible en los alrededores, además de una variedad mayor de taxa que no fueron elegidos (i.e. Adesmia boroniodes, Senecio filaginoides, Atriplex lampa) por lo cual, se infiere que existió una selección por una madera de mayor densidad y producción de brasa. Si bien en los sitios anteriores se registró presencia de moluscos, y en algunos casos en asociación a fogones (i.e. fogón A del Alero 4), en este sitio se registra esta acción con mayor precisión, dando información acerca de la funcionalidad del fogón y las actividades domésticas alrededor del mismo. 
En el mismo sector sur de la ría Deseado, pero nuevamente en el subsector Bahía del Oso Marino se ubica el sitio Cueva del Negro, un sitio conchero en cueva, a $21 \mathrm{~m}$ de la línea actual de mareas y a $4 \mathrm{msnm}$. Para este sitio se obtuvieron una serie de fechados por lo que se lo ubica cronológicamente entre 1390-1170 años AP (Zubimendi et al. 2011). El registro arqueológico de este sitio, con una gran densidad de restos zooarqueológicos (mamíferos marinos y terrestres, aves y peces), restos malacológicos, arpones en hueso y madera, líticos y artefactos en valvas evidencia el aprovechamiento intensivo de la costa para el Holoceno tardío. El análisis de carbones dispersos de un sondeo de la cuadrícula 1 permitió registrar para la capa 1 una prevalencia de Schinus con el $75 \%$ de densidad relativa porcentual. Para la capa 2 y 3 se registra la combinación de Schinus (ca. 44\%) y Senecio/Baccharis (ca. 38\%) entre los taxa con mayor densidad de carbones. En la capa 4 es Senecio/Baccharis el taxa que adquiere mayor predominancia con el $71 \%$ densidad mientras que en la capa 5 se vuelve registrar la combinación de Schinus y Senecio/Baccharis para alcanzar juntas el 80\% de densidad de carbones por litro de sedimento. Entonces, en este sitio conchero en cueva, cuya importancia se encuentra en la intensidad de explotación de los recursos costeros en tan poco tiempo, se mantiene la combinación de leñas de mayor densidad y brasa con maderas muy blandas y de rápido encendido. Estos taxa se encuentran disponibles alrededor del sitio.

Es relevante del sitio Cueva del Negro, la presencia de siete cabezales de arpones, entre ellos el cabezal fragmentado de madera de Berberis, mencionado en párrafos previos (capítulo 11). Este es el primer arpón en madera en estratigrafía recuperado en CNSC y en Patagonia argentina (Capparelli et al. 2009). Como se discutió en el capítulo 11, los arpones recuperados del recinto oscuro, cuadrículas 1 y 3 del alero, asociados a dataciones radiocarbónicas permiten discutir el sistema de captura de pinnípedos en asociación con otros artefactos de CNSC como son los rompecráneos (Moreno 2008 y Beretta et al. 2013a). Si bien el fragmento de arpón podría estar asociado a la pesca en pozones (Molina 1967-1970:178, Emperaire 2002) el conjunto de instrumentos de este tipo asociado a los rompecráneos, constituyen un repertorio tecnológico que se diferencia del resto para el Holoceno tardío en la región patagónica argentina (Orquera 1987, Beretta et al. 2013a). Estos instrumentos están manufacturados con materias 
primas locales, con diseños específicos que evidencian un profundo conocimiento de las especies explotadas (Beretta et al. 2013a).

El sitio 112, de menor extensión e intensidad que Cueva del Negro presentan resultados similares en cuanto a la selección de Schinus (en el sitio 112 con una densidad de carbones del 88\%, en Cueva del Negro varía según las capas) y Senecio/Baccharis (en el sitio 112 con una densidad de 5,8\% y en Cueva del Negro varía según la capa).

En el Holoceno tardío final, en el sector margen sur de la ría Deseado, en el subsector Bahía del Oso Marino se ubica el sitio Las Hormigas, a $80 \mathrm{~m}$ de la línea de costa actual. El sitio se encuentra conformado por una lente de valvas asociadas entre sí (fábrica de tipo bioclasto-sostenida) emplazada sobre un manto eólico (Hammond 2013) Se realizó un fechado radiocarbónico sobre carbón vegetal, cuyo resultado es de $370 \pm 40$ años AP (LP 2504). El estudio desarrollado por Hammond (2013 y tesis en preparación) identificó unas 20 especies de moluscos entre las que predominaron los mitílidos y en menor medida las lapas, restos óseos entre los que predominaron los pinnípedos y material lítico. Los restos malacológicos se presentaban en muy buen estado de conservación y habrían estado expuestas al fuego y al calor por poco tiempo para abrir las valvas (Hammond 2013). Se estudiaron los carbones dispersos de dos cuadrantes del nivel 2, entre los que predomina Schinus acompañado por Senecio/Baccharis y Atriplex/Suaeda. Como en los sitios anteriores, estos taxa se encuentran disponibles en los alrededores del sitio y nuevamente se observa la combinación de maderas de alta y baja densidad. En el sitio 112, mencionada más arriba, se registró una tendencia similiar en el uso de leñas (con predominio de Schinus). Sin embargo, la presencia de valvas calcinadas podría sugerir que las mismas fueron cocidas directamente al fuego. Considerando que las leñas utilizadas como combustible son iguales en ambos sitios, la técnica de consumo de los moluscos (aplicación de calor para que se abran las valvas vs. cocción) sería lo que diferiría entre los dos sitios. También se podría tener en consideración que en el sitio 112 los moluscos podrían haber estado sometidos al calor por un tiempo más prolongado.

El sitio conchero 160, también en el sector margen sur de la ría Deseado, subsector Punta Medanosa, presenta un fechado similar al anterior: $370 \pm 50$ AP (LP-2507) (Hammond 2013). Este sitio se encuentra emplazado en un médano sobre una planicie de mareas inactivas. En el nivel superficial se registraron restos malacológicos, 
fragmentos de cerámica, cáscaras de huevo de ñandú, lítico y óseo. Los carbones analizados se encontraban en forma de lente en el nivel 3 superior e inferior asociados restos de valvas, estas últimas, termoalteradas. Como en los sitios anteriores el taxa que predominó fue Schinus con un 95,6\%. En Punta Medanosa es llamativo el tamaño y densidad de Schinus, que si bien se encuentran dispersos por todo el Golfo San Jorge, en esta localidad presentan mayor ubicuidad y desarrollo de fuste. Como se mencionó en el capítulo 3 esta ubicuidad puede estar asociada al aporte de nitrógeno de los nidos de Spheniscus magellanicus (Pizarro Pinochet 2005).

En el sector Cabo Blanco los sitios analizados se encuentran ubicados cronológicamente en el Holoceno tardío final. El sitio La Estrella, se encuentra localizado en una zona de transición entre la meseta alta y el cañadón La Estrella, a $17 \mathrm{Km}$ de distancia a la costa (Zubimendi 2010). A diferencia de los sitios anteriores, este sitio es a cielo abierto y de actividades logísticas, con escaso material arqueológico. El análisis de carbones dispersos del nivel fértil arqueológico se realizó a lo largo de cuatro cuadrículas. Se observaron diferencias en el porcentaje de prevalencia de los taxa entre cada una de ellas. En la cuadrícula 1, Berberis presenta el 50\% de densidad acompañada por Senecio/Baccharis con un 20\%. Este resultado es similar a los anteriores en cuanto a la combinación de una madera de alta densidad (i.e. Berberis) con maderas muy blandas (Senecio/Baccharis). Sin embargo, es en el primer sitio que Berberis alcanza un porcentaje tan alto y si bien ha aparecido en otros sitios (i.e. Alero 4) acompañada con Senecio/Baccharis también de maderas de mayor dureza como Schinus. En las cuadrículas 2 y 4 predomina Senecio/Baccharis ( $83 \%$ y 62\% respectivamente) mientras que en la cuadrícula 3 alcanza el 100\%. En este caso parecería haber una vinculación entre una ocupación corta y maderas de calibre pequeño (Piqué i Huerta 1999, Caruso 2012) como Senecio/Baccharis que se consumen rápidamente y una madera con capacidad de producir brasa (i.e. Berberis) pero que predomina sólo en una cuadrícula. En el sector Golfo San Jorge, para la misma ubicación cronológica, se registró el sitio Palo Alto. Se compara con el sitio La Estrella porque, además de tener fechados similares, son sitios a cielo abierto y de ambos se recuperaron carbones dispersos, sin embargo, el primero se encuentra a $17 \mathrm{~km}$ de la costa y el segundo es un conchero ubicado a $60 \mathrm{~m}$ de la costa. Palo Alto se encuentra en la localidad arqueológica de Bahía Lángara, sobre el primer escalón del flanco de meseta y presenta una gran extensión 
abarcando una superficie de 50 × $25 \mathrm{~m}$ de forma oval con uno de sus lados paralelos al borde de la barranca y la línea de costa (Zubimendi et al. 2010). En este sitio como en el anterior no se registraron fogones ni lentes de carbones sin embargo, se recuperaron 407 fragmentos de cáscara de huevo de ñandú, algunas de ellas con evidencias de exposición al fuego. El registro de este sitio presenta además, restos de valvas dispersas con predominio de Nacella magellanica, que a diferencia de los sitios concheros 112, $160 \mathrm{o}$ Las Hormigas, se disponen aleatoriamente sin estructura. Entre los restos faunísticos identificados se registraron principalmente peces, guanaco y pinnípedos. En los niveles 1 y 3 a diferencia de todos los sitios anteriores predominó Lycium, en el caso del nivel 2 acompañado por Atriplex/Suaeda que en conjunto alcanzaron el 60\% de la densidad de carbones, mientras que en el nivel 3 prevaleció junto con Atriplex/Suaeda y Schinus, los cuales alcanzaron el $80 \%$ de la densidad de carbones. En el nivel 4, Atriplex/Suaeda prevalece y junto con Lycium alcanzan el $40 \%$ de la densidad de carbones. Por último, en el nivel 5 Lycium y Atriplex/Suaeda alcanzan el 70\% de la densidad de los carbones dispersos. Como en los casos anteriores los taxa identificados se encuentran en los alrededores del sitio, sin embargo, es llamativo que en este caso, no se seleccione Schinus como en los casos anteriores y predomine una madera de menor densidad. Es posible que el registro de cáscaras de huevo de ñandú termoalterado, así como la cantidad de restos de peces recuperados pueda estar sugiriendo cocción de alimentos marinos y terrestres a bajas temperaturas.

En el caso de los sitios arqueológicos Cormorán Quemado y Nido del Águila se encuentran en el sector Cabo Blanco y presentan una cronología del Holoceno tardío final, el primero de $360 \pm 50$ años AP y una datación relativa pos-contacto para el segundo (cuenta de vidrio). Se comparan estos sitios no sólo por tener una ubicación cronológica similar, ambos son sitios a cielo abierto, sino también porque en ambos se registraron fogones a partir de los cuales se realizaron los estudios antracológicos. El sitio Cormorán Quemado, se encuentra en el sur de la laguna Sur de Cabo Blanco a 5 km de la costa atlántica (Zubimendi 2010). En superficie se recuperó: material lítico (puntas de proyectil y productos de talla), fragmentos de cerámica, un fragmento de cobre, puntas destacadas, perforadores, artefactos de molienda, restos óseos (huesos de cormorán quemado) y malacológicos. Se identificaron los carbones provenientes del fogón en cubeta subsuperficial registrando el predominio de Atriplex/Suaeda con el 
90\% de la densidad. En este sentido, el registro muestra que se seleccionaron las maderas halófitas próximas al sitio, siendo ésta una madera pesada y dura pero que produce poca brasa. Se sugiere que la obtención de ceniza o sal pueden haber sido dos de los criterios por los que se eligió dicha madera. En el caso del uso de su ceniza puede deberse a la preparación de lejía como ha sido documentada en grupos ranqueles (Andreoni 2014) y en el caso de la extracción de sal para la preparación de alimentos En el caso del sitio Nido del Águila, se encuentra en un cañadón a 9 km de la costa y en superficie se registraron los siguientes materiales: productos de talla, tiestos de cerámica aborigen, un caracol de Adelomelon ancilla, restos óseos, y una cuenta de vidrio. En este sitio también se registró un fogón en cubeta a partir del cual se realizaron los estudios antracológicos (Zubimendi 2010). Los taxa que predominaron fueron Lycium y Schinus que en conjunto alcanzan el $60 \%$ de la densidad de los carbones. También se recuperaron 26 frutos y 6 hojas carbonizadas de Schinus (discutida su presencia en la contrastación de la Hipótesis 1) y las maderas seleccionadas en este caso se encuentran próximas en el sitio, y en el cañadón en particular presentan mayor altura y ubicuidad.

En suma, considerando la frecuencia y ubicuidad de los taxa a lo largo del tiempo, tanto en el Holoceno medio como en el tardío se combinaron maderas de mayor calibre y densidad (i.e. Schinus, Berberis) con leños de maderas muy blandas y livianas que sirvieran de iniciadoras del fuego. Se observó que la gestión de los recursos leñosos no estuvo asociada al tipo de sitio, puesto que sitios aleros, concheros y a cielo abierto comparten esta misma estrategia. Sí existen variaciones en la prevalencia de uno u otro taxa pero que se consideran están relacionados con las actividades desarrolladas en el sitio, la duración de la ocupación y la funcionalidad del fogón. Por ejemplo, el sitio Cormorán Quemado, si bien, se encuentra en una laguna en la cual se registra una alta redundancia de ocupación a su alrededor, así como también en el tómbolo cercano a la costa (Zubimendi 2010), es un sitio de poca extensión con una ocupación de corta duración. En este sentido se puede pensar que la selección de Atriplex/Suaeda estuvo vinculada a alguna actividad específica. Se considera que los resultados obtenidos permiten apoyar la hipótesis 3.

Es importante mencionar, que además de los resultados obtenidos a través de la identificación taxonómica de las especies el análisis de la densidad de carbones arqueológicos en los distintos sitios analizados permitió realizar la siguiente estimación. 
Si consideramos la totalidad de los valores de densidad de carbones ( $\mathrm{n} / \mathrm{l}$ de sedimento) calculados para los sitios analizados de CNSC se observa que valores de 0,1 a $16,4 \mathrm{n} / 1$ corresponden exclusivamente a carbones dispersos (el valor de 2 n/l del fogón Nido del Águila no se tiene en cuenta en esta descripción porque parte de los carbones de este contexto han sido enviados a datar previo a nuestro análisis por lo que la cantidad de carbones recuperada se encuentra subrepresentada). Por otro lado, valores desde 305 a 2966 n/l corresponden exclusivamente a fogones. Por último existe un rango de solapamiento entre ambos tipos de registros desde los 16,5 a 304 n/l. Los valores más bajos de densidad se presentaron en forma de carbón disperso en los Sitios La Estrella y Palo Alto, mientras que los más altos se presentaron en los fogones A, B, C, F, D, E y J del sitio Alero El Oriental, fogón de Cormorán Quemado, y el fogón B y C de Alero 4. Estos resultados permitirán en futuras excavaciones registrar con mayor precisión las lentes de carbones y su clasificación como fogones y lentes dispersas teniendo en cuenta la existencia de contextos complejos como los sitios concheros. 


\begin{tabular}{|c|c|c|c|c|c|c|}
\hline $\begin{array}{c}\text { Sitio } \\
\text { Arqueológico }\end{array}$ & $\begin{array}{l}\text { Tipo de } \\
\text { sitio }\end{array}$ & $\begin{array}{c}\text { Tipo de } \\
\text { material } \\
\text { antracológico }\end{array}$ & $\begin{array}{c}\text { Fechados del } \\
\text { sitio }\left(C^{14} \text { años }\right. \\
\text { AP) }\end{array}$ & $\begin{array}{l}\text { Materiales } \\
\text { asociados }\end{array}$ & $\begin{array}{c}\text { Funcionalidad del } \\
\text { sitio }\end{array}$ & Resultados antracológicos \\
\hline $\begin{array}{l}\text { Palo alto } \\
\text { Sondeo } 1\end{array}$ & $\begin{array}{c}\text { Cielo } \\
\text { abierto, } \\
\text { conchero, } \\
\text { con } \\
\text { alteración } \\
\text { antrópica }\end{array}$ & Disperso & $690 \pm 90 \mathrm{AP}$ & $\begin{array}{c}\text { Restos óseos } \\
\text { (i.e.guanaco, } \\
\text { pinnípedos), } \\
\text { malacológicos y } \\
\text { líticos. Cerámica } \\
\text { Cáscaras de huevo } \\
\text { expuestas al fuego. } \\
\text { Posible presencia de } \\
\text { postes. }\end{array}$ & $\begin{array}{c}\text { Actividades de } \\
\text { explotación y consumo } \\
\text { de recursos marinos y } \\
\text { terrestres. }\end{array}$ & $\begin{array}{c}1 \text { nivel: Lycium } 100 \% \\
2 \text { nivel: Lycium/Atriplex } / S .60 \% \\
3 \text { nivel: Lycium, Atriplex/S. y Schinus } 80 \% \\
4 \text { nivel: Atriplex/S. y Lycium } 40 \% \\
5 \text { nivel: Lycium y Atriplex } / S 70 \%\end{array}$ \\
\hline $\begin{array}{l}\text { Cormorán } \\
\text { Quemado }\end{array}$ & $\begin{array}{l}\text { Cielo } \\
\text { abierto }\end{array}$ & $\begin{array}{l}\text { Fogón en } \\
\text { cubeta sub- } \\
\text { superficial }\end{array}$ & $360 \pm 50 \mathrm{AP}$ & $\begin{array}{l}\text { En superficie: } \\
\text { material lítico, } \\
\text { cerámica, conanas, } \\
\text { cobre, restos óseos y } \\
\text { malacológicos. }\end{array}$ & $\begin{array}{l}\text { Espacio residencial con } \\
\text { estructuración a nivel } \\
\text { intrasitio con } \\
\text { delimitación de zonas } \\
\text { como basureros. }\end{array}$ & Atriplex $/ S .90 \%$ \\
\hline $\begin{array}{l}\text { Nido del } \\
\text { Águila }\end{array}$ & $\begin{array}{l}\text { Cielo } \\
\text { abierto }\end{array}$ & $\begin{array}{l}\text { Fogón en } \\
\text { cubeta sub } \\
\text { superficial } \\
\text { Carporrestos }\end{array}$ & $\begin{array}{l}\text { Poscontacto } \\
\text { (cuenta de } \\
\text { vidrio) }\end{array}$ & $\begin{array}{c}\text { En superficie: } \\
\text { cerámica, cuenta de } \\
\text { vidrio, lítico, restos } \\
\text { óseos, malacológicos. } \\
\text { En estratigrafía: } \\
\text { lítico, restos óseos. }\end{array}$ & Logístico & $\begin{array}{c}\text { Lycium y Schinus } 60 \% \\
\text { Frutos y hojas de Schinus }\end{array}$ \\
\hline La Estrella & Cielo & Dispersos & $690 \pm 70 \mathrm{AP}$ & Artefactos líticos, & Logístico & Cuad 1:Berberis $50 \%$ y Senecio $/ B 20 \%=70 \%$ \\
\hline
\end{tabular}




\begin{tabular}{|c|c|c|c|c|c|c|}
\hline & abierto & & & $\begin{array}{l}\text { restos óseos (marcas } \\
\text { de corte y quemados). }\end{array}$ & & $\begin{array}{l}\text { Cuad 2: Senecio/B. 83\% } \\
\text { Cuad 3:Senecio/B: } 100 \% \\
\text { Cuad. } 4 \text { Senecio/B: } 62 \%\end{array}$ \\
\hline Alero 4 & Alero & $\begin{array}{l}\text { Disperso y } \\
\text { Fogones }\end{array}$ & $\begin{array}{l}2760 \pm 70 \mathrm{AP} \\
1690 \pm 90 \mathrm{AP}\end{array}$ & $\begin{array}{c}\text { Restos óseos } \\
\text { (guanaco y } \\
\text { pinnípedos), líticos } \\
\text { (gran cantidad de } \\
\text { raspadores), } \\
\text { malacológicos. }\end{array}$ & $\begin{array}{l}\text { Sitio unicomponente } \\
\text { donde se habrían } \\
\text { realizado actividades } \\
\text { múltiples. }\end{array}$ & 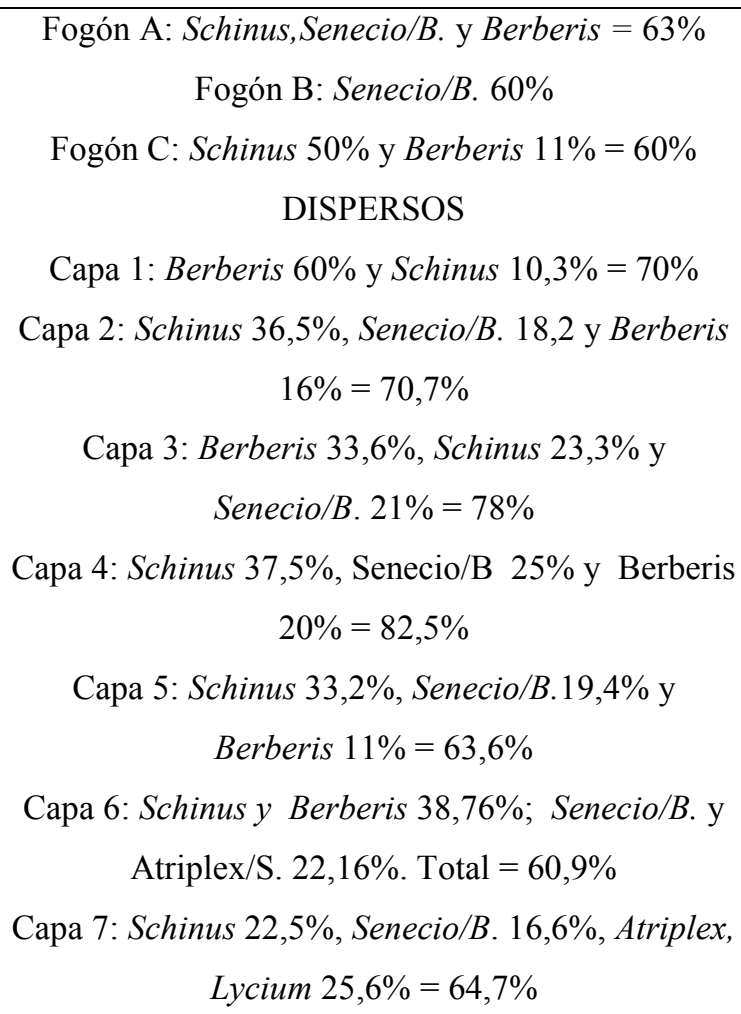 \\
\hline $\begin{array}{l}\text { Alero El } \\
\text { Oriental }\end{array}$ & Alero & $\begin{array}{l}\text { Fogones } \\
\text { planos en los } \\
\text { tres } \\
\text { componentes }\end{array}$ & $\begin{array}{c}6930 \pm 100 \\
5810 \pm 110 \\
5860 \pm 90,5150 \\
\pm 80,1530 \pm 60\end{array}$ & $\begin{array}{l}\text { Artefactos líticos, } \\
\text { restos óseos, y } \\
\text { valvas. }\end{array}$ & $\begin{array}{l}\text { Holoceno temprano: } \\
\text { exploración de la costa, } \\
\text { ocupación del sitio } \\
\text { efímera. Holoceno }\end{array}$ & $\begin{array}{c}\text { Fogón A: Senecio/B. } 80 \% \\
\text { Fogón B: Senecio/B. } 58,5 \% \text {,' Atriplex } / S 26,6 \%= \\
85 \% \\
\text { Fogón C:Senecio/B. } 81 \%\end{array}$ \\
\hline
\end{tabular}




\begin{tabular}{|c|c|c|c|c|c|c|}
\hline & & $\begin{array}{l}\text { y uno en } \\
\text { cubeta en el } \\
\text { superior. }\end{array}$ & & & $\begin{array}{l}\text { tardío final: refugio de } \\
\text { corta duración en el } \\
\text { marco de rangos de } \\
\text { acción diarios. }\end{array}$ & $\begin{array}{c}\text { Fogón D: Schinus 67\% y Berberis 16\% } \\
\text { Fogón E:Senecio/B. } 94,7 \% \\
\text { Fogón F: Senecio/B. } 92,3 \% \\
\text { Fogón H: Schinus } 44 \% \text { y Senecio/B 28\% } \\
\text { Fogón J: Schinus } 61 \% \text { y Senecio/B: } 14 \% \\
\text { Fogón L: Schinus } 65 \%\end{array}$ \\
\hline $\begin{array}{c}\text { Cueva del } \\
\text { Negro }\end{array}$ & $\begin{array}{l}\text { Sitio } \\
\text { conchero } \\
\text { en cueva. }\end{array}$ & Disperso & $\begin{array}{c}c a .1390-1170 \\
\text { años AP }\end{array}$ & $\begin{array}{l}\text { Restos líticos, óseos, } \\
\text { artefactos en hueso, } \\
\text { artefacto en madera, } \\
\text { cuenta de collar en } \\
\text { valva, restos óseos } \\
\text { humanos } \\
\text { Cerámica en } \\
\text { superficie }\end{array}$ & $\begin{array}{l}\text { Actividades de } \\
\text { procesamiento y } \\
\text { consumo de especies } \\
\text { sobre todo marinas. } \\
\text { Ocupación intensiva de } \\
\text { la cueva. }\end{array}$ & $\begin{array}{c}\text { Capa 1: Schinus } 75 \% \\
\text { Capa 2: Schinus 44\%, Senecio/B. } 37,5 \%=81,5 \% \\
\text { Capa 3: Schinus } 45 \% \text {, Senecio/B. } 39 \%=84 \% \\
\text { Capa 4 Senecio/B: } 71 \% \\
\text { Capa 5: Schinus y Senecio B. }=80 \%\end{array}$ \\
\hline Las Hormigas & Conchero, & Dispersos & $\begin{array}{c}370 \pm 40 \text { años } \\
\text { AP. }\end{array}$ & $\begin{array}{l}\text { Restos de hierro, } \\
\text { valvas, lítico y óseo }\end{array}$ & $\begin{array}{c}\text { Actividades de } \\
\text { explotación de } \\
\text { moluscos, productos de } \\
\text { talla en las etapas } \\
\text { finales }\end{array}$ & $\begin{array}{c}\text { 2A : Schinus } 72 \% \\
\text { 2C: Schinus } 44 \% \text {, Senecio/B. } 26,5 \%, \text { Atriplex } / S . \\
20,6 \%=91 \%\end{array}$ \\
\hline 112 & Conchero & Dispersos & $\begin{array}{c}2870 \pm 60 \text { años } \\
\text { AP. }\end{array}$ & $\begin{array}{l}\text { Mandíbula humana, } \\
\text { restos de cetáceo, } \\
\text { boleadoras, valvas, } \\
\text { lítico, óseo }\end{array}$ & $\begin{array}{c}\text { Actividades de } \\
\text { explotación de } \\
\text { moluscos, productos de } \\
\text { talla en las etapas } \\
\text { finales. }\end{array}$ & N1: Schinus $88 \%$ \\
\hline
\end{tabular}




\begin{tabular}{|c|c|c|c|c|c|c|}
\hline 160 & Conchero & $\begin{array}{l}\text { Lente de } \\
\text { carbones }\end{array}$ & $370 \pm 50 \mathrm{AP}$ & $\begin{array}{l}\text { Cerámica, cáscara de } \\
\text { huevo de ñandú, } \\
\text { puntas de proyectil, } \\
\text { restos de cetáceo, } \\
\text { valvas, lítico, óseo. }\end{array}$ & $\begin{array}{c}\text { Actividades de } \\
\text { explotación de } \\
\text { moluscos, productos de } \\
\text { talla en las etapas } \\
\text { finales. }\end{array}$ & $\begin{array}{l}\text { N3sup: Schinus } 95,24 \% \\
\text { N3 inf. Schinus } 96,10 \%\end{array}$ \\
\hline
\end{tabular}

Tabla 14.1. Información abreviada de de los sitios arqueológicos de CNSC y los resultados del análisis arqueobotánico. 
Para contrastar la Hipótesis 4: "Los grupos cazadores recolectores a través de tecnología especifica desarrollaron procesamientos poscolecta de los vegetales", se realizaron distintos tipos de análisis. En primer lugar, se registró en las fuentes documentales analizadas de Patagonia continental Argentina (capítulo 4), las técnicas de procesamiento más frecuentemente descriptas: maceración, remojo, molienda, tostado, hervido y asado. También se relevaron las partes de las plantas procesadas: comúnmente frutos y órganos subterráneos. En segundo lugar, el estudio etnobotánico realizado en CNSC (capítulo 5) indagó sobre el procesamiento poscosecha de las plantas vegetales silvestres. Se registró limpieza y/o pelado en dos casos (macachín y Azorella monantha), cortado (tuna), tostado (Malva sp.) y, en el caso de Berberis sp., la elaboración de dulces y licores. Un solo informante mencionó la molienda como técnica de procesamiento para uso cosmético de los frutos de una Cactaceae que luego de su trituración eran hervidos (cf. Opuntia/cf. Maihuenopsis), sólo una mención refiere que las vainas de Prosopis denudans son comestibles.

Por otra parte, en el registro arqueobotánico de Patagonia continental argentina (capítulo 6) se realizaron inferencias sobre el procesamiento y las partes de las plantas utilizadas: tallos (secos y carbonizados), órganos subterráneos almacenadores (secos), frutos y semillas (carbonizados), fibras (secas), entre otras. Éstos han sido interpretados como derivados del consumo de partes de plantas cocidas (i.e. rizomas carbonizados asociados al fogón de Oxalis articulata; vainas carbonizadas de (Prosopis alpataco, Prospis denudans), de la recolección y procesamiento de fibras para la realización de cestería (i.e. Ephedra sp.), de la carbonización de leños utilizados como combustible (i.e. Chuquiraga avellaneadae y Anarthrophyllum rigidum) y de la manufactura y decoración de cañas (i.e. cañas decoradas de Chusquea culeou) (tabla 6.1).

Una vez establecidas las prácticas poscolecta posibles de ser inferidas a través del registro arqueológico, se indagó sobre los instrumentos asociados a un tipo de procesamiento: los artefactos de molienda. Se realizó una recopilación bibliográfica sobre las actas de congresos y Jornadas de Patagonia que mencionaran para la Patagonia continental argentina la presencia de estos instrumentos en los sitios arqueológicos y su análisis morfológico y arqueobotánico en caso de que hubieran sido realizados. Se registraron los fechados más tempranos y más tardíos para el registro arqueológico de Patagonia continental Argentina: $4880 \pm 130$ AP (Sanguinetti de Bórmida y Curzio 
1996) y el más moderno entre el siglo XVI y el año 1891 (Silveira 1996). Ambas cronologías se registraron para artefactos de molienda de sitios de Neuquén. Sin embargo, la distribución de dichos instrumentos continúa hasta la provincia de Santa Cruz, siendo el sitio Costa del Lago Guitarra (Goñi et al. 2010) el más al sur registrado hasta el momento y para el recorte bibliográfico realizado. En cuanto a la distribución de estos artefactos se registraron en mayor frecuencia en la provincia de Chubut, si bien esto puede deberse a la presencia de dos trabajos específicos sobre este tipo de instrumentos. Se observó que fueron analizados escasa cantidad de artefactos tanto desde un enfoque arqueobotánico como desde la aplicación de análisis químicos. Esto refuerza la necesidad de realizar estudios sistemáticos tecno-morfológicos y tecnofuncionales de los instrumentos de molienda (Babot 2004) para profundizar en el conocimiento de estas prácticas, no sólo sobre vegetales sino también de pigmentos destacando la multifuncionalidad de dichos artefactos.

La gran cantidad de artefactos de molienda registrados permiten resaltar la importancia de esta tecnología lítica para la Patagonia continental Argentina. El análisis de los mismos ha sido escaso desde la arqueobotánica, a excepción del trabajo de Lema et al. (2012) para esta región y de los numerosos trabajos de Babot (1999, 2004, 2007 entre otros) para el noroeste Argentino. En este sentido, para Patagonia es necesario el estudio desde una perspectiva arqueobotánica como lo han hecho Lema y colaboradores (ídem) y Babot (ídem) en el NOA, considerando la gran cantidad de artefactos registrados.

Como se mencionó para la contrastación de la hipótesis uno, las vías de consumo de los recursos vegetales silvestres deben ser exploradas con mayor profundidad debido a su escasa visibilidad en el registro arqueológico. En este sentido, los estudios realizados por Lema et al. (2012) son positivos y permiten generar expectativas de que de estos artefactos hayan sido utilizados para procesar plantas silvestres. Como advierte Babot (1999) no debe atribuirse función a la forma y por eso la necesidad de realizar estudios de microvestigios para identificar fehacientemente su función. Por otra parte, se debe resaltar la cronología de estos hallazgos, ya que, hacia los 4.200 años AP habría entonces, procesamiento de recursos vegetales silvestres como Prosopis y, para el caso de la incorporación de los recursos vegetales domesticados el fechado más temprano para Patagonia sería el del sitio Michacheo (1.750 años AP, Lema et al.2012). 
En el área CNSC se realizó una prospección asistemática en el sector sur de la ría Deseado en la que se registraron 20 artefactos potencialmente utilizados en la molienda en superficie (capítulo 13). Uno de ellos se recuperó y fue analizado en el laboratorio registrándose evidencias de procesamiento de plantas silvestres. Se recuperaron restos de tejido y células vegetales: elementos de vaso, uno de ellos con las paredes celulares rotas y desgarradas que daría cuenta de los daños sobre el tejido producto del procesamiento (Cueto et al. 2010) Por otra parte, se recuperó un fragmento de tejido epidérmico con un aparato estomático anomocítico, en el que los estomas se encuentran al mismo nivel que las células epidérmicas así como tricomas (pelos unicelulares de cutícula verrucosa) y corpúsculos de resina, un grano de almidón esférico con cruz de polarización entre otros numerosos microvestigios. Es importante destacar que las muestras y el sedimento control no registraron residuos vegetales. La identificación taxonómica del fragmento de parénquima como Prosopidastrum globosum y las referencias sobre las propiedades químicas de esta especie (capítulo 13) podría sugerir un uso medicinal del mismo.

Asimismo, se tomaron muestras de cinco artefactos de la colección del Museo del Hombre y su Entorno (Caleta Olivia). De estos últimos se analizaron los residuos de los cinco artefactos, registrándose en un caso granos de almidón aff. Prosopis sp. Este taxa ha sido mencionado anteriormente como alimenticio principalmente y medicinal (Capparelli 2007, Capparelli y Prates 2009)

Se considera que los resultados obtenidos permiten apoyar la hipótesis 4, no sólo para CNSC sino también para Patagonia continental Argentina. Se cree que sería de gran interés para ampliar el conocimiento de la utilización de los recursos vegetales silvestres en el pasado que se establezcan protocolos de experimentación para identificar en el registro arqueobotánico otras prácticas de procesamiento relevadas en las fuentes documentales, etnobotánicas y del registro arqueológico de otras áreas de Patagonia (i.e. preparación de bebidas, tostados de frutos).

Por otra parte como se mencionó en relación a los resultados que permitieron contrastar las hipótesis 1 y 2, las plantas de CNSC desarrollan una alta producción de metabolitos secundarios. En primer lugar, cabe destacar que, a través del estudio antracológico de macrorrestos leñosos datados en $c a 7000$ años AP hasta el Holoceno tardío final, se observaron características anatómicas que evidencian la adaptación de estas plantas al 
ambiente xerófito desde este período a la actualidad (colección de referencia). Que el desarrollo de productos secundarios brinda a estas plantas distintos caracteres organolépticos (i.e. sabor amargo, aroma, textura, color de su tintura) que actúan como una guía nemotécnica para el reconocimiento de las mismas por parte de los grupos humanos (Molares 2010). Por otra parte, que para mayor palatabilidad de las plantas las prácticas de procesamiento poscosecha permite su transformación en sustancias más digeribles y sin toxicidad (Stahl 1989). A través de las mismas, se producen alimentos con formas, texturas y gustos distintos, pero sobre todo se obtiene mayor bioaccesibilidad de macronutrientes (proteínas, lípidos, carbohidratos y fibras) y micronutrientes (minerales y vitaminas) para el consumo y digestión humana (Parada y Aguilera 2007, Wollstonecroft 2007). En particular, las prácticas de molienda, fermentación o calor, pueden promover la bioaccesibilidad de nutrientes porque transforman la microestructura del tejido vegetal, rompiendo las paredes celulares, cambiando el complejo matriz de nutrientes y/o transformando las sustancias de los tejidos en estructuras moleculares más activas (Parada y Aguilera 2007).

Si bien el registro arqueobotánico de CNSC y el estudio isotópico de los restos humanos de los grupos que habitaron el área no evidencian una incorporación redundante, alta, en la dieta de plantas silvestres (Zillio et al. 2014), los resultados obtenidos en el análisis de microvestigios permiten abrir nuevas preguntas respecto a las categorías de uso de las plantas. Los procesamientos poscolecta podrían haberse desarrollado no sólo para una mayor bioaccesiblidad de nutrientes, en el sentido de consumo de alimentos vegetales sino también por sus propiedades medicinales (Etkin 1994).

\subsection{Perspectivas Futuras}

A partir de los resultados obtenidos en esta tesis se evidencia la importancia de estudios holísticos para abordar el análisis de las prácticas de recolección en los grupos cazadores recolectores. Se estudiaron los criterios de selección de las plantas de CNSC y su potencial como fuente de nutrientes, medicina, combustible, tintóreos, bebidas entre otras categorías de uso. Sin embargo, es necesario advertir sobre el solapamiento de estas categorías de uso en la interpretación del registro arqueobotánico. Por otra parte, el estudio antracológico permitió avanzar y discutir sobre estrategias de movilidad 
y subsistencia de los grupos cazadores recolectores de CNSC para el Holoceno medio y tardío. En este sentido se alcanzaron todos los objetivos propuestos en esta tesis, aspecto relevante siendo ésta una tesis exploratoria.

Se propone continuar el estudio del registro arqueobotánico de CNSC a partir de otras vías indirectas que puedan aportar resultados sobre el consumo de plantas silvestres. En este sentido aumentar la muestra de artefactos de molienda analizados que ya se han recuperado. Indagar sobre la asociación entre estos instrumentos y los restos cerámicos que se han recuperado en el área de estudio. También analizar e identificar microvestigios a partir de los restos cerámicos para profundizar en el procesamiento poscolecta de los recursos vegetales silvestres. Los resultados obtenidos permiten plantear nuevas hipótesis, entre las que se considera que los procesamientos poscolecta se desarrollaron a fin de obtener los principios activos de las plantas silvestres. A través de estas nuevas líneas se propone continuar el estudio de las prácticas de recolección y poscolecta de plantas silvestres en CNSC. 


\section{Anexo}

\section{Carbones Arqueológicos identificados}
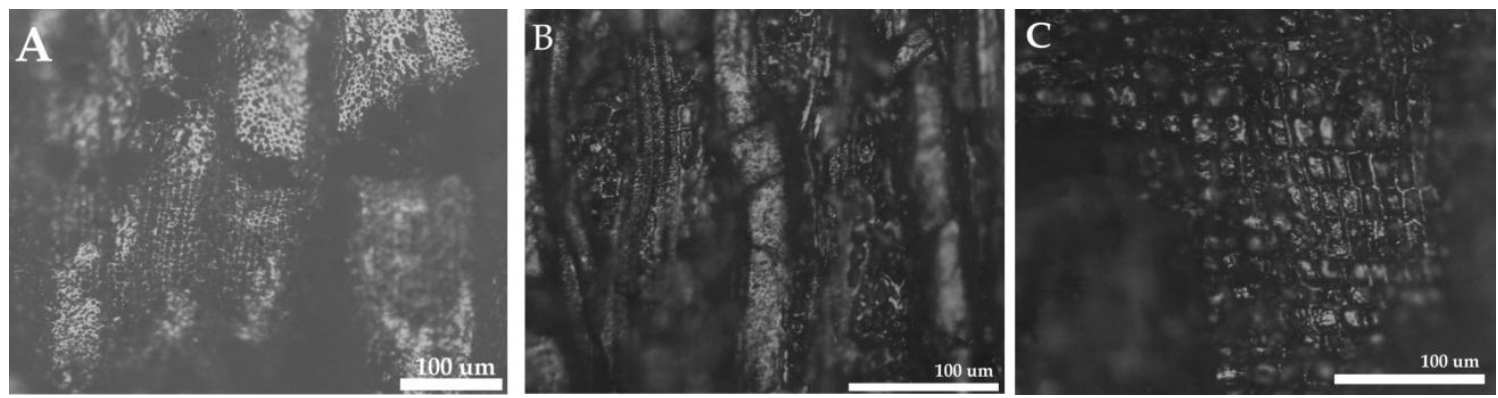

Figura 1.1 Adesmia, A: CT, B; CLTg y C: CLrd
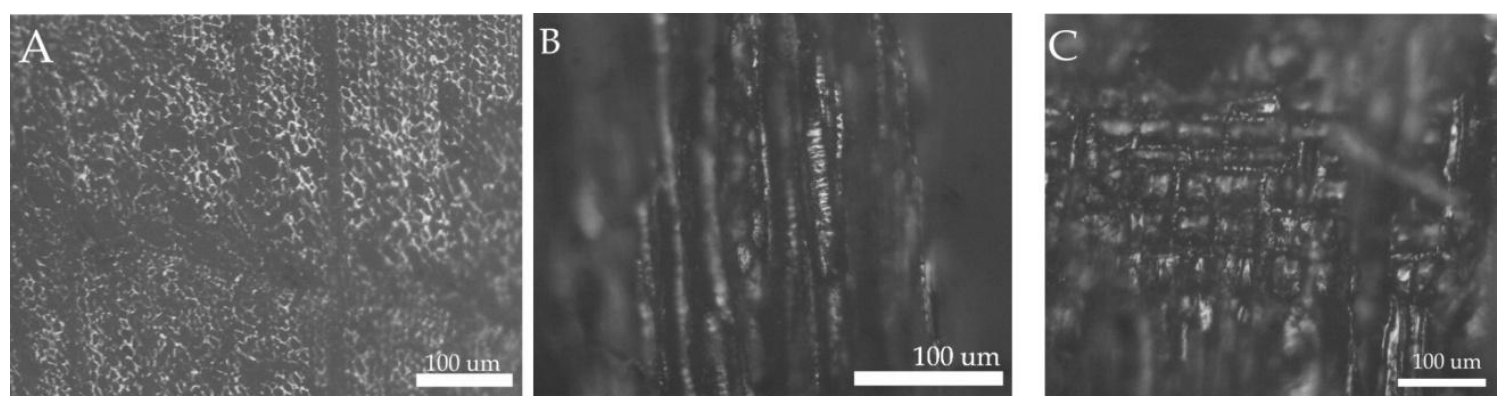

Figura 1.2 Senecio/Baccharis A: CT, B:CLTg y C: CLrd
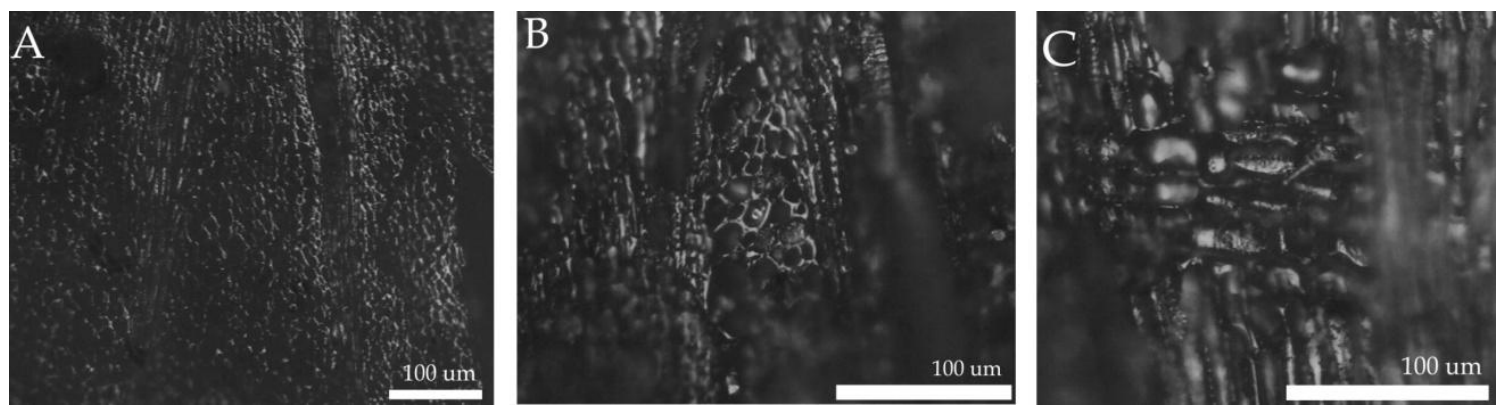

Figura 1.3 Berberis A: CT, B: CLTg y C: CLrd 

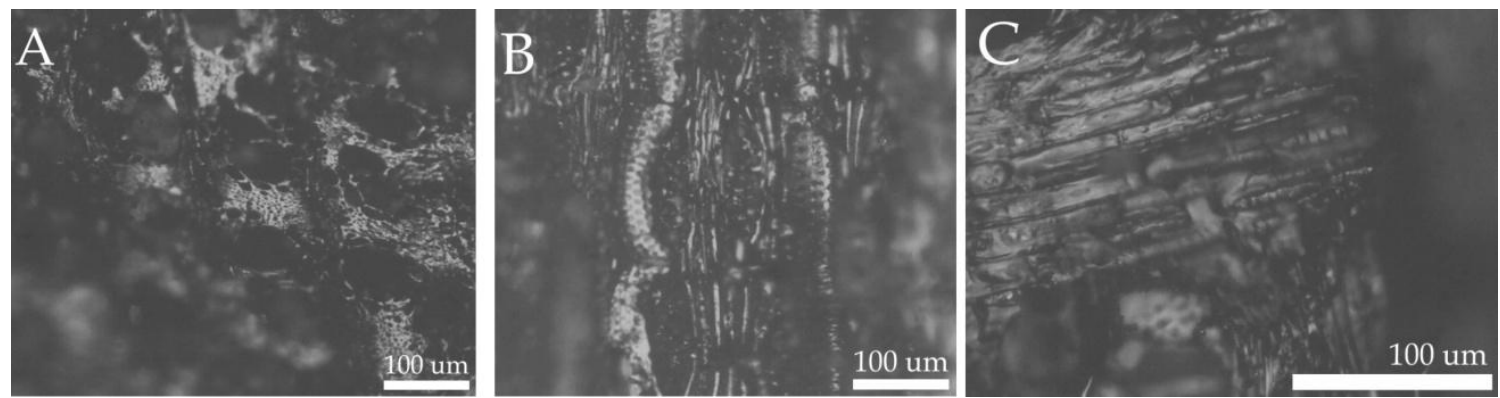

Figura 1.4 Bulnesia A: CT, B: CLTg y C: CLrd
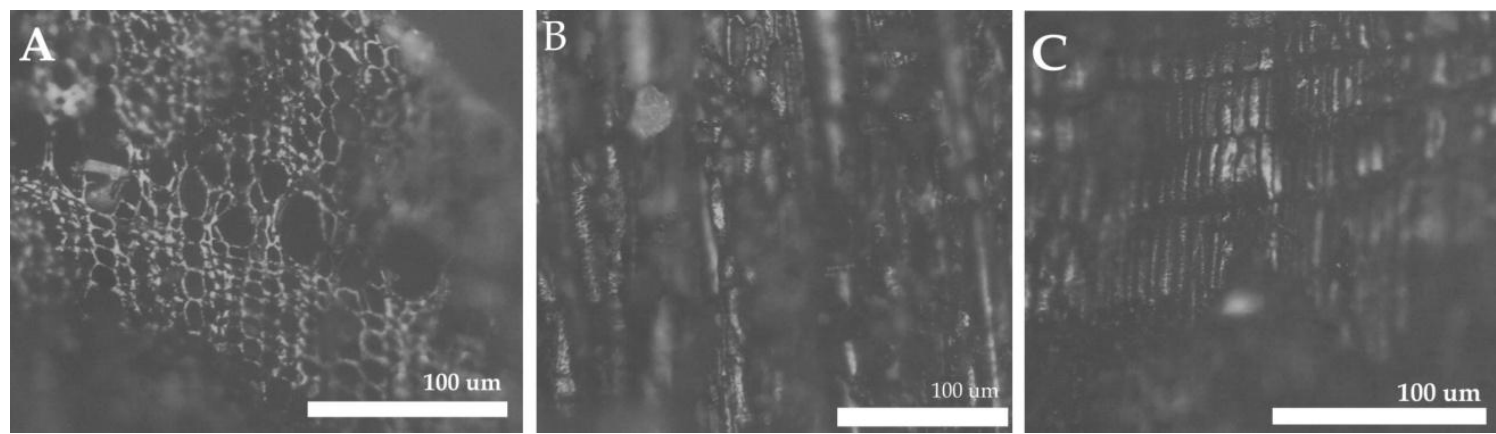

Figura 1.5 Chuquiraga A: CT, B: CLTg y C: CLrd
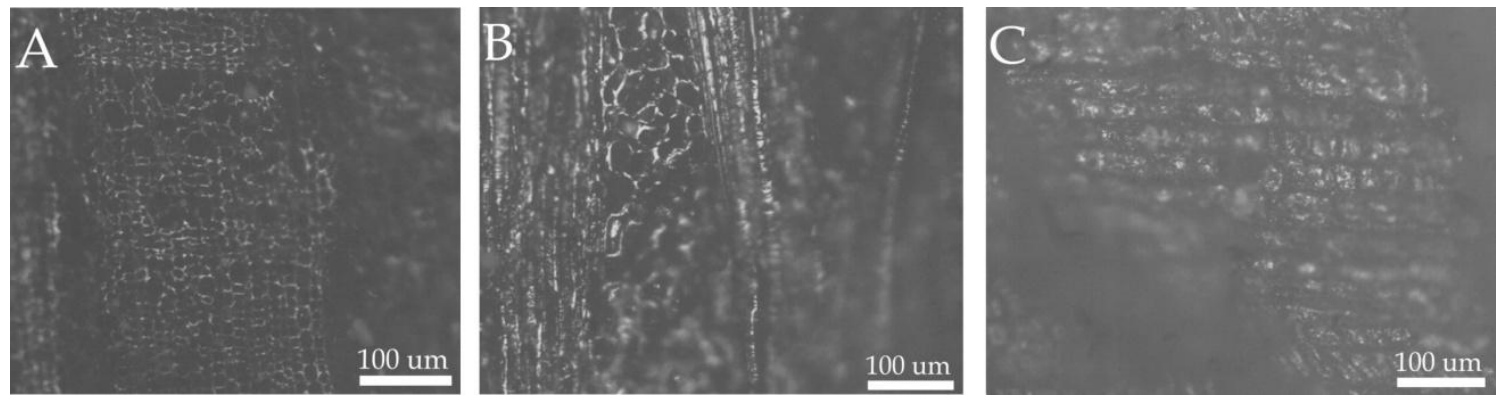

Figura 1.6 Ephedra A: CT, B: CLtg y C: CLrd
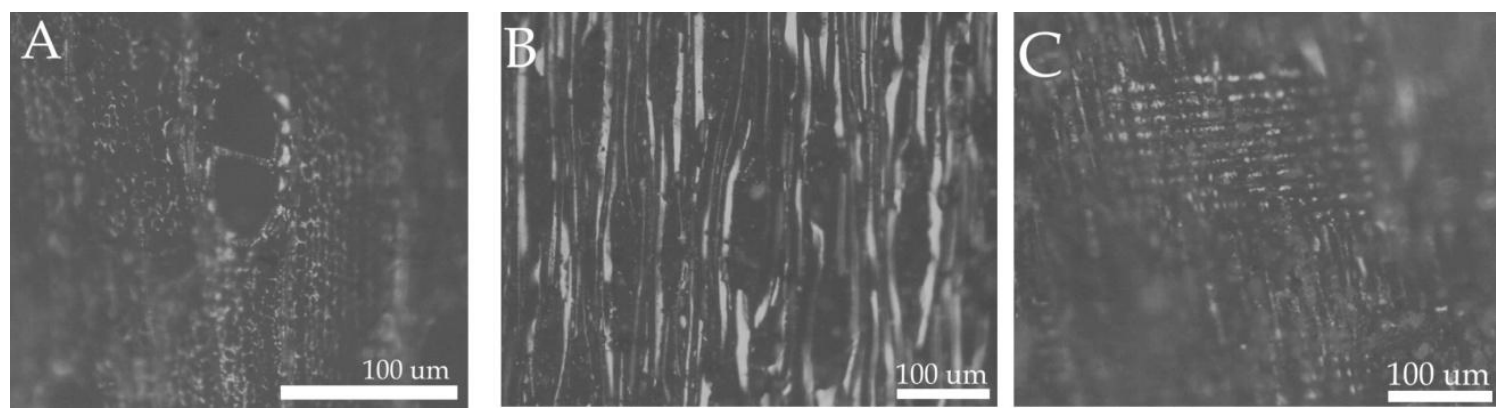

Figura 1.7 Fabaceae (cf. Cercidium) A: CT, B: CLTg y C: CLrd 

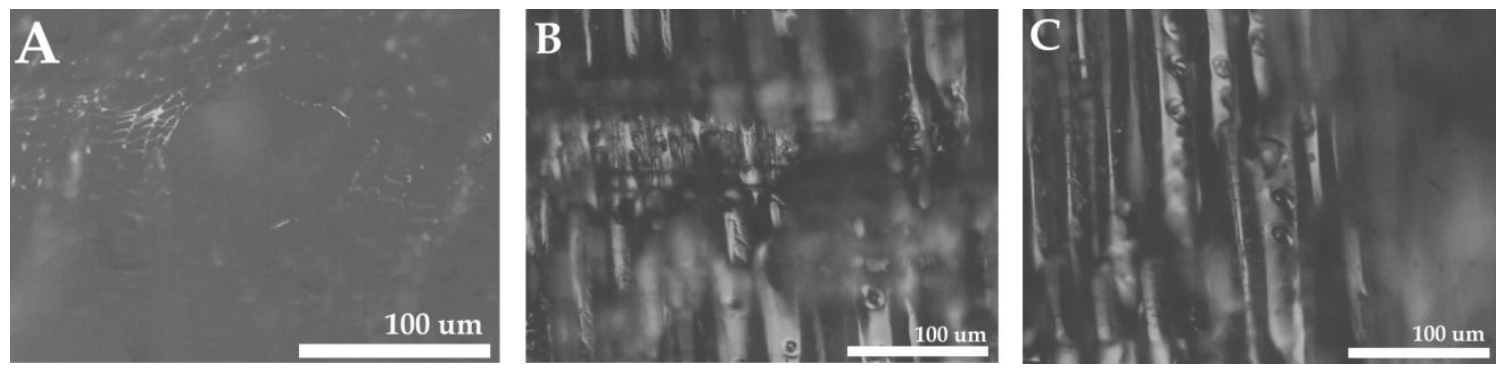

Figura 1.8 Pinus A: CT, B; CLTg y C: CLrd
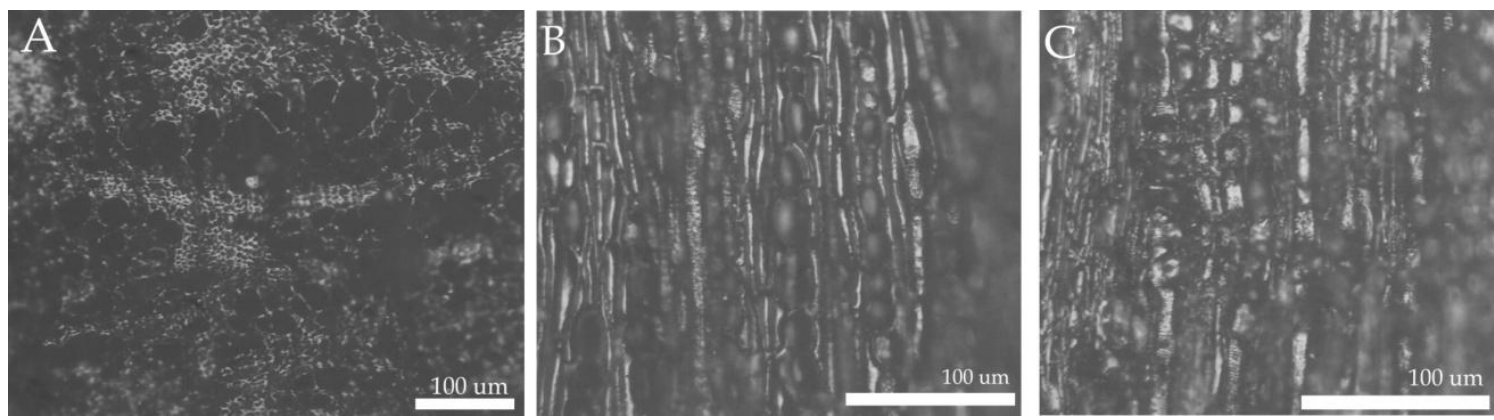

Figura 1.9 Lycium A: CT, B: CLtg y C: CLrd
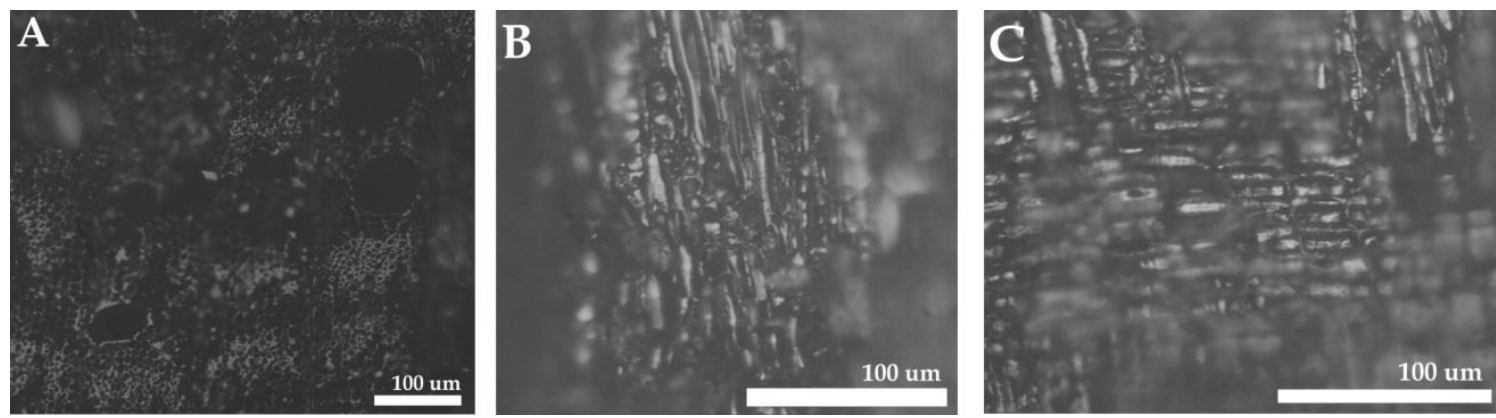

Figura 1.10 Prosopis A: CT, B: CLtg y C: CLrd
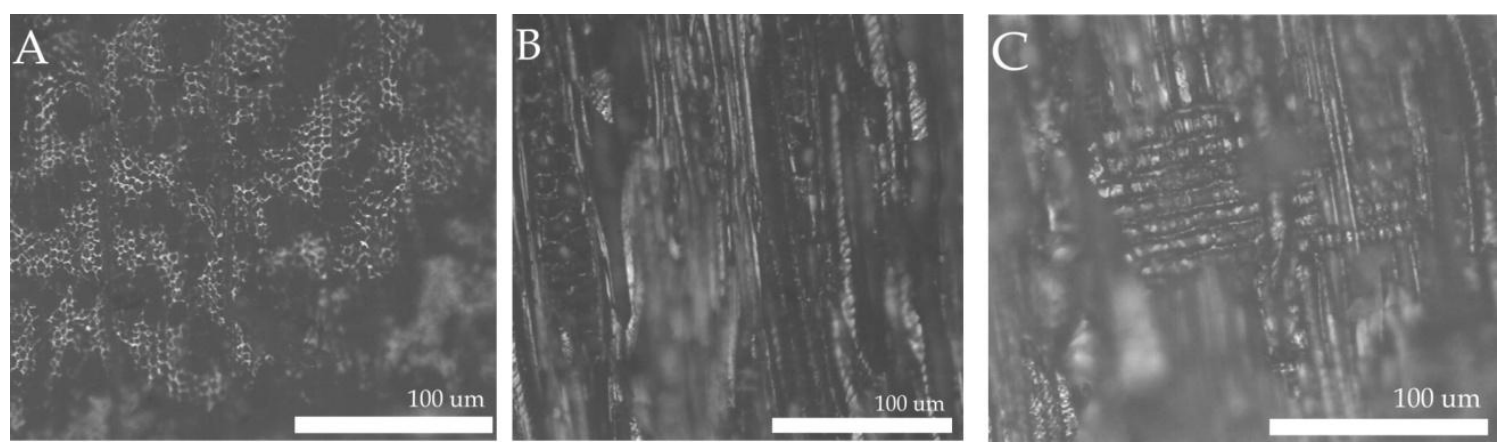

Figura 1.11 Schinus A: CT, B: CLTg y C: CLrd 

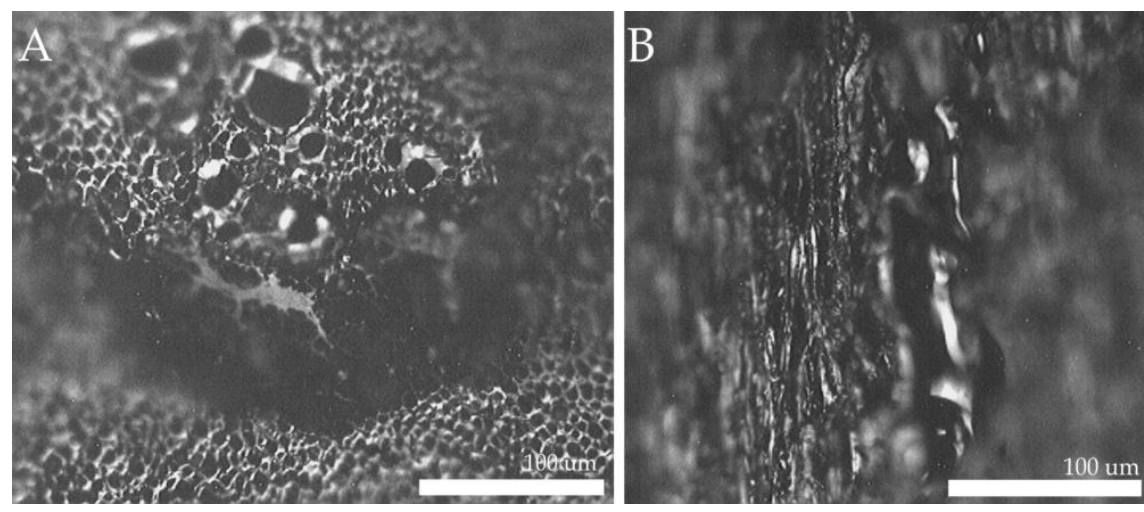

Figura 1.12 Atriplex/Suaeda A: CT y B: CLtg.
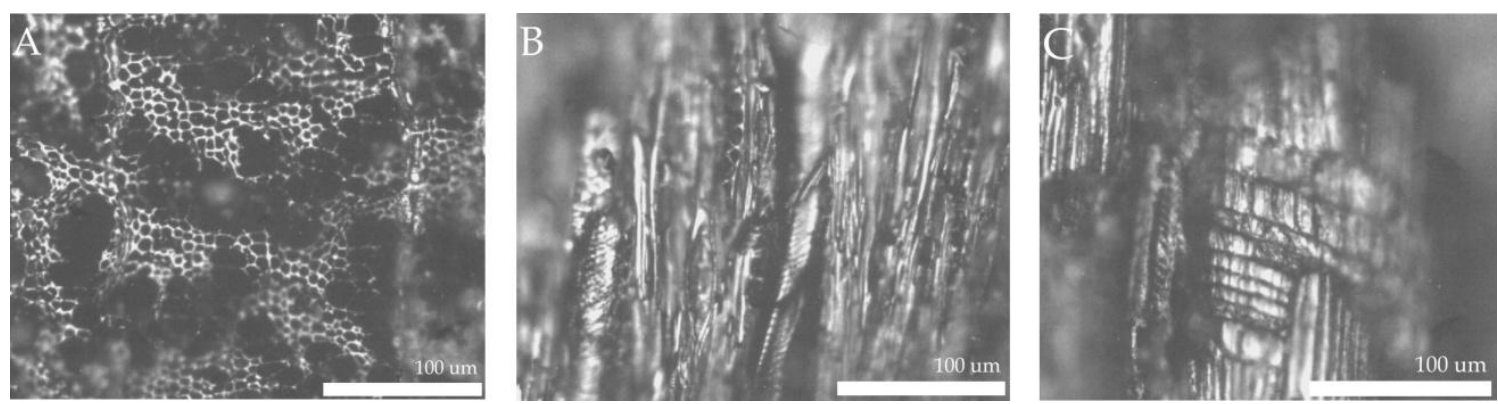

Figura 1.13 Colliguaja A. CT, B: CLtg. Y C: Clrd
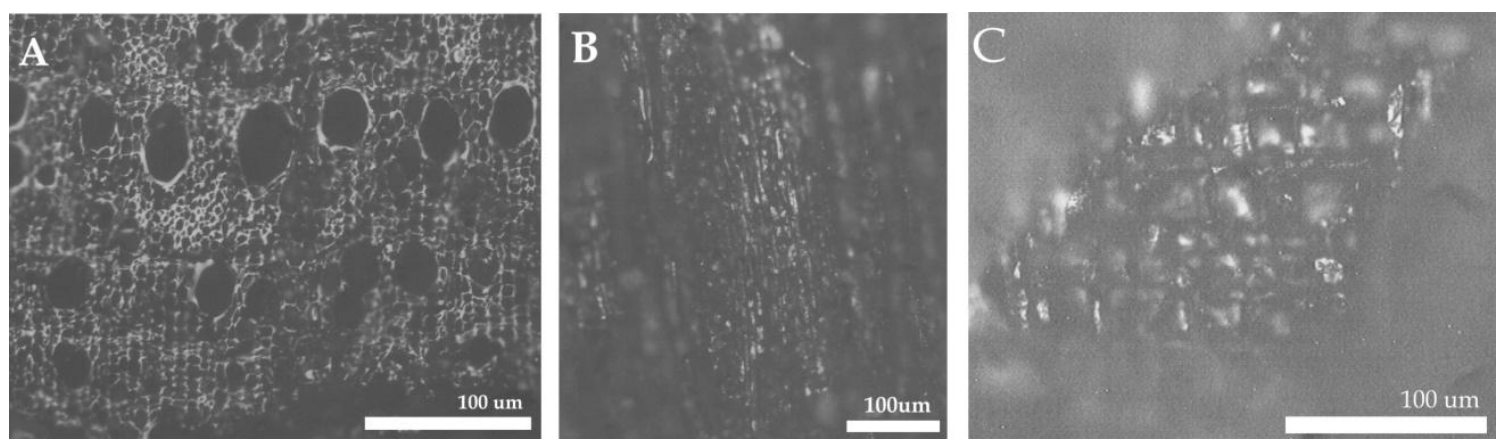

Figura 1.14 Discaria A: CT, B: CLtg y C: CLrd 


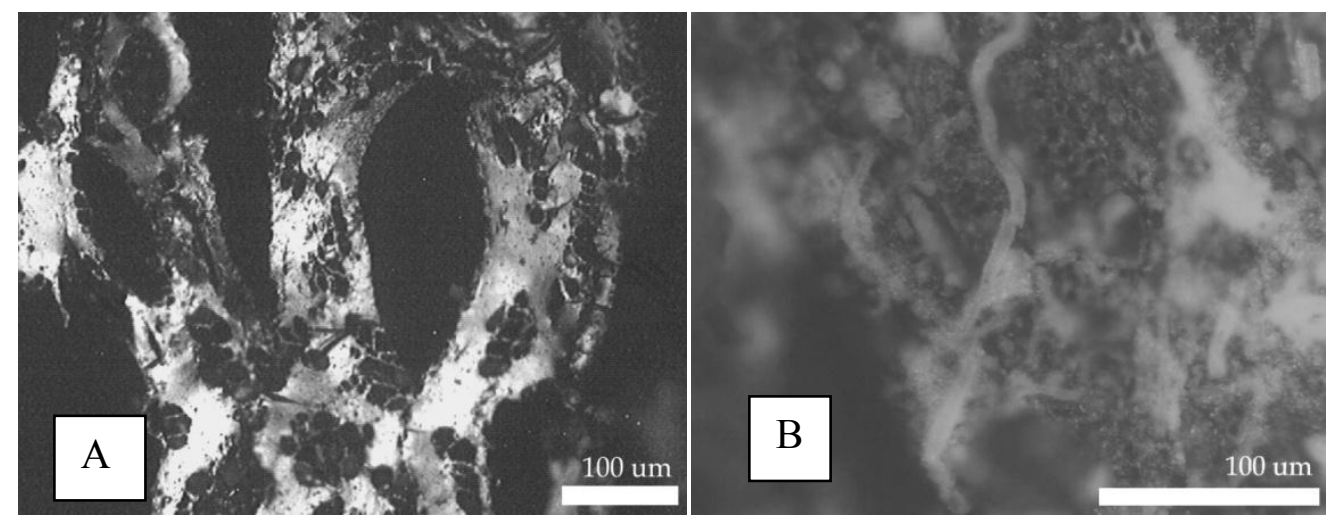

Figura 1.15 A: Ejemplo de especie vitirficada, B: ejemplo del carbón con precipitado mencionado en el sitio 112 y Las Hormigas (Capítulo 10). Debido al estado de alteración de la estructura anatómica de estos carbones no pudieron ser determinados taxonómicamente. 


\section{Bibliografía}

ACEVEDO D, NAVARRO M, MONTERO P. 2013. Composición química del aceite esencial de las hojas de toronjil (Melisa officinalis L.). Información Tecnológica 24, $\mathrm{n}^{\mathrm{o}}$ 4: $49-54$

AGNESE AM, CHIALE CA, CABRERA JL, JULIANI HR. 1986. Two new flavonoids from Prosopidastrum globosum. Journal of Natural Products Vol. 49 (3): 528-529.

AGUERRE AM. 2000. Las vidas de Pati en la toldería Tehuelche del Río Pinturas y el después. Facultad de Filosofía y Letras. Universidad de Buenos Aires. Pp 294.

AGUIRRE M y FARINATI EA. 2000. Moluscos del Cuaternario Marino de la Argentina. Boletín de la Academia Nacional de Ciencias de Córdoba 64: 235-333.

ALCALDE D, ARRATIA C, MERLO R, PINTO VITORINO G, CÓRDOBA O, FLORES ML. 2010. Bioactividad y composición química de un extracto purificado de Colliguaya integerrima (Euphorbiaceae). Dominguezia 26, $\mathrm{n}^{\circ} 2: 63$

ALMEIDA CF, DE LIMA E SILVA T, AMORIM E, MAIA M, ALBURQUERQUE UP. 2005. Life strategy and chemical composition as predictors of the selection of medicinal plants from the caatinga (Northeast Brazil). Journal of Arid Environments 62: $127-142$.

ÁlAVAREZ G. 1963. Alimentación del antiguo aborigen del Neuquén En: Actas del primer Congreso de la Araucanía Argentina. Provincia del Neuquén y Junta de Estudios Araucanos, San Martín de los Andes, Neuquén, Argentina. Pp.7-10,

AMBRÚSTOLO P. 2010. Análisis preliminar del Componente inferior del Alero "El Oriental": una ocupación del Holoceno medio en la Costa Norte de Santa Cruz. En: Actas del XVII Congreso nacional de Arqueología Argentina. Tomo V: 1835-1840. Universidad Nacional de Cuyo. Mendoza, Argentina.

AMBRÚSTOLO P. 2011. Estudio de las estrategias de aprovisionamiento y utilización de los recursos líticos por grupos cazadores recolectores en la costa norte de Santa Cruz, (Patagonia Argentina). Tesis doctoral, Facultad de Ciencias Naturales y Museo. Universidad Nacional de La Plata.

AMBRUSTOLO P, CASTRO A, ZUBIMENDI MA, MAZZITELLI L. 2011. Instrumentos líticos con filos denticulados en la Costa Norte de Santa Cruz. Un análisis tecno-funcional. Cazadores Recolectores del Cono Sur, 5: 79-94. 
AMBRÚSTOLO P, ZUBIMENDI MA, CIAMPAGNA ML, TROLA V. 2011. Alero El Oriental: evidencias de las primeras ocupaciones de la Costa Norte de Santa Cruz (Patagonia, argentina). Revista Werkén 14: 9-22.

AMBRÚSTOLO P, CIAMPAGNA ML. 2014 Alero 4 rock shelter, north coast of Deseado estuary (Patagonia, Argentina): Hunter-gatherer mobility strategies during the Late Holocene. Quaternary International.

http://dx.doi.org/10.1016/j.quaint.2014.10.035.

ANCIBOR E. 1981/82. Estudio anatómico de la madera de los "porta hachas" neolíticos procedentes de Truquico, Neuquén. Relaciones de la Sociedad Argentina de Antropología 14(2): 121-124.

ANCIBOR E. 1988/90. Materiales leñosos: madera, caña y otros. Anales de Arqueología y Etnología Número Especial La Cueva de Haichol, Arqueología de los Pinares cordilleranos del Neuquén 43/45(2): 337-372.

ANCIBOR E, PÉREZ DE MICOU C. 1995. Identification of firewood species in the archaeological record of the Patagonian Steppe. Journal of Etnobiology 15(2): 189-200. ANCIBOR E, PÉREZ DE MICOU C. 2002. Reconocimiento de especies vegetales combustibles en el registro arqueológico de la estepa patagónica. En: Pérez de Micou C. (Comp.) Plantas y Cazadores en Patagonia. Universidad de Buenos Aires, Facultad de Filosofía y Letras, Ciudad autónoma de Buenos Aires, Argentina. Pp. 15-31.

ANDRADE L. 2012. Producción y ambiente en la Meseta Central de Santa Cruz, Patagonia austral en Argentina: desencadenantes e impacto de la desertificación. Ambiente y Desarrollo 16 (30): 73-92.

ANDREONI D. 2010. La importancia de la colección de referencia para los análisis antracológicos, en el sur de Mendoza. Actas 5-ICES 30-39.

ANDREONI DF. 2014. Plantas leñosas y estrategias humanas en el sur de Mendoza: una aproximación arqueobotánica. Tesis Doctoral. Facultad de Ciencias Naturales y Museo, Universidad Nacional de La Plata. La Plata, Buenos Aires, Argentina.

ANDREONI D, GIL A, CAPPARELLI A. 2010. Efectos de la carbonización en especies leñosas de las Provincias Fitogeográficas Patagónica y del monte (Mendoza, Argetnina): Una perspectiva arqueológica. Tradiciones y transformaciones en Etnobotánica. Ed. Pocchettino ML, Ladio A, Arenas P. RISAPRET, CYTED.

ANDREONI D, CAPPARELLI A. 2012. El ser humano y la leña en la cordillera de 
Mendoza (Argentina) a lo largo del Holoceno: sitio arqueológico Arroyo Malo 3. Magallania Vol. 40 (1): 203-228.

ARANCIABIA L, NASPI C, PUCCHI G, ARCE M. 2013. Biological activity of a furanoeremophylane isolated from Senecio filaginoides var. filaginoides Boletín Latinoamericano y del Caribe de Plantas medicinales y aromáticas,Vol. 12 (1) Pp. 1823.

ARCHILA MONTAÑEZ S. 2005. Arqueobotánica en la Amazonía Colombiana: Un modelo etnográfico para el análisis de maderas carbonizadas. FIAN-UNIANDESCESO, Bogotá Pp 359.

ARRIGONI G. 2002. Estudio de un macrovestigio vegetal rescatado en la matriz arqueológica del Alero del Sendero de Interpretación (Parque Nacional Los Alerces, Prov. de Chubut) En: Pérez de Micou, C. (Comp.) Plantas y cazadores en Patagonia. Universidad de Buenos Aires, Facultad de Filosofía y Letras, Ciudad autónoma de Buenos Aires, Argentina. Pp. 105-113.

ASCHERO C A, 1975. Ensayo para una clasificación morfológica de artefactos líticos aplicada a estudios tipológicos comparativos. Informe al CONICET. Manuscrito.

ASCHERO C. 1981-82. Nuevos datos sobre la arqueología del Cerro Casa de Piedra, sitio CCP5 (Parque Nacional Perito Moreno, Santa Cruz, Argentina). Relaciones de la Sociedad Argentina de Antropología 14(2): 267-284.

ASGARPANAH J, KHOSKHAM R. 2012. Phytochemistry and pharmacological properties of Ruta graveolans L. Journal of Medicinal Plants Research Vol. 6 (23): 3942-3949.

ASGARPANAH J, MOHAJERANI R. 2012. Phytochemistry and pharmacologic properties of Urtica dioica L. Journal of Medicinal Plants Research. Vol. 6 (46): 57145719.

BABOT MP. 1999. Recolectar para moler. Casos actuales de interés arqueológico en el Noroeste Argentino. En: En los tres reinos: prácticas de recolección en el cono sur de América. Aschero C, Korstanje A, Vuoto P. editores. Magna Publicaciones Ediciones, Instituto de Arqueología y Museo, Universidad Nacional de Tucumán.

BABOT MP. 2004. Tecnología y utilización de artefactos de molienda en el Noroeste Prehispánico. Tesis Doctoral en Arqueología Facultad de Ciencias Naturales e I. M. L. Universidad Nacional de Tucumán. 
BABOT MP. 2007. Organización social de la práctica de molienda: casos actuales y prehispánicos del noroeste Argentino. En: Procesos sociales prehispánicos en el sur andino: la vivienda, la comunidad y el territorio.Nilsen A, Rivolta MC; Seldes V., Vázquez MM, Mercolli P. compiladores. Editorial Brujas, Córdoba. Pp. 259-290

BADAL E, CARRIÓN Y, RIVERA D, UZQUIANO P. 2003. La arqueobotánica en cuevas y abrigos: objetivos y métodos de muestreo. En: La recogida de muestras en arqueobotánica: objetivos y propuestas metodológicas, Editado por el Museo d'eArqueologia de Catalunya, Barcelona, Pp. 19-29.

BALL J. [1865] 1884. Contributions to the Flora of North Patagonia and the adjoining territory. Journal of the Linnean Society. Botany 21: 203-240.

BALMACEDA N, PORRO DE DIGIUNI, J. 1979. Descripción de las características morfológicas de la epidermis de las especies vegetales de la zona de Monte cercano a Viedma. Dirección de Bosques y Praderas, Ministerio de Agricultura y Ganadería. Pp. 30 .

BARBERIA E. 2011. Los dueños de la tierra en la Patagonia Austral 1880-1920. Universidad de la Patagonia Austral Río Gallegos, Santa Cruz, Argentina.

BARROSO JR. 1987. Cuadernos temáticos materiales, técnicas y tecnologías: Maderas. Instituto para la Normalización y difusión de Información técnica para la arquitectura y la construcción. Año 1, No2.

BASTIDA R, RODRÍGUEZ D, SECCHI E, DA SILVA V. 2007. Mamíferos acuáticos de Sudamérica y Antártida. Manzini Editores, Buenos Aires. Argentina.

BERETTA M, CORINALDESSI L, CASTRO A. 2011. Recursos marinos versus recursos terrestres: análisis arqueofaunístico en el sitio Cueva Del Negro, costa norte de Santa Cruz. Arqueología 17: 1-23.

BERETTA M, ZUBIMENDI MA, CIAMPAGNA ML, AMBRÚSTOLO P, CASTRO A. 2013a. Puntas de arpón en la Costa Norte de Santa Cruz: primeros estudios de piezas recuperadas en estratigrafía en el sitio Cueva del Negro. Magallania 41 (1): 211-221.

BERETTA M, ZUBIMENDI MA, CASTRO A, AMBRÚSTOLO P. 2013b. Ganchos de hueso en el sitio Cueva del Negro: evidencias de propulsores en la costa norte de Santa Cruz (Patagonia Argentina). Atek Na 3: 9-34.

BEREZOSKY J, MAZZUCA M. 2010. Actividad biológica del aceite esencial de Acantholippia seriphiodes (A.Gray) Moldenke de la región del Golfo San Jorge 
(Chubut). Resúmenes del II Congreso Argentino-Chileno- Hispano La Diversidad Química y Biológica de Organismos de la Región Patagónica. Dominguezia Vol. 26 (2): 56.

BERIHUETE M. 2006. Aportaciones de la carpología al análisis de la gestión de recursos vegetales en las sociedades cazadoras recolectoras: el grupo Selknam de Tierra del Fuego (Argentina). Trabajo de Investigación del Tercer ciclo. Universidad Autónoma de Barcelona.

BERIHUETE M. 2009. El papel de los recursos vegetales no leñosos en las economías cazadoras recolectoras: propuesta para el estudio de su gestión el caso del estudio de Tierra del Fuego (Argentina) Tesis doctoral, Departamento de prehistoria, Facultad de Letras UAB.

BERIHUETE M, CARUSO L, MANSUR E, MASSACCESI G, MENSUA C, PIQUÉ R. 2009. El aprovechamiento de los recursos vegetales entre los Selknam de Tierra del Fuego (Argentina), una aproximación etnoarqueológica. En: Capparelli A, Chevalier A, Piqué R. (Coors.) La alimentación en la América precolombina y colonial: una aproximación interdisciplinaria. Treballs D’Etnoarqueología 7, Consejo Superior de Investigaciones Científicas, Madrid, España. Pp 21-41.

BERLIN B .1992. Ethnobiological classification, principles of categorization of plants and animals in traditional societies. Princeton University Press Pp 333.

BERÓN M.1994. El recurso y el método: estrategias de movilidad y asentamiento en la subregión Pampa Seca. Revista Arqueología 4.

BHUVANESHWARI L, ARTHY E, ANHITA C, DHANABALAN K, MEENA M. 2007. Phytochemical analysis and antibacterial activity of Nerium oleander Ancient Science of Life 26 (4): 24-28.

BINFORD L. R. 1977. Forty- Seven trips. En: Stone tools as cultural markers. R. V. S. Wright. Canberra. Australia. Australian Institute of Aboriginal Studies pp. 24-36.

BINFORD, L. R., 1980. Willow smoke and $\operatorname{dog}^{\text {ee }}$ tails: hunter-gatherers settlement system and archaeological site formation. American Antiquity, 45(1): 4-20.

BITTNER M, JAKUPOVIC J, BOHLMAN F, SILVA M. 1988. 5-methilcoumarins from Nassauvia species. Phytochemistry Vol 27 (12):3845-3847.

BÓRMIDA M, CASAMIQUELA R. 1958-59. Etnografía günuna- kena. Testimonios del último Tehuelche septentrional. Runa 9: 153-193. 
BONINO N, BORRELLI L. 2006. Variación estacional en la dieta del conejo silvestre europeo (Oryctolagus cuniculus) en la región andina de Neuquén, Argentina. Ecología Austral 16:7-13.

BONOMO M. 2006 Un acercamiento a la dimensión simbólica de la cultura material pampeana. Relaciones de la Sociedad Argentina de Antropología 31:89-115.

BORELLA F, CARDILLO M, FAVIER DUVOIS C, SCARTASCINI F, ALBERTI J, MARANI H, BORGES VAZ E. 2013. Las ocupaciones humanas entre Punta Pórfido y Punta Odriozola, costa oeste del golfo San Matías: nuevos hallazgos y perspectivas. Trabajo presentado en el XVIII Congreso Nacional de Arqueología Argentina INCIHUSA (CONICET)- Universidad Nacional de La Rioja, La Rioja.

BORRERO L. 1989-1990. Evolución cultural divergente en la patagonia austral. Anales del Instituto de la Patagonia 19: 133-140.

BORRERO L. 1994-1995. Arqueología de la Patagonia. Palimpsesto. Revista de Arqueología 4: 9-69.

BOURDIEU, P. 1972. Outline of a theory of practice. Cambridge Studies in Social Anthropology. Cambridge University Press. Cambridge.

BORDIEU, P 1991. El sentido práctico. Taurus. Madrid

BRAADBAART F, POOLE I. 2008. Morphological, chemical and physical changes during charcoalification of wood and its relevance to archaeological contexts. Journal of Archaeological Science 35:2434-2445.

BRAADBAART F, POOLE I, HUISMAN D, VAN OS B. 2012. Fuel, fire and heat: an experimental approach to highlight the potential of studying ash and char remains from archaeological contexts. Journal of Archeological Science 39: 836-847.

BURMEISTER C. 1888. Últimas exploraciones en Patagonia, incluyendo los datos recogidos en sus viajes por el ingeniero Asahel P. Bell, y seguido de un mapa descriptivo. Revista de la Sociedad Geográfica Argentina 6: 193-272.

CABALLERO J. 1987. Etnobotánica y desarrollo: la búsqueda de nuevos recursos vegetales. En: Congreso Latinoamericano de Botánica. Simposio de Etnobotánica, Medellín 1986 ICFES, Serie Memorias Eventos Científicos Colombianos 46.

CABALLERO JO. 2000. Hidrografía y recursos hídricos. En: El gran libro de la Provincia de Santa Cruz. Milenio Ediciones y Alfa Centro Literario. Pp 116-139. 
CABRERA A. 1971. Regiones Fitogeográficas Argentinas. Boletín de la Sociedad Argentina de Botánica 14: 1-2.

CABRERA AL, WILLINK A. 1973. Biogeografía de América Latina. Monografías Científicas de la OEA. Serie de Biología, Monografía Nro. 13 (Washington), Pp. 120.

CAPPARELLI A. 1997. Reconstrucción ambiental de la instalación arqueológica Inka El Shincal. Tesis Doctoral. Facultad de Ciencias Naturales y Museo. Universidad Nacional de La Plata. Buenos Aires, Argentina.

CAPPARELLI A. 2007. Los productos alimenticios derivados de Prosopis chilensis (Mol.) Stuntz y P. flexuosa DC., Fabaceae, en la vida cotidiana de los habitantes del NOA y su paralelismo con el algarrobo europeo. Kurtziana Tomo 33 (1) Volumen especial de Etnobotánica Pp 103-119.

CAPPARELLI A, CASTRO A, CIAMPAGNA ML. 2009. Descripción macroscópica e identificación anatómica de un instrumento de madera (¿arpón?) hallado en el sitio Cueva del Negro (costa norte de Santa Cruz Argentina) En: Salemme M, Santiago F, Álvarez M, Piana E, Vázquez M, Mansur E. (Eds) Arqueología de la Patagonia-Una mirada desde el último confin. Editorial Utopías, Ushuaia, Argentina. Pp 433-443.

CAPPARELLI A, LEMA V. 2010. Prácticas postcolecta /post- aprovisionamiento de recursos vegetales: una perspectiva paleoetnobotánica integradora aplicada a casos de Argentina En: Bárcena J. y Chiavazza H. (Eds.) Arqueología Argentina en el Bicentenario de la Revolución de Mayo, Actas del XVII Congreso Nacional de Arqueología Argentina. Mendoza, Argentina. Pp. 1171-1176.

CAPPARELLI A, LEMA V. 2011. Recognition of post-harvest processing of algarrobo (Prosopis spp.) as food from two sites of Northwestern Argentina: an ethnobotanical and experimental approach for desiccated macroremains. Archaeological and Anthropological Sciences; Vol. 3 Pp 71 - 92.

CAPPARELLI A, MANGE E. 2014. El registro arqueobotánico del sitio Cueva Galpón (Sierras de Pailemán, Provincia de Río Negro, Argentina) En: IX Jornadas de Arqueología de la Patagonia, 20 al 25 de octubre, Coyhaique, Chile.

CAPPARELLI A, PRATES L. 2010. Identificación específica de frutos de algarrobo (Prosopis spp., Fabaceae) y mistol (Ziziphus mistol Grises., Rhamnaceae) en un sitio arqueológico de Patagonia. En: Pochettino ML, A. Ladio, Arenas P. (Eds.) Traditions 
and transformations in Ethnobotany (ICEB 2009). San Salvador de Jujuy, Argentina Pp. 13-19.

CAPPARELLI A, PRATES L. 2014. Explotación de frutos de algarrobo (Prosopis sp.) por grupos cazadores recolectores del sur de Sudamérica: el caso de Patagonia. Chúngara En prensa.

CAPPARELLI A, OLISZEWSKI N, POCHETTINO ML. 2007. Historia y estado actual de las investigaciones arqueobotánicas en la Argentina. En: Arqueología Argentina en los inicios de un nuevo siglo, Tomo III, Oliva, De Grandis, Rodríguez (Comps.), UNR, Rosario, Pp 701-717.

CAPPARELLI A, VALAMOTI S, WOLLSTONECROFT M. 2010. Recent research in post-harvest traditions in human prehistory: Old and New World palaeoethnobotanical approaches to linking the archaeology and ethnobotany of plant processing. In: Pochettino ML, Ladio A, Arenas P. (Eds.) Traditions and transformations in Ethnobotany, Jujuy, Argentina. Pp. 104.

CAPPARELLI A, ZAGORODNY N, BALESTA B. 2003. Wood remains from Andean Argentina: The use of Prosopis sp. L. in hut construction. Journal of Ethnobiology 23(1):143-154.

CARDEN N. 2007. Estudio de las manifestaciones rupestres de la meseta central de Santa Cruz. El área de los zanjones blanco y rojo al sur del río Deseado. Tesis doctoral, Facultad de Ciencias Naturales y Museo. Universidad Nacional de La Plata. CARDILLO M. 2009. Variabilidad en la manufactura y el diseño de artefactos en el área costera patagónica. Un enfoque integrador. Tesis doctoral Facultad de Filosofía y Letras. Universidad de Buenos Aires.

CARDOSO B. 2013. Utilización de especies combustibles leñosas en comunidades locales del Noroeste de Patagonia: bienes culturales y ambientales en la subsistencia rural. Tesis doctoral. Universidad Nacional del Comahue, Centro Regional Bariloche.

CARDOSO B, LADIO A, LOZADA M. 2009. Utilización de especies combustibles en una comunidad rural de la estepa patagónica. En: Pochettino ML, Ladio A, Arenas P. (Eds.) Tradiciones y Transformaciones en Etnobotánica. CYTED, RISAPRET, Argentina. Pp 496-501.

CARLQUIST S. 1966. Wood anatomy of compositae: a summary, with comments on factors controlling wood evolution. Aliso 6 (2):25-44. 
CARLQUIST S. 1987. Diagonal and tangential vessel agregation in wood function and relationtship to vasicentric tracheids. Aliso 11(4) Pp. 451-462.

CARRARA I. 1952. Lobos marinos, pingüinos y aguaneras de las costas del litoral marítimo e islas adyacentes de la República Argentina. Informe técnico. Facultad de Ciencias Veterinarias, Universidad Nacional La Plata. Buenos Aires, Argentina.

CARUSO L. 2012. Modalidades de adquisición y uso del material leñoso entre grupos cazadores-recolectores patagónicos (Argentina). Métodos y técnicas de estudios del material leñoso arqueológico. Tesis doctoral, Universitat Autònoma de Barcelona (July 2012).

CARUSO L. 2013. Los recursos vegetales en arqueología, estrategias de muestreo y estudio del material leñosos. Editorial Dunken, Buenos Aires.

CARUSO L, ÁLVAREZ M, VÁZQUEZ M. 2011. Análisis arqueobotánico de piezas de madera del extremo austral americano. Magallania 39 (1):221-240.

CARUSO L, MANSUR E, PIQUÉ R. 2008. Voces en el bosque: uso de recursos vegetales entre cazadores recolectores de la zona central de Tierra del Fuego. Darwiniana 46 (2): 202-212.

CARUSO L, CAPPARELLI A. 2013. Plants and Patagonian hunter gathererers: archaeobotany of Cerro Casa de Piedra 7 (Santa Cruz, Argentina) En: 16TH Conference of the international work group for Paleoethnobotany.Thessaloniki Greece, 17 to 21 June.

CARUSO L, IRIARTE E. 2011. Caracterización bajo microscopio electrónico de barrido y análisis de la composición química de partículas y precipitados minerales en material leñoso. En: 3er Congreso Internacional de Arqueología experimental Banyoles, 17 a 19 de Octubre de 2011, Girona.

CARUSO L. THÉRY - PARISOT I, PIQUÉ I HUERTA R. 2013 ¿Recolectar o cortar? Modalidades de adquisición del material leñoso en cazadores recolectores de Patagonia. En: Tendencias teórico-metodológicas y casos de estudio en la arqueología de la Patagonia. Zangrando F, Barberena R, Gil A et al. (eds.) Museo de Historia Natural de San Rafael, Sociedad Argentina de Antropología e Instituto Nacional de Antropología y Pensamiento Latinoamericano Buenos Aires: Pp 281-287.

CASAMIQUELA R. 1960. Sobre la significación mágica del arte rupestre norpatagónico. Cuadernos del Sur,. Inst. de Humanidades UNS, Bahía Blanca. Pp. 55. 
CASAMIQUELA R. 1999. Proyecto Etnobotánico de la Patagonia: primer informe Disponible en: http://ag.arizona.edu/OALS/ICBG/aspectos/casamiquela.htlm. Última revisión: 14 de septiembre de 1999.

CASAS A. 2001. Silvicultura y domesticación de plantas en Mesoamérica En: Estudio sobre las relaciones entre seres humanos y plantas en los albores del siglo XXI. UAMSMARN y P, México.

CASSIODORO G. 2005. Equipamiento tecnológico del espacio en la cuenca del Lago Salitroso (Santa Cruz) En: Entre Pasados y Presentes. Trabajos de las VI Jornadas de Jóvenes Investigadores en Ciencias Antropológicas. Coord. A. Cetti, A. Re, D. Rindel y P. Valeri. INPL Buenos Aires.

CASSIODORO G. 2008. Movilidad y uso del espacio de cazadores recolectores del Holoceno tardio: estudio de la variabilidad del registro tecnológico en distintos ambientes del noroeste de la provincia de Santa Cruz. Tesis de Doctorado. Facultad de Filosofía y Letras. Universidad de Buenos Aires. Buenos Aires, Argentina.

CASSIODORO G, LUBLIN G, PIRIZ MF. 2000. Los primeros pasos del Alero Destacamento Guardaparque: análisis lítico y faunístico (NO provincia de Santa Cruz, Argentina). En: Desde el país de los gigantes: perspectivas arqueológicas en PatagoniA Espinosa S. (ed.) Universidad Nacional de la Patagonia Austral. .

CASSIODORO G, FLORES CONI J. 2010. Los parapetos del sitio Guitarra 10 (Meseta del Lago Guitarra, Santa Cruz) Una aproximación tecnológica. En: Arqueología Argentina en el Bicentenario de la Revolución de Mayo Actas del XVII Congreso Nacional de Arqueología Argentina. Bárcena R. Chiavazza H. Editores, Mendoza, Argentina.

CASTRO A, MAZZITELLI L. 2011. Hallazgos líticos en Cueva del Negro, Provincia de Santa Cruz, Análisis funcionales y tecno-morfológicos. En: VIII Jornadas de Arqueología de la Patagonia, Malargüe, Argentina.

CASTRO A, MORENO E. 1996-1998 Cabo Tres Puntas un sitio del Holoceno medio en la costa de Patagonia continental Informes Palimpsesto Revista de Arqueología ${ }^{\circ} 5$. CASTRO A, MORENO E. 2000. Noticia sobre enterratorios humanos en la costa norte de Santa Cruz, Patagonia Argentina. Anales Instituto Patagonia 28: 225-231. 
CASTRO A, MORENO E, ANDOLFO M, ZUBIMENDI MA. 2001. Distribución espacial de sitios en la Localidad de Punta Medanosa. Santa Cruz (Argentina). Relaciones de la Sociedad Argentina de Antropología 26: 303-321.

CASTRO A, MORENO JE, ANDOLOFO MA, ZUBIMENDI MA, GIMENEZ R, MAZZITELLI L, AMBRÚSTOLO P. 2003. Análisis distribucionales en la costa de Santa Cruz (Patagonia Argentina): alcances y resultados. Magallania 31: 69-94.

CASTRO A, MORENO E, MARTINELLI K, PEPE F. 2000. Restos faunísticos artefactos líticos: más información sobre la Costa Norte de Santa Cruz. En: Desde el país de los gigantes: perspectivas arqueológicas en Patagonia. Tomo II. Universidad Nacional de la Patagonia Austral, Río Gallegos.

CASTRO A, MORENO E, IZETA A. 1999. Descripción del material lítico del sitio Cabo Blanco 1. En: Actas del Congreso Nacional de Arqueología Argentina T. III La Plata.

CASTRO A, SALCEDA S, PLISCHUK M, DESÁNTOLO B. 2009. Bioarqueología de rescate: sitio Carso (costa norte de Santa Cruz, Argentina) En: Salemme M, Santiago F, Álvarez M, Piana E, Vázquez M, Mansur E. (Eds.) Arqueología de la Patagonia-Una mirada desde el último confin. Editorial Utopías, Ushuaia, Argentina. Pp 629-638.

CASTRO A, ZUBIMENDI MA, AMBRÚSTOLO P. 2011. Archaeological littoral sites on the northern coast of Santa Cruz: valuable evidence of sea level changes on the continental Patagonian coasts (Argentina). Quaternary International 245:111-121.

CASTRO A, ZUBIMENDI MA, GRASSI L, AMBRÚSTOLO P, MAZZITELLI L. 2007. Sitio Arqueológico Carsa (Puerto Deseado, Patagonia Argentina): reflexiones sobre la práctica de una arqueología social y pública. Revista de Arqueología Pública São Paulo 2: 7-21.

CASTRO A, ZUBIMENDI MA, PEÑA C. 2000. Proyecto arqueológico de rescate en el Cañadón del Duraznillo (Reserva Natural Fundación Vida Silvestre). Informe técnico, Fundación Vida Silvestre.

CASTRO A, ZUBIMENDI MA, AMBRÚSTULO P, MAZZITELLI L, BERETTA M, CIAMPAGNA ML, TROLA V, HAMMOND H, ZILIO L, PLISCHUCK M. 2010. Sitio Cueva del Negro: un caso de aprovechamiento intensivo de los recursos marinos en la Costa Norte de Santa Cruz (Patagonia Argentina). En: Bárcena R, Chiavazza H. 
(Eds.). Arqueología Argentina en el Bicentenario de la Revolución de Mayo. Actas del XVII Congreso Nacional de Arqueología Argentina. Mendoza, Argentina. Pp. 309-314.

CASTRO A. 2010. Rutas indígenas y arqueología en la Provincia de Chubut. Tesis doctoral. Facultad de Filosofía y Letras. Universidad de Buenos Aires.

CAVALLI-SFORZA L, FELDMAN MW, CHEN KH, DOMBUSH SM. 1982. Theory and observation in cultural Transmission. Science 218 (4567): 19-27.

CHASE A. 1989. Domestication and domiculture in northern Australia: asocial perspective. En: Foraging and Farming. The evolution of plan exploitation D. Harris y G Hillman (eds.) 45:53. Londres, Unwin Hyman.

CIAMPAGNA ML. 2012. Prácticas poscolecta-molienda- de grupos cazadores recolectores de la costa norte de Santa Cruz (Holoceno tardío). En: IX Jornadas de Jóvenes investigadores en Ciencias Antropológicas, Instituto Nacional de Amtropología y Pensamiento Latinoamericano 5 al 9 de noviembre de 2012, Buenos Aires.

CIAMPAGNA ML, CAPPARELLI A. 2012. Historia del uso de las plantas por parte de las poblaciones que habitaron la Patagonia continental Argentina. Cazadores Recolectores del Cono Sur Revista de Arqueología 6: 45-75

CIAMPAGNA ML, TROLA V, BORRELLI L, CAPPARELLI A. 2011 El uso de recursos vegetales por parte de grupos cazadores recolectores de la costa norte de Santa Cruz: análisis de instrumentos de molienda. VIII Jornadas de Arqueología de la Patagonia.

CLARAZ G. [1865-66] 2008. Viaje al río Chubut, Aspectos naturalísticos y etnológicos. Ediciones Continente, Buenos Aires, Argentina. Pp 286.

CODIGNOTTO JO. 1987. Cuaternario marino entre Tierra del Fuego y Buenos Aires. Revista de la Asociación Geológica Argentina 42: 208-212.

CODIGNOTTO JO. 2000. La costa de la Provincia de Santa Cruz. En: El gran libro de la Provincia de Santa Cruz. Milenio Ediciones y Alfa Centro Literario. Pp 171-187. CODIGNOTTO JO, KOKOT R, MARCOMINI SC. 1992. Neotectonism and sea level changes in the coastal zone of Argentina. Journal of Coastal Research 8 (1): 125-133. CORDERO JA. 2010. Explotación animal een el Holoceno del Noroeste de la Patagonia Argentina. Cambios climáticos y transformaciones del comportamiento humano: una primera aproximación. Tesis doctoral. Facultad de Filosofía y Letras. Universidad de Buenos Aires 
CORREA MN. 1969. Flora Patagónica. Colección Científica del INTA. Buenos Aires, Argentina.

CORREA MN. 1999. Flora Patagónica. Colección Científica del INTA. Buenos Aires, Argentina.

COX G. [1862-63] 2006. Exploración de la Patagonia Norte, Un viaje en el Nahuel Huapi. Ediciones Continente, Buenos Aires, Argentina. Pp 224.

CRIVELLI MONTERO E, PARDIÑAS U, FERNÁNDEZ M. 1996. Introducción, procesamiento y almacenamiento de macro vegetales en la Cueva Epullán Grande (Provincia del Neuquén). En: Gómez Otero J (Ed.) Arqueología solo Patagonia, Ponencias de la Segundas Jornadas de Arqueología de Patagonia. CENPAT, Chubut, Argentina. Pp. 49-59.

CRUZ I. 2007. Avian taphonomy: observations at two Magellanic penguin (Spheniscus magellanicus) breeding colonies and their implications for the fossil record. Journal of Archaeological Science 34: 1252-1261.

CUADRA D. 2000. Dinámica de la composición poblacional de Santa Cruz entre 1895 y 1991. En: El gran libro de la provincia de Santa Cruz. Ed. Oriente Alfa Centro Literario Pp 827-867.

CUETO M, CAPPARELLI A, CIAMPAGNA ML, PAUNERO M, CASTRO A. 2010. Prácticas postcolecta y material leñoso: análisis de residuos y huellas microscópicas de origen vegetal, sobre artefactos de roca tallada, utilizados en contextos experimentales. En: Bárcena R y Chiavazza H. (Eds.) Arqueología Argentina en el Bicentenario de la Revolución de Mayo, Actas del XVII Congreso Nacional de Arqueología Argentina. Universidad de Filosofía y Letras de Cuyo, Mendoza, Argentina. Pp. 1205-1210.

CUTLER, DF, RUDALL PJ, GASSON PE. 1987. Root Identification Manual of trees and shrubs. A guide to the anatomy of roots of trees and shrubs hardy in Britain and Northern Europe. London Chapman and Hall.

CONSTANTE M. 2001. Geomorfología y geología de Ensenada Ferrer, Provincia de Santa Cruz. Ph. thesis, Departamento de Ciencias Geológicas, Universidad de Buenos Aires, Argentina.

DARWIN C. [1833] 2006. Diario de la Patagonia: Notas y reflexiones de un naturalista sensible. Ediciones Continente, Buenos Aires, Argentina. Pp 126 
DELLA NEGRA C. NOVELLINO P 2002 Nuevos estudios sobre los antiguos habitantes de la cuenca del Río Limay: Sitio Grande, Depto. Picún Leufú, Provincia del Neuquén. Relaciones de la Sociedad Argentina de Antropología XXVII.

DE PORRAS E. 2010. Dinámica de la vegetación de la Meseta Central de Santa Cruz durante los últimos 11.000 años: forzantes bióticos y abióticos. Tesis doctoral. Facultad de Ciencias Exactas y Naturales. Universidad Nacional de Mar del Plata.

DOS SANTOS LOPES M. 2012. El campo Deseado y su gente. Ediciones Culturales El Orden. Pp 212.

DUFRAISSE A. 2012. Firewood and woodland management in their social economic and ecological dimensions. New perspectives. Wood and charcoal evidence for human and natural history. SAGVNTVM Extra-13, 65-74.

EMBON A. 1950. Fuentes Históricas con noticias etnográficas y arqueológicas del indígena patagón (Aoni kenk) Tesis doctoral, Facultad de Humanidades y Ciencias de la educación Universidad Nacional de La Plata. Buenos Aires, Argentina.

EMPERAIRE J.2002. Los Nómades del mar. LOM Edicienes, Santiago de Chile. Pp 340.

ERIZE E. 1989 Mapuche 5 Editorial Yepún pp.147

ESCALADA F. 1949. El complejo Tehuelche, estudios de la etnografía patagónica. Instituto Superior de Estudios Patagónicos, Buenos Aires. Pp. 353.

ESTOMBA D, LADIO AH, LOZADA M. 2005. Plantas medicinales nativas y exóticas usadas por una Comunidad Mapuche en las Cercanías de Junín de los Andes, Neuquén. Boletín Latinoamericano y del Caribe de plantas medicinales y aromáticas 4(6): 107112.

ESTOMBA D, LADIO AH, LOZADA M. 2006. Medicinal wild plant knowledge and gathering patterns in a Mapuche community from North-Western Patagonia. Journal of Ethnopharmacology 103: 109-119.

Espinosa L. 2000 Los conjuntos artefactuales líticos de la estepa y el bosque en el Parque Nacional Perito Moreno (Santa Cruz, Argentina). En: Desde el país de los gigantes: perspectivas arqueológicas en Patagonia Espinosa S. (ed) Universidad Nacional de la Patagonia Austral. 
ETKIN N. 1994 Eating on the wild side, the pharmacologic, ecologic, and social implications of using noncultigens. Nina L. Etkin editor. The University of Arizona Press, Tucson, London Pp. 305.

ETKIN N, ROSS P. 1994. Pharmacologic implications of "wild" plants and Hausa diet. En: Eating on the wild side, the pharmacologic, ecologic, and social implications of using noncultigens Nina L. Etkin editor. The University of Arizona Press, Tucson, London. Pp.85-101.

EYSSASTIER C. 2011 Conocimiento hortícola y de recolección de recursos vegetales silvestres en comunidades rurales y semirurales del Noroeste de Patagonia: Saber cómo (How-know) y resiliencia Tesis doctoral. Facultad de Ciencias Exactas y Naturales, Universidad de Buenos Aires. Buenos Aires, Argentina.

FALKNER T. 1911. Descripción de la Patagonia y de las partes contiguas a la América del Sur, traducción, anotaciones, noticia biográfica y bibliográfica Lafone Quevedo, Samuel. Universidad Nacional de La Plata Buenos Aires, Argentina. Pp. 392. FAVERO M, SILVA RODRÍGUEZ MP. 2005. Estado actual y conservación de aves pelágicas que utilizan la plataforma continental argentina como área de alimentación. Hornero 20 (1): 95-110.

FERNÁNDEZ J. 1981/82. Cronología y tecnología de las hachas salineras de Truquico, Neuquén, Relaciones de la Sociedad Argentina de Antropología 14 (2): 109-120.

FERNÁNDEZ M. 2006 Economía y sistemas de asentamiento aborigen en la Cuenca del Río Limay. Memoria Americana 14: 37-73.

FERNÁNDEZ P, BELLELLI IC, CARBALLIDO M, PODESTÁ M, VASINI A. 2010. Primeros resultados de las Investigaciones Arqueológicas en el sitio Población Anticura (Río Negro, Argentina) En: Arqueología Argentina en el Bicentenario de la Revolución de Mayo, Actas del XVII Congreso Nacional de Arqueología Argentina Editores Roberto Bárcena y Horacio Chiavazza, Mendoza, Argentina.

FERRO E, MOLARES S, WILVERS N. 2004. Educando con las plantas nativas de la Estepa Patagónica. Educación Ambiental. Rio Negro, Argentina.

FERUGLIO E. 1933. I terrazzi marini della Patagonia. Giornale di Geologia Annali del R. Museo Geológico di Bologna, 2, 8 bis.

FERUGLIO E. 1950. Descripción geológica de la Patagonia. Tomo III. Dirección General de Yacimientos Petrolíferos Fiscales, Buenos Aires. 
FIGUERERO TORRES MJ, LAZA J, BOND M, CICCHINO A. 1982. Los coprolitos como indicadores paleoambientales en arqueología. En: Primera Reunión Nacional de Ciencias del Hombre en zonas Áridas. Mendoza 26 al 29 de mayo.

FONTANA J. [1885-86] 2006. Viaje de exploración de la Patagonia austral. Ediciones Continente, Buenos Aires, Argentina. Pp. 128.

FORD R. 1979. Paleoethnobotany in American Archaeology. En Schiffer (Ed.). Advance in archaeological method and theory vol. 2: 285-336. Academic Press. New York

FOURNIER P, FREEMAN A. 1991. El razonamiento analógico en etnoarqueología, el caso de la tradición alfarera de mata Ortiz, chihuahua, México. Boletín de Antropología Americana 23:109-118.

FRANK A. 2011. Tratamiento térmico y manejo del fuego en sociedades cazadoras recolectoras de la Meseta Central de Santa Cruz. Tesis doctoral. Facultad de Ciencias Naturales y Museo, Universidad Nacional de La Plata, Buenos Aires, Argentina..

FRERE E, QUINTANA F, GANDINI PA. 2005. Cormoranes de la costa patagónica: estado poblacional, ecología y conservación. Hornero 20 (1): 35-52.

GALANIDOU N. 2000. Patterns in Caves: Foragers, Horticulturists, and the Use of Space. Journal of Anthropological Archaeology 19: 243-275.

GÁNDARA M. 2006 La inferencia por analogía: más allá de la analogía etnográfica. En: Etnoarqueología de la Prehistoria más allá de la analogía. Treballs D’Etnoarqueología 6. Deparatemt d'Arqueologia i Antropología, Institució Milá i Fontanals, CSIC. Pp. 13-23.

GANDINI PA, FRERE E. 2000. Las aves marinas de la costa santacruceña. En: El gran libro de la Provincia de Santa Cruz. Milenio Ediciones y Alfa Centro Literario. Pp 347359.

GARIBOTTI I A. 1998. Análisis de la estructura anatómica de carbones arqueológicos de sitios incaicos (ca. 1480-1530 d.C.) del valle de Uspallata (Mendoza, Argentina). Boletín de la Sociedad Argentina de Botánica 33 (3-4):195-205.

GERSHENZON J.1994. Metabolic costs of terpenoids accumulation in higher plants. Journal of Chemical Ecology 20 (6):1281-1328.

GIACOSA RE, CÉSARI O, GENINI A. 1998. Descripción de la Hoja Geológica 4766 - III y IV. Puerto Deseado, Provincia de Santa Cruz, Tomo 240 de Boletín del 
Programa Nacional de Cartas Geológicas de la República Argentina 1:250.000. Ministerio de Economía, Buenos Aires.

GIMENEZ GOWLAND MB.2001. Flora Nativa Norpatagónica Ilustrada. Editado por el Instituto Nacional de Tecnología Agropecuaria. EEA Bariloche, Fundación Vida Silvestre Argentina y Administración de Parques Nacionales. Bariloche, Argentina. Soporte digital.

GIOVANETTI MA, LEMA V, BARTOLI C, CAPPARELLI A. 2008. Starch grain characterization of Prosopis chilensis (Mol.) Stuntz and P. flexuosa DC., and the analysis of their archaological remains in Andean South America. Journal of Archaeological Science (35) 2973-2085.

GÓMEZ CASTELLANOS JR. 2008. Epazote (Chenopodium ambrosioides). Revisión a sus características morfológicas, actividad farmacológica, y biogénesis de su principal principio activo, ascaridol. Boletín Latinoamericano y del Caribe de Plantas Medicinales y Aromáticas 7 (1) 3-9.

GOMEZ M. 2008. Las formas de interacción con el monte de las mujeres tobas (qom). Revista Colombiana de Antropología 44 (2): 373-408.

GÓMEZ OTERO J. 1996. Primera noticia sobre el hallazgo de un anzuelo de madera en Patagonia: sus implicancias en el contexto de la arqueología regional En: Arqueología: sólo Patagonia II Jornadas de Arqueología de la Patagonia, Ponencias, Centro Nacional Patagónico (CONICET), Puerto Madryn. Pp. 59-68

GÓMEZ OTERO, J., 2006. Dieta, uso del espacio y evolución en poblaciones cazadoras recolectoras de la costa centro-septentrional de Patagonia durante el Holoceno medio y tardio. Tesis Doctoral, Universidad de Buenos Aires. Tesis doctoral inédita para optar al titulo de Dr. en Filosofía, Facultad de Filosofía y Letras, Universidad Nacional de Buenos Aires

GÓMEZ OTERO J. BELARDI JB, TYKOT R, GRAMMER S. 2000. Dieta y poblaciones humanas en la costa norte del Chubut (Patagonia Argentina). En: Desde el país de los gigantes. Perspectivas arqueológicas en Patagonia. Tomo 1, Universidad Nacional de la Patagonia Austral, Río Gallegos. Pp. 109-122.

GONZALES BONORINO G, BUJALESKY F, COLOMBO F, FERRERO M. 1999. Holocene coastal paleoenvironment in Atlantic Patagonia, Argentina. Journal of South American Earth Sciences 12: 325-331. 
GONZÁLEZ F. [1798] 1965. Diario del viaje que hizo por tierra desde Puerto Deseado al Río Negro. En: Vignati (Coord.) Cronistas y Viajeros del Río de la Plata Tomo II. Academia Nacional de la Historia. Buenos Aires, Argentina .Pp. 21-121.

GONZÁLEZ SB, MOLARES S. 2004. Plantas medicinales utilizadas en comunidades rurales del Chubut, Patagonia- Argentina. Boletín Latinoamericano y del Caribe de Plantas Medicinales y Aromáticas 3(3): 58-62.

GONZÁLEZ SB, BANDONI A, VAN BAREN C, DI LEO LIRA P, CERDA GARCÍA ROJAS C, JOSEPH NATHAN P. 2004. The essential oil of the aerial parts of Adesmia boronioides Hook. f., Journal of Essential Oil Research 16:513-516.

GONZÁLEZ SB, GUERRA PE, VAN BAREN C, DI LEO LIRA P, BANDONI A 2011 El aceite esencial de tallos y hojas de Schinus patagonicus (Phill.) Johnst. en el ecotono de la Patagonia Argentina. Dominguezia Vol. 27 (1): 33-39.

GOÑI R. 1995. El uso actual de los aleros: algunas implicancias arqueológicas. Cuadernos del Instituto Nacional de Antropología y Pensamiento Latinoamericano 16: 329- 341 .

GOÑI R, CASSIODORO G, RE A, BOURLOT T, RINDEL D, GUICHON F. 2010. Arqueología de la meseta del lago Guitarra (Santa Cruz). En: Arqueología Argentina del Bicentenario de la Revolución de Mayo, XVII Congreso Nacional de Arqueología Argentina, Tomo V, editado por Bárcena R. y Chiavazza H., UNCuyo-CONICET, Mendoza Pp. 1923-1928.

GRADIN C. 1978. Las pinturas del Cerro Shequen. Revista del Instituto de Antropología 6: 64-92.

GRADÍN C, AGUERRE A. 1994. Restos vegetales del enterratorio Puesto El Rodeo, curso medio del Río Pinturas, Prov. de Santa Cruz. En: Contribución a la arqueología del Río Pinturas, Prov. de Santa Cruz. Búsqueda de Ayllu, Concepción del Uruguay, Argentina Pp. 315-316.

GRADÍN C, ASCHERO C, AGUERRE AM. 1987. Primeros niveles culturales en el área Río Pinturas, Prov. De Santa Cruz. Búsqueda de Ayllu, Concepción del Uruguay, Argentina. Pp. 315-316.

GUBER R. 2001. La etnografia, método de campo y reflexividad. Grupo Editorial Norma Pp. 100 
GUERRA P, PASQUINI M, TRONCOSO A.1994. Estudio xilológico del leño de coníferas nativas de los bosques andino- patagónicos. Publicación Técnica 18. Centro de Investigación y Extensión Forestal Andino Patagónico. Universidad Nacional de la Patagonia. Esquel.

GUERRA P, GONZÁLEZ S, KIRNER H, RETTA D, DI LEO LIRA P, GÓMEZ M. 2012. Aspectos anatómicos del leño y composición de los aceites esenciales de especies arbustivas- leñosas del ecotono y la estepa del noroeste de la Provincia de Chubut. Dominguezia Vol. 28 (1): 13-44.

GUINNARD A. [1856-59] 1971. Tres años de esclavitud entre los Patagones, relato de mi cautiverio. Colección Austral Espasa-Calpe, Argentina.

GUSINDE M. 1936. Plantas medicinales que los indios Araucanos recomiendan. Anthropos: 850-873.

GUTIÉRREZ ZUGASTI I. 2008. Análisis tafonómico en arqueomalacología: el ejemplo de los concheros de la región cantábrica. Revista Krei 10: 53-74. España.

HAJDUK A, ALBORNOZ AM. 1999. El sitio Valle Encantado I. Su vinculación con otros sitios: un esbozo de la problemática local diversa del Nahuel Huapi. En: Soplando en el Viento. Terceras Jornadas de Arqueología de la Patagonia, Neuquén. Pp. 371391.

HARLAN J, DE WET J. 1965. Some thoughts about weeds. Economic botany 19(1): 16-24.

HAMMOND H. 2013. Propuesta metodológica para el estudio de conjuntos malacológicos de sitios concheros: su aplicación en la costa norte de Santa Cruz (Patagonia Argentina) La Zaranda de Ideas. Revista de Jóvenes Investigadores en Arqueología 9(2): 77-102.

HAMMOND H. 2014. Taphonomic analysis of archaeomalacological assemblages: shell middens on the nothern coast of Santa Cruz (Patagonia Argentina) Intersecciones en Antropología, Volumen especial 1. En prensa

HAMMOND H y ZUBIMENDI MA. 2013 Estudio de la composición de sitios concheros en la costa norte de Santa Cruz. En: Zangrando A, Barberena R, Gil A, Neme G, Giardina M, Luna L, Otaola C, Paulides S, Salgán L, Tívoli A. (Comps.). Tendencias teórico-metodológicas y casos de estudio en la arqueología de la Patagonia. Coeditado con el Museo de Historia Natural de San Rafael y el INAPL. Pp 405-415. 
HAMMOND H, ZUBIMENDI MA, ZILIO L. 2013. Composición de concheros y uso del espacio: aproximaciones al paisaje arqueológico costero en Punta Medanosa. Anuario de Arqueología 67-84.

HAMMOND H, TROLA V, MAZZITELLI L. 2009. Procesamiento del material lítico de dos sitios de la localidad "Isla Lobos" Subsector Sur de la costa norte de Santa Cruz. En: Entre pasados y presentes II Estudios contemporáneos en Ciencias Antropológicas Bourlot T, Bozzuto D, Crespo Hetch C, Kuperszmit N (ed) Fundación de Historia Natural Félix de Azara, Buenos Aires.

HARRIS D. 2007. An evolutionary continuum of people- pant interaction En: The emergence of agriculture, a global view Ed.Denham T. y White P., Routledge Ed, HARRINGTON T. 1943 El keñewe o yamjatrráwich. En: Proyecto Etnobotánico de la Patagonia: primer informe Casamiquela R. http://ag.arizona.edu/OALS/ICBG/aspectos/casamiquela.htlm. Última revisión: 14 de septiembre de 1999.

HARRINGTON T. 1968. Toponimia del indio günuna Küne. Academia Nacional de la Historia Investigaciones y ensayos 5: 331-362.

HELBAEK H. 1959. The domestication of food plants in the Old World, Science 130: 365-372.

HENRY D. 2012 The palimpsest problem, hearth pattern analysis, and Middle Paleolithic site structure.Quaternary Internationa 247:246-266

HERNANDO A. 2006. Etnoarqueología y globalización. Propuesta para una etnoarqueología estructuralista. En: Etnoarqueología de la Prehistoria más allá de la analogía. Treballs D'Etnoarqueología 6. Deparatemt d'Arqueologia i Antropología, Institució Milá i Fontanals, CSIC. Pp 25-32.

HERMO D. 2008. Los cambios en la circulación de las materias primas líticas en ambientes mesetarios de Patagonia, una aproximación para la construcción de los paisajes arqueológicos de las sociedades cazadoras recolectoras.Tesis doctoral, Facultad de Ciencias Naturales y Museo, Universidad Nacional de La Plata.

HODDER, I. 1986. Reading the Past. Current Approaches to Interpretation in archaeology, Cambridge University Press, Cambridge. 
HURRELL J. 1987. Las posibilidades de la etnobotánica y un nuevo enfoque a partir de la ecología y su propuesta cibernética. Revista Española de Antropología Americana $17: 35-258$

IANTANOS N. 2003. Dinámica sedimentaria de la ría del Deseado, Provincia de Santa Cruz. Tesis doctoral. Facultad de Ciencias Naturales, Universidad Nacional de la Patagonia San Juan Bosco, Comodoro Rivadavia, Argentina.

IANTANOS NJ, MORENO E, ANDOLFO, ISLA F, CASTRO A. 2009. Características y evoloución del Tómbolo Cabo Blanco, Provincia de Santa Cruz, Argentina. Naturalia Patagonica 4, $\mathrm{n}^{\circ}$ 2: 33-45.

IAWA 1989. List of microscopic features for hardwood identification. E. Wheeler, P. Baas \& P. Grason (eds.) IAWA Bulletin 10: 219-332.

IAWA 2004 List of Microscopio features for sofwood identification. Richter H., D.

Grosser, I. Heinz \& P. Gasson (eds.) IAWA Journal 25(1):1-70

INDEC 1991. CENSO. Instituto Nacional de Estadísticas y Censos. Disponible en http://www.indec.mecon.ar/nivel4 default.asp?id tema 1=1\&id tema 2=16\&id tema $\underline{3=81}$

INDEC 2001. CENSO. Instituto Nacional de Estadísticas y Censos. Disponible en http://www.indec.mecon.ar/nivel4_default.asp?id_tema_1=1\&id_tema_2=16\&id tema $\underline{3=81}$

INDEC 2010. CENSO. Instituto Nacional de Estadísticas y Censos. Disponible en: www.censo2010.indec.gov.ar/

IBARROULE A, SAMPAOLI P, TAGLIORETTE A. 2011. Estancias del Noreste de la Provincia de Santa Cruz. Su historia y su Patrimonio en la primera mitad del siglo XX. Universidad Nacional de la Patagonia Austral, Argentina.

INGOLD T. 1993. Hunting and gathering as ways of perceiving the environment. En:

Fukui K y Ellen R (Eds.). Beyond Nature and Culture. Berg. Oxford.

ISLA F, IANTANOS N, ESTRADA E. 2004. Dinámica submareal y condiciones ambientales de la ría Deseado, Santa Cruz. Revista de la Asociación Geológica Argentina 59 (3): 367-375.

IZETA AD. 1999. Los ictiorestos arqueológicos del sitio Moreno (Costa Norte de la provincia de Santa Cruz, República Argentina). En: Díaz Marin C. (Ed.). Actas del XII Congreso Nacional de Arqueología Argentina 3: 489-492. 
JOHNS T. 1994 Ambivalence to the Palatability Factors in wild food plants En: Nina L. Etkin editor. Eating on the wild side, the pharmacologic, ecologic, and social implications of using noncultigens. The University of Arizona Press, Tucson, London. Pp 46-61.

KATINAS L. 2001. El herbario, significado, valor y uso. Serie técnica y didáctica ${ }^{\circ} 1$, Probiota ISSN n 15159349 La Plata Argentina.

KNAAK N D, DA SILVA L, ADREIS TF, FIUZA ML. 2013.Chemical characterization and antifunal activity of plant extracts and essential oils on the Bipolaris oryzae and Gerlachia oryzae phytopathogens. Australasian Plant Pathology Society 42: 469-475.

KHOSHKHAM, ASGARPANAH JR. 2012. Phytochemistry and pharmacological properties of ruta graveolens L. Journal of Medicinal Plant research 6, $\mathrm{n}^{\mathrm{o}}$ 23: 39423949.

KOFALT R, MASCÓ M 2000 La distribución de la vegetación en la provincia de Santa Cruz. En: El gran libro de la Provincia de Santa Cruz, Patagonia, Argentina, T. I, editado por C.J. Godoy Manríquez, Milenio Ediciones, España Pp. 191-229.

LADIO AH. 2001. The maintenance of wild plants gathering in a Mapuche community of Patagonia. Economic Botany 55(3): 243-254.

LADIO AH. 2004. El uso actual de plantas nativas silvestres comestibles en comunidades Mapuches del NO Patagonico. Boletín Latinoamericano y del Caribe de plantas medicinales y aromáticas 3 (2): 30-36.

LADIO AH. 2006 a. Wild Plant Foods with medicinal use in a Mapuche Community of NW Patagonia En: Pieroni A y Price L (Eds.) Eating and healing: explorations of traditional food as medicines. Haworth Press. USA. Pp: 297- 321.

LADIO AH. 2006 b. Uso y conservación de plantas silvestres con órganos subterráneos comestibles en comunidades Mapuche de la estepa patagónica argentina En: De Alburquerque P, de Andrade Maris F, de F. Castelo Branco Rangel de Almeida C. (Eds.) Tópicos em conservacao e etnobotanica de plantas comestíveis. UNUPEEA, Brasil. Pp. 53-72.

LADIO AH. 2011. Underexploited wild plant foods of north western Patagonia. En Filip R (Ed.) Multidisciplinary approaches on food science and nutrition for the XXI century. Pp. 1-16. 
LADIO AH y LOZADA M. 2000. Edible wild plant use in a Mapuche community of northwestern Patagonia. Human Ecology 28(1): 53-71.

LADIO AH, LOZADA M. 2003. Comparison of edible wild plant diversity used and foraging strategies in two aboriginal communities of NW Patagonia. Biodiversity and Conservation 12(5): 937-951.

LADIO AH, LOZADA M. 2004. Summer cattle transhumance and wild edible plant gathering in Mapuche comunity of northwestern patagonian. Human Ecology 32(2): $225-240$

LADIO AH, LOZADA M. 2009. Human ecology, ethnobotany and traditional practice in rural populations inhabiting the Monte Region: Resilience and ecological knowledge. Journal of Arid Environment 73(2): 222-227.

LADIO AH, LOZADA M, WEIGANDT M. 2007. Comparison of traditional wild plants use between two Mapuche communities inhabiting arid and forest environments in Patagonia, Argentina. Journal of Arid Environments 69: 695-715.

LATOUR MC, PELLIZA SBRILLER A. 1981. Clave para la determinación de la dieta de herbívoros en el NO de la Patagonia. RIA 17 (1): 109-157.

LLANO C. 2010. Aprovechamiento de los Recursos Vegetales entre las Sociedades Cazadoras - Recolectoras del Sur de Mendoza. Tesis doctoral. Universidad Nacional del Comahue.

LARRY, ANDRADE.2012. Producción y ambiente en la meseta central de Santa Cruz, Patagonia austral en Argentina: desencadenantes e impacto de la desertificación. Ambiente y Desarrollo 16 (30): 73-92.

LEMA SV. 2009. Domesticación vegetal y grados de dependencia ser humano-planta en el desarrollo cultural prehispánico del noroeste argentino. Tesis Doctoral. Facultad de Ciencias Naturales, Universidad Nacional de La Plata. Buenos Aires, Argentina.

LEMA V, DELLA NEGRA C, BERNAL V. 2012. Explotación de recursos vegetales silvestres y domesticados en Neuquén: implicancias del hallazgo de restos de maíz y algarrobo en artefactos de molienda del Holoceno tardío. Magallania 40 (1): 229-249. LEMONNIER P. 1992 Elements for an anthropology of technology. Anthropological papers, Museum of Anthropology, University of Michigan. Ann Arbor, Michigan. LEÓN RJ, BRAN D, COLLANTES M, PARUELO MJ, SORIANO A. 1998. Grandes unidades de vegetación de la Patagonia extraandina. Ecología Austral 8: 125-144. 
LEONTI M.F., RAMÍREZ, O., STICHER \&Heinrich M 2003. Medicinal flora of the Popoluca México: a botanical systematical perpective. Economic Botany 57 (2):218230.

LIRA SAN MARTIN N, LAVIER C. 2014. Maderas de las embarcaciones de tradición indígena de la Patagonia septentrional. En: IX Jornadas de Arqueología de la Patagonia, del 20 al 25 de octubre de 2013, Coyhaique, Chile.

LISTA R. [1879/1894]. 2006. Viaje a la Patagonia Austral y Los Indios tehuelches. Ediciones Continente, Buenos Aires, Argentina. Pp. 128

LEROI-GOURHAN A. 1979. Structures de combustion et strucdures d'excavation. Revista do Museu Paulista XXVI: 9 - 10.

LOGAN M. y DIXON A. 1994. Agriculture and the acquisition of medicinal plant knowledge. En: Eating on the wild side. The pharmacologic, ecologic, and social implications of using noncultigens, de Etkin N. Tucson and London: The University of Arizona Press, PP. 305.

LOPES LUTZ D, ALIVIANO DS, ALIVIANO CS, KOLODZIEJCZYK PP. 2008. Screening of chemical composition, antimicrobial and antioxidant activities of Artemisia essential oils. Phytochemistry 69:1732-1738.

MAGNIN L. 2010. Distribuciones arqueológicas en la meseta central de Santa Cruz. Implicancias para el estudio del uso del espacio y movilidad en sociedades cazadoras recolectoras. Facultad de Ciencias Naturales y Museo. Universidad Nacional de La Plata.

MALIZIA RA, CARDELL DA, MOLLI JS, GONZÁLEZ SB, GUERRA PE, GRAU, RJ. 2005. Volatile constituents of leaf oils from the genus Baccharis. Part II. B. obovata Hooker et Arnott and B.salicifolia (Ruiz et. Pav.) Persoon species from Argentina. Journal of Essential Oil Research 17: 194-197.

MANCINI MV. 1998. Vegetational changes during the Holocene in Extra-Andean Patagonia, Santa Cruz, Argentina. Palaeogeography,Palaeoclimatology, Palaeoecology 138: $207-21$.

MANERO A. 2000. Carnívoros marinos o pinnípedos. En: El gran libro de la Provincia de Santa Cruz. Milenio Ediciones y Alfa Centro Literario. Pp 387-389.

MANOSALVA L, MUTIS A, DÍAZ J, URZÚA A, FAJARDO V, QUIROZ A. 2014. Identification of isoquinoline alkaloids of Berberis microphylla by HPLC ESI-MS/MS. 
Boletín Latinoamericano y del Caribe de Plantas Medicinales y Aromáticas 13(4):324335 .

MANZI L, SPIKINS I. 2008. El fuego en las altas latitudes: Los Selk“enam de Tierra del Fuego como referente etnográfico para el Mesolítico europeo. Complutum 19 (1):79-96. MARCHIONI PC, BELLELLI C. 2013. El trabajo del cuero entre los cazadores recolectores de la Patagonia Centro Septentrional. Campo Moncada 2 (Valle Medio del Río Chubut) Relaciones de la Sociedad Argentina de Antropología 38 (1): 223-246 MARCONETTO B. 2002. Análisis de los vestigios de combustión de los sitios Alero Don Santiago y Campo Moncada En: Pérez de Micou C. (Comp.). Plantas y cazadores en Patagonia. Universidad de Buenos Aires, Facultad de Filosofía y Letras. Pp 33-51. MARCONETTO MB. 2005. Recursos forestales y el proceso de diferenciación social en tiempos prehispánicos en el valle de Ambato, Catamarca. Tesis Doctoral. Facultad de Ciencias Naturales y Museo, Universidad Nacional de La Plata. Buenos Aires, Argentina.

MARGUERIE D, HUNOT J. 2007. Charcoal analysis and dendrology: data from archaeological sites in north-western France. Journal of Archaeological Science 34: 1417-1433.

MARTÍNEZ CROVETTO R. 1968. Estudios Etnobotánicos III. Nombres de plantas y su utilidad según los indios araucano pampas del oeste de Buenos Aires. Etnobiologica 12: $1-24$.

MARTÍNEZ CROVETTO R. 1982. Breve panorama de las plantas utilizadas por los indios de Patagonia y Tierra del Fuego. Suplemento Antropológico 17(1): 61-97.

MARTÍNEZ FLORES S, GONZÁLEZ GALLEGO J, CULEBRAS JM, TUÑÓN MJ. 2002. Los flavonoides: propiedades y acciones antioxidantes. Revista Nutrición Hospitalaria XVII (6): 271-278.

MARTÍNEZ SARASOLA C. 1992. Nuestros paisanos lo indios, Vida, historia y destino de las comunidades indígenas en la Argentina. Emecé Editores. Pp. 659.

MARTÍNEZ A, TRESSERRAS J., RODRÍGUEZ ARIZA MO, BUNEDÍA ROVIRA N. 2000 Muestreo arqueobotánico de yacimientos al aire libre y en medio seco. En: La recogida de muestras en Arqueobotánica: objetivos y propuestas metodológicas. La gestión de los recursos vegetales y la transformación del paleopaisaje en el Mediterráneo occidental, Barcelona: Museo de Arqueología de Catalunya Pp. 31-48. 
MARTÍNEZ A,YAGUEDDÚ C. 2012. Identificación de microrrestos vegetales en un coprolito humano del sitio Cerro Casa de Piedra, Santa Cruz, Argentina. Magallania 40(1): 333-339.

MARTINIC M. 1995. Los Aoni kenk, historia y cultura. Ediciones Universidad de Magallanes, Chile. Pp. 379.

MARSTON J. 2009. Modeling wood adquisition strategies from archaeological charcoal remains. Journal of Archaeological Science 36(10): 2192-2200

MASON S y HATHER J. 2002. Hunter-Gatherer Archaeobotany, Perspectives from the northern temperate zone. Institute of Archaeology, University College London.

MAZZITELLI L. 2013. Análisis de materiales líticos de la localidad arqueológica de Isla Lobos (Santa Cruz). En: Actas de XVIII Congreso Nacional de Arqueología Argentina en el Bicentenario de la Asamblea General Constituyente del año 1813, La Rioja 22-26 de abril. Pp. 65-66.

MAZZITELLI L. 2014. Análisis exploratorio sobre artefactos líticos de la localidad de Punta Medanosa (Provincia de Santa Cruz). Magallania 42(2): 183-198.

MAZZONI, E. 2000. Las formas del paisaje. En: El gran libro de la Provincia de Santa Cruz. Milenio Ediciones y Alfa Centro Literario. Pp 1140-1170.

MAZZONI E, VAZQUEZ M. 2004. Ecosistemas de mallines y paisajes de la Patagonia Austral (Provincia de Santa Cruz). Ediciones Instituto Nacional de Tecnología Agropecuaria, Buenos Aires, Argentina

MC PARLAND L, COLLINSON M, SCOTT A, CAMPBELL G. 2009. The use of reflectance values for the interpretation of natural and anthropogenic charcoal assemblages. Journal of Archaeological and Anthropological Science 1: 249-261.

MC PARLAND L, COLLINSON M, SCOTT A, CAMPBELL G, VEAL R. 2010. Is vitrification in charcoal a result of high temperature burning of wood? Journal of Archaeological Science, en prensa.

MEHL A, FRANCO N. 2009 Cambios en la morfología de los reparos rocosos: el caso de los sitios arqueológicos Chorrillo Malo 2 y Río Bote 1(Provincia de Santa Cruz, Argentina) En: Salemme M, Santiago F, Álvarez M, Piana E, Vázquez M, Mansur E. (Eds) Arqueología de la Patagonia-Una mirada desde el último confín. Editorial Utopías, Ushuaia, Argentina. Pp 893-900. 
MENDIONDO ME, JUÁREZ BE, SEELIGMANN P. 2000. Flavonoid profiles of some Argentine species of Chuquiraga (Asteraceae). Biochemical Systematics and Ecology 28 282-285.

MENÉNDEZ L. 2010. Patologías bucales en cráneos humanos del noreste de Patagonia: tendencias temporales en la dieta y estado de salud de las poblaciones del Holoceno tardío del Valle Inferior del Río Negro. Magallania 38(2):115-126.

MILLER N. 1988. Ratios in palaeoethnobotanical analysis. En: Current Palaeoethnobotany: analytical methods and cultural interpretations of archaeological plant remains. Hastorf C. A. y Popper V.S. (Eds). The University of Chicago Press, Chicago y London. Pp.72-85.

MOGLIA JG, GIMÉNEZ AM. 1998. Rasgos anatómicos característicos del hidrosistema de las principales especies arbóreas de la Región Chaqueña Argentina. Investigación Agraria 71 (1 y 2): 53-71 Publicaciones Ministerio de Agricultura, Pesca y Alimentación.Madrid.

MOHAJERANI, ASGARPANAH JR. 2012. Phytochemistry and pharmacologic properties of Urtica dioica L. Journal of Medicine Plants research 6, nº 46: 5714-5719.

MOLARES S. 2010. Flora medicinal aromática de la Patagonia: características anatómicas y propiedades organolépticas utilizadas en el reconocimiento por parte de la terapéutica popular. Tesis doctoral. Centro Regional Universitario Bariloche. Universidad Nacional del Comahue. Argentina.

MOLARES S, GONZÁleZ B, LADIO A, AGUEDA CASTRO M. 2009. Etnobotánica, anatomía y caracterización físico- química del aceite esencial de Baccharis obovata Hook et. Arn (Asteracaee, Asterae) Acta Botánica Brassilica 23(2): 578-589.

MOLARES S, LADIO A. 2008. Plantas medicinales en una comunidad mapuche del NO de la Patagonia Argentina: clasificación y percepciones organolépticas relacionadas con su valoración. Boletín Latinoamericano y del Caribe de Plantas Medicinales y Aromáticas 7(3): 149-155.

MOLARES S, LADIO A. 2009. Ethnobotanical review of the Medicinal Mapuche Flora: use patterns on a regional scale. Journal of Ethnopharmacology 122: 251-260.

MOLARES S, LADIO A. 2012a. The usefulness of edible and medicinal Fabaceae in Argentine and Chilean Patagonia: environmental availability and other sources of 
supply. Evidence-Based Complementary and Alternative Medicine. doi:10.1155/2012/901918

MOLARES S, LADIO A. 2012b. Plantas aromáticas con órganos subterráneos de importancia cultural en la Patagonia Argentina; una aproximación a sus usos desde la etnobotánica, la percepción sensorial y la anatomía. Darwiniana Vol $50 \mathrm{n}{ }^{\circ} 1$.

Molares S, Ladio A. 2014. Medicinal plants in the cultural landscape of a MapucheTehuelche community in arid Argentine Patagonia: an eco-sensorial approach. Journal of Ethnobiology and Ethnomedicine, 10:61. doi:10.1186/1746-4269-10-61.

MOLINA M J. 1967-1970. Arpones monodentados de la Patagonia Meridional. Acta Prcehistórica VIII/X, 173-179.

MORELLO J. 1958. La provincia fitogeográfica del Monte. Opera Lilloana 2. Universidad Nacional de Tucumán.

MORENO F. [1876-77] 2007. Exploración de la Patagonia sur I, por las cuencas del Chubut y Santa Cruz. Ediciones Continente, Buenos Aires, Argentina.

MORENO F. [1877] 2007. Exploración de la Patagonia Sur II, El lago Argentino y los Andes meridionales. Ediciones Continente, Buenos Aires, Argentina.

MORENO E. 2008. Arqueología y etnohistoria de la Costa Patagónica Central en el Holoceno Tardío. Fondo Editorial Provincial, Secretaría de Cultura del Chubut. Chubut, Argentina.

MORENO E, CASTRO A. 1995. Sitio Moreno: datos preliminares de un chico en la Costa Norte de Santa cruz, Argentina. Anales del Instituto de la Patagonia. Serie Ciencias Humanas. 23: I·B-I-19.

MORENO E, CASTRO A. 1995-1996. Costa Norte de Santa Cruz como excepción al modelo de cazadores de guanaco. Anales de Arqueología y Etnología 50-51 Pp.13-22 MORENO E, CASTRO A, MARTINELLI K, ABELLO A. 1998. El material faunístico del sitio Cabo Blanco I, Anales del Instituto de Patagonia Serie Ciencias Sociales 26: 169-179.

MORENO JE, IZETA AD. 1999. Estacionalidad y subsistencia indígenas en Patagonia Central según los viajeros de los Siglos XVI-XVII. En: Soplando en el viento.Actas de las Jornadas de Arqueología de la Patagonia. Universidad Nacional del Comahue, Instituto Nacional de Antropología y Pensamiento Latinoamericano Pp 477-790. 
MORENO J, VIDELA B. 2008. Rastreando ausencias: la hipótesis del abandono del uso de los recursos marinos en el momento ecuestre de la Patagonia continental. Magallania 36 (2): 91-104.

MORENO E, ZANGRANDO F, TESSONE A, CASTRO A, PANARELLO H. 2011. Isótopos estables, fauna y tecnología en el estudio de cazadores recolectores de la Costa Norte de Santa Cruz. Magallania 39 (1): 265-276.

MORENO E, CASTRO A. 1995-1996. Costa Norte de Santa Cruz como excepción al modelo de cazadores de guanaco. Anales de Arqueología y Etnología 50-51:13-22.

MUSAUBACH MG, PLOS A. 2010. Conociendo las plantas de los cazadores recolectores de La Pampa En: Bárcena J, Chiavazza H. (Eds.) Arqueología Argentina en el Bicentenario de la Revolución de Mayo. Actas del XVII Congreso Nacional de Arqueología Argentina. Mendoza, Argentina. Pp. 1193-1198.

MUSTERS G. [1869] 1964. Vida entre los Patagones: Un año por tierras no frecuentadas, desde el Estrecho de Magallanes hasta el Río Negro. Solar, Buenos Aires, Argentina Pp. 437.

NACUZZI L. 1998. Identidades Impuestas: Tehuelches, Aucas y Pampas en el norte de Patagonia. Sociedad Argentina de Antropología, Colección tesis doctorales.

NACUZZI L, PÉREZ DE MICOU C. 1983-85. Los recursos vegetales de los cazadores de la cuenca del Río Chubut. Cuadernos del Instituto nacional de Antropología 5: 407-423.

NAWWAR M., EL MOUSSALAMY A, BARAKAT H, BUDDRUS J, LINSCHEID M. 1989. Flavonoids lactates from leaves of Marrubium vulgare Phytochemistry 28, $\mathrm{n}^{\circ}$ 11 (1989): 3201-3206.

NAZAREA 1998 Cultural memory and biodiversity. University Arizona Press

NELSON M, LIPPMEIER H. 1993. Grinding-tool design as conditioned by land-use pattern. American Antiquity 58(2): 286-305.

NEME G, GIL A, DURÁN V. 2005. Late Holocene in Southern Mendoza (Northewestern Patagonia): Radiocarbon pattern and human occupation. Before Farming 2 (5): 1-18.

OCHOA J, LADIO AH. 2011. Pasado y Presente del uso de plantas silvestres con órganos de almacenamiento subterráneos combustibles en la Patagonia. Bonplandia 20 (2) $265-280$. 
O'CONNOR E. 1884-85. Exploración del Alto Limay y del Lago Nahuel Huapi (continuación). Boletín del Instituto Geográfico 5: 232-240.

OJEDA J, PALACIOS O, RONCEROS S. 2012. Efecto del aceite esencial de Aloysia triphylla BRITTON (cedrón) sobre el Trypanosoma cruzi en ratones. Revista Peruana de Medicina Experimental y Salud Pública 29 (1):61-68.

OJEDA ROJAS I. 2013. Estudio fitoquímico y actividad de plantas utilizadas en medicina mapuche. Tesis de Grado. Facultad de Ciencias Escuela de Química y Farmacia. Universidad Austral de Chile. Valdivia, Chile.

OLIVA G, GONZÁLEZ L, RIAL P. 2001. El ambiente en Patagonia austral. En: Borrelli P, Oliva G. (Eds.) Ganadería sustentable en la Patagonia Austral. INTA Región Patagonia Sur.

ONETO A. [1883] 1884-85. Puerto Deseado, Informe presentado a S. E. el Señor Ministro del Interior, Dr. Bernardo de Yrigoyen, por el Capitán Antonio Oneto. Comisionado del Gobierno Nacional, Miembro Activo del Instituto Geográfico Argentino. Boletín del Instituto Geográfico Argentino 5: 20-29

ORLANDO M. 2009 Instrumentos de molienda y uso del espacio en la costa norte de la Provincia de Río Negro: una primera aproximación. En: Arqueología de Patagonia: una mirada desde el último confin, editado por M. Salemme, F. Santiago, M. Álvarez, E. Piana, M. Vázquez y M.E. Mansur, Editorial Utopías.

ORQUERA, L. A. 1987. Advances in the archaeology of the Pampa and Patagonia. Journal of World Prehistory 1(4) 333-413

ORQUERA L, PIANA E 1999a La vida material y social de los Yámana. Instituto Fueguino de Investigaciones Científicas, editado por Eudeba, Buenos Aires, Argentina. ORQUERA L, PIANA E 1999b Arqueología de la Región del Canal Beagle (Tierra del Fuego, República Argentina). Publicaciones de la Sociedad Argentina de Antropología, Buenos Aires, Argentina.

ORTEGA F. 2012. "A la luz de los datos" de un análisis antracológico en la costa norte de Patagonia (Río Negro) La Zaranda de Ideas Vol. $8 \mathrm{n}^{\circ} 2$.

ORTEGA F, MARCONETTO B. 2009. Una discusión "encendida". Primeros resultados de los análisis de vestigios de combustión en concheros de la costa norte de la Provincia de Río Negro: una primera aproximación. En: Salemme M, Santiago F, 
Álvarez M, Piana E, Vázquez M, Mansur E (Eds.) Arqueología de la Patagonia, Una mirada desde el último confin. Editorial Utopías. Pp. 1141-1148.

ORTEGA F, MARCONETTO B. 2012. La explotación de recursos combustibles: su uso y representación en la costa rionegrina a través de los restos antracológicos. En: Borella F y Cardillos M (Comp.) Arqueología de pescadores y marisqueadores en Nordpatagonia, Descifrando un registro de más de 6000 años. Editorial Dunken. Pp 111-127.

OTAEGUI AV, ZAIXSO HE. 1974. Distribución vertical de los moluscos marinos del litoral rocoso de la Ría de Puerto Deseado (Santa Cruz). Una guía para reconocer los diferentes pisos y horizontes litorales. Physis, 33(86): 321-334.

OUTES F. 1915. La gruta sepulcral del cerrito Las Calaveras. Con un examen anátomopatológico por Ángel H. Roffo. Anales del Museo de Historia Natural de Buenos Aires 27: $365-400$.

OUTES F. 1917. Observaciones etnográficas de Francisco Javier Muñiz. Physis 3:197215.

PALACIOS O. 2007 El complejo 03 de la cueva Epullán Grande, Provincia del Neuquén. Análisis de los artefactos. En: Actas del XVI Congreso Nacional de Arqueología Argentina. Facultad de Humanidades y Ciencias Sociales. Universidad Nacional de Jujuy. San Salvador de Jujuy, Jujuy. Pp. 421-427.

PARADA J, AGUILERA JM. 2007. Food microestructure affects de vioabailability of several nutrients. Journal Food Science. 2007 Mar; 72(2): 21-32.

PARUELO JM, GALLUSCIO R, JOBBÁGY E, CANEVARI M, AGUIAR M. 2005. Situación ambiental en la estepa Patagónica. Fundación Vida Silvestre.

PAUNERO, RS.2003. Las cuevas como sitios arqueológicos y los diferentes usos del espacio en sociedades colonizadoras de la Meseta Central de Santa Cruz. Presentado en el 51 International Congress of Americanists, Santiago de Chile. En prensa.

PAUNERO, RS. 2004. Las cuevas como sitios arqueológicos y los diferentes usos del espacio en sociedades colonizadores de la Meseta Central de Santa Cruz. $51^{\circ}$ Congreso Internacional de Americanistas: Santiago de Chile.

PEARSALL D. M. 2000 Paleoetnobotany, A handbook of procedures. Academic Press. Second Edition. United States of America. 
PEDOJA K, REGARD V, HUSSON L, MARTINOD J, GUILLAUME B, FUCKS E, IGLESIAS M, WEILL P. 2010. Uplift of Quaternary shorelines in eastern Patagonia: Darwin revisited. Geomorphology 127: 121-142.

PÉREZ DE MICOU C. 1979/82. Sitio Piedra Parada (PP1) Dpto. Languiñeo. Prov. de Chubut. Cuadernos del INA.

PÉREZ DE MICOU C. 1985/87 Obtención de recursos vegetales y territorio de explotación de un sitio. Arqueología contemporánea 2 (1) 3:10

PÉREZ DE MICOU C. 1988 Paleoetnobotánica y determinación de territorios de explotación en asentamientos cazadores recolectores. Precirculados IX Congreso Nacional de Arqueología Argentina, Buenos Aires. Pp. 53-63

PÉREZ DE MICOU C. 1991 Fuego, fogones y señales. Una aproximación etnoarqueológica a las estructuras de combustión en el Chubut medio, Arquelogía. Revista de la Sección de Prehistoria 1. Pp. 125-150.

PÉREZ DE MICOU C, BELLELLI C, ASCHERO C. 1992. Vestigios minerales y vegetales en la determinación del territorio de explotación de un sitio. En: Lanata J y Borrero L (Comp.) Análisis espacial en la Arqueología Patagónica Pp. 53-82.

PÉREZ DE MICOU C. 2002. Plantas y cazadores en Patagonia. Facultad de Filosofía y Letras. Universidad de Buenos Aires. Buenos Aires.

PÉREZ DE MICOU C, TRIVI DE MANDRI M, BURRY S. 2009. Imágenes de un Alero, investigaciones multidisciplinarias en Río Mayo, Provincia de Chubut. Patagonia Argentina. Pp 177.

PÉREZ A, ERRA G. 2011. Identificación de maíz en vasijas recuperadas de la Patagonia Noroccidental Argentina. Magallania 39 (2): 309-316.

PICORNELL L. 2009. Quemar la prosperidad: Leña y vida cotidiana en los pueblos fang de Guinea Ecuatorial Afro Hispanic Review 28: 2.

PIQUE I HUERTA R. 1999. Producción y uso del combustible vegetal: una evaluación arqueológica. Universidad Autónoma de Barcelona. Consejo Superior de Investigaciones Científicas, Treballs D Etenoarqueologia, 3. Madrid

PIGAFETTA A. [1520] 1971. Primer viaje en torno del globo. Biblioteca fundamental del hombre moderno $n^{\circ} 12$, Centro Editor de América Latina. Pp.159.

PIZARRO PINOCHET JC. 2005. Densidad nidal en colonia de pingüino de Magallanes (Spheniscus magellanicus Foster 1781 Aves en seno Otway, Chile y su 
relación con algunos factores ambientales. Memoria de Título presentada a la Facultad de Medicina para optar por el título de médico veterinario.

POCHETTINO M. L. Botánica Económica: Las plantas interpretadas según tiempo, espacio y cultura. Sociedad Argentina de Botánica. En prensa.

POCHETTINO M, LEMA V. 2008. La variable tiempo en la caracterización del conocimiento botánico tradicional. Darwiniana 46(2): 227-239.

PODESTÁ C, PEREDA I. 1979. Excavación del cementerio Las Lajitas Provincia de Neuquén. Relaciones de la Sociedad Argentina de Antropología 13:117-135.

POLITIS G., MARTÍNEZ G, RODRÍGUEZ J. 1997 Caza, recolección y pesca como estrategia de explotación de recursos en las florestas tropicales lluviosas: los Nukak de la Amazonía Colombiana. Revista Española de Antropología Americana, 27:167-197. Servicio Publicaciones UCM. Madrid, 1997

POLITIS G. 2007 Nukak: Ethnoarcheology of an Amazonian people. Univ Col London Inst Arch Pub Ser Pp. 412

PONCE JF, RABASSA J, CORONATO A, BORROMEI AM. 2011. Palaeogeographical evolution of the Atlantic coast of Pampa and Patagonia from the last glacial maximum to the Middle Holocene. Biological Journal of the Linnean Society 103: 363-379.

PRATES L. 2008. Los antiguos habitantes del Río Negro desde una visión arqueológica. Colección de Tesis Doctorales dirigida por Horvitz V. Sociedad Argentina de Antropología, Buenos Aires. Pp. 321.

PRATES L. 2009. El uso de recursos por los cazadores recolectores posthispánicos de Patagonia continental y su importancia arqueológica. Relaciones de la Sociedad Argentina de Antropología 34: 201-229.

PRASAD PM. 2014. Phytochemical analysis and DNA fingerprinting of Mentha species using rapd molecular markers. International Journal of Advanced Biotechnology and research 5: 31-35.

PRATES L, DI PRADO V, SERNA A, MANGE E. 2011. Cueva Galpón. Un sitio con entierros humanos y representaciones rupestres en las Sierras de Pailemán (este de Río Negro) En Zangrando A, Barberena R, Gil A, Neme G (Comp.): Libro de Resúmenes VIII Jornadas de Arqueología de la Patagonia. Museo de Historia de San Rafael, Mendoza. 
RAGONESE AE, MARTÍNEZ CROVETTO R. 1947. Planta indígenas de la Argentina con frutos o semillas comestibles. Revista de Investigaciones Agrícolas: 147-215.

RAPOPORT EH, LADIO AH, SANZ E. 1999. Plantas nativas comestibles de la Patagonia andina argentino-chilena. Ediciones Alternatura. National Geographic Society. Bariloche, Argentina.

RAPOPORT EH, SANZ E, LADIO AH. 2001. Plantas silvestres comestibles de la Patagonia andina Parte II - Exóticas. Ediciones Alternatura. Secretaría de Extensión universitaria. UNC. Fundación Antorchas. Bariloche, Argentina.

RATHER MA, DAR BA, SOFI SN, BHAT B, QURISHI M. 2012. Foeniculum vulgare: A comprehensive review of its traditional use, phytochemistry, pharmacology, and safety. Arabian Journal of Chemistry. In press doi:10.1016/j.arabjc.2012.04.011

RATTO N. MARCONETTO B. 2011. Proyectiles en acción, 20 años después...Diseños en la fabricación de astiles fueguinos de colecciones etnográficas En: Armas prehispánicas: múltiples enfoques para su estudio en sudamérica (eds. J. Martínez y D. Bozzuto) Fundación de Historia Natural Félix de Azara Buenos Aires Pp. 135-150.

RAVETTA D, SORIANO A. 1998. Alternatives for the development of new industrial crops of Patagonia. Ecología Austral 8 297-307.

RICHERI M, LADIO A, BEESKOW A. 2013. Conocimiento tradicional y autosuficiencia: la herbolaria rural en la Meseta Central del Chubut (Argentina). Boletín Latinoamericano y del Caribe de Plantas Medicinales y Aromáticas 12 (1):44-58.

RINGUELET RA, AMOR A, MAGALDI NH, PALLARES RE. 1962. Estudio ecológico de la fauna intercotidal de Puerto Deseado en Febrero de 1961 (Santa Cruz, Argentina). Physis. 23(64): 35-54.

RÍOS YK, OTERO A, MUÑOZ DL, ECHEVERRY M, ROBLEDO SM, YEPES MA. 2008 Actividad citotóxica y leischmanicida in vitro del aceite esencial de manzanilla (Matricaria chamomilla) Revista Colombiana de Ciencias Químico Farmacéuticas, 2008: 200-211.

RIVERA SM. 1996 Tratamiento y diagnóstico del material leñoso de la Cueva Epullán Grande (Provincia de Neuquén. Praehistoria 2: 283-301.

RINDOS D. 1984.The origins of agriculture: an evolutionary perspective. Nueva York, Academic Press. 
RODRÍGUEZ F. 2008. Recursos vegetales y tecnofacturas en un sitio arqueológico de la Puna Meridional Argentina, Área Centro-Sur Andina. Darwiniana 46(2): 240-257.

ROIG FA, VIDELA E. 2006/2010. Anatomía de la madera de arbustos de montaña del NW de Mendoza, Argentina. Xama 19-23: 157-238.

ROJAS J, PALACIOS O, RONCEROS S. 2012. Efecto del aceite esencial de Aloysia triphylla Britton (Cedrón) sobre el Trypanosoma cruzi en ratones. Revista Peruana de Medicina Experimental y Salud Pública Vol. 29 (1):61-68.

RONCAGLI G. 1884. Da Punta Arenas a Santa Cruz. Bolettino della Societá Geografica Italiana Serie II, Vol. IX, Año XVIII, Fasc. 10, Roma.

ROSTAMI K, PELTIER WR, MANGINI A. 2000. Quaternary marine terraces, sealevel changes and uplift history of Patagonia, Argentina: comparisons with predictions of the ICE-4G (VM2) model of the global process of glacial isostatic adjustment. Quaternary Science Reviews 19: 1495-1525.

RUTTER N, SCHNACK EJ, DEL RIO J, FASANO JL, ISLA FI, RADTKE U. 1989. Correlation and dating of Quatenary litoral zones along the Patagonian Coast, Argentina. Quaternary Science Reviews 8: 213-234.

SALCEDA S, MÉNDEZ G, CASTRO A, MORENO J. 1999-2001. Enterratorios indígenas de Patagonia: el caso del sitio Heupel- Caleta Olivia Santa Cruz (Argentina). Xama 12-14: 161-171.

SANGUINETTI DE BORMINA A, CURZIO D. 1996 Excavaciones arqueológicas en el sitio Piedra del Águila 11. Praehistoria $\mathrm{n}^{\circ} 2$

PELLIZA SBRILLER A. 1993. Acerca de la microhistología. Comunicación técnica $n^{\circ}$ 32 Recursos Naturales- Dieta. Estación Experimental Agropecuaria Bariloche. INTA PELLIZA SBRILLER A, WILLEMS P, MANACORDA M. 2001. Dietary structural types of polygstric herbivores at different environments and seasons. Journal of range management Vol. 54(4) 334-337.

SKARBUN F. 2009. La organización tecnológica en grupos cazadores recolectores desde las ocupaciones del Pleistoceno final al Holoceno tardio, en la Meseta Central de Santa Cruz. Tesis doctoral. Facultad de Ciencias Naturales y Museo, Universidad Nacional de La Plata. MS 
SCHIAVINI A, CRESPO EP, SZAPKIEVICH V. 1999. Estado de la población del lobo marino de un pelo (Otario flavescens) en las provincias de Santa Cruz y Tierra del Fuego. Informes técnicos del Plan de Manejo Integrado de zona costera Patagónica 40. SCHIAVINI A, YORIO P, GANDINI PA, RAJA REY A, DE BOERMA P. 2005. Los pingüinos de las costas argentinas: estado poblacional y conservación Hornero 20(1): 523.

SHOJAII A, FAR ABDOLLAHI. 2012. Review of Pharmacological properties and chemical constituents of Pimpinella anisum. Pharmaceutics, 2012.

SIEWERT C. 1896. Un viaje a Patagonia (Región austral del Territorio de Santa Cruz). Boletín del Instituto Geográfico Argentino Tomo XVII, cuadernos 7, 8 y 9: 363-404 SILVEIRA M. 1996 Alero Los Cipreses (Provincia del Neuquén, República Argentina) En: Arqueología Solo Patagonia, Ponencias de las Segundas Jornadas de Arqueología de Patagonia. Ed. Gómez Otero J. CENPAT

SILVEIRA M. 1999 Alero Cicuta (Dpto. Los Lagos, Provincia del Neuquén, Argentina) En. Soplando el viento Actas de las Terceras Jornadas de Patagonia. Buenos AiresNeuquén, INPL, Universidad Nacional del Comahue.

SOLARI ME. 2000. Antracología, modo de empleo: en torno a paisajes, maderas y fogones. Revista austral de Ciencias Sociales 4: 167-174.

SROKA Z, RZADKOWSKA-BODALSKA H, MAZOL I. 1994. Antioxidative effect of extracts from Erodium cicutarium L. Zeitschrift für Naturforschung C. (49) 11-12:881884.

STEIBEL PE. 1997. Nombres y usos de las plantas aplicados por los indios Ranqueles de La Pampa (Argentina). Revista de la Facultad de Agronomía, Universidad Nacional de La Pampa 9 (2): 1-40.

STHAL A. 1989 Plant-food processing implications for dietary quality. Foraging and Farming , The evolution of plant exploitation. Ed. Harris D. y G- Hillman. Institute of Archaeology, University College London.

STUIVER, M. y BRAZIUNAS, T. F. 1993 Modeling atmospheric 14C influences and radiocarbon ages of marine samples back to 10,00 BC. Radiocarbon, this issue.

SUJANA P, SRIDHAR TM, JOSTHNA P, NAIDUV C.2013. Antibacterial activity and phytochemical analysis of Mentha piperita L., (Perpermint) An important multipurpose medicinal plant. American Journal of Plant Science 4 (2013): 77-83. 
TENGÖ, M., BELFRAGE K. 2004 Local management practices for dealing with change and uncertainty; a cross scale comparison of cases in Sweden and Tanzania. Ecology and Society 9 (3):4.

TESSONE A. 2010. Arqueología y Ecología Isotópica. Estudio de isótopos estables de restos humanos del Holoceno tardio en Patagonia meridional. Tesis doctoral. Facultad de Filosofía y Letras. Buenos Aires, Argentina.

THÉRY- PARISOT I, HENRY A. 2011. Seasoned or green? Radial cracks analysis as method for identifying the use of green wood as fuel in archaeological charcoal. Journal of Archaeological Science. En prensa: doi:10.1016/j.jas.2011.09.024

THIÉBAULT S. 1989 Apport de l’analyse anthracologique à la connaissance des combustibles ligneux En: Nature et fonction des foyers préhistoriques. Olive M. y Taborin Y. (Dir) Colloque Internacional de Némours. Pp. 81-86.

TRIGGER BG.1991. Distinguished lecture in archeology: Constraint and freedom a new synthesis for archeological explanation. American Anthropologist 93: 551-569.

TOLEDO V. 1992. What is ethnoecology? Origins, scope and implications of a rising discipline. Etnoecologica 1: 5-21.

TORTORELLI L. 2009. Maderas y Bosques Argentinos. Orientación Gráfica Editora 2da Edición- Buenos Aires, Argentina Tomo I, Pp. 576.

TROLA V, CIAMPAGNA ML. 2011. Primeros análisis de tiestos cerámicos en la costa norte de Santa Cruz. Póster. En: VIII Jornadas de Arqueología de la Patagonia, Malargüe, Argentina.

URRUTIA ME, BOGAZZI E. 1996. Determinación taxonómica de una semilla de Cucurbitaceae procedente de la Cueva Epullán Grande (Provincia de Neuquén). Praehistoria 2: 303-305.

VALLES M. 1997. Técnicas cualitativas de investigación social. Reflexión metodológica y práctica profesional. Madrid: Síntesis.

VIEDMA A, VILLARINO B. [1780-83] 2006. Diarios de navegación: expediciones por las costas y ríos patagónicos. Ediciones Continente, Buenos Aires, Argentina.

VIGNATI M. 1941 El "Pan" de los Patagones Protohistóricos, contribución a la etnobotánica indígena Instituto del Museo de la Universidad Nacional de La Plata, Notas del Museo de la Plata. Tomo VI, Antropología 23: 321-336. 
WHALLON R. 2006.Social network and information: non utilitarian mobility among hunter- gatherers. Journal of Anthropological Archaeology 25: 259-270.

WILLIAMS O. 1969. An improve technique for identification of plant fragment in herbivore feces. Journal Range Manage 21:264-265.

WINTON A, WINTON K. 1935. The structure and composition of foods. Vol. II Wiley \& Sons Inc. New Corck.

WOLLSTONECROFT M. 2007. Post-harvest intensification in late Pleistocene Southwest Asia: plant food processing as a critical variable in epipalaeolithic subsistence and subsistence change. Unpublished $\mathrm{PhD}$ thesis, UCL Institute of Archaeology, London

WOLLSTONECROFT M. 2011. Investigating the role of food processing in human evolution: a niche construction approach. Archaeological and Anthropological Sciences 3:141-150.

YEN DE. 1980. Food crops. South Pacific Agriculture: Choices and Constraints. Ward RB y Proctor A. (Eds.), Agricultural Development Bank: Manila.

YORIO P. 2005. Estado poblacional y de conservación de gaviotines y escúas que se reproducen en el litoral marítimo argentino. Hornero, 20 (1): 75-93.

YORIO P, BERTELLOTI M, GARCÍA BORBOROGLU P. 2005. Estado poblacional y de conservación de gaviotas que se reproducen en el litoral marítimo argentino. Hornero, 20 (1): 53-74.

ZAPATA PEÑA, L. 2000 La recolección de las plantas silvestres en la subsistencia mesolítica y neolítica, Datos Arqueobotánicos del país Vasco En: Revista Complutum vol. 11, pp.157- 169 .

ZILIO L. 2013. Chenques en paisaje costero: análisis de estructuras de entierro en Punta Medanosa. Anuario de Arqueología 5: 253-267.

ZILIO L, GORDON F, BÉGUELIN M, CASTRO A 2014. Paleodietas humanas en el sur del Golfo San Jorge Provincia de Santa Cruz a partir del análisis de isótopos estables Revista Argentina de Antropología Biológica 16(1): 51-64.

ZILIO L, MORITA MM, BILMES G. 2013. Uso producción de objetos de cobre por cazadores recolectores en la costa norte de Santa Cruz: análisis composicional y experimentación del proceso de elaboración. En: Bárcena JR, Martín SE. (Comp.) 
Arqueología Argentina, en el Bicentenario de la Asamblea General Constituyente del Año 1813. UNLAR, INCIHUSA y CONICET: 101.

ZUBIMENDI MA. 2006. Informe de Actividades de Campo remitido a la Secretaría de Cultura de la Provincia de Santa Cruz. La Plata.

ZUBIMENDI MA. 2007. Discusión sobre las malacofaunas presentes en sitios arqueológicos de la Patagonia Continental Argentina. En: VI Jornadas de Arqueología e Historia de las Regiones Pampeana y Patagónica. Universidad Nacional de Mar del Plata.

ZUBIMENDI MA. 2009. Análisis de distribuciones de restos artefactuales líticos en el área de Cabo Blanco, Costa Norte de Santa Cruz. En: Bourlot TJ, Bozzuto D, Crespo C, Hecht AC, Kuperszmit N. (Eds.) Entre pasados y presentes II: estudios contemporáneos en ciencias antropológicas. Fundación de Historia Natural Félix de Azara. Buenos Aires Pp 443-458.

ZUBIMENDI MA. 2010. Estrategias de uso del espacio por grupos cazadores recolectores en la Costa Norte de Santa Cruz y su interior inmediato. Tesis Doctoral. Facultad de Ciencias Naturales y Museo, Universidad Nacional de La Plata. Buenos Aires, Aregentina.

ZUBIMENDI MA. 2012. La variabilidad del registro arqueomalacológico en la costa norte de Santa Cruz (Patagonia argentina): resultados exploratorios a partir de estudios estratigráficos. Intersecciones en Antropología 13: 359-375.

ZUBIMENDI MA. 2013. Primera caracterización de los objetos adorno colgantes recuperados en la costa norte de Santa Cruz. Poster. XVIII Congreso Nacional de Arqueologia Argentina, organizado por el Instituto de Ciencias Humanas, Sociales y Ambientales, CCT CONICET, Mendoza y la Universidad Nacional de La Rioja. Realizado en la ciudad de La Rioja, La Rioja, entre los días 22 y 26 de Abril de 2013. ZUBIMENDI MA. 2014. Distributional archaeology in central San Jorge gulf sector. Quaternary International. Disponible en http://dx.doi.org/10.1016/j.quaint.2014.11.008 ZUBIMENDI MA, AMBRÚSTOLO P, BOGAN S. 2007. Análisis de tres sitios ubicados al sur de la ría Deseado, Santa Cruz (Patagonia, Argentina). En: Actas del XVI Congreso Nacional de Arqueología Argentina (Resúmenes Ampliados), Tomo III, Pp 461-467. Universidad Nacional de Jujuy. 
ZUBIMENDI MA, BERETTA M. 2014. Caracterización y análisis de las puntas de arpón de la Patagonia continental Argentina. Revista Relaciones de la Sociedad Argentina de Antropología, enviado.

ZUBIMENDI MA y BOGAN S. 2006. Lestodelphys halli en la Provincia de Santa Cruz. Primer hallazgo en un sitio arqueológico en la Costa Patagónica. Magallania 34(2): 107-114.

ZUBIMENDI MA, CASTRO A, MORENO E. 2004. Una aproximación hacia la definición de modelos de uso de la Costa Norte de Santa Cruz. Magallania 32: 85-88.

ZUBIMENDI MA, CASTRO A, MORENO E. 2005. El consumo de moluscos en la Costa Norte de Santa Cruz. Intersecciones en Antropología 6: 121-137.

ZUBIMENDI MA, CASTRO A, MORENO E, MAZZITELLI L. 2009. Tiempo y espacio en el uso de la Costa Norte de Santa Cruz, Patagonia Argentina. En: La Arqueología como profesión: los primeros 30 años. XI Congreso Nacional de Arqueología Uruguaya. Primera Edición, Asociación Uruguaya de Arqueología. Pp. 755-762.

ZUBIMENDI MA y HAMMOND H. 2009. Análisis de los restos malacológicos en el sitio Los Albatros, Bahía del Oso Marino (Provincia de Santa Cruz). En: Salemme M, Santiago F, Álvarez M, Piana E, Vázquez M, Mansur E. (Eds) Arqueología de la Patagonia-Una mirada desde el último confín. Editorial Utopías, Ushuaia, Argentina. Pp. 865-877.

ZUBIMENDI MA, MAZZITELLI L, NAVARRO A, ZILIO L, HAMMOND H. 2010 Primeras excavaciones en el sitio Palo Alto, Bahía Lángara, Costa Norte de Santa Cruz.En: Arqueología Argentina en el Bicentenario de la Revolución de Mayo, Actas del XVII Congreso Nacional de Arqueología Argentina. Editores: Roberto Bárcena y Horacio Chiavazza, Mendoza, Argentina Tomo V.

ZUBIMENDI MA, AMBRÚSTOLO P, BERETTA M, MAZZITELLI L, HAMMOND H, ZILIO L, CIAMPAGNA ML, TROLA V, PLISCHUCK M, CASTRO A. 2011. Sitio Cueva del Negro: un caso de aprovechamiento intensivo de los recursos marinos en la costa norte de Santa Cruz (Patagonia Argentina). Revista de Estudios Marítimos y Sociales 4: 51-59.

ZUBIMENDI M. A, AMBRÚSTOLO P, ZILIO L, CASTRO A. 2014. Continuity and discontinuity in the human use of the north coast of Santa Cruz (Patagonia Argentina) 
through its radiocarbon record. Quaternary International. Disponible en: doi:10.1016/j.quaint.2014.09.035

ZUBIMENDI MA y ZILIO L. 2013. Estudios distribucionales en el subsector de las Bahías Barco Hundido y Oso Marino (Sector Sur de la ría Deseado, Costa Norte de Santa Cruz). En: En: Tendencias teórico-metodológicas y casos de estudio en la arqueología de la Patagonia. Zangrando F, Barberena R, Gil A et al. (eds) Museo de Historia Natural de San Rafael, Sociedad Argentina de Antropología e Instituto Nacional de Antropología y Pensamiento Latinoamericano Buenos Aires: Pp 544-555.

ZULOAGA F, MORRONE O. 1999. Catálogo de las plantas vasculares de la República Argentina. II Monographs in Systematic Botany, Missouri Botanical Garden. Disponible en: www.darwinion.gov.ar (acceso Abril, 2014). 